VOWEI SOUNDS IN POETRY their Music and Tone-Colour

Volume I

by

Mary M. Macdermott 
ProQuest Number: 13849777

All rights reserved

INFORMATION TO ALL USERS

The quality of this reproduction is dependent upon the quality of the copy submitted.

In the unlikely event that the author did not send a complete manuscript and there are missing pages, these will be noted. Also, if material had to be removed, a note will indicate the deletion.

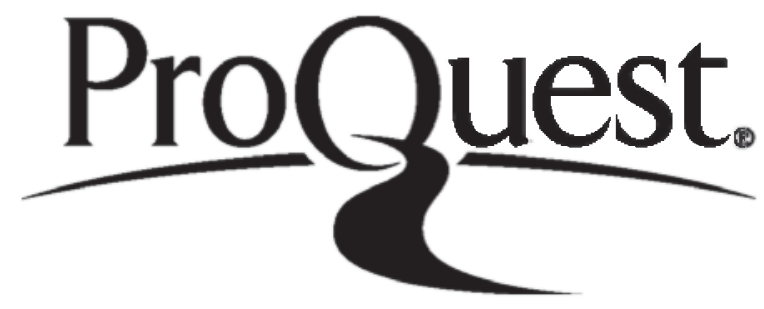

ProQuest 13849777

Published by ProQuest LLC (2019). Copyright of the Dissertation is held by the Author.

All rights reserved.

This work is protected against unauthorized copying under Title 17, United States Code Microform Edition (C) ProQuest LLC.

ProQuest LLC.

789 East Eisenhower Parkway

P.O. Box 1346

Ann Arbor, Ml 48106-1346 


\section{TABZE OF CONRENTS.}

VOEUNE I.

No. of

Page.

ACKNOWLEDGINENTS

$\nabla$

I. PREFACE.

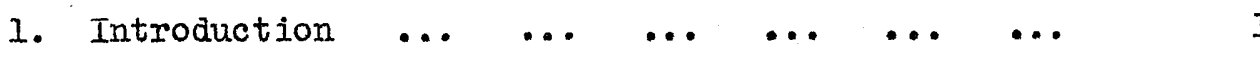

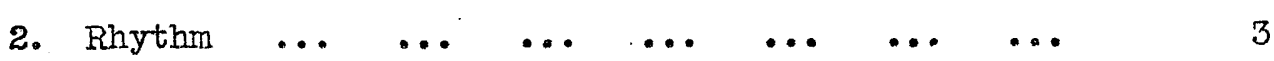

3. The Music of Single Sounds $\ldots$...

4. The Tone-Colour of Consonants and Vowels . ... 15

II. THE TONE-COIOUR OF VOWEL SOUNDS.

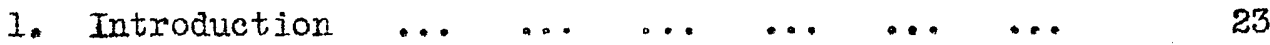

2. The Contrast in Tono-Colour between Front and Back

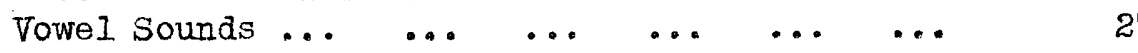

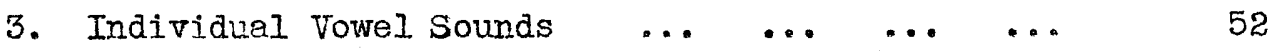

4. The Introduction of Contrast . ... $\ldots$... $\quad 76$

5. The Combination of Vowel. Sounds and Consonants. 79

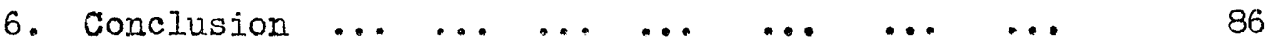

III. THE SIGNIFICANCE OF THE PHONUTIC SYMBOIS.

1. The Phonetic Alphabet $\ldots$\begin{tabular}{llllll} 
& $\ldots$ & $\ldots$ & $\ldots$ & $\ldots$ & \\
\hline 9
\end{tabular}

2. The Relative Strength of Vowel Sounds:

a) The Influence on Relative Strengths of Sentence

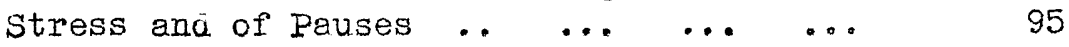

b) Relative Strengths expressed Numerically .. 99 
3. The Reduction of Vowel Sounds: ...

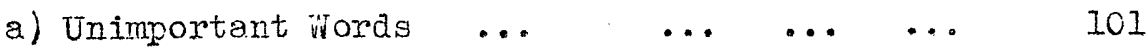

b) Prefixes and Suffixes . $\quad \ldots \quad \ldots . \quad \ldots . \quad 115$

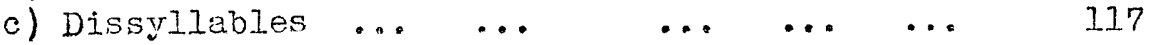

d) Trisyllables and Folysyllables . ... ... 127

4. The Effect of Metres other than Double Metres on the Reduction of Vowel Sounds ... ... ... 136

VOIUME II.

THE WORDS AND WOWEIS OF THE PASSAGES ANALYZEDD.

VOIJUIE III.

THE NINETEREN $=$ COLLMNED TABUIATIONS.

IHE SEQUTNCHS.

\section{VOIUUME IV.}

I. THE EANDS OF RESONAINCE.

1. Front and Back Vowel Sequences ... ... ... 1

2. Simple Relationships between Vowel Sounds . ... 6

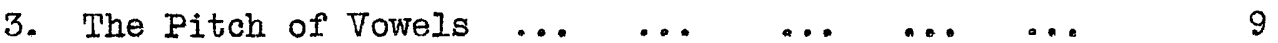

4. The Harmony of Vowels .. ... ... ... ... $\quad 20$

5. The Common Vowels and the Band Theory ... ... 32

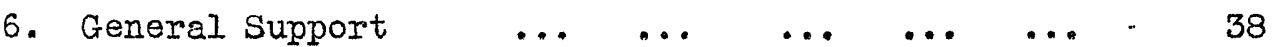

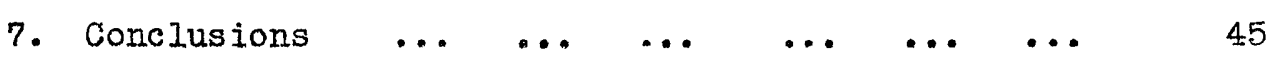

II. THE MEIHOD OF ANAIYSIS.

1. The First Stages ... ... ... ... ... 
2. The Problem of $c$ and the other Common Towels:

The Contribution to its Solution by the Calculation

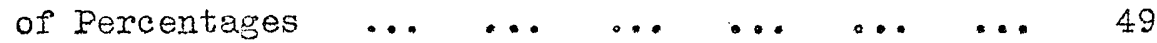

3. The Deep Band Solves the $u: u$, $i$, $i$ : Froblen. 55

4. The Character of the Different Groups of Poems . ... 58

5. The Necessity for the Iine-by-Line Calculations. ... 62

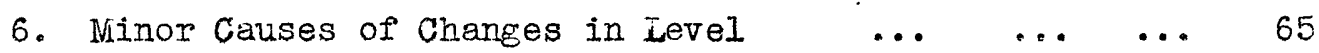

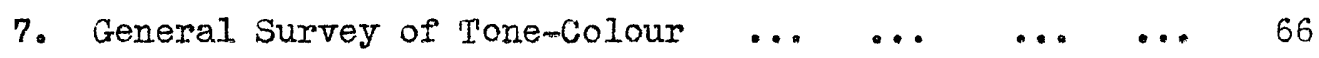

III. THE IIINE-BY-LINE CALCULATIONS $\ldots \ldots \ldots \ldots$

IV. THE FITCH AIND TONE COIOUR OF ITHE WOWELS IN TACH UNIT $\ldots .200$

V. AFPENDICES.

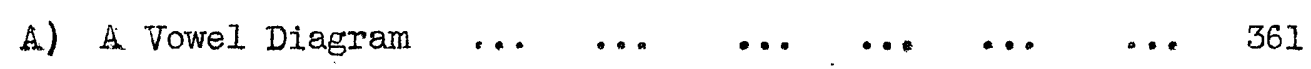

B) The Relative Frequency in the English Ianguage of
a) all Consonantal and b) all Vowel Sounds... ... 362

C) Sir Richard Paget's Chart of Resonances _... ... 364

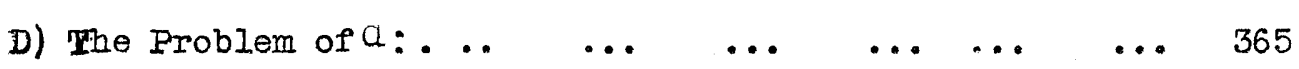

\#) The Last Stages of the Scientific Exploration.. ... 381

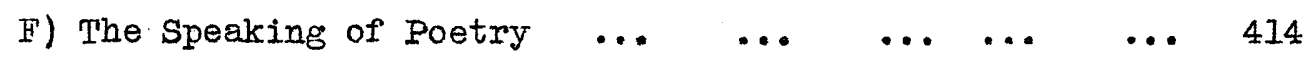

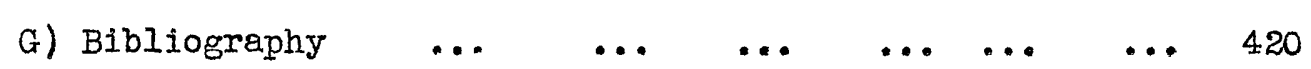

H) Index of Passages Anelyzed. . . . . . . . . . . 424 


\section{ACKNOTLEDGNINITS.}

Not the least pleasant side of an investigation which has proved fascinating and absorbing has been the kindness I have met. Professor Deniel Jones' books on phonetics provided the authoratative description of the Raceived English whose vowels I was examining; to Professor Jones I am indebted also for time syent in discussion, for the loan of one of Dr. G. O. Russell's books, and especially for the kind permission to reproduce his vowel diagram. The librarian of University College, Iond on University, on Professor Jones recommendation, kindly allowed me to borrow the college copy of Dr. Carl Von Stumpf's "Die Sprachlaute".

I look back with pleasure on the stimulating experience of conversation with Sir Richard Paget, whom I sincerely thank for permission to reproduce his vowel chart, the discovery of which marked such a definite advance in the progress of my investigation.

Towards the end of my investigation I sought information about the relative intensity of the two main resonances of each vowel. Although I had ransacked the libraries of the British Museum, the Science Museum, and the Patents Office without finding exactly what I sought, I still hoped to discover it. Dr. vowels Sir Richard Paget demonstrated, when I approached him on the subject, was so extremely kind as to make a fresh electric synthesis of some of the vowels and to free his assistant, MI. S. Byard, B.Sc., to make another syathesis; Mr. Byard generously followed up his synthesis by explaining technical matter in as non-technical language as possible. 
To Dr. Wr. Nacfarlane of the Natural Philosophy department of $\therefore$ asgow University, I owe most sincere thanks for his valuabl enaly is of a election of vowels and for his clear explanations. To $\mathrm{Mr}$. Charles Cochrane, M.A., B.Sc., of the sme department, I am also indebted, especially for the particular version of the Fletcher curves reproauced. Curves and charts made by Dr. Harvey Fletcher and other members of the Bell Telephone Laboratories, the result of the mo:t comprehensive and objective analyses of the vorrels yet made, have been of great assistance to me. From the results of Dr. Carl Von Stumpi's analyses of the most importent vomels, reproduced in Appendix $\mathbb{E}$, useful corroborative evicience was derived.

Captain B. S. Cohen very kindly invited me to visit the Post Office Research Station at Dollis Hill, where he put me into touch with Mr. W. West, whose discussion of vowel resonances was interesting and profitable.

To my personal friends and particularl to Dr. William Boyd of Glasgow University I am grateful for their forbearance and encouragement; Dr" Boyd's sympathetic interest and support over a long period of years have never waned, and his penetrating and stimulating questions have been an inspiration to me as to many others of his former students. 
I. PRE E C E.

Page

1. Introduction $\ldots \ldots \ldots \ldots \ldots \ldots 1$

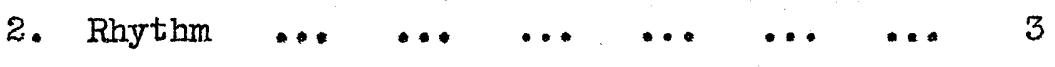

3. The Music of Single Sounds ... ... ... 12

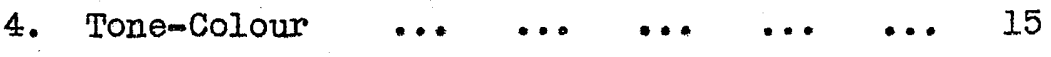




\section{PREFACE.}

1. Introduction.

The investigation described in the following chapters is the unexpected outcome of an earlier examination into the music of poetry, some account, of which will be given in the later sections of this preface. Confined to a more specialized subject than its predecessor, it is based on the pleasure derived from the music of vowels, and aims at analysing the precise nature and effect of this music. As a glance is sufficient to show, it soon invades the province of phonetics and at a later stage even ventures across the borders of the realm of physics. Yet, if it has not the advantage of the single appeal made by an investigation conducted within only one department of knowledge, it uses phonetics and physics not as ends in themselves but as means towards an end that is in the main literary and psychological. And if the excursion into physics is undertaken by one who is no physicist, it is undertaken with the hesitation becoming in such an enquirer, and the more strictly scientific paths along which only a physicist could travel in security are indicated in the Appendix but not entered upon alone. The hope is, however, that, tentative as it originally was, the excursion beyond the usual bounds of the realm of literature brings back something new, something of both interest and value.

To prosecute an exhaustive analysis of such a subject 
as vowel music in poetry is, to some, to cast oneself into the outer darkness of Philistinism. Only one who is deaf to any call of the spirit and insusceptible to any appeal of beauty seems to them capable of its perpetration. Yet, when the subject was approached, there was no question of "writing down the mistakes of the Spring on a slate". The examination proved, in fact, constructive rather than destructive; for, if analysis succeeded appreciation, it was itself succeeded by a deeper and fuller appreciation after the new knowledge gained had sunk below the surface of the mind which, no longer conscious of it, was yet enriched by it. There was no attempt at reducing art to a rule of thumb; and in the end the paradox remained true that, the more its music was analysed, the more inspired and incomprehensibly magic did a poem appear.

The content and the form of a work of art are inseparable. It is difficult to say where the one begins and the other ends; in painting, indeed, some theorists declare them to be one and the same. In poetry, however, the first probably gives birth to the second rather than the second to the first; besides being the more impelling, content is also the more consciously determined, for most poets, in choosing the form of a poem, seem not so much, consciously and systematically, to select according to a body of laws they have constructed, as to obey an inner necessity, an instinctive sense of rightness. Yet, despite this, in poetry as in other branches of literature, form is as personal as content; to take an illustration 
from fiction, Tolstoi and Jane Austen could no more have poured their novels into the same mould than they could have written about the same subjects and the same characters.

The fact that content and form share one being is of importance here mainly because of the dignity it confers on the study of the latter: the nature of the one in some degree determines the nature of the other, with the result that content cannot be fully understood until form is fully understood; and if, despite their union, the one can be in part dissociated from the other and the white light of analysis thrown on each, the value of the analysis lies in its revelation of how sensitively and subtly form gives expression to content.

\section{Rhythm.}

Before the investigation into the music of vowels can be proceeded with, some account must be given of the parent investigation for, although this was comparatively simple, aiming in fact by means of numerous illustrations at fulfilling the secondary function of serving as an anthology, yet it led towards certain conclusions which are accepted as a basis in its successor.

Proceeding from a recognition of the wide-spread influence of rhythm in art, in nature, in the functions and activities of the human body and mind, the earlier investigation first examined poetry 
on its rhythric side. of the two rhythric elements, stress and quantity of syllable, the former was decided to be the more fundamental in Finglish poetic rhythm; for even if the contention were justified that syllables can be divided into long and short as accurately in English as in Greek and Latin, it is yet true that to the majority of people the quantitative distinction is at most a secondary one; and if the minority, whose ears are trained to classical rhythms, consider it to be the primary distinction and therefore declare the rhythm of English poetry to be quantitative, yet it remains true that, traditionally, English rhythm is based on stress, and that poetry deliberately written on a quantitative metric scheme is to most ears no more than an interesting literary exercise. The purely quantitative method of measuring rhythm was therefore rejected. The method based on musical notation was also rejected because, alm though it combines stress and quantity, it emphasizes the latter rather than the former, and is forced to represent rising metres as syncopated and so to suggest that the commonest double and the commonest triple metre are irregularities, variations from the norm. The stress systein thus came to be accepted, with its classification of feet as rising double|x/, falling double $|/ x|$, rising triple $|x \times|$, falling triple $|/ x \times|$, turned $|x| x \mid$, strong steady $|/|$, and weak steady $|\times x|$. The four commonest metres are based on a succession of one of the first four types of foot, for the natural accent of words obviously prevents the existence of steady 
metre, whether strong or weak, and it is at least doubtful if turned (I)

metre exists. Usually the number of feet in a line is four or fire but, whatever it is, it most often remains constant throughout a poem; (2)

except in free verse, which was not examined, if the number varies, it does so according to a regular pattern. The metric beat is comparable to the beat of a metronome and the rhythmic movement of the words as they flow alongside the metre, now over now under it, now behind now before the beat, is comparable to the movement of notes in music as they flow alongside their metric norm, most often but not always coinciding with it. The pleasure in both poetic and musical rhythm is thus derived not from a mechanically regular norm but from a norm which, if securely established, is yet delicately modified in other words, from unity in difference. The simplest modifications are substitutions of one type of footfor another; these occur in the first feet of truncated and in the last of hypermetrical and catalectic lines but may occur in any feet in any line, so long as they are not frequent enough to destroy the norm or render it unstable. They will be found so frequent and so effective in those poems whose vowel music is later analysed that examples of the commonest types are inserted here:

a) Especially at the beginning of a line, $\mid\langle x|$ may be substituted for $|x| \mid$ :

Fame is the spur that the clear spirit doth raise

(1) For "mixed metre" ․ p.136 .

(2) V.Vol. IV, p. 6I. 
b) The contrary substitution also occurs. Sometimes in poems which, like L'Allegro and Lines on the Mermaid Tavern, are constructed on a falling double framework, whole lines are written in rising double metre.

c) Especially effective is the substitution of $|x| /||$ or $|/||x x|$ for two rising feet; usually the substituted feet are adjacent to each other but when, as in the illustration, they are not, their suggestion of the meaning can be all the more delicate:

$$
\text { or sinking as the light wind Lives or dies }
$$

d) The rarer substitution of ||$x x \mid$ for ||$x \mid$ is most likely to occur before a câesura or end-pause. The poem from which this line is taken is written in a catalectic falling double metre:

\section{$|, x \times|$ \\ What Elysium have ye known}

e) Similarly $|x \times 1|$ may be substituted for $|x /|$ :

Fame is the spur that the clear spirit doth raise

f) On the other hand, $|<x|$ may be substituted for ||$x x \mid$. Before pauses, especially in catalectic lines, a foot consisting of a single stressed syllable may be substituted not merely for $|/ x|$ but even for $|/ \times x|$ :

(i) Just for a handful of silver he left us

Just for a riband to stick in his cót

Piper play: Piper l'́l!

g) In a similar fashion, especially in truncated lines, $x /$ may be 
substituted for $|\times / /|$ :

Among women who chatter and cry, and children who
mumble a prayer

h) Turned feet, usually substitutions for rising double feet, are

most likely to occur in hypermetrical lines. The second quotation gives parallel substitutions of $\left|x x^{\prime} x\right|$ for $\left|x x^{\prime}\right|$ :

(i) And snowy summits old in story

(ii) And the spear was a Desert Physician who cured not a few of ambition And drove not a few to perdítion with medicine bitter and strong

The most subtle and significant deviations from the norm, however, are wrought not by such metrical substitutions but by quantitative modifications; for quantity or duration, rejected as the basis of metre, is accepted not only as the strongest modifying influence on it, but also as one of the most sensitive means of conveying what the poet has to say. Its influence on the metric nom, where long (1)

syllables fall in stressed positions and short in unstressed, is effectively illustrated in the following lines. The words, "day", "moon", and "round" palline in unstressed positions, retard the movem

(1) The opportunity is taken of acknowledging a debt to Frofessor i. $A$. Sonnenschein's What is Rhythm?, in which the rules for the syllabification of words and also for the measurement of the length of syllables were found. Frofessor sonnenschein judged that syllables ending in a short vowel sound, unaccented syllables ending in a single consonant sound preceded by a short vowel sound, and accented syllables containing a short vowel sound followed by a "divided" consonant sound (e.g. Iifen) are relatively short, and that accented syllables containing a short rowel sound followed by one or more consonants, unaccented syllables containing a short vowel sound followed by two or more consonants, and syllables containing a lone vowel sound are relatively long. 
ment and so suggest the length of the day, the slowness of the moon"s climbing, and the long moan of the deep; the effect is increased by the contrast of the more metrical first line, whose swifter movement suggests the little lights quickly twinkling in and out and whose sole irregularity (the fact that "from" owing to its complete lack of sentence stress is unable to carry ordinary metric stress) has the opposite effect.

\author{
The lights begin to twinkle from the rocks; \\ The long day wanes; the slow moon climbs; the deep \\ Moans round with many voices.
}

Other, minor, rbythmic factors were next examined. Differm ences of speed and consequently of effect were discovered between the different metres, between long and short lines, and between end-stopped and run-on lines. The incidence and the nature of caesuras and endpauses were considered: any stop longer than a comma marks a long pause $(\Lambda)$ and no stop is needed to mark a short one $(\Lambda)$; whether towards the middle or at the end of lines, and whether long or short, pauses vary in duration, those after run-on lines, for instance, being slighter than those after end-stopped.

The nature of the metre and its modifications, the length of the lines, the presence or absence of enjambment, the length and frem quency of the pauses, and, in addition, the nature of the most frequent letter-sounds, all combine to create the general tempo of a poem. A quick 
tempo suggests quick movement, happiness, gaiety; and a slow suggests inactivity, seriousness, sadness. Another general effect of a poem, its force, bears towards the stresses of individual syllables something of the same relationship as tempo bears towards their lengths. It is created chiefly by the loudness of stressed syllables, considered both absolutely and in relation to the loudness of unstressed syllables; but it is also affected by some of the factors which determine tempo, notably by the nature of the dominant letter sounds. It may be abrupt of smooth, and strong or weak; it can suggest, for instance, energy, excitement, strength, joy, passivity, calm, weakmess, or dejection. Tempo and force do not of necessity remain steady throughout a lyric, but, except in more elaborately constructed poems, their modifications tend to be slight.

The composite effect of stress and duration is now represented, (1) first by a system of double scansion and then by a diagram which, since it is better able to suggest the fusion of the two elements, is more effective.

(1) This system measures unaccented syllables which are without sentence stress exactly as trofessor Sonnenschein measured then. Words or syllables with sentence stress are not, however, treated as Sonnenschein treated them, for it is felt that stress and duration have a mutual ininfluence: thus "soft" derives medium stress from its length and the first syllable of "thi-cket" medium length from its stress. Another difference between the two systems concerns common words such as "I", "at", "my", "whose", "so", "nor", "upon", "each", "wherevith", words normally slurred over owing to their lack of sentence stross: accordine to the system evolved in the process of the previous investigation and adopted in the present, more words are included in this class than vere included by Sonnenschein; in unstressed positions, these words are reduced more often and more systematically than by him; and although it was contrary to his practice to reduce them in stressed positions, they are so reduced here. 
I cannot see what flowers are at my feet,

Nor what soft incense hangs upon the boughs,

But in embalmed darkness, guess each sweet

(1)

Wherewith the seasonable month endows

The grass, the thicket and the fruit-tree wild;

While hawthorn and the pastoral eglantine:

(1) This symbol signifies that the reader, conscious that "ab" falls in a stressed position, may pause for a fraction of a second on it, but does not actually stress it. 
I].

(I) Syllables preceding a long pause are protracted by the arbitrary measures of $1 / 4$ of their own length, those preceding a short pause by $1 / 8$. 
The sense of rhythm is too personal for any rhythmic system to be universally accepted. It is claimed, however, that this system, whereby stress and duration are combined, would win more general acceptance than any other; and the diagrammatic method of representing it has the merit of being elastic enough to indicate just as many or as few shades of difference between the syllables as any speaker of verse could desire.

\section{The Music of Single Sounds.}

Yet, fundamental and sensitive as rhythm is, it does not reveal the whole secret of the music of poetry. An attempt was therefore made to pursue this music into its shyer retreats. Clearly it depends in part on repetition, repetition of lines, phrases, words, rhyming syllables. Could it not also, it was argued, depend in some considerable measure on the repetition of melodious letter-sounds? Consonants are noisier than vowels because, in their articulation, various regions of the mouth cavity obstruct the air after it issues through the vocal cords; nasals, liquids, and semi-vowels suffer less obstruction than continuants, and continuants less than stops. Thus, other factors being equal, those poems must be amongst the most melodious which contain $a$ large number of long vowels, a low proportion of consonants to vowels, and a low proportion of the noisier to the less noisy con- 
sonants. It was therefore decided to examine a number of poems and to estimate the relative strengths of all the sounds in each, with a view to aiscovering the nature of the contribution of musical letter-sounds to the music of poetry. The analysis of rhythm outlined in the last section was accepted as a basis for the estimation of these strengths; and the method originally evolved for estimating them was, except for a few trifling alterations made for the sake of consistency, the method adopted for the purposes of the present investigation and explained in a later chapter. After a few musical poems had been analysed and the total strengths of the various consonants calculated for each, it seemed that one, two, or three consonants always stand out sufficiently from the rest of the consonantal sequence to be regarded as forming a theme; but when more poems had been analysed, it was discovered that this is not so, and that, on the other hand, some (1)

unmusical, bad "poems" contain a consonantal theme. Similarly it was found that the presence of a vowel theme is not a necessary characteristic of a musical poem nor the absence of one a necessary characteristic of an unmusical. The calculation of relative strengths had not, however, been fruitless, for a number of impressions, so definite as to become conviations, emerged from it: firstly, most short lyrics consist of single, long "units" throughout which the same dominant sounds prevail, but poems which are longer or which, like sonnets, contain closely packed

(1) Care was taken that the poems selected for analysis were such as would be generally accepted as musical or unmusical. 
thought, may consist of a number of units, whose dominant sounds change with the changing meaning; secondly, the dominance of a unit by a group of sounds tends to be pleasant when the strongest consonants are either a small group of related sounds such as the nesals and liquids, the labjals, or a few voiced and unvoiced consonantal pairs; thirdly, al though alliteration appeals to the eye more strongly when, as in Swinburne's poetry, the dominant consonants often occur initially and other consonants are repeated initially within single phrases, yet it seems to permeate a passage more effectively when, as in Shakespeare's poetry, a considerable number of the dominant consonants are imbedded in the words; fourtbly, assonance appeals less to the eye than alliteration, both because vowel sounds are seldom initial and because they are spelt in a greater variety of ways than consonantal sounds; fifthly, vowel sequences seem to be dominated by either front or back sounds, front units being commoner than back because, in English, front vowels are both commoner and more frequent; sixthly, there is more variety in the composition of vowel than of consonantal themes, for no vowels exceed the others in relative strength so much as $r$, (I) $t, n, s, I, d$, exceed the other consonants; and seventhly, although the tone of a poem is created more by the vowels than the consonants, its tone-colour, that is, the emotional effect of its sound, is created by both vowels and consonants, but by consonants more obviously than vowels.

\section{(1) V.Appendix B.}




\section{The Tone-Colour of Consonants and Vowels.}

We unconsciously but habitually give physical expression to our emotions: we approach something loved, repel something hated, shrink from something feared; when we are elated, we raise the head, walk buoyantly, and speak in clear, ringing tones, but when we are de jected, droop the head, drag the feet, and speak in dull tones. Similarly poets, the better to convey their feelings and thoughts, express themselves in words whose sound suggests their sense; and this they do, not so much by translating each concept into an imitative word, as by making the general effect of the dominant consonants and vowels within a unit suggest the meaning of the whole unit.

Each sound was therefore examined in a considerable number of short illustrations in which it was so frequent as to make itself evident without any calculation of relative strengths. Although it is clear that the one can modify the other, yet, for the sake of simplifying the issue, the tone-colours of consonants and those of vowels were examined in separate chapters, it being assumed that in the passages examined the one emphasized the other. The first consonants to be considered were the stops. These easily suggest noise, distinct and perhaps angular forms, the separation of object from object, sharp movement, interruption; in the description of other than physical phenomena, they suggest a series of actions or the repetition of the 
same action, haste and unexpectedness, intense effort, agony, dislike, scorn, hatred. Tarying somewhat according to the sounds with which they are associated, especially those with which they are immediately associated, and also according to whether they themselves ere unvoiced or voiced, in general they have a sharp effect. All stops can suggest this sharpness, which may be of sound, form, effort, or feeling. Yet all cannot do so equally well in every connection; and some can describe effects which are not sharp: $P$, for instance, in addition to the usual subjects characteristic of the group, can help to describe upright and stately forms, and also pride and pomp. The sounds which its voiced form, $b$, tends to describe (the sound of blowing, for instance) are less unpleasant than those described by some of the group; the forms are bending or bulging rather than jagged; the effort, such as the bursting of some force beyond its usual confines, may be less painful but more muscular than that described by $\mathrm{p} ; \mathrm{b}$ appears frequently in descriptions of brightness and beauty rather than of pride and pomp; and only if it is supported by other stops does it help to suegest hate and scorn. The unvoiced stop, $t$, is less associated with sounds than most stops, but it is often used to suggest separate or jagged forms; it may describe a series of actions or one continued action of a clear-cut, definite type, which, if it makes less demand on the ultimate resources of strength than the effort described by $p$, is usually more conclusive. Its voiced form, $d$, is more pleasant; it frequently suggests downward motion; and it sometimes describes deter- 
mination issuing in action, action which is sustained and may be irrevocable and which, aiming at conservation and permanence rather than lestruction, is more often defensive than offensive. The unvoiced stop, 15 , suggests clanking sounds, abruptly angular shapes, the cleaving of part from part, coldness of colour or temperature, desolation, and, at its best, in place of the pride and pomp of $p$ and the brightness and beauty of $b$, strength and courage. Its woiced counterpart, $g$, most often, especially when it immediately precedes $I$, helps to describe ugly sounds, forms, or feelings; yet it has the faculty of intensifying the general effect of any texture in which it finds itself and frequently helps to describe a glittering or golden glory.

Poems in which nasals and liquids are dominant were found most (I) often to express delight and the continuance of it: $\eta$ suggests continuance rather than delight, but since it is usually associated with $\mathrm{m}$ and $\mathrm{n}$, it is most often used to describe the continuance of lovely objects and states. It is difficult to distinguish between $m$ and $n$, both of which suggest fluidity and ease of movement, richness of sound, colour, emotion; but $m$ tends to describe a lower, more murmuring, sound than $n$, and $n$ to suggest a clearer serenity (2)

than $m$. One liquid, $r$, can be unpleasant, suggesting roaring

(1) The final sound in sing.

(2) Modern phonetic theory does not group $I$ and $r$ together as liquids but places the former in a class by itself as a 'lateral' consonant and groups the usual S. Eng. $r$ with the fricatives. A semi-rolled or "flapped" I is, however, used by many speakers of Received English, especially in certain csitions, and many other speakers always use a frictionless continuant, which is classed as a semi-vowel. Since both 
or rumbling noises, irregular rolling movements, ugly sights and feelings; but, associated with 1 , long vowels, and nasals, it can be musical and help to describe beautiful subjects. The other liquid, 1 , always describes a continuity, usually a lovely continuity, of sound, sight, movement, or emotion.

The continuants or fricatives, as their name indicates, primarily suggest continuity. Before the examination of the pairs of voiced and unvoiced sounds which fall within this group, $h$, which is little more than stressed breath, was examined. Often used to describe upward or downward motion, and often to describe breathless action such as climbing hills or raising weights, in connection with less concrete subjects, it can suggest heaviness of body or mind; the physical effort it helps to describe may be inspired by hatred and directed against an enemy, but it is the breathlessness of the exertion which it emphasizes rather than its conclusiveness; in another context, it can also suggest a peaceful hushing sound or the sudden hush of horror. The unvoiced continuants differ somewhat from the voiced: with more power to suggest motion but less to suggest achievement, beauty, stability, and security, they are on the whole less pleasant. Yet the voiced and the unvoiced forms closely resemble each other and are most often found together. Like all sibilants, s

(footnote contd.)

these variants fit easily into a nasal texture and since both $r$ and $I$ frequently unite with the nasals to form the consonantal texture of a poem, the general term "liquid" was, for the sake of convenience, retained. When the consonantal texture of a poem is musical, the semirolled or the frictionless sound is preferable; when it is not musical, and when $r$ occurs in such combinations as "tr", "dr", "fr", the fricative variant is preferable. 
and $z$ can describe thin but not necessarily hissing sounds, swift movements, gestures banishing undesired presences, hush and silence. More mellow effects are suggested by $z$, but $s$ can be associated with it in the description of mystery and awe and other not unpleasant subjects; in ugly textures both sounds can suggest loathsomeness, z being more repulsive but no more hateful than $S$. Despite their occurrence in $t \int$ and $d z$, both $\int$ and $\zeta$ are infrequent in Inglish, yet, because they can be continued so long and are so noisy, they soon make themselves felt; $\zeta$ is the less unpleasant, but both are found in the description of unpleasant sounds; the unvoiced form can suggest the action of wind or wave, a hushing sound, the stillness and peace such a sound produces, and also the unsubstantiality of a shadow. Neither $A$ nor $t$ occurs frequently in words which receive sentence stress but both occur frequently in unimportant words; $J$, the voiced form, can help to weave a pleasant, if rather neutral, background out of which more vivid colours rise. Examination proved $I$ to be strongly individual; it often assists in the description of a flutter, a flicker of light or flame, the gentle motion of air or water, faint colours, fading forms, frailty, or delicacy; not always pleasant, it may suggest the fierceness of fury, the shiver of fever, cold, or fear, or a frailty which is pathetic or blameworthy. Thus such continuity as it suggests is merely a renewal of a feeble, possibly fickle, effort, which most certainly, results in failure. Its voiced (1) form, $V$, may support and enrich it; in nasal-1iquid textures it can The symbol $\int$ indicates the initial sound in ship, 3 the initial and the final sound in judge, $\theta$ the initial in thin, and the initial in then. 
be almost as musical as the nasals and liquids themselves. Some sibilants, notably $s, f, z, z$, are frequently associated with each other in the same passage; the not infrequent combination of $\mathrm{S}$ and $\mathrm{W}$ is pleasant, suggesting quick, liquid movement; when, however, as sometimes happens, $\mathrm{s}$ is repeatedly and immediately followed by a stop, the effect is unpleasant because untuneful. Of the two semi-vowels, $W$ has the more definite character and the higher frequency; closely related to $f$, it can suggest an undulating, horizontal movement reminiscent of the vertical movement described by it; like $f$, too, it can suggest a wavering, feeble emotion; in addition, it can help to describe a hushing sound, width of extent, loneliness and desolation, weariness and woe. The other semi-vowel, $j$, which is infrequent, is fluid and musical. The tone-colour of a poem, however, is derived not from a single sound but from the interaction of all its sounds, consonants and vowels, the effect of one being clearly able to modify that of another. The examination of the tone-colour of vowels, which was accordingly entered upon next, is included in the account of the present investigation, the decision to include it in full being made for more than one reason: the detailed account shows, better than a sumnary of it could, the manner in which the vowels suggest the poet's meaning, a manner different from that of the consonants; more important, it shows how the path was opened up to the discoveries of the present book to which its numerous illustrations give valuable support. 
The table of Contents indicates the line of development of the investigation. In the present folume, after the chapter illustrating the tonemcolour of vowels, there follows an explanation of the precise nature of the phonetic symbols. Volume II contains the words and, in the order of their occurrence, the vowels of each poem examined; Volume III contains firstly, the tabulation from which the vowel sequences were obtained and, secondly, for easy reference, a collection of all the sequences. Volume IV groups the vowels according to the band or bands of resonance to which each belongs, explains in a detailed fashion how the vowels of each passage were classified, gives the line-by-line classifications, and concludes with a statement of the dominant level and the initial and final percentages of each unit, followed by a description of its content calculated to prove the tone-colour theories evolved. 
II. THE TONE-COIOUR O VOWEI SOUNDS

No. of

Page

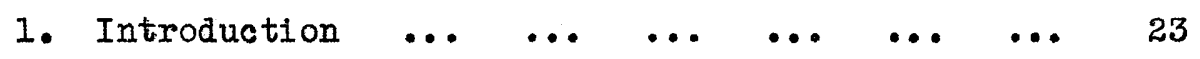

2. The Contrast in Tone-Colour between Back and

Front Vowel Sounds .. ... ... ... ... 27

3. Individual Vowel Sounds. ... $\ldots . . . . \quad \ldots .52$

4. The Introduction of Contrast . ... ... ... 76

5. The Combination of Vowel Sounds and Consonants . 79

6. Conclusion . 


\section{Introduction.}

The content of most poems is, fundamentally, emotional rather than intellectual, feeling having given birth to idea rather than idea to feeling. The poet primarily seeks to convey impressions rather than ideas or objective facts. He therefore selects words whose connotation is wider than their denotation, in contrast to the scientist who strives to find words whose connotation and denotation are as nearly as possible identical. At the same time he uses the tone-colour of words to aid him in suggesting those emotional associations which their mere denotation would fail to convey. The description may be of something which appeals to the senses, colour, form, heat, sound, or the movement which causes it, or it may be of something less physical, a mood, a feeling, or an idea; but whatever it is, the sound of the words helps to describe it. Something less mechanical than a narrow onomatopôia is involved; it is not merely that the sense of each word is suggested by its sound but that the sense of a whole intellectual or emotional unit is suggested by its dominant sounds.

It is true that in some poems, notably in some recent poems, there seems to be no harmony between meaning and sound. The explanation may occasionally be that the poet himself is insensitive to tone-colour or that he is affected differently from other people by the various 
sounds of speech. Another possible explanation is the nature of the content. If it is fundamentally intellectual, lack of harmony does not of necessity result; for even in intellectual poems there is feeling to be communicated and even there tone colour can be used with such sensitiveness that the listener, although he may be ignorant of the means by which he is induced to do so, reflects the exact shade of the poet's feeling more directly, more quickly, and perhaps more truly than he could have done without its aid. Sometimes, however, in fundamentally intellectual poems, the poet's range of words is so limited that an attempt to choose them for their sound would involve a loss of expressiveness in one direction as great as the gain in another. Again, the nature of the emotional content may itself cause an absence of effective tone-colour: when it is vague or confused or unusually subtle, the words which most accurately express it are unlikely to be consistent in colour; and thus the sound of lyrics and of the more lyrical speeches in poetic drama has often a greater significance than that of the more "dramatic" speeches, where the emotion as well as the thought is apt to develop and change so quickly that there is no room for any significant tone-colour to establish itself. Lastly, a number of contemporary poets deliberately reject the symbolism of sound. They may do this either in reaction against Swinburne's too facile use of it or in imitation of Browning's practice, deliberate or undeliberate as it may have been; or they may be impelled by a conviction that the old poetic instruments are outworn, 
that, to describe a new world, new instruments must be wrought, or even by a conviction that, since the new world is turbulent and noisy and meaningless, it must be described in a medium which is chaotic and cacophonous.

Clearly, then, in some poems the sound of the words does not help to convey the meaning. On the other hand, it seldom, if ever, actually contradicts it; and it would be impossible for it to do so without creating in the listener a real uneasiness, whether or not he was able to trace this to its source. At the same time, the theory that tone-colour helps to communicate meaning must not be overstated. No claim must be made that the range of Fnglish speech-sounds and the gamut of human feelings are comextensive, that the sounds and the feelings are identical in number and can be paired off in as tidy a procession as that which entered the Ark. What is claimed here is, simply, that, although a number of sounds seem to suggest almost equally well the same emotion, and although the same sound in different textures may suggest different emotions, yet, on the whole, every sound has a more natural affinity with one emotion or one group of emotions than with any other, and that most poets, whether deliberately or not, avail themselves of these latent affinities.

Just as the vowels were ignored during the examination of the tone-colour of consonants, so the consonants are ignored during the following examination of the tone-colour of vowels, it being assumed that, in the poems quoted, the general quality of their colour harmonizes 
with that of the vowels. Obviously, as is shown in the last section of the chapter, the effect of the one type of sound can considerably modify the other.

The difference in tone-colour between vowels is at first sight less easy to explain than that between consonants, for the positions of the various organs of the mouth cavity differ less in the articulation of the former sounds than in that of the latter. The first step in the analysis of their colour was a consideration of what is perhaps the most obvious distinction between vowel sounds, that between the long and the short group, a distinction comparable to that between the nasals and the stops. Iittle observation is necessary to see that long vowels have the power to suggest length of space or time, slowness, silemnity, and deep thought, while short vowels have the power to suggest shortness of space or time, speed, gaiety and light-heartedness. Since the stronger the vowels are in comparison with the consonants the more tuneful the general effect is, a poem with a high proportion of long vowels is more tuneful than one with a high proportion of short. Yet, useful as the distinction between long and short vowels may be as a poetic instrument, it has its limitations: by itself, for instance, it fails to distinguish between mere triviality and delicate beauty; in addition, its influence belongs more properly to the sphere of tempo than to that of tone-colour. The next step, therefore, was to consider the distinction between open

(1) This term is used throughout as a comprehensive term for vowels and diphthongs. 
and closed vowels. Although, perhaps, the former give a richer, less tense effect than the latter, it was, however, soon decided that the distinction between these two types of sound advances the analysis of tone-colour but little. Indeed, the enquiry along those lines was not pursued far, because the examination of the vowel sequences of (1) poetry had given so clear an indication that the vital distinction is between front and back sounds. Without further delay, therefore, this suggestion was explored.

2. The Contrast in Tone-COlour between Back and Front Vowel Sounds.

Front vowels convey, better than back, the impression of sounds which are high and clear or distant and, faint:

When the fiddlers play their tunes, you may sometimes hear, very softly chiming in, magically clear, Magically high and sweet, the tiny crystal notes of fairy voices bubbling free from tiny fairy throats. (2)

And all of these were hearkening as to singing of far-off voices thin and delicate, voices too fine for any mortal wind

To blow into the whorls of mortal ears. (3)

The sounds they describe may be sharp, metallic, grinding or rattling:

A shrilling trompett sownded from on hye, And unto battaill bad them selves addresse: Their shining shieldes about their wrestes they tye, And burning blades about their heads doe blesse, The instruments of wrath and heavinesse,

(1) V.VOI. IV, p. 49 .

(2) $\bar{R}$. Fyleman, Hairy Music.

(3) W.J. Turner, Ecstasy. 
With greedy force each other doth assayle

And strike so fiercely, that they do impresse

Deepe dinted furrowes in the battred mayle:

The yron walles to ward their blowes are weake and fraile. (I)

And the fenders grind and heave,

And the derricks clack and grate, as the tackle hooks the crate,

And the fall-rope whines through the sheave.(2)

When back rowels dominate, the sounds described are lower:

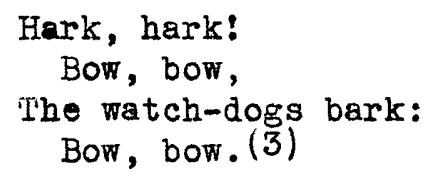

Or by a cider-press, with patient look, Thou watchest the last oozings, hours by hours. (4)

The coming musk-rose full of dewy wine, The murmurous haunt of flies on summer eves. (5)

While, as the last two illustrations show, back vowels may suggest mellower tones than front, in a suitable consonantal texture they may also suggest roaring, thundering, hollow. noises:

He cryde, as raging seas are wont to rore When wintry storms his wrathful wreck does threat; The rolling billowes beat the ragged shore, As they the earth would shoulder from hor seat. (6)

then in the key-hole turns

the intricate wards, and every bolt and bar Of massy iron or solid rock with ease Unfastens: on sudden open fly with impetuous recoil and jarring sound

(1) E. Spenser, 'the raerie queene, 1,5, VI.

(2) R. Kipling, the Long Irail.

(3) W. Shakespeare, lhe 'lempest, I, 2, 38I-384.

(4) J. Keats, Ode to Autumn.

(5) J. Karts, ude to a Nightingale.

(6) E. Spenser, The fierie queene, I,11,XXI. 
ihe infernal doors, and on their hinges grate Harsh thunder, that the lowest bottom shook Of Erebus. (I)

And million horrible bellowing echoes broke From the red-ribb'd hollow behind the wood And thunder'd up into Heaven. (2)

The front vowels may give the impression of height in space instead of in pitch, and also of upward motion:

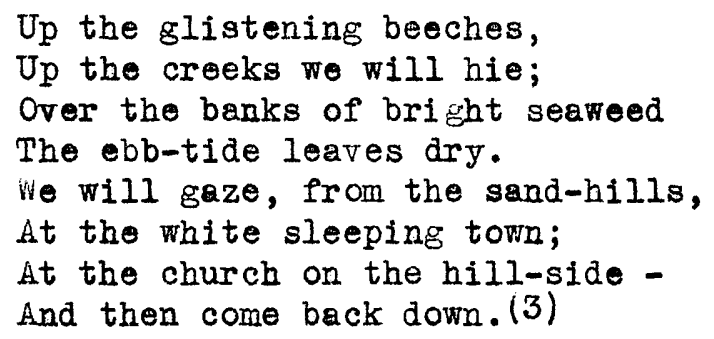

His spear, to equal which the tallest pine, Hewn on Norwegian hills to be the mast of some high anmiral, were but a wand. (4)

$$
\text { Kise, } O \text { ever } r i s \theta,
$$

Rise like a cloud of incense from the Earth: thou kingly Spirit throwed among the hills, Thou dread ambassador from Earth to Heaven, Great hierarch! tell thou the silent sky, And tell the stars, and tell yon rising sun Earth, with her thousand voices praises God. (5)

On the other hand, the back vowels give the impression of depth and downward motion:

\section{A dungeon horrible, on all sides round Ass one great furnace flamed. (6)}

(1) J. Milton, Paradise Lost, II, 876-883.

(2) Lord I'ennyson, Maud, XXIII.

(3) M. Arnold, The Forsaken Merman.

(4) J. Milton, Paradise Lost, I, 290-292.

(5) S.T. Coleridge, Hymn before Sun-rise in the Vale of Chamouni.

(6) J. Milton, Paradise Lost, I, 61-62. 
Down, down, down:

Down to the depths of the sea: (1)

Then with a slow incline of his broad breast, Like to a diver in the pearly seas, Forward he stoop'd over the airy shore, And plung:d all noiseless into the deep night (2)

High vowels are used to describe high, exposed, or barren scenes:

No: penury, inertness and grimace

In some strange sort, were the land's portion. "See

"Or shut your eyes," said Nature peevishly,

"It nothing skills: I cannot help my case:

"Tis the Last Judgment's fire must cure this place

"Calcine its clods and set my prisoners free." (3)

Not see? because of night perhaps? why, day

Came back again for that: before it left,

The dying sunset kindled through a cleft:

The hills, like giants at a hunting, lay

Chin upon hand, to see the game at bay,

"Now stab and end the creature - to the heft!" (4)

Low vowels are used to describe the hidden and sheltered objects and states:

Ye valleys low, where the mind whispers use

of shades, and wanton winds, and gushing brooks,

On whose fresh lap the swart star sparely looks ... (5)

The delicacy of scent, suggested by the front vowels in the first two illustrations, is contrasted with the heaviness suggested by the back vowels in the last two:

The fields breathe sweet, the daisies kiss our feet (6)

(1) M.Arnold, The Forsaken Merman.

(2) J.Keats, Hyperion, I, 354-357.

(3) R.Browning, "Childe Roland to the Dark Tower Came".

(4) Ibid.

(5) J.MiIton, Lycidas.

(6) T.Nash, Spring. 
The jessamine that twinkles in the light, Still watches idly through the window-pane:

While scented stocks do weave their spell each night In case you come again. (1)

And the smell, cold, oppressive, and dank, Sent through the pores of the coffin plank; (2)

Veiled with a soft air, drench'd in the roses' musk or the dusky, dark carnation's breath of clove. (3)

The front vowels describe cool, pale colours more naturally than the back:

Art thou pale for weariness

of climbing heaven, and gazing on the earth, Wandering companionless

Among the stars that have a different birth And ever-changing, like a joyless eye That finds no object worth its constancy?

'0 what can ail thee, knight-at-arms, Alone and palely loitering?

The sedge is withered from the lake, And no birds sing.

'O what can ail thee, knight-at-arms, So haggard and so woebegone?

The squirrel's granary is $\mathrm{full}$, And the harvest's done.

I see a lily on thy brow With anguish moist and fever dew, And on thy cheeks a fading rose Fast withereth too."

The back are better able to describe warm, rich colours:

While barrèd clouds bloom the soft-dying day And touch the stubble-plains with rosy hue; (6)

Roses that down the alleys shine afar. (7)

(1) A. NacGregor, The Deserted Garden.

(2) P.B. Shelley, The Sensitive Plant, III.

(3) F.B.Young, Prothalamion.

(4) F.B. Shelley, To the Moon.

(5) J.Keats, La Belle Dame sans Merci.

(6) J.Keats, Ode to Autumn.

(7) M.Arnold, The Scinolar Gipsy. 
The warmth or coolness may be not of colour but of temperature:

All in a hot and copper sky

The bloody Sun, at noon, Right up above the mast did stand, No bigger than the Moon. (1)

Lifting the cool-hair'd creepers stealthily. (2)

The keen sharpness of cold is best expressed by front vowels:

The night is chill; the forest bare; Is it the wind that moaneth bleak?

Freeze, freese, thou bitter sky: (4)

Its numbing, dull effects are better expressed by back:

When all aloud the wind doth blow, And coughing drowns the parson's saw, And birds sit brooding in the snow, And farian's nose looks red and raw; (5)

The owl, for all his feathers, was a-cold;

The hare limp'd trembling through the frozen grass, And silent was the flock in woolly fold. (6)

Since most of the front vowels are short, they are used to describe slender, angular shapes, especially clear-cut shapes separated

from each other:

Thou shalt see the field-mouse peep
Meagre from its celled sleep;
And the snake all winter-thin
Cast on sunny bank his skin; (7)

(1) S. T. Coleridge, The Ancient Mariner, 111-114.

(2) M.Arnold, The Scholar Gipsy.

(3) S. T. Coleridge, Christabel, 43-44.

(4) W.Shakespeare, As You Like It, II, 7, 184.

(5) W. Shakespeare, Love's Labour Lost, V, 2, 931-934.

(6) J.Keats, The Eve of St. Agnes, I.

(7) J.Keats, The Realm of Fancy. 
or where bitumen lakes,

On bare black pointed islets ever beat

With sluggish surge: (1)

And each particular hair to stand on end,

Iike quills upon the fretful porpentine.

Full, rounded, or shapeless forms are described by back:

Conspiring with him how to load and bless

With fruit the vines that round the thatch-eves run;

To bend with apples the mos'd cottage-trees,

And fill all fruit with ripeness to the core; (3)

Thou watchest the last oozings hours by hours. (4)

Small, unsubstantial, trivial or petty things are described by front vowels:

Where, peaks above the gentians and the linss, Undreamed of seeds fly feckless, and the slight

Celestial Poppies rise from shale and slate. (5)

A veil of purple vapour flowed and trailed its fringes along the Straits; The upper air like sapphire glowed;

And roses filled Heaven's central gates. (6)

... and every bush you see

With scarlet patches tagg'd and shreds of grey.

On the other hand, weight, magnitude, emphasis, importance, significance, are described by back:

(1) P.B.Shelley, Alastor.

(2) W. Shakespeare, Hamlet, I, 5, 15-20.

(3) J.Keats, To Autumn.

(4) Ibid.

(5) D.Wellesley, Old Call.

(6) J.Davidson, In Romney Marsh.

(7) M. Arnold, The Scholar Gipsy. 
Before the Heavens, thou wert, and at the voice of God, as with a mantle, didst invest

The rising World of waters dark and deep

Won from the void and formless Infinite.

Forest on forest hung about his head Iike cloud on cloud.

(2)

The broad circumference

Hung on his shoulders like the moon, whose orb Through optic glass the Tuscan artist views.

Nor is aught from the foaming reef to the snow capp d grandest

Peak, that is over the feathery palms, more fair Than thou, so upright, so stately, and still thou standest.

Spiritual, delicate beauty, fantasies or suppositions, and the fading away of light or forms are described by front vowels:

She holds her little thoughts in sight, Though gay they run and leap;

She is so circumspect and right;

She has her soul to keep. She walks the lady of my delight -

A shepherdess of sheep.

$$
\text { daffodils, }
$$

That come before the swallow dares, and take

The winds of March with beauty; violets dim, But sweeter than the lids of June's eyes Or Cytherea's breath.

(6)

(1) J.Milton, Paradise Lost, III, 8-12.

(2) J.Keats, Hyperion, 1, 6-7.

(3) J.Milton, Paradise Lost, I, 286-288.

(4) Sir Robert Bridges, A Fasser-by.

(5) A.ineynell, The Shepherdess.

(6) W. Shakespeare, A.Winter'S Tale, IV, 3, 118-122. 
The visioned city vanished too, And fall'n beneath my fingers lay.

In me thou see'st the twilight of such day

As after sunset fadeth in the west,

Which by and by black night doth take away,

Death's second self, and seals up all in rest.

Rich beauty and the physical reality of material things are described by back:

There grew broad flag-flowers, purple prank'd with white, And starry river buds mong the sedge And floating water-lilies, broad and bright, Which lit the oak that overhung the hedge With mionlight bcams of their own watery light;

Out in the night there's autumn-smelling gloom Crowded with whispering trees; across the park A hollow cry of hounds like lonely bells: And I know that the clouds are moving across the moon; The low, red, rising moon. Now herons call And wrangle by their pool; and hooting owls Sail from the wood above pale stooks of oats.

the climbing sourd-plant's leaves

Ifuffled its walls, and on the stone-strewn roof

Iay the warm golden gourds; golden, within, Under the eaves, peer'd rows of Indian corm.

The effect of front vowels and that of back remain unaltered when the subjects described are less physical. Thus the lightness described may be not of weight but df quick and tremulous movement:

(1) G.Gould, Fallen Cities.

(2) W. Shakespeare, That time of year thou mayst in me behold.

(3) P.B. Shelley, A Dream of the Unknown.

(4) S.Sassoon, Falling Asleep.

(5) M.Arnold, Aream. 
The one red lear, the last of its clan, That dances as often as dance it can, Hanging so light, and hanging so high,

on the topmost twig that looks up at the sky. (1)-

The heaviness may be that of slow, sleepy movement:

His drowsy flock streams on before him, Their fleeces charged with gold, To where the Sun's last beam leans low on Nod the shepherd's fold. (2)

Radiant light, and regions of dim half-lights, which may inspire a gentle meditativeness, are described by front vowels:

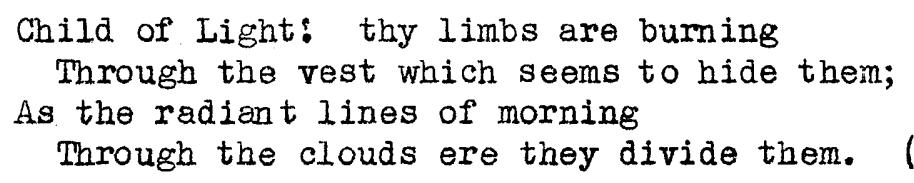

The day begins to droop, Its course is done:

But nothing tells the place

of the setting sun.

The hazy darkoness deepens, And up the lane

You may hear, but cannot see The homing wain. (4)

I leant upon a coppice gate When Frost was spectre-gray, And Winter's dregs made desolate The weakening eye of day.

(1) S.T.Coleridge, Christabel, 49-52.

(2) W.de la Mare, Nod.

(3) P.B.Shelley, Prometheusunbound, II, 5625.

(4) Sir Robert Bridges, Winter Nightfall.

(5) T. Hardy, The Darkling Thrush. 
Darkness is suggested by back:

Out in the dark over the snow

The fallow fawns invisible go

With the fallow doe;

And the winds blow

Fast as the stars are slow.

Stealthily the dark haunts round

And, when a lamp goes, without sound

At a swifter bound

Than the swiftest hound

Arrives and all else is drowned. (1)

Aloft on footless levels of the night

A pilot thunders through the desolate stars,

Sees in the misty deep a fainting light

of far-off cities cast in coal-dark bars

of shore and soundless sea; and he is lone,

Snatched from the universe like one forbid,

Or like a ghost caught from the clay and thrown

Out on the void, nor God cared what he did.

Perhaps because most of them are unrounded while most of the back are rounded, front vowels are better able to give the impression of a flat and even surface, flat monotony, continuity or peace:

The sea was calm and on the level brine

Sleek Panope and all her sisters played.

(1) E. Thomas, Out in the Dark.

(2) F.V. Branford, Night Flying.

(3) J. Milton, Iycidas. 
Day after day, day after day,

We stuck, nor breath nor motion;

As idle as a painted ship

Upon a painted ocean.

careless Quiet lyes

Wrapt in eternall silence farre from enimyes.

Now teach me, maid composed,

To breathe some soften'd strain

Whose numbers, stealing through thy darkening vale, May not unseemly with its stillness suit;

As, musing slow, I hail

Thy genial loved return.

Roughness, ruggedness, turmoil, chaos, and war are, on the other hand, more easily described by back rowels:

We, we have chosen our path -

Path to a clear-purposed goal

Path of adrance! but it leads

A long, steep journey, through sunk

Gorges, o'er mountains in snow!

Cheerful, with friends, we set forth;

Then, on the height, comes the storm:

Thunder crashes from rock

To rock, the cataracts reply;

though the yesty waves

Confound and swallow navigation up;

Though bladed corn be lodged, and trees blown down;

Though castles topple on their warder's heads;

Though palaces and pyramids do slope

Their heads to their foundations; though the treasures

of nature's germens tumble all together,

Even till destruction sicken; answer me

To what I ask you.

(5)

(1) S.T. Coleridge, The Ancient Mariner, 115-118.

(2) E. Spenser, The Faerie Queene, I, XII.

(3) W. Collins, Ode to Evening.

(4) M. Arnold, Rugby Chapel.

(5) W. Shakespeare, Macbeth, IV, 53-6I. 
Now move to war her sable Matadores,

In show like leaders of the swarthy Noors,

Spadillio first, unconquerable lord:

Led off two captive trumps, and swept the board.

Serenity of mind is suggested by front vowels:

that serene and blessed mood,

In which the affections gently lead us on. -

Until, the breath of this corporeal frame

And even the motion of our human blood

Almost suspended, we are laid asleep

In body, and become a living soul.

A pent-up, confused, and troubled state of mind is suggested by back:

No, you unnatural hags,

I will have such revenges on you both,

That all the world shall - I will do such things, -

inat they are, yet I know not.

(3)

Calm, restful sleep is best suggested by front vowels:

Sleep that knits up the ravell'd sleave of care The death of each day's Iife, sore labour's bath, Balm of hurt minds, great nature's second course, Chief nourisher in life's feast.

(4)

Come Sleep: 0 Sleep! the certain knot of peace, The baiting place of wit, the balm of woe, The poor man's wealth, the prisoner's release, Th' indifferent juage between the high and low.

Heavy slumber is best suggested by back:

Fast asleep? It is no matter;

Injoy the honey-heavy dew of slumber;

Thou hast no figures nor no fantasies,

(1) A. Pope, The Rape of the Lock, III, 47-50.

(2) W. Wordsworth, Tintern Abbey.

(3) W. Shapeskeare, King Lear, I, 4, $274-277$.

(4) W. Shakespeare, Macbeth, II, 2, 36-39.

(5) Sir Philip Sidney, Astrophel and Stella, XXXIX. 
Wich busy care draws in the brains of men;

Therefore thou sleeps't so sound.

And slumbrous waters pool a slumbrous world.

Gentle passivity is described by front vowels:

I laid me down upon the shore And dreamed a little space;

I heard the great waves break and roar; The sun was on my face.

My idle hands and fingers brown Played with the pebbles grey;

The waves came up, the waves went down, Most thundering and gay.

The pebbles, they were smooth and round And warm upon my hands,

Like little people I had found Sitting among the sands.

Far from the madding crowd's ignoble strife

Their sober wishes never learn'd to stray;

Along the cool sequester'd vale of life

They kept the noiseless tenor of their way.

Strenyous activity is described by back:

It is good to be out on the road, and going one knows not where, Going through meadow and village, one knows not whither nor why; Through the grey light drift of the dust, in the keen cool rush of the air,

Under the flying white clouds, and the broad blue lift of the sky.

I know not where the white road runs, nor what the blue hills are, But a man can have the Sun for friend, and for his guide a star; And there's no end of royaging when once the voice is heard, For the river calls and the road calls, and oh: the call of a bird:

Gaiety and care-free happiness are best conveyed by front vowels:

Haste thee, Nymph, and bring with thee Jest, and youthful hollity, Quips, and cranks, and wanton wiles, Nods and becks and wreathed smiles,

(1) W. Shakespeare, Julius Caesar, II, 1, 229-233.

(2) V. Sackville-West, Evening.

(3) F. Cornford, Pre-existence.

(4) T. Gray, Elegy written in a country Churchyard.

(5) J. Nasefield, Tewkesbury Road.

(6) G. Gould, iander-thirst. 
Such as hang on Hebe's cheek,

And love to live in dimple sleek;

Sport that winkled Care derides,

And Laughter holding both his sides.

come, and trip it as you go

On the light fantastic toe;

find in thy right hand lead with thee

The mountain nymph, sweet Iiberty;

And if I give thee honour due,

Mirth, admit me of thy crew,

To live with her, and live with thee

In unreproved plessures free;

Come unto these yellow sands, And then take hands:

Court'sied when rou bave, and kiss'd, -

The wild waves whist,

Foot it featly here and there;

And, sweet sprites, the burthen bear.

Greatness, majesty, solemnity, moral or spiritual fervour are best conveyed by back:

Ye, vastest breathers of the air, Shook down with slow and mighty poise

Your coolness on the human care.

Your wonder on its toys,

Your greenness on the heart's despair,

Your darkness on its voice.

Anon they move

In perfect phalanx to the Dorian mood

of flutes and soft recorders; such as raised

To highth of noblest temper heroes old

Arming to battle: (4)

Because in thee

Love hath abounded more than glory abounds,

Therefore thy huniliation shall exalt

With thee thy manhood also to this throne;

Here shalt thou sit incarnate, here shalt reign

Both God and man, Son both of God and man,

Anointed universal King.

(5)

Innocence, purity and the freshness of youth, morning, or spring, are suggested by front vowels:

Two children did we stray and talk Wise, idle, childish things.

(1) J.Milton, I'sllegro.

(2) W. Shake speare, The Tempest, I, 2, 375.

(3) H. Trench.

(4) J.Milton, Paradise Lost, I, 549-553.

(5) J.Milton, paradise Lost, III, 311-317. 
She listen'd with big-lipp'd surprise,

Breast-deep 'mid flower and spine:

Her skin was like a grape, whose veins

Ran snow instead of wine.

She knew not those sweet words she spake,

Nor knew her own sweet way;

But there's never a bird so sweet a song

Throng'd in whose throat that day!

When I did wake this morn from sleep,

It seemed I heard birds in a dream;

Then I arose to take the air -

The lovely air that made birds scream;

Just so a green hill launched the ship

of gold, to take its first clear dip.

Spring goeth all in white,

Crowned with milk-white may!

In fleecy flocks of light

o'er heaven the white clouds stray:

Wite butterflies in the air;

White daisies prank the ground:

The cherry and the hoary pear

Scatter their snow around.

Oh, I must pass nothing by

Without loving it much,

The raindrops try with my lips,

The grass at my touch;

For how can I be sure

I shall see thee again

The world at the first of May

Shining after the rain?

The fulfilment and dignity of age, of evening, of autumn, are suggested

by back vowels. In the first illustration, the parentheses are

dominated by contrasting, front vowels:

But I have seen

Pointing her shapely shadows from the dawn

An image tumbled on a rose-swept bay

(1) F. Thompson, Daisy .

(2) W.H. Davies, Early Morn.

(3) Sir Robert Bridges.

(4) S. Teasdale, May Day. 
A drowsy ship of some yet older day;

And, wonder's breath indrawn,

Thought I - who knows - who knows - but in that same

(Fished up beyond Aeaea, patched up new

- Stem painted brighter blue - )

That talkative, bald-heoded seaman came

(Twelve patient conrades sweating at the oar)

From Troy's doom - crimson shore,

And with great lies about his wooden horse

Set the crew laughing, and forgot his course,

It was so old a ship - who knows - who knows?

- And yet so beautiful, I watched in vain

To see the mast burst open with a rose,

And the whole deck put on its leaves again. (1)

What is it to grow old?

Is it to lose the glory of the form,

The lustre of the eye?

Is it for Beauty to forego her wreath?

Yes; but not this alone.

(2)

Rose-bosom'd and rose-limb'd,

With eyes of dazzling bright,

Shakes Venus 'mid the twined boughs of the night;

Rose-limb'd, soft stepping

From low bough to bough,

Shaking the wide-hung starry fruitage - dimmed

Its bloom of snow

By that sole planetary glow.

For we have seen

The glory of the shadow of the

likeness of thine handmaid,

Yea, the glory of the shadow

of thy Beauty hath walked

Upon the shadow of the waters

In this thy Venice,

And before the holiness

of the shadow of thy handmaid

Have I hidden mine eyes

0 God of waters.

(4)

(1) J.E. Fletcher, The Old Ships.

(2) M. Arnold, Growing Old.

(3) J. Freeman, The Evenins Sky in March.

(4) E. Found, INight Litany. 
O Autumn, laden with fruit, and stained

With the blood of the grape, pass not, but sit

Beneath my shady roof; there thou mayest rest

And tune thy jolly voice to my fresh pipe,

And all the daughters of the year shall dance:

sing now the lusty song of fruits and flowers.

Wailing and lamenting, pathos, desolation, plaintiveness, loneliness and weariness are suggested by front vowels:

The hills stand steep, the dells lie deep,

The fields are green and gold:

The hill-streams sing, and the hill-sides ring As ours at home of old.

But hills and flowers are nane of ours, And ours are oversea:

And the kind strange land whereon we stand, It wotsna what were we

or ever we came, wi' scathe and shame, To try what end might be.

Scathe and shame, and a waefu' name, And a weary time and strange, Have they that seeing a weird for dreeing Can die and cannot change. (2)

Forlorn: the very word is like a bell

To toll me back from thee to my sole self. Adieu: the fancy cannot cheat so well

As she is famed to do, deceiving elf. Adieu! adieu! thy plaintive anthem fades

Past the near meadows, over the still stream,

Up the hill-side; and now 'tis buried deep In the next valley-glades;

Was it a vision, or a waking dream? Fled is that music: do I wake or sleep?

(1) W. BIake, To fiutumn.

(2) A.C. Swinburne, 年Jacobite's Exile, 1746.

(3) J. Keats, Ode to a Nightingale. 
Yet now despair itself is mild

Even as the winds and waters are;

I could lie down like a tired child, And weep away the life of care

Which I have borne and yet must bear,

Till death like sleep might steal on me, And I might feel in the warm air

Mly cheek grow cold, and hear the sea

Breathe o'er my dying brain its last monotony. (1)

A deeper mourning, a sorrow which involves struggle or approaches tragedy, is more naturally suggested by means of back vowels:

Most musical of mourners, weep anew!(2)

The homely beauty of the good old cause

Is gone; our peace, our fearful innocence, And pure religion breathing household laws. (3)

I would have poured my spirit without stint

But not through wounds; not on the cess of war.

Foreheads of men have bled where no wounds were. (4)

0 dark dark dark, amid the blaze of noon

Irrecoverably dark, total eclipse

Without all hope of day! (5)

The last illustration forms a strong contrast to the following lines, which occur later in the same poem, and which describe the sense of achievement and peace up to which we are borne when Samson's struggle is over and his divine task accomplished. Front vowels predominate:

Nothing is here for tears, nothing to wail Or knock the breast; no weakness, no contempt, Dispraise or blame, nothing but well and fair, And what may quiet us in a death so noble.(6)

(1) P.B. Shelley, Stanzas Written in Dejection near Naples.

(2) P.B. Shelley, Adonais, IV.

(3) W. Wordsworth, England, 1802.

(4) W. Owen, Strange Neet ing.

(5) J. Milton, Samson Agonistes, 80-82.

(6) Ibid., 1721-1724. 
Front vowels dominate in many lyrics which describe the light-heartedness and security of young love:

It was a lover and his lass

Wth a hey and a ho, and a hey nonino!

That o'er the green corn-field did pass

In the spring time, the only pretty ring time, When birds do sing hey ding a ding:

Sweet lovers love the Spring. (I)

Who is Silvia? What is she,

That all our swains commend her?

Holy, fair, and wise is she;

The heaven such grace did lend her,

That she might admirèd be.(2)

When the lover expresses a deeper longing or a richer experience, back vowels are strongest:

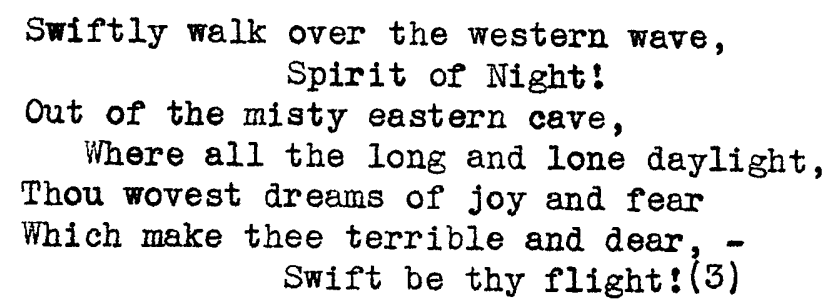

John Anderson my jo, John, When we were first acquent

Your locks were like the raven

Your bonnie brow was brent;

But now your brow is bald, John, Your locks are like the snow;

But blessings on your frosty pow

John Anderson, my jo.

John Anderson, my jo, John, ie clamb the hill thegither,

And many a canty day, John, We've had wi' ane anither:

(1) W. Shakespeare, As You Like It, V, 3, 18.

(2) W. Shakespeare, Fwo GentIemen of Verona, IV, 2, 39.

(3) P.B. Shelley, To the Night. 


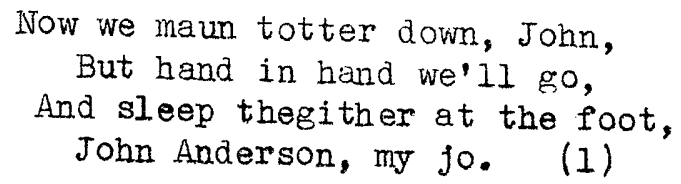

Biting hatred and scorn are most easily suggested by front vowels:

If I can catch him once upon the hip,
I will feed fat the ancient grudge I bear him.

Within thine eyes sat twenty thousand deaths

In thy hands clutch'd as many millions, in

Thy lying tongue both numbers, I would say

'Thou liest' unto thee, with a voice as free

As I do pray the gods.

(3)

Railing and praising were his usual themes, And both, to show his judgment, in extremes.

Back vowels predominate over front when the hatred is uglier, when it becomes a loathing which is almost physical:

mine emulation

Hath not that honour in't had: for where

I thought to crush him in an equal force,

True sword to sword, I'll potch at him some way,

Or wrath, or craft may get him. (5)

So can I give no reason, nor I will not,

More than a lodged hate and a certain loathing

I bear Antonio, that I follow, thus

A losing suit against him. (6)

In the middle of this passage, when, the evil becoming more and more corrupt, Lear's hatred deepens, the transition from front to back vowels

(1) R. Burns \& John Anderson, my jo, John.

(2) W. Shakespeare, The Merchant of Venice, I, 3, 42-43.

(3) W. Shak espeare, Coriolanus, III, 3, 70-74.

(4) J. Dryden, Absolom and Achitophel, I, 555-556.

(5) Ibid., I, 10, 12-16.

(6) W. Shakespeare, The Merchant of Venice, IV, 59-6I. 
But yet thou art my flesh, my blood, my daughter;

Or rather a disease that's in my flesh,

Which I must needs call mine; thou art a boil,

A plague-sore, an embossed carbuncle,

In my corrupted blood. (1)

Tendermess and patience are described by front vowels:

Most blameless is he, centred in the sphere

of common duties, decent not to fail

In offices of tenderness, and pay

Meet adoration to my household gods,

When I am gone. (2)

His prayer he saith, this patient, holy man;

Then takes his lamp, and riseth from his knees,

And back returneth, meagre, barefoot, wan,

Along the chapel aisle by slow degrees.

Wrath, punishment, and torment are usually described by back:

The monstrous sight

Struck them wi th horror backward; but far worse

Urged than behind; headlong themselves they threw

Down from the verge of heaven; eternal wrath

Burn'd after them to the bottomless pit.

Lack of courage, fear, feebleness, frailty, and fickleness are suggested by front vowels:

Noiseless as fear in a wide wilderness.

(1) W. Shakespeare, King Lear, II, 4, 220-224.

(2) Alfred, Lord Tennyson, Unysses.

(3) J.Keats, The Eve of St. Agnes, II.

(4) J. Milton, Paradise Lost, VI, 862-866.

(5) J. Keats, The Eve of St. Agnes, XXVIII. 
I guess, 'twas frightful there to see

A lady so richly clad as she -

Beautiful exceedingly.

This Life, which seems to fair,

So like a bubble, blown up in air,

By sporting children's breath.

Strength and stout courage and also horror, and terror are suggested by back:

In arms not worse, in foresight much advanced,

We may with more successful hope resolve

To wage by force or guile eternal war,

Irreconcileable to our grand foe,

Who now triumphs.

and tho'

We are not now that strength, which in old days

Moved earth and heaven; that which we ore, we are.

In the drowsy gloom,

The dull of midnight, at her couch's foot

Lorenzo stood, and wept: the forest tomb

Had marr'd his glossy hair which once would shoot,

Lustre into the sun, and put cold doom

Upon his lips, and taken the soft lute

From his lorn voice.

(5)

Front vowels express aspiration and exaltation:

0 how I long to travel back, And tread again that ancient track: That I might once more reach that plain Where first I left my glorious train; From whence th'enlighten'd spirit sees That shady City of palm trees.

(1) S.T.Coleridge, Christabel, 66-68.

(2) W.Drummond, This life which seems so void.

(3) J. Milt on, Paradise Lost, I, 119-123.

(4) Lord Tennyson, Ulysses.

(5) J.Keats, IsabeI $\overline{1 a_{2}}$ XXXV.

(6) $\mathrm{H}$, Vaughan, The Retreat. 
O Morld invisible, we view thee,

0 world intangible, we touch thee,

0 world unknowable, we know thee, Inapprehensible, we clutch thee!

If ever happiness hath lodged with man,

That day consumate happiness was mine,

Wide-spreading, steady, calm, contemplative.

Back vowels express depression and heaviness of mood:

All day long I have been working,

Now I am tired,

I cal1: 'Where are you?'

But there is only the oak tree rustling

in the wind.

The house is very quiet,

The sun shines in on your books,

on your scissors and thimble just put down.

But you are not there.

Suddenly I am lonely:

Where are you?

I go about searching.

Supernatural or legendary beings described by front vowels are delicate and eairy-like; their world is strange and fanciful rather than fearsome:

A damsel with a dulcimer

In a vision once I saw;

It was an Abyssinian maid,

And on her dulcimer she play'd,

Singing of Mount Abora.

(4)

\footnotetext{
(1) F. Thompson.

(2) W. Wordsworth, The Prelude, IV, 150.

(3) A.Lowe11, Madonna of the Evening Flowers.

(4) S.T.Coleridge, Kubla Khan.
} 
When the fiddlers play their tunes, you may sometimes hear, Very softly chiming in, magically clear, Magically bigh and sweet, the tiny crystal notes of fairy voices bubbling free from fairy throats.

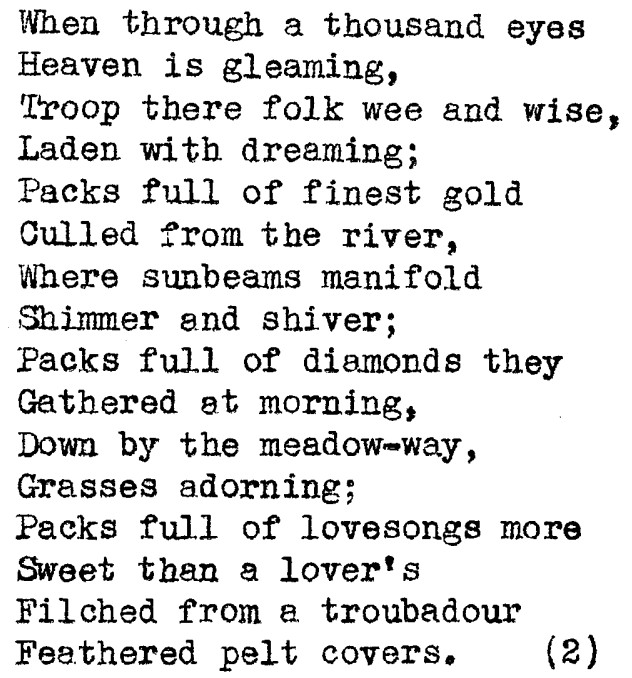

Supernatural beings or forces which excite mystery or awe rather than make a beautiful picture are described by back vowels:

But only a host of phantom listeners That dwelt in the lone house then Stood listening in the guiet of the moonlight

To that voice from the world of men:

Stood thronging the faint moonbeams on the dark stair,

That goes down to the empty hall, Hearkening in an air stirred and shaken

ky the Ionely Traveller's call.

(1) R.Fyleman, Fairy Music.

(2) M.Nightingale, A Faery Song.

(3) W.de la Mare, The Listeners. 
Our Souls have sight of that immortal sea

Which brought us hither,

Can in a moment travel thither,

And see the Children sport upon the shore,

And hear the mighty waters rolling evermore.

A motion and a Spirit, that impels

All thinking things, all objects of all thought, And rolls through all things. (2)

their fatal hands

No second stroke intend, and such $z$ frown

Each cast at the other, as when two black clouds, With heaven's artillery fraught, come rattling on

Over the Caspian; then stand front to front, Hovering a space, till the winds the signal blow To join their dark encounter in mid air:

So frown'd the mighty combatants, that hell Grew dorker at their frowns, so matchid they stood; For never but once more was either like To meet so great a foe. (3)

\section{Individual Vowel Sounds.}

The members of the two main groups of vowels can, however, in some degree at least, be distinguished from each other with regard to tone-colour, for, though most of the feelings associated with efther group can be expressed by any member of it, certain of these are more characteristically expressed by some members than by others. A more

(I) W.Wordsworth, ode on Intimations of Imrortality.

(2) W.Wordsworth, Tintern Abbey.

(3) J.Milton, Faradise Lost, II,712. 
precise idea of the tone-colour of individual vowel sounds was reached by collecting for every one a number of passages where it is frequent and afterwards generalizing on the tone-colour of each in turn. Yet the three vowels which ara formed farthest back in (1) the mouth, $u:, u$, and the $u$ of ju: are scarcely distinguishable from each other. This is not only because of the close rem semblance existing between them but also because of the low frequency of $u$ and $j u$ : in the language, which causes them rather to appear in support of $u$ : than to be domfnant without it. Since all three are rounded vowels, they suggest rounded objects:

Slowly, silently, now the moon Walks the night in her silver shoon;

It was the lovely moon that lovelike Hovered over the wandering, tired Earth, her bosom grey and dovelike, Hovering beautiful as a dove ....... The lovely moon: - her soft light falling

- Lightly on roof and poplar and pine -

Tree to tree whispering and calling, Wonderful in the silvery shine of the round, lovely, thoughtful moon.

(1) The phonetic symbols used in this chapter are fully explained in Chapter III.

(2) W.de la Mare, Silver.

(3) J. Freeman, It was the Lovely Moon. 
They suggest rich loveliness in these lines:

Season of mists and mellow fruitfulness, Close bosom-friend of the maturing san;

Conspiring with him how to load and bless

With fruit the vines that round the thatch-eaves run;

To bend with apples the moss'd cottage-trees, And fill all fruit with ripeness to the core.

Here the poet loves and longs for the rich beauty which he describes:

$$
\begin{aligned}
& \text { Death will come when thou art dead, } \\
& \text { Soon, too soon - } \\
& \text { Sleep will come when thou art fled; } \\
& \text { Of neither would I ask the boon } \\
& \text { I ask of thee, beloved Night - } \\
& \text { Swift be thine approaching flight, } \\
& \text { Come soon, soon: }
\end{aligned}
$$

The same vowels help to describe a secluded and sheltered existence:

\author{
A noise like of a hidden brook \\ In the leafy month of June, \\ That to the sleeping woods all night \\ Singeth a quiet tune. (3)
}

Sabrina fair,

Listen when thou art sitting

Under the glassy, cool, translucent wave,

In twisted braids of lilies knitting

The loose train of thy amber-dropping hair. (4)

Thus they are fit instruments for the feeling to be expressed in

(1) J.Keats, Ode to Autumn.

(2) P.B.Sheiley, To the Night.

(3) S.T.Coleridge, The Ancient Mariner, 369-372.

(4) J.Milton, Comus, 859-863. 
lullabies and in some carols:

From out of a wood did a cuckoo fly,

Cuckoo,

He came to a manger with joyful cry,

Cuckoo,

He hopped, he curtsied, round he flew

And loud his jubilation grew,

Cuckoo, cuckoo, cuckoo.

A pigeon flew over to Galilee,

Vrercroo,

He strutted, and cooed and was full of glee, Vrercroo,

And showed with jewelled wings unfurled,

His joy that Christ was in the world,

Vrercroo, Vrercroo, Vrercroo.

A dove settled down upon Nazareth,

Tsucroo,

And tenderly chanted with all his breath,

Tsucroo:

'O you', he cooed,'so good and true

My beauty do I give to you,

Tsucroo, Tsucroo, Tsucroo."(1)

The diphthong ou: is closely related to the last group,

both because it is rounded and because its second element is $u$.

Thus it, too, is able to suggest shelter and seclusion:

A violet by a mossy stone

Half hidden from the eye!

- Fair as a star, when only one

Is shining in the sky. (2)

Home is the sailor, home from the sea,

And the hunter home from the hill. (3)

The poets sing of love in lines where the same diphthong prevails: :

(1) The Birds' Carol (from the Czech).

(2) W. Wordsworth, She dwelt among the untrodden ways.

(3) R.I. Stevenson, Requiem. 
o mistress mine, where are you roaning?

0 , stay and hear! your true Iove's coming,

That can sing both high and low. (1)

Hy own OEnone,

Beautiful-brow'd OEnone, my own soul.

Here it helps to describe rich beauty:

The rainbow comes and goes

And lovely is the rose.

Wuch have I travelled in the realms of gold

And many goodly states and kingdoms seen;

Round many western islands have I been

Which bards in fealty to Apollo hold.

Oft of one wide expanse had I been told

That deep-brow'd Homer ruled as his demesne;

Yet did I never breathe its pure serene

Till I heard Chapman speak out loud and bold.

Because of the shape of the lips when it is formed, the diphthong ou: can help to describe the act of blowing:

Blow, bugle, blow, set the wild echoes flying, And answer, echoes, answer, dying, dying, dying.

Blow, blow thou winter wind.

It is because of its association with blowing that, as the first verse (7)

of The Eve of St. Agnes shows, it has the power of suggesting cold. Akin to this, is its power of suggesting moaning and sorrow:

(1) W. Shakespeare, Twelfth Night, II, 3, 42-44.

(2) Lord Tennyson, OFnone.

(3) W. Wordsworth, ode on Intimations of Immortality.

(4) J.Keats, on first lookine into Chapman's Homer.

(5) Lord Tennyson, The splendour falls on castle walls.

(6) W. Shakespeare, As you Like it, II, 7, 174 .

(7) V. p.32, where part of thi eong is quoted. 
Then can I drow an eye, unused to flow, For precious friends hid in death's dateless night,

And weep afresh love's long-since-cancell'd woe, And moan the expense of many a vanish'd sight.

Then can I grieve at grievances foregone, And beavily from woe to woe tell o'er

The sad account of forembernogned moan, Which I new pay as if not paid before.

Not a flower, not a flower sweet, On my black coffin let there be strown;

Not a friend, not a friend greet My poor corse, where my bones shall be thrown.

The vowel sounds, $0:, 0 i *$, and 0 are best considered together for the two monothongs do not differ much from each other in tone-colour and the diphthong is so infrequent that it has little effect except when it supports the monothon $\tilde{E}^{5}$. They are all three used to suggest low noises, sometimes associated with turmoil:

for always night and dey

I hear lake water lapping with low sounds by the shore.

And 'mid this tumult Kubla heard from far Ancestral voices prophesying war!

(4)

Where the mountain riven

Exposea those black depths to the azure sky, Ere yet the flood's enormous volume fell Even to the base of Caucasus, with sound That shook the everlasting rocks, the mass Filled with one whirlpool all that ample chasm.

The same vowels may also appesr in rich textures when glorious beauty is

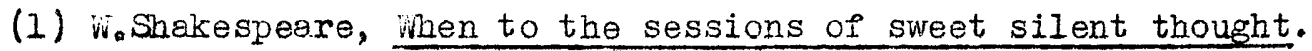

(2) W. Shakespeare, Twel fth Night, II, 4, 59m62.

(3) W.B.Yeats, The Take Isle of Innisfree.

(4) S.T.Coleridge, Kubla Khan.

(5) P.B. Shelley, Alastor. 
described:

The splendour falls on castle walls, And snowy sumnits old in story:

The long light shakes across the lakes, and the wild cataract leaps in glory. (I)

So all their praises are but prophecies of this our time, all you prefiguring;(2)

Transparent forms, too fine for mortal sight, Their fluid bodies half dissolved in light. (3)

The heaviness of these lines is in part expressed by 0 : and 0 :

Or on a half-reap'd furrow sound asleep, Drows'd with the fume of poppies, while thy hook Spares the next swath and all its twined flowers. (4)

The same vowels can suggest hollowness, literal or metaphorical:

Pompey is an arrogant high hollow fateful rider

In noisy triumph to the trumpet's mouth

Doomed to a clown's death, laughing into old age

Never pricked by Brutus in the statue's shade.

But Calgar and Pompey were dead pawns to me

Moving down fields for ever fallow, near bearing,

And I cared not which killed the other

Snatching his mock-life of me;

While Donne and Cargantua, each in his sphere, Walks without me and has the populace to work upon. (5)

o, follow, follow:

Through the caverns hollow, As the song floats thou pursue, By the woodland noontide dew; (6)

(1) Lord Tennyson, The splendour falls on castle walls.

(2) W. Shakespeare, When in the chronicle of wasted time.

(3) A. Pope, The Rape of the Lock, 59-62.

(4) J. Keats, Ode to Autumn.

(5) S. Sitwell, Dr. Donne and Gargantua, III.

(6) P.B. Shelley, Prometheus Unbound, II, I. 
But all was false and hollow; though his tongue Dropp'a manna. (I)

They may express sadness:

And she forgot the stars, the moon, and sun, And she forgot the blue above the trees, And she forgot the dells where waters run, And she forgot the chilly autumn breeze; She had no knowledge when the day was done, And the new morn she saw not: but in peace Hung over her sweet Basil evermore, And moisten'd it with tears unto the core. (2)

The diphthong au: ${ }^{(3)}$ frequently accompanies $a:$ Both may help to describe a low-pitched sound:

Thou watchest the last oozings, hours by hours. (4).

The lowness may be of position:

While the sound whirls around, Down, down:

As the fawn draws the hound. (5)

Supported or unsupported by $0:$, these sounds may also suggest heaviness of form or mood:

But 0 the heavy change, now thou art gone Now thou art gone, and never must return. (6)

Or on a half-reap'd furrow sound asleep

Drows'd with the fume of poppies. (7)
(1) J. Milton, Paradise Lost, II, 112-115.
(2) J. Keats, Isabella, LII.
(3) Cf. p.92, p. 118, andVol. IV, p. 18..
(4) J. Keats, Ode to Autumn.
(5) P.B. Shelley, Prometheus Unbound, II, 3 .
(6) J. Milton, Iycidas.
(7) J. Keats, ode to Autumn. 
Both $a u$ : and $a$ : may aid in the description of blackness and tumult:

the darkness came early

With streakings of flame in the west and then darkness indeed Moonless and starless a lightning-blencht blackness of tumult, With seas roaring out from wind roaring, and wind in the shrouds Shrieking. (I)

In the next illustration not only darkness but also majesty and awe are described:

On a starred night Prince Iucifer uprose. Tired of his dark dominion swung the fiend Above the rolling ball in cloud part screened, When sinners hugged their spectre of repose. Poor prey to his hot fit of pride were those. And now upon his western wing he leaned, Now his huge bulk o'er Afric's sands careened, Now the black planet shadowed Arctic snows. Soaring through wider zones that pricked his scars With memory of the old revolt from Awe, He reached a middle height, and at the stars, Which are the brain of heaven, he looked, and sank. Around the ancient track marched, rank on rank, The army of unalterable law. (2)

The same sounds may assist in the description of richness. In the following verse, the openness of $a$ : helps to suggest how strong and unimpeded is the course of the love which, as has already been shown, u: can suggest:

Death will come when thou art dead, Soon, too soon -

Sleep will come when thou art fled; of neither would I ask the boon

I ask of thee, beloved Night Swift be thine approaching flight Come soon, soon! (3)

(1) J. Nasefield, The Wanderer.

(2) G. Vieredith, Lucifer in Starlight.

(3) P.B. Shelley, To the Night. 
The colour of $a$ : is, however, more variable than that of most vowels.

Despite the fact that it usually suggests heaviness, when it occurs in a poem where front vowels are strongly dominant, it acquires something of their lightness:

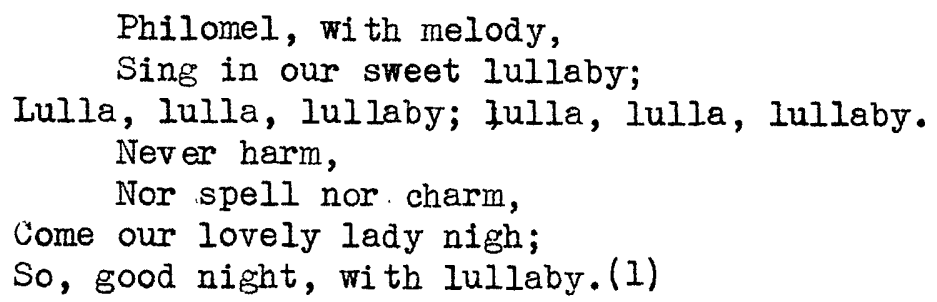

The $\Delta$ of "love" occurs frequently in love-songs:

This thou perceiv'st, which makes thy love more strong To love that well which thou must leave ere long. (2)

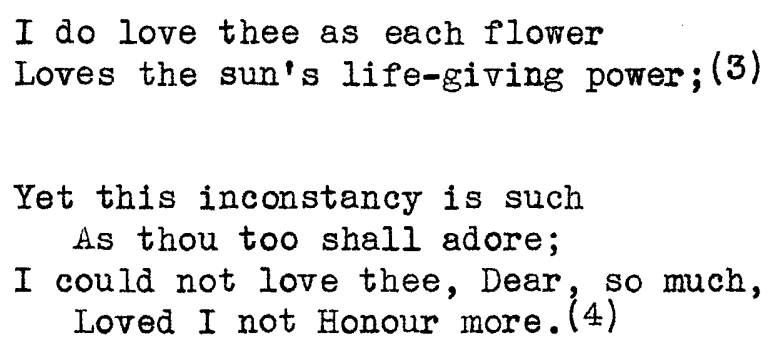

It suggests an enveloping power which may offer shelter and safety:

And watch the warm green-muffled Cumner hills. (5)

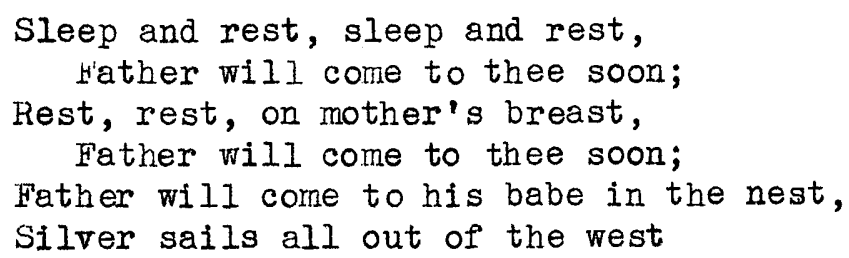

(1) W. Shakespeare, A Midsummer IJight's Dreain, II, 3,13-19.

(2) W. Shakespeare, That time of year thou may'st in me behold.

(3) H. Constable, Diaphenia.

(4) R. Lovelace, To Lucasta on going to the Wars.

(5) if. Arnold, The Scholar Gipsy. 
62.

Under the silver moon:

Sleep, my little one, sleep, my pretty one, sleep.(1)

How oft do they their silver bowers leave

To come to succour us, that succour want:(2)

Like $A$ in the last illustration, the closely-related $\theta$ and $\theta$ add more substance and richness to an $i, i$ :, texture:

Strew on her roses, roses, And never a spray of yew!

In quiet she reposes; Ah! would that I did too.

Her mirth the world required;

She bathed it in smiles of gler,

But her heart was tired, tired, And now they let her be.

Her life was turning, turning, In mazes of heat and sound; But for peace her soul was yearning, And now peace laps her round.

Her cabin'd, ample spirit, It flutter'd and failed for breath;

To-night it doth inherit

The rasty hall of death. (3)

If $i$ is substituted for every $\ni$ : in the next illustrations, the richer quality of $\partial$ : will at once be appreciated:

World-losers and world-forsakers on whom the pale moon gleams: (4)

As the birds do love the spring, or the bees their careful king;

Then in requite, sweet virgin, love me! (5)

(1) Alfred, Lord Tennyson, Sweet and low.

(2) E. Spenser, The Frerie Queene, II, 8, 11.

(3) M. Arnold, Requiescat.

(4) A. T. E. O'Shaughnessy, Ode.

(5) H. Constable, Diaphenia. 
Forget not yet when first began

The weary life ye know, since whan

The suit, the service none tell can

irorget not yet:(I)

The weaker $\theta$, which is more neutral in character than $\theta$ : may

form a background for other colours:

Beautiful must be the mountains whence ye come,

And bright in the fruitful valleys the streams, wherefrom

Ye learn your song:

Where are those starry woods? 0 might I wander there,

Among the flowers, which in that heavenly air

Bloom the year long!(2)

It is natural that the diphthong ai:, whose second element

is $i$, should combine pleasantly with $i$ and $i$ :. Often they express

happiness and security which have their source in love.

His heart in me keeps him and me in one, My heart in him his thoughts and senses guides:

He loves my heart, for once it was his own,

I cherish his because in me it bides:

My true-love hath my heart, and I have his. (3)

Till a' the seas gang dry, my dear, And the rocks mellt wi' the sun;

I will luve thee still, my dear, while the sands o' life shall run.(4)

The same diphthong may be associated with front vowels in the

description of beauty:

Sometimes whoever seeks abroad may find

Thee sitting careless on a granary floor,

thy hair soft-lifted by the winnowing wind; (5)

(I) Sir thomas wyatt, Forget not yet the tried intent.

(2) Sir Robert Bridges, Nightingales.

(3) Sir Philip Sianey, My true-love hath my heart and I have his.

(4) R. Burns, o my Luve's like a red, red rose.

(5) J. Keats, Ode to Auturn. 
By the rushy-fringed bank,

There grows the willow and the osier dank,

ify sliding chariot stays,

Thick set with agate and the azurn sheen

of turkis blue and emerald green

That in the channel strays,

Whilst from off the waters fleet

Thus I set my printless feet

o'er the cowslip's velvet head,

That bends not as I tread,

Gentle swain, at thy request

I am here. (I)

When expression is given to the pathos of unsatisfied longing or

unrealized hope, ai: is often dominant:

I wish I were where Helen lies;

Night and day on me she cries;

0 that I were where Helen lies

on fair Kirconnell lea!(2)

When to the sessions of sweet silent thought

I summon up remembrance of things past,

I sigh the lack of many a thing I sought,

And with old woes new wail my dear time's waste. (3)

0 mother Ida, many-fountain'd Ida,

Dear mother Ida, harken ere I die. (4)

I am but a voice;

My Iife is but a life of wind and tides,

No more than winds and tides can I avail. (5)

Appearing, however, in more varied textures than most vowel sounds, ai:

varies in colour more than most. Associated with back vowels, it may

thus help to suggest a richer beauty or a deeper longing:

(1) J. Milton, Comus, 890-901.

(2) Anon, I wish I were where Helen lies.

(3) W. Shakespeare, When to the sessions of sweet silent thought.

(4) Lord Tennyson, Qinone.

(5) J. Keats, Hyperion, I, 340-342. 
The rainbow comes and goes,

And lovely is the rose;

The moon doth with delight

Look round her when the heavens are bare;

Waters on a starry night

Are beautiful and fair;

The sunshine is a glorious birth;

But yet I know, where'er I go,

That there hath pass'd away a glory from the earth.(I)

Our song is the voice of desire, that haunts our dreams, A throe of the heart

Those pining visions dim, forbidaen hopes profound,

No dying cadence nor long sigh can sound, For all our art.(2)

The vowel $æ$ is not infrequently associated with unpleasant,

clanging or clattering noises:

Dry clash'd his harness in the icy caves

And barren chasms, and all to left and right

The bare black cliff clang'd round him, as he based

His feet on juts of slippery crag that rang

Sharp-smitten with the dint of armed heels. (3)

There lay the "Wanderer" helpless, sea-beaten, sail-tattered, All three topgallant masts broken and swinging aloft still

Raining down pennants and blocks as they tore off in rolling, Her spanker gaff vanisht, her jiggermast bent with the strain. (4)

What passing bells for those who die like cattle?

Only the monstrous anger of the guns.

Only the stuttering rifles' rapid rattle

can patter out their hasty orisons. (5)

The clattering noise in the next passage is suggested by the sound of the words, not by their meaning. The repetition of $æ$ harmonizes also with the desolation and danger:

(1) W. Wordsworth, Ode on the Intinations of Immortality.

(2) Sir Robert Bridges, Nightingales.

(3) Lord Tennyson, Morte d'Arthur.

(4) J. Nasefield, The Wanderer.

(5) W. Owen, Anthem for Doomed Youth. 
The engineman ran to the lamp-room and lighted the lamps, And carried them aft, there to hoist them aloft at the peak; But, as he was hoisting, the flames were blown out in all three, He had to return to the lamp-room to light them again. (I)

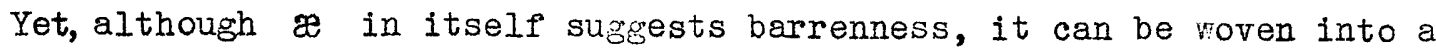
rich texture, as in the second verse of John Anderson, my jo, John. (2) It is, perhaps, at its most sonorous when interwoven with a:

$$
\begin{aligned}
& \text { yet had his temple high } \\
& \text { Rear'd in Azotus, dreaded through the coast } \\
& \text { of Palestine, in Gath, and Ascalon, } \\
& \text { And Accaron, and Gaza's frontier bounds. (3) }
\end{aligned}
$$

for to bear all naked truths, And to envisage circumstances, all calm, That is the top of sovereignty. Nark well! As Heaven and Earth are fairer, fairer far Than Chaos and blank Darkmess, though once chiefs; And as we show beyond that Heaven and Earth In form and shape compact and beautiful, In will, in action free, companionship, And thousand other signs of purer life... (4)

The front vowels differ from each other in degree rather than quality: the farther forward a member of this group is, the less rich and the colder and clearer its tone-colour is. A substitution of $i$ : , $i$, or even. ei: for every $\boldsymbol{\varepsilon}$ in the next illustrations makes this evident:

By fairy hands their knell is rung, By forms unseen their dirge is sung: There Honour comes, a pilgrim grey, To bless the turf that wraps their clay; And Freedom shall awhile repair To dwell, a weeping hermit, there. (5)

(1) J. Masefield, The Wanderer.

(2) Cf. p. 47 .

(3) J. Wilton, Paradise Lost, I,463-466.

(4) J. Keats, Hyperion, II,203-211.

(5) W. Collins, Ode written in MDCCXIVI. 
There was no leaf upon the forest bare, No flower upon the ground,

And little motion in the air,

Except the mill-wheel's sound.(I)

But yet I know, where'er I go

That there hath pass'd away a glory from the earth.(2)

The chief characteristic of $e$, the next member of the

group, is that it is intermediary between the richer $\varepsilon$ and the

thinner $i:$, as is clearly shown if first $\varepsilon$ and then $i:$ is

substituted for it throughout these passages:

Jenny kissed me when we met. (3)

Then to Silvia let us sing, That Silvia is excelling;

She excels each mortal thing Upon the dull earth dwelling;

To her let us garlands bring. (4)

What is love? 'tis not hereafter;

Present mirth hath present laughter;

What's to come is still unsure:

In delay there lies no plenty -

Then come kiss me, sweet-and-twenty,

Youth's a stuff will not endure. (5)

She has virgins many

Fresh and fair. (6)

The diphthong $e i$ : has a more characteristic colour of its

own. It may suggest paleness:

(1) P.B. Shelley, A widow bird sate mourning for her love.

(2) W. Wordsworth, ode on Intimations of Immortality.

(3) I. Hunt, Jenny kissed me.

(4) W. Shake speare, Two Gentlemen of Verona, IV,2,49-53.

(5) W. Shakespeare, Twelfth Night, II, 2,48-53.

(6) R. Herrick, To Violets. 
Why so pale and wan, fond lover?

Prythee, why so pale?

Will, when looking well can't move her, Looking ill prevail?

Prythee, why so pale?(I)

An impression of the youth, coolness, and freshness of spring can be conveyed by it:

The palm and may make country houses gay, Lambs frisk and play, the shepherds pipe all day, And we hear aye birds tune this merry lay, Cuckoo, jug-jug, pu-we, to-witta-woo! (2)

It raised my hair, it fanned my cheek Like a meadow-gale of spring It mingled strangely with my fears Yet it felt like a welcoming. (3)

In other textures these qualities are intensified into coldness and greyness, which may be quiet and calm as in the two first passages or more desolate as in the last two:

Now came still evening on, and twilight grey Had in her sober livery all things clad; Silence accompanied; for beast and bird, They to their grassy couch, these to their nests Were slunk, all but the wakeful nightingale;(4)

And morning came quietly in upon sandals of peace, The maiden-eyed morning who wakens the birds in the dew; With greyness in heaven, and silver in streaks on the sea She came to that harbour of rest where the "Wanderer" lay And shone on her ruin all scurfing with patches of salt Till shadows of beauty were tranquilly stirred at her side.(5)

(1) Sir John Suckling, Encouragements to a Lover.

(2) T. Nash, Spring.

(3) S.T. Coleridge, The Ancient Nariner, 456-459.

(4) J. Milton, Paradise Lost, IV,598-602.

(5) J. Rasefield, The Wanderer. 


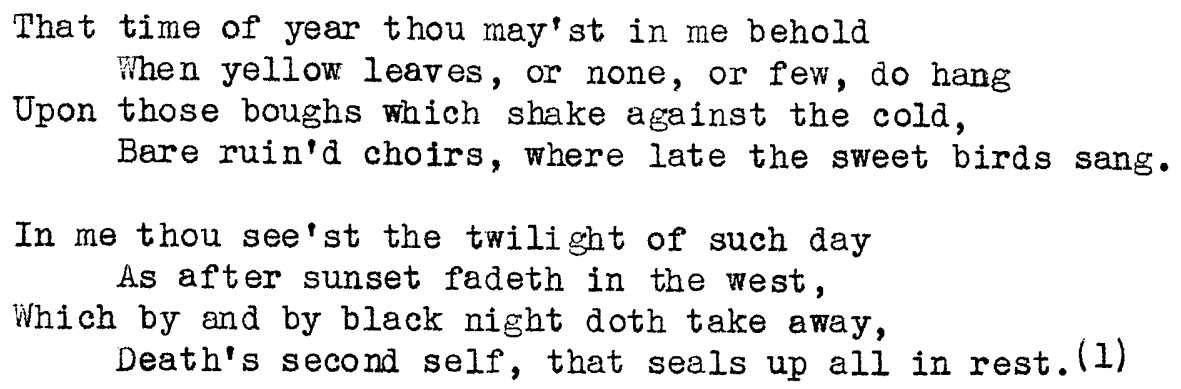

Rough winds do shake the darling buds of May, And surmer's lease hath all too short a date:(2)

The feeling of gentle desolation may be increased to pathos or

lamentation:

Come away, come away, Death, And in sad cypres let me be laid;

Fly away, fly away, breath;

I am slain by a fair cruel maid. (3)

Fair daffodils, we weep to see

You haste away so soon:

As yet the early ri sing sun

Has not attain'd his noon. Stay, stay

Until the hasting day

Has run

But to the even-song;

And, having prayed together, we

Will go wi th you along. (4)

The transition from the warmer $e$ of the first four happy lines to the sadder $e i:$ of the next three is interesting:

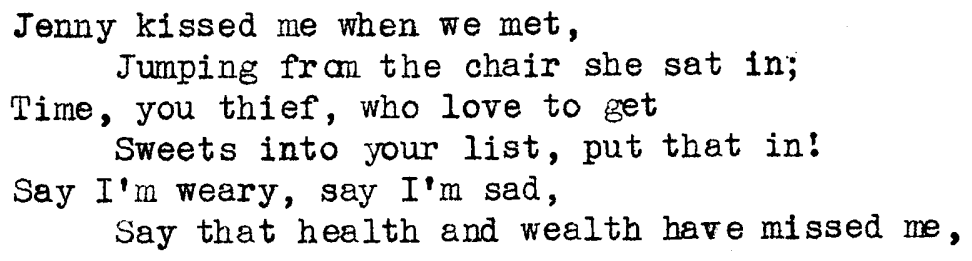

(I) W. Shakespeare, That time of year thou may'st in me behold.

(2) W. Shakespeare, Shall I compare thee to a summer's day?

(3) $\mathrm{N}$. Shakespeare, Twelfth Night, II,4,51-54.

(4) R. Herrick, To Daffodils. 
Say I'm growing old, but add, Jenny kiss'd me.

Strangeness and weariness are sometimes suggested byei: :

And straight the Sun was flecked with bars,

(Heaven's Mother send us grace!)

As if through a dungeon-grate he peered

With broad and burning face. (2)

Nothing of him that doth fade

But doth suffer a sea-change

Into something rich and strange.

The effect of $i$ depends partly on its shortness. It oftem

isuggests the quick and, perhaps, gay movement of slight forms:

Willows whiten, aspens quiver,

Little breezes dusk and shiver

Thro' the wave that runs for ever

By the island in the river

Flowing down to Camelot. (4)

When the hounds of spring are on winter's traces,

The mother of months in meadow or plain

Fills the shadows and windy places

With lisp of leaves and ripple of rain;

It may help to express a mood of gaiety although no movement is described:

Heigh ho: sing heigh ho: unto the green holly:

Most friendship is feigning, most loving folly:

Then, heigh ho: the holly:

This life is most jolly. (6)

(1) L.Hunt, Jenny kissed me.

(2) S.T.Coleridge, the Ancient Mariner, 177-180.

(3) W. Shakespeare, The Tempest, I, 2,397-399.

(4) Alfred, Lord Tennyson, The Lady of Shalott.

(5) A.C.Swinburne, Atalanta in Calydon, 65-72.

(6) W. Shakespeare, is You Like It, II, 7, 180-183. 
li.y true-love hath my heart, and I have his,

By just exchange one for another given:(I)

'I'rip no further, pretty sweeting;

Journeys end in lovers meeting -

Every wise man's son doth know. (2)

Its slightness causes it to be used in descriptions of unsubstantial

forms:

Thin glittering textures of the filmy dew,

Dipt in the richest tincture of the skies. (3)

It is engender'd in the eyes

With gazing fed; and Fancy dies

In the cradle where it lies:

Let us all ring Fancy's knell;

I'll begin it - Ding, dong, bell.

- Ding, dong, bell. (4)

The same quality fits it for descriptions of thin, light sounds:

0 hark, $O$ hear: how thin and clear,

And thinner, clearer, farther going:

0 sweet and far from cliff and scar

The horns of Elfland faintly blowing:(5)

There is but sound of sedges dry, And still they sing.

It is within my breast they sing, As I pass by.

Within my breast they touch a string, They wake a sigh.

There is but sound of sedges dry;

In me they sing.(6)

(1) Sir Philip Sidney, iny true-love hath my heart and I have his.

(2) W. Shakespeare, Twelfth Night, II, 3,45-47.

(3) A. Pope, the Rape of the Lock, II, 65-66.

(4) W. Shakespeare, The Werchant of venice, III, 2,67-72.

(5) Lord Tennyson, The splendour falls on castle walls.

(6) George Meredith, Song in the Songless. 
In these lines there is a marked contrast between the sounds describing the dying and those describing the living echoes:

0 love, they die in yon rich sky, They faint on hill or field or river;

Our echoes roll from soul to soul, And grow for ever and ever.

Similarly it is used, often in association with $i$ : or $e i$, to suggest white light, radiance, or paleness:

Slowly, silently, now the moon

Walks the night in her silver shoon;

This way, and that, she peers, and sees

Silver fruit upon silver trees;

One by one the casements catch

Her beams beneath the silvery thatch; (2)

I saw pale Kings and Princes too,

Pale warriors, death-pale were they all;

They cried - La belle Dame sans lerci

Thee hath in thrall!" (3)

The longer vowel $i$ : is frequently associated with $i$.

The difference between the tone-colour of the two arises chiefly from the difference between their lengths; while the greater duration of the former makes it less suited than the latter to the description of short forms, it also gives it a stronger colour. It has a clear ring and often describes music:

We are the music-makers

And we are the ereaners of arearas,

wandering by lone sea-breakers,

Anả sitting by desolate streams; -

(i) Alfred, Lord Tennyson, The splenaour falls on castle walls.

(2) W. de la Mare, Silver.

(3) J. Keats, La Belle Dame sans Merci. 
World-losers and world-forsakers,

On whom the pale moon gleams:

Yet we are the movers and shakers

of the world for ever, it seems.(1)

Nine bean rows will I have there, a hive for the honey bee, And live alone in the bee-loud glade. (2)

She roams maternal hills and bright,

Dark valleys safe and deep;

Into that tender breast at night

The chastest stars may peep.

She walks - the lady of my delight -

A shepherdess of sheep. (3)

The same vowel, like ei:, expresses freshness and purity:

When I did wake this morn from sleep,

It seemed I heard birds in a dream;

Then I arose to take the air -

'ihe lovely air that made birds scream;

Just as a green hill launched the ship

of gold, to take its first clear dip. (4)

As the passages used to illustrate the colour of $\mathrm{e} i$ : show, it may also be associated wi th this diphthong in the description of coldness; but here it suggests coldness and barrenness without any support from ei: :

How like a winter hath my absence been

Hrom Thee, the pleasure of the fleeting year! What freezings have I felt, what dark days seen, what old December's bareness ever ywhere! (5)

Perched on my city office-stool

I watched wi th envy, while a cool And lucky carter handled ice...

ind I was wandering in a trice,

(1) A.w.E. O'Shaughnessy, Ode.

(2) V.B. Yeats, lhe Lake Isle of Innisfree.

(3) A. Meynell, The Shepherdess.

(4) W.H. Davies, Early Iiorn.

(5) W. Shakespeare, How like a winter hath my absence been. 
Far from the gray and grimy heat

Uf that intolerable street

o'er sapphire berg and emerald floe,

Beneath the still, cold ruby glow

Of everlasting Polar night

Bewildered by the queer half-light,

Until I stumbled, unawares,

Upon a creek where bio white bears

Plunged headlong down with flourished heels,

And floundered after shining seals

Through shivering seas of blinding blue.(I)

The coldness it helps to describe may be metaphorical rather than

literal. In the next passages, as in many others, although the other

dominant vowels are almost as frequent as it, they are so few that $i$ :

rings out very clearly. The effect is to be compared to that of a

texture where a few distinguishable colours rise out of a neutral

background rather than to that of a "mixture" where a greater number

of closely interwoven colours tend to merge into a single general

impression. The coldness of desolation is described in:

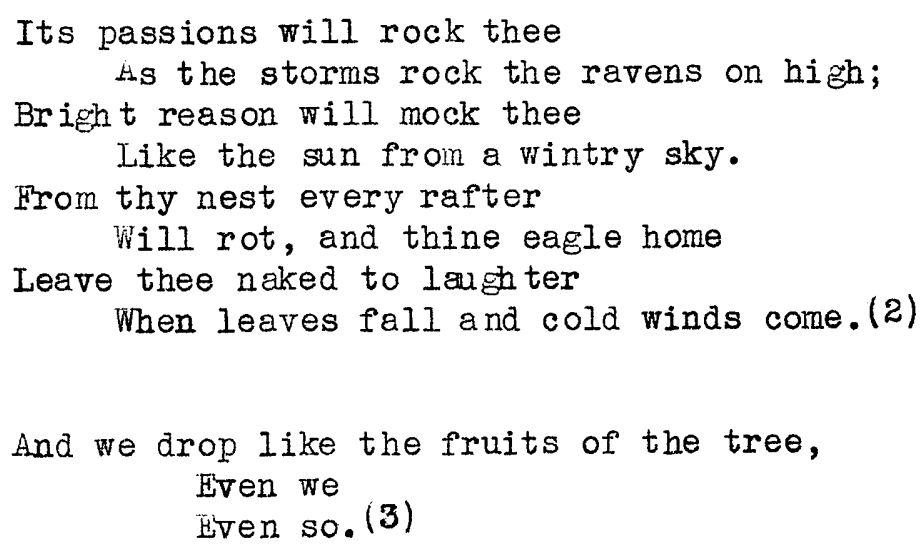

(1) W.W. Gibson, Ice-cart.

(2) P.B. Shelley, ihe Flight of Love.

(3) G. Meredith, Dirge in Woods. 
Yet in a different texture $i$ : can be gay. It would seem, indeed, although its range is not unlimited - it would be powerless, for instance, to suggest strugsle and turmoil - that it can be the symbol of a number of contradictory feelings. Lxamined more closely, however, the contradiction is only apparent, for the fundanental power of $i$ : is not so much to define a feeling as to suggest it is unmixed and keen. Ihus in these passages it helps to suggest, not the desolation and sadness it suggested in previous passages, but security and happiness:

Diaphenia, like the spreading roses, ihat in thy sweets all sweets encloses, Fair sweet, how 1 do love thee!(I)

So long as men can breathe, or eyes can see, So long lives this, and this gives life to thee. (2)

It can aid in the description of beauty that is bright, clear, and serene:

And moveless fish in the water gleam, By silver reeds in a silver stream. (3)

A bow-shot from her bower-eaves, He rode between the barley-sheaves, The sun came dazzling thro' the leaves, And flamed upon the brazen greaves of bold Sir Iancelot. A red cross knight for ever kneel'd To a lady in his shield, That sperkled on the yellow field, Beside remote Shalott. (4)

(I) H. Constable, Diaphenia.

(2) W. Shakespeare, Shall I compare thee to a summer's day?

(3) W. de la Mare, Silver.

(4) Lord Tennyson, The Lady of Shalott. 
The serenity is nore spiritual in these lines:

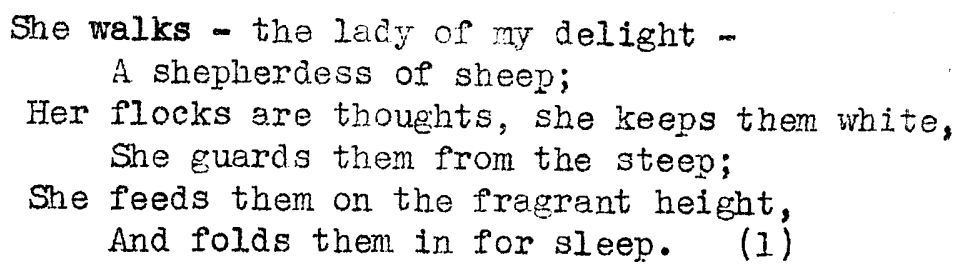

\section{The Introduction of Contrast.}

A poem containing only front or only back vowels could not exist since it would be impossible for its author to express himself adequately without using words in which contrasting vowels appeared. Even if not impossible, artistically it would be a mistake, for its music would be monotonous. Artistry as well as necessity, then, decrees that in every good poem, as in every good picture, there should be an element of contrasting colour. Usually this appears, subdued but persistent, throughout the whole texture. Sometimes, however, the contrast is so strong and so sustained tbat it introduces a new "unit" dominated by the contrasting vowels; if there are more than two units, their succession may follow such a. regular pattern that it helps to build the structure of the poem. The contrast, for instance, between the back vowels in the last line of this verse and the previous front vowels is important, not only because it has the effect of throwing the birds chorus into relief, but also because, being repeated in the same line of every verse, it serves to bind them all nore closely together: Spring, the sweet Spring, is the year's pleasant king; Then blooms each thing, then maids dance in a ring,

(1) A. Ifeyne11, The Shepherdess. 
Cold doth not sting, the pretty birds do sing, Cuckoo, jug-jug, pu-we, to-witta-woo:

Wven when the contrasting unit is not identical in all the verses, its effect may be comparable to that of rhyme, for its recurrences may resemble each other more than any other parts of the poem do and they may be placed at regular intervals and in parallel positions. A more sensitive use of tone-colour is, however, to be heard when the meaning undergoes more subtle changes. In the next poem the front vowels in the first four lines of the first verse and also in the first two lines of the second help to suggest the thinness and clearness of the horns of Elfland, whereas the back vowels in the third and fourth lines of the second verse help to suggest the richness and solemnity of the echoes of humanity. In the first part of the fifth and sixth lines of each verse, beck vowels describe the full notes of the bugle sounding at the poet's side; but in the second pert of the lines, front vowels describe the faint echo from the other side of the glen. The alternation is thus structural as well as expressive of changes in meaning.

O hark, O hear: how thin and clear, And thinner, clearer, farther going:

0 sweet and far from cliff and scar, The horns of Elfland faintly blowing:

Blow, let us hear the purple glens replying: Blow, bugle; answer, echoes, dying, dying, dying.

0 love, they die in yon rich sky, They faint on hill or field or river:

(1) T.Nash, Spring. 
Our echoes roll from soul to soul, And grow for ever and for ever. Blow, bugle, blow, set the wild echoes flying, And answer, echoes, answer, dying, dying, dying. (1)

Within any unit there may be single phrases of vividiy contrasting colour. The back vowels in the last line of the next illustration help to convey the impression of the sea-beasts sinking down into their heavy pasture ground:

\footnotetext{
Sand-strewn caverns, cool and deep,

Where the winds are all asleep;

Where the spent lights quiver and gleam;

Where the salt weed sways in the stream

Where the sea-beasts rang'd all round

Feed in the ooze of their pasture ground.
}

In these lines the merman's sorrow and his desire to go down to the depths of the sea are suggested by back vowels, while the contrasting phrase contains front vowels which make the little grey church stand out, clear and cold:

Come, dear children, come away down: Call no more!

One last look at the white wall'd town,

And the little grey church on the windy shore, Then come down.

She will not come though you call all day, Come away, come away. (3)

Hollow, back vowels help to describe the low passage through which Porphyro creeps, while clear, front vowels suggest the cold silence of the room into which he emerges:

(1) Alfred, Lord Tennyson, The splendour falls on castle walls.

(2) M.Arnold, The Forsaken Wierman.

(3) Ibid. 
He follow d through a lowly arched way, Brushing the cobwebs with bis lofty plume;

And as she mutter'd 'Well-a-m--well-a-may!"

He found him in a little moonlight room

Pale, latticed, chill, and silent as the tornb.

The contrasting phrase nay owe its beauty less to its suggestive power than to tts sheer music; for example, if thin, front vowels are substituted for the resonant, back rowels of "Mount Abora", the magic fades:

A damsel with a dulcimer In a vision once I saw: It was an kbysinian maid, And on her dulcimer she played, Singing of liount Abora.

\section{The Combination of Vowel Sounds and Consorants.}

An unnatural divorce has been made between the tone-colour of consonants and that of vowels but, though a necessary, this must be only a temporary expedient. Some aspects of the relationship between the two have, indeed, al ready been illustrated. It has been shown how a high proportion of vowels, especially of long vowels, to consonants makes a poer melodious and suggests ease and fluidity, whereas a high porportion of consonants to vowels, a low proportion of long to short vowels, and the presence of a number of consonantal clusters combine to suggest obstructions and difficuities, tefin, the tone-colour of some consonants

(1) J.Keats, The tive of St. Agnes, XIII.

(2) S.T.Coleridge, Kubla Khan. 
and some vowels was shown to be particularly susceptible to the colour of the consonants and vowels with which they are associated. Another obvious relationship is to be seen in such a passage as the following, where the complement of a vowel sequence which is less rich in tone than one might have expected is a consonantal sequence which is unusually rich:

Make me a willow cabin at your gate, And call upon my soul within the house; Wirite loyal contons of contemned love And sing them loud even in the dead of night; Halloo your name to the reverberate hills, And make the babbling gossip of the air Cry out "Olivia".(I)

The comparative thinness of $e i$ : and $i$, which form the vowel theme, is compensated by the fullness and richness of 1 and $n$, which form the consonantal theme.

The strongest tone-colours are composed of dominant vowels and consonants which arouse the same feelings independently of each other. Thus liquids, nasals, and back vowels, more naturally than any other combination, suggest richness of sound, colour, or scent, oppressive heat, numbing cold, and, more metaphorically, acquiescence and passivity:

And call the vales and bid them hither cast Their bells and flowerets of a thousand hues, Ye valleys low, where the mild whispers use Uf shades, and wanton winds, and gushing brooks, On whose fresh lap the swart star sparely looks, Throw hither all your quaint enamell'd eyes That on the green turf suck the honey'd showers And purple all the ground with vernal flowers. (2)

(1)W. Shakespeare, Twelfth Night, 1,5,289-295.

(2) J. Milton, Lycidas. 
The coming musk-rose, full of dewy wine, 'lihe murmurous haunt of flies on summer eves. (1)

As when, upon a trancèd surmer-night, Those green-rob'd senators of mighty woods, liall oaks, branch-charmed by the earnest stars Dream ..... (2)

At the other extreme is a texture mainly composed of voiceless continuants, stops, and front vowels. Instead of passivity or richness, these suggest fierce activity, clanging noises, or barrenness:

With greedy force each other doth assayle And strike so fiercely that they do impresse Deep dinted furrows in the battred mayle. (3)

As for the grass, it grew as scant as hair In leprosy; thin dry blades pricked the mud Which underneath looked kneaded up with blood. (4)

Since the back vowels are not only back but, with the exception of $a:$, round, the first texture is also the natural medium for the description of rounded, lovely forms and the expression of love itself:

The lovely moon: - her soft light falling

lightly on roof and poplar and pine Tree to tree whispering and calling, Wonderful in the silvery shine of the round, lovely, thoughtful moon. (5)

She whom I love is hard to catch and conquer, Hard, but 0 the glory of the winning were she won:(6)

Similarly, since the unrounded vowels, except for the addition of the

(1) J. Keats, Ode to a Nightingale.

(2) J. Keats, Fyperion, I,72-75.

(3) E..Spenser, The Faerie queene, I,5,VI.

(4) R. Browning, Childe Roland to the Dark Tower Came.

(5) J. Freeman, It was the Lovely Moon.

(6) G. Meredith, Love in a Valley. 
comparatively colourless "mid" group, are the same as the front vowels, the second texture is the natural medium for the description of pointed, unlovely forms and for the expession of hatred and scorn:

And eke the pennes that did his pineons bynd, Were like mayne-yardes with flying canvas lynd. (I)

Higgledy piggledy, packed we lie, Rats in a hamper, swine in a stye, Wasps in a bottle, frogs in a sieve, Worms in a carcase, fleas in a sleeve. Hist: square shoulders, settle your thumbs And buzz for the bishop - here he comes. (2)

A second musical combination is that of long vowels with nasals, liquids, and voiced continuants, the combination which most easily suggests greatness, of time or space or spirit:

One moon, with alternations slow, had shed Her silver seasons four upon the night And still these two were postured motionless. (3)

Mighty Prophet: Seer blest:

On whom those truths do rest Which we are toiling all our lives to find, In darkness lost, the darkness of the grave; Thou, over whom thy Immortality Broods like the Day, a liaster o'er a Slave, A Presence which is not to be put by; (4)

In contrast to this texture, the association of short vowels with voiceless continuants and stops suggests shortness in space or time, slightness, or insignificance:

(1) E. Spenser, The Faerie queene, $I, 11, X$.

(2) R. Browning, Holy-Cross Day.

(3) J. Keats, Hyperion, I,83-85.

(4) Wordsworth, Ode on Intimations of Immortality. 


$$
\begin{aligned}
& \text { Time, you old eipsy man, } \\
& \text { will you not stay, } \\
& \text { Put up your caravan } \\
& \text { Just for one day? }
\end{aligned}
$$

Gums and pomatums shall his flight restrain, While clogged he beats his silken. wings in vain; Or alum styptics with contracting power Shrink his thin essence like a rivelled flower.

The vowel and consonant combinations so far illustrated have been two varieties of rich textures with the opposite of each. Nothing richer could exist unless both varieties were combined in one, unless, that is to say, the dominant vowels of a liquid-nasal texture were not only back but also long; and owing to the comparative infrequency of long back vowels in the language, it would be difficult to weave more than a line or two of such a texture. Wany intermediate textures, all with distinctive tonemcolours, exist between the two contrasting members of each pair of textures. Thus, when liquids and nasals are combined not with back but with front vowels, neither richness nor barrenness is normally described; such a combination is a natural vehicle for the description of fadine colours and slight, though not sharp, sounds:

Now fades the glimmering landscape on the sight, And all the air a solem stillness holds,

Save where the beetle wheels his droning flight, And drowsy tinklings lull the distant folds.
(1) R.Hodgson, Time, you old gipsy men.
(2) A.Pope, The Rape of the Lock, II, 129-132.
(3) M. Arnold, Sohrab and Rustum, 129-130.
(4) T. Gray, 列egy written in a Country Church-yard. 
In comparison with textures where the vowels are rounded, this texture expresses a love which has less hope of fulfilment; when $a \dot{i}$ : and $i$ : are frequent, there is a strong undercurrent of pathos:

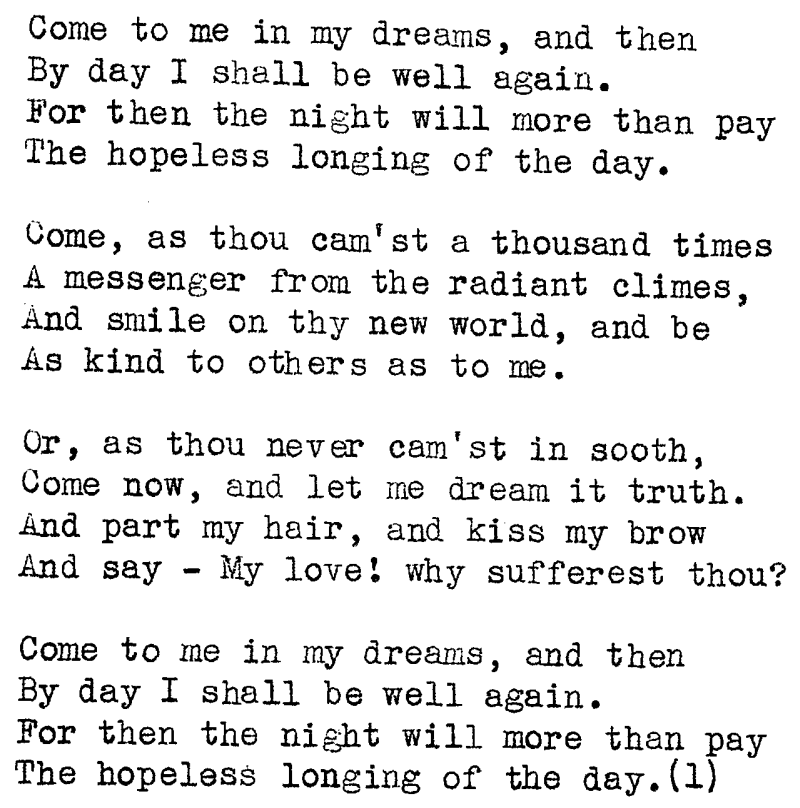

On the other hand, when voiceless continuants and stops are associated not with front but with back vowels, the effect is, if not richly melodious, yet not metallic:

'I'hou watchest the last oozings hours by hours. (2)

The same combination tends to describe appearances which, if heavy and unlovely, have yet a certain richness:

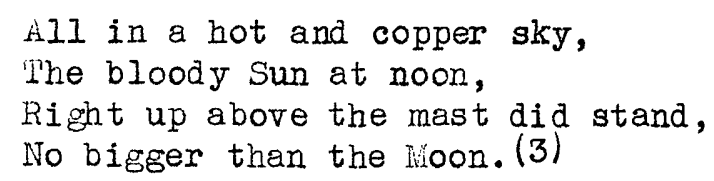

(1) H. Arnold, Longing.

(2) J. Keats, ode to Autumn.

(3) S.T. Coleridge, the Ancient Wariner, 111-114. 
A texture composed mainly of liquids, nasals, and short vowels, which is intermediary between the members of the second pair of contrastingtexturesprovides a fitting instrument for the description of small things which are delicate rathe $r$ than trivial:

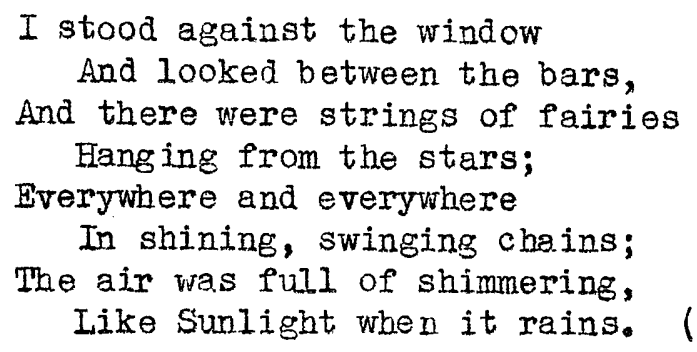

The opposite intermediary texture, that woven of stops and long vowels, can be at least as beautiful, if it is enriched by a nasal or liquid tronead:

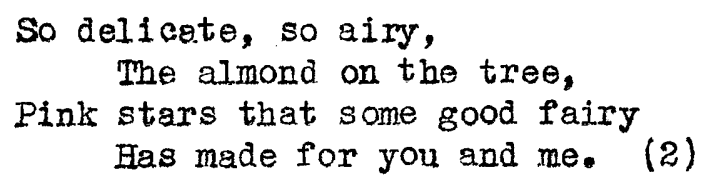

When the rhythm is slower, the stops tend to suggest determination and finality:

When I have seen by Time's fell hand defaced

The rich proud cost of out-worn buried age; When sometime lofty towers I see down-razed, And brass eternal slave to mortal rage.

When the proportion of consonants to vowels is higher, however, the same combination of sounds can suggest obstruction and difficulty:

(I) R.Fyleman, I stood against the window.

(2) K.T.Hinkson, Pink Almond.

(3) W. Shakespeare, When I have seen by 'Time's fell hand defaced. 
Ihrough many a dark and dreary vale

They pass'a, and many a region dolorous.

o'er many a frozen, many a fiery Alp,

Rocks, caves, lakes, fens, bogs, dens and shades of death. (I)

\section{Conclusion.}

'Ihus the tone-colour of vowels, like that of consonants, varies within a wide range and has many shades. Yet, if any exhaustive attempt to classify its shades would therefore be so futile as to be ridiculous, this does not depreciate the value of tone-colour as a poetic instrument but rather makes it all the more valuable because all the more sensitive. It was, however, decided not to carry the examination of consonants any farther. Their contribution to the sound of a poem and to its effect had been shown to be vital: the degree of tone in a poem largely depends on what their numerical strength is in comparison with that of the vowels; and their tone-colour is a potent influence in the communication of the meaning. Nevertheless, this having been admitted, the problem of their contribution seemed to have been carried as far as it profitably could, whereas the problem of the vowels teased one into farther thought. The old Jewish theologians, commenting on the omission of vowels from Hebrew script, made a comparison which, applied to the sound of words, is, if exaggerated, highly suggestive. 'lo them the consonants were the body and the vowels the soul. Hegarded also from a less mystical and more scientific point of view, the vowels are of greater importance: they are on an average ten times as Iong as the

(1) J. Milton, Paradise Lost, II, 618-62I. 
(1)

(2)

consonants and they are much more powerful, facts which more than

counterbalance the numerical preponderance of consonents in words.

The strongest incentive to a closer examination of them, however, lay

in the growing conviction that, less noisy than consonants and approach(3)

ing pure tone more nearly, they bear towards aach other a musical re-

lationship which is nonethe less definite because difficult to analjse.

One seemed to be on the brink of discovery. The elusive secret of the

music of poetry seemed at last to be within grasp.

Two lines of investigation were pursued concurrently but independentiv of each other. Firstiy, the estimation of the rowel sequences of poems was steadily continued. The method of estimating these was re-examined and minor inconsistencies were eliminated; $\quad$ a detailed account of this being given in the next chapter. Secondly, a search, later described in Volume IV, Chapter 1, was made for information about the precise nature of vowel sounds.

(1) R.M.Ogden, Hearing, p.22I, quotes Iarage (Comptes Rendus Academie des Sciences, CIXXXII, pp.1265-1267, 1911) to this effect.

(2) D. Jones, English Phonetics, pp.23-24, and E.A.Sonnenschein, ihat is Rhythm? p.24. Later, further confirmation was found in Sir Richard Paget's Human Speech, p.38 and p.124, I.B.CrandeII's The Sounds of Speech (Bell System Technical Journal, IV, p.616, 1925), C.F. Sacia and C.J.Beck's The Power of Fundamental Speech Sounds (Bell System Technical Journal, $V, p .401,1926)$, and HoFletcher's Speech and Hearing, p.74.

(3) R. M. Ogden, Op.cit., p.206, contrasts the noise of consonants with the resonance of vowels. I.E.Crandall's analyses, which were not discovered until later, show that consonants are more confused than vowels because they have a greater number of strong components. 
III. THE SIGNIFICANCE OF THE PHONETIC SYMBOLS.

No. of

Page

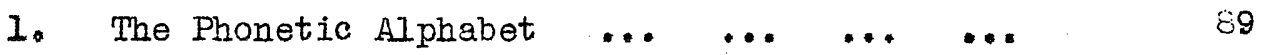

2. The Relative Strengths of Vowel Sounds

a) The Influence on Relative Strengths of Sentence Stress and of Pauses..

b) Relative Strengths expressed Numerically

3. The Reduction of Vowel Sounds

a) Unimportant words ... ... ... ... $\quad 101$

b) Prefixes and Suffixes ... ... ...

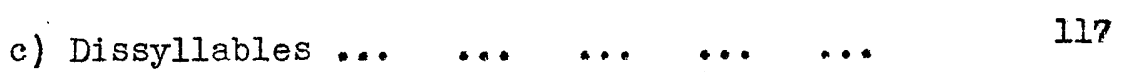

d) Trisyllables and Polysyllables ... ... I27

4. The Effect of Metres other than Double Metres on the Reduction of Vowel Sounds 
III. THE SIGNIFICANCE OF THE PHONETIC SMMBOLS.

1. The Phonetic Alphabet.

The alphabet adopted is that of the International Phonetic Association, which is used by Professor Daniel Jones in his books on phonetics and in his English Pronouncing Dictionary. This system of symbols had, however, to be slightly expanded because the sounds it was to represent are more carefully enunciated than those of ordinary conversation, which the E.P.D. symbols represent. The vowels for which modified signs had to be found were mainly those of unstressed syllables (1)

which as Professor Jones and the editors of the Oxford English

(2)

Dictionary are agreed, retain more of their full quality in careful speech than in conversation. In an attempt to represent the sounds of careful speech, the O.E.D., besides the long (e.g. $\bar{U})$ and the "ordinary" (e.g. $\omega)$ form it gives for most vowel sounds, also gives an "obscure" (e.g. form for those reduced sounds most of which the E.P.D. flattens into $\dot{\theta}$. No method of treating these reduced vowels could have vitally affected the analyses of poems; but for the sake of consistency and accuracy some method of treating them had to be adopted. Accordingly it was decided to accept the O.E.D. "obscure" sounds and to represent them by $\dot{e}, \dot{b}, \dot{u}$, etc., that is by E.P.D. symbols modified in such a manner a.s to make them equivalent to the O.E.D. "obscure" symbols. Even in verse, on occasions when their stronger forms are not among the dominant group of vowels, such sounds may sink beyond "obscurity" into $\partial$; but, although they may not be longer than the neutral $\theta$, low vowels in a low unit or high in a high should always retain something of their own quality.

(1) The Pronunciation of English p.47, 1909.

(2) O.E.D., p.XXIV. 
If on the one hand verse has the effect of preventing

unstressed sounds from always becoming nondescript in quality, yet on the other hand, since its metrical stress reinforces accent, it has also the effect of reducing the comparative strength of those long vowels which are both unaccented and unstressed. Thus symbols such as $u$ : and ái: indicate fully stressed, long vowels in accented syllables, whereas ul(:) and aif) indicate rowels which, differing from the former both because they are shorter and unaccented in ordinary speech and also because they are unstressed in verse, hove half their total strength. The E.P.D. symbols show that the same reduction sometimes takes place in ordinary, non-metrical speech: the $e$ and $\partial$, which are the vowels of entrance, become $i\left[e^{\left(\frac{1}{)}\right)}\right.$ and $\alpha$ : in entránce; and the ju: of human is ju as often as ju: in humanity. The effect of metre is to increase the reduction and to make what was a tendency become a rule, so that, in verse, not only is the E.P.D. $u$ : or $u$ of frugality definitely reduced to the sound represented in this investigation as $u(:)$ and the $0:$, 0 , or of authority definitely reduced to $\%(:)$ but the $c:$ of barbarity is reduced to $a(:)$ and the $j u$ : of virtue to jul:)

The E.P.D. system uses : the symbol for length, only when, as in $u:$, it is necessary as a means of preventing confusion between a long and a short vowel; it therefore only occasionally uses it for diphthongs. In this investigation, however, since it offers a means of distinguishing between strong and reduced forms, the symbol is used for all diphthongs and long vowels.

(1) Square brackets in the E.F.D. enclose less frequent sounds. 
The attribution to long vowels and diphthongs of twice the (1)

length of short vowels is accepted here. Admittedly, the comperison is only approximately true: variations in length exist between members of both the lone and the short group and also between occurrences of the same sound, whether long or short, in different woras. Yet it is possible that, in verse, the metre has an equalizing influence and the variations are even slighter than in prose. Whether this is true or not, it is certain that, in view of the use to which it is put, the generalization is accurate enough to warrant its acceptance here. And without its acceptance such endless complications would have arisen that the Whole of this investigation. would have been rendered impossible.

\begin{tabular}{|c|c|c|c|}
\hline Key Words. & O.E.D.Symbols & E.P.D.Symbols & $\begin{array}{l}\text { Symbols adopted } \\
\text { for the vowels } \\
\text { in verse. }\end{array}$ \\
\hline two & $\bar{u}$ & u: & ú: \\
\hline frugality & $u$ & $u:, u$ & $u(:)$ \\
\hline together & $\check{u}$ & $\partial[u]$ & $\dot{u}(:)$ \\
\hline full & u & $\mathfrak{u}$ & $\dot{u}$ \\
\hline beautifull & u & $\theta[u]$ & $\dot{u}$ \\
\hline few & $i \bar{u}, ' i \tilde{u}$ & ju: & jú: \\
\hline virtue & $i k$ & ju: & $j u(:)$ \\
\hline circular & $i \check{u}$ & $j u, j \theta$ & $\dot{j u}(:)$ \\
\hline pure & $i \bar{u}, i \bar{u}$ & juv & júə: \\
\hline duration & iu & juə, jov & juo(: : \\
\hline verảure & iü & $\partial$ & juә(: ) \\
\hline poor & $\bar{u}\left(\bar{u}^{\partial}\right)$ & uə & úə: \\
\hline so & $\bar{O}\left(\bar{D}^{\omega}\right)$ & ou & óu: \\
\hline
\end{tabular}

(1) Lascelles Abercrombie, Principles of English Prosody, p.81, and E.A. Sonnenschein, What is hhythm? p.218.

(2) Cf. p.100, footnote (2). 


\begin{tabular}{|c|c|c|c|}
\hline Key Words. & O.E.D.Symbols. & E.P.I.Symbols. & $\begin{array}{l}\text { Symbols adopted } \\
\text { for the vowels } \\
\text { in verse. }\end{array}$ \\
\hline hero & 2 & ou & ou(: $)$ \\
\hline violet & 0 & $\theta[0]$ & ou $(:)$ \\
\hline a)got, b) what & a) $0, b)$ & 0 & ó \\
\hline connect & 0 & $\theta[0]$ & $\dot{0}$ \\
\hline 이1 & $0 i$ & oi & ói: \\
\hline a) thorn, b) author & a) $\overline{0}, b) \bar{o}$ & $0:$ & ó: \\
\hline Quthority & 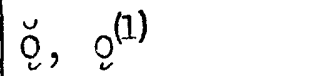 & $0:[0,0]$ & $o(:)$ \\
\hline forget & 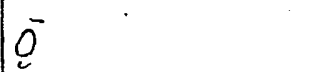 & $\theta[0]$ & $\dot{o}(:)$ \\
\hline core & $\bar{O}\left(\bar{o}^{2}\right)$ & $0:[0 \partial]$ & อ́ə: \\
\hline therefore & $\emptyset^{u}, \theta$ & $\partial:[0 \theta]$ & $\partial \theta(:)$ \\
\hline a) pass, b) alms & a) $a, b) \bar{a}$ & $a:$ & á: \\
\hline barbarity & $a$ & $\alpha:$ & $a(:)$ \\
\hline nectar & $\check{a}$ & $\theta$ & $\dot{\mathrm{a}}(:)$ \\
\hline Ioud & au & au & áu: \\
\hline foundations & au & au & $\operatorname{au}(:)$ \\
\hline lower & $\operatorname{au} \theta\left(a u^{2}\right)$ & aur & áuə: \\
\hline cunt & D & $\Lambda$ & $\hat{\Lambda}$ \\
\hline datum & b̆ & $\theta$ & $\dot{\Lambda}$ \\
\hline (a) curl, b) fir & a) $\overline{0}, b) \bar{a}$ & $\partial:$ & ó: \\
\hline surmise & $-0, \bar{D}$ & ə: & $\theta(:)$ \\
\hline shepherd & $\theta$ & $\theta$ & $\dot{\partial}(:)$ \\
\hline ever & $\theta$ & 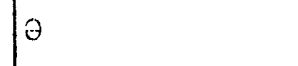 & a \\
\hline a) bind, b) aye & (a) ai, b) ai & $2 i$ & éi: \\
\hline
\end{tabular}

(1). The symbol given for the vowel in the list of key words differs

(2) from that given in the dictiona
Cf. p. 1,8 and Vol. IV, p. 18 . 


\begin{tabular}{|c|c|c|c|}
\hline Key Words. & O.E.D.Symbols. & E. D. Symbols. & $\begin{array}{l}\text { Symbols adopted } \\
\text { for the vowels } \\
\text { in verse. }\end{array}$ \\
\hline daylight & $0 \mathrm{i}$ & $a . i$ & eil $(:)$ \\
\hline fire & $\partial \dot{i}^{2}$ & ait & sio: \\
\hline$\underline{\operatorname{man}}$ & $æ$ & $æ$ & $\ddot{x}$ \\
\hline a) amoeba, b) accept & a) $\breve{a}$, b) $\breve{æ}$ & $\theta$ & $\dot{\ddot{ }}$ \\
\hline there & $\bar{e}\left(\bar{e}^{a}\right)$ & $\varepsilon_{\partial}$ & $\varepsilon$ દ́: \\
\hline therein & $\bar{e}\left(\bar{e}^{\partial}\right)$ & $\varepsilon \theta$ & $\varepsilon \theta(:)$ \\
\hline bet & e & e & é \\
\hline moment & e & a & $\dot{e}$ \\
\hline rein & $e\left(e^{-i}\right)$ & ei & éi: \\
\hline survey & $e$ & ei & ei(:) \\
\hline separde te & $e^{u}$ & $i$ & $\dot{e} i(:)$ \\
\hline sit & i & i & $i^{\prime}$ \\
\hline bier & $i\left(i^{\partial}\right)$ & ie & $i^{\prime}=$ \\
\hline thief & $i$ & i: & í: \\
\hline Psyche & $i$ & $i:, i$ & $i(:)$ \\
\hline regard & $i$ & i & $\dot{i}(:)$ \\
\hline
\end{tabular}

Notes.

1). All the unreduced rowel sounds appear in this list. If a few of the less common reduced forms are omitted (sapphire, for Instance, contains aio(:) and rhomboid oi(:) ), these can easily be 
deduced from the forms which appear. The only vorels wich have no dotted or obscure form in the analyses are $\partial$ and $i$. Since the virtue of a dotted form is that it marks a point where something of the vowel's characteristic quality emerges out of the neutral $\theta$, a dotted form for $\theta$ would be meaningless; and if it were not so, it would differ in quantity so little from ordinary $\theta$ that, as with other dotted forms, it would be considered possible, without any appreciable inaccuracy, to give the two sounds the same numerical relative strength. Similarly such sounds as "ity" are not represented by an $i$ form because $i$, unlike the other short vowels, is never reduced to $\partial$ in the E.P.D.

(2). The O.E.D. distinctions between $a$ and $a, \ddot{a}$ and $\ddot{a}$, $Q$ and $\mathcal{V}, \bar{O}$ and $\bar{O}, \bar{D}$ and $\partial, \partial \dot{i}$ and $a \dot{i}$, are neglected because the E.P.D. neglects them. Professor Jones expressly states that, except in (2) diphthongs, a does not exist in the type of speech he describes. (3). On the other hand, since the vowels of con and for are 0 and 0 : respectively, a distinction is made here between the rowels of the first syllables of connect and forget, the first being represented by $\dot{j}$ and the second by $\zeta(:)$. Yet it is doubtful if there is actually any difference between these sounds or between $\dot{u}(:)$ and $u, \dot{d}:)$ and $\theta$, $i(:)$ and $i$. Certainly the question is quite immaterial, for in the last stages of the analyses, when the vowels are classified into the three (3) main groups, high, low, and common, no distinction is made between the different vowels composing each group.

(I) V. p. 100 for numerical relative strengths.

(2) English Phonetics, p.102. For his substitation of al for au in his later books vide. pol. IV, p. 18.

(3) V. Vol. IV, Chapter III. 
2. The Relative Strengths of Vowel Sounds.

a). The Influence on Relative Strengths of Sentence Stress and of Pauses.

Since the "strength" of a vowel sound, like that of a syllable, is a composite measure embracing both stress and length, rowels are measured by a system which closely resembles that used for (1)

the measurement of syllables. The symbols employed in the two systems are, however, not identical. The fundamental differences are two: in the measurement of vowels, firstly, the $x$ of unstressed syllables is omitted entirely; and, secondly, the symbol : replaces the - of long syllables, its absence after an unreduced vowel being sufficient to indicate that the sound is by nature short. Thus if á: and $\dot{\&}$ are taken as typical unreduced vowels, their different strength values (which, owing to the additional factor of metrical stress, are more in number than those tabulated in the last section for the vowels of ordinary speech) are, in decreasing order, $\dot{d}:$ and $\dot{\gtrless},(\hat{d})$ and $\stackrel{(v)}{\gtrless}, a(:)$ and $æ, \dot{d}(:)$ and $\dot{\gtrless}$. The first pair of sounds have full length but only medium stress; the second pair fall in metrically stressed positions but, although the mind hovers on them for a fraction of a second, they cannot actually carry metric stress; for they have no sentence stress; the third pair have half their full lengths and no stress; and the fourth pair are still further reduced in both directions. The sounds 2 and $a(:)$ have the same strengths, the former, in comparison with the latter, gaining in stress what it loses 
in length.

Since, therefore, vowels like syllables cannot have full strength unless they are stressed, strong vowels normally belong, in a rising metre, to the last syllable of each foot, and in a faling metre, to the first. The rhythmic modification of the metric norm, however, affects vowels as much as syllables. Thus not only can a strong or a weak vowel, owing to the presence of a substitution, fall in any position in any foot of any metre, but also the strength of vowels, like that of syllables, is modified by the operation of varidus rhythmic princtples (1) involving length and sentence stress.

The first two of these rhythmic principles apply only when the words or syllables concerned have sentence stress. The distinction between words or syllables with and without sentence stress is the result of the fact that even in prose or ordinary conversation strength is affected by sentence stress: when the words are spoken in isolation, the two members of the pairs at and hat, in and win, are and bar, be and see, contain identical vowels, but when they are placed in sentences, the vowel of the first member of each pair is reduced in strength below that of the second because the latter is reinforced by sentence stress and the former is not. In poetry, when metrical stress reinforces sentence stress, the vowels of the second members have full strength while those of the first have at most half strength $(æ, i, a(:), i(:))$. The first principle is that length confers medium stress. When they fall in metrically unstressed positions, hat, bar, etc.,

(I) Cf. p.5 and p.9. 


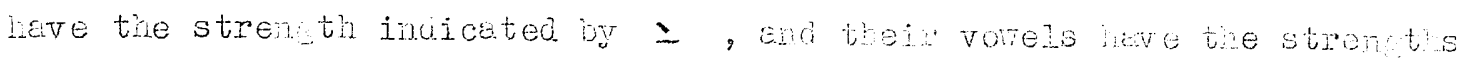
indicated by $\dot{X}$ and $\dot{d}$ : respectively, symbols which indicate strentths

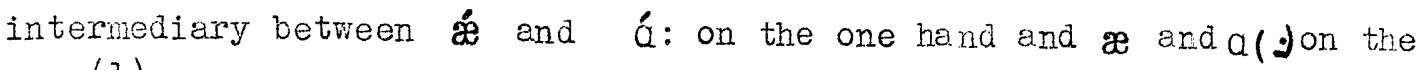
(1) other.

The second principle is that stress increases length. Whereas, however, short syllables in metrically stressed positions derive medium length, so that the first syllable of dojXar and thifcket have the strength indicated by $\leftleftarrows$, the vowels of such syllables, being as long and therefore as strong as in doldrums and thickpess, have the values $\dot{b}$ and $i$ respectively.

The third principle is that lack of sentence stress reduces strength. Unimportant words or syllables, which have little weight in the sentence, are reduced whether or not they fall in metrically stressed positions. It is the operation of this principle which prevents long syllables which are unaccented and therefore devoid of sentence stress from folloving the first principle and deriving medium stress from their length; the lest syllable of incense and that of eglantine. have the strength symbolized by $\underline{x}$ while their vowels are no stronger than $e$ and ai(:) respectively. Again, it is the operation of the same principle which prevents the penultimate syllable of seasonable from

(I) When relative strengths are given numerical values (p.100), æ is classed with ǽ, since, although it is not identical with it, it is nearer $æ$ than $æ$. This is done for the sake of avoiding the introduction of such a small distinction as thet between 1 and $\frac{3}{4}$ and between $\frac{3}{4}$ and $\frac{J}{2}$, a listinction which would have affected the ultimate stages of the analysis but little, and would have complicated the calculations unnecessarily.

(2) Since medium length is judged not to increcse stress just as medium stress is judged not to incresse length, if both syllables of thifcket fel] in unstressed positions (as they might well do in a triple metre) the strength of the pirst syllable mould be symbolized by $\underline{x}$. Its vowel, hovever, would be $i$, just es in a netrically stressed position it would be $i^{\prime}$ 


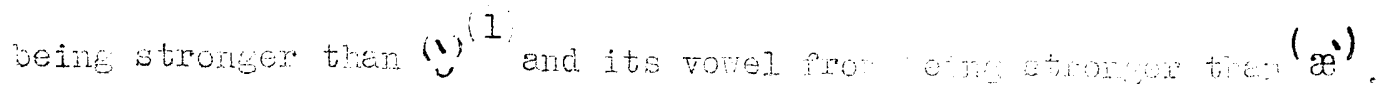
A more usual application of the third principle is to be found, however, not in the prevention of stress and length from mitually influencing each other, but in a more direct reduction of strength in voris and syllables which, having no weight of meaning, are habituelly slurred over. These woris can be classified and a satisfactorily rieid line drawn between them and other words. Hven when they occur in metrically stressed positions, their vowels rarely rise above the (2) strengths indicated by $\ddot{\&}, \dot{d}:$, etc; not infrequentIy they are reduced to ()$,(\mathbb{Q}(:)$, in stressed positions and to $\dot{\otimes}, \dot{\alpha}(:)$, in unstressed. For the sake of consistency in the treatment of them, the degree of reduction the vowels suffer in different circumstances is considered in detail in the third section of this chapter.

The fourth principle, which is unimportant since it affects very few lines, is that exceptionally strong sentence stress increases the strength of a vowel in an unstressed position. Thus in the line And with old woes new wail my dear time's waste the opposition between old and new raises their vowels from ou: and ju(:) to óu: and jú:. Similarly words which are normally reduced may retain full strength: the vowel of my in the first line, although it is an unstressed position, is ai: , that of thy in the second is ái: , and that of not in the second and third lines, although it is in en unstressed position, is $\dot{b}$ :

(1) Cf. p. 10 .

(2) In these reduced words such symbols are more accurately regarded as representing not corposite measures in which the length element is stronger than the stress, but total relative strengths lying between á:, , anc $a(:), \mathscr{Q}$; in fact, both length and stress are reduced. 
With luciry words fevour my destined urn. (-)

But thy eternal sumer shall not fade.

Think not of them-thou hast thy music too.

The fifth principle, which is also of minor importance, concerns the protraction which precedes pauses. Pauses, whether short or lone, protract the vowels of words which have sentence stress, so that they are increased from, for example, æ⿱亠乂 or $\dot{a}$, to $\notin$ or á: (4) Slurred words or syllables need not be affected by this principle: the vowel of me may be $\hat{i}$ : even when it receives metrical stress; and the tabulations of words with more than one syllable, given in the third section of this chapter, show that pauses scarcely affect their reduced vowels.

b). Relative Strengths Expressed Numerically.

The relative strengths of all typical vowels are expressed numerically in the tabulation which follows; those of other vowels can be seen by analogy. The total strength of each sound is given and also the strength of each element of those diphthongs and triphthongs which, in the analyses, had to be broken up.

(I) V. Vol. II No. I 2 .

(2) $\bar{V}$. Vol. II, No. C7l.

(3) $\overline{\mathrm{V}} . \mathrm{Vol}$. II, No. B 62.

(4) $\overline{\mathrm{Cf}}$. p. Il, where syllables precedine a lone pause are judged to be proticated by a quarter of their own length and those preceding a short peuse by an eishth. 


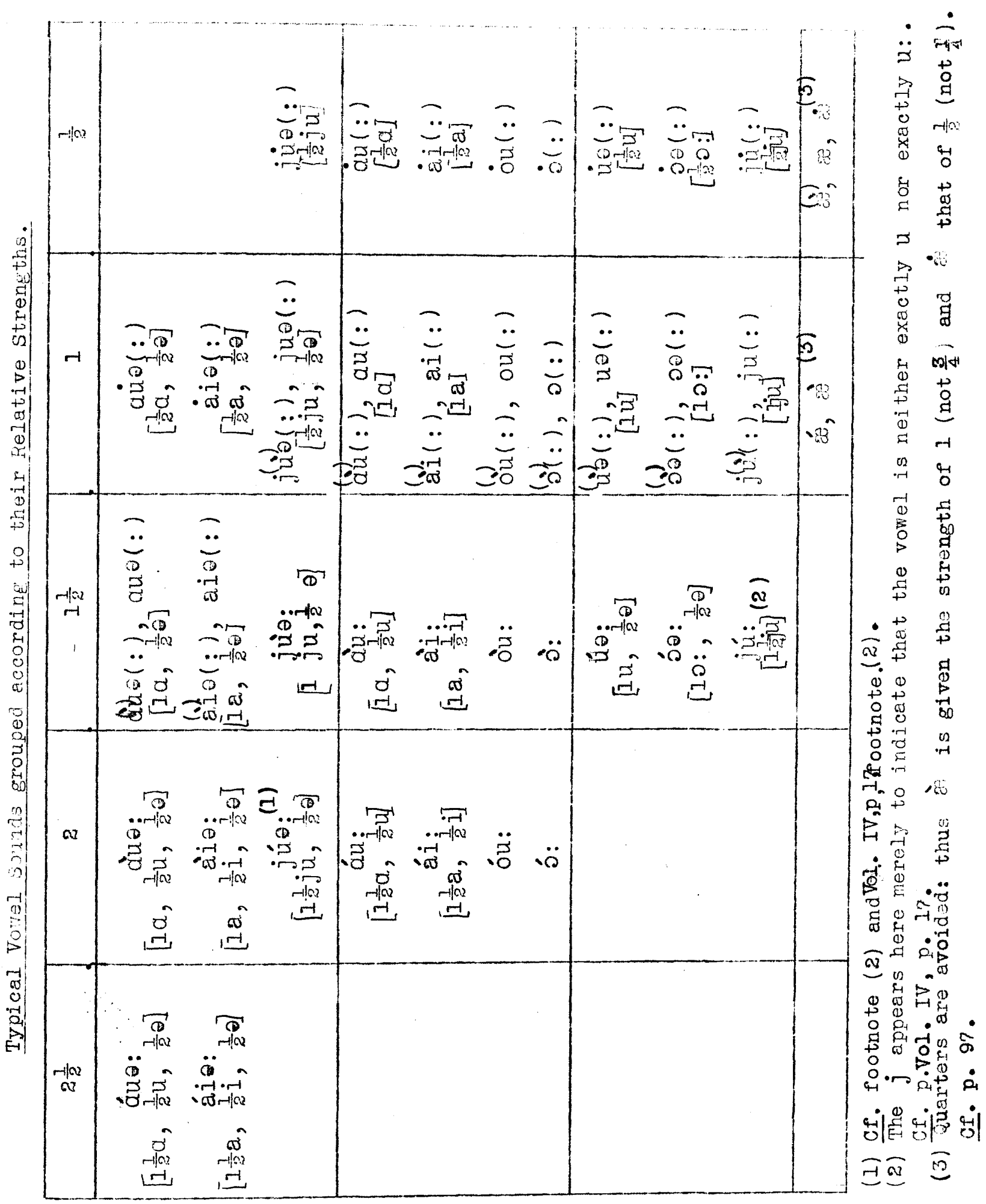


Notes.

1) All the diphthongs except ól: are divided into their component parts because it becomes necessary in the analyses to range each part with the other members of the main group to which it belongs.

2) When two or three symbols appear together in the same column, the strongest is placed first though there is little, if any, appreciable difference between them.

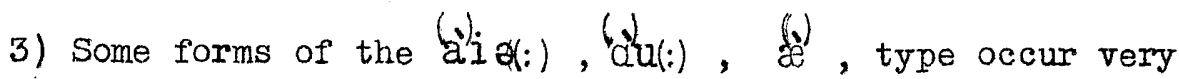
seldom, if ever; but others are common. All such forms represent sounds which are so reduced in ordinary speech that even the incidence of metrical stress cannot make them ài

4) Diphthongs often do not reach the full $i$ or $u$ position of their second element. However, when the second element is not exactly $i$, it is yet a front vowel; and when it is not $u$, it is yet a back vowel. Therefore, in view of the manner in which the sounds are (2) ultimately classified, it is happily safe to disregard any slight dism crepancy between symbol and sound.

\section{The Reduction of Vowel Sounds.}

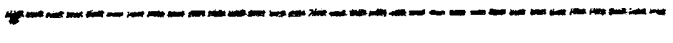

a) Unimportant Words.

To facilitate the process of estimating the degree of reduction effected in different cases, only vowels in the commonest, that is, in double, metres were at first examined; almost without exception, therefore, the examples are taken from poems in which triple feet do not occur even occassionally.

(1) Cf.pp.93-4, the examples from p.1060nwards, and the tabulations from p. 12 Ionwards.

(2) Cf. p.94, footnote (3). 
The vowel sounds in these, unimportant, words iffer from those

examined in the sections on dissylables and triaylables because they are not reduced so automatically as the sounds of unaccented syllables are. Thus, as examples IB.ld.i, IIB.I.i, and IIB.I.ii show for my and thy and I, it is possible for them, probably but not necessarily owing to the incidence of sentence stress, to have the values which the vowels of other words would have in the same circumstances. Yet normally they are reduced, so that the speaker who attempts to give them full strength absurdly mism represents the poet's meaning.

If there are no absolutely hard and fast rules by which the degree of reduction can be determined, yet the following detailed examination of the manner in which such sounds usually behave in typical circumstances will show that something more than the whim of the moment determined the degrees of reduction to which they were subjected in the analyses of poems. For the rest, the degree in which they are reduced actually affects the final result of the analyses but little. The sounds are divided into two main classes each of which is subdivided into A) short vowels, and B) long vowels. The list of words belonging to each subdivision was drawn up after Lycidas and most of the poems in the original Good and Bad groups had been analysed. The two main classes are:

I. Those which the E.P.D. shows are either weakened into $\theta$ or omitted entirely in ordinary conversation. Almost all of these are prepositions, confunctions, pronouns, possessive adjectives, and auxiliary verbs.

II. Those which have not weak forms in conversation but

(1) Some of the words included in the present section are dissyllables, and consequently their unaccented vowels suffer reduction as those of other dissyllables do; but in this section it is their accented vowels whose reduction is examined. 
which are reduced in poetry, where their weakress is increasea by lack of metrical stress. These include the commonest adverbs in addition to less comon examples of words of the same types as those in Class I. The degree of reduction, especially in IIB.I, tends to be rather less than in $I$.

The slurred word often occurs irmediately after the câesura, so that it seerns by its shortness to cornensate for it and thus to restore the metrical time of the line. E.g. IB.2b.iii, IB.2b.iv, IB.2c.ii, IIA.2b.ii.

To facilitate the explanation of the different degrees of reduction which the vowel sounds of these words may suffer, the symbol ' $z$ and its attendant weaker forms are used as generic signs for short vowels, and the symbol 'x: and its weaker forms as parallel signs for long vowels. Such sounds are reduced more in some circumm stances than in others:

1. They tend to be less reduced

a) when they occur before a pause. E.8. IIB.I.viii. In this line were, which is sometimes reduced to $(\vec{E})(:)$, has full strength whereas I is reduced from ail: to ail: ).

b) when the mejority of the stressed syllables in the line contain long vowel sounds. E.g. IB.2b.ii, IIA.2b.i.

c) when they are low sounds and occur in a low unit, or when they are high sounds and occur in a high. E.E. IA.2a.i, IIA.20.i, IIA.2a.i-iii. 
d) When the same sound occurs in other worls in the same Iine. E.... IB.20.ii, IB.2a.ii, IIA.29.ii.

e) when the geteral movencht of the line is slow, it may be because a solerm, weighty, or enphatic statenent is made. E.g. IB.Ia.i. Contrast the movement of IB.le.i with that of IB.Ie.iii and IB.Ie.iv, lines which are taken from the same poem.

f) when in some other less definable way it makes the rhythm of the line more onomatopoeic. E.g. IB.Ic.ii, where he, which might have been reduced to $\dot{i}(:)$ before $x^{\prime}$, remains as $i(:)$ to suggest stability.

2. They tend to be more reduced

a) when the majority of the stressed syllables in the line contain short vowel sounds. I.g. IB.2a.i, IB.2a.ii, IB.2c.iii, IIA.2a.iv.

b) when, although the general movement may not be slow, the reduction is compensated for by the presence, in a metrically unstressed position, either of $\dot{x}$ or $x(:)$ in a line most of whose stressed vowels are $\dot{x}$, or else of $\dot{x}:$ in a line most of whose stressed vowels are Í: E.g. IB.2b.iii, IB.2c.iv, IIA.2b.1i. The reduced vowel need not be adjacent to the heavy foot. Not infrequently it occurs in a line where, owing to the substitution of a risine for a falling double 
foot or vice versa, one unstressed syllable succeeds another $[|/ x| x / !]$. The (U) $[$ : $)$ of IIB.I.vii, for example, is compensated for by the fact that the unstressed syllables of the first two feet are as strong as $\mathrm{x}(\mathrm{i})$.

c) when, in a line whose general movement is not slow, the reduction is compensated for by the presence of an extra syllable in one of the feet. E.g. IA.2b.iv, IB.Ib.iv.

d) when the unstressed word is repeated. E.g. IB.Id.iv. If the repetition occurs in the same line, the first vowel may be $x(:)$ or $\dot{x}$ and the second $\dot{x}(y)$ or $(\dot{x}$. E.g. IB.la.iil, IB.Id.ii, IB.Id.iv.

e) when swift movement or the eruption of an abrupt force is described. E.g. IB.Ia.iv, IB.Ic.iii, IB.ic.iv.

f) when, in some other less definable way, it makes the rhythm more onomatopôeic. E.g. IB.Ib.iii.

g) when it is desired to suggest intensity of feeling by increasing the comparative strength of another word in the line and thus emphasizing it. E.g. longed in IB.Ia.iii, and watches in IA.2d.ii.

\section{Class I.}

A) The words which were found to belong to this class are:'a, am, an, and, as, at, but, could, dost, doth, from, had, has, hast, 
(I)

have, is, such, of, shall, should, some, than, that, upon, was, would.

I. Unstressed: $x$, i:

The vowel sounds of such monosyllables are frequently

reduced to $\dot{x}$; but to decide when they are so much reduced seems to involve personal opinion more than to decide about the reduction in some other classes of monosyllables. Consequently, since the difference between $x$ and $\dot{x}$ is in any case so slight that the two sounds are given the same numerical relative strengths, no attempt is made in words belonging to this class to distinguish between them.

2. Stressed: $-\dot{x}, \mathbf{k}$ :

Lines are quoted which contain some of the words most often slurred. These illustrate how in different contexts the vowels may suffer different degrees of reduction. The tempo of the neighbouring lines sometimes affects that of the line under examination; but the quotations are so well-known that they will immediately evoke their context。

a) 으: $-\dot{x}$

$i$. In show like leaders of the swarthy Moors i óu: aifil $i: \theta \wedge$ ò $\theta$ ó: $i$ úə:

ii. The pilot of the Galilean lake

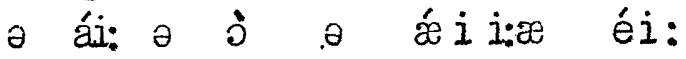

(I) But for this exception all the words in Class I. are monosyllables. 
(.)

iii. Or with the tankles of Neaere's hair

o: $i$ a

iv. Sleep'st by the fable of Bellerus old

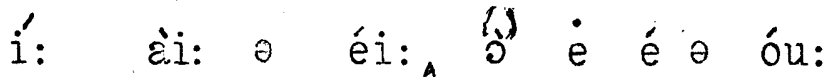

b) and: - $\dot{x}$

i. And grow for ever and for ever \& óu: $\dot{\jmath}(:)$ é $\partial_{\wedge}$ æè $\dot{\partial}(:)$ é $\partial$

ii. The air was calm and on the level brine

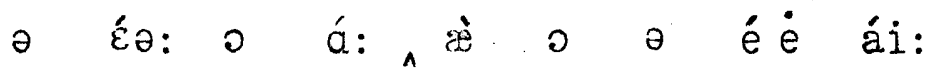

$\left(\frac{1}{2}\right.$

iii. Looks towards Namancos and Bayona's hold

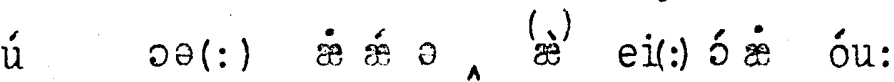

iv. O fountain Arethuse, and thou honour'd flood

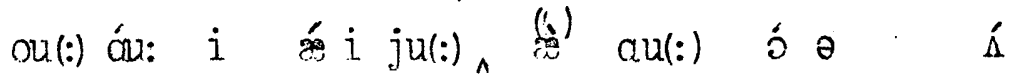

c) 2 : $:-\dot{x}$

i. As idle as a painted ship

※ ái: ^ æèi(:) éi: i í

$\left(\frac{1}{x}\right.$

ii. I do love thee as each flower

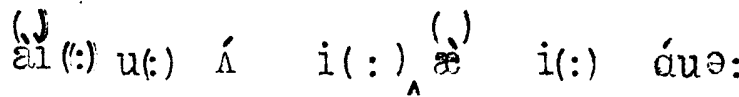


d) Pron:- i

i. And wipe the tears corever from his eyes e ái: o íá

\section{(i)} $x$ ii. He watches from his mountain walls $\dot{i}(:)$ ó $i$ a jo $i$ áu: $i$ ó:

B) The words which were found to belong to this class are:do, to; or, for, nor; be, he, me, she, thee, we, ye; her; by, my; are, art; their, there(is, are); were; you, your; who, whom; no, so, though; may, they. With the exception of the first word, the words at the beginning of the list are reduce? oftener than those at the end. 1. Unstressed:- $\dot{x}:, x(:), \dot{x}(:)$.

a) to: $-x(:)$

i. Thou, thou and all thy mates to keep áu: , áu: „ $æ$ ó: ai(:) éi: u(:) í:

ii. She has her soul to keep

i: क,

$\dot{x}(:)$

iii. Here he lies where he longed to be $i^{\prime} \circ:$ i (:) ái: a $\varepsilon \partial(:) \quad \dot{i}(:)$ ó $\dot{u}(:) \quad i^{\prime}:$

iv. And think to burst out into sudden blaze ge $i^{\prime} \dot{u}(:)$ ó: ću: , $\dot{i} \dot{u}(:)$ í éi:

b) or, for, nor:- $x(:)$ accompanied for besst and bird ái: $\dot{e} \ddot{\otimes} \Delta \circledast{ }^{\prime} \wedge(:) \quad i^{\prime}: \quad æ \quad \dot{\theta}:$ 
ii. For, so to interpose a little ease o(:) òu: $\dot{u}(:) i^{\prime}$ a óu: $\dot{e} i(t) \quad i \quad \dot{i}:$

$\dot{x}(:)$

iii. Or sinking as the light wind lives or dies o: ) $i^{\prime}{ }_{\wedge} \approx$ a ái: ái: $\dot{i}^{\prime}$ ó(:) ái:

1v. But for peace her soul was yearning $\wedge \dot{\partial}(:) \quad \dot{i}:$, $\partial(:)$ óu: o $\dot{a}: \quad i$

c) he, she, etc.:- $x($ : $)$

i. The weary life ye know since when ə ío: i ái: i(:) áu ^

ii. Ring'd with the azure world, he stands

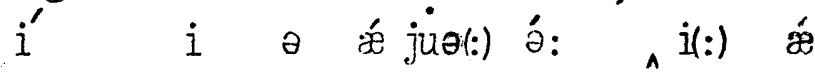

$x(:)$

iii. And like a thunderbolt he falls

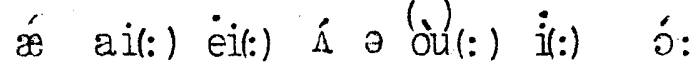

iv. Swift be thine approaching flight

$i^{\prime}$, $\dot{i}(:)$ ái: $\dot{\otimes}$ ou: $i$ ái:

d) by, my: - $\dot{x}$ :

i. With lucky words favour my destined urn i $̂$ i ó: éi: $\theta$ ài: é $i \quad \dot{\theta}$ :

And as he passes turn

And bid fair peace be to my sable shroud

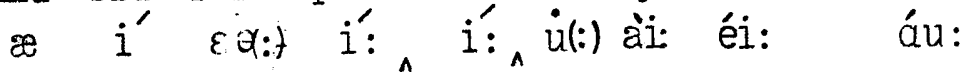


al :)

ii. It raisea my hair it fann'd my cheek

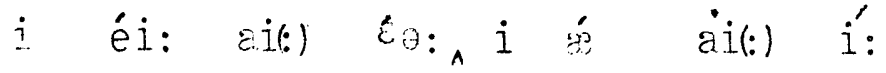

iii. One by one the casements catch í ail(:) ́r n éi: $\dot{e} \quad \dot{a}$

$\dot{x}(z)$

iv. By scaly Triton's winding shell.... ail(:) éi: i ái: 0 a ái: $i$ é By Leucothea's Iuvely hands....

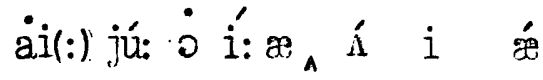
By Thetis' tinsel-slipper'd feet

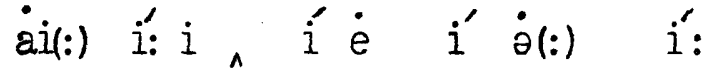

e) her:- $x(\vdots)$

i. And now peace laps her round æ áu: ^ ì: ǽ ә(:) áu:

i1. Had in her sober livery all things clad $\ddot{z} \quad$ i $\quad \theta(:)$ óu: $\theta$ í $\dot{i}_{\text {, }}$ ò $\quad i^{\prime} \approx$

$\dot{x}(:)$

iii. But her heart was tired, tired

$\Lambda \dot{\theta}(:)$ á: o áia: áiə:

iv. Her cabin' ample spirit $\dot{a}:) \notin i \propto i^{\prime} i$

2. Stressed: $-\dot{x}:, \quad\left(\frac{1}{x}(:)\right.$

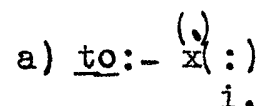

i. She took me to her elfin grot $\dot{i}(:) \quad \dot{u} \quad \dot{i}(:) \wedge(\dot{u}(:) \quad \partial(:) \quad$ é $i$ ó 


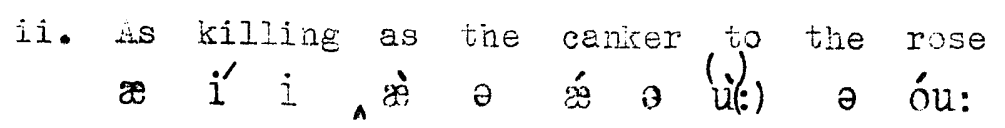

b) or, for, nor: $-\dot{x}$ :

j: $i$ ə á:

ii. Or as the pearls of morning dew

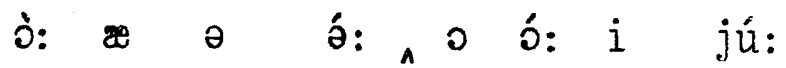

(D)

iii. Iisten, for dear honour's sake

$\dot{i}^{\prime} \wedge(\hat{\theta}:) \quad i$ of $)$ ó a éi:

iv. I made a garland for her head

ail(:) éi: èi(z) á: \& a ól:) $\dot{x}_{(:)} \quad$ é

c) he, she, etc: $-\dot{x}$ :

She is so circumspect and right

ì: i òu: ó: $\dot{\Lambda}$ è,$æ$ ái:

ii. She has her soul to keep

ì: $\&$ a(:) óv a $u(:)$ í:

$(x):)$

iii. To be beloved of God, I have not lost

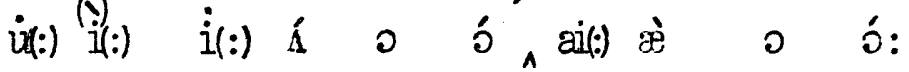

iv. The pallor of girls' brows shall pe their pall

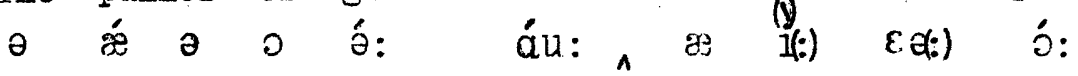

d) by,my: - $\dot{x}$ :

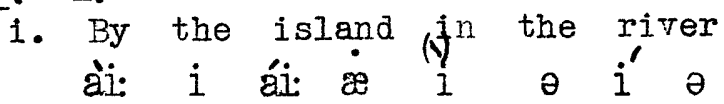




\section{ii. Why hair sort- listed by the mimowine wind

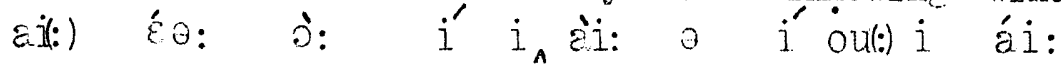

\section{Ola.ss II.}

A) The words mich were found to belone to this class ere:across, among, beyond, every, hath, hither, in, into, it, let, much, not, on, one, since, then, till, under, until, unto, up, what, when, whence, which, with, within, yonder. Besides the vowels of their accented syllables, which are being considered in this section, those of some of their unaccented syllables are also reduced.

\section{Unstressea : $-x_{2} \dot{x}_{0}$}

As with the words of IA, no attempt is made to distinguish between $\mathbf{x}$ and $\dot{x}$ values in monosyllables, since to do so would serve no purpose. The accented elements of dissyllables are normally stressed and are therefore treated as the words in IIA.2.

2. Stressed:- $\dot{x_{2}}$,

a) in : $-\dot{x}$

i. But she is in her grave, and oh

$$
\wedge \text { 'i: } i \text { 'i } \propto(:) \text { éi: ^ æ óu: }
$$

ii. That sine, and singing in their glory move

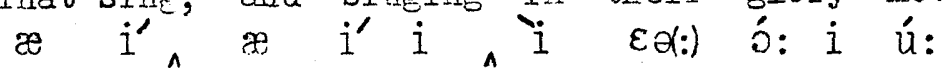

(3)

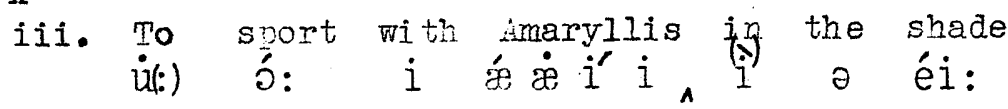

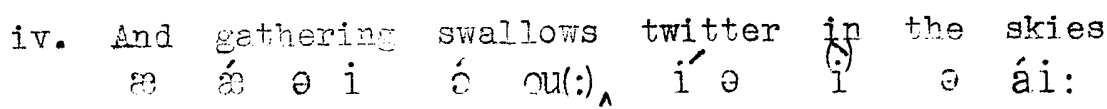

(1),(2) These wores are less ept to be rebuced then most of the others. (3) $\mathrm{CP} \cdot 2 \mathrm{p} \cdot 117-135$. 
b) on: $-\dot{x}$

1. Waters on a starry night

$$
\text { ó: ò j̀ èi(:) á: } i \text { ái: }
$$

\section{(y)}

ii. Though castles topple on their warders' heads ou(:) á: ó ^ ó $^{\prime} \varepsilon \partial(:)$ ó:

B) The words which were found to belong to this class are:about, after, against, all, although, around, away, behind, below, beneath, beside, down, each, either, ere, even, far, forth, half, here, how, I, (at)

(1)

least, like, might, more, most, oft, oh, only, our, out, over, own, round, these, those, thou, towards, througg, thy, too, two, where, while, whilst, whose, why, without. Here again, it is accented syllables which are under consideration.

It is perhaps no longer necessary to treat all the words in the group separately.

1. Unstressed:- $\mathbf{z}:$

i. Think not of them, thou hast thy music too

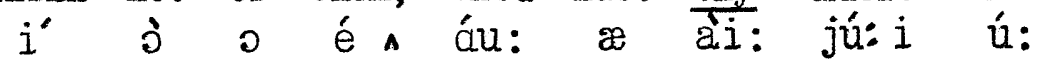

ii. And there I dreamed - Ah! woe betide: æ $\dot{\partial}:$ ài: $i^{\prime}: \wedge$ á: ^ óu: $\dot{i}(:)$ ái:

iii. But that two - handed engine at the door

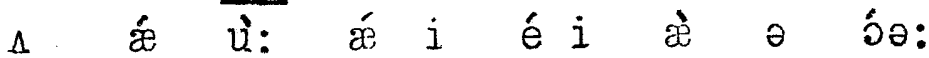

iv. That to the sleeping woods all night

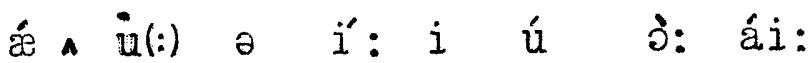

$x($ :)

v. This thou perceiv'st, which makes thy love more $i^{\prime}$ au(:) $\theta$ í: ^ $i$ éi: ai(:) $\Lambda$ oo(:) strong 


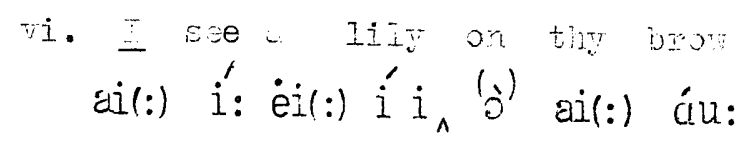

vii. Thou art more lovely and nore te perate

áu: a (:) $\infty(:)$ Í $i_{\wedge} \mathscr{F}$ óa: é $\theta$ èl) (:)

viii. I wish $I$ were where Helen lies

ai(:) $\dot{i}^{\prime}$ ail(:) $\varepsilon_{\theta}:{ }_{\wedge} \varepsilon \theta(:)$ é $\dot{e}$ ái:

ix. Look round her when the heavens are bare

ú au(:) $\theta(:)$ è $\partial$ é $\dot{\alpha}(:) \dot{\varepsilon}_{\theta}$ :

2. Stressed: $-\dot{x}:$

i. Neanwile the rural ditties were not mute

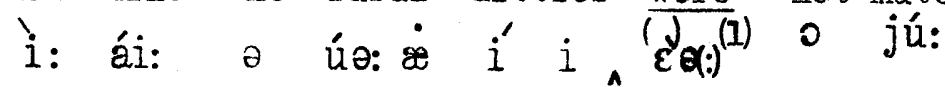

ii. Whilst from off the waters fleet
ài:
o ó:
ə ว่: ə í:

iii. oier the cowslip's velvet head dəo(:) $\theta$ áu: $i$ é $i \quad$ é

(1) : :)

iv. All losses are restored and sorrows end

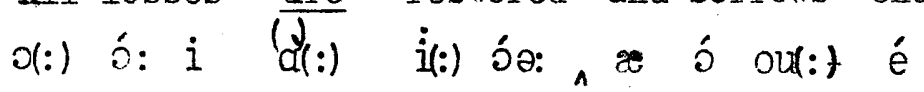

v. What candles may be held to speed them all - $\quad$ é èi(:) $\dot{i}(:)$ é $\dot{u}_{(:)} \quad \dot{i}: \quad$ e ò:

vi. Anā I will come again, my Luve,

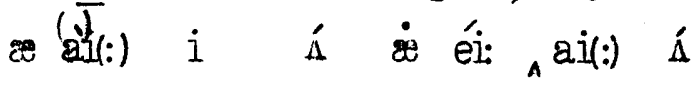

The reduction of the vowel sounds in unimportant words may

therefore, be suimarized thus:-

(1) rois fom, for a rumur jiphthong, is parallel to ì: for a lone rovel sound. 


\begin{tabular}{|c|c|c|c|}
\hline & Class of Word & 1. Unstressed. & ¿. Stressed. \\
\hline \multirow{2}{*}{$I$} & A & $x$ & $x, \frac{(1)}{x}$ \\
\hline & B & $\begin{array}{c}\text { x: (exceptionaliy), } \\
x(:), \dot{x}(:)\end{array}$ & $\dot{x}:, \frac{(1)}{x}(:)$ \\
\hline \multirow{2}{*}{ II } & A & $x$ & $i x, \frac{(y)}{x}$ \\
\hline & $\mathbf{B}$ & , $\quad \frac{1}{x}:, x(:)$ & $\frac{1}{x}:, \frac{(y}{x}(:)$ \\
\hline
\end{tabular}

b). Prefixes and. Suffizes.

Both the O.E.D. and the E.P.D. values are given for the more reduced forms occurring in the comonest frefixes and suffixes, the 0.E.D. symbols as usual being translated into their equivalents in the alphabet adopted. Except for the group of suffixes headed by-ige, it is the O.E.D. sound which, being less flattened into $\partial$, is adopted.

Prefixes.

\begin{tabular}{|c|c|c|c|}
\hline $\begin{array}{l}\text { Prefixes in } \\
\text { which vowel } \\
\text { sounds occur. }\end{array}$ & O.E.D. Symbols. & E.P.D. Symbols. & Symbols adopted. \\
\hline $\begin{array}{l}a, a b, a c, a d, \\
a f, a g, a l, \\
a m, a n, a p, a r \\
\text { as, at. }\end{array}$ & $\dot{\approx}($ sometimes $\dot{\mathrm{a}})$ & $\partial, \mathscr{Z}$ & $\ddot{B}$ \\
\hline $\begin{array}{l}\text { ef, el, en, } \\
\text { er, es, ex. }\end{array}$ & $e, \quad i(:)$ & $i \quad[e]$ & $\begin{array}{c}\dot{e} \text { (e.g. endure). } \\
\text { or } \dot{i}(:) \text { (e.g. eternal). }\end{array}$ \\
\hline $\begin{array}{l}\text { be, de, pre, } \\
\text { re, se. }\end{array}$ & $i(:)$ & $i$ & $i(:)$ \\
\hline
\end{tabular}




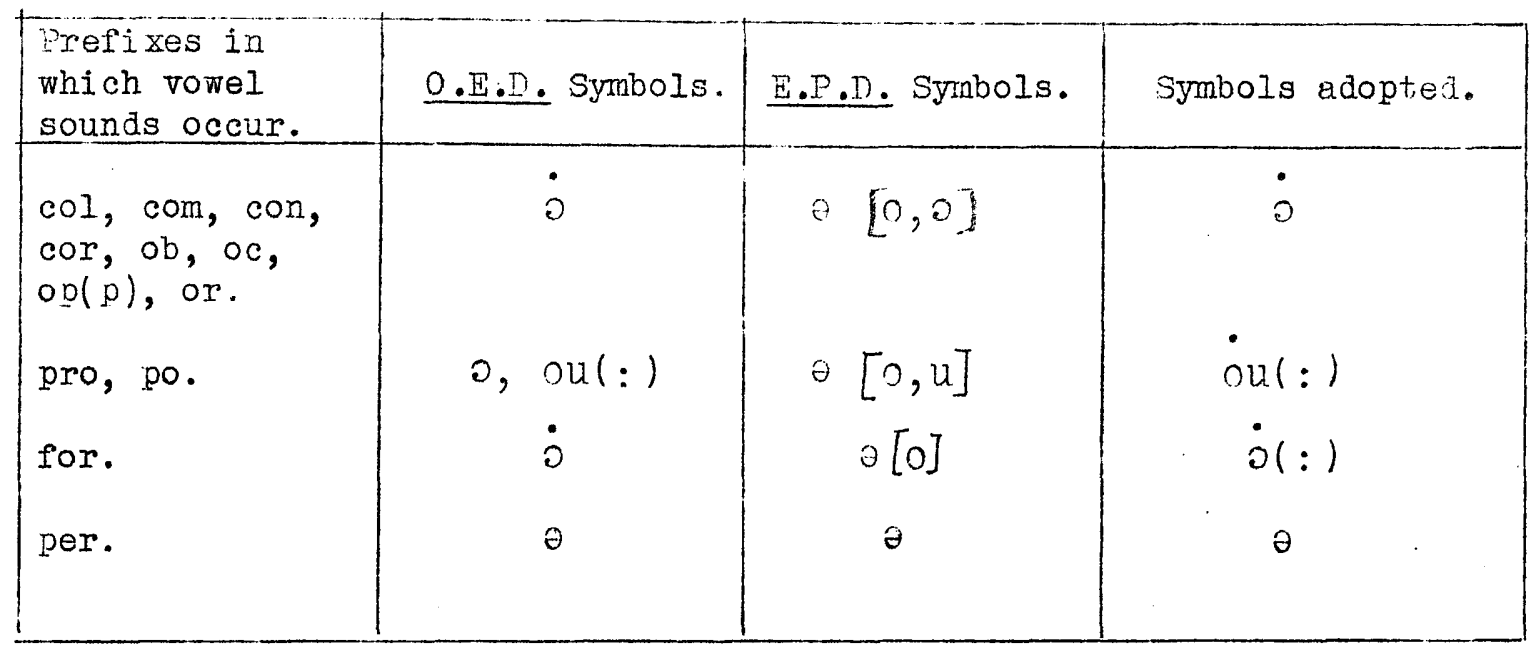

Suffizes.

\begin{tabular}{|c|c|c|c|}
\hline $\begin{array}{l}\text { Suffizes in } \\
\text { which vowel } \\
\text { sounds occur. }\end{array}$ & O.E.D. Symbols. & E.P.D.Symbols. & Symbols adopted. \\
\hline $\begin{array}{l}\text {-a, -able, -i)an, } \\
\text {-(i)ald, ance, } \\
\text {-ancy, -ant, } \\
\text {-ary, -and } \\
\text { (usually), -ard } \\
\text { (usually). }\end{array}$ & $\dot{x}[\dot{a}]$ & $\theta$ & $\dot{æ}$ \\
\hline $\begin{array}{l}\text {-el, -en(s), } \\
\text {-ence, -ent. }\end{array}$ & $\dot{e}$ & $\partial$ & $\dot{e}$ \\
\hline $\begin{array}{l}\text {-ed, -es(s), } \\
\text {-est, -et, -eth, }\end{array}$ & $\dot{\theta}$ & $i$ & $i$ \\
\hline $\begin{array}{l}\text {-eon, -(i)on, } \\
\text {-(i)ot, - (i)od, } \\
\text {-(i)or, ock, } \\
\text {-ol, -om, -ond, } \\
\text {-orys our, } \\
\text {-(o)us. }\end{array}$ & $\partial$ & $\theta$ & $\theta$ \\
\hline $\begin{array}{l}\text {-age, -ain, } \\
\text {-ege. }\end{array}$ & $\dot{\theta}$ & i & i \\
\hline & $e, e i(:)$ & $i, e i(:)$ & 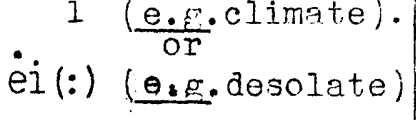 \\
\hline
\end{tabular}




\begin{tabular}{|c|c|c|c|}
\hline $\begin{array}{l}\text { Gufizes in } \\
\text { woich vowel } \\
\text { scunds occur. }\end{array}$ & O.E.D. Symbols. & I.P.D. Symbols. & Wrabols adopted. \\
\hline -ine, -iIe, & $i, a i$ & $i, \quad a i$ & ail: $)$ \\
\hline$-\varepsilon x$ & $\partial, \dot{\vec{x}}, \dot{\mathrm{a}}$ & o [occasionally a: & $\dot{a}(:)$ \\
\hline -wara, & $\partial, \dot{j}(:)$ & $\theta$ & $\dot{j}(:)$ \\
\hline -er + consonent & $\partial$ & $\partial$ & $\dot{\partial}(:)$ \\
\hline -sure, -ture, & $\dot{j u}(:)$ & $\theta, \int \partial$ & $j \dot{u} \theta(:)$ \\
\hline -une, & $i \ddot{u}, \int \partial$ & $\partial$ & $\dot{j u}(:)$ \\
\hline
\end{tabular}

Notes.

1) Although the tabulation indicates the usual behaviour of the vowel sounds, each word had to be considered separately; it was found, for instance, that, contrary to the velues given in the tabulation, the second vowel in open and altar, is $\partial$ and that the second in poet and palace is $\dot{e}$.

2) The prefix un frequently receives stress in ordinary speech e.e. ùnquíet, únénviable, úntródden. Such words appear in the c.i) subdivision of all types of dissyllables, trisyllables, snd polysyllables.

\section{c). Dissyllables.}

Both the O.I.D. and the E.P.D. were consulted for almost every word. The air was, on the one hand, to avoic flattenjng a reduced vowel into $\partial$ if either dictionary warrented attributing to it sometuine 
of its owin quality, and yet, on the other hand, to discover the degree of reduction suffered by long vovels in syllabies which are neither

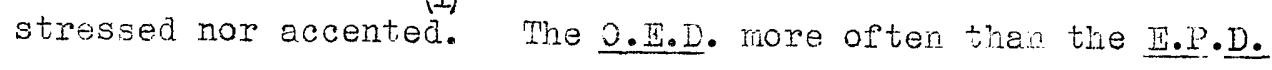

furnished the unflattened velues adopted for those vowel sounds which, whether long or short, are considerably reduced. So far as less

reduced lone vowel sounds are concerned, the degree of strength ascribed to then by the $\underline{0 . E .1}$. Was adopted except in two classes of sylleble, those which fall under class c.iil in the following notes and are dealt with there, and those which contain an accented ard stressed au, $a i$, or $0 i$. For these three diphthongs and only for these the O.E.D. has "ordinary" and "bbscure" but no "Iong" forms, with the result that the au of loud and that of foundation are represented by the same symbol. Here, however, the former diphthong is represented byáu: to distinguish it from the letter, which, lacking both accent and stress, is represented by $a u(:)$.

Types of Dissyllables:-

I) $1^{\prime} I$ and $11^{\prime}$

III) $\quad 1 \frac{1}{2} 1 \frac{1}{2}$ and $1 \frac{1}{2} I^{\prime} \frac{1}{2}$

IV) $2^{\prime} 1$ and 1 '́

v) $I^{\prime} 2$ and $21^{\prime}$

VI) $1 \frac{1}{2} 1$ and $1 \frac{1}{1} \frac{1}{2}$

VII) $I^{\prime} 1$ and $1 \frac{1}{2} 1^{\prime}$

VIII) $2^{\prime} I \frac{l}{2}$ and $1 \frac{1}{2} 2^{\prime}$

IX) $\quad 1 \frac{1}{2} 2$ and $2 i^{1} \frac{1}{2}^{(2)}$

(1) Cf. p.20 for the effect of accent on entrance.

(2) A triphtions, whose relative strenethis 2 , may be substituted anywhere fron I to Ix for a lo:le vowel or diphthone. 
Two verieties of word are inclabed in ech tye, for the cegree of the reduction is unaffected $\mathrm{D}_{\mathrm{f}}$ the position of the vovel. The stressed figures inaicate that sounds of that value aie present at, full strength. Whe unstressed figures indicate what the fuIl value of the sounds would be if they were not in unaccented and unstressed positions.

As the examination of dissyllables progressed, it was found that each of the nine types may be subdivided according to the strength of the reduced vowel. The vowel sounds may

a. i) be reduced to $\theta$. 画. beckon $\left(\begin{array}{ll}1 & 1\end{array}\right)$.

ii) be reduced to $i$. E.g. cottage $\left(i^{\prime}\right.$ 2).

iii) be reduced to $\dot{\alpha}, \dot{o u}(:)$, etc. $\mathrm{E}_{\mathrm{g}} \cdot \operatorname{signal}\left(I^{\prime} 1\right)$.

b. i) retain more of their own quality yet be unable to carry stress. E.E. pilgrim (I' I), servile ('́l 2).

c. i) belong to syllables which have some degree of accent in the O.E.D. or the E.P.D. E.g. Uncoúth ( $\dot{I}^{\prime}$ í),

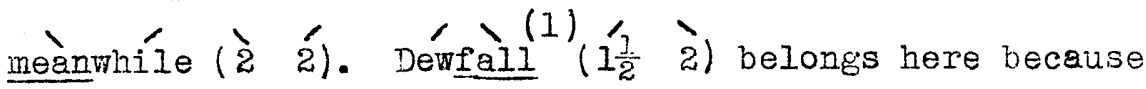
it would have had a secondary accent if it had appeared in either dictionary.

ii) belong to syllables which have no secondary accent in the 0.E.I. and the E.P.D., but are treated here as if they had because, originglly independent words, they still retain sometinis of their proper meanins. 


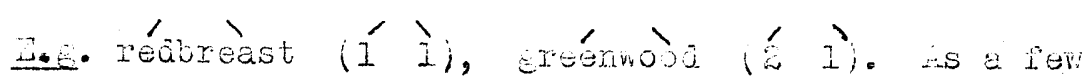
of the examles tabulated uncer IIb and $Y \mathrm{~b}$ show, it would occasionally be difeicult to eccide whether a word belcnes to the b) or the c.iil subcivision, if it were not for the rhythical context.

In the tabulation which follows no attempt has been made to give exomples of every subdivision of dissyllables. The object simply was, for the sake of achieving consistency in the treatment of then, to tabulate typical woras which were actually met in the analyses.

Pauses, whether short $\left({ }_{\Lambda}\right)$ or $\operatorname{long}\left({ }_{\Lambda}\right)$, are credited with affecting reduced vowels less than ordinary vowels. Metrical stress, which is strong enough to affect them more, very seldom falls upon them; and the brackets round the stressed vorels of the a) subdivisions are intended to indicate that these forms never occur. Stress might exceptionally fall on the reduced vowels of b) words in types II, T, and VII, and, less exceptionally, but not often, on those of c) words in any type, for instance, when, as the result of a substitution, two unstressed syllables are followed by two stressed. 


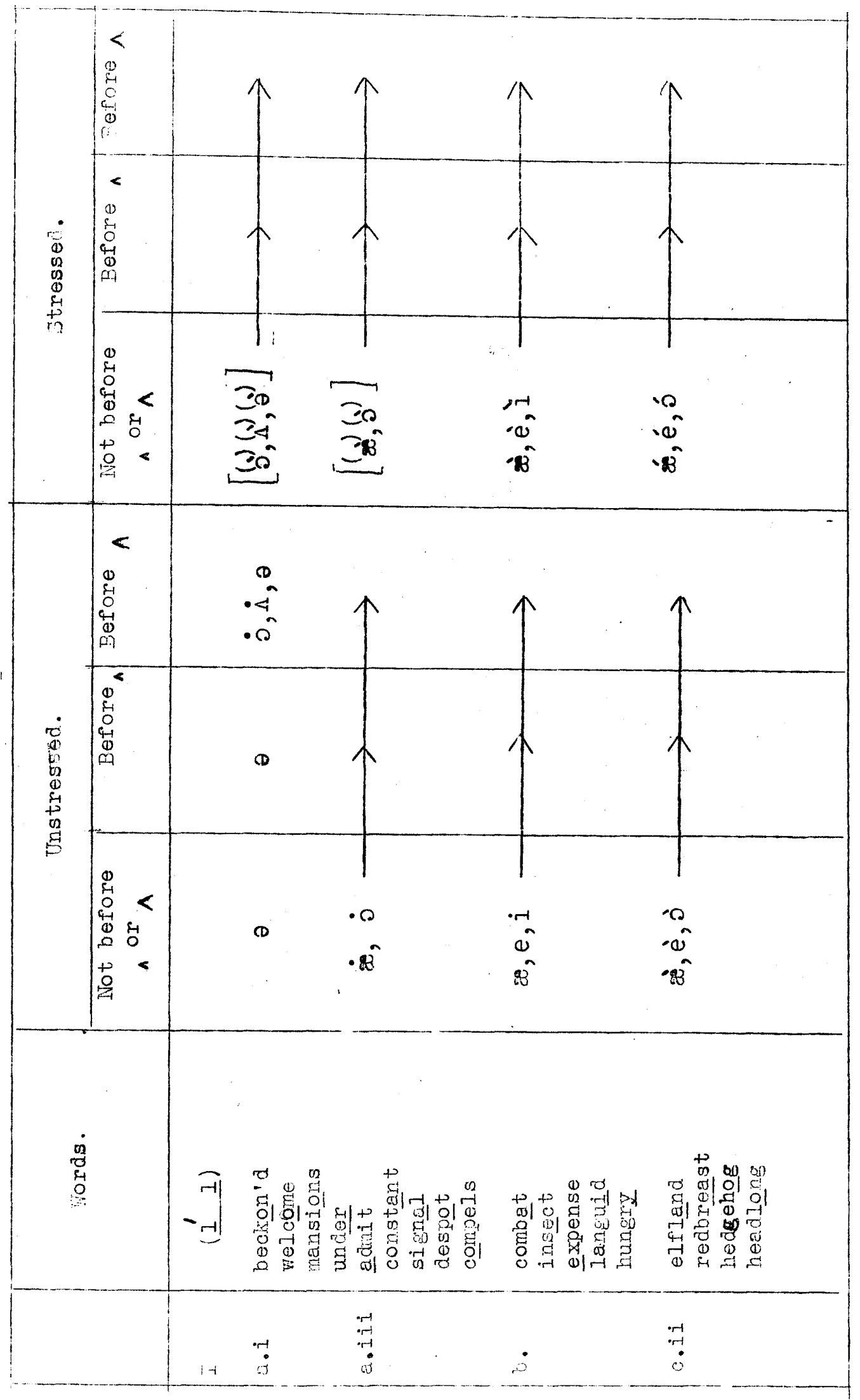




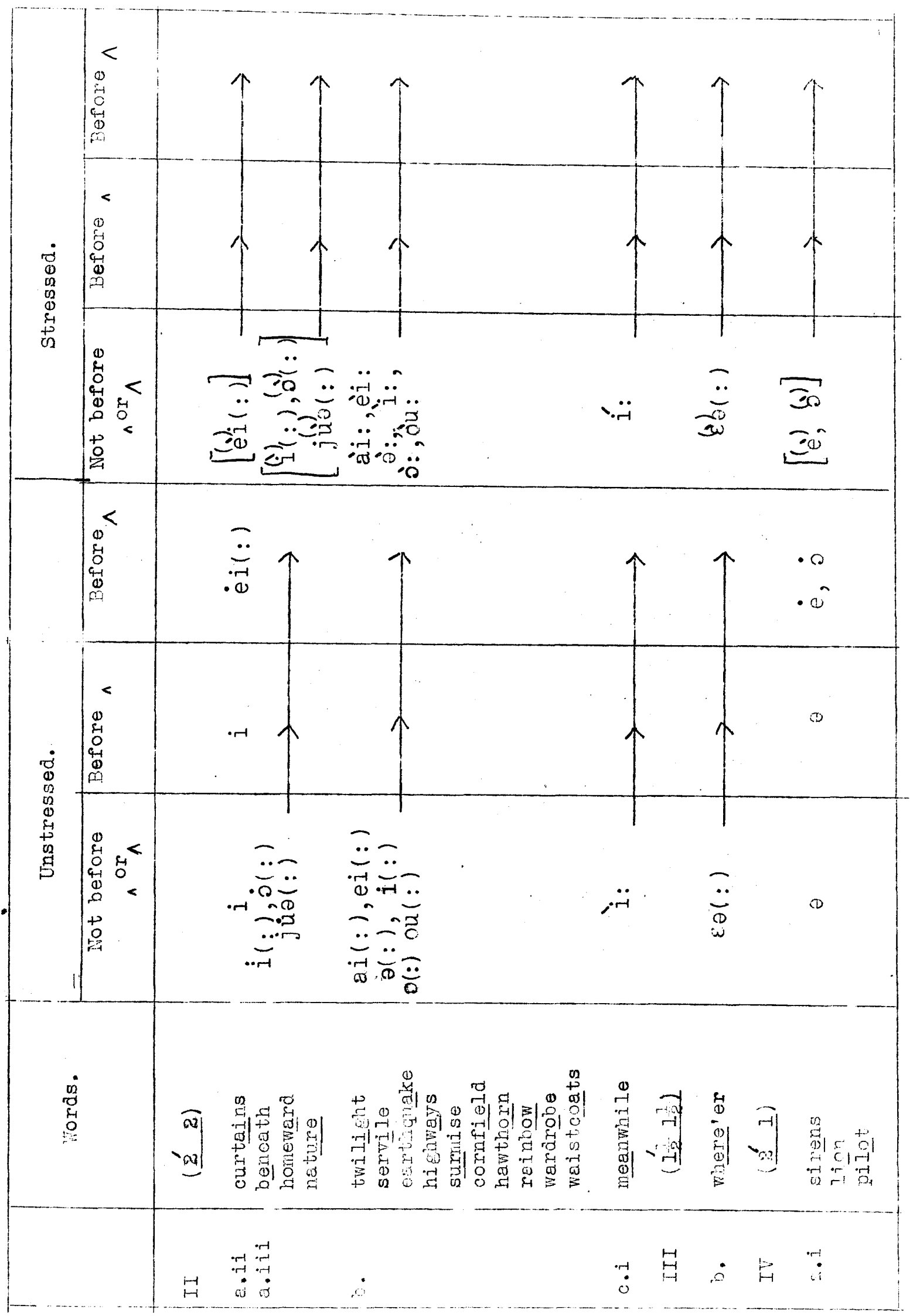




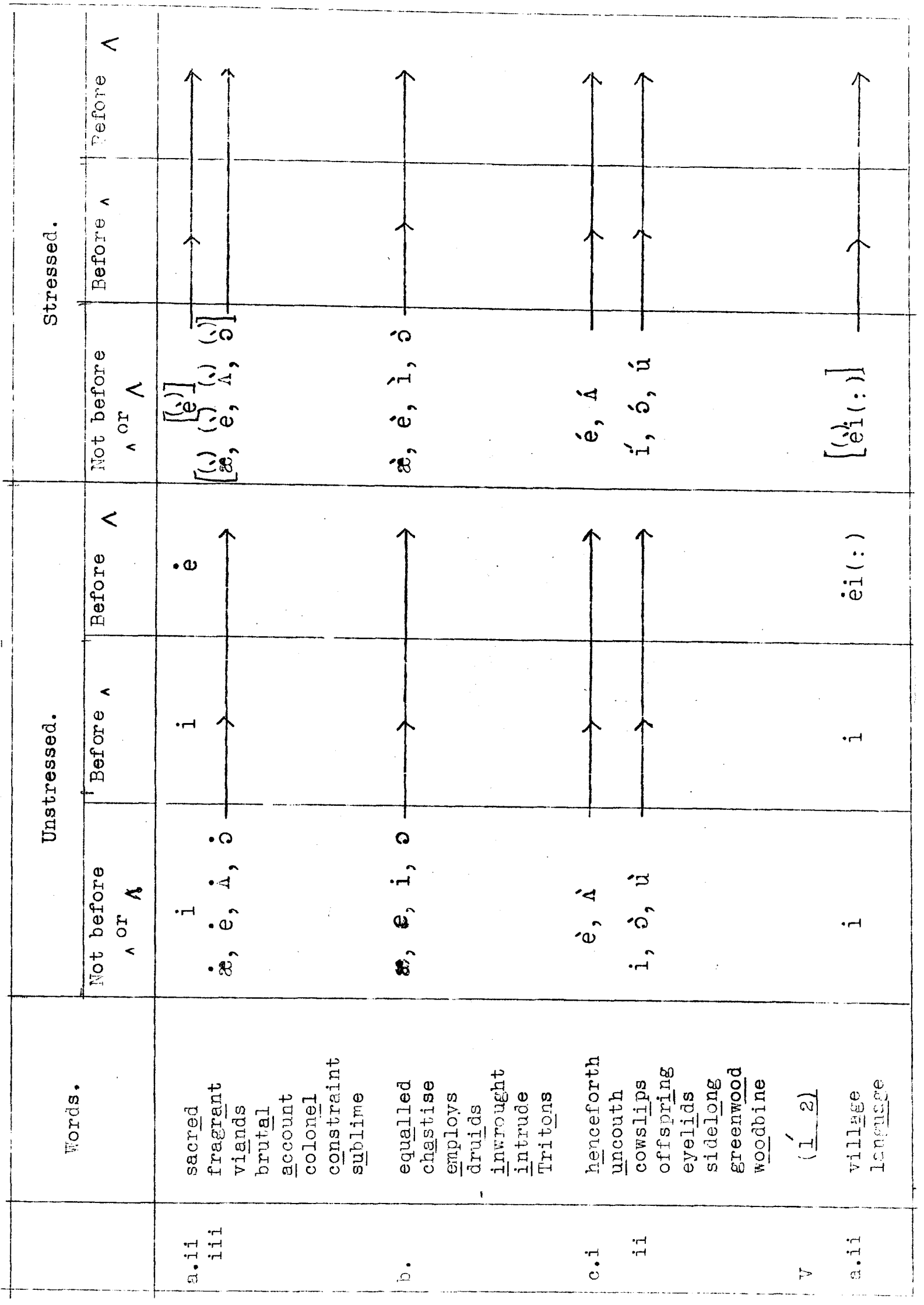




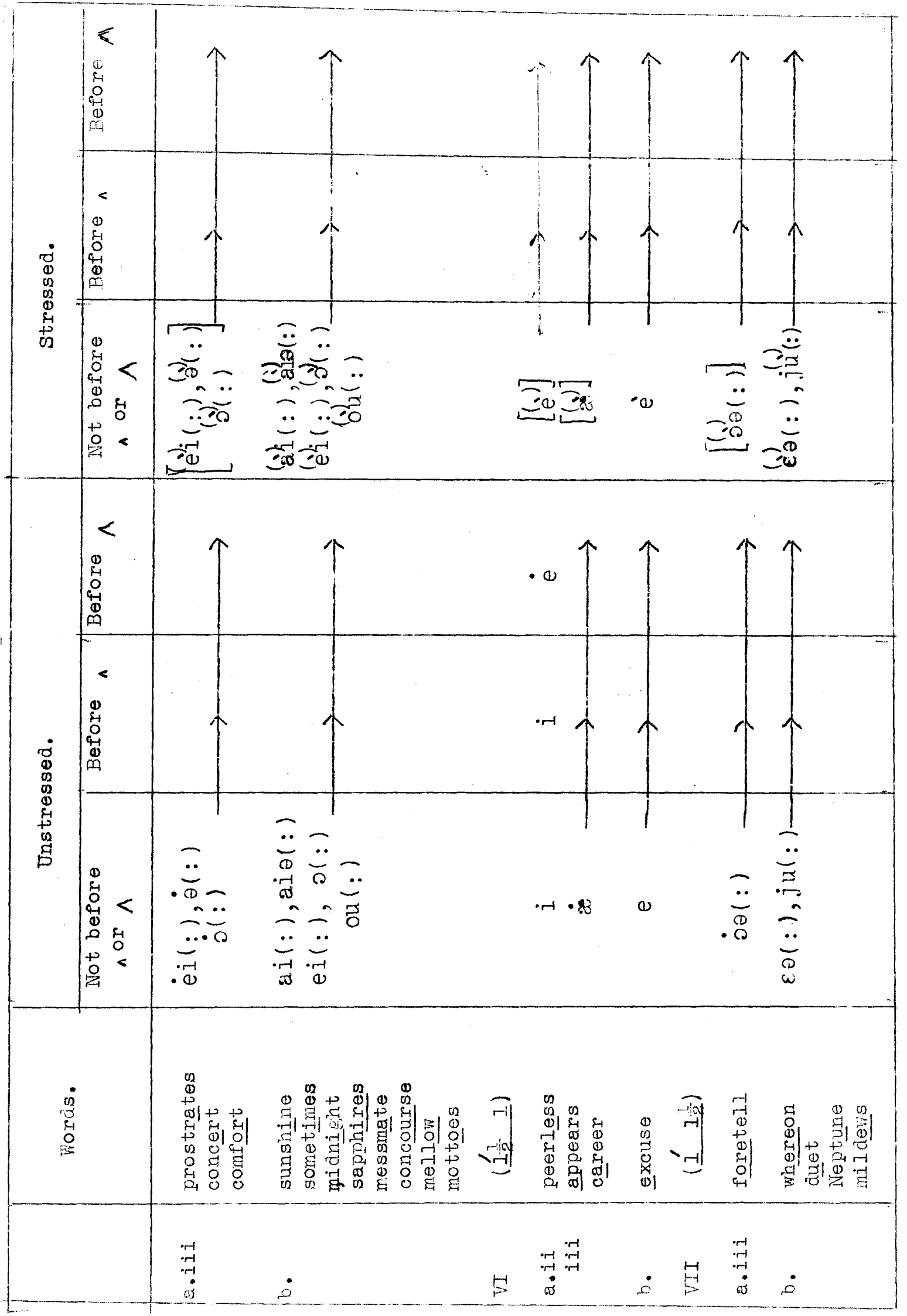




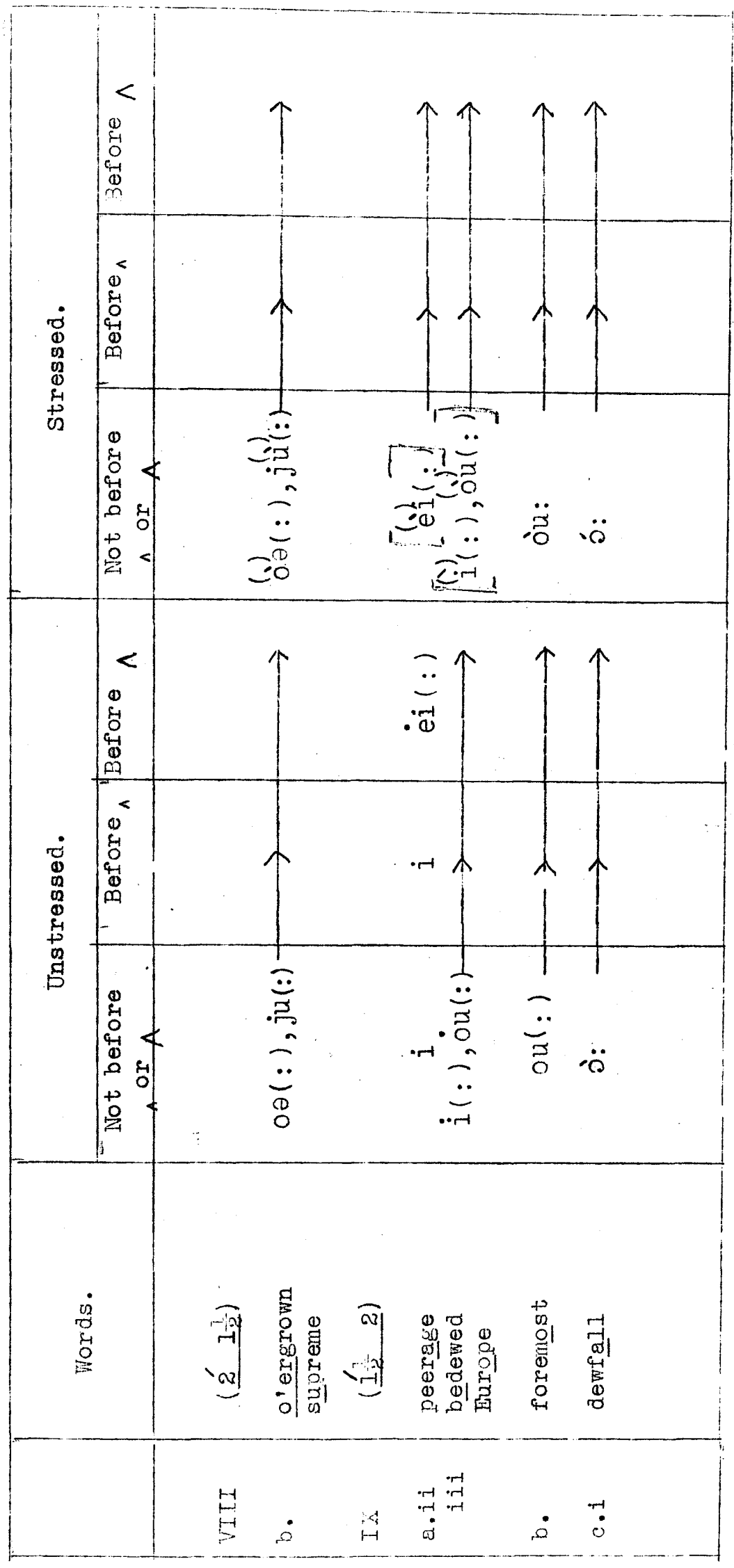


Notes.

1) In all the nine types into which dissyllables are classified, te vowels of the a) subdivisions are treated in exactly the same menner; and the saue is true for the c) subdivisions. In the b) subdivisions of types II and IX the treatment is identical; in type IV paraliel treatment is given to short vowels, and in types III and VII to vowel sounds whose maximum strength is 1 . The value given to the stressed form of the reduced vowels in $\mathrm{Vb}$ is, however, weaker than that given to the same vowels in other types; this is because no influence can strengthen a reduced vowel to such a degree that it becomes stronger than the main, accented vowel, which in this case has a relative strength of only 1 .

2) Hyphened words as a rule demand no special consideration, since they are treated exactly as if they were two separate words. However, although self-same is so treated in Iycidas, in Keats' Ode to a Nightingale, where the same seems less able to bear full weight, it. is, despite its hyphen, treated as the single word which both the O.E.D. and the E.P.D. represent it to be. Similarly the second vowel of musk-rose is óu: in Iycidas but ìu in the ode to a rightingale. No other compound Fords were found to depart from the rule.

3) Very occasionally the vowel of a IIb syllable has more strength than nomally belongs to sounds of this type. Thus in To the Night the second diphthong of daylipht, although it is not stressed, is yet represented as à $i$ : because it belones to a rhymine syllable and 


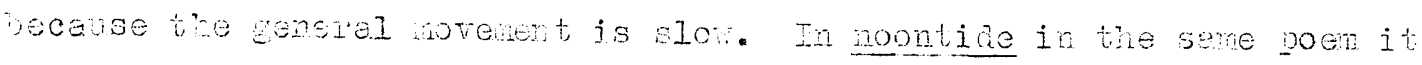
is because it, is stressed that the secona diphthong if iren the sane strencth.

4) The only other excejtional vonel sounds are those in words like herself, that is in dissyllables one of whose elements hes (1)

already been examined; the sounds of the aissyllables are reduced in exactly the same manner as those of the monosyllables.

\section{d). Trisjilables and Polysyllables.}

The list of worcs tabulated, like that in the previous section, is not exhaustive, incluaing as it does only typical exarnples which occur in the original Cood and Bad Groups of poems and in Iycidas. The reduction of sounds in the subdivisions which are neglected can, however, easily be deduced from that of those in the subdivisions which are included.

The types and subdivisions of the last section reappear, the only difference being that the two syllables which deternine the classification are in the longer words accompanied by one or more unaccented syllables containirge either short vowels like the e of contemplate and the $\dot{\dot{x}}$ of ignorance or much reduced long vowels like the $\dot{i}(:)$ of consecrated and the $\dot{j}(:)$ of fortuitous.

Longer words were sepgreted from dissylables because the presence of a secondary accent is comparatively frequent in the forrer. A second main accent (which is indicated above the word, in the wran)

(I) I. . 110 (e.g. herself) and p. 113 (e.g. thyself). 
also ocurs oftener in the former than in the latter. Rhythmically, in e. Iine where two unstressed syllables are followed by two stressed, it would be possible for the two stresses of any word to fall on two adjacent syllables; but in practice, the distribution of accents prevents this unless the word is wrenched in a manner to be found only in nonsense verse. Thus words with two accents are stressed in verse, as in ordinary speech, according to one of these patterns:- $\backslash \times /$, $/ x \backslash,|x \backslash x,>x / x, x / x\rangle, x>x /$. 


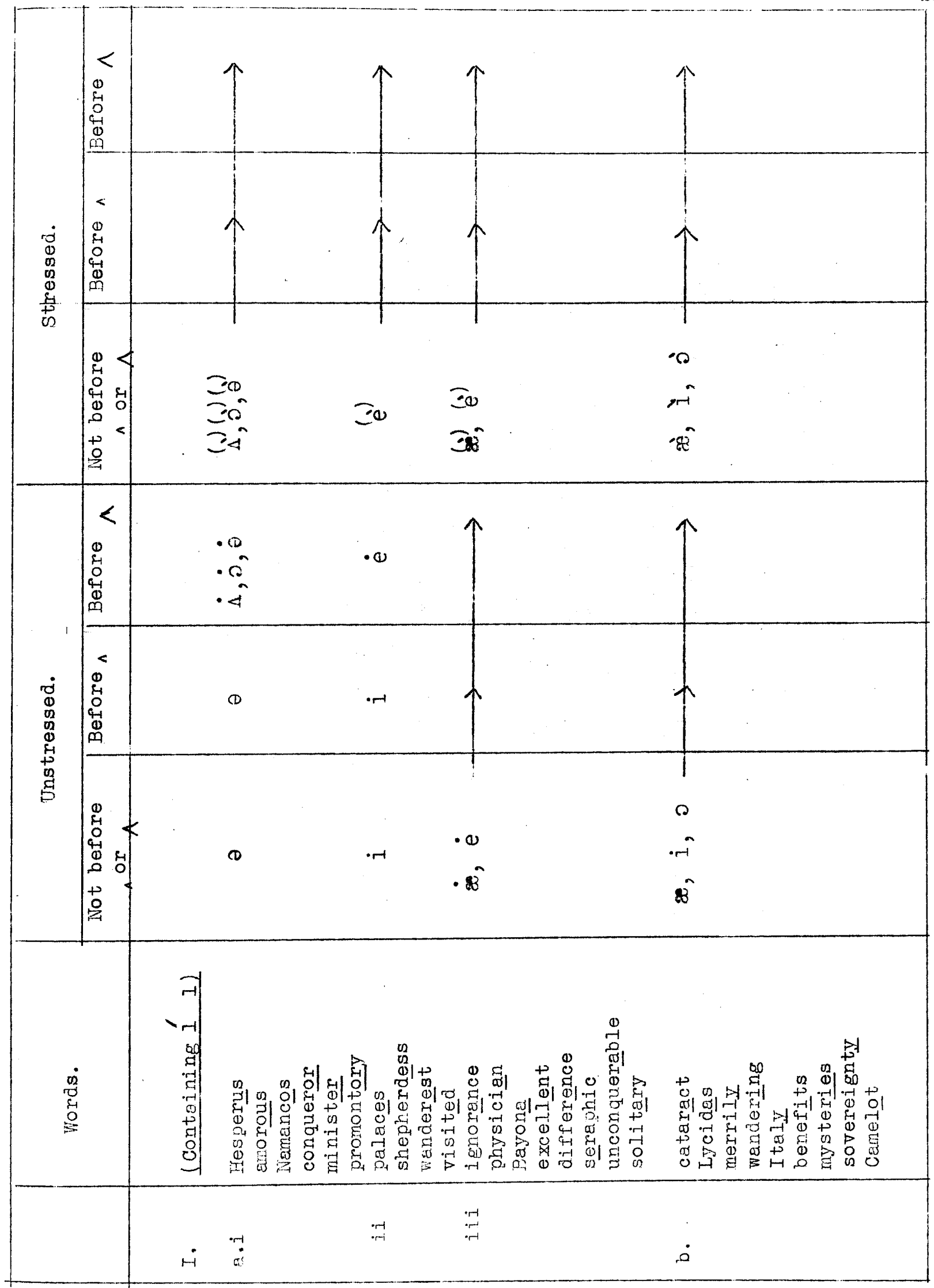




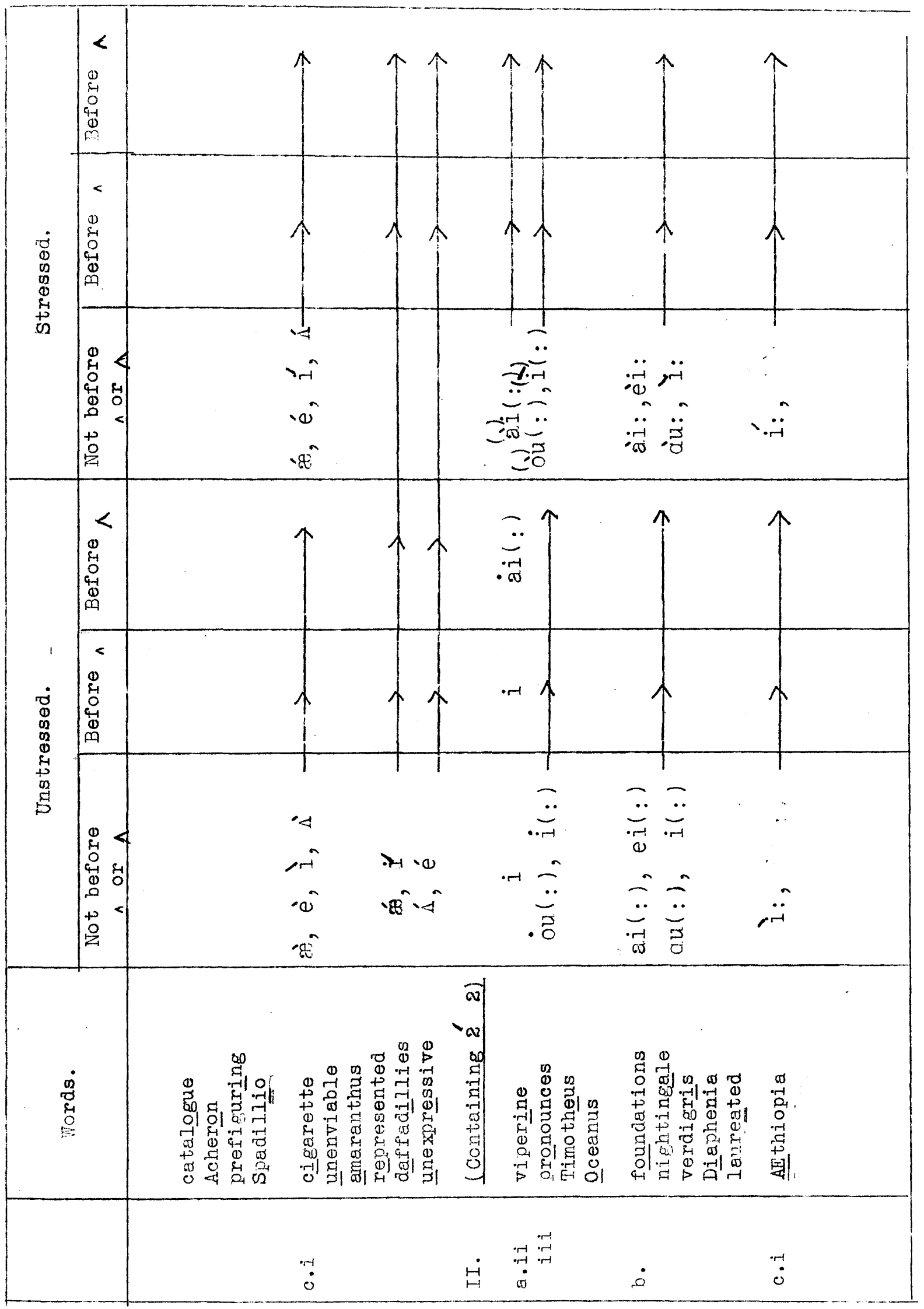




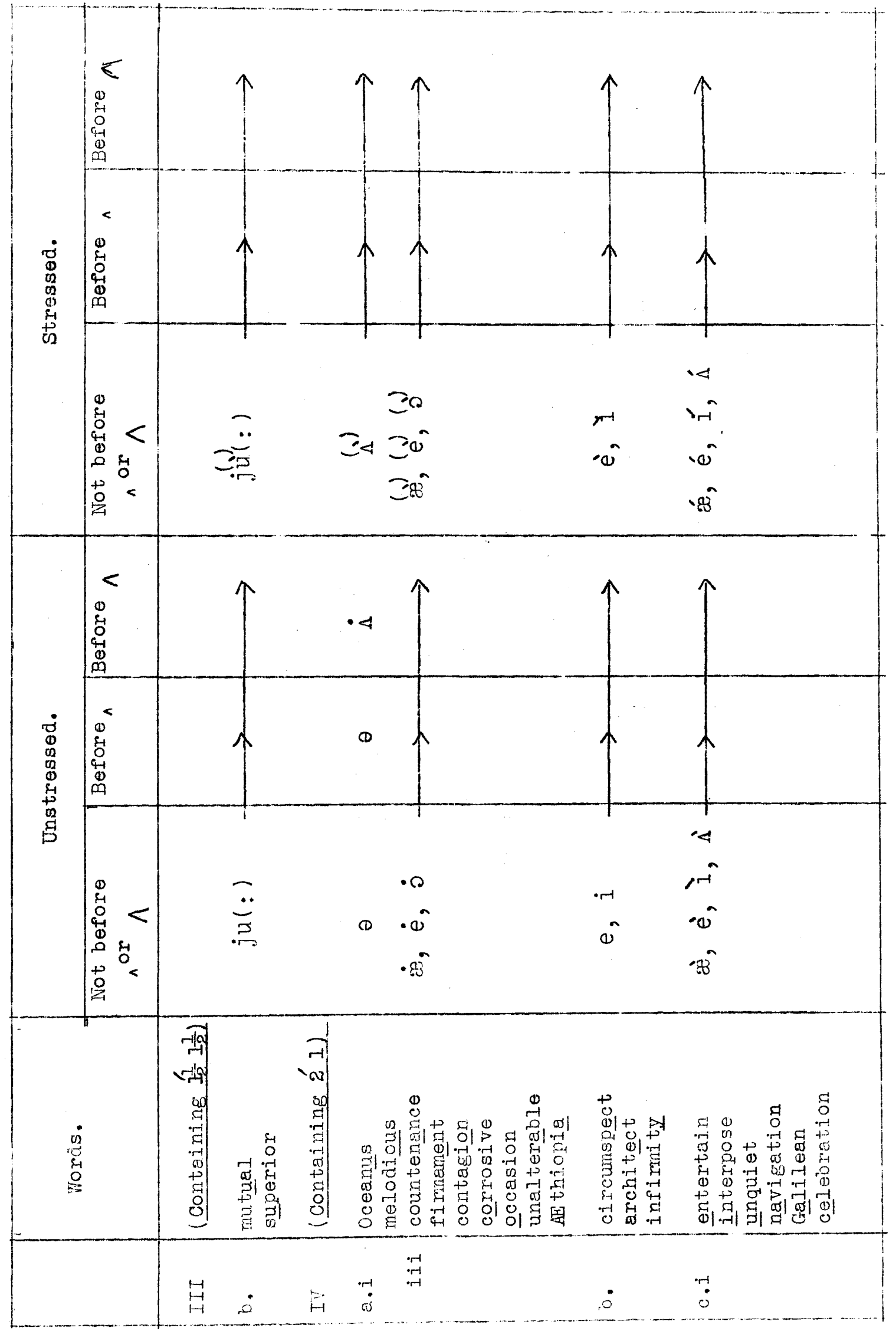




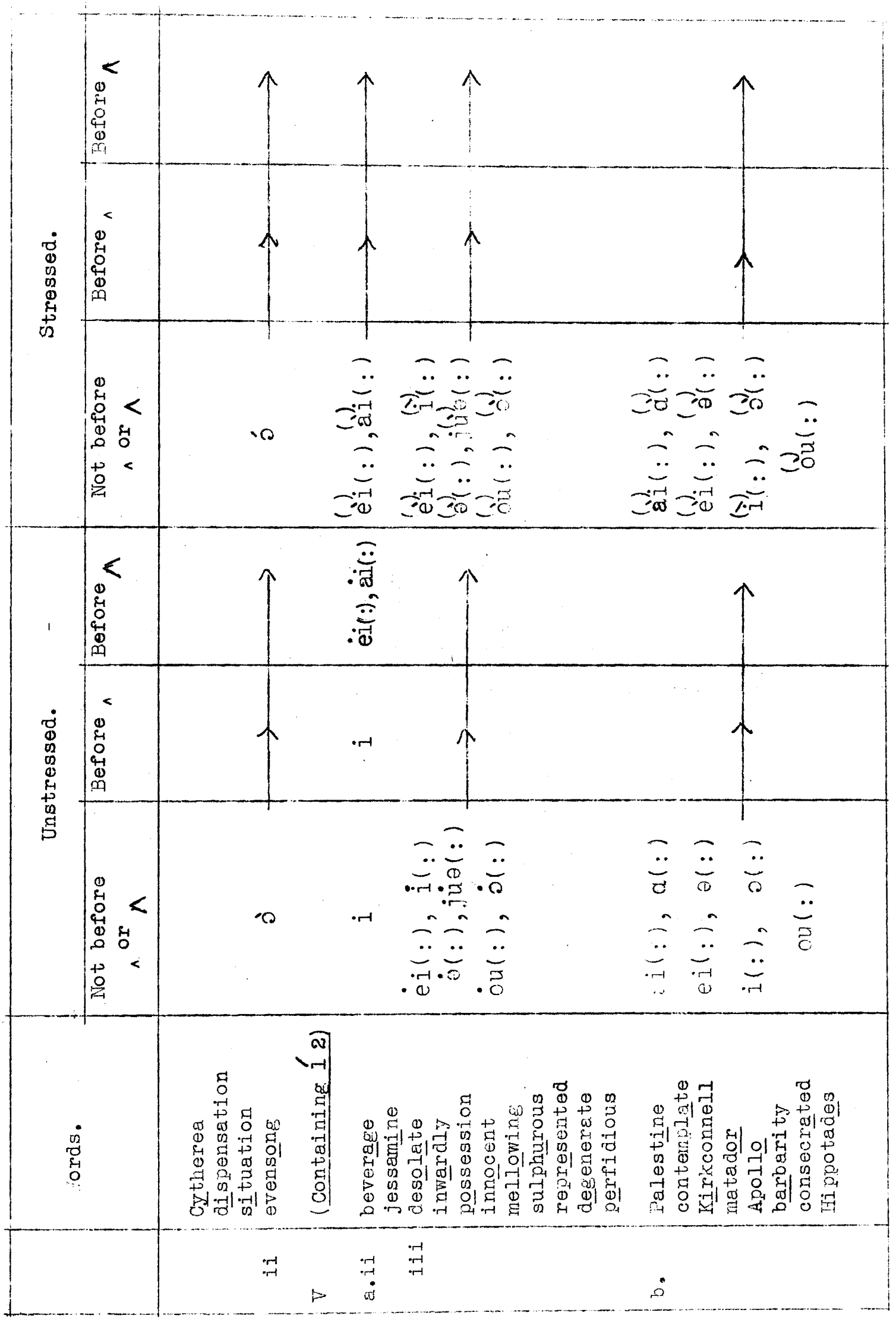




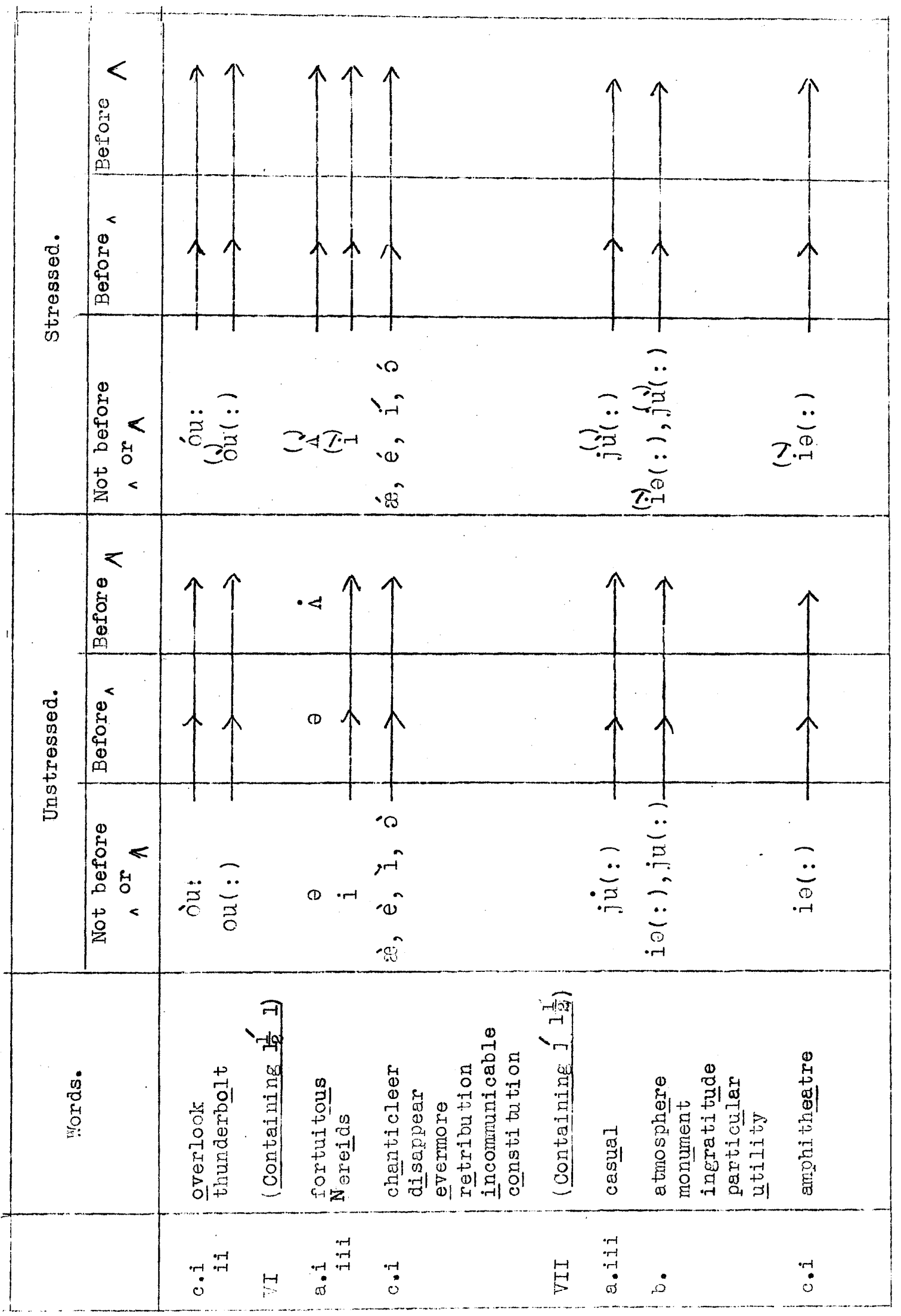




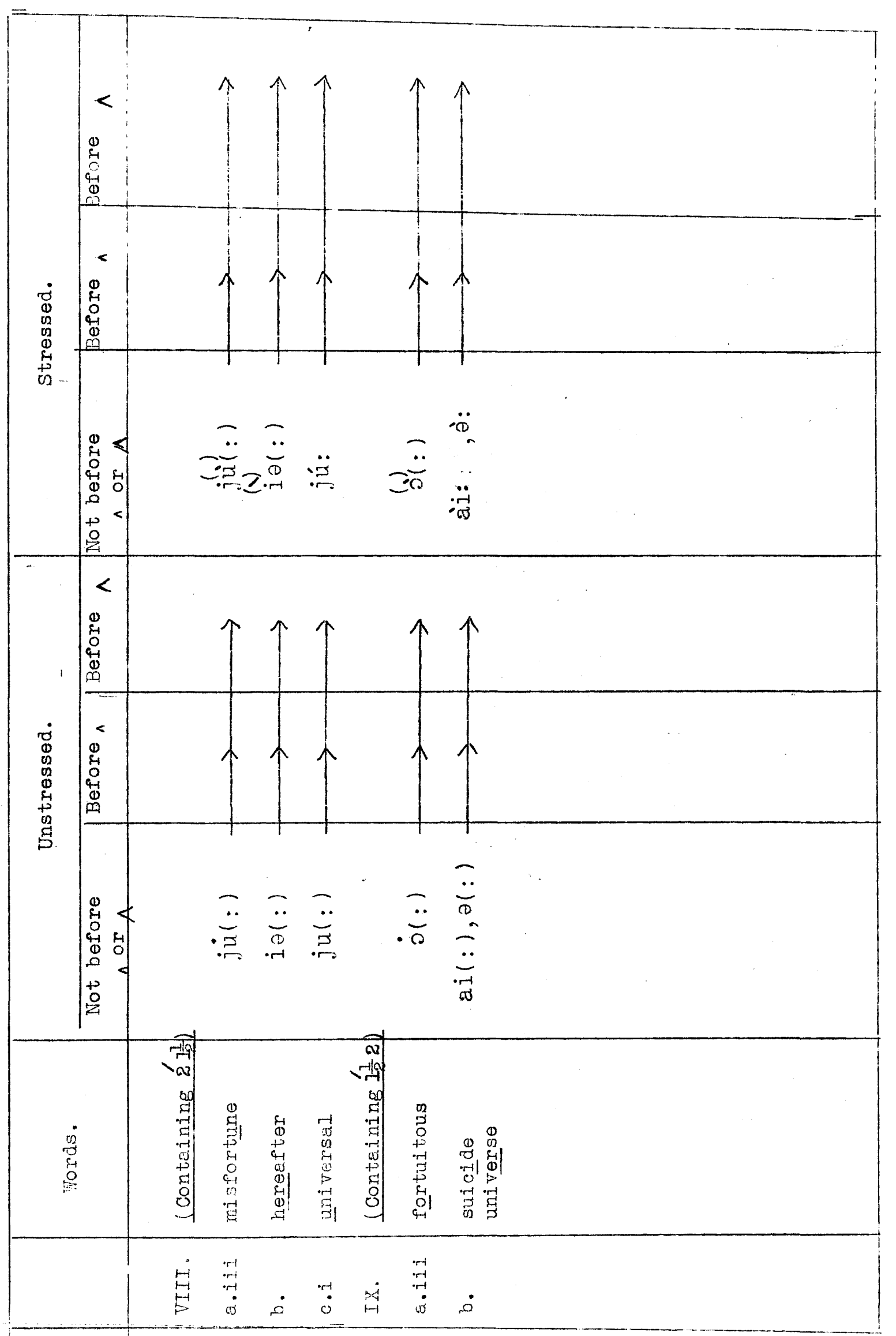


Notes.

1) After considerable hesitation it was decided that, when the last syllable of words like merrily is in a stressed position and there is no unusually strong foot near it to compensate for its weakness, its vowel rises to the strength indicated by $\dot{i}$, that is, it is nearer $i^{\prime}$ than $i$. Parallel to this, the last vowel in a word belonging to the b) subdivision of type II rises, when it is stressed, to $\dot{x}:$, as in nightingale. Consequently the first vowel sound of AEthiopia, and even of overlook in type $V$, members of c) subdivisions, rise when stressed to $\dot{x}:$ 。

2) The reduced vowels of a) subdivisions are not bracketed for, although they are unaccented, it is, in double metres, more possible for them to fall in metrically stressed positions than it is for the similarly reduced vowels of dissyllables. Fxamples actually met are jessamine and viperine.

3) In $\mathrm{Vb}$, as in the $\mathrm{Vb}$ subdivision of dissyllables, the reduced vowel sound can, however, in no circumstances rise above an (ง) x(:) level for otherwise, as in the last syllable of Palestine and Apollo, it would exceed the strength of the unreduced, stressed vowel. Similarly the last vowel sound of thunderbolt in Vc (unlike the first of overlook) never rises above $(y)$ ou(:), and the second last of amphitheatre in VIIC never rises above (I) $(:)$. On the other hand, in IXb the $\theta(:)$ of universe can, when stressed, become $\dot{v}$ : without exceeding the strength of jú:.

(1) V. V0.1. II, No. A 37 and No. L 9. 
4. The Effect of Metres other than Double Metres

on the Reduction of Vowel Sounds.

The reduction of vorel sounds in four other types of metre was next examined, in triple metres, in the "mixed" metre so frequently used by Kipling and Masefield, in double metres which are rhythmically modified by the introduction of triple feet, and, lastly, in triple metres which are rhythmically modified by the introduction of double feet.

The first two measures can be quickly dismissed for they present nothing new: in triple metres, in comperison with double, since the proportion of unstressed to stressed syllables is greater, the general tempo is quicker; but, as this does not affect the relative speed of unstressed and stressed syllables, vowel sounds are reduced in the same degree as in double metres. It was found that the refrain of some of Shakespeare's songs is in triple metre although the main part is in double. The line, with a hey and a ho and a hey nonino" (1) in It was a lover and his lass is one example of this, and the end of (2)

each verse of Blow, blow thou winter wind is another; perhaps the "Come (3)

hither" line of Under the greenwood tree is a third, although the extra syllable in this line is, partly at least, explained by the caesura after "-er". The vowel sounds in these refrains are reduced exactly as those in poems built on a triple metre throughout; and here, as there, feet
(1) V.Vol. II, No. A ?.
(2) $\bar{V} \cdot$ Vol. II, No. B 61 .
(3) $\overline{\mathrm{V}}$.Vol. II, Nos. A 4 and A 5 . 
of the $\mid x \times\langle\times|$ or even the $|x|\langle x|$ type appear at the end of lines, being parallel to the $|x| x \mid$ type in hypermetrical double metres.

In the second type of metre, "mixed" metre, which is composed of rising double and rising trible feet in almost equal proportions, and whose tempo is therefore midway between that of double and that of triple metres, such unstressed vowels as are not reduced below $\dot{x}$ or $\dot{x}:$ occur oftener in double than in triple feet, for, if their retarding effect made itself felt in the latter, a too evident disproportion between the lengths of the two types of foot would result. In the verse from Atalanta in Calydon beginning "When the hounds of (1) spring:, no $\dot{x}$ appears in an unstressed position and the single $\dot{x}:$, occurring as it does in the double foot $\mid$ bright night!, is used for the purpose of focusing attention on the subject of the last four lines (2) of the verse. Hardy's Afterwards, as verses three and five clearly show, is written in the same metre; in double feet $\dot{x}$ occurs six times (3) in unstressed positions and $\dot{x}$ : five, but in triple feet, while $\dot{x}$ occurs only five times, $\dot{x}$ : occurs not at all. In the verse from $0^{\prime}$ Shaughnessy's (4) Ode beginning "We are the music makers", there is no $\dot{x}$ in any unstressed position and $\dot{x}$, which occurs only thrice, does so twice in a double foot and twice in a foot immediately before a pause. No other poem in "mixed" metre had been analysed when the subject of the reduction of vowels was first considered; but it was soon clear that this measure presents no problem of its own: most of the vowels about whose degree

(1) V. Vol. II, IJo.4 30.

(2) $\overline{\mathrm{V}}$. Vol. II, Nos. $118-122$

(3) Owing to the influence of a pause, one $\dot{x}$ becomes ' $x$ and one $\dot{x}$ : becomes $\dot{x}$ : (4) V. Vol. II, No. A 31. 
of reduction there could be any hesitation occur in double feet and should therefore be treated as if they were in a double metre; the few which occur in triple feet should be treated as they would in the exceptional triple feet of a double metre, that is, in the kind of foot examined in the next paragraph.

In the third type of measure, the extra syllable often occurs before either a câesura or an end-pause: for example, the second, fourth, fifth, and sixth lines of each verse in The splendour falls on (1)

castle walls are hypermetrical. An extra syllable may, however, occur in any foot in a line: there is one in the second line of every verse

and also in other lines of Requiescat; a number occur in the passage (3) from Fra Lippo Lippi, and also at the beginning of the passage from The (4)

Pied Piper, where they suggest speed; and the first line of each verse (5)

of Diaphenia contains at least three. Whether placed before a pause or not, such syllables generally are weak, and their vowels are reduced to the lowest values possible for them in the words concerned. Reduced sounds rise above $\frac{1}{2}$ in five of the fourteen triple feet of the Lake Isle (6)

of Innisfree; but although, in other contexts, all these could have a relative strength of 2 , only one rises here to $1 \frac{1}{2}$. Similarly the vowels of "while" and "though" are reduced to 1 in My Luve's like a red, red (7) rose. In the foot, $/$ upon her ! of Violets the last vowel is reduced to $\dot{\partial}(:)$; and in Requiescat, also, the vowel of the same word is al: in a triple foot (just as that of "for" in / But for péacel is $\left.\dot{\partial}()^{\prime}\right)$ whereas that of "her" in double feet is $\theta(:)$ unless there is special reason for its being further reduced. In Hardy's Afterwards

(1) V.Vol.II,Nos.B6:3,B64, andC87 (5) V.Vol. II, No. AlO.

(2) V.Vol. II, NO.B67. (6) V. VOI.II, NO. 560.

(3) $\bar{V}$. Vol. II, No. Sils. (7) $\bar{V}$. Vol. II, No. Al8.

(4) $\bar{V} \cdot$ Vol. II,NO. ill6. (8) $\bar{V} \cdot$ VOL. I, No. AI2. 


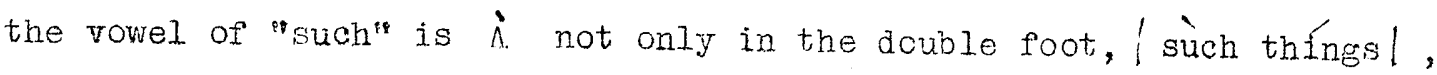
but also in the first foot of f for such mys (-teries); in the triple foot, however, it might well have been $\Lambda$ or $\dot{\Lambda}$ if the weakness of the ${ }_{i}$ in the last foot had not called for compensation. Yet triple feet in a double metre occasionally have $\dot{x}$ or $\dot{x}$ : in an unstressed position, for they occasionally contain more than one word with some degree of sentence stress; examples are $\mid \stackrel{x}{-y}$ ring time! in It was a lover and his lass, |love's coming in in omistress mine, and came túmblî̀ng! in The Pied Piper; similarly, in the lines from A Grammarian's Funeral, beginning |His hunidrể's sóon hìt| the last vowel is 'i because "hit" has too much sentence stress to be slurred, whereas the vowel of "him" and "it", which occur in the same position in other lines, is only $i$. It is, however, uncharacteristic for a triple foot in this metre to contain more than one syllable with an appreciable degree of sentence stress.

In the triple feet of the fourth type of metre, vowels are reduced exactly as in ordinary triple measures. In the exceptional double feet, the vowels could not individually be longer than they sometimes are in ordinary double measures, but without creating a greater sense of obstruction than exists there, their average length could be longer; yet in the poems analysed they were not found to be so. In (3) Dirge, the syllables in the unstressed position of the double feet are with one exception weak, in the last two Iines so weak that they disappear entirely from the second feet and have no vowel in the first; apart

(I) V. Vol. II, No. C69.

(2) $\bar{V}$. Vol. II, No. A29.

(3) $\bar{V}$. Vol. II, No. C88. 
from the one exception none of their rowels rises above $\frac{1}{3}$. On the other hand, as many as five of the triple feet contain $\dot{x}$ or $\dot{x}$ : thus being retarded more than they would be in "mixed" metre. A comparison of the different passages from the Wanderer illustrates the onomatopôeic effect of substituting double for triple feet in this metre and also of varying the relative strength of the vowels in unstressed positions in both types of feet. Except in the initial (1) feet of its truncated lines, the description of the dawn contains no double feet; the unstressed syllable of one double foot has a relative strength of 1 ; in the triple feet $\dot{x}$ : occurs only twice and $\dot{x}$ not at all. Hence the calm scene is described in a smooth, calm rhythm. The (2) passage describing the engineman lighting the lamps has also only the initial double feet; but the rhythm in the last two lines, where his difficulty increases, is jerkier and suggests obstruction more, because $\dot{x}^{(3)} \dot{x}:$, and $x(:)$ all appear in triple feet. In the description of the (4) tumult at night the rhythm is less regular: two of the initial feet, which are again double, are of the falling type; there are two other double feet; and the sense of obstruction is increased because $\dot{x}$ occurs four times and $\dot{x}$ : three in unstressed positions of triple feet. In the description of the ship beaten and battered by the tempest, the subject and sound are alike more chaotic. Three of the initial double feet are of the falling type; two of them have unstressed syllables as strong as 1; there are five other double feet with unstressed syllables of different strengths; the triple feet also convey an impression of
(1) V. Vol. II, No. C92.
(2) $\bar{V}$. Vol. II, No. BIol.
(4) V.Vol. II, No. Elo2.
(3) Cf.p.137 footnote (3).
(5) V.Vol. II, No. S103. 
irregularity and obstruction because they contain both $\dot{x}$ and $\vec{x}$ :

at least half a dozen times.

The treatment of vowels in triple feet has thus been

shown to be the same as in double except that in "mixed" metre, and still more in double rhythms containing a strong triple element, vowels are reduced to their lowest values oftener than they are in the double feet of comparatively metrical double rhythms. 


\section{TOWEL SOUNDS IN POTTRY their Music and Tone-Colour}

\section{Volume II}

by

Mary M. Macdermott 


\section{THE WORDS AND VOWELS \\ O $\mathrm{FH} \mathrm{E}$}

PASSAGEST A ALYZED 


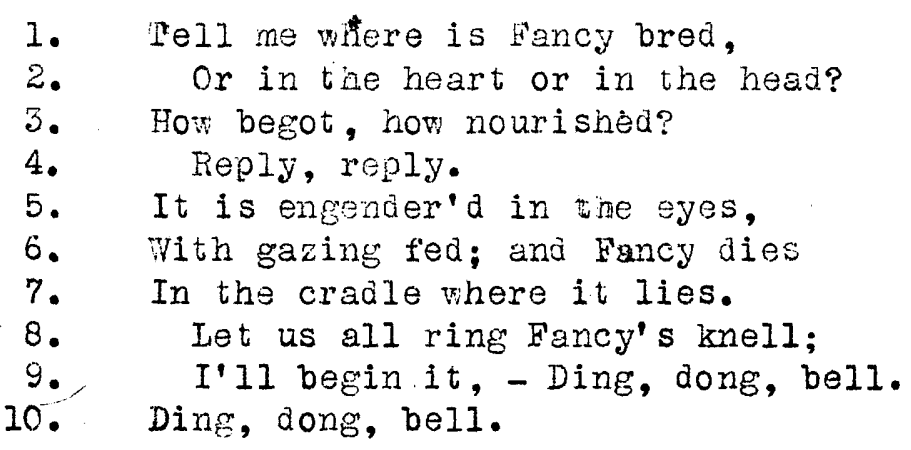

Song by Whake speare,

("The Merchant of Venice" III.2.63).

1. 白 $i(:)_{\wedge} \varepsilon_{\partial}: \quad i \quad \dot{z} \quad i \quad \dot{\theta}_{A}$

2. ว: $i$ o $\dot{a}_{A}$ j: $i \quad \theta_{\wedge}$

3. au: $i(:)$ on $a(:)$ i $i \quad \hat{e}_{A}{ }^{\wedge}$

4. $i(:)$ ái: $i(:)$ ái:

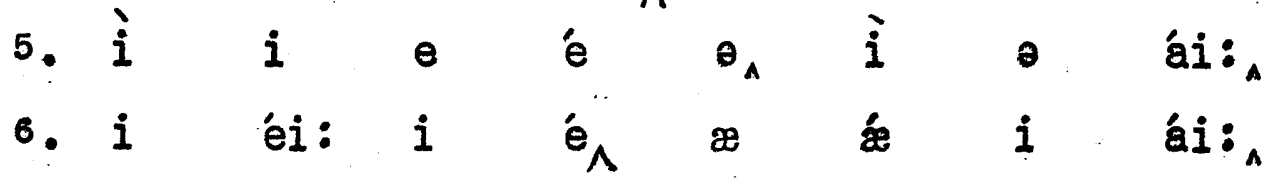

7. i

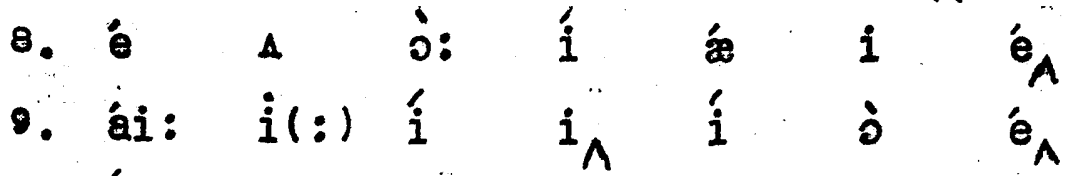

10. $i \quad s \quad e_{A}$ 
1. Who is Silvia? What is she?

2. That all our swains commend her?

3. Holy, fair, and wise is she;

4. The heaven such grace did lend her,

5. That she might admireà be.

6. Is she kind as she is fair?

7. For beauty lives with kindness:

8. Love doth to her eyes repair,

9. To help him of his blindness;

10. And, being help'd, inhabits there.

11. Then to Silvia let us sing,

12. That Silvia is excelling;

13. She excels each mortal thing

14. Upon the dull earth dwelling:

15. To her let us garlands bring.

Song by $W$. Shakespeare.

(TwO Gentlemen of Veronemp $2,2,39)$.
1. ú: i . '
i
$x_{A}$
ذे
$i \quad i: \Lambda$
2. ə ó: áuə(: léi:
j é
$\dot{\theta}(:) \wedge$

3. ou: $i$ ยै :

ái: i

i: $\wedge$

4. 2 é

$\triangle$ éi :

i

é

$\dot{\partial}(:)$

5. $\ddot{i} \quad \dot{i}(:)$ ài: $\dot{\circledast}$

áie: i

i.

6. $i$

i(:) ái: \&

i: $i$

$\varepsilon \theta: \wedge$

7. $j(:)$ jú: $i$ í

i

ái:

$\dot{e}_{A}$

8. 1

1

$\dot{u}(:$

$\dot{\theta}(:)$

ái:

il: $)$

Eə:

- $\dot{u}(:) \dot{\theta} i$

i

i

ái:

$\dot{\theta}_{A}$

10. $\ddot{A}_{A} i(:) \quad i$

é

i

11. é

$\dot{u}(:) \grave{i}$

i

$w_{\wedge}$

2́

i

è

4

$\varepsilon \theta$

12. $æ$ í

i

i

é

é

é

$\mathbb{2}_{\text {A }}$

i(:) o:

$\dot{x}$

$i_{A}$

14. i

b

$\theta$

A

क्s

é

15. นิ:

$\theta(:)$, è

$\Lambda$

á:

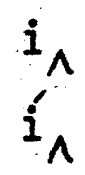




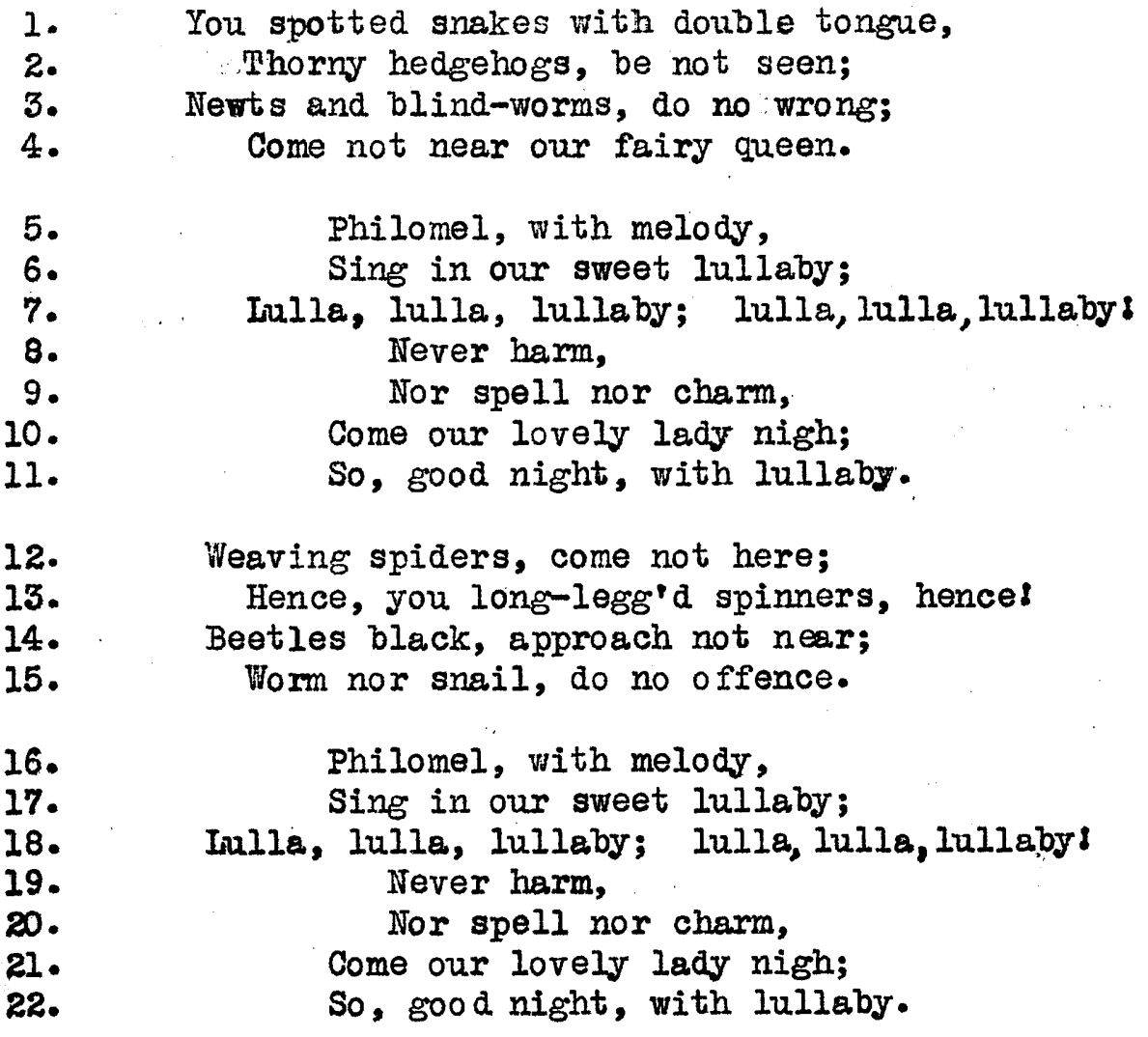

"A Midsumer Hight's Dream" (II.3.9.) Song by W. Shakespeare. 
1. jul: ! o i éi: $i$ i $i_{\wedge}$

2. o: $i$ o $\partial_{\wedge}$ i: 0 i:

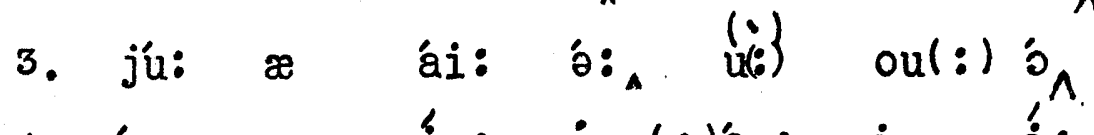

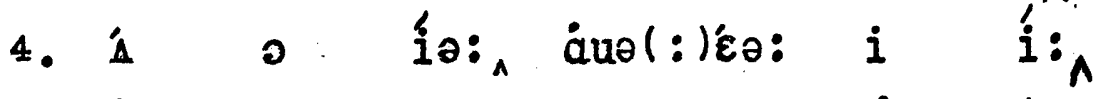

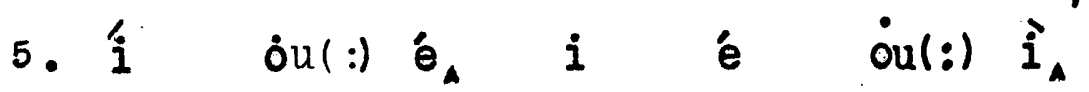

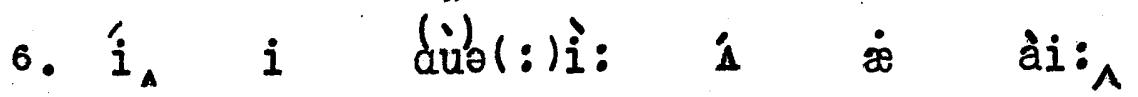

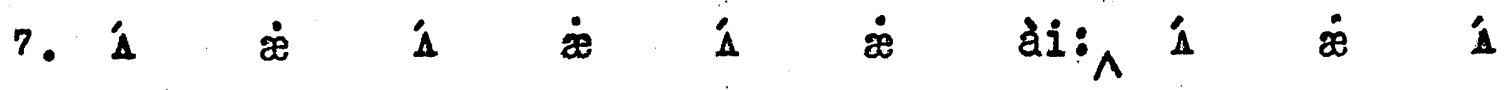
$\dot{\ddot{z}} \quad \dot{\mathbf{A}} \dot{\mathfrak{z}} \quad \dot{\mathrm{a} i}:_{\wedge}$

8. é ว á:

๑. $\dot{\partial}(:) e_{A} \dot{b}(:) \quad a:_{A}$

10. is áuol: lá $i$ éi: $i$ ai ${ }_{\Lambda}$

11. ous ì ái: $i$ í $\dot{a}$ ài:

12. $i:$ i ái: $\theta_{A}$ i 0 io:

13. $\left.\dot{\theta}_{A} j \dot{j u}:\right)^{\prime} \dot{o}$ è $i \quad \theta_{A} \dot{e}_{\wedge}$

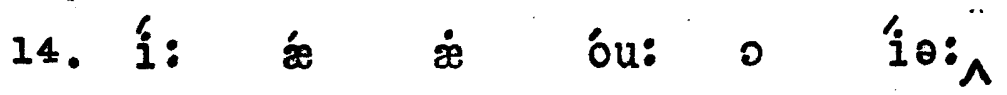

15. ó: ol: éi: $u(:)$ du: $\dot{j} \dot{e}_{\wedge}$

16. '́ $\dot{i}(:) \dot{e}_{A} i \quad \dot{o u}(:) \hat{i}_{A}$

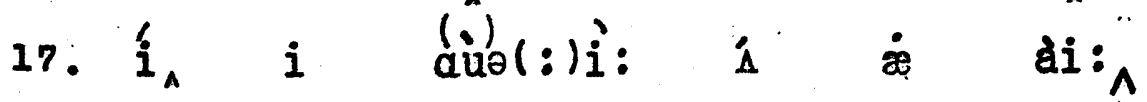

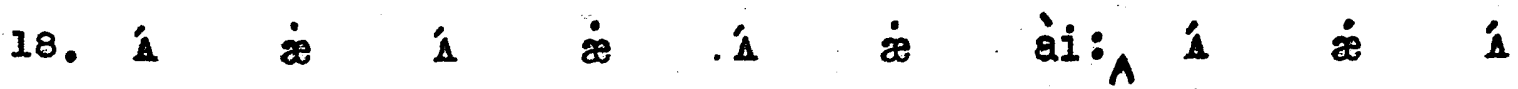
$\dot{z} \dot{\mathbf{A}} \dot{\boldsymbol{z}}$ ài $\dot{\wedge}_{\wedge}$

19. é ə a:

20. $\dot{\partial}(:) e_{\wedge} \quad \dot{\partial}(:) \quad a:_{A}$

21. I áuว(:)ís $i$ éi: $i$ ái: $\wedge$

22. ou: $\dot{a}$ ái: $i$ is $\dot{z}$ ài $:_{\wedge}$ 
1. Under the greenwood tree

2. Who loves to lie with me,

3. And tarn his merry note

4. Unto the sweet bird's throat -

5. Come hither, come hither, come hither.

6. Here shall he see

7. No enemy

8. But winter and rough weather.

"Under the Greenwood Tree" (

by W. Shakespeare.

("Twelfth Night" II.5.1.)

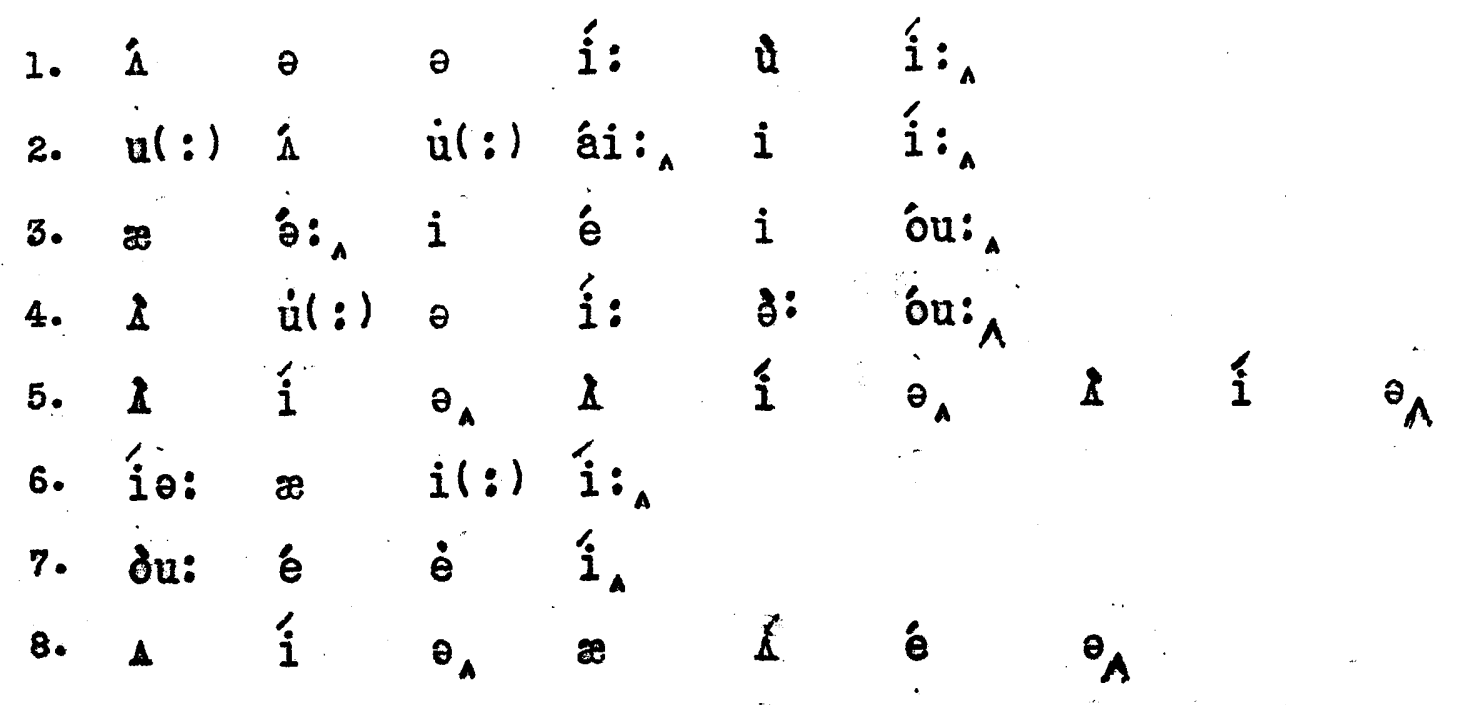


A 5

1. Who doth ambition shun

2. And loves to live i' the sun,

3. Seeking the food he eats

4. And pleased with what he gets -

5. Come hither, come hither, come hither?

6. Here shall he see

7. No enemy.

8. But winter and rough weather.

"Under the Greenwood Tree" (v.2.) by W. Shakespeare

("As You Like It" II.5.38.)

1. $\mathfrak{u}(:) \mathbb{R}$

2. $\approx \dot{\Lambda}$

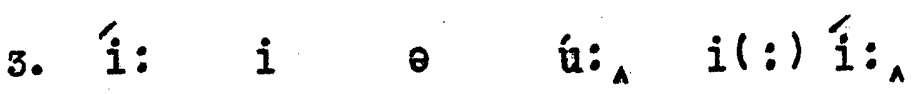

4. $\approx i i_{A} i \quad j \quad i(:) \dot{e}_{A}$

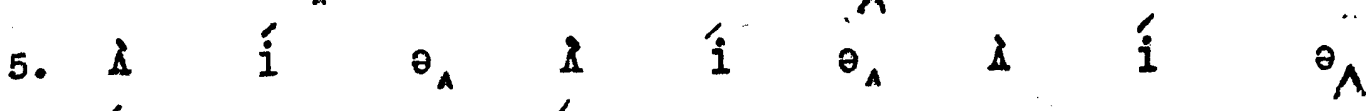

6. 'in: æ $i(:)$ 'i:

7. dou: es $\dot{e} \grave{i}_{\wedge}$

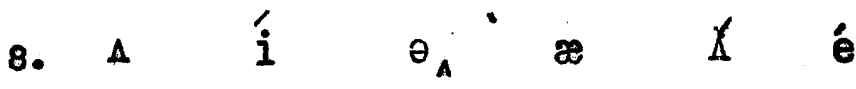


1. deffodils

2. That come before the swallow dares, and take

3. The winds of March with beauty; violets dim,

4. But sweeter than the lids of Juno's eyes

5. Or Cytherea's breath.

"A Winter's Tale" (IV.3.118)

by W. Shakespeare.

1. \& oul:) í

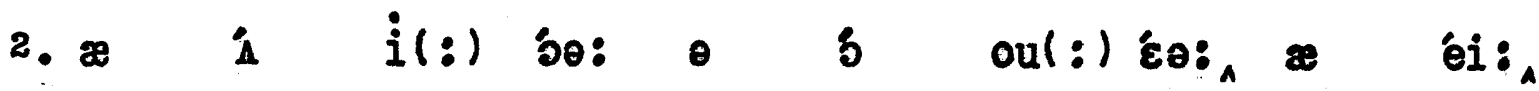

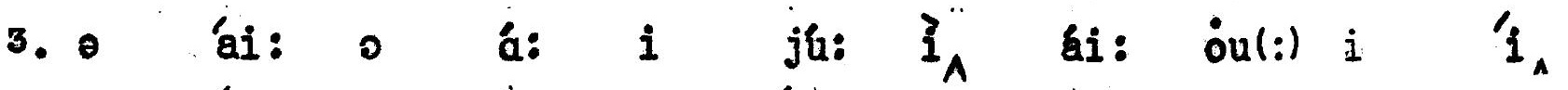

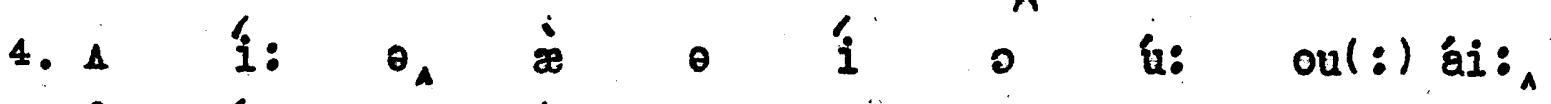

5. $\dot{j}(:)$ i $\theta$ í $\dot{*} \quad \hat{e}_{A}$ 
1. It was a lover and his lass

2. With a hey and a ho, and a hey-nonino

3. That o'er the green cornfield did pass

4. In the spring time, the only pretty ring time,

5. When birds do sing hey ding a ding ding:

6. Sweet lovers love the Spring.

7. Between the acres of the rye

8. These pretty country folks would lie:

9. This carol they began that hour, 10. How that a life was but a flower:

11. And therefore take the present time

12. With a hey and a ho, and a hey-nonino!

13. For love is crowned with the prime

14. In spring time, the only pretty ring time,

15. When birds do sing hey ding a ding ding:

16. Sweet lovers love the Spring.

Song by W. Shakespeare, ("As You Like It", V.3.18). 


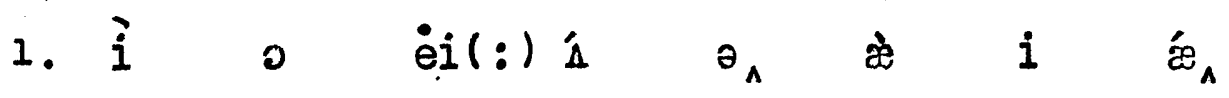

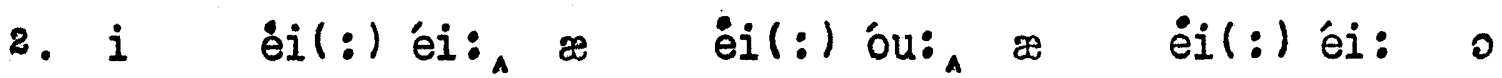

i ou:

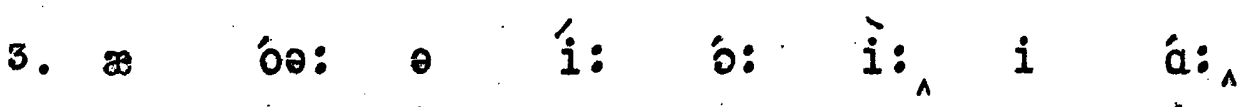

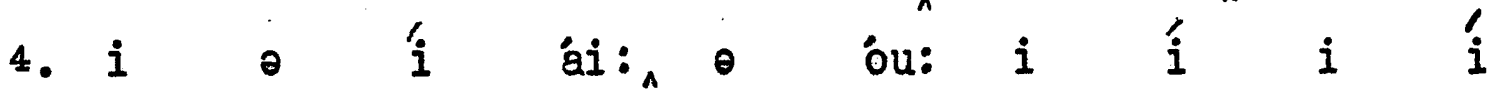

ài:

5. e ó: $u(:) \hat{i}_{A}$ ei(:)'i $\dot{e}_{i}(:) i \quad i_{\wedge}$

6. i: $i$ o $\theta_{\wedge}$ i $\quad \theta \quad i_{\Lambda}$

7. $i(:)$ i: $i$ éi: o $\theta$ ái:

8. $i(:)$ i $i$ i $i$ ou: $u$ ái:

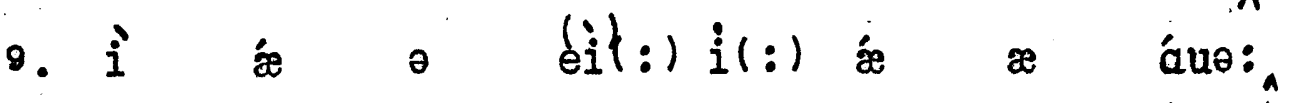

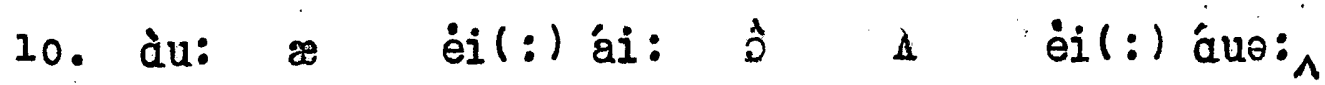

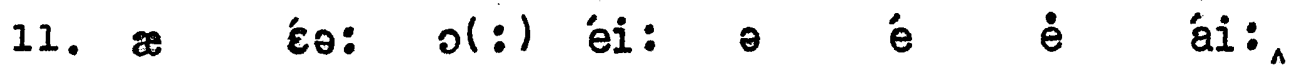

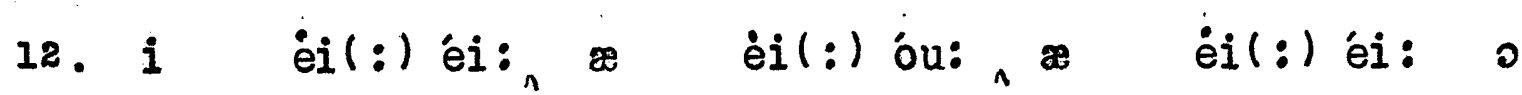

i ou:

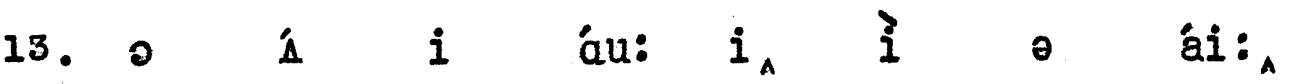

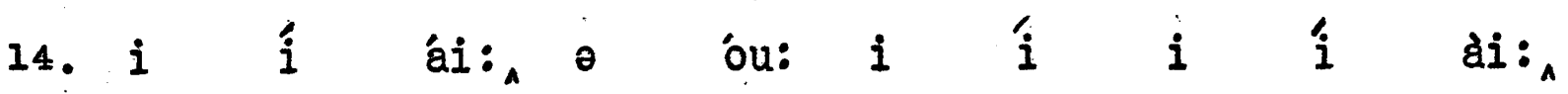

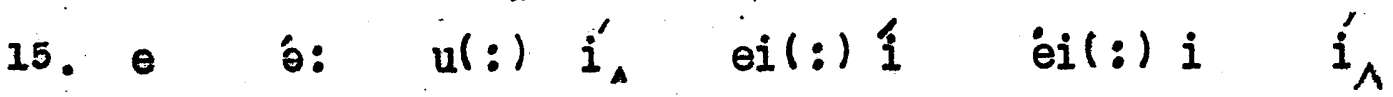

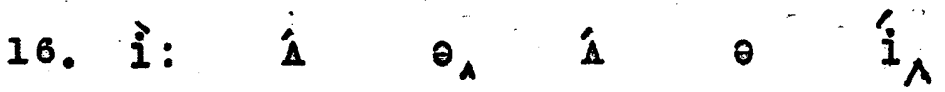




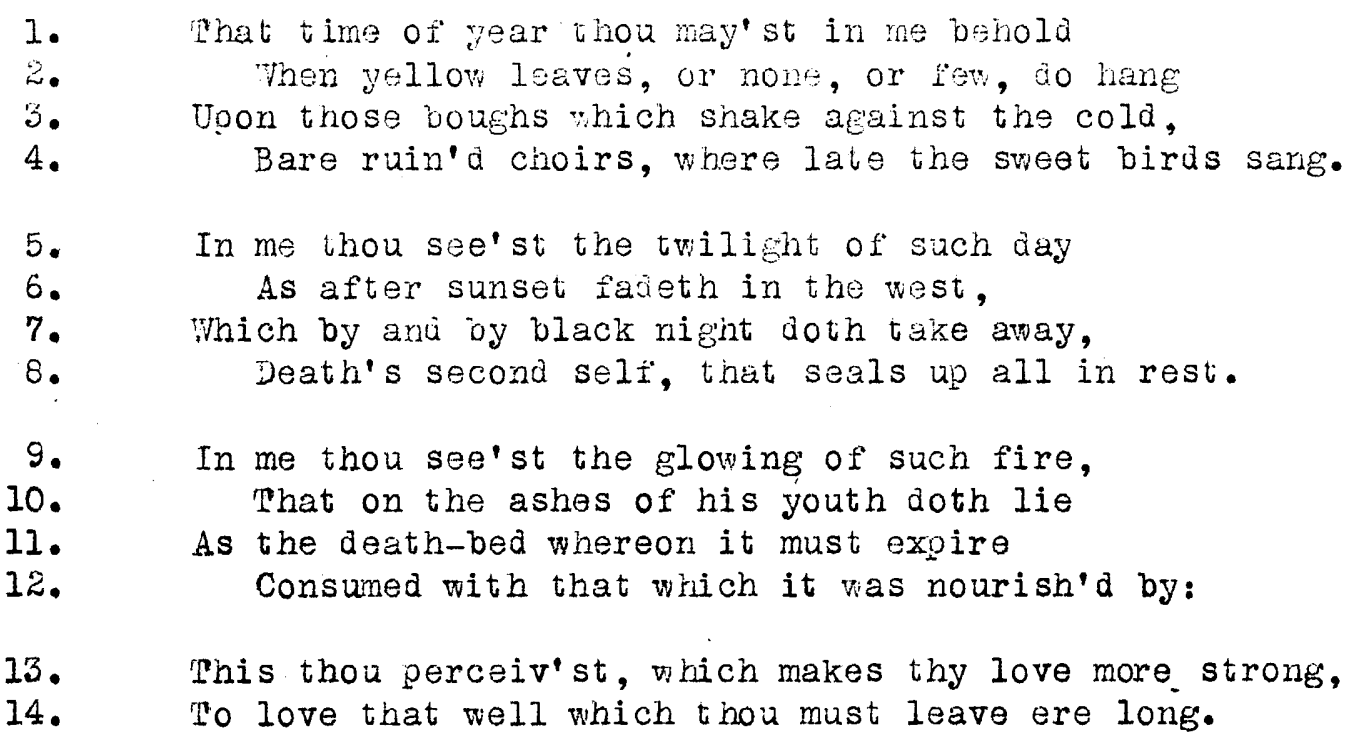

W. Shakespeare.

1. ǽ ài: o 'io: $a u(:)$ éi: $i$ í: $i(:)$ ou:

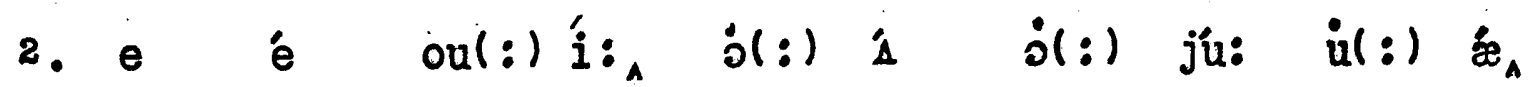
3. $\dot{i}$ o oul $:)$ áu: $i$ éi: $\dot{z}$ èi: $\theta$ óu:

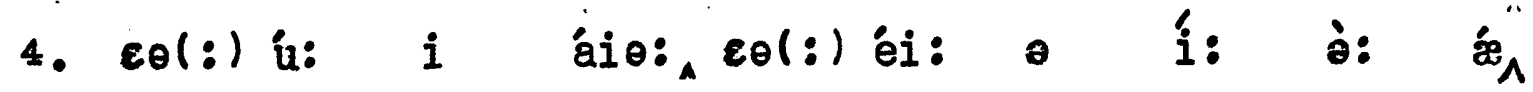
5. $i$ í $a(:){ }^{\prime} i:_{\wedge}$ o ái: ail: 0 a éi:

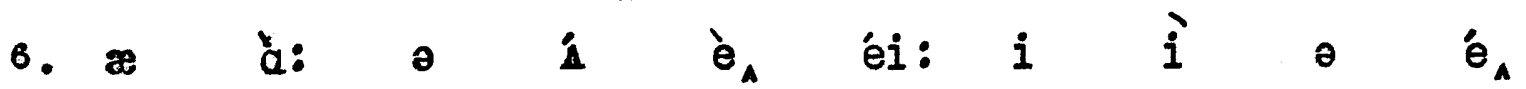

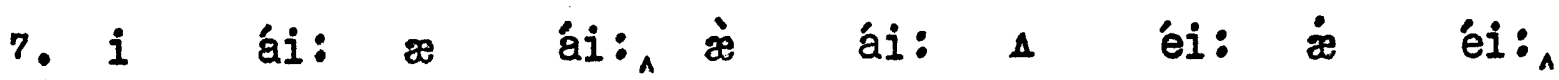

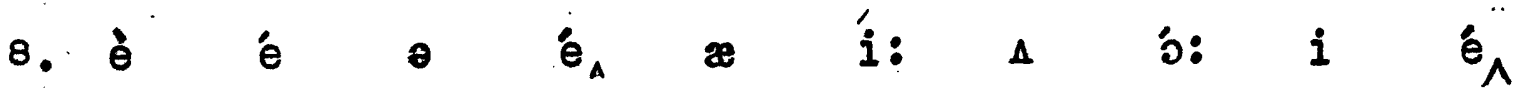
9. $i$ i: $a u(:)$ í ${ }_{\wedge}$ o ou: $i$ o $i$ áiə:

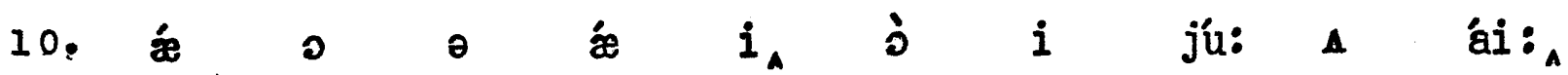

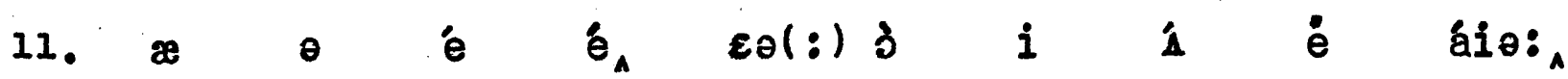

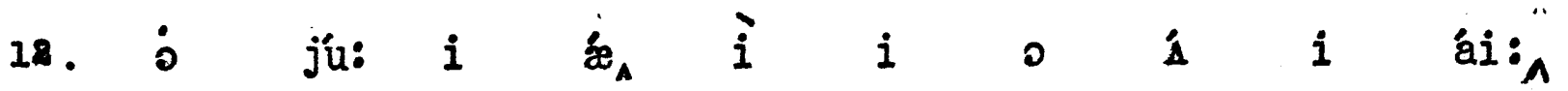

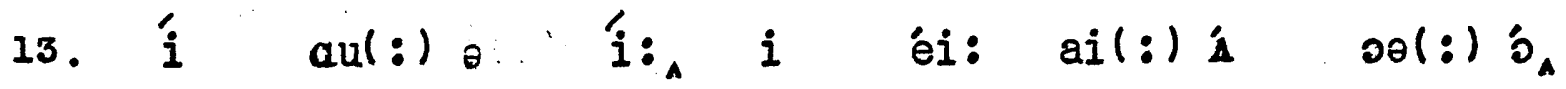
14. $\dot{u}(:)$ i $\dot{e} \dot{\theta}_{\wedge} i$ du: $i$ i: $\varepsilon \partial(:) \partial_{\wedge}$ 
A. 9

1. Take, 0 take those lips away,

2. That so sweetly were forsworn;

3. And those eyes, the break of day,

4. Lights that do mislead the morn!

5. But my kisses bring again,

6. Bring again;

7. Seals of love, but seal'd in vain,

8.

Seal'd in vain

Song by W. Shakespeare

("Measure for Measure" IV.I.I.)

1. éi: ^out(:) éi:

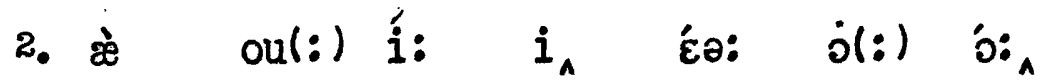

3. æ out(:) ái: $\theta$ éi: 0 éi:

4. ái: $\approx$ u(!) $i$ i: 0 o

5. $i$ ail: $\dot{i}^{\prime} \quad i_{\wedge} \quad \dot{i} \quad \dot{z}$ di $i_{\wedge}$

6. $\dot{i} \dot{\gtrless}$ ii

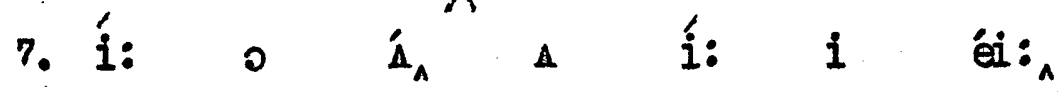

8. í: i ci: 


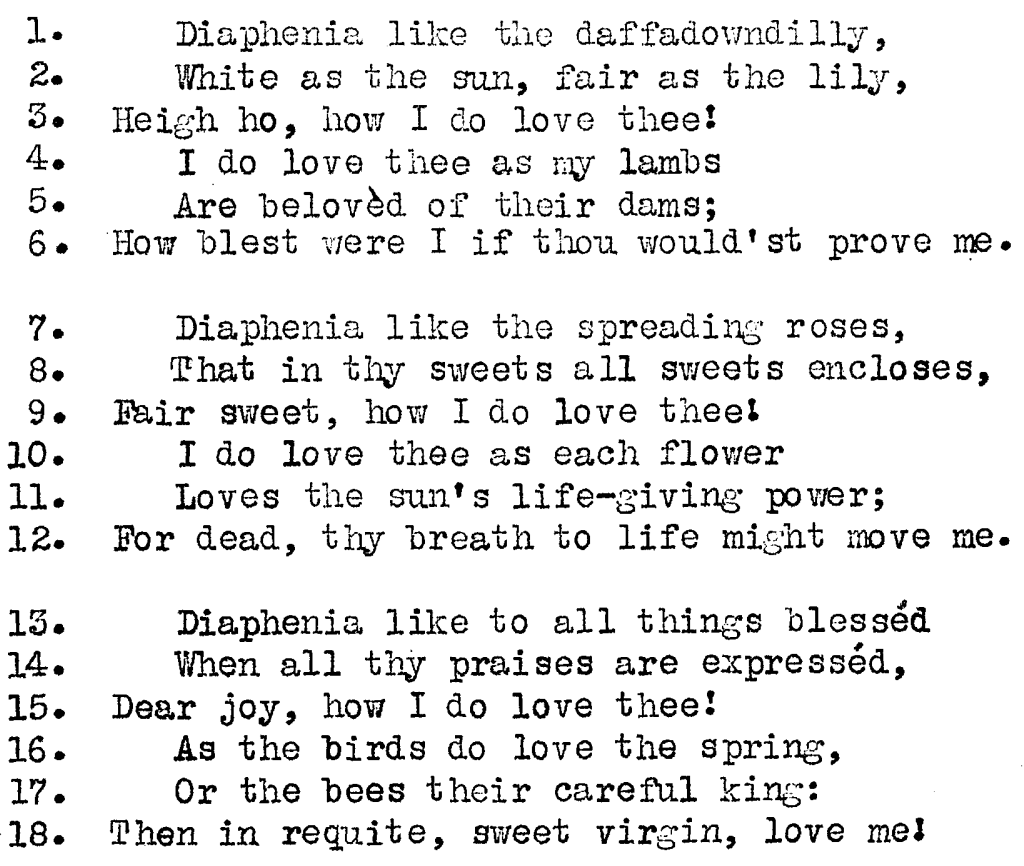

"Diaphenia"

by H. Constable.

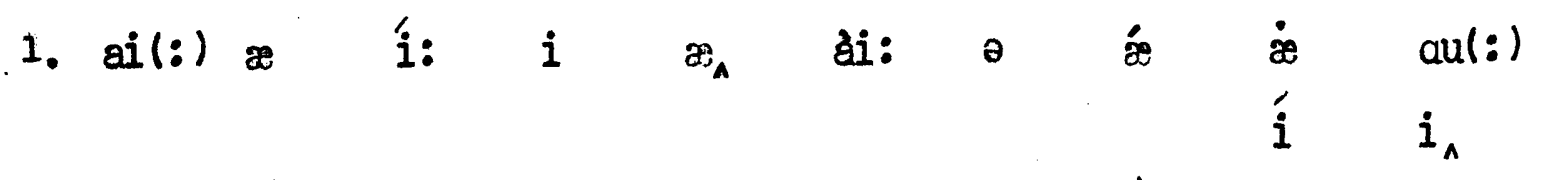

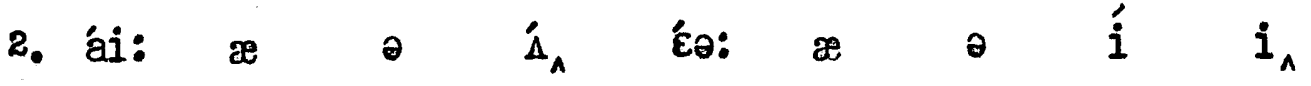

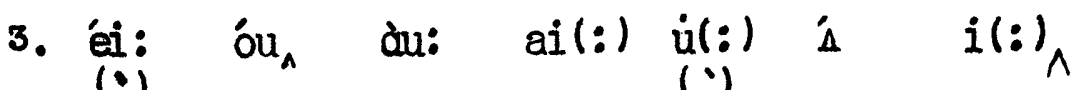

4. ail:) $u(:)$ i $i(:) \stackrel{(}{a}$ ail(:) $\dot{x}_{\wedge}$

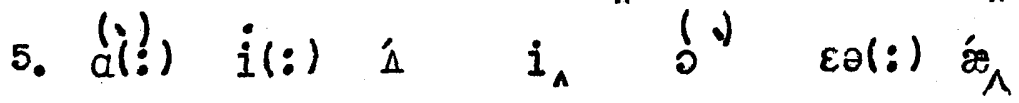

6. $a$ (:) é $\varepsilon_{\theta}(:)$ ài: $i$ dù: $u$ ú $i(:) \wedge$

7. äi(:) $¥$ í: $i$ à $\mathfrak{x}_{\wedge}$ ài: $\curvearrowright$ é $i$ óu: $i_{\wedge}$.

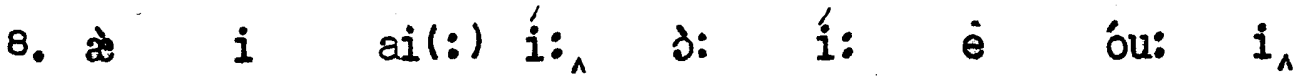

9. Eə: $i:{ }_{\wedge}$ du: $a i(:) \quad u(:)$ $A$ i(:)

10. àl:) $u(:)$ i $i(:)_{\wedge} \stackrel{(}{ }^{\prime} \quad i(:)$ ámo:

11. $\dot{A}$ a $i_{\wedge}$ ai: $i$ i Guә: 
12. $\dot{\partial}(:)$ é ail: $)$ é $u(:)$ ái: ai(:) ú: $i(:) \wedge$ 13. $\operatorname{ai}(:) \approx$ i: $i \quad x_{\wedge}$ di: $u(:)$ b: $i$ é $i_{\wedge}$ 14. e 3: ai(:) éi: $i_{\wedge} \quad(a)$ a $e$ é $i_{\wedge}$ 15. i̇: ói: ${ }_{\wedge}$ du: $a i(:)$ ul: $)$ is $i(:)_{\wedge}$

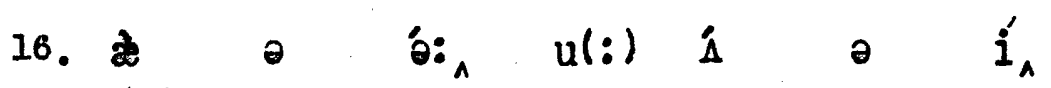

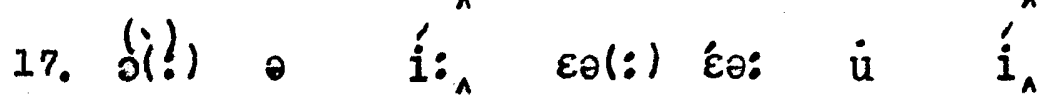
18. $i$ il(:) ái: $\grave{i}$ ó: $i$ a $i(:) \wedge$ 
1. Forget not yet when first began

2. The weary life ye know, since whan

3. The suit, the service none tell can;

4. Forget not yet?

from "Forget not yet"

by Sir Thomas Wyatt.

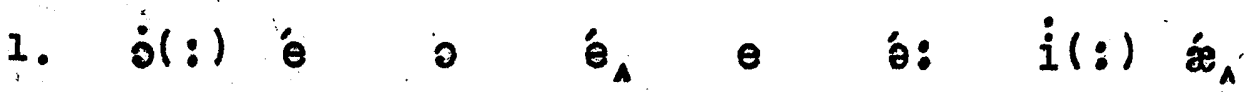

2. $\theta$ io: $i$ ai: $i(:)$ ou: $\hat{\imath} \dot{z}_{A}$

3. $\theta$ jú: $\theta$ a: $i_{A}$ a $\dot{e} \dot{z}_{A}$

4. $\dot{\partial}(:)$ 'e $\supset$ è 


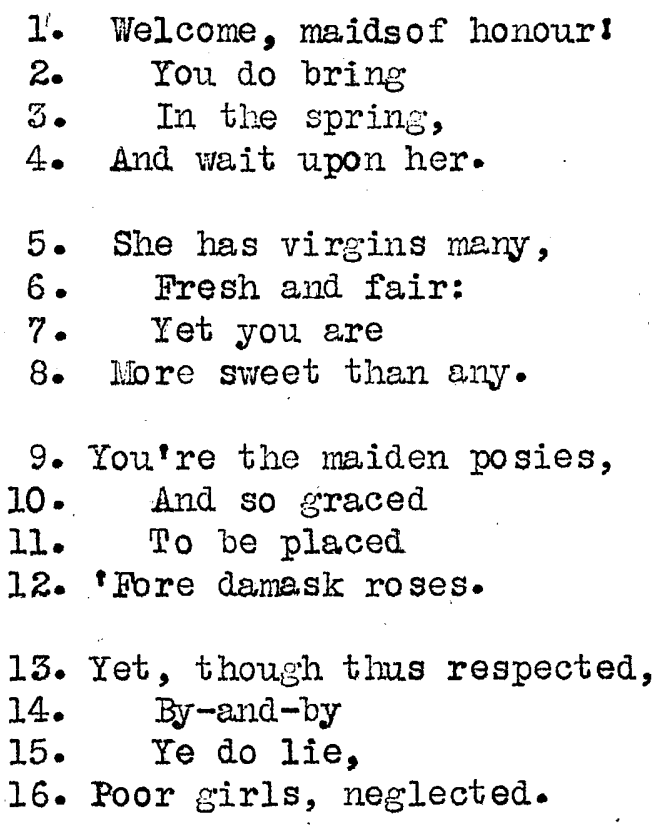

"Tro Violet s"

by R. Herrick.

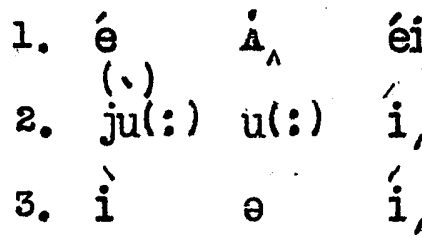

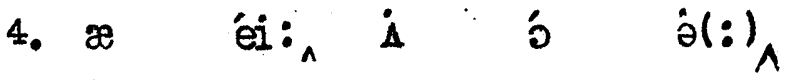

5. i: $\circledast$ ó: $i$ é $i_{\wedge}$

6. é ஐ เว:

7. é jul:) á:

8. $ə(:)$ í $i_{\wedge}$ é $i_{\wedge}$

9. jüu: ${ }_{\wedge} \partial$ éi: $\dot{e}$ óu: $\cdot i_{\wedge}$

10. ¿ ou(:) éi:

11. $u(!) \quad i(:)$ éi:

12. oə(:) ஜ́ $\dot{\gtrless}$ ou: $\dot{e}_{\wedge}$

13. é ou(:) í il(:) é $i_{\wedge}$

14. ái: æ ái:

15. $(i(:)) u(:)$ ái:

16. uə(:) ó: ${ }_{\wedge} \dot{i}(:)$ é $\dot{e}_{\wedge}$ 
1. Drink to me only with thine eyes,

2. And I will pledge with mine;

3. Or leave a kiss but in the cup

4. And I'll not look for wine.

6. Whe thirst that from the soul doth rise

6. Doth ask a drink divine,

7. But might I of Jove's nectar sup,

8. I would not change for thine.

9. I sent thee late a rosy vireath,

10. Not so much honouring thee

11. As giving it a hope that there

12. It could not wither'd be;

13. But thou thereon didst only breathe

14. And send'st it back to me;

15. Since when it grows, and smells, I swear,

16. Not of itself but thee:

$$
\begin{aligned}
& \text { "To Celia" } \\
& \text { by B. Jonson. }
\end{aligned}
$$

1. $i^{\prime} \quad \dot{u}(:) \quad i(:)$ òu: $i_{A} \quad \grave{i}$ ail $(:)$ ái:

2. $¥$ ài: $i$ é $i$ ái:

3. ol: $\dot{i}: \quad \dot{e} i(:) i_{A} \quad \grave{i} \quad i \quad \theta \quad i_{A}$

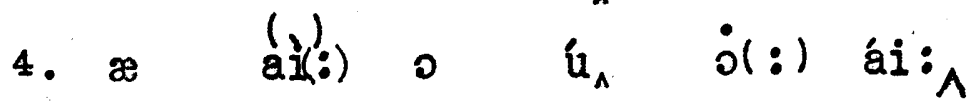

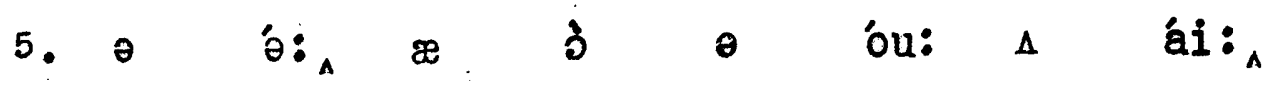

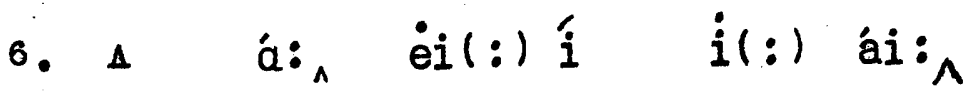

7. $\Delta$ ài: ài: 0 òu: é $a(:)$ is

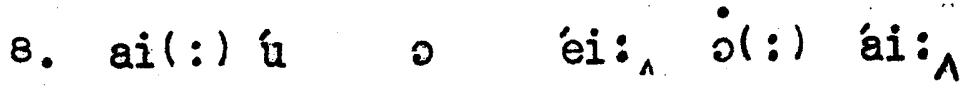

\begin{tabular}{|c|c|c|c|c|c|c|}
\hline $1 \cdot 0$ & oul : : & $\dot{A}_{\Delta}$ & ó & $\stackrel{\ominus}{\bullet}$ & i & $i: A$ \\
\hline 11. æ & i & i & $i$ & ei(:) & ou: & $\dddot{\circledast}$ \\
\hline . $i$ & ú & D & $\grave{i}$ & $\partial$ & $\wedge$ & \\
\hline 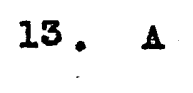 & áu: & $\varepsilon \theta(:)$ & $\dot{b}_{A}$ & $i$ & òu: & $\mathbf{i}$ \\
\hline 14. $¥$ & é & i & $\mathfrak{⿱}_{\wedge}$ & $\mathrm{u}(:$ : & $n$ & \\
\hline s. $i$ & é & i & ou: & $\dddot{x}$ & A. & $a i(:)$ \\
\hline • & 0 & i & é & $\boldsymbol{\Lambda}$ & $i:_{\wedge}$ & \\
\hline
\end{tabular}

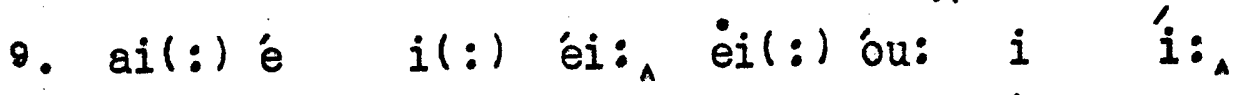




\footnotetext{
1. Why so pale and wan, fond lover?

2. Prythee, viny so pele?

3. Will, when looking well can't move her,

4. Looking ill prevail?

5. Prythee, why so pale?

b. Why so dull and mute, young sinner?

7. Prythee, why so mute?

8. Will, when speaking well can't win her,

9. Saying nothing do't?

10. Prythee, why so mute?

11. Quit, quit, for shame: this will not move,

12. This cannot take her;

13. If of herself she will no iove,

14. Nothing can make her:

15. The devil, take her:
}

"Why so pale and wan, fond lover?" by Sir John Suckling.

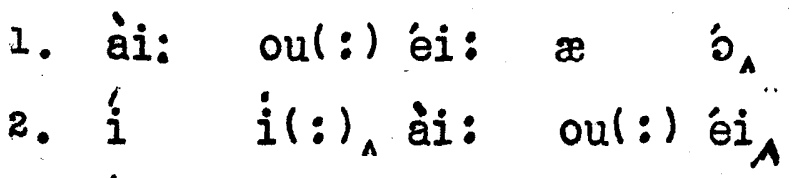

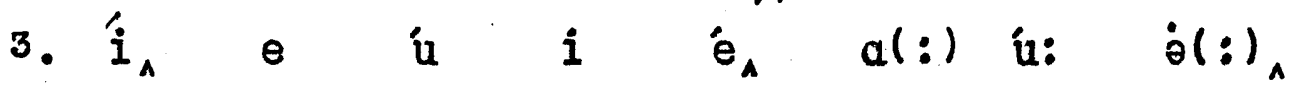

4. u $i$ is $\quad i_{\wedge}(:)$ éi:

5. 'i $i(:)$, ài: oul: $)$ éi:

6. ài: oul:)i $\approx$ jú $:_{\wedge}$ i ${ }^{\prime}{ }_{\wedge}$

7. $i \quad \dot{i}(:)$, ài: oul : $)$ ju:

8. $\hat{i}_{\wedge} e$ i: $i$ é, $a(:)$ i $\quad \dot{\theta}(:)_{\wedge}$

9. éi: $i$ i $\quad i_{\wedge} \quad \hat{u}_{\wedge}$

10. $\dot{i}$ il(:) ài: oul : $)$ jú:

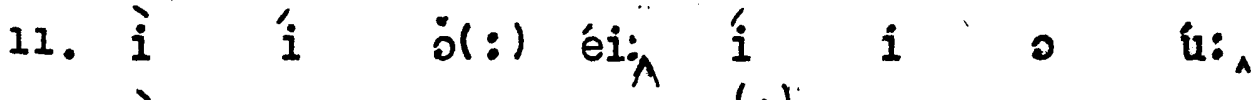

12. $i$ æ 0 éi:

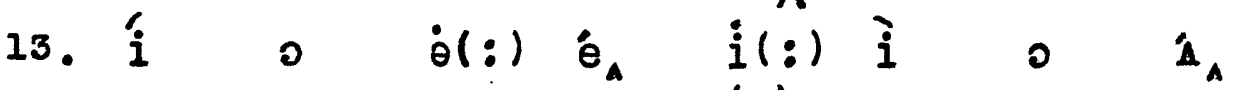

14. I $i$ éi: $\theta(\dot{\theta})$

15. จ é $i$ éi: $\partial$ (ต) 
1. By the rushy-fringèd bank,

2. Where grow the willow and the osier dank,

3 . Iny sliaing chariot stays,

4. Thick set with agate, and the azurn sheen

5. Of turkis blue, and emerald green,

6. That in the channel strays;

7. Whilst from off the waters fleet

8. Thus I set my printless feet

\% O'er the cowslip's velvet head,

10. That bends not as I tread.

11. Gentle swain, at thy request

12 .

I am here:

"Comus" (890-901)

by J. Milton.

1. ài : $\begin{array}{lllllll}\theta & \mathbb{\Lambda} & i & i & i & \dot{B}_{\wedge}\end{array}$

2. $\varepsilon \partial(:)$ óu: $\theta$ o $i$ (: $)_{\wedge} æ$ $i$ óu:

3. ai(:) ái: $i$ \&́ i $\theta$ éi :

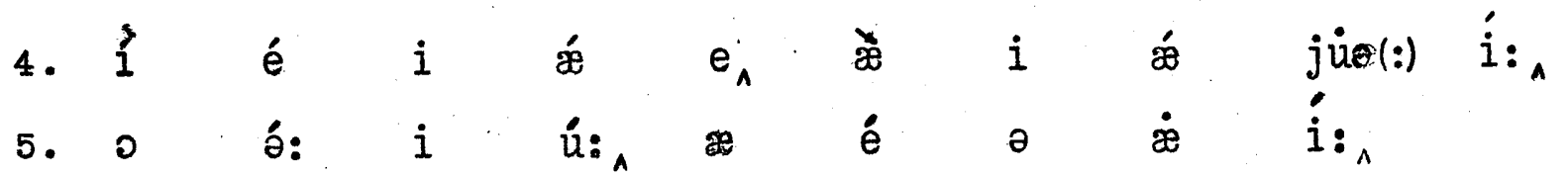

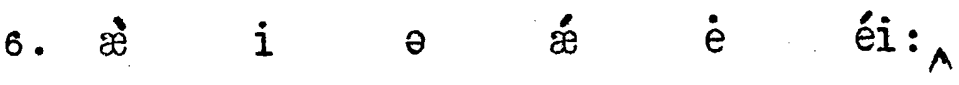

7. ài: ○ ó: $\theta$ ว́:

8. $\hat{A}$ ai(:) é $e_{\wedge}$ ai(:) $i^{\gamma} i \quad i:_{\wedge}$

9. $\quad$ Oə(:) $\theta$ áu: $i$ é $i$ é

io. æ é ó $æ$ a $a i(:) e_{\Lambda}$

11. é éi: $\&$ ái; il(:) é

12. ái $æ$ iə: 


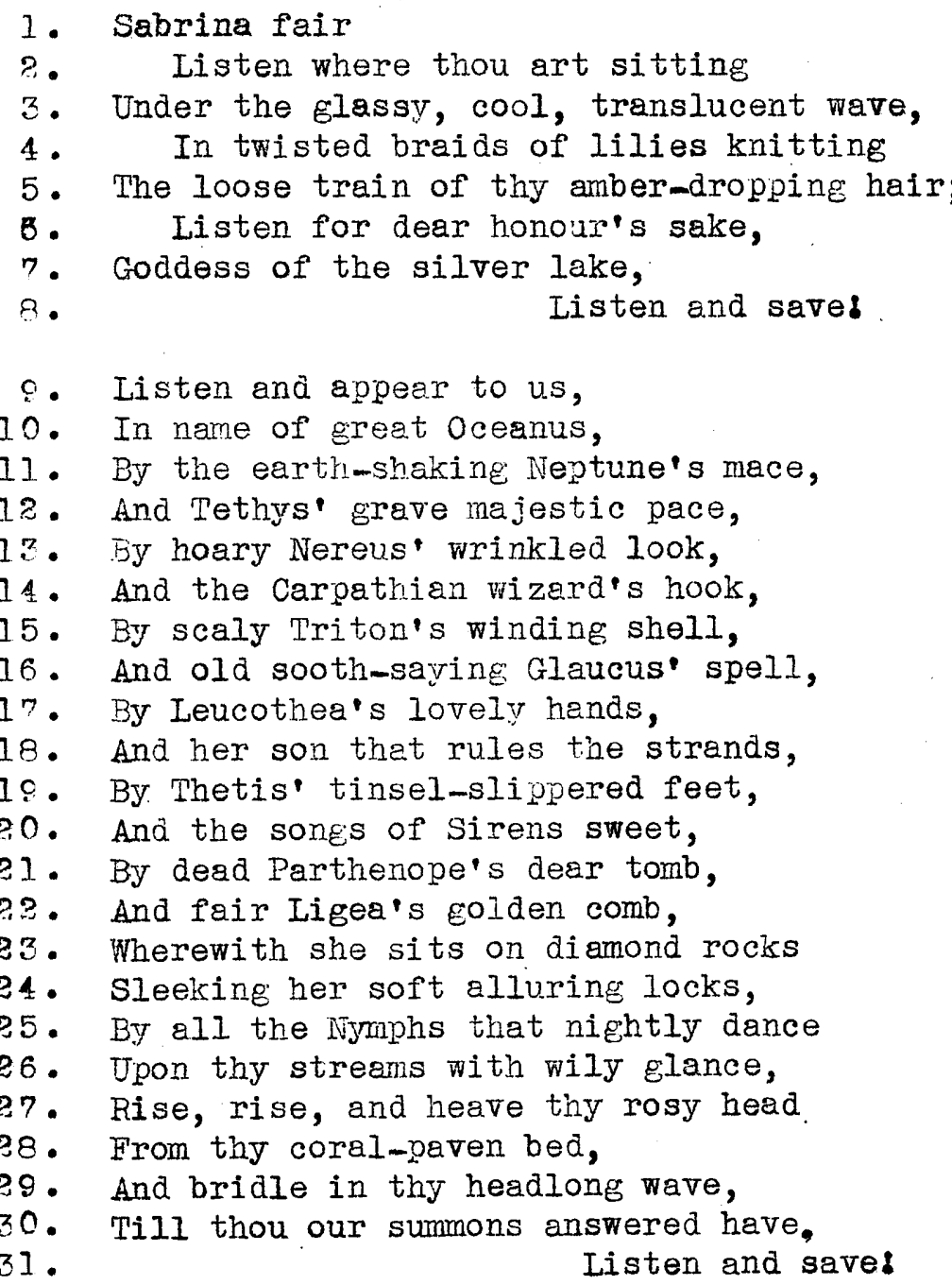

"Comus" ( 859-889)

by J. Milton.

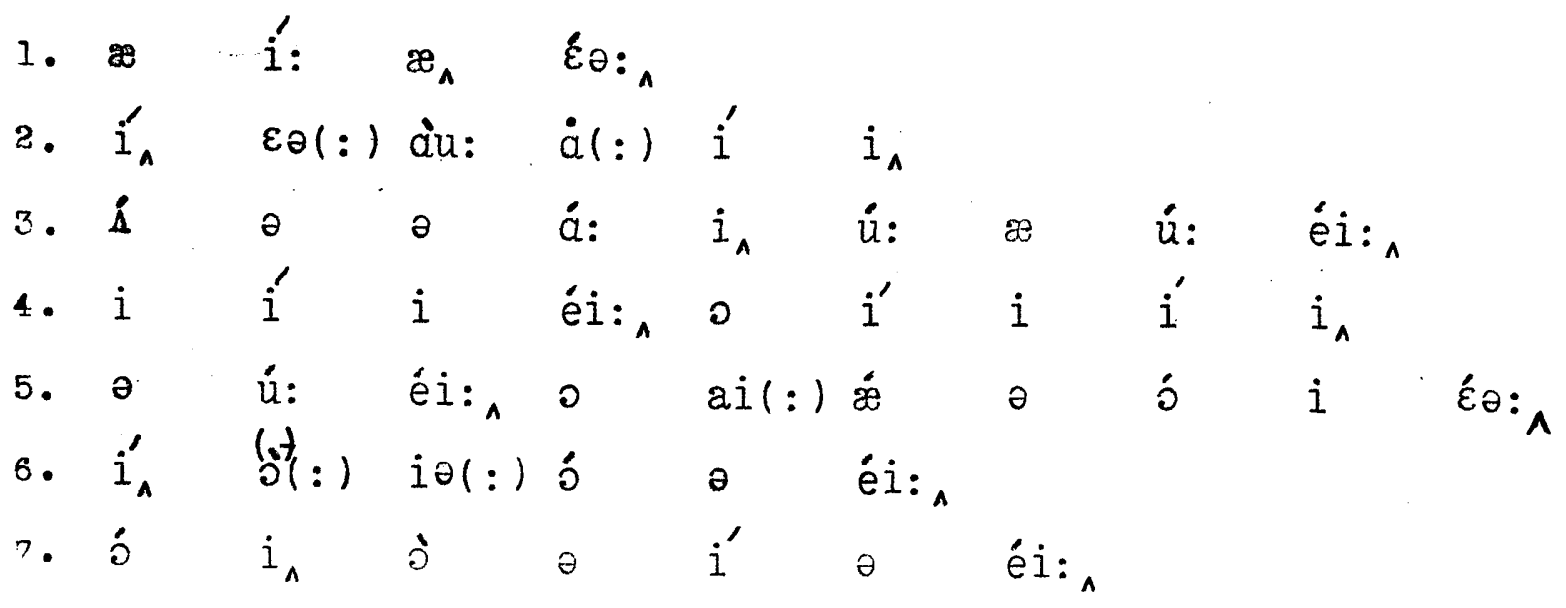


8. $i^{\prime} æ \quad e ́ i: \wedge$

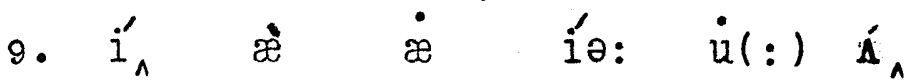

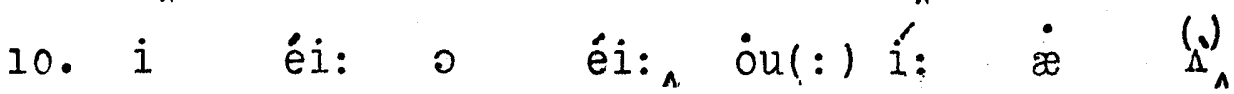

11. ai(:) $\theta$ ó: éi: $i_{\wedge}$ é ju(:)éi:

12. æ í: î éi: $\dot{\gtrless}$ é $\cdots i$ éi:

13. ai(:) อ́ə: $i$ íə: ju(:) $\hat{i}^{\prime} \dot{u}_{\wedge}$

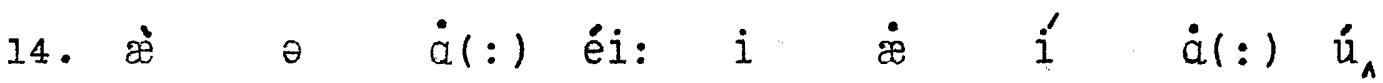

15. ài(:) éi: i ái: on ái: i é

16. æóu: ù: éi: i áu: $\theta$ é

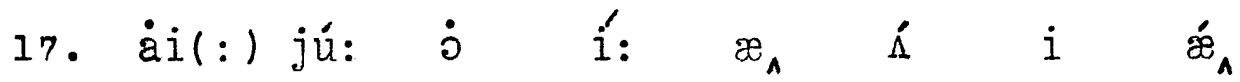

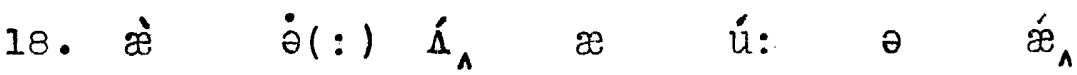

10. $\dot{a} i(:) i: \quad i_{\wedge} \quad i \quad$ e $\quad \dot{i} \quad \dot{\partial}(:) \quad i_{A}$

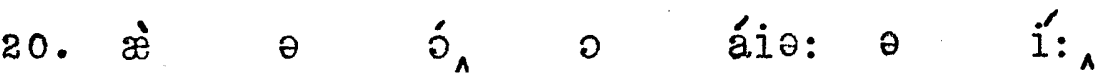

21. $\dot{a} i(:) e^{\prime} \dot{a}(:)$ é $\dot{o u(:)} \dot{e} i(:){ }_{\wedge} i_{\theta}:$ ú:

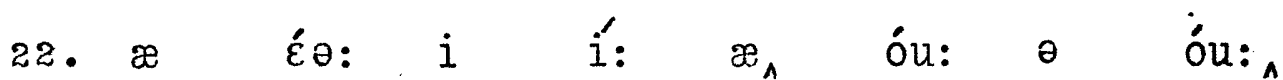

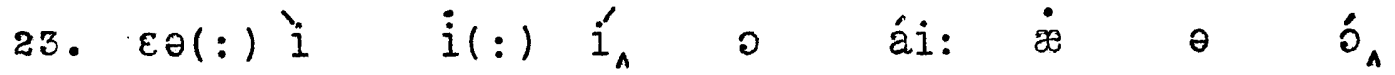

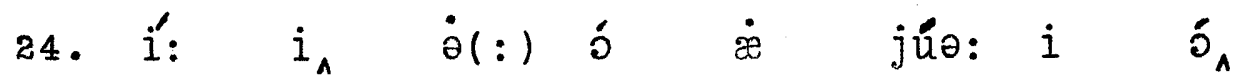

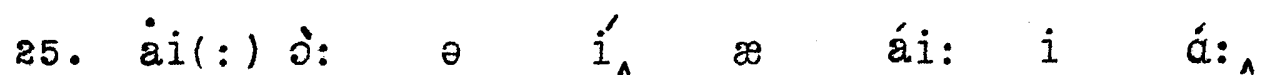

26. $\dot{A}$ o $\operatorname{ai}(:) i^{\prime}{ }_{\wedge} \quad i \quad$ ái: $i$ á:

27. ài: ái: $¥$ í: ai(:) óu: $i$ é

28. ๖े ai(:) ó $\dot{2}$ éi: é

20. ஐ ái: ‘ $i \quad a i(:) e ́$ ò éi:

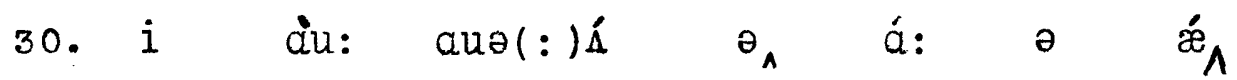

31. í æéi: 
1. Revenge, revenge, Timotheus cries,

2. See the Furies arisel

3. See the snakes that they rear

4. How they hiss in their hair,

5. And the sparkles that flash from their eyes!

"Alexander's Feagt" (106-110) by J. Dryden.

1. $\dot{i}(:)$ é $\quad \dot{i}(:)$ é, $i$ óu: $i(:)$ o ái:A

2. $i:$ júə: $i_{\wedge} \dot{\otimes}$ ái: $\wedge$

3. i: $\theta$ éi: $\approx$ ei(:: ì $_{\wedge}$

4. $a u(:)$ ei(:) $\dot{i}_{\wedge} i$ $\varepsilon \theta(:) \varepsilon \theta$ A $_{\wedge}$

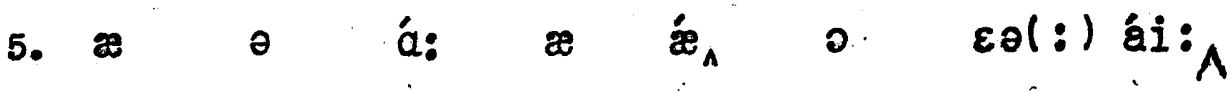


1. O my Iuve's like a red, red rose

2. Thet's newly sprung in June:

3. O my Inve's like the melodie

4. That's sweetly play'd in tune.

5. As fair art thou, my bonnio lass,

6. So deep in luve am I:

7. And I will luve thee still, my dear,

8. Till a' the seas gang dry:

9. TIII a' the seas gang dry, my dear,

10. And the rocks melt wi' the sun;

11. I will luve thee still, dear,

12. While the sands o' life shall run.

13. And fare thee weel, only Inave

14. And fare thee weel awhilel

15. And I will come again, my Iuve,

16. Tho' it were ten thousand mile.

R. Burns. 


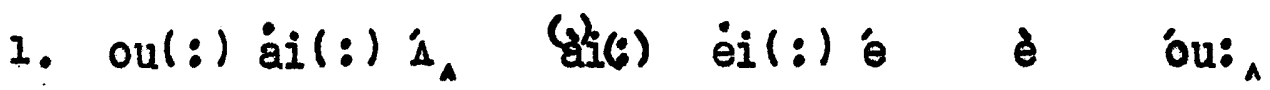
2. $\approx$ jú: $i$ is $i \quad \mathfrak{u}:_{\wedge}$

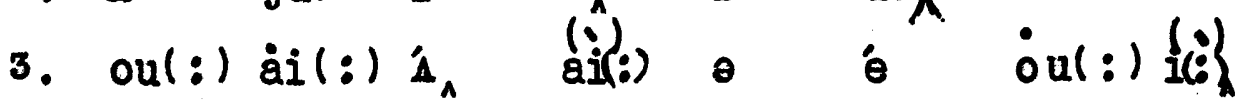
4. æ í: i éi: $i$ ju: $\wedge$

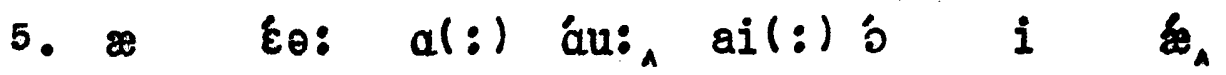
○. òu: $\hat{i}:$ i $\dot{A}_{\wedge} \quad \approx \quad$ ai :

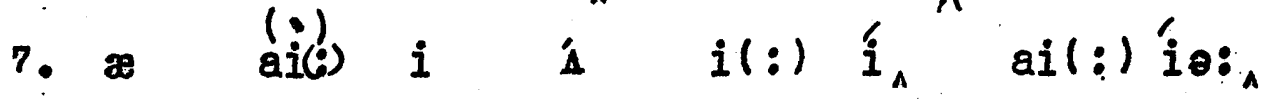
8. i b: ə $\quad \mathfrak{i}:$ a ๑. i b: ə $i:$ z̀ ái:

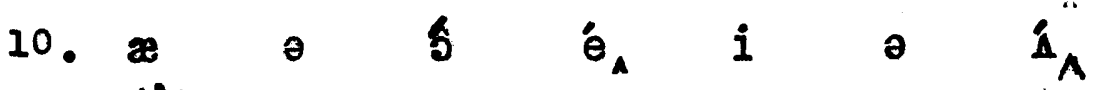

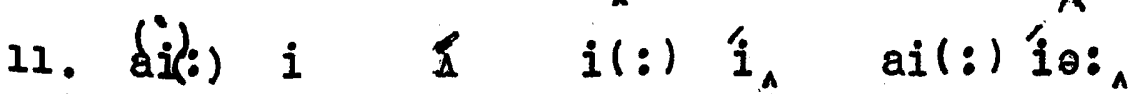

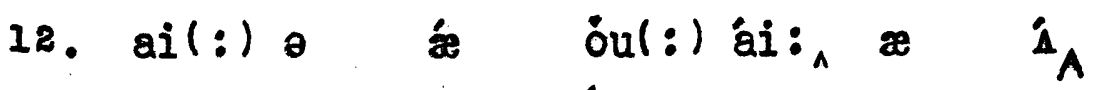
13. $\varepsilon_{\theta}: i(:)$ i: ail: $)$ ou: $i \quad i_{A}$

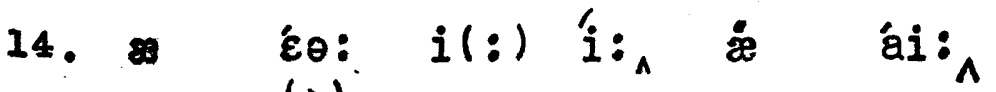

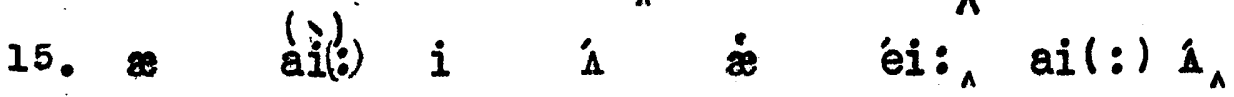
16. oul:) i éa: \& áu: ə ái: 
1. I wish I were where Helen lies;

2.' Night and day on me she cries;

3. O that I were where Helen lies

4. On fair Kirconnell lea:

Anonymous.

1. ail: $)^{\prime}$ ail(:) $\varepsilon_{\theta}:_{\wedge} \varepsilon \theta(:)$ é $\dot{\theta}$ ái: $\wedge$

2. ái: a éi: 0 í: il: ái:"

3. ou: $¥ \quad a i(:) \varepsilon \varepsilon_{\wedge} \quad \varepsilon \theta(:)$ é $\dot{\theta}$ ái:

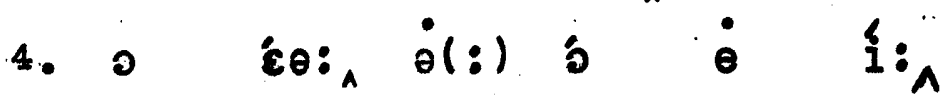


1. How sleep the Brave who sink to rest

2. By all their Country's wishes blestd

3. When Sprine, with dewy fingers cold,

4. Returns to deck their hallow'd mould,

5. She there shall dress a sweeter sod

6. Than Fancy's feet have ever trod.

"Ode written in VDCCXIVI" ( $v . I)$

by $W$. Collins.

1. oul(:) 1́: $\theta$ éi: $u(:)$ í $u(:) \quad e_{A}$

2. ail:) b: $\varepsilon \theta(:)$ i $i \quad i \quad{ }^{\prime} \dot{e}_{\wedge}$

3. $e$ $i_{\wedge} i$ ju: $i$ i $\theta$ ou:

4. $\dot{i}(:)$ ó: $\dot{u}(:)$ é $\varepsilon_{\Lambda} \quad \varepsilon(:)$ \& oul: $)$ óu:

5. $i(:) \varepsilon_{\theta}: \approx \quad \dot{\theta}_{A} \quad \dot{e} i(:) \dot{i}:$ ə $\dot{b}_{\wedge}$

6. $\approx$ \& $i \quad \dot{i} i_{\wedge} \approx$ é 
1. By fairy hands their knell is rung,

2. By forms unseen their dirge is sung:

3. There Honour comes, a pilgrim grey,

4. To bless the turf that wraps their clay;

5. And Freedom shall awhile repair

6. To dwell, a weeping hermit, there:

"Ode Written in MDCCXLVI" ( $v \cdot 2)$ by W. Collins.

1. $\operatorname{ai}(:) \varepsilon_{\partial}$ i $\stackrel{x}{A}_{A} \varepsilon_{\theta}(:)$ é $i \quad \dot{A}_{\wedge}$

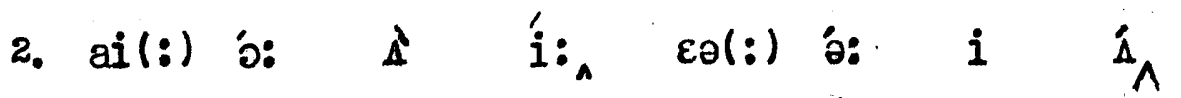

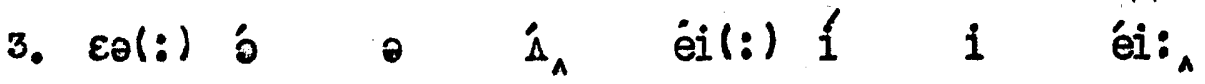

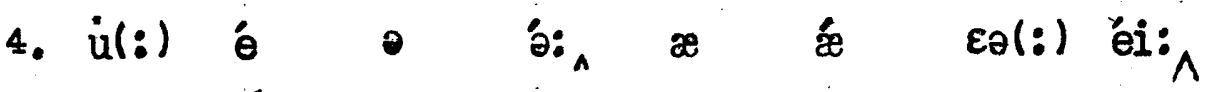

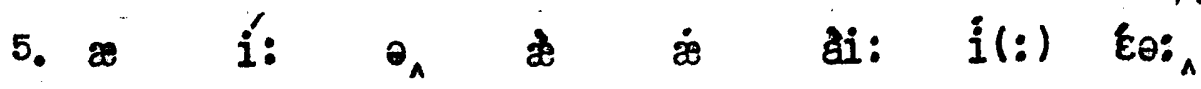

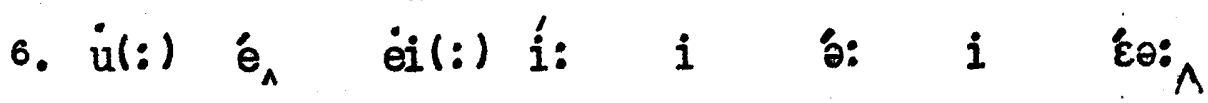


The rainbow comes and goes,

2 . And lovely is the rose;

The moon doth with delight

3.

Look round her when the heavens are bare;

Waters on a starry night

Are beautiful dair;

5 .

6.

\section{Are beautiful and fair;}

The sunshine is a glorious birth;

7. But yet I know, where'er I go,

9. That there has pass'd away a glory from the earth.

From "Ode on Intimations of Immortality"

ky Wordsworth.

1. $\theta$ éi: oul: $\dot{\Lambda}_{\wedge}$ \& ou:

2. $\infty \quad i \quad i_{A} i \quad \theta \quad$ ón:

3. จ ú: $\dot{\Lambda}$ i $i(:)$ ái:

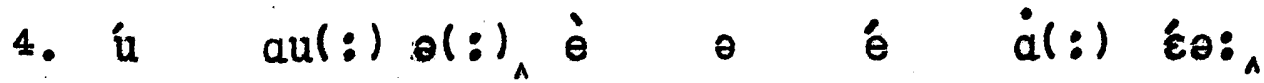

5. ๖: $\theta_{\wedge}$ j èi(:) á: $i$ ái:

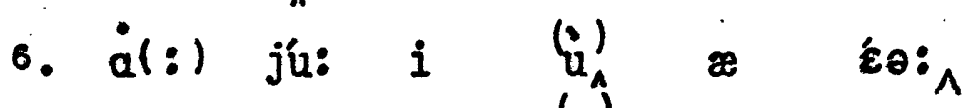

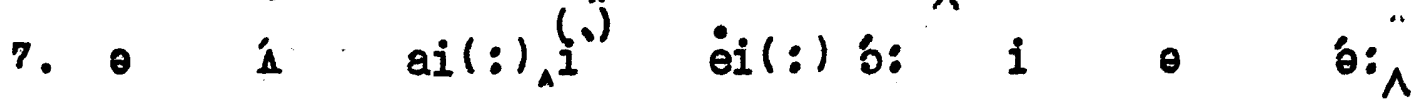

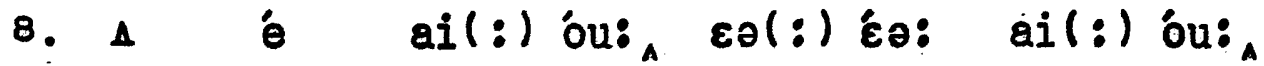

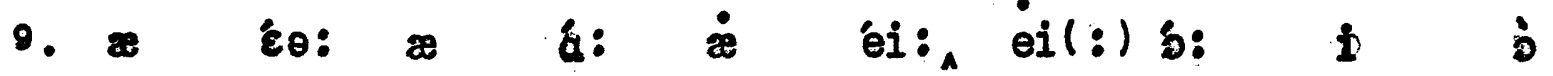


1. Art thou pale for weariness

2. Of Climbling heaven, and gazing on the earth,

3. Wandering companionless

4. Among the stars that have a different birth, -

5.And ever-changing, like a joyless eye

6 . That finds no object worth its constancy?

"Lo "The Noon"

by P.B. Shelley.

1. á: $a u(:)$ éi: $o(:)$ î: $i \quad e_{A}$

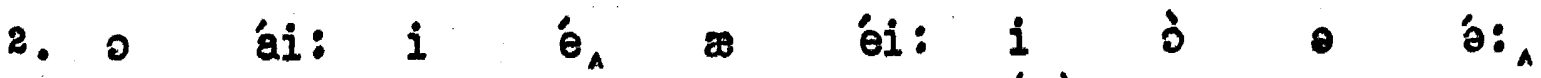

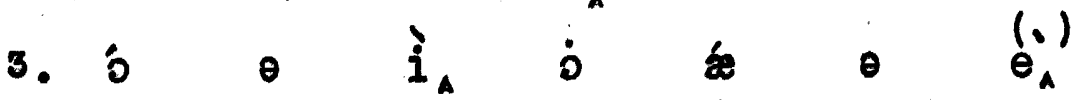

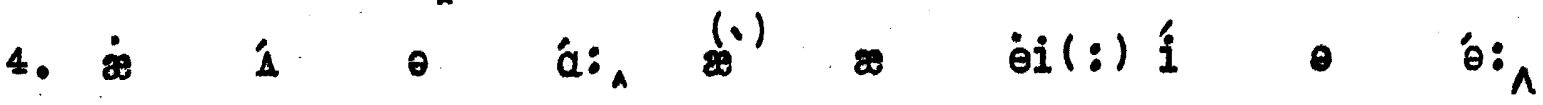

5. é éi: $i_{\wedge}$ ài: èi(:) ói: $i$ ái:

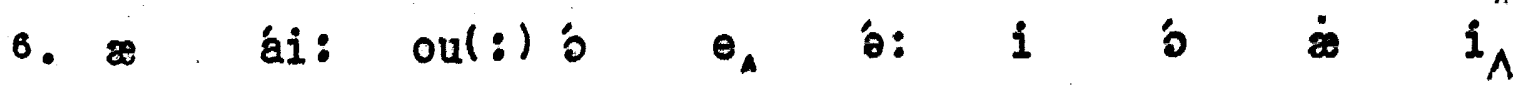


1. Death will come when thou art dead,

2. Soon, too soon -

3. Sleep will come when thou art fled;

4. Of neither would I ask the boon

5. I ask of thee, beloved Night -

6. Swlft be thine approaching flight,

7. Come soon, soond

"To the Night" (v. 5)

by P.B. Shelley.

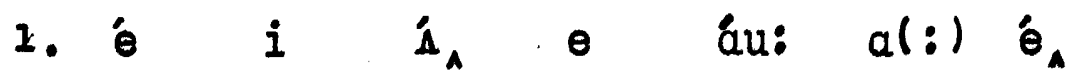

2. นิ: $\wedge$ ù:

3. i: $i$ is $\theta$ áu: $a(:) \dot{\theta}_{A}$

4. 0 ái: $\theta_{A}$ ú $a i(:)$ á: $\theta$ hi

5. ai(:) á: o $1: \wedge i(:)$ i $i$ ai:

6. $\hat{i}_{A} \dot{i}(:)$ âi: $\dot{8}$ óu: $i$ ái:

7. \&A b: í: 
1. Jenny kissed me when we met,

2. Jumping from the chair she sat in:

3. Time, you thief, who love to get

4. Sweets into your list, put that in!

5. Say I'm veary, say I'm sad,

6. Say that health and vealth have missed me,

7. Say I'm growing old, , but add,

8. Jenny kiss'd me.

I. Ifount

1. $\dot{e} i$ i $i(:)_{\wedge} \dot{e} \quad i(:) \dot{e}_{\wedge}$

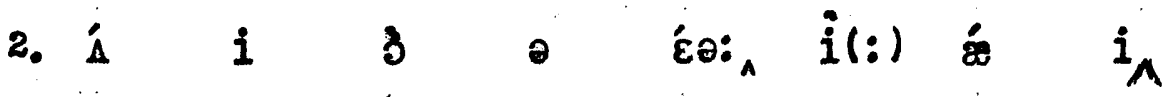

3. ái: $j u(:)$ i: $u(:)$ i $u(:) \quad \dot{e}_{\wedge}$

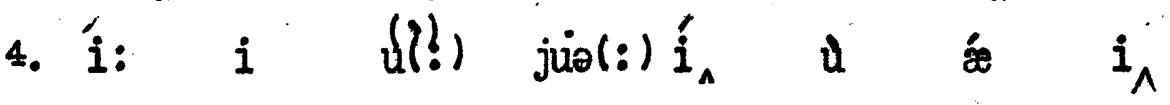

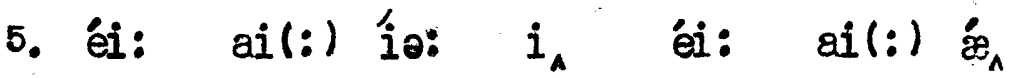

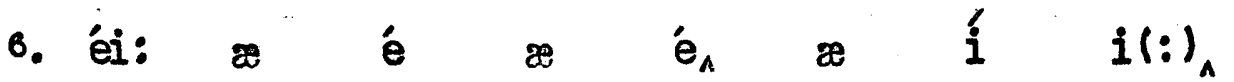

7. éi: ai(:) óu: $i$ óu: $A$ \&

8. é i i $i(:)_{A}$ 
A 26

1. And every tongue, through utter drought,

2. Was withered at the root;

3. We could not speak, no more than if

4. We had been choked with soot.

From "The Rime of the Ancient Irariner" by S. T. Coleridge, (135-138).

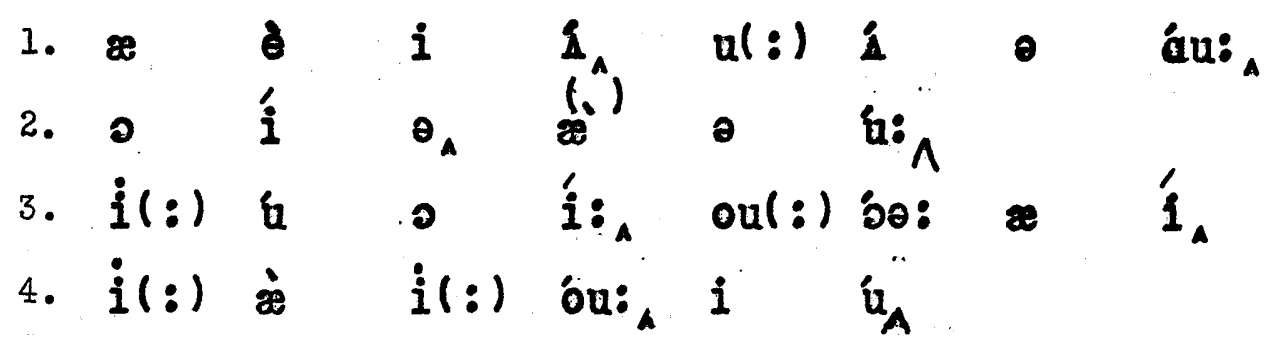


1. And straight the sum was flecked with bars,

2. (Heaven's Mother send us grace!)

3. As if through a dungeon-grate he peered

4. With broad and burning face.

From "The Rime of the Ancient Ifariner" by S. T. Coleridge.

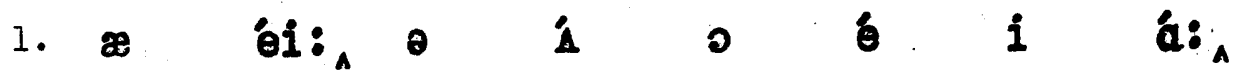

2. 8 i $\theta_{A}$ \& $\Delta$ éi:

3. $i \quad u(:)$ èi(:)i $\quad$ ei: $i(:)$ io:

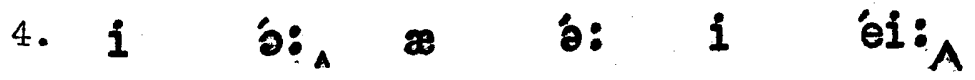


1. It raised my hair, it fann'd mo cheek

2. Iike a meadow-gale of spring -

3. It mingled strangely with uv fears,

4. Yet it felt like a welcoming.

"Whe Rime of the Ancient Mariner"(456-459) by S. T. Coleridge.

1. $i$ éi: $a i(:) \varepsilon_{\theta}:_{A} i$ zo ail(:) $\dot{i}:$,

2. ai(:) ei (:) $e^{\prime}$ oul : ) éi: $:_{\wedge} \quad i_{\wedge}$

3. $i$ i éi: $i_{A} \hat{i}$ åil $:$ ) $\hat{i}_{\theta}:_{A}$

4. $e \quad i \quad \dot{e}_{A} \quad a i(:) \dot{\theta i}(:) \dot{e} \quad \theta \quad \grave{i}_{\wedge}$ 
1. That low man seeks a little thing to do,

2. Sees it and does it:

3. This high man, with a great thing to parsue,

4. Dies ere he knows it.

5. That low man goes on adding one to one,

6. His handred's soon hit:

7. This high man, aiming at a million,

8. Misses an unit.

9. That, has the world here - should he need the next,

10. Let the world mind him!

11. This, throws himself on God, and rinperplexed

12. seoking shall find him。

"A Grammarian's Funeral" (113-124) by $R$. Browning.

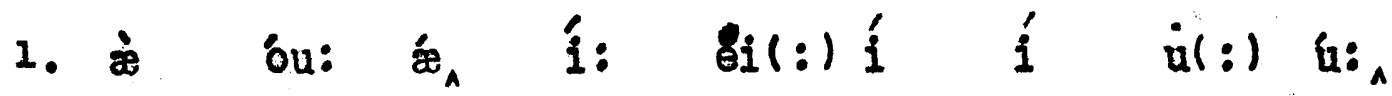

2. i: $i_{A} \approx$ i $i_{\wedge}$

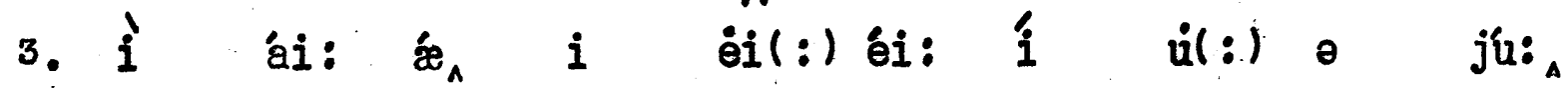

4. ai: $\varepsilon \theta(:)$ il(:) ou: i

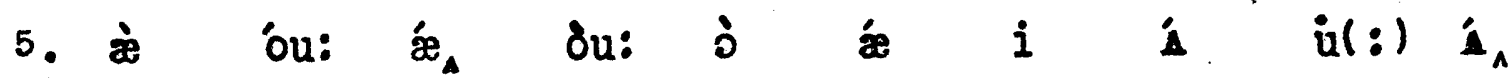

6. $i$ i $i_{\wedge}$ ú: $\hat{i}_{\wedge}$

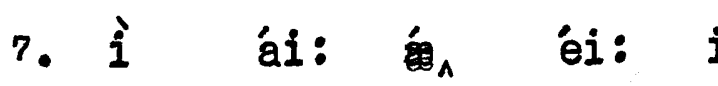

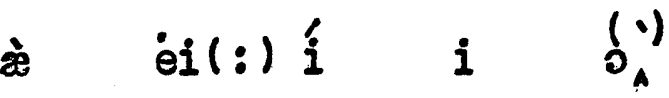

8. $i$ i $i_{\wedge} \approx$ jú: $i_{\wedge}$

๑. 尔 ஐ

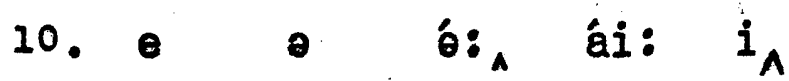

11. $\dot{i}_{A}$ ou: $i$ é 0 ó

12. í: $i_{\wedge} \mathbb{a}$ ái: $\dot{i}_{\wedge}$ 
1. When the hounds of spring are on winter's traces,

2. The mother of months in meadow or plain

3. Fills the shadows and windy places

4. With lisp of leaves and ripple of rain;

5. And the brown bright nightingale amorous

6. Is half assuaged for Itylus,

7. For the Thracian ships and the foreign faces.

8. The tongueless vigil, and all the pain.

"Atalanta in Calydon" (65-72) by A.C. Swinburme.

\begin{tabular}{|c|c|c|c|c|c|c|c|c|c|}
\hline 1. e & $\theta$ & áu: & 0 & $\dot{i}_{a}$ & $\dot{a}(:)$ & 0 & $\dot{i}$ & & éi: \\
\hline 2. 0 & i & $\partial$ & 0 & $i_{A}$ & $\mathbf{i}$ & é & oul : ) & $\dot{o}(:)$ & éi: \\
\hline 3. i & $\theta$ & æ̇ & oul : ) & $\wedge^{x}$ & $\stackrel{\prime}{\mathbf{i}}$ & i & éi: & $i_{A}$ & \\
\hline i & í & o & $\hat{i}:$ A & $\boldsymbol{x}$ & 'i & o & éi: & & \\
\hline - $\boldsymbol{x}$ & . & áu: & ài: & ái: & $i$ & $e i(:)$ & 象 & $\dot{3}$ & h) \\
\hline 6. $i$ & á: & $\dot{\mathfrak{X}}$ & éi: & $\dot{o}(:)$ & $\dot{i}$ & i & $\left(i_{A}^{\prime}\right)$ & & \\
\hline 7. $\dot{\partial}(:)$ & $\theta$ & éi: & i & $\boldsymbol{\circledast}$ & $\hat{i}_{A}$ & $\boldsymbol{\circledast}$ & $\theta$ & 3 & $\mathbf{i}$ \\
\hline • & i & $i$ & í & $i_{A}$ & $\approx$ & $\dot{0}$ & $\theta$ & éi: & \\
\hline
\end{tabular}




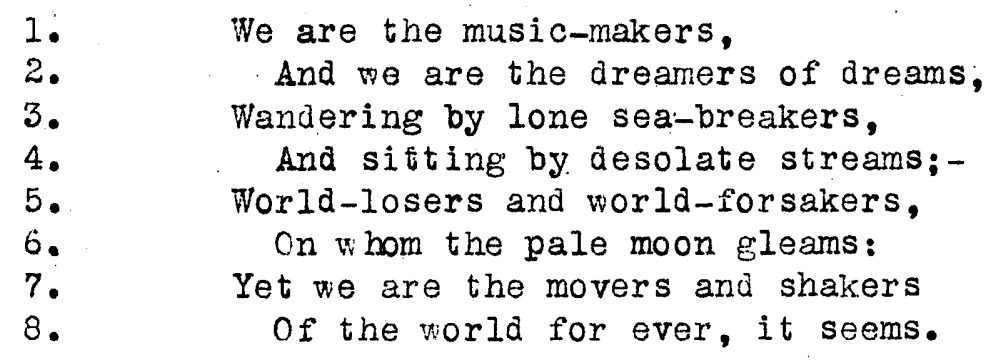

From Ode

by A.W.E. O' Shaughnessy.

1. İ: al: $\theta$ ju: $i$ éi: $\theta_{A}$

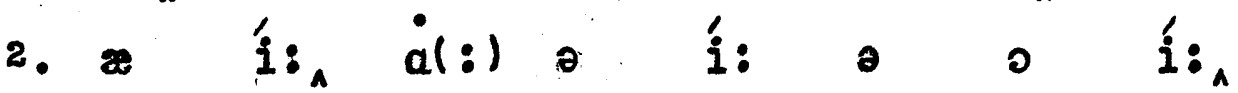

3. 3 a $i_{A}$ ail $:$ ) ou: $\dot{1}$ : eil $\theta_{A}$

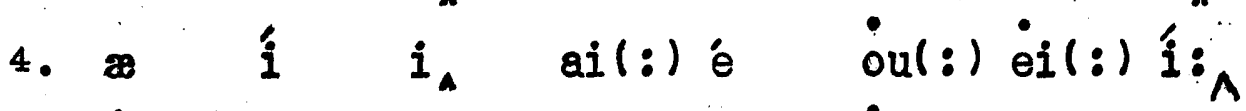

5. $\dot{\theta}:$ ú: $\theta_{\wedge}$ z $\dot{\theta}: \dot{o}(:)$ éi: $\theta_{\wedge}$

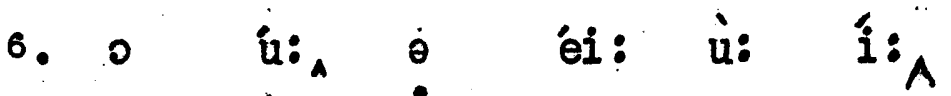

7. $\theta$ í: $\dot{a}(:)$ o $u:$ $\theta$ e ei: $\theta_{\wedge}$

8. 0 o a: $\dot{0}(:)$ é $\theta$ i $\quad \dot{i}: \wedge$ 
7. She walks - the lady of my delight -

2. $I$ shepherdess of sheep;

3. Her flocks are thoughts, she keeps them white,

4. She guards them from the steep;

5. She feeds them on the fragrant height,

6. And folds them in for sleep.

"ine Shepherdess" $(\tau \cdot I)$

by A. Meynell.

1. $i(:) \quad \theta_{\wedge}$ ə éi: $i$ o ai: $i(:)$ ái:

2. $\dot{\theta i}(:) \dot{e}^{\wedge} \dot{\partial}(:) \dot{\theta}_{\wedge}^{(0)} 0 \quad \hat{i}:_{\wedge}$

3. $\dot{\theta}(:)$ ó $\dot{a}(:)$ ó: $\quad i(:)$ i: e ái:

4. $i(:)$ á: $e_{A} \quad 3$ o $i i_{\wedge}$.

5. $i(:)$ I: $e_{A}$ o ə éi: $\dot{x}$ ái:

6. $x$ ól e $i$ ol: $\mathfrak{i}_{\wedge}$ 
1. She roams maternal hills and bright,

2. Dark valleys safe and deep;

3. Into that tender breast at night

4. The chastest stars may peep.

5. She walks - the lady of my delight -

6. $A$ shepherdess of sheep.

"The Shepherdess" (V.2)

by $\mathbf{A}$. Meynell.

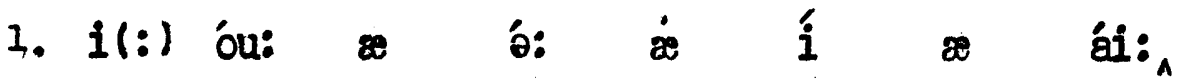

2. d: \& $i_{\wedge}$ éi: $\approx$ i:

3. $i \quad \dot{u}(:) \approx$ a $\approx \dot{\theta}_{A} \approx$ ái:

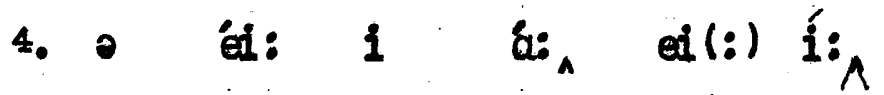

5. $i(:)$ o: $\wedge$ ói: $i$ ai: $i(:)$ ái:

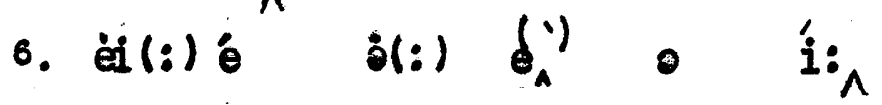


1. She holds her little thoughts in sight,

2. Though gay they run and leap;

3. She is so circumspect and right;

4. She has her soul to keep.

5. She walks - the lady of my delight -

6. A shepherdess of sheep.

"The Shepherdess" (V.3)

by A. Meyne11.

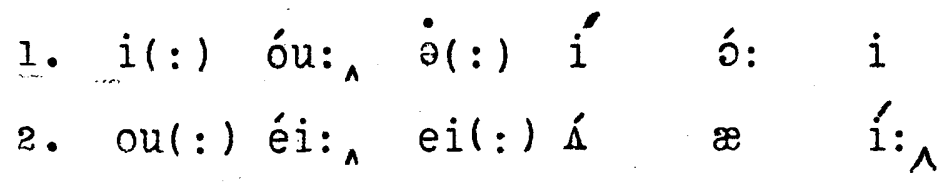

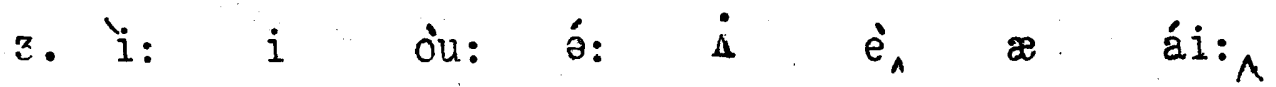

4. i: $\mathbb{Q} \quad \theta(:)$ óu: $u(:) \quad i: \wedge$

5. $i(:)$ o: $\wedge$ a éi: $i$ o ài: $i(:)$ ái: $\wedge$

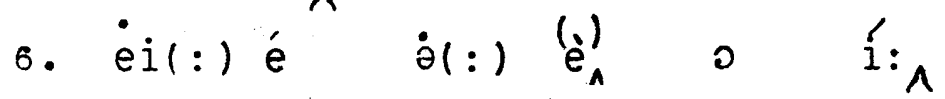


1. They have no song, the sedges dry,

2. And still they sing.

3. It is within my breast they sing,

4. As I pass by.

5. Within my breast they touch a string.

6. They wake a sigh.

7. Phere is but sound of sedges dry;

8. In me they sing.

"Song" in the Songless" by G. Meredith.

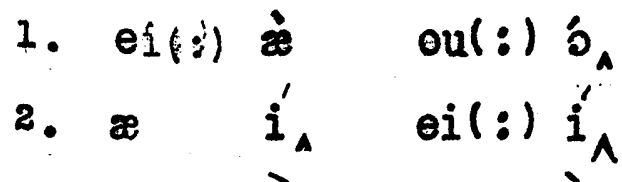

$\begin{array}{llll}\text { 3. } & \grave{i} & i & \grave{i} \\ \text { 4. } & \text { ái: } & \text { à } & \text { ái }\end{array}$

5. $i$ i $\quad \dot{a}(:) e_{A}$

- $\dot{\theta} i$ ái

6. ei(:) éi: ei(:) ái:^

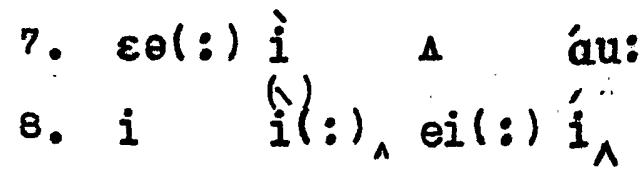

ai (: ) é.

eil : ) ín

ei( : ) \&

ei (:) $\dot{i}_{A}$ 


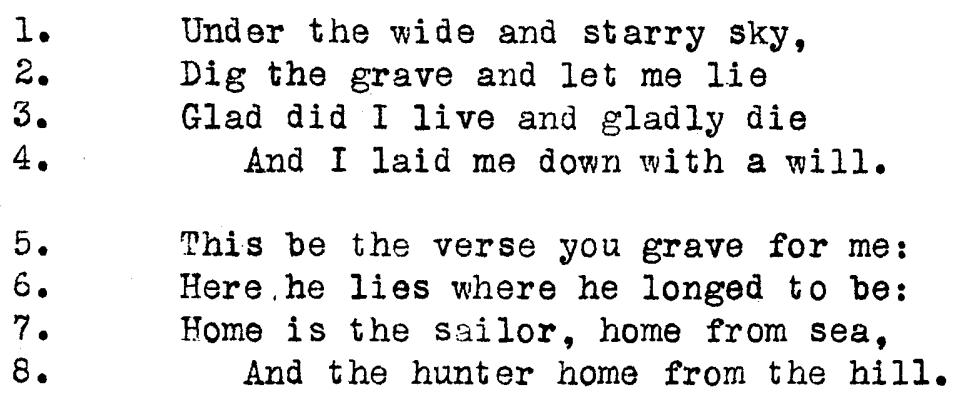

"Requiem"

by R.I. Stevenson.

1. $\mathfrak{1}$

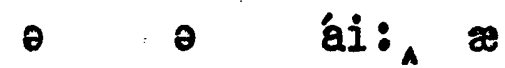

a:

1

ái:

2. 1

o ei: $\boldsymbol{x}$

$\dot{\theta}$

i(:) ái:

3. ǽ

i

ai $(:) \hat{i}_{A}$

జ

\&

4. $\mathscr{X}$

ai(:) éi:

$i(:) \quad \dot{q} u_{A} \ldots i$

i ái:

ei (:) $\dot{i}^{\prime}$

5. $\hat{1}$

i(:)

3:

ju(:) éi:

o(:) ín

6. io

il:

ái:

$\varepsilon \dot{a}(\vdots)) \dot{i}(:)$

3

7. ou: $i$

$\theta$

éi:

ou:

ul :

8. 2

$\theta$

a

$\theta_{A}$ ou:

o

- $i_{A}$

i 
1. And seals, that scrape along the ice and shine

2. In their eleek coats, and wolves with yellow ejine

3. And white-pelt bears, with small heads viperine.

From "The Wanderer" (p.92)

by J. Masefield.

\begin{tabular}{|c|c|c|c|c|c|c|c|}
\hline $\boldsymbol{x}$ & $i: \quad x$ & èi: & $\dot{\boldsymbol{x}}$ & 's & $\theta$ & ái: & $\boldsymbol{z}$ \\
\hline$i$ & $\varepsilon \theta(:)$ í: & ou: & $\dot{\theta}$ & $\mathfrak{a}$ & $\mathbf{i}$ & é & oul: : \\
\hline & ái: & $\varepsilon \theta_{a}$ & $i$ & b: & 6 & ái: & $\ddot{\theta}$ \\
\hline
\end{tabular}


1. : And more to lulle him in his slumber soft,

2. A trickling streame from high rock tumbling downe,

3. And ever-drizling raine upon the loft,

4. Mixt with a murmaring winde, much like the sowne

5. Of swarming Bees, did cast him in a swowne.

6. No other noyse, nor peoples troublous cryes,

7. As still are wont t'annoy the walled towne,

8. Might there be heard; but careless vuiet lyes

9. Wrapt in eternall silence farre from enimyes.

"The Frerie Queene" (I.I.4I)

by B. Spenser.

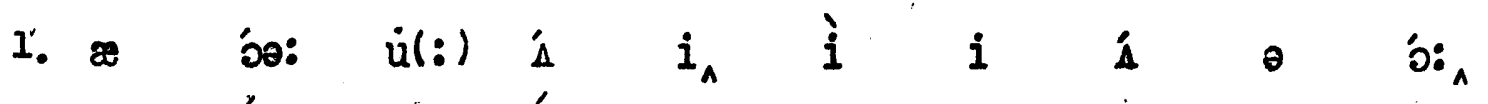

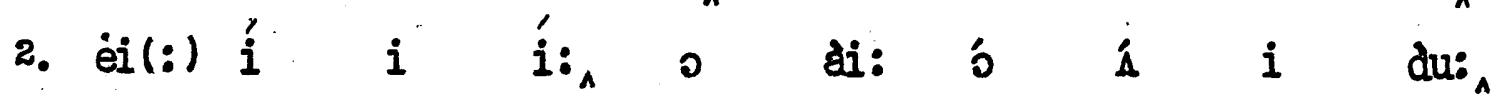

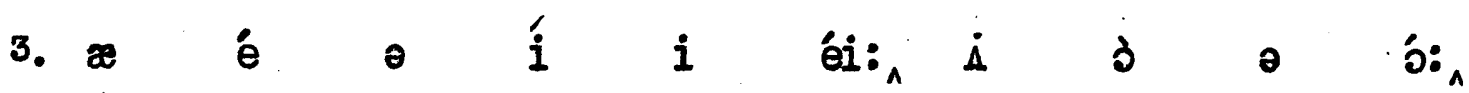

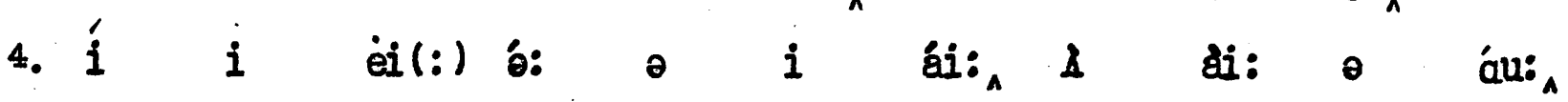

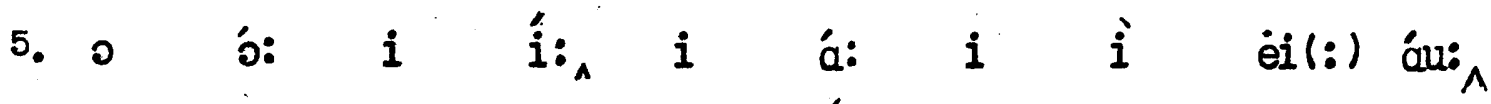

6. oul: $i$ o ói: $0(:)$ í: $i$ o ái:

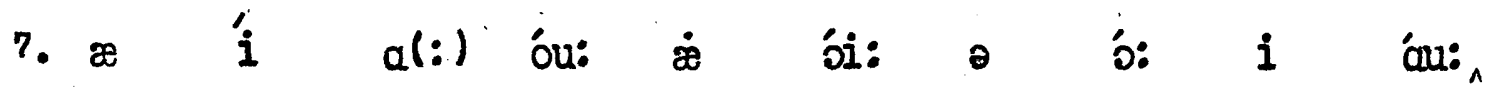

8. ai(:) É: $i(:)$ ö: $\Lambda$ ćo: $i$ ái: $\dot{e}$ ái:

9. 毛 $\dot{i} \dot{i}(:)$ á: $¥$ ái: $\dot{e}_{\wedge}$ á: 0 é $\dot{i}$ 
1. Wy true-love hath my heart, and I have his,

2. By just exchange one for another given:

3. I hold his dear, and mine he cannot miss,

4. There never was a better bargain driven:

5. Hy true-love hath my heart, and I have his. "My true loye hath my heart, and I have his" (v.l)

\begin{tabular}{|c|c|c|c|c|c|c|c|}
\hline $\begin{array}{l}a i(:) \text { u: } \\
\dot{a}_{i}(:) \text { a }\end{array}$ & $\begin{array}{l}\dot{i} \\
\dot{e}\end{array}$ & $\begin{array}{l}\dot{æ} \\
\text { éi : }\end{array}$ & $a_{i}(:)$ & $\begin{array}{l}\dot{a}_{A} \\
\dot{b}(:)\end{array}$ & $\begin{array}{l}\text { æ } \\
\dot{z}\end{array}$ & ái: & æ \\
\hline ai (:) ou: & $\grave{i}$ & î: & $æ$ & ái: & $i(:)$ & ǽ & 0 \\
\hline$\varepsilon_{\theta}(:)$ é & $\theta$ & $\dot{\partial}_{A}$ & $\dot{e i}(:)$ & $\dot{\theta}$ & $\theta$ & á: & $\mathbf{i}$ \\
\hline ai(:) ư & $\grave{i}$ & $\dot{\ddot{z}}$ & $a i(:)$ & '́: & $æ$ & ái: & $æ$ \\
\hline
\end{tabular}




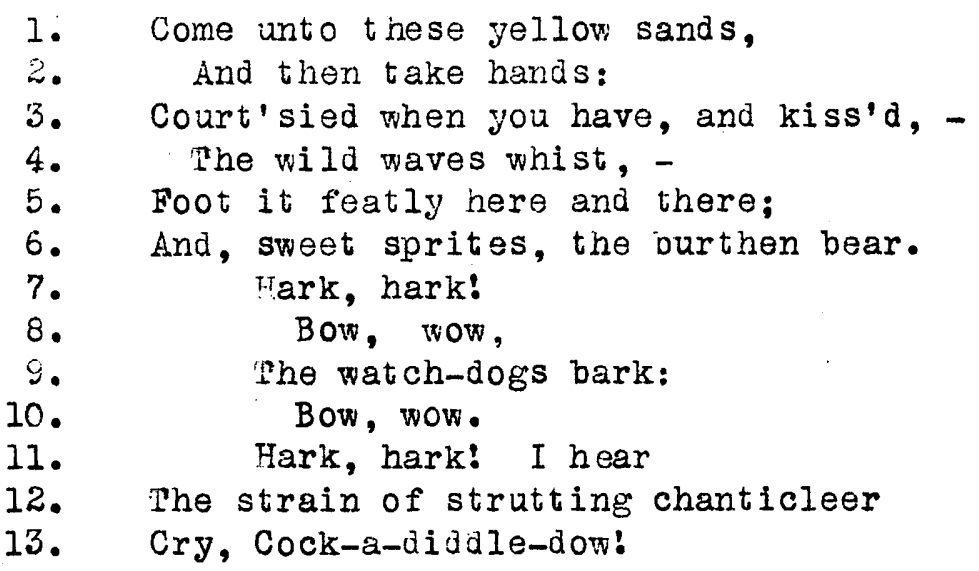

"The Tempest" (I.2.375)

Song by . Shakespeare.

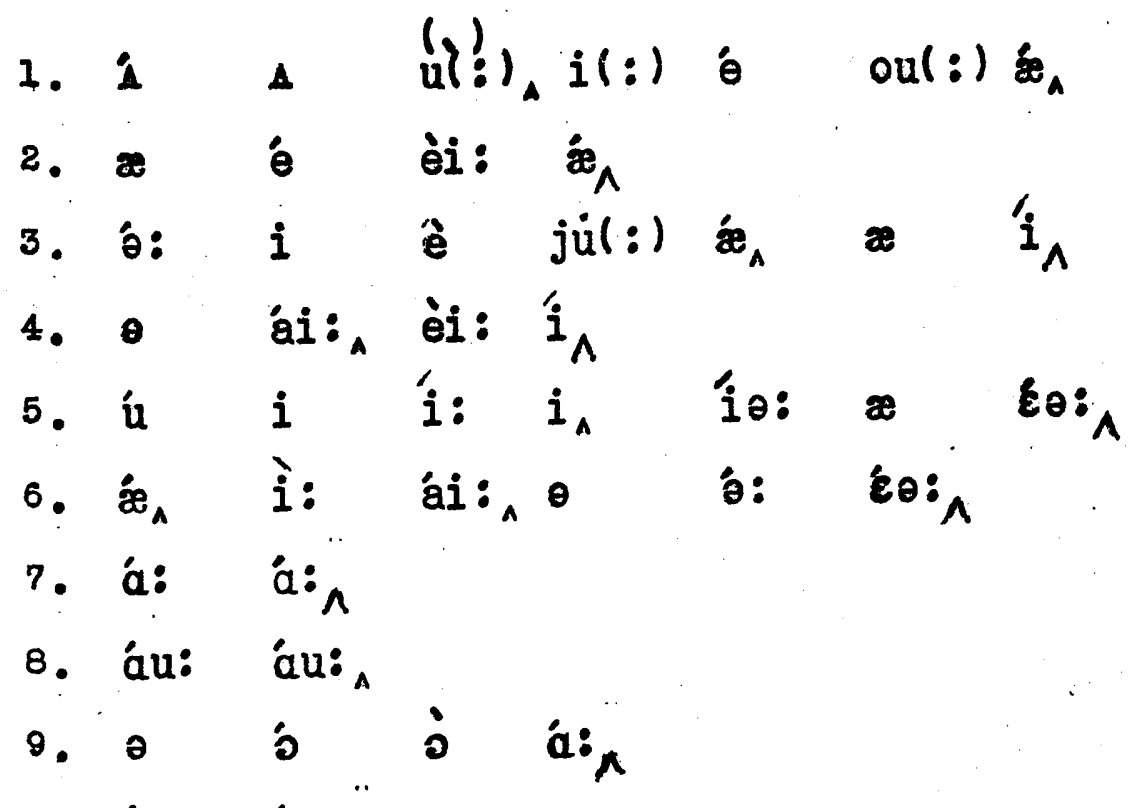

10. áu: áu:

11. á: á: $a i(:)$ ĺs:

12. $\theta$ éi: 0 i $i$ \& 1 ì:

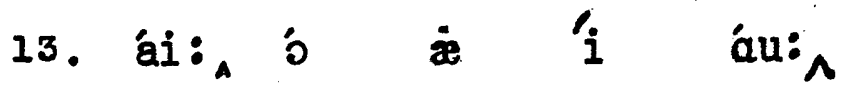


1. Then to the sessions of sweet silent thought

2. I sumrion up remembrance of things past,

3. I sigh the lack of many a thing I sought,

4. And with old woes new wail my dear time's waste;

5. Then can I drown an eye, unused to flow,

6. For precious friends hid in death's dateless night,

7. And weep afresh love's lon:-since-cancell'd woe,

a. And moan the expense of many a vanish'd sight.

9. Then can I grieve at grievances foregone,

10. And heavily from woe to woe tell o'er

11. The sad account of fore-bemoanéd moan,

12. Which I new pay as if not paid before:

13. - But if the while I think on thee, dear friend,

11. All losses are restored, and sorrows end.

W. Shakespeare.

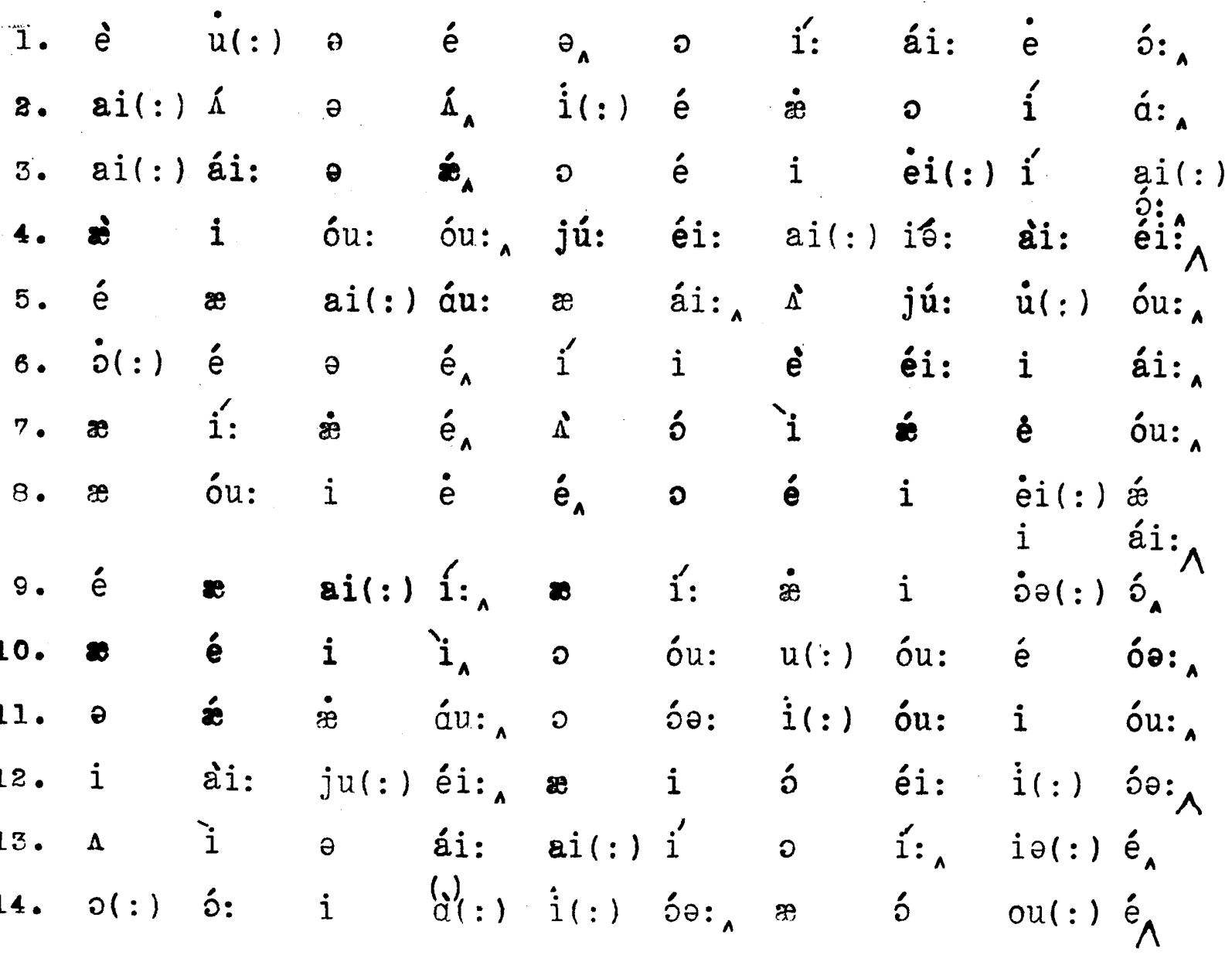


1. Come away, come away, death,

2. And in sad cypress let me be laid;

3. Fly away, fly away, breath;

4. I am slain by a fair cruel maid.

5. My shroud of white, stuck all with yow,

6. 0 prepare it:

7. My part of death, no one so true

8. Did share it.

9. Not a flower, not a flower sweet,

10. On my black coffin let there be strown;

11. Not a friend, not a friend greet

12. My poor corse, where my bones shall be thrown:

13. A thousand thousand sighs to save,

14. Lay me, 0 , where

15. Sad true lover never find my grave

16. To weep there!

\begin{tabular}{|c|c|c|c|c|c|c|c|c|c|}
\hline & 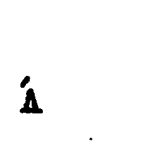 & $\ddot{z}$ & ei(: ) & & $\ddot{叉}$ & $\begin{array}{l}\text { Sorig bj } \\
\text { ("nwel } \\
\text { ei ( : ) }\end{array}$ & $\begin{array}{l}\text { W. Sna } \\
\text { high } \\
e_{A}\end{array}$ & t" II.4. & \\
\hline 2 & $æ$ & $i$ & ǽ & ái: & $i_{\wedge}$ & è & $i(:)$ & $i(:)$ & \\
\hline 3. & ái: & $\dot{æ}$ & ei $(:)$ & ái: & $\dot{\ddot{Z}}$ & ei(: ) & $A$ & & \\
\hline 4. & ai $(:)$ & $æ$ & éi : & ai (: ) & $\dot{e i}(:)$ & घ́o: & $\dot{\mathbf{u}}$ & $\dot{\theta}$ & \\
\hline 5. & $a i(:)$ & áu: & 0 & ái & $i$ & j: & i & & \\
\hline 6. & ou: & $i(:)$ & É: & & & & & & \\
\hline 7. & $\operatorname{ai}(:)$ & á: & 0 & $e_{\hat{e}}$ & oul: : & $\ddot{\Lambda}$ & òu: & ú: & \\
\hline 8. & $\mathbf{i}$ & $\hat{\varepsilon}_{\theta:}$ & & & & & & & \\
\hline 9. & $\dot{0}$ & $\dot{e} \dot{i}(:)$ & áue: & j & $\dot{e} i(:)$ & Ex: & í: & & \\
\hline 10. & 0 & $a i(:)$ & 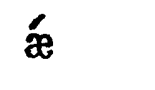 & '́ & & $\grave{e}$ & $\varepsilon \partial(:)$ & $\dot{i}(:)$ & \\
\hline 11. & 0 & èil: ) & $\dot{e}_{A}$ & o & éi (:) & $\dot{\theta}$ & $i: A$ & & \\
\hline 12. & ail (:) & uə(: : & b: & $\varepsilon \theta(:)$ & ai (:) & óu: & $\mathscr{X}$ & $i(:)$ & ou \\
\hline 13. & & áu: & $\dot{æ}$ & áu: & $\dot{\ddot{\bigotimes}}$ & ái: & $\dot{\mathrm{u}}(:)$ & & \\
\hline 15. & ஐ & ù: & $\partial u:_{A}$ & $\varepsilon_{\theta}:_{\wedge}$ & & & & & \\
\hline 16 & $\mathrm{u}(:)$ & i. & $\varepsilon_{\partial}$ l: & $n$ & $\mathrm{~A}$ & $\theta$ & ái: & $\operatorname{ai}(:)$ & \\
\hline
\end{tabular}


1. Make me a willow cabin at your gate,

2. And call upon my soul within the house;

3. Write loyal cantons of contemed love

4. And sing them loud even in the dead of night;

5. Halloo your neme to the reverberate hills

6. And make the babbling gossip of the air

7. Cry out 'Olivial'

"Twelfth Night" (I.5.289)

bo Whakespeare.

1. éi: il : )

oul : : ) i

æ jüo: éi:A

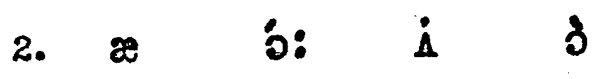

ail : ) ou: $i$

i

ə

áu:

3. घิi: bi:

$\notin$

(j) i

é

i

$\AA_{A}$

4. æ

áu: i: i

$\dot{e}$

○

5. $\dot{\gtrless} \quad \dot{u}$

e

ə

i(:) b:

$\dot{e}$

ái:

ú: júe: éi: $\quad \dot{u}(:)$ o

6. æ 61:

\&

i

b

i

3

ə èi(厃) î

7. ai: au: oul : ) í

$i \approx$ 
1. Where the bee sucks, there suck I:

2.

In a cowslip's bell I lie;

3.

There I couch when owls do cry.

4.

On the bat's back I do fly

5.

After summer merrily:

6.

Merrily; merrily, shall I live now,

7. Under the blossom that hangs on the bough.

Song by $W$. Shakespeare.

("The Tempest" V.1.88.)

1.

2. i èil: 1 áu: $i \quad \dot{\theta}_{\wedge}$ ai $(:)$ ái $:_{\wedge}$

3. Ee: ail: áu: $e$ áu: u(:) áai:

4. 0 क क क्षि $a l^{\prime}(:) \mathrm{u}(:)$ ái:

5. $\dot{a}: \dot{\theta} \quad \dot{\Delta} \theta_{\wedge} \quad \dot{\theta} \quad i \quad i_{\wedge}$

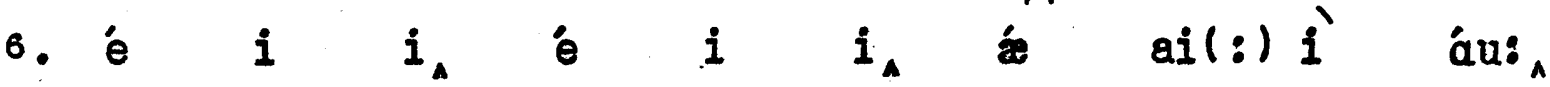

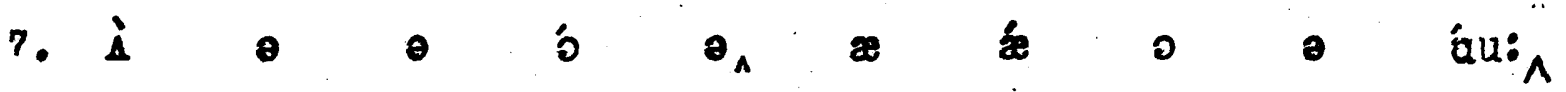


1. She should have died hereafter;

2. There would have been a time for such a word.

3. To-morrow, and to-morrow, and to-morrow,

4. Creeps in this petty pace from day to day,

5. To the last syllable of recorded time;

6. And all our yesterdays have lighted fools

7. The way to dusty death. Out, out, brief candlel

8. Life's but a walking shadow, a poor player

9. That struts and frets his hour upon the stage,

10. And then is heard no more: it is a tale

11. Told by an idiot, full of sound and fury,

12. Signifying nothing.

Macbeth" ( $\mathrm{V} \cdot 5 \cdot 15 \cdot)$

by W. Shakespeare.

1. i: u $u$ ái: $\quad$ iə(:) á:

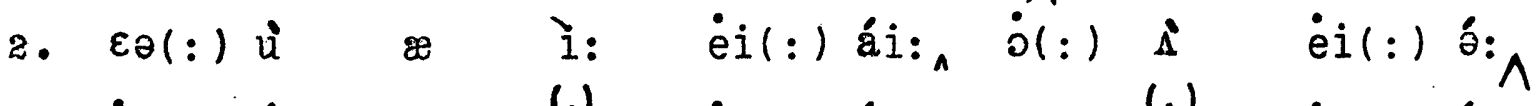

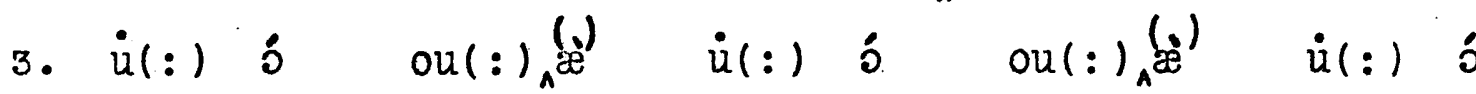

ou( : )

4. 'i: ‘i

5. $u(:)$ ə $\quad$ á: $\dot{i}^{\prime} \otimes_{\wedge} \quad \dot{j} \quad \dot{i}(:)$ ó: $i \quad$ ái:

6. ஐ ذ: auə(:)é

7. $\theta$ éi: $u(:) \quad \dot{\Lambda}$ i $\dot{e}_{\wedge} d u:_{\wedge}$ áu: i: $\ddot{x}_{\wedge}$

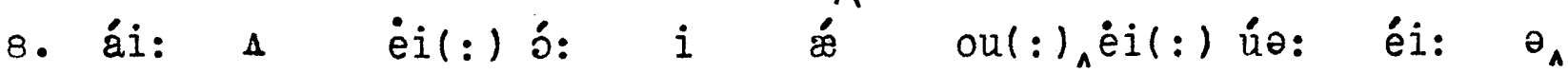

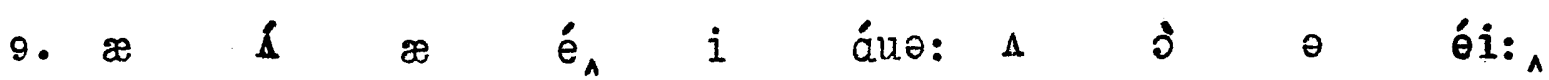

10. $¥$ è $i$ ó: ou(:) óo: $\wedge_{\Lambda}$ 官 èi(:) éi:

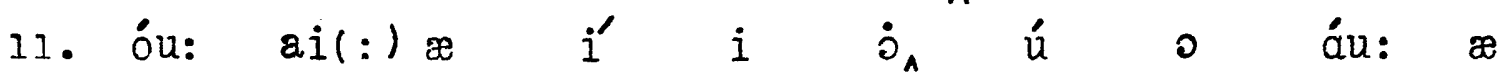

12. $i$ i 'à $i$ i $\quad i \quad i_{\wedge}$

júə: $i_{\wedge}$ 
1. The sky, it seens, would pour down stinking pitch,

2. But that the sea, mounting to the welkin's cheek,

3. Dashes the fire out. 0 , I have suffer'd

4. With those that I saw suffer! a brave vessel,

5. Who had, no doubt, some noble creatures in her,

6. Dash'd all to pieces. 0 , the cry did knock

7. Against my very heart: Poor souls: they perish'd.

8. Had I been any god of power I would

9. Have sunk the sea within the earth, or e'er

10. It should the good ship so have swallow'd, and

11. The fraughting souls within her.

"The Tempest" (I.2.3)

by W. Shakespeare.

1. - ái: $i$ í: $u$ oø: du: $\dot{i}$ i $i_{\wedge}$

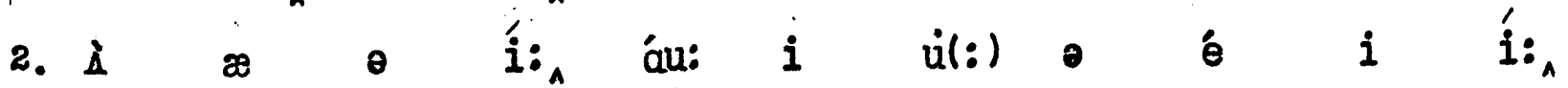

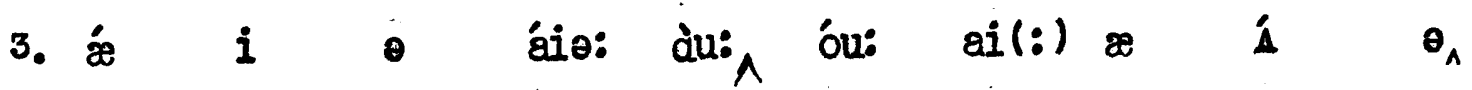

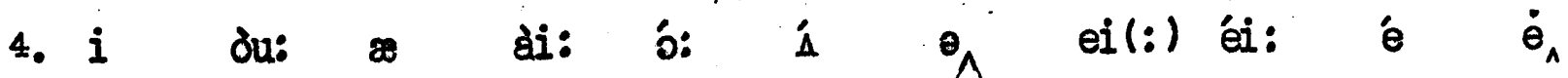

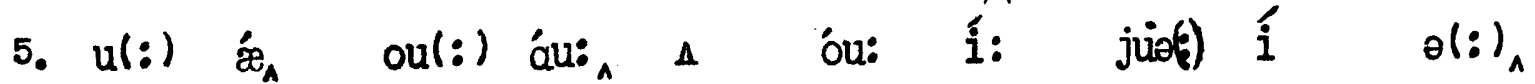

6. 囟 ol: $\dot{u}(:)$ í: $i_{\wedge}$ óu: o ái: $i \quad \partial_{\wedge}$

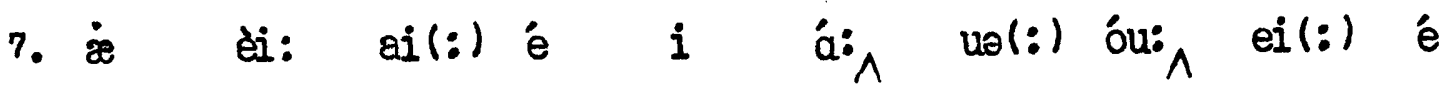

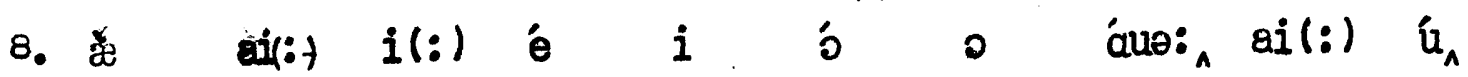

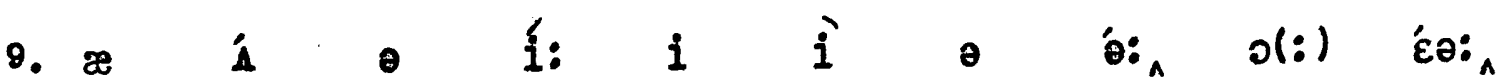

10. $i$ du $\ominus$ ú

11. $\theta$ o: $i$ óu: $i$ i $\theta(:) \wedge$ 
1. I have liv'd long enough: my way of life

2. Is fall'n into the sear, the yellow leaf;

3. And that which should accompany old age,

4. As honour, love, obedience, troops of friends,

5. I mast not look to have; but, in their stead

6. Curses, not loud, but deep, mouth-honour, breath,

7. Which the poor heart would fain deny, and dare not.

"Macbeth" (V.3.22)

by W. Shakespeare.

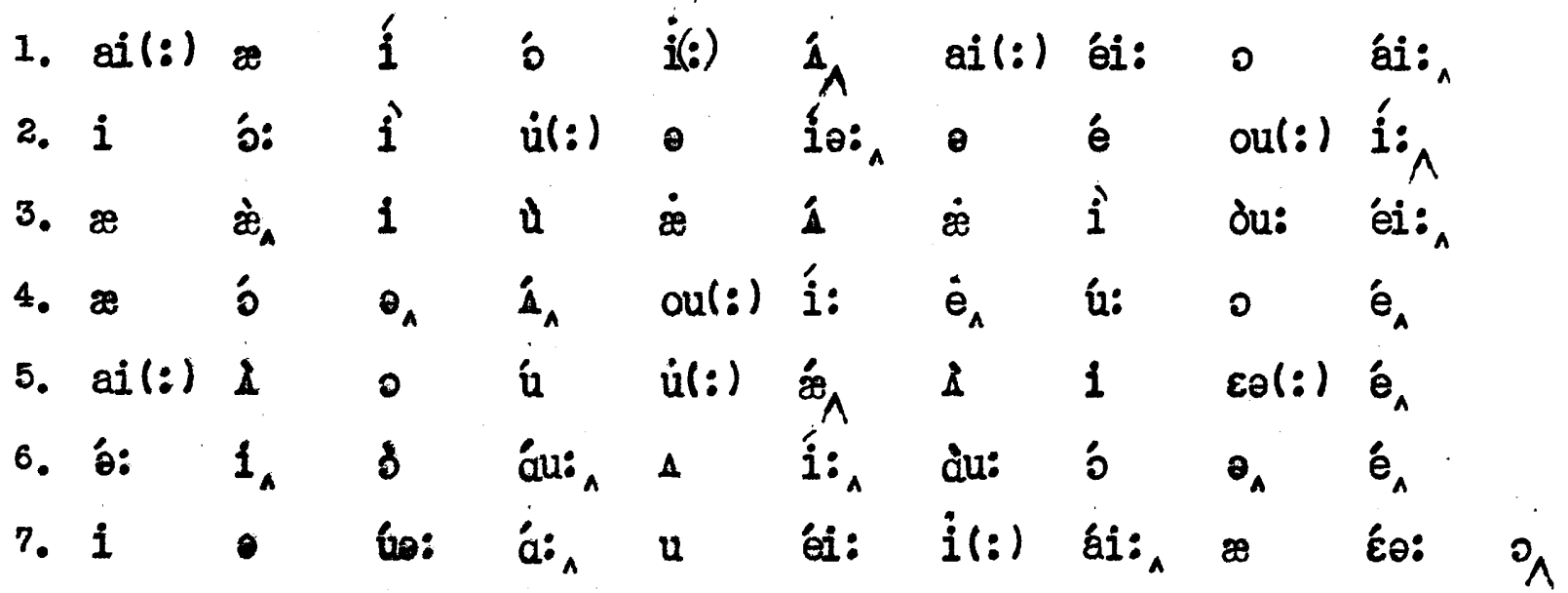


1. Next came one

2. Who mourn'd in earnest, when the captive ark

3. Maim'd his brute image, head and hands lopt off

4. In his own temple, on the grunsel edge,

5. Where he fell flat, and shamed his worshippers:

6. Degon his name; sea-monster, upward man

7. And downward fish: yet had his temple high

8. Rear'd in Azotus, dreaded through the coast

9. Of Palestine, in Gath, and Ascalon,

10. And Accaron and Gaza's frontier bounds.

11. Him follow'd Rimmon, whose delight ful seat

12. Was fair Damascus, on the fertile banks

13. Of Abbana and Pharphar, lucid streams.

14. He also 'gainst the house of lod was bold:

15. A leper once he lost, and gain'd a king,

16. Ahaz his sottish conquerer, whom he drew

17. God's altar to disparage and displace

18. For one of Syrian mode, whereon to burn

19. His odious offerings, and adore the gods

20. Whom he had vanquish'd. 
1. é èi: 'sA

2. $u(:)$ อə: $i$ ó: $i_{A} \dot{\theta}$ o

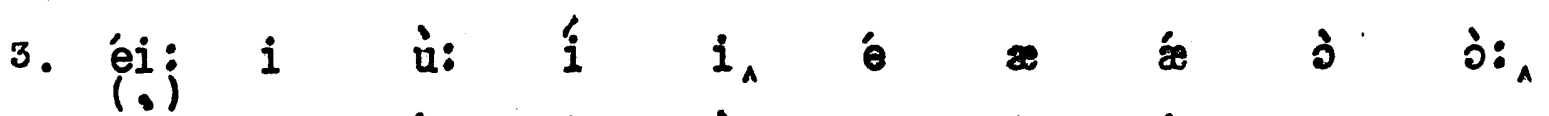

4. $i^{i}$ òu $\dot{\theta}_{A} \dot{j} \quad \partial \quad i \quad \dot{e}_{A}$

5. $\varepsilon \theta(:) i(:)$ a $\dot{z}_{A} \approx$ ei: $i$ á: $i$ (,)

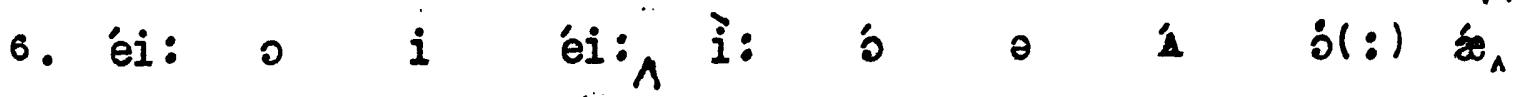

7. $x$ áu: $\dot{\partial}(:) i_{\wedge}^{\prime} \quad \dot{\theta} \quad x \quad i \quad$ e ái:

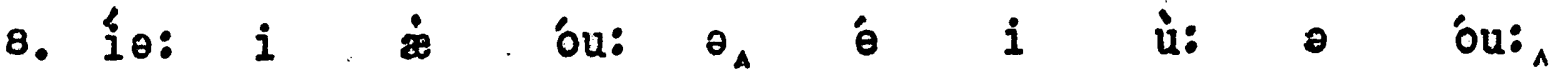

๑. ○ ஐ́ é

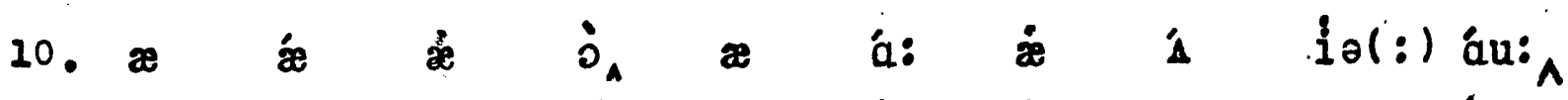

11. $i$ o oul : $) \dot{i}^{\prime}$ $\theta_{\wedge} \quad \dot{u}: \quad \dot{i}(:)$ ái: $\dot{u}$ i:

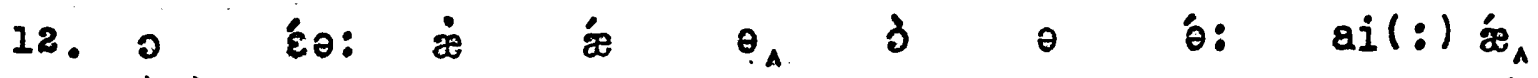

13. (口) $\approx$ á: $\approx$ a a: al:) ul $i$ i:

14. ì: j: oul: $)_{\wedge}$ eil(:) $\theta$ áu: 0 ó 0 óu:

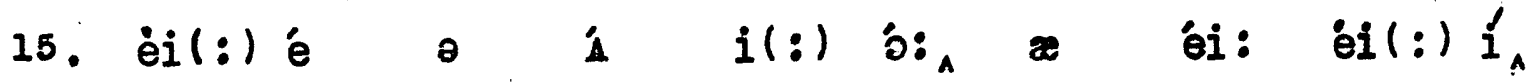

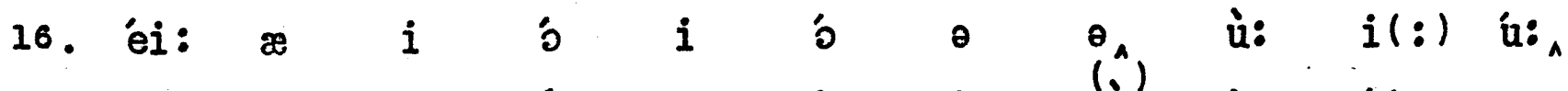

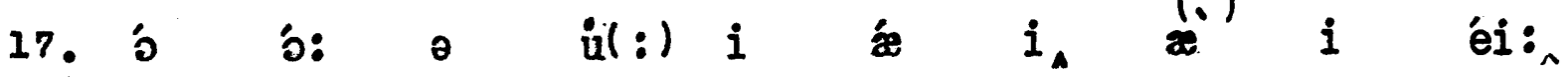

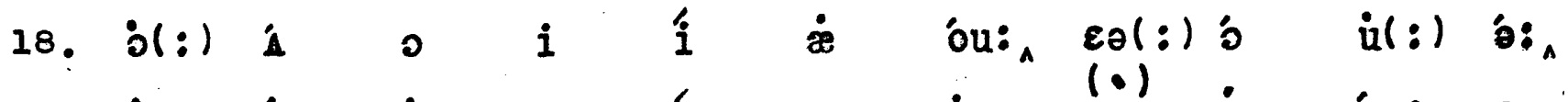

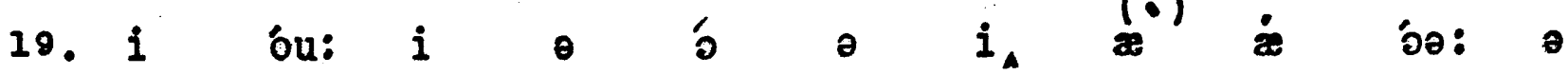

ò

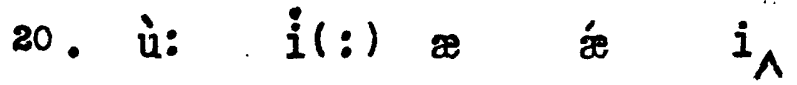


1. And all who since, baptized or infidel,

2. Jousted in Aspramont or Montalban,

3. Demasco, or Miaracco, or Trebi sond,

4. Or whom Biserta sent from Afric shore,

5. When Charlemain with all his peerage fell

6. By Fontarabia.

"Paradise Lost" (582-587)

by J. Milton.

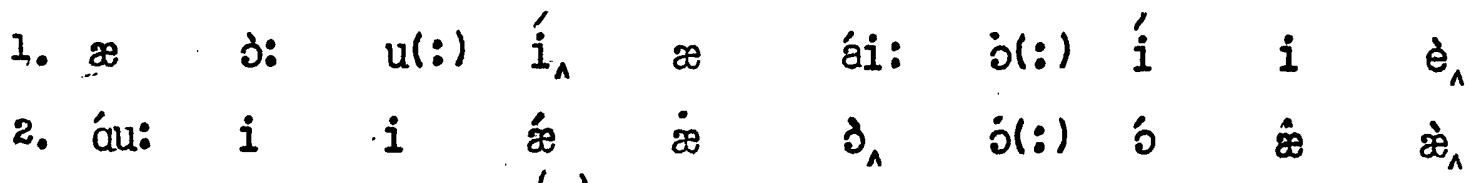

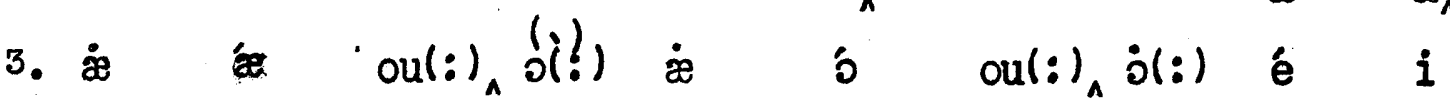

4. ol:) ú: $i$ ó: $\dot{z}$ 它

5. e á: $\theta$ éi: $i$ b: $i$ le: $i$ '́

6. àil:) ó $\dot{\otimes}$ éi: $i \quad \Re_{A}$ 
1. Some to the sun their insect-wings unfold,

2. Waft on the breeze, or sink in clouds of gold;

3. Transparent forms, too fine for mortal sight,

4. Their fluid bodies half dissolved in light.

5. Ioose to the wind their airy germents flew,

6. Thin gitt'ring textures of the filmy dew,

7. Dipped in the richest tincture of the slries,

8. Where light disports in ever-mingling dyes;

9. While ev'ry beam new transient colours flings,

10. Colours that change whene'er they wave their wings.

"The Rape of the Lock" (II.59-69) by A. Pope.

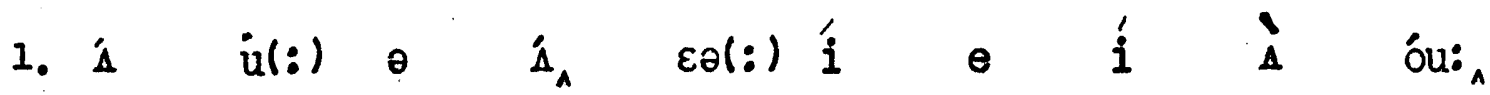

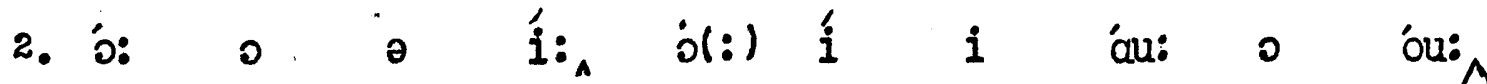

3. ஐ Ė: è อ́: ù: ái:

4. $\varepsilon \partial(:)$ ú: 1 ó $i_{\wedge}$ á: $i$ ó $i$ ái:

5. ú: $\dot{u}(:)$ ə $\hat{I}_{\wedge} \varepsilon \partial(:)$ cə: $i$ á: $\dot{e}$ ú:

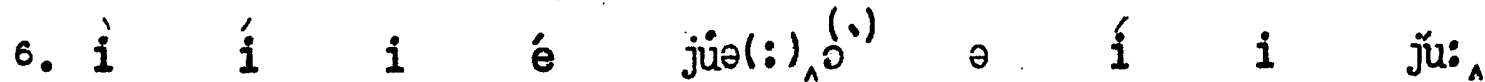

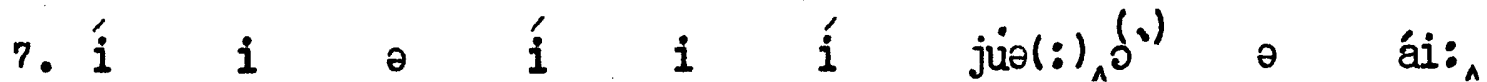

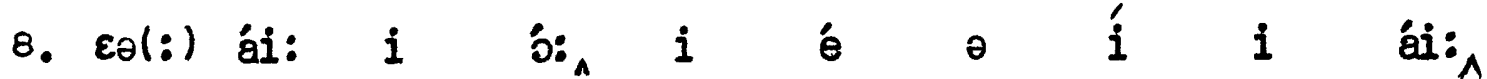

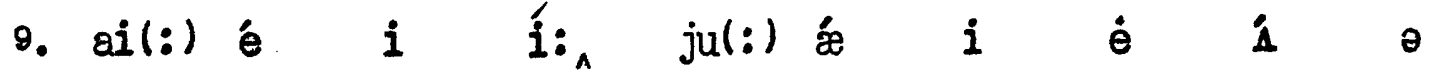

$i_{\text {A }}$

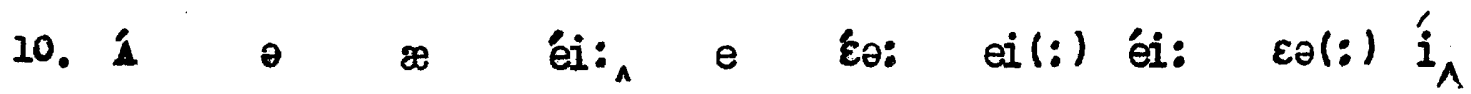


1. And perti-coloured troops, a shining train,

2. Draw forth to combat on the velvet plain.

3. The skilful nymph reviews her force with care:

4. Let spades be trumps she said, and trumps they were.

5. Now more to war her sable Matadores,

6. In show like leaders of the swarthy Noors.

7. Spedillio first, unconquerable lord:

8. Led off two captive trumps, and swept the board.

From "The Rape of the Iock" (IIIfby A. Pope.

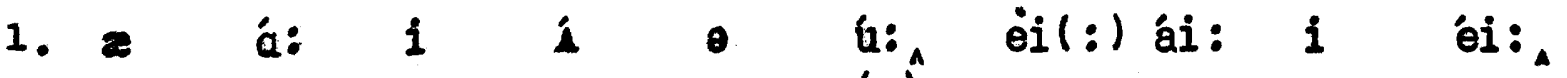

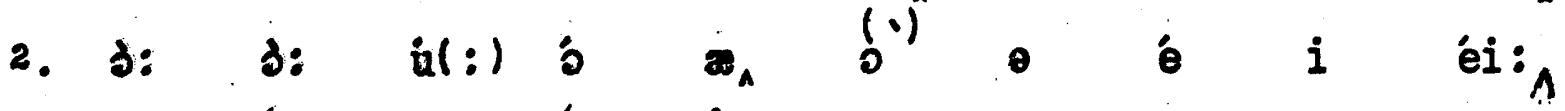

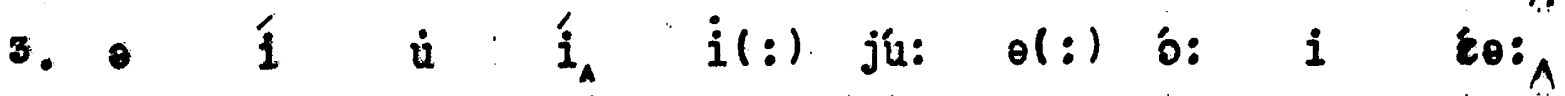

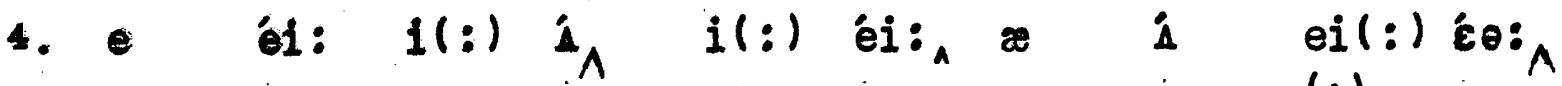

5. du: í: $u(:)$ b: ${ }_{\wedge} \theta(:)$ éi: \&

- 1 ou: all:)i: $\theta_{\wedge} \quad j$ o j: $i$ uo:

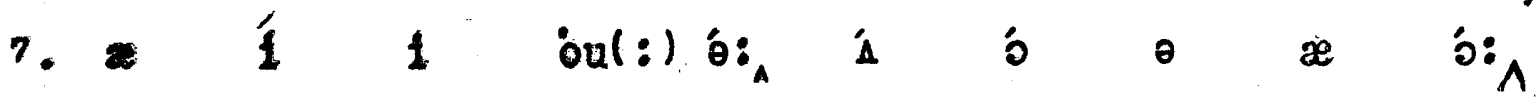

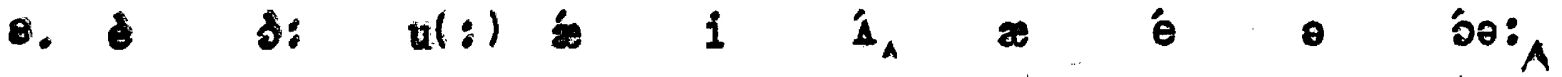


1. Meart leaps up when I behold

2. A rainbow in the sky:

3. So was it when life began,

4. So is it now I am a man,

5. So be it when I shall grow old,

6. Or let me die!

7. The Child is father of the Man:

8. And I could wish my days to be

9. Bound each to each by natural piety.

W. Wordsworth.

1. qi(:) á: ì: $\hat{A}_{A} \theta$ ài: $i(:)$ ou:

2. èi(:) éi: ou(:) ${ }_{\wedge}^{i}$ o ái:

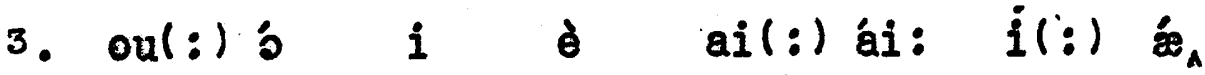

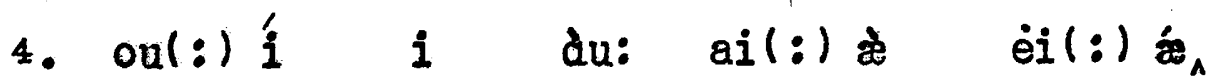

5. oul: $)_{1}^{\prime}: \quad i$ ail $\left.i\right)$ \& bu: ou:

6. j: e $i(:)$ ái:

7.

8. ài: $u$ $\mathfrak{1}$ ai(:) éi: $u(:)$ í,

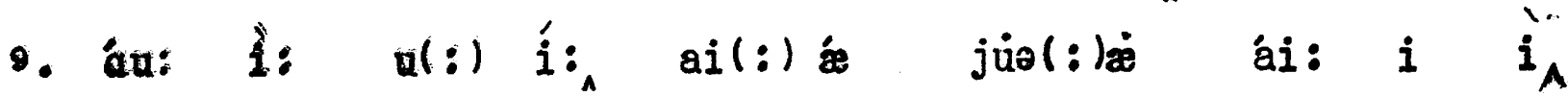


1. Season of mists and mellow fruitfulness,

2. Close bosom-friend of the maturing sun;

3. Conspiring with him how to load and bless

4. With fruit the vines that round the thatch-eves run;

5. To bend with apples the moss'd cottage-trees,

6. And fill all fruit with ripeness to the core;

7. To awell the gourd, and plump the hazel shells

8. With a sweet kernel; to set budding more,

9. And still more, later flowers for the bees,

10. Until they think warm days will never cease;

11. For sumer has o'erbrimm'd their clamm cells.

"Ode to Anturn" (v.1.)

by J. Keat 8 .

1. 1́ 0 í $¥$ é oul $:)$ ú $\dot{u}(\dot{e})$

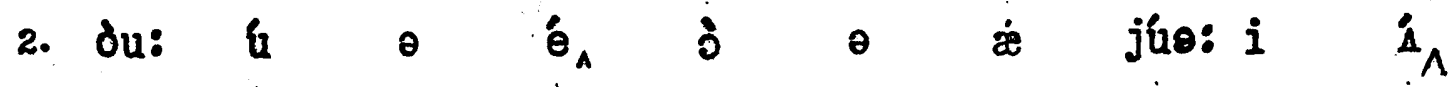

3. j lio: $i$ i $i_{\wedge}$ du: $u(:)$ ou: $z$ í

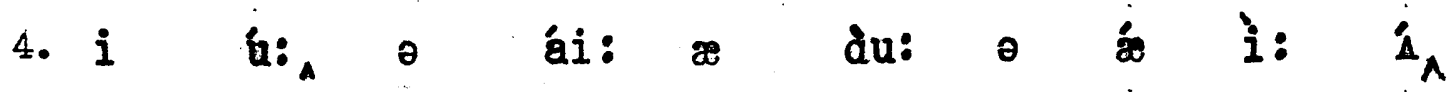

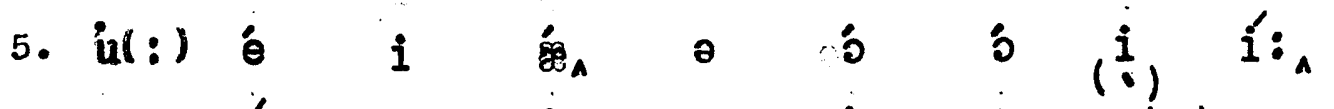

6. $i^{\prime}$ ol: u: $_{A} i$ ái: $i_{\wedge} u(:)$ o

7. $\dot{u}(:)$ é $\theta$ ú $\theta:_{\wedge} æ$ I o éi: é,

8. $i$ eil(:)íl $\dot{\theta}_{\wedge} \quad \dot{u}(:) \dot{e}$ i $i$ bo:

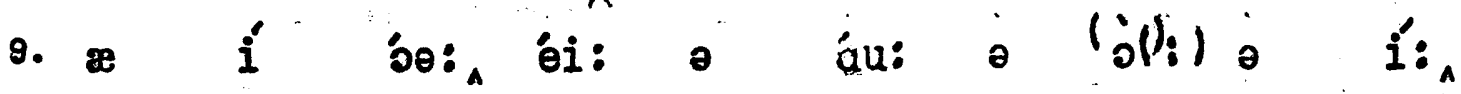

10. $\Delta \quad \dot{i}$ eil : $\ddot{i}_{\wedge}$ b: éi: $i$ é o $\quad \dot{i} \dot{A}_{\wedge}$

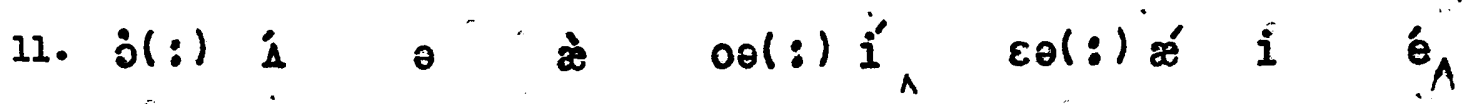


1. Who hath not seen thee oft amid thy store?

2. Sometimes whoever seeks abroad ma find

3. Thee sitting careless on a granary floor,

4. Thy hair soft-lifted by the winnowing wind;

5. Or on a half-reap'd furrow sound asleep,

6. Drows'd with the fume of poppies, while thy hook

7. Spares the next swath and all its twined flowers

8. And sometimes like a sileaner thou dost keep

9. Steady thy laden head across a brook;

10. Or by a cider-press, with patient look

11. Thou watchest the last oozings, hours by hours.

"Ode to Auturgn" (v.2)

by I. Keats.

\begin{tabular}{|c|c|c|c|c|c|c|c|c|c|}
\hline I. ú: & $\dddot{x}$ & 0 & í: & $i(:)$ & ó: & $\dot{æ}$ & 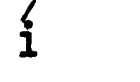 & ai (:) & \\
\hline 2. Í & $\operatorname{ai}(:)_{\wedge}$ & $u(:)$ & é & $a$ & 'i: & $\dot{æ}$ & ว’: & $e i(:)$ & ái: \\
\hline 3. $i(:)$ & $\dot{i}$ & i & '́ย: & $i_{A}$ & 0 & $\dot{e} i(:)$ & $\ddot{æ}$ & $\dot{\mathscr{X}}$ & i \\
\hline 4. ail:) & 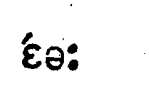 & ১: & $\dot{i}$ & $i_{\wedge}$ & ài: & $\partial$ & 1 & oul: $)$ & ; \\
\hline 5. 3: & 0 & èi(:) & á: & i: & Ĺ & oul: $)_{\wedge}$ & 'ou: & $\dot{æ}$ & \\
\hline 6. áu: & $i$ & $\theta$ & jú: & 0 & ó & $i_{\wedge}$ & ài: & ai $(:)$ & $\mathfrak{u}_{\wedge}$ \\
\hline 7. ह่: & $\partial$ & $\mathbf{e}$ & o: & $æ$ & 3: & i & ái: & $\mathbf{i}$ & \\
\hline 8. æ & Á & $a i(:)_{\wedge}$ & dì: & $\dot{e} i(:)$ & i: & $\theta$ & ám: & $\Delta$ & \\
\hline 9. é & $i$ & $a i(:)$ & éi: & $\dot{e}_{A}$ & $\dot{\ddot{\nexists}}$ & ๖: & $\dot{e} i(:)$ & $\mathfrak{u}_{\Lambda}$ & \\
\hline . o(!) & ail: $)$ & $\ddot{e} i(:)$ & ái: & $\partial$ & $\dot{e}_{\Lambda}$ & $\mathbf{i}$ & éi: & $\dot{\mathrm{e}}$ & \\
\hline oul: : & ó & $\mathbf{i}$ & $\partial$ & á: & ú: & $i_{\wedge}$ & '́ù: & ail: $)$ & \\
\hline
\end{tabular}


1. As when, upon a trancèd summer-night,

2. Those green-rob'd senators of mighty woods,

3. Trill oaks, branch-charmed by the earnest stars,

4. Dream, and so dream all night without a stir

5. Save from one gradual solitary gust

6. Which comes upon the silence, and dies off,

7. As if the ebbing air had bat one wave;

8. So came these words and went.

"Hyperion" (4.72-79)

by J. Keats.

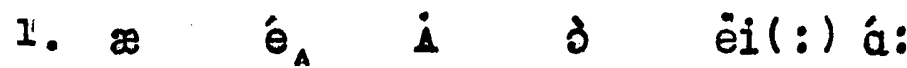

2. ou(:) í: ou: é $\dot{e}$

$\dot{\ddot{\theta}} \quad \dot{a}$

i $\hat{\mathbf{A}}$

(1)

á: i

aif

$\theta$

i

jul : ) $\dot{æ}$

b

ái: ê

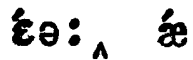

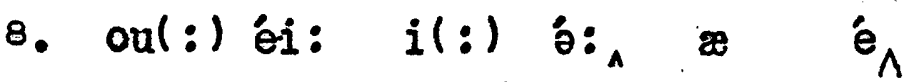

A $\partial$ ái:

ái: i $\mathbf{u}_{\wedge}$ ó: $i$ á: du: $\dot{e} i(:)$ é: $1 \stackrel{(}{\circledast}) \quad i$ a ái: ó: A 1 1 éi: 
1. On either side the river lie

2. Iong fields of barley and of rye,

3. That clothe the wold and meet the sky;

4. And thro' the field the road runs by

5. To many tower'd Camelot;

6. And up and down the people go,

7. Gesing where the lilies blow

8. Round an island there below,

9. The 18land of Shelott.

"The Lady of Shalott" (v.1.)

by Lord Tennyson.

\begin{tabular}{|c|c|c|c|c|c|c|}
\hline 1. 0 & ai: & $\theta$ & ái: & $\theta$ & i & $\theta$ \\
\hline 2. 5 & I: & i & á: & $i_{A}$ & 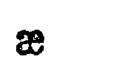 & 0 \\
\hline 3. 2 & bu: & $\theta$ & ous: & $\approx$ & $\xi:$ & $\theta$ \\
\hline 4. $\approx$ & A: & $\theta$ & $i: A$ & $\theta$ & oís & 8 \\
\hline 5. $\dot{u}(:)$ & $\dot{\theta}$ & $i$ & áu: & $\dot{\theta}_{\Lambda}$ & $\dot{\infty}$ & $i$ \\
\hline 6. $\approx$ & i & 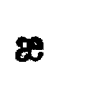 & áu: & $\theta$ & i: & óv: A \\
\hline 7. éi: & 1 & $\varepsilon \theta:$ & $\theta$ & $\mathfrak{l}$ & $\mathbf{i}$ & ou: \\
\hline 8. da: & $\approx$ & ai: & $w_{4}$ & $\varepsilon_{\theta:}$ & $i(:)$ & ou: \\
\hline 3. $i$ & 64 & $x_{k}$ & & $\dot{\ddot{a}}$ & $\dot{0}$ & \\
\hline
\end{tabular}


1. Willows whiten, aspens quiver,

2. Iittle breezes dusk and shiver

3. Thro' the wave that runs for ever

4. the island in the river

5. Flowing dom to Camelot.

6. Four gray walls, and four gray towers,

7. Overlook a space of flowers,

8. And the silent isle imbowers

9. The Ledy of Shrlott.

"The Lady of Shelott" (v. 2) by Lord Tennyson.

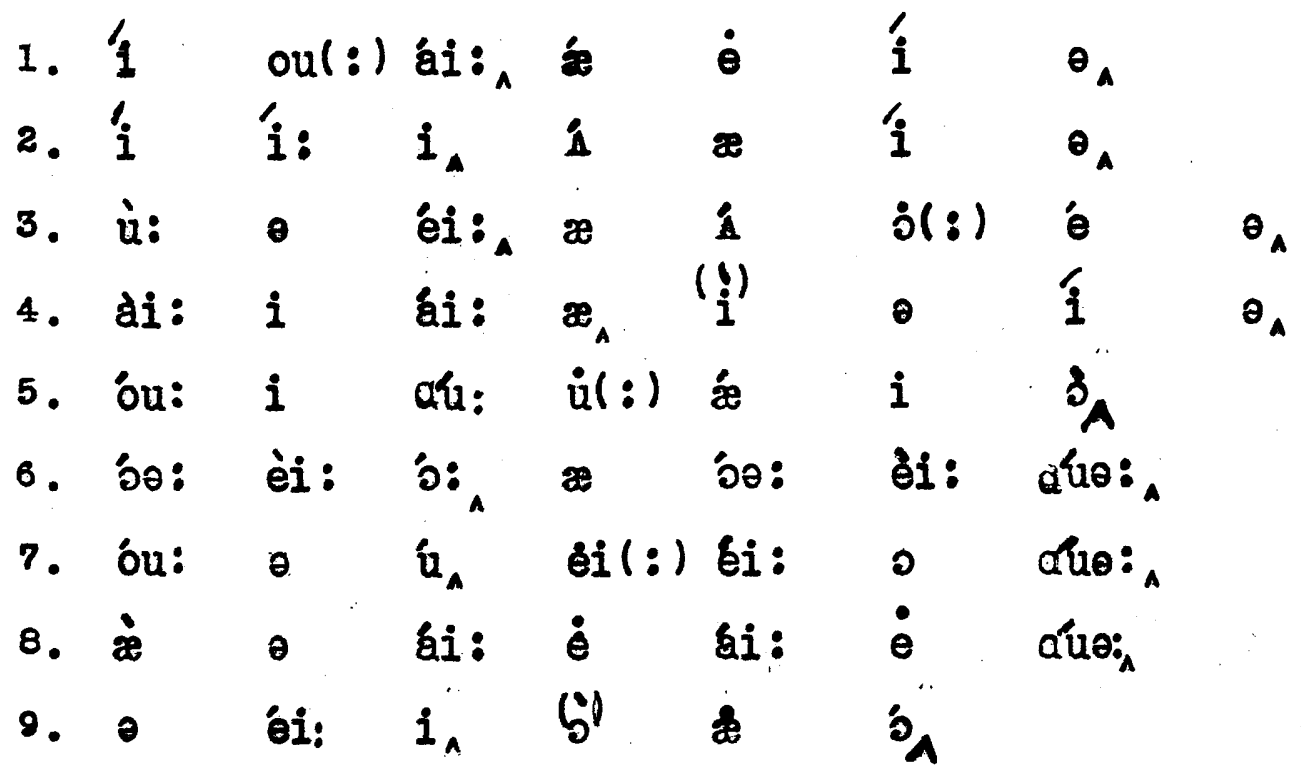


1. Alone, aloud in the raptured ear of men

2. We pour our dark nocturnal secret; and then,

3. As night is withd rawn

4. From these sweet-springing meads and bursting boughs of iley,

5. Dream, while the innumerable choir of day

6.

Welcome the dawn.

"Nightingales" (

by Sir Robert Bridges.

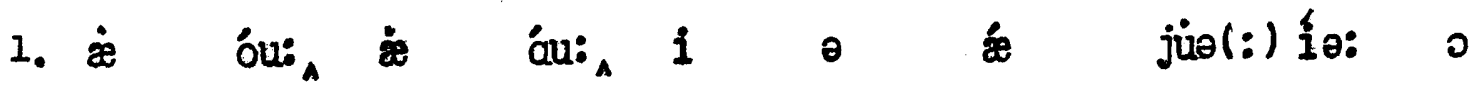

$\dot{e}_{\Lambda}$

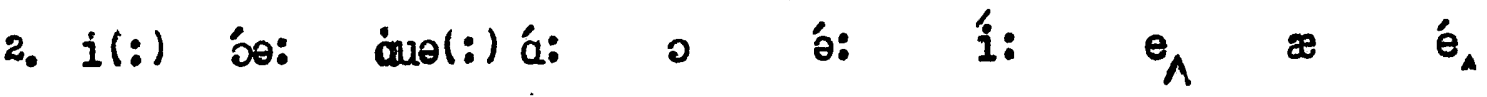

3. æ ái: $i$ i o:

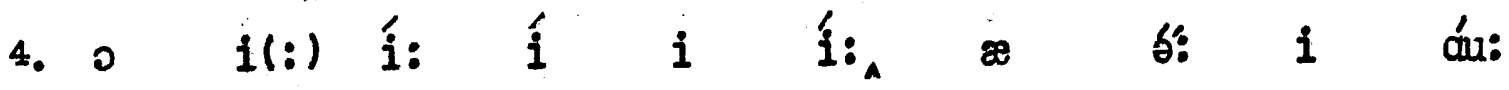

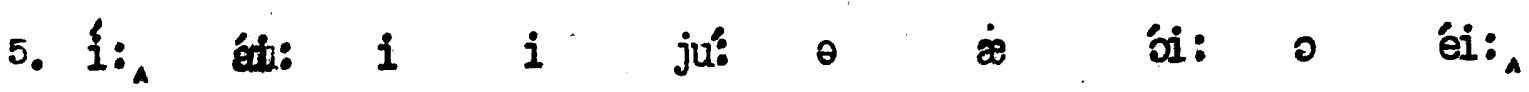

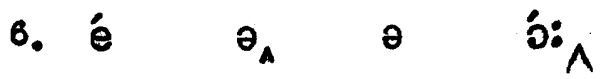


1. That passing-bells for these who die as cattle?

2. Only the monstrous anger of the guns,

3. Only the stuttering rifles' rapid rattlo

4. Can patter out their hasty orisons.

5. No mockeries for them; no prayers nor bells,

6. Nor any voice of mourning save the choirs, -

7. The shrill, demented choirs of wailing shells;

8. And bugles calling for them from sad shires.

9. What candles may be held to speed them all?

10. Not in the hands of boys, but in their eyes

11. Shall shine the holy glimmers of good-byes.

12. The pallor of girls' brows shall be their pall;

13. Wheir flowers the tenderness of patient minds,

14. And each slow dusk a drawing-down of blinds.

"Anthem for Doomed Youth"

by W. Owen.

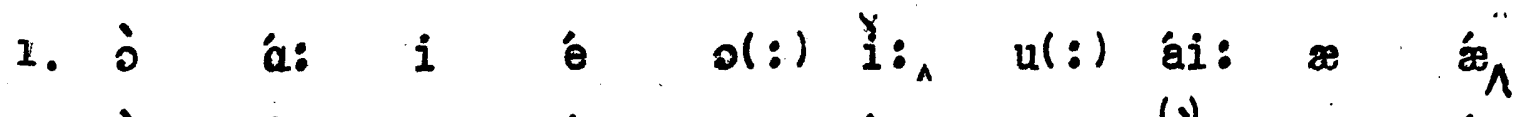

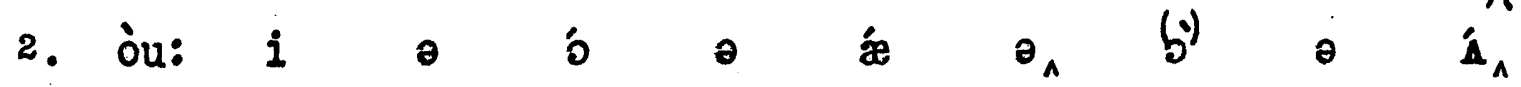

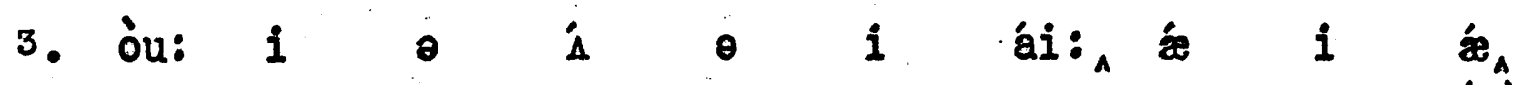

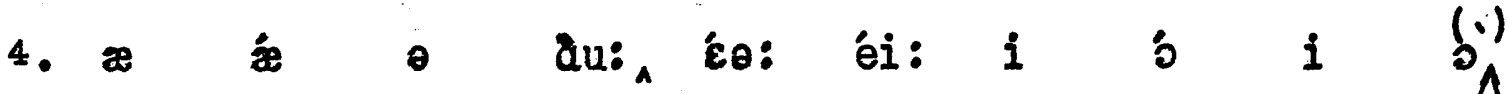

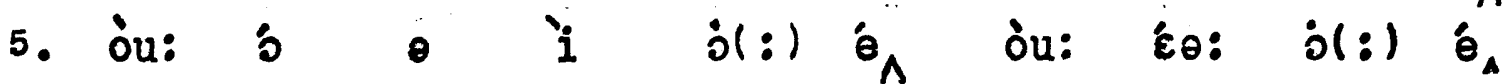

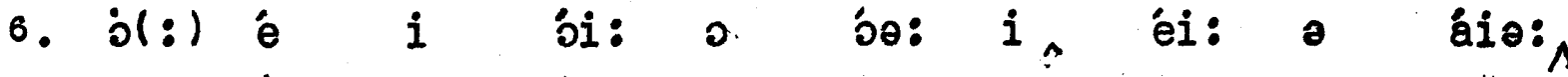

7. $\theta i_{\wedge} \quad i(:)$ e $i$ áio: 0 éi: $i$ é

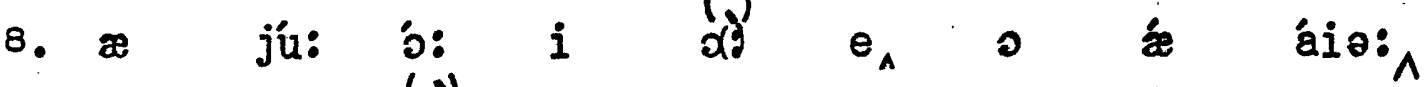

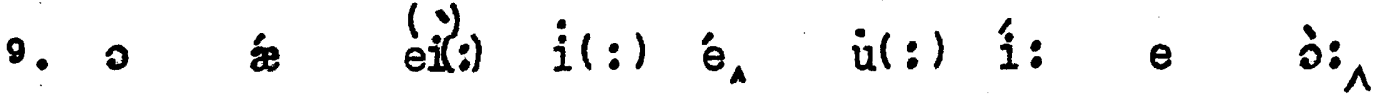

10.

11. $\boldsymbol{x}$ ái: o ou: $i$ i

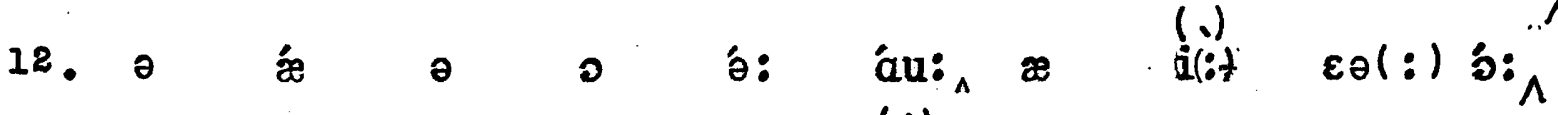

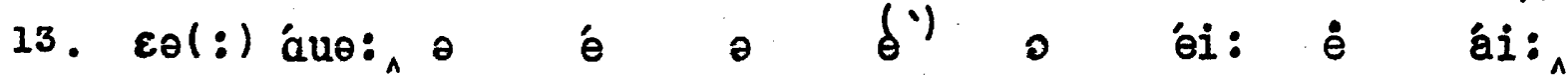

14. $\approx$ i: òu: ín éi(:) o: $i$ áu: o ái: 
1. I will arise and go now, and go to Innisfree,

2. And a small cabin build there, of clay and wattles made;

3. Nine bean rows will I have there, a hive for the honey bee,

4. And live alone in the bee-loud glade.

5. And I shall have some peace there, for peace comes dropping slow,

6. Dropping from the veils of the moming to where the cricket sings;

7. There midnight's all a glimmer, and noon a purple glow,

8. And evening full of the linnet's wings.

9. I will arise and go now, for always night and day

10. I hear lake water lapping with low sounds by the shore;

11. While I stand on the roadway, or on the pavements gray,

12. I hear it in the deep heart's core.

mphe Lake Isle of Inniafree" by W. B. Yeats.

1. ai: $i$ æ̇

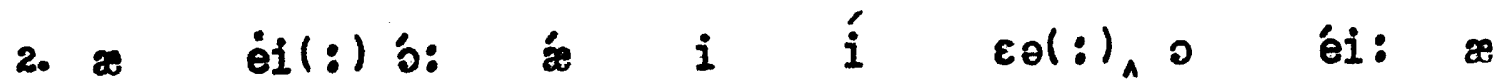

¿ él: $\Lambda$

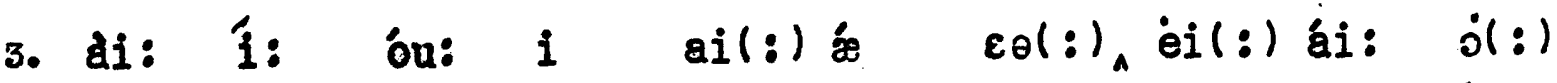

4. $\approx$ i $\dot{i}$ on: $i$ o $i:$ du: éi:

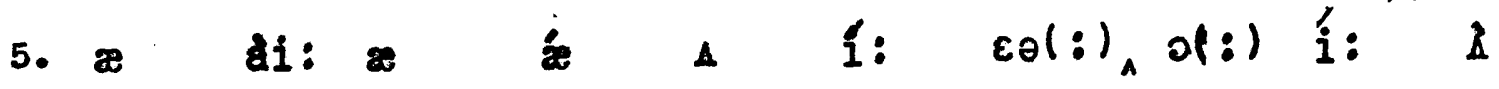

o $i$ óu:

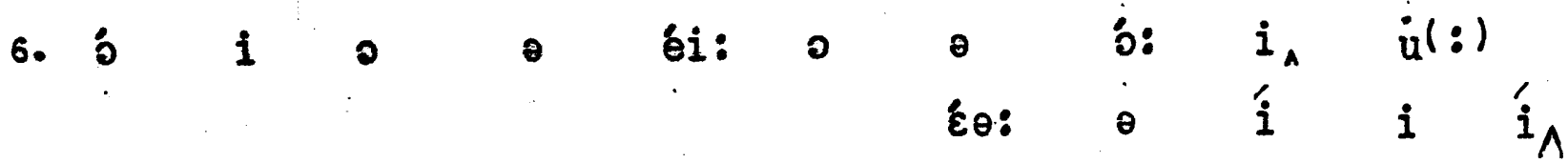

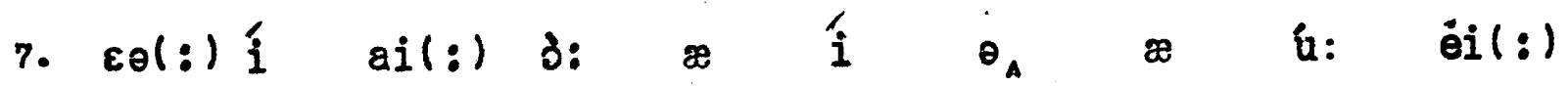

í: óu: 


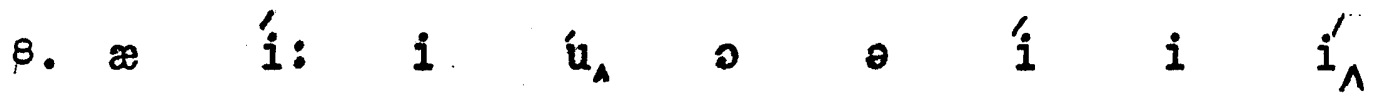

9. d̀i: $i$ æ ái: $\approx$ bu: áu: $\dot{\wedge}(:)$ ó: eil:

ái: æ éi:A

10. ail: ) iø: èi: ó: $\theta$ Ł $i_{\wedge} i$ ou: áu:

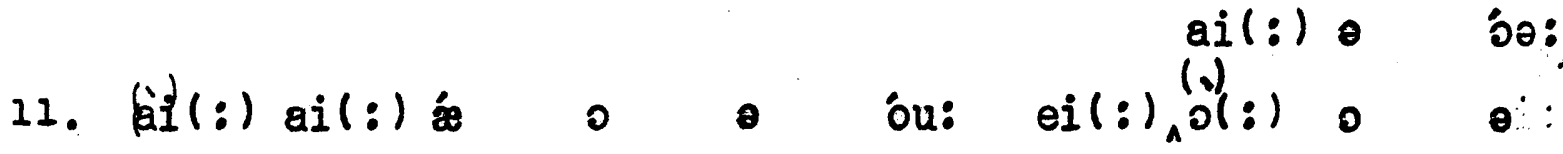

éi: è éi:

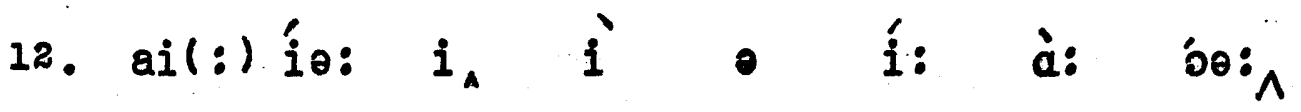


1. Blow, blow, thou winter wind,

2. Thou are not so unitind

3. As man's ingratitude;

4. Thy tooth is not so keen,

5. Because thou art not seen,

6. Although thy breath be rude.

7. Heigh ho! sing, heigh ho! unto the green holly:

8. Most friendship is feigning, most loving mere folly:

9. Then heigh ho: the holly!

10. This life is most jolly.

11.

12.

13.

14.

15.

16.

Freeze, freeze, thou bitter sky,

As friend remember'a not.

17. Heigh ho: sing, heigh ho: unto the green holly:

18. Most friendship is feigning, most loving mere folly:

19. Then heigh ho, the holly!

20. This life is most jolly.

Song by W. Shakespeare.

("As You Like It" II.7.174)

1. óu: óu: $a u(:)$ i $\theta$ ái:

2. $a u(:)$ à:

- ठu:

4 ái:

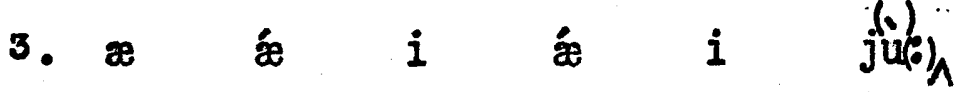

4. ai(:) ú: $i$ ó ou(:) í,

5. $i(:)$ o $a u(:)$ d: 0 i:

6. $j(:)$ ou: ail: é $i(:)$ ú:

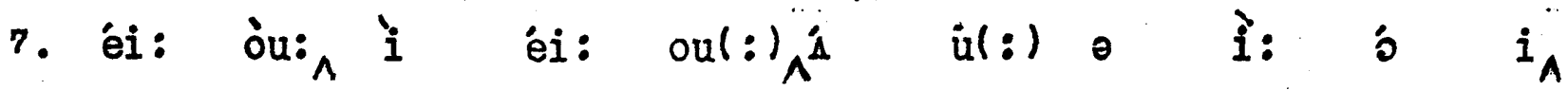

8. oul: )é $i$ i éi: is oul:) i $i$ iol:)

9. e éi: ou(:) ${ }_{\Delta} \theta$ o $i_{\wedge}$

10. $i$ ái: $i$ oul $:$ ) o $i_{\wedge}$

11. $i:$ í ${ }_{1}$ aul: $)^{\prime}$ o ái: 
12. æ i 0 ái: oul : $)$ ái:A

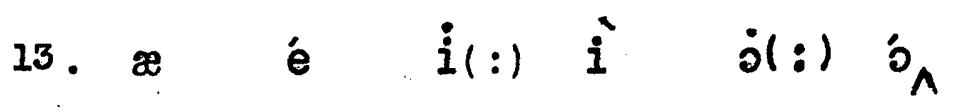

14. ou(:) áu: ${ }_{\wedge}$ ə o: $\theta$ o:

15. ail: $)^{\prime} i$ i oul $\left.:\right)^{\prime} a:_{A}$

16. $\approx$ e $i(:)$ e $\theta$ ô

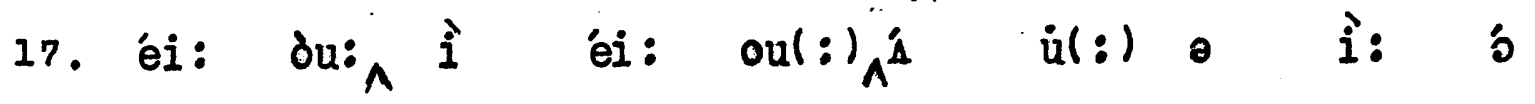

18. oul: : é $i$ $i$ éi: $i_{\wedge}$ oul: $) i$ $i$ iol:

o $i_{\wedge}$

19. $\theta$ éi: ou(: $)_{\wedge} \theta$ is $i_{A}$

20. $i$ ái: $i$ oul: $)^{\prime}$ i 
1. Where are the songs of Spring? Aye, where are they?

2. Think not of them, - thou hast thy masic too,

3. While barréd clorids bloom the soft-dying day

4. And touch the stubble-plains with rosy bue;

5. Then in a wailful choir the small gnats mourm

6. Among the river sallows, bome aloft

7. Or sinking as the light wind lives or dies;

8. And full-grown lambs loud bleat from hilly-boum;

9. Hedge-crickets sing, and now with treble soft

10. The redbreast whisties from a garden-croft,

11. And gathering swallows twitter in the skies.

$$
\begin{aligned}
& \text { "Ode to Auturm" (v. } 3 \text { ) } \\
& \text { by J. Keats. }
\end{aligned}
$$

1. Ė: $\dot{a}(:)$ o ó o $\dot{i}_{\wedge}$ ái: $\varepsilon_{\theta}:$ à: éi:

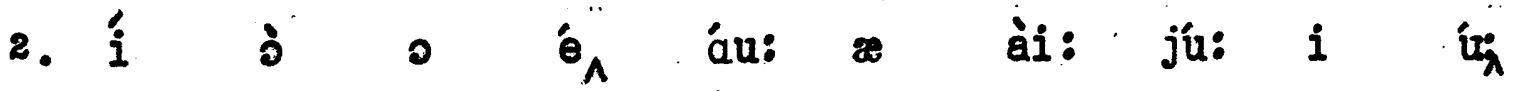

3. ai(:) á: $i$ áu: ${ }_{\wedge}$ u: $\theta$ j: ái: $i$ éi:

4. $\approx$ i $\quad \theta$ \& éi: $i$ ou: $i$ jú $\wedge$

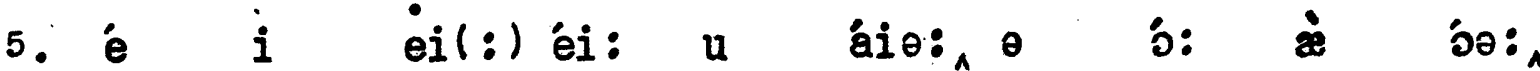

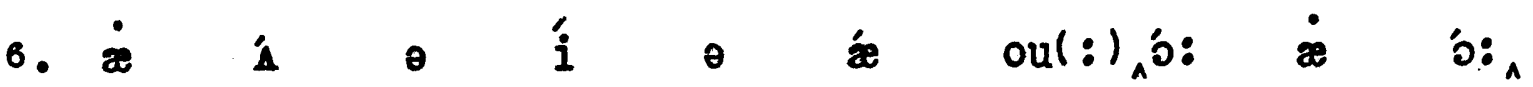

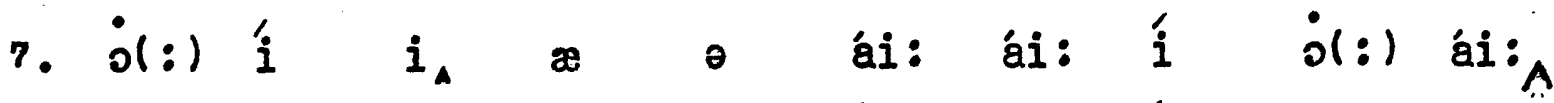

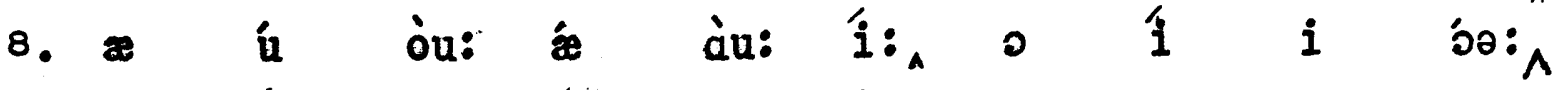

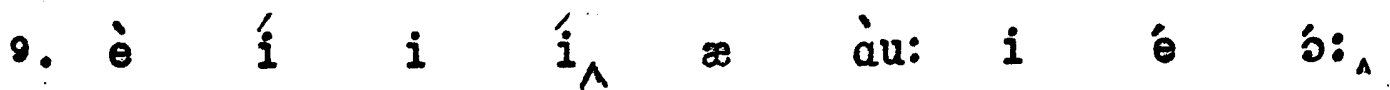

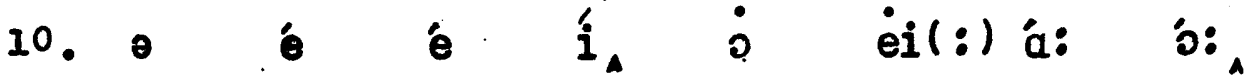

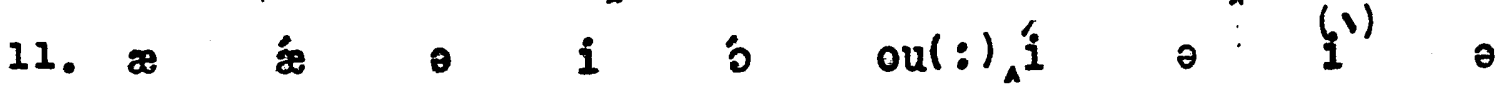




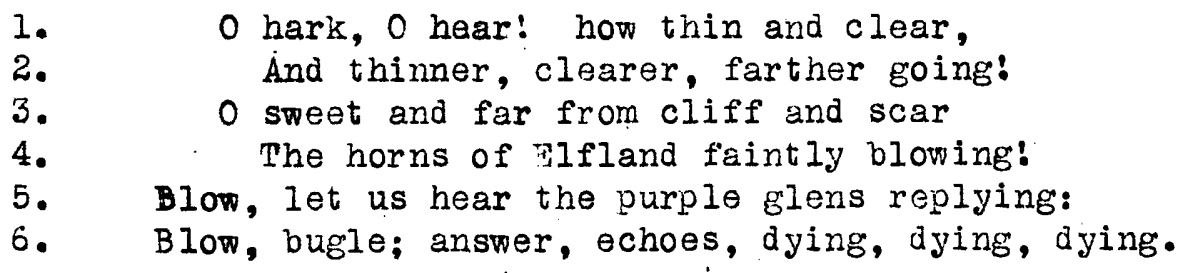

The splendour falls on castle walls" ( by Lord Tenny son.

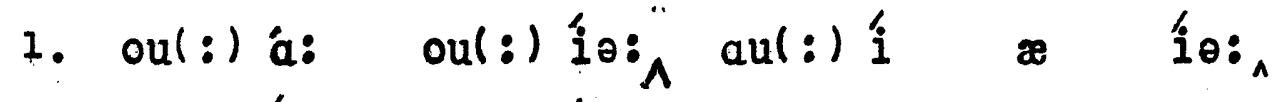

2. 2 I $\partial$ lo: $\theta_{\wedge}$ á: $\theta$ ou: $i_{\wedge}$

3. ou(:) í: æ á:

4. จ o: 0 ê $\dot{w}_{A}$ éi: $i$ ou: $i_{\wedge}$

5. ou: $\theta$ a fo: $\theta$ b: $\quad$ e $i(:)$ Gi: $i_{A}$

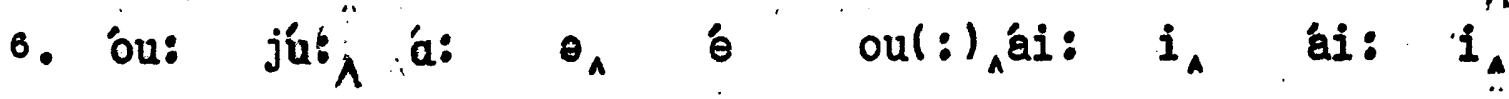

ái: $i_{\wedge}$ 


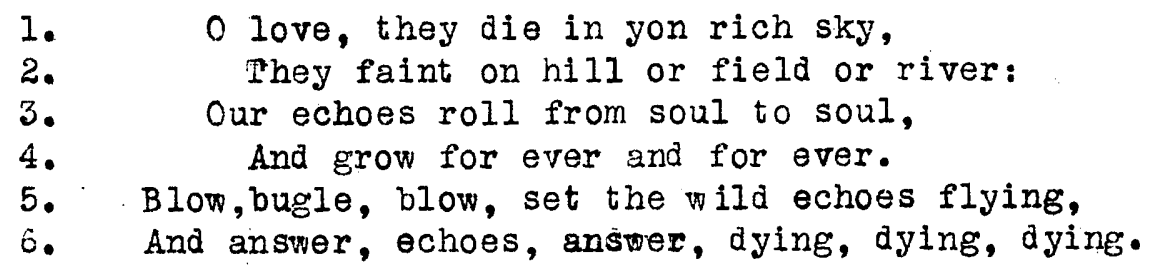

"The splendour fàlls on -castle walls" (v.3) by Lor anyson.

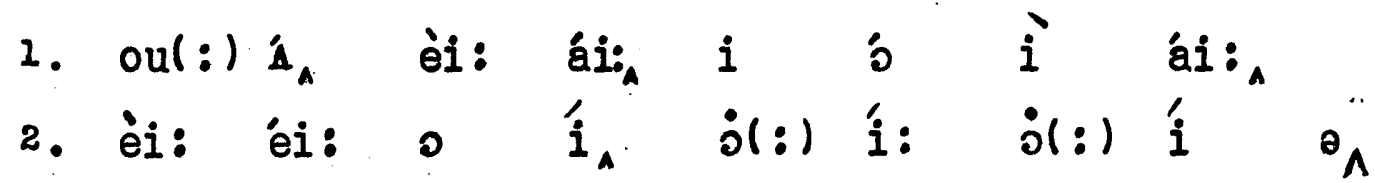

3. aùl: lé ou(:) ou: ${ }_{\wedge}$ o ou: $u(:)$ ou:

4. $x$ ou: $\dot{o}(:)$ é $\dot{\theta}_{\wedge} \quad \dot{z} \quad \dot{o}(:) \quad \varepsilon \quad \theta_{\wedge}$

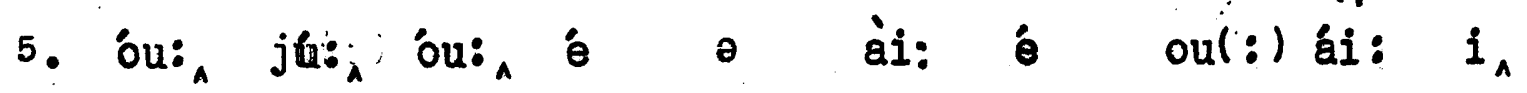

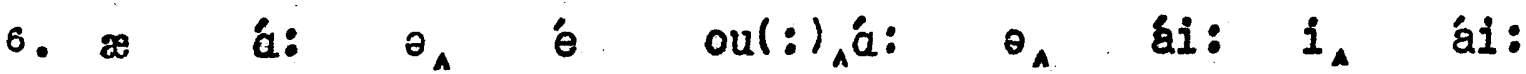

i. ái: $i_{\wedge}$ 
1. A widow bird sate mourning for her love

2. Upon a wintry bough;

3. The frozen wind crept on above,

4. We freezing stream below.

5. Ihere was no leaf upon the forest bare,

6. No flower upon the ground,

7. And little motion in the air

8. Bxcept the mill-wheel's sound.

P.B. Shelley.

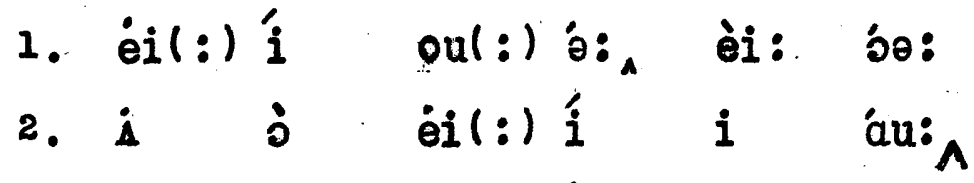

3. ə ou: ái: $\dot{A}$ ó $\dot{z} \mathbb{A}_{A}$

4. จ í $i$ í, $\quad \dot{i}(:)$ ou: $\wedge$

5. $\varepsilon \theta(:)$ j ou: $\mathfrak{i}:_{\wedge}$ i fl $^{\wedge}$ o

6. òu: áue: $i$ ì $i$ áu:

7. $\approx$ i ou: $\theta_{A} \quad \dot{i}$ o $\varepsilon_{\theta}:_{A}$

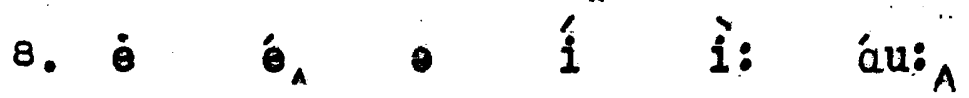




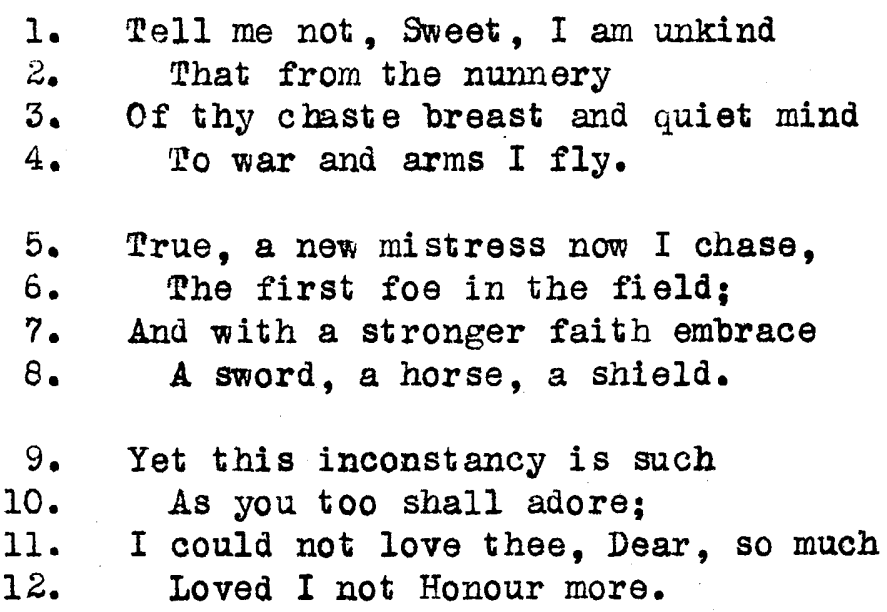

From "To Lucasta, on going to the Warg" by R. Lovélaco.
7. ̊́. $i(:)$ ̀े
i: $\quad$ ail : $)$ æ
$\Lambda \quad$ ái:

2. 离

$0 \quad \theta$

i. $\dot{e} i_{A}$

3. 0

ai (:) éi: é

æ ái:

e. ái:

4. $u(:)$ o: æ áa ai(:) ái: $\wedge$

5. ú: eil: $j u(:) \stackrel{l}{i} i_{\wedge}$ àu $a i(:)$ éi:

6. $\theta$ อ̊ ou: $i$ o $i:_{\wedge}$

7. 向 $i$ eil(:) ó $\partial$ éi: $\dot{\theta}$ éi:

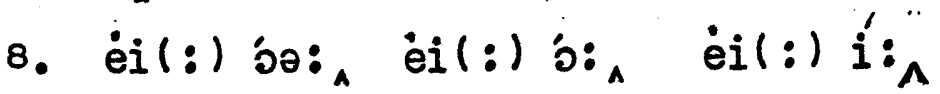

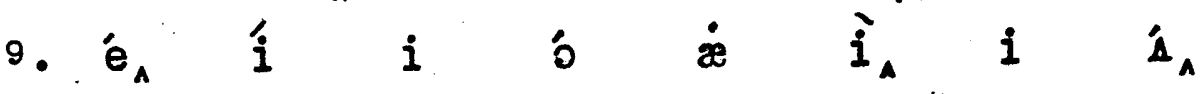

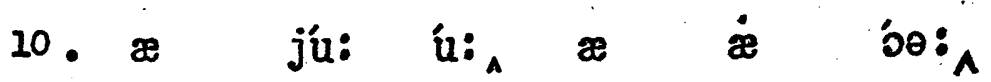

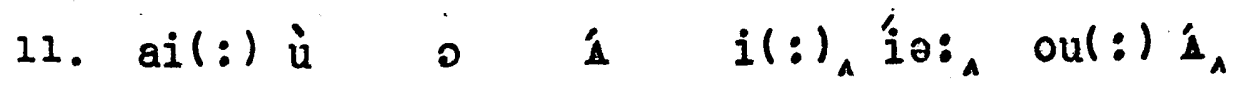

12. I $a i(:)_{\wedge} 0 \quad$ ó $\partial_{\wedge} \partial_{\Lambda}$ 
1. Jtrew on her roses, roses,

2. Ind never a spray of yew:

3. In quiat she reposes;

4. Ah: would that I did too.

5. Her mirth the world recuired;

6 . Sine bathed it in smiles of $g l e \theta$.

7. But her heart vias tired, tired,

8. And now they let her be.

9. Her life was turning, turning,

10. In mazes of heat ana sound;

11. But for peace her soul was yearning,

12. And now peace laps her round.

13. Her cabin'd, ample spirit,

14. It flutter'd and fail'd for breath;

15. To-night it doth inherit

16. The vasty hall of death.

I. ú 0 a(:) óu: $i_{A}$ ou: $i_{A}$

2. $\approx$ é $\theta$ èi(:) éi: ${ }_{\wedge}$ ju:

3. $i$ ái: $\dot{e}_{\wedge} \dot{i}: \quad \dot{i}(:)$ ou: $\dot{e}_{\wedge}$

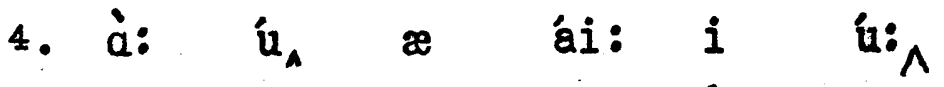

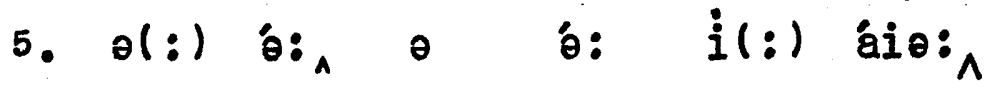

6. $i(:)$ éi: $i_{\wedge} i$ ái: 0 í^

7. $\Delta \quad \dot{\theta}(:)$ á: 0 áiə: $\wedge$ áio:

8. æ áu: ${ }_{\wedge}$ ei(:) é $\dot{\theta}(:)$ í:

ค. $\theta(:)$ ái: 0 á: $i$ o: $i_{\wedge}$

10. $i$ éi: $i$ o $1:_{\wedge} \approx$ áu:

11. $\Delta$ o(:) $i:_{\wedge} \quad \partial(:)$ ou: 0 í: $i_{A}$

12. æ áu: $\dot{i}:$ æa $\theta(:)$ au:

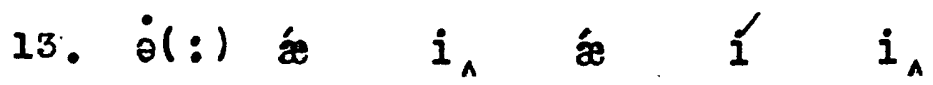

14. $i$ i $\theta_{\wedge} \approx$ éi: $j(:) \dot{e}_{\wedge}$

15. u ái: $\quad \begin{array}{llllll}i & \dot{\Delta} & i & e & i\end{array}$

16. ə $\dot{a}:$ i 
1. His heart in me keeps him and me in one,

2. My heart in him his thoughts and senses guides:

3. He loves my heart, for once it was his own,

4. I cherish his because in me it bides:

5. My true-love hath my heart, and I have his.

"My true love hath heart, and I have his"(v.2) By Sir Philip Sịtine

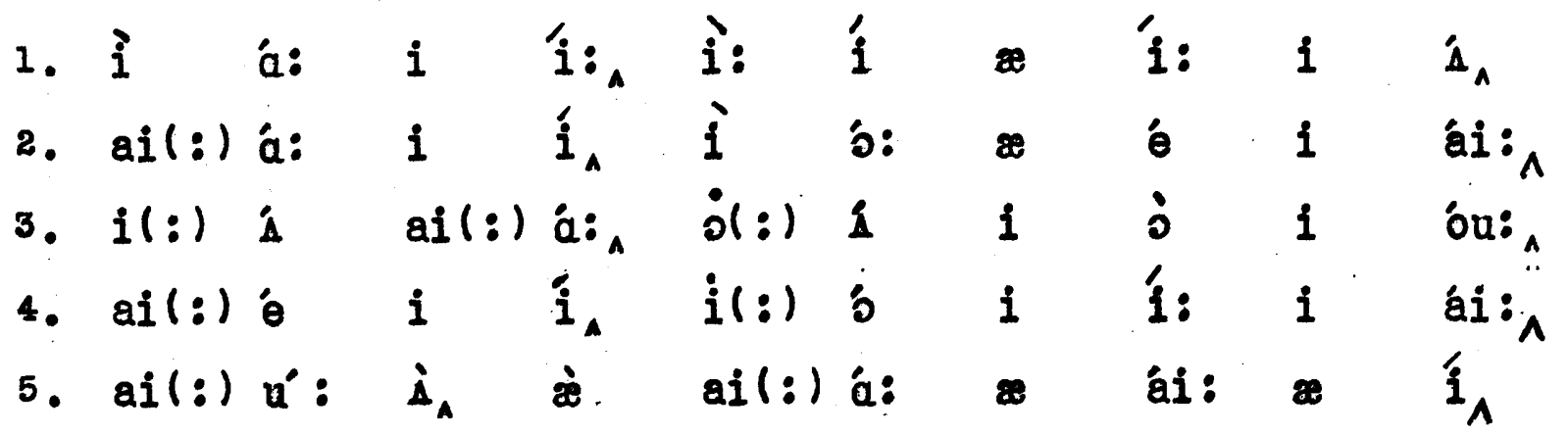


1. 0 Migtress mine, where are you roaming?

2. 0 stay and hear! your true love's coming,

3. That can sing both high and low:

4. Trip no further, pretty sweeting;

5. Journeys end in lovers meeting,

6. : Every wise man's son doth know.

"O mistress mine, where are you roaming?" (v.1.) Song by Shaikespeare

("Twelfth Night" II.3.42)

\begin{tabular}{|c|c|c|c|c|c|c|c|c|}
\hline 1. & oul: : & $i$ & $\partial$ & ái: & દંə: & $\dot{a}(:)$ & ju( : ) & óu: \\
\hline 2. & oủ $(:)$ & éi: & $æ$ & $\mathfrak{i}_{0}:{ }_{A}$ & $j u \partial(\vdots)$ & ú: & $\lambda$ & $\dot{a}$ \\
\hline 3. & ま & $\approx$ & $\hat{i}$ & oul $:)$ & ái: & $\mathbf{x}$ & ou: & \\
\hline 4. & 自 & oul: $)$ & ó: & $\partial_{\Lambda}$ & $\grave{i}$ & $i$ & $\hat{i}:$ & $i_{\wedge}$ \\
\hline 5. & é: & $i$ & $\dot{\theta}_{\Lambda}$ & $i$ & $\dot{\Lambda}$ & $\theta$ & $i$ & $i_{A}$ \\
\hline 6. & é & $i$ & ái: & æ & $\dot{\Delta}_{a}$ & $\Lambda$ & ơ: & \\
\hline
\end{tabular}


1. What is love? itis not hereafter;

2. Present mirth hath present laughter;

3. What's to come is still unsure:

4. In delay there lies no plenty;

5. Then come kiss me, sweet-and-twenty

6. Youth's a stuff will not endare.

"O mistress mine, where are you roaming?" (v.2.)

Song by W. Shakespeare

("Twelfth Night" II.3.50.)
1. 5
$i$
i
3
io(:) á:
$\theta$
2. é
- $\dot{\theta}:$
$\boldsymbol{\circledast}$
é
6. á:
$\theta$
3.
$\dot{u}(:) \quad \dot{A}_{A}$
i
i
I น́⿴囗十
4. i
il: : éi:
عə(:) ái:
ou(: ) é
i(:) $\hat{i}$ :
\&
é
${ }^{i}{ }_{\wedge}$
6. jú:
é1(:) LA
i ó
๕. jů: 
1. Shall I compare thee to a summer's day?

2. Lhou art more lovely and more temperate:

3. Rough winds do shake the darling buds of May,

4. And summer's lease hath all too short a date:

5. Sometime too hot the eye of heaven shines,

6. And often is his gold complexion dimm'd:

7. And every fair from fair sometime declines,

8. By chance, or nature's chanking course, untrimm'd.

9. But thy eternal summer shall not fade

10. Nor lose possession of that fair thou owest;

11.

Nor shall death brag thou wanderest in his shade, Then in eternal lines to time thou growest:

13.

So long as men can breathe, or eyes can see,

So long lives this, and this gives life to thee.

W. Shaike speare.

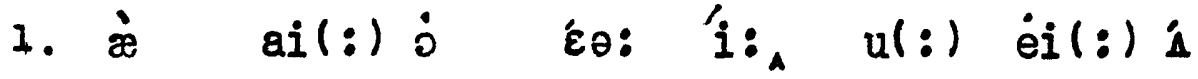

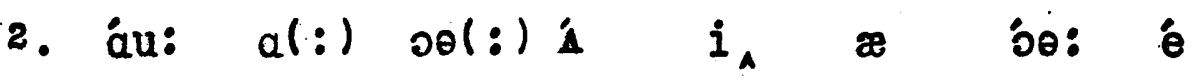

- éi:^

3. i ái: $u(:)$ éi:

จ á: i i

- éi:

4. æ I $\theta \quad$ i:

อ̀: ù: ว́:

$\ddot{e i}(:)$ éi:

5. i

ail : $) u(:)$ ó

i ái: o

é ái:

6. æ

ذ: $\theta_{A} \quad \grave{i}$

i ou: $\dot{0}$

é

- $\quad i_{\Lambda}$

7. $\infty$

é i غ́ə:

ว $\quad \dot{\varepsilon}_{\theta}:_{\wedge} \quad \grave{\Lambda}$

ái:

il :

ái :

8. ail: á: $j(:)$ éi: jủol: léi: $i$

๑. $\Delta$

ái: $\mathfrak{i}(:)$ b:

í

æ

อə:

$\Delta$

î

10. ol: ) u: oul: $)$ é

11. $(0(\vdots)) \approx$ è

$\theta_{A} 3$ \&ə: $a(:)$ ou:

1

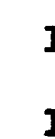

1

13. oul: : :

i(:) í:

aul : ) ó

$i$

$\grave{i}$

i

éi:

æ ái: $u(:)$ ái:

æ $1:$ ol $\quad$ ái:

æ

i i

ái:

$a u(:)$ ou:

æ $\mathbf{i}:$ A

i $i_{A}$

i

$u(:) i_{:}$ 
1. Full fathom five thy father lies;

2. Of his bones are coral made;

3. Those are pearls that were his eyes:

4. Nothing of him that doth fade,

5. But doth suffer a sea-change

6. Into something rich and strange.

7. Sea-nymphs hourly ring his knell:

8.

9. Ding-dong.

Hark ! now I hear them -

10.

Ding-dong belld

Song by W. Shakespeare

("The Tempest" I.2. 394)

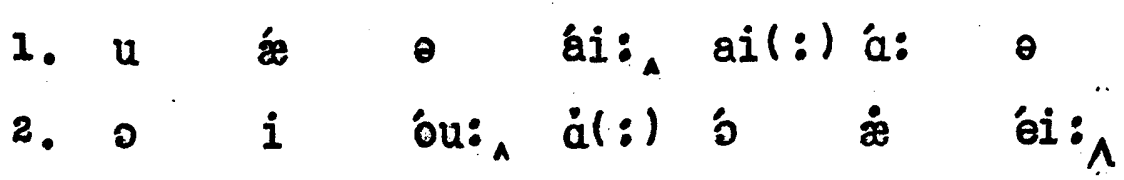

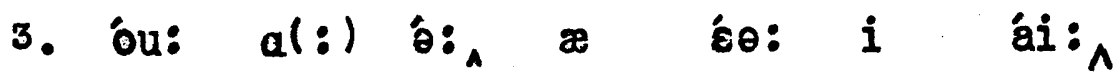

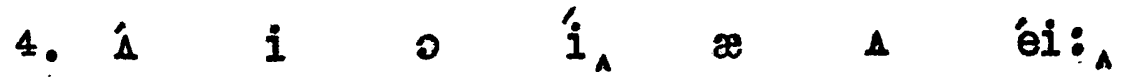

5. $i \quad \Delta \quad \dot{A} \quad \partial_{A}$ èi(:) 1 : éi:

6. $i \quad \dot{u}(:)$ i $i \quad i \quad$ éi

7. i: $i$ áno: $i$ i $i$ é

8. $i_{\wedge} \dot{o}_{\wedge}$

๑. á $\wedge$ du: ai(:) io: e.

10. í $\dot{o}_{A} \quad e_{\wedge}$ 
1. When in the chronicle of wasted time

2. I see sescriptions of the fairest wights,

3. And beauty making beautiful old rhyme

4. In praise of ladies dead, and lovely knights;

5. Then in the blazon of swet beauty's best

6. Of hand, of foot, of lip, of eye, of brow,

7. I see their antique pen rould have exprest

8. $\quad$ itn such a beauty as you master now.

9. So all their praises are but prophecies

10. Of this our time, all you prefiguring;

11. And, for they look'd but with divining eyes,

12. They had not skill enough your rorth to sing:

13. For we, which now behold these present days,

14. Have eyes to wonder, but lack tongues to praise.

W. Shatespeare.

1. é $i$ o ó $i_{\wedge} \quad 0$ éi: $i$ ái:

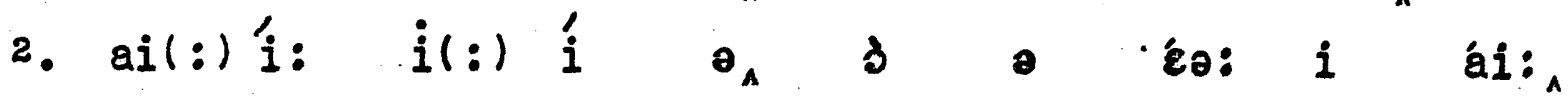

3. $\approx$ jú: $i_{\wedge}$ éi: $i$ jú $i$ ì óu: ái:

4. $i$ éi: 0 éi: $i$ é $\approx$ i $i$ ái:

5. é $i$ o éi: 0 'i: ju: $i$ é

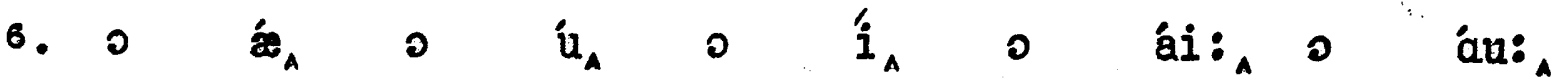

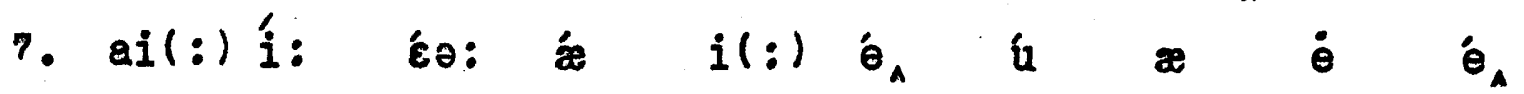

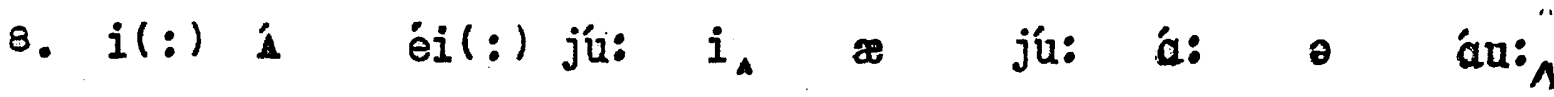

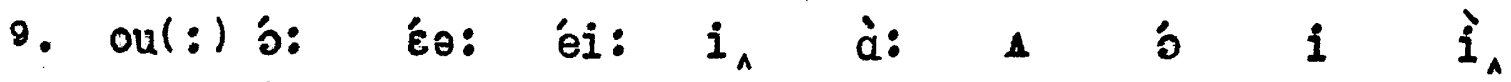

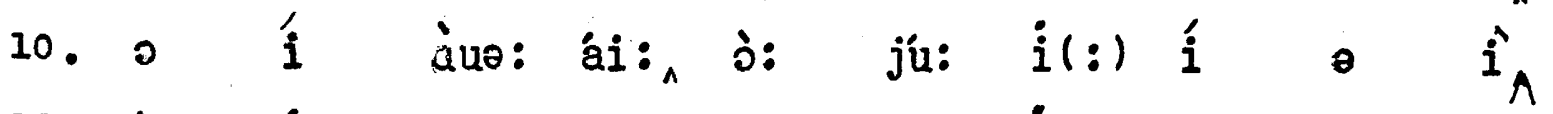

11. $\dot{z}_{\wedge} \dot{\partial}(:)$ ei(:) $\mathfrak{u}_{\wedge} \mathbb{\imath} i \quad i(:)$ ái: $i$ ái:

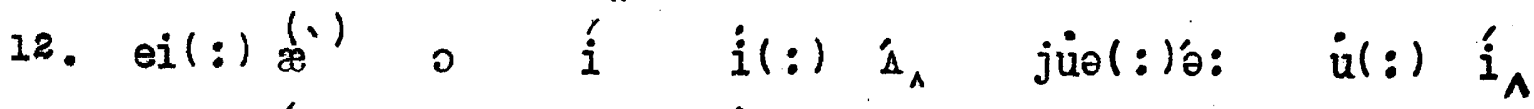
13. $x(:)$ í: $i$ du: $i(:)$ ou: $i(:)$ é $\dot{e}$ éi: ,

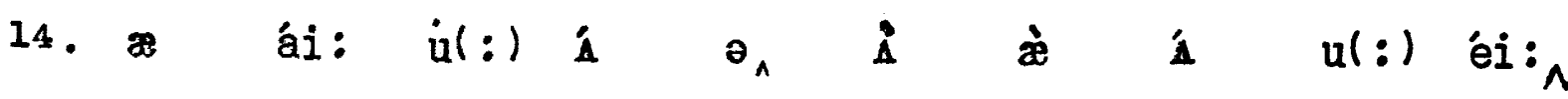


1. The quality of mercy is not strain'd,

?. It droppeth as the gentle rain from heaven

$z$. Tjpon the place beneath: it is twice bless'd,

4. It blesseth him that gives, and him that takes:

5. Tis mightiest in the mightiest; it becomes

6. The throned monirch, better than his crown:

7. His sceptre shows the force of temporal power,

8. The attribute to awe and majesty,

$\therefore$ Wherein doth sit the dread and fear of kings:

10. But mercy is above this sceptred sway,

11. It is enthroned in the hearts of kings;

12. It is an attribute to cod himself:

13. And earthly power doth then show likest God's,

14. When mercy seasons justice.

"The Merchant of Venice" (IV.1.184)

by $W$. Shakespeare.

\begin{tabular}{|c|c|c|c|c|c|c|c|}
\hline '́ & $\mathrm{i}$ & $\grave{i}$ & 0 & ó: & $i$ & $\grave{i}$ & 0 \\
\hline ْ & $i_{\wedge}$ & æ̀ & $\partial$ & é & éi: & 0 & $\dot{e}_{A}$ \\
\hline & $\partial$ & éi: & $\dot{i}(:)$ & $\grave{i}: \wedge$ & $i$ & $i$ & ài: \\
\hline & $\mathrm{i}$ & $i^{\prime}$ & $\dddot{Z}$ & $i_{A}^{\prime}$ & $æ$ & $i^{\prime}$ & $\mathscr{\circledast}$ \\
\hline & i & i & $\grave{i}$ & $\partial$ & ái: & $\mathrm{i}$ & $\begin{array}{l}\dot{i}_{\wedge} \\
\dot{i}(:)\end{array}$ \\
\hline
\end{tabular}

óu i ó $\dot{a}(:)_{1}$ é $\theta$ æ̀ $i$ áu:

é

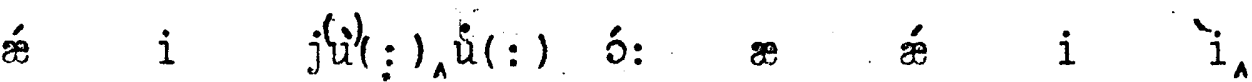

ค. $\varepsilon \vartheta(:)$ i

i $\Delta$

$\Delta$

$i_{\wedge}^{\prime}$

é $\quad \not$

í: 0

$i_{1}^{\prime}$

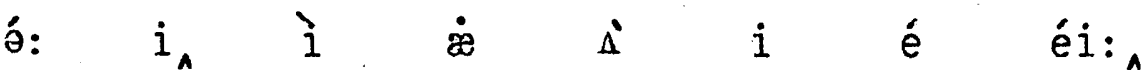

i $\dot{e}$ óu: $i_{\wedge} \quad \grave{i}$

i $\quad$ a

$i_{\Lambda}^{\prime}$

i $æ$

毛 $\left.i \quad j \quad \mathfrak{u}^{\prime}(:)\right)_{\wedge} \dot{u}(:)$ o $i$

o

én

ə́: $\quad$ i duə: $\Lambda \Lambda$

òu: ài: $i$

ó

ó: $\quad \mathrm{i} \quad i^{\prime}: \quad \dot{\Lambda} \quad i_{\wedge}$ 
1. Sprine, the sweet Spring, is the year's pleasant king;

2. Then blooms each thing, then mids dance in a ring,

3. Cold doth not sting, the pretty birds do sing,

4. Cuckoo, jug-jug, pu-we, to-witta-wood

5. The palm and may make country houses gay,

6. Lambs frisk and play, the shepherds pipe all day.

7. And we hear aye birds tune this merry lay,

8. Cuckoo, jug-jus, pu-we, to-witta-woo.

9. The fields breathe sweet, the daisies kiss our feet,

10. Young lovers meet, old wives a-sunning sit,

11. In every street these tunes our ears do greet,

18. Cuckoo, jug-jus, pu-we, to-vitta-woo \&

13. Spring! the sweet Spring!

"Spring"

by T. Nash.

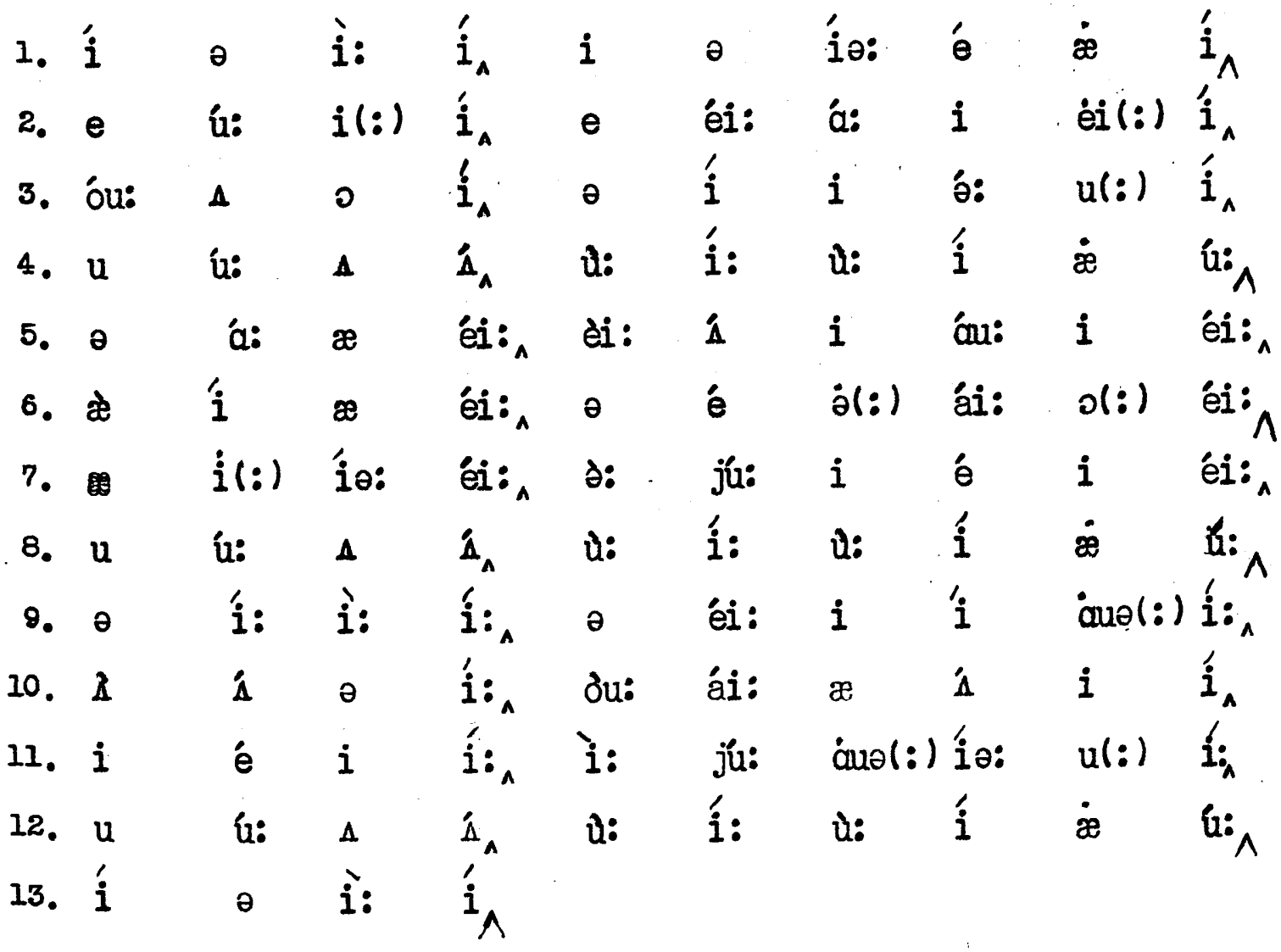


1. Now came still evening on, and twilight gray

2. Had in her sober livery all things clad

3. Silence accompanied; for keast and bird,

4. They to their Erassy couch, these to their nests,

5. Were slunk, all but the wakeful nightingale;

6 . She all night long her amorous descant sung;

7. Silence was pleased; now glow'd the firmament

8. With living sapphires; Hesperus that led

9. The starry host rode brightest, till the moon

10. Rising in clouded majesty at length

11. Apparent queen unveiled her peerless light

12. And o'er the dark her silver mantle threw.

From "Paradise Lost". (IV.598-609) by J. Milton.

1. àu: éi: $i$ í $i$ b́, $x$ ái: ail: éi:

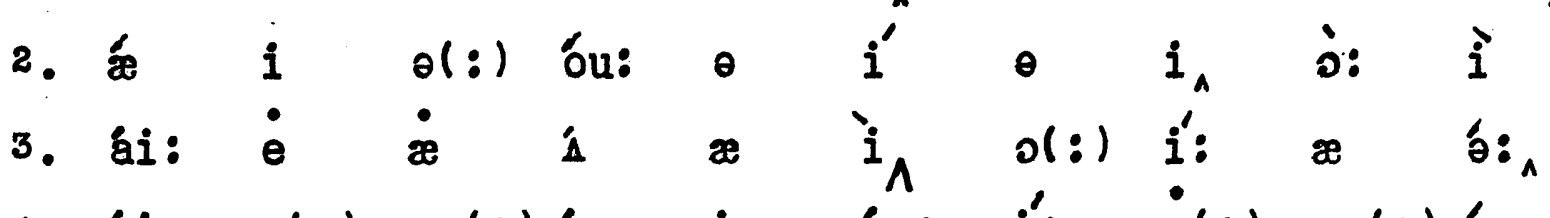

4. éi: $u(:) \quad \varepsilon \theta(:)$ á: i áu: $i^{\prime}:$ ul: $\varepsilon_{\theta}(:)$ é $_{A}$

5. $\varepsilon_{\theta}(:) L_{A}$ o: $\Delta$ o éi: $\dot{u}$ ái: $i$ èi

6. í: ò: ái: b́a

7. ái: $\dot{e}$ o $1: \wedge$ àu óu:

8. $i \quad i \quad i \quad \&$ aio(:) ${ }_{\Lambda}^{\prime}$

$\theta \quad(\theta)$ \& $\dot{\theta}_{\wedge}$

9. ค á: $i$ óu: òu: ái: $i_{\wedge} 1$

○

ó: $\dot{2}(\dot{e})$

$\mathscr{x}_{\wedge}$

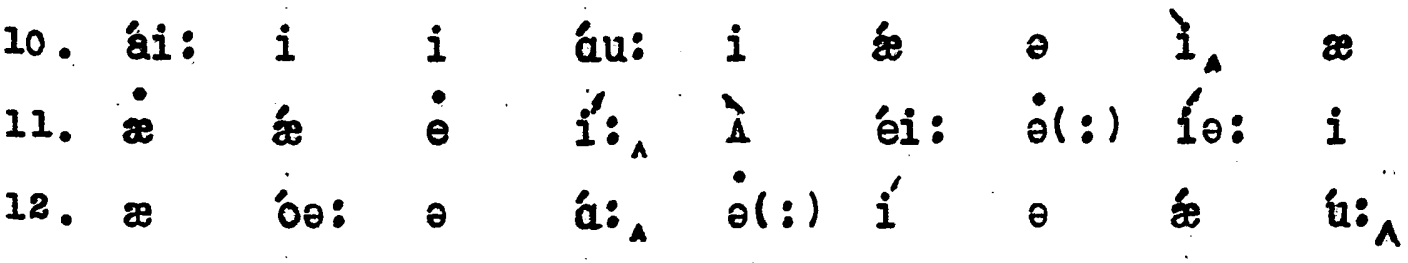


1. Tho' I have lost

2. Nuch lustre of my native brightness, lost

3. To be beloted of God, I have not lost

4. To love, at least contemplate and admire

5. What I see excellent in good, or fair,

6. Or virtuous; I should so have lost all sense.

"Parrdise Regrined" ( I.378-383) by J. lilizton.

1. ơ: ai $(:) \approx$ ว:
2. $\mathbf{A}$
(i)
○
ai (:) éi:
i
ái: $i_{A}$
b:
3. $\dot{u}(:) \quad \dot{i}(:) \quad \dot{i}(:) \quad \dot{\Delta}$
- Ja $\quad$ oi $(:)$ ま
o ó: a
4. $\dot{u}(:) \quad \hat{L}_{A}$
i:
5. ó
ail: $i:$
é
e éi(:)
ஷ áiə:
$\dot{e}$
(v) $i$
a
$j(:)$ E्:

6. 引(:) 手:

$j u ̛(:) \dot{A}_{A}$

6

:

ái:

u óu: æ

o: $\quad$ o(:) 


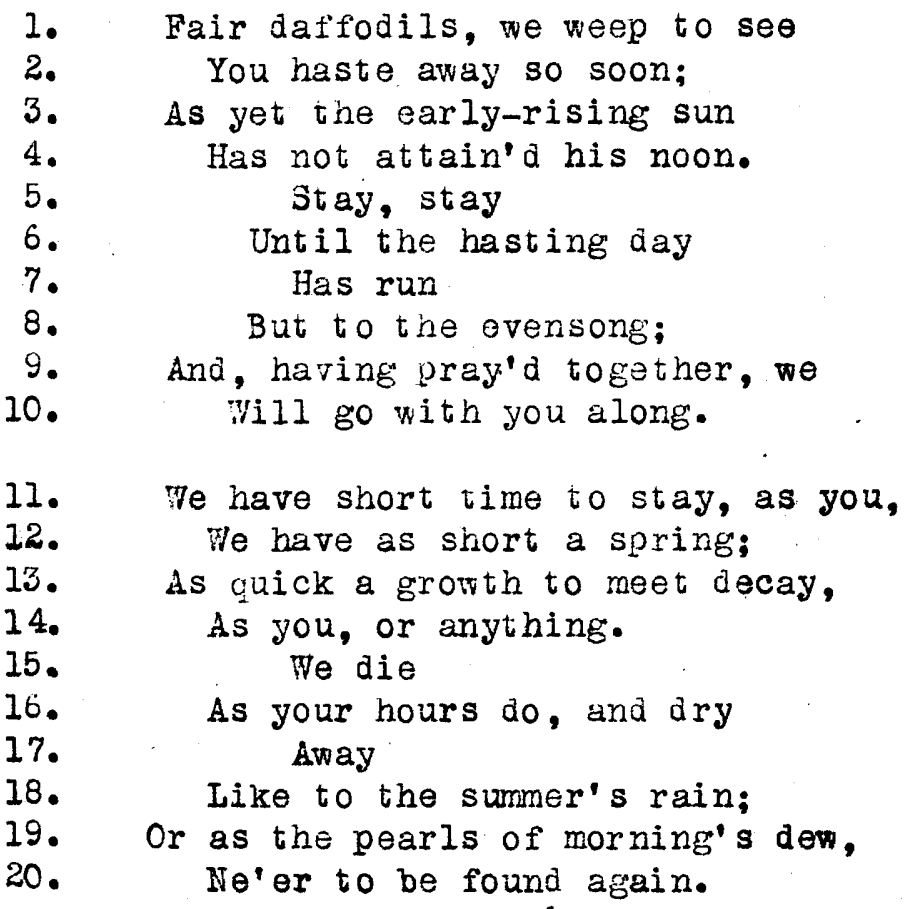

"To Daffodils"

by R. Herrick. 
1. $\varepsilon \theta(:) \notin$ oul $:) \grave{i}_{n} \quad i(:)$ i: $u(:)$ i:

2. jul: ) éi: æ̇ éi: ${ }_{\wedge}$ ou: $\mathfrak{k}:_{\wedge}$

उ, $\dot{e}_{A}$ o á: $i$ ái: $i$ i

4. $\dot{\circledast}$ ○ $\dot{\circledast}$ éi: $i$ ú:

5. éi: А́ ei:

6. $\Delta$ i o éi: $i$ éi:

7. 先 $\mathbf{A}_{\wedge}$

8. $\dot{A}_{\wedge} \dot{u}(:)$ ə $\dot{i}: \dot{e} \quad \dot{0} \wedge$

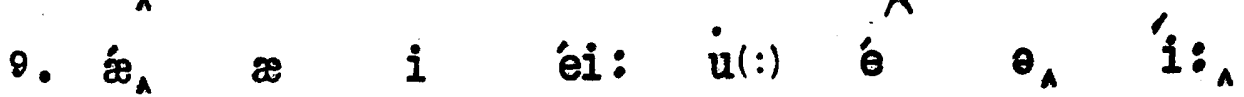

10. $i$ ou: $i$ jü $\dot{z}$ ôA

11. 'i: æ ذ̀: ái: ul:) éi: $¥$ jü:

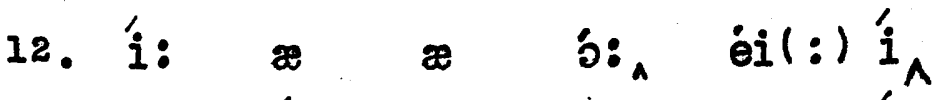

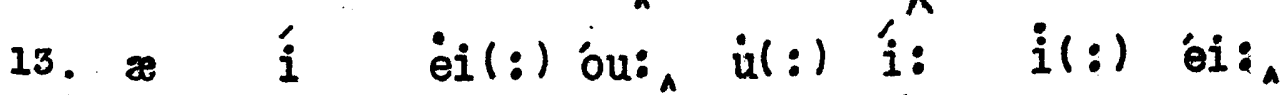

14. $z$ jú: $\dot{\partial}(:) \dot{e}$ i $i_{\wedge}^{\prime}$

15. i: ái:

16. æ juo: áuə: u(:) $æ$ ái: ,

17. $\dot{\nexists}$ éi :

18. ài: $\quad$ úl: $)$ ə í

19. ว: $\approx$ ค

20. Ea: $\dot{u}(:) \quad \dot{i}(:)$ áu: $\dot{z}$ éi: 
1. Or if chill blustering winds or driving rain

2. Prevent my willing feet, be mine the hut

3. That, from the mountain's side,

4. Views wilds and swelling floods,

5. And hamlets brown, and dim-discover'd spires;

6. And hears their simple bell; and marks o'er all

7. Thy dewy fingers draw

8. The gradual dusky veil.

From "To Erening"

by W. Collins.

1.

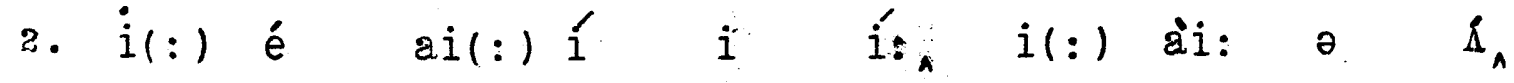

3. æ̀ 0 o d́u: i ái:

4. ju(:) ái: $\mathbb{A}$ é $i \quad \Lambda_{\wedge}$

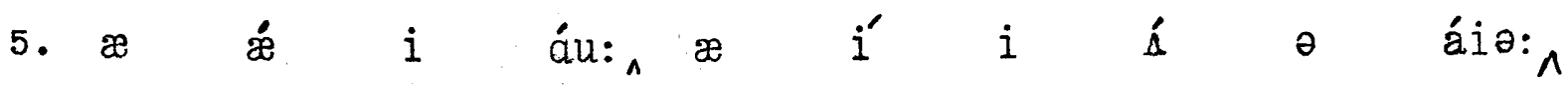

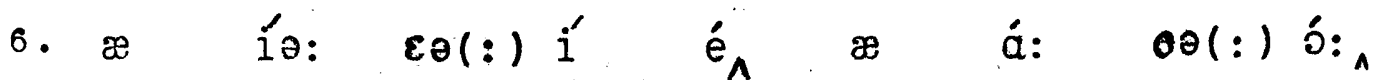

7. $a i(:)$ jú: $i$ í $\theta$ ó

8. $ә$ ǽ $j \dot{u}(:) \circledast_{\wedge}$ A i éi: 
1. John Anderson my jo, John,

2. When we were first acquent

3. Your locks were like the raven,

4. Your bonnie brow was orent:

5. But nov your brow is beld, John,

6. Your locks are like the snow;

7. But blessings on your frosty pow,

8. John anderson my jo.

9. John Anderson my jo, John,

10. We clamb the hill thegither,

11. And mony a canty day, John,

12. We've had wi' ane anither:

13. Now we maun totter down, John,

14. But hand in hand vie'll go,

16. And sleep thegither at the foot;

16. John Anderson, my jo.

"John Anderson"

by R.Burns.

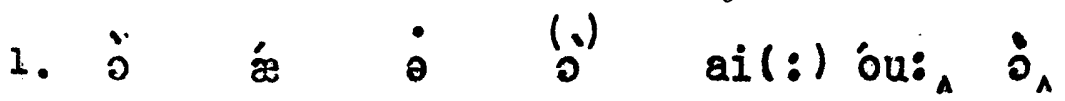

2. $\odot$ i: $\varepsilon_{\theta}(:) \dot{\partial} \quad \dot{z} \quad \dot{\theta}_{\wedge}$

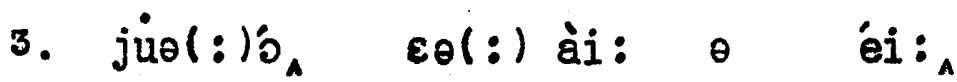

4. jưol: lo $i$ áu: 0 is

5. $\Delta$ áu: jùr : láu: $i$ ó: $\dot{o}_{\wedge}$

6. jưl: $) \dot{o}_{\wedge} \dot{a}(:)$ ài: $\theta$ ou:

7. $\Delta$ é $i_{\Delta} \dot{j}$ juol: $)^{\prime}$ i áa:

8. ذे ¿

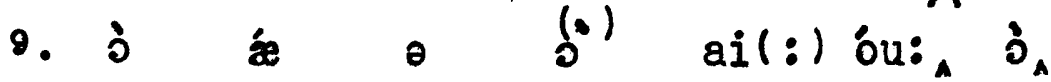

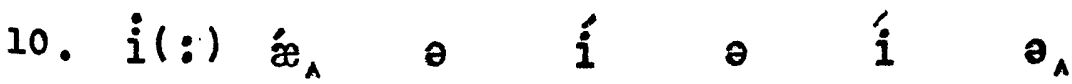

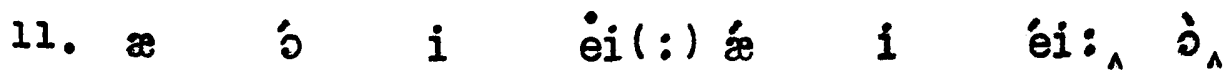

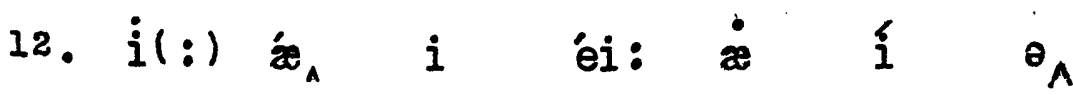

13. au: $i(:)$ ol: $\dot{0}$ a iu: ${ }_{A}$

14. $\Delta \quad \stackrel{x}{i} \quad \dot{x}_{\wedge} \quad i(:)$ ou:

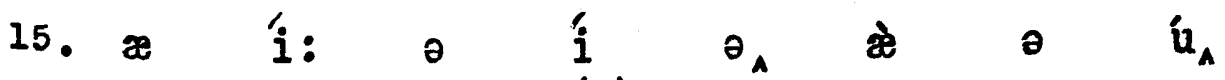

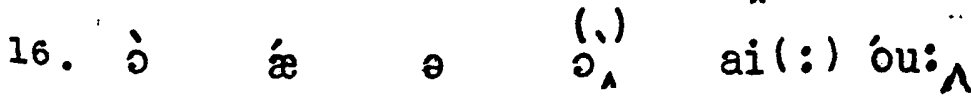


1. She dwelt among the untrodden ways

2. Beside the springs of Dove;

3. A maid whom there were none to praise,

4. And very few to love:

5. A violet by a mossy stone

6. Holf hidden from the eye:

7. Fair as a star, when only one

8. Is shining in the sky.

9. She lived unknown, and fer could know

10. When lucy ceased to be;

11. But she is in her grave, and oh,

12. The difference to me!

W. Wordsworth.

\begin{tabular}{|c|c|c|c|c|c|c|c|}
\hline 1. $i(:)$ & $\dot{e}_{\wedge}$ & $\dot{ஐ}$ & $\grave{\Lambda}$ & $i$ & $i$ & ó & éi: \\
\hline 2. $\quad \dot{i}(:)$ & ài: & $\theta$ & $\dot{i}^{\prime}$ & 0 & ${ }_{\Lambda}^{i}$ & & \\
\hline 3. $\dot{e} i(:)$ & éi: & ù: & $\varepsilon \partial(:)$ & $\varepsilon \partial(:)$ & Á & $\dot{u}(:)$ & éi: \\
\hline 4. æ & é & $i$ & jú: & $\dot{u}(:)$ & $\hat{\Lambda}_{\Lambda}$ & & \\
\hline 5. $\dot{e} i(:)$ & ái: & oul : $)$ & $i_{\wedge}$ & ài: & $\dot{e} i(:)$ & ó & $\mathrm{i}$ \\
\hline 6. d: & $i_{\wedge}^{\prime}$ & $\grave{j}$ & $\theta$ & ái: & & & \\
\hline 7. $\dot{\varepsilon} ə:$ & $\dddot{Z}$ & $\dot{e} i(:)$ & $\dot{\alpha}:{ }_{\wedge}$ & e & ou: & $i$ & $\dot{\Lambda}_{\wedge}$ \\
\hline 8. $i$ & ái: & $i_{\wedge}$ & 'i & $\partial$ & ái: & & \\
\hline 9. $\quad \dot{i}(:)$ & $i^{\prime}$ & $\grave{\Lambda}$ & óu: & $\dddot{Z}$ & $j \mathfrak{u}:$ & $\grave{u}$ & óu: \\
\hline . è & א. & i & í: & $\dot{u}(:)$ & $i: \wedge$ & & \\
\hline 1. $\Lambda$ & i: & $\mathrm{i}$ & i & $\partial(:)$ & éi: ^ & $æ$ & óu: \\
\hline . & $i^{\prime}$ & $\partial$ & $(\dot{e})$ & $u(:)$ & & & \\
\hline
\end{tabular}


1. Day after day, day after day,

2. We stuck, nor breath nor motion;

3. As idle as a painted ship

4. Upon a painted ocean.

"The Rime of the Ancient Mariner"(115-118) by S. T. Coleridge.

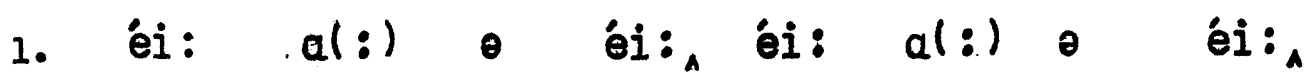

2. $i(:)$ is ol: $\dot{A}_{A} \quad \dot{b}(:)$ ou: ' $\dot{o}_{\wedge}$

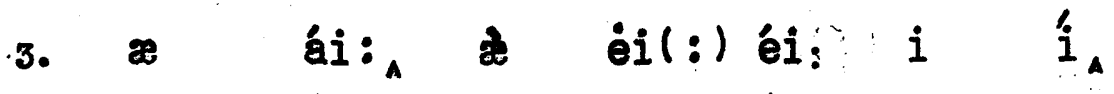

4. $i$ i eilléei: $i_{\wedge}$ óu: $x_{\wedge}$ 


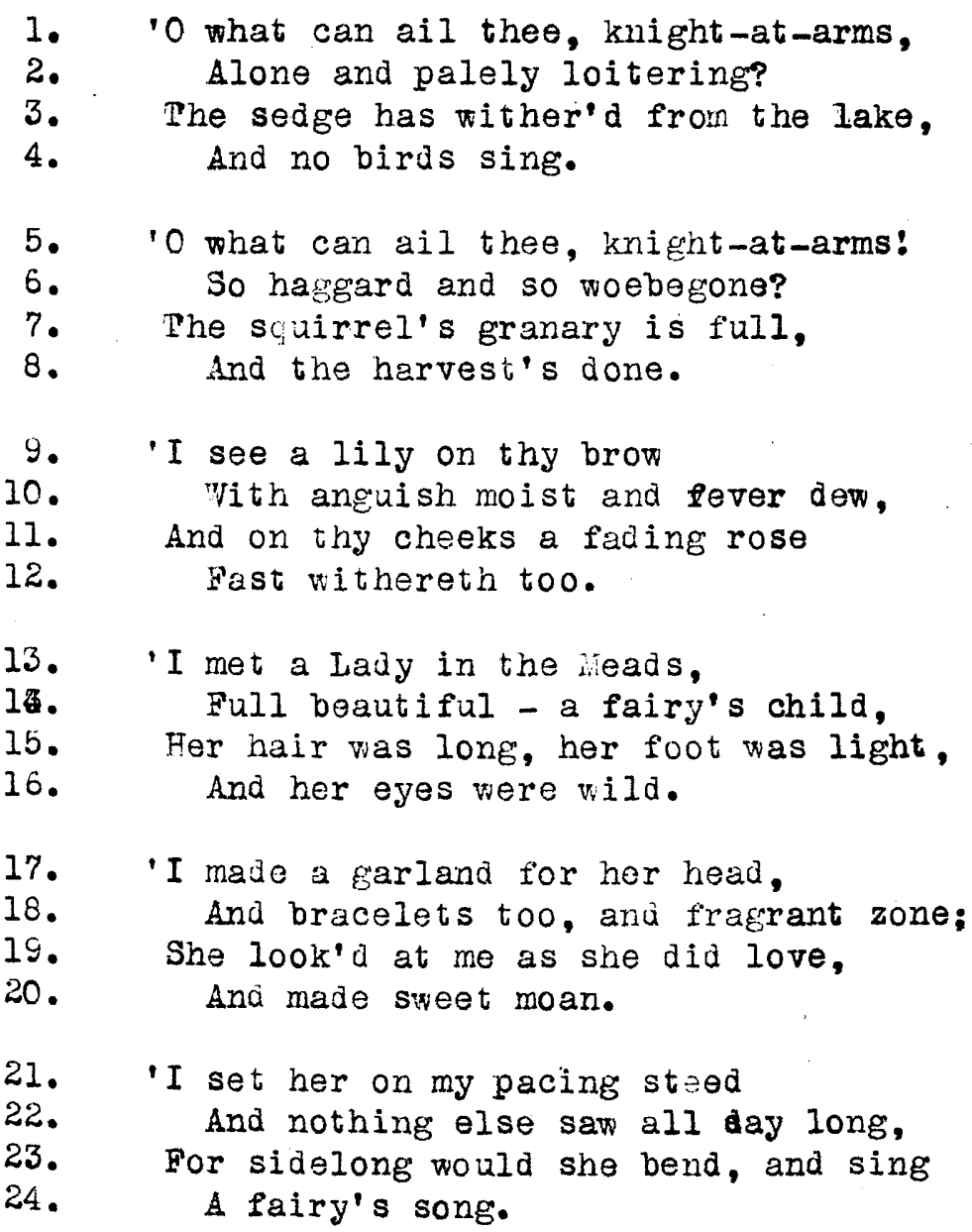




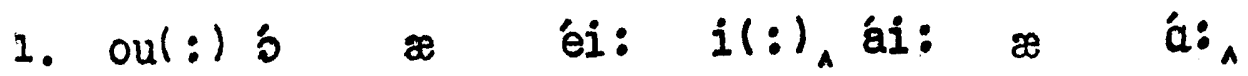

2. $\dot{z}$ ou: $\approx$ ei: $i_{A}$ bi: $\theta$ (o) $i_{\wedge}$

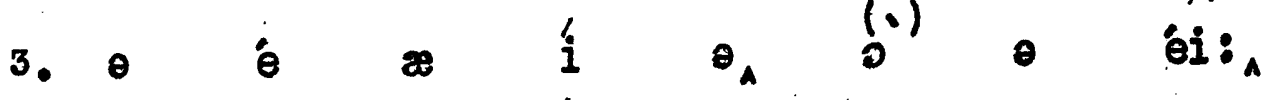

4. z ou: ว̀: 'î

5. oul:) ó $\approx$ éi: i(:), ái: $\approx \quad a:_{\wedge}$

6. oul: $)$ z $\dot{a}(:)_{A} \approx$ bu: ou: $\dot{i}(:)$ bे

7. $\begin{array}{llllllll}\dot{1} & \dot{e} & \dot{z} & \dot{z} & \grave{i}_{A} & i & \dot{u}_{A}\end{array}$

8. $¥$ จ á $i_{\wedge} i_{\wedge}$

9. $\operatorname{ai}(:) \hat{i}:$ ei(:) $\hat{i} \quad \hat{i}_{\wedge} \quad(0)$ ai(:) áu:

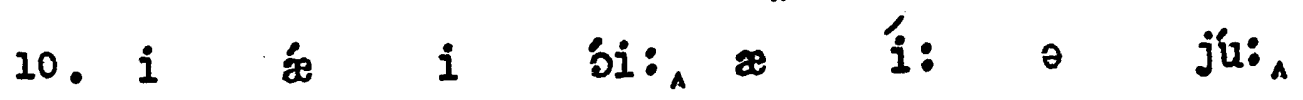

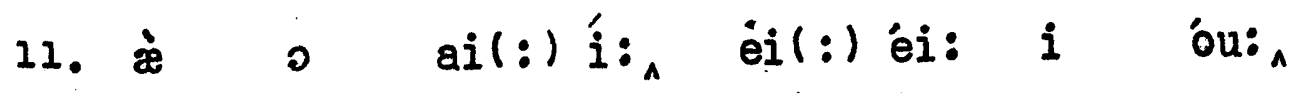

12. d: $\dot{i}$ o $i_{\wedge} \quad \grave{u}:{ }_{\wedge}$

13. ai(:) e ej(:) éi: î $i$ o $i:_{\wedge}$

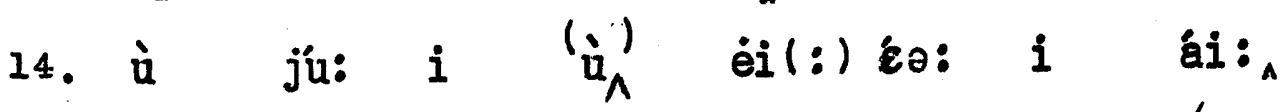

15. $\dot{\theta}(:) \quad \varepsilon \theta: \quad 0 \quad \dot{b}_{A} \quad \dot{\theta}(:) \quad \mathfrak{u} \quad 0 \quad a_{i}:_{A}$

16. æ $\partial(:)$ ái: $\varepsilon \partial(:)$ ái:

17. ail: $)$ éi: eil(:) á: $\left.x_{A} \quad b_{\dot{b}}\right)^{\prime} \quad \dot{\theta}(:) \dot{e}_{A}$

18. $\approx$ éi: $i$ ú: $\approx$ éi: $\dot{\&}$ óu: ${ }_{\wedge}$

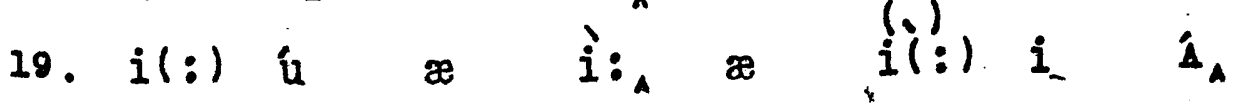

20, æ ei: i: ou:

21. ail: $)^{\prime}$ ol: $),(\cdot)^{\wedge}$ ail $(:)$ éi: $i$ i:

22. $x$ i $i$ é

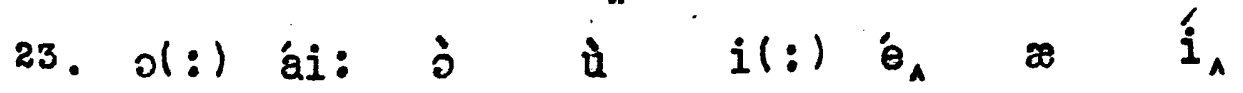

24. eil(:) $\varepsilon_{\partial}: i_{A} \quad \partial_{A}$ 


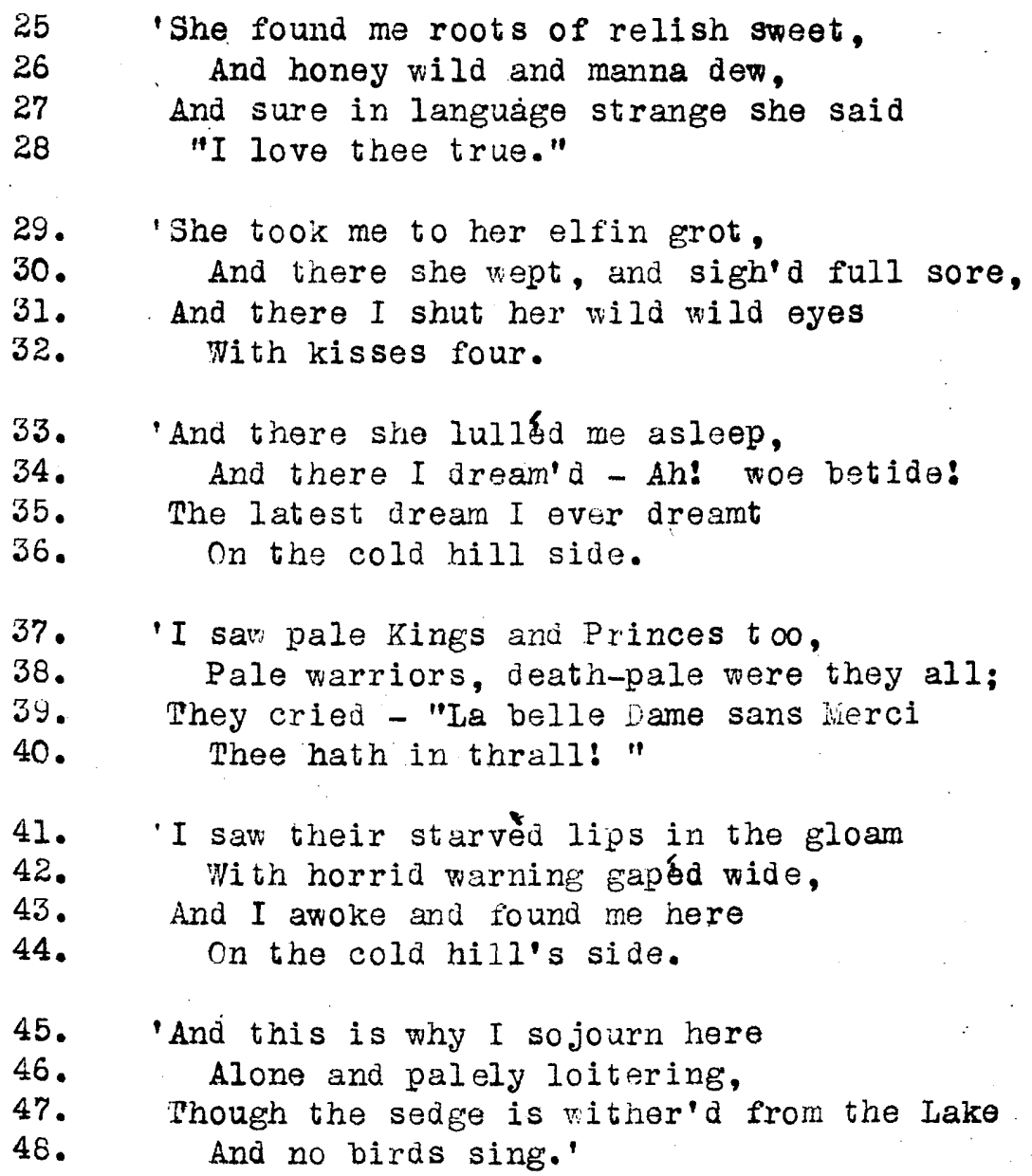

"Ia Belle Dame Sans Merci" by J. Keats. 
25. $i(:)$ áu: $i(:) \quad u_{A}$ o e $\quad i \quad i:_{A}$ 26. $\approx \quad \dot{4} i \quad$ ái: $\approx$ \& $\approx$ jú: 27. $\approx$ ü: $i$ i $i$ ei: $i(:) \dot{\theta}_{A}$ 28. ail: $i_{A} \quad i(:)$ ú

29. $i(:)$ i $i(:)$, $(\hat{l}:)$ ol: é $i$ ó

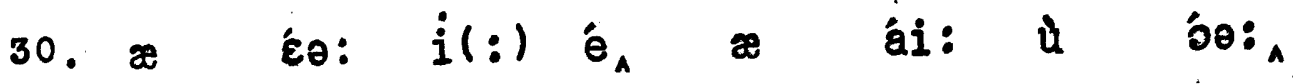

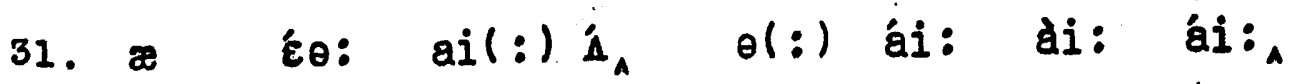
32. $i$ i $i_{\wedge} \quad \partial \theta: \wedge$

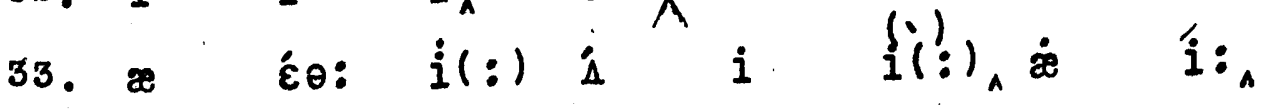

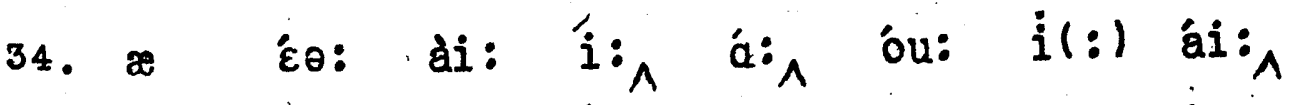
35. $\theta$ éi: $i$ í $\quad$ ail $:)_{A}$ é $\theta \quad \dot{e}_{A}$ 36. o $\theta$ ou: 1 ái: 37. ai(:) ó èi: $\hat{1}_{A}$ æ ${ }^{\prime}$ i $i:_{A}$

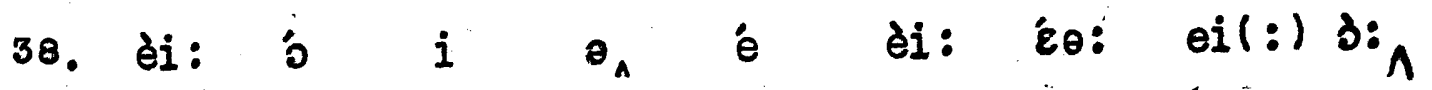

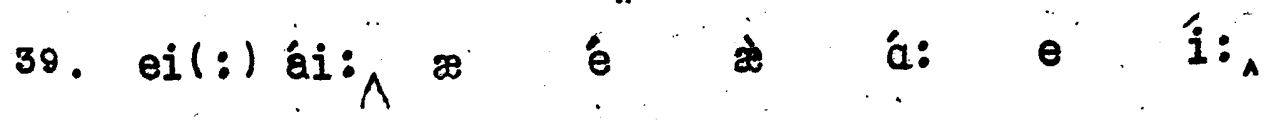
40, $i(:) \&$ \& $i$ 41. ail:) b: $\varepsilon \theta(:)$ a: $i$ i $i_{A} i$ o. ou: 42. $i$ o $i$ ó: i éi: $i$ ái:

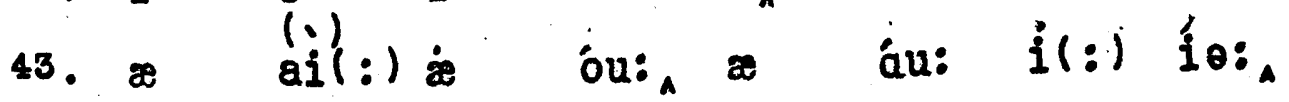
44. $0 \quad \theta$ ou: $i$ ái:

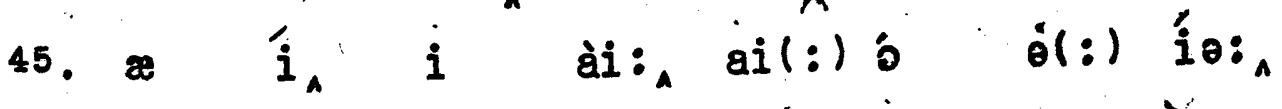

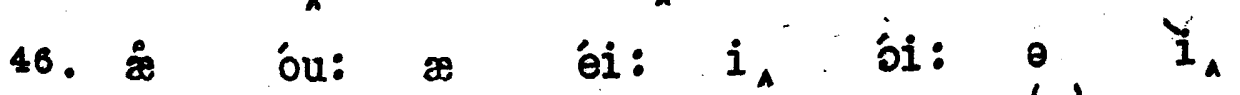

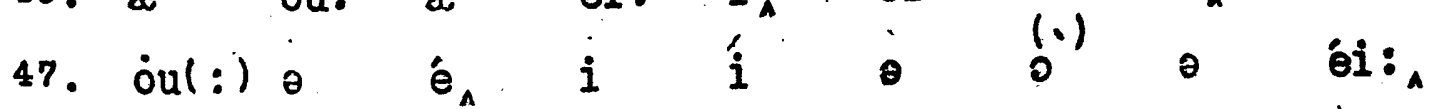
48. $\approx$ ou: $\dot{a}: \mathfrak{i}_{\wedge}$ 
1. Deep in the shady sadness of a vale

2. Far sunken from the healthy breath of morn,

3. Far from the fiery noon, and eve's one star,

4. Sat gray-hair'd Saturn, quiet as a stone,

5. Still as the silence round about his lair;

6. Forest on forest hung about his head

7. Like cloud on cloud. No stir of air was there,

8. Not so much life as on a summer's day

9. Robs not one light seed from the feather'd grass,

10. But where the dead leaf fell, there did it rest.

11. A stream went voiceless by, still deadened more

12. By reason of his fallen divinity

13. Spreading a shade: the Naiad 'mid her reeds

14. Press'd her cold finger closer to her lips.

"Hyperion" (I.1-14)

by J. Keats.

\begin{tabular}{|c|c|c|c|c|c|c|c|c|c|}
\hline I. $\quad i^{\prime}:$ & i & $\theta$ & éi: & $i$ & $\ddot{\otimes}$ & $i_{A}$ & $(j)$ & $\dot{\mathrm{e}} i(:)$ & ei: \\
\hline 2. $\quad \dot{\alpha}:$ & $i_{\Lambda}$ & $(6)$ & $\partial$ & é & i & $\dot{e}$ & 0 & ○́ & \\
\hline z. á: & 0 & $\theta$ & áiə: & $i$ & $\dot{u}:{ }_{A}$ & $\mathscr{Z}$ & $i:$ & ì & \\
\hline 4. ææ & éi: & $\varepsilon \theta(:)$ & $\ddot{\circledast}$ & $\theta_{A}$ & ái: & $\dot{\mathrm{e}}$ & $\mathscr{P}$ & $\dot{e} i(:)$ & \\
\hline 5. $\quad i^{\prime}$ & $\dddot{x}$ & $\partial$ & ái: & $\dot{e}_{\wedge}$ & du: & $\dot{\ddot{Q}}$ & du: & $\mathrm{i}$ & \\
\hline 6. j & $\mathrm{i}$ & 0 & ó & $i_{\wedge}$ & Á & $\dot{æ}$ & du: & $\mathrm{i}$ & \\
\hline 7. $\quad a i(:)$ & áu: & 0 & áu: & ou(: $)$ & ة́: & 0 & $\dot{\varepsilon} \partial:$ & 0 & \\
\hline 8. 5́ & oul: $)$ & $\grave{\Lambda}$ & ái: & $\grave{2}$ & 0 & $\dot{e} i(:)$ & $\dot{\mathbf{A}}$ & $\partial$ & $:_{1}$ \\
\hline ๑. & $\grave{j}$ & $\dot{\Lambda}$ & ài: & $i:$ A & 0 & $\theta$ & é & $\partial$ & \\
\hline 0. $\quad \Lambda$ & $\dot{\varepsilon} ə:$ & $\partial$ & é & 'i: & $\dot{e}_{\wedge}$ & દ́ə: & $\mathrm{i}$ & $i$ & \\
\hline - $\dot{e}_{i}(:)$ & $1:$ & $\grave{e}$ & ói: & i & $\grave{a}:_{\wedge}$ & i & $\dot{e}$ & อ่ə: & \\
\hline ai(:) & $\dot{i}:$ A & $\grave{j}$ & $\mathrm{i}$ & ó: & i & $i$ & i & $\grave{i}_{\wedge}$ & \\
\hline ]z. é & i & éi(:) & éi: & $\partial$ & ái: & $\mathscr{X}$ & & $\partial(:)$ & \\
\hline - é & $\partial(:)$ & òt & $\ddot{i}^{\prime}$ & $\theta_{\wedge}$ & óu: & $\partial$ & u $\{: 1$ & $\partial(:)$ & \\
\hline
\end{tabular}


1. March have I travell'd in the realms of gold

2. And many goodly states and kingdoms seen;

3. Round many western islands have I been

4. Which bards in fealty to Apollo hold.

5. Oft of one wide expanse had I been told

6. That deep-brow'd Homer ruled as his demesne;

7. Yet did $I$ never breathe its pure serene

8. Till I heard Chapman speak out loud and bold;

9. Then felt I like some watcher of the skies

10. When a new planet swims into his ken;

11. Or like stout Cortez, when with eagle eyes

12. He stared at the Pacific - and all his men

13. Look'd at each other with a wild surmise -

14. Silent, upon a peak in Darien.

"On Firgt Looking into Chapmen's Homer" by J. Keats.

\begin{tabular}{|c|c|c|c|c|c|c|c|c|c|}
\hline 1. A & $\mathfrak{z}$ & $\mathrm{ai}(:)$ & $\dot{æ}$ & $e_{\Lambda}$ & 1)$. & $\theta$ & $\dot{\theta}$ & 0 & óu: \\
\hline . $\not$ & é & $i$ & $\mathfrak{u}$ & $i$ & éi: & $\mathscr{Z}$ & & $\theta$ & \\
\hline 3. $\mathrm{aul}:$ ) & é & $\mathbf{i}$ & é & $\dot{a}(:)$ & ái: & $\mathbb{w}_{\wedge}$ & $\mathfrak{æ}^{(1)}$ & $a i(:)$ & \\
\hline - $\mathbf{i}$ & á: & $\mathfrak{i}$ & i: & $\dot{\mathfrak{x}}$ & $i_{A}$ & $(6)$ & $\dot{\ddot{z}}$ & ó & oul $(:)$ \\
\hline - $\quad 3:$ & 0 & $\dot{a}$ & ài: & $\dot{e}$ & $\dot{\varpi}_{A}$ & æ & ài: & $i(:)$ & $u:_{A}$ \\
\hline • $\quad æ$ & í: & du: & ou: & $\partial_{\Lambda}$ & ú: & $\boldsymbol{x}$ & i & $\dot{i}(:)$ & \\
\hline - é & $\mathbf{i}$ & $a i(:)$ & é & $\theta$ & $1:$ A & $i$ & jûo: & $i(:)$ & i: \\
\hline . $\mathbf{i}$ & $a i(:)$ & é: & 追 & $\boldsymbol{z}_{\wedge}$ & i: & àn: & áu: & $\boldsymbol{x}$ & óu: \\
\hline : $\theta$ & é & $a i(:)$ & ai $(:)$ & $\Delta$ & 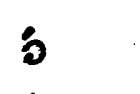 & $\theta$ & $\mathfrak{o}^{(1)}$ & $\theta$ & ái: \\
\hline$e$ & èi (:) & jú: & $\ddot{z}$ & $i_{\wedge}$ & $\hat{\mathbf{i}}$ & $\mathbf{i}$ & $\dot{u}(:)$. & $\mathbf{i}$ & $\dot{e}^{\prime}$ \\
\hline$\partial(:)$ & ài : & du: & อ: & $i_{\wedge}$ & é & $\mathbf{i}$ & î: & ái: & \\
\hline i: & $\hat{\varepsilon}_{\theta:}$ & $æ$ & i & $\dot{\boldsymbol{z}}$ & $' i$ & $i_{\wedge}$ & $\dddot{x}$ & $3:$ & $i$ \\
\hline $\begin{array}{l}\mathfrak{u} \\
\hat{a} i:\end{array}$ & $\begin{array}{l}x \\
\dot{e}_{\wedge}\end{array}$ & $\begin{array}{l}i(:) \\
A\end{array}$ & $\begin{array}{l}\dot{1} \\
(0)\end{array}$ & $\begin{array}{l}\partial_{A} \\
\dot{e}_{i}(:)\end{array}$ & 'i: & $\begin{array}{l}\dot{e i}(:) \\
\dot{i}\end{array}$ & $\begin{array}{l}\text { ái: } \\
\text { co: }\end{array}$ & $\begin{array}{l}\theta(:) \\
i\end{array}$ & ${ }_{(\bullet)}{ }^{\prime}$ \\
\hline
\end{tabular}


1. He clasps the cras with hooked hands;

2. Close to the sun in lonely lands,

3. Ring'd with the azure world, he stands.

4. The wrinkled sea benesth him crawls;

5. He watches from his mountain walls,

6. And like a thunderbolt he falls.

1. $i(:)$ á:

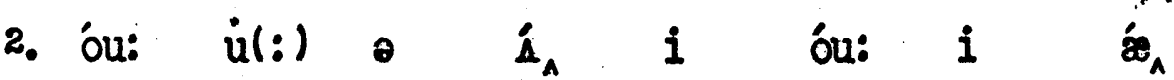

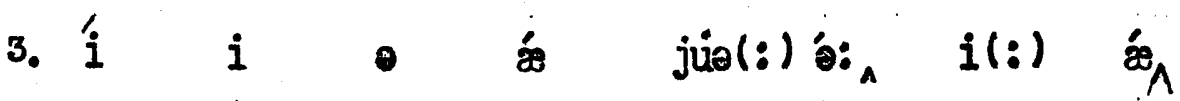

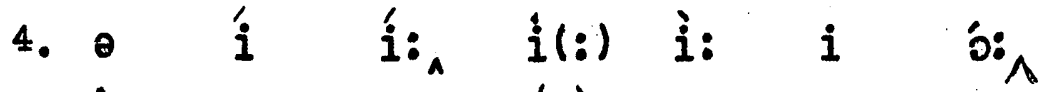

5. $i(:)$ o $i_{A}$ (N) $i$ ál $i$ ó:

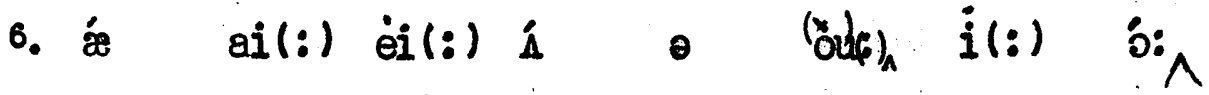


1. The splendour falls on castle walls

2. And snowy sumits old in story:

3. The long light shakes across the lakes,

4. And the wild cataract leaps in glory.

5. Blow, bugle, blow, set the wild echoes flying,

6. Blow, bugle; answer, echoes, dying, dying, dying.

"The splendour falls on castle walls" (v.l) by Lord Tennyson.

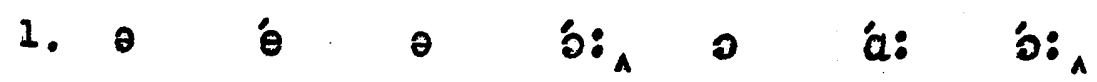

2. $x$ ou: $i$ i $i_{\wedge}$ ou: $i$ ó: $i_{\wedge}$

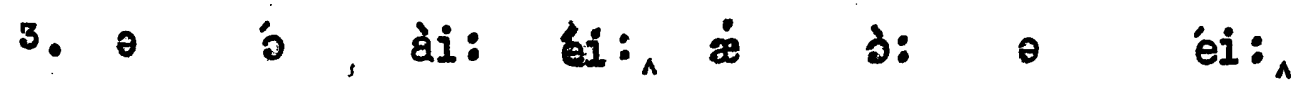

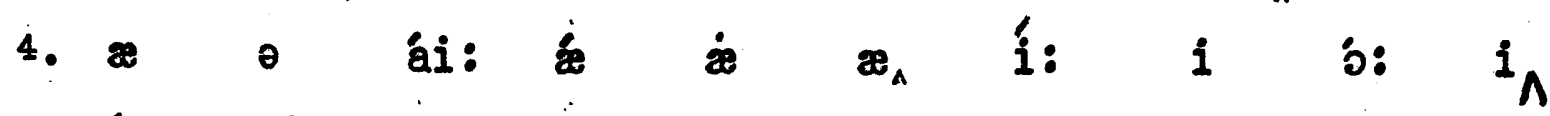

5. ou: ju: où $\dot{a}$ o

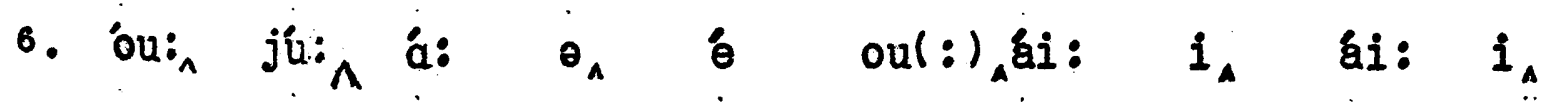
ái: í 
1. A wind sways the pines,

2. And below

3. liot a breath of wild air;

4. Still as the mosses that glow

5. On the flooring and over the lines

6 . Of the roots here and there

7. The pine-tree drops its dead;

8. They are quiet, as under the sea.

y. Overhead, overhead

10. Rushes life in a race,

11. As the caouds the clioids chase;

12. And we go,

13. And we drop like the fruits of the tree,

14. gven we,

15. Tiven so.

"Dirge in Woods"

by G. Meredith.

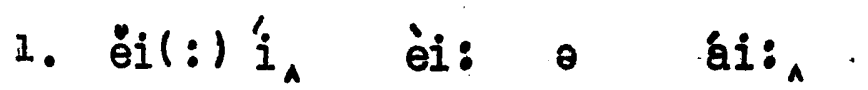

2. $\approx \quad \dot{i}(:)$ ou:

3. 0 éil: $)^{\prime} e_{A} \supset$ ài: $\varepsilon_{A}$

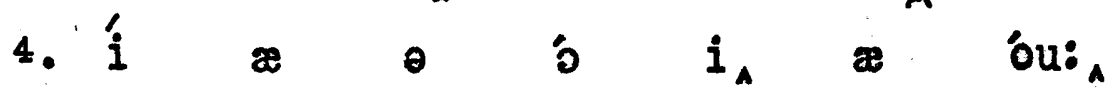

5. 0 อ อง: $i_{\wedge} \approx$ ou: $\theta$ o ái:

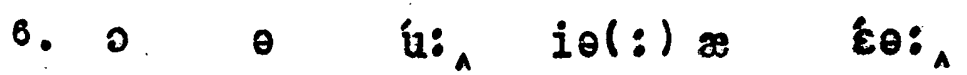

7. $\theta$ ái: í: ô $i \quad \dot{\theta}_{\wedge}$

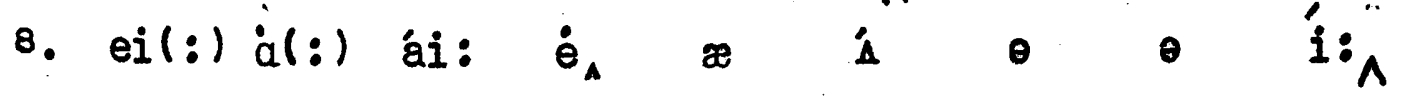

9. oul: $\theta$ e $e_{A}$ oul: $)_{\theta} \dot{e}_{A}$

10. i $i$ ái: $i$ èi(:) éi:

11. $\approx$ o áu: $\theta$ du: éi

12. $¥$ ì: ou: a

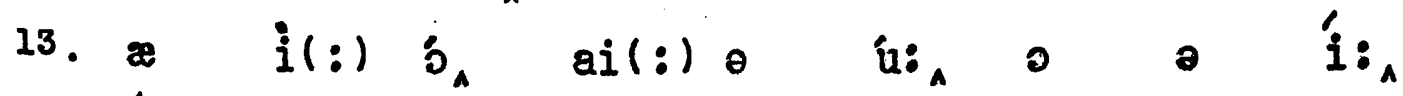

14. 'i: $i:$,

15. i: ou: 
1. On a starr'd night Prince Lucifer uprose. Tired of his dark dominion swung the fiend

3. Above the rolling ball in cloud part screen'd,

4. Where sinners hugg'd their spectre of repose.

5. Poor prey to his hot fit of pride were those.

6. And now upon his western wing he lean'd

7. Now his huge bulk o'er Afric's sands careen'd

8. Now the black planet shadow d Arctic snows.

9. Soaring through vider zones that prick'd his scars

10. With memory of the old revolt from twe,

11. He reach'd a middle height, anci at the stars,

12. Which are the brain of heaven, he look'd, and sank.

13. Around the ancient track march'd, rank on rank,

14. The army of unalterable law.

"Lucifer. in Starlight"

by G. Neredith.

1. o ėi(:) á: ái: $\mathfrak{i}$ ú: $i$ o $i$ ou:

2. Gio: 0 i á: obul: $)^{\prime}$

3. $\dot{z} \quad$ Á

- ou: $i$ o:

4. $\varepsilon \theta(:) \stackrel{i}{i}$

o i. $\left.\varepsilon_{\theta}(:)\right)^{\prime}$

$\theta_{\wedge}$

i

$\theta$

i:

5. uo(:) éi: $\dot{u}(:) \quad i$

3 '

i áu: à: í:

๑. æau: a

i j

i é

(o)

i(:) bu:

7. áu: i jul: ) i

ool: : æ⿱㇒㠯

- ái: $\dot{\varepsilon}_{\theta}(:)$ óu:

8. áu: ə

æ 官

i. 齐

$\dot{\theta}(:) \mathfrak{i}$

i(:) $\mathfrak{i}$,

9. อง: $i$

$u($ : ) ái

i

色

$\dot{\boldsymbol{z}}$

oul : ) á:

i

í:

10. i é

j $i_{A}$

ó:

æ

i

(5)

ou:

il: $)$ ou:

ái: ^ æ

$\boldsymbol{x}$

?

á:

12. $i$ a (i)

o éi: 0

$\dot{\theta}_{A}$

il :

甶

a: a

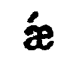

$\boldsymbol{z}$

象

13. æ áu:

éi : $\dot{e}$

14.

14.

○

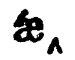


1. Beautiful must be the mountains whence ye come,

2. and bright in the fruitful valleys the streams, wherefrom

3. Ye learn your song:

4. Where are those starry woods? 0 might I wander there,

5. among the flowers, which in that heavenly air

6. Bloom the year long:

"Night ingaleg" ( $\nabla \cdot I)$

by Sir Robert Bridges.

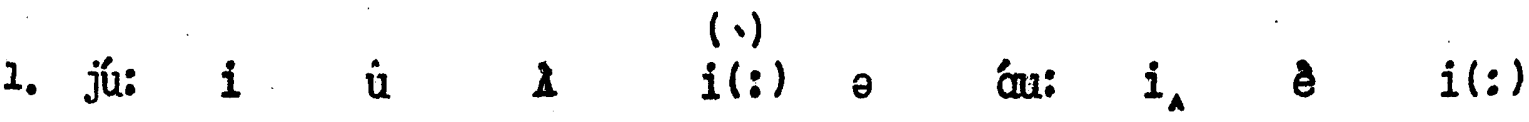

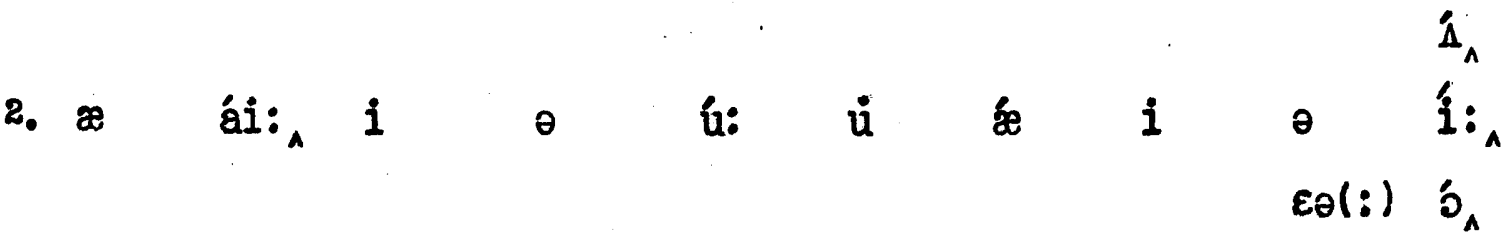

3. $i(:)$ ó: juol(:) ó

4. $\varepsilon \partial(:)$ á: ठu: á: $i$ ú $u_{\wedge}$ óu: ail: ài: ó

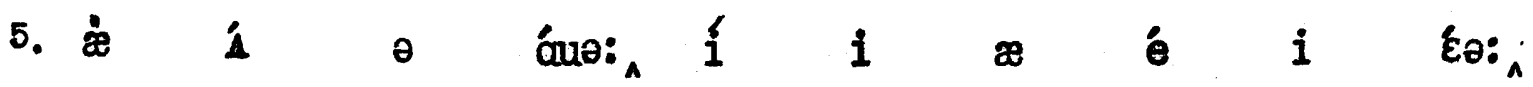

6. ú: $\theta$ iəl:) $b_{\wedge}$ 
1. Nay, barren are those mountains and spent the streams:

2. Our song is the voice of desire, that haunts our dreams,

3. A throe of the heart,

4. Whose pining visions dim, forbidden hopes profound,

5. No dying cadence nor long sigh can sound,

6. For all our art.

"Night ingaleg" ( $v \cdot 2)$

by Sir Robert Bridges.

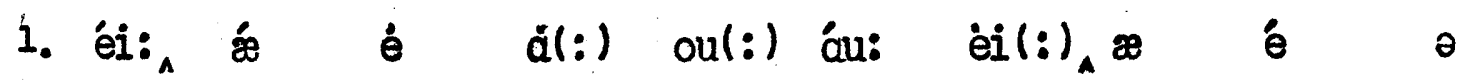

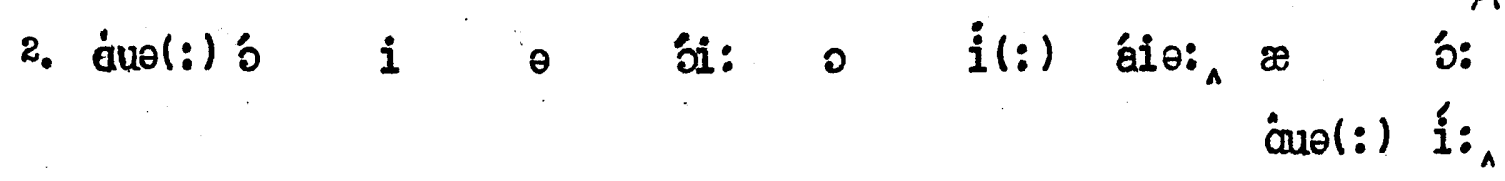

3. èi (:) óu: 0 $\curvearrowright \quad a_{\wedge}$

4. $u(:)$ ái: $i$ i $\quad$ $\quad i_{\wedge}$ j(:) $i$ óu: ou(:)

ád:

5. ôu: ái: $i$ éi: $e_{A}$ ó(:) o ói: $x$ áu:

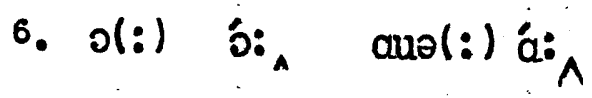


1. And morning came quietly in upon sandals of peace,

2. The maiden-ejed morning who wakens the birds in the dew:

3. With grayness in heaven, and silver in streaks on the sea

4. She came to that harbour of rest where the "Wanderer" lay

5. And shone on her ruin all scurfing with patches of salt

6. Till shadows of beauty were tranquilly stirred at her side.

From "The Wanderer" (p.24)

by J. liasefield.

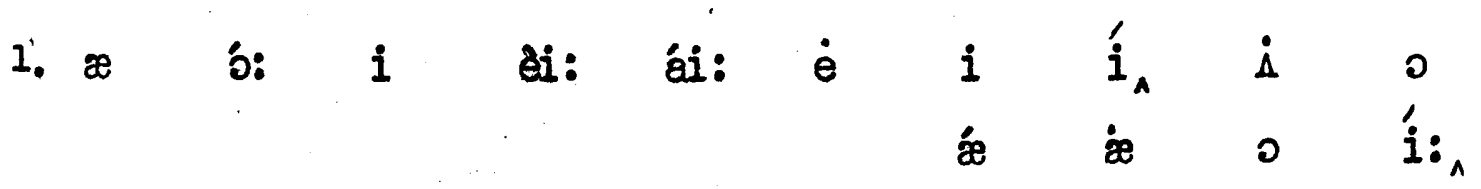

2. $\theta$ êi: $\theta$ ài: b́: $i_{\wedge}$ ul: éi: $\theta$ $\theta$

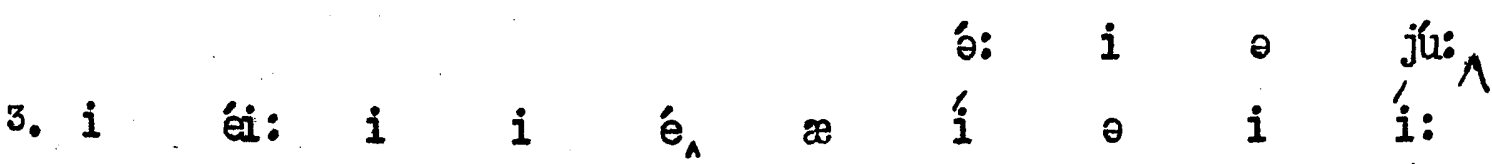

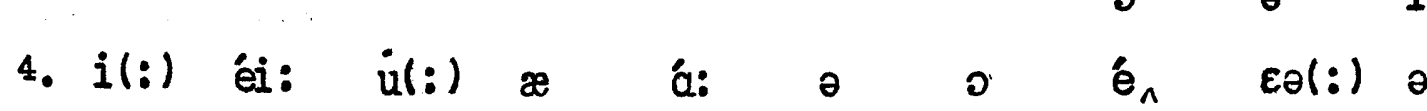

○े $\partial$ éi:^

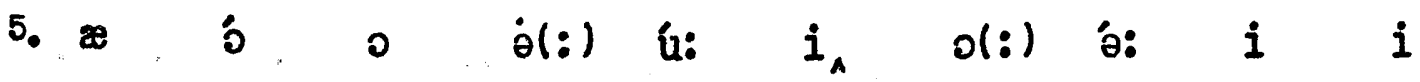

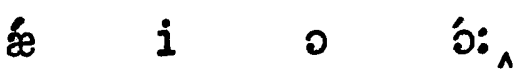

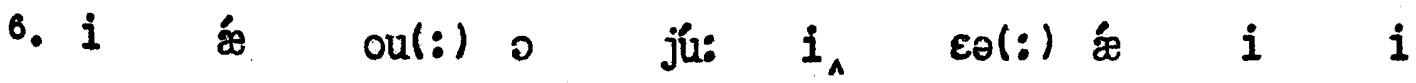

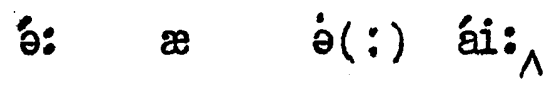


1. Slowly, silently, now the moon

2. Walks the night in her silver shoon;

3. This way, and that, she peers, and sees

4. Silver fruit upon silver trees;

5. One by one the casements catch

6 . Her beams beneath the silvery thatch;

7. Couched in his kennel, like a log,

8. With paws of silver sleeps the dog;

9. From their shadowy cote the white breasts peep

10. Of doves in a silver-feathered sleep;

11. A harvest mouse goes scampering by,

12. With silver claws, and silver eye;

13. And moveless fish in the water gleam,

14. By silver reeds in a silver stream.

"Silver"

by Walter de la Mare.

1. óu: i $i_{\wedge}$ ái: $\dot{e}$ i $a$ áu: $\theta$ ú:

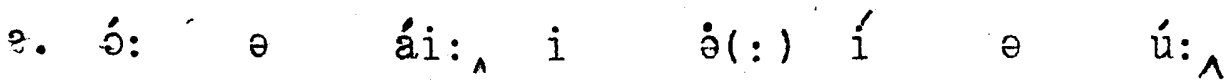

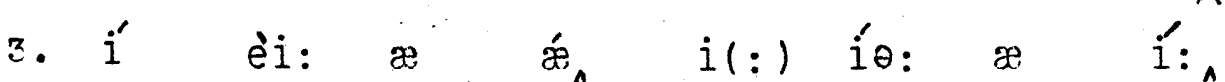

4. $\dot{i}^{\prime} \quad \theta \quad \dot{u}:{ }_{A} \quad \dot{i} \quad 0 \quad i^{\prime} \quad \theta \quad \dot{i}:$

5. $i$ ail : $) i_{A} \theta$ éi: $\dot{e} \dot{x}_{A}$

6. $\dot{\partial}(:) \quad 1: \quad \dot{i}(:) \quad i:{ }_{\wedge} \quad \theta \quad i^{\prime} \quad \theta \quad i \quad \dot{x}_{\wedge}$

7. áu: $i$ i é

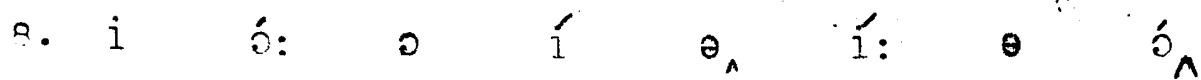

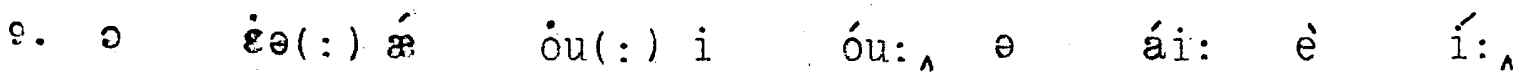

10. $0 \dot{A}_{\wedge} \quad i \quad \dot{e} i(:) i^{\prime} \quad \theta \quad$ é $\theta$ i:

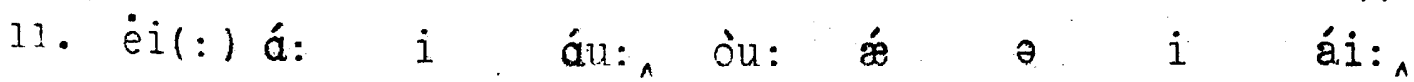

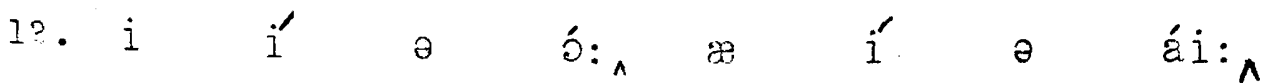

12. $\dot{u}:$ i $\quad i^{\prime}$ i $\theta$ ó: $\theta$ í:

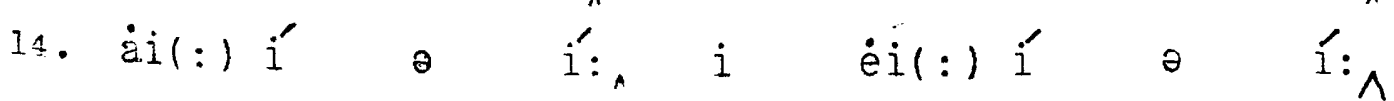


1. A noise like of a hidden brook

2. In the leafy month of June,

3. That to the sleeping woods all night

4. Singeth a quiet tune.

"Phe Rime of the Ancient Mariner" (369-372) by S.T. Coleridge.

1. èi(:) ói: ài: $0 \quad$ eil(:) ${ }^{\prime} \quad \mathfrak{u}_{\Lambda}$

2. $i \quad \theta \quad i: \quad i \quad i_{A} \quad 0 \quad u_{A}$

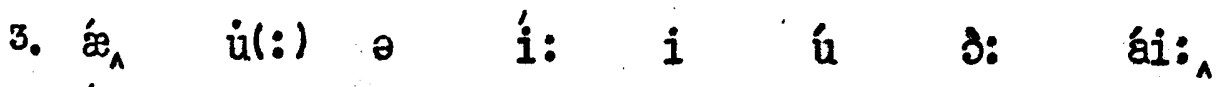

4. '̊ $i i_{\wedge} \quad \dot{e i}(:)$ ái: $\dot{e}$ jü: 
1. Perhaps some dungeon hears thee groan,

2. Maim'd, mangled by inhuman men;

3. Or thou upon a desert thrown

4. Inheritest the lion's den;

5. - Or hast been summon'd to the deep,

6. Thou, thou, and all thy mates, to keep

7. An incommunicable sleep.

From "The Affliction of liargaret" by W. Wordsworth.

1. $\theta$ \& 4 A $\theta_{A}$ io: $i(:)$ bu:

2. éi: $\dot{a}$ ail $:)$ j jü $\ddot{*}$ é

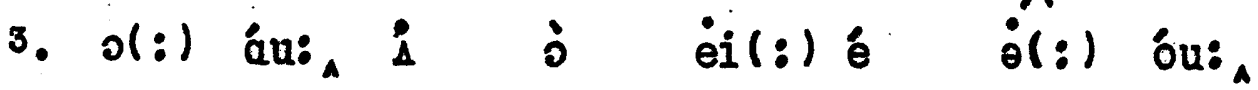

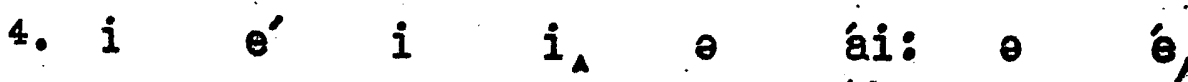

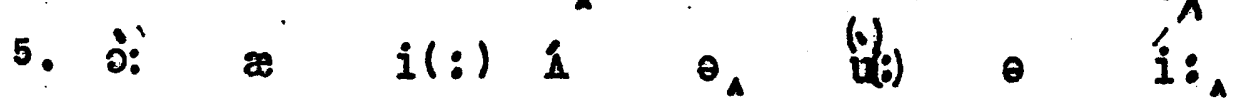

6. áu: áu: æa j: ai(:) éi: $u(:)$ i: a

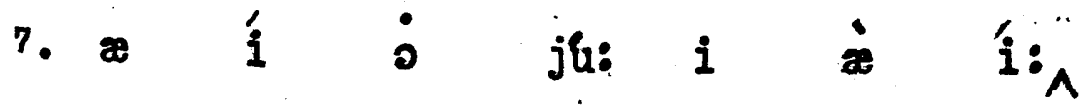


1. 'I have no name;

2. I am but two days old.'

3. What shall I call thee?

4. 'I happy am;

5. Joy is name.'

6. Sweet joy befall thee!

7. Pretty joy:

8. Sweet joy, but two days old;

9. Sweet joy I call thee:

10. Thou dost smile:

11. I sing the while,

12. Sweet joy befall theel

"Infant Joy" by W. Blake.

1. ail:) æ óu: éi: ,

2. ai(:) æ $\Delta$ ú: èi: óu:

3. ว 2 ai(:) o: $i(:) \wedge$

4. $\operatorname{ai}(:) \ddot{z} i$ 安

5. อ̃i: $i$ ail : $)$ éi:

6. i: ói: $i(:)$ o: $i(:)_{\wedge}$

7. $i$ i bi:

8. i: oil ${ }_{\wedge} \Delta$ u: ei: ou:

๑. i: ói: ai(:) o: $\dot{i}(:)_{\wedge}$

10. áu: $\Lambda$ ái $\wedge$

11. ail: ) $\hat{i}_{\wedge}$ o ái:

12. i: ói: $i(:)$ o: $i(:)_{A}$ 
1. though the yesty waves

2. Confound and swallow navigation up;

3. Though bladed corn be lodged, and trees blown down;

4. Though castles topple on their warders'heads;

5. Though palaces and pyramids do slope

6. Their heads to theirfoundations; though the treasure

7. Of nature's germens tumble all together,

8. Even till destruction sicken; answer mo

9. To what I ask you.

"Necbeth", (IV.1.53)

by W. Shakespeare.

1. ou: ə é i ä: ,

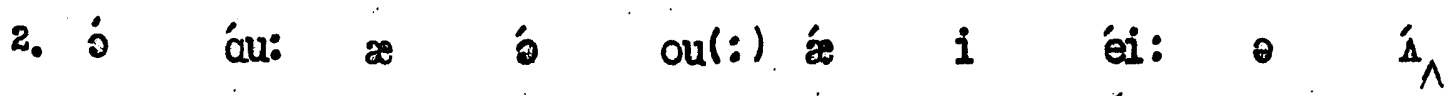

3. oul:) éi: $i$ o: jil:) $\dot{\partial}_{\wedge}$ æ $\dot{i}:$ du: au:

4. oul:) á: $\left.\dot{\partial}_{\wedge} \quad f^{\prime}\right) \quad \varepsilon \theta(:)$ o: $\theta \quad e_{\wedge}$

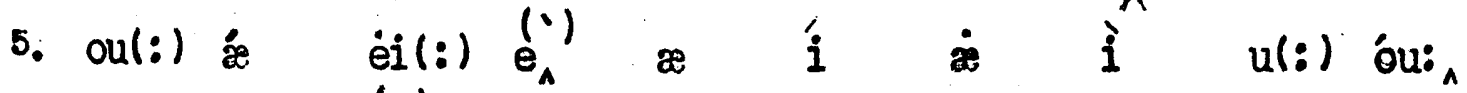

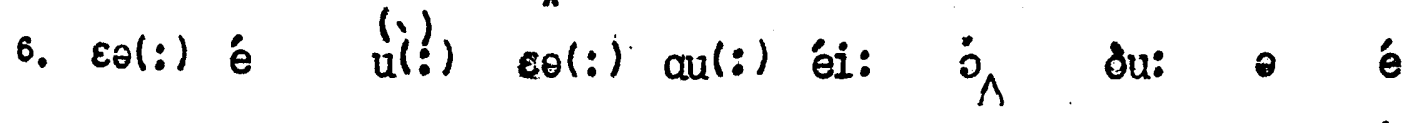
uol: $)_{\wedge}$

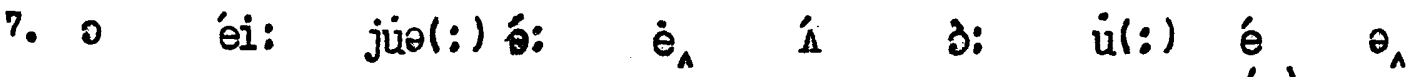

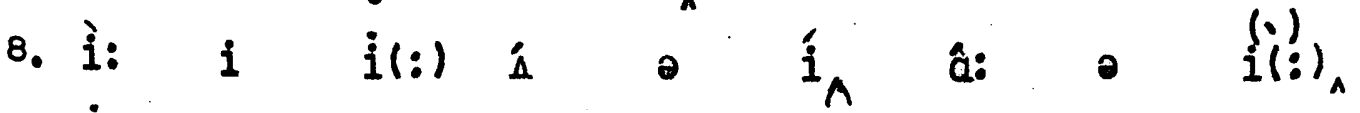

จ. $\dot{u}(:)$ ai(:) á: $j u(:) \wedge$ 
1. Ay, in the catalogue ye go for men;

2. As hounds and greyhounds, mongrels, spaniels, curs,

3. Shoughs, water-rugs, and demi-wolves, are clept

4. All by the name of dogs:

"Macbeth" (III.1.92)

by W. Shakespeare.

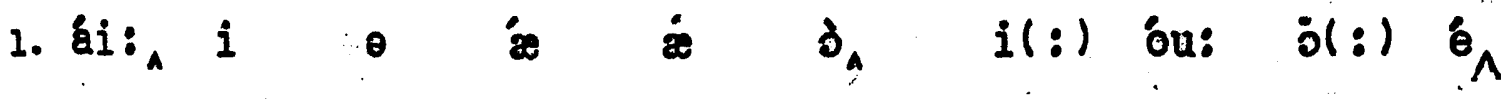

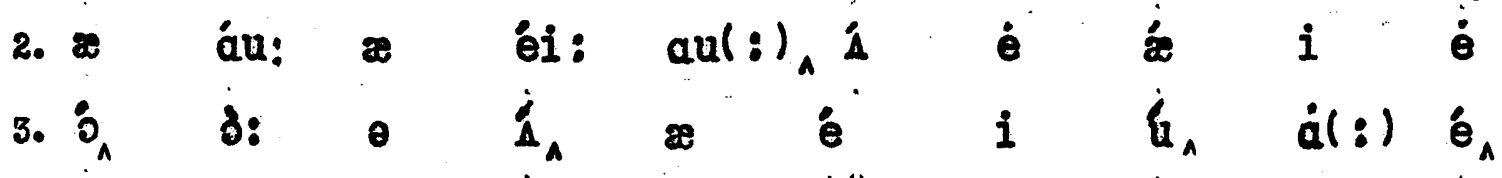

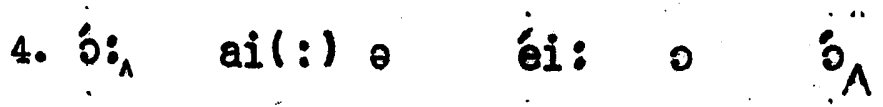


1. Inform her full of my particular fear;

2. And thereto add such reasons of your own

3. As may compact it more. Get you gone,

4. And hasten your return. IJo, no, my lord,

5. This milky fentleness and course of yours

6. Though I condemn not, yet, under pardon,

7. You are much more attask'd for want of visdom

8. Than prais'd for harmful mildness.

"King Lear" (I.4.362)

by W. Shakespeare.

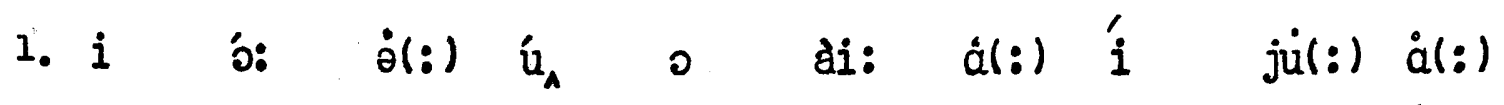
iə:

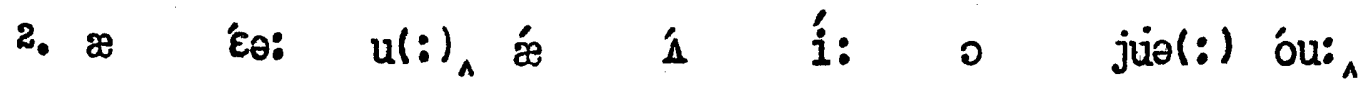

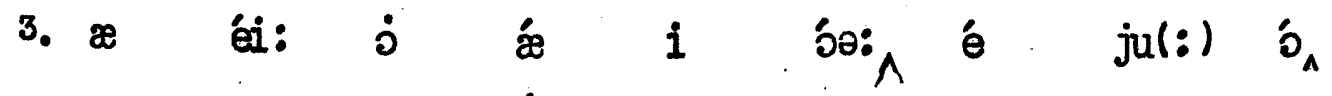

4. æ éi: jüa(:) $\dot{i}(:)$ á: ${ }_{\wedge}$ ou: óu: ai(:) ó:

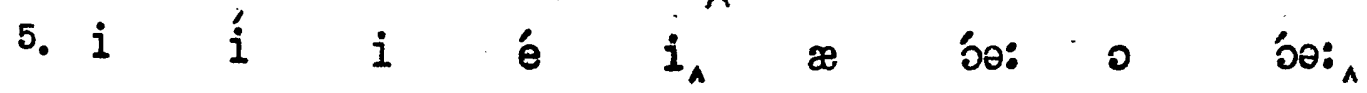

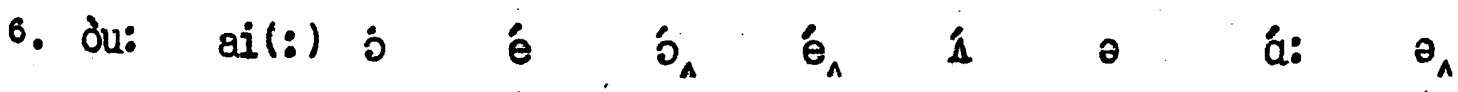

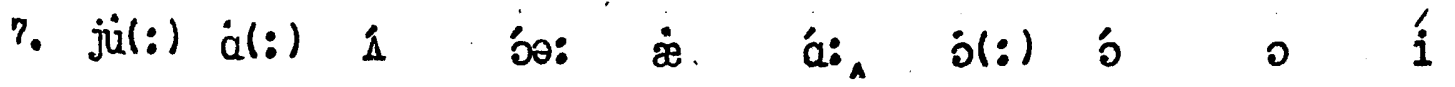

8. æ éi: j(:) á: $\mathfrak{u}$ ái: $\dot{e}_{\wedge}$

$\boldsymbol{\theta}_{\boldsymbol{A}}$ 
1. Lock up doors; and, when you hear the drum,

2. And the vile squealing of the wry-neck'd fife,

3. Clamber not you up to the casements then,

4. Nor thrust your head into the public street,

5. To gaze on Christian fools with varnish'd faces;

6. But stop my house's ears. - I mean my casements:

7 . Let not the sound of shallow foppery enter

8. My sober house.

"The Merchant of Venice" (II.4.29.) by W. Shake speare.

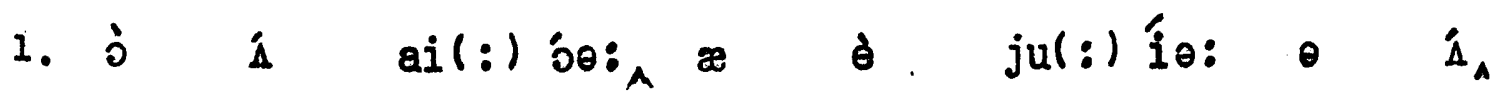

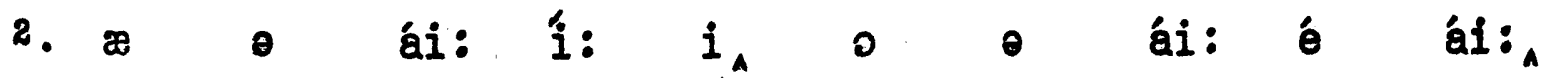

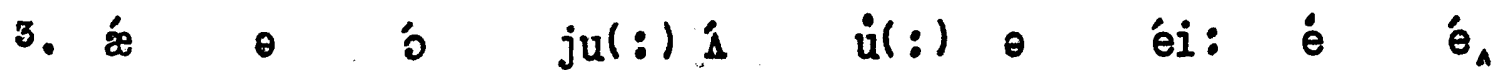

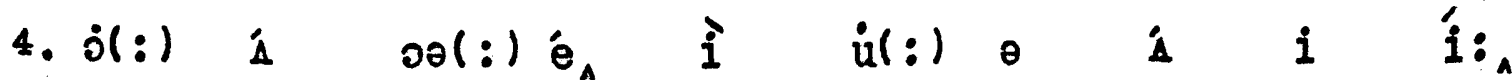

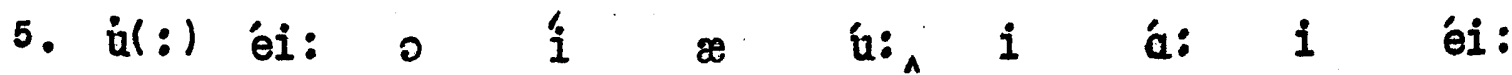

$i_{\wedge}$

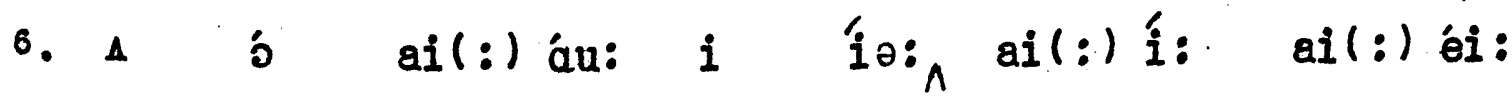

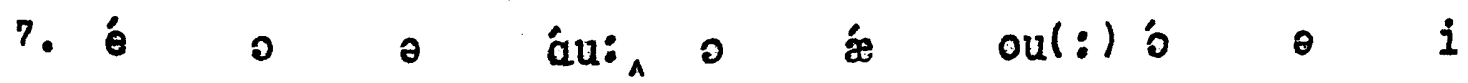

${ }^{\theta} \wedge$

$\dot{\theta} \quad \partial_{\wedge}$

8. ài: óu: ə áu: 
1. The engineman ran to the lamp-room and lighted the lamps,

2. And carried them aft, there to hoist them aloft at the peak;

3. But as he was hoisting, the flames were blown out in all three,

4. He had to return to the lamp-room to light them ogin.

"The Wanderer" (p.20)

by J. Masefield.

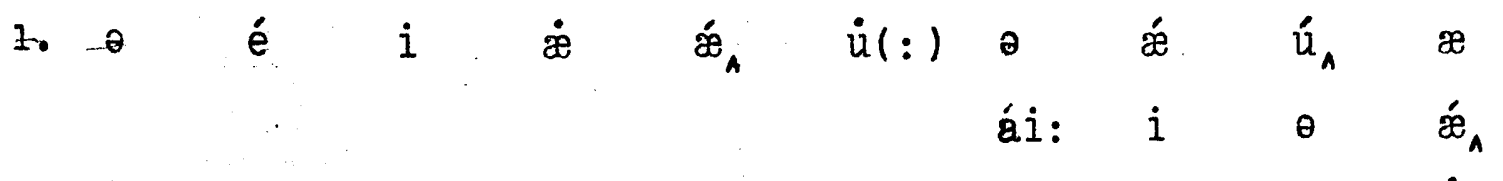

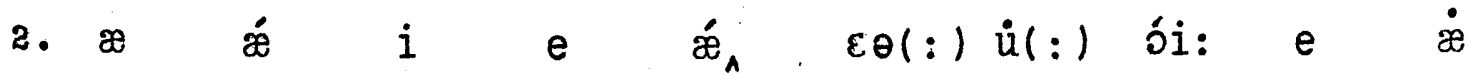
ó: $\quad$ o $\quad i^{\prime} \wedge$

3. $\Delta$ æ $\dot{i}(:)$ o ói: $i_{\wedge}$ a éi: $\dot{\varepsilon} \partial(:)$ ơ

áu: $i \quad o(:) \quad i^{\prime}{ }_{\wedge}$

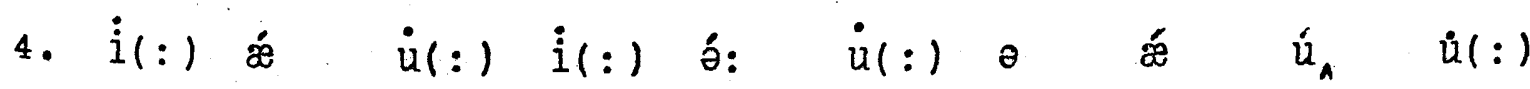

ái: e $\dot{x} \quad \dot{e} i:_{\wedge}$ 
1. The darkness came early

2. With streakings of flame in the west and then darkness indeed

3. Hoonless and starless a lightning-blencht blackness of tumult,

4. With seas roaring out from wind roaring, and wind in the shrouds

5. Shrieking, and iron blocks batting, and swinging ports streaming,

6. And smoke streaming from her, the ship-shattered water like smoke.

From "The Wanderer" (p.18)

by J. Masefield.

1. $\theta$ á: $i$ ei: á: $i_{\wedge}$

2. $i$ i: $i$ o éi: $i$ o $\dot{\theta}_{A} \approx$ o

. . á: $i$ i íl

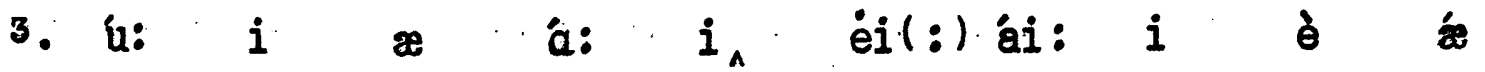

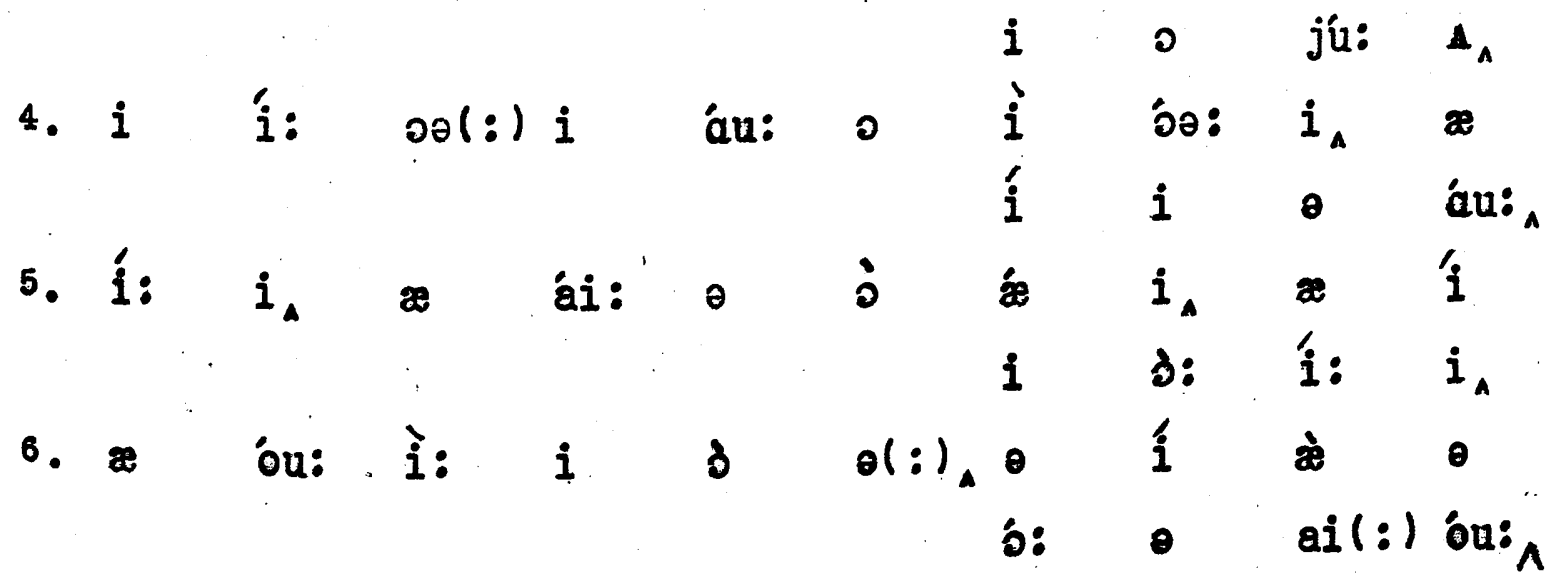


1. There lay the "Wanderer" helpless, sea-beaten, sail-tattered,

2. All three topgallant masts broken and swinging aloft still

3. Raining down pennants and blocks as they tore off in rolling,

4. Her spanker gaff vanisht, her jiggermast bent with the strain,

5. Her captisin unconscious, six seamen disabled from wounds,

6. Half the rest drunken or mutinous, hiding below deck,

7. The ship heading hither and yonder hove-to with a cloth,

8. Beaten rail-under by tempest and delnged by billows

9. Her mate lighting blue lights and rockets in sign of distress 10. The Codling Bank light showing danger to leeward and near.

"The Wanderer" (p.22)

by J. Masefield.

1. $\varepsilon \theta(:)$ éi: $\theta$ o èi : 羊 $\theta_{\wedge}$

2. i $\dot{z} \quad$ o: $\quad \grave{i}_{A}$

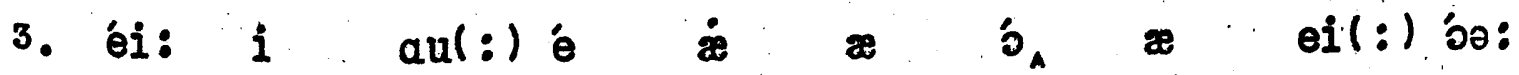

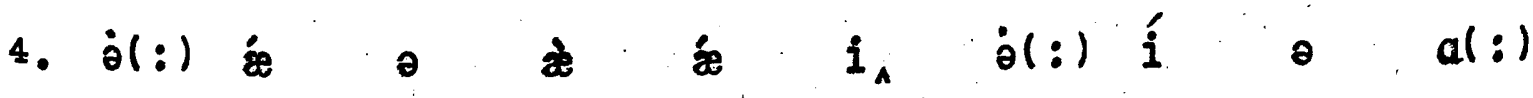

o(:) $i$ ou: $i_{\text {A }}$

é i $\quad \theta$, éi:

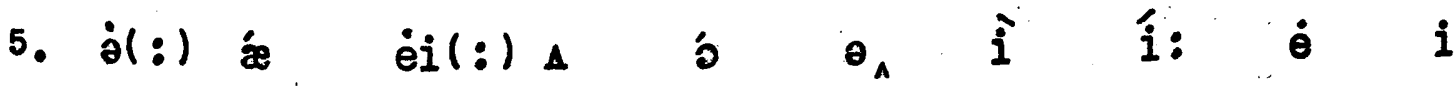

éi: 0 u:

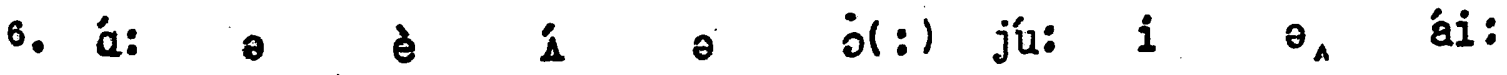

$i \quad i(:)$ ou: è

7.

\{́: $i$ eil $:$ ) ó:

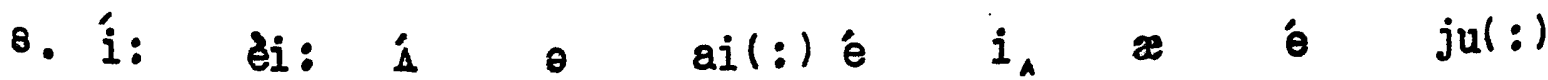
ai (:) $\mathfrak{i}$ oul : $)_{\wedge}$ 


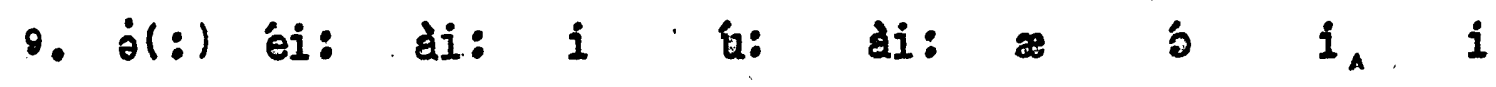

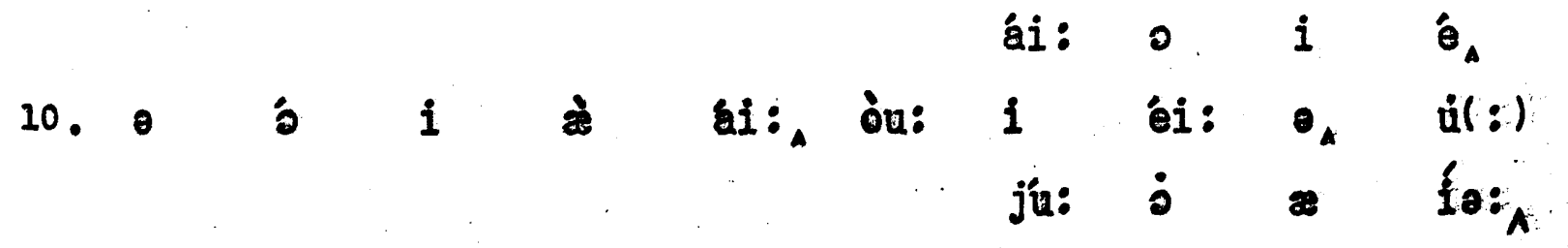


1. By fits less frequent from the crowd

2. Was heard the burst of laughter loud;

3. For still, as squire and archer stared

4. On that dark face and matted beard

5. Their glee and game declined.

6. All gazed at length in silence drear,

7. Unbroke, save when in comrade's ear

8. Some yeoman, wondering in his fear,

9. Thus whispered forth his mind.

"Marmion" (III.6.90) by Sir Walter Scott.

1. $\operatorname{ai}(:)$ í

e í:

e

3

o áu:

2. 0 ว่:

ə ว่: ${ }_{\Lambda}, 0$

á:

$\theta$

áu:

3. $\partial(:) \hat{i}_{\wedge}$

áiə: æ

á:

ə

ยə:

4. $0 \quad \mathscr{\infty}$

d:

éi: $¥$

$\notin$

i

1̇:

5. $\varepsilon \partial(:)$ 1́.

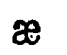

éi: $\quad \dot{i}(:)$ ái:

6. ol: éi:

é $\quad i$

ái:

$\dot{e}$

io:

7. 4 óu:

éi:

e

๖

èil: ) î:

8. 4

óu:

ณ

i

i

$i$

iอะ

9. $\mathrm{A}$

3: $\quad i$

ái: 
1. Fit retribution! Gaul may champ the bit

2. And foom in fetters; - but is Earth more free?

3. Did nations combat to make one submit;

4. Or league to teach all kings true soverelgnty?

5. What shall reviving Thraldom again be

6. The patch'd up idol of enlighten'd days?

7. Shall we, who st ruck the lion down, shall we

8. Pay the Wolf homage? proferring lowly gaze

9. And servile knees to thrones? No; prove before ye praise\}

"Childe Harold" (III.19)

by Iord Byron.

1. $i$ e $i$ jú $\dot{\partial}_{\wedge}$ ó: eil

2. $\approx$ óu: $i$ é

${ }^{\partial} \wedge \perp \quad i \quad \dot{\theta}:$

3. i éi: $\theta$

o

$æ_{\wedge} \quad \dot{a}(:)$ éi: is

4. $\partial(i) \quad i: \wedge$

$\dot{u}(:)$ i:

$o(:) i_{\wedge}$ ù:

5. $\partial_{\wedge} \approx$

il: $)$ ái: i

อ́:

2

อ่

6. 2

æ

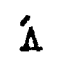

ái:

$\theta_{\wedge}$

o

e

$\dot{x}$

o $\dot{i}_{\text {A }}$

7. $\quad$ i: $\quad \dot{u}(:)$ í

- ái:

ə

éi ( : ) ${ }_{\wedge}^{\prime}$

ái: éi :

8. éi: $\partial$

ù ’́

ə

áu: $\underset{\wedge}{ } \mathbb{x}$

i:

i ou: $\mathbf{i}$

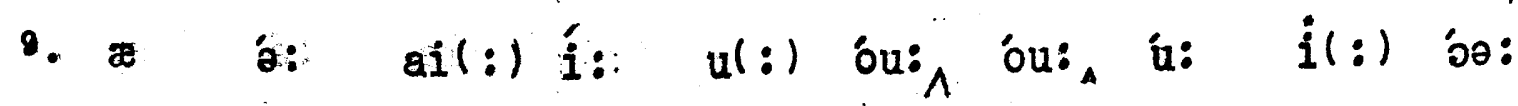

il: ) éi: 
1. Dusky and huge, enlarging on the night,

2. Nature's volcanic amphitheatre,

3. Chimaera's alps extend from left to right:

4. Beneath, a living valley seems to stir;

5. Flocks play, trees wave, streams flow, the mountain-fir

6. Nodding above; behold black Acheron!

7. Once consecrated to the sepulchre.

8. Plutol if this be hell I look upon,

9. Close shamed Elysium's gates, mo shade shall seek for none.

"Childe Haro:ld" (II.5I)

by Lord Byron.

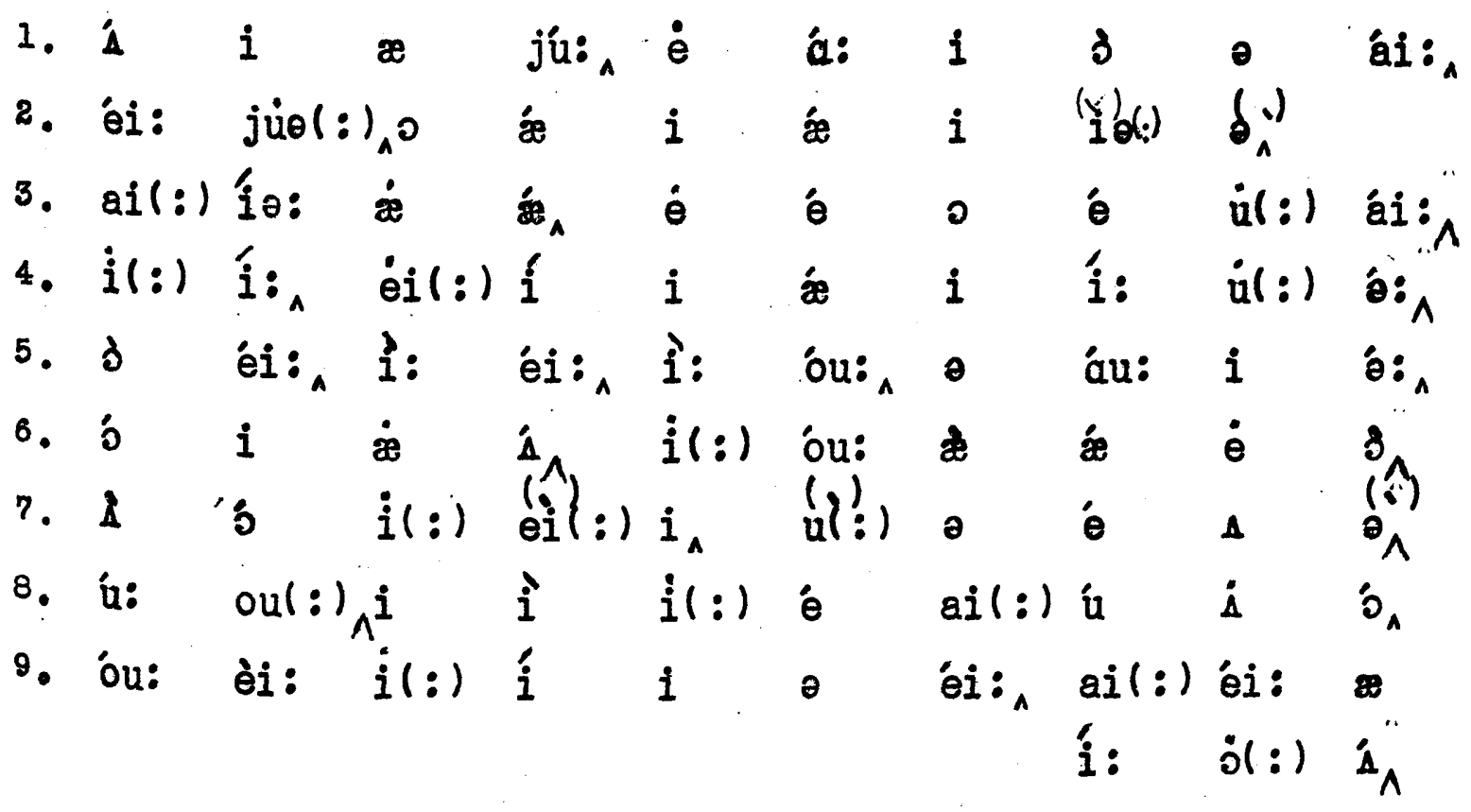


1. Conqueror and captive of the earth art thoul

2. She trembles at thee still, and thy wild name

3. Was ne'er more bruited in men's minds than now

4. That thou art nothing, save the jest of Fame,

5. Who woo'd thee once, thy vassal, and became

6. The flatterer of thy fierceness, till thou wert

7. A god unto thyself; nor less the same

8. To the astounded kingdoms all inert,

9. Who deem'd thee for a time whate'er thou didst assert.

"Childe Harold" (III.37)

by Lord Byron.

1. qu:

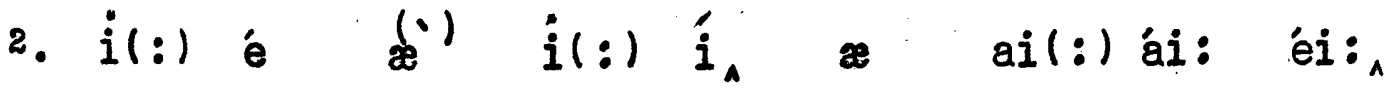

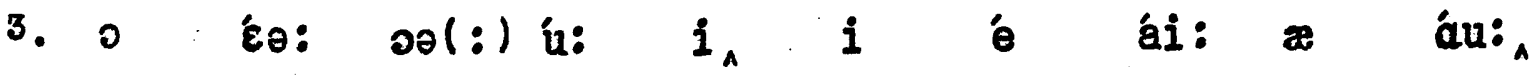

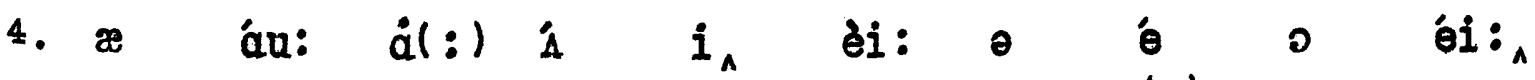

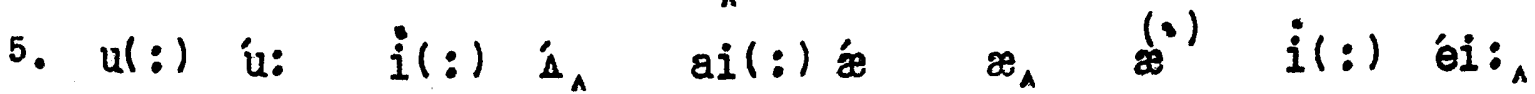

6. $\theta \quad \partial \quad \partial \quad \partial \quad a i(:) i_{\theta} i_{A} i \quad a(:)$

ө:

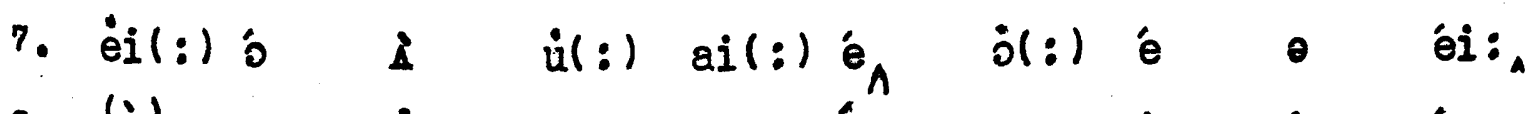

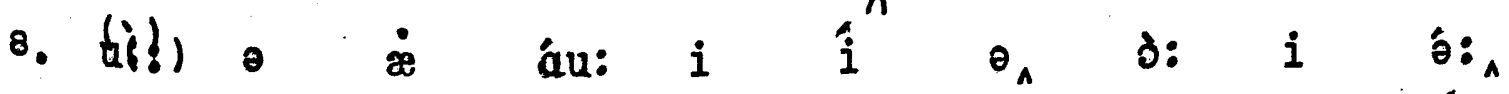

9. $u(:)$ i: $i(:)$ bie) eji(:) ái: 0 é: au(:) í

$\ddot{\ddot{\theta}} \quad \dot{\wedge}$ 
1. Away with these! tme Wisdom's world will be

2. Within its own creation, or in thine,

3. Maternal Nature! for who teems like thee,

4. Thas on the banks of thy majestic Rhine?

5. There Harold gazes on a work divine,

6. A blending of all beauties; streams and dells,

7. Fruit, foliage, crag, wood, comfield, mountain, vine,

8. And chiefless castles breathing stern farewells

9. From gray but leafy walls, where huin greenly dwells.

"Childe Harold" (III.46)

by Iord Byron.

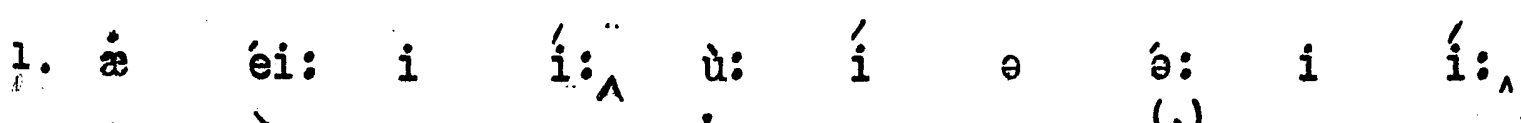

2. $i$ i $i$ óu: $i:$ éi: $\partial_{\wedge}$ o(:) $i$ ál:

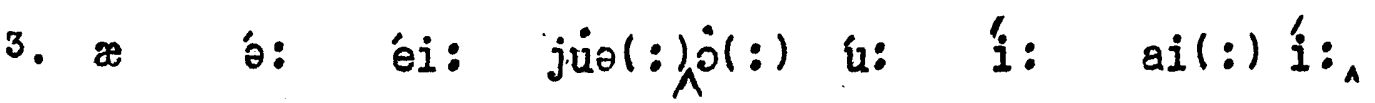

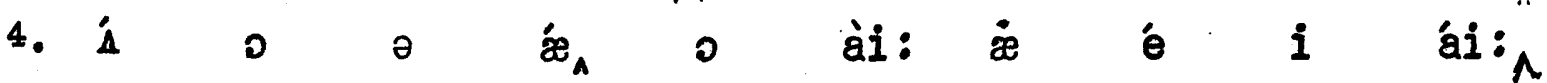

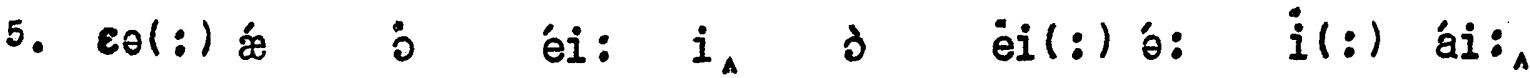

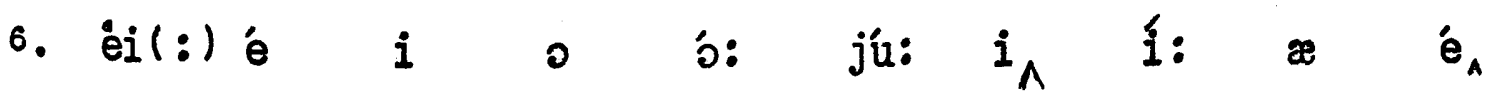

7. ù: ou: $i$ i $\mathscr{\boxplus}_{A}$ ù ó $i(:)$ áu: $i$

ái :

8. æ í: i áa

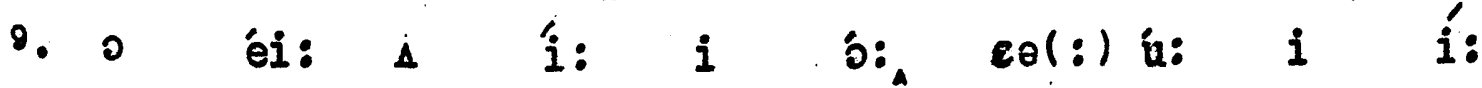

i $\dot{e}_{\wedge}$ 
1. The horrid crags, by toppling convent crown'd,

2. The cork-trees hoar that clothe the shaggy steep,

3. The mountain-moss by scorching skies imbrown'd,

4. The sunken glen, whose sunless shrubs must weep,

5. The tender azure of the unruffled deep,

6. The orange tints that gild the greenest bough,

7. The torrents that from cliff to valley leap,

8. The vine on high, the willow branch below,

9. Mix'd in one mighty scene, with varied beauty glow.

"Childe Harold" (I.19) by Lord Byron.

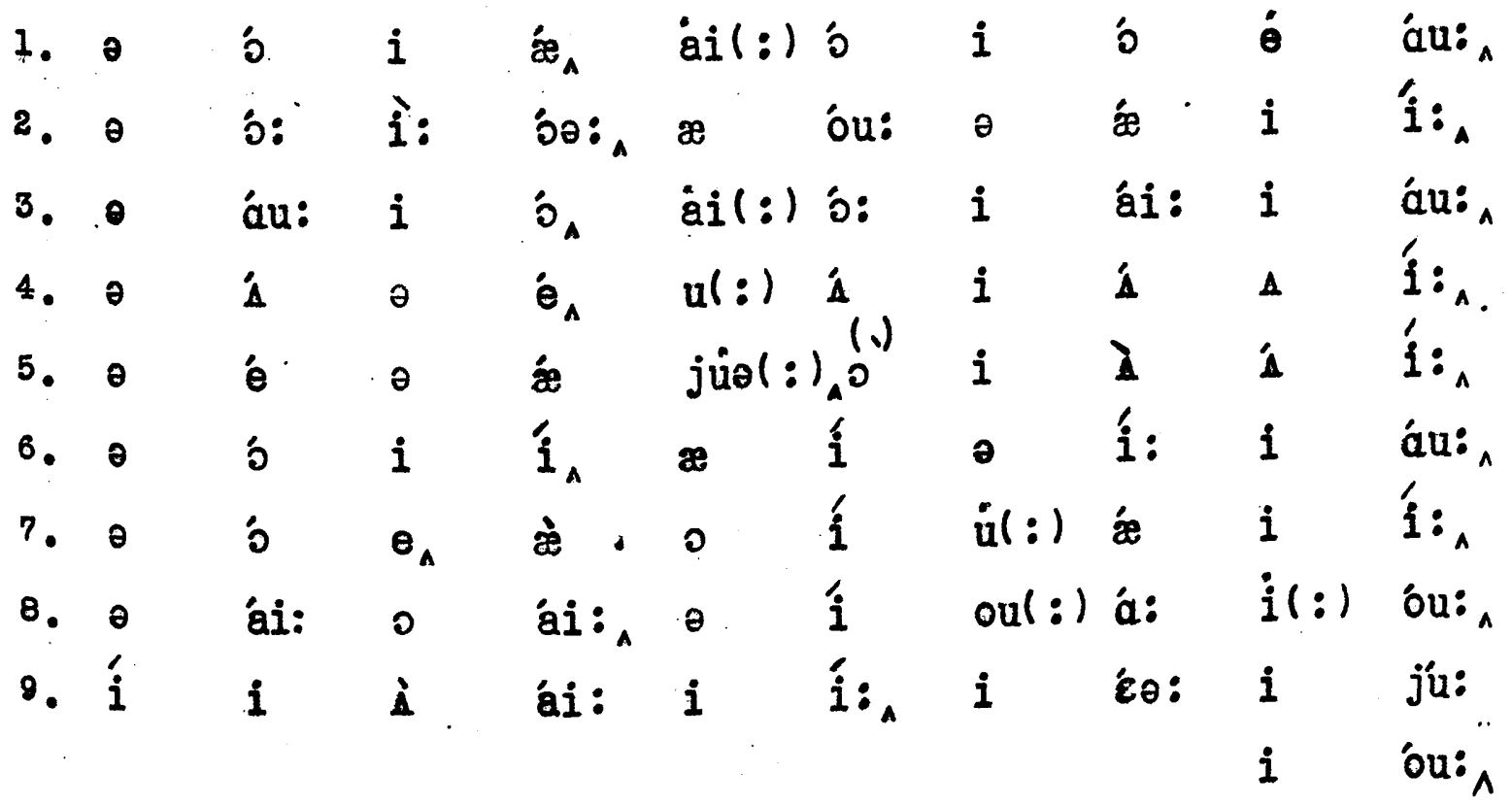


1. But Thou, exulting and abounding rivers

2. Making thy waves a blessing as they flow

3. Through baniss whose beauty would endure for ever,

4. Could man but leave thy bright creation so,

5. Nor its fair promise from the surface mow

6. With the sharp scythe of conflict, - then to see

7. Thy valley of sweet waters, were to know

8. Earth pared like Heaven; and to seern such to me,

9. Even now what wants thy stream? - that it should Lethe be.

"Child Harold" (III.50)

by Lord Byron.

1. 1 áu: $\dot{A}$ i $i$ \& $\dot{\mathbf{e}}$ áu: i

2. éi: $i$ ai(:) éi: èi(:) é $i_{\wedge} \notin$ ei(:) óu:

3. $u(:)$ \& $u(:)$ ju: $i_{A}$ ì è jla: $\dot{o}(:)$ é

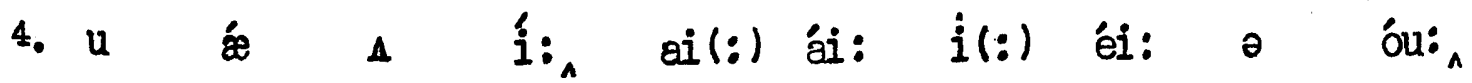

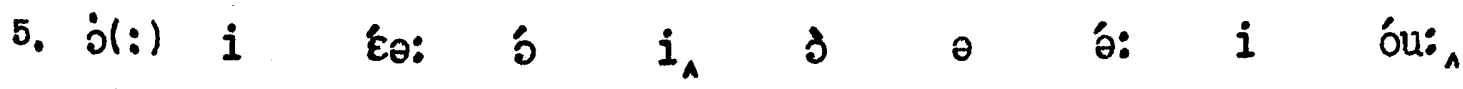

6. $i$ o á: ái: 0 o $i_{\wedge}$ é $u(:) \quad i:_{\wedge}$

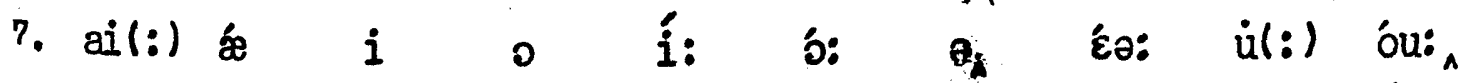

8. d: éi: ai(:) é

9. $i(:)$ áu: o ó $a i(:){ }^{i}:_{\wedge}$ \& $i$ u $i:$

i(:) ${ }^{i}:_{A}$ 
1. This makes the madmen who have made men mad

2. By their contagion; Conquerors and Kings,

3. Founders of sect and systems, to whom add

4. Sophists, Bards, Statesmen, all unquiet things

5. Which stir too strongly the soul's secret springs,

6. And are themselves the fools to those they fool;

7. Envied, yet how unenviable! what stings

8. Are theirs! One breast laid open were a school

9. Which would unteach mankind the lust to shine or rule:

"Childe Harold" (III.43)

by Lord Byron.

1. i éi: $\theta$ ǽ $e_{A} u(:)$ æ éi: é $\dot{x}_{A}$

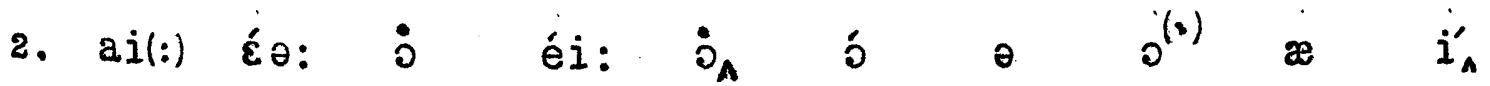

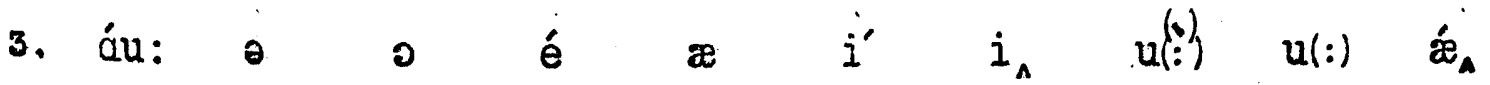

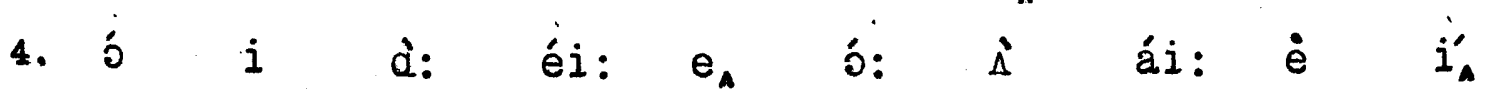

5. $i$ á $u(:) \quad j \quad i_{A} \quad \dot{0}$ óu: $i^{\prime}:$ i $i_{\wedge}^{\prime}$

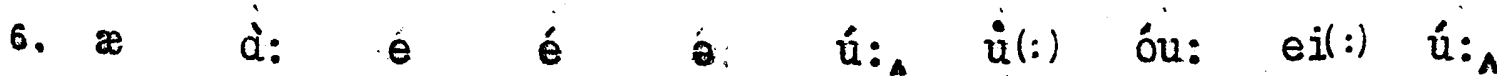

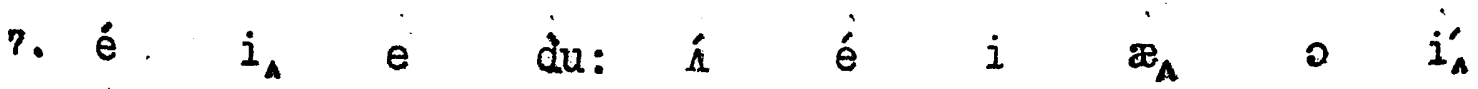

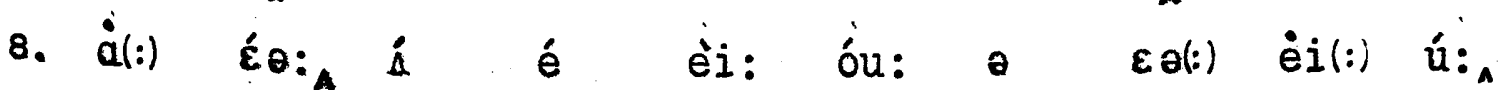

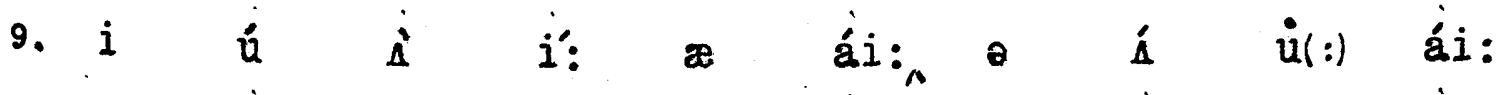

$\dot{\partial}(:) \quad \dot{u}:{ }_{A}$ 
1. He who ascends to mountain-tops, shall find

2. The loftiest peaks most wrapt in clouds and snow;

3. He who surpasses or subaues mankind,

4. Must look down on the hate of those below.

5. Though high above the sun of glory glow,

6. And far beneath the earth and ocean spread,

7. Round him are icy rocks, ana loudly blow

8. Contending tempests on his naked head,

9. And thus reward the toils which to those surmits led.

"Childe Harold" (III.45)

by Lord Byron.

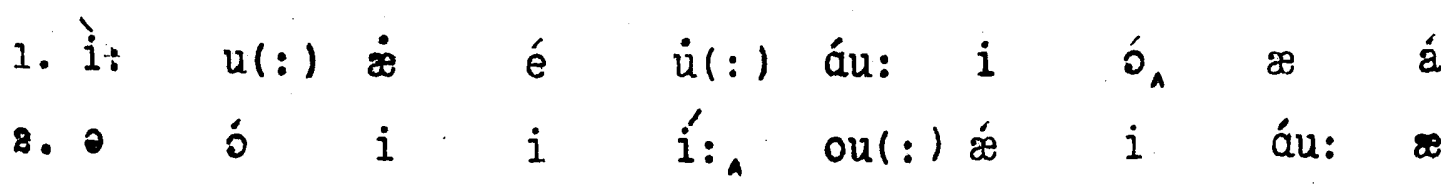
óu: $\wedge$

3. ì $u(:)$ ॰ á: $i_{\wedge}$ b̆l: $\dot{i}$ jú: æ̇ ái:

4. $\Lambda$ ú du: 0 $\theta$ éi: 0 ou: $i(:)$ ou: $\wedge$

5. ou(:) ái: $\dot{\nexists} \cdot \dot{\Lambda}_{\wedge}$ ○ $\dot{\Lambda} \quad 0 \quad$ ó: $i$ óu:

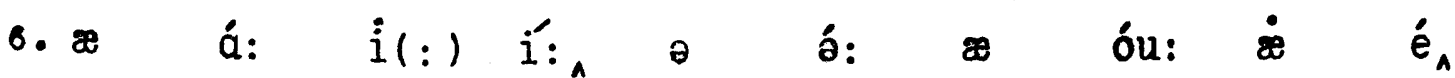

7. áu: $i$ a(:) ái: $i$ ó $\circledast$ áu: $i$ óu:

8. $\dot{0}$ é $i$ é $i_{\wedge}$ ò $i$ éi: $i$ é

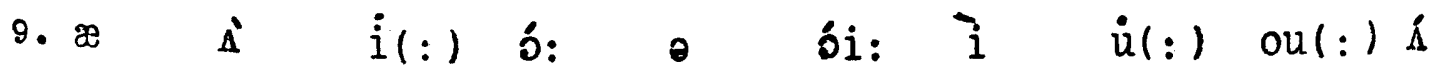

i $\quad e_{\Lambda}$ 
1. Roll on, thou deep and dark blue ocean - rolld

2. Ten thousand fleets sweep over thee in vain;

3. Man marks the earth with min - his control

4. Stops with the shore; upon the watery plain

5. The wrecks are all thy deed, nor doth remain

6. A shadow of man's ravage, save his own,

7. When, for a moment, like a drop of rain,

8. He sinks into thy depths with bubbling groan,

9. Without a grave, unknell'd, uncoffin'd, and unknown.

"Childe Harold" (IV.179)

by Lord Byron.

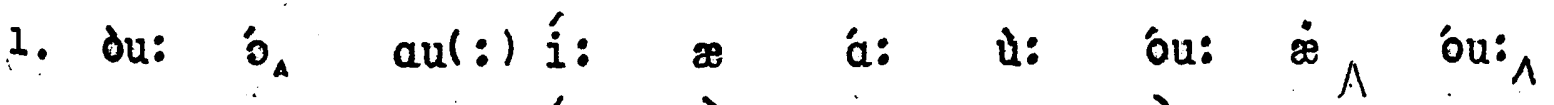

2. e áu: $\theta$ i: $i:$ ou: $\theta$ i: $i$ éi: $_{\wedge}$

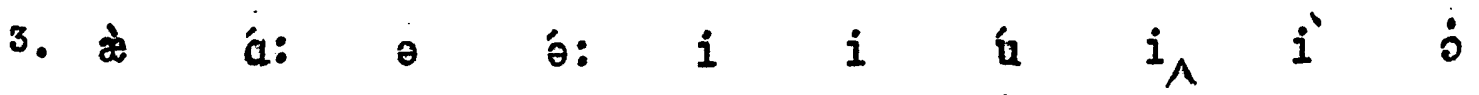

ou:

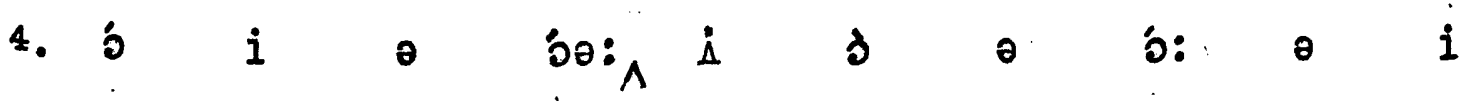

éi :

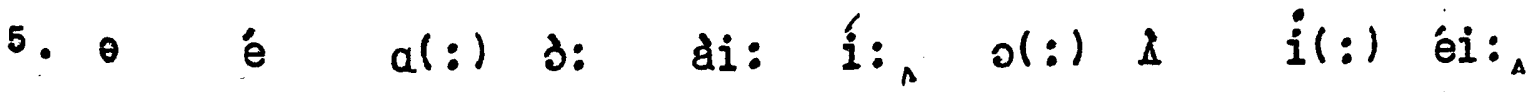

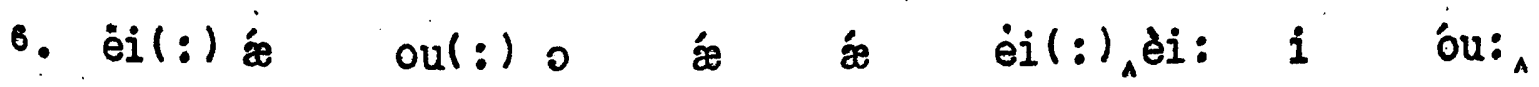

7. é

8. $i(:) i \quad i \quad \dot{u}(:)$ ai(:) $\dot{\theta}_{A} i \quad$ i $i$ ou:

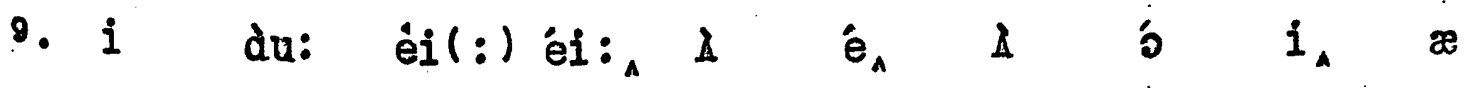

$\lambda$ ou: 
1. The castled crag of Drachenfels

2. Frowns o'er the wide and winding Rhine,

3. Whose breast of waters broadly swells

4. Between the banks which bear the vine,

5. And hills all rich with blossom'd trees,

6. And fields which promise corn and wine,

7. And scatter'd cities crowning these,

8. Whose far white walls along them shine,

9. Have strew'd a scene, which I should see

10. With double joy wert thou with me.

11. and peasant girls, with deep blue eyes,

12. And hands which offer early flowers,

13. Walk smiling o'er this paradise;

14. Above, the frequent feudal towers

15. Through green leaves lift their walls of gray;

16. And many a rock which steeply lowers,

17. And noble arch in proud decay,

18. Look o'er this vale of vintage-bowers;

19. But one thing want these banks of Rhine, -

20. Thy gentle hand to clasp in mined

"Childe Harold" (III.55)

by Lord Byron. 


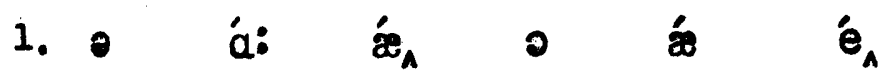

2. áu: oo(:) ○ ái: $¥$ ái: $i$ ái:

3. $u(:)$ é 0 ó: $\partial_{A}$ o: 1 é

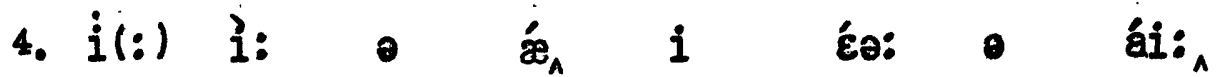

5. $\approx \quad i \quad o(:) i_{\wedge} i \quad j \quad$ o $i_{\wedge}$

6. $\approx$ i: $\quad$ i ó $i$ ó: $\approx$ ái:

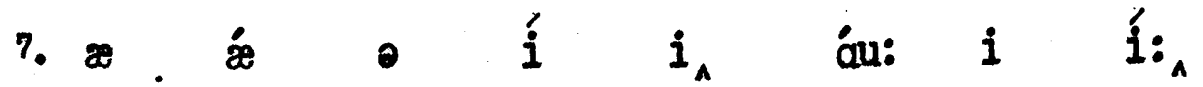

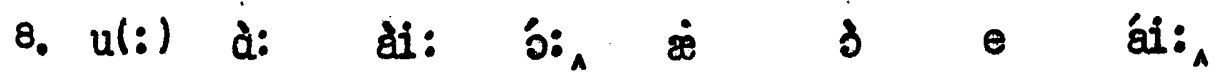

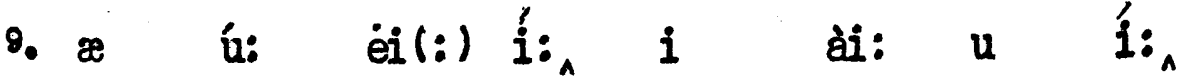

10. $i$ i bo: $\left.{ }_{\wedge} \circ:\right)$ du: $i$ i:

11. $¥$ e $\dot{\otimes}$ á: $i$ í d: घi:

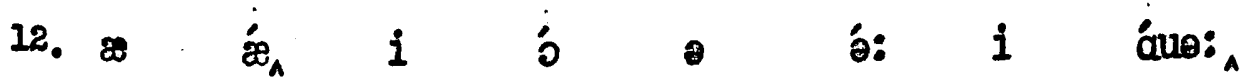

13. 3: áai: $i_{\wedge}$ ó: $i$ \& $\dot{\&}$ ái:

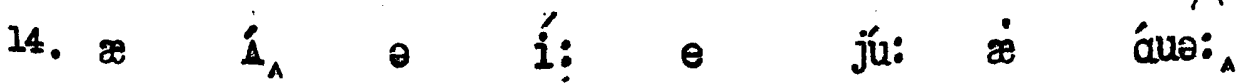

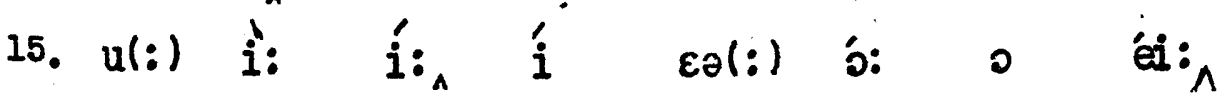

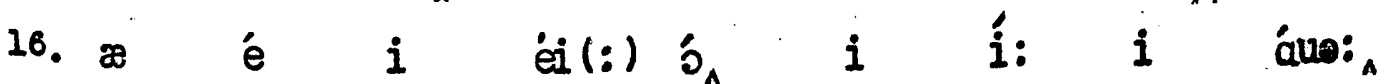

17. $x$ óu: á: $i$ áu: $i(:)$ éi:

18. $\dot{u}_{A} \quad j_{\theta}(:) \quad i \quad$ éi: 0 i $i$ ámo:

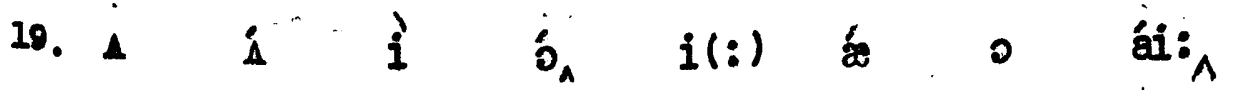

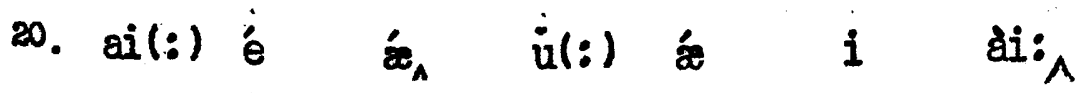


1. And hereupon he bade me daub away.

2. Thank you ! my head being crammed, the walls a blank,

3. Never was such prompt disemburdening.

4. First, every sort of monk, the black and witite,

5. I drew them, fat and lean: then, folk at church,

6. From good old gossips waiting to confess

7. Their cribs of berin-aroppings, canale-ends,-

8. To the breathless fellow at the altar-foot,

9. Fresh from his muind, saf and sitting there

10. With the little chilaren round hir in a row

11. Of admiration, half for his beard and half

12. For that white anger of his Victim's son

13. Shaking a fist at him with one fierce arm,

14. Signing himself with the other because of Christ

15. (Whose sad face on the cross sees only this

16. After the passion of a thousand years).

From "Fra Ltppo Lippi"

by $\mathrm{R}$. Browning. 


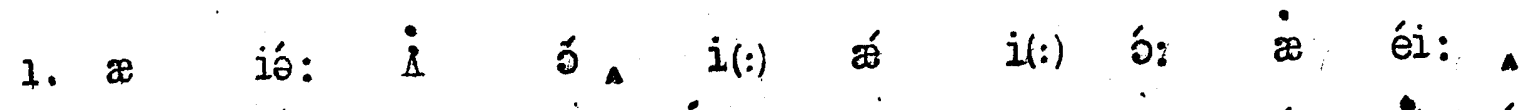

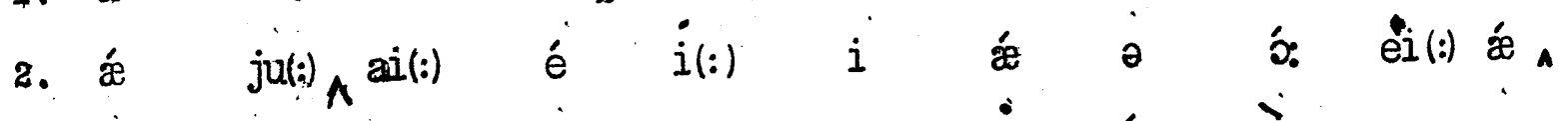

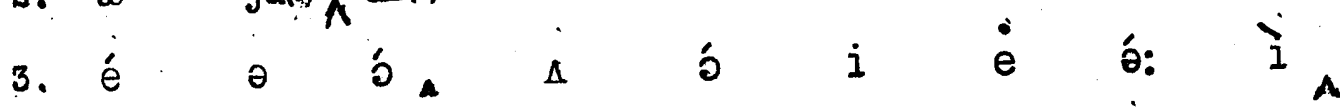
4. ว́:

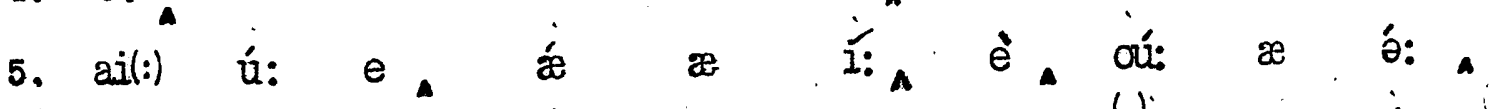
6. 0 ú à: $\dot{0} i$ ái: $i$ ùl:) 0 é a

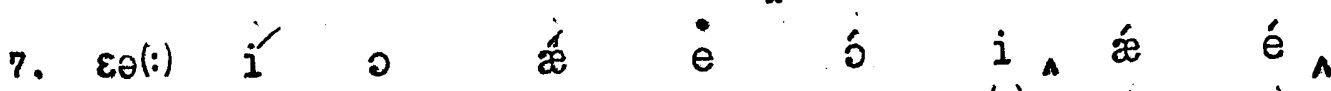

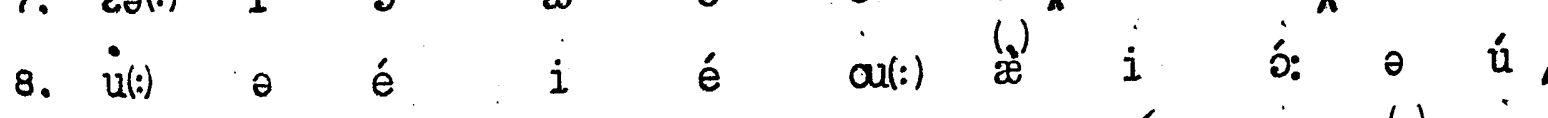

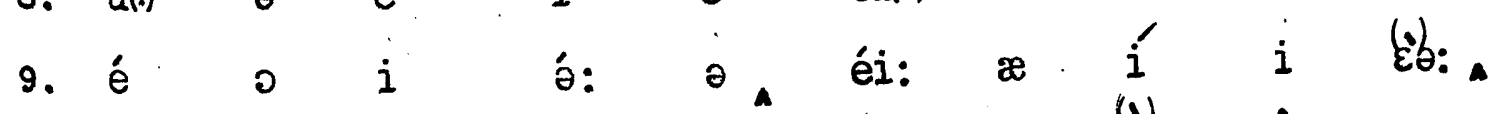

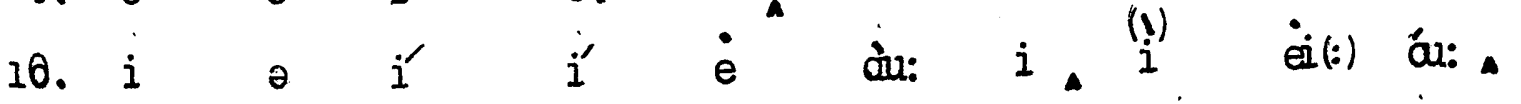

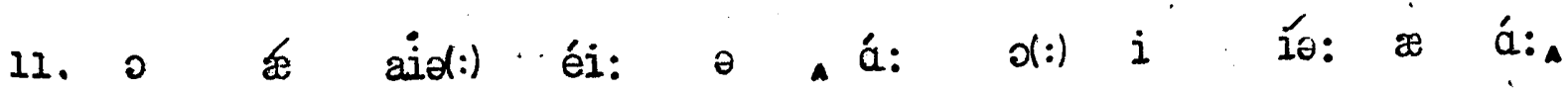

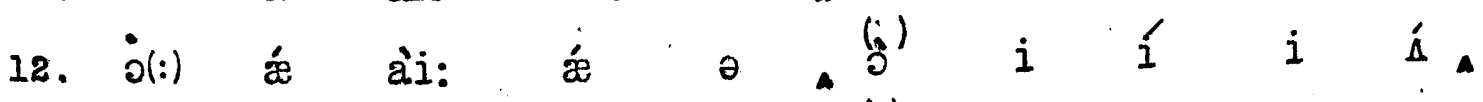

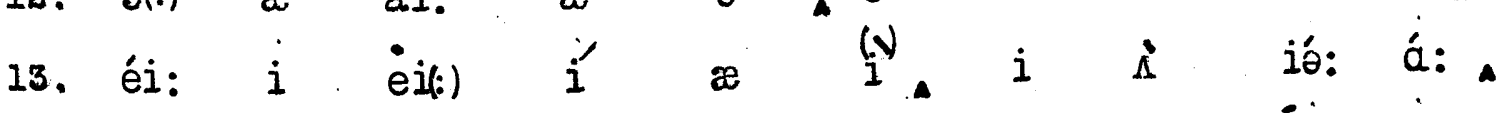

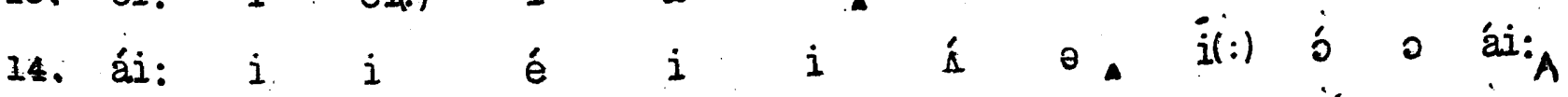
15. $u(:) \ddot{z}$ éi: $j$ o ja

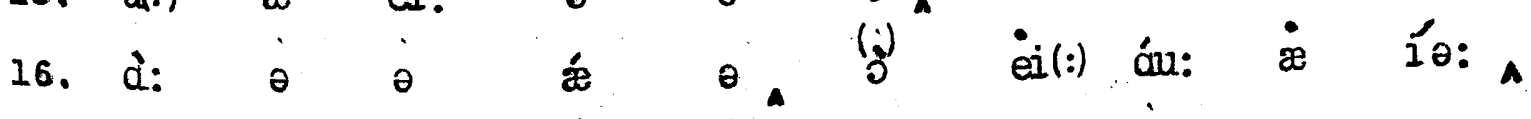


1. And the muttering grew to a grumbling;

2. And the grumbling grew to a rumbling;

3. And out of the houses the rats came tumbling.

4. Great rats, small rats, lean rats, bramy rats,

5. Brown rats, black rats, gray rats, tawny rats,

6. Grave ola plodders, gay joung friskers,

7. Fathers, mothers, uncles, cousins,

8. Cocking tails, and pricking whiskers,

9. Families by tens and dozens.

From "Phe Pied Piper of Hamelin" (

by R. Browning.

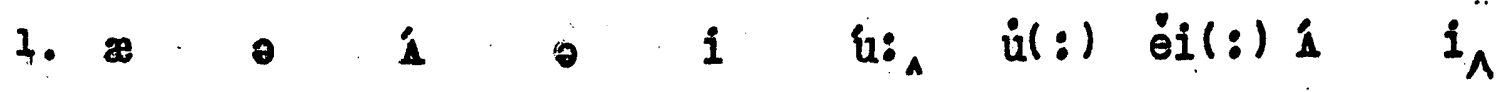

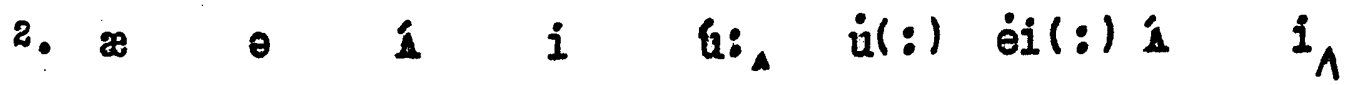

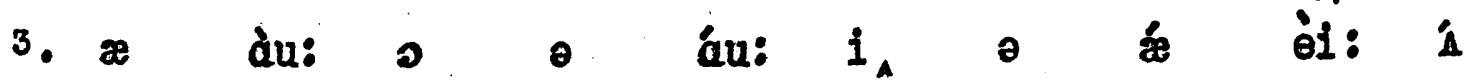

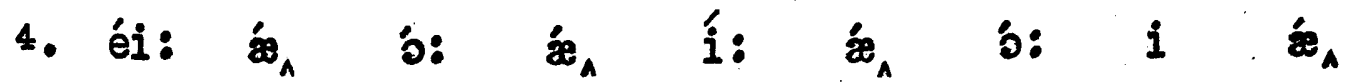

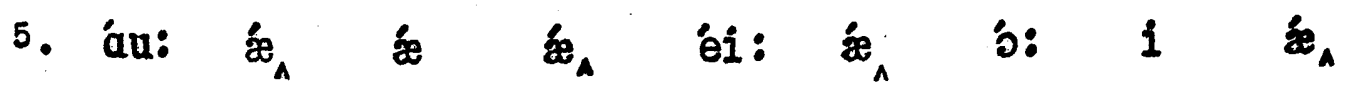

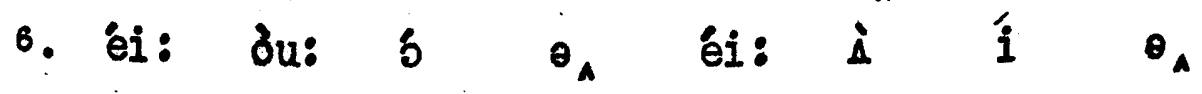

7. i: $\theta_{\wedge} i \quad \theta_{A} i \quad$ i $i_{A}$

8. ๖ $i$ éi: $\approx$ 'i $i$ i

๑. \& $i$ i 
1. The year's at the spring,

2. And day's at the morn;

3. Morning's at seven;

4. The hill-side's dew-pearled;

5. The lark's on the wing;

6. The snail's on the thorn;

7. God's in his heaven -

8. AII's right with the world.

R. Browning. :

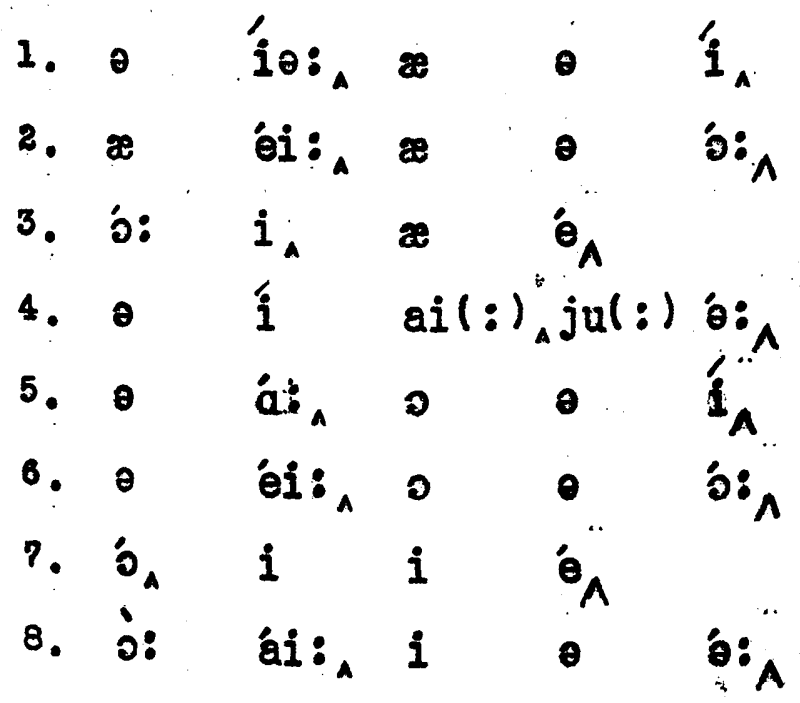


1. When the Present has latched its postern behind tremulous stay,

2. And the May month flaps its glad green leaves like wings,

3. Delicate-filmed as new-spun silk, will the neighbours say,

4. "He was a man who used to notice such things"?

$$
\begin{aligned}
& \text { "Afterwards" (v. } 1) \\
& \text { by T. Hardy. }
\end{aligned}
$$

\begin{tabular}{|c|c|c|c|c|c|c|c|c|c|}
\hline 1. $e$ & $\theta$ & $\dot{e}_{A}$ & $\boldsymbol{z}$ & 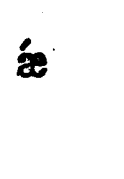 & $\begin{array}{l}i \\
\operatorname{ai}(:)\end{array}$ & $\begin{array}{l}\text { ou: } \\
6\end{array}$ & $\begin{array}{c}\bullet(:) \\
\dot{j u}(:)\end{array}$ & $\begin{array}{l}i(:) \\
\theta\end{array}$ & $\begin{array}{l}\text { ài: } \\
\text { éi: }\end{array}$ \\
\hline 2. $\approx$ & $\theta$ & êi: & A & $\dot{w}_{A}$ & $i$ & $\mathscr{m}$ & iे: & i: & $\begin{array}{l}a i(:) \\
i_{1}\end{array}$ \\
\hline 3. i & $\mathbf{i}$ & eil: & í & $\boldsymbol{x}$ & jü: & i & $\begin{array}{l}\hat{e}_{A} \\
\text { éi: }\end{array}$ & $\begin{array}{l}1 \\
\theta\end{array}$ & $\begin{array}{l}o \\
\text { éi: }\end{array}$ \\
\hline 4. i: & 3 & eil: & $\oiint_{A}$ & $\vec{u}(:)$ & ju: & $\mathbf{u}(:)$ & ou: & $i_{a}$ & $\begin{array}{l}\dot{i} \\
\dot{1}\end{array}$ \\
\hline
\end{tabular}


1. If it be in the dusk when, like an eyelid's soundless blink,

2. The dewfall-hawk comes crossing the shades to alight

3. Upon the wind-warped upland thorn, a gazer may think,

4. "To him this must have been a familiar sight."

"Afterwards" (v. 2)

by T. Hardy.

1. $i$ i i:

i

$\theta$

$\mathbf{\Lambda}$

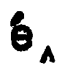

$\operatorname{ai}(:) \approx$

ál:

i áu: $\mathfrak{i}$

2. 2

jư: อ̀:

b: A 1 .

อ: $\quad$ i

$\theta$

êi: $\quad \dot{u}(:)$

$\dot{\otimes}$

ái :

3. 1 :

- 1 j:

a

$\approx$ \&:

oil : ) éi:

4. $\dot{u}(:)$

$i \quad i$

* $\quad \dot{i}(:)$ oi $\dot{\theta}(:) \dot{a}$

i

ei(:), î

$\dot{a}(:)$

ái: 
1. If I pass during some nocturnal blackness, mothy and warm,

2. When the hedgehog travels furtively over the lawn,

3. One may say, "He strove that such innocent creatures should come to no

4. But he could do little for them; and now he is gone," harm, "Afterwards" ( • 3) by T. Hardy.

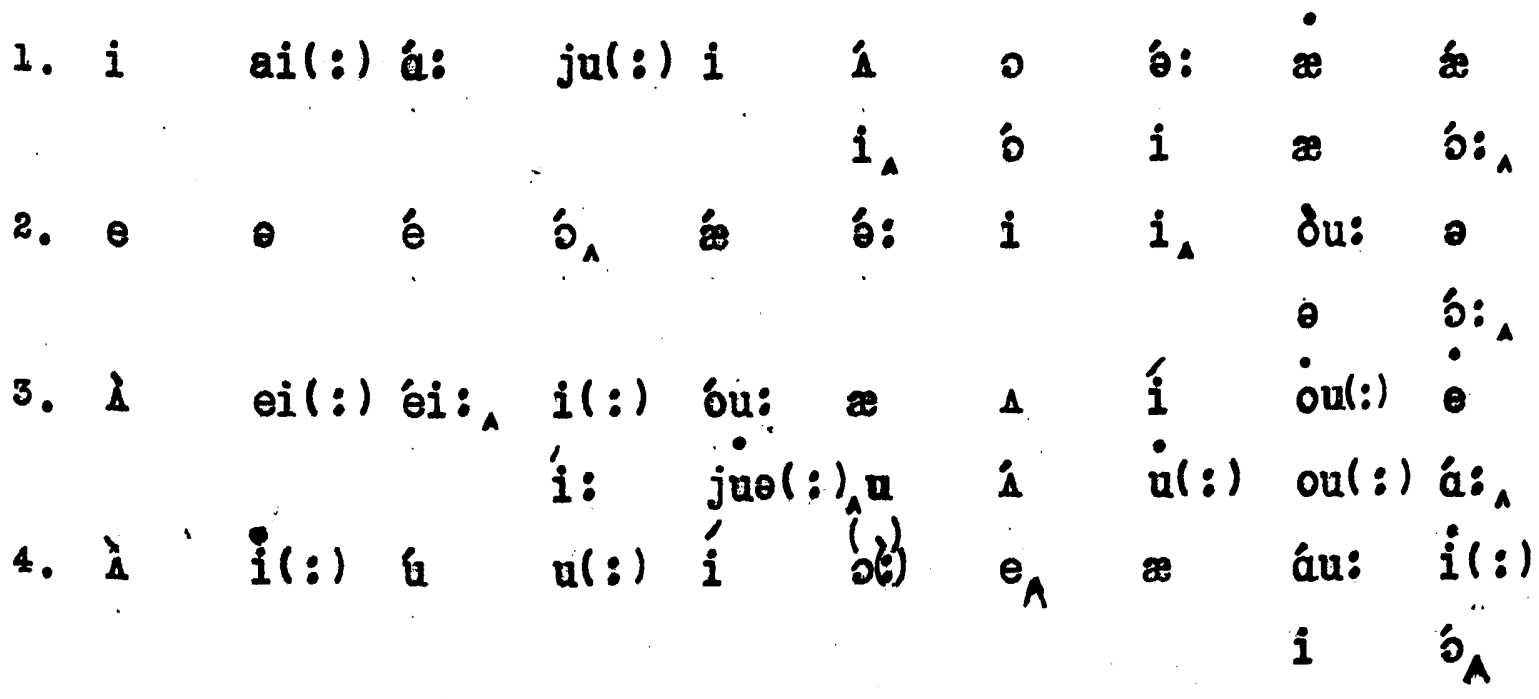


1. If, when hearing that I have been stilled at last, they stand

2. Watching the full-starred heavens that winter sees,

3. Will this thought rise on those who will meet my face no more,

4. "He was one who had an eye for such mysteries"?

$$
\begin{aligned}
& \text { "Afterwards" ( }(\nabla .4) \\
& \text { by T. Hardy. }
\end{aligned}
$$

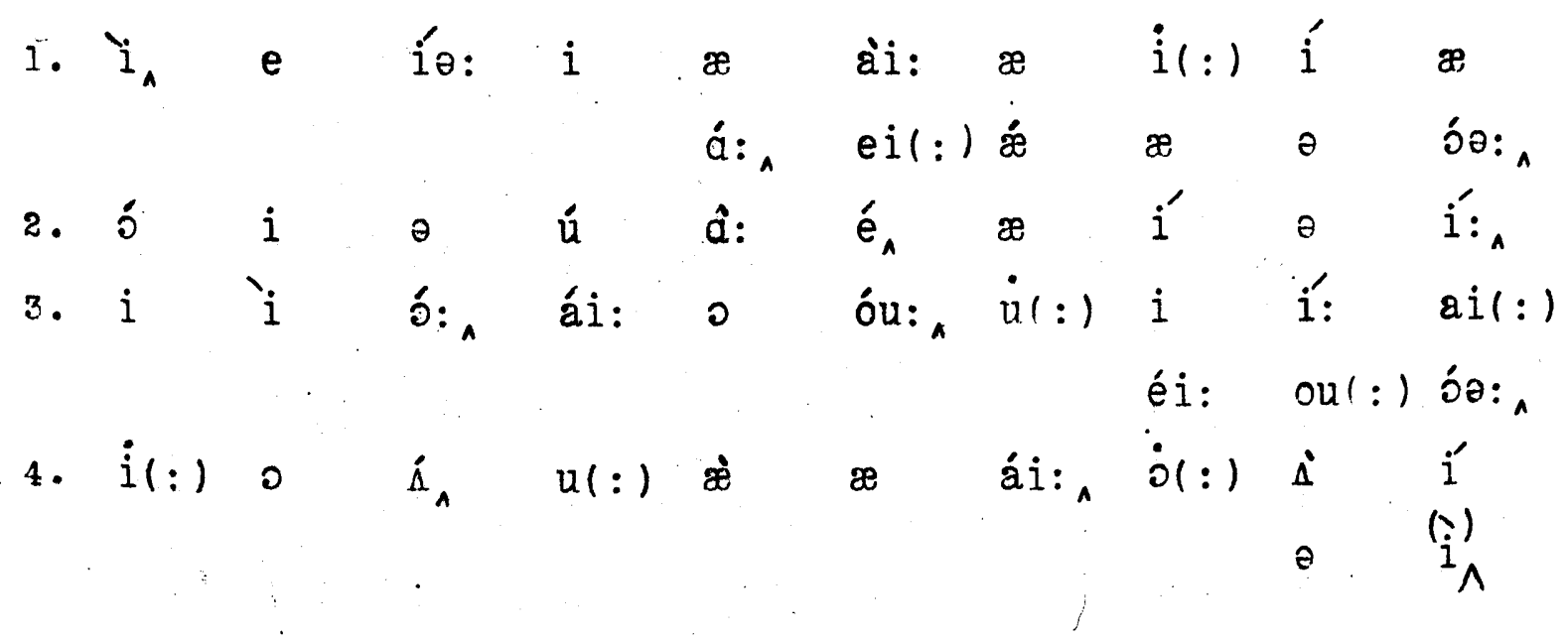


1. And will any say when my bell of quittance is heard in the gloom,

2. And a crossing breeze cuts a pause in its out-rollings,

3. Till they rise again, as they were a new bell's boom,

4. "He hears it not now, but used to notice such things"?

"Afterwardg" (v. 5)

by T. Hardy.

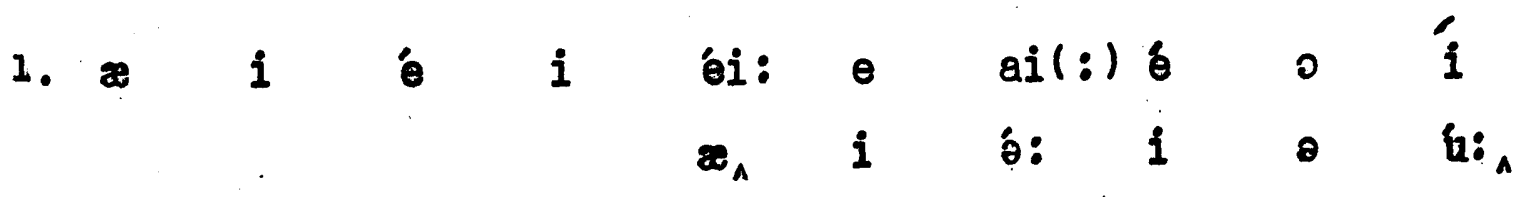

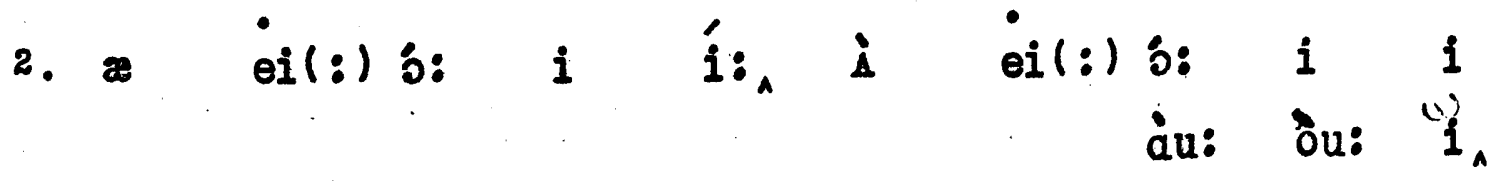

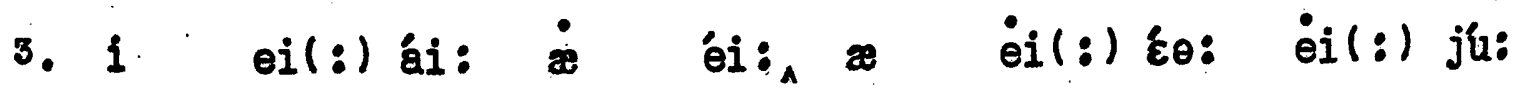

$e^{\circ} \quad$ u:

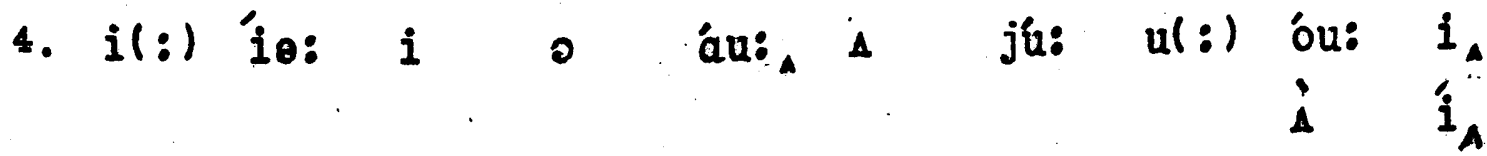


1. But though full noble is my theme,

2. Full urgent is my call

3. To soften sorrow, and forbid

4. The burgting tear to fall:

From "Resignation" Part I (p.55,v.I)

by E. Young.

1. 4 ou: í ou: ${ }_{\wedge} i$ ail : í:

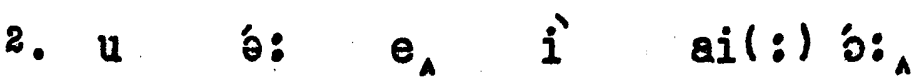

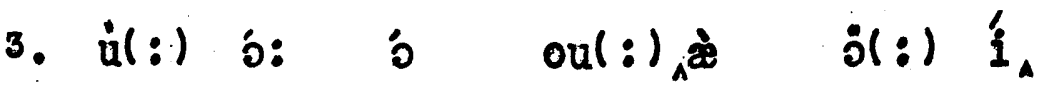

4. $\theta$ o: $i$ lio: $u(:)$ o: 
1. How proud the poet's billow swellst

2. The Godl the Godd his bosst:

3. A boest how vain! What wrecks abound!

4. Dead bards stench every cosst.

From "Resignation" Part I (p.55, v.3)

by E. Young.

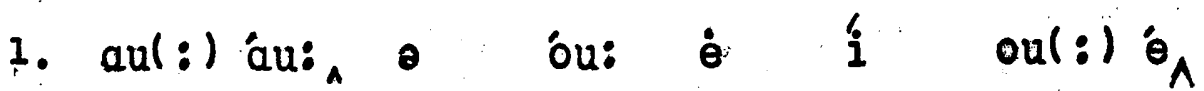

2. $\dot{b}_{\wedge} \cdot \theta \quad \dot{b}_{\wedge} i$ ou:

3. eil(:) ou: aul: $)$ éi: $:_{\wedge}$ é is áu:

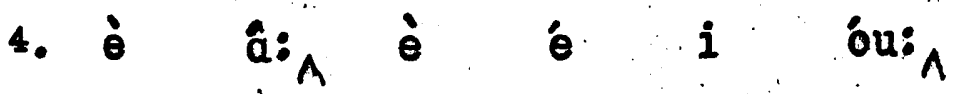


1. Wild rove the flocks, no burdening fleece they bear,

2. In fervid climes: Nature gives naught in vain.

3. Carmenian wool on the brosd tail alone

4. Resplendent swells, enormous in its growth:

5. As the sleek ram from green to green removes,

6. On alding wheels his heavy pride he draws,

7. And glad resigns it to the hatter's use.

From "The Fleece" Bk. II (p.67)

by J. Dyer.

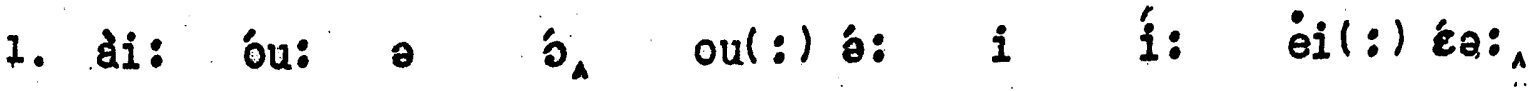

2. $i$ ó: $i$ áa: éi: jưl:lî̀ o: 1 éi:

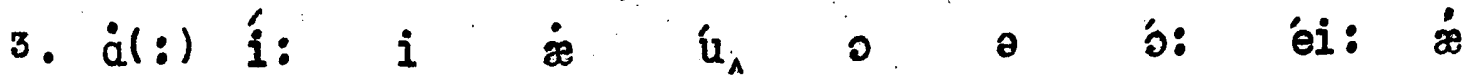

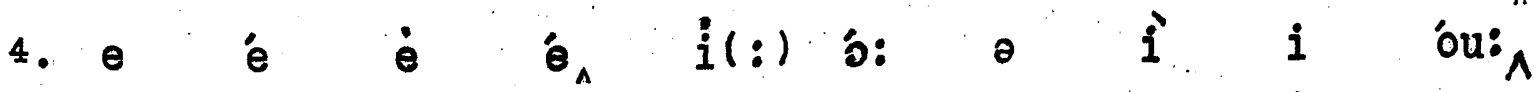

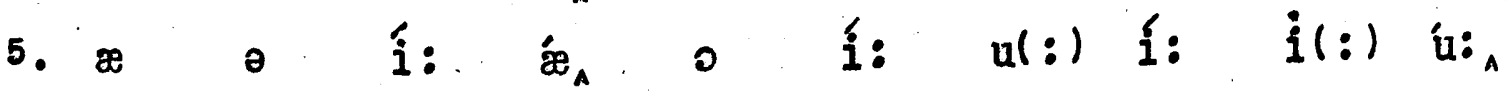

6. - ei: $i$ í $i$ é $i$ ái: $i(:)$ b:

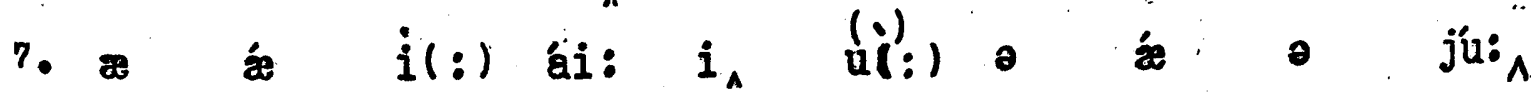


1. And have we lost another friend?

2. How aad the news to telld

3. Alas poor Mr. Yarker's gone -

4. Hark to the tolling belld

5. Alas! how many now drop off -

6. What numbers are unwell;

7. Another mortal borne away -

8. Hark to the tolling belld

"In Respectful Memory of Mir. Yarker" (\$.206) by J. Close.

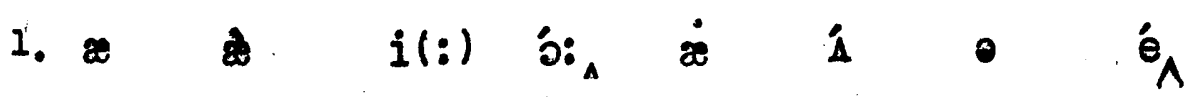

2. $q u(:) \dot{x}_{\Lambda}$ ə jü: $\dot{u}(:) \dot{e}_{\Lambda}$

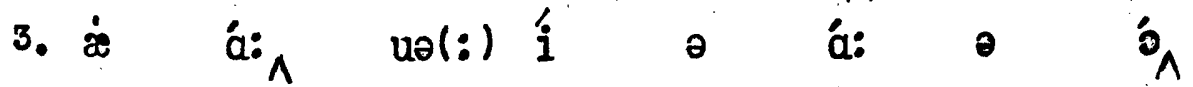

4. á: $u(:)$ ॰ ou: $i$ é,

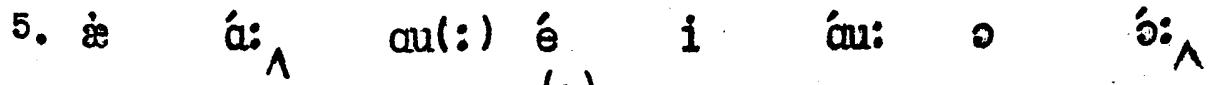

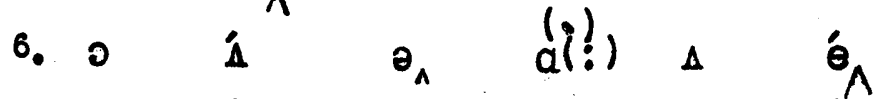

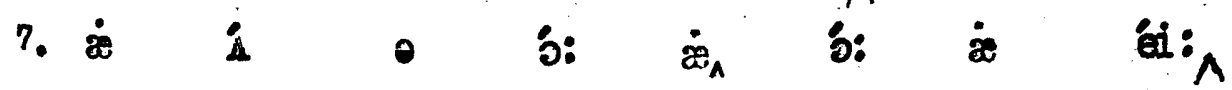

8. 'a: $u(:)$ ə ón: i $\dot{e}_{\wedge}$ 
1. And ere she left with tottling steps

2. The low-roofed cottage door,

3. The bettle and the cricket loved

4. The young child on the floor.

5. And every insect dwelt secure

6. Where little Eva played;

7. And piped for her its blithest song

8. When she in greenwood strayed.

9. With wing of gauze and mailèd coat

10. They gathered round her feet,

11. Rejoiced, as are all gladsome things,

12. A truthful soul to greet.

13. Whey taught her infant lips to sing

14. With them a hymn of praise,

15. The song that in the woods is heard

16. Through the long sumer days.

From "The Sinless Child" (p.161)

by E. Smith. 


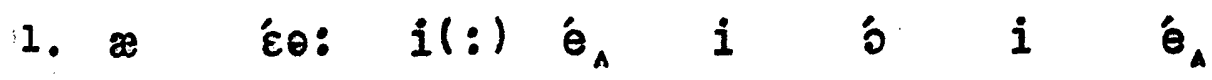

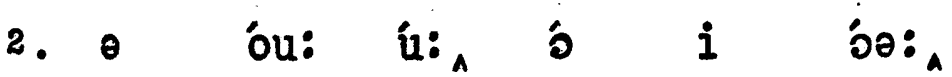

3. $\theta \quad i: ~ \gtrsim \quad \theta \quad i \quad i_{A} i_{A}$

4. $\partial$ I ái: 0 ค Do:

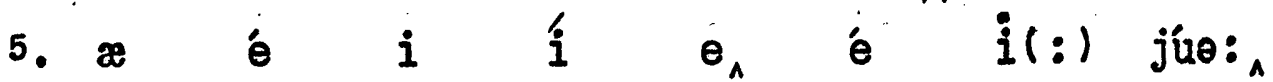

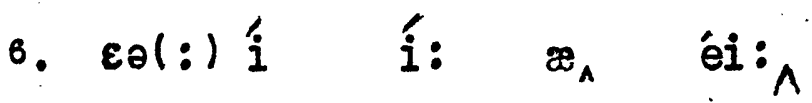

7. æ ái: $j(:)$ ó: $i$ ái: $i$ ó

8. e i: $i$ í ì. éi:

๑. $i$ i 0 ó: $¥$ éi: $i$ ou:

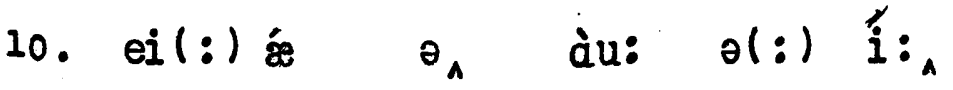

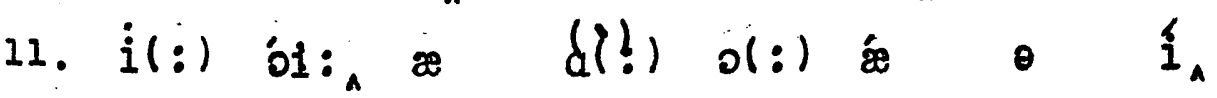

12. è(:) ú: iu ou: $u(:) \quad$ í

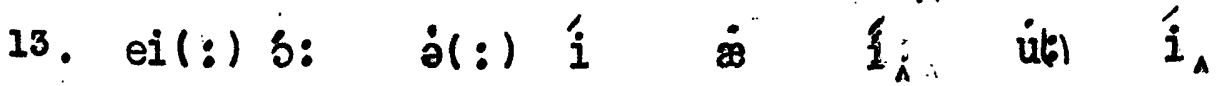

14. $i$ é éil : $)^{i}$ จ éi:A

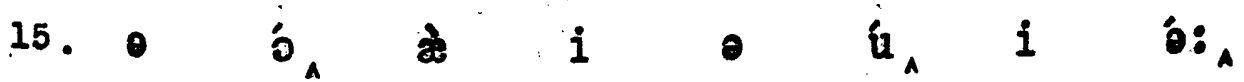

16. $u(:) \circ \dot{o}_{\wedge} i \quad \theta \quad$ ei $:_{\wedge}$ 
1. See, cherish'd by her sister, Peace,

2. She levies gain on every place,

3. Religion, habit, custom, tongue, and name.

4. Agrin she travels with the sun,

5. Again she draws a golden zone

6. Round earth and main, - bright zone of wealth and famel

From "Imperium Pelagi" (p.56, v.3)

by E. Young.

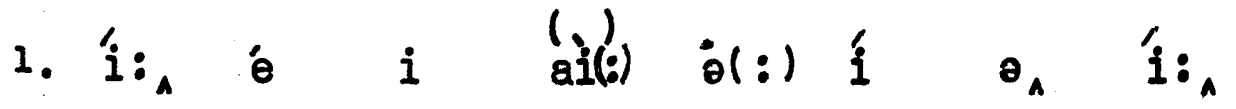

2. $i(:)$ é $i$ éi: ${ }_{\wedge} 0$ é $i$ éi:

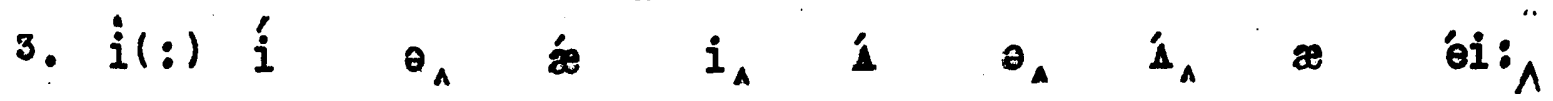

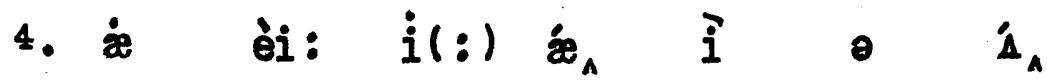

5. $\dot{x}$ èi: $\dot{i}(:)$ ó: eil(:) ou: $\theta$ ou:

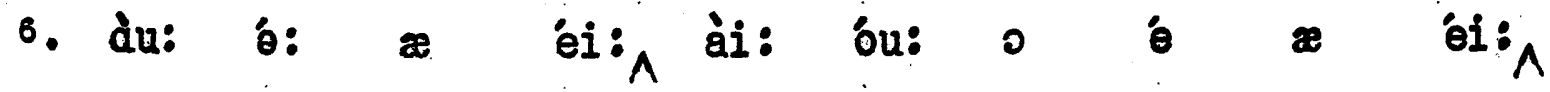


1. A brighter era is begun;

2. Our fame advances with the sun;

3. A virgin Senate blooms: her bosom heaves

4. With something great, with something new;

5. Something our god-like sires may view,

6 . And not abash'd shrink back into their graves.

From "The Foreign Address" (p.63, v.5)

by $E$. Young.

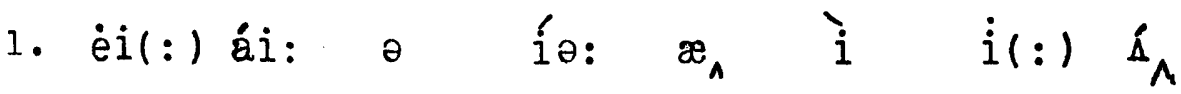

2. auv(:)éi: $\dot{\otimes}$ á: $i_{\wedge} \quad \grave{i} \quad \partial \quad \hat{A}_{\wedge}$

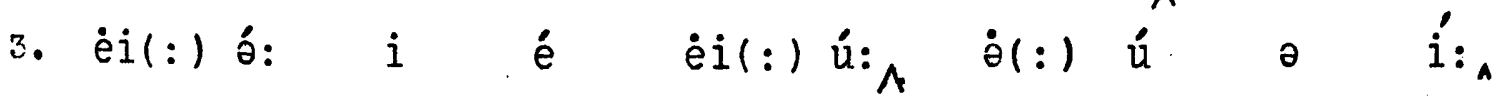

4. i $\quad$ i $i$ éi: $i$ Á $i$ jú:

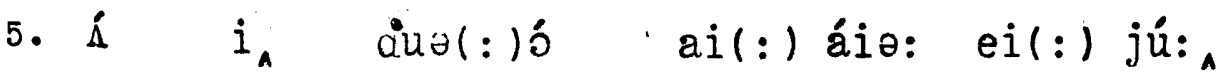

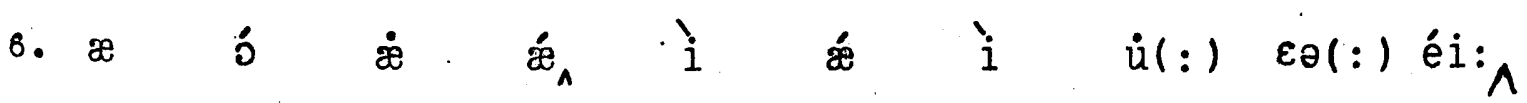


1. Oh, nol we never mention her,

2. Her name is nover heard;

3. My lips are now forbid to speak

4. That once familiar word;

5. From sport to sport they marry me

6. To banish my regret;

7. And when they win a smile from me

8. They think that I forget:

9. They bid me seek in change of scene

10. The charms that others see,

11. But were I in a foreign land

12. They'd find no change in me.

13. "is true that I behold no more

14. The valley where we met;

15. I do not see the, hawthorn tree,

16. But how can I forget?

17. They tell me she is happy now,

18. The gayest of the gay;

19. They hint that she's forgotten me,

20. But heed not what they say.

21. Like me, perhaps, she struggles with

22. Fach feeling of regret;

23. But if she loves as I have loved,

24. She never can forget.

"Oh, Nol We Never Mention Her" (p.157) by T.H. Bayly. 
1. ò: ou: 1 i(:) é $\theta$ é $\theta$ ó: 2. $\partial(\vdots)$ éi: $i$ é $\theta$ ó:A

3. $a i(:) i_{\wedge} a(:)$ au: $j(:) i^{\wedge} u(:)$ i:

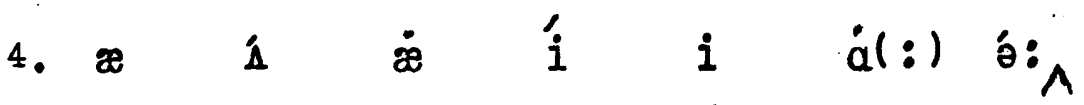

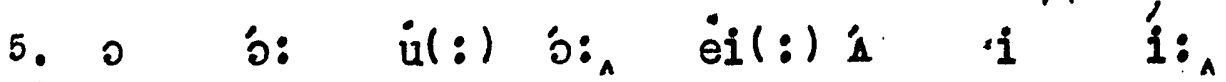
6. $i(:) \stackrel{x}{i} i_{A}$ ài: $i(:) \dot{\theta}_{\wedge}$

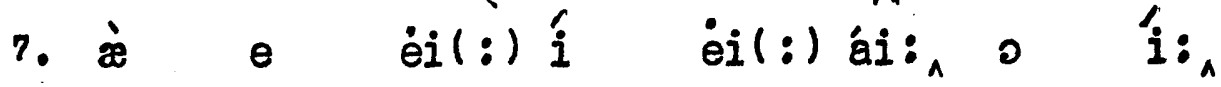
8. èi(:) $\dot{i}_{\wedge}$ \& ái: $\dot{o}(:) e_{\wedge}$ 9. èi(:) $i$ i(:) $\mathfrak{i}_{\wedge} \quad i \quad$ éi: 0 'i:

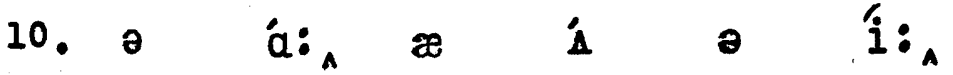

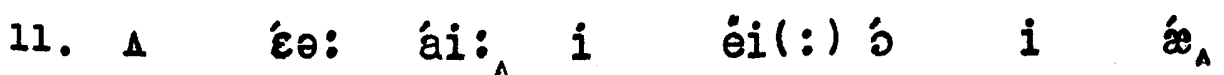
12. ei(:) ái: òu: éi: $i$ í 13. $i$ ú: $¥$ ài: $i(:)$ ou: ou: oo: 14. $\theta$ \& $i_{A} \varepsilon \theta: i(:) \dot{e}_{\wedge}$ 15. $\operatorname{ail}(:)$ ù: 0 i: ${ }_{\wedge}$ o

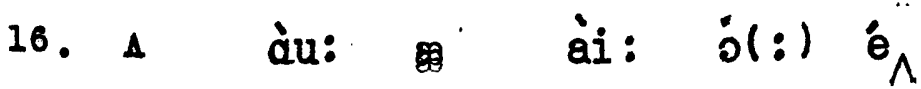
17. èi(:) é $i(:)$ Á $i$ æ $i$ áu: 18. éi: $i_{\wedge} \dot{0} \diamond$ éi:A 19. $\dot{e} i(:) \hat{i}_{\wedge}$ \& $\hat{i}:$ jl: $)$ 20. $\Delta$ í o, ó èi(:) éi:

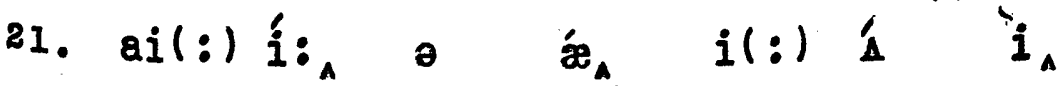
22. i: i: $\left.i_{\wedge} \quad f^{\circ}\right) \quad i(:) e_{\wedge}$

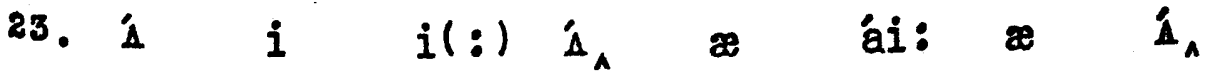

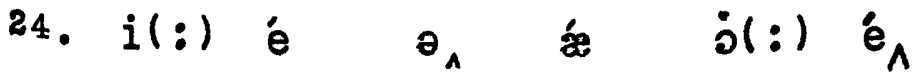


1. Many a lip is gaping for drink,

2. And mady calling for rain

3. And some hot brains are beginning to think

4. Of a messmate's opened vein.

From "Song of the Sea-Weed" (p.191) by E. Cook.

\begin{tabular}{|c|c|c|c|c|c|c|c|}
\hline 1. $\dot{\theta}$ & $\mathbf{i}$ & $\ddot{e i}(:)$ & $\mathfrak{i}_{\Lambda}$. & $i$ & éi: & $i$ & $\dot{\partial}(:)$ \\
\hline 2. æ & జ́ & $\mathbf{i}$ & ó: & $i_{A}$ & $\dot{b}(:)$ & éi:A & \\
\hline & Á & 3 & ei: & $\dot{a}(:)$ & $\dot{I}(:)$ & $\dot{1}$ & $\mathbf{i}$ \\
\hline & èil(:) & $\dot{\theta}$ & ei $(:)$ & & ? & $\ddot{e} i_{\lambda}$ & \\
\hline
\end{tabular}


1. Carrie's age was twenty-three,

2. A married lady, too, was she -

3. A mournful partine had to be,

4. From Carrie Honro.

5. It's just before her spirit fled

6. Her husband stood by her bed;

7. "Prove faithful, birdie, to me," said

8. Sweet Carrie Monro.

"Carrie Nonro" (p.223)

by J. Mloore.

1. 囟 1 éi: 0 é $i$ i:

2. èi(:) ǽ $i$ éi: $i_{\wedge} \quad$ ú: $_{\wedge}$

- ín

3. èi(:) ó: $\dot{u}$ á: $i \quad$ 囟 $u(:)$ i:

4. 0 ஐ $i \quad$ o ou: $\wedge$

5. $i$ i $\quad \dot{i}(:)$ อə: $\dot{\theta}(:)$ i $\quad i_{\wedge} \dot{\theta}_{\wedge}$

6. $\dot{\theta}(:) \quad i \quad \dot{u_{A}}$ áll:) $\dot{\partial}(:) \quad \dot{e}_{\wedge}$

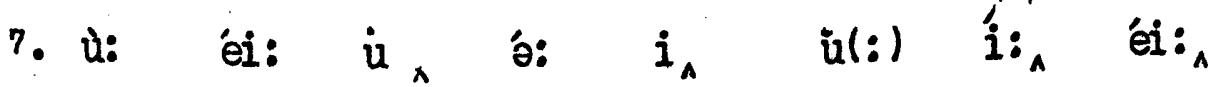

8. í 甶 $i$ A óu: 
1. While eating dinner, this dear little child

2. Was choked on a piece of beef.

3. Doctors came, tried their skill awhile

4. But none could give relief ....

5. Her friends and schoolmates will not forget

6. Iittle Iibbie that is no more;

7. She is waitine on the shining step,

8. To welcome home friends once more.

"Iittle Libbie" (p.223)

by $\mathrm{J}$. Moore.

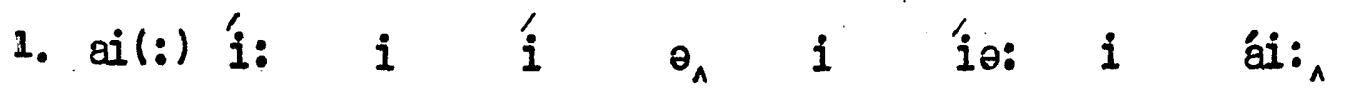

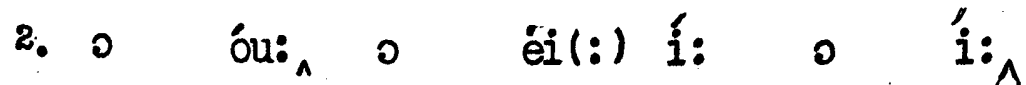

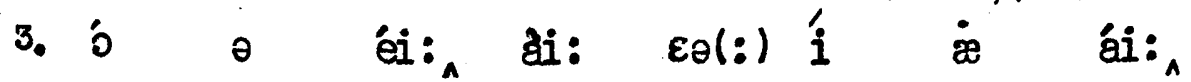

4. $\Lambda$ i $i_{\wedge}$ u $i \quad \dot{i}(:)$ i:

5. $\dot{\theta}(:)$ é $¥ \quad$ ú $\quad$ ei(:) $i \quad j \quad j(:) \quad \dot{\theta}_{A}$

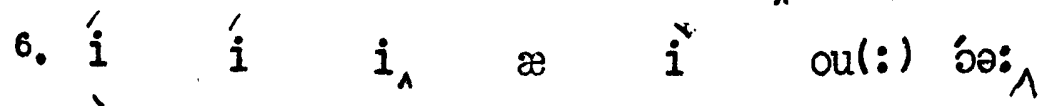

7. i: $i$ éi: $i_{A} \quad 3 \quad \partial \quad$ ái: $i \quad e_{\wedge}$

8. $\dot{u}(:)$ é $\partial_{\wedge}$ du: é $\&$ วo: 
1. As yowns an earthquake, when imprison'd air

2. Struggles for vent, and lays the centre bare,

3. The whale extends his jaws' enormous size;

4. The Prophet views the cavern with surprise;

5. Measures his monstrous teeth, afar descried,

6. And rolls his wond'ring eyes from side to side:

7. Then takes possession of the spacious seat,

8. And sails secure within the dark retreat.

From "The Last Day" (p.55)

by E. Youns.

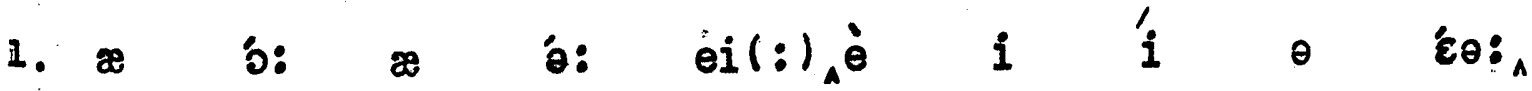

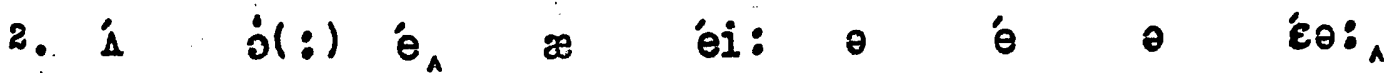

3. $\theta$ éi: $\dot{\theta}$ é $\dot{\theta}_{A} i$ o: $i(:)$ o: $\theta$ á

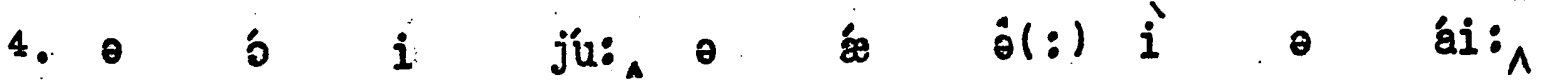

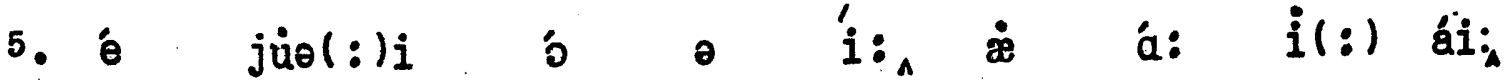

6. $¥$ ou: $i$ i $i$ ái: 0 ái: $u(:)$ ái:

7. o éi: oul:) é $\theta_{A}$ o. $\theta$ éi: $\theta$ i:

8. $x$ éi: $\dot{i}(:)$ jua: $i$ i $\theta$ a: $i(:) \stackrel{i}{i} \wedge$ 
1. Minnie Mray Houge she had to go,

2. And leave her friends that loved her so -

3. She was a girl in her teens,

4. As lovely a flower as e'or was seen.

William House and Family" (p.222)

by J. Moore.

1. '́ $i$ èi: áu: $\mathfrak{A}(:)$ æo ùl: $)$ ou:,

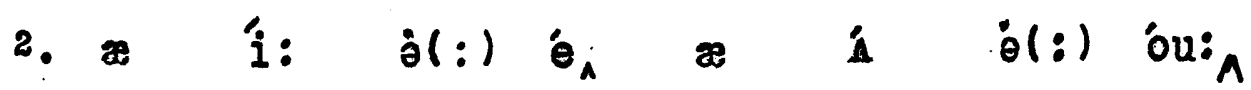

3. ì จ eil(:) á:

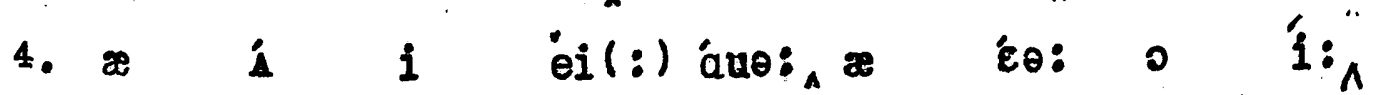


1. Wide around

2. Hillock and valley, farm and village, smile:

3. And ruddy roofs and chimney-tops appear,

4. Of busy Leeds, up-wafting to the clouds

5. The incense of thanksgiving: all is joy;

6. And trade and business guide the living scene ....

7. Io, in throngs,

8. For every realm, the careful factors meet,

9. Whispering each other. In long ranks the bales,

10. Like war's bright files, beyond the sight extend,

11. Straight, ere the sounding bell the signal strikes,

12. Which ends the hour of traffic, they conclude

13. The speedy compect; and, well-pleas'd, transfer

14. With mutual benefit, superior wealth

15. To many a kingdom's rent, or tyrant's hoard.

From "The Fleece" Bk.III (p.68)

by J. Drer. 
1. ái: $\dot{x}$ áu:

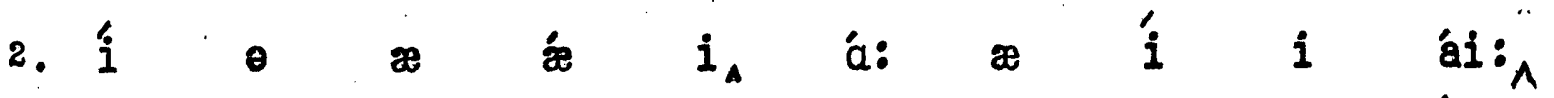

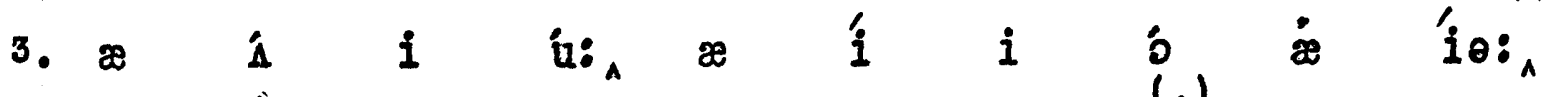

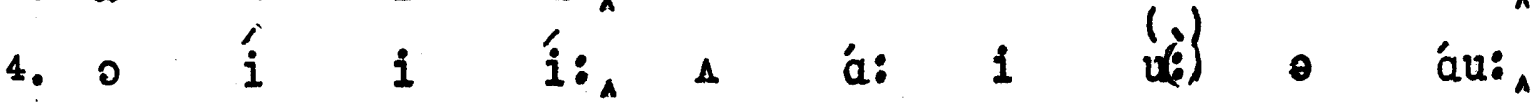

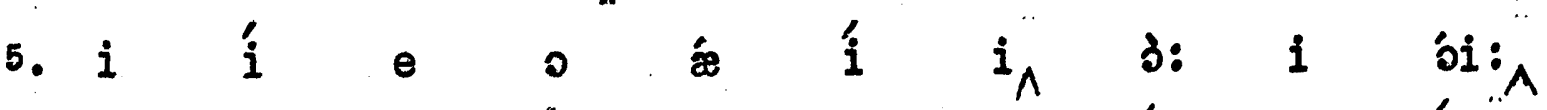

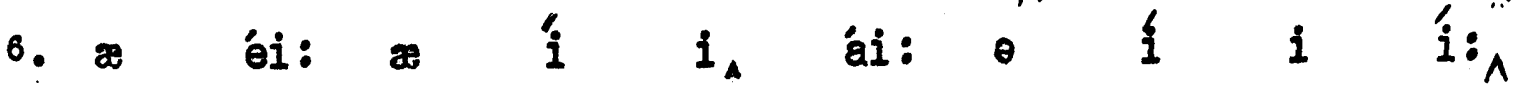
7. ou: $i$ ว́

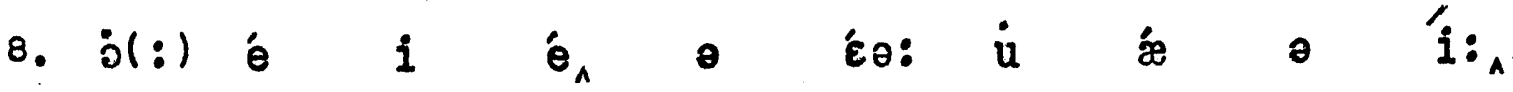

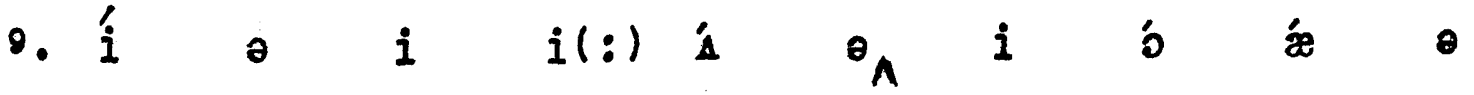
éi: 10. ail:) ó: ài: ái: ${ }_{\wedge} \dot{i}(:)$ j o ái: $\dot{e} \quad \dot{e}_{\wedge}$ 11. éi: $\varepsilon \theta(:)$ ə áu: $i$ e $\theta$ l $\dot{x}$ ai:

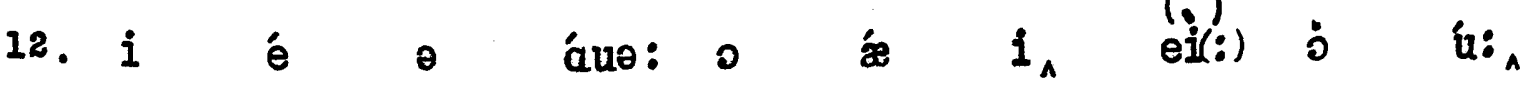

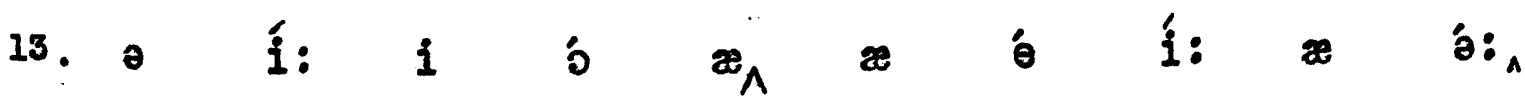

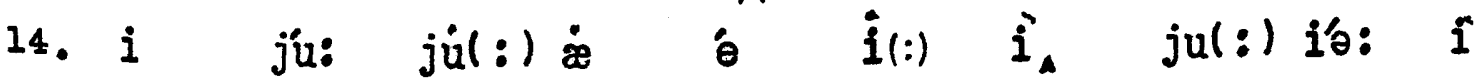
o $\dot{\theta}_{\Lambda}$

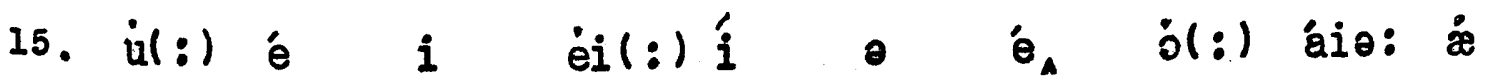
is 
1. O sympathy, of birth divine,

2. Descend, and round my heart-strings twine!

3. Touch the fine nerve, whene'er I breathe

4. Where Della Crusca dropt his wreath:

5. Iead me the sacred way of Rome,

6. Iead me to kneel at Virgil's tomb,

7. Where he th'enduring marble round

8. With fresh-wove laurels, graceful bound.

9. Then guide where still with sweeter note

10. Than flowed from Petrarch's tuneful throat,

11. On Laura's grave he poured the lay

12. Amidat the sighs of sinking day:

13. Then point where on the sod his tear

14. Fell from its crystal source so clear,

15. That there my mingling tear may sink,

16. And the same dust its moisture drink.

From "To Delle Crusce" (p.112) by H. Cowley. 
1. oul: $)^{\hat{i}} \quad \dot{x} \quad \grave{i}_{A} \quad 0 \quad$ ó: $\quad \dot{i}(:)$ ái:

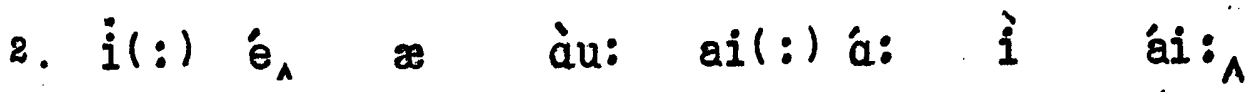

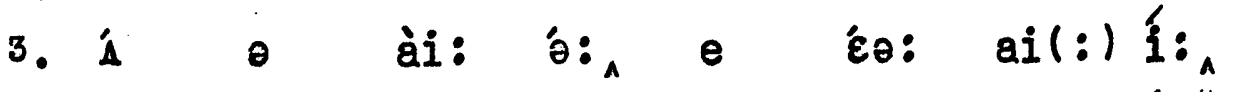

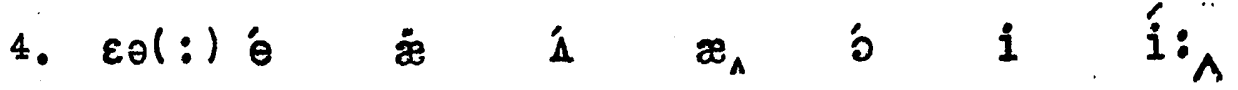

5. 'i: $i: \wedge$ a éi: $i$ éi: 0 ou:

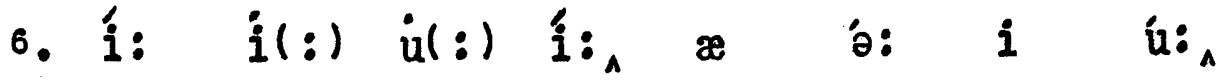

7. $\left.\varepsilon_{\theta}(:)\right)^{i}:_{\wedge}$ è jü: $i$ á: áu:

8. $i$ é òu ́o $\dot{\theta}_{\wedge}$ éi: $\dot{u}$ áu:

๑. e ái: $\varepsilon \partial(:) l_{\wedge} i$ i: $\theta$ ou:

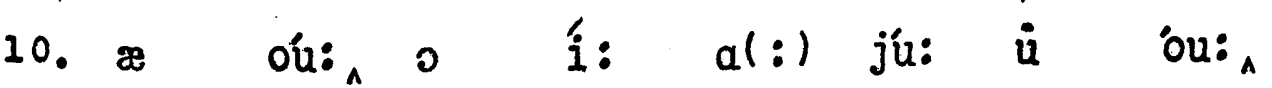

11. ○ o: $\dot{x}$ éi: $i(:)$ óa: ə éi:A

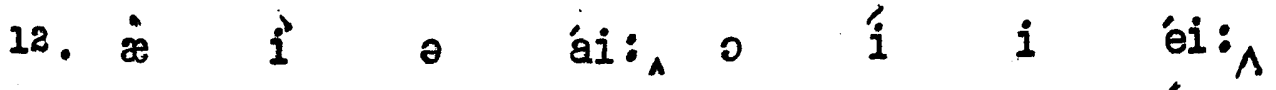

13. e ó1: $\varepsilon_{\theta}$ : 0 o o $i$ í:

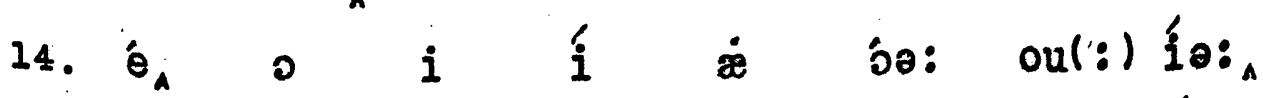

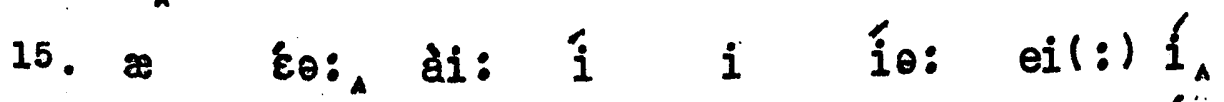

16. $\approx$ o éi: $i_{\wedge} i$ si: jül: $)_{\wedge}^{\prime \prime}$ 
1. Ohl what's the matter? what's the matter?

2. What is't that ails young Harry Gill?

3. That evermore his teeth they chatter,

4. Chatter, chatter, chatter, stilld

5. Of waistcoats Harry has no lack,

6. Good duffle grey, and flamel fine;

7. He has a blanket on his beck,

8. And coats enough to smother nine.

9. In March, December, and in July,

10. 'Tis all the same with Harry Gill:

11. The neighbours tell, and tell you truly,

12. His teeth they chatter, chatter still.

13. At night, at moming, and at noon,

14. 'Tis all the same with Harry Gill;

15. Beneath the sun, beneath the moon,

16. His teeth they chatter, chatter still.

From "Goody Blake and Harry Gill"(p.134 by W. Wordaworth. 


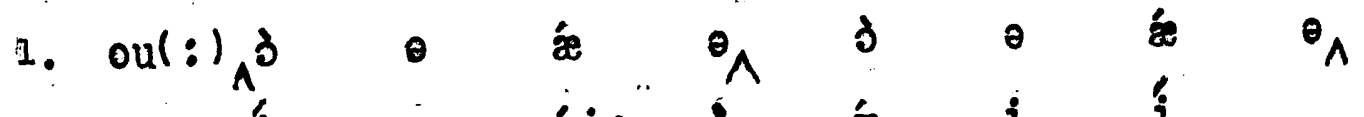

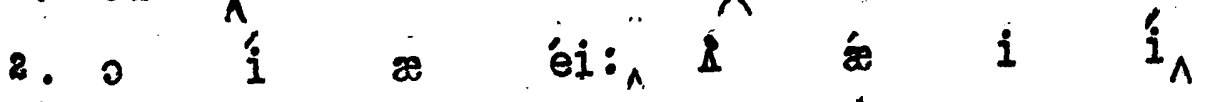

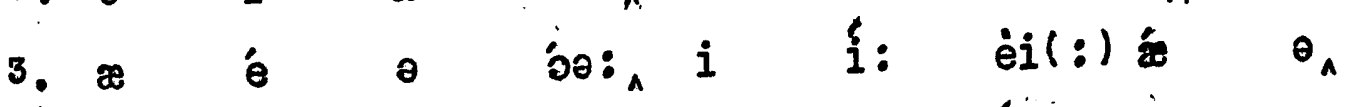

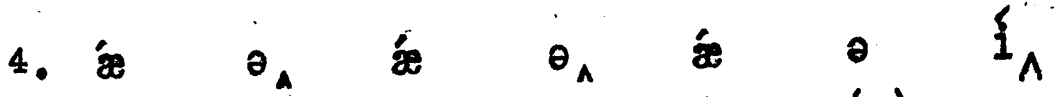

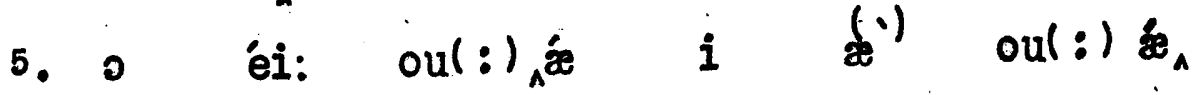

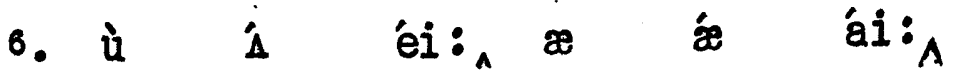

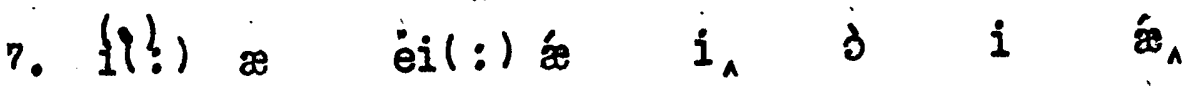

8. \& ou: $i(:) \dot{A}_{A} \quad u(:)$ i $\theta$ ái:

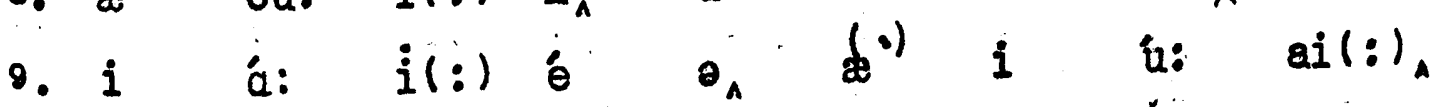

10. $i$ j: $\theta$ éi: $i$ \& $i \quad i_{A}$

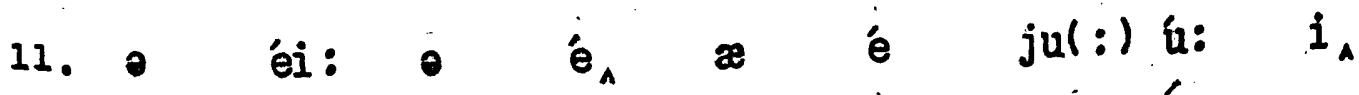

22. i

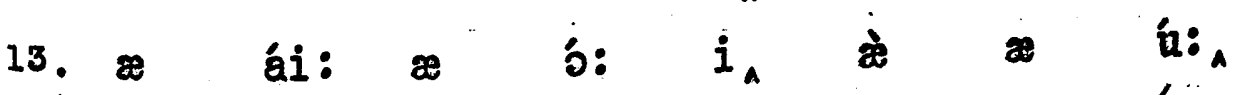

14. $i$ 3: $\theta$ éi $i$ \& $i \quad i_{\wedge}$

15. $i(:) \quad i:$ o $i_{\wedge} i(:) \quad i:$ o $i: \wedge$,

16. $i$ i: $\dot{e} i(:)$ 安 $\theta_{\wedge}$ \& 
1. Iife scums the cream of Beauty with Time's spoon,

2. And draws the claret-wine of Blushes soon;

3. Then boils it in a skillet clean of Youth,

4. And thicks it well with crumbled bread of routh;

5. Sets it upon the fire of life which does

6. Burn clearer much when Health her bellows blows;

7. Then takes the eggs of fair and bashful tyos,

8. And puts them in a countenance that's wise,

9. Cuts in a lemon of the sharpest Wit -

10. Discretion as a knife is used for it -

11. A handful of chaste Thoughts, double refined,

12. Six spoonfuls of a noble and gentle Mind,

13. A grain of Mirth to give it a little taste,

14. Then takes it off for feer the substance waste,

15. And puts it in a basin of good Health,

16. And with this meat doth Nature please herself.

"A Posset for Nature's Breakfast" (p.18) by Margaret Cavendieh, Duchess of Newcrstie. 


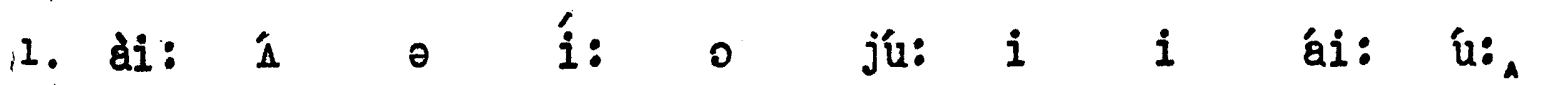

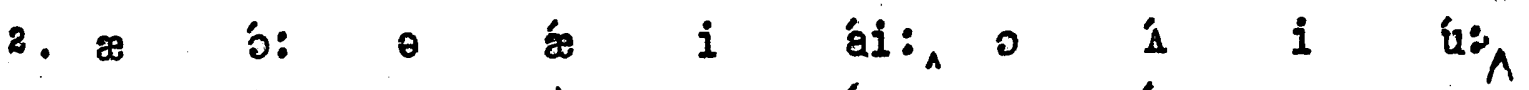

3. e ói: $i_{\wedge} \quad \grave{i}$ eil: $)^{\prime} i$ i $i:$ jú,

4. z $\begin{array}{llllllll}i & i & e_{A} & i & \dot{A} & e & 0 & u\end{array}$

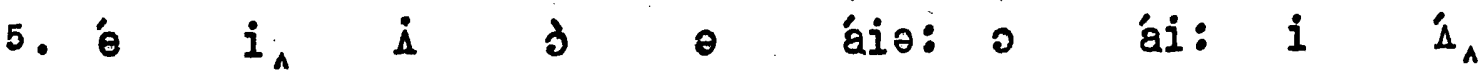

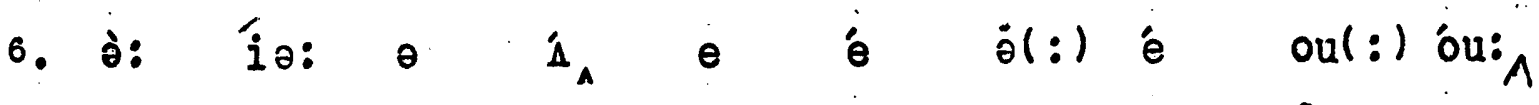

7. $\theta$ éi:

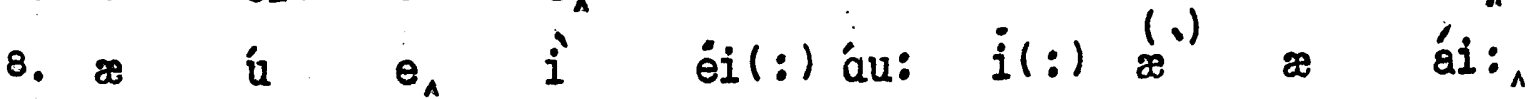

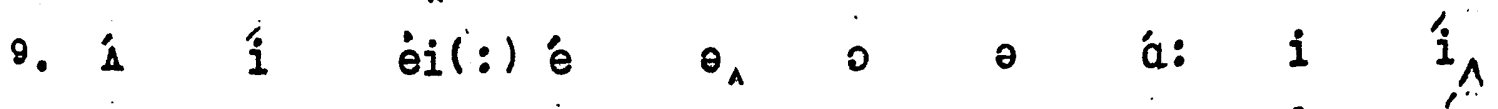

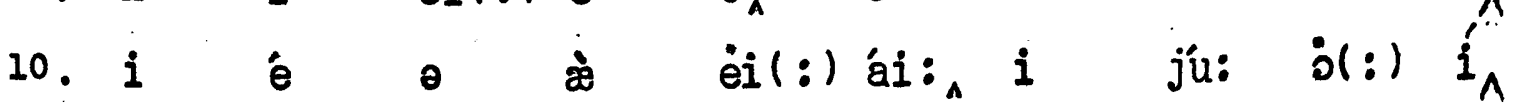

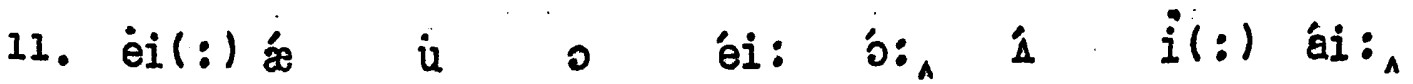

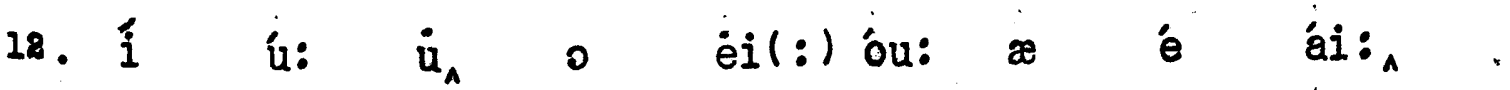

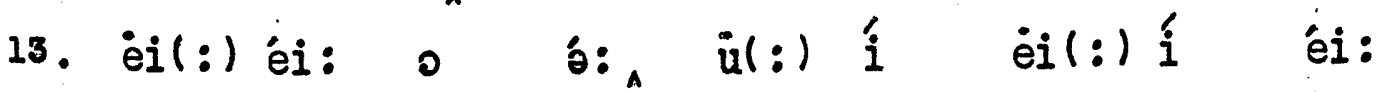

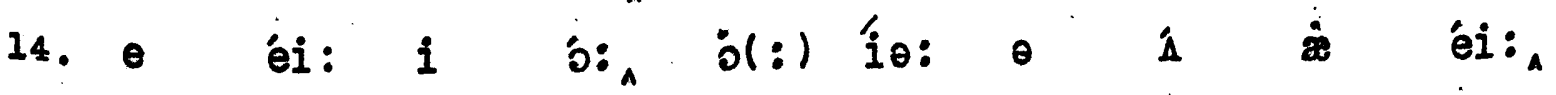

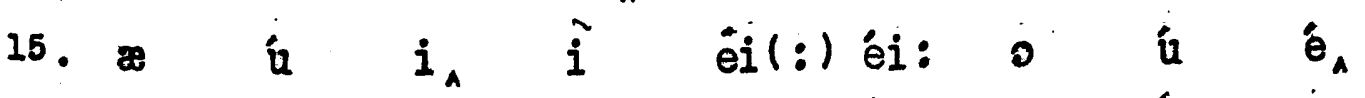

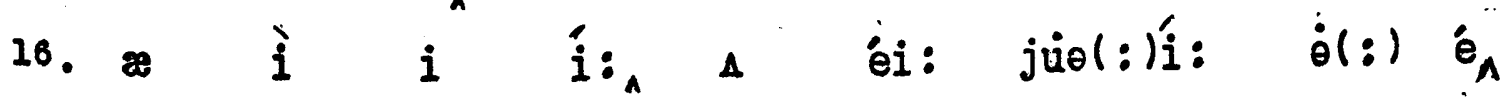


1. Heaven was impatient of our crimes,

2. And sent his minister of death

3. To scourge the bold rebellion of the times,

4. And to demand our prophet's breath;

5. He cane commissioned for the fates

6. Of awful liead and charming Bates;

7. There he essayed the vengeance first,

8. Then took a dismal aim, and brought great Gouge to dust.

From "An Elegy on Mr. Thomas Gougen(12.39.) by I. latts.

1. é

- i éi: $\dot{e}_{\wedge}$

d aù(: )ái:

2. æ

e $i$

i

(.)

i

2 0

$\hat{\theta}_{A}$

3. $\dot{\mathrm{u}}(:)$ 手:

o ó: $\dot{i}(:)$ é

$\theta_{\wedge}$

ว

$\theta$

ái:

4.

ul :

i(::) á:

àur : )'

5. i(:) éi:

i

(a)

i

ə

ə

é

6. 0

ว:

u. í:

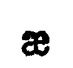

á: $i$

éi:

7. غə: $i(:)$ e

éi:

é

$\dot{\infty}$

éi :

8. $\theta$

u $\quad \dot{i}(:) \dot{i}$

$\ddot{\gtrless}$

éi: $\approx$

อ́

o: èi: ú: $\dot{u}(:) \quad \Delta_{A}$ 
1. 0 could I sing as you have fought,

2. I'd raise a monument of thought,

3. Bright as the sun! - How you burn at heart

4. How the drums all around

5. Soul-rousing resound!

6. Swift drawn from the thigh

7. How the swords flame on hight

8. . How the cannon, deep knell,

9. Fates of kingdoms foretelld

10. How to battle, to battle, sick offeminine art,

11. How to battle, to conquest, to glory, we dart?

From "The Foreign Address" (p.64) by E. Young.

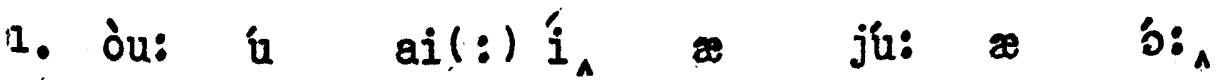

2. ai(:) éi: eil(:) b ju(:) bl 0 b:

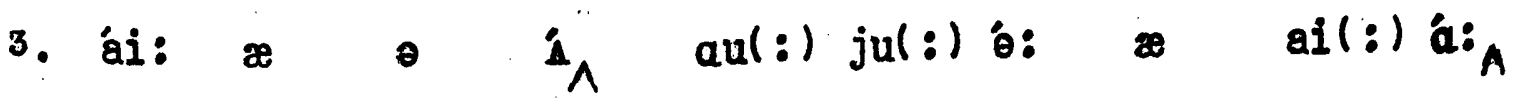

4. $a u(:)$ o $\Delta_{\wedge}$ ol: $) \dot{z}$ au:

5. òu áu: $i_{\wedge} \quad \dot{i}(:)$ áu:

6. i ว:

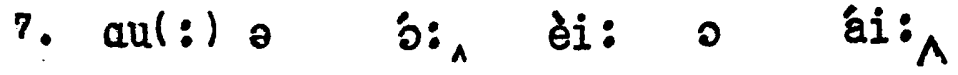

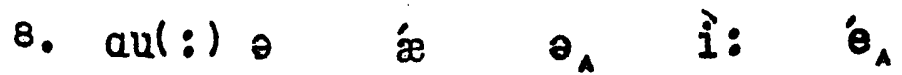

- èi: 0 i $\theta_{A} \quad \dot{\nu}_{\theta}(:) \dot{e}_{\wedge}$

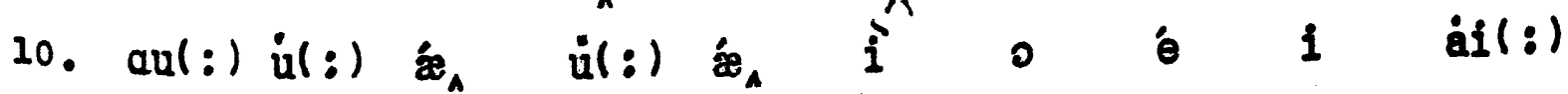

11. $a u(:) \dot{u}(:) \dot{m}_{A} \quad \dot{u}(:)$ o $e_{A} \quad \dot{u}(:)$ b: 1 il: 
1. I dwelt alone

2. In a world of man,

3. And ny soul was a stagnant tide,

4. Till the fair and gentle Bulalie became my blushing bride -

5. Till the yellow-haired young Eulalie became w smiling bride.

6. Ah less - less bright

7. The stars of the night

8. Than the eyes of the radiant girl!

9. And never a flake

10. That the vapour can make

11. With the moon-tints of purple and pearl,

12. Can view with the modest Enlalie's most unregarded curl -

13. Can compare with the bright-eyed Bulalie's most humble and careless curl.

14.

15.

16.

17.

18.

19.

20 .

2l.

Now Doubt - now Pain

Come never again,

For her soul gives me sigh for sigh,

And all the day long

Shines bright and strong

Astarte within the sky,

While ever to her dear Frialie upturns her matron eye -

While ever to her young Bulalie upturns her violet eye.

"Bulalie" (p.172)

by E.A. Poe. 
1. ail: $)^{\prime} e_{\wedge} \dot{\mathscr{E}}$ ou:

2. $i \quad \dot{e} i(:)$ á: o ou:

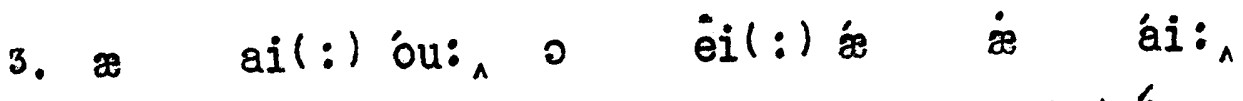

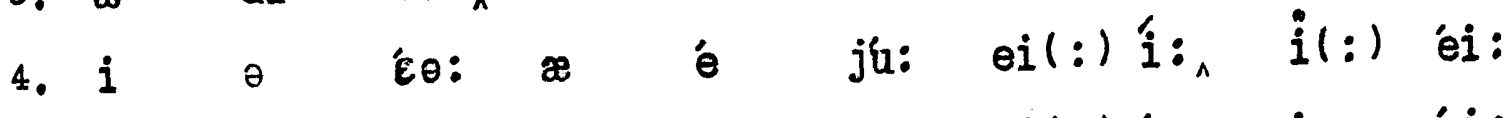

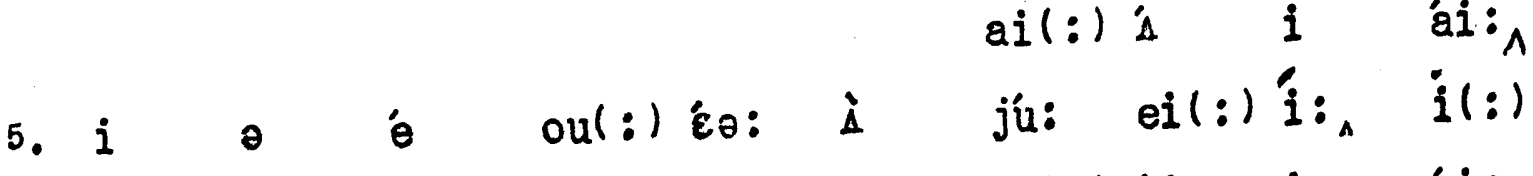
éi: ail:) ái: $i$ ái :

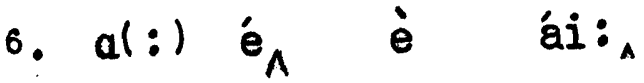

7. $\theta \quad a:{ }_{A} \quad 0 \quad \theta \quad a i:_{\wedge}$

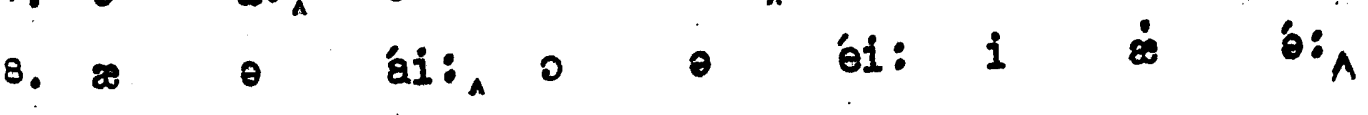

9. æ é $\theta_{\wedge}$ eil: $)$ éi:

10. $\approx$ ค éi: $\theta_{\wedge} \approx$ éi:

11. $i$ o ú $\hat{i}_{a} \quad 0$ a: $\approx$ ó

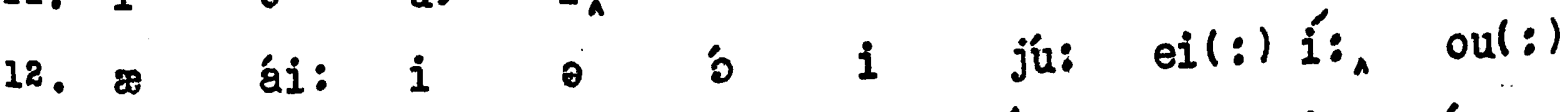

i $i(:)$ á: $i$ á:

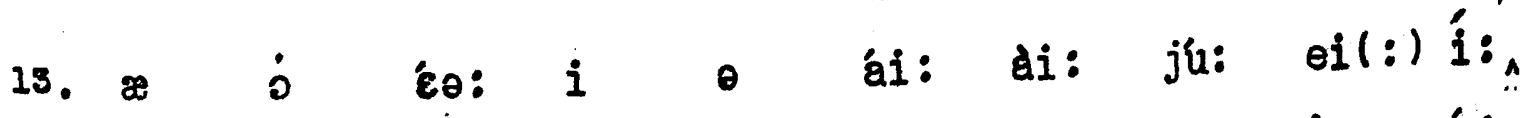

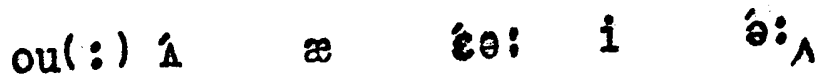

14. $a u(:)$ au: $a$ aul : ) éi:

15. $\Delta$ é $\theta_{\wedge} \dot{z}$ é $i:_{\wedge}$

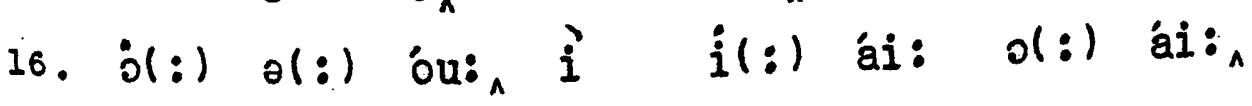

17. $¥$ bे

18. ài: ái: $æ$ ’

19: æ á: $i_{\wedge} i$ i $\quad$ a ai:

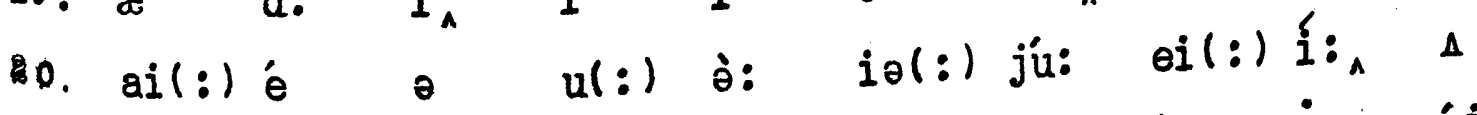

ó: $\theta(:)$ éi: j ái:

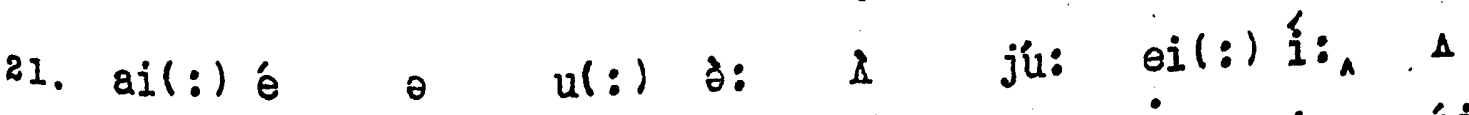

a: $(:)$ ái: oul: $i$ ái: 
1. I'd be a Butterfly born in a bower,

2. Where roses and lilies and violets meet;

3. Roving for ever from flower to flower,

4. And kissing all buds that are pretty and sweet:

5. I'd never languish for wealth, or for power;

6. I'd never sigh to see slaves at my feet:

7. I'd be a Butterfly born in a bower

8. Kissins all buds that are pretty and sweet ....

9. What, though you tell me each gay little rover

10. Shrinks from the breath of the first auturn day ?

11. Surely 'tis better, when sumer is over,

12. To die when all fair things are fading away.

13. Some in life's winter may toil to discover

14. Leans of procuring a weary delay -

15. I'd be a Butterfly; living, a rover,

16. Dying when fair things are fading away.

"I'd be a Butterfly" (p.159)

by T.H. Bayly. 


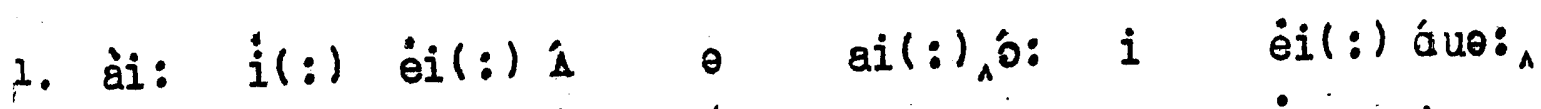

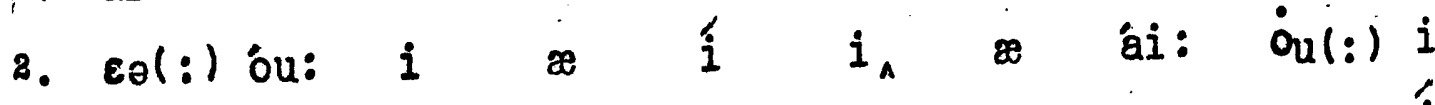
i:

3. ou: $i$ $\dot{b}(:)$ é $\theta_{A} \quad 0$ áue: $u(:)$ áue:

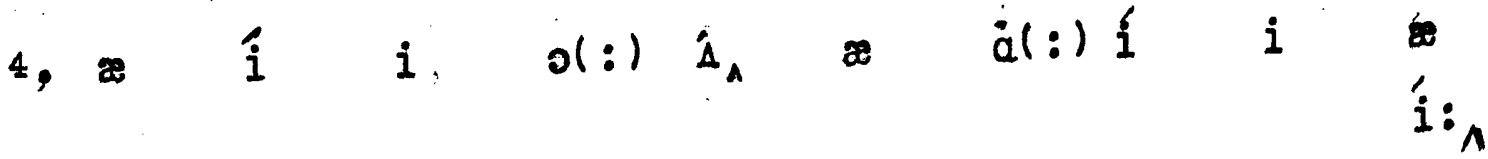

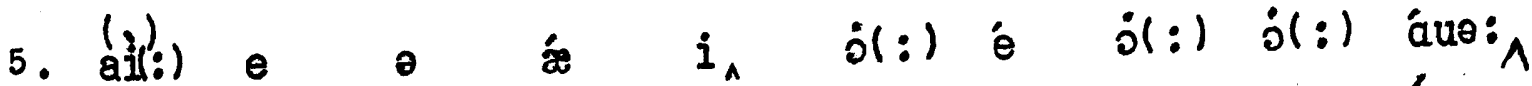

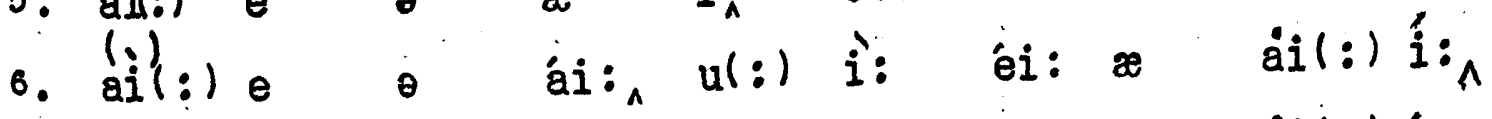

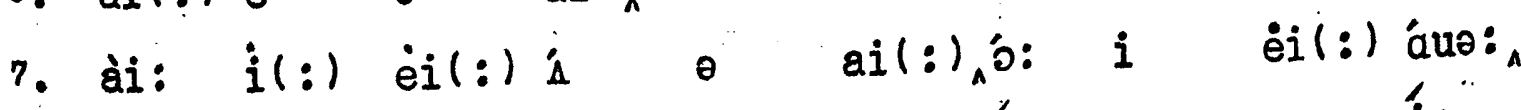

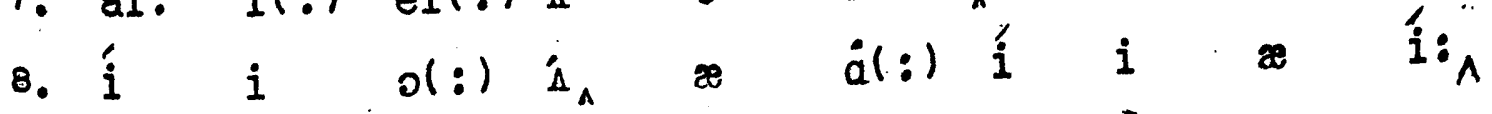
จ. Ó oul: jul: $)_{\text {é }} i(:)_{A} i(:)$ éi: $i$ ou: $\theta_{A}$

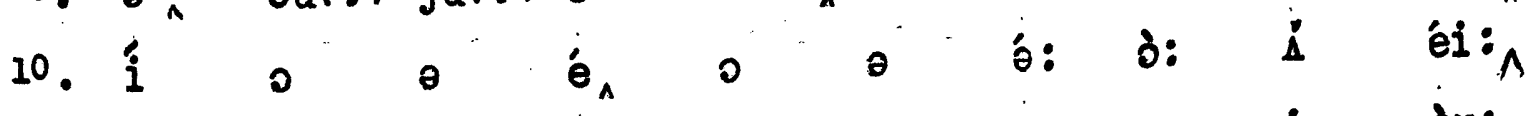

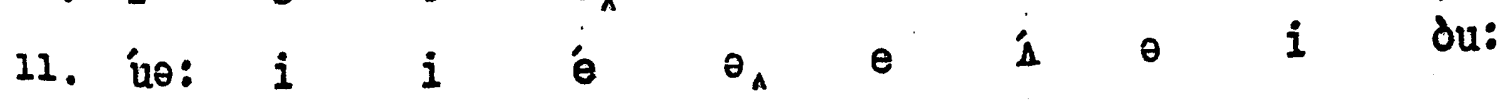
$\theta_{A}$

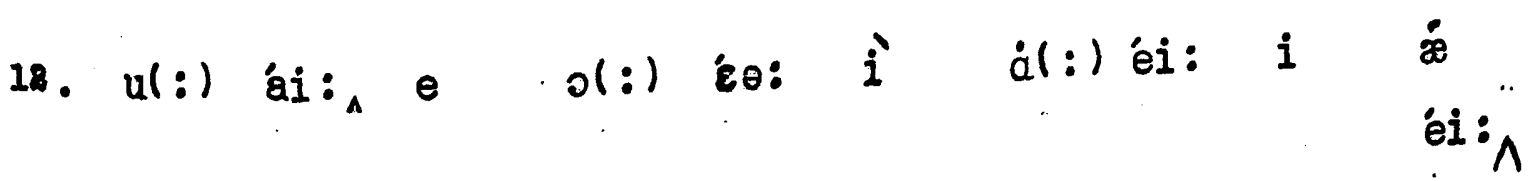

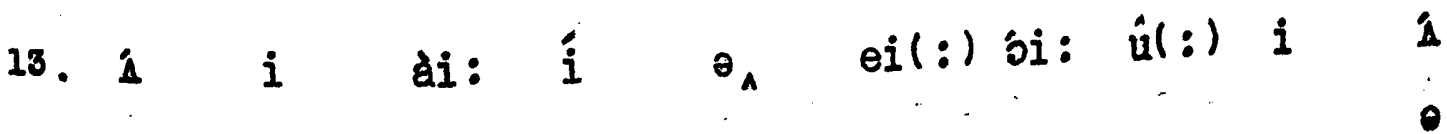

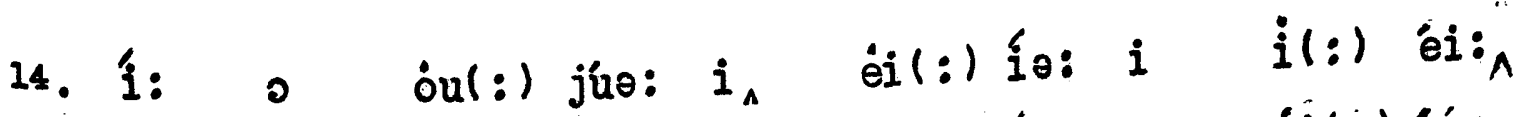

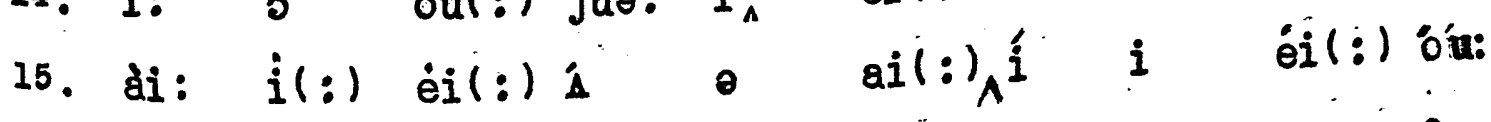
16. ái: i e éo: ì âl $(:)$ éi: $i \quad \dot{z}$ éi: 
1. The Nerves are France, and Italy, and Spain;

2. The Liver Britain, the Narrow Sea each Vein;

3. The Spleen is Aethopia, wherein

4. Is bred a people of black and tawny skin;

5. The Stomach is like Aegypt, and the Chyle,

6. Which through the body flows, is as the Nile;

7. The Head and Heart both Indies are; each

8. Doth like the South and Northern Poles appear;

9. The Irungs are rocks and caverns, whence rise winds,

10. Where life, which passes through, great danger finds.

From "Upon the Theme of Love" (p.17) by Margaret Cavendish, Dachess

of Newcastle.

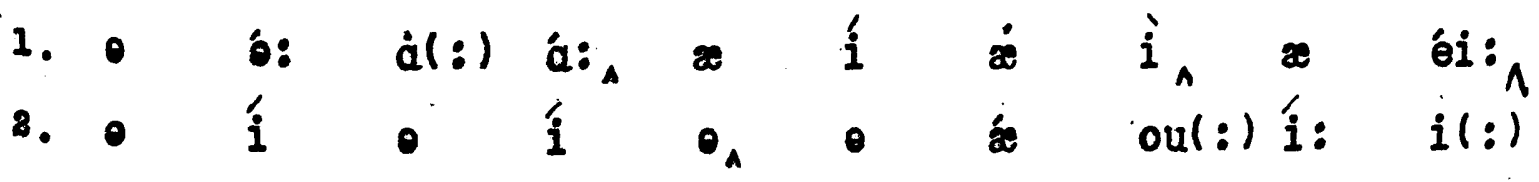

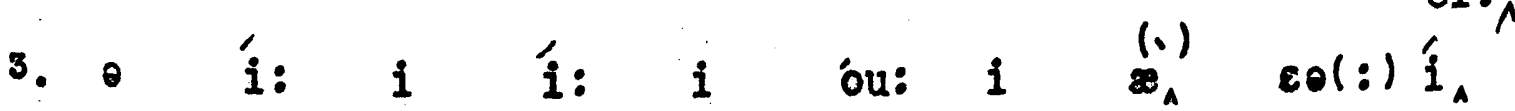

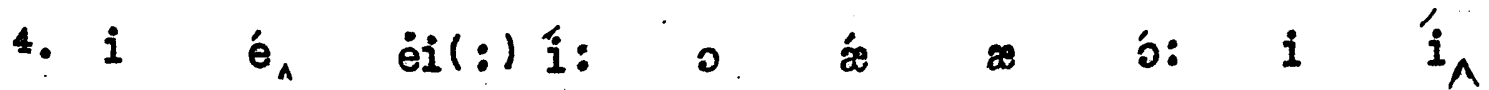

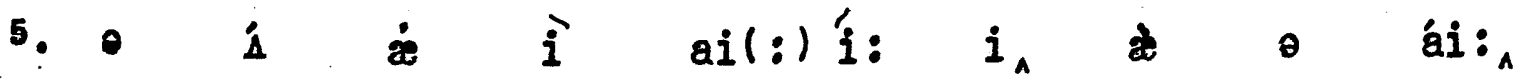

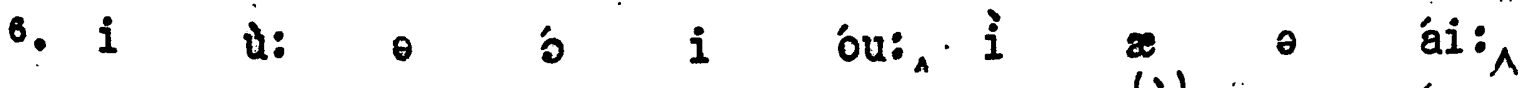

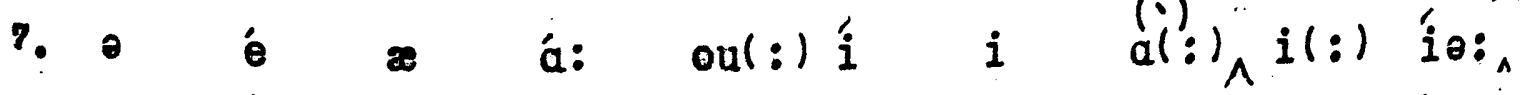

8. i ail:) o áu $x$ o: $\dot{\theta}(:)$ ou: $\dot{z}$ io:

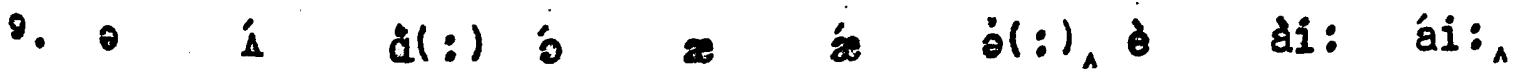

10. $\varepsilon_{\theta}(:)$ ái: $i$ á: $i$ ú: ei: éi: $\theta$ ái:^ 
1. Sweet stream, that dost with equal pace

2. Both thyself fly, and thyself chase,

3. Forbear awhile to flow,

4. And listen to my woe.

5. Then go, and tell the sea that all 1tg brine

6. Is fresh, compar'd to mine;

7. Inform it that the gentle dame,

8. Who was the life of all my flame,

9. In th' giory of her bud

10. Has pass'd the fatal flood.

11. Death by this only stroke triumphs above

12. The greatest power of love:

13. Alas, alas! I mant give o'er,

14. My sighs will let me add no more.

15. Go on, sweet stream, and henceforth rest

16. No more than does troubled breast;

17. And if uy sad complaints hath made thee stay,

18. These tears, these tears shall mend thy way.

"On His Mistress Drowned" (p.2A) by T. Sprat. 


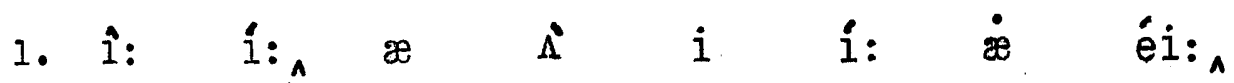

2. ou(:) ai(:) é ái: $₫$ ail: é éi:

3. j(:) $\varepsilon_{\theta}:$ æ ái: $u(:)$ óu:

4. æ $i_{\wedge}^{\prime} \quad \mathfrak{u}(:)$ ai(:) óu: $\wedge$

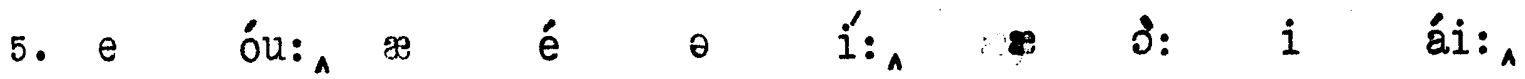

6. $i \quad \dot{e}_{\wedge} \dot{0} \quad \varepsilon \partial: \dot{u}(:) \quad \dot{a} i: \wedge$

7. $i$ ó: $i_{\wedge}$ æ $\quad \partial$ é éi:

8. ù: 0 o ái: ${ }_{\wedge} 0$ ó: $a i(:)$ éi:

9. $i$ ə $\dot{0}: i_{\wedge} \dot{j} \dot{\theta}(:) \dot{\Lambda}_{\wedge}$

10. \& á: ${ }_{\wedge}$ o éi: $\dot{a} \dot{\Lambda}_{\wedge}$

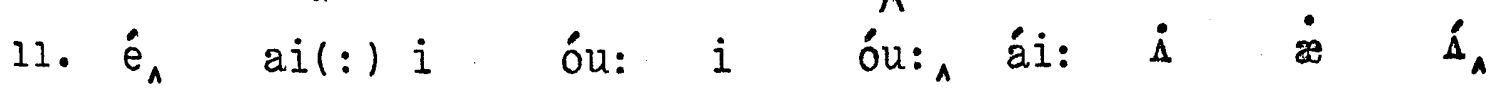

12. $\theta$ éi: $i$ áuə: $\supset$ Á

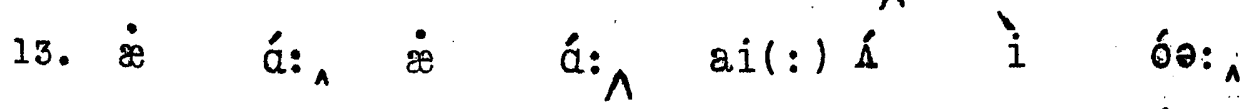

14. ài: ái: $i$ è $i(:) \not{\&}$ ơu: ว่ə: $\wedge$

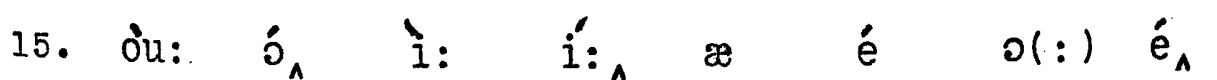

16. òu: อ́ə: æ $\dot{\Lambda}_{\wedge}$ ail:) $\dot{\Lambda} \quad e_{\Lambda}$

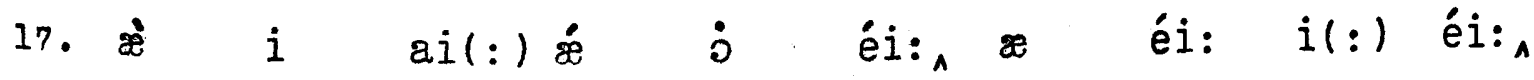

18. i(:) ío: $i(:)$ ío: $¥$ é $a i(:)$ éi: 
1. Where, Industry, thy daughter fair?

2. Recall her to her native air;

3. Here was trade born, here bred, here flourish'd long;

4. And ever shall she flourish here.

5. What, though she languish'd? 'twas but fear:

6. She's sound of heart, her constitution strong.

From "Imperium Pelegi" (p.56, v.I)

by B. Young.

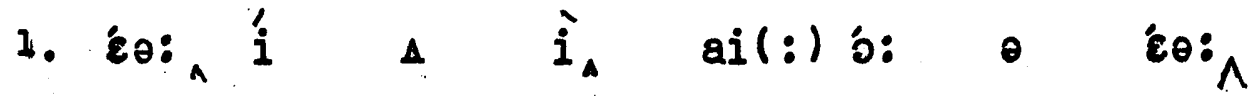

2. $i(:)$ ó: o: $\quad$ ul(:) $\theta(:)$ éi: $i$ co:

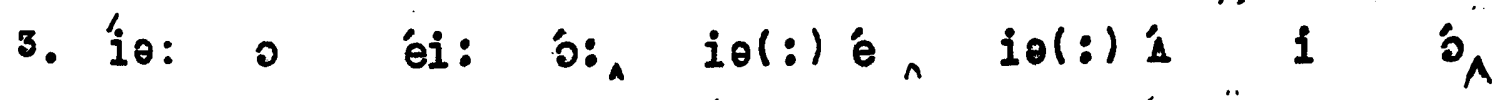

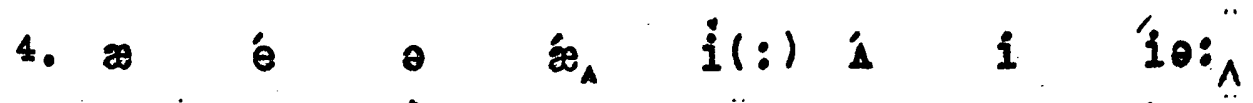

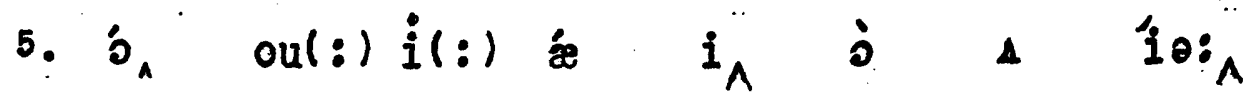

6. $i(:)$ áu: 0 á: ${ }_{A} \dot{\theta}(:)$ o $i$ ju: $\theta$ ó 
1. When mo soul wings her flight to the regions of night,

2. And my corse shall recline on its bier,

3. As ye pass by the tomb where my ashes consume,

4. Oh moisten their dust with a Tear.

From "Hours of Idleness" $(p \cdot 130, v \cdot \beta)$

by Lord Byron.

1. e ail: óu: $i \quad \dot{\theta}(:)$ éi: $\dot{u}(:)$ o

o ái:

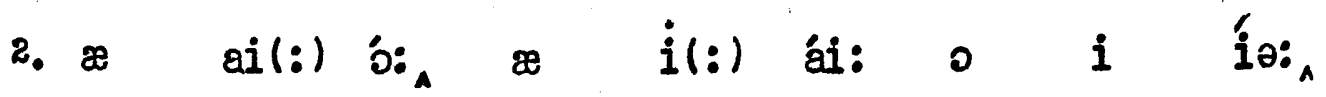

3. $\approx$ il: $a:$ ail: $\theta$ b: $\varepsilon_{a}(:)$ ail: \& $i$

i jü a

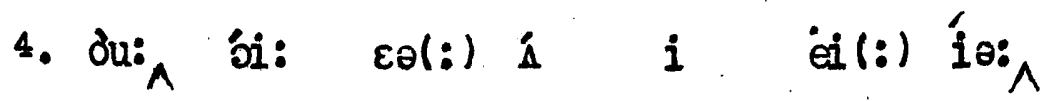


1. I dream'd that I walked in Italy,

2. When the day was going down,

3. By a water that silently wander'd by

4. Thro' an old dim-lighted town.

5. Till I came to a palace fair to $8 \theta \theta$

6. Wide open the windows were.

7. My love at a window sat; and she

8. Beckon'd me up the stair ....

9. When I came to the little rose-colour'd room,

10. From the curtains out flew a bat

11. The window was open; and in the gloom

12. My love at the window sat.

13. She sat with her guitar on her knee,

14. But she was not singing a note,

15. For someone had drawn (ah, who could it be?)

16. A knifo across her throat.

From "Going Back Again" (p.209) by Owen Meredith. 


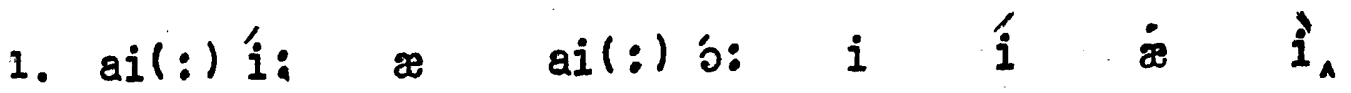

2. $e$ éi: 0 óu: $i$ áu:

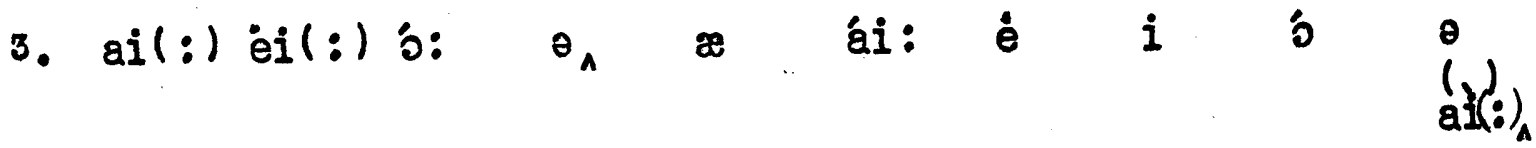

4. $u(:) \approx$ ou: $\grave{i}$ ái: $i$ au:

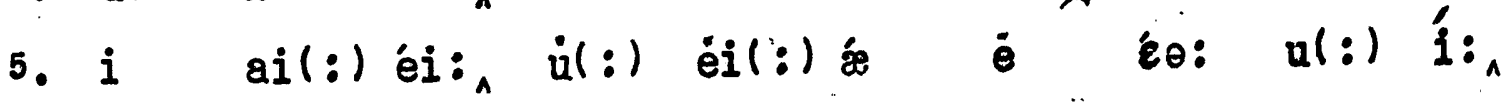

6. ài: ou: $\theta_{\wedge} \quad \theta \quad$ i $o u(:) \varepsilon \theta_{0}{ }_{\wedge}$

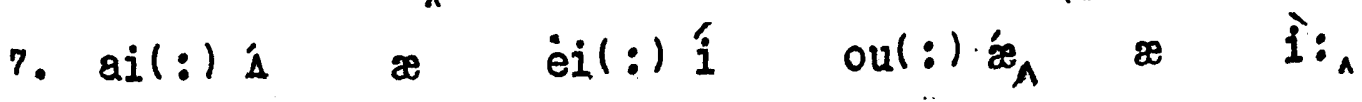

8. é $\theta \quad i(:)_{\wedge} i \quad$ o

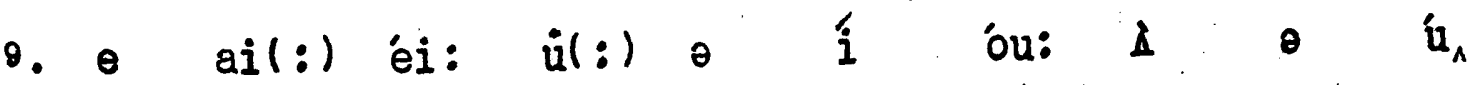

10. 0 ə $\partial:$ i $i_{\wedge}$ áu: ù: $\ddot{e} i(:) m_{\wedge}$

11. o $\mathfrak{i}$ oul: $)$ o ou: $\dot{\theta}_{A}$ \& $i \quad \theta \quad \dot{u}_{A}$

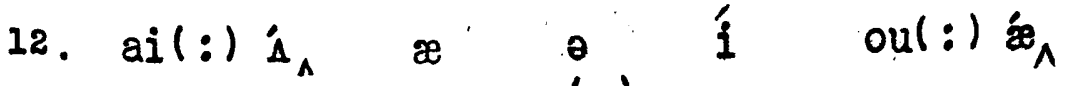

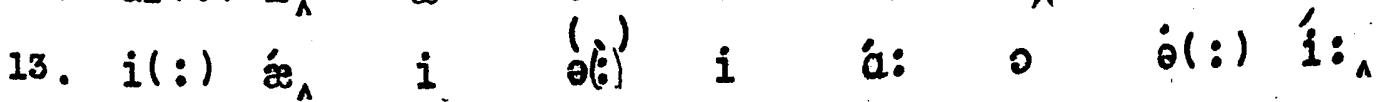

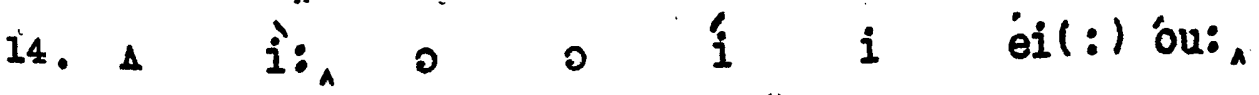

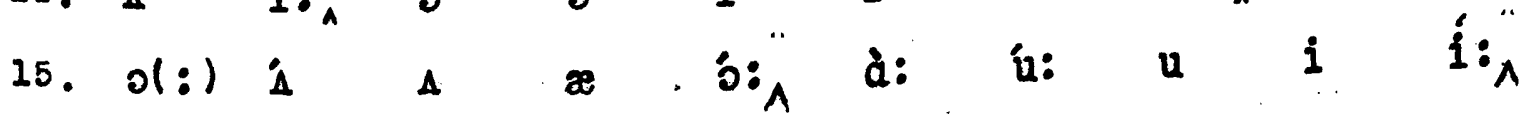

16. èil: ái: æ o: 


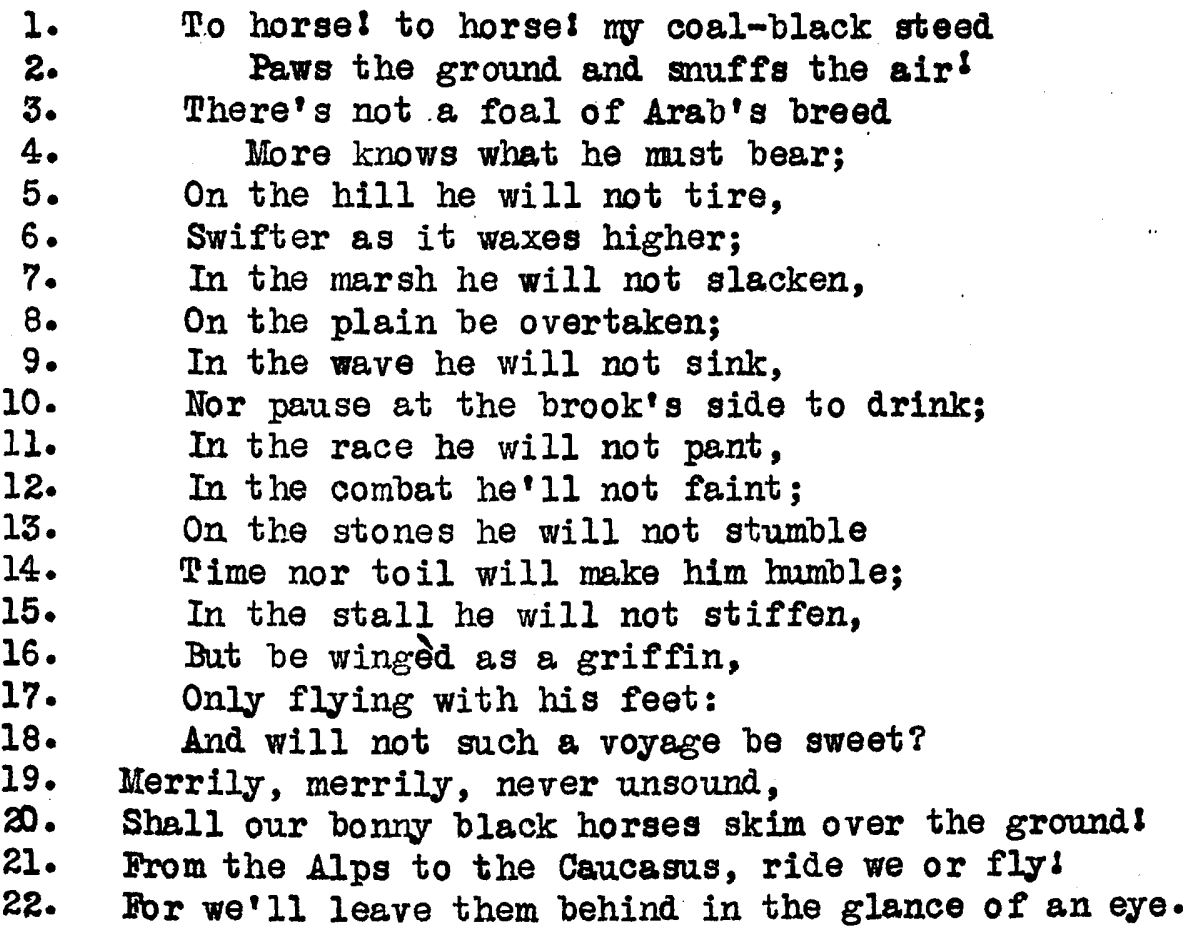

From "The Deformed Transformed"

by Lord Byron. 


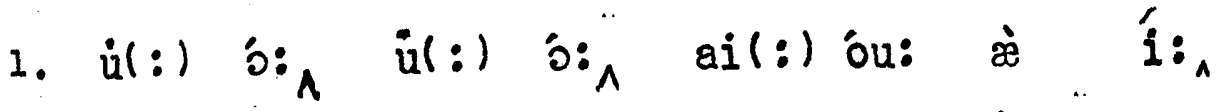

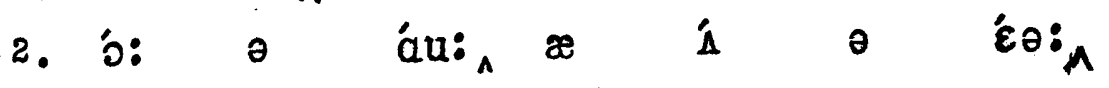

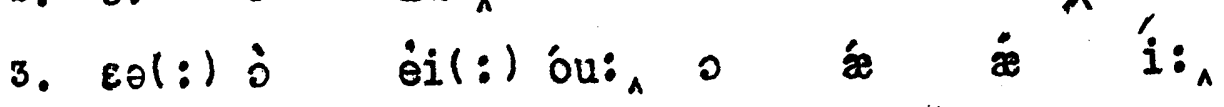

4. oə(:) ou: $\dot{0}$ il:) A $\varepsilon_{\theta}:_{\wedge}$

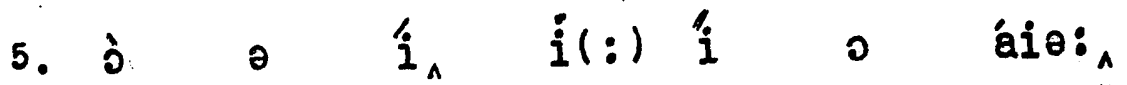

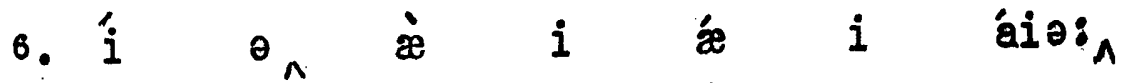

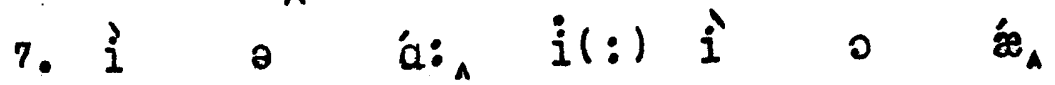

8. ว $ว$ éi: $i(:)$ ou: $\theta$ éi: ${ }_{\wedge} \wedge$

ค. $i$ o ei: $\quad \dot{i}(:) \quad j$ o $\dot{i}_{A}$

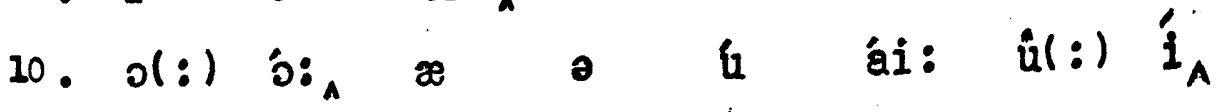

11. $i$ o éi: $\dot{i}(:)$ i 0 æa

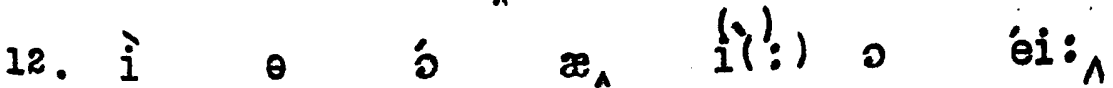

13. j $\theta$ ou: $i(:) i \quad$ o $\mathbf{1}_{A}$

14. ái: ol:) bi: $i$ éi: $i$ is

15. i 0 o: $i(:)$ i 0 î

16. $i \quad i(:) \stackrel{i}{i} i_{\wedge} \gtreqless \quad \ddot{e} i(:) \dot{i}_{A}$

17. ou: $i$ ái: $i_{\wedge} \quad i \quad i \quad i:_{\wedge}$

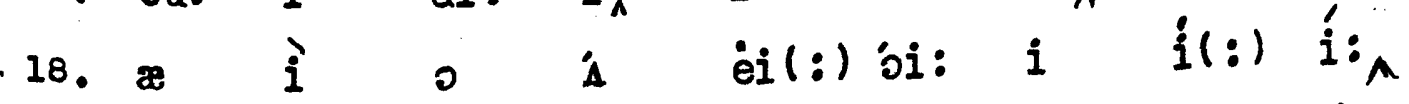

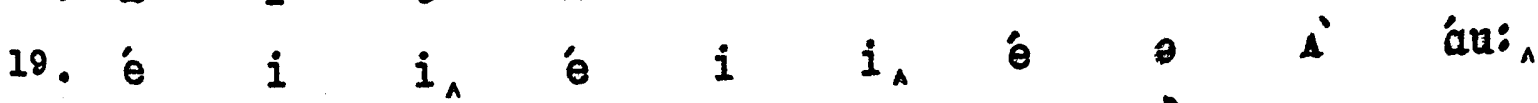

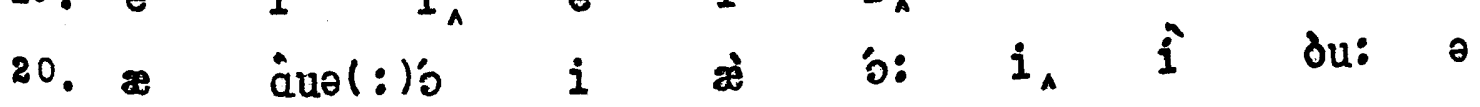

ə áu:

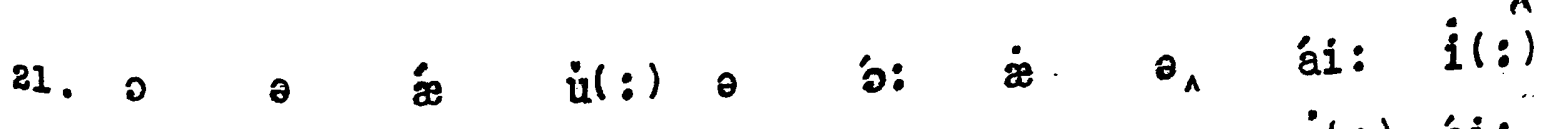

$\dot{j}(:)$ ái:A

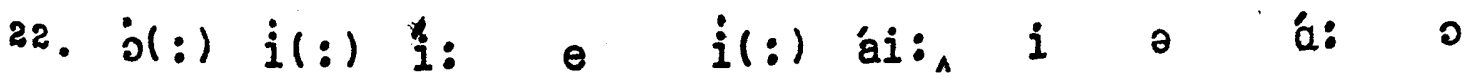
$æ \quad$ ái :A 
1. The task I dread; dare I to leave

2. Of humble prose the shore,

3. And put to sea? a dangerous sea?

4. What throngs have sunk before!

From "Resignation" Part I (p.55, v.2)

by E. Young.

1. ə áa $a i(:) e_{\wedge} \quad \varepsilon \theta$ ail: $\dot{u}(:) \quad \mathfrak{i}:_{\wedge}$

2. 0 i ou: ${ }_{A}$ o bo: A

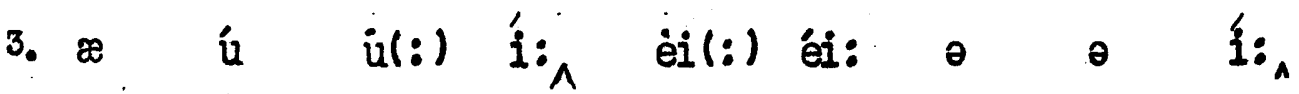

4. 0 o 
1. Frown you? Frown on; your hour is past?

2. The sigmal wafted in that blast

3. Speaks Britain's awful Senate met: beware

4. Iest in her scale (the vomb of right 1)

5. With all your arms, you're found too light,

6. Till smiles increase that weight your frowns impair.

From "The Foreign Address" (p.63, 72 )

by E. Young.

1. áu: jü: du: 'ô juə(:) áuə: $i$ áa

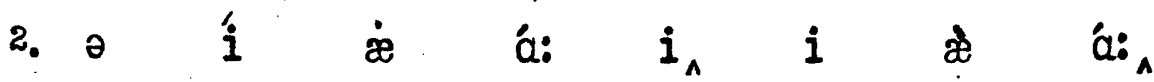

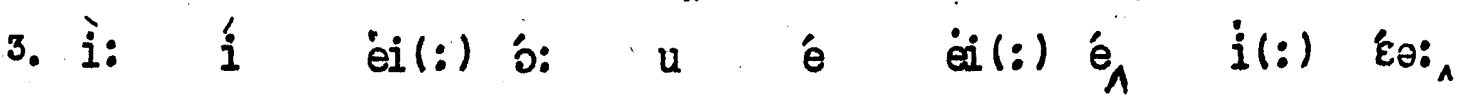

4. é $i$ ol(:) éi: $\wedge$ $\partial$ ú 0 ái:

5. i ó: juə(:) áa ${ }_{\wedge}$ juol: $)^{\prime}$ áu: ù: ái:

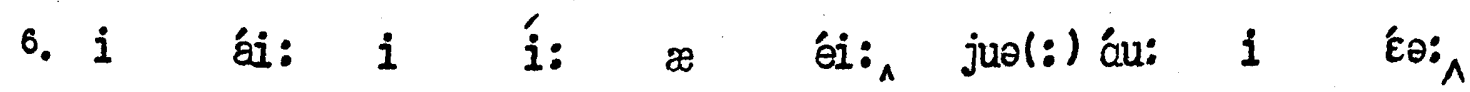


1. O Britain, infamous for suicided

2. An island in thy mannerst far disjoin'd

3. From the whole world of rationsls beside!

4. In ambient waves plunge thy polluted head,

5. Wash the dire stain, nor shock the Continent?

From "Night Thoughts," Night V, (p.65) by E. Young.

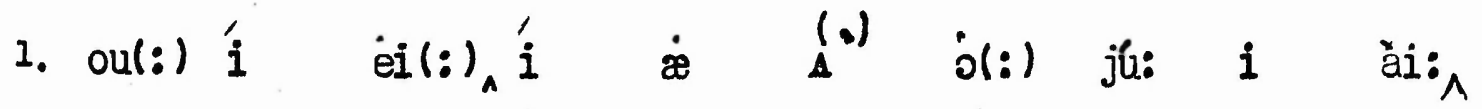

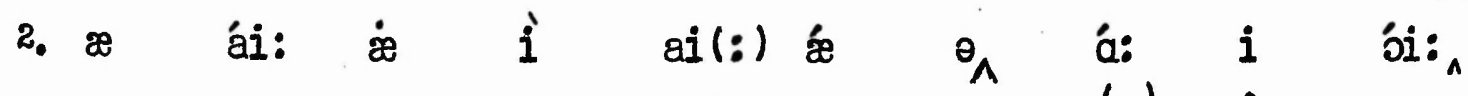

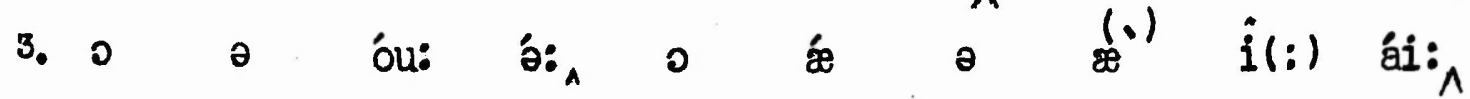

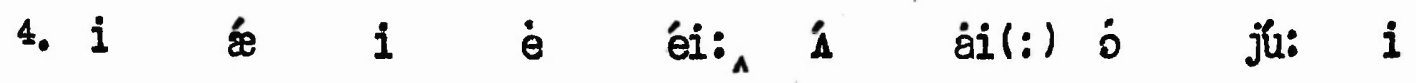

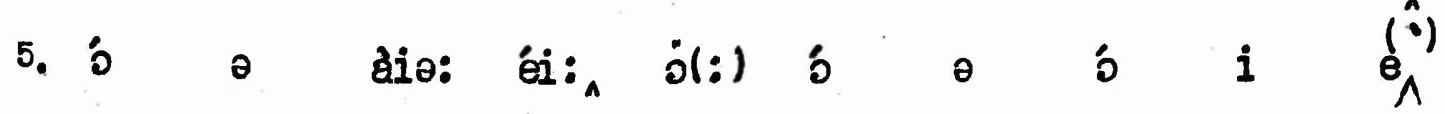


1. Ascend, my Muse, on Sorrow's sable plume,

2. Let the soft number meet the swelling sigh;

3. With laureated chaplets deck the tomb,

4. The blood-stained tomb where Smith and comfort lie.

"Elegy on Mr. W11l1am Smith" (p.100) by T. Chatterton.

1. $\ddot{e}$ A

ai(:) jú:

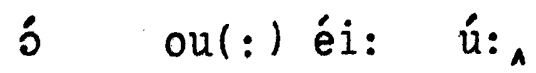

2. è

j:

A $\partial$

i:

é

i

ái: $\wedge$

3. $i$

ว่:

i( : )

èi: $\quad i$

$\dot{8}$

é

ú:

4. 2

ณ́

èi: $\dot{u}:$

$\varepsilon \partial(:) i^{\prime}$

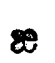

2

ol: ái: 
1. May no marble bestow the splendour of woe,

2. Which the children of vanity rear;

3. No fiction of fame shall blazon my name;

4. All I ask - all I wish-is a Tear.

From "Hours of Idleness" (p.130,v・7) by Lord Byron.

1. eil(:) oul(:) á: $i(:)$ óu: ${ }_{\wedge}$ o é

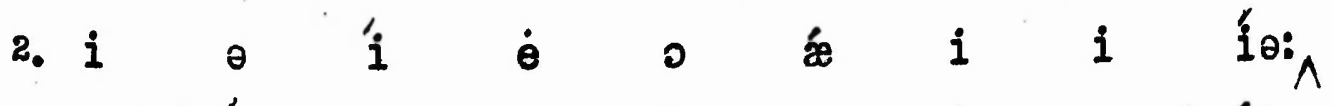

3. oul: $) \stackrel{1}{1}$ o 0 éi: $¥$ éi: ail(:) éi:

4. ol: ai(:) á: 
1. In the year eighteen seventy-gix,

2. A Fourth of Iuly celebration

3. Was held in Grand Rapids city

4. In honor of our nation.

5. The largest city in the county of Kent,

6. Is this city, and it is respected,

7. For thousands of people was here to see

8. The beautiful arch erected.

9. The paintings and mottoes on the arch

10. Was viewed by many people;

11. It was Colonel Joseph Penney's design,

12. And his work could not be equalled.

13. Wr. C.H. Gifford was architect,

14. He formed the noble structure,

15. A momento to the Centennial year,

16. A pride of our nation's calture.

17. A cabin was built, too, I believe,

18. That nicely represented

19. One that the traders built years ago,

20. This was the only one invented.

21. Pen thourand people respected it,

22. This token of early years, with joy;

23. The honor of this little hat

24. Was due to Mr. Godfroy.

From "The Ceñtennial Celebration" (p.221) by J. Mioore. 


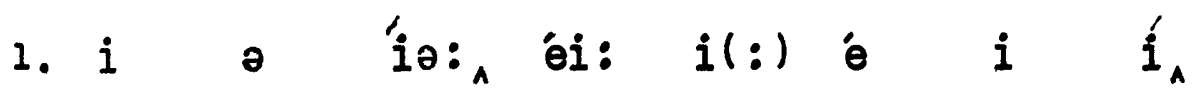

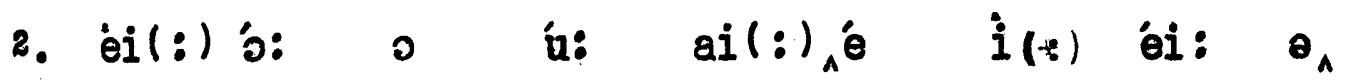

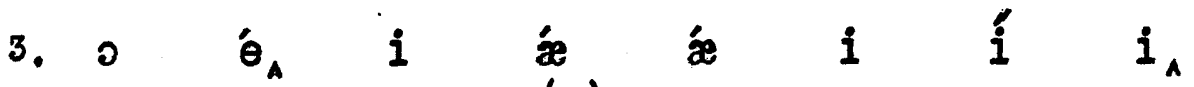

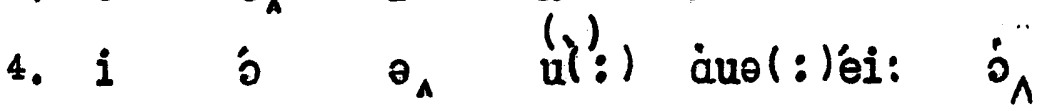

5. $\theta$ á: $i$ i $i_{\wedge} \quad i \quad$ a au: $i$ o

$\dot{e}_{A}$

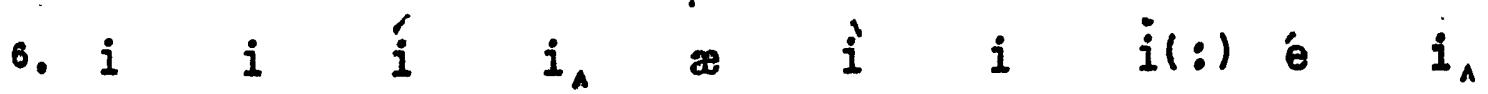

7. o(:) áu: o $\mathfrak{i}:$ A 0 ía: $u(:)$ í:

8. - ju: $i$ ú á: $\quad \dot{i}(:)$ é $\dot{\theta}_{\wedge}$

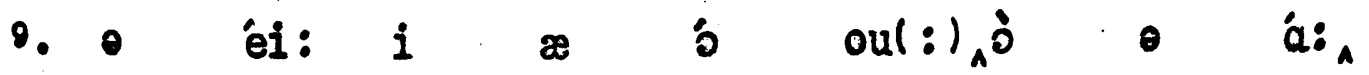

10. O ju: ail:) e $i \quad i:_{\wedge}$

11. $i$ o á: $\dot{e}$ ou: $\dot{e}$ é $i$ il(:) ái:A

12. $\approx$ i $\quad \dot{\theta}:_{\wedge}$ ù 0 il : $)$ í: a $_{\wedge}$

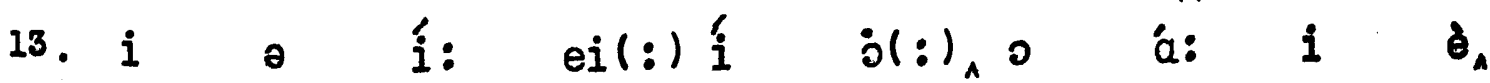

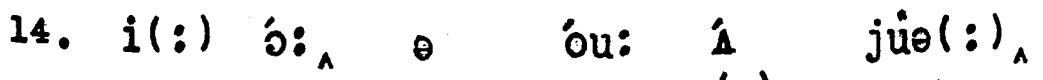

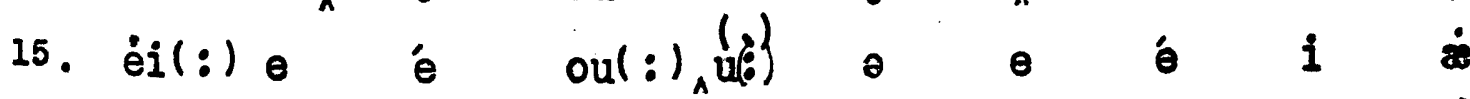
1́o:

16. èi(:) ái: o aùr(: l'éi: ə i jür(:)

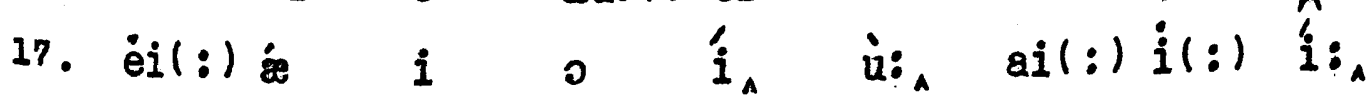

18. ái: $i_{A} \quad$ é $\quad \dot{i}(:)$ é $i_{\wedge}$

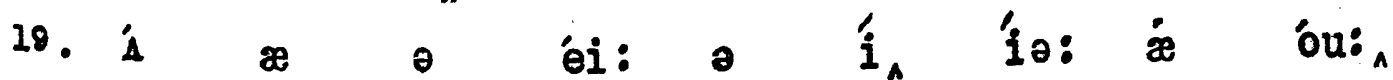

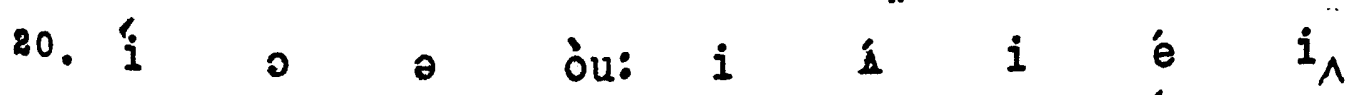

21. è áu: $\dot{z}$ í: $\quad \dot{i}(:)$ e $\quad \dot{i} \quad i_{A}$

22. i ou: ə 0 a: $i$ ía: $i$ bi:

23. $\theta$ o $\begin{array}{llllll} & 0 & (0) & i & i & i_{A}\end{array}$

24. О ju: $\dot{u}(:) \stackrel{i}{i}$ ə 0 ói: 
1. For he was sick, and very bad -

2. Poor boy, he thought, no doubt,

3. If he came home in a smoking car

4. His money would hold out.

5. He started to come back alone -

6. He came one-third the way -

7. One evening in the car alone

8. His spirit fled away,

From "John Robinson" (p.222)

by J. Moore.

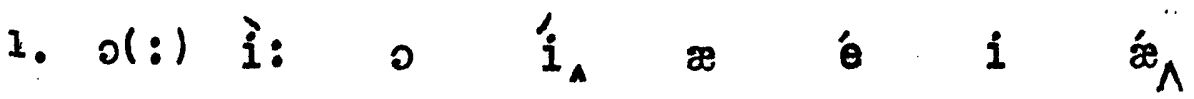

2. uə(:) ój: $i(:)$ ó: òu áu:

3. i il::) èi: ou: $i$ èi(:) óu: $i$ á:

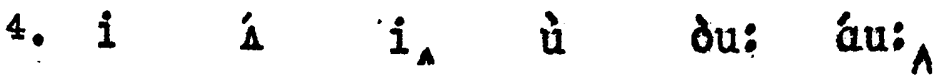

5. $\dot{i}(:)$ á $i_{A} \dot{u}(:)$ i $\dot{z} \dot{z}$ ou:

6. $i(:)$ éi: $i$ á:

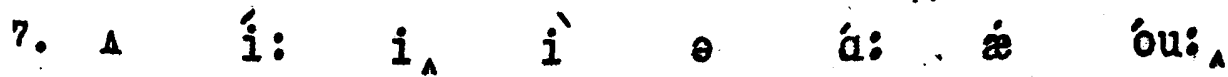

8. $i \quad \stackrel{i}{i} i_{A} \ddot{e} \dot{z}$ éi ${ }_{\wedge}$ 
1. Twas only a passing thought, my love,

2. Only a passing thought,

3. That came o'er my mind like a ray of the sun

4. In the ripples of waters caught;

5. And it seemed to me, and I say to thee,

6. That sorrow and shame and sin

7. Might disappear from our happy sphere,

8. If we knew but to begin;

9. If we knew but how to profit

10. By wisdom dearly bought:

11. Twas only a passing thought, wy love,

12. - Only a passing thought.

"Only a Thought" (p.169)

by C. Mackay.

1. 0 òu: $i$ eil : $)$ á: $i$ ó: $a i(:) \dot{A}_{A}$

2. òu: $i_{\wedge} \quad \dot{\theta i}(:)$ á: $i$ ó

3. a éi: oo(:) ai(:) ái: ail: êil : éi: o $\theta$

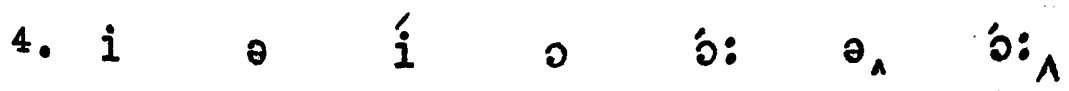

5. $\approx$ i $i: \quad u(:)$ i: $\approx$ ai(:) éi: $u(:)$

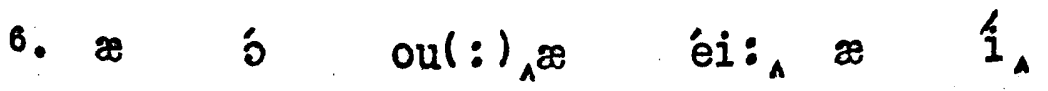

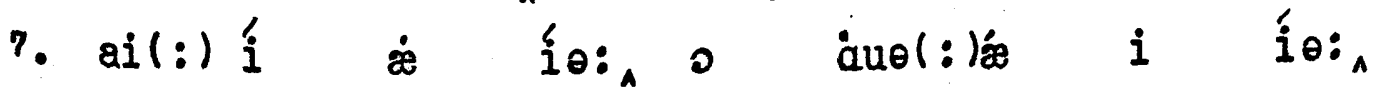

8. $i \quad i(:)$ ju: $A$ ul: $i_{1} i(:){ }^{i}{ }_{\wedge}$

9. $i \quad \dot{i}(:)$ jú $:_{\wedge} \wedge$ àu: $\dot{u}(:)$ ó $\dot{i}_{\wedge}$

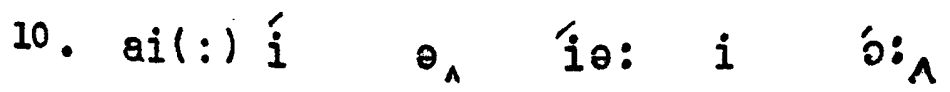

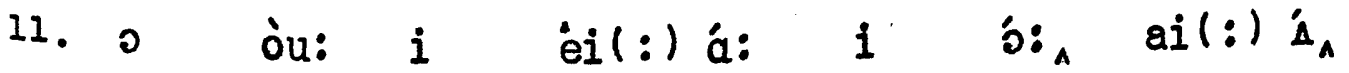

12. òu: î èi(:) á: i ó 
1. When the lion was young

2. In the pride of his might,

3. Then 'twas sport for the strong

4. To embrace him in fight;

5. To go forth, with a pine

6. Hor a spear, 'gainst the mammoth,

7. Or strike through the revine

8. At the foaming Behomoth;

9. While man was in stature

10. As towers in our time,

11. The first-born of Nature,

12. And, like her, sublime?

"The Deformed Trangformed", III,I (p.131)

by Iord Byron.

1. $\theta \quad \theta$ ái: $\theta_{\wedge} \quad 0 \quad \dot{A}_{\wedge}$

2. $i$ o ái: 0 i ái:

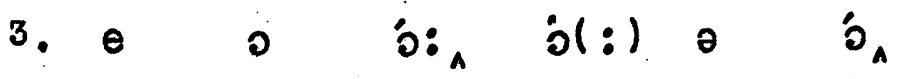

4. $\dot{u}(:) \dot{e}$ éi: is $i$ ái:

5. $\dot{u}(:)$ òu: ó: $i$ èi(:) ái:

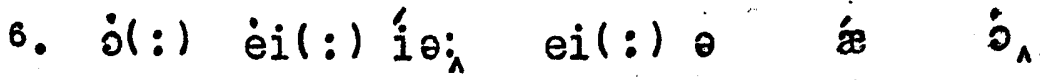

7. o(:) ái: $u(:)$ ə $\ddot{\&} \quad \dot{i}$ A

8. $\approx$ o ou: $i_{\wedge} i(:)$ i: $\dot{o}_{\wedge}$

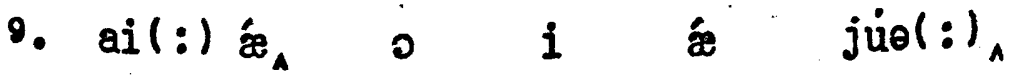

10. æ áuə: $i$ áuo: ài:

11. $\theta$ à: ó:

12. $\circledast_{\wedge}$ ái: $\theta(:)_{\wedge} \dot{\Lambda}$ ái: 
1. Something to love, some tree or flow'r,

2. Something to murse in lonely bow'r,

3. Some dog to follow, where'er I roam,

4. Some bird to warble molcome home,

5. Some tame gazelle, or some gentle dove:

6. Something to love, oh, something to love!

7. Something to love, oh, let me see!

8. Something that's filled with a love for mo;

9. Beloved by none, it 18 sad to live,

10. And 'tis sad to die and leave none to grieve;

11. And fond and true let the lov'd one prove.

12. Something to love, oh, something to loved

"Something to Lore" (p.158) by $\mathrm{T.H}$. Beyly.

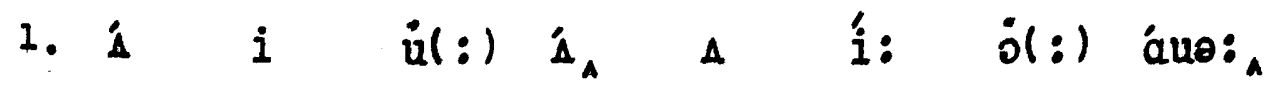

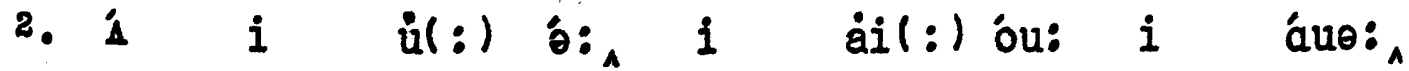

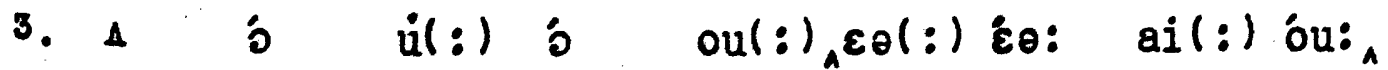

4. 4 ó: $\dot{u}(:)$ ó: $\wedge$ ai(:) é $\theta$ óu:

5. $\Delta$ éi: $\dot{z} \quad \dot{e}_{\wedge} \dot{\partial}(:) \Delta \quad$ é ${ }_{\wedge}$

6. $\dot{A} i \quad \dot{u}(:) \dot{A}_{A}$ oul: $)_{A} \dot{A} \quad i \quad \dot{u}(:) \dot{A}_{\Lambda}$

7. $i \quad i \quad \dot{u}(:) \dot{A}_{\wedge}$ oul $\left.:\right)_{A} \dot{e} \quad i(:) \quad i:{ }_{\wedge}$

8. $i \quad i \quad$ \& $\dot{i}_{\wedge} i \quad$ ei(:) 4

$\dot{o}(:)$ i:

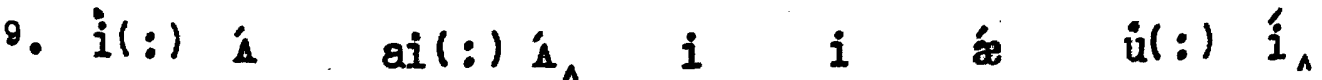

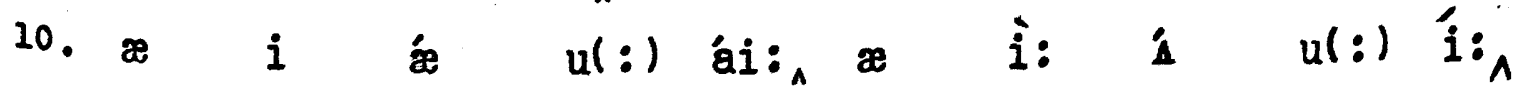

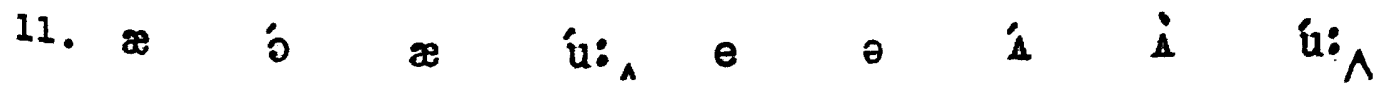

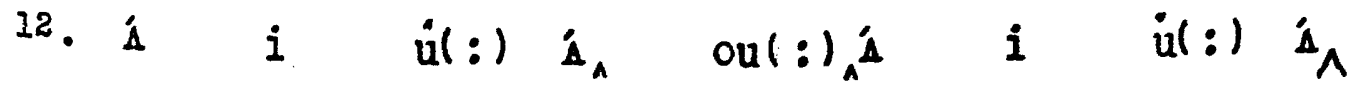


1. Upon a hill he turned,

2. To take a last fond look

3. Of the valley and the village church,

4. And the cottage by the brook.

5. He listened to the sounds

6. So familiar to the ear,

7. And the soldier leant upon his sword

8. And wiped away a tear....

9. He turned and left the spot,

10. Ohl do not deem him weak,

11. For dauntless was the soldier's heart,

12. Tho' tearg were on his cheek.

13. Go watch the foremost ranks,

14. In danger'g dark career.

15. Be oure the hand most daring there

16. Has wi ped awas a tear. 
1. $\dot{i} \dot{o}$ ei $(:))_{\Lambda} \quad i(:)$ á:

2. $u(:)$ éi:

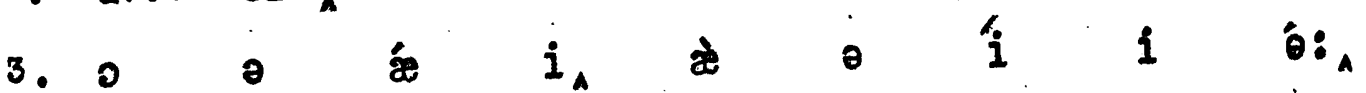

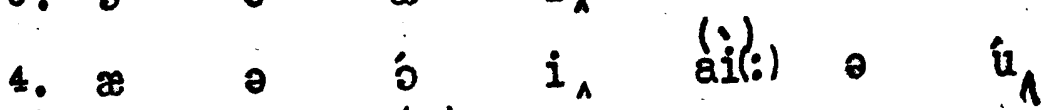

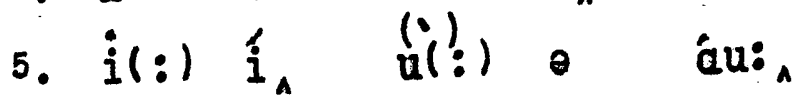

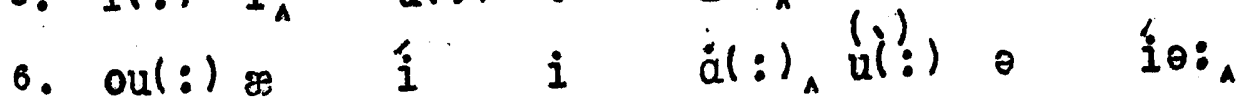

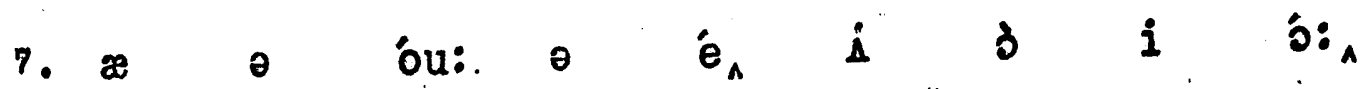

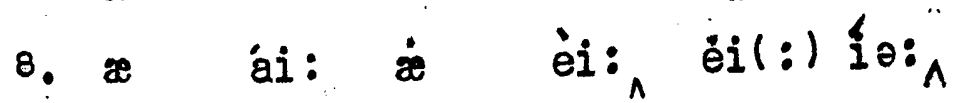

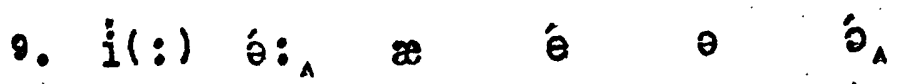

10. du: $\wedge$ ù: 0 i: ${ }_{\wedge} \quad \mathfrak{i}:$,

11. $0(:)$ o: $i_{A} \quad j$ o ou: $\theta$ á:

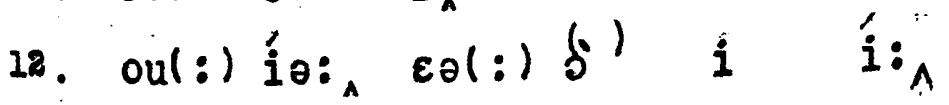

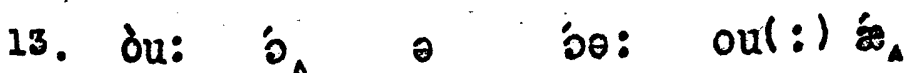

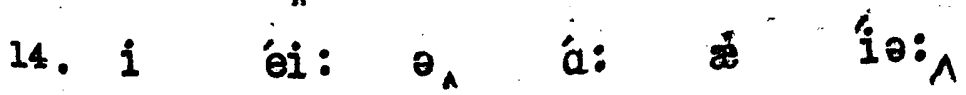

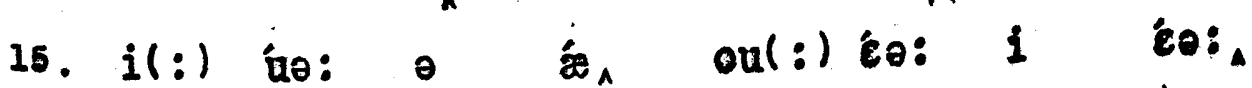

16. áa: a èi $:_{\wedge}$ èi(:) ĺo: $_{\wedge}$ 
1. Be not deaf to the sound that warns,

2. Be not gull'd by a despot's plea!

3. Are figs of thistles? or grapes of thorns?

4. How can a despot feel with the Free?

5. Form, Form, Riflemen Form!

6. Ready, be ready to neet the storm!

7. Riflemen, Riflemen, Riflemen form!

8. Iet your reforms for a moment go!

9. Look to your butts, and take good aims!

10. Better a rotten borough or so

11. Than a rotten fleet and a city in flames

12. Storn, Storm, Riflemen form!

13. Ready, be ready against the storm!

14. Riflemen, Riflemen, Riflemen forml

Printed in "The Times", Vay 1859 (p•231) by Lord Tennyson.
1. $\dot{i}(:)$
2. $1(0)$

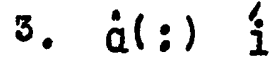
o. $i_{A}$
$\dot{e}_{1} \quad \dot{u}(:)$ ə áu: $\underset{x}{ }$
A àil: $)$ eill: $)$ é
- $\stackrel{i}{A}_{A}$
ol:

4. dù: æ

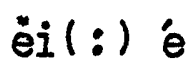

0

ái:

$\theta$

íl: $)$ é

$i_{\wedge}$

ái:

$e_{A}$

juәl: :)íl: : o:

9. ú

$\dot{u}(:)$ jül: $:)_{A}$

10. é

$\theta_{A}$ ei $i(:)$ ó

11. æ

éil: : 'o

i:

o:

i $\quad \dot{u}(:)$ í:

ə

a:

ái: e $e_{A}$

$\dot{b}(:)$ eil: ${ }^{\prime}$ ou:

$\dot{\theta}$

ou:

12. o: ‘ o: ái: é b:

13. é î $\quad \dot{i}(:)$ e $i \quad \dot{m}$ ei:

14. ái: e $e_{\wedge}$ ái: $e_{\wedge}$ ái: $e_{\wedge}$ o: 
1. I love it, I love it; and who shall dare

2. To chide me for loving that old Arm-chair?

3. I've treasured it long as a sainted prize;

4. I've bedewed it with tears, and embalmed it with sighs.

5. Iis bound by a thousand bands to my heart;

6. Not a tie will break, not a link will start.

7. Would ye learm the spell? - a mother sat there;

8. And a sacred thing is that old Arm-chair.

From "The Old Arm-chair" (p.192) by E. Cook.

1. ai(:) is

$i_{\lambda}$ ai(:) is

$i_{\wedge}$

$\approx$

ù:

$æ$

Éว:

2. ul: ái:

$i(:)$ ol(:) Í

i

* óu:

d:

$\varepsilon \theta{ }_{\wedge} \wedge$

3. ail(:) é $\dot{u} \theta(:) i \ldots \dot{o}_{\wedge}$

2

èi(:) éi: $i$

ái:

4. ail:) il(:) jú: $i$

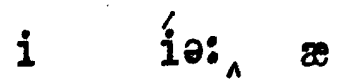

è á: $i$

i

ái:

5. i áu: ai(:) èi(:) áu: $\dot{\sharp}$

$\dot{a}_{\wedge}$

$\dot{u}(:)$

ai(:) áa

6. 0 èil:) ái: $i$ éi: ^ eil: $)^{\prime}$

i

á:

7. $u$ i(:) ว́: ə

é èil: i

$\theta$

\& $\varepsilon_{\theta}: \wedge$

8.

ëi (:) éi: $i$

$i_{A}$

$\mathbf{i}$

* óu:

d:

'ยว: $\wedge$ 
1. Be curgt the time of Bullen's fatal birth;

2. Wrinkles like age anticipate her youth;

3. Mildews and blasts devour her wanton beauties;

4. Small-pox and leprosy rough-cast her o'er,

5. Dig up her charms and features by the roots,

6. And bury them in pits as deep as graves.

From "Anna Bullen" (I., p.23)

by J. Banks.

1. $i(:)$ ó: o ái:

2. $\stackrel{1}{1}$ ail(:) éi: \&

- $\mathfrak{u}$

i

éi: $\dot{x}$

$\dot{\theta}: 1$

3. 1 jul : ) $\approx$ a: $\quad \dot{i}(\dot{)}$ que: $\dot{\theta}(:) \quad b$

eil(:) o(:) ju: . jul:) $a_{\text {a }}$ a.

4. ó j

$\boldsymbol{\theta}$ o

¿ á:

$\dot{\theta}(:$

jú:

5. $i$

$\dot{\theta}(:) \quad \dot{a}:$.

a

i:

jüol : lail : ) o

is

B. $æ$

ó

i

ê $i$

í

a í:

$\boldsymbol{x}$

uี

éi: 
1. If casusl concourse did the world compose,

2. And things from hits fortuitous arose,

3. Then anything might come from anything;

4. For how from chance can constant order spring?

5. The foreat oak might bear the blushing rose,

6. And fragrant mytles thrive in fusgian snows;

7. The fair pomegranate might adorn the pine,

8. The grape the bramble, and the sloe the vine;

9. Fish from the plains, birds from the floods, might rise,

10. And lowing herds break from the starry skies.

From "The Creation" (III, p.32)

by Sir Bichard Blackmore.

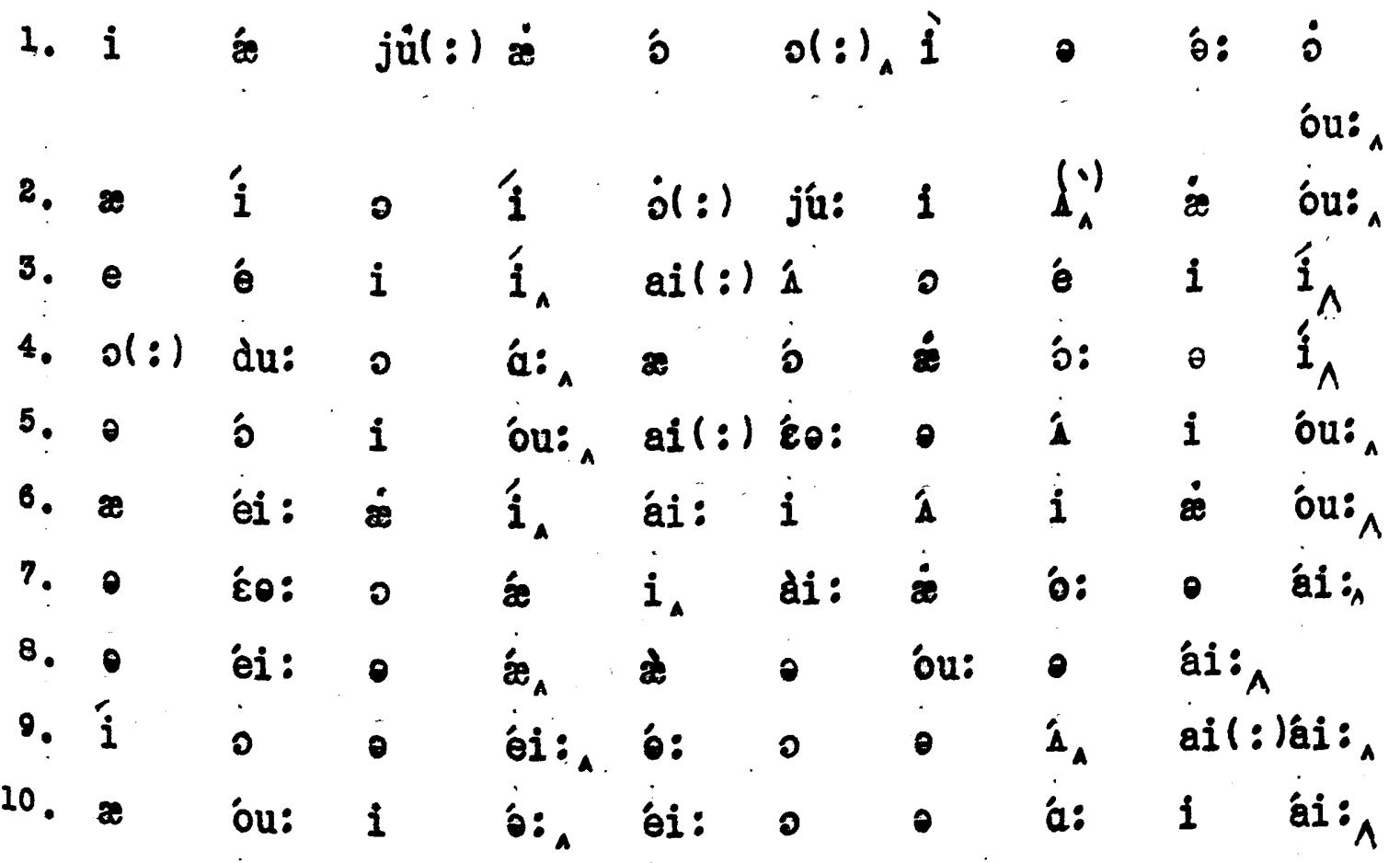


1. Oh, the pleasing, pleasing anguish,

2. When we love, and when we languish

3. Wishes rising?

4. Thoughts surprisings

5. Pleasure courting!

6. Charms transporting!

7. Fancy viewing

8. Joys ensuing!

9. Oh, the pleasing, pleasing anguisht

"Ro samond" I.4. (p.36)

by $J$. Addison.

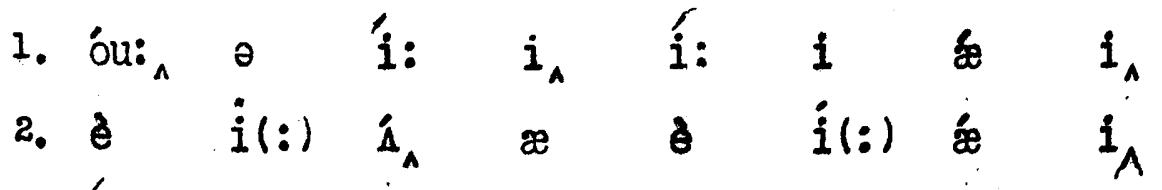

3. $i \quad i_{\wedge}$ ái: $i_{\wedge}$

4. ó. $\theta$ ái: $i_{\wedge}$

5. é jür(:) $)_{\wedge}^{\prime}$

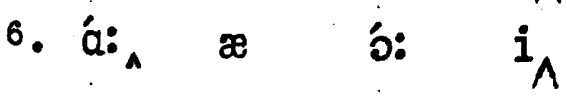

7. 追 $i_{A}$ ju: $i_{\wedge}$

8. ói: e $_{\wedge}$ ju: $i_{\wedge}$

9. ou: $\curvearrowright$ i: $i_{\wedge}$ i: 1 \& 
1. Ye sirens, sing; ye Tritons, blow;

2. Yellereids, dence; ye billows, flow;

3. Roll to measures, 0 ye starry throng:

4. Ye winds, in concert breathe around;

5. Ye Navies, to the concert bound

6. From pole to pole; to Britain all belong;

7. Britain to Heaven; from Heaven descends my song.

From "Imperium Pelegi" (p.63, The Chorras) by E. Young.

1. $i(:)$ áiə: $\partial_{\wedge} \hat{i}_{\wedge} i(:)$ ái: 0 ou: $\wedge$

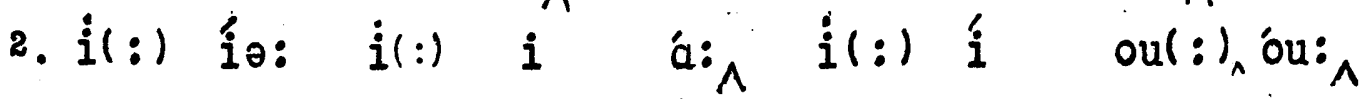

3. ous $\dot{u}(:)$ ail: $)$ é jưol: loou: $i(:)$ á: $i$ ó

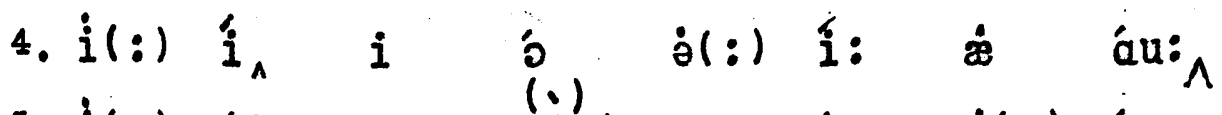

5. $i(:)$ éi: $i_{A} \quad(j)$ o $(:)$ o $\partial(:)$ áu:

6. o ou: $\dot{u}(:)$ ou: $\dot{u}(:){ }^{\prime} \quad \dot{e} i(:) b: \quad \dot{i}(:) o_{\wedge}$

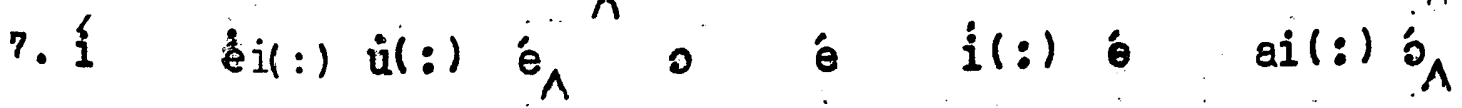


1. Ho, ye poor, who seek,

2. Among the dwellings of the diligent,

3. For sustenance unearned; who strolll abroad

4. From house to house, with mischievous intent,

5. Feigning misfortune: Ho, ye lame, ye blind;

6. Io languid limbs, with real want oppressed,

7. Who tread the rough highways, and mountains wild,

8. Through storms, and rains, and bitterness of heart:

9. Ye children of affliction, be compelled

10. To happiness: the long-wished dawlight dawns,

11. When charitable rigour shall detain

12. Your step-bruig'd feet. Even now the sons of trade,

13. Where'er the cultivated hamlets smile,

14. Brect the mansion: here soft fleeces shine;

15. The card awaits you, and the comb, and wheol;

16. Here shroud you from the thunder of the storm;

17. No rain shall wet your pillow; here abounds

18. Pure beverage; here your viands are prepared;

19. To heal each sickness the physician waits,

20. And priest entreats to give your Maker praise.

From "The Fleece" Bk.III (p.68) by J. Dyer. 
1. óu: $i(s)$ úə: $u(:)$ í:

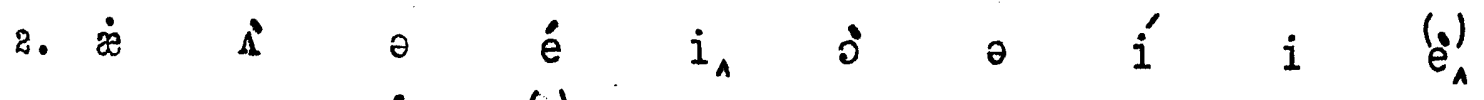

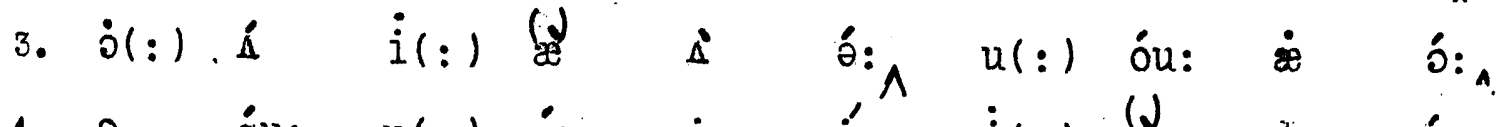

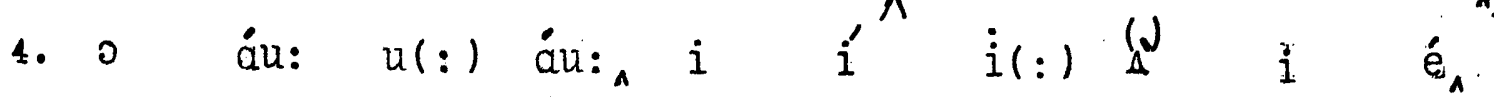

5. éi: $i$ i ó: ju(l:) ^óu: $i(:)$ éi: $i(:)$ ái: $\wedge$

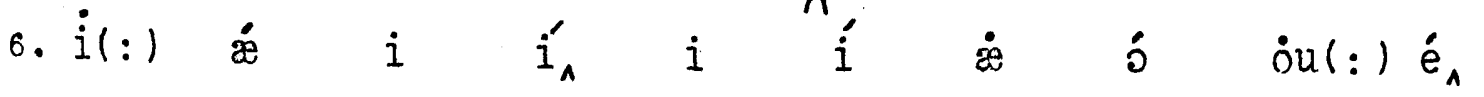

7. $u(:) \dot{e} \partial$ a ái: ei(:) $)_{\wedge}$ áu: $i$ ái:

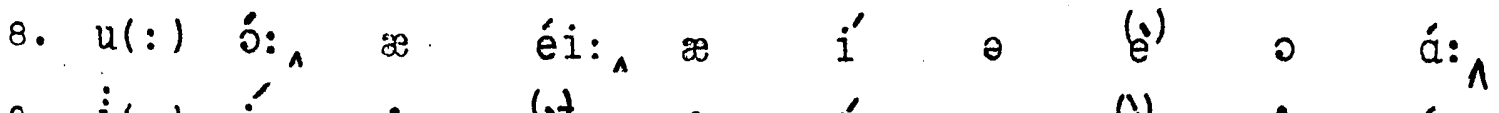

9. $\dot{i}(:) \quad \dot{i}$ e $b^{t} \quad \dot{z} \quad \dot{i}^{\prime} \partial_{A} \quad\left(i^{\prime}(:) \quad \dot{j} \quad \dot{e}_{A}\right.$

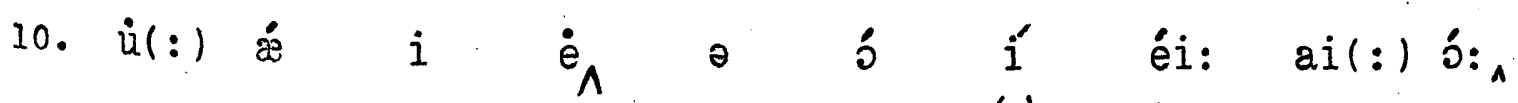

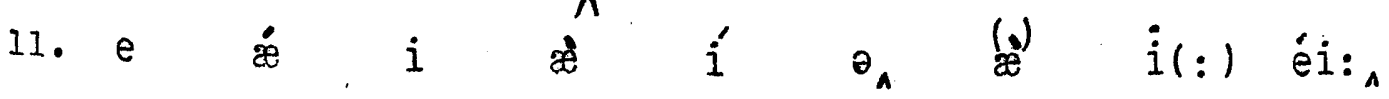

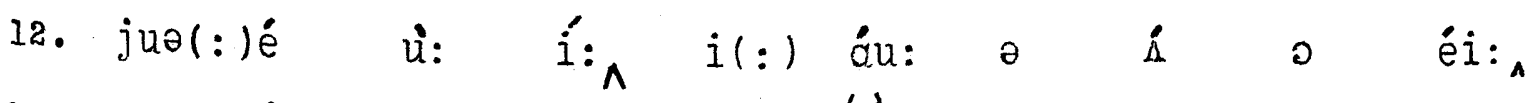

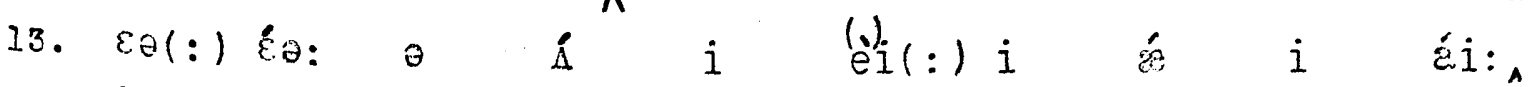

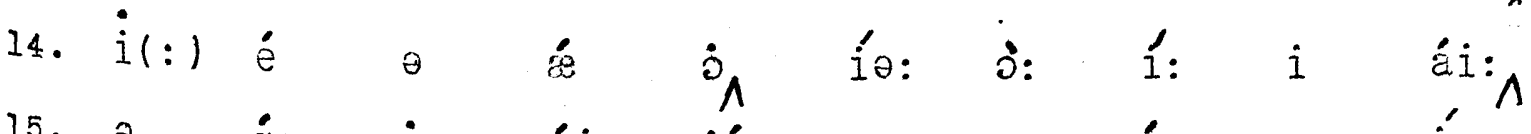

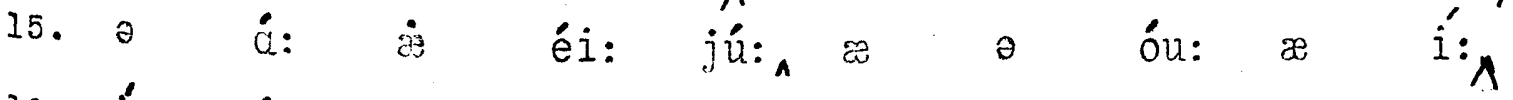

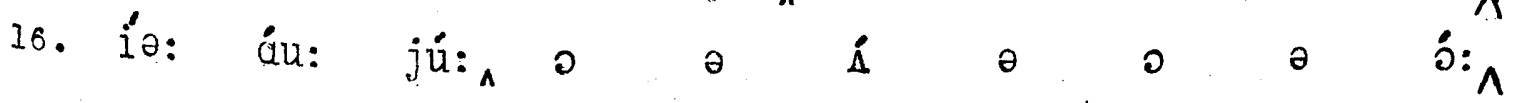

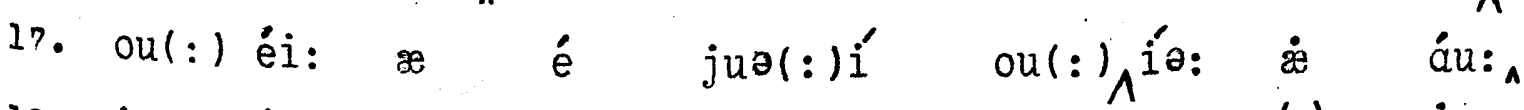

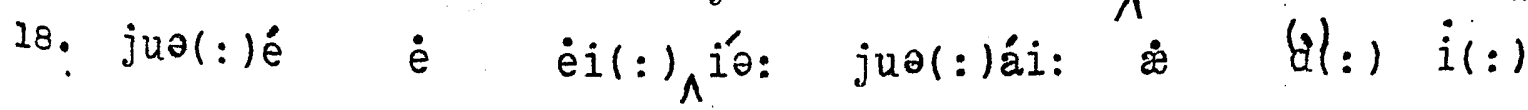
$\varepsilon \partial: \wedge$

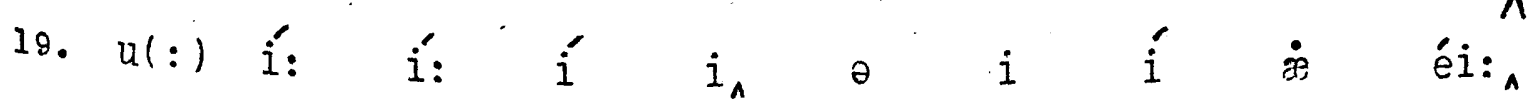

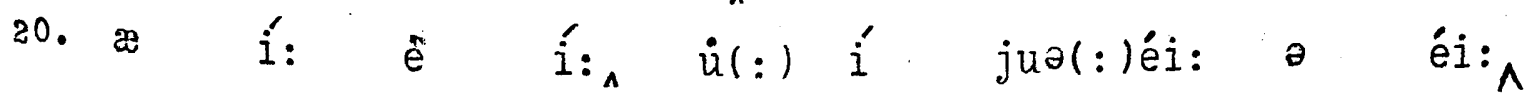


1. For, mark the scene of deep debate,

2. Where Britons sit on Europe's fate;

3. What loom'd exploit adorns it and inspires?

4. The walls, the very walls advise,

5. Bach mean, degenerate thought chastise,

6. And rouse the sons with all the ir fathers' fires;

From "The Foreign Address" (p.63, v.2) by E. Young.

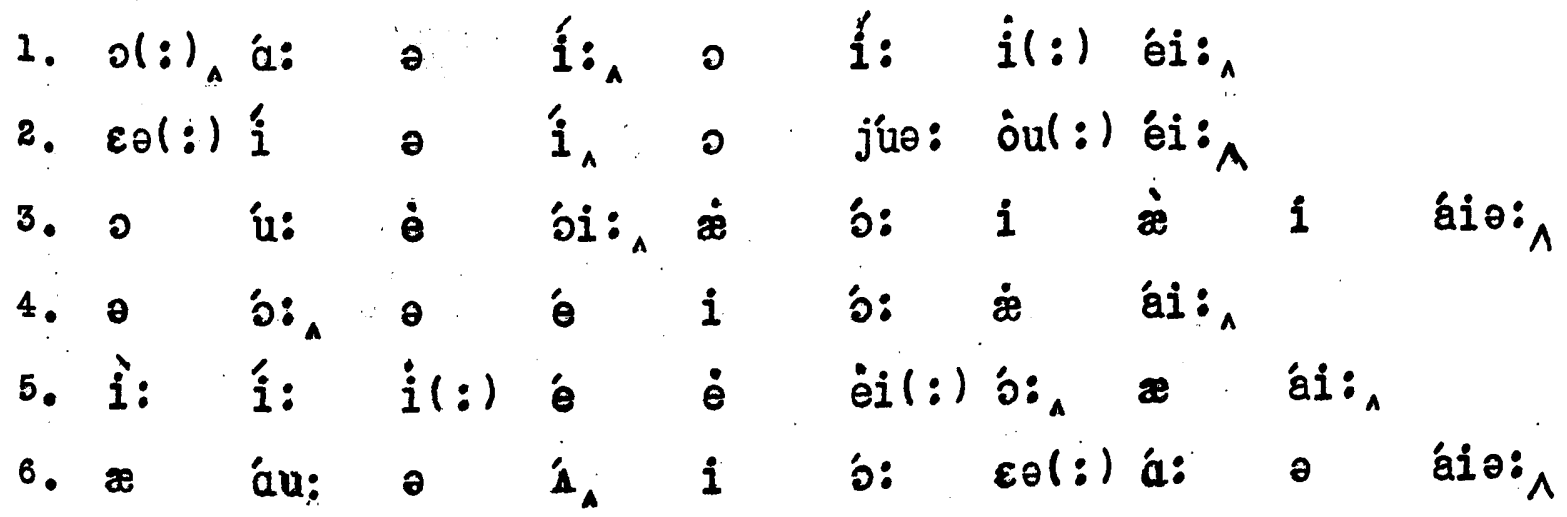


1. Mon'motape's cosst

2. Is seldom visited; and the rough shore

3. Of Caffres, land of savage Hottentots,

4. Who se hands unnatural hasten to the grave

5. Their aged parent s: what barbarity

6. And brutel igmorance, where social trade

7. Is held contemptible.

From "The Fiteece" Bk. IV (p.67) by J. Dyer.

1. $\dot{0} \dot{8} \dot{z}$ ou:

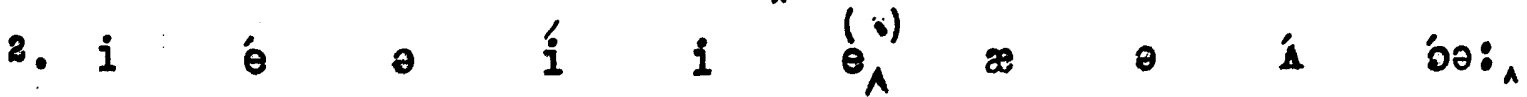

3. 0 安

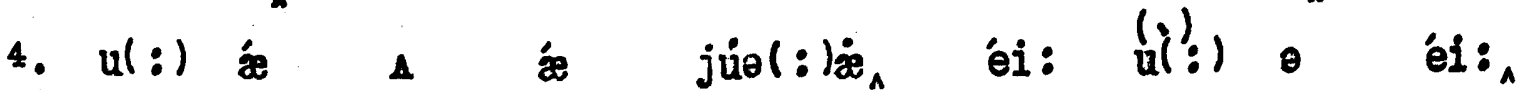

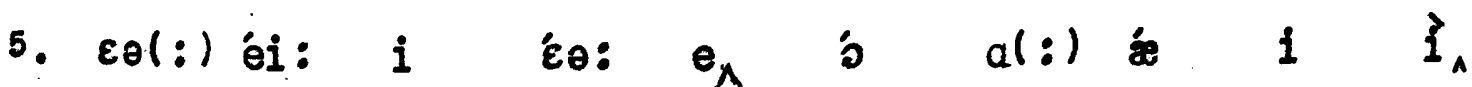

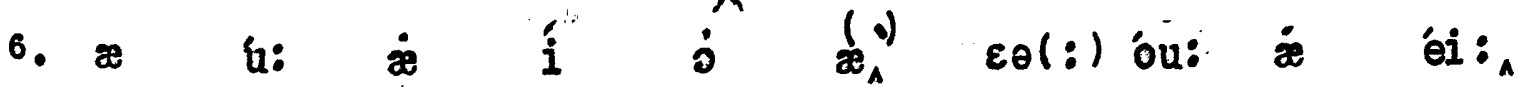

7. $i \quad \dot{\theta} \dot{j} \quad \dot{\theta} \quad i_{\wedge}$ 
1. Gods, and their noblest offspring here,

2. Soft terms refused, impose severe:

3. Ye nations know! know, all ye sceptred powers!

4. In sulphurous night, and mossy bells,

5. And floods of flame, the tempest falls,

6. When Pride presumes, and Britain's Senate lours.

From "The Foreign Address" (p.63, v.4) by F. Young.

\begin{tabular}{|c|c|c|c|c|c|c|c|c|c|}
\hline$\dot{b}_{a}$ & $\boldsymbol{x}$ & $\varepsilon \theta(:)$ & ou: & $\mathbf{i}$ & ว: & $\mathbf{i}$ & 'io: & & \\
\hline $3:$ & ó: & $\dot{i}(:)$ & jú & $\mathbf{i}$ & ou: & $i(:)$ & 1o:, & & \\
\hline$i(:)$ & ei : & - & ou: & ou: & $o(:)$ & $\dot{i}(:)$ & é & $\theta$ & áue: \\
\hline $\mathbf{i}$ & i & jüol: & & ái: a & $\approx$ & 6 & $i$ & o: A & \\
\hline $\boldsymbol{x}$ & i & 0 & éi : A & $\dot{\partial}$ & é & $i$ & $6:$ A & & \\
\hline$\theta$ & ái: & $\dot{i}(:)$ & jú: & $\approx$ & $\mathfrak{i}$ & $\dot{e i}(:)$ & $\dot{\theta}$ & $\dot{e} \mathbf{i}(:)$ & \\
\hline
\end{tabular}


1. In cold stiff soils the bleaters oft complain

2. Of gouty ails, by shepherds termed the halt:

3. Those let the neighbouring fold or ready crook

4. Detain: and pour into their cloven feet

5. Corrosive druts, deep searching arsenic,

6. Dry alum, verdigris, or vitriol keen.

7. But if the doubtful mi schef scarce appears,

8. Twill serve to shift them to a drier turf,

9. And salt again: thiutility of salt

10. Teach thy slow swains: redundant humours cold

11. Are the diseases of the bleating kind.

From "The Fleece", Bk. I (p.66)

by J. Dyer.

\begin{tabular}{|c|c|c|c|c|c|c|c|c|}
\hline 1. i & ou: & $i$ & ó : & $\theta$ & í: & $\theta$ & 3: & 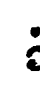 \\
\hline 2. 0 & áu: & i & éi : & $\dot{a i}(:)$ & $\dot{e}$ & $\dot{\theta}(:)$ & é: & $\theta$ \\
\hline ou: & $\theta$ & $\theta$ & éi: & ə & 1 & ou: & $\dot{o}(:)$ & $e$ \\
\hline
\end{tabular}

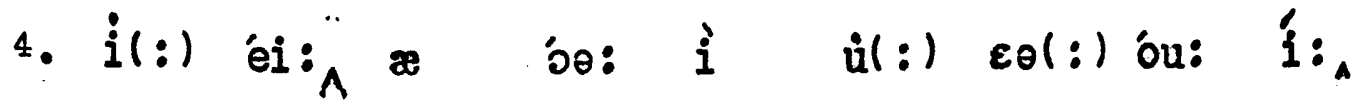

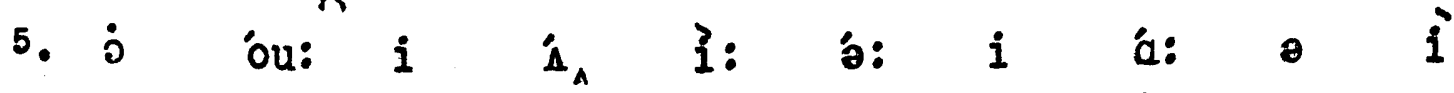

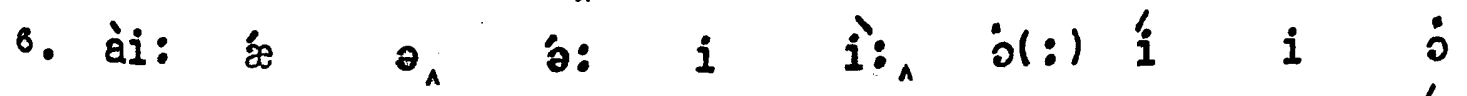

i:

7. $i$ i a áu: il $\dot{i}$ il (:)

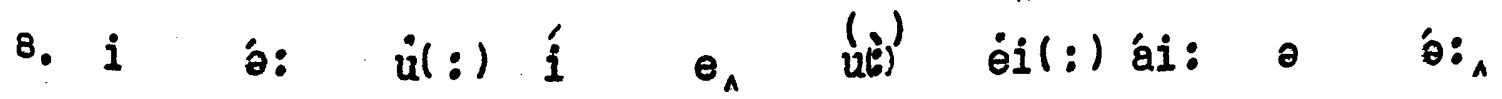

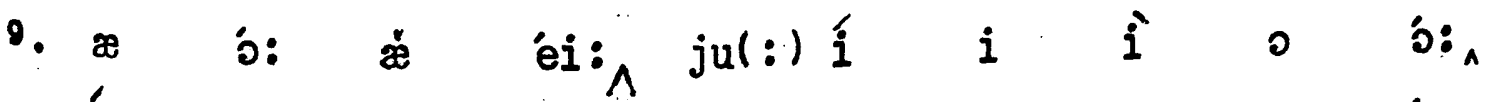

10. 'i: ail: $)$ ou: éi: $\hat{\wedge}_{\wedge} i(:)$ i $\dot{z}$ ju: $\theta$ ou:

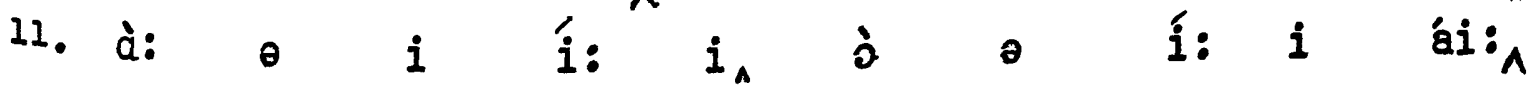


1. But in a dark and trying hour

2. (Man hath his days of woe!),

3. He found in vegetable power

4. A dreadful, deadly foo:

5. His heart corroded - sank to rest,

6. No more to ope life's way;

7. His hand no longer on thee pressed,

8. Thyself no more his stay:

9. He resteth where the nettles spring,

10. Not having aid from thee;

11. On that account I of thee sing,

12. Who now belongst to med

From "The Unfortunate Geratleman" (p.149) by C. Whar.

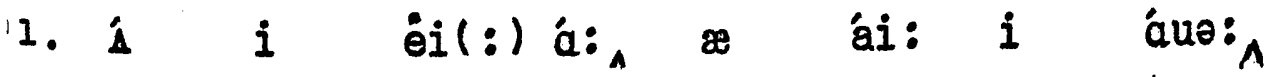

2. ǽ $¥$ i éi:

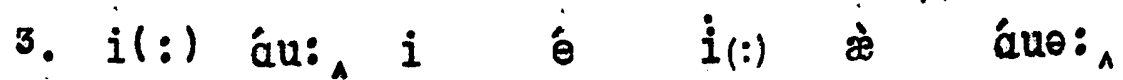

4. $\dot{e} i(:) \dot{e} \quad \dot{u}_{\wedge} \quad \dot{e} \quad i \quad$ ou:

5. i á: o ou: $i_{\wedge} \dot{m} \quad \dot{u}(:) \dot{e}_{A}$

6. ou(:) bə: $u(:)$ óu: ài: éi:^

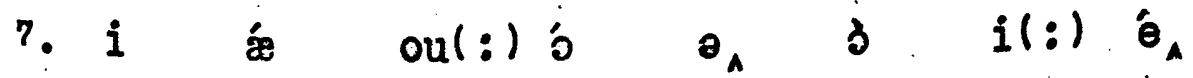

8. ai(:)ée oul: ) bo: $i$ éi:^

๑. $i(:) \dot{\theta} i_{\wedge} \varepsilon_{\theta}:$ $\theta \dot{\theta} i_{\wedge}$

10. o $\dot{i}$ i éi: 0 ín

11. 0 \& $\dot{z}$ áu: ài: 0 il: $\dot{i}_{\wedge}$

12. $u(:)$ du: $i(:)$ o $u(:)$ i: 
1. Thou greatest beauty of the sex,

2. When will the little god perplex

3. The mansions of thy breast?

4. When wilt thou own a flame as pure

5. As that seraphic souls endure,

6. And make thy Baker blest?

node to Miss Hoyland" (T.2,p.100)

by T. Chat terton.

\begin{tabular}{|c|c|c|c|c|c|c|c|c|}
\hline 1. & $a u(:)$ & éi: & $\mathbf{i}$ & jú: & $\mathbf{i}_{\wedge}$ & $\begin{array}{l}1.1 \\
0\end{array}$ & $\partial$ & $\dot{\theta}_{A}$ \\
\hline & e & i & $\theta$ & $i$ & $\dot{\partial}_{\wedge}$ & $\theta$ & é, & \\
\hline & $\theta$ & $\dot{a}$ & & 3 & $a i(:)$ & $\dot{e}$ & & \\
\hline & $\hat{\theta}$ & $i$ & $\operatorname{cu}(:)$ & ou: & éi $(:)$ & éi: & $\boldsymbol{x}$ & júr: A \\
\hline & 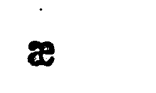 & $\dot{a}_{a}$ & $\ddot{\theta}$ & $\dot{2}$ & $\mathbf{i}$ & 'ou: & e & juo: A \\
\hline & $\approx$ & $\therefore$ & ai (:) & éi: & $\theta_{A}$ & $e_{A}$ & & \\
\hline
\end{tabular}


1. You think I have a merry heart

2. Because my songs are gay,

3. But oht they all were taught to me

4. By friends now far away:

5. The bird will breathe her silver note

6. Though bondage binds her wing; -

7. But is her song a happy one?

8. I'm saddest when I sing!

9. I heard them first in that sweet home

10. I never more shall see,

11. And now each song of joy has got

12. A mournful turn for me:

13. Alas! 'tis vain in winter time

14. To mock the songs of spring,

15. Each note recal is some withered leaf -

16. I'm saddest when I sing:

17. Of all the friends I used to love

18. My harp remains alone;

19. Its faithful voice still seems to be

20. An echo to my own:

21. My tears when I bend over it

22. Will fall upon its string,

23. Yet those who hear me little think

24. I'm saddest when I sing.

"I'm Seddest when I Sing" (p.158) by T.H. Bayly. 


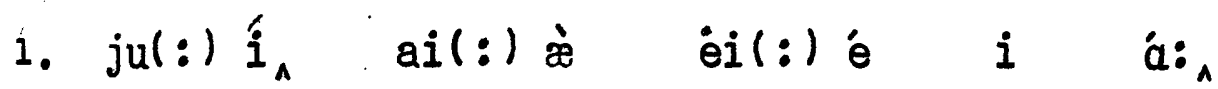

2. $i(:)$ ó $a i(:) b_{\wedge} a(:)$ éi:

3. $\Lambda$ ou: $:_{A}$ eil: $\varepsilon_{\theta}:$ b: ó: $u(:)$ i:

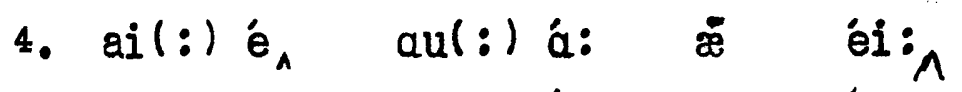

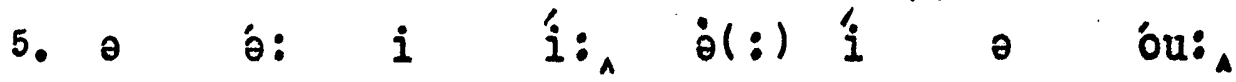

6. oul: ) o $i$ ái: $\dot{\theta}(:) \dot{i}_{\wedge}$

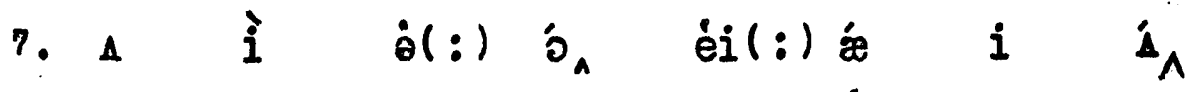

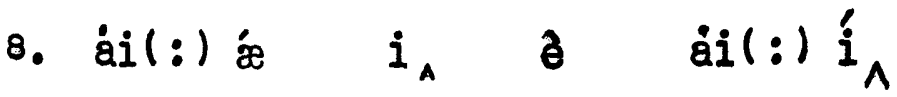

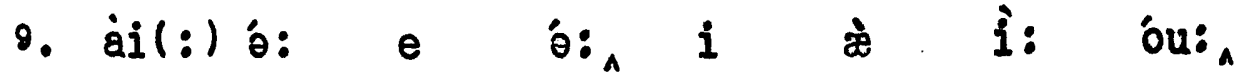

10. ài(:) é $\partial$ bo: $¥$ é

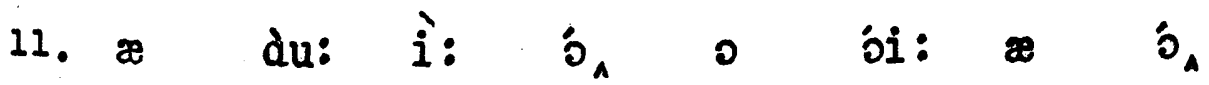

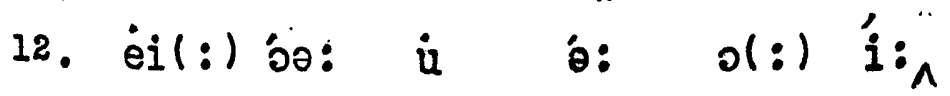

13. $\dot{x}$ á: $i$ éi: $i$ i

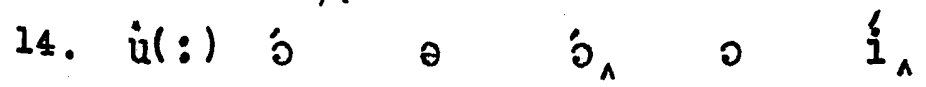

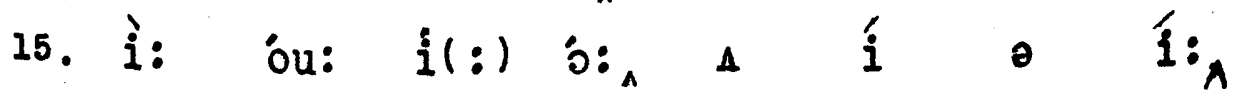

16. $\dot{a} i(:))_{g} \quad i_{\wedge}$ e $\quad \dot{a} i(:) i_{\wedge}$

17. 0 b: $\partial \quad \dot{e}_{A} \quad$ ail $(:)$ ju: $\dot{u}(:) \dot{\Delta}_{A}$

18. ail: $)^{\alpha}: \quad \dot{i}(:)$ éi $:_{\wedge} \dot{z}$ ou:

19. i éi: u oi:

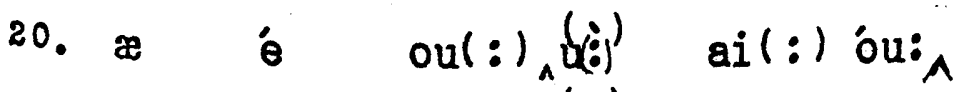

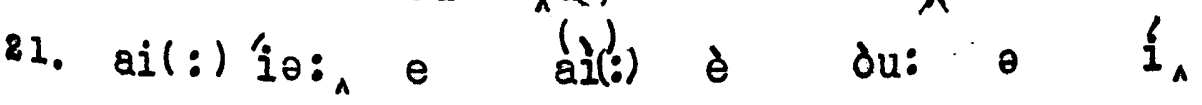

22. $i$ o: $\quad \dot{i}$ o $i \quad i_{A}$

23. e du: $u(:)$ í: $i(:))_{A} \hat{i}_{A}$

24. ai(:) 岜 $i_{A}$ è $\left.\quad \dot{a i}(:)\right)_{\wedge}$ 
1. Wake, sting her up: - Tradeb lean no more

2. On thy fixed anchor; push from shore:

3. Farth lies before thee;every climate court,

4. ind see, she's rous'd, absolved from fears,

5. Her brow in cloudless azure rears,

6. Spreads all her sail, and opens every port.

From "Imperium Pelagi" (p.56, v.2)

by E. Young.

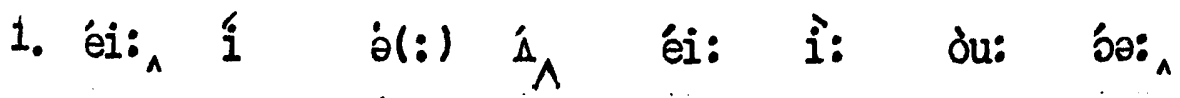

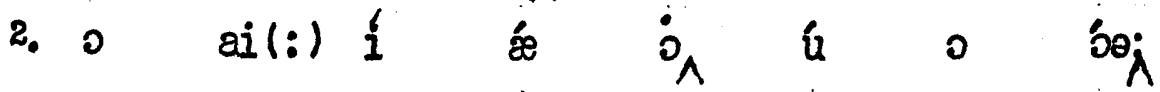

3. 3: ái: $\dot{i}(:)$ ob: $i(:) \wedge$ é $i$ ái: èi(:) óa

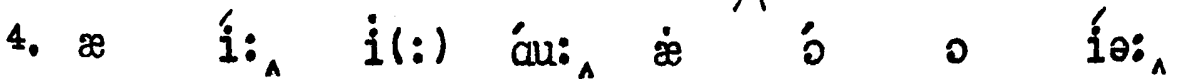

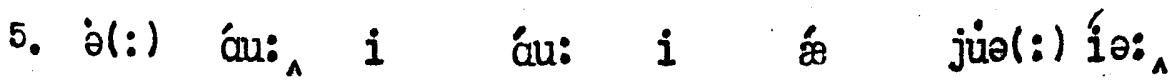

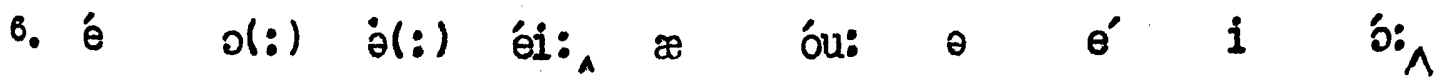


1. Teach them the style they used of old.

2. Would Britain have her anger told?

3. Oh, nover let a meaner language sound

4. Than that which through black ether rolls,

5. Than that which prostrates muman souls,

6. And rocks pale realms, when angry gods have from'd!

From "The Foreign Address" (p.63, T.3)

- by E. Young.

1. 'i: $\theta$ o ái: ${ }_{A}$ eil: $)$ ju: 0 ou:

2. $u$ i $\dot{i} i(:)_{A} \dot{\theta}(:) \dot{z}$ o ou:

3. ou(:) ${ }_{A} \dot{\theta}$ จ $\dot{\theta}_{A}$ eil(:)

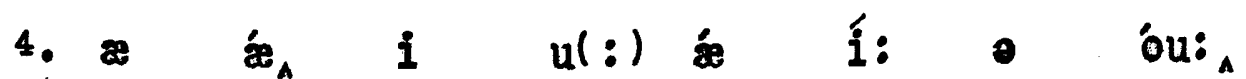

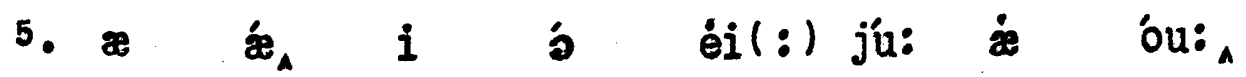

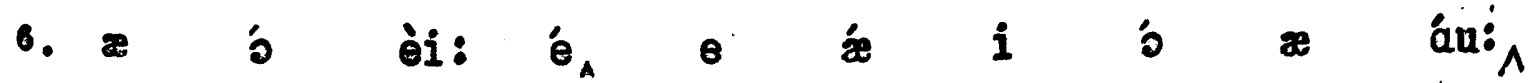


1. Ahl Hoyland, empress of my heart,

2. When will thy breast admit the dart,

3. And own a matual fiame?

4. When, wendering in the myrtle groves,

5. Shall matual pleasures geal our loves -

6. Pleasures without a name?

"Ode to ufss Hoyland"! (v.1, p.100) by $\mathbf{T}$. Chatterton.

1. al: $)_{\Lambda}$ ói: $x_{A}$ é $i$ o ái: áa

2. $̇ i$ ail : $)^{e_{A}} \dot{z} \quad \dot{i}$ o $a:_{A}$

3. \& ou: èil: jú jul: $)$ \& éi:

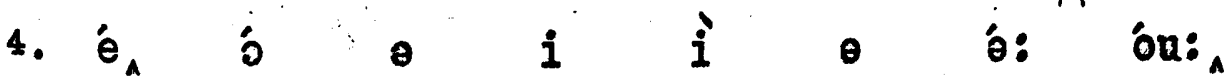

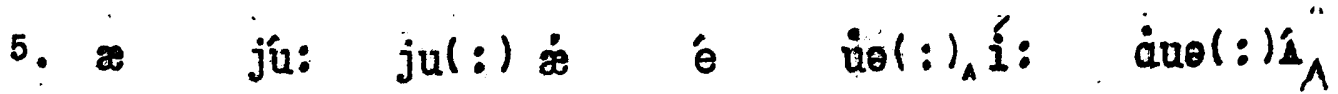

6. é de(:) $)_{A}$ du: éil: $)$ éi ${ }_{\wedge}$ 
1. God took their little treamure,

2. And his name I'll tell you now,

3. He has gone from earth forever,

4. Their little Charles Henry House.

"Iittle Henxy" (p.222)

by J. Moore.

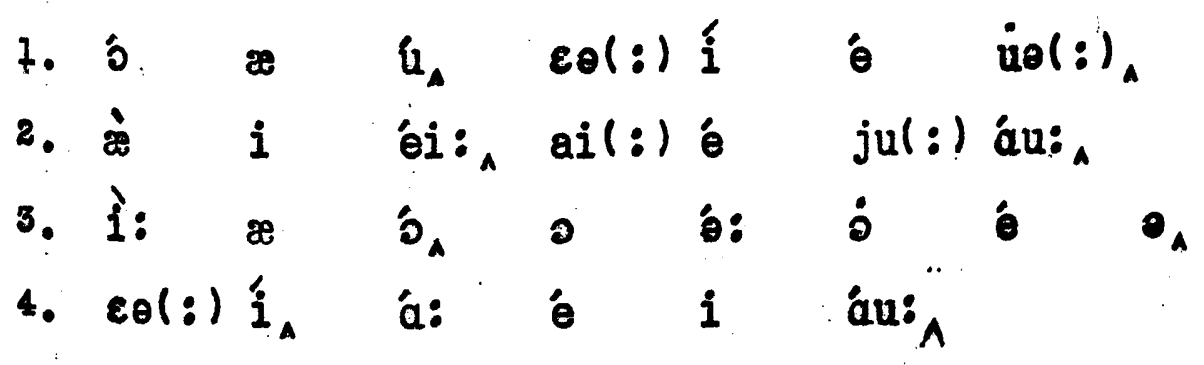


1. For he would never thas have flown,

2. And left me twice so doubly lone, -

3. Lone - as the corse within its shroud,

4. Ione - as a solitary cloud,

5. A single cloud on a sunny day,

6. While all the rest of heaven is clear,

7. A frown upon the atmosphere,

8. That hath no business to appear

9. When skies are blue, and earth is gay.

From Nhe Prisoner of Chillon" by Lord Byron. (p.130)

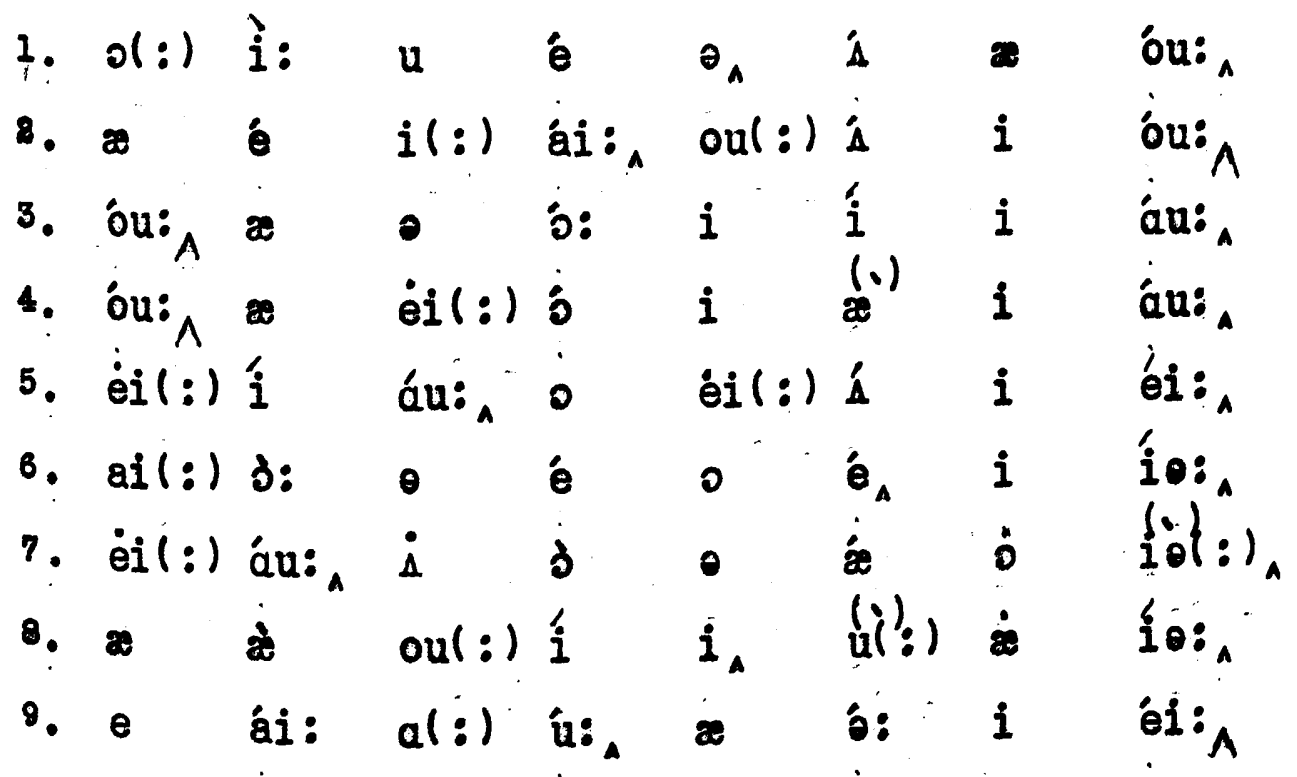


1. "Alast Alas" the father said,

2. "O what a dispensation

3. How can we be by mercy led,

4. In such a situation?

5. Be not surprised at my alarms,

6. The dearest boy is without arms ....

7. "I have no hope, no confidence,

8. The scene around is dreary;

9. How can I meet such vast expense?

10. I am by trying weary.

11. You must, my dearest, plainly see

12. This armiess boy will min me."

From "The Armless Artist" (\$.15I) by C. Whur.

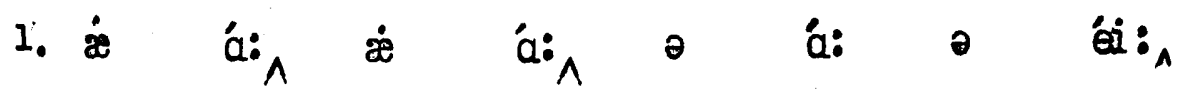

2. oul: $)$ ó éi(:) $i$ e éi: $\dot{o}_{\wedge}$

3. áu: $¥$ i(:) $i:_{\wedge}$ ail:) ว: $i$ é

4. $i \quad \dot{A}_{\Lambda}$ ëil(:) $\dot{i}$ ju(:) éi: $\dot{o}_{\Lambda}$

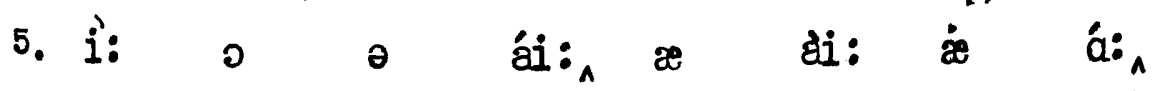

6. ค 'iə: $i$ ói: $i$ i $a(l)$ á:

7. ail: $)$ \& oul(:) óu: ${ }_{\wedge}$ oul(:) b $i$ $e_{\wedge}$

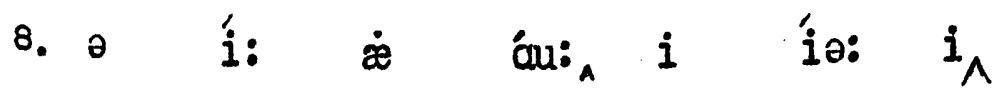

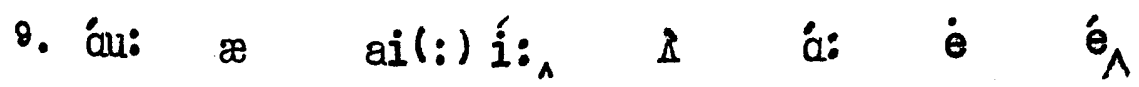

10. ai(:) ǽ ai(:) ái: $i_{\wedge}$ ío: $i_{\wedge}$

11. ju(:) $\dot{A}_{A}$ ai(:) iə: $i_{\wedge}$ éi: $i$ 'i:

12. $i$ á: $i$ ói: $i$ ú: $i$ ì 
1. Recount the years, ny song (a mournful round),

2. Since he was seen on earth no more;

3. Te fought in lower seas and drown'd;

4. But victory and peace are found

5. On the superios shore.

6. There now his tuneful breath in sacred songs

7. Employs the European and the Bastern tongues.

Heor "On the death of an aged and Honoured Relative".(P.38.)

by I. Watts.

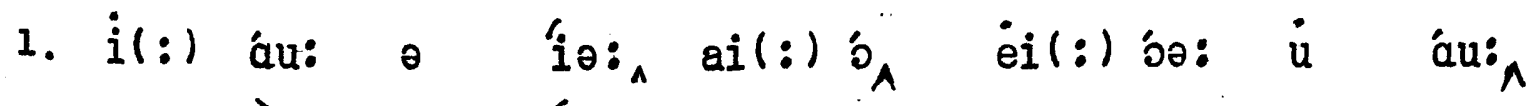
2. $i$ i: 0 i: 0 ó: du: bo:

3. $i(:)$ o: $i$ ou: $\partial \quad i_{\wedge}$ æ áu:

4. 1 i 0 ì 0 i: $a(:)$ áu:

5. 3 o jul: $)_{i \theta:} i$ o

B. $\varepsilon_{\theta}(:)$ áu: $i$ jú: $\dot{u}$ é $i$ éi: $i$ ó

7. e oi: o jứl(:)oul:) í: $\dot{x}$ \& $\theta$ í:

$\dot{\partial}(:) \quad \dot{\Lambda}_{\Lambda}$ 
1. If I had but two little wings,

2. And were a little feathery bird,

3. To you I'd fly, my dear!

4. But thoughts like these are idle things,

5. And I stay here.

6. But in ny sleep to you I fly:

7. I'm always with you in my sleepl

8. The world ig all one's own.

9. But then one wakes, and where am I?

10. All, all alone.

11. Sleep stays not, though a monarch bids,

12. So I love to wake ere break of day:

13. For though my sleep be gone,

14. Yet, while itis dark, one shuts one's lids,

15. And still dreams on.

"Something Childish, but Very Natural" by S.T. Coleridge.

1. $i$ di: $\approx$ u ù: $\quad \dot{1} \dot{i}_{\wedge}$

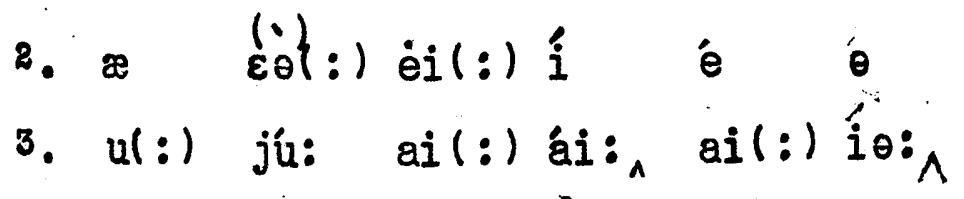

4. A ó: ail:) ì $a(:)$ ái: $i_{\wedge}$

5. æ ài: èi: $\hat{i}_{\theta}{ }_{\wedge}$

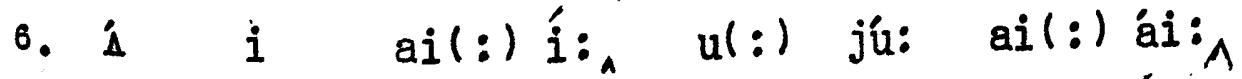

7. ai(:) b: ei(:) $i$ ju(:) ${ }_{\wedge}$ ai(:) $i: \wedge$

8. $\theta$ ó: $i$ ๖: $\Lambda$ ou:

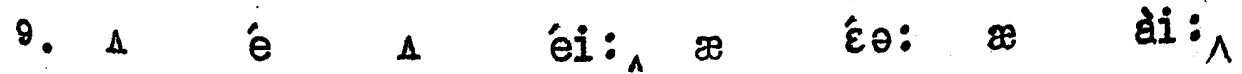

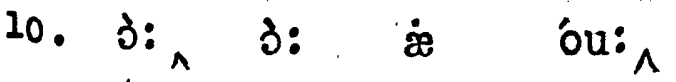

11. i: éi: $o_{\wedge}$ oul $\left.:\right)$ ei $\left.(:)\right)^{\prime} \quad \dot{a}(:) i_{\wedge}$

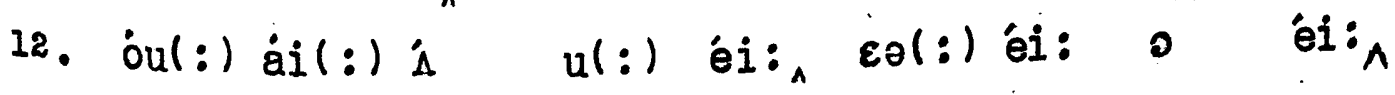

13. o(:) bu: ail: $i:$ il: $)_{1}$

14. $e_{\wedge}$ aili) $i \quad a:_{\wedge} \Delta i_{\Delta} \quad \Delta \quad i_{\wedge}$

15. $\approx$ i $i: \quad b_{\wedge}$ 
1. Thre was a mon was holf a clown

2. (It's so ry fatier tells of it),

3. Ie sev the chrren in Glemont Town

4. And lan hed to hear the bells of it.

5. Ie laughed to hear the bells that ring

6. In Clemont church and round of it;

7. He heard the vorger's daughter sing,

8. And loved her for the sound of it.

9. The verger's daughter said him nay

10. (She had the right of choice in it);

11. He left the town at break of day

12. (He hadn't had a voice in it).

13. The road went up, tise road went down,

14. And there the matter ended it;

15. He broke his heart in Clermont rown,

16. At Pantoiband they mended it.

"Auvergnat"

by H. Belloc.

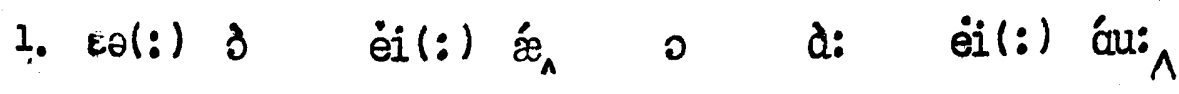

2. $i \quad \delta u:_{\wedge}$ ai(:) á: $\theta$ é $0 \quad i_{\wedge}$

3. i(:) ó: ә ว́: 1 á: 0 ád

4. $\circledast$ á: $\dot{u}(:)$ ĺa: $\theta$ é $0 \quad i_{\wedge}$

5. $\dot{i}(:)$ á: $\dot{u}(:)$ ĺ:

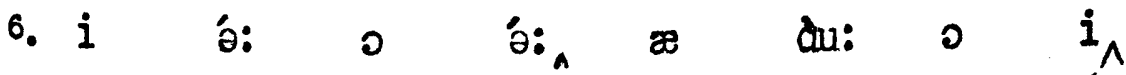

7. $\dot{i}(:)$ ó:

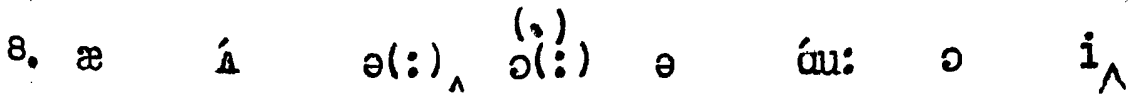

9. $\partial$ ó: $\theta$ ó: $\partial_{\wedge}$ é $i$ éi:

10. $i:_{\wedge} \approx$ a ái: 0 ói: $i \quad i_{\wedge}$

11. $\dot{i}(:)$ é

12. $\dot{i}(:)$ æ) $\dot{x}_{\wedge}$ éil(:) ói: $i \quad i_{\wedge}$

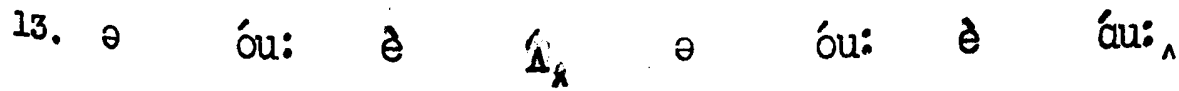

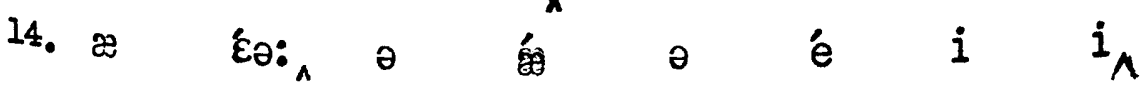

15. $\dot{i}(:)$ ou: $i$ á: $i$ ó: 0 cu:

16. $¥ \quad \stackrel{i}{i} \dot{x}_{\wedge}$ ei(:) é $i \quad i_{\wedge}$ 
1. Wen I consider how my light is spent

2. Ere half my days, in this dark world and wide,

3. And that one talent which is death to hide

4. Lodged with me useless, though my soul more bent

5. To serve therevith my likker, and present

6. Mig true account, lest He retuming chide, -

7. Doth God exact daj-labour, light denied?

8. I fondly ask: - But Patience, to prevent

9. That marmur, soon replies; Cod doth not need

10. Either man's work, or His own gifts: who best

11. Bear His mild yoke, they serve Him best: His state

12. Is kingly; thousands at His bidding speed

13. And post o'er land and ocean without rest: -

14. They also serve who only stand and wait.

"On his Blindness"

by J. Milton.

1. \& ai(:) 0 i $\partial_{\wedge}$ du: ail:) ái: $i$ é,

2. $\varepsilon_{\theta}(:)$ d: ail $\left.:\right)$ éi: $i$ i d: ó: $¥$ ái:

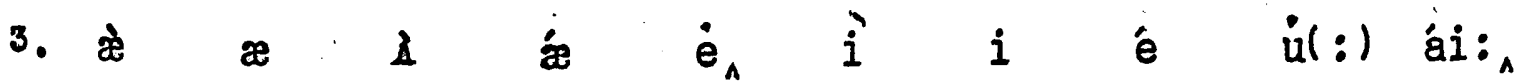

4. o $i$ il : $)$ ju: $i_{\wedge}$ du: ai(:) ou: ov(:) $e_{\wedge}$

5. $u(:)$ à: $\varepsilon \theta(:)$ i ai(:) éi: $\theta_{\wedge} \approx \quad i(:)$ é,

6. ail:) ú: $\dot{x}$ áu: e $_{\wedge} \dot{1}: \dot{i}(:)$ ó: $i$ ái:

7. 1 ó $\dot{e}$ \& èi éi: $\theta_{\wedge}$ ái: $i(:)$ ái:

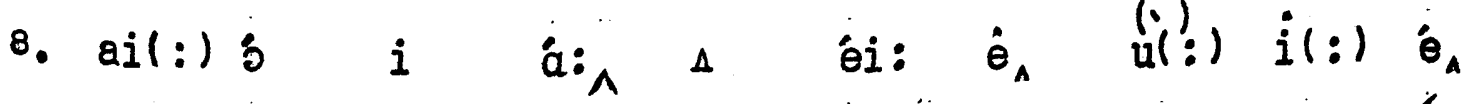

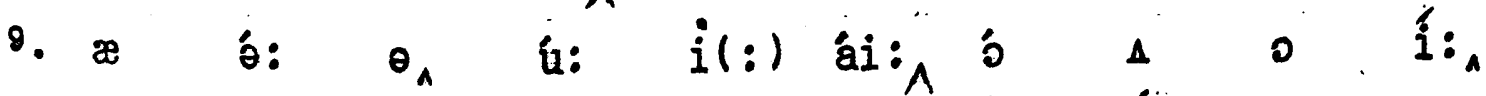

10. ài: $\theta$ \& $\dot{\theta}_{\wedge} \quad j(:) \quad i \quad$ ou: $i_{\Lambda}$ ü: $\dot{e}_{A}$

11. $\varepsilon \theta(:)$ '́ ài: où ${ }_{\wedge}$ èi: ó: $i$

12. $i$ i $i_{\wedge}$ áu: $\theta_{\wedge}$ æ $i$

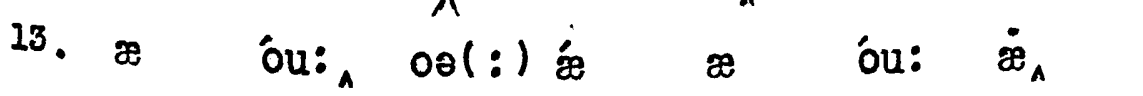

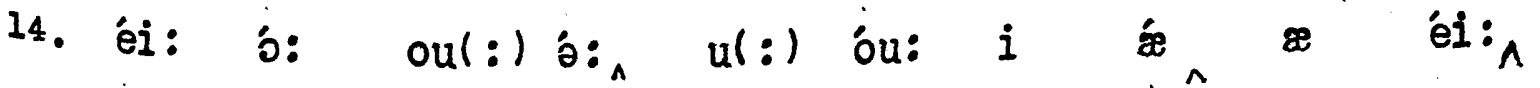


1. I had a dove and the sweet dove died;

2. And I have thought it died of grieving:

3. Oh, what could it grieve for? It s feet were tied,

4. With a silken thread of my own hands' weaving;

5. Sweet little red feet! why should you die?

6. Why should you leave me, sweet birdl why?

7. You lived alone in the forest tree;

8. Why, pretty thing! would jou not live with me?

9. I kissed you oft and gave you white peas;

10. Why not live sweetly, as in the green trees?

"The Dove"

by J., Keats.

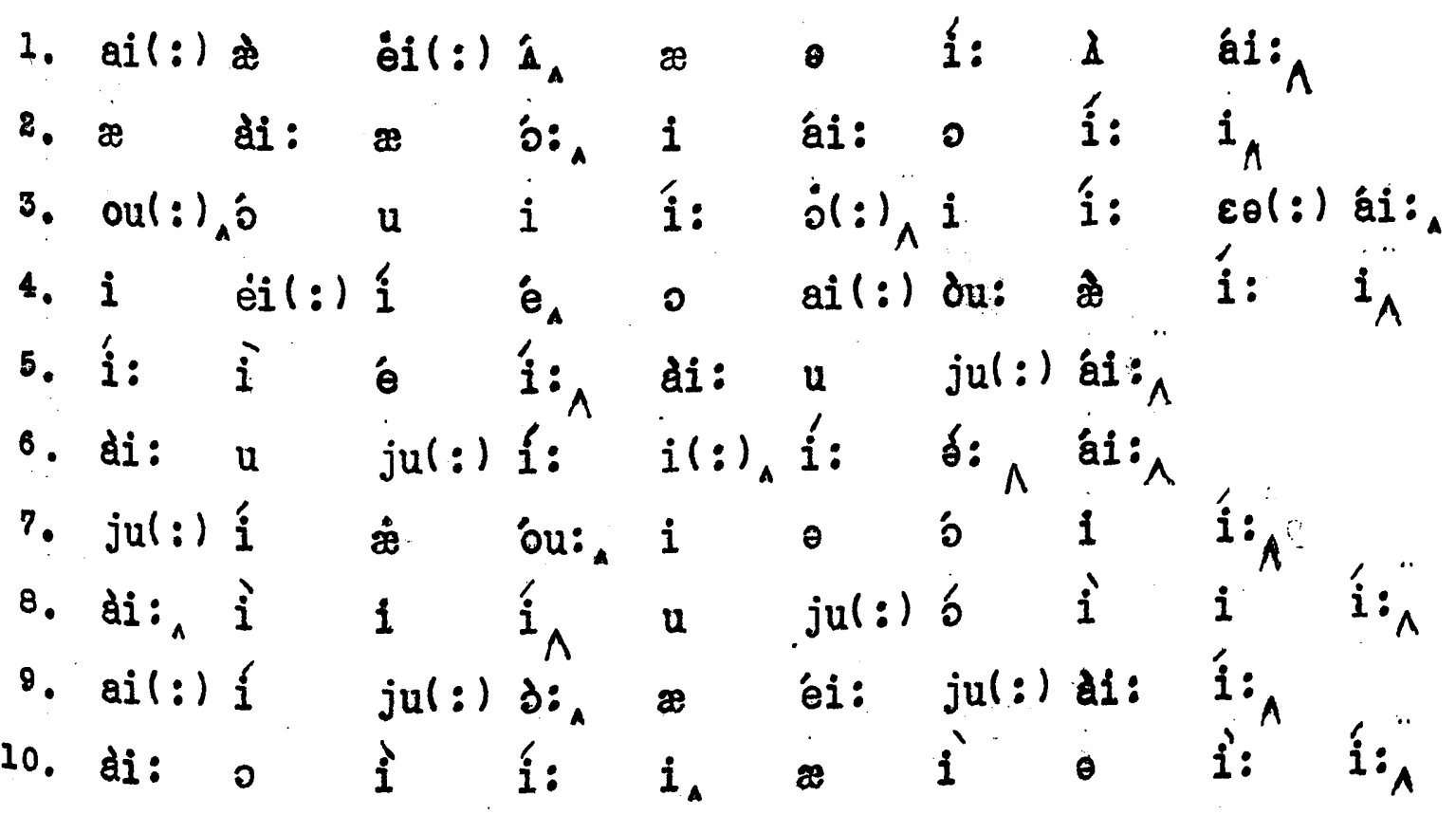


1. I have seen dew and sunset on rnoors and windy hills

2. Coming in solem beauty like slow old tunes of Spain:

3. I have seen the lady April bringine the daffodils,

4. Bringing the springing grass and the soft warm April rain.

5. I have heard the song of the blossoms and the old chant of the sea,

6. And seen strange lands from under the arched white sails of ships;

7. But the loveliest things of beauty God ever has showed to me

8. Are her voice, and her hair, and eyes, and the dear red curve of her lips.

"Beauty"

by J. Masefield.

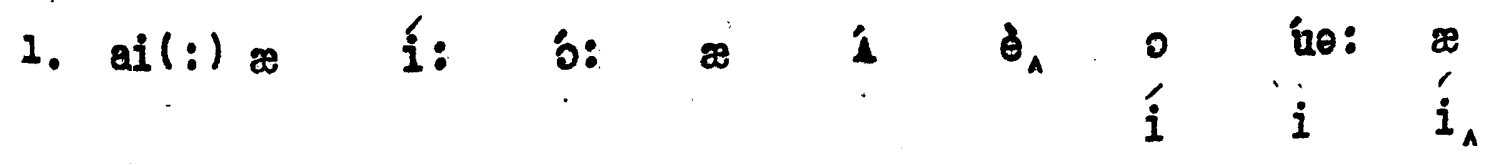

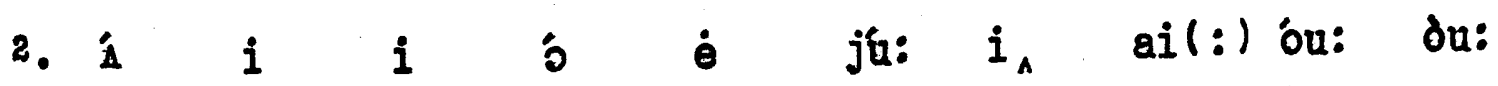

. jú: 0 éi:

3. $\operatorname{ail}:)_{\circledast}$ í $\theta$ éi: $i$ éi: $i_{A} \hat{i} i$ o $\dot{o u l}: i_{A}$

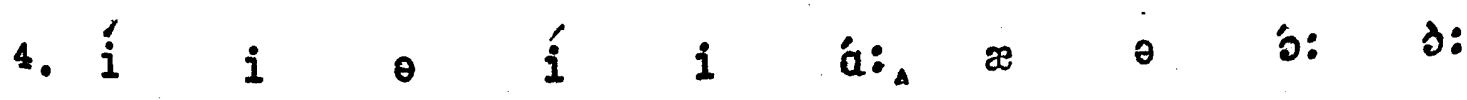

éi: i éi:^

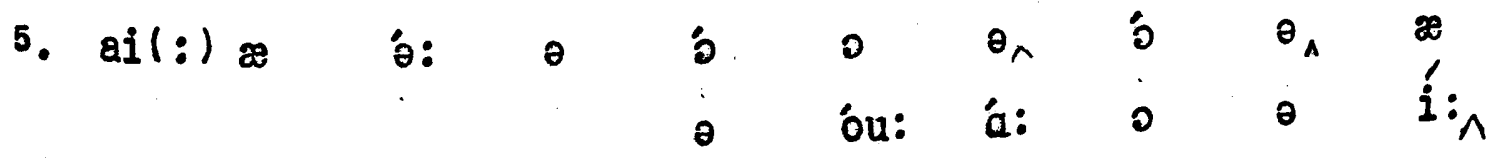

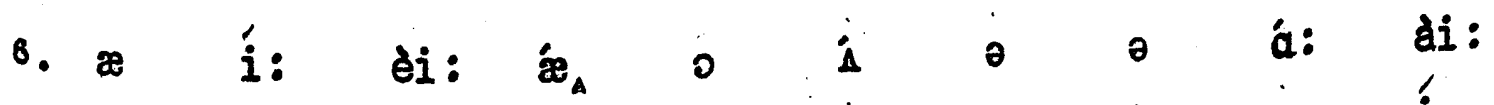

éi: $\quad$ ín

7. $\Delta \quad \begin{array}{llllllll}\Delta & i & i & i & i & 0 & j u: & i_{A}\end{array}$

é $\curvearrowright$ ou: $u(:)$ i:

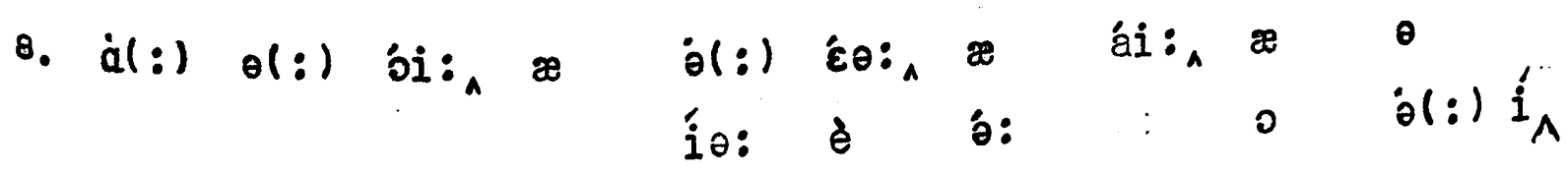


1. Swiftly wall over the western wave,

2. Spirit of Night!

3. Out of the misty eastern cave,

4. Where, all the long and lone daylight,

5. Thou wovest dreams of joy and fear

6. Which make thee terrible and dear, -

7. Swift be thy flight!

Wo the Night" (v.1)

by P.B. Shelley.

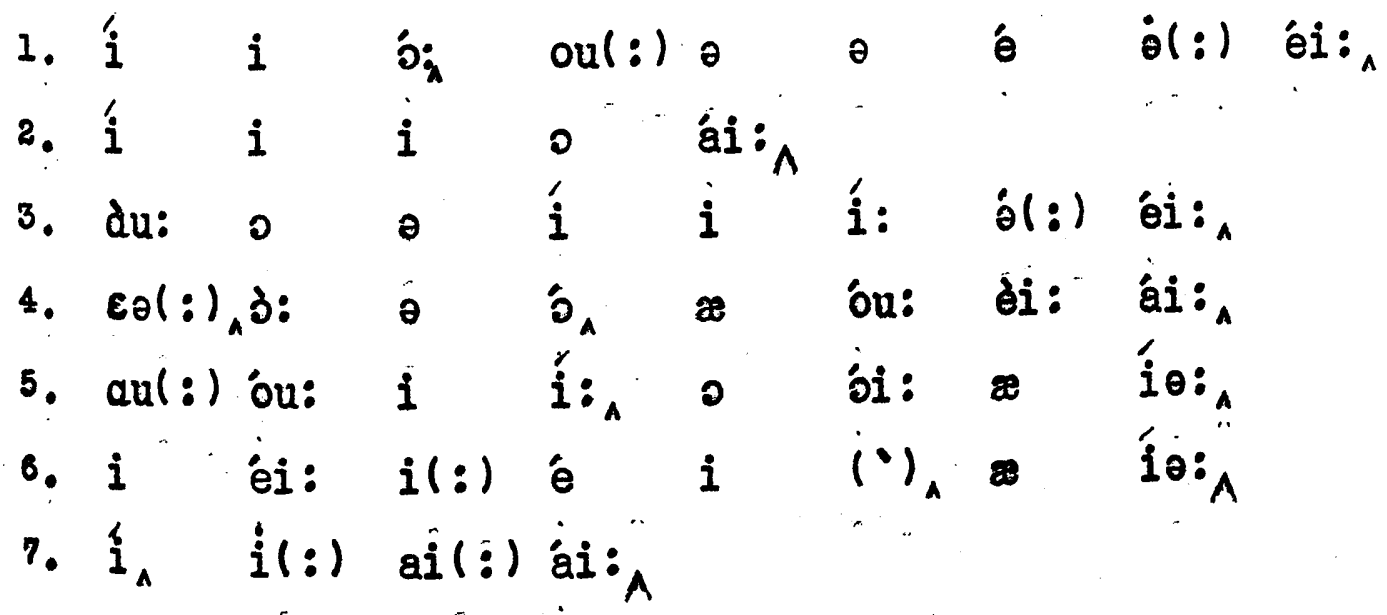


1. Wrap thy form in a mantle grey

2. Star-inwrought!

3. Blind with thine hair the eyes of Day,

4. Kiss her until she be wearied out,

5. When wander o'er city, and sea, and land,

6. Touching all with thine opiate wand -

7. Come, long-sought ?

"Po the Night" (

by P.B. Shellay.

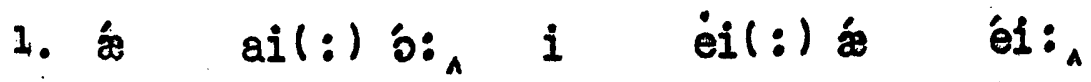

2. á: i o:

3. ái: $i$ ail $(:) \varepsilon \theta \wedge$ a $\theta$ ai 0 éi:

4. $i \quad \theta(:) \wedge$ i $i(:) \quad i(:)$ lo: $i$ áu:

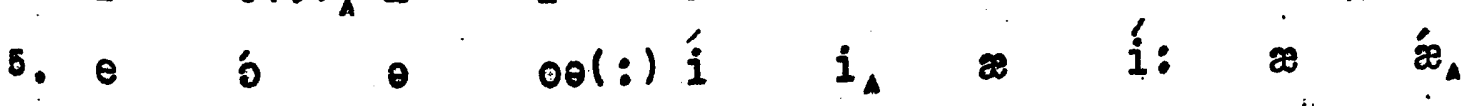

b. $i$ i b: $i$ ail: ou: $i$ i

7. is 3 o 
1. When $I$ arose and saw the dawn,

2. I sigh'd for thee;

3. When light rode high, and the dew was gone,

4. And noon lay heavy on flower and tree,

5. And the weary Day turn'd to his rest,

6. Lingering like an unloved guest,

7. I sigh'd for theo.

"To the Night" (

by P.B. Shelley.

$\begin{array}{llll}\text { 1. } & \text { ài: } & \dot{8} & \text { ou: } \\ \text { 2. ail }) \text { ái: } & \dot{b}(:) \text { i: }\end{array}$

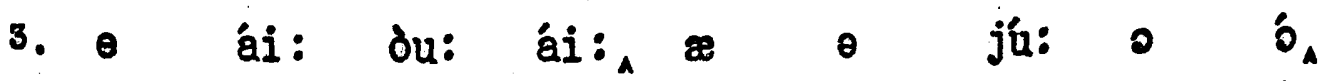

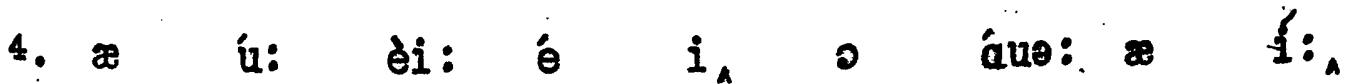

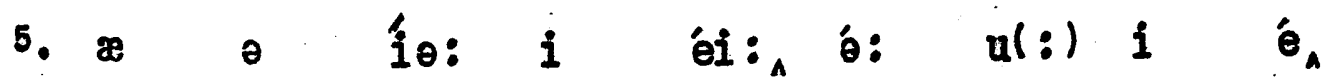

6. $i \quad \theta \quad i_{A}$ ài $\approx \quad \lambda \quad i \quad e_{A}$

7. ai(:) ái: $\quad \dot{o}:$ ) $i: \wedge$ 
1. Thy brother Death came, and cried,

2. 'Wouldst thou me?'

3. Thy sweet child Sleep, the filmy-eyod,

4. Mrurmur'd like a noontide bee,

5. 'Shall I nest le near thy side?

6. Wouldst thou me?' - And I replied,

7. 'No, not thee!'

"To the Night" (v.4)

by P.B. Shelley.

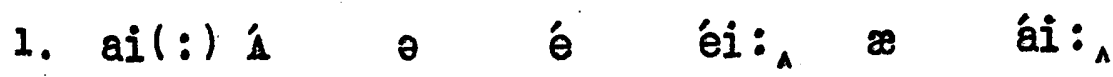

2. ú du: $i: \wedge$

3. ai(:) 1 : ài: $i:_{A}$ $\theta$ i $i$ ái:

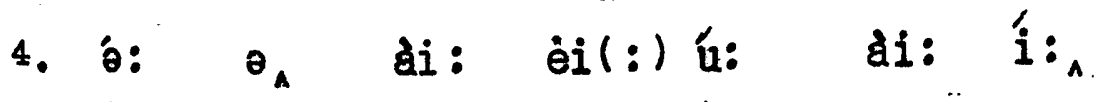

5. æ ái: \&

6. ú du:

7. ou: i $i:{ }_{A}$ 
1. Loveliest of trees, the cherry now

2. Is hung with bloom along the bough,

3. And stands about the woodland ride

4. Wearing white for Eastertide.

5. Now, of my threescore years and ten,

6. Twenty will not come again,

\%. And take from seventy springs a score,

8. It only leaves me fifty more.

9. And since to look at things in bloom

10. Fifty springs are little room,

11. About the woodlands I will go

12. To see the cherry hung with snow.

A.E. Housman.

\begin{tabular}{|c|c|c|c|c|c|c|c|}
\hline 1. A & $\mathbf{i}$ & $e^{(1)}$ & 0 & $\mathfrak{i}:$ A & $\theta$ & $\dot{e}$ & i \\
\hline 8. $i$ & i & i & á: & $\dot{æ}$ & 3 & $\dot{\theta}$ & áu: \\
\hline 3. $\quad 2$ & $\dot{⿱ 亠 凶}_{\wedge}$ & $\mathbf{c}$ & du: & $\theta$ & ú & $\dot{z}$ & ai : \\
\hline 4. $\varepsilon_{\theta}:$ & $i$ & ai : & 0 & í: & $\dot{\theta}$ & ái: & \\
\hline 5. ád: & 0 & ài: & í: & $\partial \theta(:)$ & í: & $\approx$ & $\mathfrak{e}_{\mathrm{A}}$ \\
\hline 6. i & $i_{\wedge}$ & $\mathbf{i}$ & 0 & is & $\dot{\ddot{x}}$ & éi : & \\
\hline 7. æ & éi ${ }_{A}$ & 0 & $\dot{e}$ & $i$ & $\dot{i}$ & $\dot{e} i(:)$ & bo: \\
\hline 8. $i$ & ou: & i & i: & $i(:)_{\wedge}$ & í & $\mathbf{i}$ & or: \\
\hline 9. $\mathbf{E}_{A}$ & $i$ & $\dot{u}(:)$ & $\hat{\mathbf{u}}$ & $\approx$ & $\stackrel{1}{\mathbf{i}}$ & $\mathbf{i}$ & u: \\
\hline$\dot{i}$ & $\mathbf{i}$ & $\dot{i}_{A}$ & $\dot{a}(:)$ & 1 & $\mathfrak{u}_{\Lambda}$ & & \\
\hline$\dot{\nexists}$ & du: & $\partial$ & $\hat{\mathbf{u}}$ & $\dot{\ddot{\otimes}}_{\wedge}$ & ai : & $i$ & ou: \\
\hline$u(:)$ & í: & $\partial$ & $\dot{e}$ & $i_{\wedge}$ & í & $i$ & ou: $A$ \\
\hline
\end{tabular}


1. The night is freezing fast,

2. To-norrow comes December;

3. And winterfalls of old

4. Are with me from the past;

5. And chiefly I remember

6. How Dick would hate the cold.

7. Fall, winter, fall; for he,

8. Prompt hand and headpiece clever,

9. Has woven a winter robe,

10. And made of earth and sea

11. His overcoat for ever,

12. And wears the turming globe.

A.E. Housman.

1. o ái: $i$ í: $i$ á:

2. $\dot{u}(:) \dot{0}$ oul: $) \dot{A} \quad \dot{i}(:) \dot{\theta}{ }^{\circ} \wedge$

3. $\infty \quad i \quad j: \quad 0$ ou:

4. $a(:) i \quad i(:), b^{(0)}$ o $\quad \dot{a}:_{A}$

5. $\approx$ i: $i$ ài: $i(:)$ è $\theta_{A}$

6. aul: I 1 u éi: a: ou: $\wedge$

7. o: 1 on

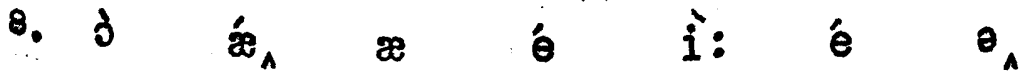

9. $x$ ou: $\dot{e i}(:) i$ ou:

10. æ éi: 0 ó: æ

11. $i$ ou: a ou: $o(:)$ é $\partial_{A}$

12. 2 iे $\dot{\varepsilon}_{\theta}$ o $\dot{\theta}:$ i ou: 
1. When the eye of day is shut,

2. And the stars deny their beams,

3. And about the forest hut

4. Blows the roaring wood of dreams,

5. From deep clay, from desert rock,

6. From the sunk sands of the main,

7. Come not at my door to knock,

8. Hearts that loved me not again.

9. Sleep, be still, turn to your rest

10. In the lands where you are laid;

11. In far lodgings east and west

12. Iie down on the beds you made.

13. In gross marl, in blowing dust, 14. In the drowned ooze of the sea, 15. Where you would not, lie you mast, 16. Lie you must, and not with me.

1. \& $\theta$ ái: 0 éi: $i$ ÁA

2. $¥$ o $a: \quad \dot{i}(:)$ ái: $\varepsilon \theta(:)$ li:

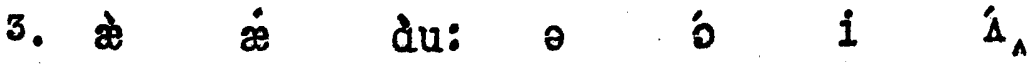

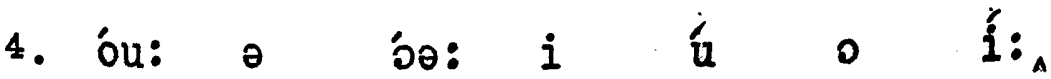

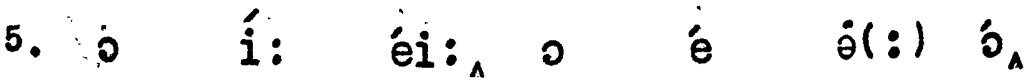

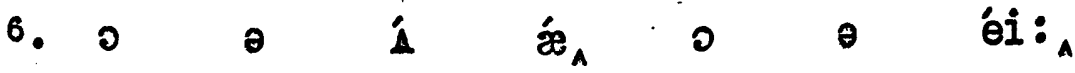

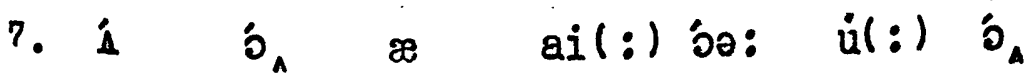

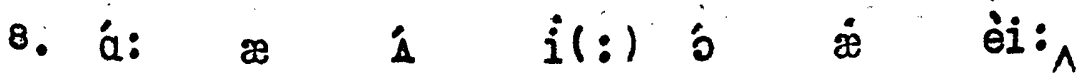

9. $\dot{i}_{A} \quad i(:) \dot{i}_{A}$ ó: $\dot{u}(:)$ juol:lé,

10. i o ǽ Ė: ju(:) al:) éi:

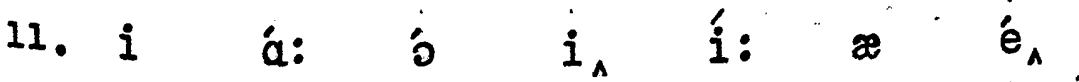

12. ài: áu: 0 $\diamond$ é ju(:) éi:

13. i ou: á: $i$ óu: $i$ 's

14. $i$ a áu: í: ${ }_{\wedge}$ o $\theta$ í

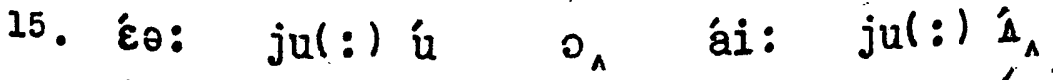

16. ái: $j u(:) i_{\wedge} \approx$ o $i \quad i_{\wedge}^{\prime}$ 
1. The western wave was a.11 a-flame;

2. The day was well nigh done!

3. Almost upon the western wave

4. Rested the broad bright Sun!

5. When that strange shape drove suddenly

6. Betwixt us and the sun.

"Whe Rime of the Ancient Mariner" (171-176)

by S.T. Coleridge.

1. $\theta$ é $\dot{\theta}(:)$ éi: 0 b: $\dot{x}$ éi:

8. $\theta$ éi: 0 é ài $\hat{A}_{A}$

3. 3: ou(:) ${ }_{A} \dot{A}$ j $\theta \quad \dot{e} \quad \dot{\theta}(:)$ éi:

4. é î o ó ail $i_{\wedge}$

5. $\theta$ \& èi: éi: bu: $i_{\text {A }} i_{A}$

6. $\dot{i}(:) \quad i \quad \& \quad \& \quad \otimes \quad{ }_{\Lambda}$ 
1. A slumber did my spirit seal;

2. I had no human fears:

3. She seemed a thing that could not feel

4. The touch of earthly jears.

5. No motion has she now, no force;

6. She neither hears nor sees;

7. Rolled round in earth's diumal course,

8. With rocks, and stones, and trees.

W. Wordsworth.

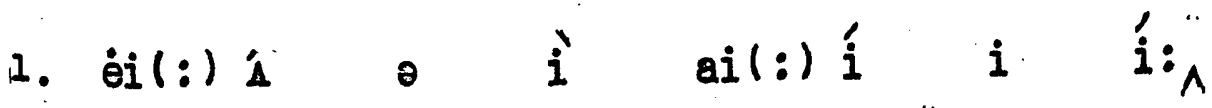

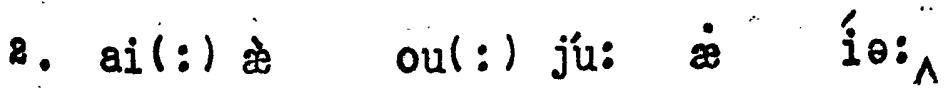

3. $i(:)$ i: $e_{i}(:) i_{A} \approx$ u 0 i:

4. $\theta$ i $\wedge$ a: $i$ io:

5. oul: $)$ ou: $\partial_{\wedge} \quad(\cdot)$ il $\left.i\right)$ du: oul $(:)$ bo:

6. $i(:)$ ái: $\theta$ í⿴囗十 ol:) $i:_{\wedge}$

7. du: du: $i$ á: ai(:) á: bo:

8. $i$ o, $\approx$ ou: $¥$ í 
1. The very God think, Abib; dost thou think?

2. So, the All-Great, were the All-Loving too -

3. So, through the thunder comes a muman voice

4. Saying, "O heart I made, a heart beats here!

5. "Face, my hands fashioned, see it in my self!

6. "Thou hast no power nor mayst conceive of mine,

7. "But love I gave thee, with myself to love,

8. "And thou mast love $m e$ who have died for theed"

An Epistle containing the Strange Modical Rxperience of Karshish, the Arab Physician by R. Browning.
1. $\theta$ é
$i \quad \dot{\partial}_{\wedge} \dot{i}_{\wedge}$
éi: î
$\Delta$
aul : $) \stackrel{h}{i} \wedge .^{.}$.
2. $\delta u_{A}$
3: éi: $\varepsilon_{\theta}: \quad i$
3:
i
i
uे: $\wedge$
3. bu: $u(:)$ o i
A
eil(:) jú:
$\dot{x}$
วi:
4. éi: $i_{A}$ oul : ) á:
ail : ) éi :
èi(:) áa:
i: $i_{\wedge}$
5. éi: ail: $)_{\sharp}$
æ
$\theta_{\wedge} \quad \mathrm{i}:$
i
i
$\operatorname{ai}(:) \dot{\theta}_{\Lambda}$
6. du: æ
oul: ) áuə: ${ }_{1}(:)$ di:
o 1 :
o
ái:
7. $A$ i
ai(:) éi: $i(:) \wedge i$
ail : $)^{\prime}$ é
$u(:)$ is
8. æ du:
$\Delta$ i. $i(:)$, น̀:
ש
ái: ol: $i \hat{\Lambda}_{\wedge}$ 
1. O latest born and loveliest vision far

2. Of all Olympus' faded hierarchy!

3. Fairer than Phoebe's sapphire-region'd star,

4. Or Vesper, amorous glow-worm of the sky;

5. Fairer than these, though temple thou hast none,

6. Nor altar heap'd with flowers;

7. Nor Virgin-choir to make delicious moan

8. Upon the midnight hours;

9. No voice, no lute, no pipe, no incense sweet

10. From chain-swung censer teeming;

11. No shrine, no grove, no oracle, no heat

12. Of pale-mouth'd prophet dreaming.

From "To Psyche"

by J. Keats.

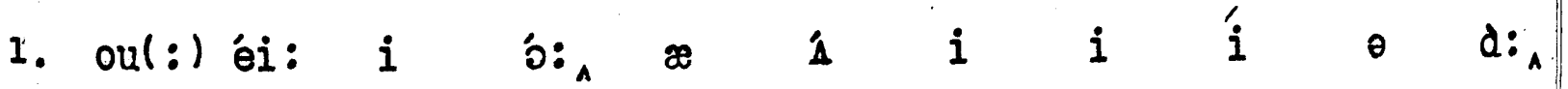

2. o b: oul: $)^{\prime} \quad i_{\wedge}$ éi: $i$ áä: $\dot{\theta}$ d: $i_{\wedge}$

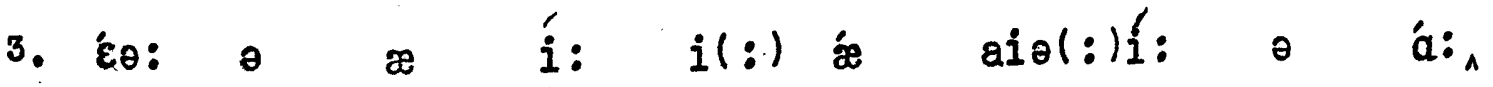

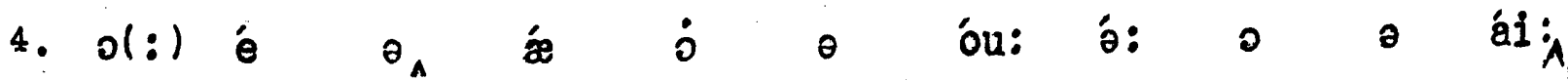

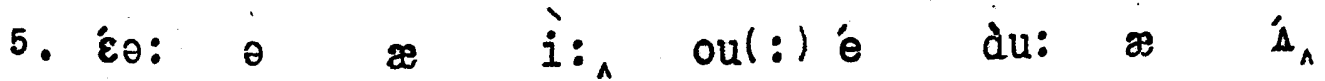

6. ol:) o: $\theta$ '́i: $i$ áue:

7. $o(:)$ á $i$ ó $i:_{A} u(:)$ éi: $i(:)$ ĺ $\theta$ ou:

8. $i$ o $\partial$ i $\quad$ ai $(:)$ áuə:

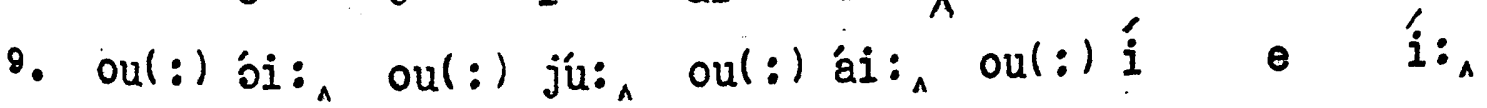

10. o ei: 1 é $\partial$ i: $i_{A}$

11. oul:) ái: , oul: ) ou:

12. o éi: du: $\dot{0}^{\prime} i_{i}^{\prime} i_{\wedge}$ 
1. How oft do they their silver bowers leave

2. To come to succour us, that succour want,

3. How oft do they with golden pineons cleave

4. The flitting skyes, like flying pursuivant,

5. Against foule feendes to aid us militant:

6. They for us fight, they watch and dewly ward,

7. And their bright squadrons round about us slant;

8. And all for love, and nothing for reward:

9. 0 , why should heavenly God to men have such regard?

"The Ferie Queene" (II.8)

by E. Spenser.

1. oul : ) b: $u(:)$ di: $\varepsilon \theta(:) \dot{i} \theta$ aus: $\dot{i}$ :

2. $\dot{u}(:)$ i $\dot{u}(:)$ i $\theta \quad \dot{A}_{A} \approx$

3. $a u(:)$ b: $u(:)$ èi: $i$ ou: $i^{\prime}$

4. จ 1 i ái: a ai(:) ái: $i$

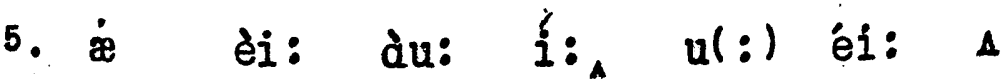

b. èi: ol:) 1 ái: eil:

7. æ દə: ài: ó

8. $\approx$ b: ol: $\dot{A}_{A}$

9. oul : ) ài: u $\theta_{\wedge} \dot{d u}: \dot{z}$

$\approx$

i 1 is

a

o: $\quad i(:) æ_{A}$

i

jú: i

du: 4 á

(l!) $i(:)$ o:

$\dot{u}(:)$ é

× $\quad 1$ $i(:) \quad a:_{A}$ 
1. Softly along the road of evening,

2. In a twilight dim with rose,

3. Wrinkled with age, and drenched with dew,

4. Old Nod, the shepherd, goes.

5. His drowsy flock streams on before him,

6. Their fleeces charged with gold,

7. To where the sun's last beam leans low

8. On' Nod the shepherd's fold.

9. The hedge is quick and green with brier,

10. From their sand the conies creep;

11. And all the birds that fly in heaven

12. Flock singing home to sleep.

13. His lambs out number a noon's roses,

14. Yet, when night's shadows fall,

15. His blind old sheep-dog, Slumber-soon,

16. Misses not one of all.

17. His are the quiet steeps of dreamland,

18. The waters of no more pain,

19. His ram's bell rings 'neath an arch of stars,

20. "Rest, rest, and rest again."

"Nod"

by W. de la Mire. 
1. o: $i \quad \dot{x} \quad 3 \quad \theta \quad$ ou: 0 í $i_{\wedge}$

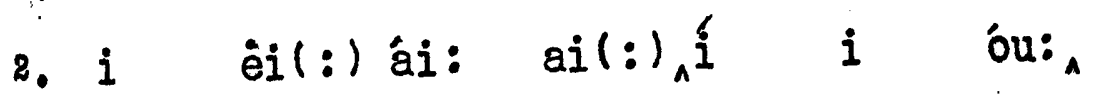

3. $i$ i éi: $x$ é $i$ ju:

4. du: ó $\partial_{\wedge}$ e $\dot{\theta}(:)_{\wedge}$ ou: ${ }_{\wedge}$

5. $i$ ál: $i$ b. $i:$ i $i(:)$ bo: $i_{\wedge}$

6. $\varepsilon \partial(:)$ i: $i_{\wedge}$ á: $i$ ou:

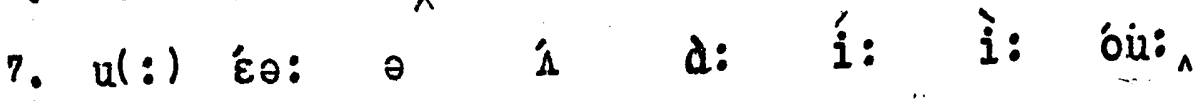

8. 0 o $\partial$ é $\dot{\theta}(:)$ ou:

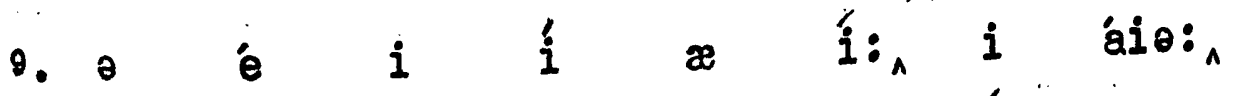

10. $0 \quad \varepsilon \theta(:) \mathfrak{\boxplus}_{\wedge}$ o ou: $i$ I :

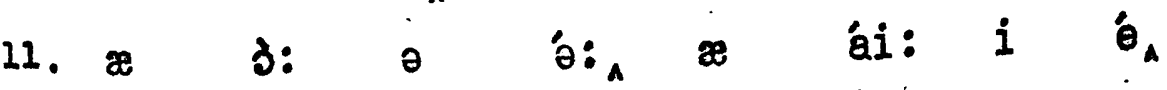

18. ó $i$ i ou: $\dot{u}(:)$ i:

13. $i$ \& du: $i$ èil: $\theta$ ú: ou: $i_{A}$ 14. $\dot{\theta}_{A}$ e ài: ’oul $:$ ) ó:

15. i ái: bu: $i: b_{A} i$ o $\mathfrak{u}_{\wedge}$

16., $\begin{aligned} & i \\ & i_{A}\end{aligned}$

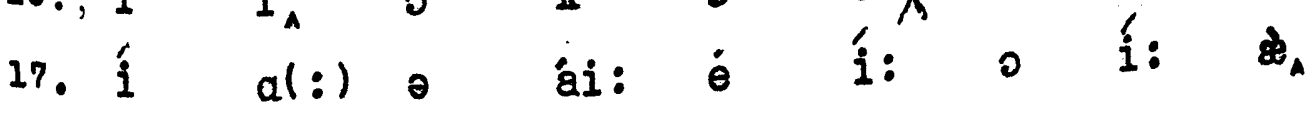

18. $\partial$ o: $\theta_{A}$ o du: orl $:$ ) éi:

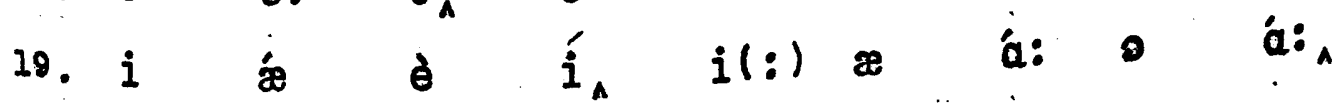

80. $\dot{\theta}_{\wedge} \dot{e}_{A} \approx$ é $\dot{z} \quad \dot{e} i \dot{A}_{\wedge}$ 
1. Sweet and low, sweet and low,

2. Wind of the western sea,

3. Low, low, breathe and blow,

4. Wind of the western sea!

5. Over the rolling

6. Come from the dying moon, and blow,

7. Blow him again to me;

8. While my little one, while my pretty one, sleeps.

9. Sleep and rest, sleep and rest,

10. Father will come to thee soon;

11. Rest, rest, on mother's breast,

12. Father will come to thee soon;

13. Father will come to his babe in the nest,

14. Silver sails all out of the west

15. Under the silver moon:

16. Sleep, my little one, sleep, my pretty one, sleep.

Lord Tenny son.

1. 1́: æ ơ:

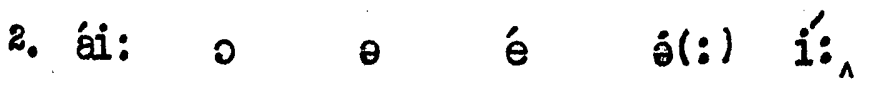

3. ou: ${ }_{\wedge}$ ou: ${ }_{\wedge}$ i: $\approx$ ou:

4. ái: 0 ə

é $\dot{\theta}(:) \quad \dot{i} \wedge^{\prime}$

5. ou: $\theta$ a ou: $i$ ó: $\theta$ ó:

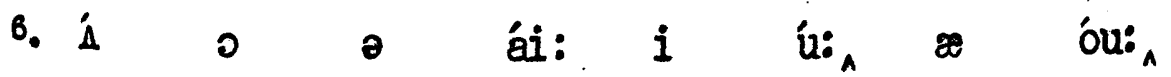

7. ou: $i$ i $\quad i i: u(:)$ i:

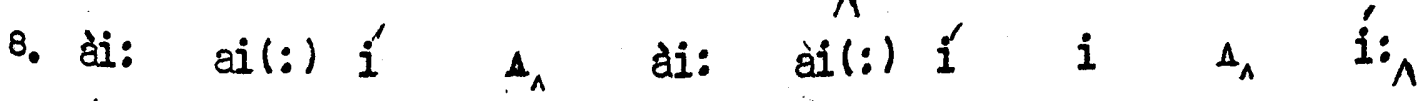

9. 1: $¥$ é

10. á: $\partial$ $i$ i $\quad \dot{u}(:) \quad i(:) \quad u_{\wedge}$

11. $\dot{e}_{\wedge} \dot{e}_{\wedge}$ o $\Lambda \Lambda^{\prime} \partial \quad \dot{e}_{\wedge}$

12. á: $\theta$ i $i \quad \dot{u}(:) \quad i(:)$ ú:

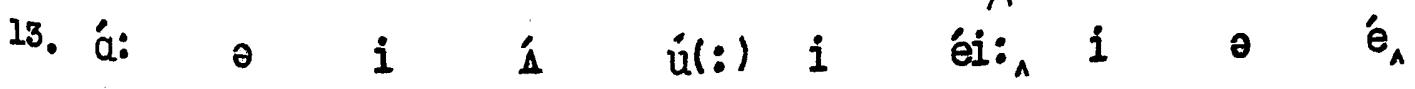

14. $i$ a éi: ol:) du: 0 o $\dot{\theta}_{\wedge}$

15. $i$ ə $\partial$ i $i^{\prime}$ ə ú $_{\Lambda}$

16. $i_{\wedge}^{\prime}$ ai(:) $i^{\prime} \quad \Delta_{\wedge} \quad i_{\wedge}^{\prime}$ ai(:) $i^{\prime} \quad i \quad \Delta_{\wedge} \quad i{ }_{\wedge}$ 
1. Make me thy lyre, even as the forest is:

2. What if my leaves are falling like its own!

3. The tumult of thy mighty harmonies

4. Will take from both a deep, autumnal tone,

5. Sweet though in sadness. Be thou, Spirit fierce,

6. My spirit. Be thou me, impetuous one!

7. Drive my dead thoughts over the universe

8. Like withered leaves to quicken a new birth!

9. And, by the incantation of this verse,

10. Scatter, as from an unextinguished hearth

11. Ashes and spariss, my words among mankind:

12. Be through my lips to unawakened earth

13. The trumpet of a prophecy! 0 Wind,

14. If Winter comes, can Spring be far behind?

"Ode to the West Wind" ( by P.B. Shelley.

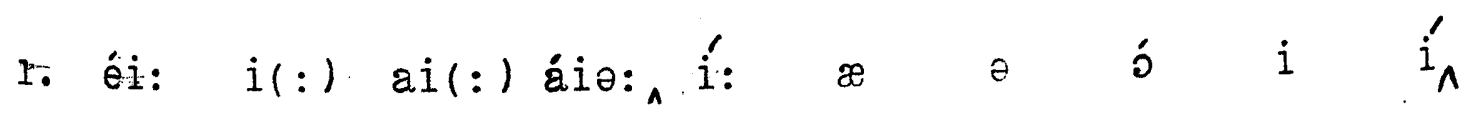

2. ó $i$ ai(:) $i^{\prime}$ a $_{\wedge} a(:)$ ó: $i$ ài: $i$ óu:

3. จ jú: $\Lambda_{\wedge}$ o ài: ái: $i$ á: $\dot{j} \grave{i}_{\wedge}$

4. i éi: o óu: $\dot{e} i(:) i^{\prime}:_{\wedge} \quad o(:) \quad{ }^{\prime}$

5. í: ou(:) $i$ \& $i_{\wedge} i(:)$ áu: $i$

6. éi: $i^{\prime} i_{\wedge} i(:)$ áu: $i_{\wedge}$

7. ái: $a i(:)$ è ó:

8. $a i(:) i^{\prime}$ a $i ́: \quad \dot{u}(:) \quad i^{\prime}$

๑. $\ddot{x}_{A}$ ai(:) $i$

$i^{\prime} \approx$ éi:

ei(:) jú: ó:^

10. $\ddot{\gtrless}$

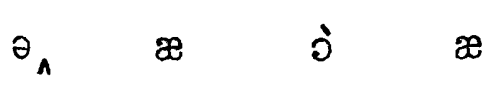

ณ́

$\dot{\mathrm{e}}$

j

i

óu:

10.

11. $\dot{x}$

i. $\quad \mathscr{Q}$

á:

ai(:) ó:

$\dot{æ}$

$i^{\prime}$

i

í⿴囗十

12. i:

$u(:) \quad a i(:) i_{\wedge}^{\prime}$

$\dot{u}(:) \quad$

$\dot{\mathscr{X}}$

$\grave{1} \dot{\gtrless}$

ái: $\wedge$

éi: $\partial \quad \dot{\theta} \wedge$

13. 2

i $i$

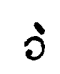

ei (: $)$ s

i

is

14. i

$i^{\prime}$

ə

$\dot{\Lambda}_{\wedge} \quad \mathscr{R}$

$i(:) \quad \dot{d}:$

oul : ) ái: il: $)$ ài: 
1. Around, around, flew oach sweet sound,

2. Then darted to the Sun;

3. Slowly the sounds came back again,

4. Now mixed, now one by one.

5. Sometines a-dropping from the sky

6. I heard the sky-lark sing;

7. Sometimes all little birds that are,

8. How they seemed to fill the sea and air

9. With their sweet jargoning:

10. And now 'twas like all instruments,

11. Now like a lonely flute;

12. And now it is an angel's song,

13. That makes the heavens be mate.

14. It ceased: yet still the sails made on

15. A pleasant noise till noon,

16. A noise like of a hidden brook

17. In the leafy month of June,

18. That to the sleeping woods all night

19. Singeth a quiet tune.

"The Rime of the Ancient Mariner" (354-372) by S.T. Coleridge. 


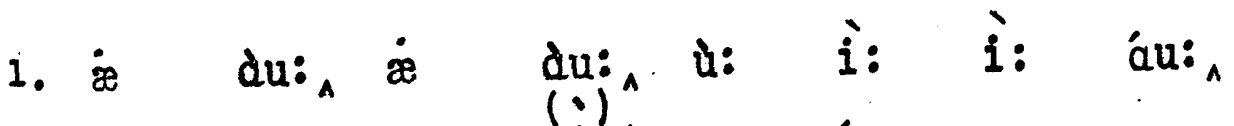

2. $e$ á: $i_{\wedge} u(:)$ ə $i_{A}$

3. ou: $i_{A}$ ə áu: èi: $\dot{\gtrless} \ddot{\otimes}$ éi:

4. $a u(:) i_{\wedge} a u(:)$ is $\quad \dot{a}(::) \dot{A}_{\wedge}$

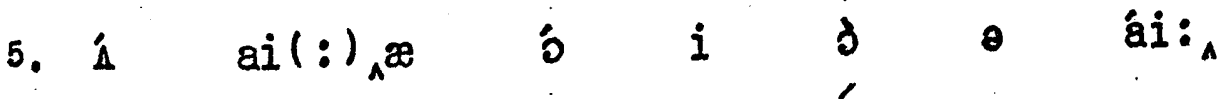

6. ail: $)$ a: $\theta$ ái: d: $\stackrel{i}{A}_{A}$

7. i $a i(:)_{A} \partial(:)$ I $\dot{\theta}: \approx d: A$

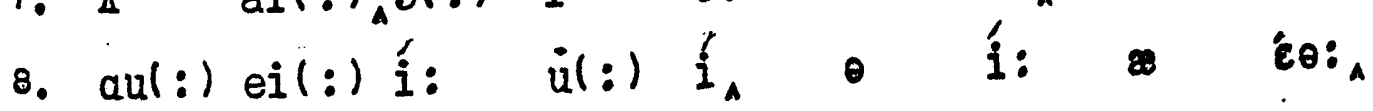

๑. $i \quad \varepsilon \theta(:)$ í á:

10. $\approx$ du: 0 di: b: $\hat{i}_{A}$ u $\ddot{\theta}_{A}$

11. du: $a i(:)$ ei(:) ou: $i \quad \mathfrak{u}: A$

12. $\approx$ du: $i$ i $\approx$ ei $: \dot{e} \dot{b}_{\wedge}$

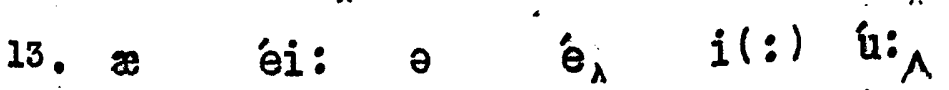

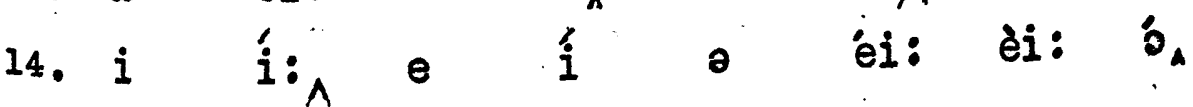

15. èil: $)$ é $\dot{e}$ ój: $i$ ú:

16. eil: $)$ oji: a di: o eil: $)^{\prime}$ ína

17. $i$ o í: $i$ i $\quad 0 \quad$ in:

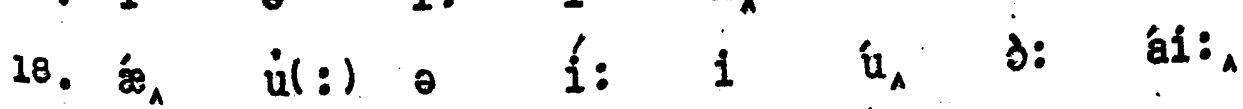

19. $\mathfrak{i}_{\wedge} i_{\wedge}$ èil : $)$ ái: $\dot{e}$ jú: 
1. Her heart is windy April weather -

2. Wite clouds adrift on sunny skies;

3. And all the bluebells dance together

4. Within her eyes.

5. Her heart is windy April weather,

6. With swaying lilies, bending trees;

7. And hope goes fluttering like a feather

8. Upon the breeze.

from "Windy Weather"

by R.C. Macfie.

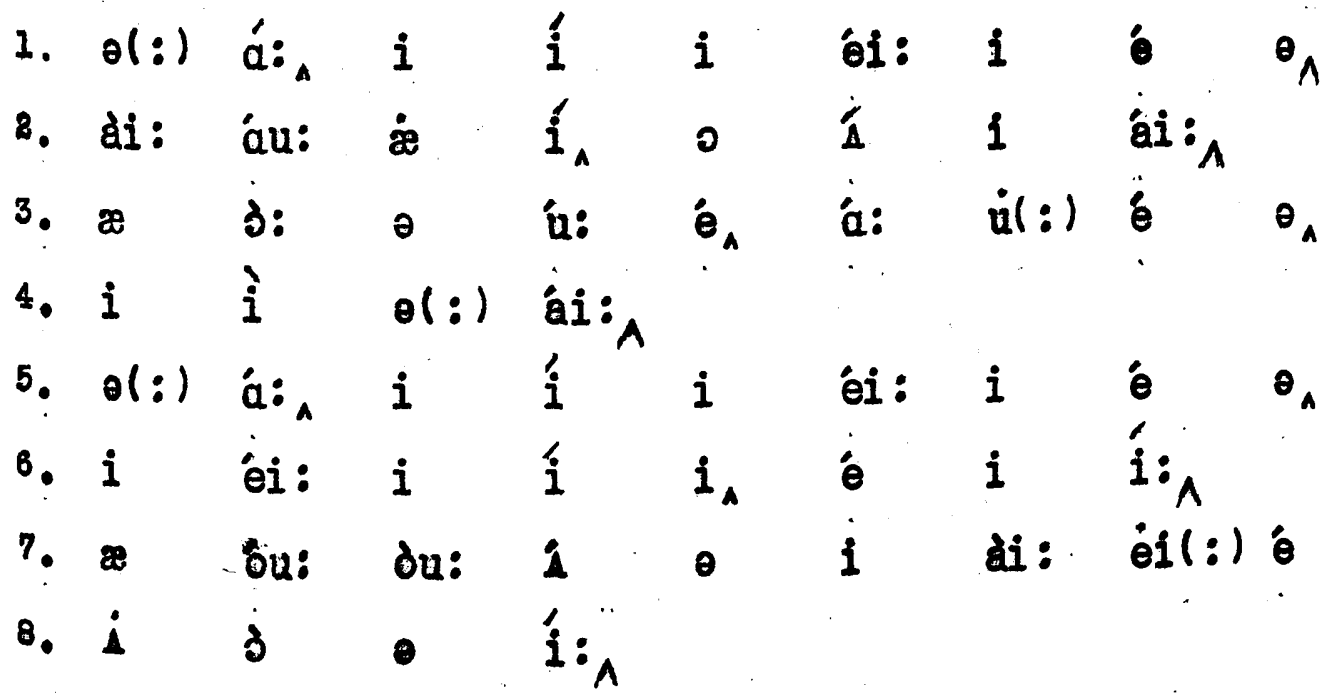


1. Nusic, when soft voices die,

2. Vibrates in the memory -

3. Odours, when sweet violets sicken,

4. Live within the sense they quicken.

5. Rose-leaves, when the rose is dead,

6. Are heaped for the beloved's bed;

7. And so thy thoughts, when thou art gone,

8. Love it self shall slumber on.

P.B. Shelley.

1. jü: i a

2. ái: ei(:) ${ }_{A} i$

3. ou:

4. í

5. $\delta \mathrm{u}$

6. $a l$ :

7. $\boldsymbol{x}$

8. i $\theta_{\wedge} \cdot \dot{\theta}$

i i

i:

$i:$,

ou:

i
ว:

$\theta$

i:

ə

$\theta$

e

(l! )

o

ail:) อ:

\&

జ bi: $\quad$ i

í

j

ái: oul: $i$

in

ei( : ) ${ }^{\prime}$

ou: $i$

i(:)

du:

○ ái: A

$i$

í

é

$i$

$a(:)$ b.

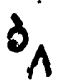


1. Loughareema, Loughareema!

2. Stars come out, an' stars are hidin';

3. The wather whispers on the stones,

4. The flittherin moths are free..

5. One'st before the mornin' light

6. The Iorsemen will come ridin

7. Roun' an' roun' the fairy lough,

8. An no one there to see.

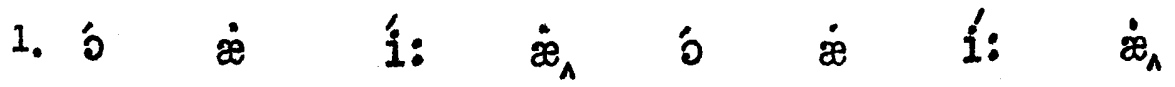

2. á: 1 du: $₫$ á: al: $\approx$ ái: $i_{\wedge}$

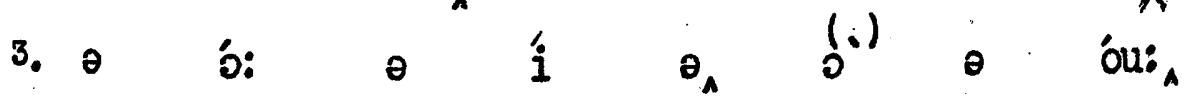

4. $\theta$ i $\quad \theta \quad i \quad j \quad a(:)$ i:

5. 1 i(:)

6. $\theta$ ó: $\dot{\theta}_{A} i$ i ái: $i_{\wedge}$

7. du: $¥$ du:

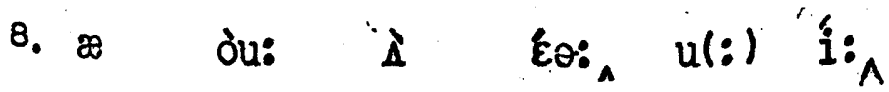


1. Loughareema! Loughareema

2. Iies so high among the heather;

3. A littlelough, a dark lough,

4. The wather's black an' deep.

5. Ould herons go a-fishin' there,

6. An' sea-gulls ali together

7. Float roun the one green island.

8. On the fairy lough asleep.

(v.1)

M. O'Neill.

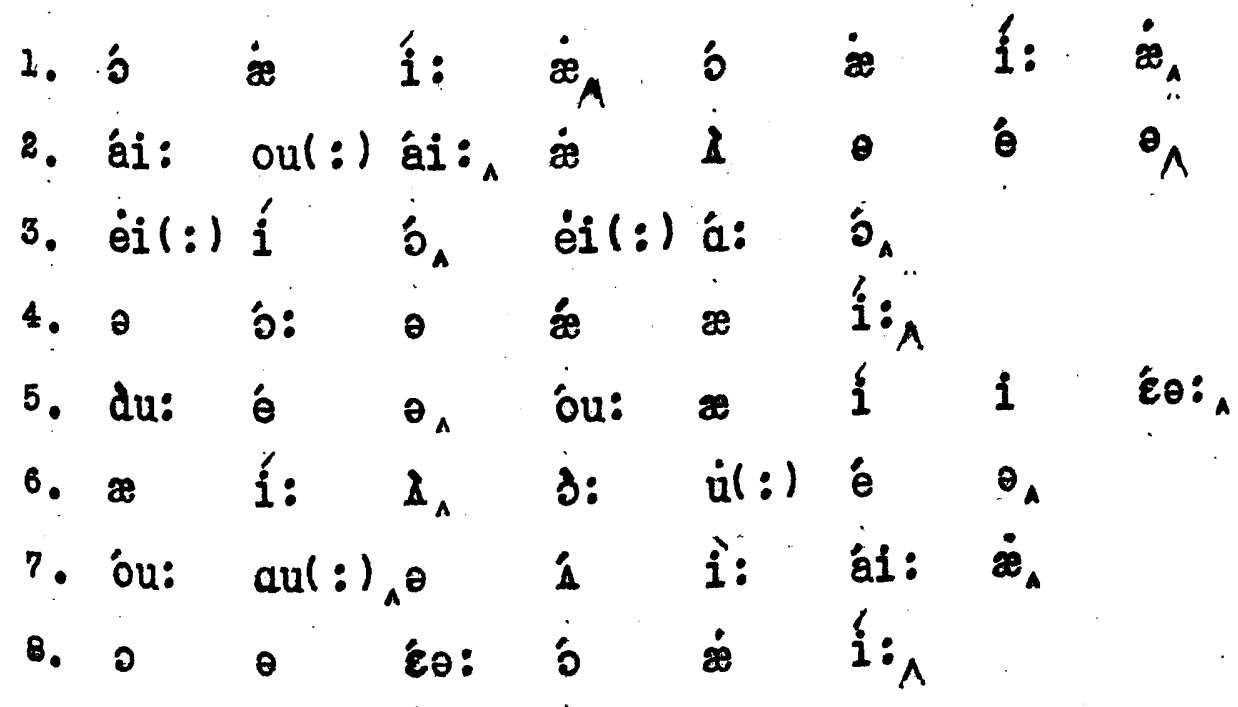


1. Loughareema, Loughareema;

2. When the sun goes down at seven,

3. When the hills are dark and airy,

4. Tis a curlew whistles sweet

5. Then somethin rustles all the reeds

6. That stand so thick an' even;

7. A little wave mans up the shore

8. An' flees, as if on feet.

1.

$\dot{\ddot{z}} \quad \dot{i}:$

i: $\quad \dot{æ}_{\mathrm{A}}$

o

$\dot{x}$

$\dot{1} \quad \dot{\boldsymbol{\otimes}}_{A}$

2. $\theta$

?

i

ou: du: ${ }_{\wedge} \approx$

甶

3. $e$

- í

$a(:)$ á:

ฉ

E⿱ $\dot{\theta}_{\text {: }}$

4. $i$

èi (:) ó:

$j u(:){ }_{a}^{\prime}$

i: $\wedge$

5. e

i

$i_{A}$

i

3:

$\theta$

1:

6. $\approx$

$\dot{a}_{1}$

oul $:) i^{\prime}$

a

í:

7. $\dot{e i}(:))^{\prime}$

éi: $\Lambda$

$\lambda$

ə

62:

8. $æ$

i:

ฉ

$i$

o t: 
1. For to bear all naked truths,

2. And to envisage circunstance, all calm,

3. That is the top of sovereignty. Mark wells

4. As Heaven and Earth are fairer, fairer far

5. Than Chaos and blank Darkness, though once chiefs;

6. And as we show beyond that Heaven and Earth

7. In form and shape cornpact and beautiful,

8. In will, in action free, companionship,

9. And thousand other signs of purer life;

10. So on our heels a fresh perfection treads,

11. A power more strong in beauty, borm of us,

12. And fated to excel us, as we pass

13. In glory that old Darkness: nor are we

14. Thereby nore conquer'd, than by us the rule

15. Of shapeless Chaos.

"Hyperion" (II.203-217) by J. Keats.

(1)

1. 0:

$u(:) \quad \varepsilon \theta$

o(:) éi: i

ü

2. æ

$\dot{u}(:) \quad \dot{e}$

i

i

อ́:

i.

$\dot{x}_{1}$

o: 'á:

3. $i$

- b

o j

$\circ$

$i_{\wedge}$

á:

ê

4. æ é

$\mathfrak{x}$

ว: $a(:) \quad \varepsilon \theta:$

ข

हैə:

5. $\circledast$

éi:

o

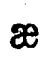

\& á: $i_{\wedge}$

ou: 1

Q:

6. $\approx$

i:

óu: $i(:)$ j

\&

é

$\infty$

7. $i$

ว่:

æ éi:

j

\&

$æ$

jú

i

i:

8. $i$

$i_{\text {A }}$

i 安

2

i:

\&

ó:

9. æ áu:

- $\dot{A}$

- ái:

จ

jư:

-

$\grave{i}_{A}$

10. ou: 0 dua: í: ëi(:) é

- é

๑

ái:

11. èil: $)$ ávo: $0 \theta(:)$

i ju: îa ó:

-

$\dot{\theta}_{A}$

12. $\approx$ éi: i

(!)

é

$A_{A}$

$\mathfrak{*}$

2

$i_{\Lambda}$

13. $i$ ว: $i$ 白

ơ: á:

$\dot{\mathrm{e}}$

i: á:

$(?)$ al: $i:$,

14. $\varepsilon \theta(:)$ ài: $\partial \theta(:)$ ó

$\partial_{\wedge} \ddot{\notin}$

ail:) í

$\theta$

U:

15. 0

éi: i éi: ${ }_{\wedge}$ 
1. She was wearingthe coral taffeta trousers

2. Someone had brought her from Ispahan,

3. And the little gold coat with pomegranate blossoms,

4. And the coral-hafted feather fan;

5. But she ran down a Kentish lane in the moonlight,

6. And skipped in the pool of the moon as she ran.

7. She cared not a rap for all the big planets,

8. For Betelgeuse or Aldebaran,

9. And all the big planets cared nothing for her, 10. That small impertinent charlatan;

11. But she climbed on a Kentish stile in the moonlight,

12. And laughed at the sky through the sticks of her fan.

"Full Moon"

by V. Sackville-West.

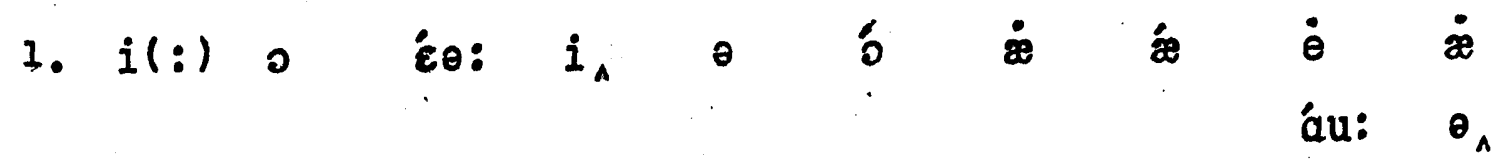

2.

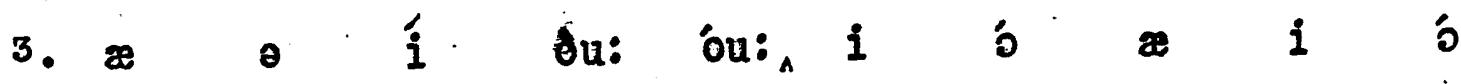

$\partial_{A}$

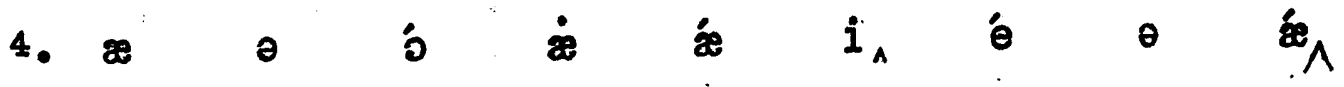

5. $\Delta \quad \dot{i}(:) \dot{q} \quad a u(:)$ èi(:) é $i$ éi: $i$ o

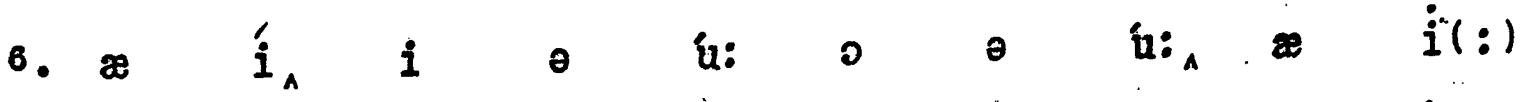

u: $\quad$ ai $(:)$,

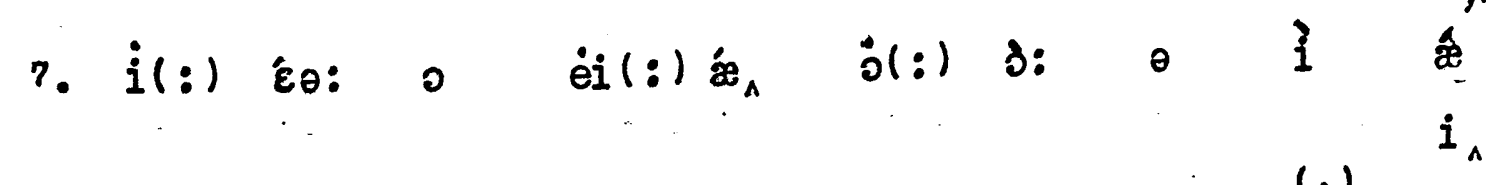

$\wedge$

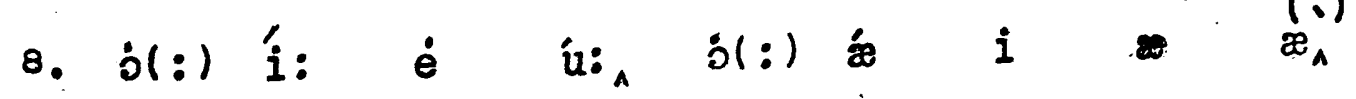

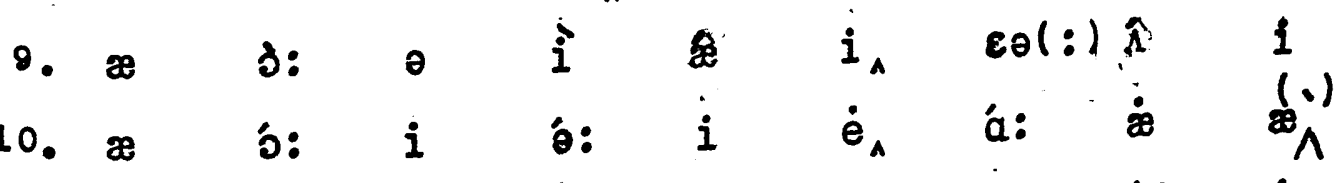

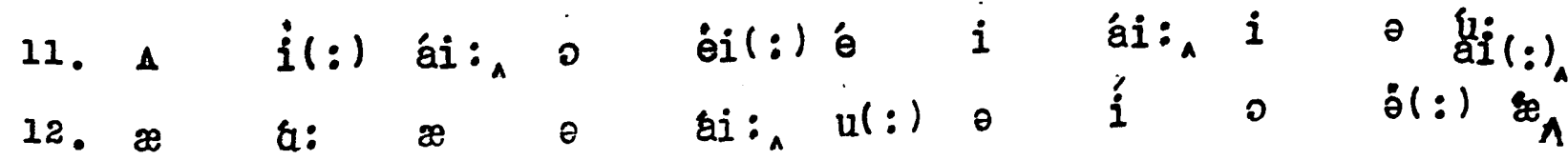


1. Sunlight, moonlight,

2. Twilight, starlight -

3. Gloaming at the close of day,

4. And an owl calling,

5. Cool dews falling

6. In a wood of oak and may.

"Dream Song" $(\nabla \cdot 1)$

by W. de la Mare.

1. $i$ ail: $)_{A} \mathfrak{u}:$ ail: $)$

2. aí: ail:) $)_{\wedge}^{a}:$ ail : ${ }_{\wedge}$

3. ou: $i$ \& $\theta$ ơ: $\theta$ éi:

4. ஐ $¥$ áu: ó: i

5. ù: jú: ว: $i_{\text {A }}$

6. i èil:) $u$ o ou: $\approx$ éi: 
1. Lantern-light, taper-light,

2. Torchlight, no-light

3 . Darkness at the shut of day,

4. And lions roaring,

5. Their wrath pouring

6. In wild waste places far away.

"Dream Song ( $(\nabla .2)$

by $\mathbf{T}$. de la Mre.

-1.

2. อ́: ai(: $)_{\wedge}$ óu: ài:

3. $\dot{a}: \quad \dot{i} \quad \dot{\&} \quad \theta \quad \dot{\Delta} \quad 0 \quad$ éi:

4. 2 ái: $\theta$ óə: $i_{\wedge}$

5. $\varepsilon \theta(:)$ ó: อ́ə: $i_{A}$

6. i ái: èi: éi: $i \quad$ d: $\dot{x}$ èi: 
1. Elf-light, bat-light,

2. Touchwood-light and toad-light,

3. And the sea a shimmering gloom of grey,

4. And a small face smiling

5. In a dream's begulling

6 . In a world of wonders far away.

"Dream Song" ( 8.3 )

by W. de le Mare.

1. é ái: ฉ ǽ ài: А

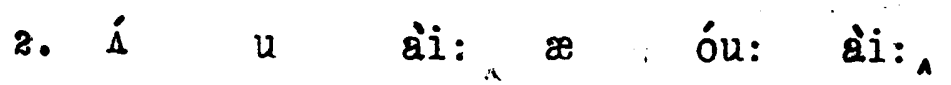

3. ஐ $\theta$ í: $\dot{e} i(:) i^{\prime}$ o $i$ ú: 0 éi:

4. æ èi(:) ó: èi: ái: în

5. $i \quad \dot{e} i(:)$ í: $i(:)$ ái: $i_{\wedge}$

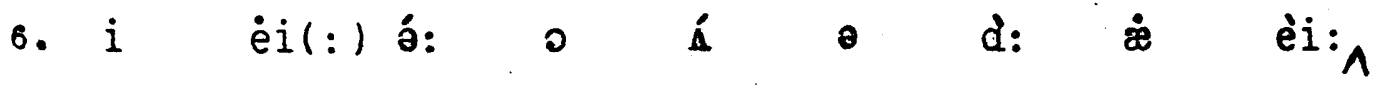


1. I come from haunts of coot and hern,

2. I make a sudden sally

3. And sparkle out among the fern,

4. To bicker down a valley.

"The Brook" (v.1)

by Iord Tennyson.

1. $\operatorname{ai}(:) i$

o

2 G:

8

ค:

2. $a i(:)$ éi: $\dot{e i}(:) i$

8

is

3. 2 á: aี:

i $\quad 0$ i

4. $\dot{u}(:)$ í

du:

बíl:)

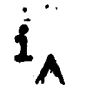


1. By thirty hills I hurry down,

2. Or slip between the ridges,

3. By twenty thorps, a little tom,

4. And half a hundred bridges.

The Brook" $(\tau \cdot 2)$

by Lord Tenny son.

1. ai(:) á: $i$ i ail:) i 1 du:

2. $\dot{b}(:) i \quad i(a) \quad i: 0 \quad i \quad i_{A}$

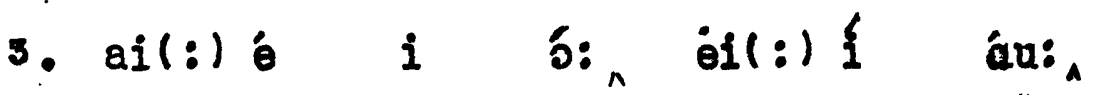

4. $\approx$ d: $\dot{\theta i l}(:) i$ i 1 i 
1. I chatter over stony ays,

2. In little sharps and trebles,

3. I babble into eddying bays,

4. I bebble on the pebbles.

"The Brook" (T.4)

by Lord Tengen.

1. ai(:)

6. 8n: 0

2. i, í

i

$\dot{\mathbf{n}}(:)$

1

$1 \quad$ of:

4. $\operatorname{ai}(:) \dot{m}$

$\diamond \quad \dot{\theta}_{A}$

on: i êl:

A

5. $\operatorname{ai}(:)$ i

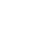


1. I chatter, chatter, as I flow

2. To join the briming river,

3. For men may come and mon may go,

4. But I go on for ever.

whe Brook" (v.6)

by Lord Tennyson.

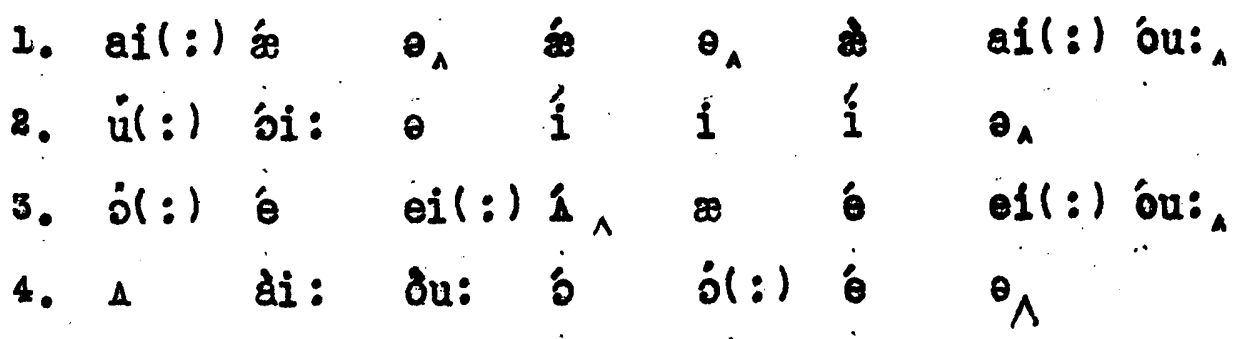


1. If you can keep your heod when all about you

2. Are losing theirs and blaming it on you;

3. If you can tmast yourself when all men doubt you,

4. But make allowance for their doubtinf too;

5. If you can wait and not be tired by waiting,

6. Or being lied about, don't deal in lies,

7. Or being hated don't give way to hating,

8. And yet don't look too good, nor talk too wise.

"If" (v.I)

by R. Kipling.

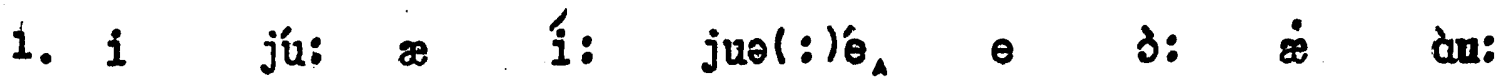

jul : )

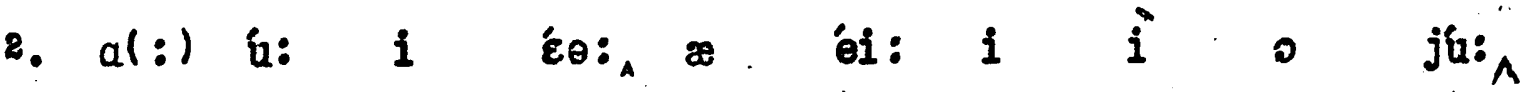

3. $i$ jú $¥$ i juol:lée $\Theta$ o: $\&$ áu:

jul : )

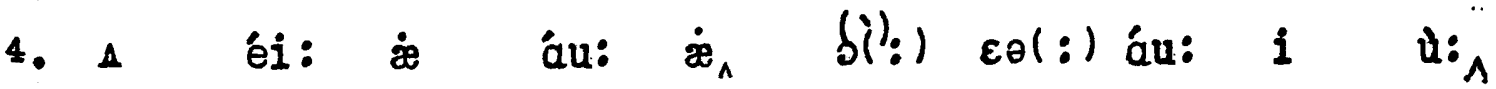

5. $i$ jú $\approx$ éi: $¥$ ó $i(:)$ áiə: ai(:) él:

$i_{A}$

6. $o(:)$ i: $i$ ái: $\dot{z}$ du: oul: í: $_{\text {í }}$ ái:

7. o(:) $i:$ i éi: $i_{\wedge}$ ou(:) $i$ éi: $u(:)$ éi:

i.

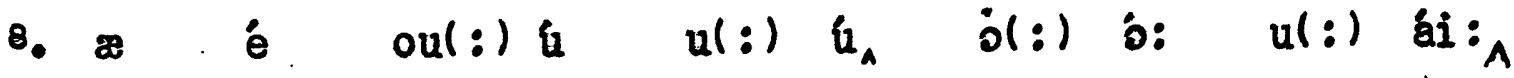


1. If you can dream - and not make dreams your master;

2. If you can think - and not make thoughts your aim;

3. If you can meet with Triumph and Disaster

4. And treat those two imposters just the same;

5. If you can bear to hear the truth you've spoken

6. Twisted by knaves to make a trap for fools,

7. Or watch the things you gave your life to broken,

8. And stoop and build em up with worn-out tools.

"If" (

by R. Kipling.

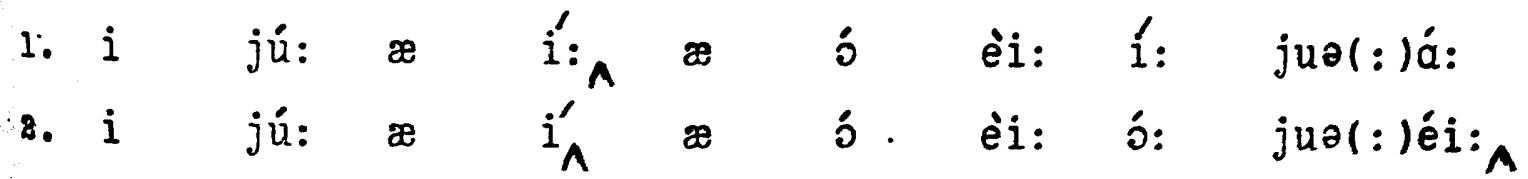

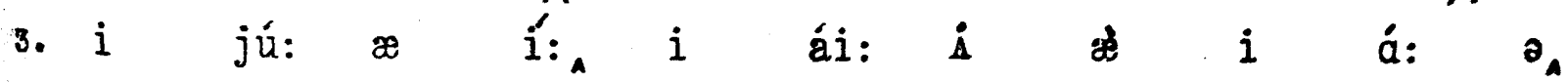
4. $\circledast$ í: ou(:) ù:

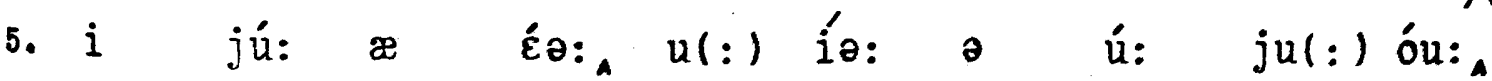

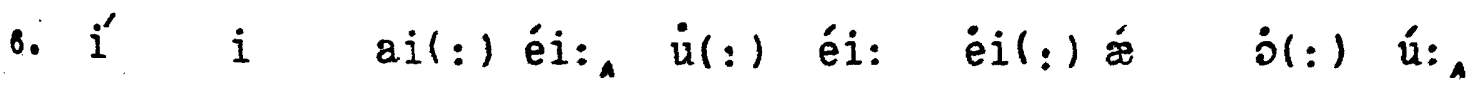
7. $\dot{\partial}(:)$ o $\quad$ o $i^{\prime}$ ju(:) éi: juә(:)ái: $u(:)$, óu:

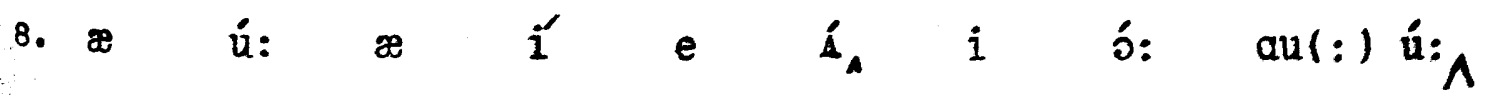


1. If you can make one heap of all your winnings

2. And risk it on one turn of pitch-and-toss,

3 . And lose, and start ggain at your beginnings

4. And never breathe a word about your loss;

5. If you can force your heart and nerve and sinew

6. To serve your turn long after they are gone,

?. And so hold on when there is nothing in you

8. Except the Will which says to them: "Hold on!"

"If" $(v .3)$

by R. KIpling.

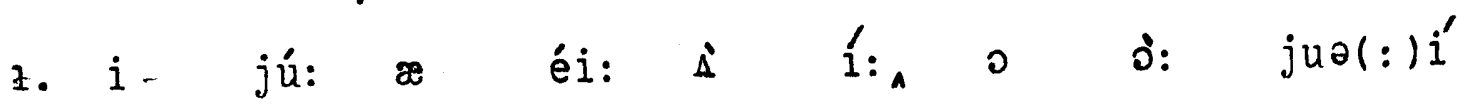

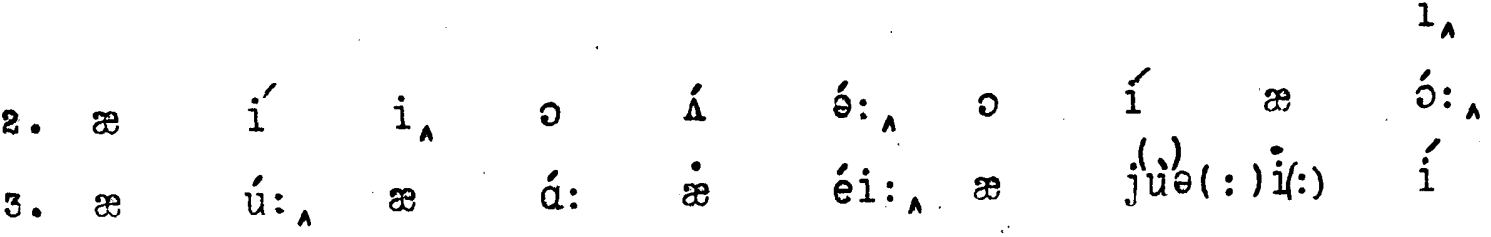

$i_{A}$

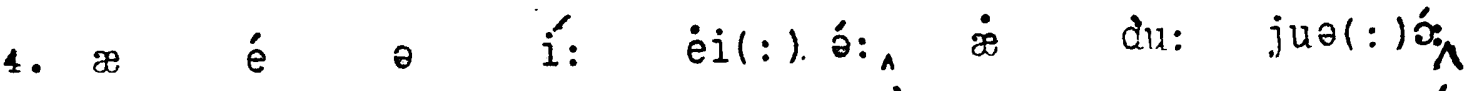

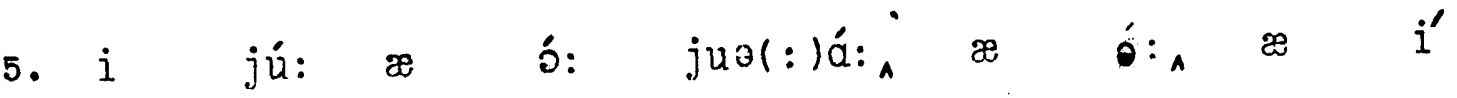

ju(: $)_{\wedge}$

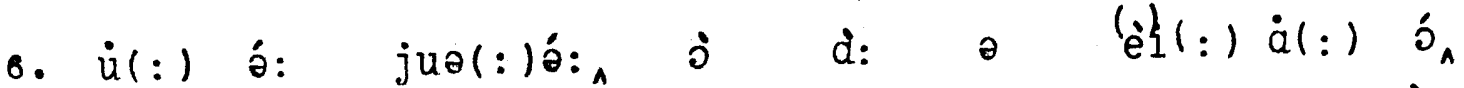

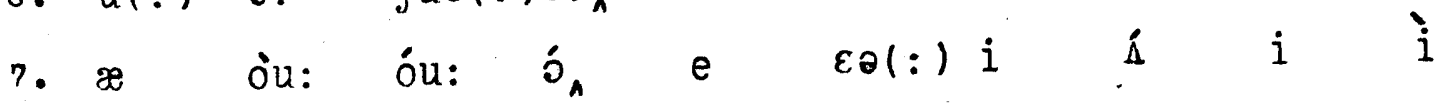

ju( : $)_{\wedge}$

8. $\dot{e}$ é o $\quad \dot{i}_{\wedge}^{\prime} \quad \dot{i}$ éi: $\dot{i}(:)$ en óu: $\hat{o}_{\Lambda}$ 
1. If you can talk with crowds and keep your virtue,

2. Or walk with Kings - nor lose the common touch,

3. If neither foes nor loving friends can hurt you,

4. If all men count with you, but none too much;

5. If you can fill the unforeiving minute

6 . With sixty seconds' worth of distance run,

7. Yours is the Earth and everything that's in it,

8. And - which is more - you'll be a Man, my sont

"If" (v.4)

by R. KIpling.

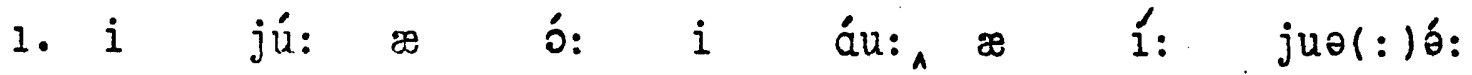

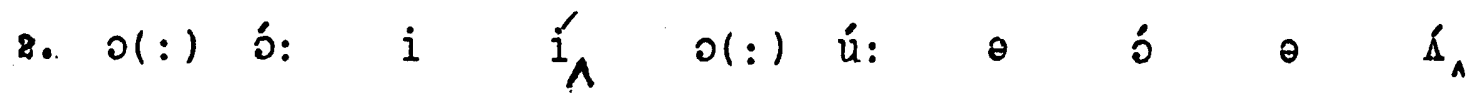

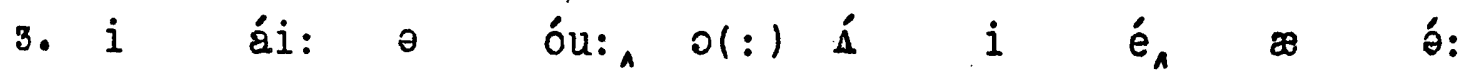

$j u(:)_{A}$

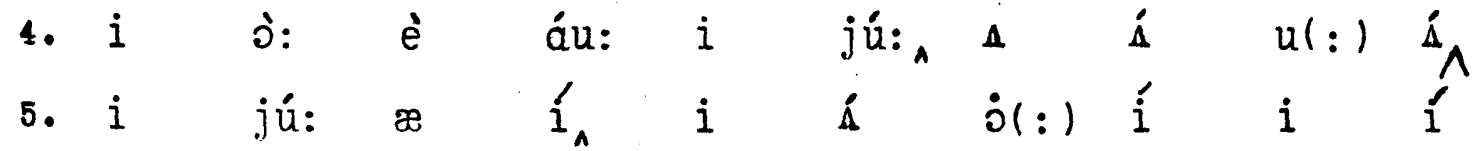

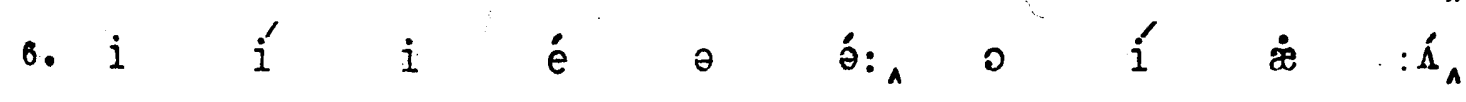

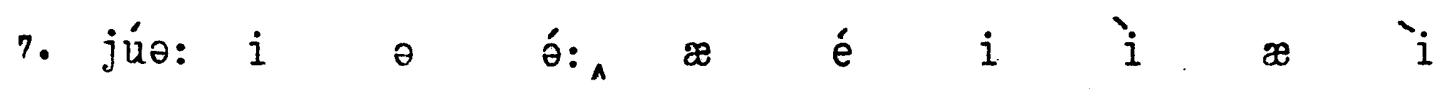

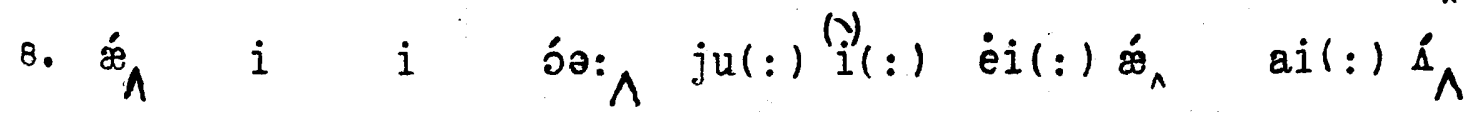


1. Ye ductile youths, whose rising sun

2. Hath many circles still to run:

3. Who visely vith the pilot's chart,

4. To steer thro' life th'unsteady heart;

5. And, all the youthful voyage past,

6. To grain a happy port at last:

7. Attend a Seer's instmactive song,

8. For moral tmaths to drearns belong.

9. I saw this wondrous vision soon,

10. Lonf ere my sun had reach'd its noon;

11. Just when the rising beard began

12. To grace my chin, and call me man.

"Visions for the Entertainment and Inst ruction of Younger Ninds" (V1sion 5.1) by Cotton.

1. i(:) i ai(:) u: $u(:)$ ái: i $\mathbb{A}_{A}$

2. $\approx$ i $i$ a: $i \quad \dot{u}(:) i_{A}$

3. $u(:)$ ái: $i$ i $\theta$ ái: o á:

4. $u(:)$ lio: $u(:)$ ái: $\wedge$ é $i$ a

5. $\dot{x}_{A} \partial(:)$ o jú $\dot{u}$ ói: $i$ á,

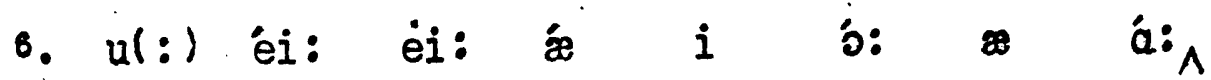

7. æ̇ é èi(:) ĺa: $i$ i $i$ ó,

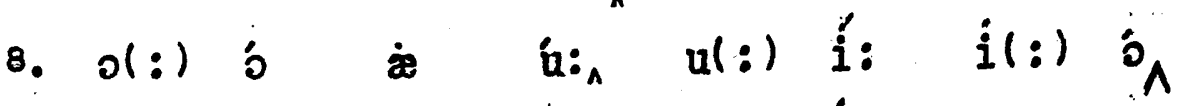

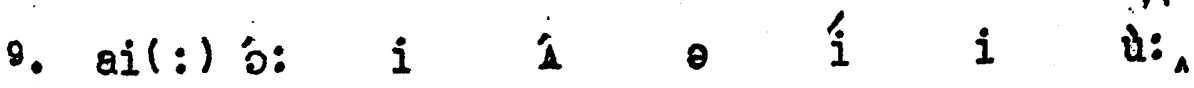

10. o $\varepsilon_{\theta}(:)$ ail : $) \dot{1}_{\wedge} \approx$ í $i$ th:

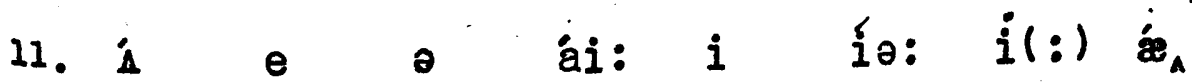

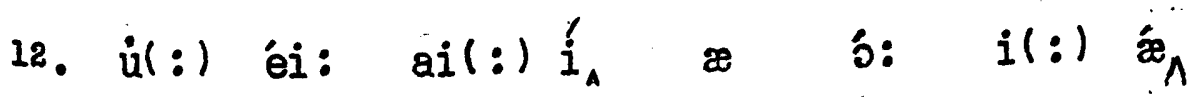


1. "A Potter, Sir, he was by trade,"

2. Said I, becoming quite collected;

3. "And wheresoever he appeared,

4. Full twenty times was Peter feared

5. For once that Peter was respected.

"Peter Bell" (201-205)

by W. Wordsworth.

1. èil: : ó

әิ

3

ai(:) éi: ,

2. $\dot{\theta}$ ail $:)_{A} i(:)$ í

$i$

ai: $\dot{0}$

3. æ ع $\theta$ : oul:) $\dot{e}$

$\theta_{1}$ $\dot{i}(:)$ \&

é

4. ป̀

é

$i$

ai: 0

í:

î:

5. $\partial(:)$ i

$\approx$ í:

$\theta_{A}$

b $\dot{i}(:)$ é

10:

$\dot{\theta} \quad i_{\wedge}$ 
1. All, all is silent - rocks and woods,

2. All still and silent - far and near?

3. Only the Ass, with motion dull,

4. Jpon the pivot of his skull

5. Turns round his long left ear.

"Poter Bel1" (411-415)'

by W. Wordeworth.

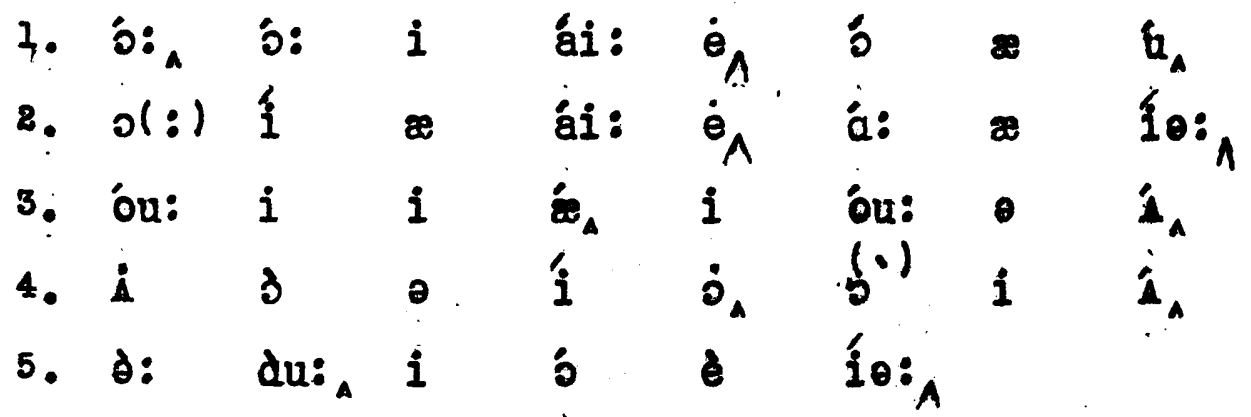


1. Let them whose voice can stop the clouda,

2. Whose cunning eye can see the wind,

3. Tell to a curious world the cause

4. Why, makint here a sudden pause,

5. The Ass turned round his head, and grinned.

"Poter Bell " (82l-825) by W. Wordsworth.

1..e é $u(:)$ bi: $\approx$

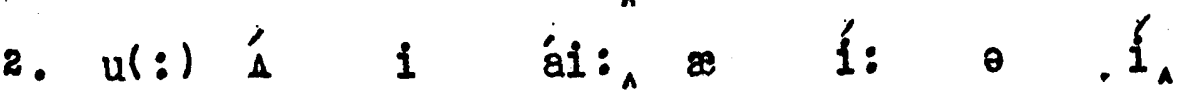

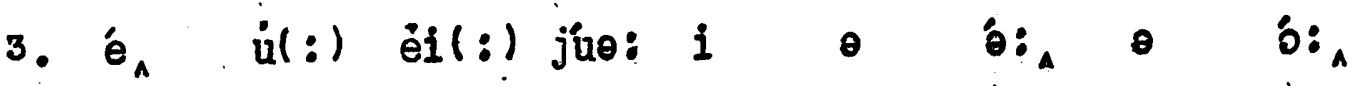

4. ài: éi: $i$ í⿴囗 èi(:) í b:

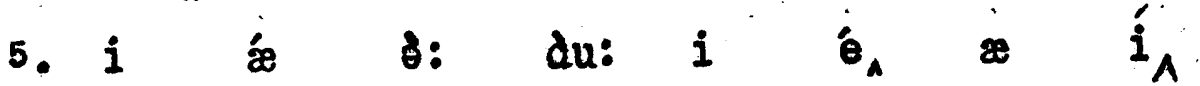


1. As ruinous a place it was,

2. Thought Peter, in the shire of Fife

3. That served ny turn, when following still

4. From land to land a reckless will

5. I married my gixth wifol

"Peter Bell" (861-865)

by W. Wordsworth.

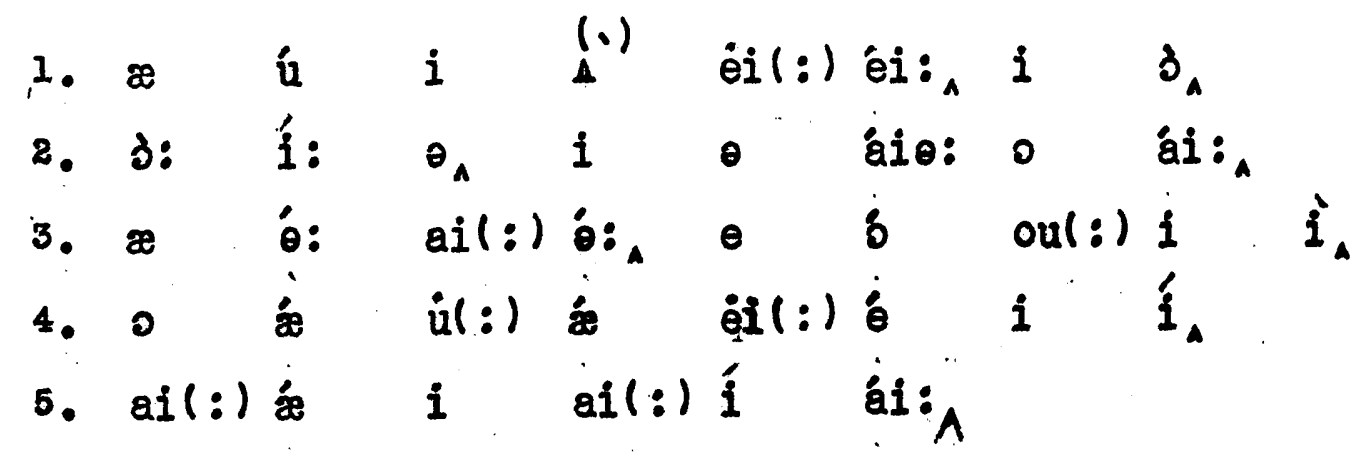


1. And Peter Bell, who, till that night,

2. Ilad been the wildest of his clan,

3. Forsook his crimes, renounced his folly

4. And, after ten months' melancholy,

5. Became a good and honest man.

"Pater Bell" (1131-1135)

by W. Wordsworth.

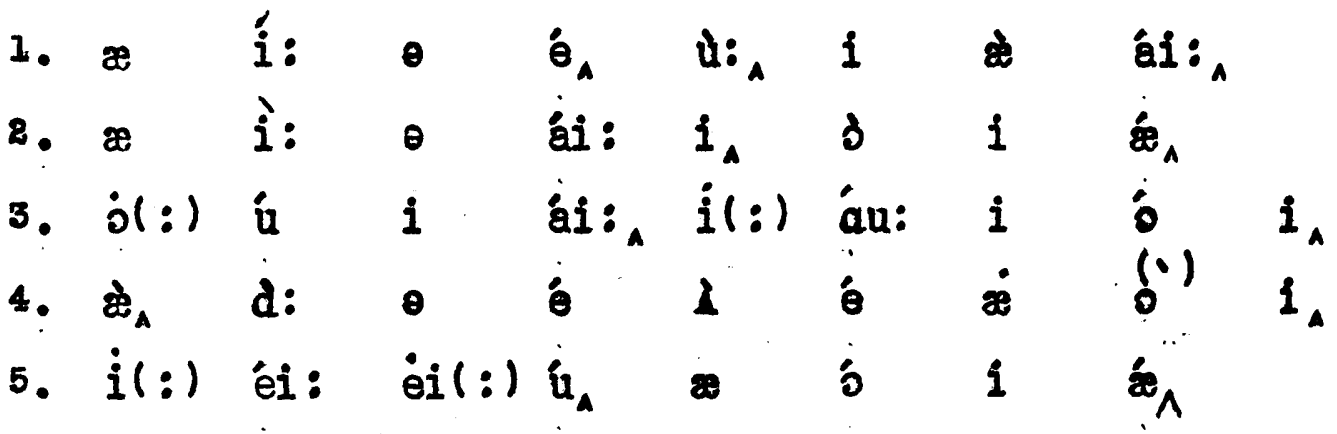


1. Then did the little laid reply,

2. "Seven Doys and girls are we:

3. Tiro of us in the church-yard lie,

4. Beneath the church-yard tree."

5. "You run about, ny little laia,

6. Your limos they are alive;

7. If two are in the church-yard laid,

8. Then ye are only five."

9. "Their graves are green, they may be seen,"

10. The little laid replied,

11. "Mvelve steps or more from my mother's door,

12. And they are side by side."

from "We are seven"

by W. Wordsworth.

1. é $i$ o $i \quad$ ei: $i(:)$ ál:

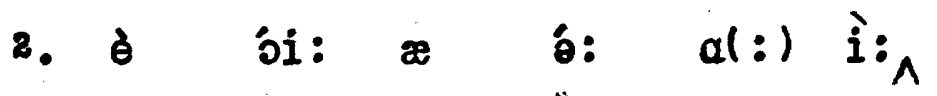

3. ù: $0 A_{\wedge}$ i $\theta$ á d: ái:

4. $\dot{i}(:)$ i: $\theta$. $\dot{\theta}:$ d: $\quad i_{\Lambda}$

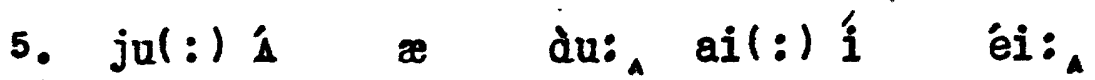

6. juel:)i, eii: $a(:) \dot{a} \quad$ ái:

7. $i$ ù: $a(:)$ ì $\theta$ b: d: éi:

8. $e_{\wedge} i(:) a(:)$ bu: $i$ ái: $\wedge$

9. $\varepsilon \partial(:)$ éi: $a(:)$ í: eil:) di: $i(:)$ $1:$,

10. $a$ i ei: $i(:)$ ái:

11. \& e o bo: 0 ail: 1 o bo:

12. zèi: a(:) ái: ail: áa: 
1. I was smoking a cigarette;

2. Maud, my wife, and the tenor McKey,

3. Were singing together a blithe duet,

4. And days it were better I should forget

5. Came suddenly back to me.

6. Days when life seemed a gray masque ball,

7 . And to love and be loved was the sum of it all.

8. They have ceased singing that old duet,

9. Stately liaud and the tenor MicKey.

10. "You are buming your coat with your cigarette,

11. And qu'avez vous, dearest, your lids are wet,"

12. Maud says as sho leans o'er me.

13. And I smile, and lie to her, husband-wise

14. "Oh it is nothing but smoke in my eyes."

"The Duet"

by E.W. Wi100x. 
1. ai(:) o ó: $i$ eil: $)^{\prime}$ \& $\dot{A}$

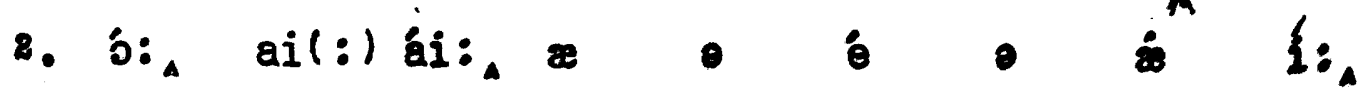

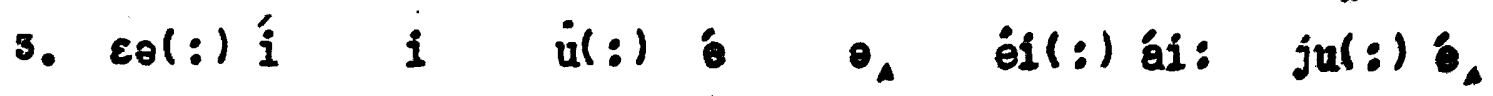

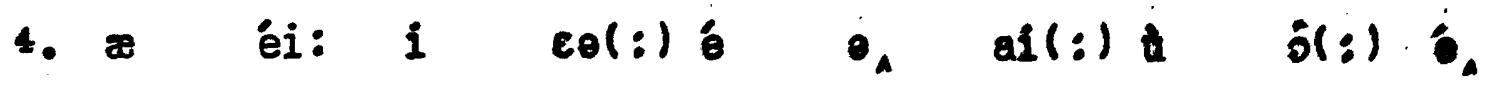

5. èi: $\Lambda^{\prime}$ i. $\notin \quad \dot{u}(:) \quad i: \Lambda$

6. éi: e ài: $\dot{i}:_{\Lambda}$ eil(:) éi: d: o:

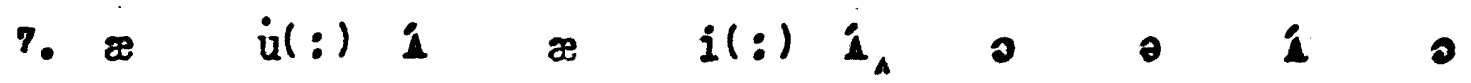

i 3:A

8. èi: $\approx$ í: $i$ is $\approx$ ou: jul:) é,

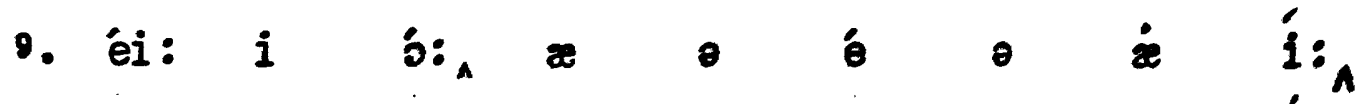

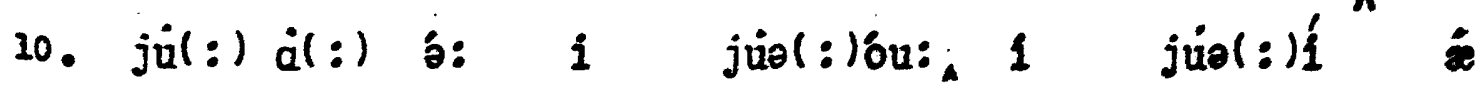

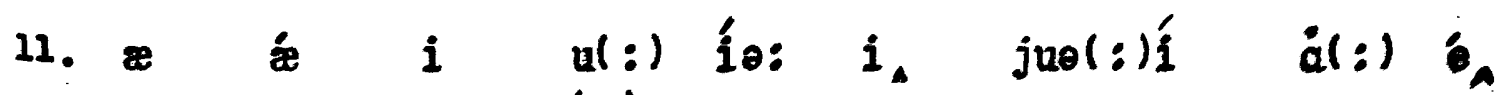
12. 3: é $\approx$ fi: i: bo: il: $)_{\wedge}$

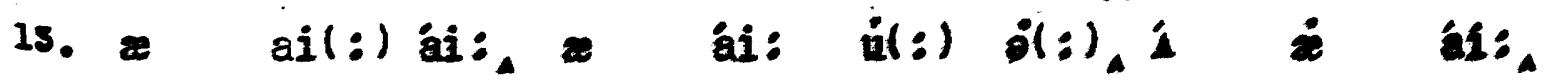
14. bu: $i$ i $i$ i $A$ bu: $i$ ail al al: 
1. Afar in the Desert I love to ride,

2. With the silent Bush-boy alone by side;

3. O'er the brown Karroo, where the bleating cry

4. Of the springbok's fawn sounds plaintively;

5. And the timorous quesga's shrill whistling neigh

6. Is heard by the fountain at twilicht grey;

7. Where the zebra wantonly tosses his mane,

8. With wild hoof scouring the desolate plain;

9. And the fleet footed ostrich over the waste

10. Speeds like a horseman who travels in haste,

11. Hieing away to the home of her rest,

12. Where she and her mate have scoop'd their nest

13. Far hid from the pitiless plunderers: view

14. In the pathless depths of the parch'd Karroo.

"Afar in the Desert" by T. Pringle, 


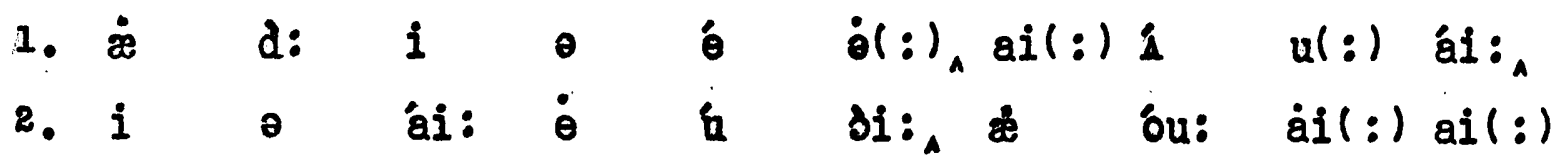

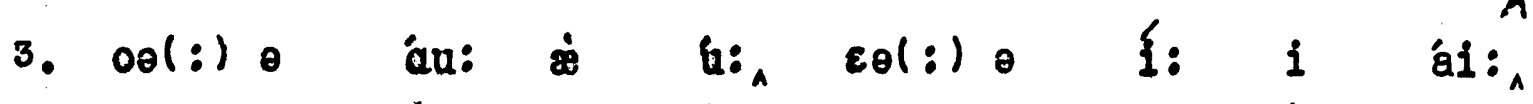
4. 0 o $\quad l \quad 3$ b: du: éi: $i$ i

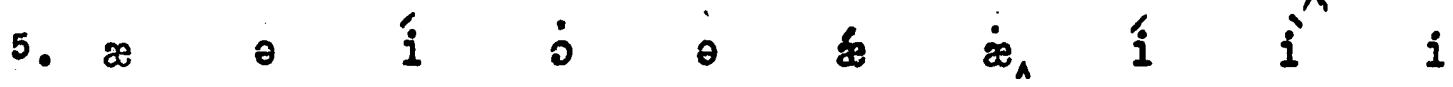

6. $i$ ó: ail:) $\theta$ áu: $i_{\wedge}$ z ái: ail: éi $_{A}$ 7. $\varepsilon \theta(:) \theta$ i: $\dot{x}_{A}$ b $\theta$ i

8. $i$ ài: ú: áuo: $i$ $\theta$ e $\dot{0}$ ëil $(:)$ éi: ๑. $\approx$ o $\dot{i}:$ i. $i$ b $i_{A}$ bu: $\theta$ o

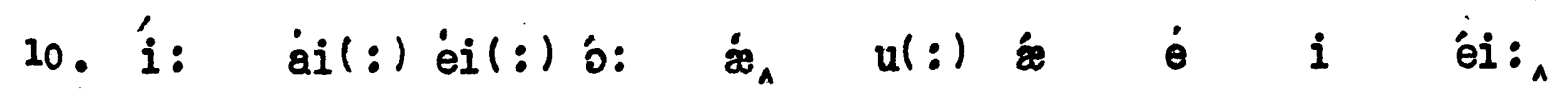
11. ái: $i$ z éi: $\dot{u}(:)$ o óu: 0 al: $\dot{e}_{\wedge}$

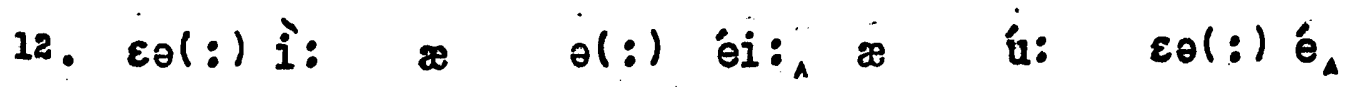

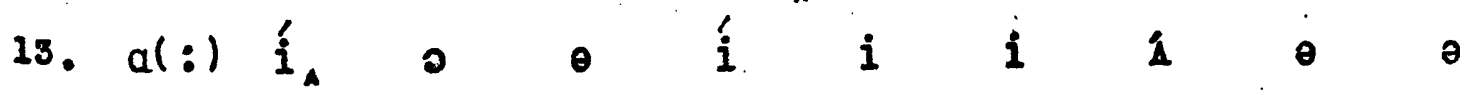
14. $i$ ə $\dot{a}: \quad i \quad \dot{e}_{\wedge} \quad 0 \quad \partial \quad \dot{a}: \quad \dot{z} \quad \mathfrak{G}: \wedge$ 
1. But at last there came a pause. I stood all vibrating with thuinder,

2. Which my soul had used. The silence drew her face up like a call.

3. Could you guess what word she uttered? She looked up as if in wonder,

4. With tears beaded on her lashes, and said "Bortrams" it was all.

5. If she had cursed me - and she micht have - or if even, with queenly bearing,

6. Which at need is used by women, she had risen up and said,

7. "Sir, you are my suest, and therefore, I have given you a full hearine -

8. Now, beseech you, choose a name exactins somewhat less, instead" -

9. I had borne its - but that "Bertram" - why, it lies there on the paper

10. A mere word, without her accents, - and you cannot judge the weight

11. Of the calm which crushed my passiont I seemed swiming in a rapour, -

12. And her gentleness did shame me,t whom her scorn made desolate.

"Lady Geraldine's Courtship" (IXXXII-IXXXIV)

by B.B. Broming. 


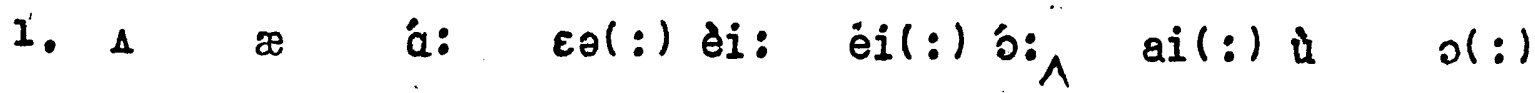
ái: eil : $i$ i $i \quad \theta_{A}$

2. i ail:) ón: æ jú: $\Lambda^{\theta}$ bi: $\dot{\theta}$ ù: $\theta(:)$ éi: 1 ai (:) éi(:) ó $\wedge$

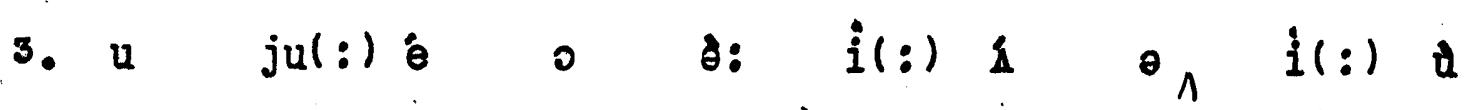

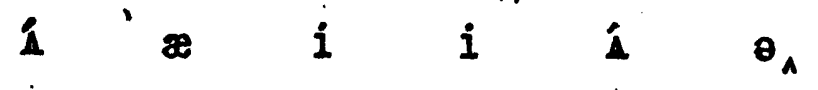

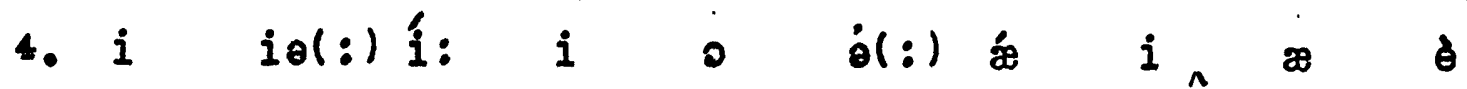
в: $\dot{z} \wedge$ i 0 b:

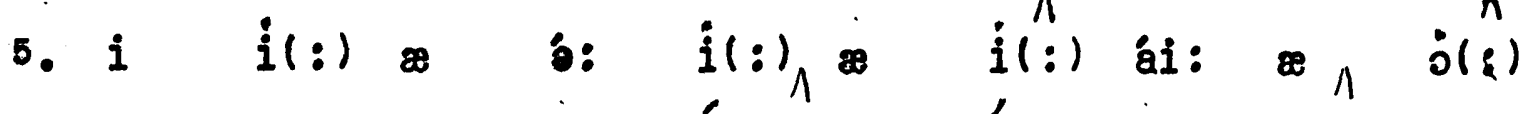
$i$ i: $\wedge_{\wedge} i:$ i $\varepsilon_{\theta}: i_{\wedge}$ 6. $i$ í $i$ jul : $)$ ail : $) \dot{1} \theta$, $i(:)$ æ $\dot{i} A \quad \approx \quad \dot{e}$

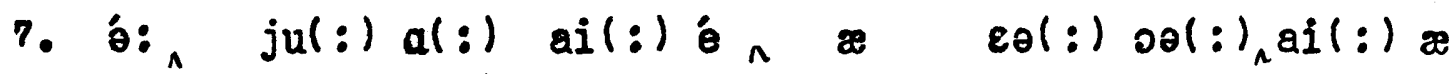
i jul: $)$ eil : $)$ u ía: $i_{\Lambda}$

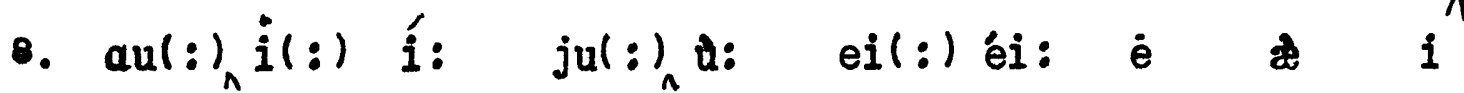
i. $\quad \gamma_{n}, i \quad e_{\Lambda}$

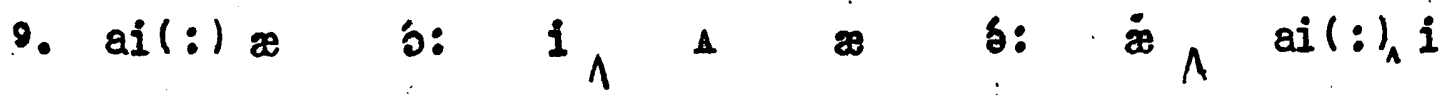
ái: $\varepsilon \theta(:)$ o $\theta$ éi: $\theta_{\wedge}$

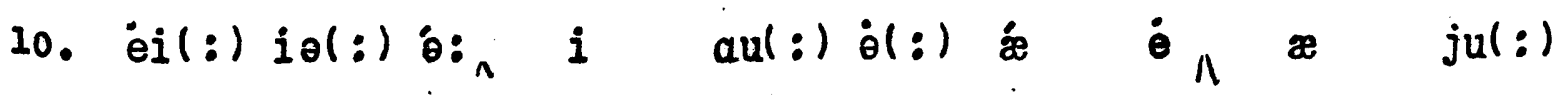
ฉ 0 's $\partial$ éi:

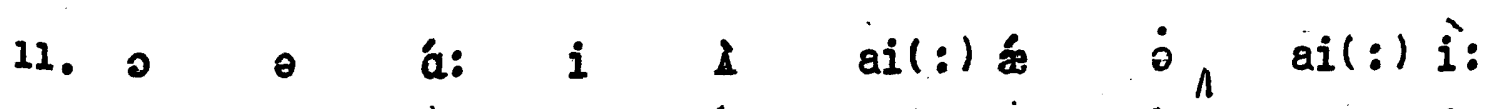
i $i$ i èi(:) éi: $\dot{b}_{\wedge}$

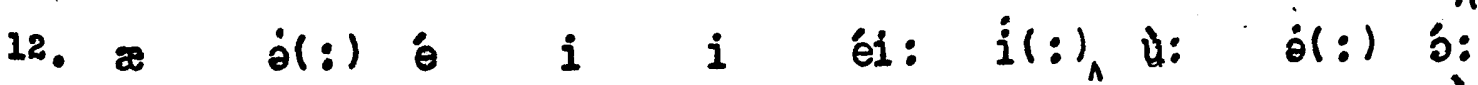
ei: i oul: $)$ होil: $)_{\wedge}$ 
1. There is a pleasure in poetic pains

2. Which only Poets know;' - 't was rightly said:

3. Whom could the linses else allure to tread

4. Their smoothest paths, to wear their lightegt chains?

5. When happiest Fancy has inspired the strains,

6. How oft the malice of one luckless wo nd

7. Pursues the Enthusiast to the social board,

8. Haunts him belated on the silent plains?

9. Yet he repines not, if his thought stand clear,

10. At last, of hindrance and obscurity,

11. Fresh as the star that crowns the brow of mom;

12. Bright, speckless, as a soft ly-moulded tear

13. The moment it has left the virgin's eye,

14. Or rain-drop lingering on the pointed thorn.

W. Word sworth. 
1. "How, little Edward, say why so:

2. Iry little Edward, tell me why." -

3. "I cannot tell, I do not know." -

4. "Why, this is strange," said $I$;

5. "For, here are woods, hills smooth and warm:

6. There surely must some reason be

7. Why you would change sweet Iiswyn farm

8. For Kilve by the green sea."

9. At this, my boy hung down his head,

10. He blushed with shame, nor made reply;

11. And three times to the child I said,

12. "Why, Edward, tell me why?"

from "Anecdote for Father 8 " by W. Wordsworth.

1. du: ${ }_{\wedge} \dot{i} \quad \dot{\theta}$ on éi: $a i(:)$ du:

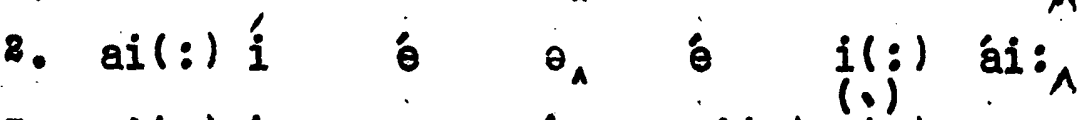

3. $a i(:) \notin$ o $e_{A} a i(:) u(:)$ o ó

4. $a_{i(:), 1} i$ éi: $\&$ di:

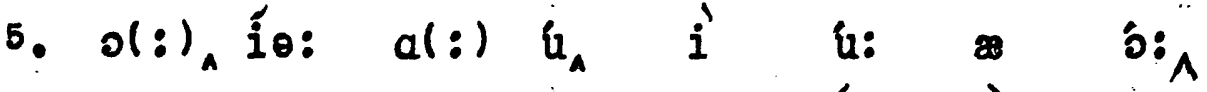

6. $\varepsilon \theta(:)$ lu: $i \quad i \quad l$ i: $i:$

7. ái: ju(:) u éi: i:

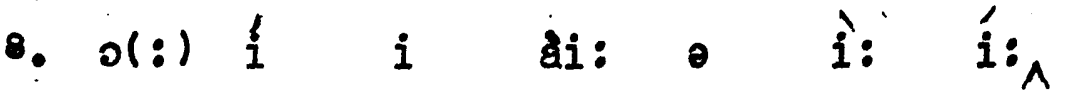

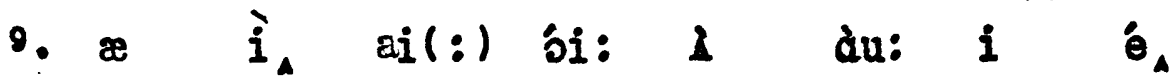

10. $i(:)$ i $i$ éi: $o(:)$ éi: $i(:)$ ái:

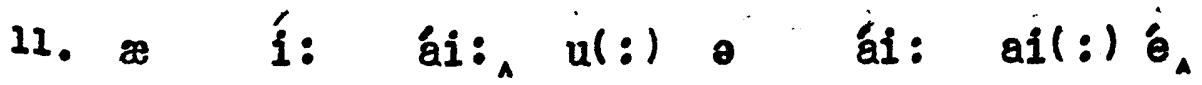

12. di: ${ }_{\wedge}$ a $a_{\wedge}$ é 
1. Wilt thou upon the high and giddy mast

2. Seal up the ship-boy's eyes, and rock his brains

3. In cradle of the rude imperious surge,

4. And in the visitation of the winds,

5. Who take the ruffian billows by the top,

6. Curling their monstrous heads and hanging them

7. With deaf'ning clamours in the slippery clouds,

8. That, with the harly, death itself awakes?

"King Henry IV" (Pt.II.III.1.18)

by W. Shakespeare.

1. $\dot{i}$ aul $:)_{\wedge} \dot{i}$

๖ จ ái: æ

$\hat{1}$

i

á:

2. i: i

i ji: ái: $\approx$

b $i$

éi :

3. i

éi : ठ

$\theta$ ú:

i

10: $i$

$\theta$

อ่:

4. æ

i

ə

i i

éi : o

3

в $\hat{\mathbf{i}}$

o

ái :

5. $\mathrm{ul}:$ ) éi:

i $\mathbf{i}$

$\hat{i}$

oul : )

(a) : $)$ o

в. ว́: i $\varepsilon \theta(:)$ o

7. $i$

é

i

\&

ə

a

é
$(1)$

$æ$

2

æ

í

ə

$i$

วิ

8. \&્a

$i$

- o: $i_{A}$

é

$i$

$\dot{\theta}$

æ

实

i

áu: A éi:A 
1. Canst thou, 0 partial sleep! give thy repose

2. To the wet sea-boy in an hour so rude;

3. And in the calmest and most stillegt night,

4. With all appliances and means to boot,

5. Deny it to a king? Then, happy low, Iie downt

6. Uneasy lies the head that wears a crown.

"King Henry IV" (Pt.II.III.1.25)

by W. Shakesperre.

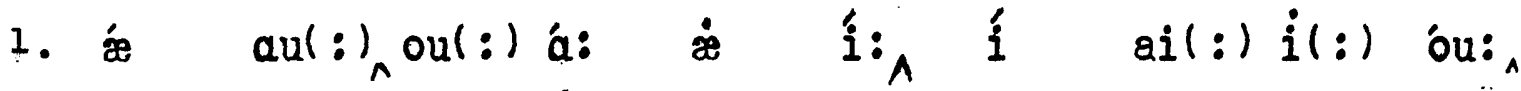

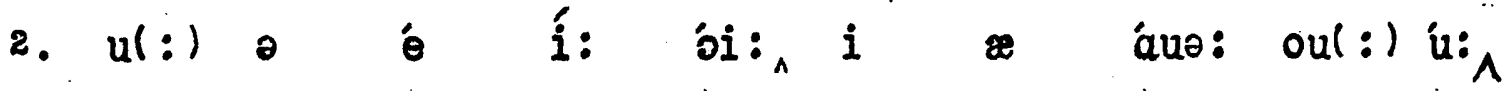

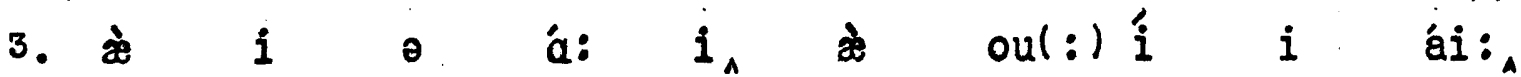

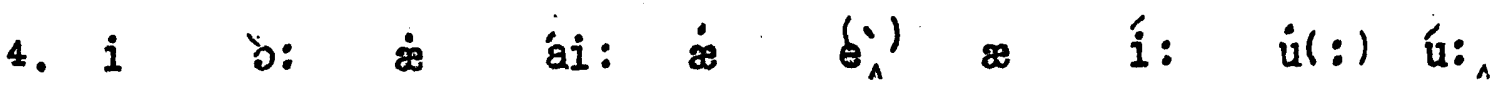

5. $i(b)$ ái: $i \quad \dot{u}(:) \quad \dot{e i}(:) \hat{i}_{\wedge} e_{\wedge} \quad \mathscr{x}$ i ou:

di: áu:

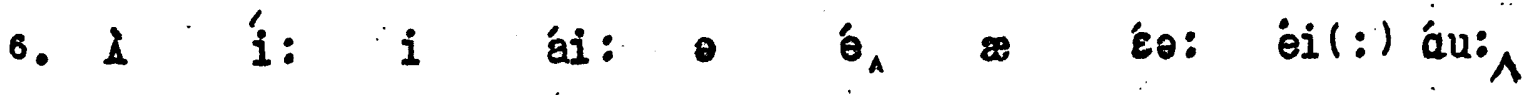


1. If thou didst ever hold me in thy heart,

2. Absent thee from felicity awhile,

3. And in this harsh world draw thy breath in pain

4. To tell my story.

"Hamlet" (V.2.360)

by W. Shalke gpeare.

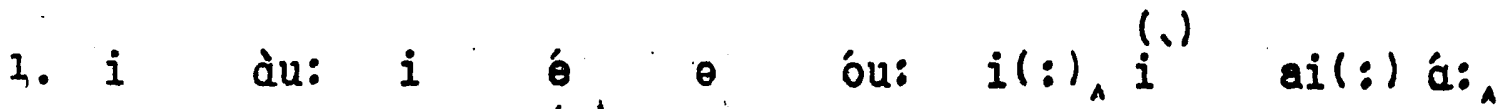

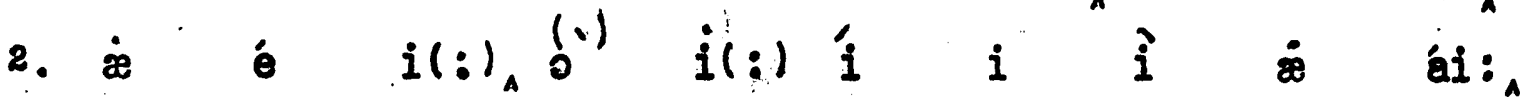

3. ஐ $i$ i á

4. $u(:) \cdot \dot{\theta}$ ail : $\dot{0}: i_{\wedge}$ 
1. Thas far these beyond

2. Compare of mortal prowess, yet observed

3. Their dread commander: he, above the rest

4. In shape and gesture proudiy eminent,

5. Stood like a tower; his form had yot not lost

6. All its original brightness, nor appear'd

7. Less than archangel min'd, and the excess

8. Of giory obscured: as winen the sun new-risen

9. Looks through the horizontal misty air,

10. Shom of lis beams; or from behind the moon,

11. In dim eclipse, disastrous twilight sheds

12. On half the nations, and with fear of change

13. Perplexes monarchs: daricen'd so, yet shone

14. Above them all the archanel; but his face

15. Deep scars of tmunder had intrench'd, and care

16. Sat on his faded cheek, but under brows

17. Of dauntless courace, and considerate pride

18. Waitine revenge: cruel his eye, but cast

19. Signs of remorse and passion to behold

20. The fellows of his crine, the followers rather,

21. Far other once beheld in bliss, condemn'd

22. For ever now to have their lot in pain,

23. Iillions of spirits for his fault amerced

24. Of heaven, and from eternal splendours flung

25. For his revolt, yet faithiul how they stood,

26. Their story wither'd: as when heaven's fire

27. Hath scathed the forest oals or mountain pines,

28. With singed top their stately srowth, thourh bare,

29. Stands on the blasted heath. He now prepared

30. To speak; whereat their doubled ranks they bend

31. From wing to wing, and half enclose him round

32. With all his peers: attention held them mute.

33. Thrice he essay'd, and thrice in spite of scorn

34. Tears, such as angels weep, burst forth; at last

35. Words interwove with sighs found out their way.

"Paradise Lost" (I.599-633) by J. Hilton. 
1. i d: $\mathfrak{i}: \dot{i}(:)$ ô

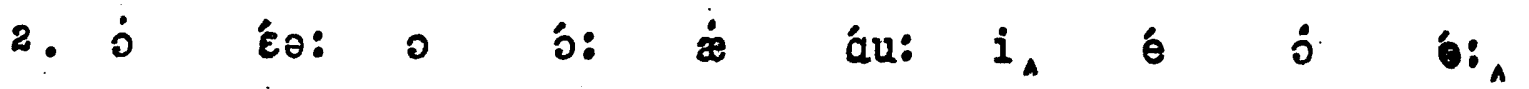

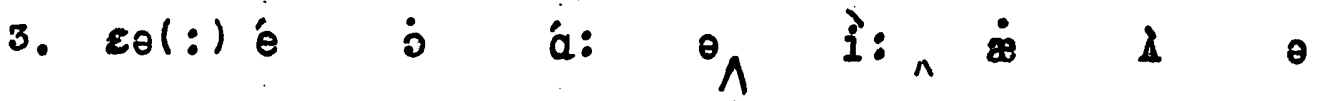

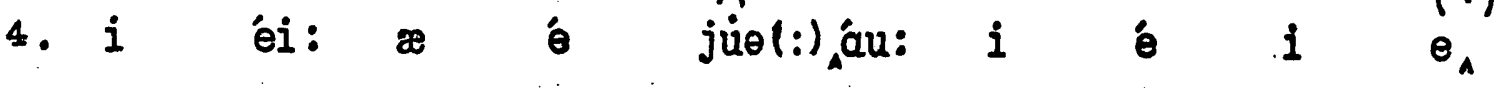

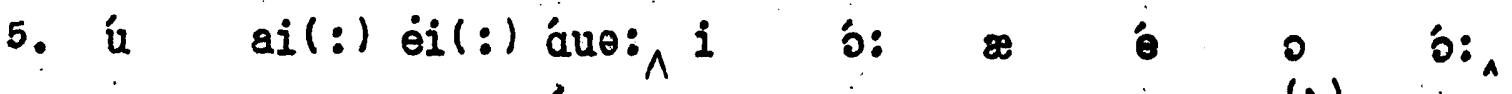

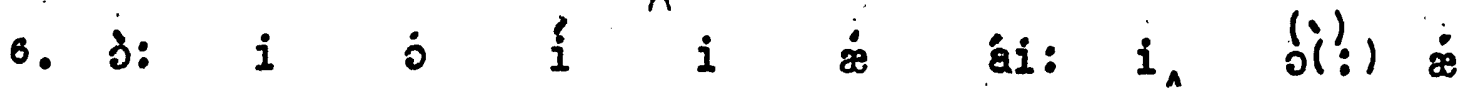
io:

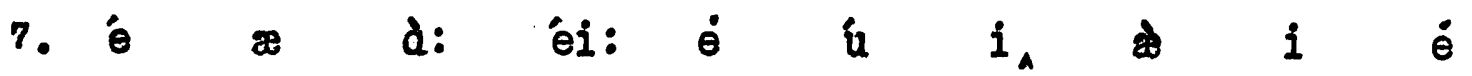

๑. 0 ว: 1 j jü: ${ }_{\Lambda}$ \& $\theta$ \& $j u(:)$

$i_{\wedge}$

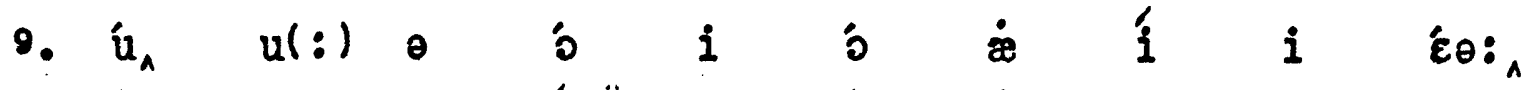
10. ó: 0 i $\quad i_{\wedge}$ b: 0 il(:) ái: $\theta$ u: 11. $i \quad\left\{\quad i(:) \dot{i}_{\wedge} i\right.$ á: $\theta$ ái: ail: $\dot{e}_{\wedge}$ 12. 0 d: $\theta$ éi: $\theta_{\wedge}$ æ $i$ í: 0 éi:

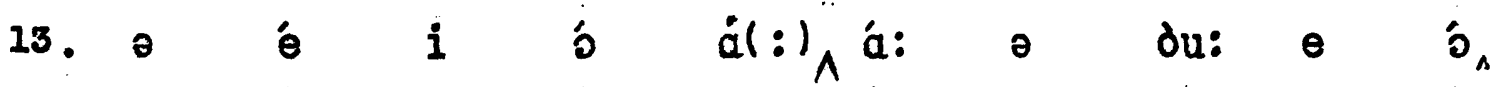
14. $\dot{x} \quad \dot{\imath} \theta \quad j: \quad i \quad$ á: éi: $\dot{e}_{\wedge} \wedge \quad i$ éi :

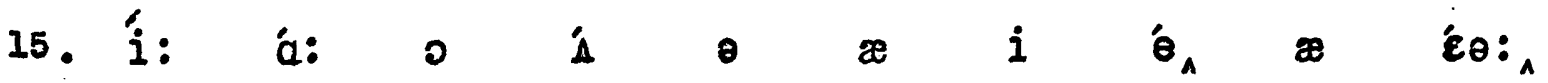

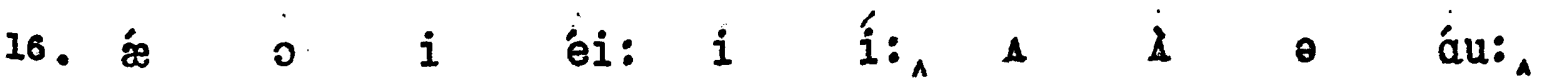

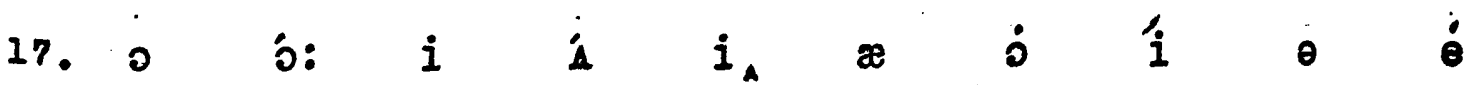
ái:

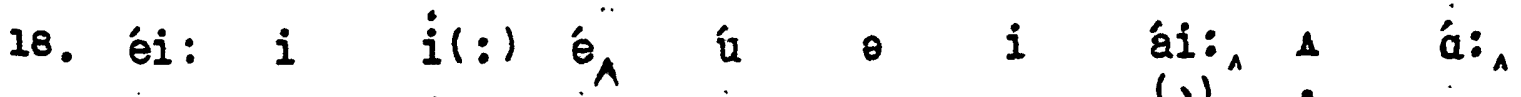

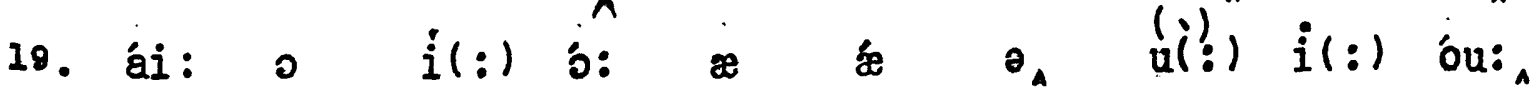
20. $\theta$ é oul(:) d̀: $\quad \theta_{\wedge}$ 
21. $a(:)$ i $\quad \theta \quad i \quad j(:)$ é $\quad i \quad i_{\wedge} \quad j \quad e_{A}$ 22. $\dot{\partial}(:)$ é $\theta$ du: $\dot{A}(:)$ \& $\varepsilon_{\theta}(:) \dot{0} i$ éi:

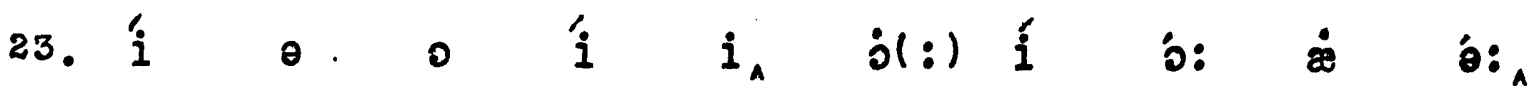

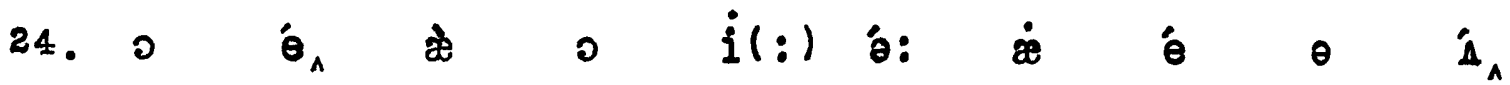

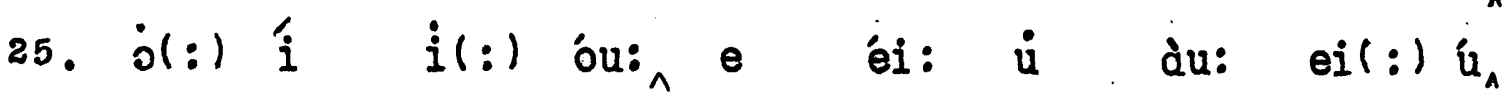
26. $\varepsilon \theta(:)$ ó: $i$ i $\partial_{\wedge}$ æe $\theta$ é ái $\theta$ :

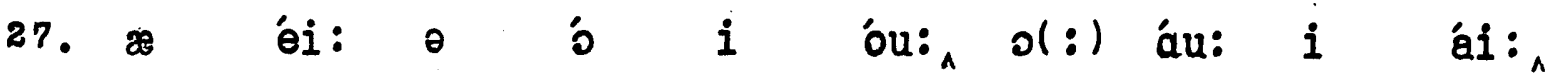
28. $i \quad j \quad i$ o $\varepsilon_{\theta}(:)$ éi: $i$ bu: ${ }_{\wedge}$ oul $\left.:\right) \varepsilon_{\partial}:$ 、

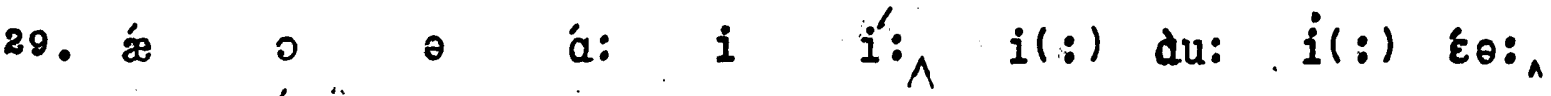

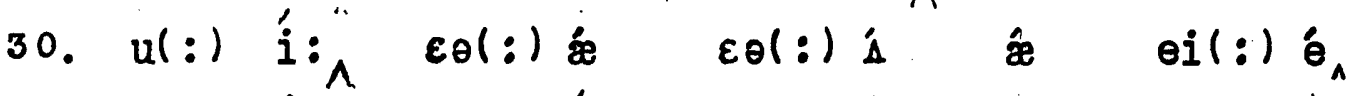
31. $0 \quad \hat{i} \dot{u}(:) \hat{i}_{\wedge} \quad d: \dot{e}$ ou: $\dot{i} d u:_{\wedge}$ 32. $i \quad 3: \quad i \quad i_{\theta}:{ }_{\wedge} \dot{z}$ é $\theta$ é $\theta$ jú: 33. ái: il:) e éi: $¥$ \&i: $i$ ái: 0 o:

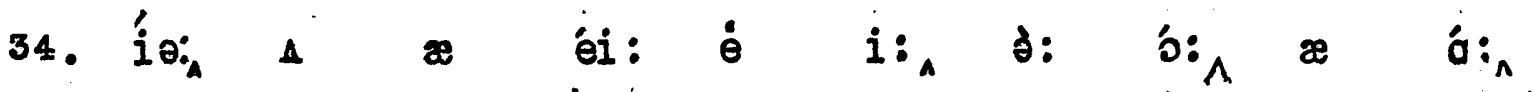
35. $\theta:$ i $\theta$ ou: $i$ ái:^ du: du: $\varepsilon \theta(:)$ éi: 
1. What though the field be lost?

2. All is not lost; the unconquerable will,

3. And study of revenge, immortal hate,

4. And courege never to submit or yield,

5. And what is else not to be overcome;

6. That glory never shall his wrath or might

7. Extort from mo.

"Paradi se Lost" (I.104-110) by J. Milton.

1. ๖ ठu: o í: il:) ó:

8. ว: 1 ค b:

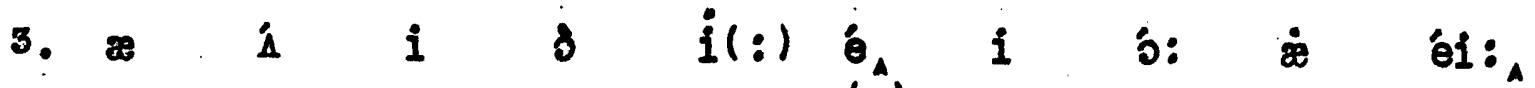

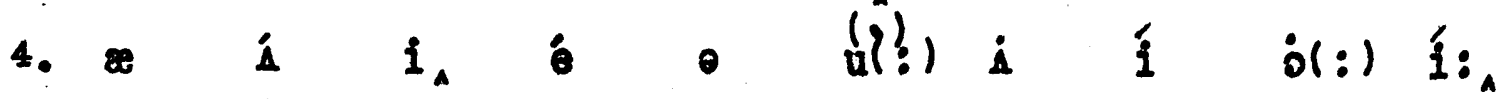

5. $\quad \dot{i} \quad \dot{\theta}_{A} \quad \dot{i}(:) \quad \dot{i}(:)$ ou: $\theta \quad i_{\wedge}$

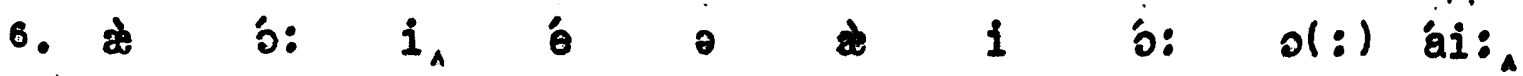

7. $\dot{\theta} \quad \dot{0}: 0 \quad \dot{i} \dot{A}_{\wedge}$ 
1. Not that fair field

2. Of Enna, where Proserpine gathering flowers,

3. Herself a fairer flower, by gloom Dis

4. Was gather'd, which cost Ceres all that pain

5. To seek her through the world.

"Paradise Iro st" (IV -268-272) by J. Milton.

1. 0 \& $\varepsilon \theta(:)$ í:

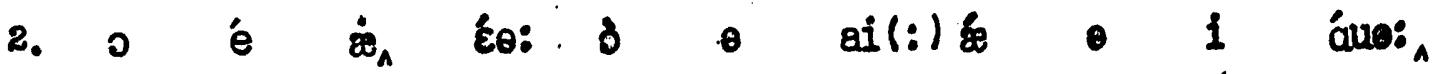

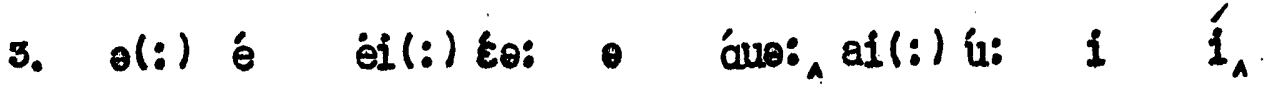

4. 0 \& $\theta_{A} \dot{1}$ b.

5. $u(:)$ i: $\theta(:)$ u: $\theta$ ह 
1. A milk-white Hind, imortal and unchenged

2. Fed on the lawns and in the for est ranged.

J. Dryden.

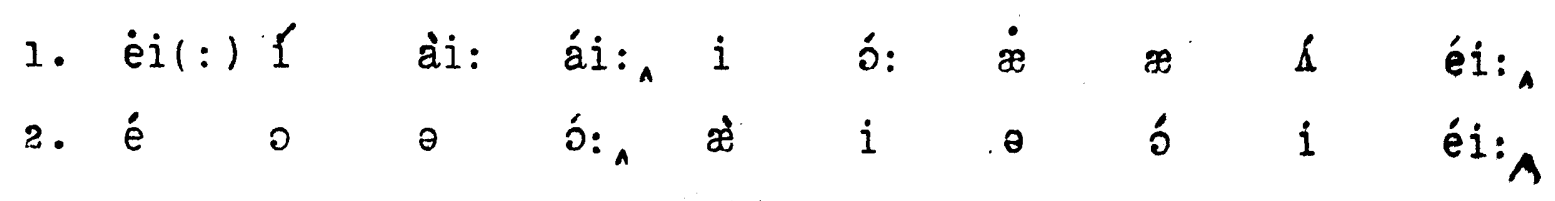


1. To Hounslow Heath I point and Banstead Dowm;

2. Thence comes your matton, and these chicks own.

A. Fope.
1. $u(:) \cdot a d a:$
oul : ) 占:
ai(:) bi:
2. $\dot{\theta}$ i
() $i(:) \quad 1$
ǽ
e juo(: :)is. ai (:) ou: $A$ 
1. Mark ruffian Violence, distain'd with crimes,

2. Rousing elate in these degenerate times;

3. View unsuspecting Innocence a prey,

4. As guileful Fraud points out the erring way;

5. While subtle Litigation's pliant tongue

6. The life-blood equel sucks of Right and Wrong.

R. Burns.

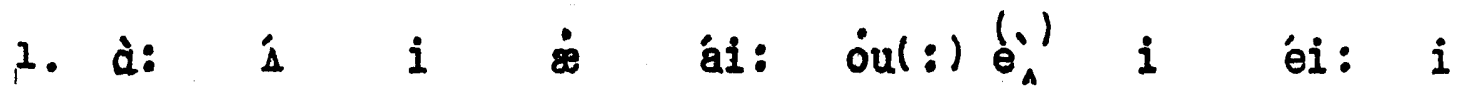

2. áu: $i$ il: éi: $i$ i: $i(:)$ é ái:

ái:

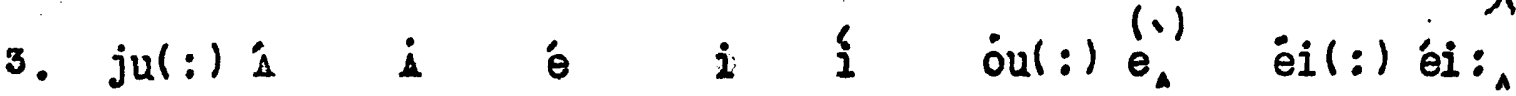

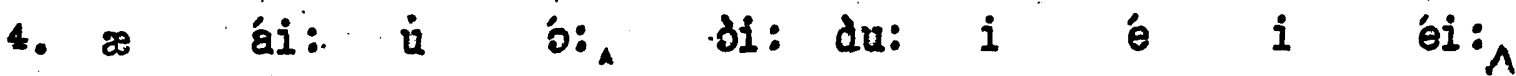

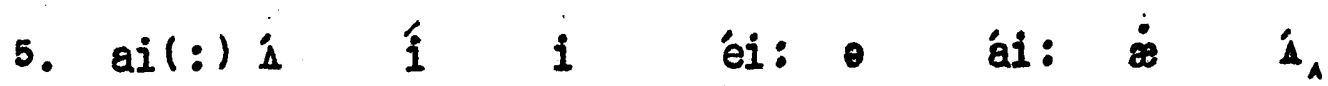

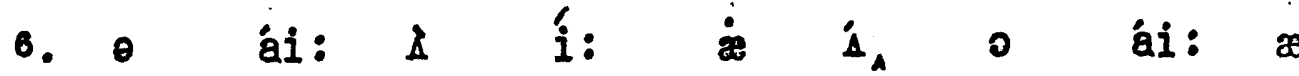

ó 
1. Leeze me on drinks it gies us mair

2. Than either school or college;

3. It kindles wit, it waukens lair,

4. It pengs us fou 0 ' $\mathrm{knowledge}$

5. Be't whisky gill or penny wheep

6. Ber ons stronger potion

7. It never fails, on drinking deep,

8. To kittle up our notion

9. By night or dey.

R. Burns.
1. $i: \quad i(:)$ o
$i_{\wedge} \quad i \quad \hat{i}:$
$\Delta \quad$ éi:
2. æ $i:$
$\partial$ u: $\dot{\partial}(:) \quad \dot{0} i_{A}$
3. $i$ i $\dot{i}_{\wedge} i$ ó: éi:
4. $i$ ǽ $\Delta_{\wedge}$ ú: $\delta(:)$ o $i_{A}$
5. $i(:)$ '
i $\hat{i}_{1} \quad j(:) \quad \dot{e}$
i i:
6. $j(:)$ o
i ’o
$\theta$ ó:
$\theta_{A}$
7. i é
ə $\quad \dot{i}:_{1} \quad 0$
i $i$
i: a
8. $u(:) \mathfrak{i}$
\& $u(:)$ o: $\quad \theta_{\wedge}$
๑. $\dot{a} i(:) i^{\prime}$
o(:) bis/ 
1. A prince can mak' a belted knight,

2. A marquis, duke, and a' that;

3. But an honest man's aboon his might,

4. Guid faith he mauna fa' that:

5. For $a^{\prime}$ that, and $a^{\prime}$ that,

6. Their dignities, and a that,

7. The pith $0^{\prime}$ sense, and pride $0^{\prime}$ worth,

8. Are higher rank than a' that.

R. Baing.

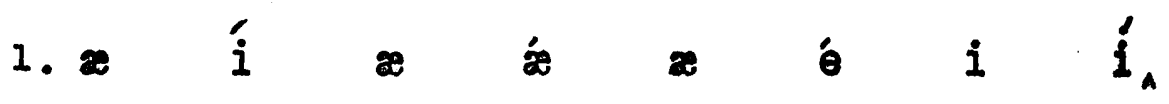

2. $2 i_{\wedge} \quad$ jú: $\approx$ o: $\mathbb{\infty}_{\Lambda}$

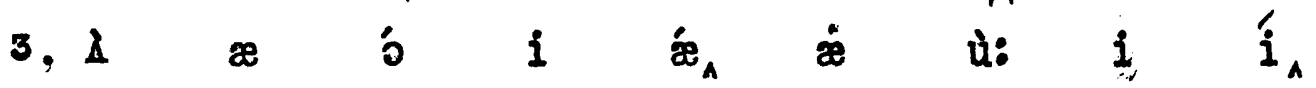

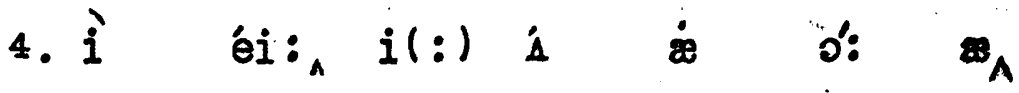

5.

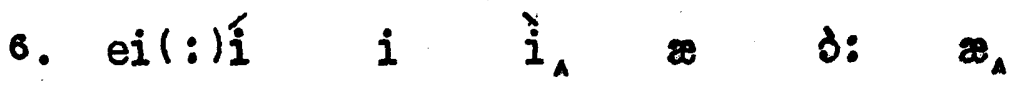

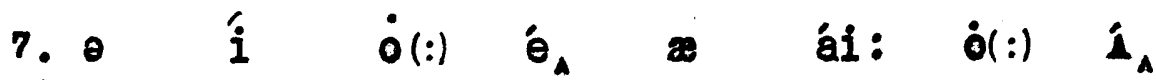

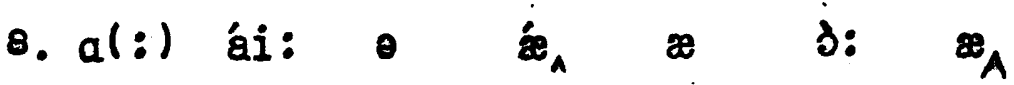


1. The sacred lowe o' weel-placed love

2. Iuxuriantly indulge it;

3. But never tempt th'illicit rove,

4. Tho' naething should divalge it.

5. I waive the quantum o'the sin

6. The hazard o'concesling,

7. But ochl it hardens a' within,

8. And petrifies the feeling.

R. Burns.

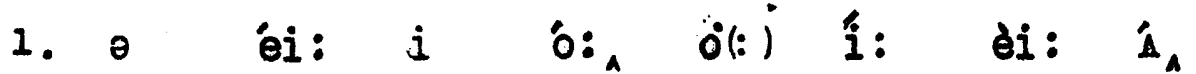

2. $\Delta$ ju: $i$ i $i \quad i \quad i \quad i_{\wedge}$

3. 1 é $\theta$ é $i$ i $i \quad$ o

4. of: éi: $i$ id $i$ i $i_{\wedge}$

5. $a i(:)$ éi: $\theta$ o $i_{A} \delta(:)$ o $i_{a}$,

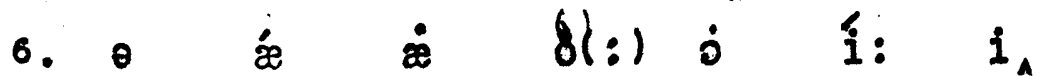

7. 4 o

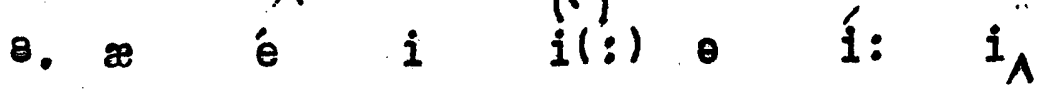


1. Who made the heart, 'tis He alone

2. Decidedly can try us;

3. He knows each chord, its various tone;

4. Each spring, its various bias.

5. Then at the balance let's be mute,

6. We never can adjust it;

7. What's done we partly may compute,

8. But know not what's resis ted.

R. Burns.

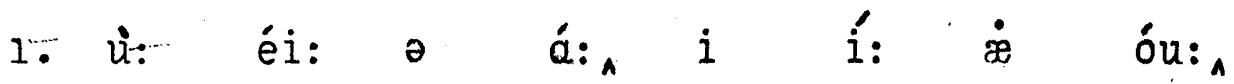

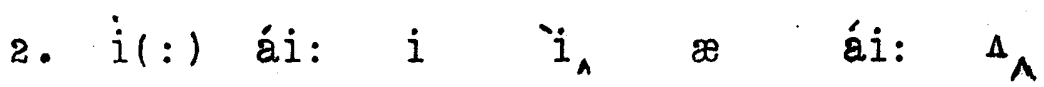

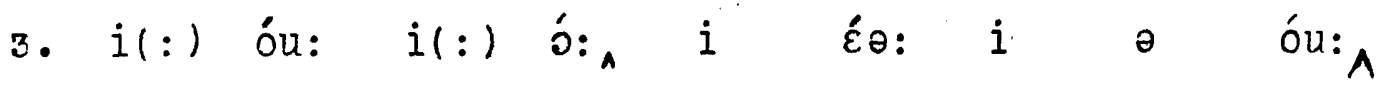

4. $i(:) i_{\wedge} i$ \&ə: $i$ ə

5. 巳́ $¥ \quad \partial \quad \ddot{E} \quad \dot{\otimes}_{\wedge}$ è $i(:) \quad j \dot{u}:_{\wedge}$

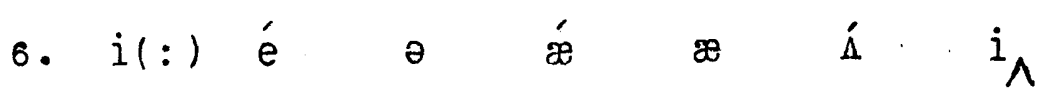

7. $0 \quad \dot{\Lambda}_{\wedge} \quad i(:)$ á: $i$ èi: $\dot{j}$ jú:

8. $\Delta$ óu: $o_{\wedge}$ ó $i(:)$ í $i_{\wedge}$ 
1. To make a happy fire-side clime

2. To weans and wife,

3. That's the true pathos and sublime

4. Of muman life.

B. Burns.

1. $u(:)$ éi: èil: $)_{\text {ǽ }} i$ áio: ài: ái:

2. $u(:)$ ei: $\approx$ áig

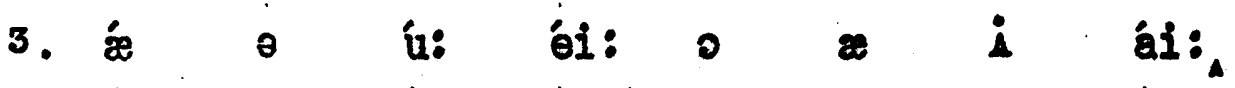

4. ค jú: \& $\dot{a} i:_{\wedge}$ 
1. Thou Fower Supreme, whose mighty acheme

2. These woes of mine fulfil,

3. Here firm I rest, they mast be begt

4. Because they are Thy Wi2ls

R. Burne.

2. aul: láue: ju(:) $\mathfrak{i}:$ al $u$ ái: 1 i: 2. il: ou: o di: u $I_{A}$ 3. $i \theta(:)$ o: ail:) $\dot{e}_{A}$ eil(:)i $1(:) \dot{\theta}_{A}$

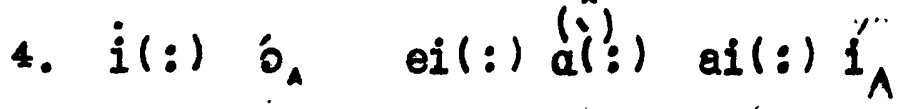


1. Had we never loved sae kindly,

2. Had we never loved sae blindly,

3. Never met, or never parted,

4. Te had ne'er been broken-hearted.

R. Burns.

1. æ̇ $i(:) \dot{\theta} \theta \hat{\Lambda}_{A}$ ei(:) ái: $i_{A}$

2. æ̇ $i(:)$ e $\theta \quad i_{A}$ ei(:) ái: $i_{A}$

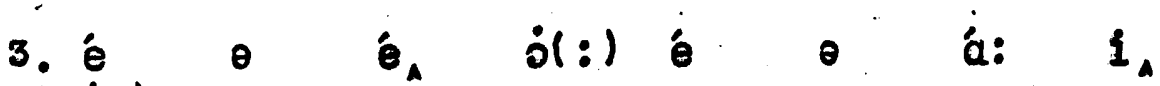

4. $\left.(i)^{\prime}\right)$ éi: $i(:)$ o: á: $i_{\wedge}$ 
1. We twe hae pidit i' the burn

2. From mornin' oun till dine;

3. But seas between us braid hae roar'd

4. Sin auld lang gyno...

R. Burns.

1. $i(:)$ ó: ei(:) éi: $i$ o

2. 0 o: 1 i 1 i ál:

3. 4 i: $i(:)$ i: 4 éi: eif:) o:

4. i ó: æ ái: 
1. On the brink of the night and the moming,

2. My coursers are wont to ingpire,

3. But the Eaxth has just whispered a warning,

4. That their flight must be swifter than fire.

P.B. Shelley.

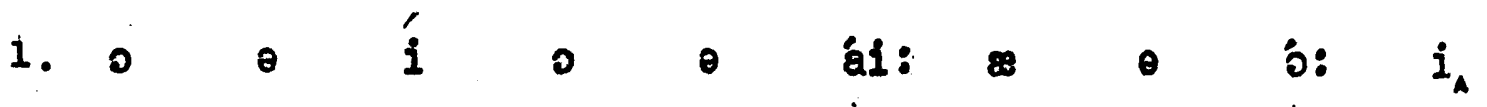

2. $a i(:)$ bo: $\theta$ a(:) bu: $\dot{u}(:) 1$ aio:

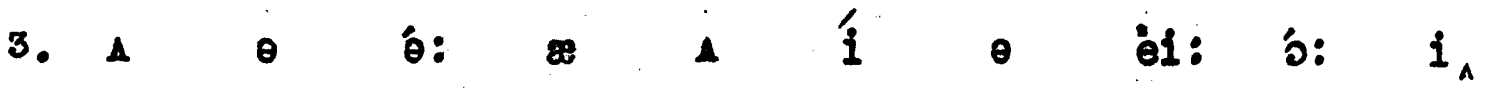

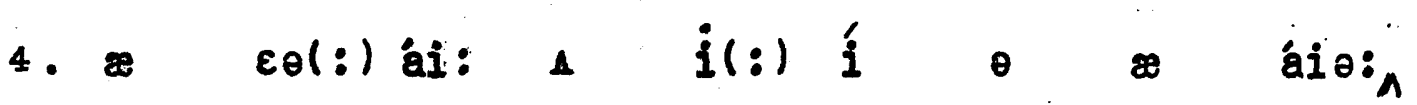


1. 14y minie does constant $2 y$ deave mo

2. And bid me beware o' young men;

3. They flatter, she says, to decelve mes

4. But whe can think ase o' Tam Glen?

I. Burne.

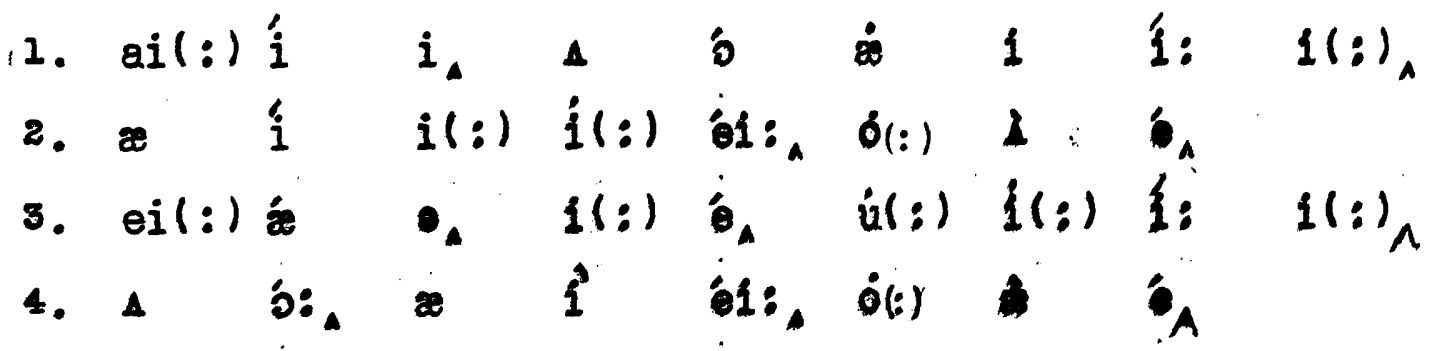


1. My heart aches, and a drowsy numbness peins

2. My sense, as thoush of hemlock I had amank,

3. Or emptied some dull opiate to the drains

4. One mimute past, and Lethe-wards had sunk:

5. Mis not through envy of thy happy lot,

6. But being too happy in thine happiness,

7. That thou, light-winged Dryad of the tre日s,

8. In some melodious plot

9. Of beechen green, and shedows numberless,

10. Singest of summer in full-throated ease.

(v.1)

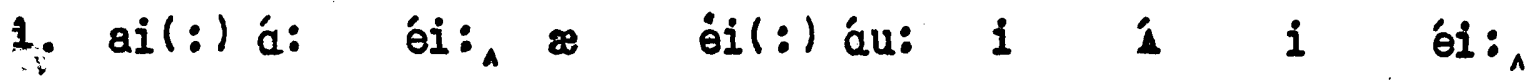

2. ai(:) $\dot{\theta}_{A} \quad \approx$ bu: 0 é 0 di: $\approx$ iA

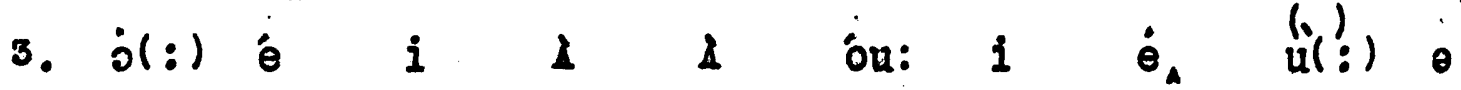

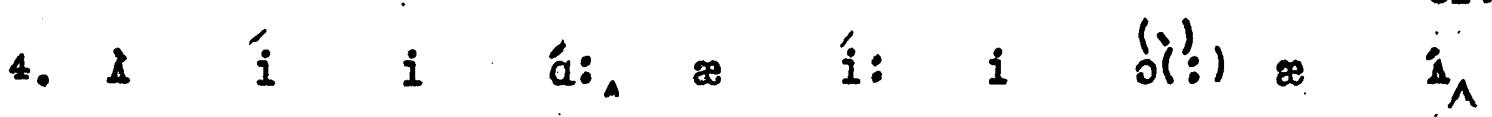

5. $i$ o $u(:)$ e $i_{A} 0$ di: $\begin{array}{llll} & 0 & \dot{b}_{A}\end{array}$

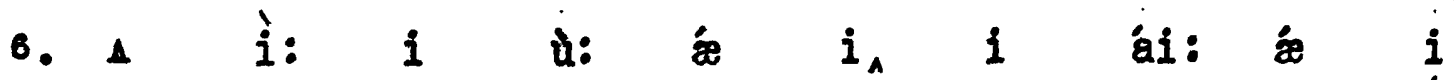

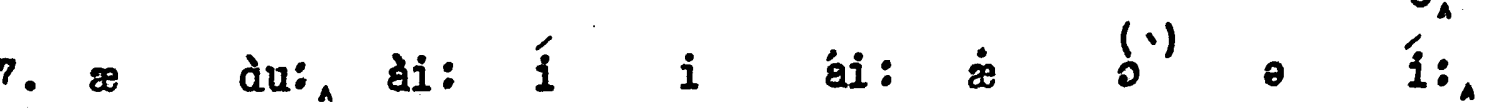

8. $i \quad \dot{\theta}$ ou: $i \quad \theta \quad b_{A}$

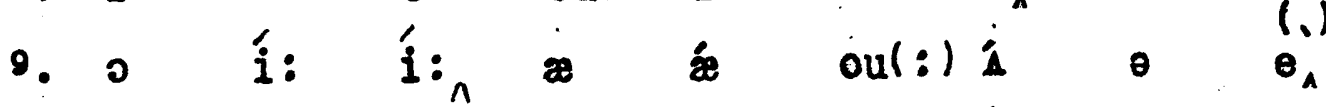

10. $i \quad j \quad 0 \quad i \quad \theta_{\wedge} i$ i ou: $i$ í 
1. 0 , for a draught of vintages that hath been

2. Cool'd a lons ge in the deop-delv6d earth,

3. Tasting of Flora and the country green,

4. Dance, and Provençal song, and sumbrant mirthl

5. O for a beaker full of the warm South,

6. Full of the true, the bluahful Hipporene,

7. With boaded bubbles winking at the brim,

8. And purple-gteined mouth;

9. That I might drink, and leave the world ungeen,

10. And with thoe fade away into the foreat dim.

$(v, p)$

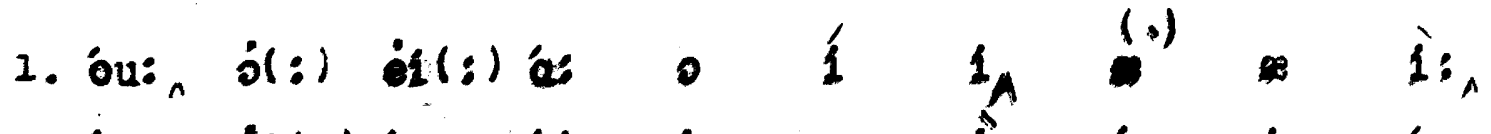

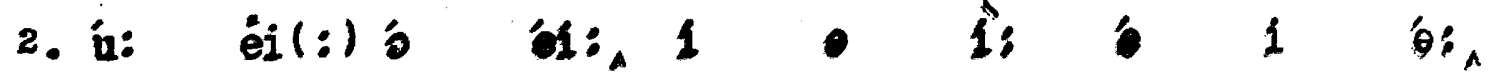

3. ei: $i$ o: bA 1 \& 1 i:

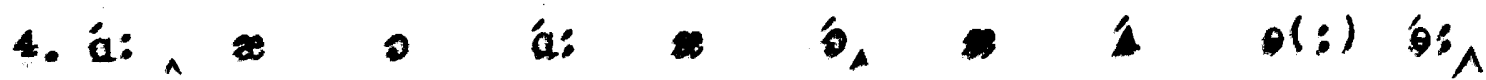

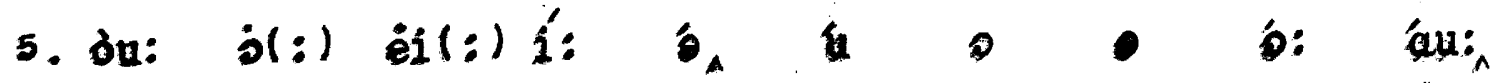

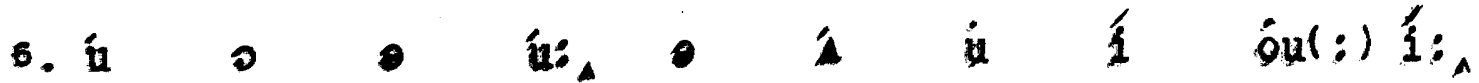

7. $i$ i: $i$ i

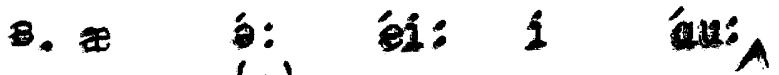

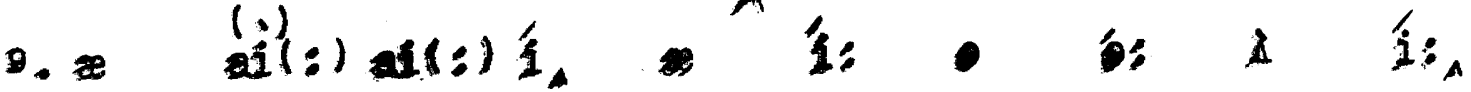

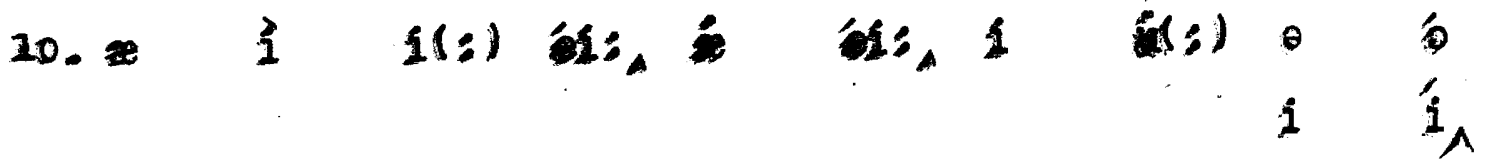


1. Fade far away, dissolve, and quite forget

2. What thou among the leaves hast never known,

3. The weariness, the fever, and the fret

4. Here, where men sit and hear each other groan;

5. Where palsy shakes a few, sad, last grey hairs,

6. Where youth grows pale, and spectre-thin, and dies;

7. Where but to think is to be full of sorrow

8. and leaden-eyed despairs;

9. Where Beauty cannot keep her lustrous ejes,

10. Or new Love pine at them beyond to-morrow.

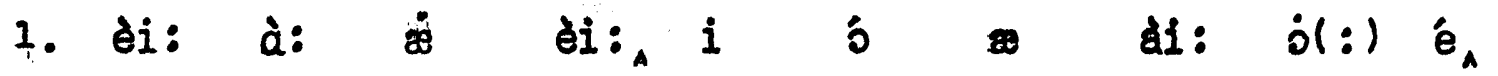

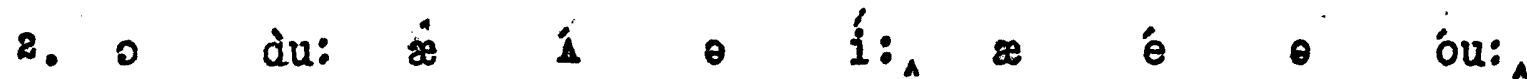

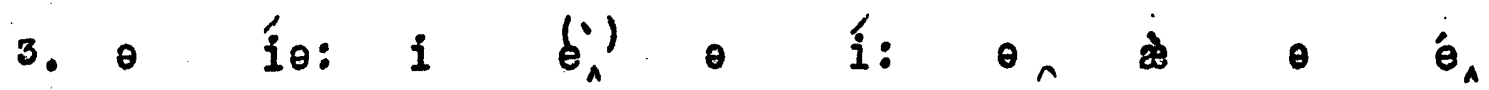

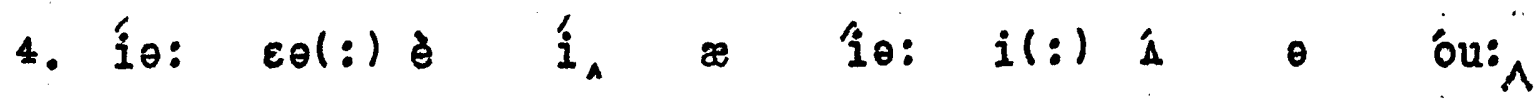

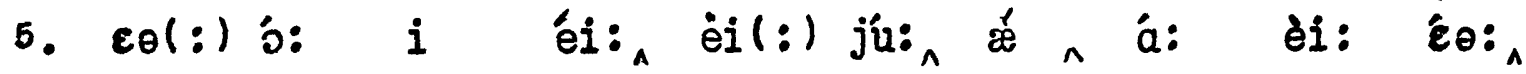

6. $\varepsilon \theta(:)$ jú: du: éi: $¥$ é

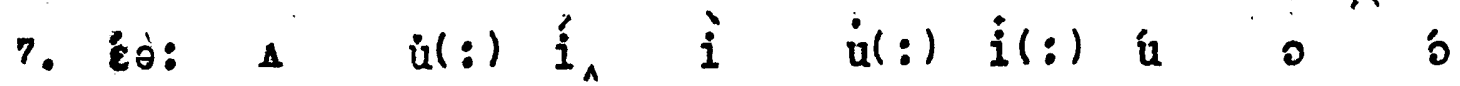

oul : $)_{A}$

8. æ é ái: $\dot{i}(:) \varepsilon_{\theta}$ A $_{A}$

9. $\varepsilon \theta(:)$ jú: $i_{\wedge}$ æo 0 i: $\dot{\theta}(:)$ i $\theta$ ái:

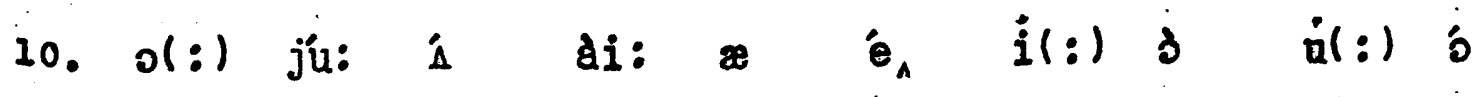

oul : $)_{\wedge}$ 
1. Away? away! for I will fly to thee,

2. Not charioted by Bacchus and his pards,

3. But on the viewless wings of Poegy,

4. Though the dull brain perplexes and retards:

5. Already with thee! tender is the night,

6. And haply the Queen-Moon is on her throne,

7. Cluster'd around by all her starry Fays;

8. But here there is no light,

9. Save what from heaven is with the breozes blown

10. Through verdurous glooms and winding mosgy ways.

$(\nabla \cdot 4)$

1. $\dot{x}$ éi: $\dot{\wedge}$ éi: $\dot{\wedge}(:)$ ài: $i$ ái: $\dot{u}(:) \quad \grave{i}:_{\wedge}$

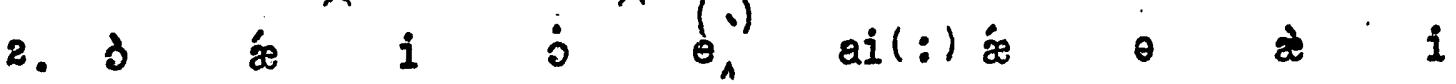

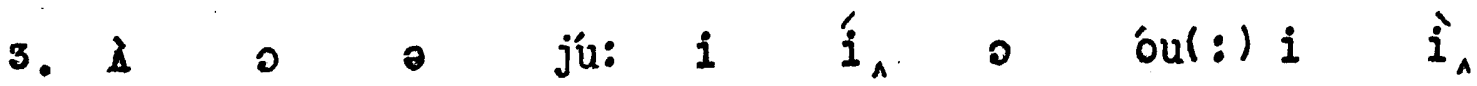

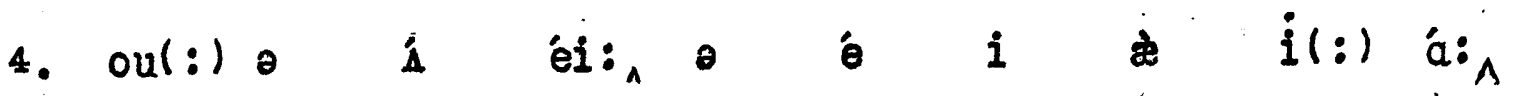

5. $\partial(:) \dot{e} \quad i \quad i^{\prime} i(:)_{\wedge} \dot{e}$ o $i \quad \theta \quad a j:_{\wedge}$

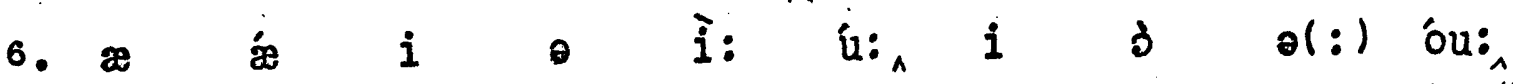

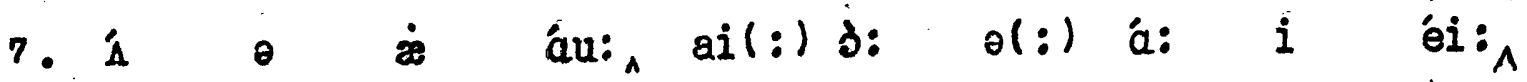

8. $\Delta$ 年: $\varepsilon \theta(:)$ i du: ái:

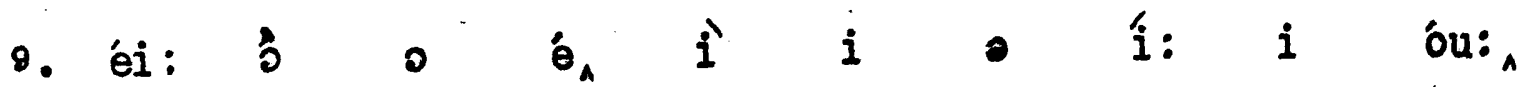

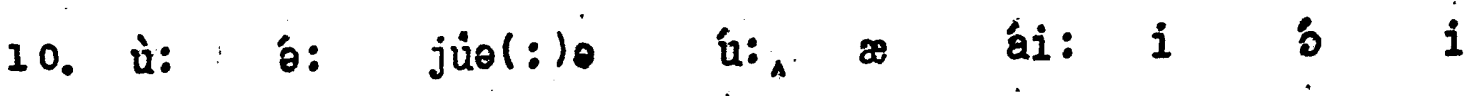


1. I cannot see what flowers are at my feet,

2. Nor what soft incense hangs upon the boughs,

3. But, in enbalmed darkness, guess each sweot

4. Wherewith the seasonable month endows

5. The grass, the thicket, and the fruit-tree wild;

6. Wite hawthorn, and the pastoral eglantine;

7. Fast-fading violets cover'd up in leaves:

8. And mid-May's eldest child

9. The coming mask-rose, full of dewy wine,

10. The marmarous haunt of flies on summer eves.

$$
(v \bullet 5)
$$

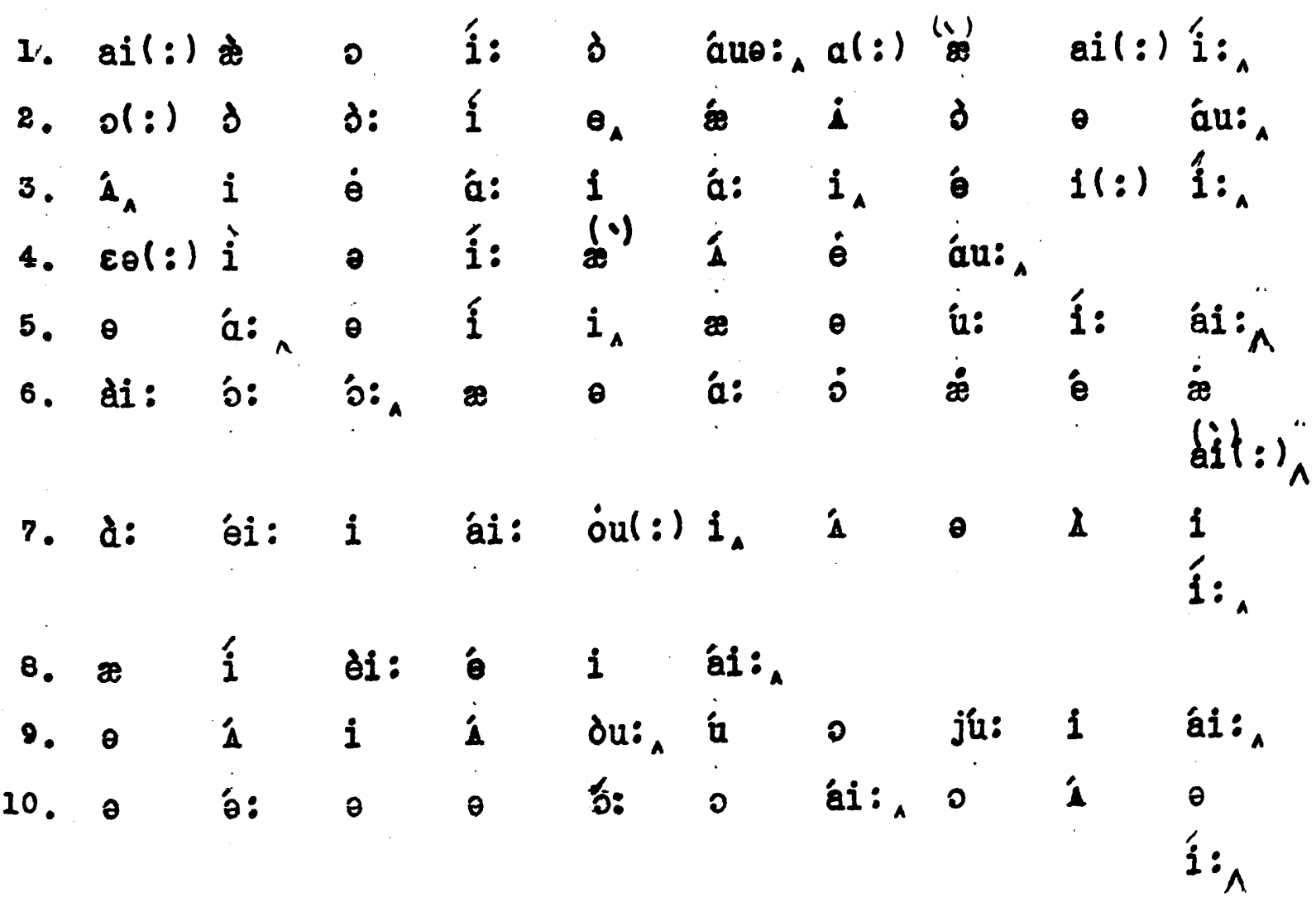


1. Darkling I listen; and, for many a time

2. I have been half in love with easeful Death,

3. Call'd him soft names in many a maséd rhyme,

4. To take into the air my quiet breath;

5. Now more than ever seems it rich to die,

6. To cease upon the midnight with no pain,

7. While thou art pouring forth thy soul abroad

8. In such an ecstasy !

9. Still wouldst thou sing, and I have ears in vain -

10. To thy high requiem become a sod.

$$
(v \cdot 6)
$$

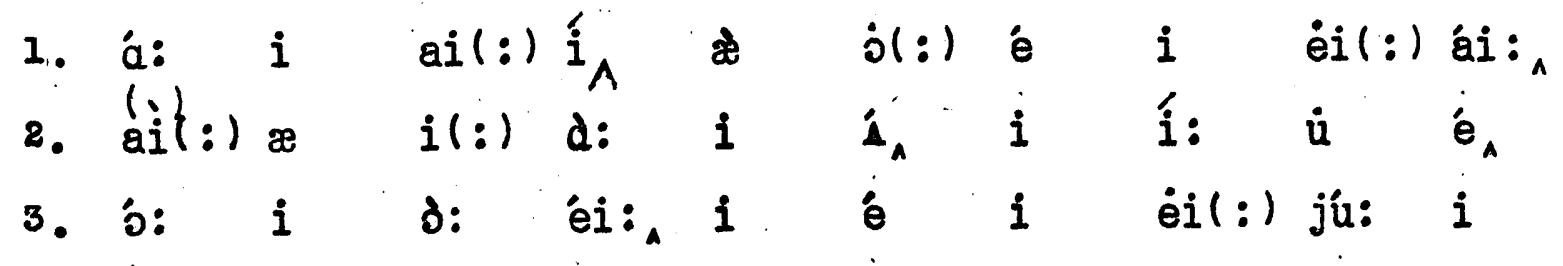

ái:

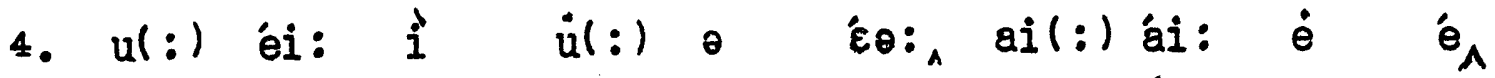

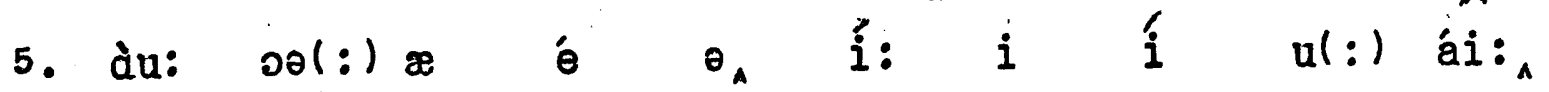
6. $u(:)$ í: $A$ j $\quad \theta$ í ail: $)_{A} i$ ou: éi: 7. ail: du: $a(:)$ bo: $i$ b: a ail: 8. $i \quad i \quad \dot{e} \quad i_{\wedge}$

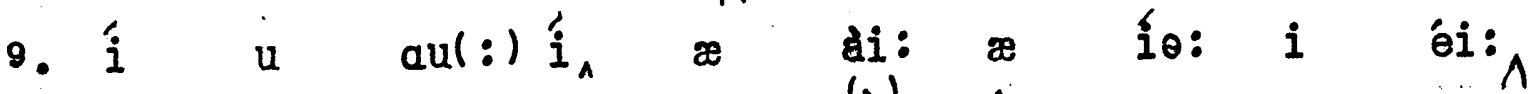
10. $u(:)$ ài: di: é $i$ (o) $\dot{i}(:)$ i èil(:) $b_{A}$ 
1. Thou wast not born for death, inortal Bird

2. INo hungry generations tread thee down;

3. The voice I hear this passing night was heard

4. In ancient days by emperor and clown:

5. Perhaps the self-same song that found a path

6. Through the sad heart of Ruth, when, sick for homo,

7. Sho stood in tears amid the alien corn;

8. The same that oft-times hath

9. Charm'd magic casements, opening on the foam

10. Of perilous seas, in faery lands forlorn.

$$
(v \cdot 7)
$$

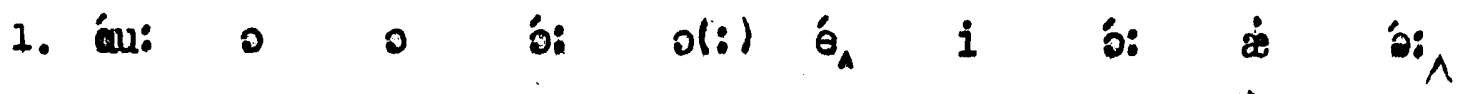

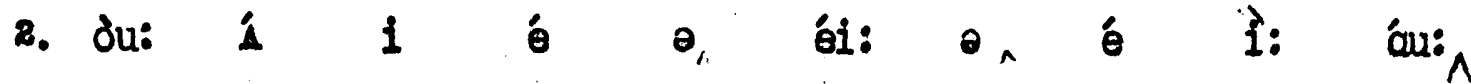

3. - ái: ail: lo: $i$ á: $i$ ái: ${ }_{\wedge}$ ä:

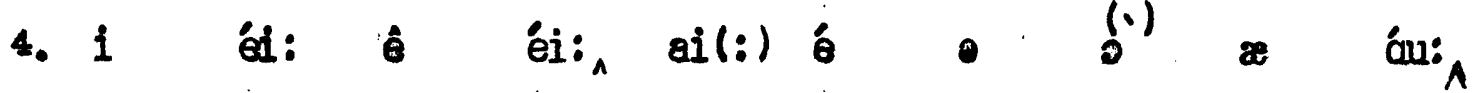

5. $\theta$ \& $\theta$ é eil(:) ó

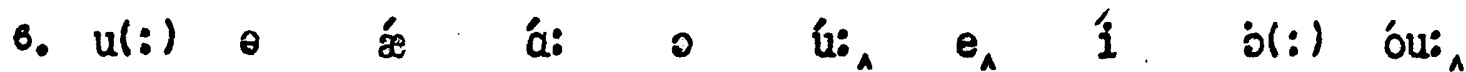

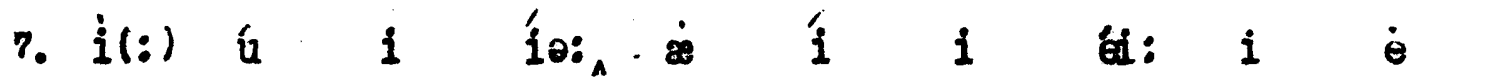

8. ái: 2 á: ài: $\mathbb{w}_{A}$

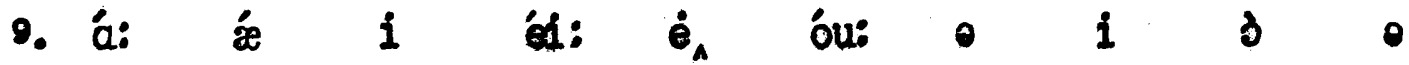

óu:

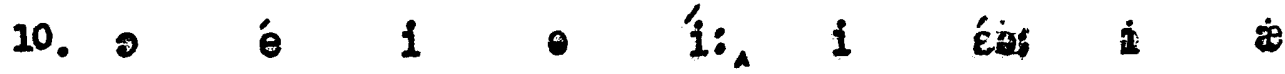

$\dot{\partial}(:) \quad \dot{\imath}: \wedge$ 
1. Forlorn the very word is like a bell

2. To toll me back from theo to mo sole self:

3. Adieut the fancy cannot cheat so well

4. As she is famed to do, deceiving elf.

5. Adieus adieul thy plaintive anthem fades

6. Past the near meadows, over the still stream,

7. Up the hill-side; and now t tis buried deep

8. In the next valley-glades:

9. Was it a vision, or a waking dream?

10. Fled is that masic: - do I wake or sleep?

$$
(\nabla \cdot 8)
$$

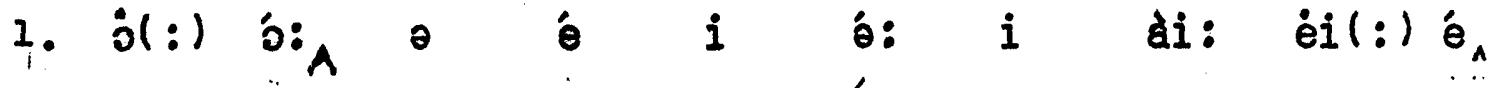

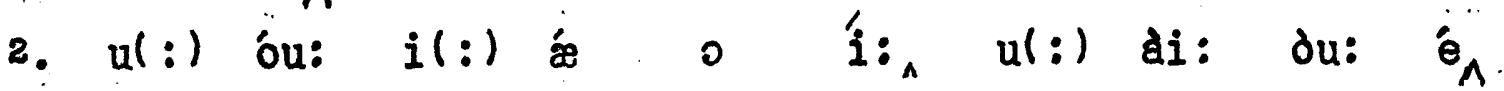

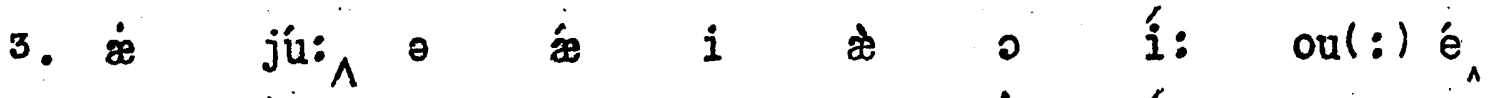

4. $\approx$ i: $i$ éi: ul(:) úl $i(:) \quad i:$ i $\dot{e}_{\wedge}$

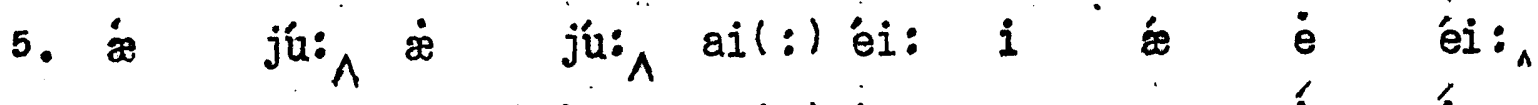

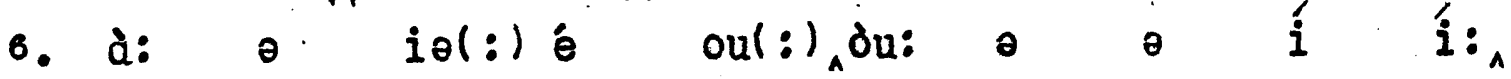

7. $\quad \theta$ i ái: ${ }_{\wedge} \approx$ du: $i$ e $i \quad i i_{\wedge}$

8. $i$ e e \& $i$ éi: $\wedge$

9. I $i$ eil(:) $i$ on oll

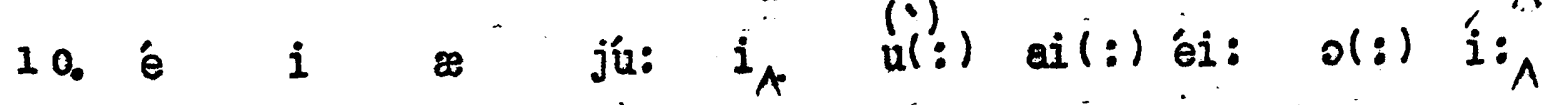


1. Yet once more, 0 ye laurels, aind once more

2. Ye nvriles brown, with ivy never sere,

3. I come to pluck your berries heish and crude,

4. And with forced fingers rude

5. Shatter your leaves before the mellowins year.

6. Bitter constraint, and sad occasion dear

7. Compels me to disturb your season due:

8. For Lycidas is dead, dead ere his prime,

9. Youns Lycidas, and hath not left his peer:

10. Who would not sing for Lycidas? he knew

11. Himself to sing, and build the lofty rhyme.

12. He must not float upon his watery bier

13. Unwept, and welter to the parching wind,

14. Without the meed of some melodious tear. 


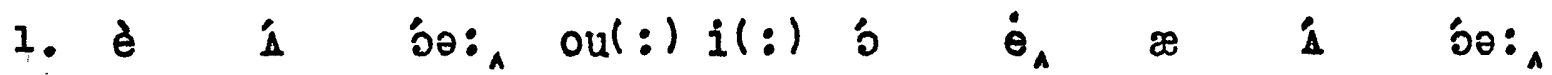
2. $i(:)$ á: áu: $i$ ái: $i$ é $\theta$ 'i

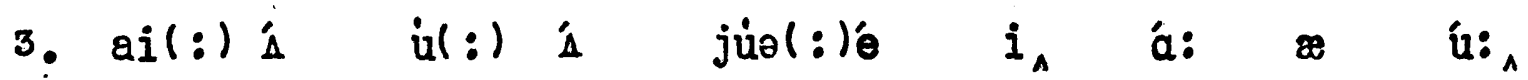
4. æ̇ $i$ ó: $i$ i

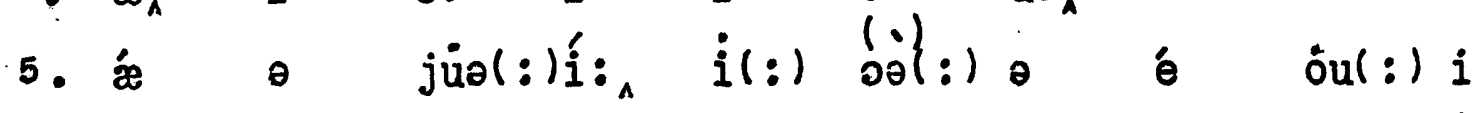
ía: 6. '⿺ ə

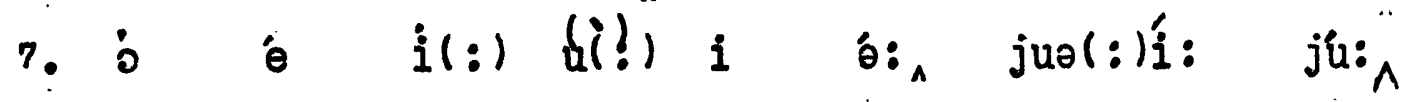
8. $\dot{b}(:) \stackrel{i}{i}$ \& $i \quad \dot{\theta}_{\wedge} \quad \dot{e} \quad \varepsilon_{\theta}(:) i \quad$ ái:

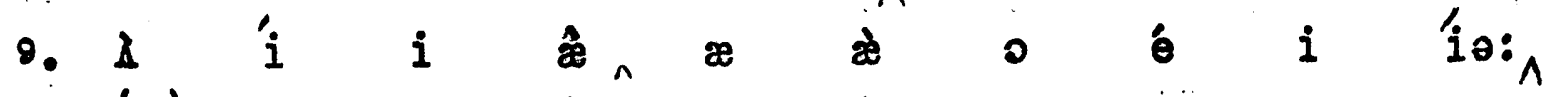

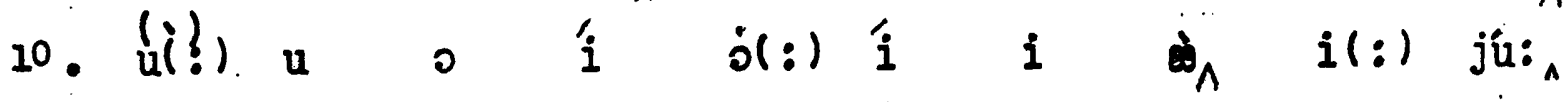

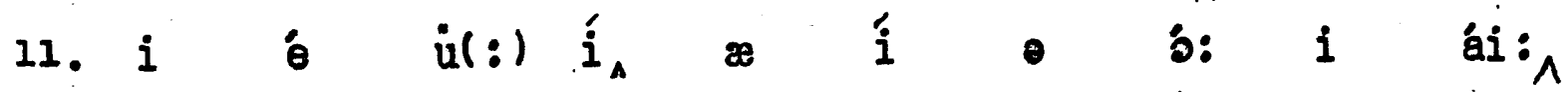
12. $i(:) \quad i \quad$ ou: $i$ b $i \quad$ o: $\theta$ i io: A

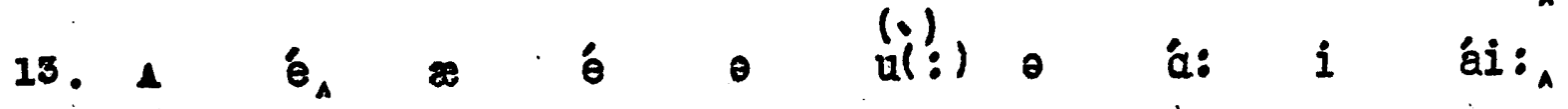

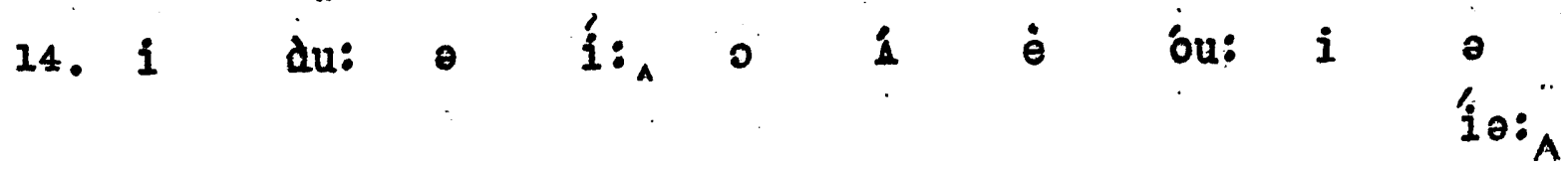


1. Begin then, Sisters of the sacred well

2. That from beneath the seat of Jove doth spring;

3. Begin, and somewhat loudly sweep the string.

4. Hence with denial vain and coy excuse:

5. So may some gentle lihse

6. With lucky words favour my destined urn;

7. And as he passes, turn

8. And bid fair peace be to my sable shroud.

1. $i(:) \quad i \quad \dot{e}_{A} \quad \hat{i} \quad \diamond \quad 0 \quad \theta \quad$ éi: $i \quad \hat{\theta}_{A}$

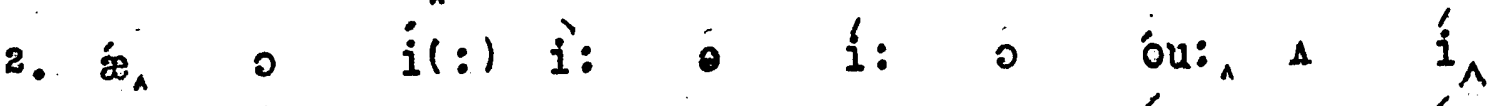

3. $i(:) i_{\wedge} \approx$ \& 0 au: $i$ i: $\theta$ $\hat{i}_{\wedge}$

4. é $i$ il : ái: $\dot{e}$ éi: $\approx$ ói: è júA

5. du: ei(:) ^ é jü:

6. $i$ i $i$ ó: éi: $\theta$ ài: é $i$ ó

7. ஐ ஐ $i(:)$ á: î

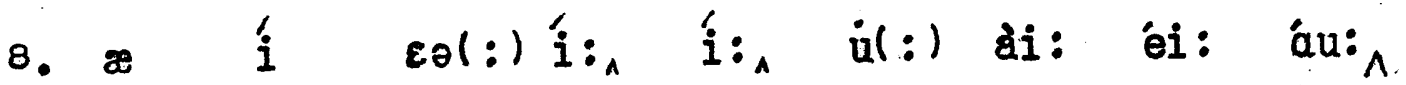


1. For we vere nursed upon the self-same hill,

2. Fed the same flock by fountain, shade, and rill,

5. Tosether both, ere the high lawns appear'd

4. Under the opening eye-lids of the morn,

5. We drove a-field, and both together heard

6. What time the sray-fly winds her sultry horn,

7. Battenine our flocks with the fresh dews of night,

8. Oft till the star, that rose at evening bright,

9. Toward heav in's descent had sloped his westering wheel.

10. Meanwile the mural ditties were not mute,

11. Temper'd to the oaten flute;

12. Rough Satyrs danced, and Fauns with cloven heel

13. From the glad sound would not be absent long;

14. And old Damoetas loved to hear our song.

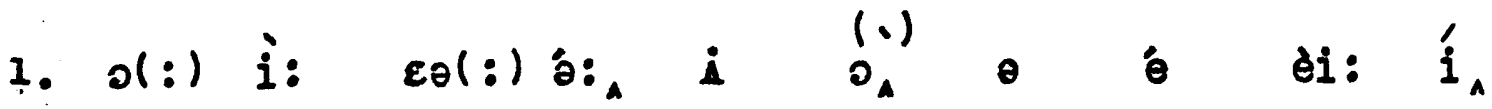

2. é $\theta$ èi $\dot{b}_{\wedge}$ ail : $)$ áu: $i_{\wedge}$ éi $i_{\wedge}$ æ $\dot{i}_{\wedge}$

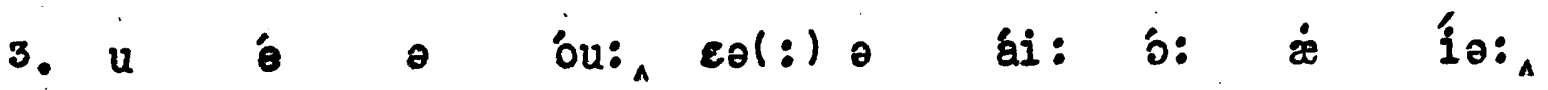

4. $i$ o $\theta$ ou: $i$ ai: $\dot{1}_{\wedge}$ o $\theta$ o:

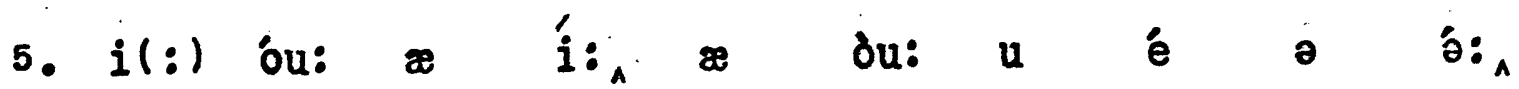

6. ๖ ái: o éi: ái: áa: $\theta(:)$ i $i$ ó:

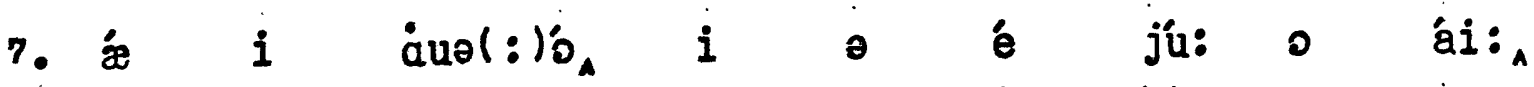

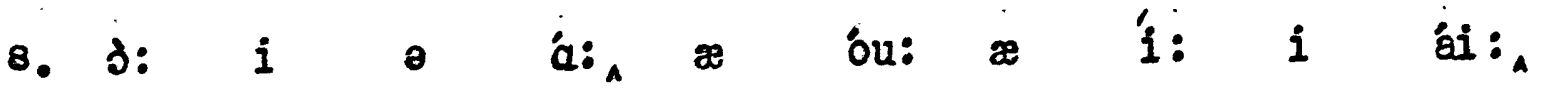

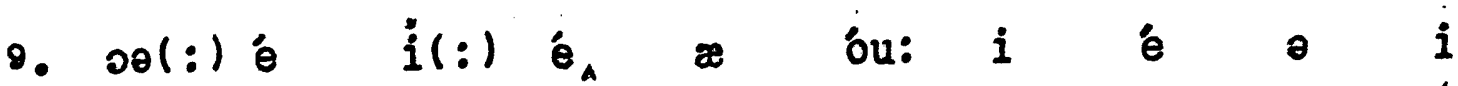

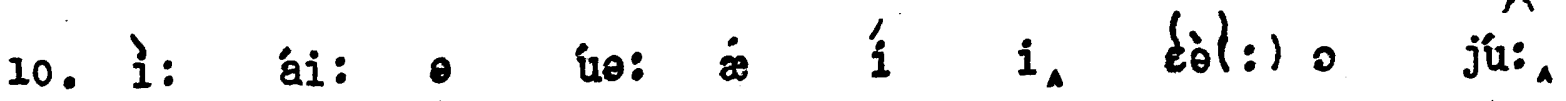

11. é o $(\mathfrak{u})$ ! $\theta$ ou: u:

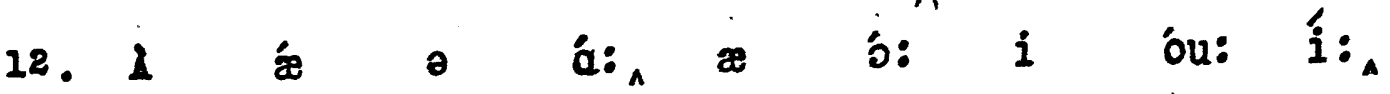

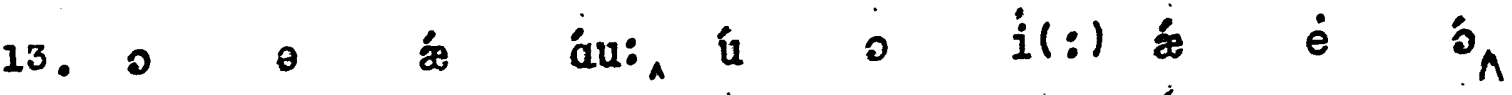

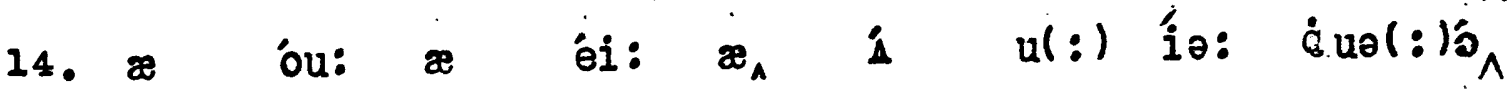


1. But, oht the heavy chance, now thou art gone,

2. Now thou art gone, and never must return!

3. Thee, Shepherd, thee the woods and desert caves

4. With wild thyme and the gadding vine o'ergrown,

5. And all their echoes, mourn:

6. The willows and the hazel copses green

7. Shall now no more be seen

8. Fanning the ir joyous leaves to thy soft lays:-

9. As killing as the canker to the rose,

10. Or taint-worm to the weanling herds that graze,

11. Cr frost to flowers, that their gay wardrobe wear

12. When first the white-thorn blows;

13. Such, Iycidas, thy loss to shepherd's ear.

$(\nabla \cdot 4)$

1. $\Delta$ ou: ${ }_{\Lambda} \theta$ é $i$ ei: ${ }_{\wedge}$ du: áu: $\dot{d}(:)$ ba

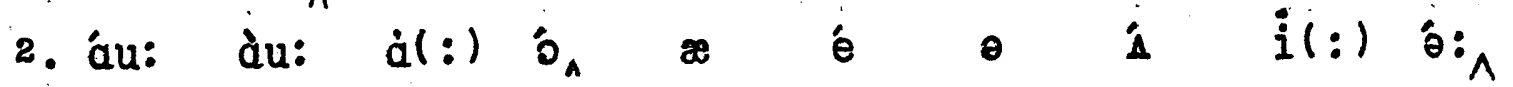

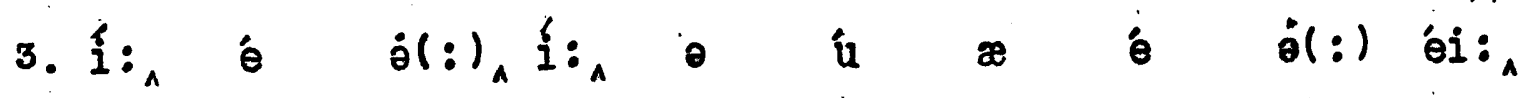

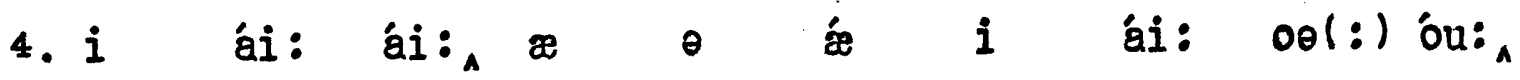

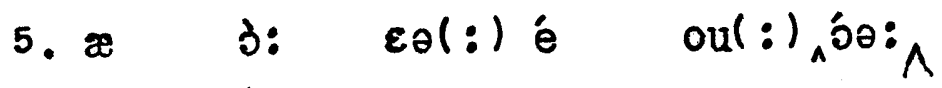

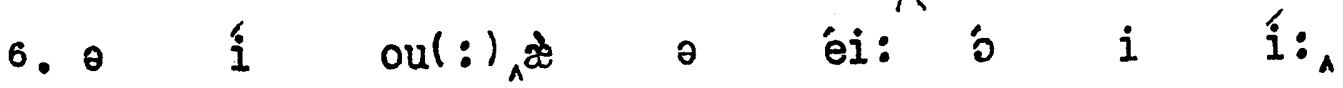

7. $⿻$ áu: bu: bo: $i(:)$ i:

8. ǽ i $\varepsilon \theta(:)$ ói: $\theta$ $i:_{\wedge} \quad u(:)$ di: 3: éi:

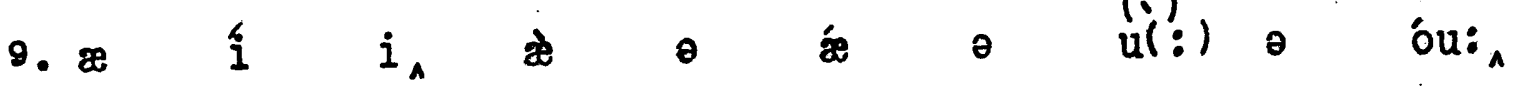

10. $\dot{\partial}(:)$ éi: á: $\dot{u}(:)$ o $\dot{1}: \quad i$ ó $\approx$ éi:

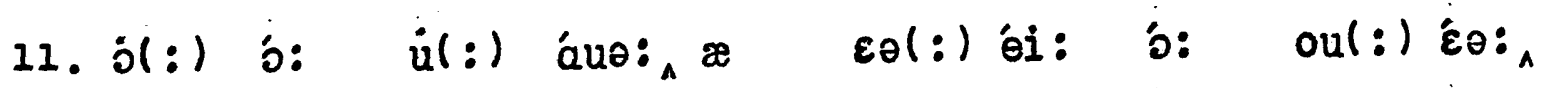

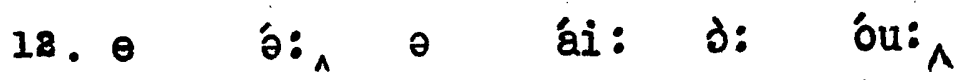

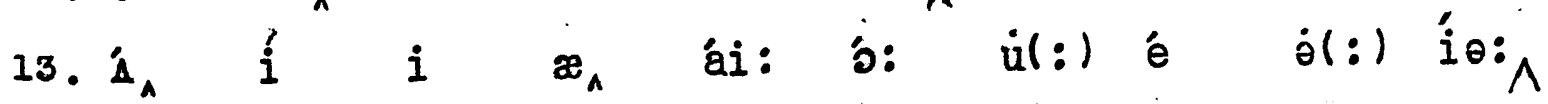


1. Where vere ye, Ifmphs, when the remorseless deep

2. Closed o'er the head of your loved Iycidas?

3. For neither were je playing on the steep

4. Where your old bards, the famous Druids, lie,

5. Nor on the shaggy top of Mona high,

6. Nor yet where Deva spreads her wizard stream:

7. Ay mel I fondiy dream

8. Had ye been there - for what could that have done?

9. What could the liase herself that orpheus bore,

10. The linse herself, for her enchanting son,

11. Whom universal nature did lament,

12. When by the rout that made the hideous roar

13. His gory visage down the stream was sent,

14. Down the swift Hebrus to the Lesbian shore?

$$
\text { (v.5) }
$$

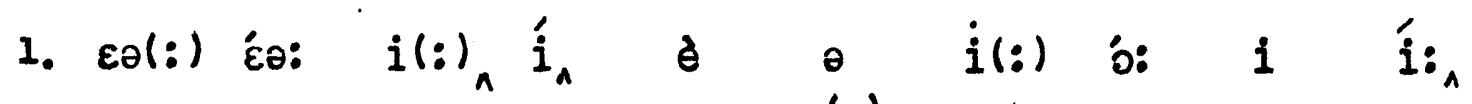

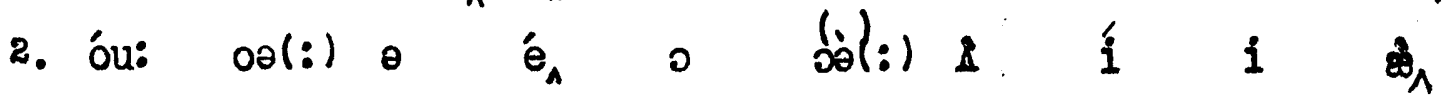

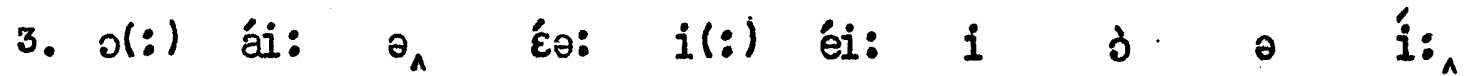
4. $\varepsilon \theta(:)$ jue(:) bu: á: ${ }_{A}$ a éi: $\theta$ ú: $i_{A}$ ái:

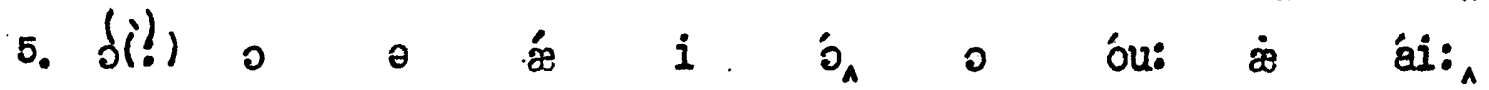
6. $\dot{\partial}(:) \quad e_{\Lambda} \quad \varepsilon \theta(:) \quad \dot{i}: \quad \dot{z} \quad e_{\Lambda} \quad \dot{\theta}(:) \quad \dot{i} \quad \dot{a}(:) \quad \dot{i}: \wedge$ 7. ài: $\stackrel{i}{\wedge}$ ai(:) ó $i \quad \stackrel{i}{i} \hat{\Lambda}_{\wedge}$

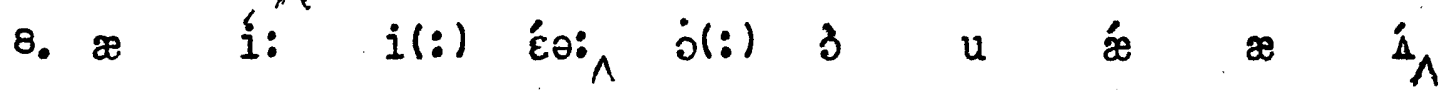
๑. 3 u ə ju: $\dot{\partial}(:)$ é

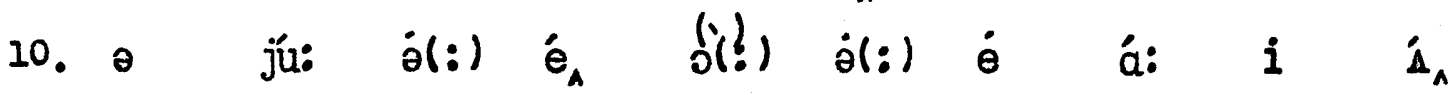

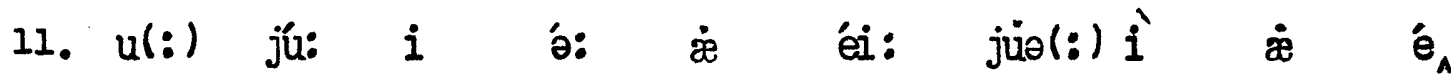
12. é ail: $)$ ə áu: $æ$ éi: ə

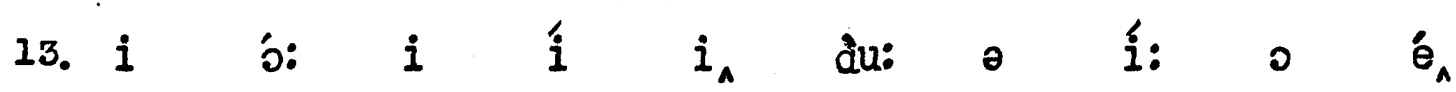

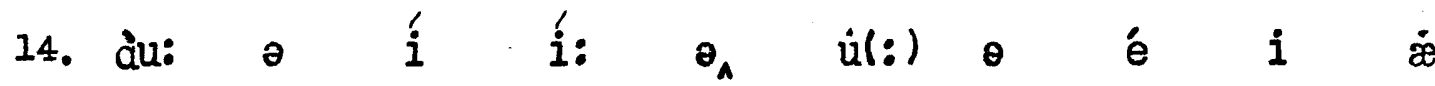

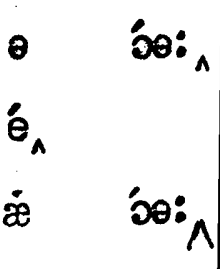


1. Alas: what boots it with uncessant care

2. To tend the homely, slighted, shepherd's trede

3. And strictly meditate the thankless lifse?

4. Were it not better done, as others use,

5. To sport with Amaryllis in the shade,

6. Or with the tangles of Neaera'g hair?

7. Fame is the spur that the clear spirit doth raise

8. (That last infirmity of noble mind)

9. To scorn delichts, and live laborious days;

10. But the fair guerdon when we iope to find,

11. And tinink to burst out into sudden blaze,

12. Comes to blind Fury with the abhorred shears

13. And slits the tinin-spun life. 'But not the praise'

14. Phoebus replied, and touch'd my trembling ears;

15. Fame is no plant that grows on mortal soil,

16. Nor in the glistering foil

17. Set off to the world, nor in broed rumour lies:

18. But lives and spreads aloft by those pure eyes

19. And perfect witness of all-judging Jove;

20. As he pronounces lastly on each deed,

2l. Of so much fame in heaven expect thy meed.' 
1. $\dot{\&} \quad \dot{a}_{\wedge} \quad 0 \quad \dot{u}: \quad i_{\wedge} \quad \dot{i} \Delta \quad \dot{e} \quad \dot{\theta} \quad \dot{\varepsilon} \theta: \wedge$ 2. $\dot{u}(:) \dot{e}$ o óu: $i_{A}$ ái: $i_{A}$ é $\dot{\theta}(:)$ éi:

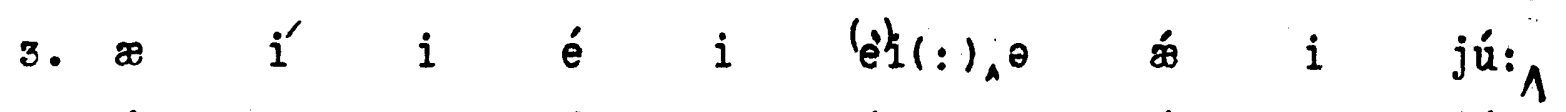

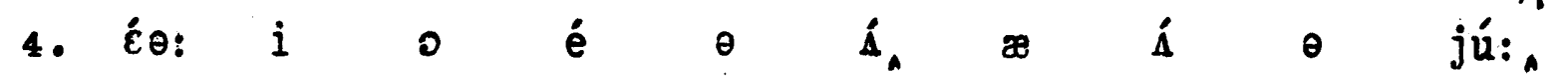

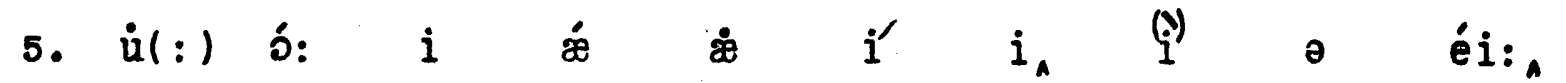

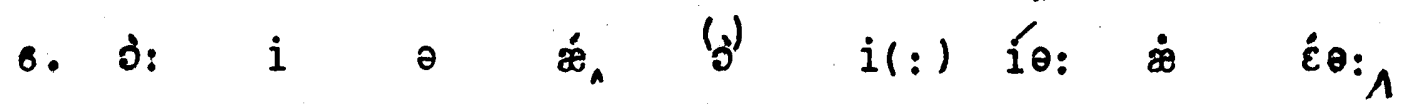

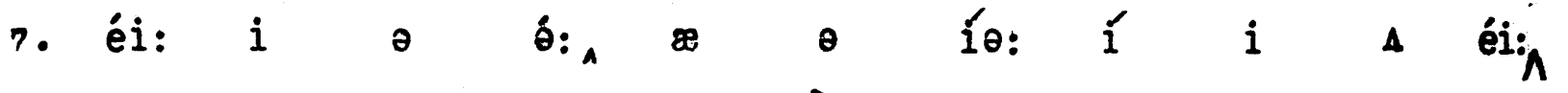
8. æ á: $\dot{i}$ á: $\dot{i} i_{A}$ o óu: ái:

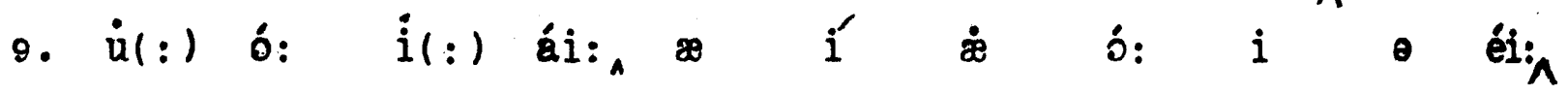

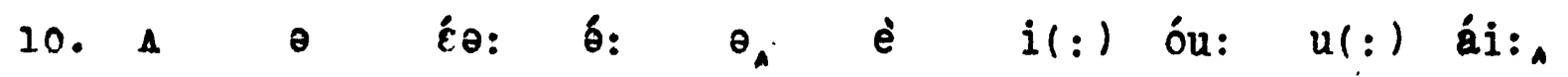

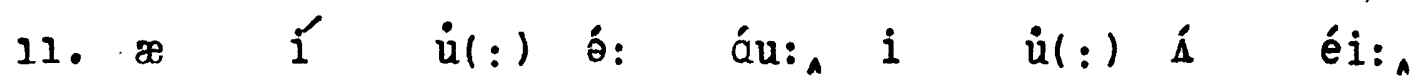
12. $\dot{\Lambda}$ a ái: júə: $i_{\wedge} i$ i \& ó: $i$ io:

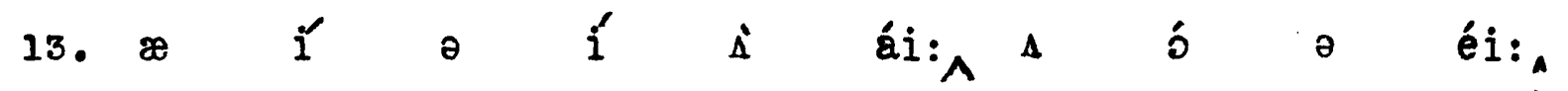
14. Í

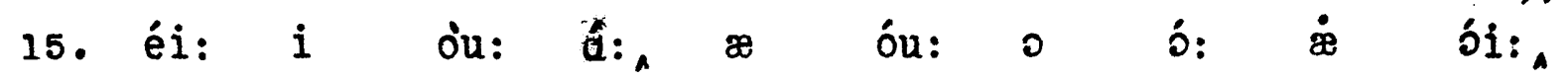
16. J: $i$ a $i \quad$ o $i$ ói: ,

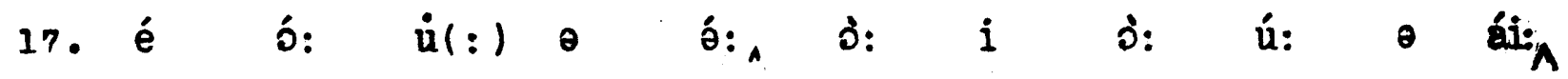

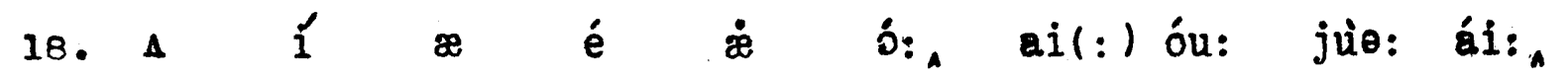
19. $\approx$ á: $e$ í $i_{A} \circ$ b: $\quad$ i $i$ óu:A 20. $\approx$ í: ou(:) áu: i á: $i_{A}$ o $i^{\prime}:$ í: 21. o óu: i éi: i é $\dot{e}$ é $8 i(:)$ í:A 
1. O fountain Arethuse, and thou honour'd flood

2. Smooth-sliding Iincius, crown'd with vocel reeds,

3. That strain I heard was of a higher mood.

4. But now oat proceeds,

5. And listens to the herald of the sea

6. That came in Neptune's plea;

7. He ask'd the waves, and ask'd the felon winds,

8. What hard mishap hath doom'd this gentle swain?

9. And question'd every gust of mugged wings

10. That blows from off each beaked promontory:

11. They knew not of his story;

12. And sege Hippotades their answer brings,

13. That not a blast was from his dungeon stray'd;

14. The air was calm, and on the level brine

15. Sleek Panope with all her siaters play'd.

16. It was that fatal and perfidious bark

17. Built in the eclipse, and rigg'd with curses dark,

18. That sunk so low that sacred head of thine.

$$
(v \cdot 7)
$$




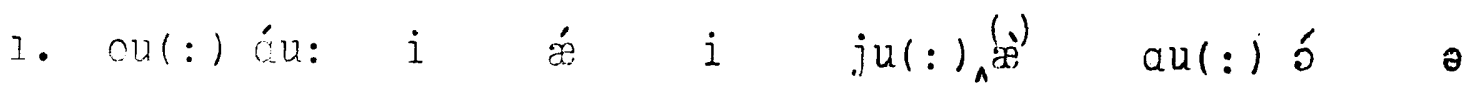

2. ù: ái: $i$ i $i^{\prime}$ ə $1:$ A

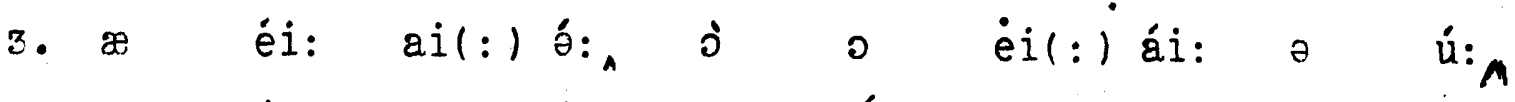
4. $\Delta$ áu: a ail:) óu: óu(:) 1 í,

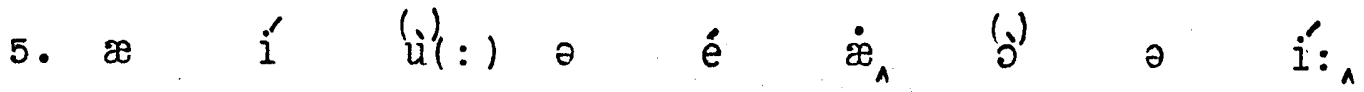

6. æ éi: i é jul:) $i^{\prime}:_{\wedge}$

7. il:) á: ə éi: $æ$ á: $ə$ é j ái:

8. ○ á: i $\dot{x}_{\wedge} æ$ ú: $i$ é éi:^

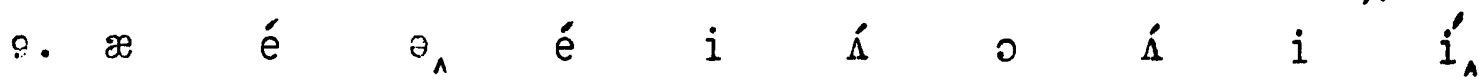

10. æ óu: 0 ó:

$i_{\wedge}$

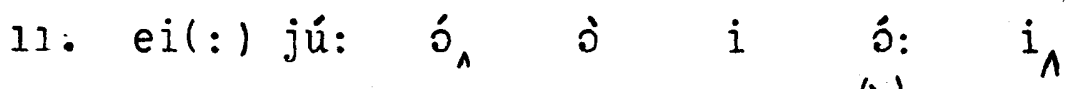

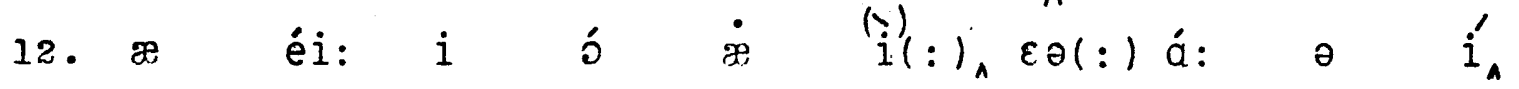

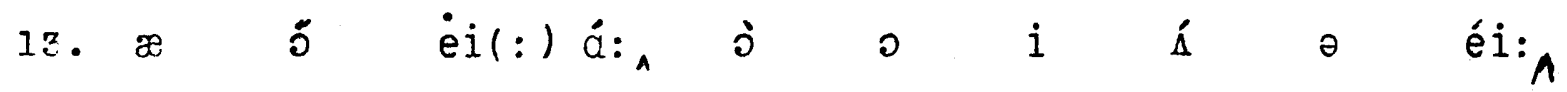

14. ə $\dot{\varepsilon} \partial$ อ

15. ì ǽ $\dot{o u}(:)$ (̂)

16. $i$ ə

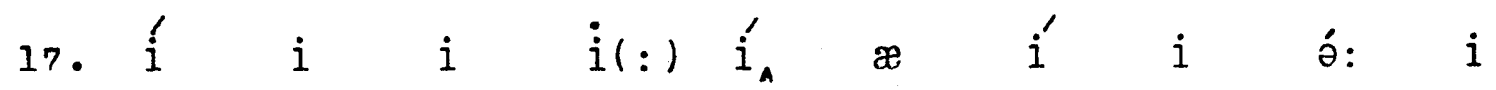

á:

á:

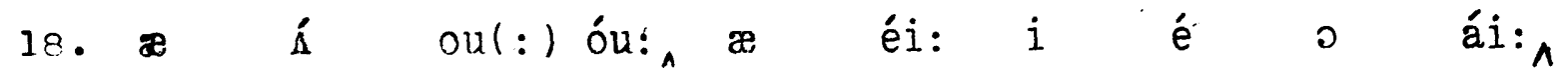


1. Hext Camus, reverend sire, went footinc slow,

2. His mantle hairy, and his bonnet sedge,

3. Inwrought with ficures dim, and on the edge

4. Like to that sanguine flower inscribed with woe:

5. 'Ahs who hath reft, ' quoth he, 'my dearest pledge?'

6. Last came, and last did 80

7. The pilot of the Galilean lake;

8. Two massy keys he bore of metals twain

9. (The golden opes, the iron shits amain);

10. He shook his initred locks, and stern bespake:

11. How well could I have spared for thee, young swain,

12. Fnew of such as for the ir bellies' sake

13. Creep and intrude and climb into the fold.

14. Of other care they little reckoning make

15. Than how to scramble at the shearers' feast,

16. And shove away the worthy bidden cuest.

17. Blind mouths: that scarce themselves know how to hold

18. A sheep-hook, or hive learn'd aught else the least

19. That to the faithiul herdman's art belongs.

20. What recks it them? What need they? Ihey are sped;

21. And when they list, their lean and flashy songs.

22. Grate on their scrannel pipes of vretched straw;

23. The hungry sheep look up, and are not fed,

24. But swoln with wind and the rank mist they draw

25. Rot inwardly, and foul contagion spread:

26. Besides what the srin wolf with privy paw

27. Daily devours apace, aind nothing said:

28. - But that two-handed engine at the door

29. Stands ready to smite once, and smite no more.' 


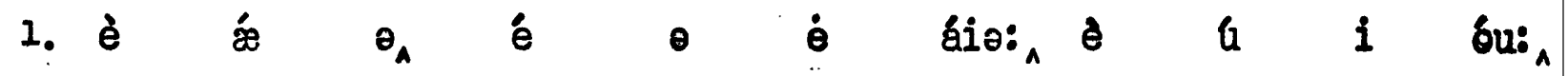

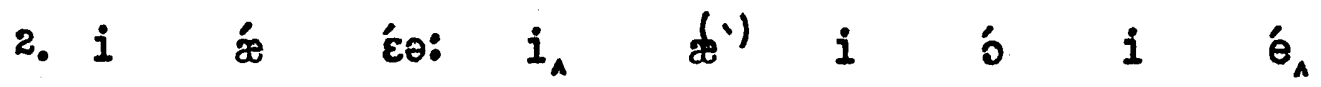

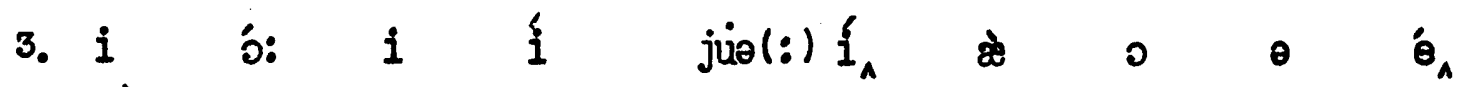

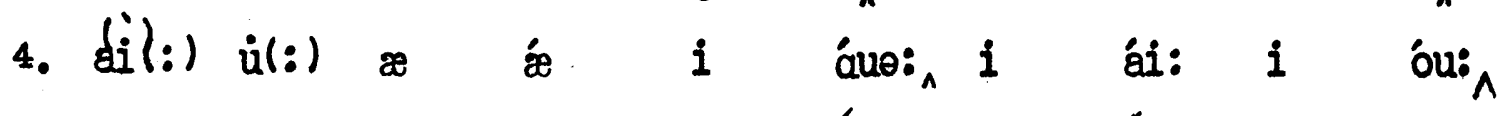

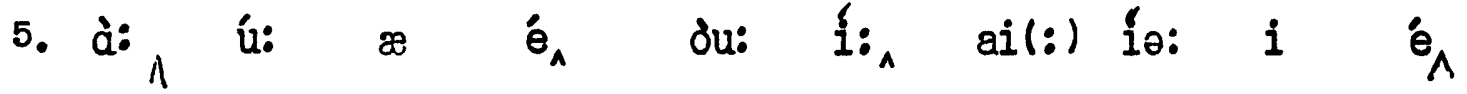

6. à: éi: $æ$ á: $i$ ou:

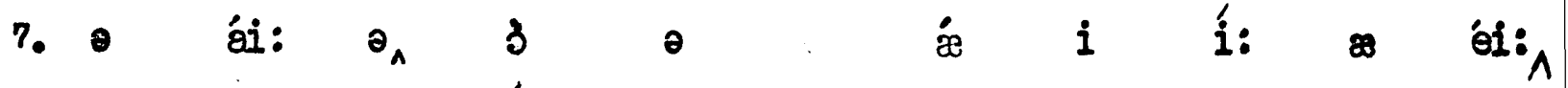

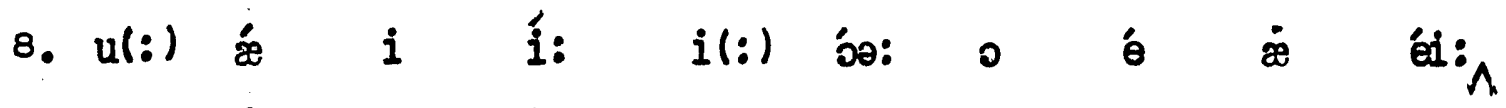

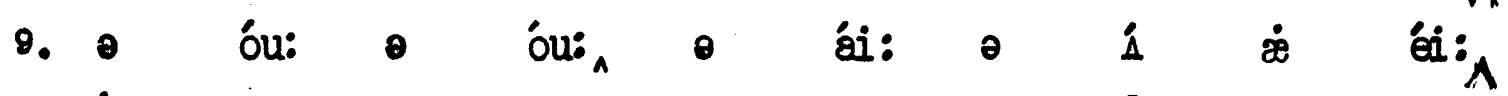

10. $\dot{i}(:)$ ú $i$ ái: $\dot{b}_{\wedge} \quad x \quad$ á: $\quad \dot{i}(:)$ éi: $\wedge$

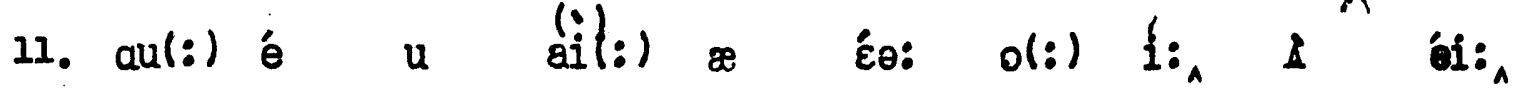

12. $i(:)$ áu: $0 \quad i_{A} \nsubseteq \quad o(:) \quad \varepsilon \theta(:)$ é $i \quad$ éi:

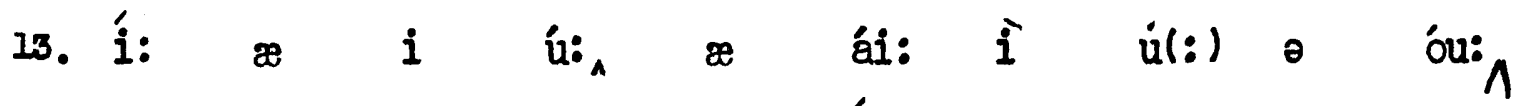

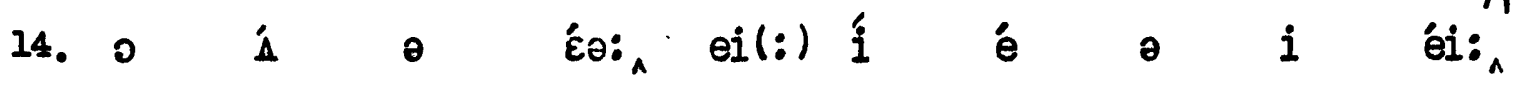

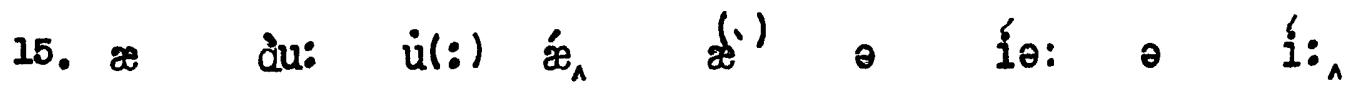

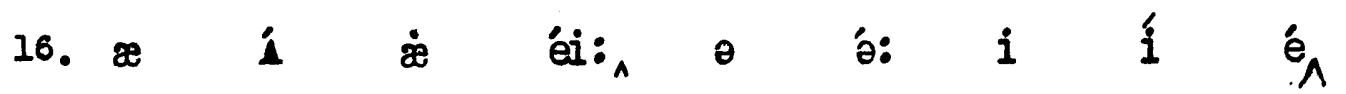

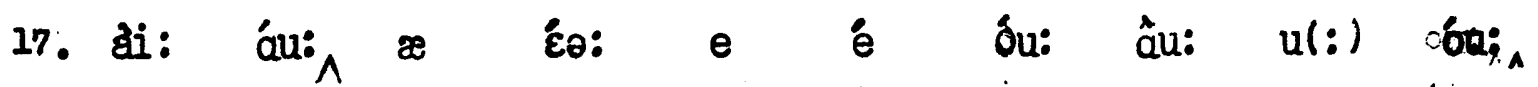

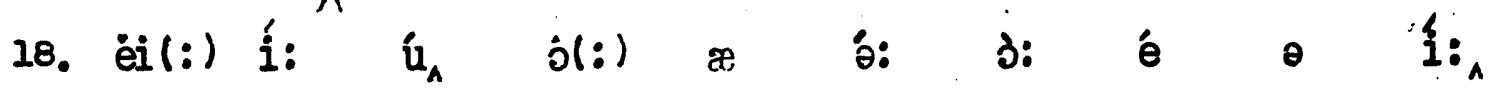

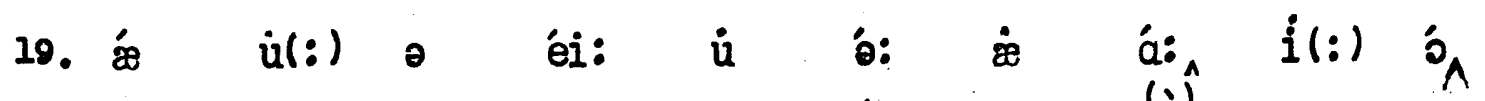

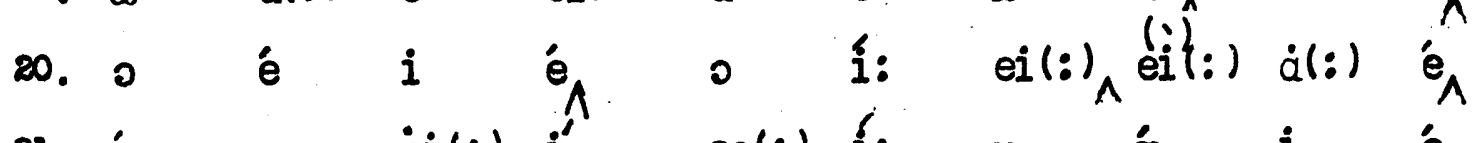

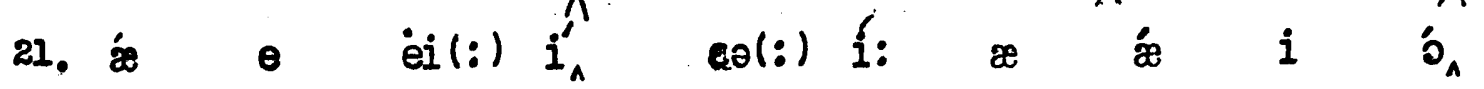

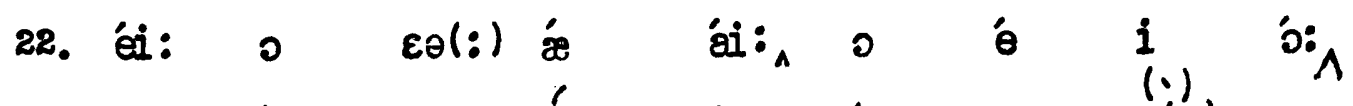

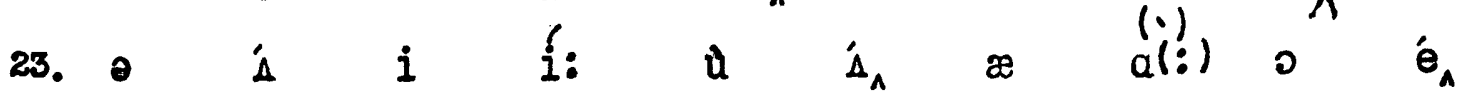

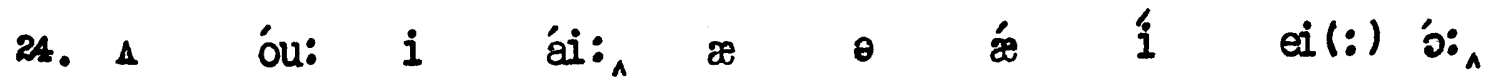




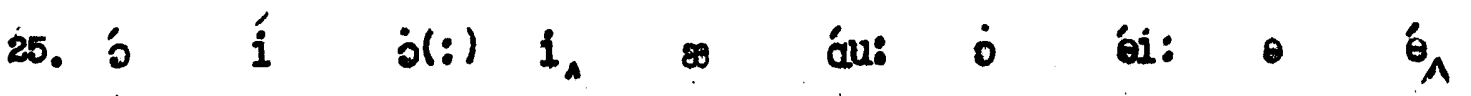
26. $i(:)$ ai: $\theta_{A} \quad-\quad i \quad$ a 1 i 1 o: 27. éi: 1 il: áuo: $\dot{x}$ êl: $\approx$ i 1 éi:

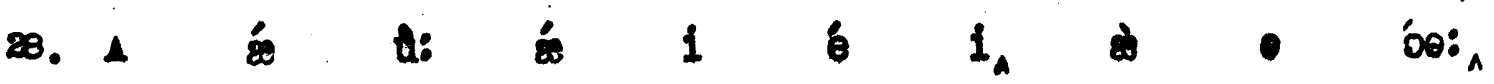

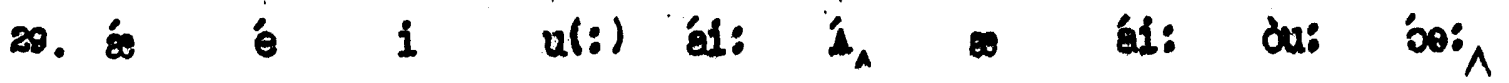


1. Return, Alpheus, the dread voice is past

2. That shrunk thy streams; return, Sicilian luse,

3. And call the vales, and bid them hither cast

4. Their bells and flowerets of a thousand hues;

5. Ye valleys low, where the mild whispers use

6. Of shades, and wanton winds, and gushing brooks,

7. On whose fresh lap the swart star snarely looks,

8. Throw hither all your quaint enameli'd eyes

9. That on the green turf suck the honey'd showers

10. And purpleall the ground with vernal flowers.

11. Bring the rathe primrose that forsaken dies,

12. The tufted crow-toe, and pale jessamine,

13. The white pink, and the pansy freak'd with jet,

14. The glowing violet,

15. The musk-rose, and the well-attired woodbine,

16. with cowslips wan that hang tine pensive head,

17. Ind every flower that sad embroidery wears:

18. Bid anarantus all his beauty shed,

19. And daffadillies fill their cups with tears

20. To strew the laureat hearse where Iycid lises.

21. For, so to interpose a little ease,

22. Let our frail thoughts dally with false surmise;

23. Ay me! thilst thee the shores and sounding seas

24. Wash far away, - where'er thy bones are hurl'd,

25. Thether beyond the stormy Febrides

26. Where thou perhaps, under the whelming tide,

27. Tisitest the botton of the nonstrous world;

28. Or whether thou, to our moist vors denied,

29. Sleep'st by the fabie of Bellerus old,

30. Where the great Vision of the guarded mount

31. Looks toward Namancos and Bayona's hold

32. - Look homeward, Angel, now, and melt with ruth:

33. - And, 0 ye dolphins, waft the hapless youth! 


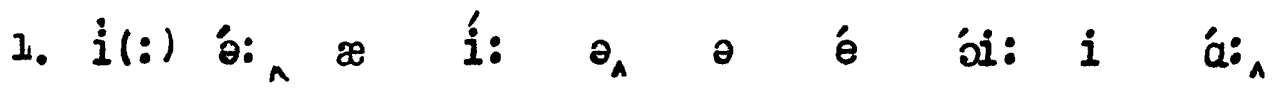

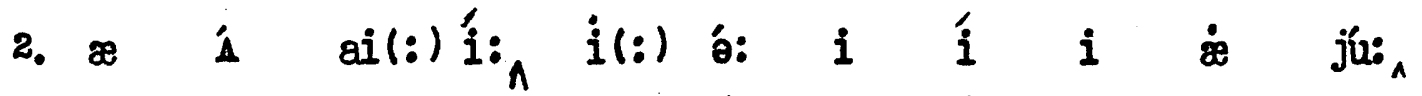

3. $¥$ ó: $\theta$ éi: $\approx$ ílllll

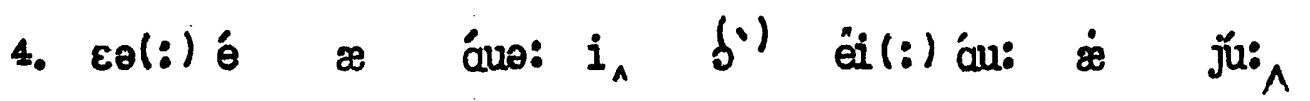

5. $i(:) \stackrel{\infty}{i}$ óu: $\varepsilon \partial(:)$ ə ái: $i$ $\theta$ jü:

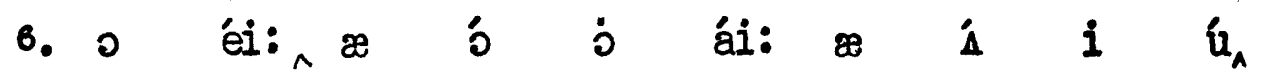

7. ○ u(:) é $\dot{x}_{\wedge}$ ə ó: d: $\varepsilon_{\theta}$ i $\mathfrak{u}_{\Lambda}$

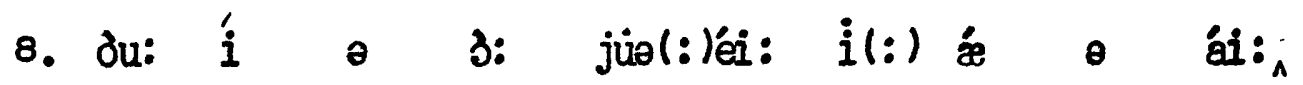

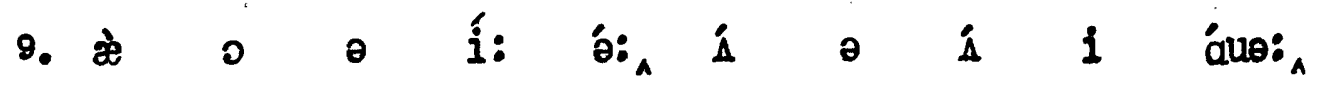

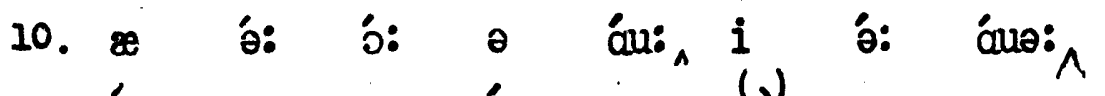

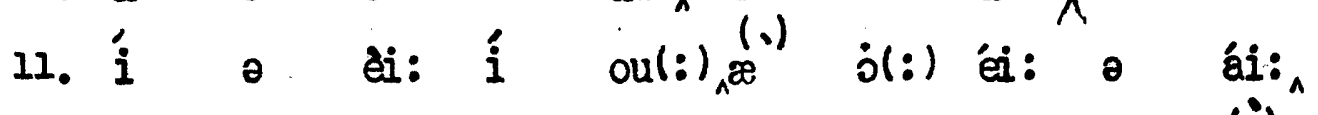

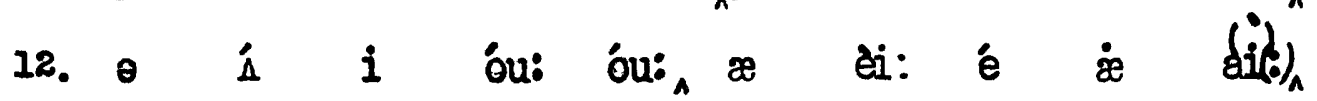

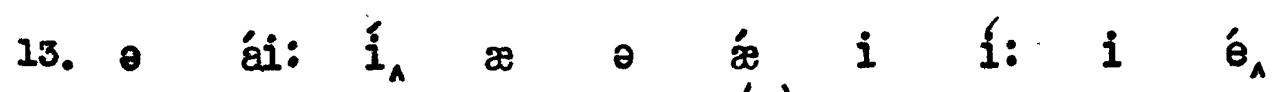

14. $\theta$ óu: $i$ ái: oul $:)_{\theta_{A}}^{(0)}$

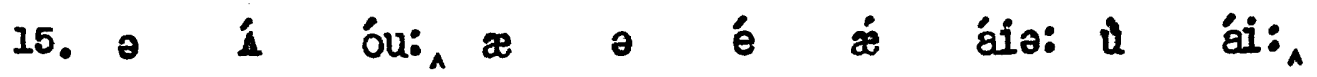

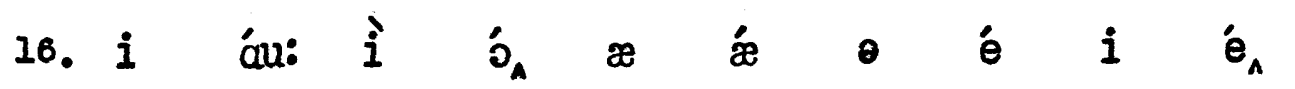

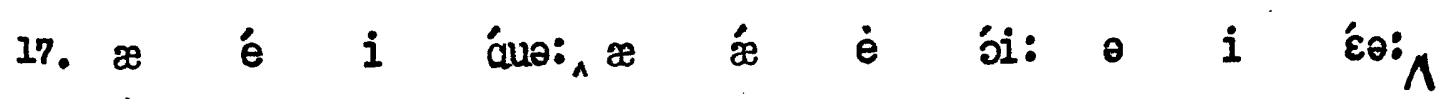

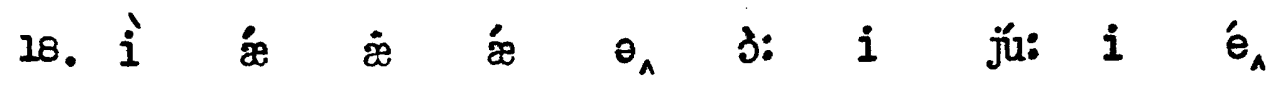

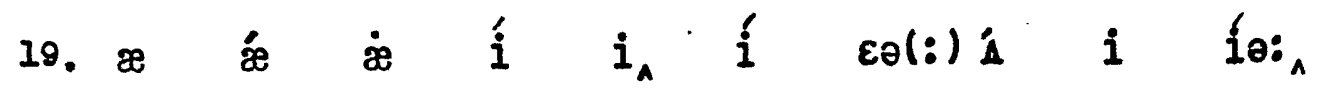

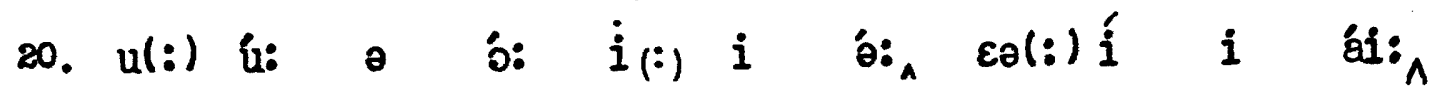

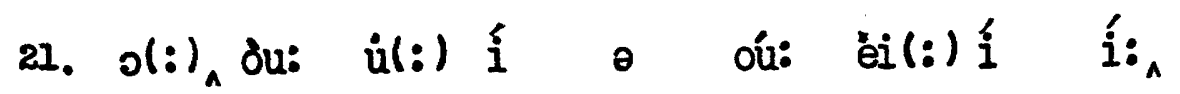

22. é quol:léi: ó: á $_{\wedge}$ i $i$ ó: $\theta(:)$ ái:

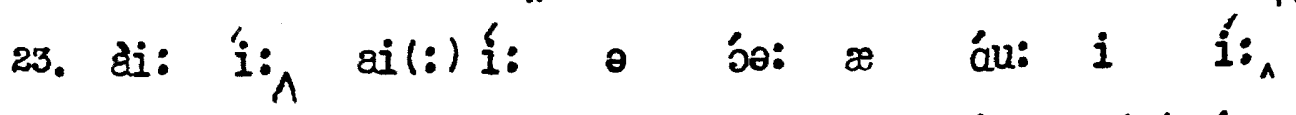

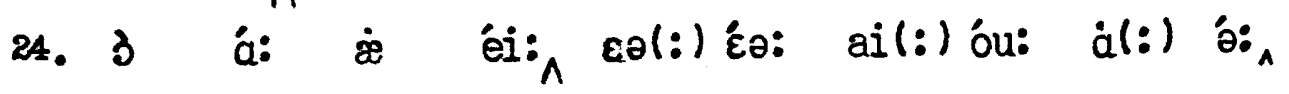


25. é o $i(:) \dot{b}_{\Lambda}$ o

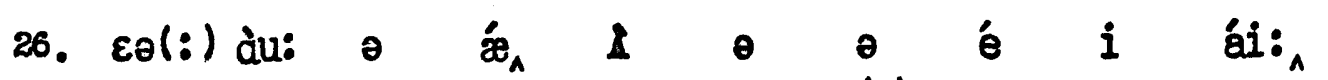

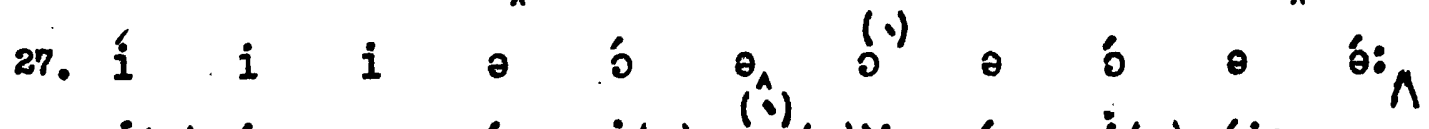
28. $\dot{j}(:)$ é a áu: $\dot{u}(:)$ qual(:)bi: áu: $\dot{i}(:)$ ái: 29. í: dai: ə éi: $f^{(0)} \dot{\theta}$ é $\theta$ ou: 30. Ė:

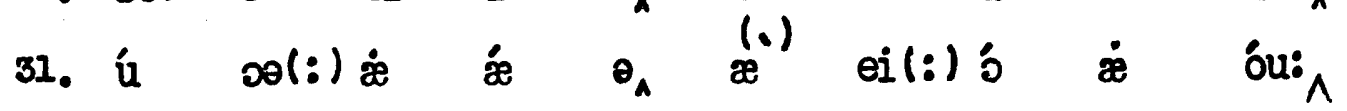

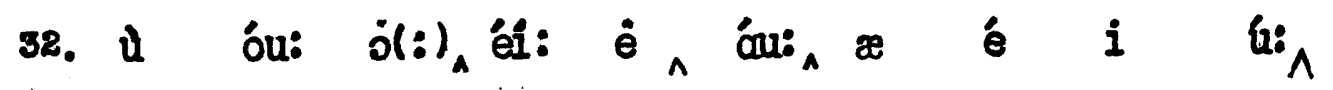

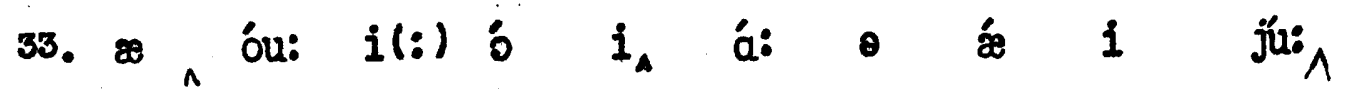


1. Weep no more, woeful shepherds, weep no more,

2. For Lucidis, your sorrow, is not dead,

3. Sunk though he be beneath the watery floor;

4. So sinks the day-star in the ocean-bed,

5. And yet anon repairs his drooping head

6. And tricks his beans, and with new-spancled ore

7. Flames in tine forehead of tile norning sky:

8. So Lycidas sunk low, jut mounted iiichil

9. Through the dear hicht of Him thet walk'd the waves;

10. Where, other jroves and other streens alonf",

11. With nectir pure his oozy locks he laves,

12. And hears ito unexpressive nuptial sons

13. In the blest kingons neek of joy and love.

14. There entertain him wll tie saints ajove

15. In solemn troops, and sweet societies,

16. That sing, and sincing in their flory move,

17. And wipe the tears for ever from his eyes.

18. Now, Lycidas, the shepherds weep no more;

19. Henceforth thou art the Genius of the shore

20. In thy large recompense, and shalt be good

21. To all that wander in that perilous flood. 
1. 1́: òu: óə: a óu: $\dot{u}$ é $\dot{\theta}(:)_{A}$ í: ơu ó

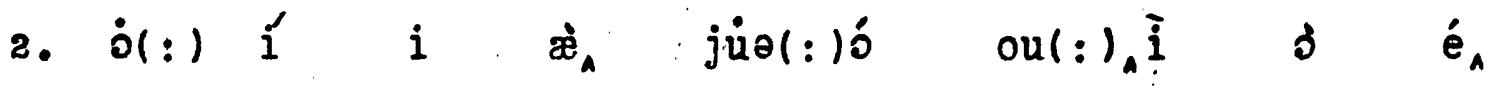
3. i ou(:) $\dot{i}(:)$ í: $\quad \dot{i}(:), i^{\prime}$ o ó: $\theta$ i bo: $\wedge$

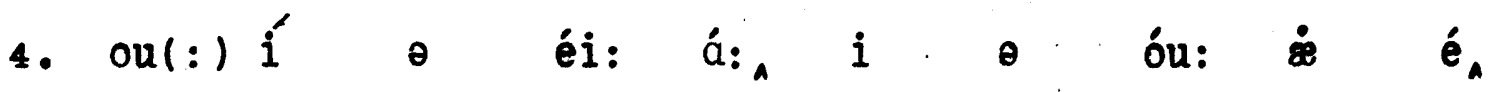

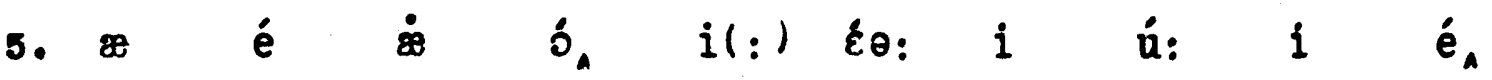

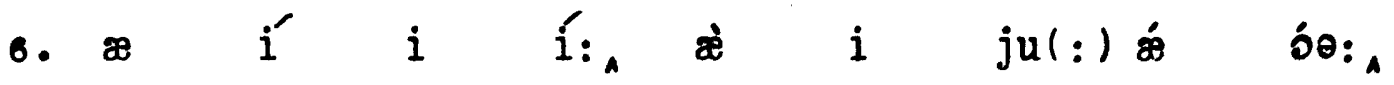

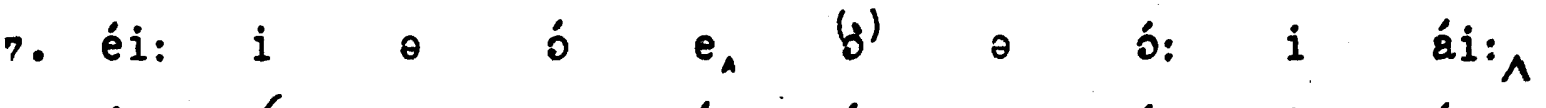
8. ơu: $i^{\prime} i$ $i$ i óu: $\Delta$ áu: $i$ ái: ๑. ù: $\theta \quad i \theta(:)$ ái: 0 í $\approx$ o: $\theta$ éi:^

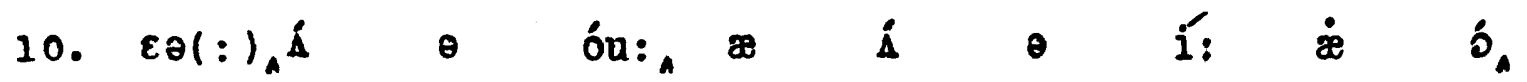

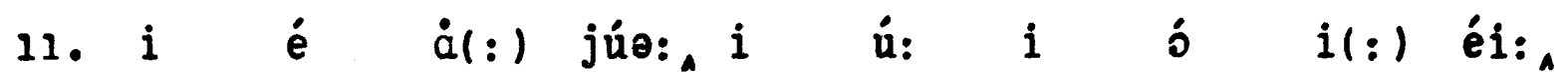

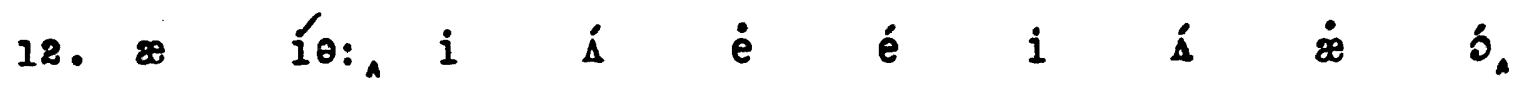

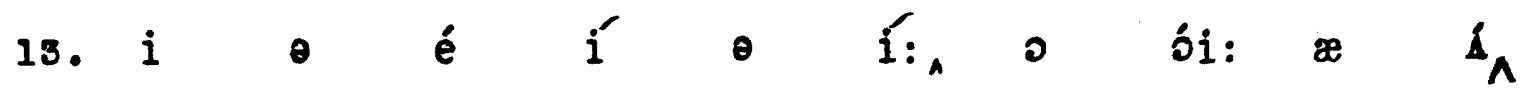
14. $\varepsilon \theta(:)$ é $\theta$ éi: $i_{A}$ b: $\theta$ éi: $\dot{z}$ íA

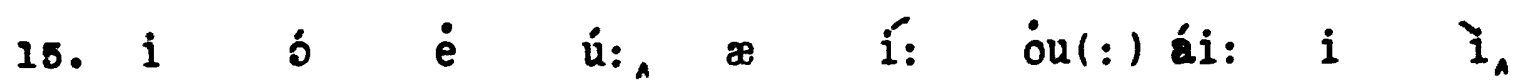

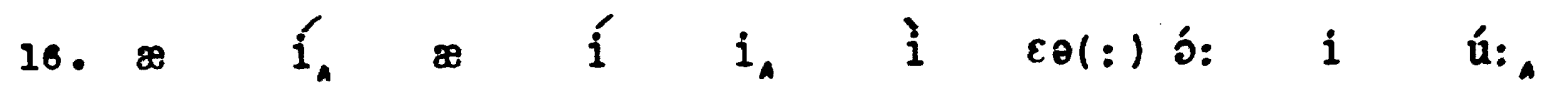
17. क ái: $\theta$ ío: $\dot{o}(:)$ é $\theta$ j $i$ ái: 18. áu: 1 i $\dot{z}_{A} \theta$ é $\dot{\theta}(:)$ í: oul: $)$ bo: $\wedge$

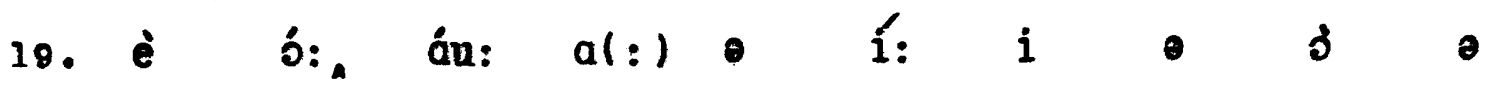
bo:

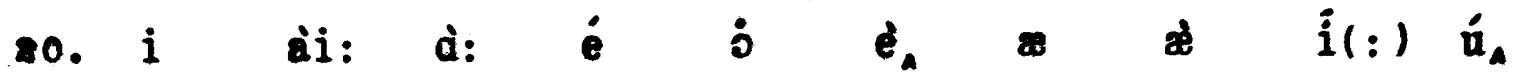

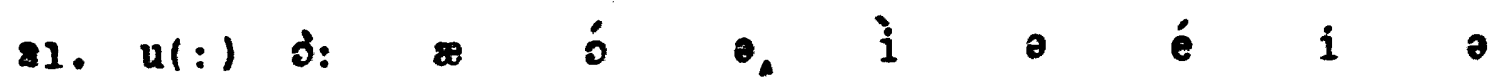


1. Thrs sang the uncouth swain to the oaks and rills,

2. Wille the still morn went out with sandala grey;

3. He touch'd the tender stops of various quills,

4. With eeger thought warbling his Doric lay:

5. And now the sun had stretch'd out all the hills,

6. And now was dropt into the weatern bay:

7. At last he rose, and twitch'd his mantle blue:

8. To-morrow to fresh woods, and pastures new.

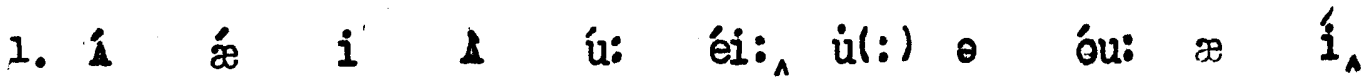

2. $\operatorname{ai}(:)_{\theta} \quad \dot{1}$ ó: $\wedge$ \& du: $i$ \& $\dot{\otimes}$ 'él: $\wedge$

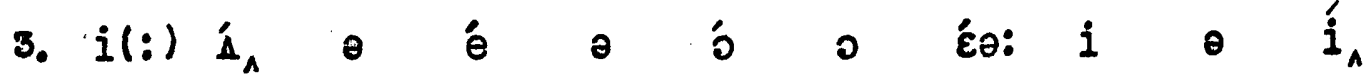

4. $i$ í: $\theta$ ó: ó: $i$ i

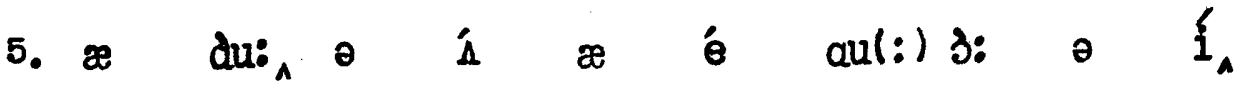

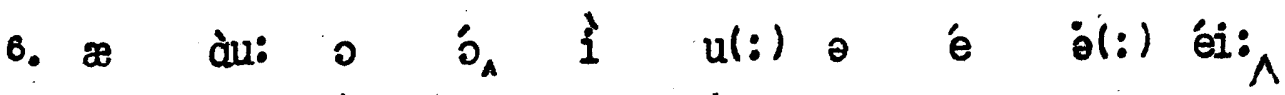

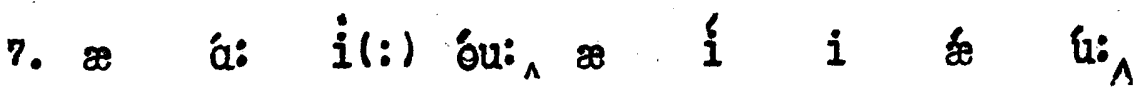

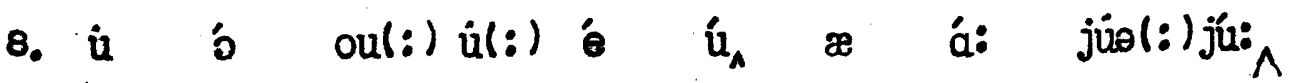




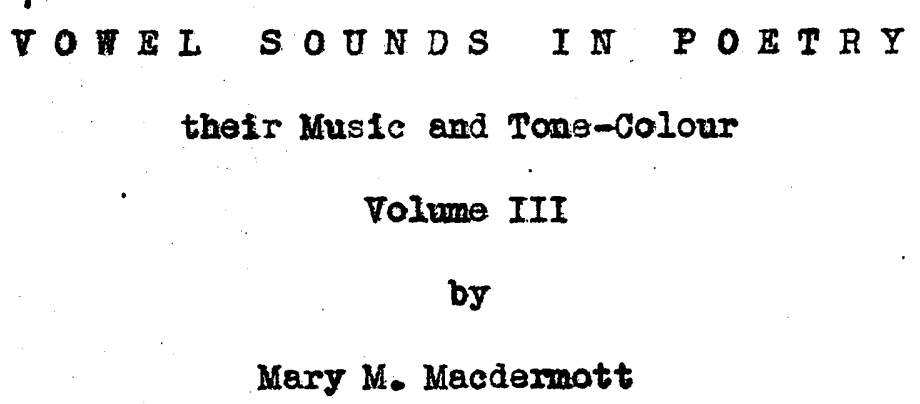




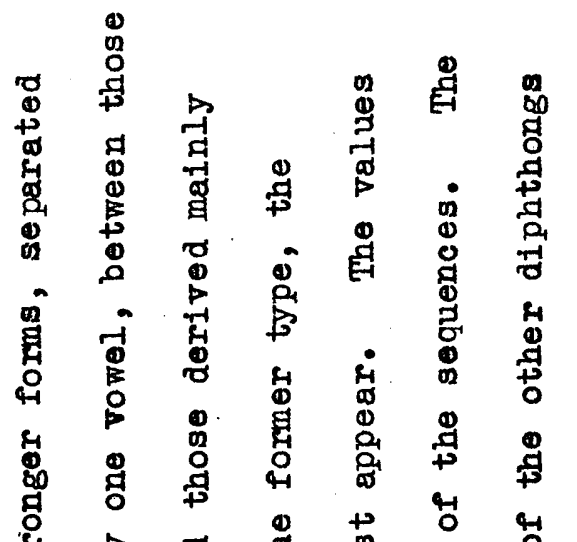

$$
\begin{aligned}
& \begin{array}{l}
0 \\
0 \\
2 \\
0 \\
H \\
0 \\
4 \\
0 \\
0 \\
0 \\
0 \\
4 \\
0-1
\end{array} \\
& \text { 察 } \\
& \text { † 岁具 }
\end{aligned}
$$

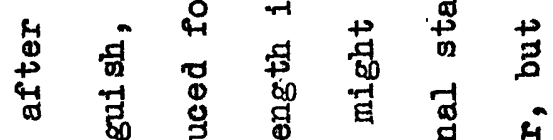

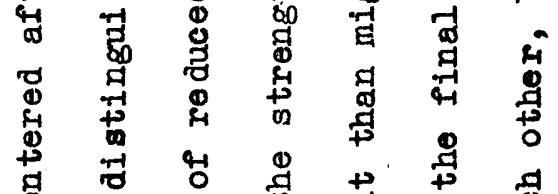

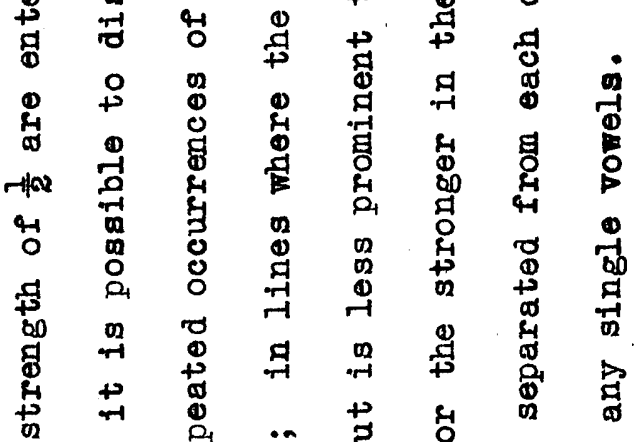

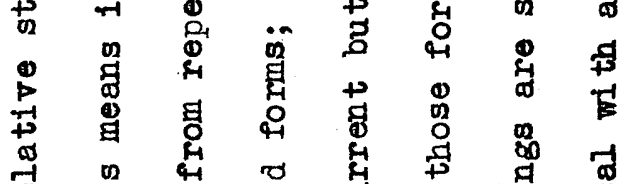

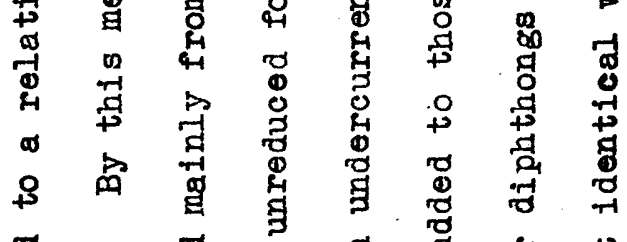

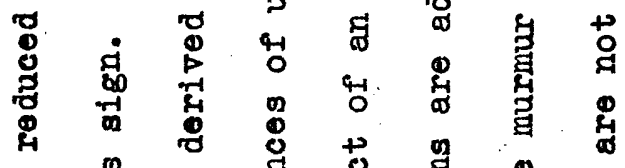

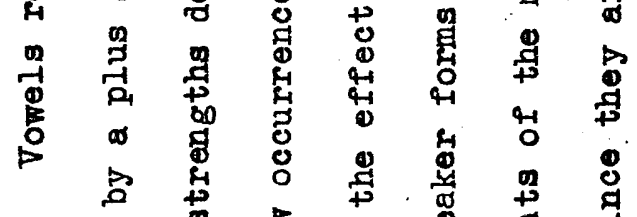

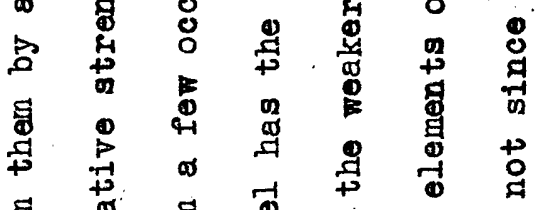

$$
\begin{aligned}
& \text { 若 }
\end{aligned}
$$




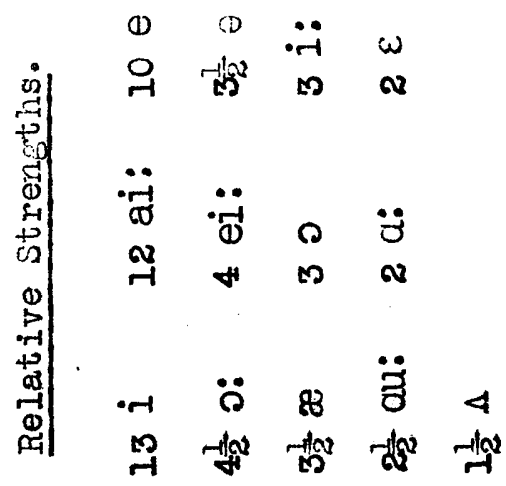

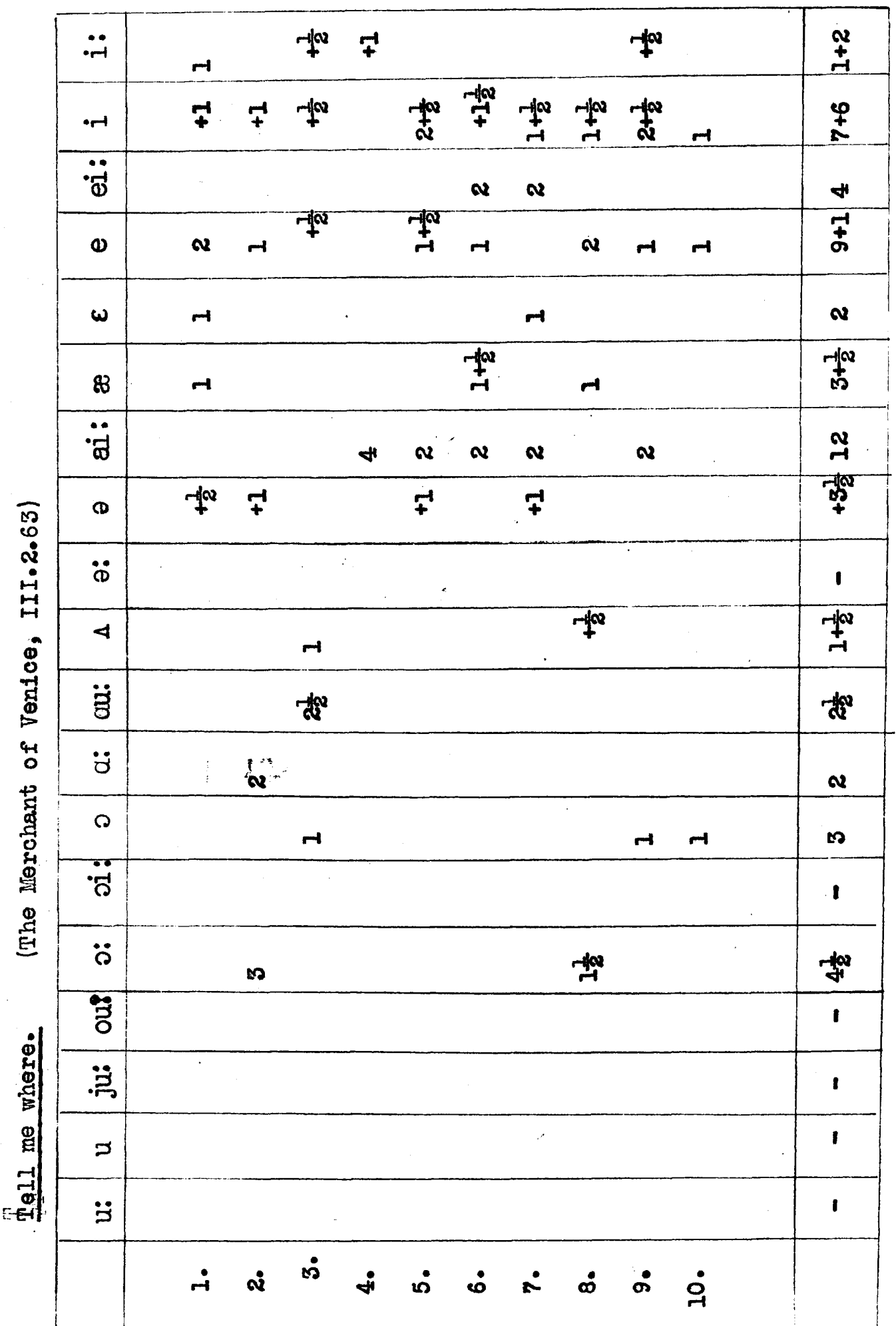




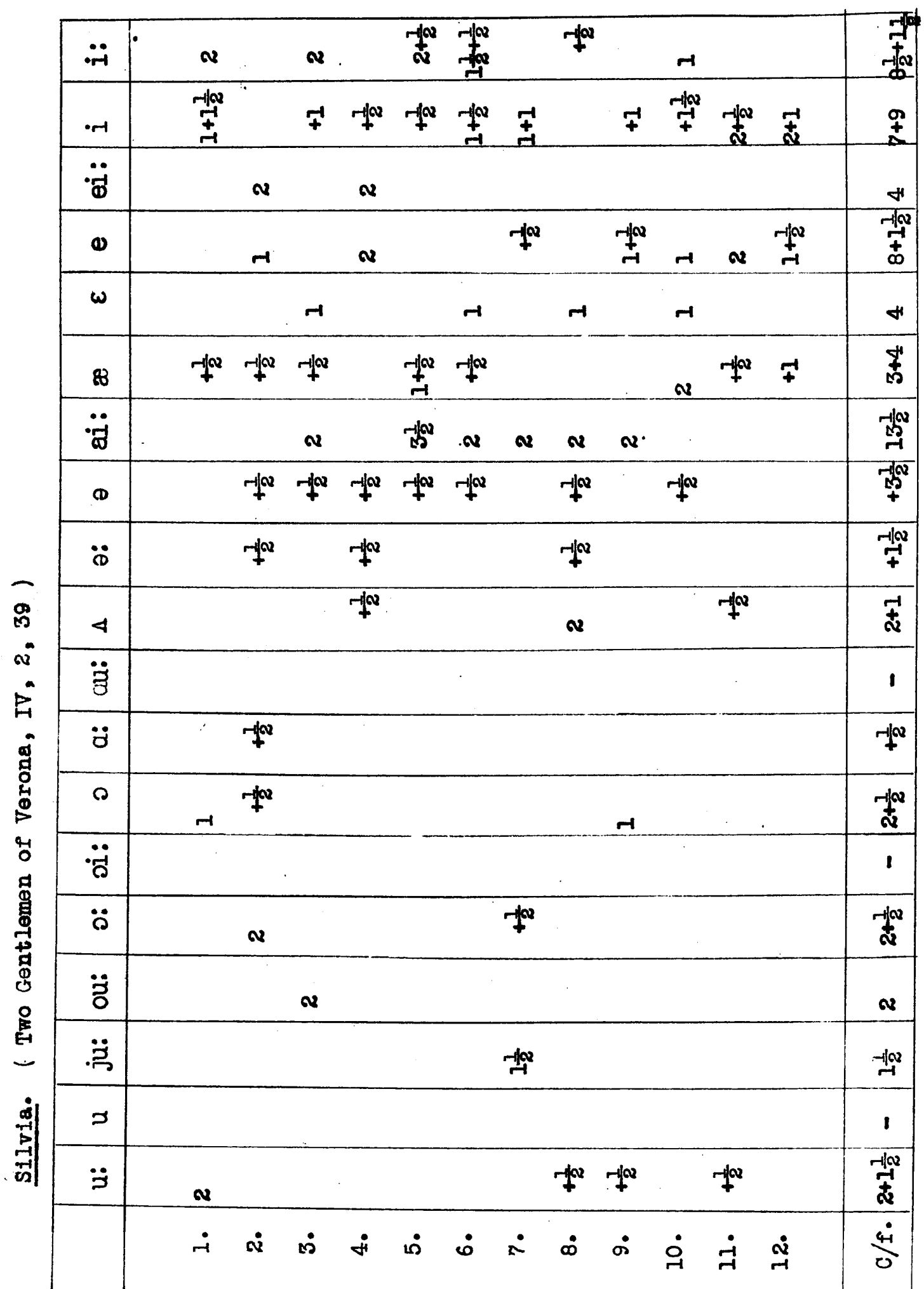




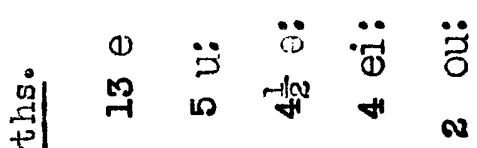

की

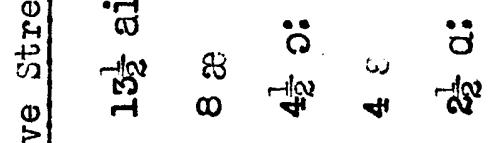

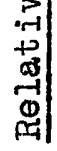

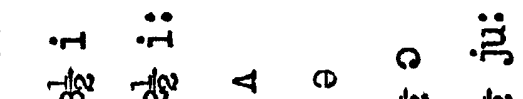

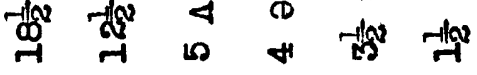

\begin{tabular}{|c|c|c|c|c|}
\hline$\ddot{-r}$ & 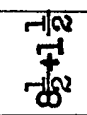 & div & & 年 \\
\hline$\cdot-1$ & $\stackrel{9}{+}$ & -1 & -10 & $\begin{array}{l}\text {-y } \\
+ \\
+\end{array}$ \\
\hline$\ddot{\ddot{\omega}}$ & + & . & & 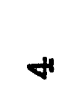 \\
\hline 0 & $\begin{array}{c}-4 a^{2} \\
+1 \\
0\end{array}$ & $\stackrel{-1}{+2}$ & & $\begin{array}{l}\sqrt{2} \\
+ \\
+1\end{array}$ \\
\hline$\omega$ & $H$ & & & $H$ \\
\hline 8 & $\frac{1}{10}$ & $-1+\infty$ & +10 & th \\
\hline$\ddot{\infty}$ & 然 & & & 㘳 \\
\hline $\mathbb{D}$ & -4c & & -10 & $\$$ \\
\hline$\ddot{8}$ & $\underset{+}{\stackrel{-1}{\rightarrow}}$ & & $H$ & 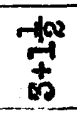 \\
\hline 4 & $\frac{1}{4}$ & & $\underset{-1}{t} \stackrel{+1}{t}$ & $\stackrel{4}{*}$ \\
\hline$\ddot{\Xi}$ & 1 & & & 1 \\
\hline$\ddot{g}$ & $-1+\infty$ & & $\boldsymbol{v}$ & $\frac{-10}{2}$ \\
\hline $\boldsymbol{O}$ & $\stackrel{-100}{a}$ & & $r$ & 些少 \\
\hline$\ddot{\vec{c}}$ & 1 & & & 1 \\
\hline$\ddot{\circ}$ & $\underset{+\infty}{+\infty}$ & $\boldsymbol{v}$ & & $\stackrel{+100}{+}$ \\
\hline$\ddot{z}$ & $\boldsymbol{\alpha}$ & & & $\boldsymbol{N}$ \\
\hline$\stackrel{3}{\circ}$ & - & & & $\underset{\sim}{-N}$ \\
\hline$x$ & 1 & & & 1 \\
\hline$\ddot{\partial}$ & 崔 & & - & 武 \\
\hline & $\frac{\dot{4}}{9}$ & $\dot{\theta}$ & $\underset{-1}{\stackrel{4}{~}}$ & \\
\hline
\end{tabular}




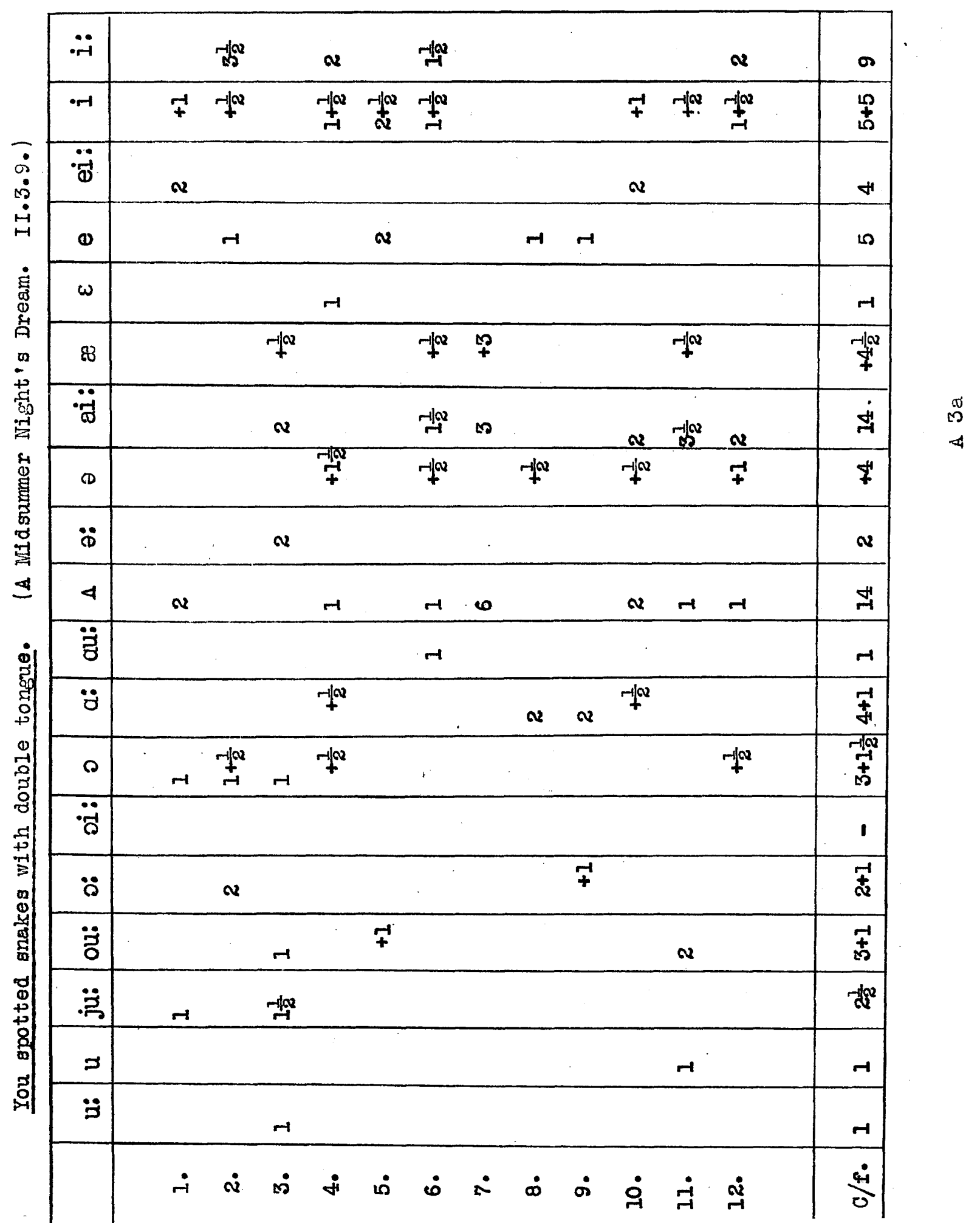




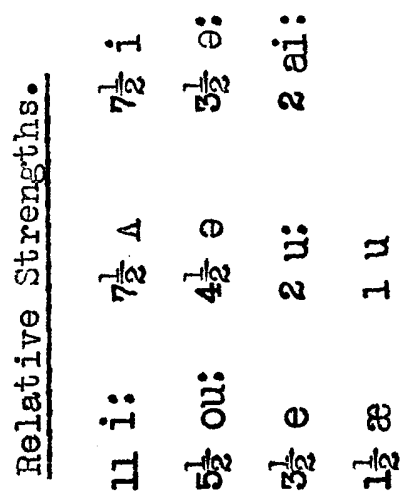

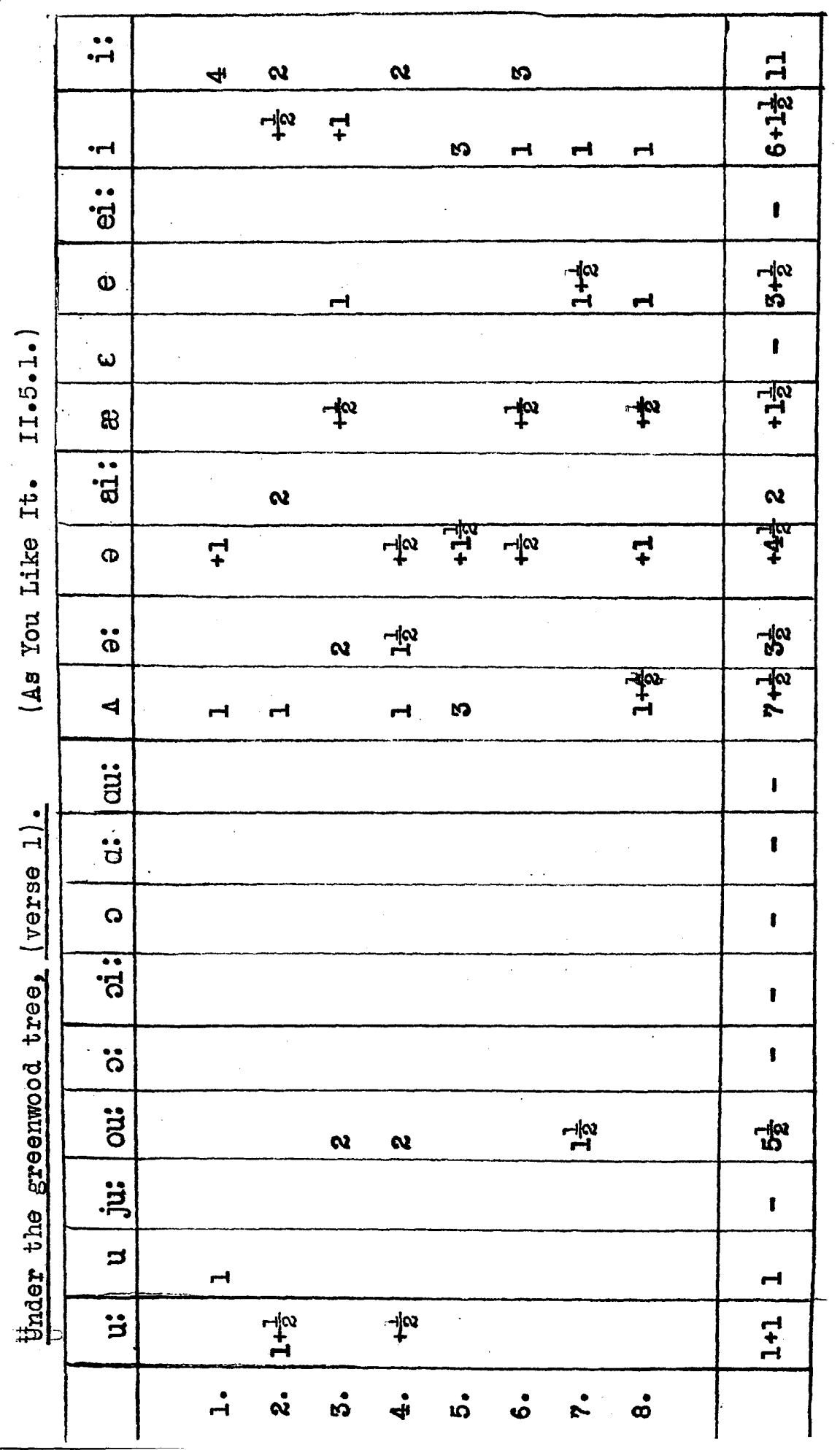




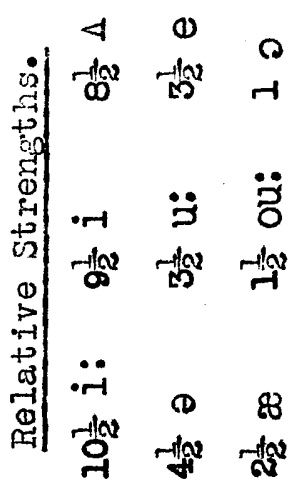

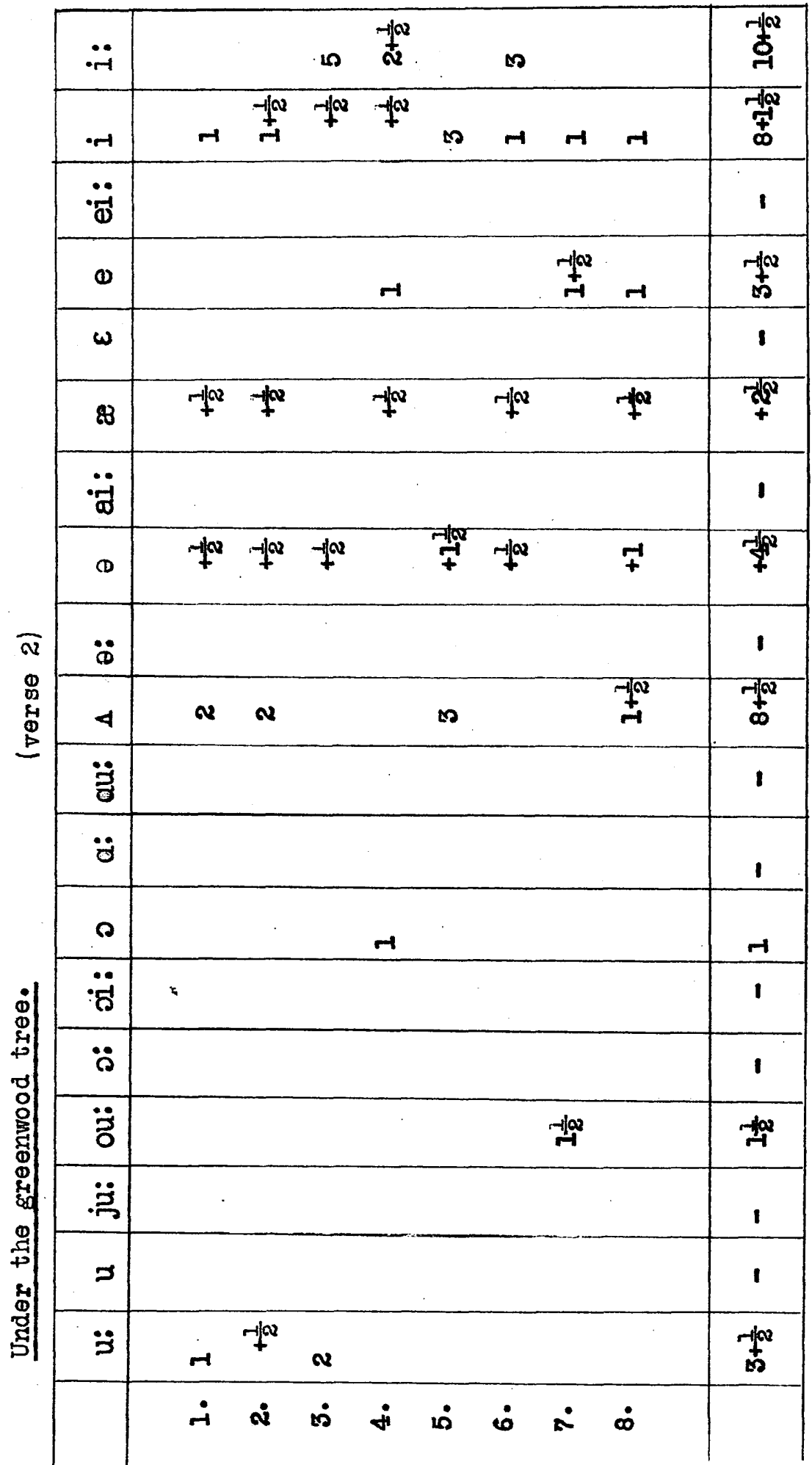




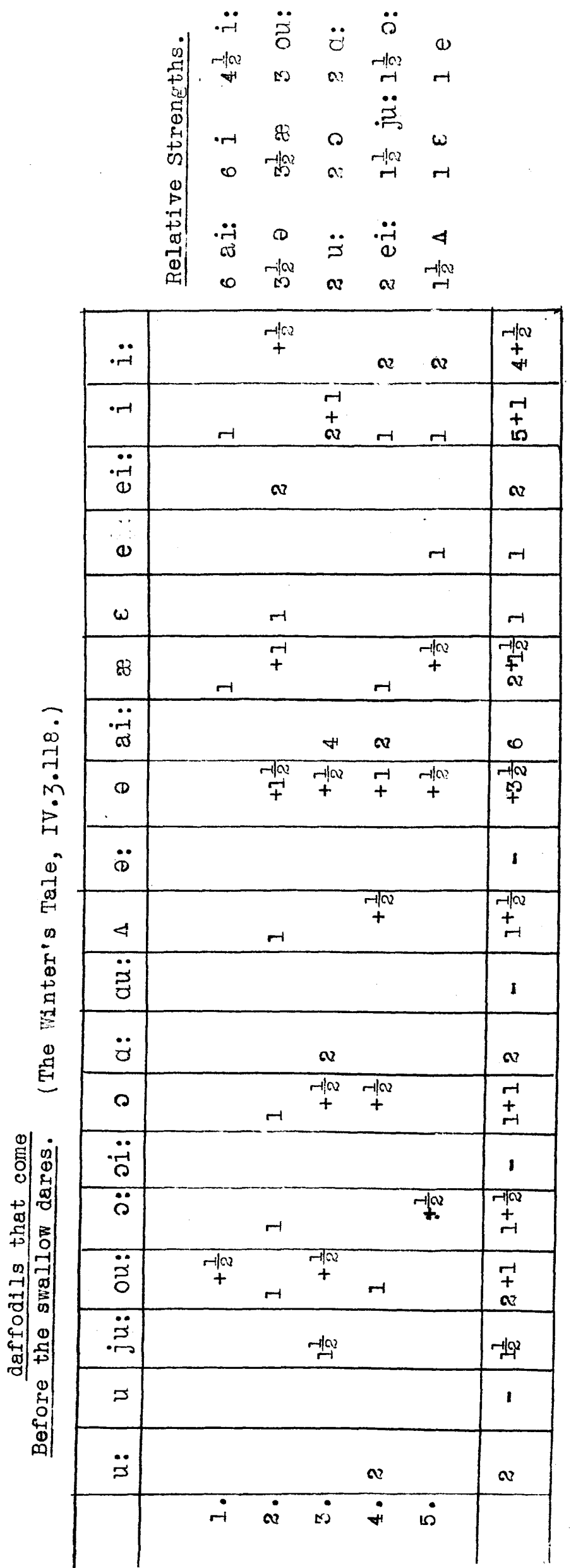




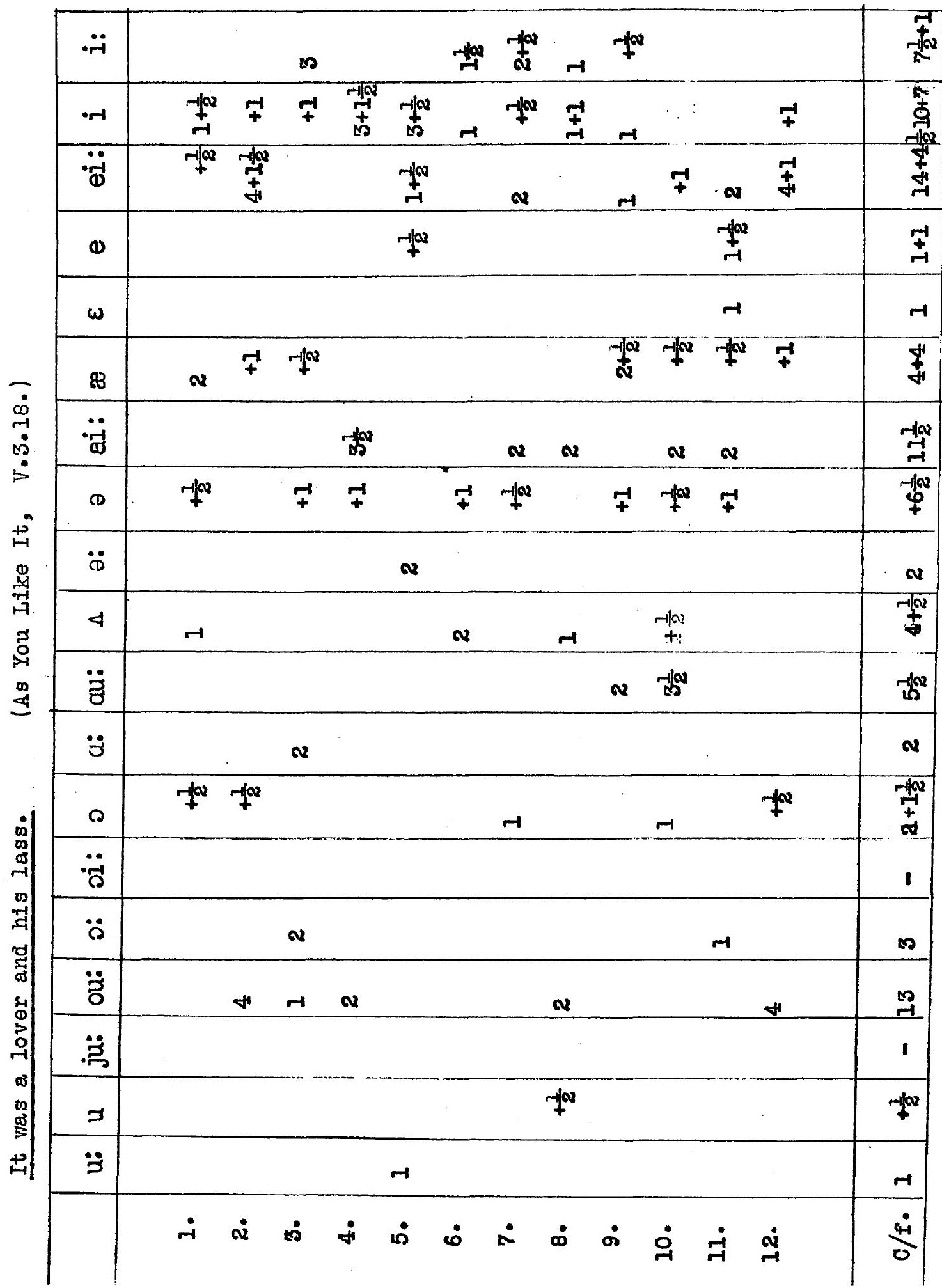




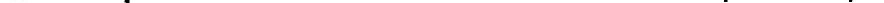




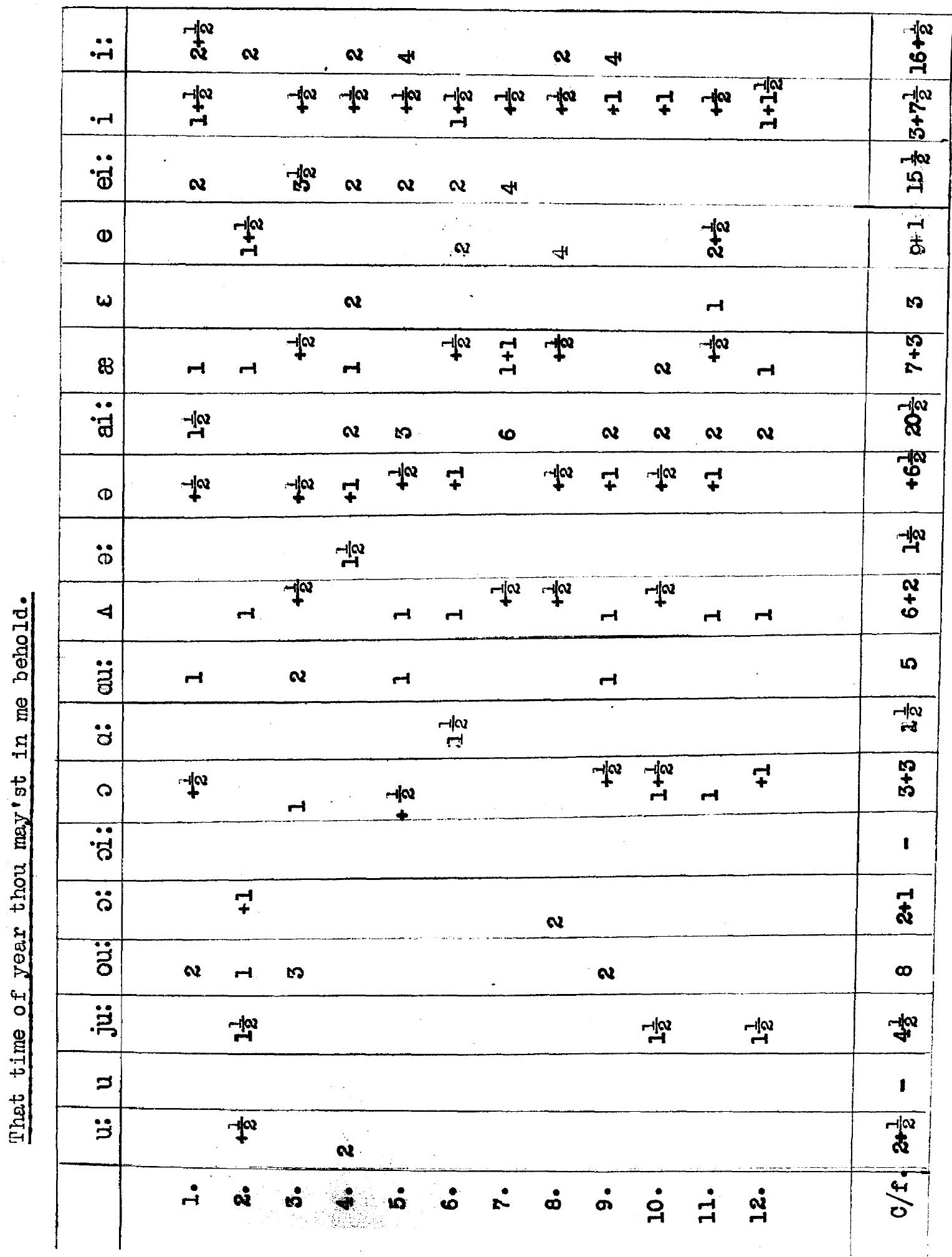




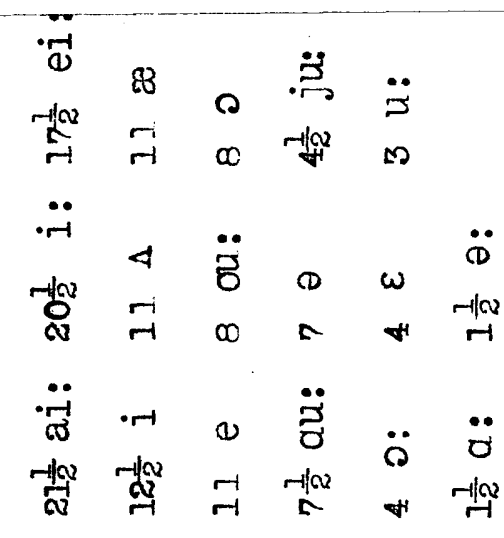

\begin{tabular}{|c|c|c|c|c|}
\hline$\ddot{\ddot{r}}$ & $\begin{array}{c}r a 0 \\
+ \\
0 \\
-1\end{array}$ & $\omega$ & $\infty$ & 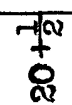 \\
\hline$\cdot r$ & $\begin{array}{l}0 \\
+ \\
0\end{array}$ & $\begin{array}{c}-1 / 00 \\
+ \\
-1\end{array}$ & नाल & $\begin{array}{c}7 \sigma^{2} \\
+ \\
+ \\
\end{array}$ \\
\hline$\ddot{\ddot{\mu}}$ & $\underset{-1}{n-10}$ & $\infty$ & & $\frac{-1}{5}$ \\
\hline (1) & $\begin{array}{l}r \\
+ \\
0\end{array}$ & & $r$ & $\underset{-1}{\stackrel{-1}{\prime}}$ \\
\hline $\boldsymbol{\omega}$ & $\infty$ & & -1 & $H$ \\
\hline 88 & $\begin{array}{l}M \\
\pm \\
N\end{array}$ & & $r$ & $\begin{array}{l}m \\
+ \\
\infty\end{array}$ \\
\hline$\ddot{\ddot{\sigma}}$ & rid & -1 & & 虹 \\
\hline D & ఝ & $\begin{array}{c}-1 / 0 \\
+\end{array}$ & & 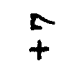 \\
\hline$\ddot{B}$ & $-1 / 2{ }^{2}$ & $i$ & & $\stackrel{-1 \omega}{-1 \omega}$ \\
\hline 4 & $\begin{array}{l}a \\
+ \\
0\end{array}$ & -1 & $\infty$ & $\begin{array}{l}\infty \\
+ \\
0 \\
\end{array}$ \\
\hline$\ddot{z}$ & ס & -1 & $\stackrel{r r o v}{r-1}$ & 2 \\
\hline$\ddot{d}$ & $\stackrel{r+\alpha}{r-1}$ & & & $\underset{-1}{-1}$ \\
\hline م & $\begin{array}{l}m \\
+ \\
m\end{array}$ & -1 & $r$ & $\begin{array}{l}m \\
+ \\
10\end{array}$ \\
\hline$\stackrel{\ddot{r}}{\circ}$ & 1 & & & 1 \\
\hline$\ddot{\rho}$ & $\begin{array}{l}-1 \\
+ \\
\infty\end{array}$ & $\mathrm{H}$ & & $\begin{array}{l}+ \\
+ \\
m\end{array}$ \\
\hline$\ddot{\vec{z}}$ & $\infty$ & & & $\infty$ \\
\hline$\ddot{\ddot{\partial}}$ & -192 & & & - \\
\hline 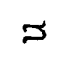 & 1 & & & 1 \\
\hline$\ddot{\jmath}$ & $\begin{array}{c}-1 \infty \\
+ \\
\infty\end{array}$ & & $-1+\infty$ & $\begin{array}{l}-1 \\
+ \\
a \\
\end{array}$ \\
\hline & & $\dot{0}$ & $\dot{+}$ & \\
\hline
\end{tabular}




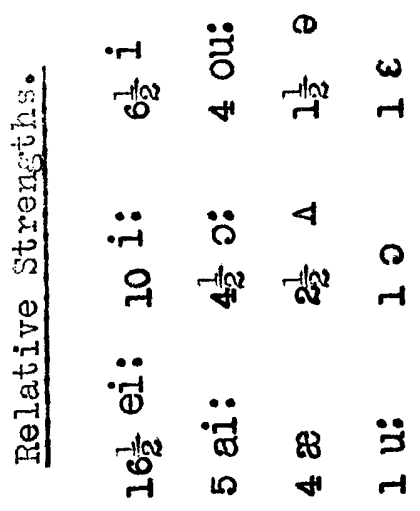

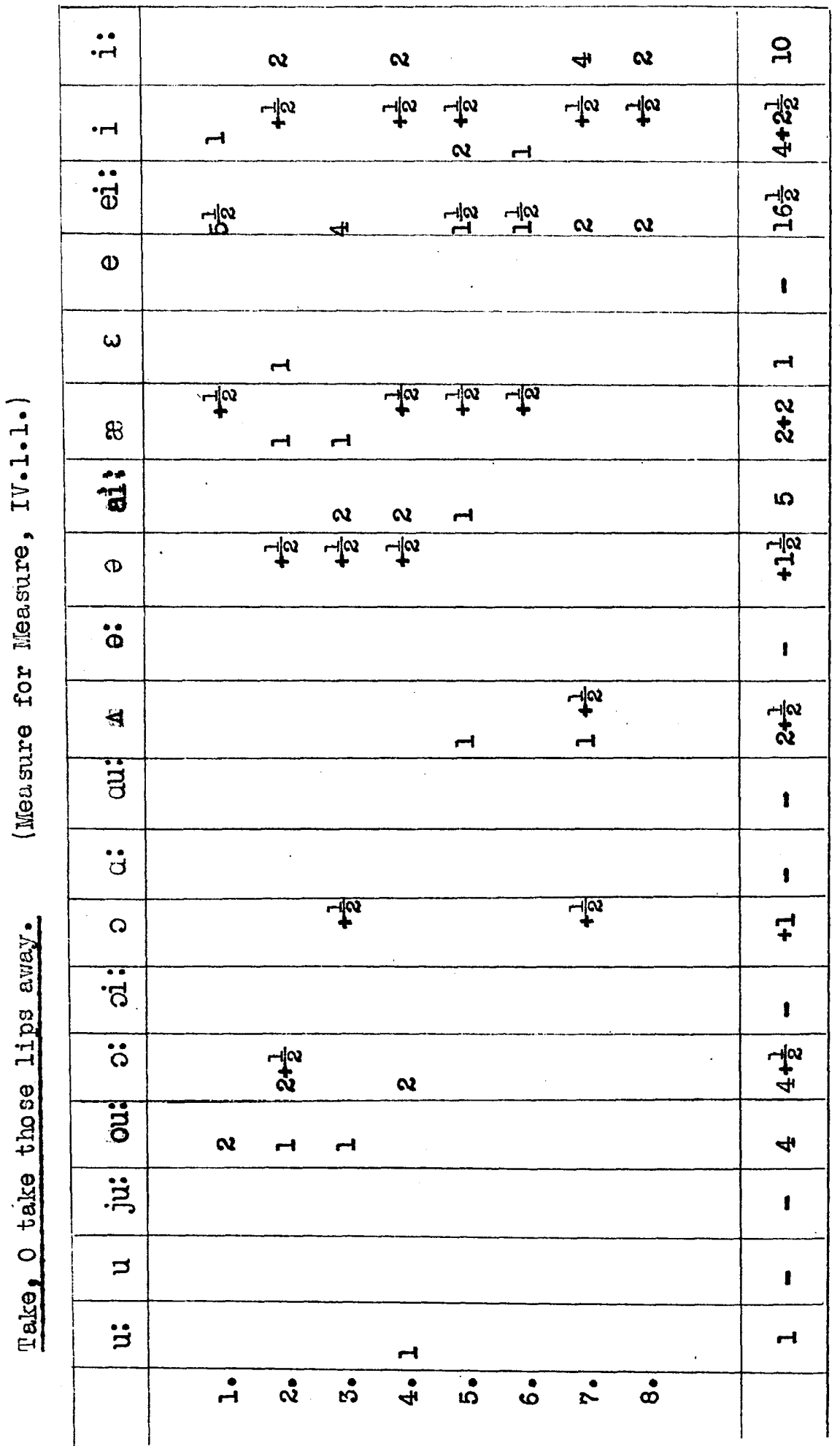




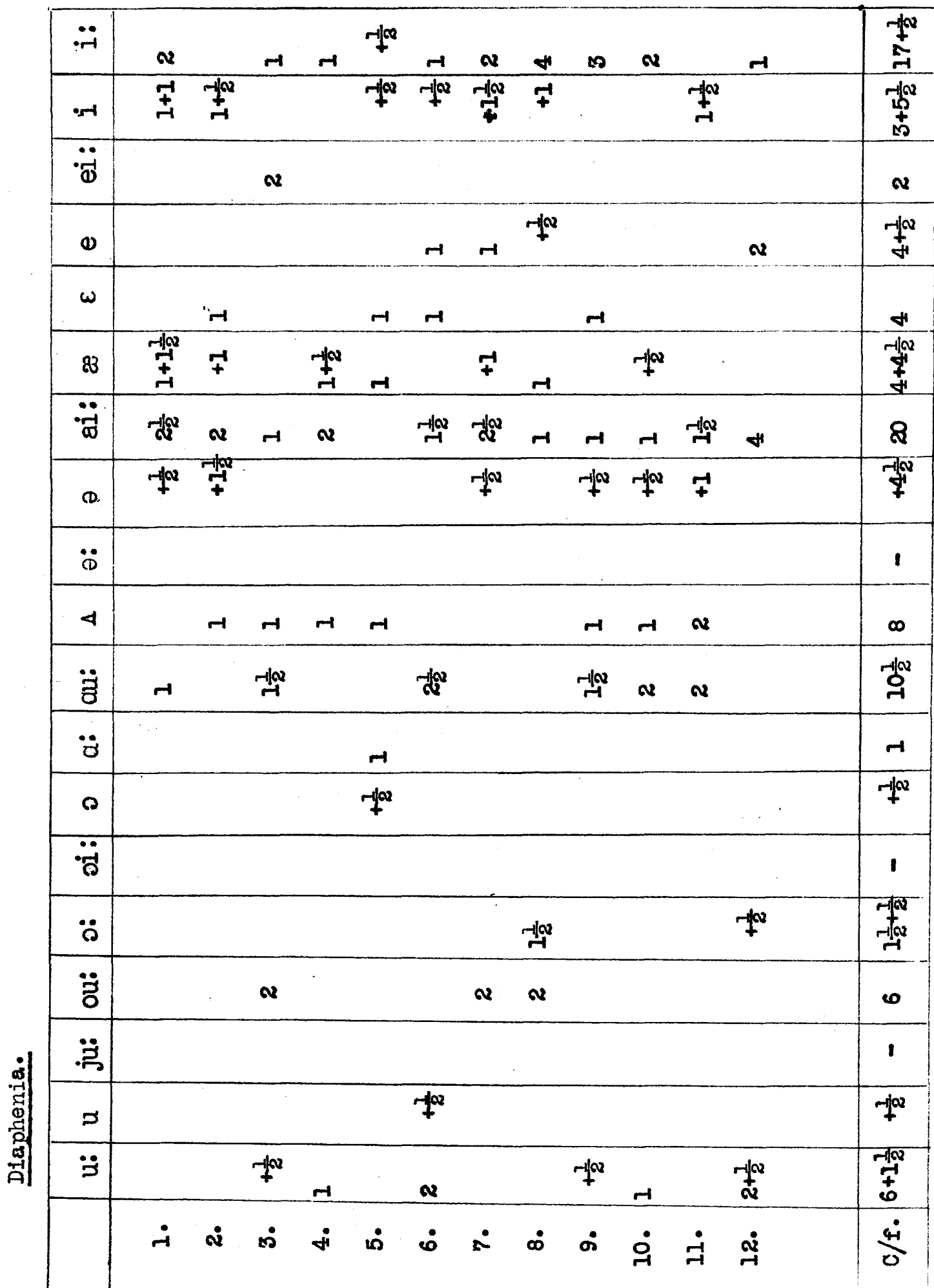




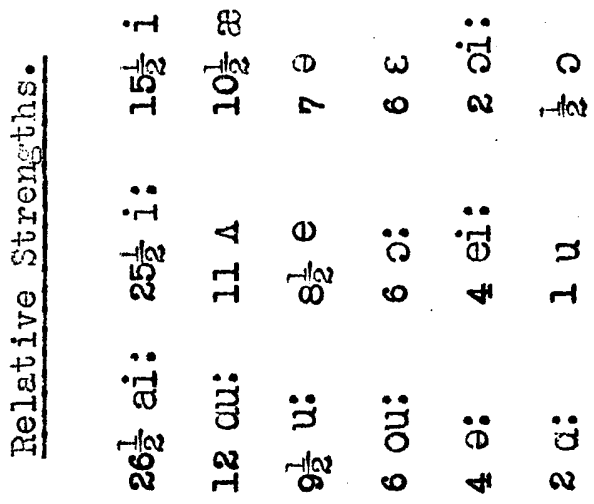

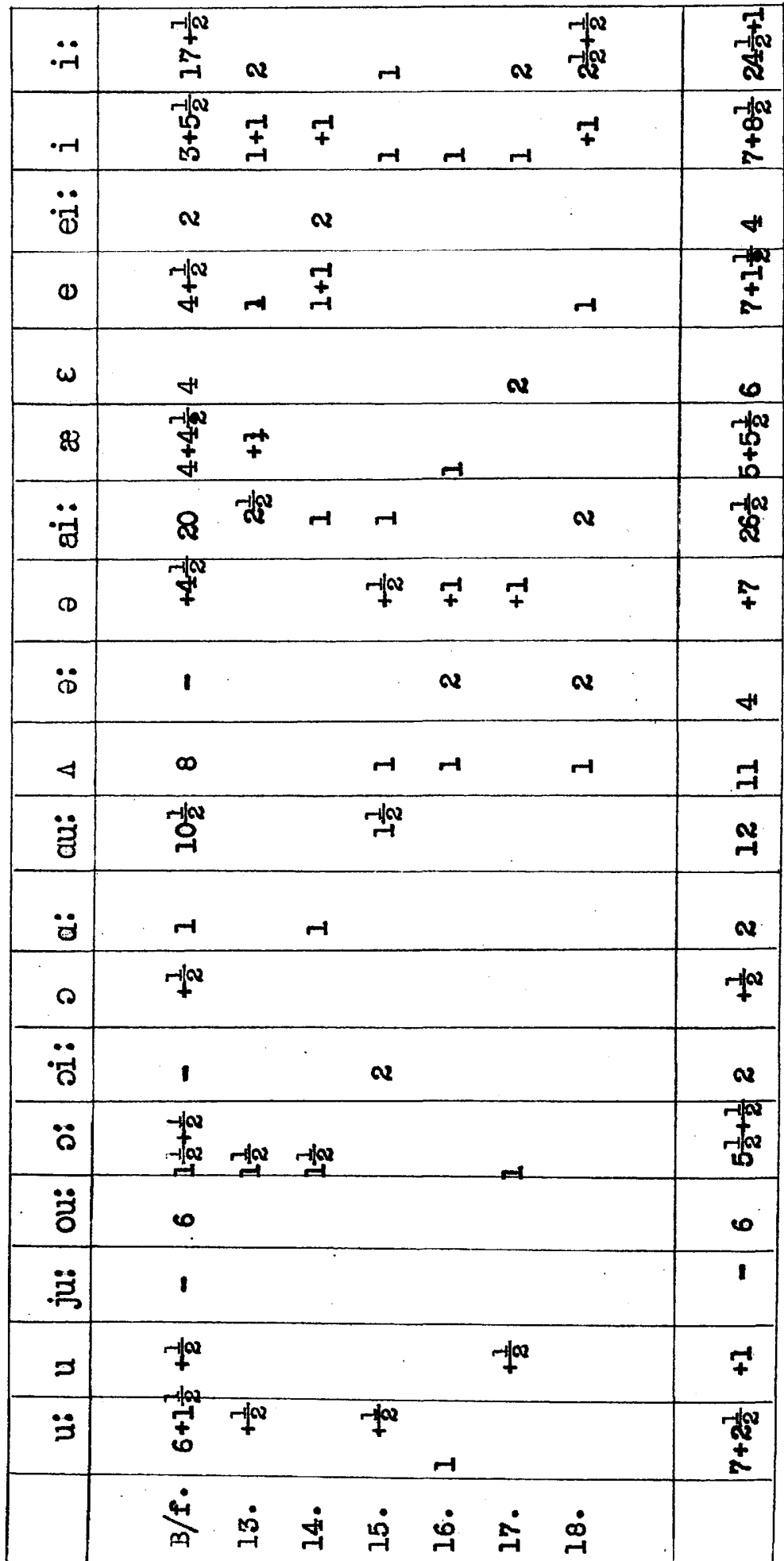




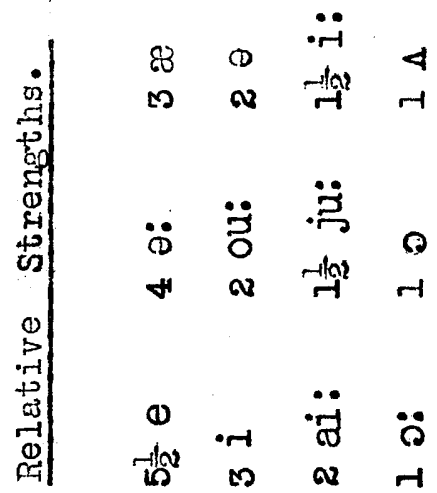

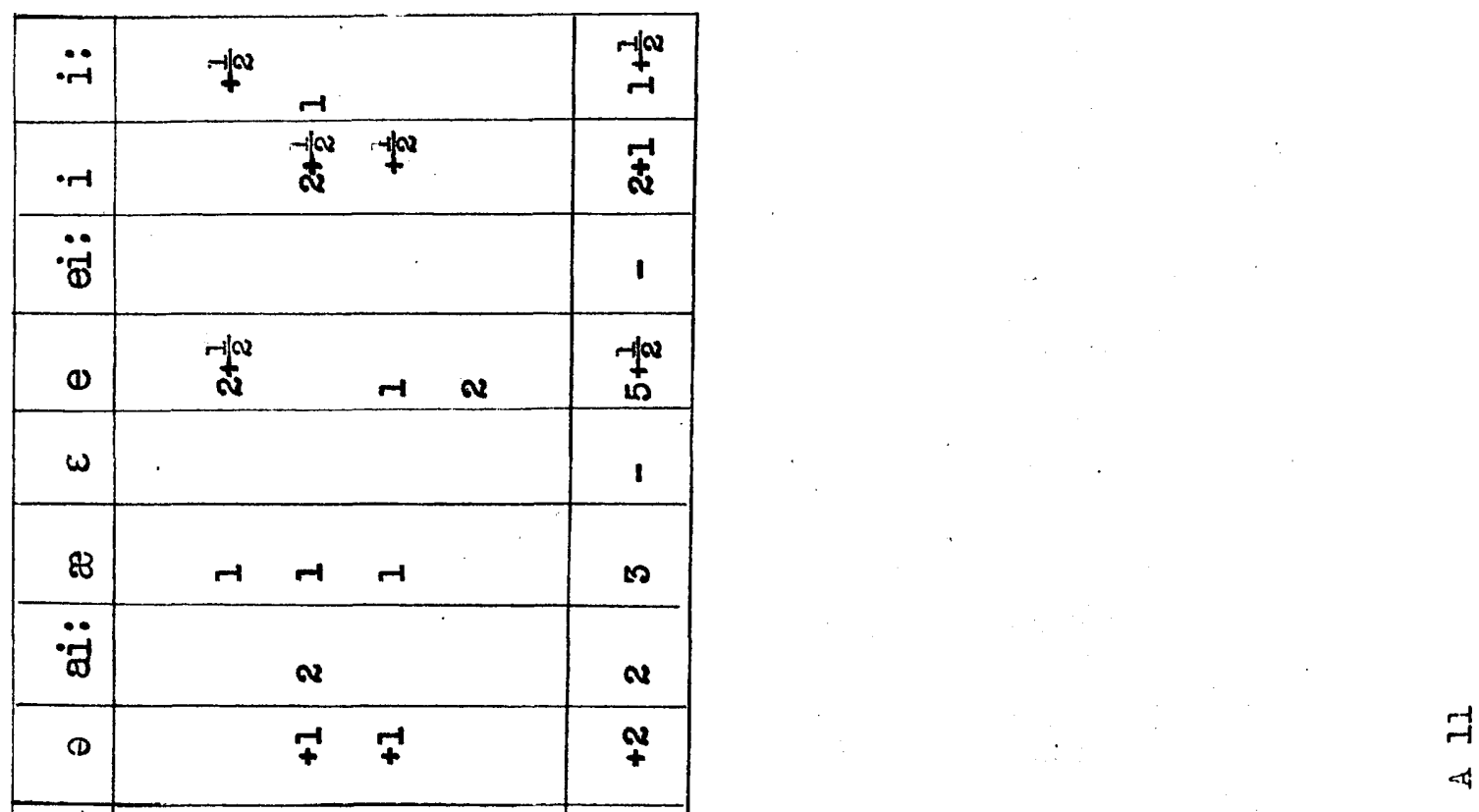




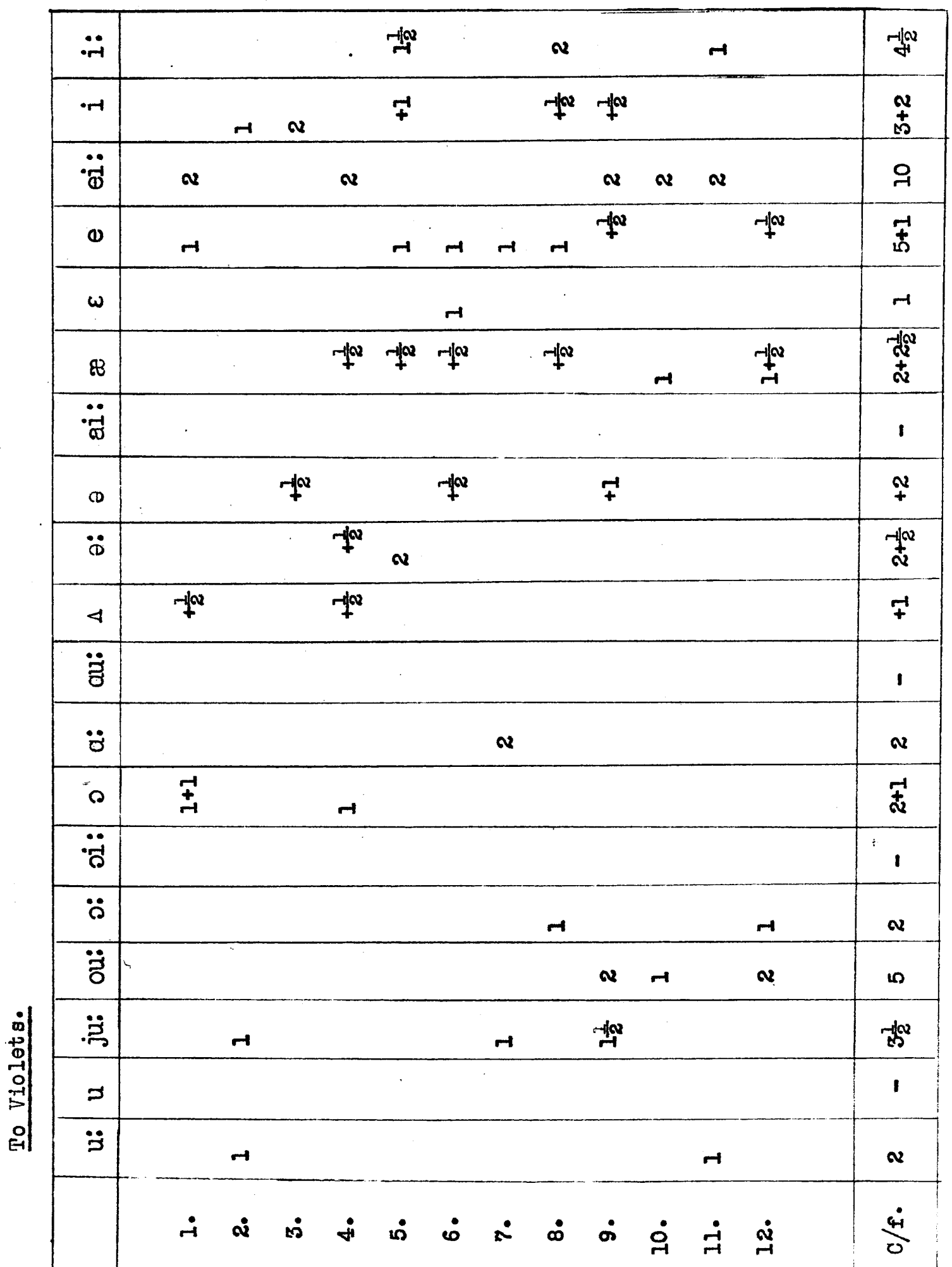




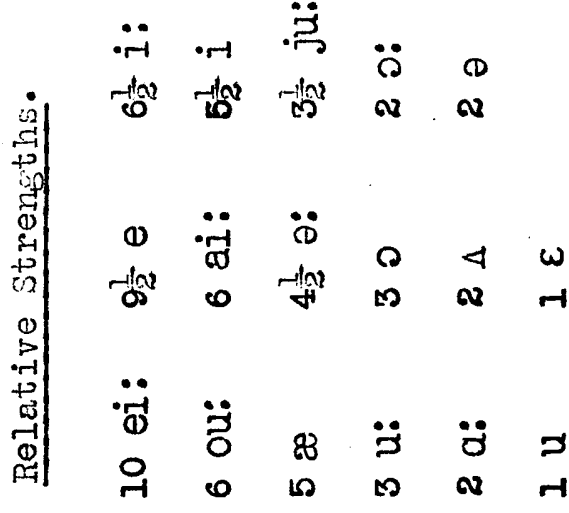

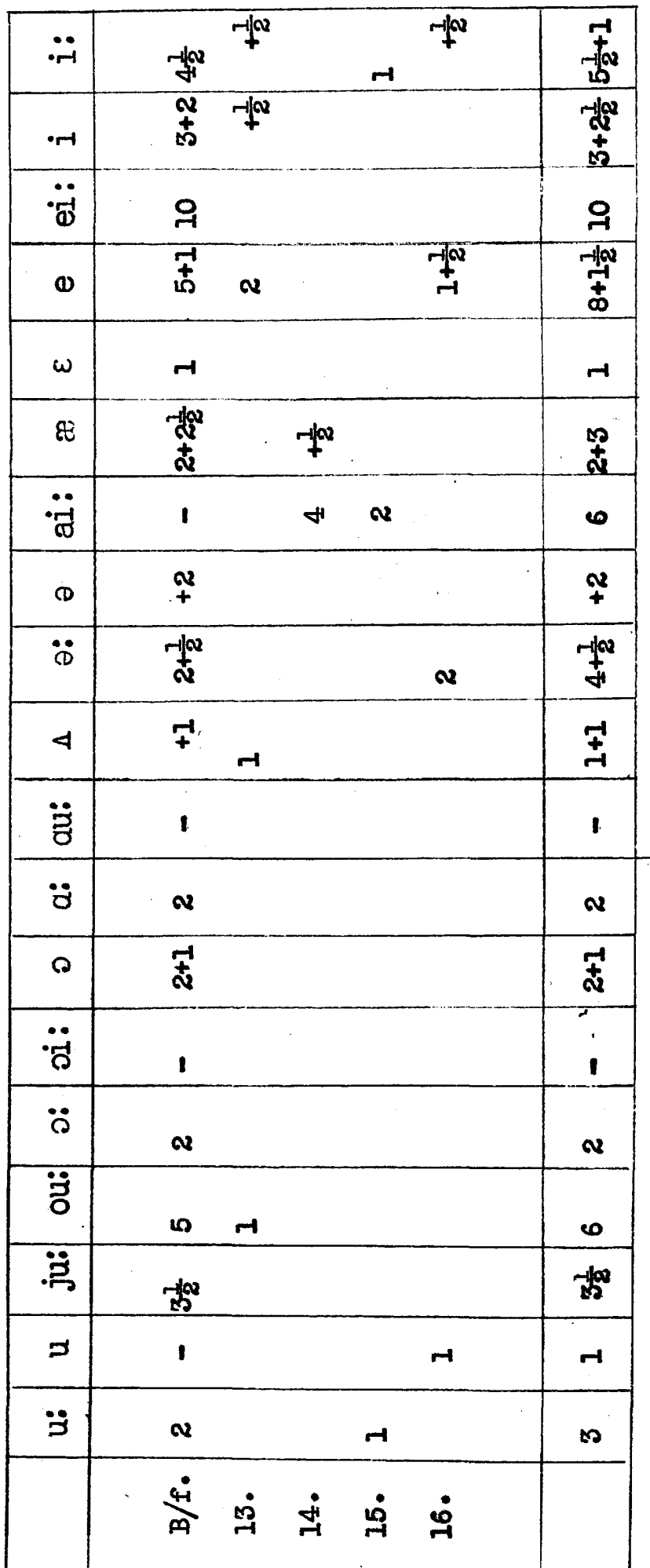




\begin{tabular}{|c|c|c|c|c|c|c|c|c|c|c|c|c|c|}
\hline$\ddot{\circ}$ & $r$ & & $\infty$ & & & $-1 \infty x$ & & & $\infty$ & $\boldsymbol{v}$ & & $\overbrace{-1}^{-1 \infty}$ & 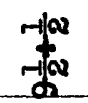 \\
\hline$\cdot r$ & $\underset{N}{+-10}$ & $\boldsymbol{t}$ & 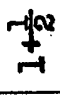 & & & -1 & & & 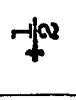 & $-10 x$ & 䀭 & $\underset{-1}{-1 / \infty}$ & $\underset{ \pm}{ \pm}$ \\
\hline$\ddot{\ddot{\theta}}$ & & & $-1+\infty$ & & & $-1+\infty$ & & v & $\stackrel{-1102}{a}$ & & $-1+2$ & & $\underset{\ddagger}{\ddagger}$ \\
\hline$\omega$ & & $r$ & & & & & $r$ & & $r$ & & & & $\infty$ \\
\hline$\omega$ & & & & & & & & & & & $r$ & & $\mathrm{H}$ \\
\hline 8 & & 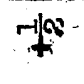 & & +1 & $-1 x^{\infty}$ & & &. & & & 7 & & - \\
\hline$\ddot{\ddot{\infty}}$ & $m$ & - 6100 & & $\infty$ & $v$ & $\boldsymbol{N}$ & $\infty$ & $\infty$ & -1 & & & & -1ل्र \\
\hline$\infty$ & & & $r \neq$ & & 7 & & & & & 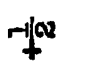 & $-1 \times$ & $-1+x$ & $\stackrel{p}{q}$ \\
\hline$\ddot{d}$ & & & & & 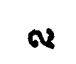 & & & & & & & & $v$ \\
\hline 4 & . & & $v$ & & 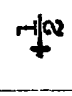 & $-1+2$ & $\stackrel{-10 x}{-10}$ & & & $r$ & & & $\underset{F}{F}$ \\
\hline$\ddot{z}$ & & & & & & & & & & & & & 1 \\
\hline$\ddot{z}$ & & & & & & & 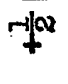 & & & & & & - \\
\hline 0 & & & & 7 & $\rightarrow$ & & 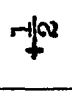 & $+1 \infty x$ & & 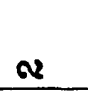 & & $-1 x^{2}$ & 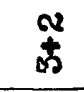 \\
\hline$\ddot{r}$ & & & & & & & & & & & & & 1 \\
\hline$\ddot{\circ}$ & & & $\pi$ & -1 & & & & $-1+\infty$ & & & & & 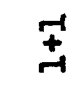 \\
\hline$\ddot{\Xi}$ & $\stackrel{-H a r}{A \rightarrow}$ & & & & $\boldsymbol{v}$ & & $\stackrel{+\infty}{\rightarrow-\infty}$ & & $\boldsymbol{v}$ & -1 & $v$ & & 우 \\
\hline 总 & & & & & & & & & & & & & 1 \\
\hline$s$ & & & & $r$ & & & & $H$ & & & & $r$ & $\infty$ \\
\hline$\ddot{\rightrightarrows}$ & $+\infty$ & & & & & & & & & & & & $+\infty$ \\
\hline & $\dot{-i}$ & $\dot{\mathfrak{x}}$ & $\infty$ & fi & $\dot{n}$ & & $\ddot{2}$ & $\dot{\infty}$ & $\dot{\sigma}$ & $\dot{\circ}$ & $\dot{-}$ & $\underset{\sim}{\stackrel{\sim}{\sim}}$ & $\frac{\dot{4}}{0}$ \\
\hline
\end{tabular}




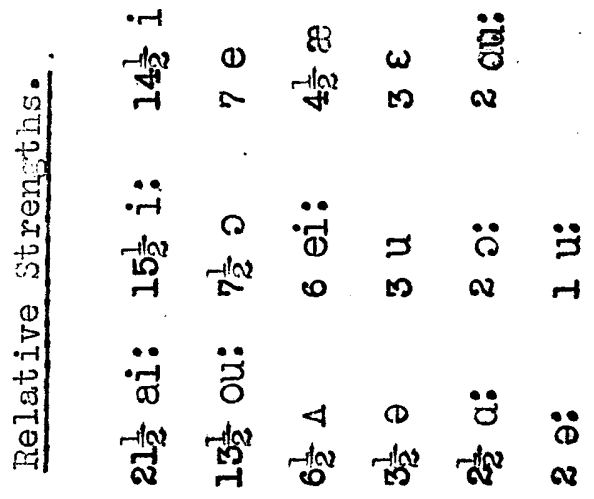

\begin{tabular}{|c|c|c|c|c|c|c|}
\hline$\ddot{\bullet-1}$ & $-1 / \infty$ & $v$ & $\stackrel{-\mu N}{\rightarrow-1}$ & & $v$ & $\underset{m}{+\infty}$ \\
\hline$\cdot r-1$ & $\underset{ \pm}{ \pm}$ & $\underset{+}{+}$ & -40 & $\stackrel{-10}{-1}$ & + & 势 \\
\hline$\cdot 0$ & $\stackrel{v}{\ddagger}$ & & & & & $\stackrel{x}{*}$ \\
\hline $\boldsymbol{\omega}$ & $B$ & & -1 & $v$ & $H$ & $\infty$ \\
\hline$\omega$ & -1 & $\boldsymbol{H}$ & & $r$ & & $\infty$ \\
\hline 8 & $\underset{t}{-d a}$ & & $+\infty$ & 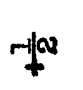 & & $+\sqrt{60}$ \\
\hline$\ddot{\ddot{\sigma}}$ & \&్ల & & & $r$ & & $\sqrt{2}$ \\
\hline (1) & $p$ & & & $-1+a$ & & + \\
\hline$\ddot{B D}$ & $\boldsymbol{v}$ & & & & & 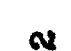 \\
\hline 4 & स & -102 & & & $7+2$ & 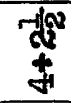 \\
\hline$\ddot{z}$ & I & $\mathbf{v}$ & & & & $\boldsymbol{N}$ \\
\hline$\ddot{\partial}$ & $\stackrel{r a x}{\alpha}$ & & & & & rev \\
\hline 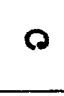 & 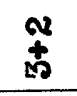 & $r$ & & & $\stackrel{-j a}{\stackrel{-j}{+}}$ & 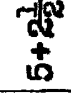 \\
\hline में & 1 & & & & & 1 \\
\hline$\ddot{\circ}$ & $\stackrel{+}{+}$ & & & & & $\underset{+}{+}$ \\
\hline$\ddot{\Xi}$ & 욱 & ${ }_{-1}^{-10}$ & & $v$ & & 然 \\
\hline$\ddot{~} \ddot{3}$ & 1 & & & & & 1 \\
\hline 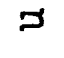 & $\infty$ & & & & & $\infty$ \\
\hline$\ddot{z}$ & $-1 x$ & & -10 & & & 7 \\
\hline & $\stackrel{4}{m}^{\dot{m}}$ & $\ddot{\theta}$ & $\dot{H}$ & $\stackrel{\dot{m}}{\dot{r}}$ & $\dot{\sim}$ & \\
\hline
\end{tabular}




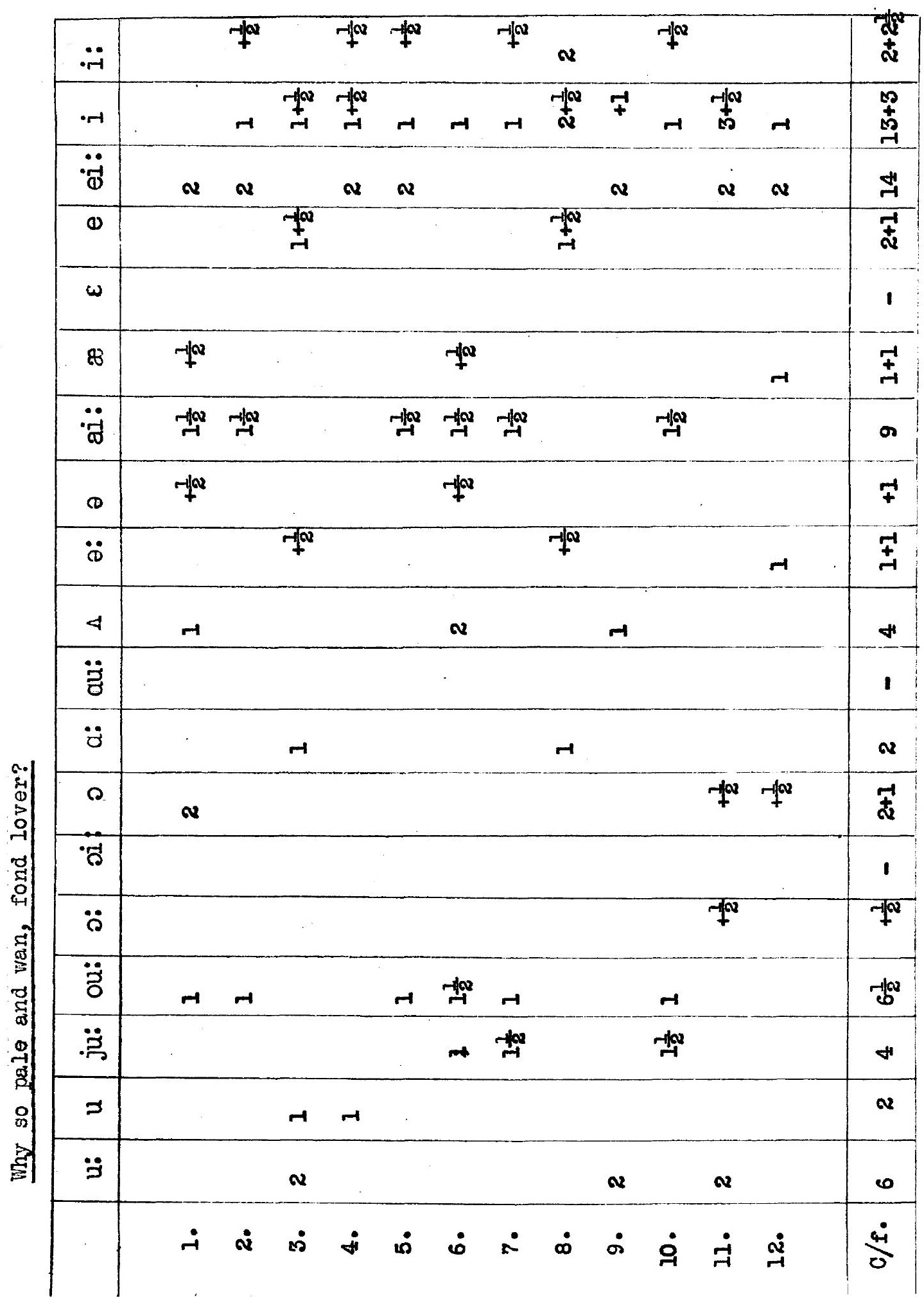




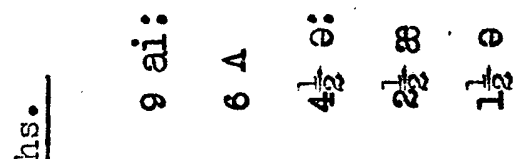

究

$\because \ddot{\circ}$

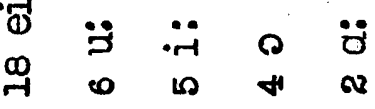

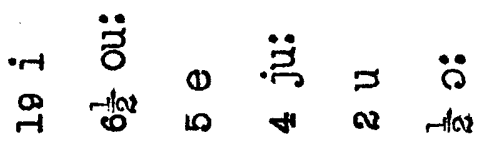

\begin{tabular}{|c|c|c|c|c|c|}
\hline$\ddot{-r}$ & \begin{tabular}{l} 
नd \\
\multirow{2}{*}{} \\
\multirow{2}{*}{}
\end{tabular} & -100 & & & \begin{tabular}{l}
$\infty$ \\
\multirow{\omega}{*}{}
\end{tabular} \\
\hline$\cdot r-r$ & $\underset{m}{M}$ & & $7 x^{2}$ & -70 & $\begin{array}{l}7 \\
\\
\text { เ }\end{array}$ \\
\hline$\ddot{\ddot{\sigma}}$ & $\stackrel{H}{H}$ & & $\mathbf{v}$ & $\mathbf{v}$ & $\stackrel{\infty}{\sim}$ \\
\hline $\boldsymbol{\omega}$ & 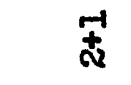 & -1 & & -1 & 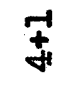 \\
\hline$\omega$ & 1 & & & & 1 \\
\hline 88 & $\stackrel{+}{+}$ & & -10 & & $\underset{+1}{\stackrel{-1}{a}}$ \\
\hline$\ddot{~ \ddot{~}}$ & os & & & & $\sigma$ \\
\hline (D) & + & & & 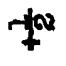 & 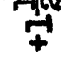 \\
\hline$\ddot{\mathbb{D}}$ & $\underset{\oplus}{ \pm}$ & $+\infty$ & -1 & $\mathrm{H}$ & 焉 \\
\hline 4 & $H$ & -1 & $\rightarrow$ & & $\boldsymbol{\omega}$ \\
\hline$\ddot{3}$ & I & & & & 1 \\
\hline$\ddot{\partial}$ & $\boldsymbol{v}$ & & & & $\boldsymbol{v}$ \\
\hline$\Omega$ & $\stackrel{-1}{a}$ & $\underset{+}{+}$ & & & 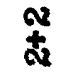 \\
\hline$\ddot{\ddot{R}}$ & 1 & & & & 1 \\
\hline$\ddot{\rho}$ & $-1 a$ & & & & $-10 x$ \\
\hline$\ddot{z}$ & to & & & & -10 \\
\hline 艿 & fl & & & & + \\
\hline 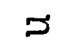 & $\sim$ & & & & $\boldsymbol{v}$ \\
\hline$\ddot{\partial}$ & $\boldsymbol{\omega}$ & & & & $\omega$ \\
\hline & $\underset{m}{\dot{q}}$ & $\dot{\infty}$ & $\dot{H}$ & $\dot{n}$ & \\
\hline
\end{tabular}




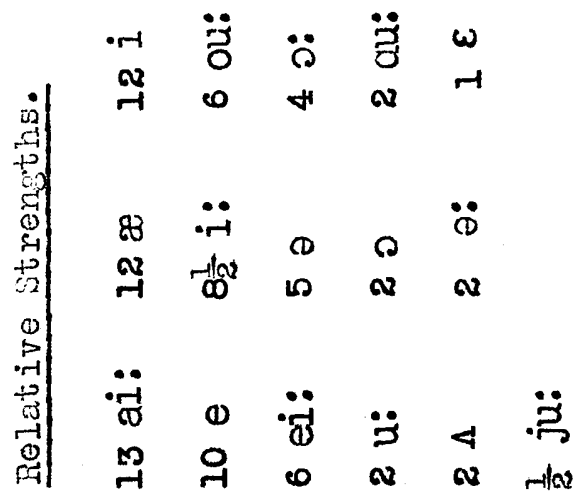

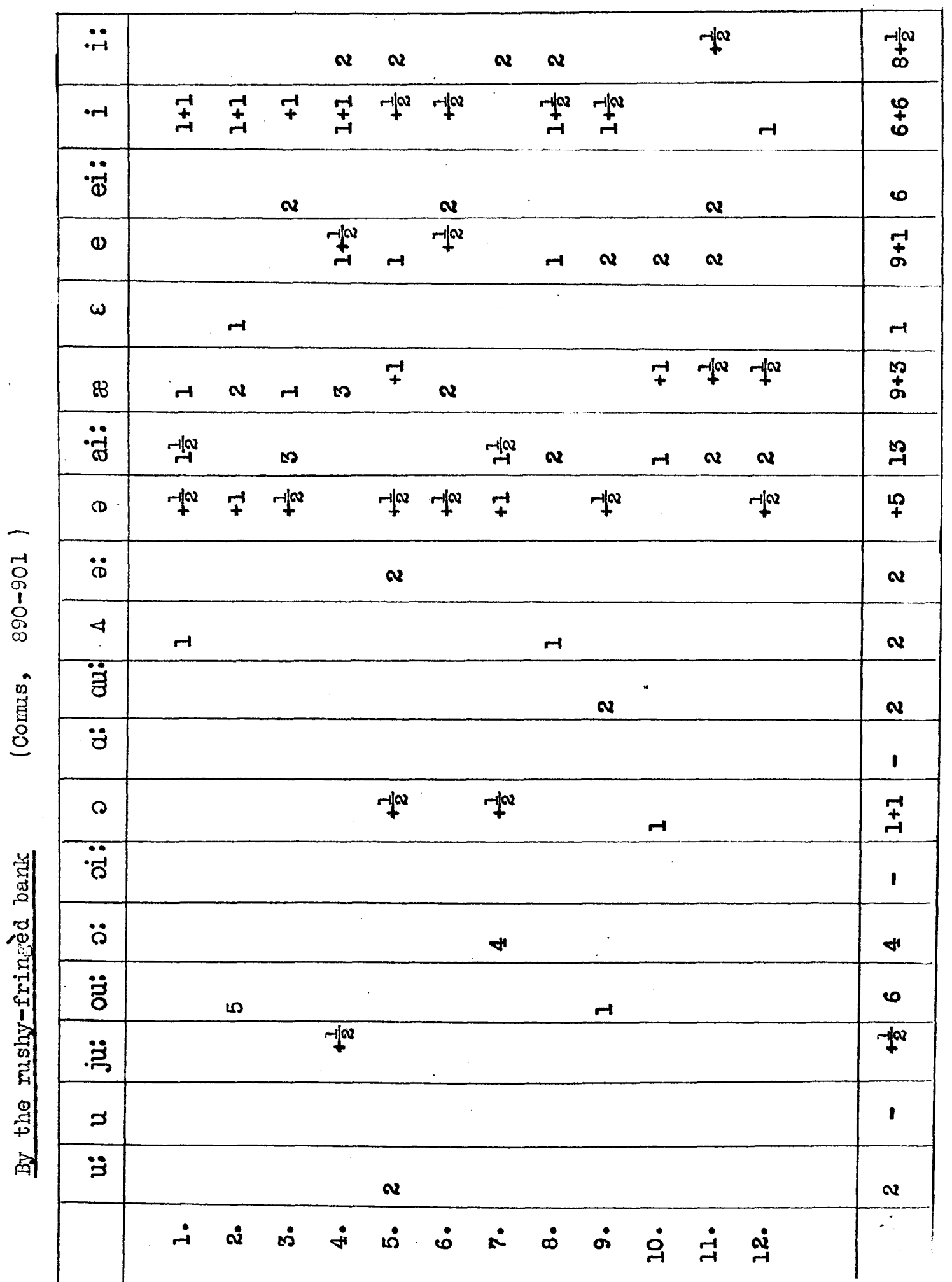




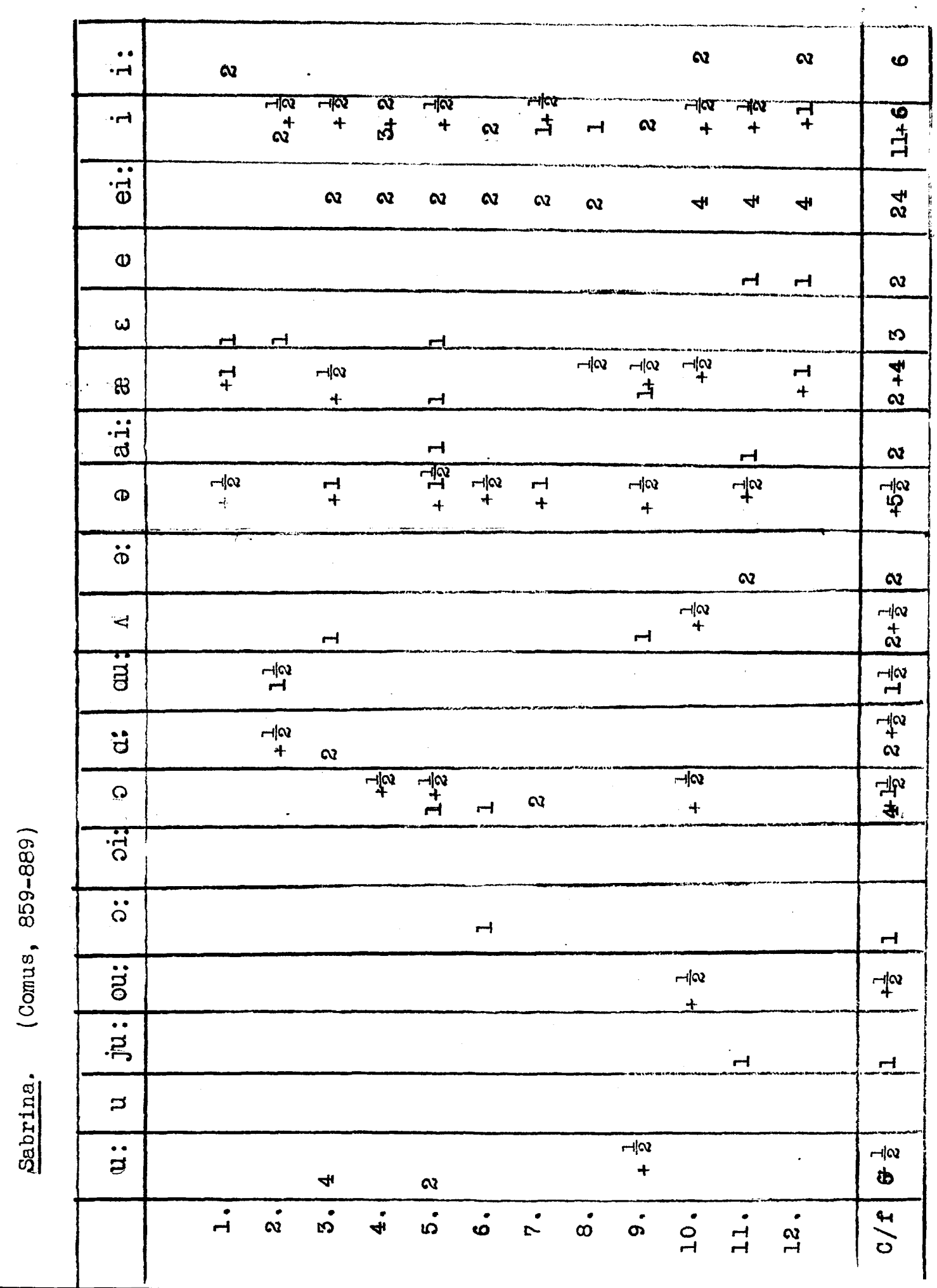




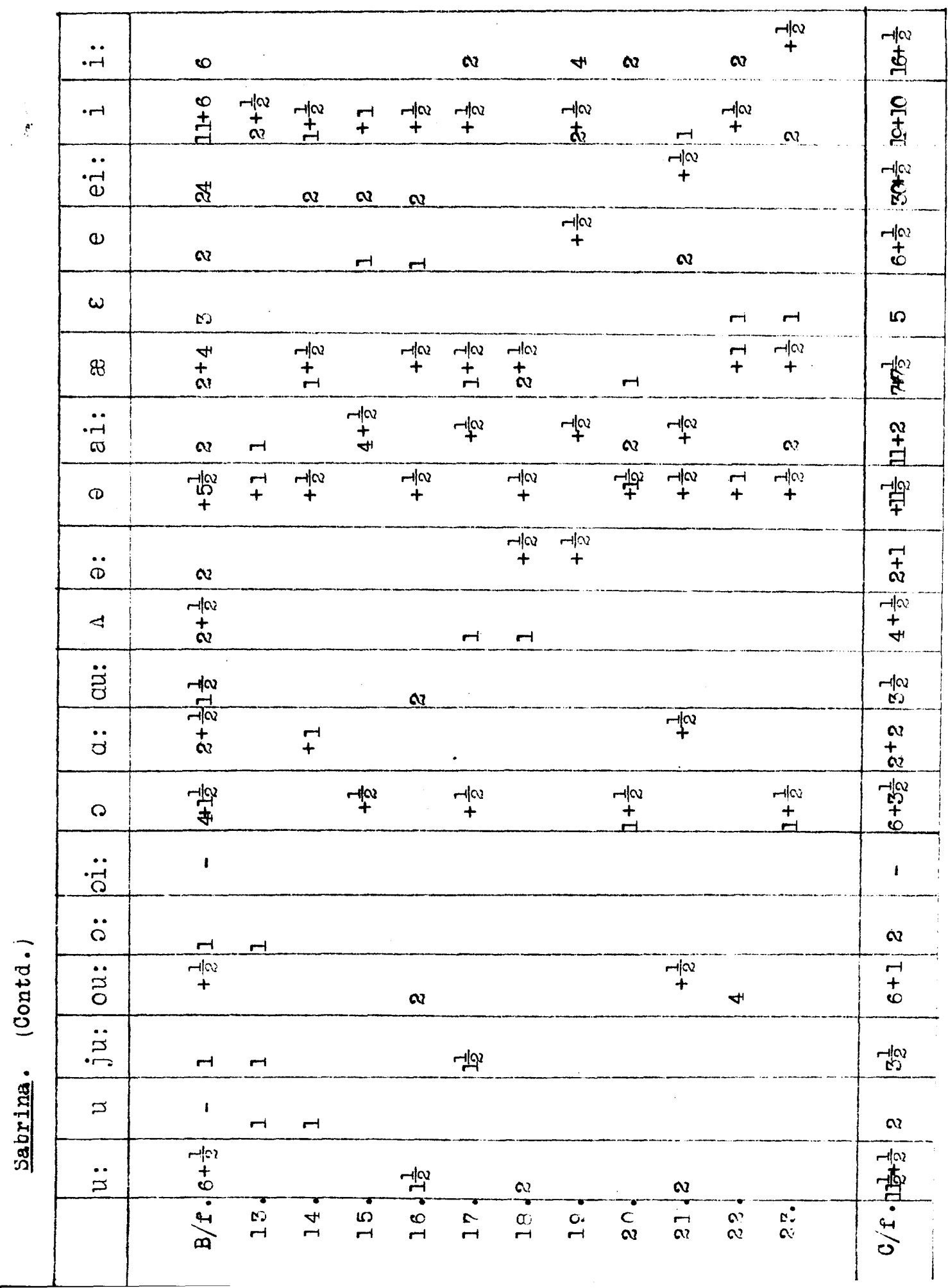

0
0
0
4 


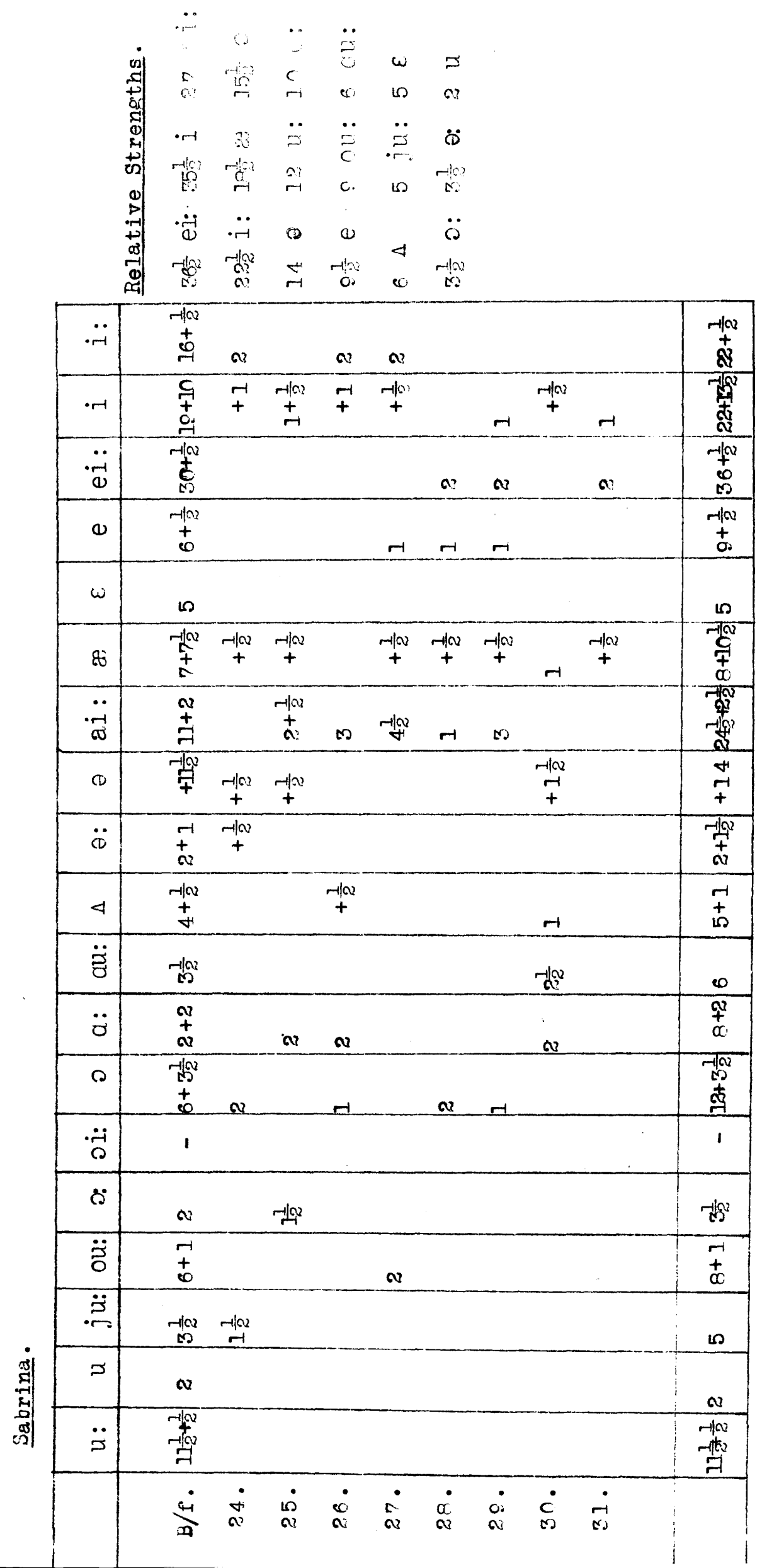




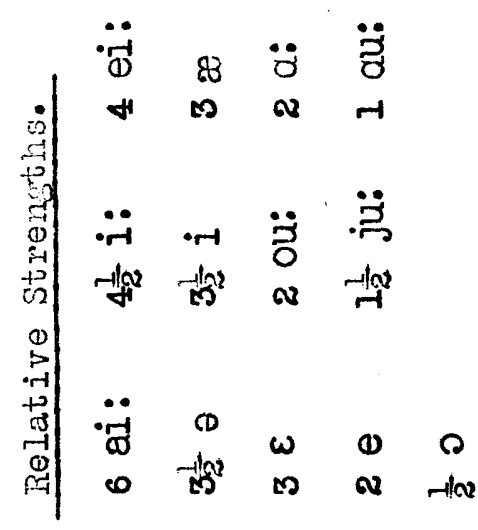

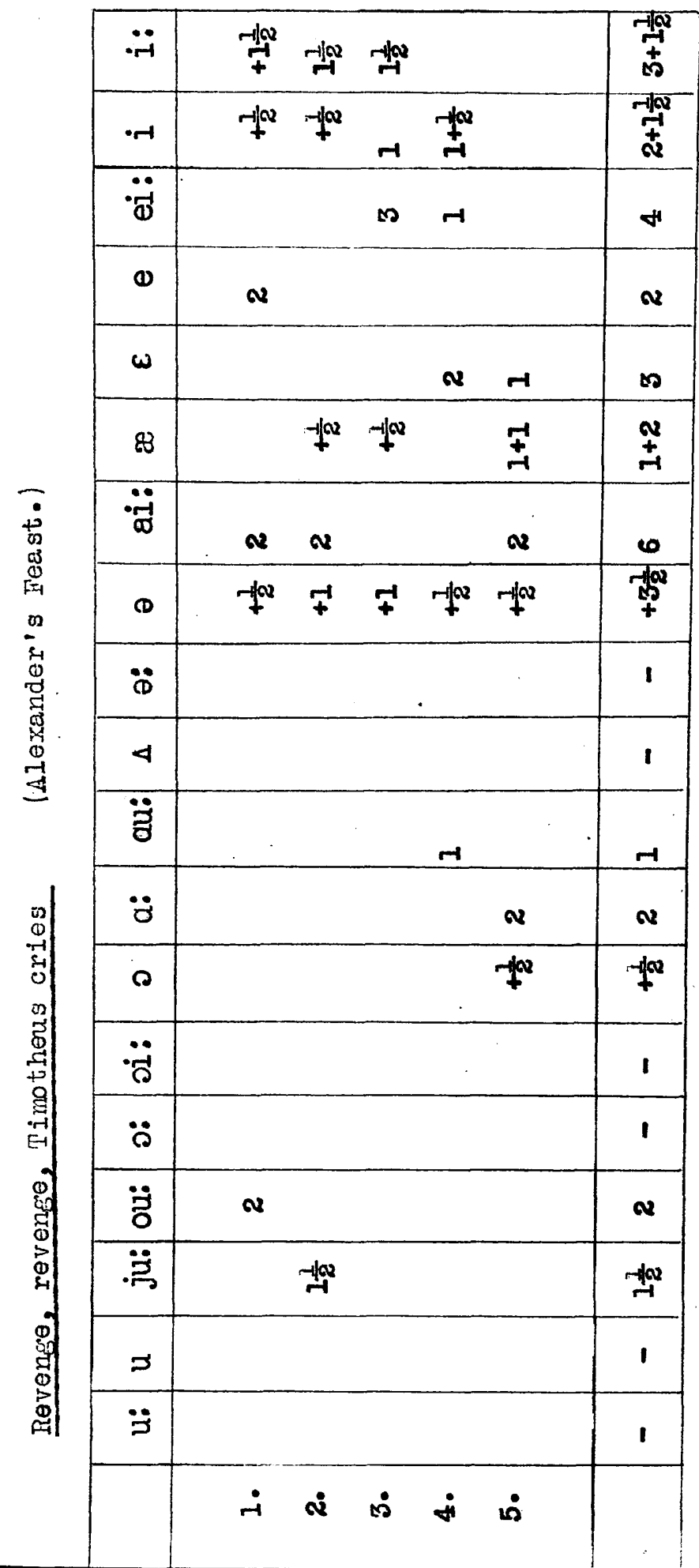




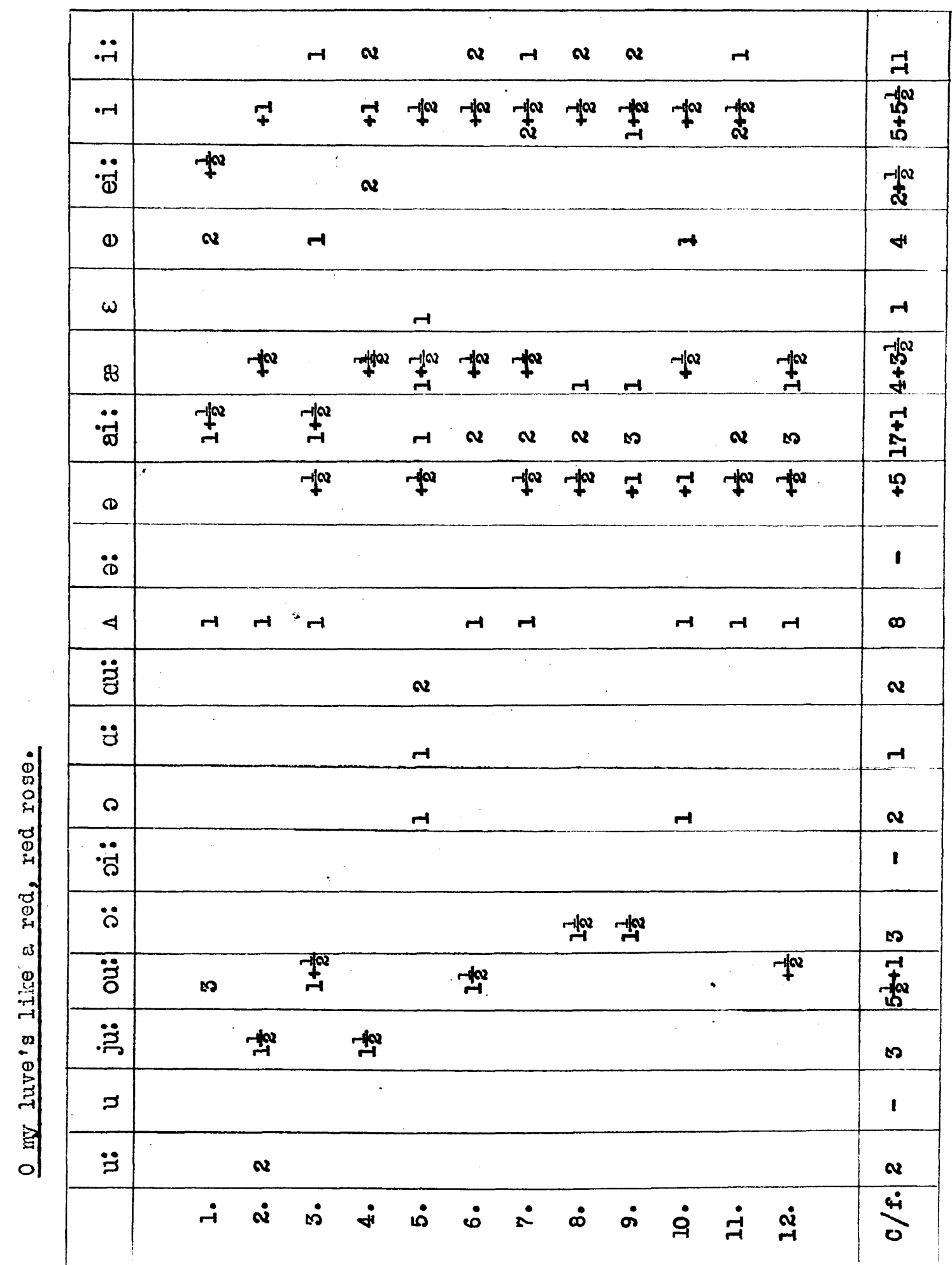




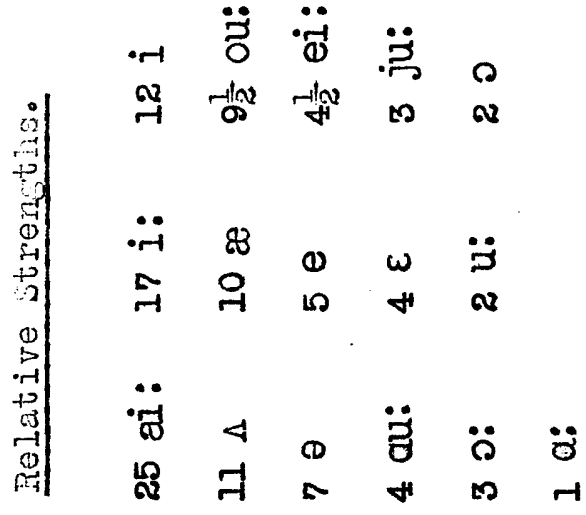

\begin{tabular}{|c|c|c|c|c|c|c|}
\hline$\ddot{\ddot{r}}$ & $\vec{F}$ & $m$ & $\infty$ & & & $\pi$ \\
\hline$\cdot \vec{r}$ & $\begin{array}{l}-10 \\
5 \\
10\end{array}$ & $r+a$ & & $t^{+h a n}$ & rfar & $\frac{5}{10}$ \\
\hline$\ddot{\ddot{\omega}}$ & $\stackrel{-1 / \alpha}{\alpha}$ & & & $\boldsymbol{v}$ & & $\stackrel{r-100}{+}$ \\
\hline 0 & 4 & & & & $r$ & (1) \\
\hline$\omega$ & $r$ & $r$ & $H$ & & $H$ & 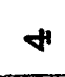 \\
\hline 88 & $\begin{array}{l}\text { fic } \\
+ \\
+\end{array}$ & $F^{+\infty}$ & $\underset{+}{+}$ & $\rightarrow$ & & $\stackrel{\varphi}{\ddagger}$ \\
\hline 苂 & $\underset{7}{ \pm}$ & $r$ & $\boldsymbol{v}$ & $\boldsymbol{v}$ & $\boldsymbol{v}$ & 売 \\
\hline (D) & +5 & $7+90$ & 7 & & + & 5 \\
\hline$\ddot{\mathbb{D}}$. & 1 & & & & & 1 \\
\hline 4 & $\infty$ & $H$ & & $\boldsymbol{v}$ & & $\vec{F}$ \\
\hline$\ddot{z}$ & $\mathbf{v}$ & & & & $v$ & \& \\
\hline$\ddot{0}$ & -1 & & & & & $\boldsymbol{H}$ \\
\hline D & $\boldsymbol{v}$ & & & & & $\mathbf{w}$ \\
\hline$\ddot{8}$ & 1 & & & . & & 1 \\
\hline$\ddot{\circ}$ & $\infty$ & & & & & $\infty$ \\
\hline$\ddot{亏}$ & $t^{+1}$ & $v$ & & & $\boldsymbol{H}$ & $-\frac{1}{6}$ \\
\hline 号 & $\infty$ & & & & & $m$ \\
\hline 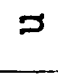 & 1 & & & & & 1 \\
\hline$\ddot{g}$ & $\boldsymbol{v}$ & & & & & $\boldsymbol{v}$ \\
\hline & $\stackrel{4}{m}$ & $\dot{m}$ & $\dot{H}$ & ம் & $\stackrel{\oplus}{\oplus}$ & \\
\hline
\end{tabular}




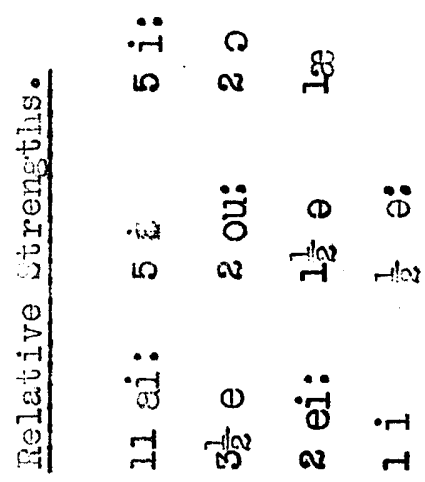

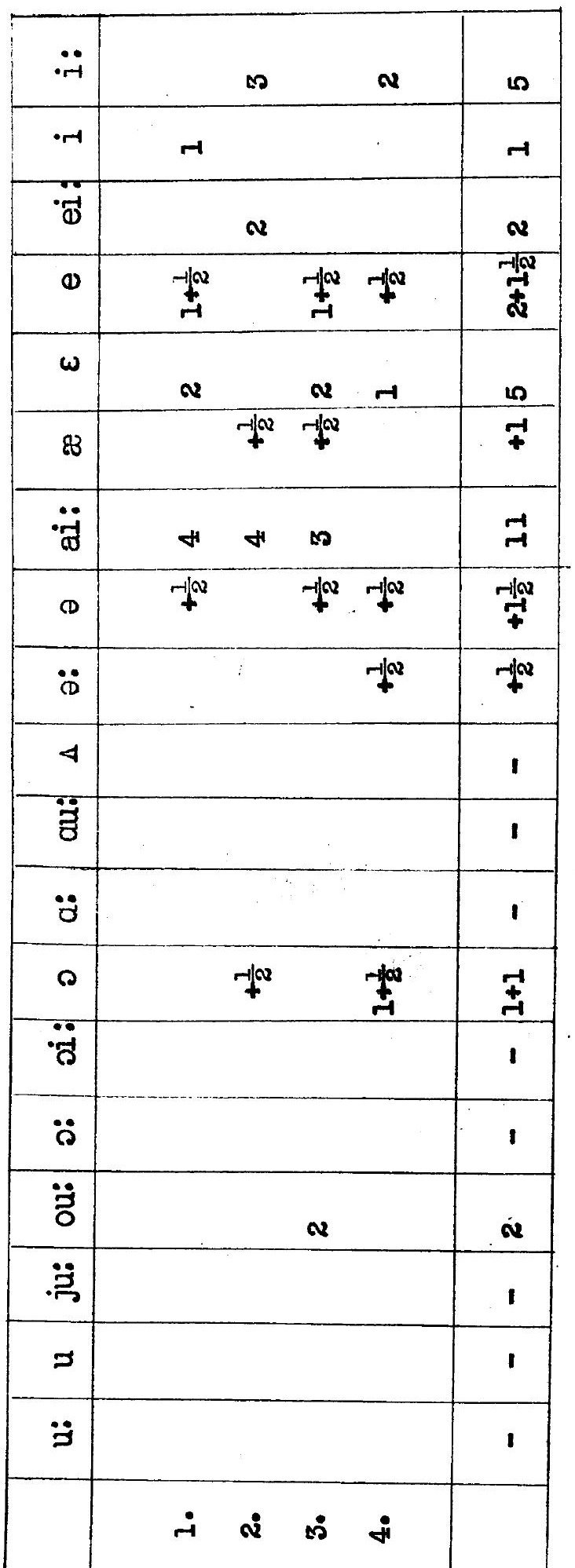




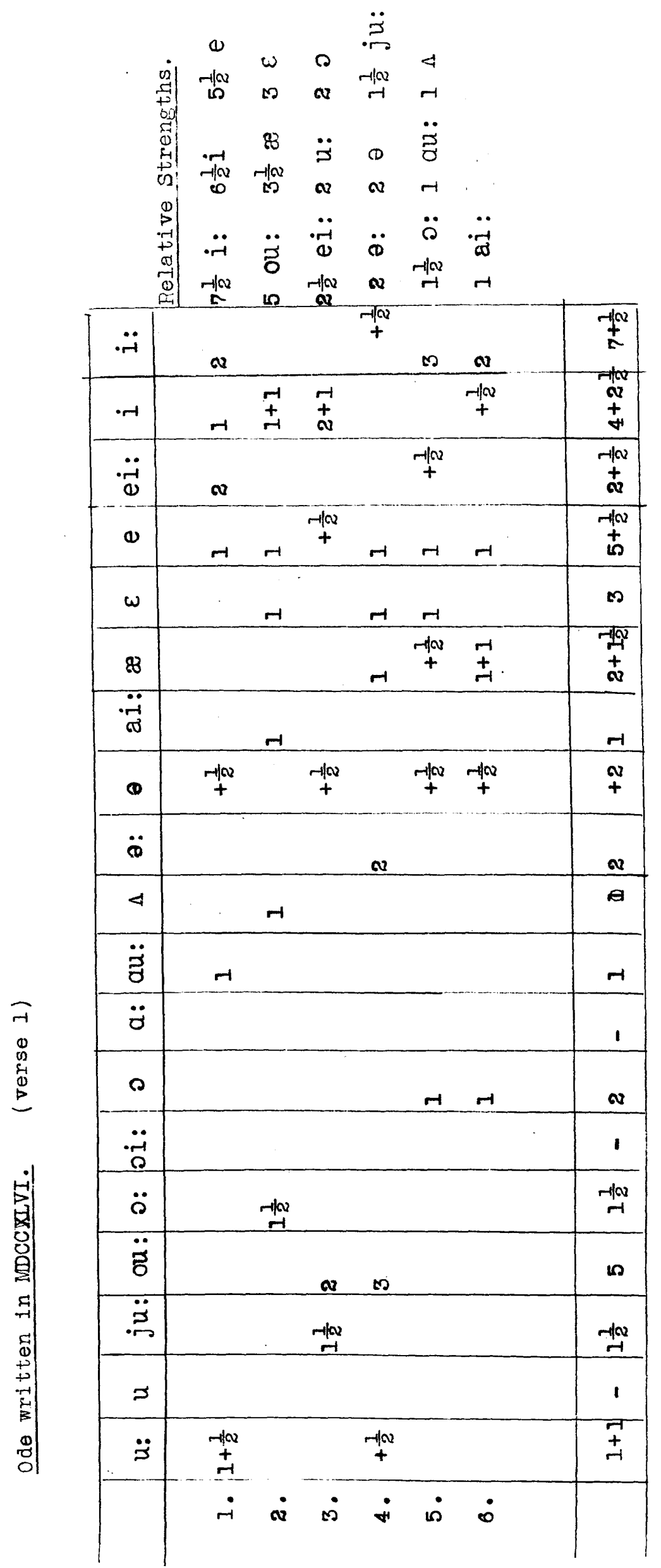




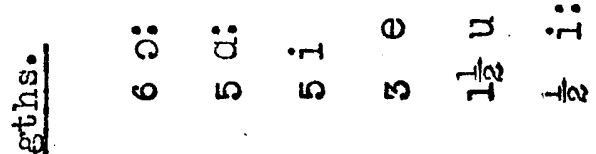

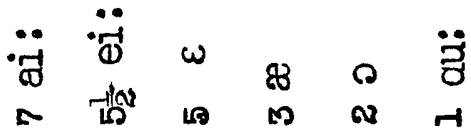

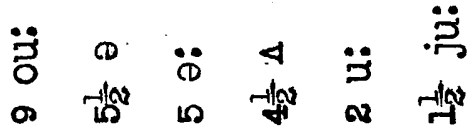

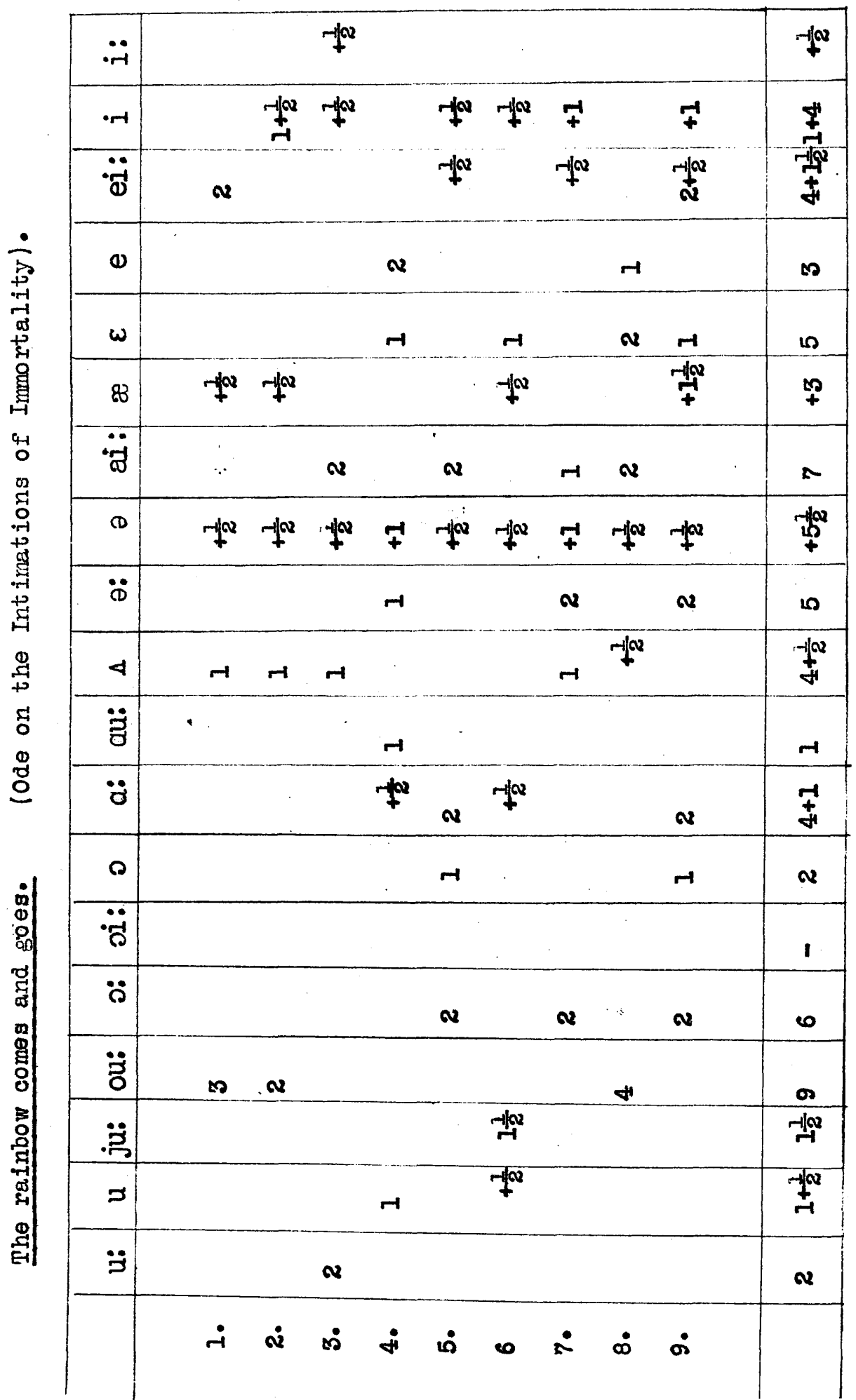




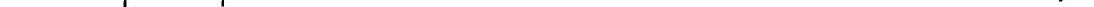




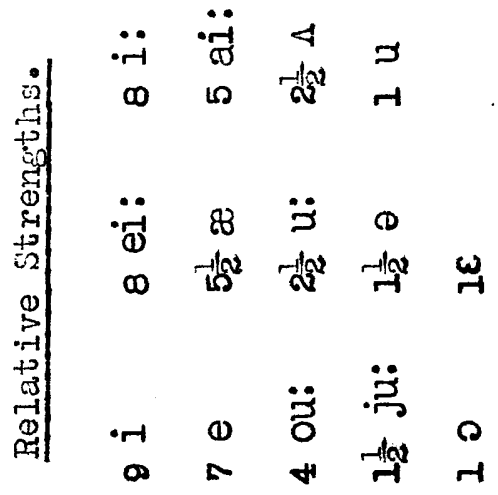

\begin{tabular}{|c|c|c|c|c|c|c|c|c|}
\hline$\because \ddot{\theta}$ & $\stackrel{-10 x}{-1}$ & $-1 x$ & $v$ & $\mathbf{v}$ & & -1 & -1 & \pm \\
\hline$\cdot r$ & $\underset{-1}{+\infty}$ & + & & $\stackrel{+1}{ \pm}$ & $\underset{-1}{+\infty}$ & -1 & $\underset{+\infty}{-10} \underset{-1}{-10}$ & $\underset{⿱ 乛}{\$}$ \\
\hline$\ddot{0}$ & & & & & + & $v$ & $N$ & $\infty$ \\
\hline $\boldsymbol{\omega}$ & $M$ & & $r$ & & & $\alpha$ & -1 & $\pi$ \\
\hline $\boldsymbol{\omega}$ & & $\boldsymbol{H}$ & & & & & & $H$ \\
\hline$\$ 3$ & & $H$ & & $r$ & $H$ & 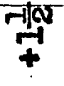 & $r$ & $\stackrel{+y_{+}^{+}}{+}$ \\
\hline • & & & $\mathbf{v}$ & & $\boldsymbol{v}$ & & -1 & L \\
\hline CD & & $\dddot{t}$ & & & -10 & & · & -1/ \\
\hline$\ddot{C}$ & & & & & & & & 1 \\
\hline$\dot{4}$ & & $\boldsymbol{H}$ & $r$ & & & & $7 / \sqrt{2}$ & नla \\
\hline$\ddot{z}$ & & & & $\cdot$ & & & & 1 \\
\hline$\ddot{z}$ & & & & & & & & 1 \\
\hline$\curvearrowright$ & & $\boldsymbol{H}$ & & & & & & $H$ \\
\hline$\ddot{\circ}$ & & & & & & & & 1 \\
\hline$\ddot{\circ}$ & & & & & & & & 1 \\
\hline$\ddot{\ddot{0}}$ & & & & & & & $\$$ & $\$$ \\
\hline$\ddot{g}$ & & & $\ddot{H}$ & & & & & $\stackrel{-100}{7}$ \\
\hline 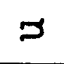 & & & & 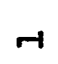 & & & & -1 \\
\hline$\ddot{g}$ & & & $\stackrel{-102}{-1}$ & $H$ & & & & 留 \\
\hline & $\dot{-}$ & $\dot{v}$ & $\dot{m}$ & $\dot{8}$ & $\dot{0}$ & $\dot{0}$ & $\ddot{\infty} \dot{\infty}$ & \\
\hline
\end{tabular}


$\begin{array}{lllll} & \ddot{z} & a & 0 & 0 \\ 0 & 0 & v & 0 & -1\end{array}$

$\begin{array}{lllll}0 & \infty & 0 & 0 & -1\end{array}$

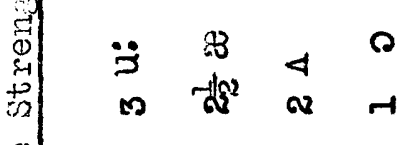

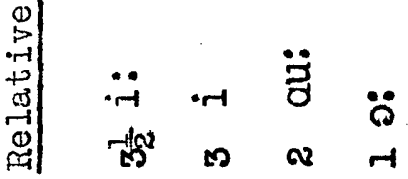

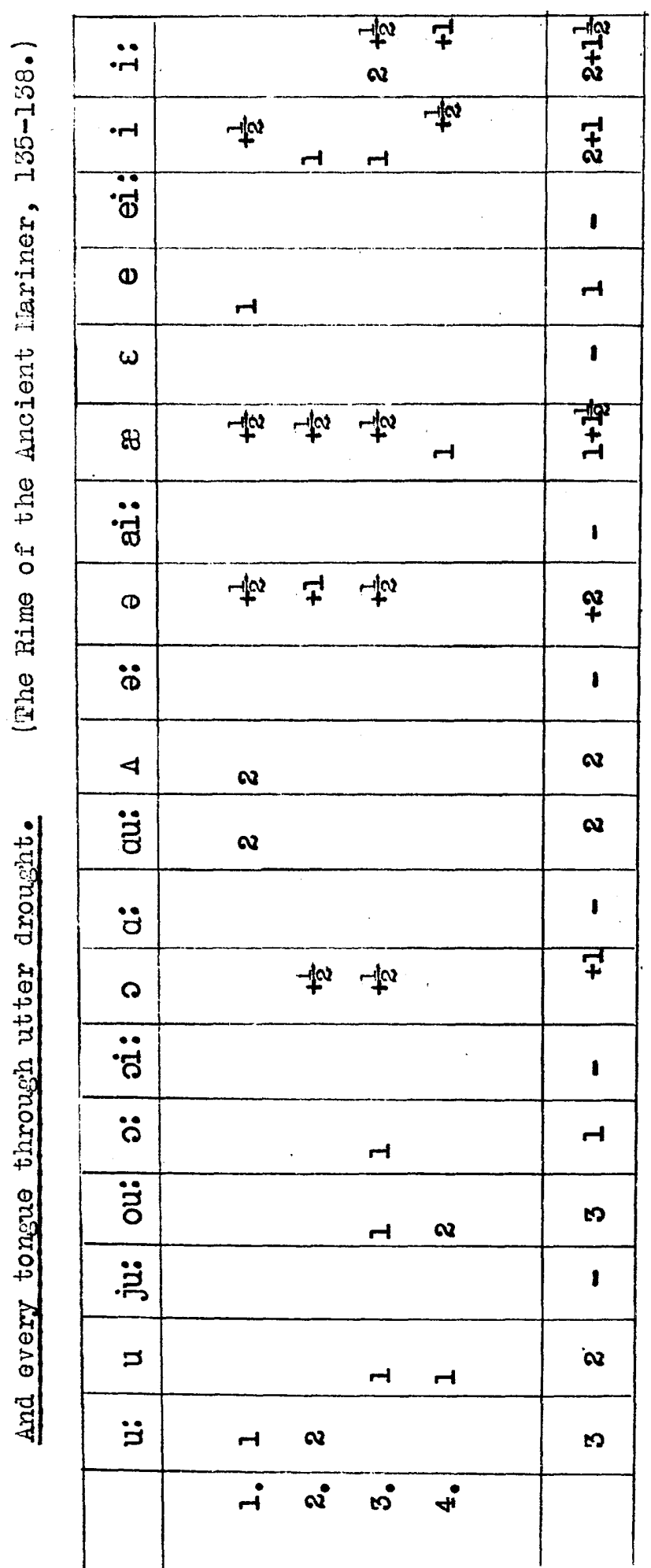




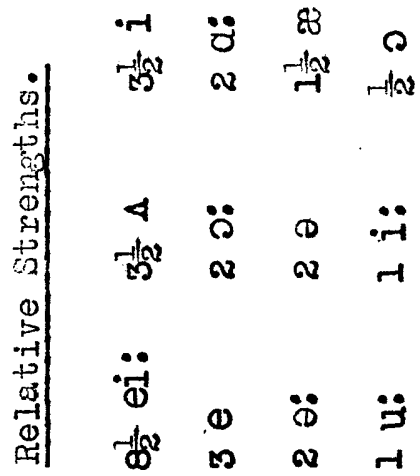

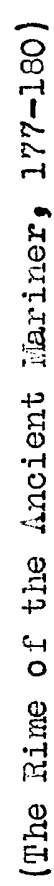

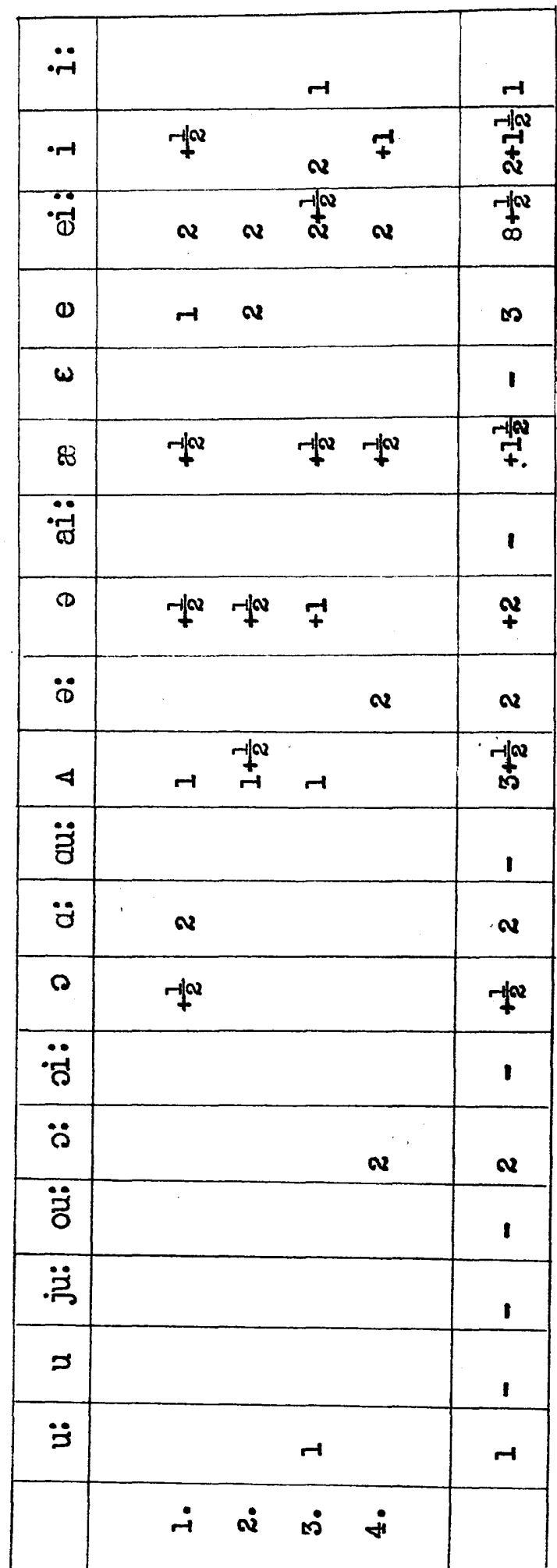




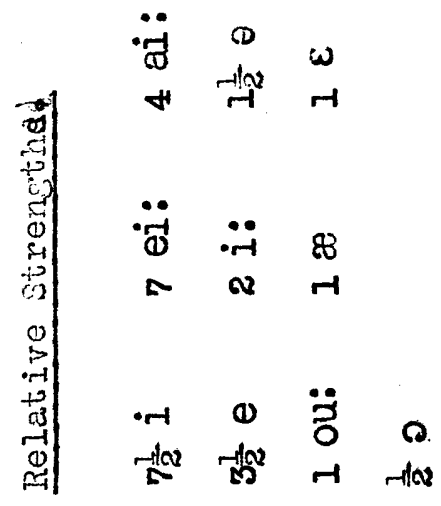

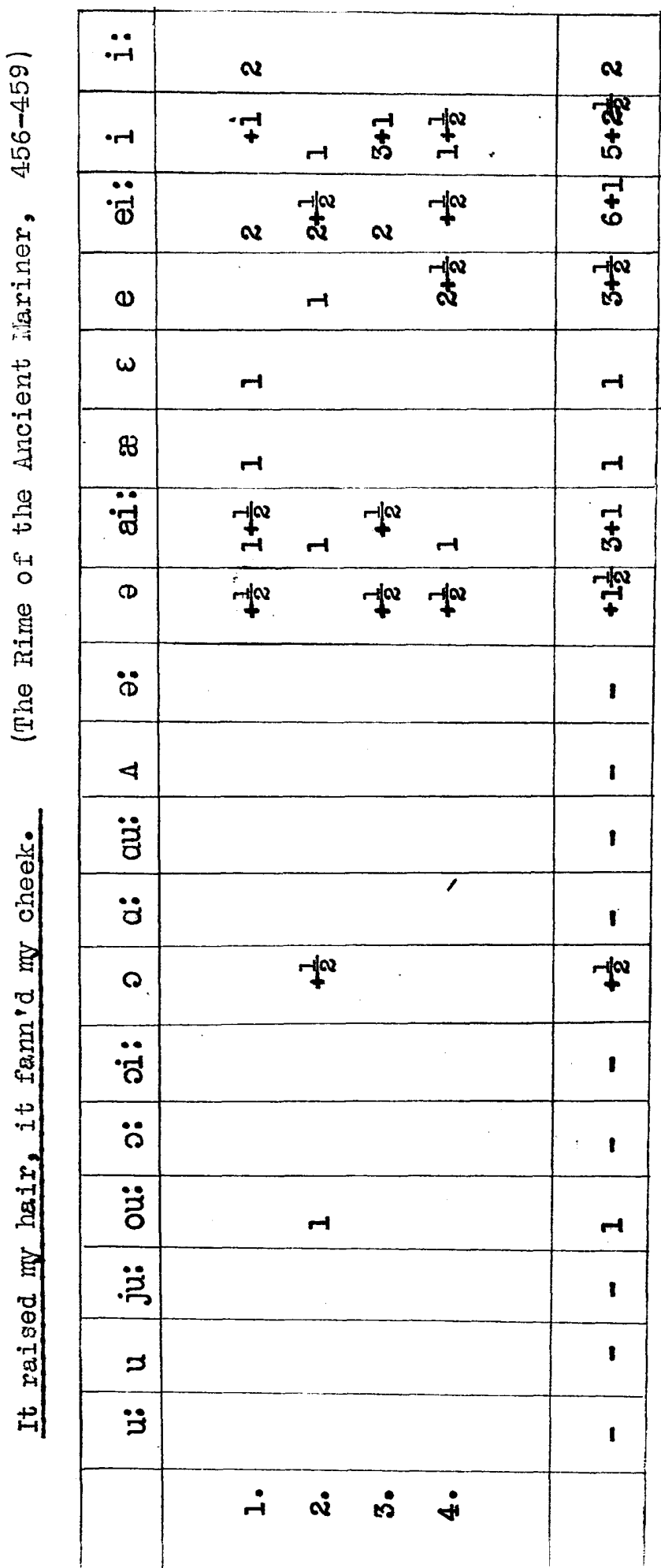



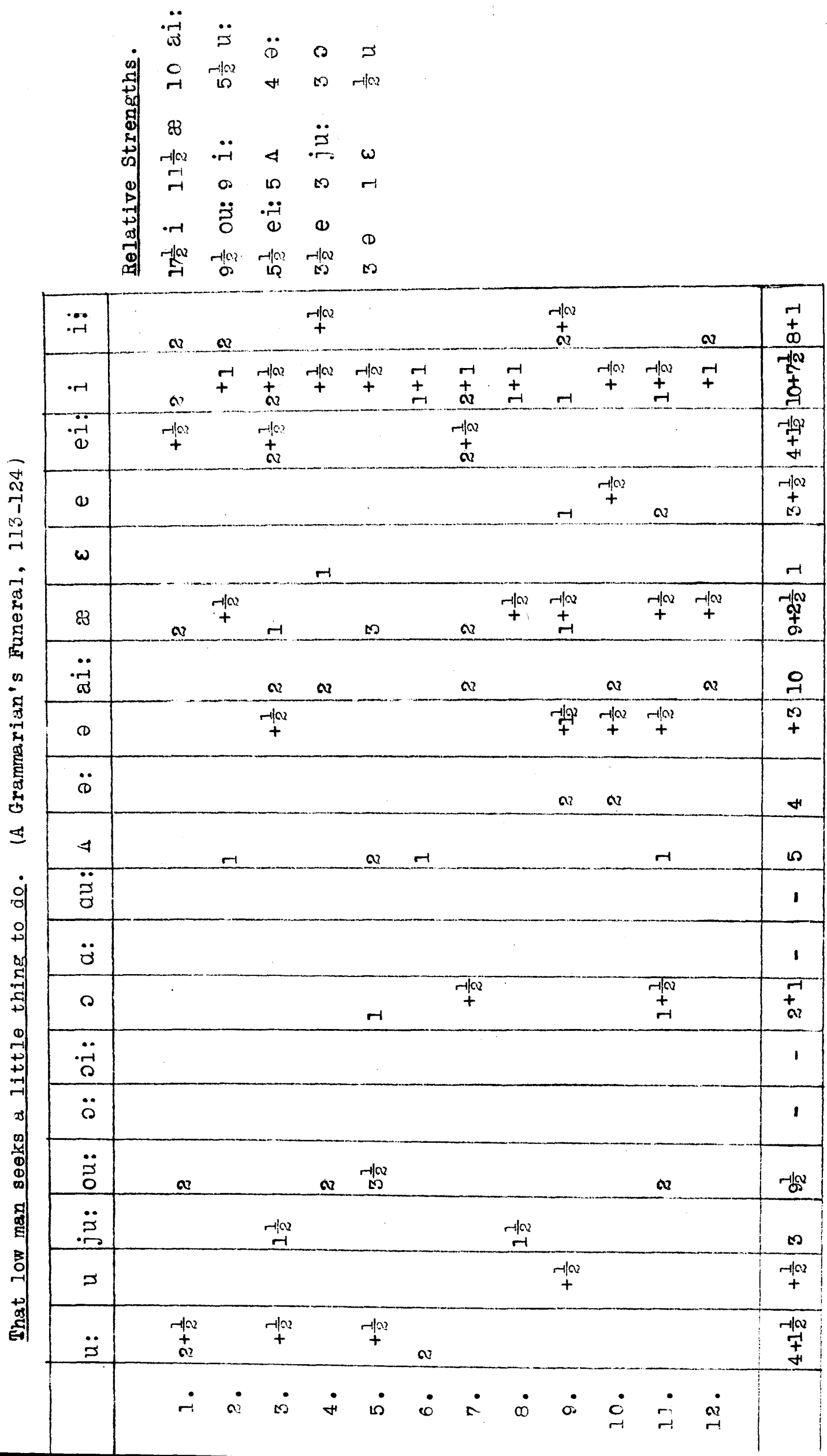


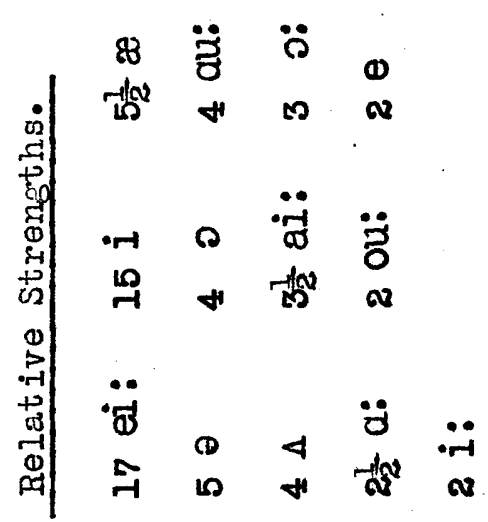

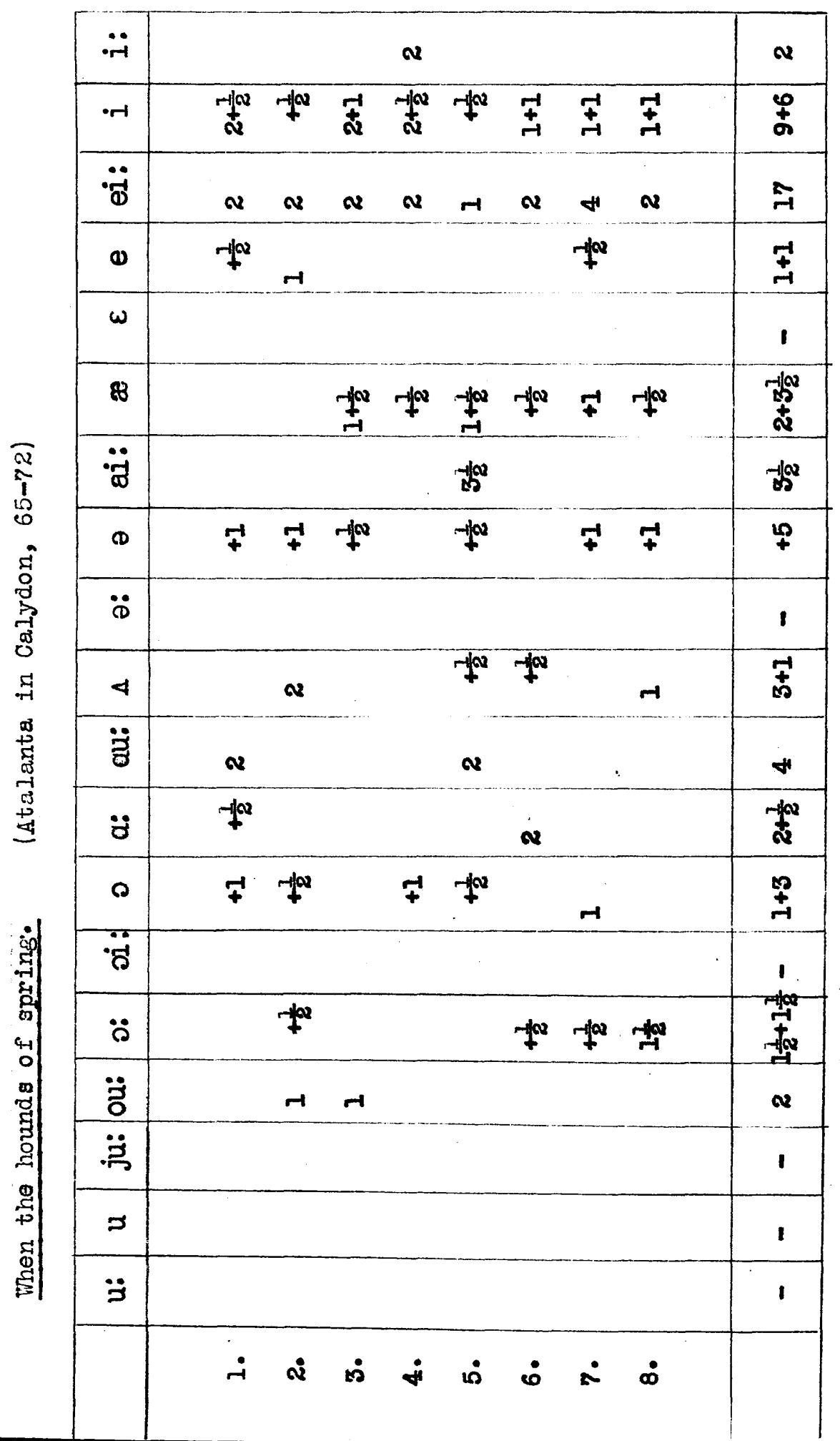




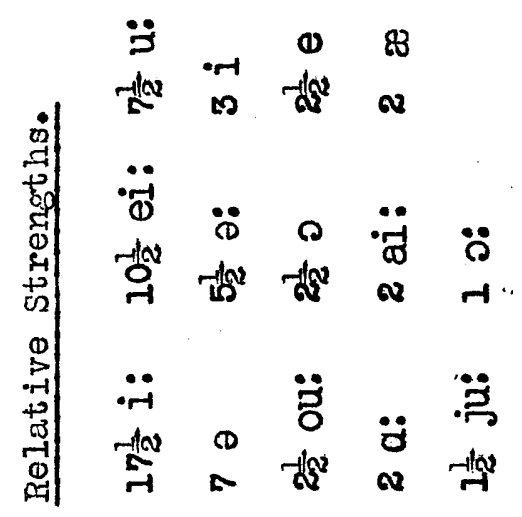

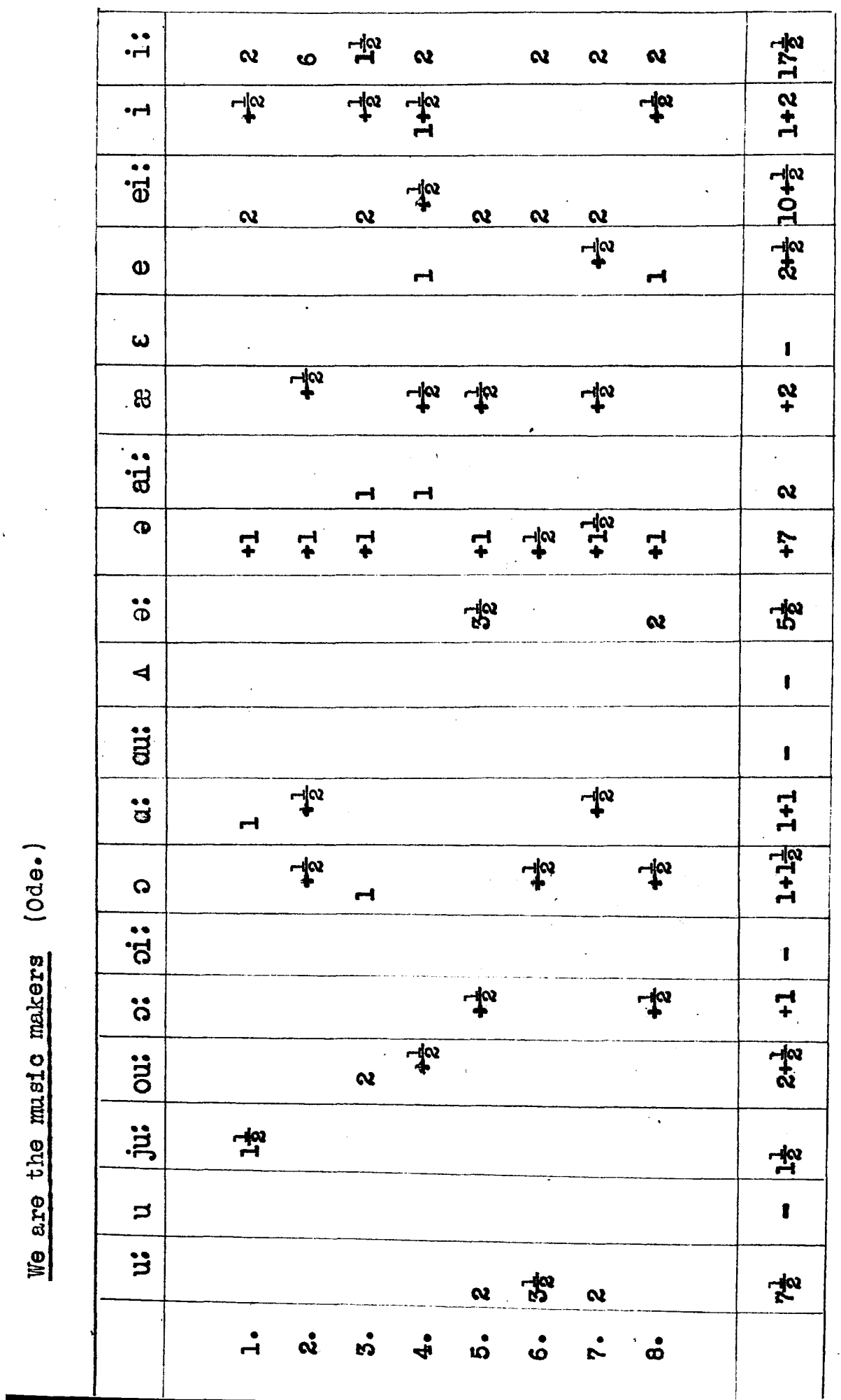



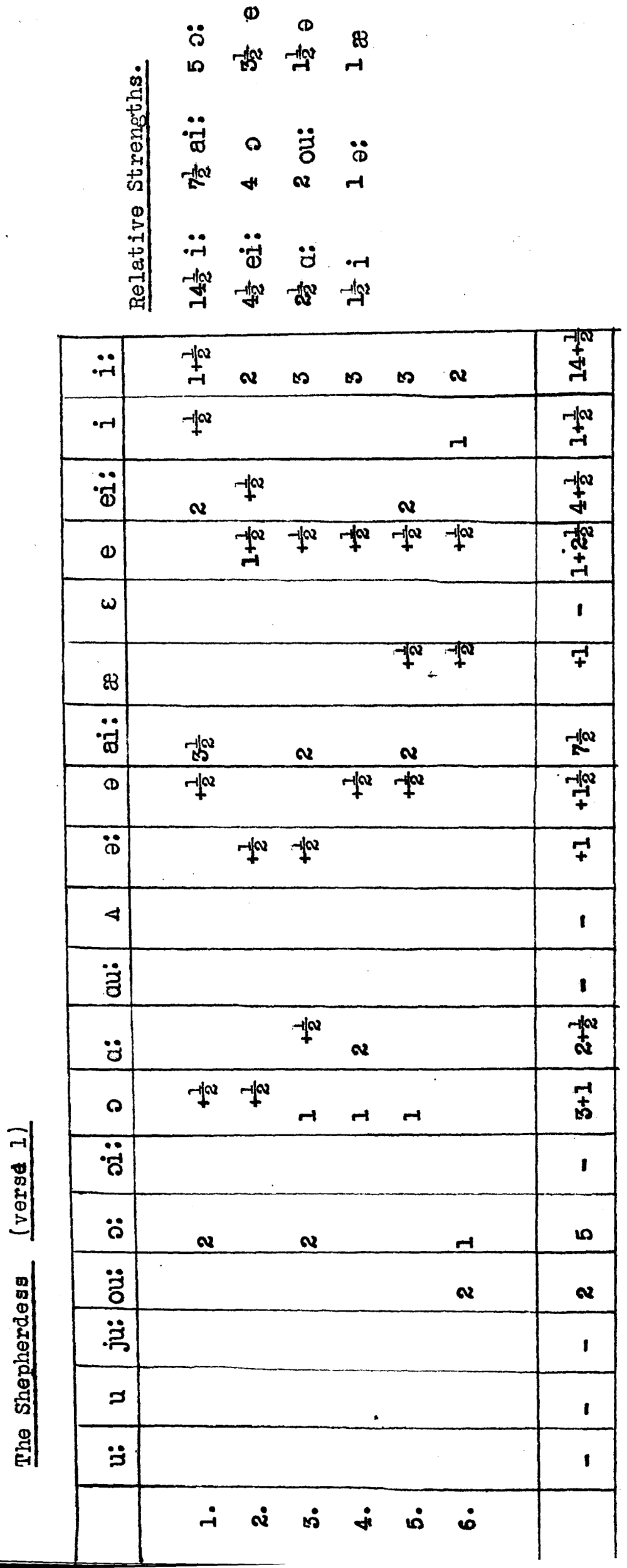


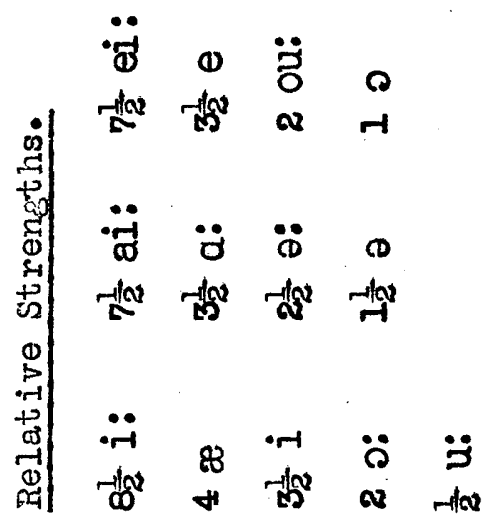

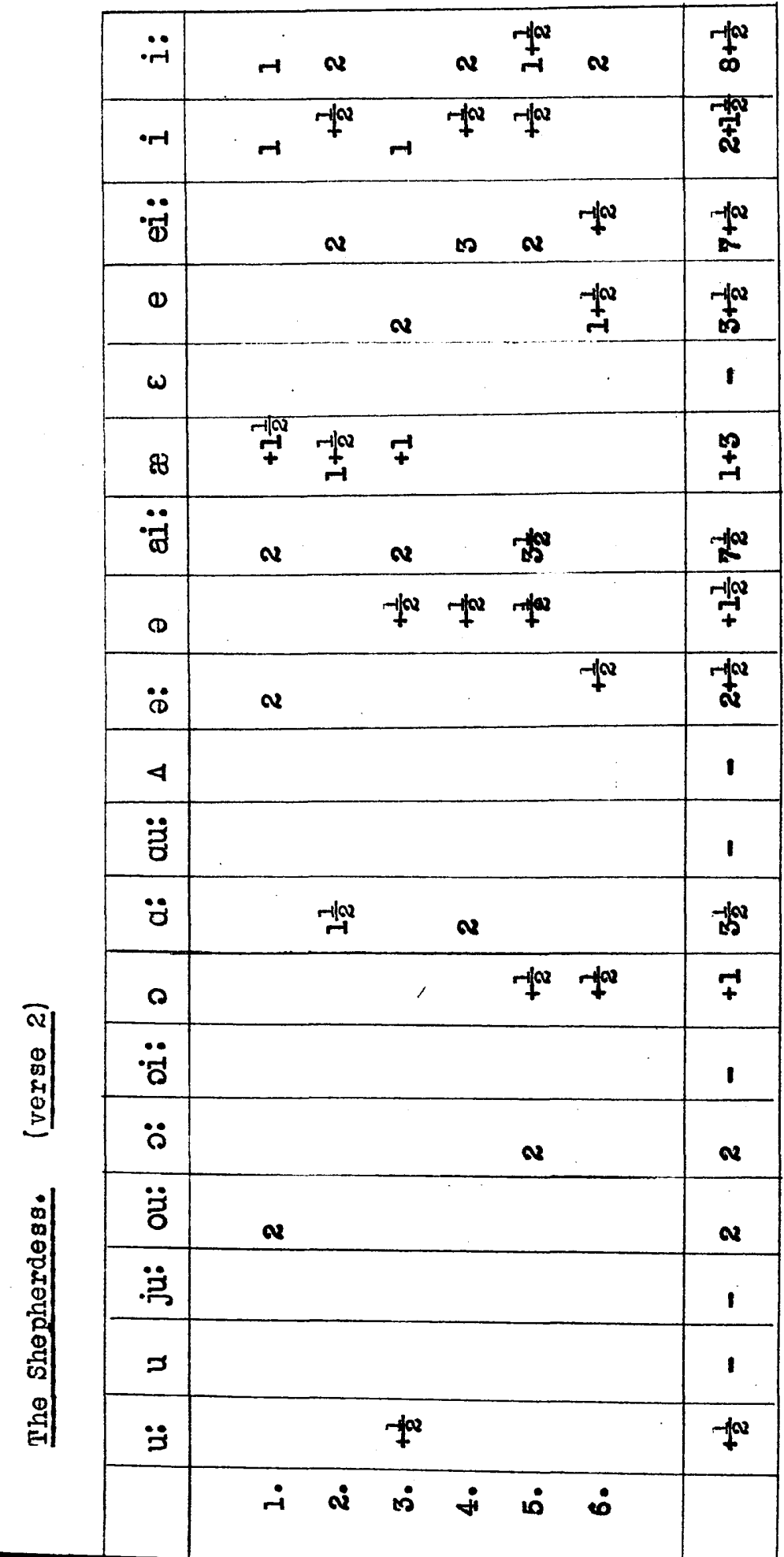




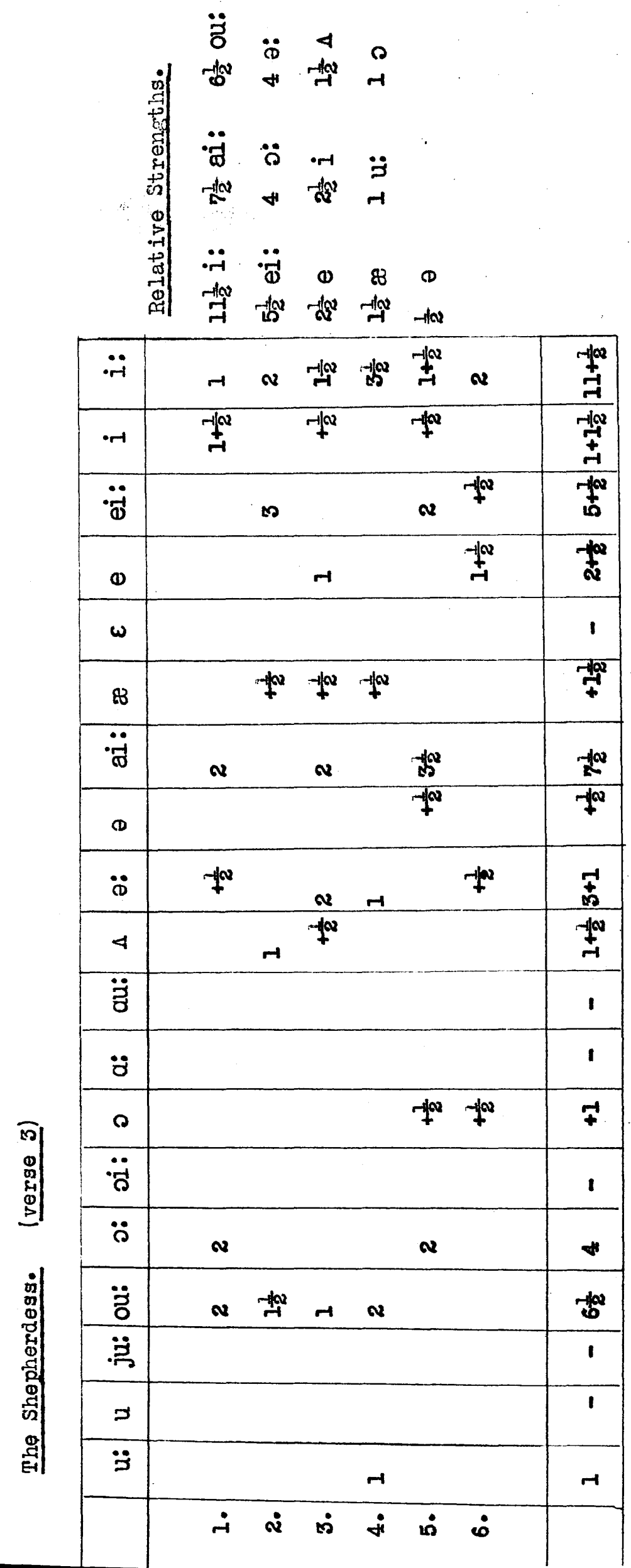




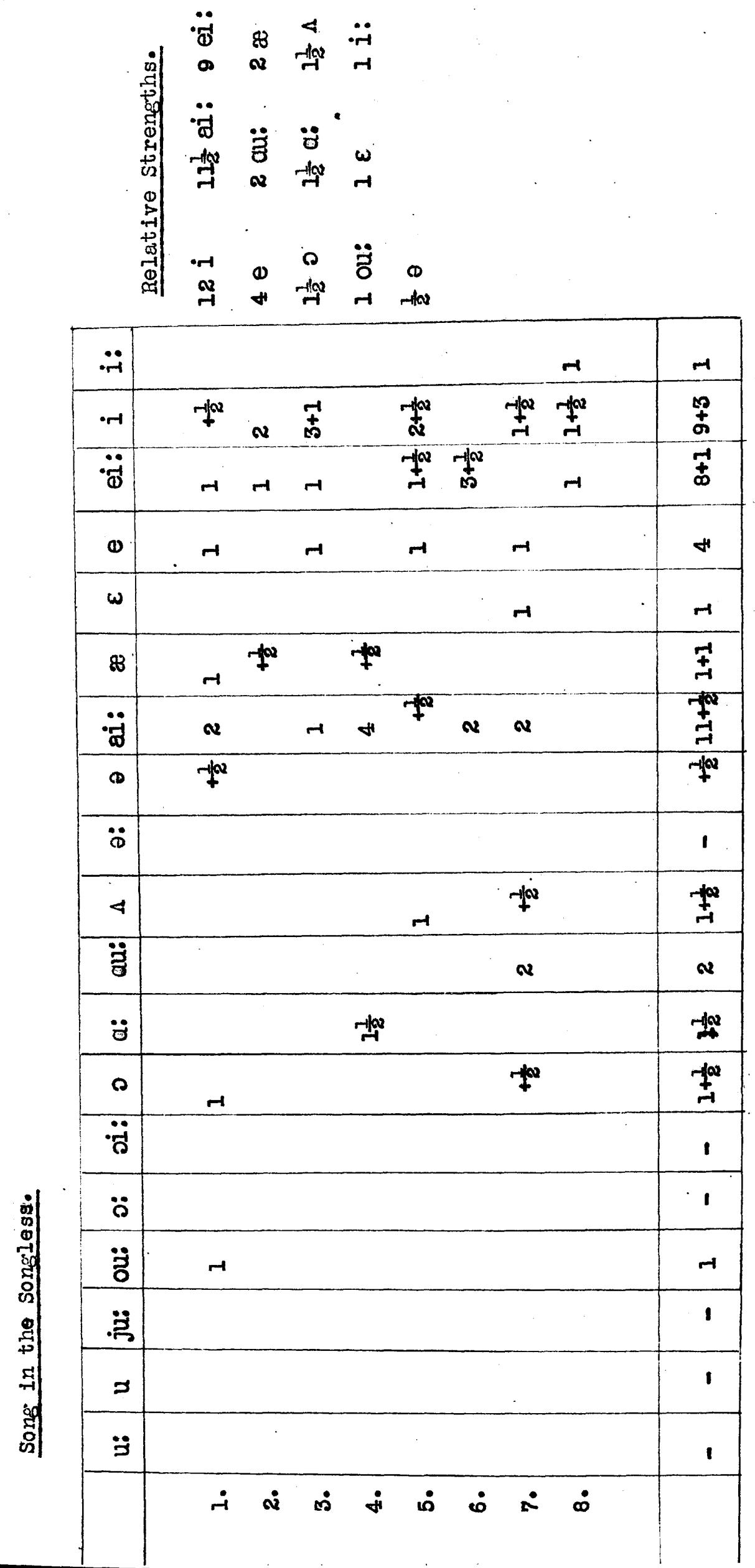




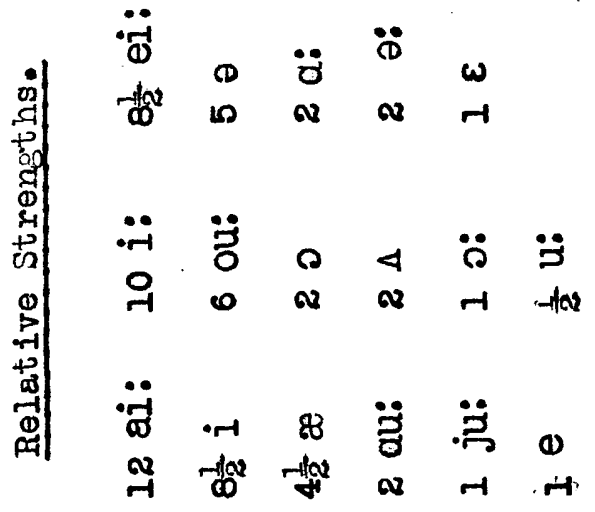

\begin{tabular}{|c|c|c|c|c|c|c|c|c|}
\hline$\ddot{-r}$ & & -1 & & 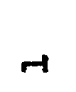 & $\frac{-1 \alpha}{\alpha}$ & $\stackrel{-1 \infty}{m}$ & $\boldsymbol{N}$ & † \\
\hline$\cdot-1$ & $+x^{x}$ & -1 & $\underset{+}{+}$ & $\stackrel{-10}{+}$ & -1 & $r$ & 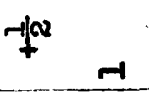 & $\begin{array}{c}-4 w^{2} \\
+ \\
0 \\
0\end{array}$ \\
\hline$\because 8$ & & Q & & $\stackrel{-1 \mid N}{\mathbb{N}}$ & $\boldsymbol{v}$ & & $v$ & $\stackrel{-10 x}{\infty}$ \\
\hline $\boldsymbol{0}$ & & $\rightarrow$ & & & & & & $\boldsymbol{H}$ \\
\hline $\boldsymbol{\omega}$ & & & & & & -1 & & -1 \\
\hline 88 & $+\infty$ & $+x$ & $\underset{⿱ ㇒}{-10 x}$ & +10 & & & $-7+2$ & 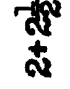 \\
\hline$\ddot{\infty}$ & $\Phi$ & $\mathbf{v}$ & $\infty$ & -1 & & $\boldsymbol{v}$ & & $\stackrel{\vartheta}{-1}$ \\
\hline D. & + & -190 & & & $-1 w$ & -10 & $\stackrel{-1}{+} \underset{+}{+}$ & LP \\
\hline$\ddot{8}$ & & & & & $\boldsymbol{v}$ & & & $\boldsymbol{v}$ \\
\hline 4 & $r$ & & & & & & $r$ & $v$ \\
\hline$\ddot{z}$ & & & & $\mathbf{v}$ & & & & $\boldsymbol{v}$ \\
\hline$\ddot{z}$ & $\boldsymbol{v}$ & & & & & & & $v$ \\
\hline 0 & & & & & & $H$ & $7+100$ & $\stackrel{+1}{+}$ \\
\hline$\ddot{\circ}$ & & & & & & & & 1 \\
\hline$\ddot{\circ}$ & & & & & $r$ & & & $r$ \\
\hline$\ddot{0}$ & & & & . & & & $\$$ & $\boldsymbol{\omega}$ \\
\hline$\ddot{g}$ & & & & & -1 & & & -1 \\
\hline $\boldsymbol{D}$ & & & & & & & & 1 \\
\hline$\ddot{3}$ & & & & & & $+\infty$ & & +40 \\
\hline & $\dot{-}$ & $\dot{0}$ & $\dot{0}$ & $\dot{H}$ & $\dot{0}$ & $\dot{0}$ & $\therefore \infty$ & \\
\hline
\end{tabular}




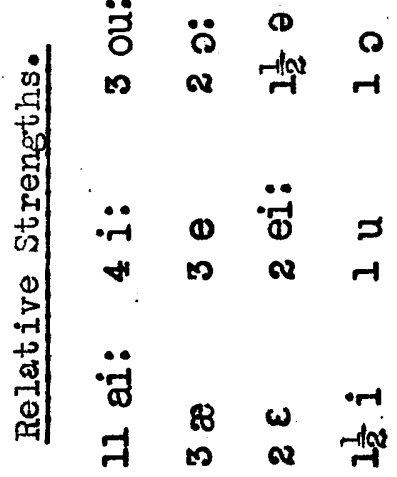

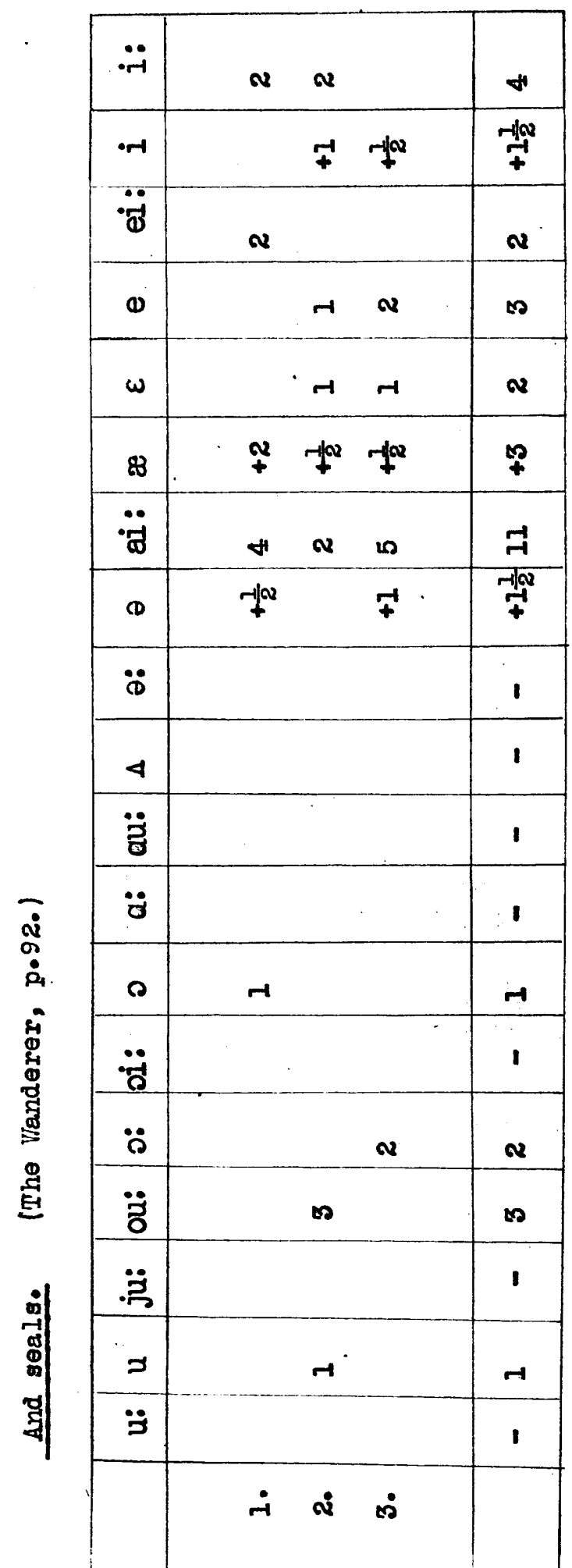




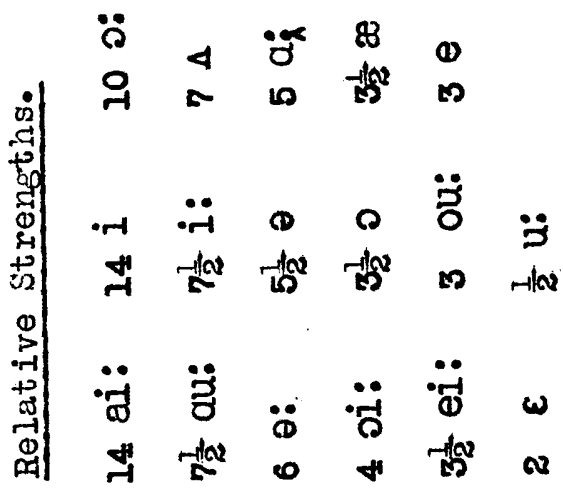

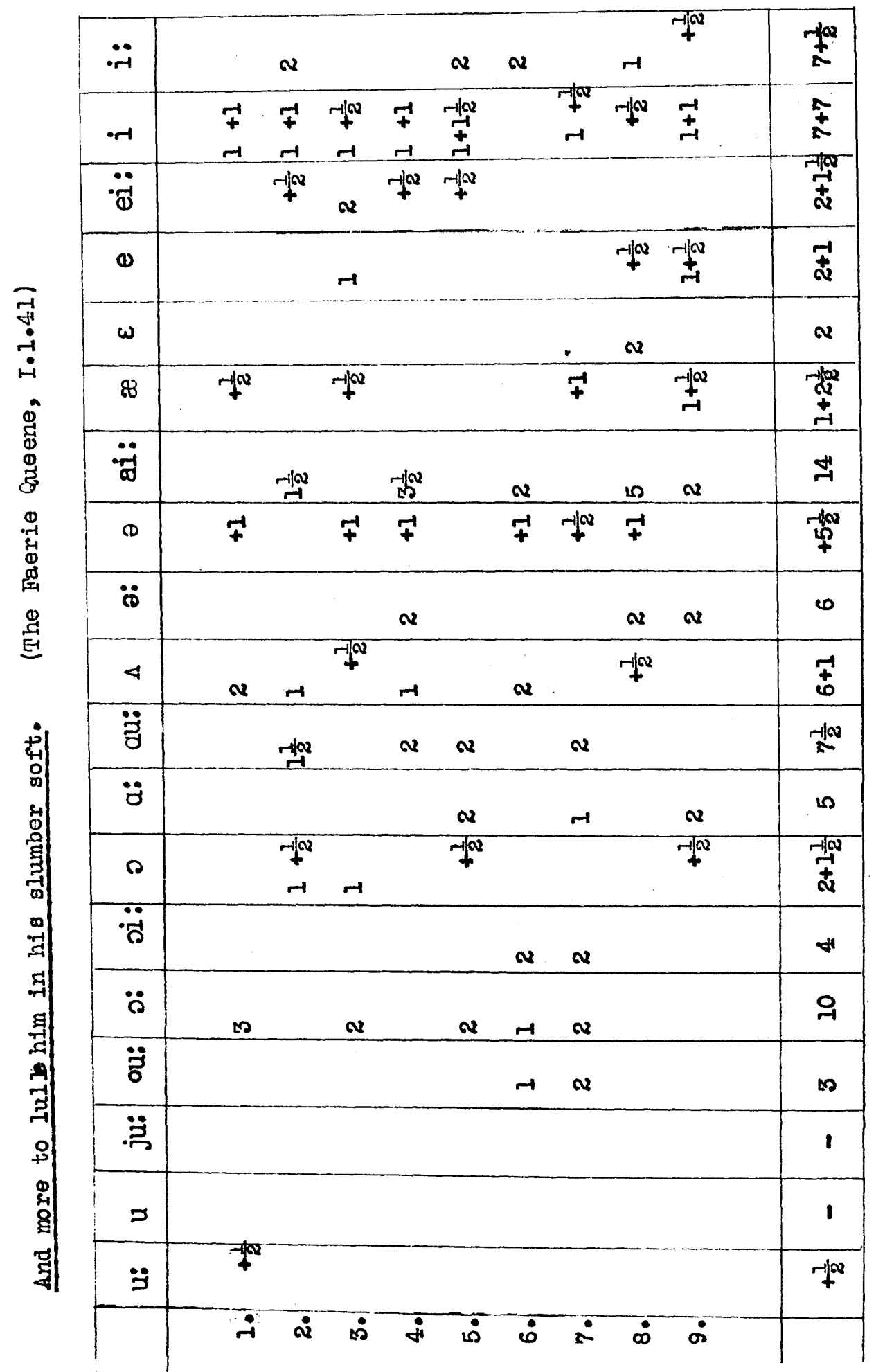




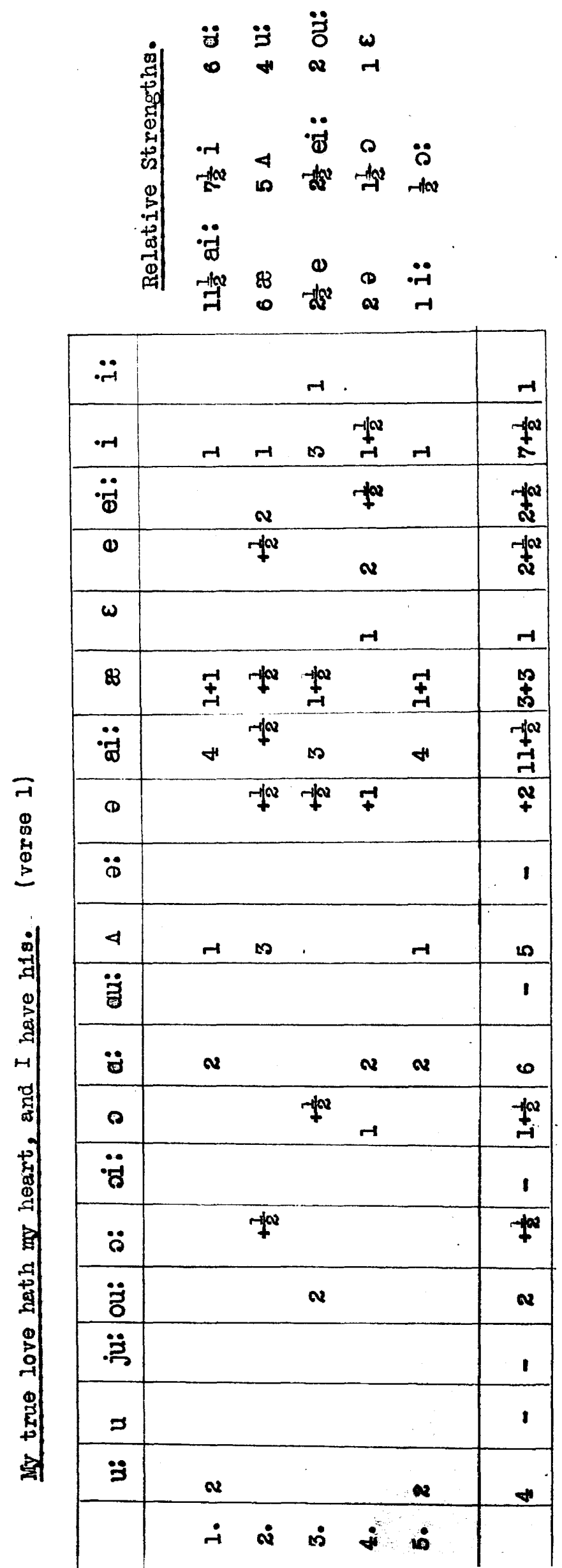




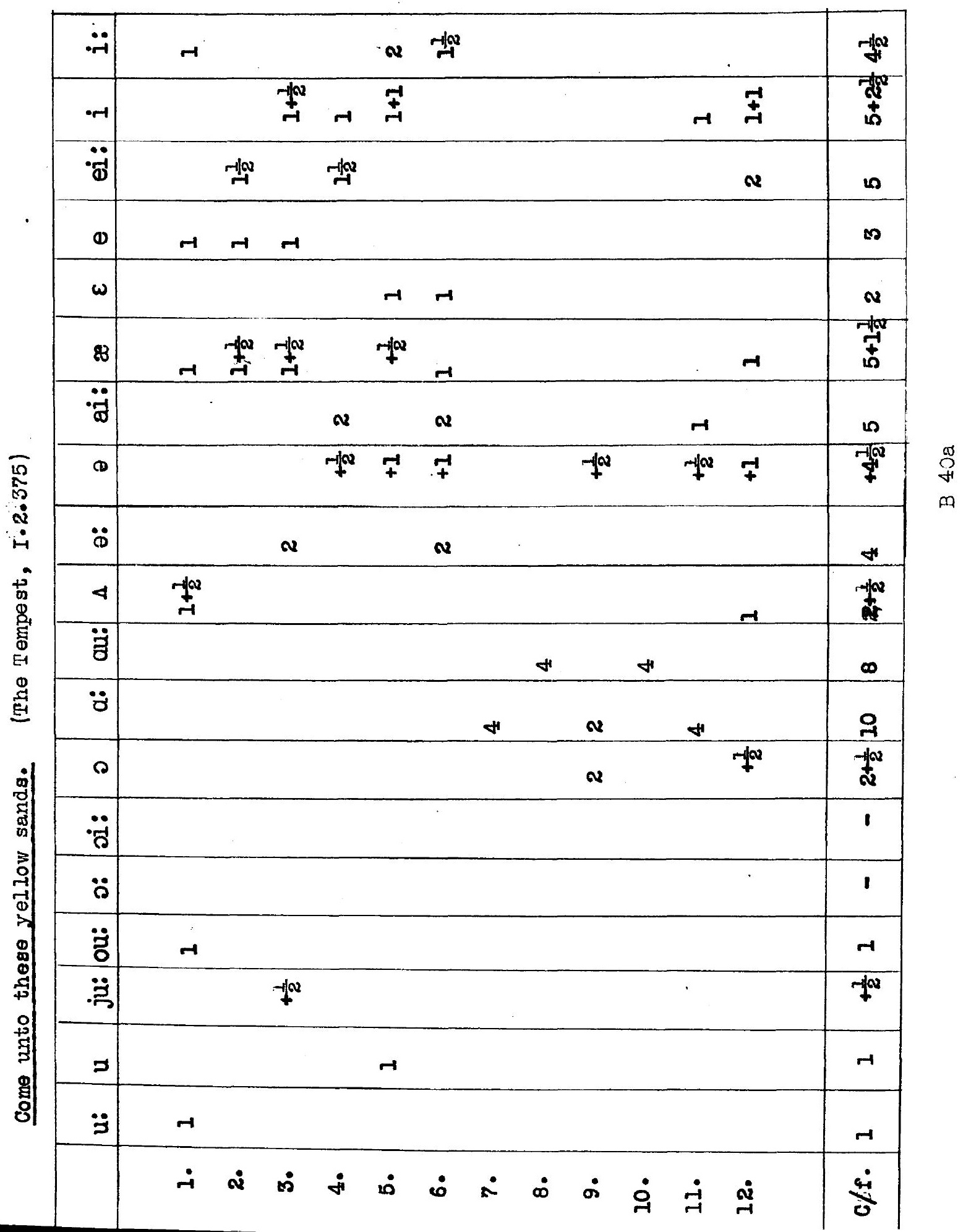




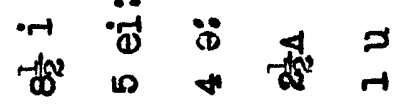

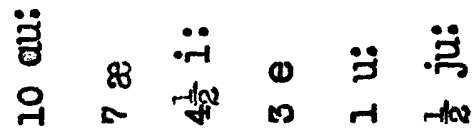

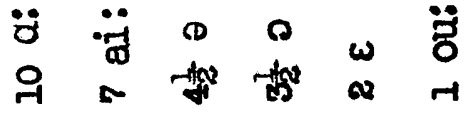

\begin{tabular}{|c|c|c|c|}
\hline$\because \ddot{r}$ & rida & & -yw \\
\hline$\cdot-1$ & 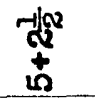 & -1 & $\begin{array}{c}-102 \\
+ \\
0 \\
0\end{array}$ \\
\hline$\ddot{0}$ & 10 & & in \\
\hline $\boldsymbol{\Phi}$ & $\infty$ & & $\infty$ \\
\hline $\boldsymbol{\omega}$ & $\mathbf{v}$ & & $\sim$ \\
\hline $\mathbb{8}$ & 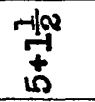 & $-1+\infty$ & $\underset{\mathbf{n}}{\mathbf{4}}$ \\
\hline$\ddot{\ddot{d}}$ & 10 & $\boldsymbol{v}$ & $\pi$ \\
\hline (D) & $\stackrel{r a}{+}$ & & 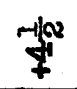 \\
\hline$\ddot{D}$ & 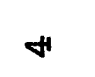 & & $\$$ \\
\hline 4 & $\frac{r-1}{\alpha}$ & & $\frac{-1}{a}$ \\
\hline ฉุ̈ & $\infty$ & $\mathbf{v}$ & 옥 \\
\hline$\ddot{\partial}$ & 욱 & & 욱 \\
\hline م & $\frac{+10}{\alpha}$ & -1 & $\frac{1}{60}^{+\infty}$ \\
\hline "ैं & 1 & & 1 \\
\hline$\ddot{0}$ & 1 & & 1 \\
\hline$\ddot{3}$ & $\pi$ & & 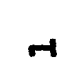 \\
\hline$\ddot{\ddot{\partial}}$ & $+\infty$ & & 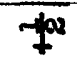 \\
\hline $\boldsymbol{D}$ & -1 & & -1 \\
\hline$\ddot{3}$ & -1 & & $r$ \\
\hline & $\stackrel{\dot{4}}{m}$ & $\dot{\theta}$ & \\
\hline
\end{tabular}




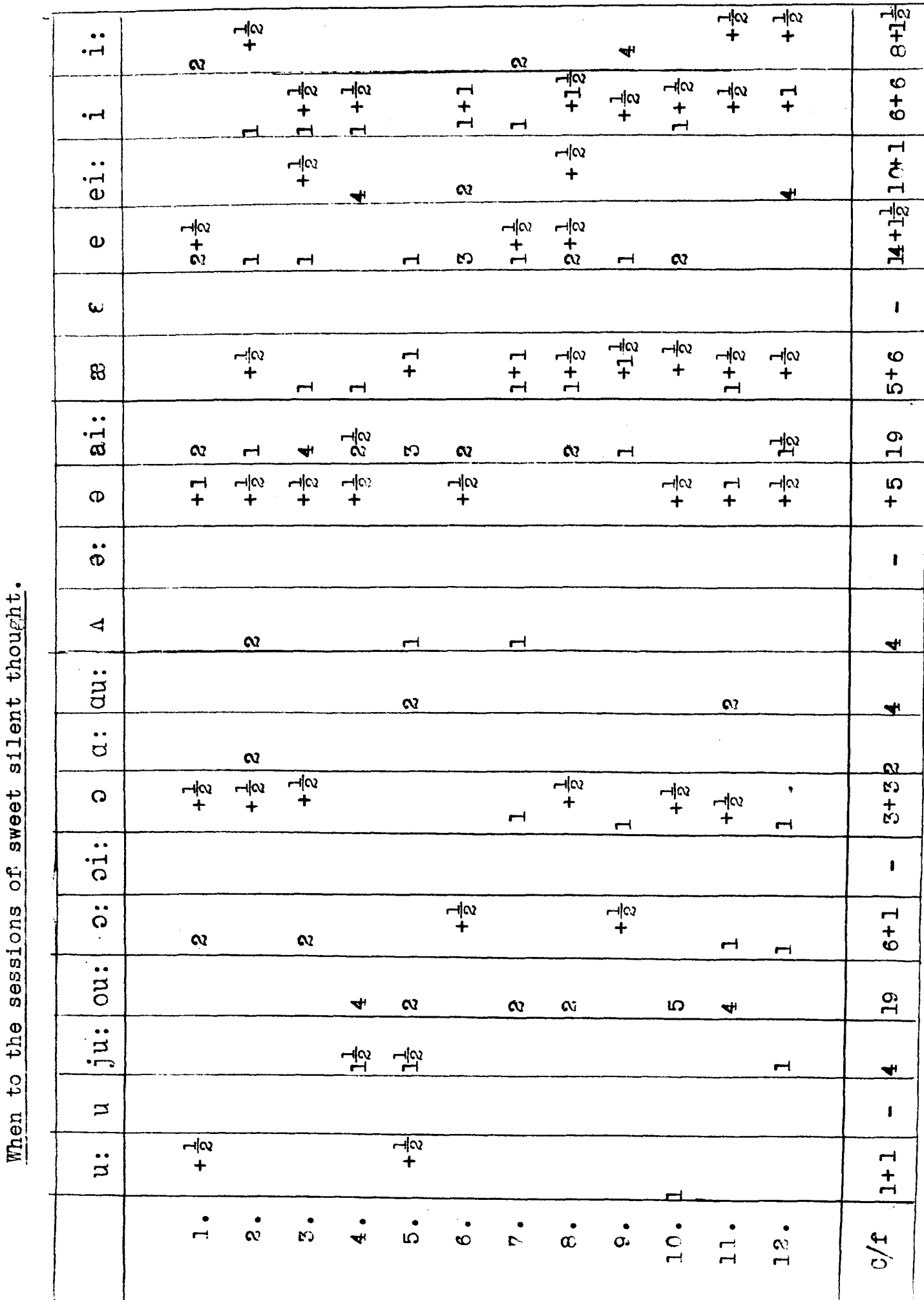




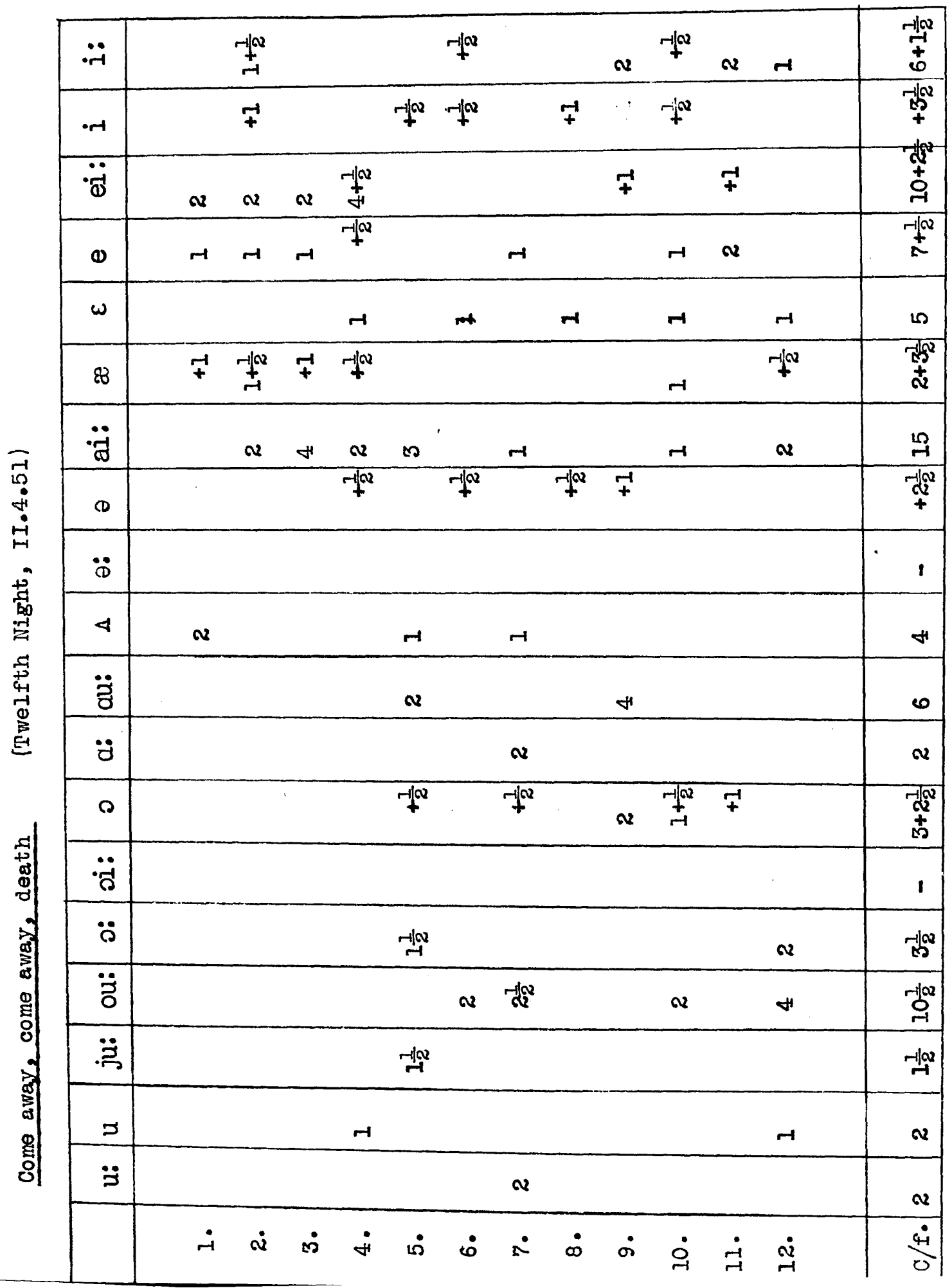




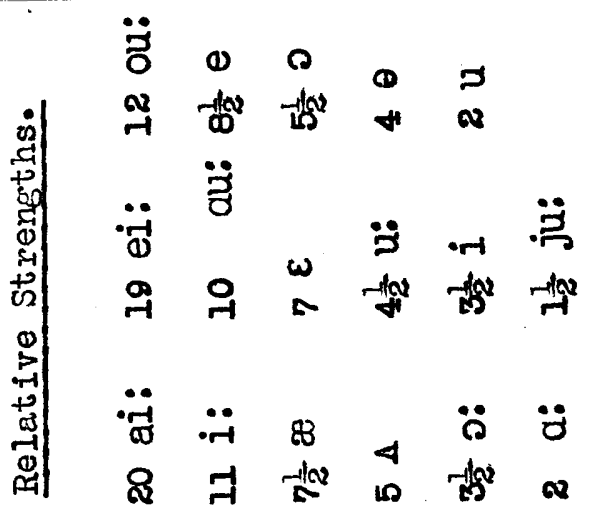

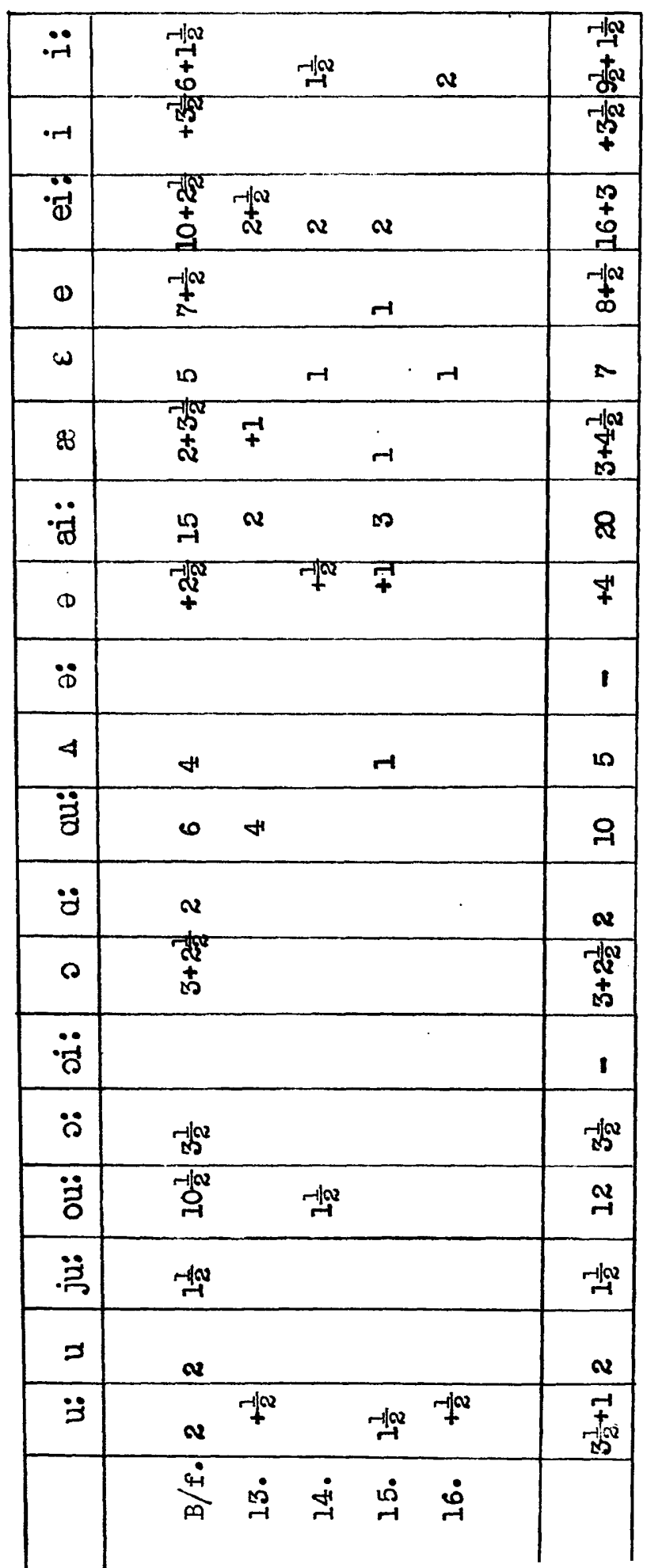




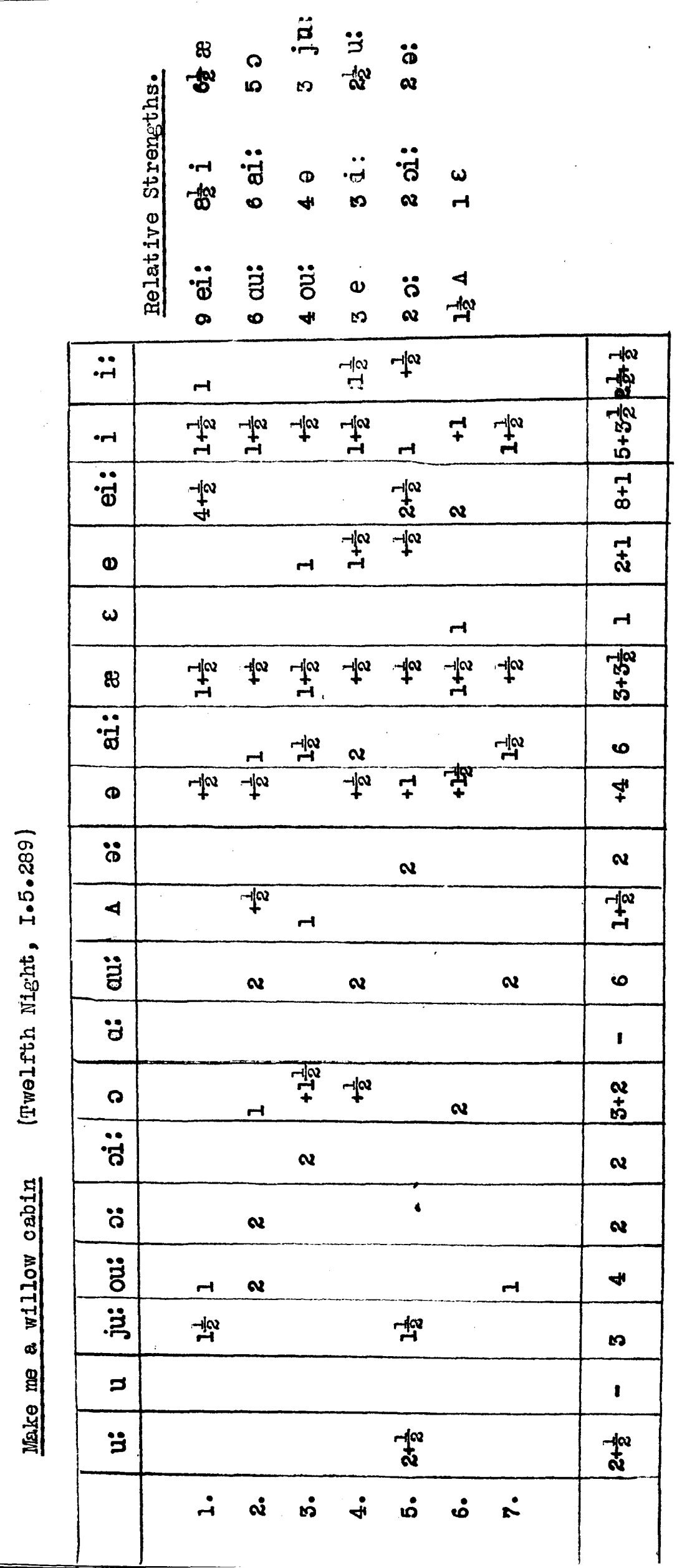




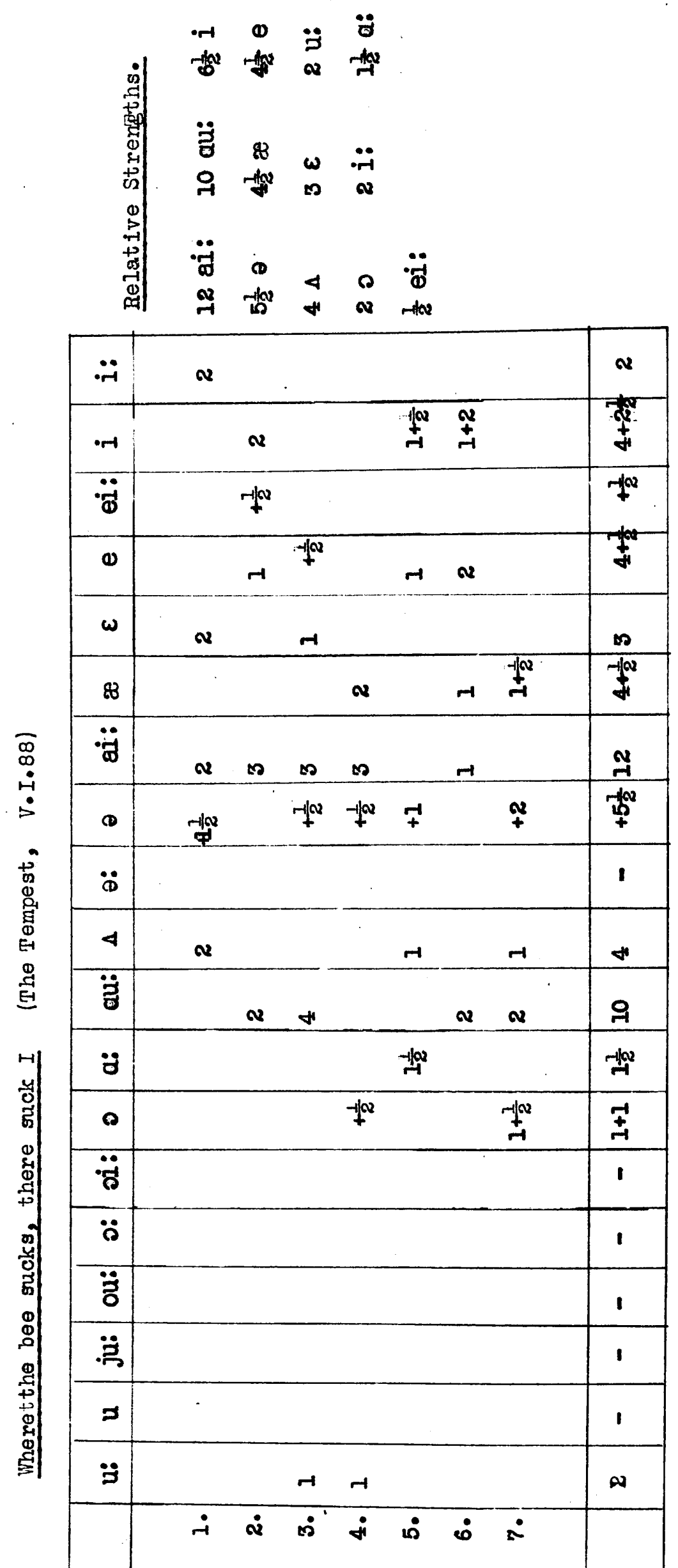




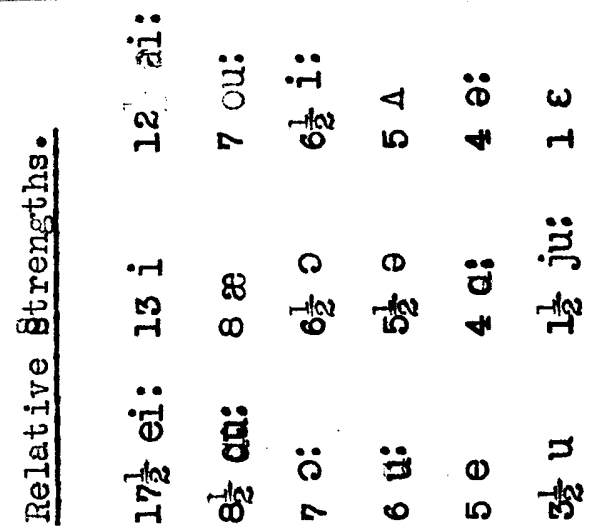

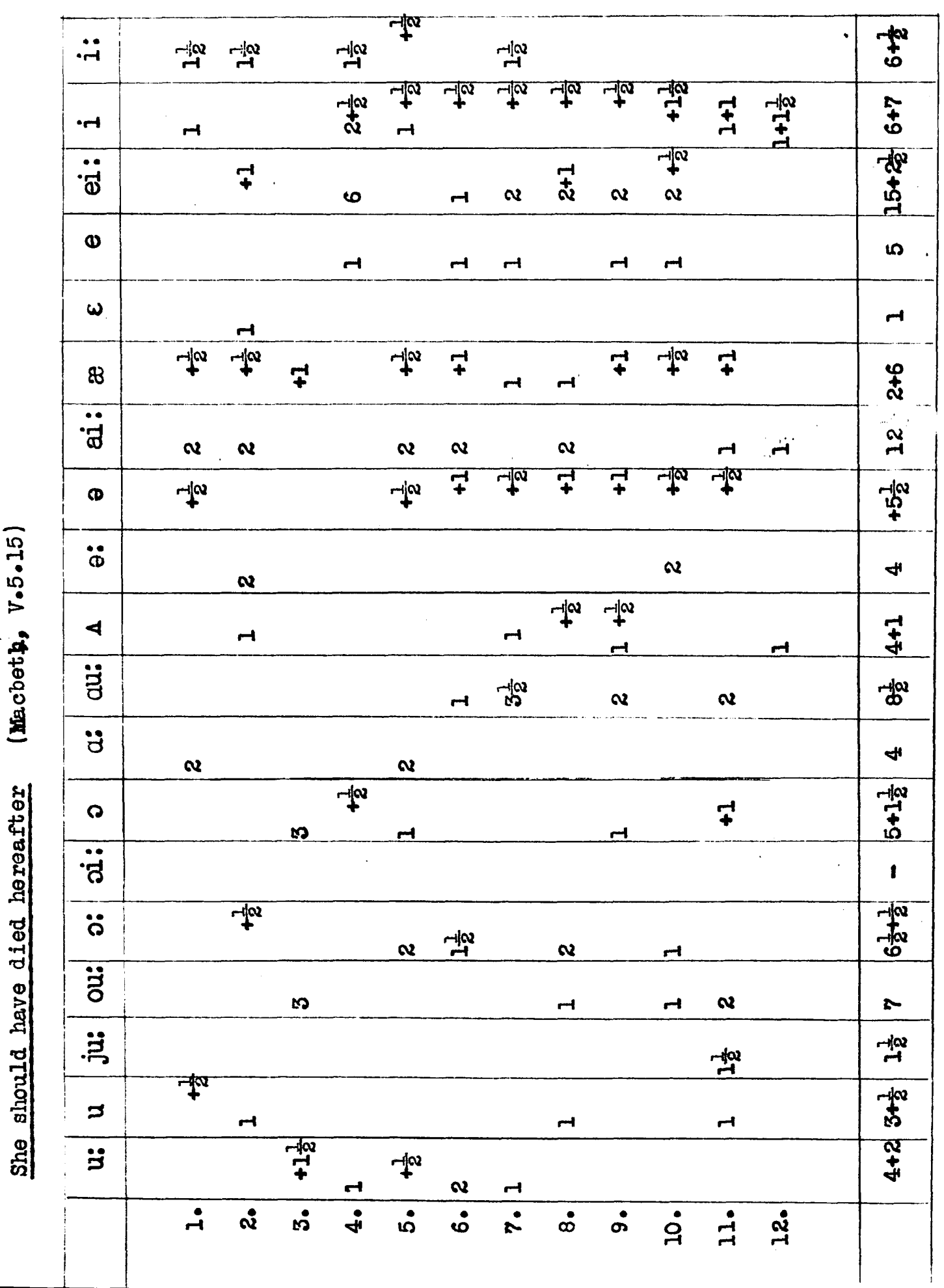


$\begin{array}{llllll}\because & 0 & 0 & 4 & \ddot{j} & \ddot{\rightrightarrows}\end{array}$

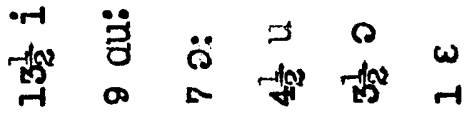

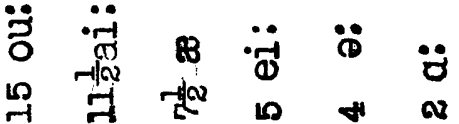

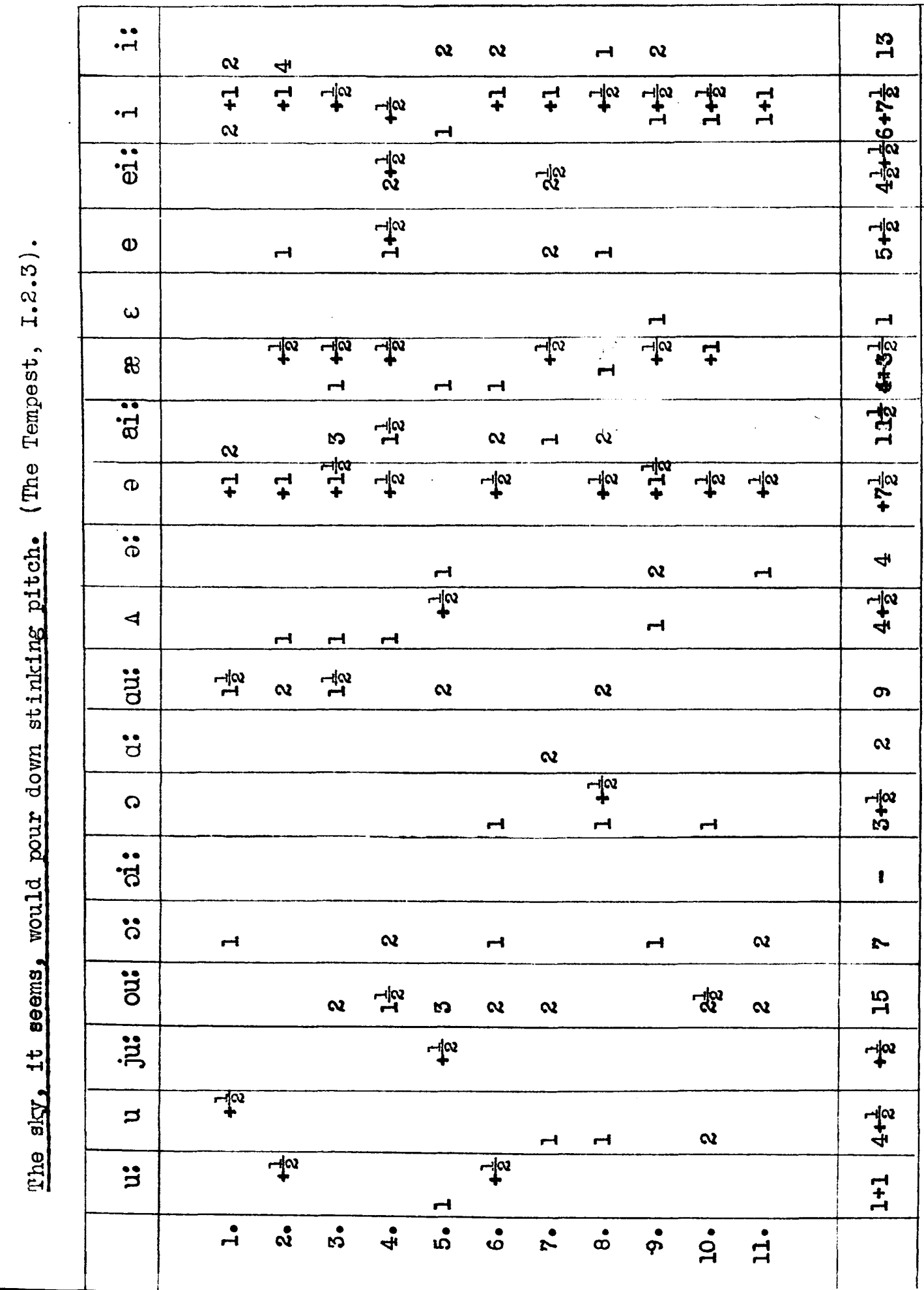




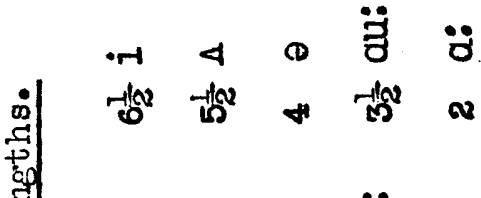

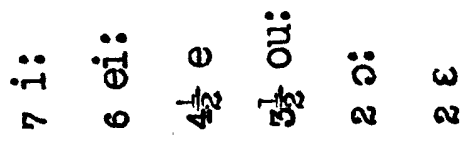

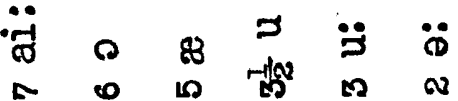

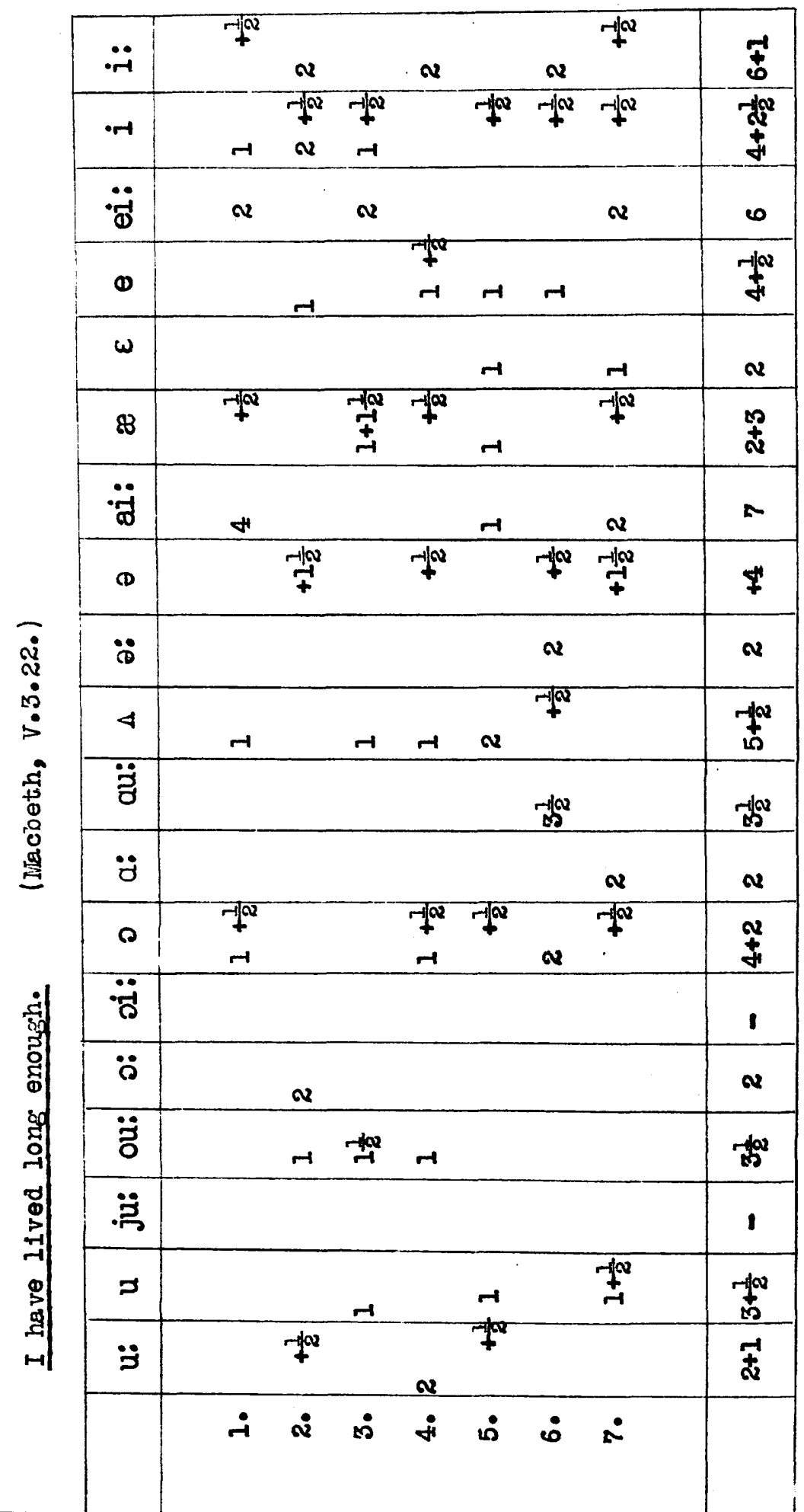




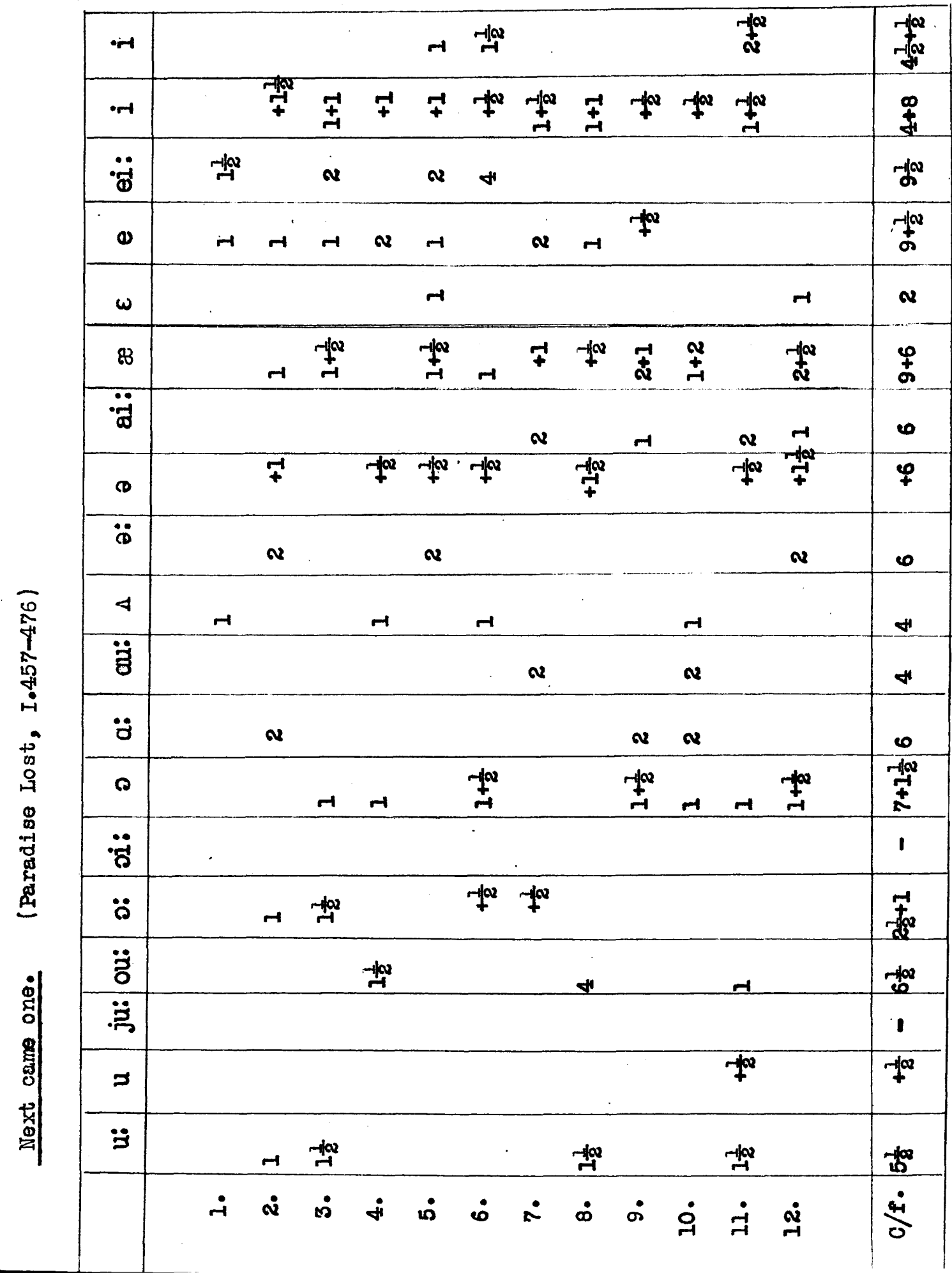




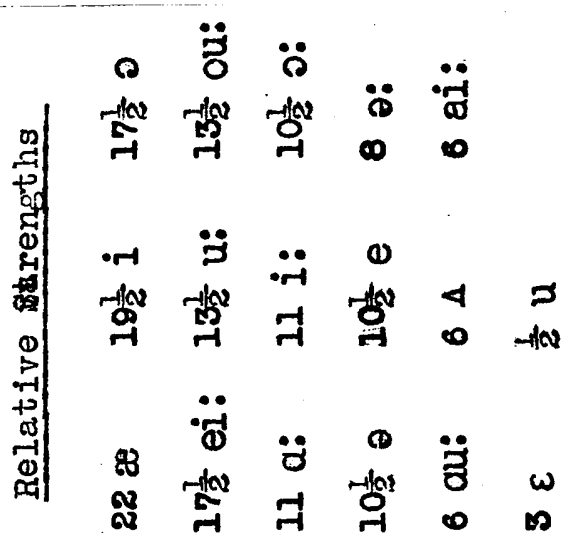

\begin{tabular}{|c|c|c|c|c|c|c|c|c|c|c|}
\hline$\ddot{-r}$ & $\begin{array}{ll}-10 \\
-10 \\
+10\end{array}$ & 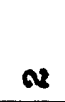 & $\stackrel{-H}{-\mu}$ & + & $r$ & & & & $t^{\prime \prime \omega}$ & $\begin{array}{l}q \\
+ \\
\dot{\alpha}\end{array}$ \\
\hline$\cdot r$ & 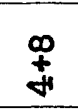 & 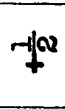 & & -1 & + & $\stackrel{+10}{+}$ & $\stackrel{+\infty}{+}$ & $\underset{+}{+\infty}$ & 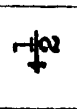 & 觜 \\
\hline$\ddot{\ddot{d}}$ & નુ & & $r$ & $\vec{t}$ & $\boldsymbol{v}$ & $\boldsymbol{v}$ & & & & $\mathbb{f l}^{+1}$ \\
\hline $\boldsymbol{\Phi}$ & $\frac{r a x}{2}$ & & & 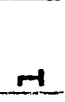 & & & & & & $\frac{+100}{9}$ \\
\hline$\omega$ & $\boldsymbol{v}$ & & & & & & $H$ & & & $\infty$ \\
\hline 83 & $\stackrel{\varphi}{\phi}$ & $\underset{+}{-1 / x}$ & & +100 & $-f^{\infty}$ & $\stackrel{-10}{\stackrel{x}{r}}$ & 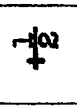 & + & $\stackrel{+\infty}{+}$ & $\underset{7}{7}$ \\
\hline 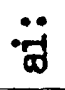 & $\boldsymbol{\omega}$ & & & & & & & & . & 0 \\
\hline (1) & $\varphi$ & & $7+2$ & -10 & $\mp$ & -100 & & $\underset{\Psi}{\Psi}$ & & - \\
\hline$\ddot{8}$ & $\boldsymbol{\omega}$ & & & & & & $\sim$ & & & $\infty$ \\
\hline 4 & A & & & $r$ & & & -1 & & & $\boldsymbol{0}$ \\
\hline$\ddot{3}$ & $\$$ & & $\boldsymbol{v}$ & & & & & . & & $\infty$ \\
\hline$\ddot{d}$ & $\omega$ & م & & & & & & & & $\vec{F}$ \\
\hline$\curvearrowright$ & $\stackrel{+a}{ \pm}$ & 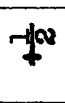 & $\underset{+}{+1}$ & & $v$ & -1 & $\underset{-1}{-10}$ & $\boldsymbol{N}$ & & $\underset{-1}{ \pm}$ \\
\hline$\ddot{~} \ddot{\circ}$ & 1 & & & & & & & & & 1 \\
\hline$\ddot{\circ}$ & 敨 & & 禁 & $v$ & & $\boldsymbol{v}$ & -10 & 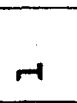 & & 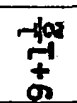 \\
\hline :̊̈ & ex & & $\infty$ & & & & $\boldsymbol{\alpha}$ & $\boldsymbol{v}$ & & ली \\
\hline 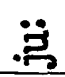 & 1 & & & & & & & & & 1 \\
\hline$\Rightarrow$ & $+\infty$ & & & & & & & & & $7 x$ \\
\hline$\ddot{3}$ & 势 & $\boldsymbol{\alpha}$ & & & सू & $r^{\prime a r}$ & $-1+\infty$ & & $\stackrel{-f a q}{-19}$ & $\underset{-1}{d x}$ \\
\hline & $\stackrel{4}{m}$ & $\dot{\infty}$ & $\stackrel{\leftrightarrow}{+}$ & $\stackrel{\dot{r}}{\dot{r}}$ & $\underset{-1}{\dot{0}}$ & $\dot{a}$ & $\underset{\sim}{\dot{\infty}}$ & $\dot{\sigma}$ & $\dot{8}$ & \\
\hline
\end{tabular}




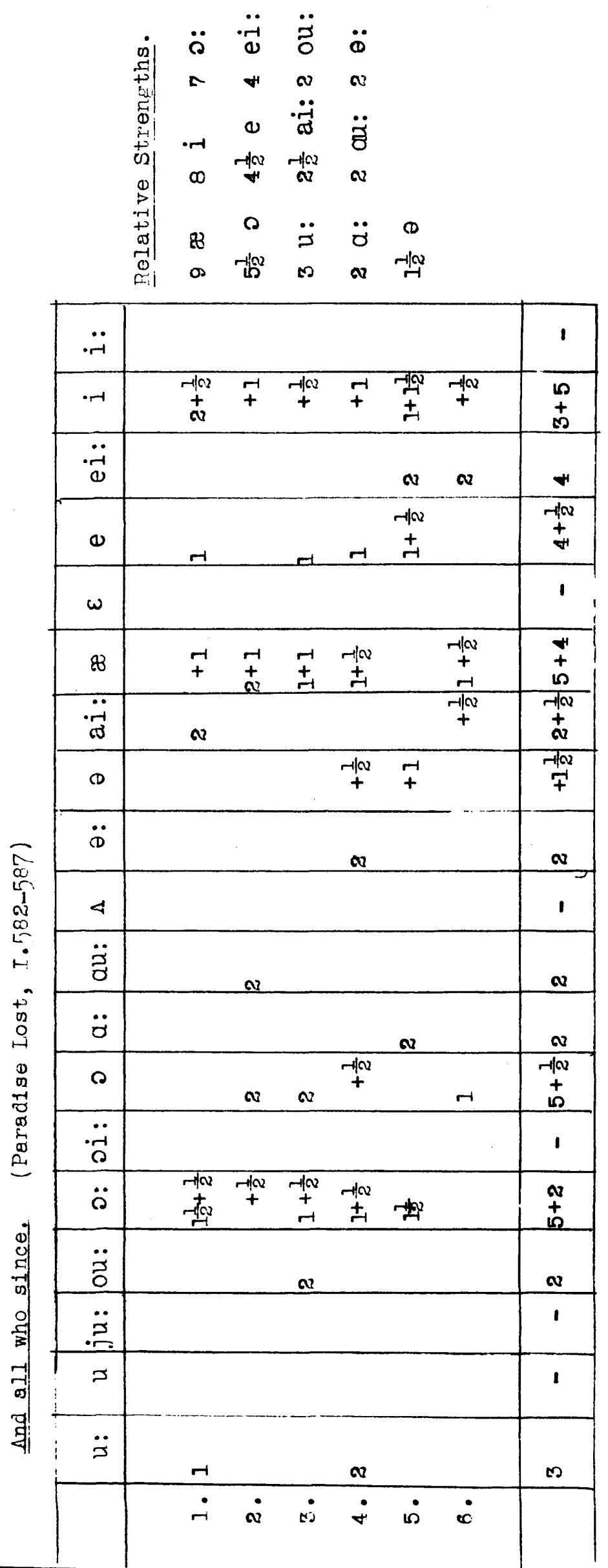




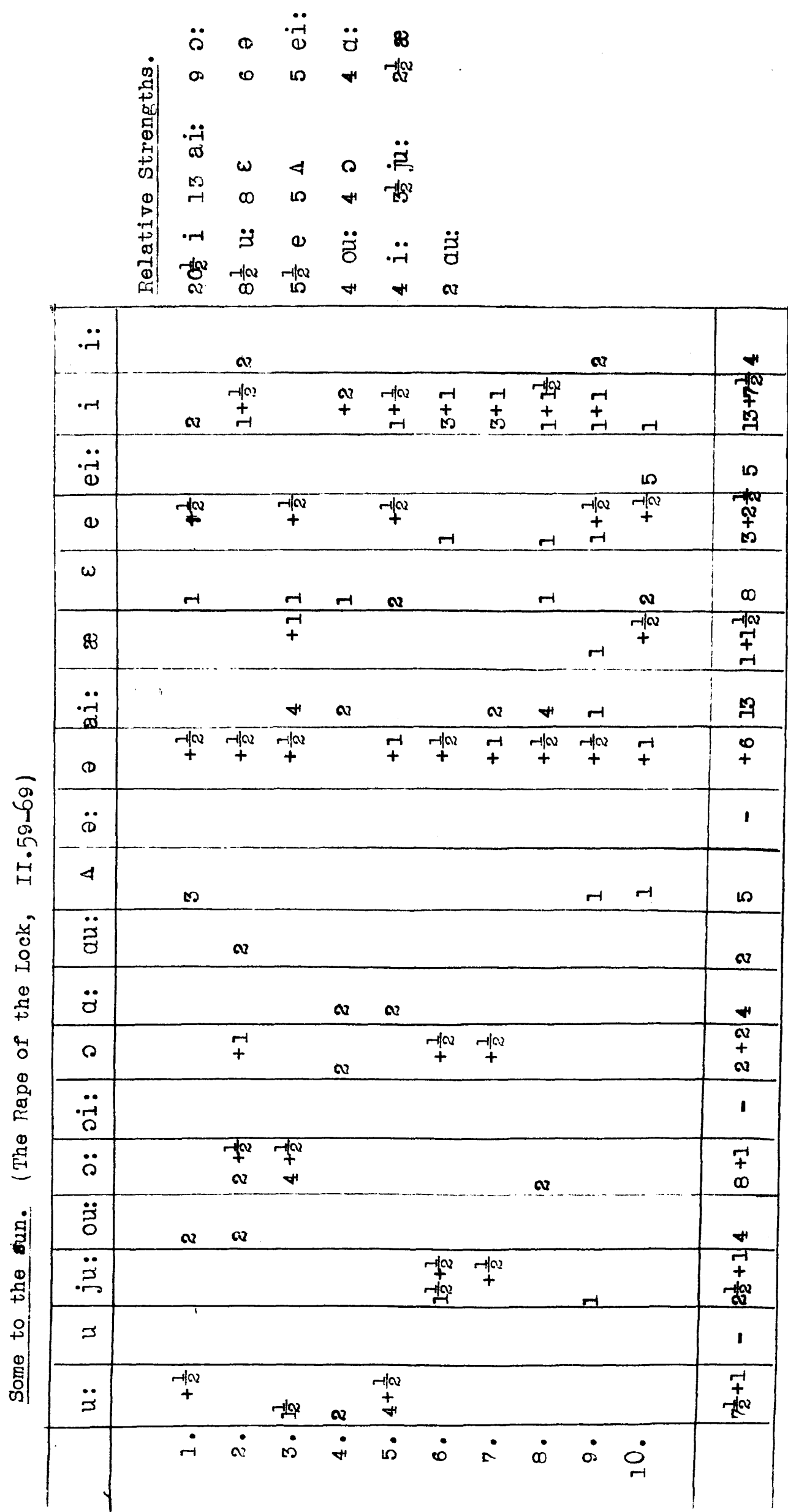




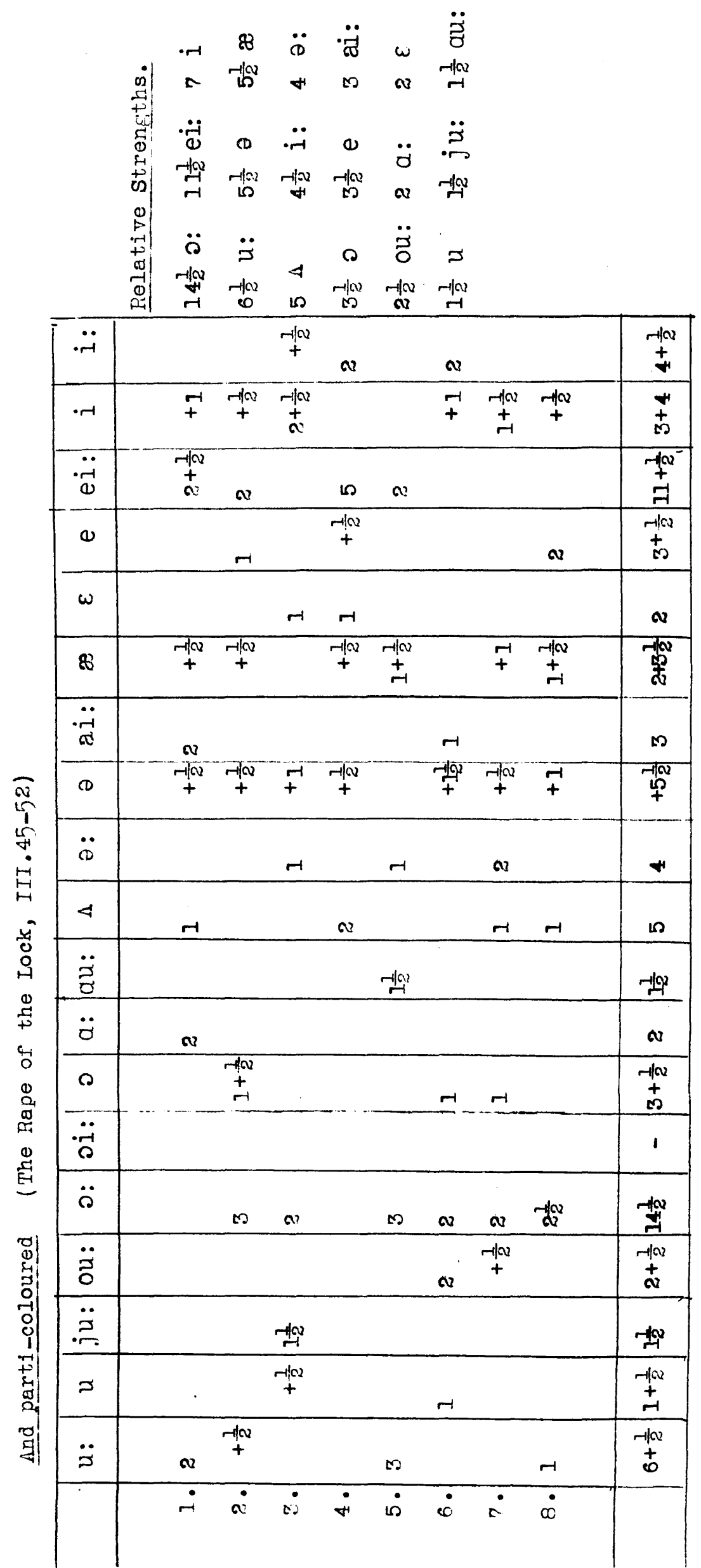




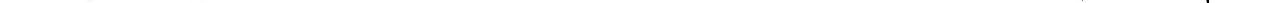




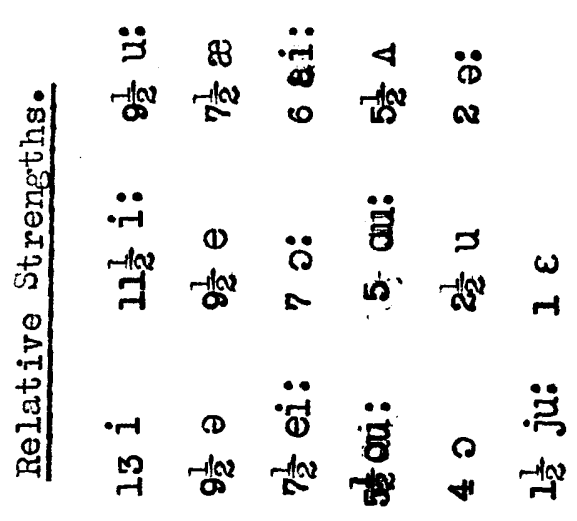

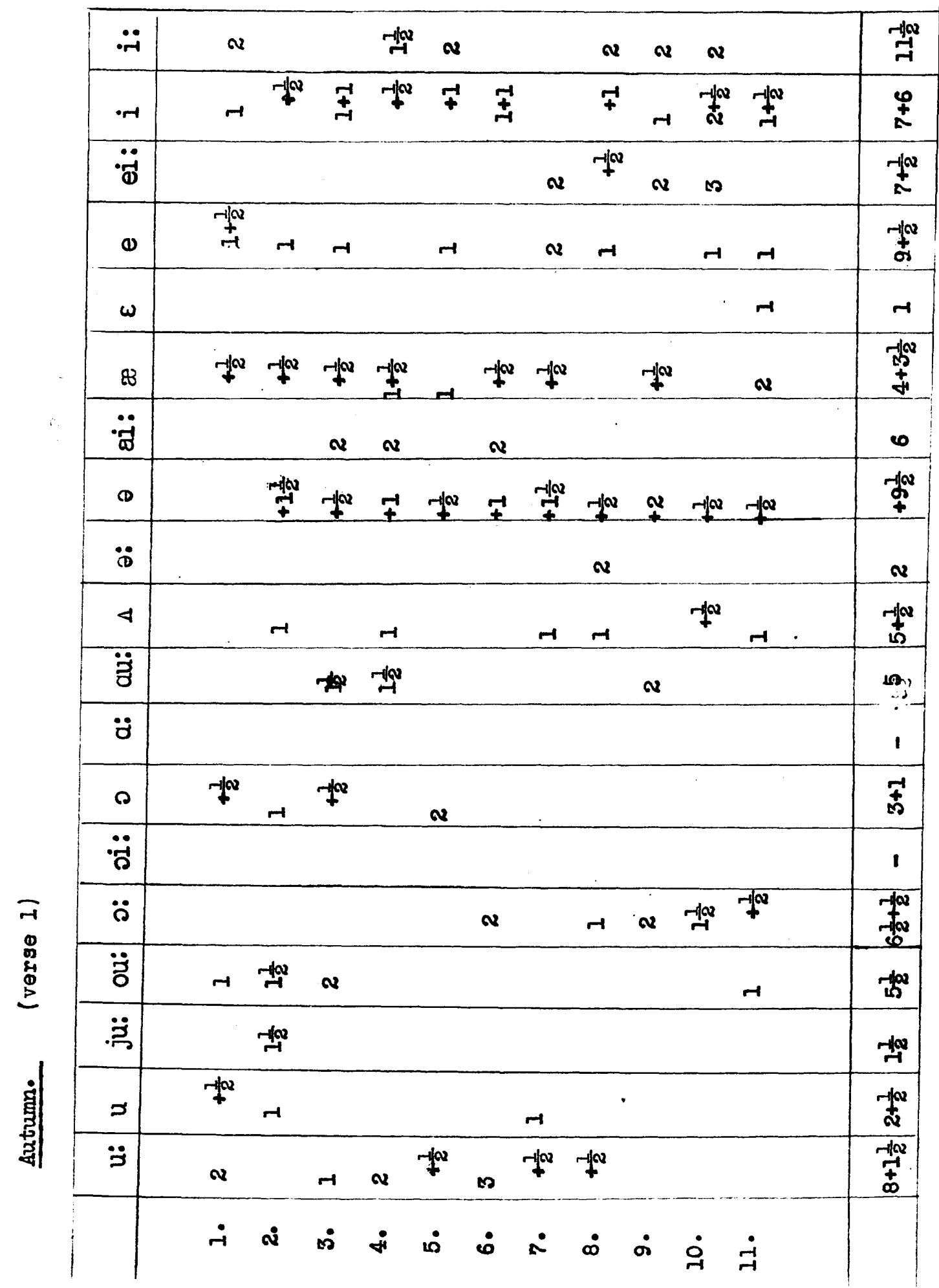




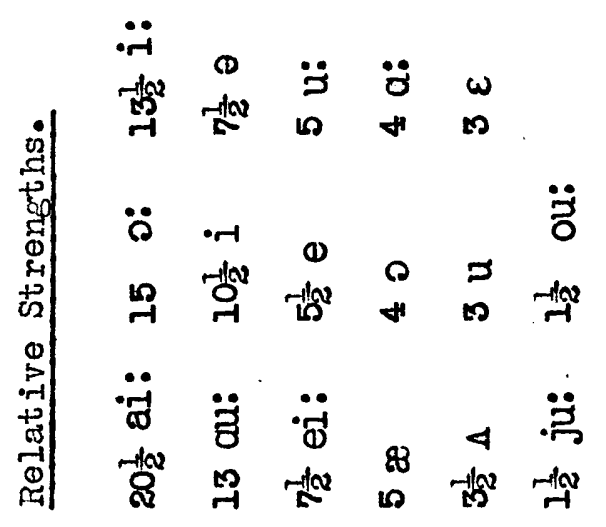

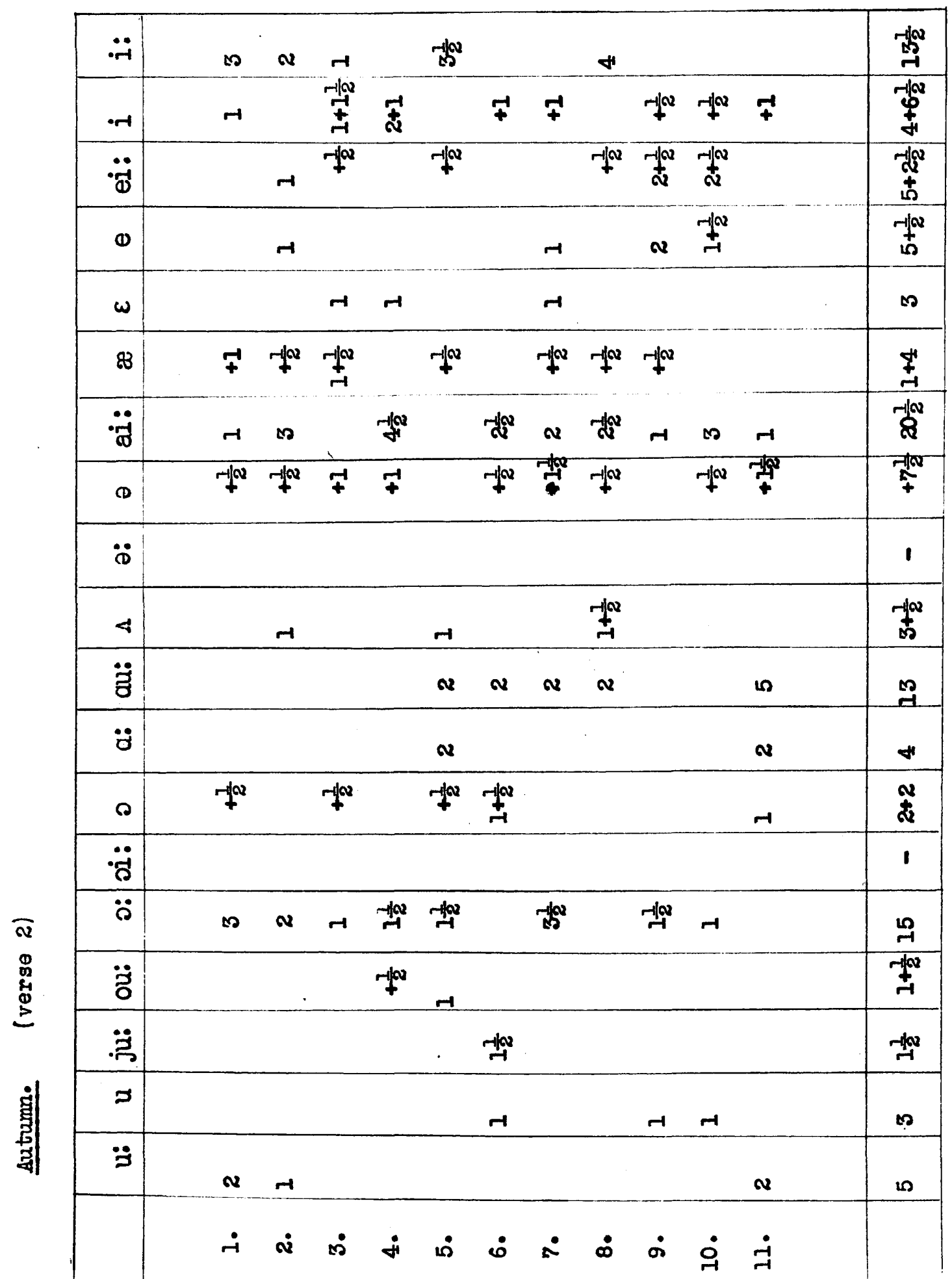




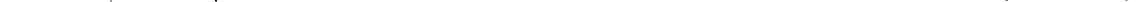




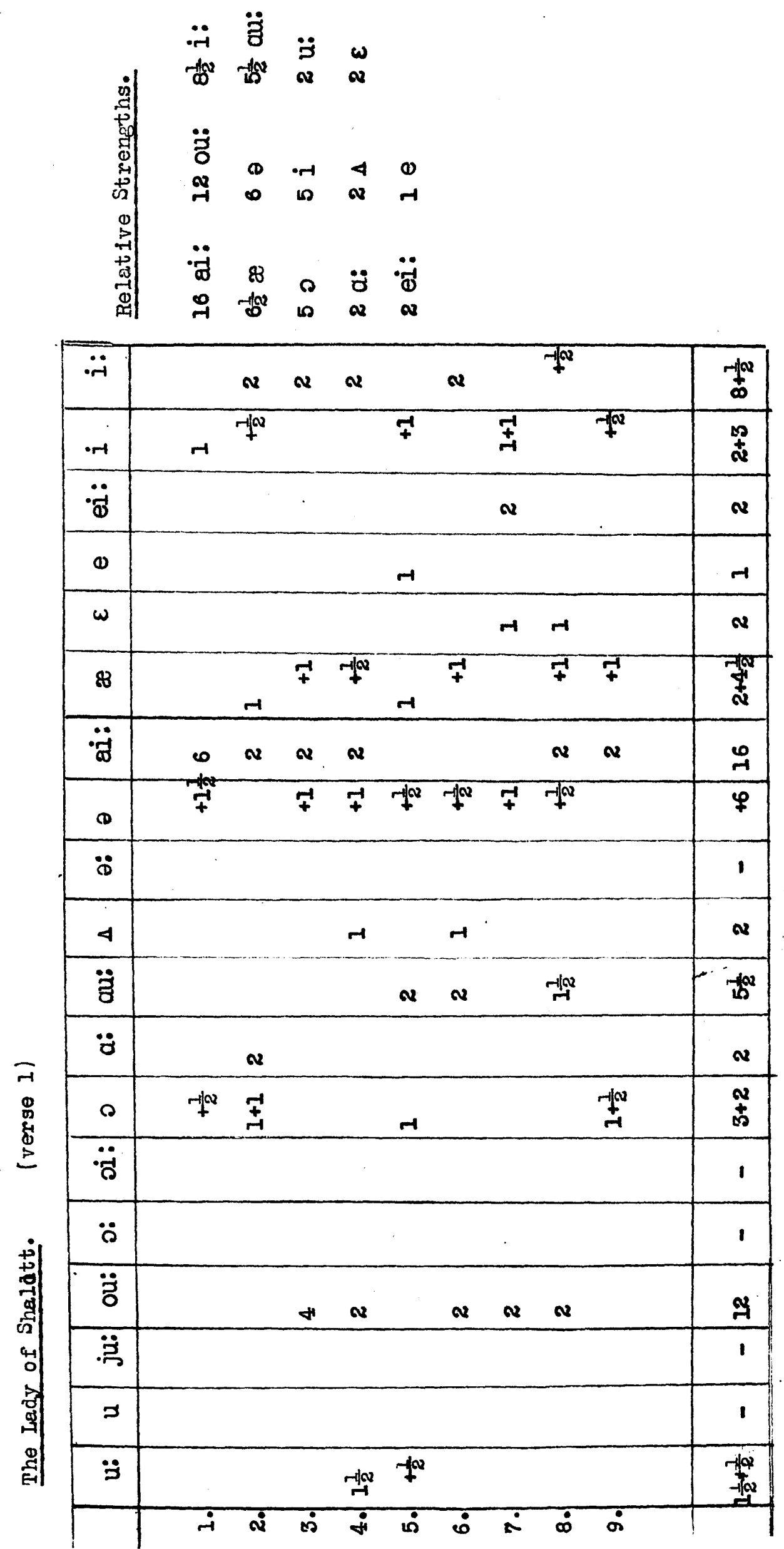




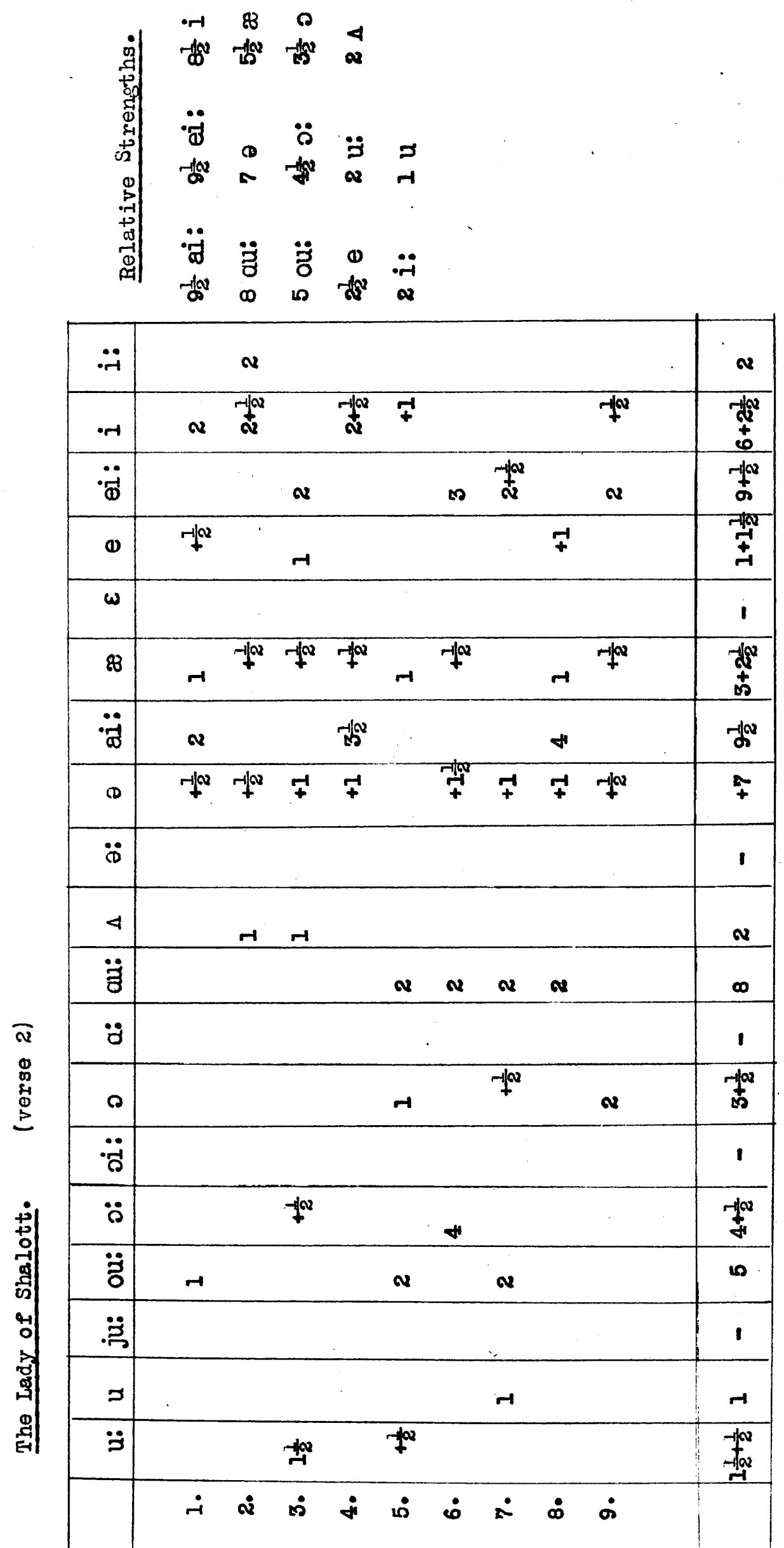




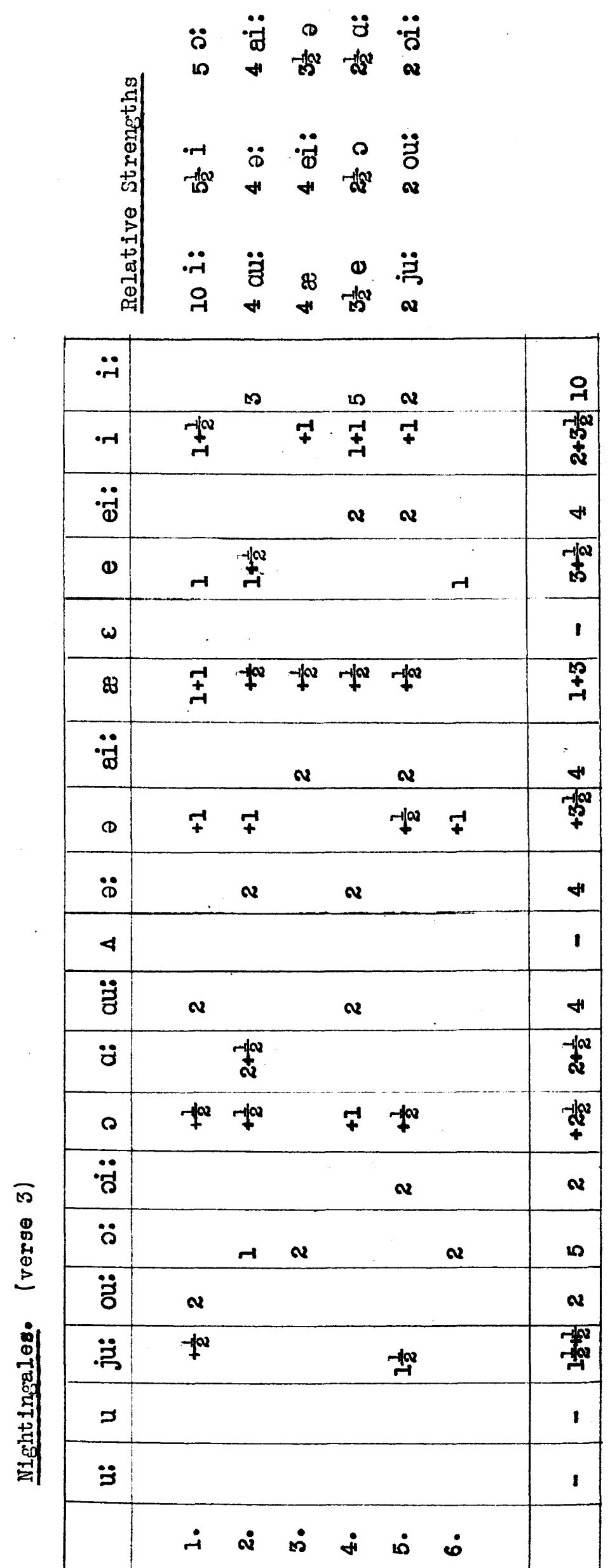




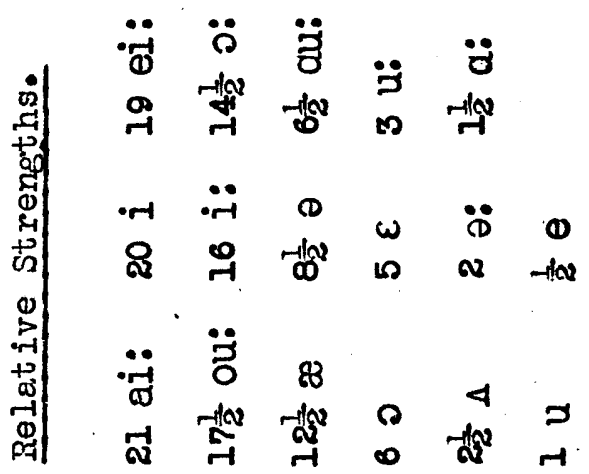

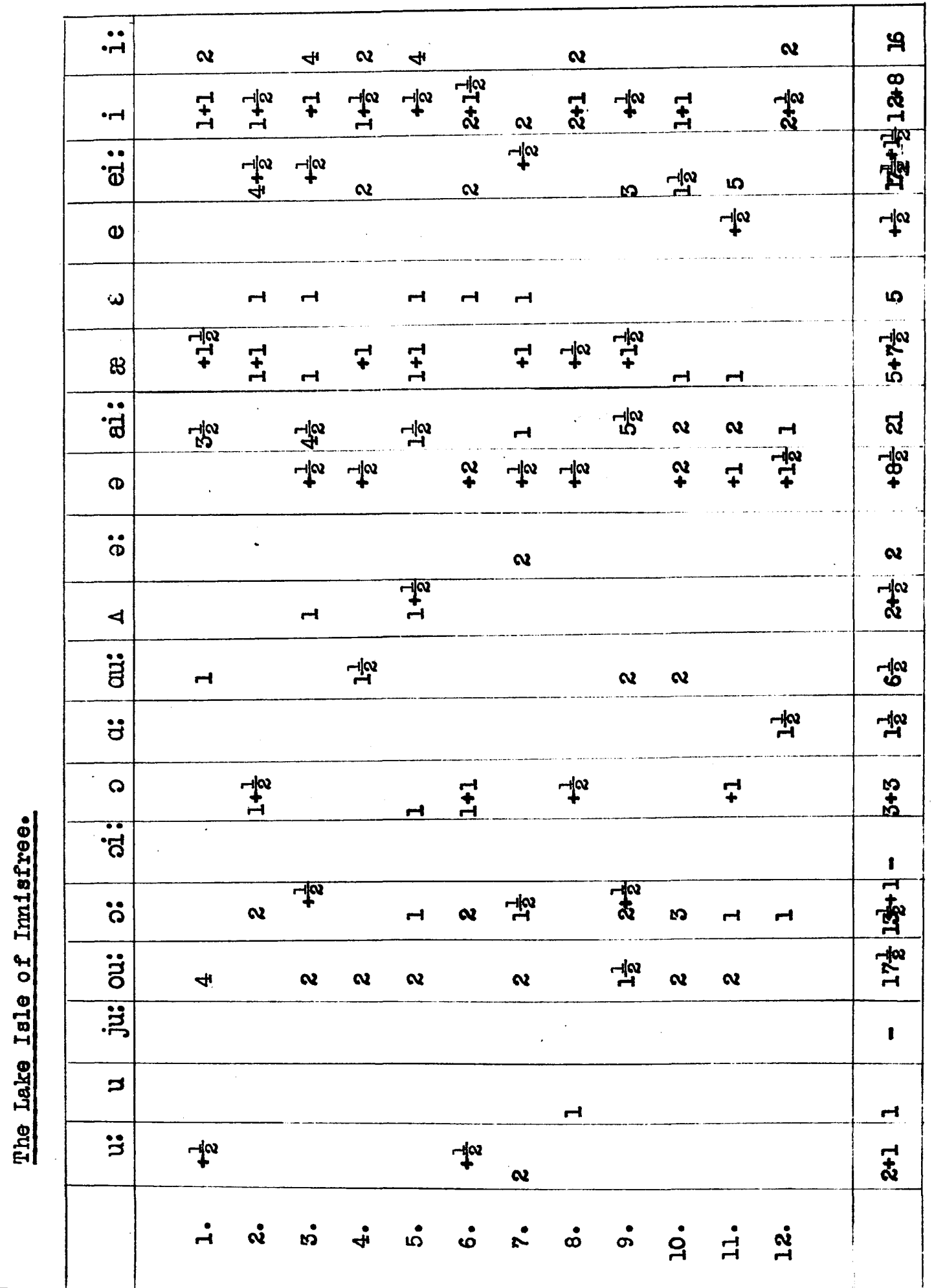




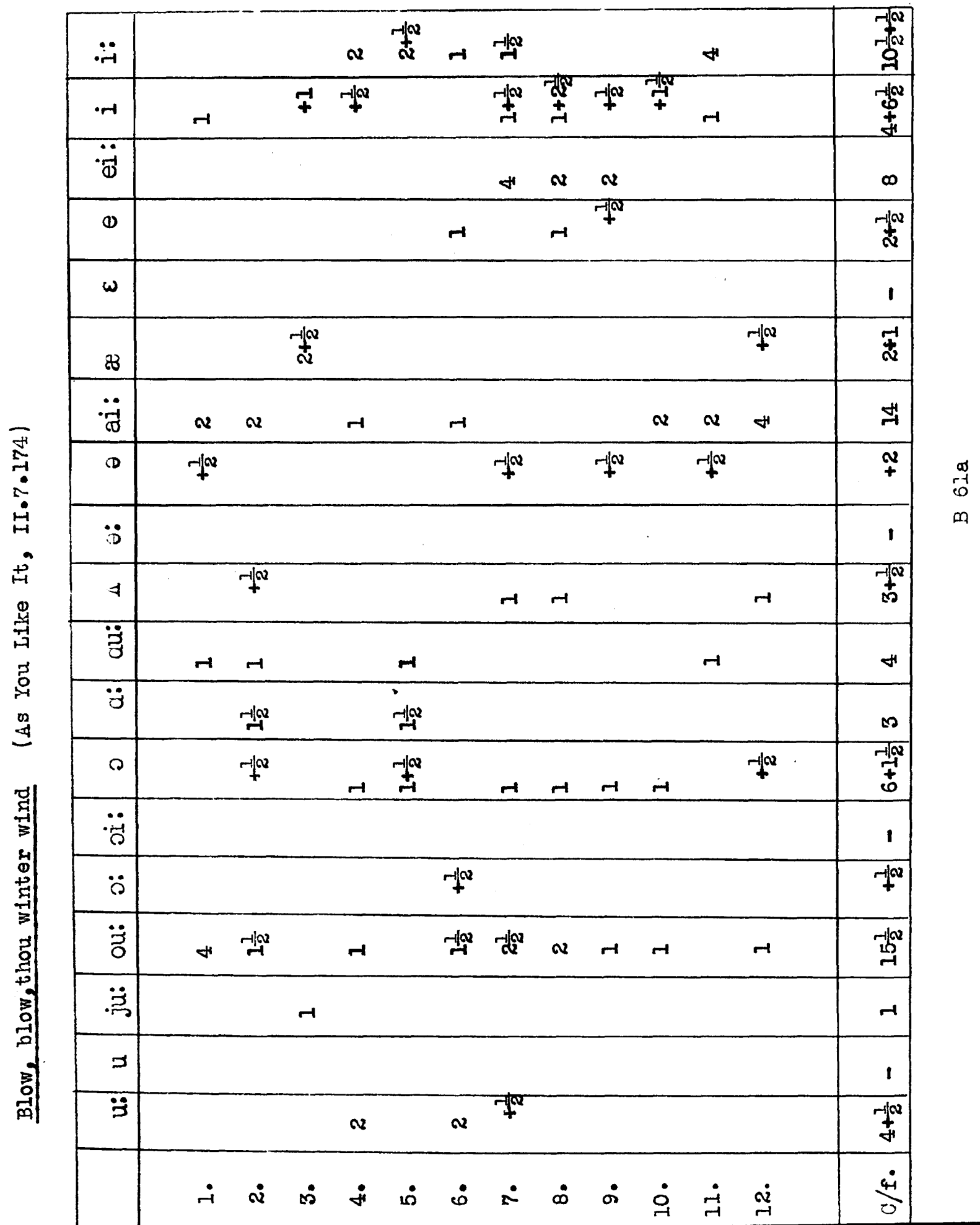




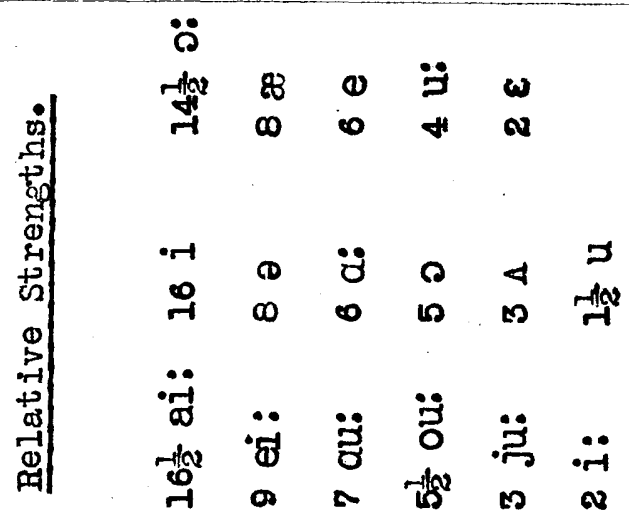

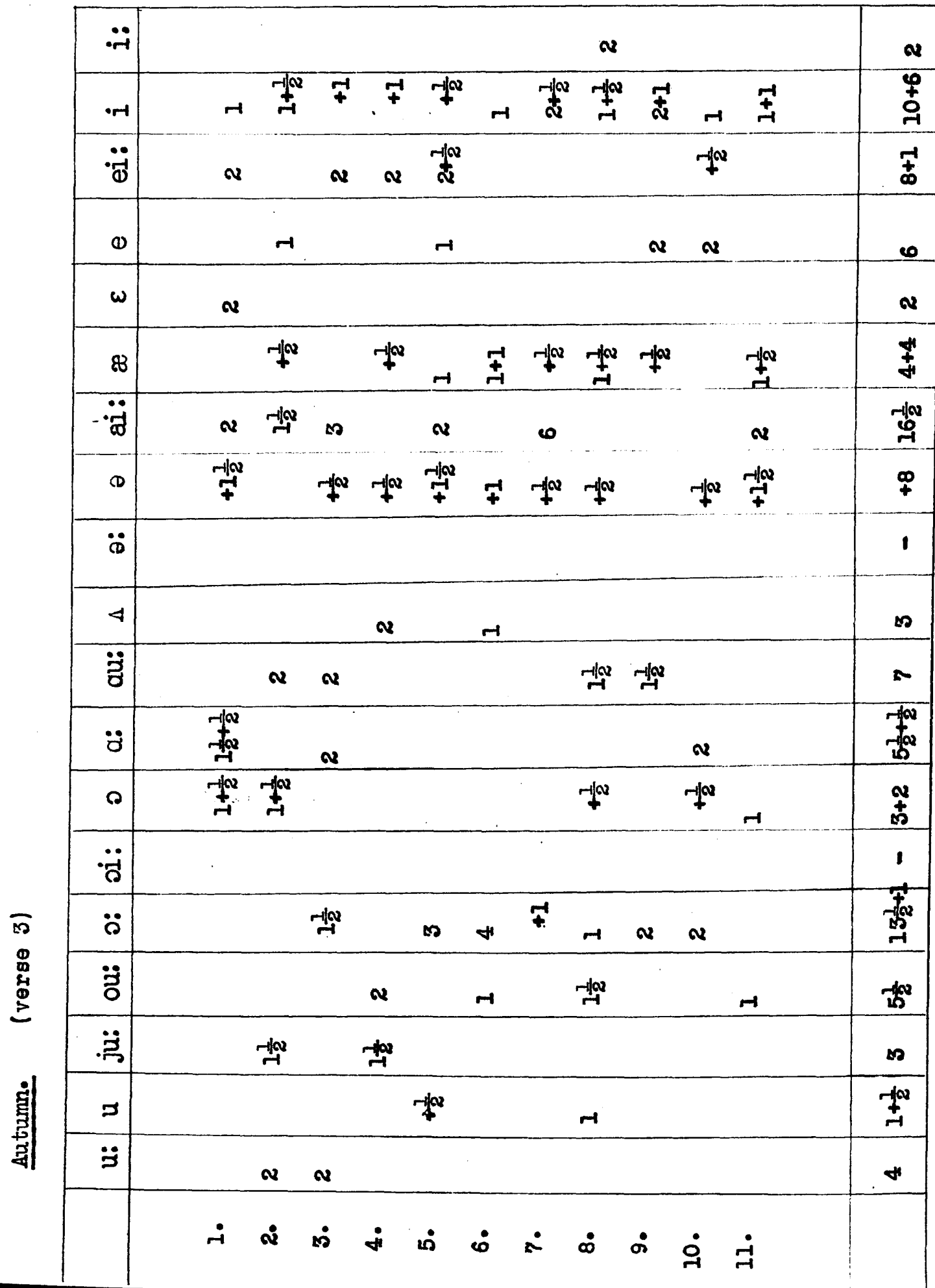




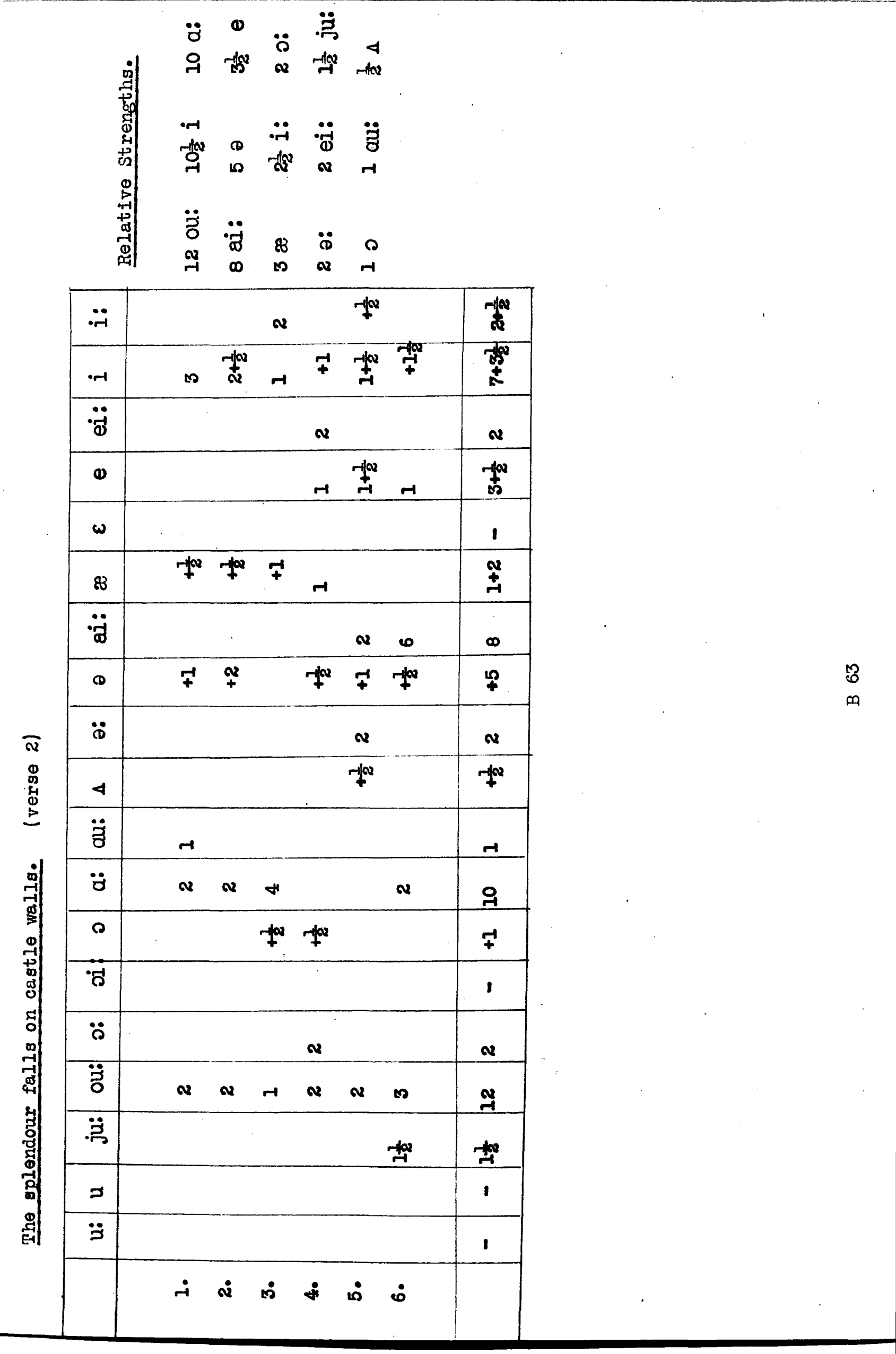




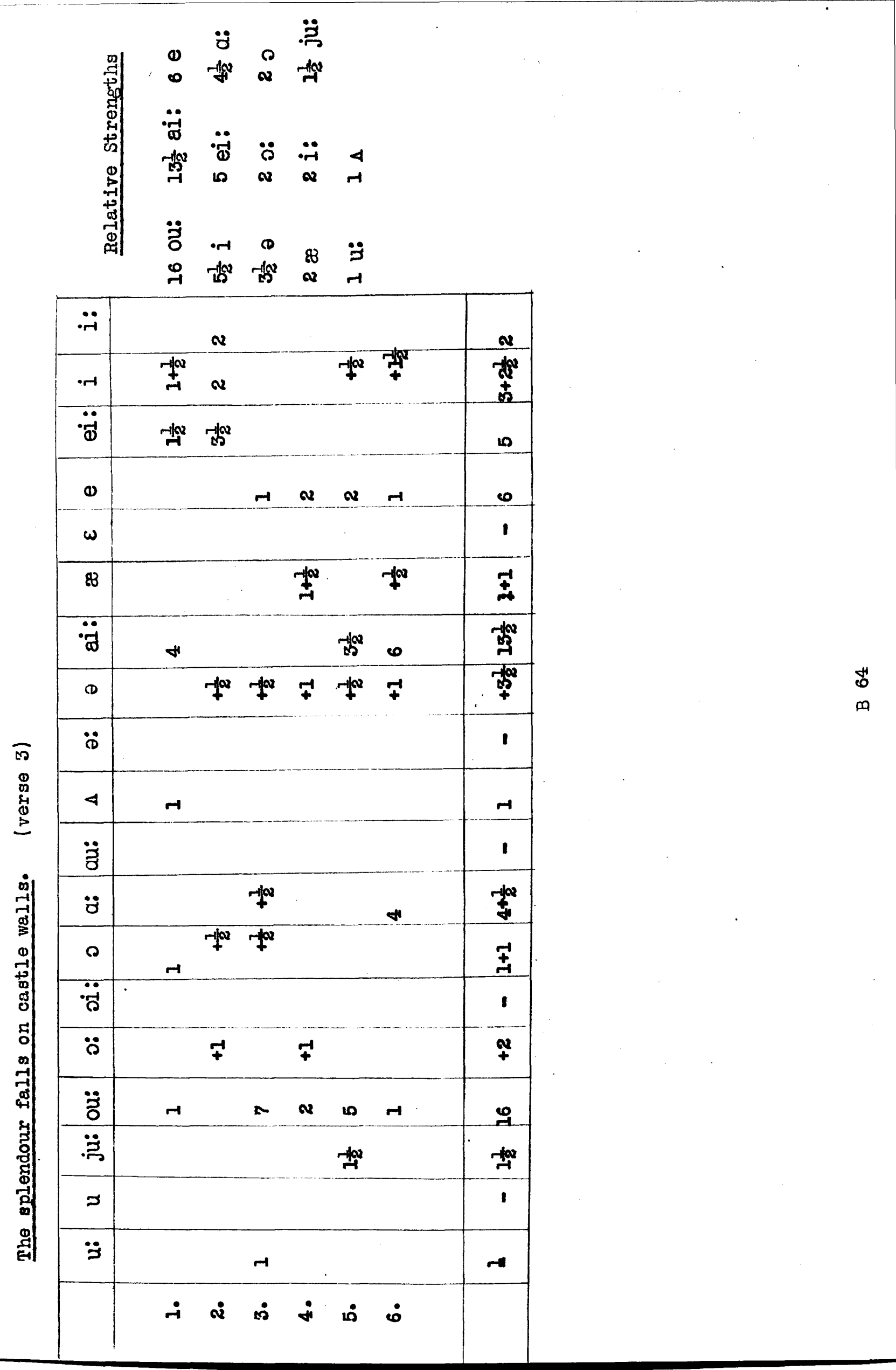




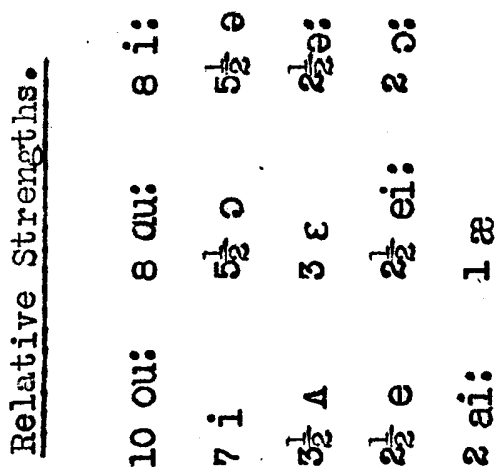

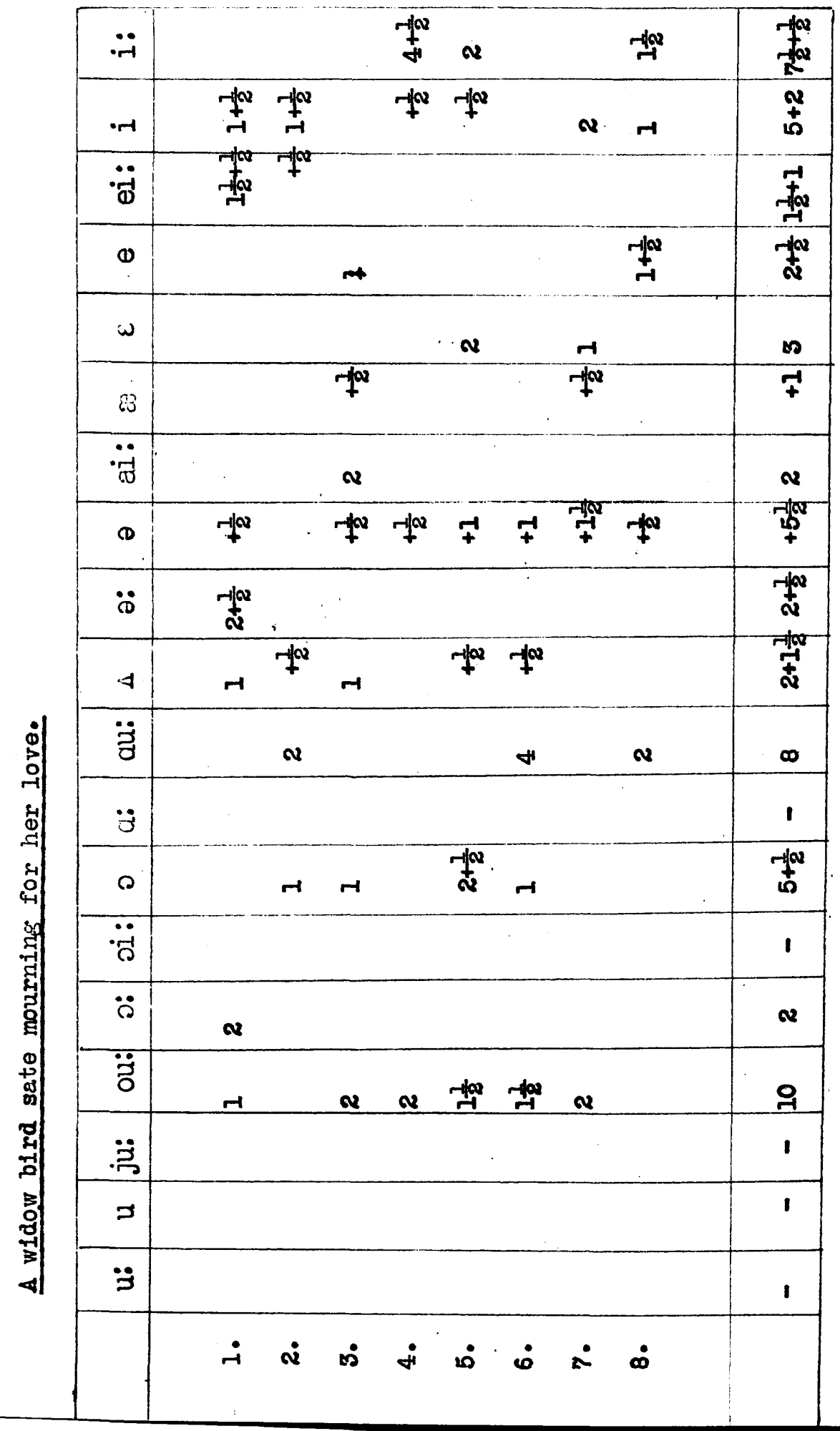




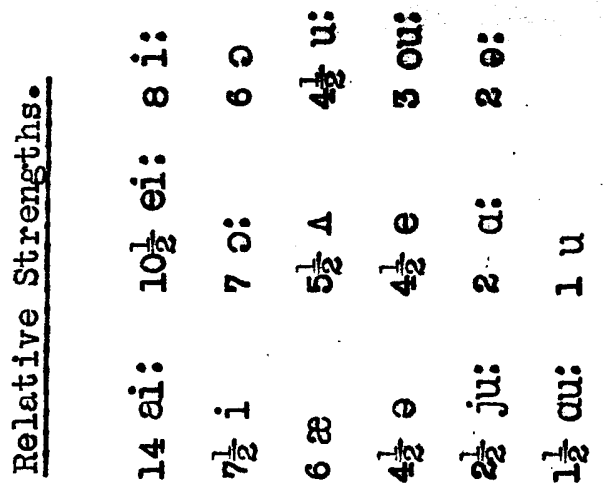

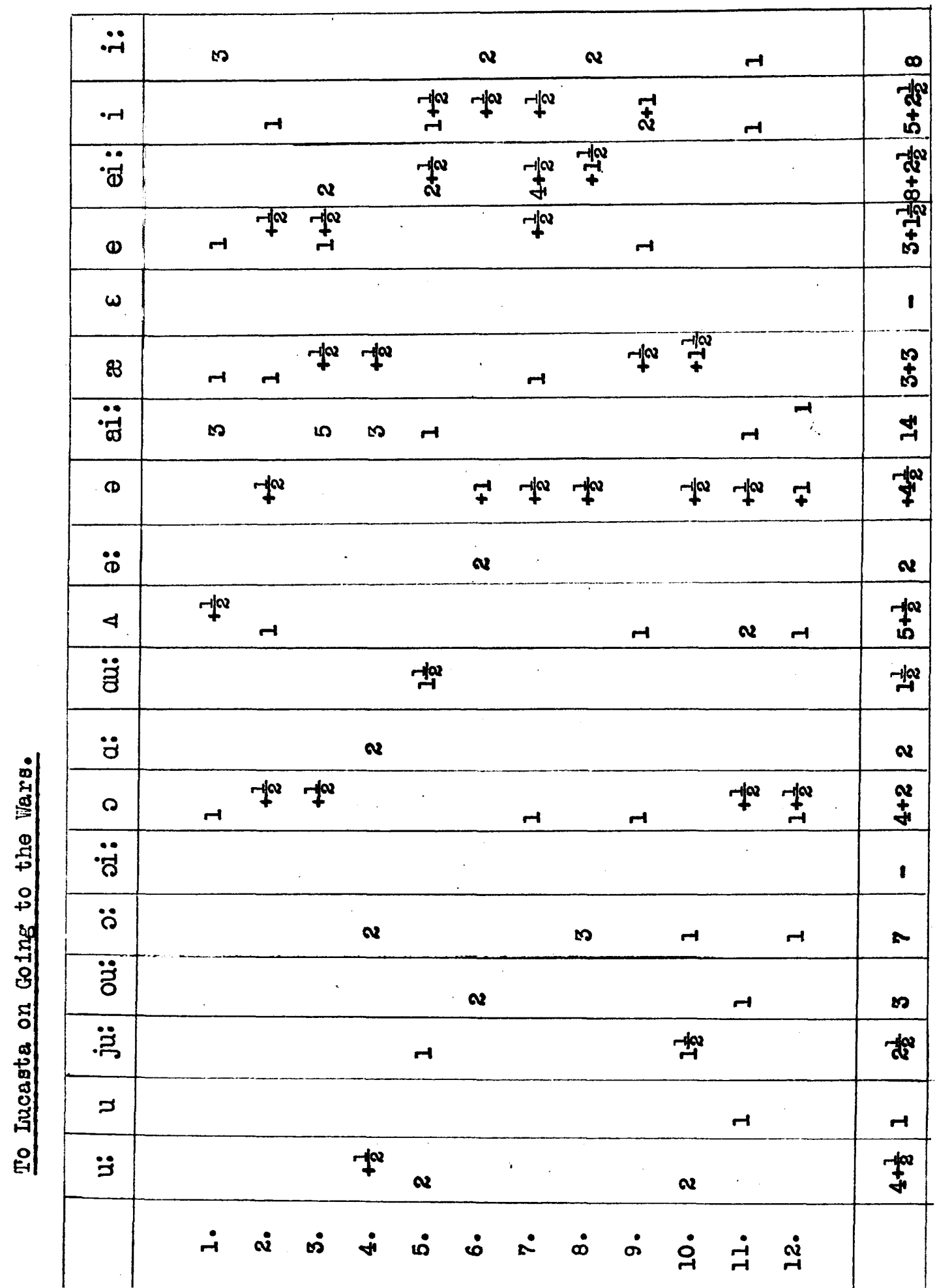




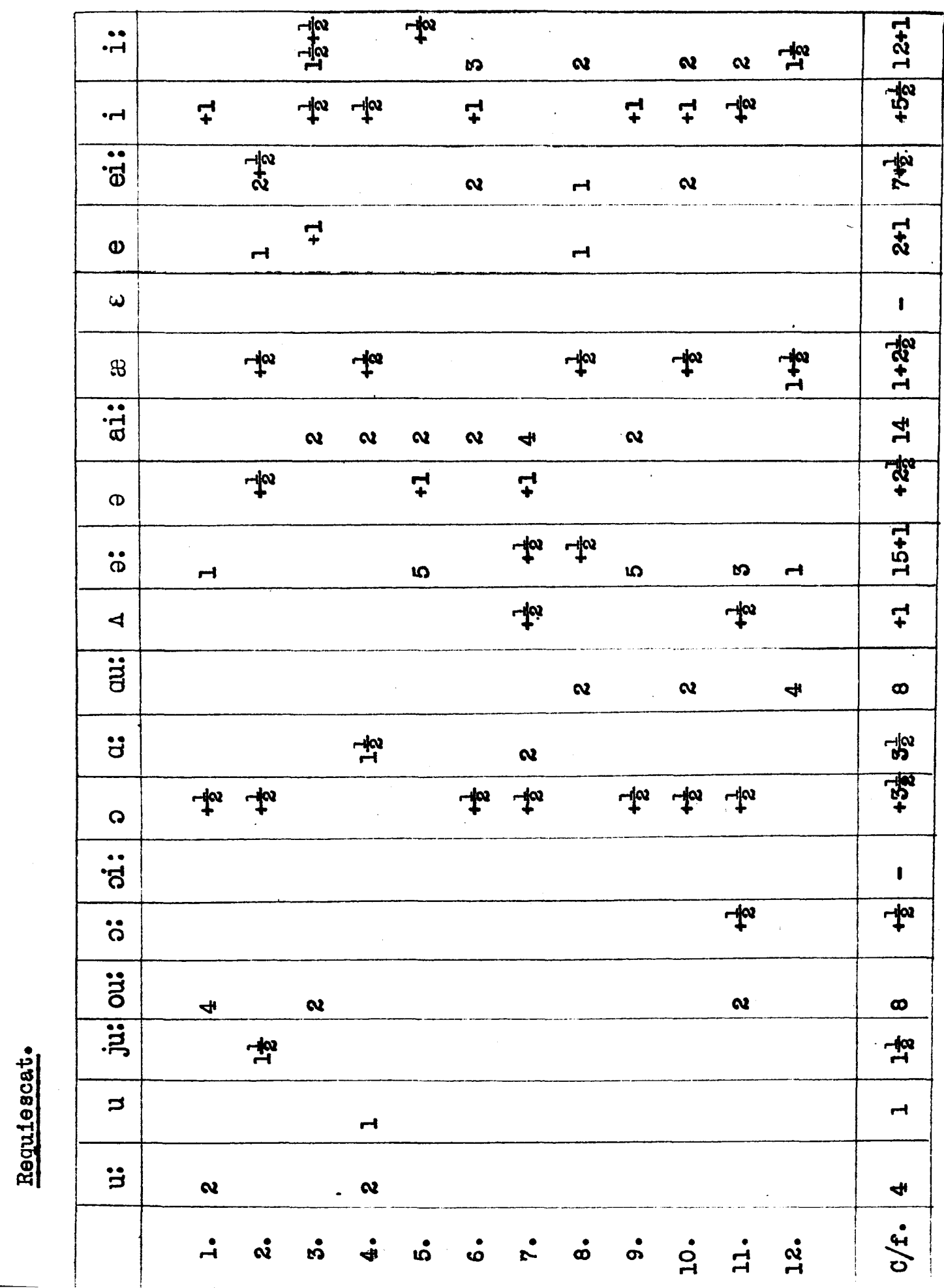




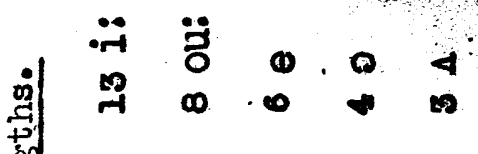

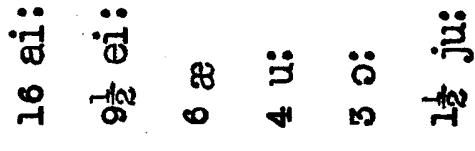

م|

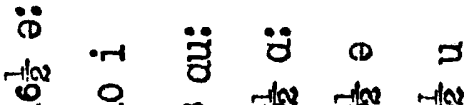

\begin{tabular}{|c|c|c|c|c|c|}
\hline$\ddot{-r}$ & 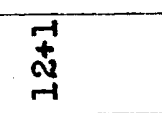 & & & & $\underset{-1}{+1}$ \\
\hline$\cdot r$ & $\underset{+}{\stackrel{7 n}{+} \underset{+}{+}}$ & $-1 \infty$ & $-\frac{\pi}{7}$ & $-1+x$ & 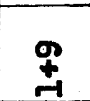 \\
\hline$\ddot{\ddot{\omega}}$ & $-\underbrace{-10 w}_{2}$ & $\boldsymbol{v}$ & & & $\stackrel{-1 p 2}{a}$ \\
\hline (1) & $\begin{array}{c}+ \\
\pm \\
\end{array}$ & $r$ & $r$ & $r$ & $\underset{\omega}{-1}$ \\
\hline$\omega$ & 1 & & & & 1 \\
\hline $\mathbb{8}$ & 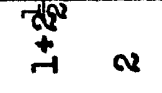 & 70 & & & 早 \\
\hline$\ddot{\ddot{\infty}}$ & $\underset{H}{\mathbb{H}}$ & & $\boldsymbol{v}$ & & $\stackrel{\leftrightarrow}{\mathscr{r}}$ \\
\hline .8 & $\stackrel{-\pi n}{+}$ & $-1 \infty$ & & $-x_{t}$ & ts \\
\hline$\ddot{\infty}$ & 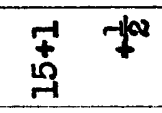 & & & & 整 \\
\hline 4 & $\mp$ & -1 & $\boldsymbol{m}$ & & 点 \\
\hline$\ddot{\Xi ̋}$ & $\infty$ & & & & $\infty$ \\
\hline$\ddot{0}$ & है & & & $v$ & w \\
\hline 0 & 政 & & & $+\frac{1}{+\infty}$ & $\$$ \\
\hline$\ddot{\circ}$ & 1 & & & & 1 \\
\hline$\ddot{\circ}$ & $-1+\infty$ & $+\infty$ & & & 志 \\
\hline$\ddot{\tilde{\sigma}}$ & $\infty$ & & & & $\infty$ \\
\hline$\ddot{\ddot{g}}$ & - 热 & & & & -4an \\
\hline 3 & -1 & & 70 & & $\underset{\rightarrow}{+\infty}$ \\
\hline$\ddot{3}$ & 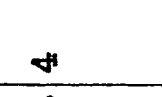 & & & & 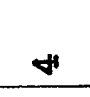 \\
\hline & $\stackrel{\dot{4}}{m} \stackrel{\dot{m}}{\dot{m}}$ & 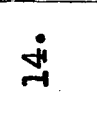 & $\dot{9}$ & $\dot{\sigma}$ & \\
\hline
\end{tabular}



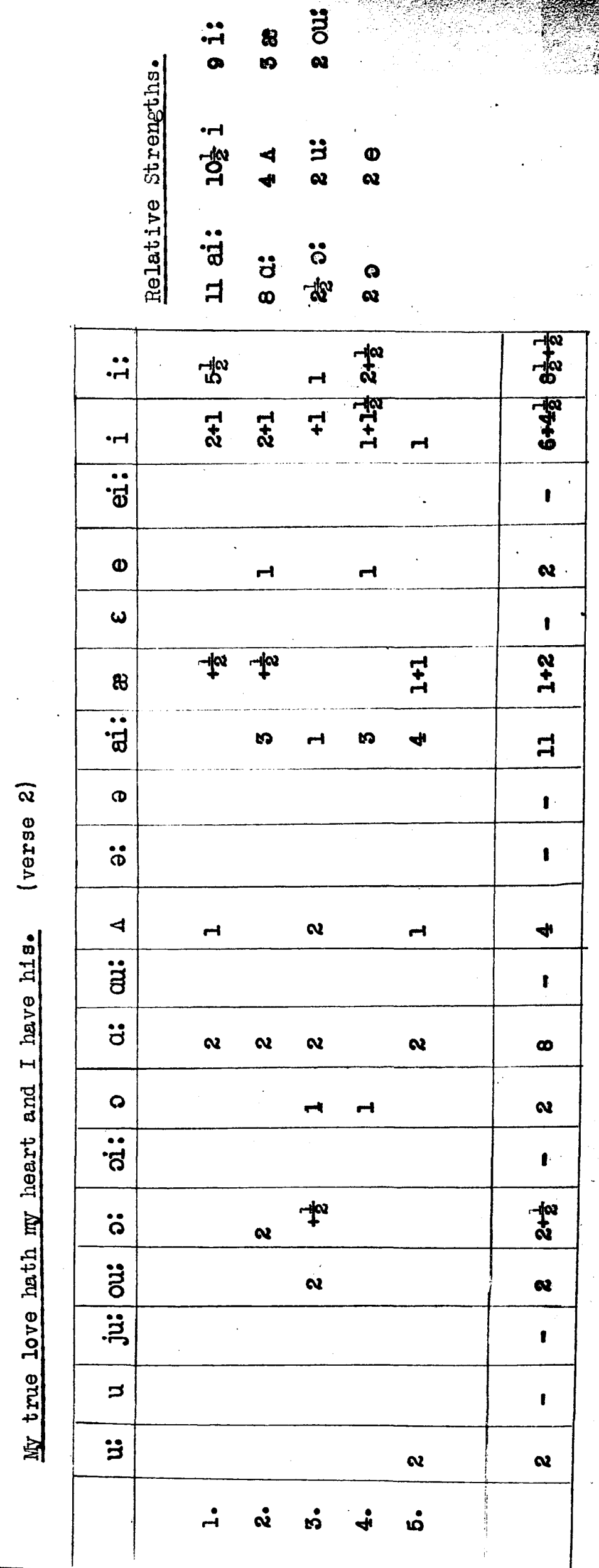


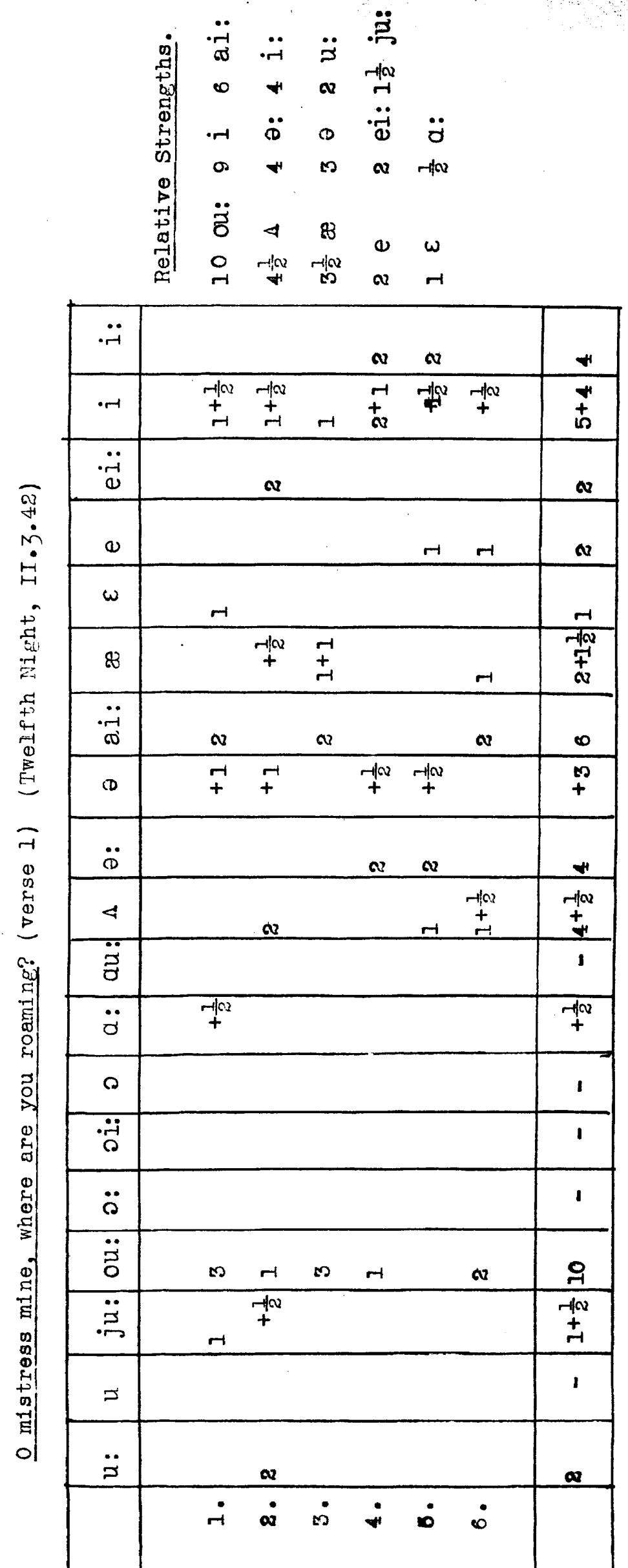




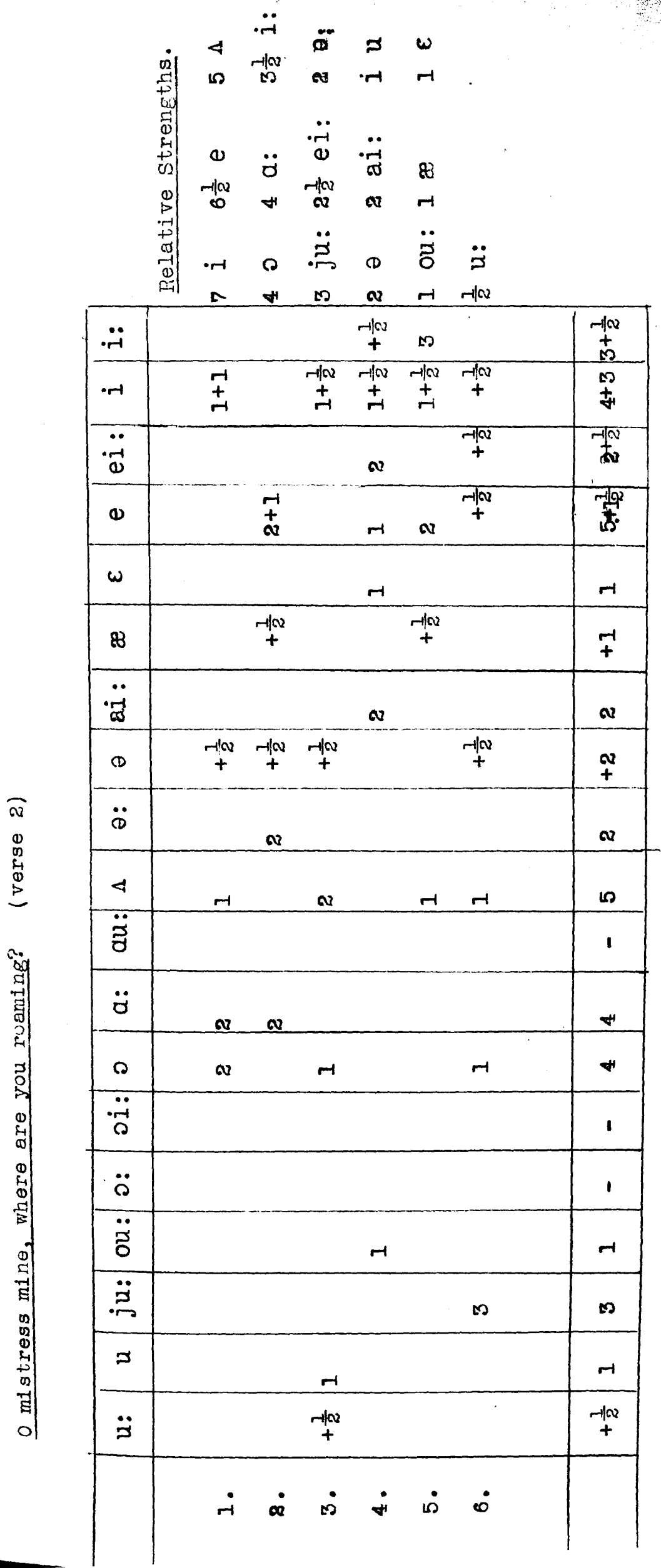




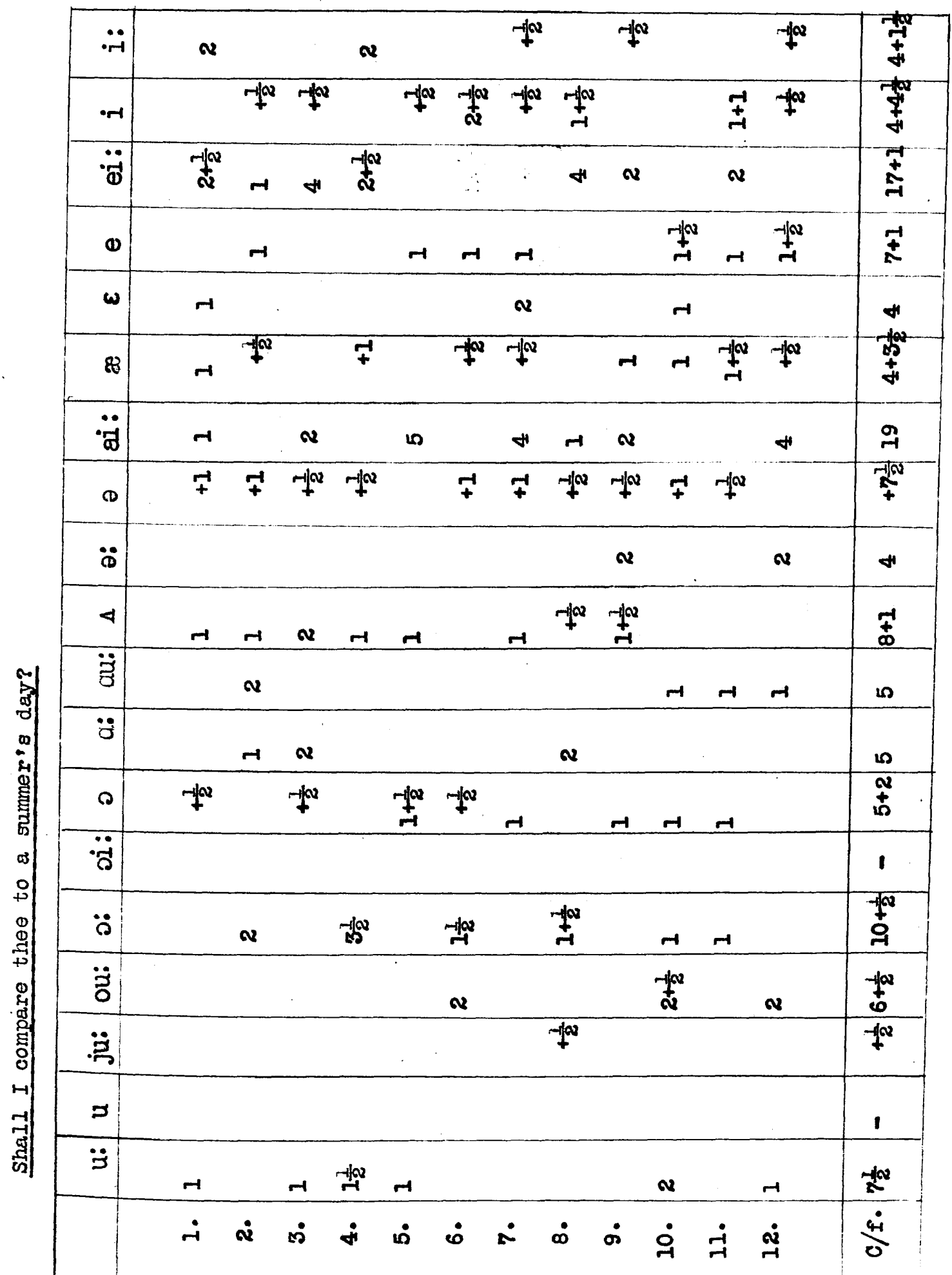




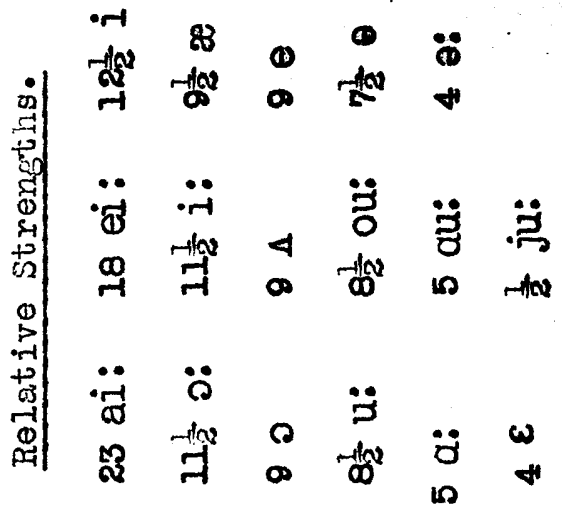

\begin{tabular}{|c|c|c|c|c|}
\hline$\ddot{\ddot{H}}$ & $\stackrel{+}{+}$ & $H$ & $\boldsymbol{N}$ & 훅 \\
\hline$\cdot r-1$ & $f$ & & $H$ & $\Phi$ \\
\hline$\ddot{\vec{\omega}}$ & $\stackrel{ \pm}{\sim}$ &. & & \begin{tabular}{l}
7 \\
\multirow{7}{*}{}
\end{tabular} \\
\hline $\boldsymbol{\omega}$ & $\stackrel{+1}{ \pm}$ & -1 & & $\underset{+}{+}$ \\
\hline$\omega$ & 4 & & & + \\
\hline 88 & $\stackrel{5}{+}$ & & 7 & $\begin{array}{c}-100 \\
+50 \\
+ \\
+\end{array}$ \\
\hline$\ddot{\ddot{\alpha}}$ & 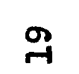 & $\boldsymbol{N}$ & $v$ & $\mathfrak{P}$ \\
\hline (D) & $\underset{+}{-\pi / N}$ & & & 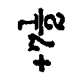 \\
\hline$\ddot{c 0}$ & +4 & & & $\$$ \\
\hline 4 & $\begin{array}{c}+1 \\
+ \\
\infty\end{array}$ & & & $\underset{\infty}{+}$ \\
\hline$\ddot{z}$ & in & & & 10 \\
\hline$\ddot{d}$ & ص & & & $\omega$ \\
\hline$\curvearrowright$ & $\stackrel{\sim}{+}$ & -1 & -1 & $\stackrel{\alpha}{ \pm}$ \\
\hline$\ddot{\circ}$ & 1 & & & 1 \\
\hline$\ddot{\circ}$ & 함 & -1 & & 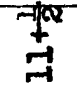 \\
\hline$\ddot{\ddot{0}}$ & $\stackrel{+102}{6}$ & $r$ & $r$ & $\underset{\infty}{-1 / 02}$ \\
\hline$\ddot{~}$ & 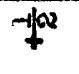 & & & $+\infty$ \\
\hline 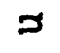 & 1 & & & I \\
\hline$\ddot{y}$ & $\underset{N}{N}$ & & -1 & - \\
\hline & $\stackrel{\dot{4}}{\dot{m}}$ & $\stackrel{\operatorname{m}}{\operatorname{r}}$ & $\stackrel{\dot{H}}{\stackrel{H}{*}}$ & \\
\hline
\end{tabular}




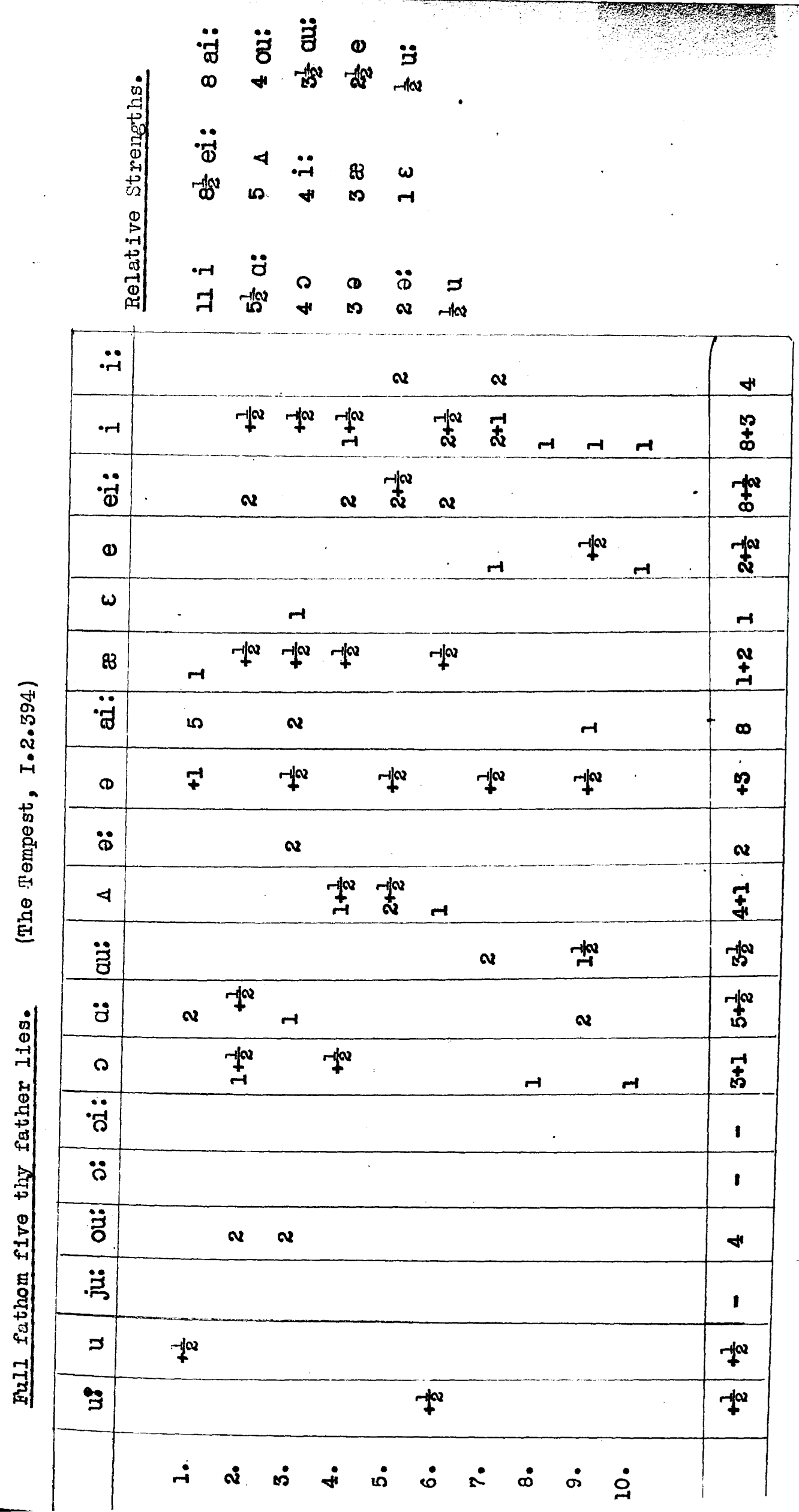




\begin{tabular}{|c|c|c|c|c|c|c|c|c|c|c|c|c|c|}
\hline$\ddot{\because}$ & & - $\frac{10 x}{N}$ & & & $\boldsymbol{v}$ & & $m$ & -1 & & + & 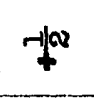 & -10 & $\underset{+}{\sim}$ \\
\hline$\cdot r-1$ & $\stackrel{r+n}{+}$ & $\underset{-1}{-10}$ & & $\frac{7 \sqrt{20}}{4}$ & 7 & -1 & & + & $\stackrel{-I}{ \pm}$ & $m$ & 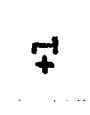 & $\underline{v}$ & - \\
\hline$\ddot{\ddot{\omega}}$ & $\boldsymbol{v}$ & & $\boldsymbol{v}$ & + & $\boldsymbol{\sim}$ & & & $f$ & $v$ & & -1 & -1 & 胥 \\
\hline $\boldsymbol{\omega}$ & -1 & & & $-H$ & $\boldsymbol{N}$ & & $\begin{array}{l}\text { Now } \\
\text { N }\end{array}$ & & & & & & $\frac{-10}{6}$ \\
\hline $\boldsymbol{\omega}$ & & -1 & & & & & -1 & & -1 & & & & s \\
\hline 88 & & & $-1 \mid \alpha$ & $-1 \infty x$ & & & $\underset{-1}{-1}$ & $-1+x$ & & & & -110 & 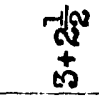 \\
\hline मี & $\boldsymbol{v}$ & $\infty$ & $\boldsymbol{v}$ & $\boldsymbol{v}$ & & $\boldsymbol{\omega}$. & $r$ & & & $\boldsymbol{\alpha}$ & $H$ & & $\stackrel{\infty}{\infty}$ \\
\hline (D) & 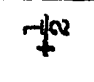 & + & & & $-1 \mid x$ & & $-7 x$ & $+\infty$ & $-7 \infty$ & 7 & & & $\stackrel{\text { ? }}{+}$ \\
\hline$\ddot{\phi}$ & & & & & & & & & & & & v & v \\
\hline 4 & & & & $H$ & & & & 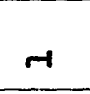 & $7+\infty$ & & -1 & $r$ & $\underset{ \pm}{+\infty}$ \\
\hline$\ddot{z}$ & & & & & & $\boldsymbol{N}$ & & 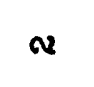 & & 浆 & & & 然 \\
\hline$\ddot{\sigma}$ & & & & & & & & & 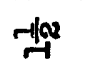 & & & & $-4 x^{2}$ \\
\hline 0 & $\stackrel{-1 \infty}{\underset{\sim}{+\infty}}$ & -1 & & $-1 \infty$ & $-1+20$ & - & & & -1 & $-1+$ & & 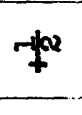 & 是 \\
\hline$\ddot{\ddot{\theta}}$ & & & & & & & & & & & & & 1 \\
\hline$\ddot{\circ}$ & & & & & & & & & & $-\infty$ & 7 & & 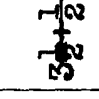 \\
\hline$\ddot{\Xi}$ & & & $\boldsymbol{N}$ & & & & & & $\rightarrow$ & & & & $\infty$ \\
\hline$\ddot{\ddot{n}}$ & & & $\infty$ & & $\stackrel{-12}{r}$ & & & $m$ & & $\underset{\mu}{\infty}$ & & $-12 x$ & $\underset{\infty}{+\infty}$ \\
\hline 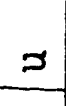 & & & -10 & & & & $r$ & & & & $\rightarrow$ & & 悲 \\
\hline$\ddot{y}$ & & & & & & & & & & & & $+\infty$ & $-1+\infty$ \\
\hline & $\dot{-}$ & $\dot{\boldsymbol{v}}$ & $\dot{\varphi}$ & $\dot{j}$ & $\dot{0}$ & $\dot{0}$ & $\dot{2}$ & $\dot{\infty}$ & $\dot{0}$ & $\dot{\circ}$ & $\dot{\vec{H}}$ & $\underset{\sim}{\dot{a}}$ & $\frac{\dot{\varphi}}{\delta}$ \\
\hline
\end{tabular}




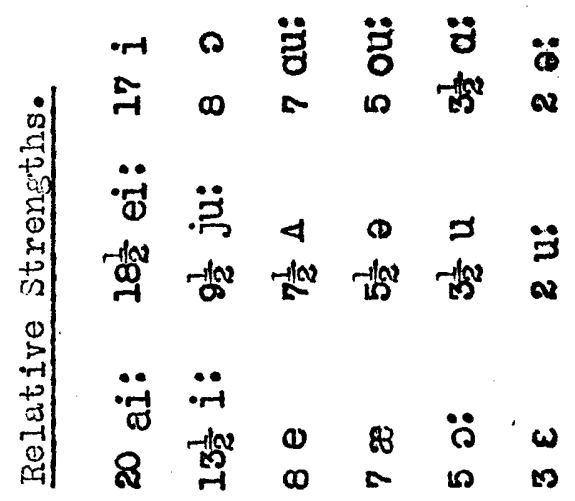

\begin{tabular}{|c|c|c|c|}
\hline$\ddot{m}$ & $\underset{\infty}{\mathfrak{W}}$ & - $\frac{1}{n}$ & $\frac{-\pi \sqrt{2}}{4}$ \\
\hline$\cdot r-1$ & $\begin{array}{l}\text { ना/ } \\
\infty \\
+ \\
\infty\end{array}$ & $-x^{\infty}$ & $\begin{array}{l}0 \\
+ \\
\infty\end{array}$ \\
\hline$\ddot{\ddot{1}}$ & $\underset{+4}{+4}$ & $\boldsymbol{Q} \quad \boldsymbol{Q}$ & $\underset{\substack{+\infty \\
+\infty}}{+\infty}$ \\
\hline $\boldsymbol{\omega}$ & $\stackrel{-\infty}{\infty}$ & $\underset{-1}{-10}$ & $\stackrel{+1}{ \pm}$ \\
\hline$\omega$ & $\infty$ & & $\infty$ \\
\hline 88 & $\begin{array}{l}-1 a^{2} \\
+ \\
\text { m. }\end{array}$ & $\underset{-1}{-1}$ & \pm \\
\hline$\ddot{\alpha}$ & $\underset{-1}{\infty}$ & $\boldsymbol{v}$ & 8 \\
\hline D & 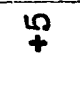 &, $7 x$ & th \\
\hline$\ddot{i}$ & $\boldsymbol{v}$ & $\therefore$ & $\boldsymbol{N}$ \\
\hline 4 & $\stackrel{-10 x}{4}$ & $\infty$ & $\stackrel{-1 x}{ \pm}$ \\
\hline$\ddot{z}$ & How & $\stackrel{-190}{A}$ & $\sim$ \\
\hline$\ddot{d}$ & - & & $+x^{\infty}$ \\
\hline$\curvearrowright$ & $\stackrel{\infty}{+}$ & & $\frac{\omega}{ \pm}$ \\
\hline$\ddot{\ddot{c}}$ & 1 & & 1 \\
\hline$\ddot{\beta}$ & - & -1 & $\begin{array}{l}-100 \\
+100\end{array}$ \\
\hline$\ddot{3}$ & $m$ & $\boldsymbol{v}$ & 10 \\
\hline$\ddot{\ddot{\beta}}$ & $\begin{array}{c}-10 \\
+\end{array}$ & & $\begin{array}{c}+\infty x \\
0\end{array}$ \\
\hline వ & 售 & & $\begin{array}{c}-10 x \\
50\end{array}$ \\
\hline$\ddot{z}$ & -10 & $\underset{-1}{+102}$ & $\ddot{t}$ \\
\hline & $\frac{\dot{4}}{m}$ & $\stackrel{\infty}{\rightarrow} \stackrel{\dot{H}}{-1}$ & \\
\hline
\end{tabular}




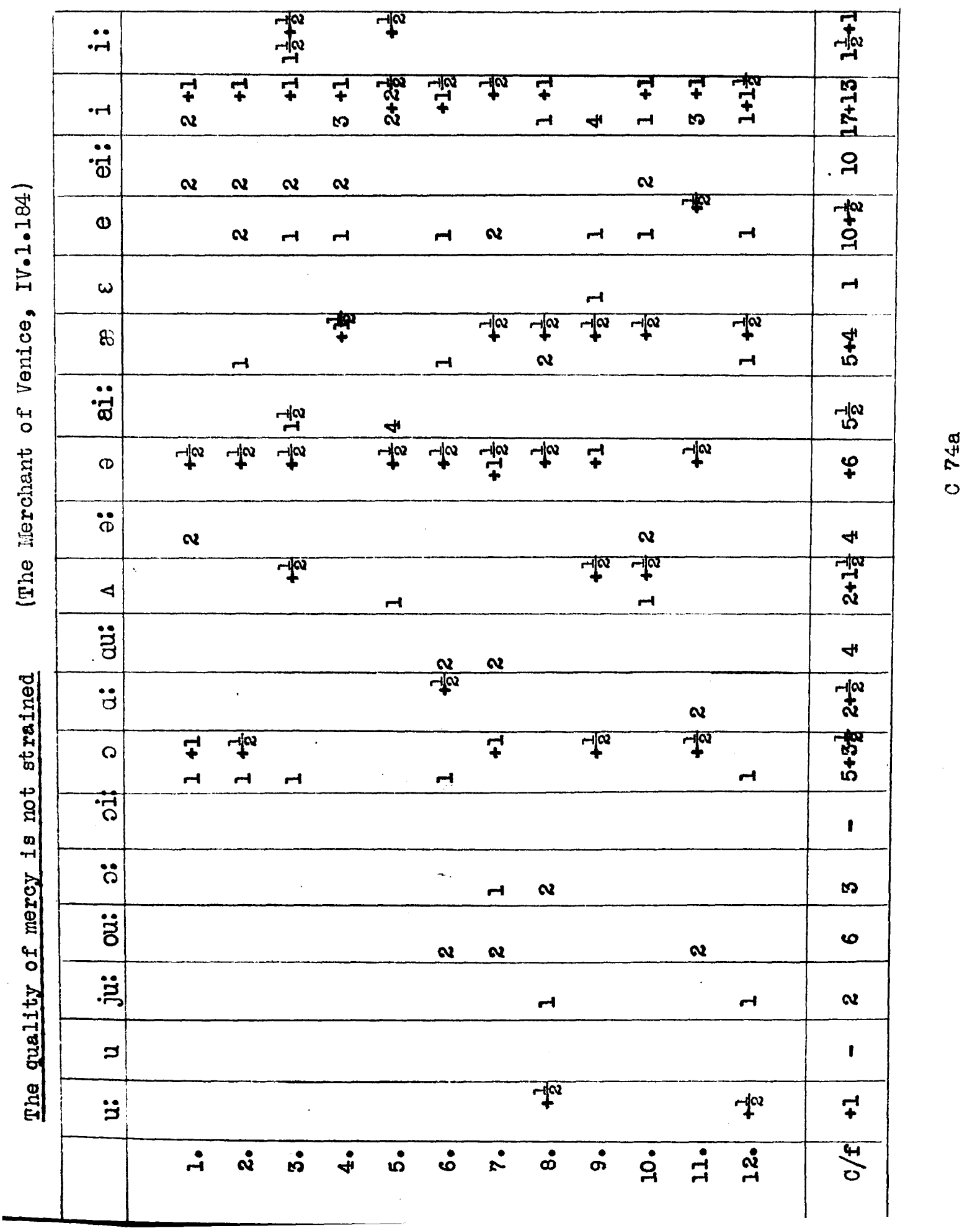




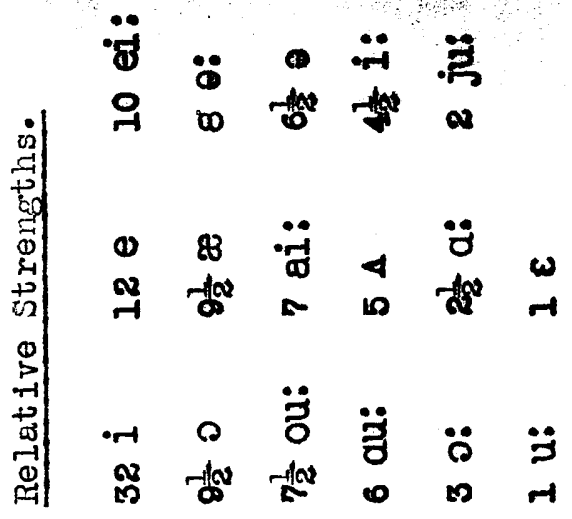

\begin{tabular}{|c|c|c|c|}
\hline$\ddot{-r}$ & $\underset{n}{n}$ & $\boldsymbol{v}$ & नुd \\
\hline$\cdot-1$ & $\begin{array}{l}+\frac{1}{7} \\
t \\
-1\end{array}$ & +7 & $\begin{array}{l}9 \\
+9 \\
9\end{array}$ \\
\hline$\ddot{\ddot{d}}$ & 유 & & 요 \\
\hline 0 & $\stackrel{-10}{+2}$ & $\rightarrow \quad+$ & $\underset{+}{\stackrel{F}{F}}$ \\
\hline$\omega$ & $r$ & & -1 \\
\hline 83 & $\begin{array}{l}7 \\
⿱ \\
10\end{array}$ & नाक & $\begin{array}{c}-10 q \\
7 \\
10\end{array}$ \\
\hline$\ddot{\circ}$ & Hen & $\underset{-1}{-N}$ & - \\
\hline (i) & $\varphi$ & $f^{\alpha}$ & $\phi^{-1}$ \\
\hline$\ddot{\infty}$ & + & $\boldsymbol{v} \quad \boldsymbol{v}$ & $\infty$ \\
\hline 4 & के & $\pi$ & 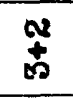 \\
\hline$\ddot{3}$ & + & $\boldsymbol{v}$ & $\omega$ \\
\hline$\ddot{8}$ & 华 & & - \\
\hline 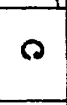 & 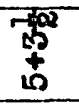 & -1 & $\begin{array}{l}x^{x} \\
+ \\
0\end{array}$ \\
\hline$\ddot{\circ}$ & 1 & & 1 \\
\hline$\ddot{\alpha}$ & $\infty$ & & $\infty$ \\
\hline$\ddot{\check{o}}$ & $\infty$ & $\stackrel{-r a x}{-r}$ & $x^{2}$ \\
\hline$\ddot{\ddot{\partial}}$ & $\boldsymbol{v}$ & & $\boldsymbol{N}$ \\
\hline 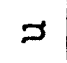 & 1 & & 1 \\
\hline$\ddot{\Xi}$ & 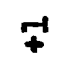 & & 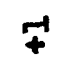 \\
\hline & $\stackrel{4}{m}$ & $\ddot{\oplus} \dot{-}$ & \\
\hline
\end{tabular}




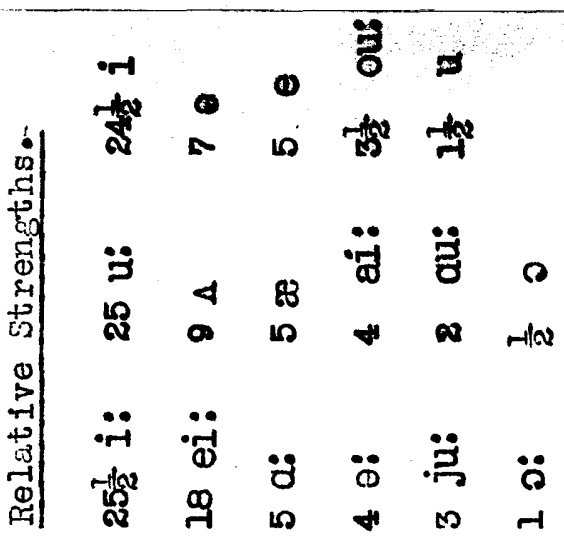

\begin{tabular}{|c|c|c|}
\hline$\ddot{\ddot{1}}$ & 敕 & 形我 \\
\hline$\cdot-1$ & 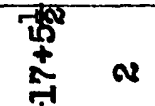 & 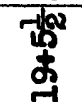 \\
\hline$\ddot{-1}$ & $-\sqrt{\infty}$ & 热 \\
\hline (1) & $\stackrel{+1}{ \pm}$ & $\stackrel{F}{+}$ \\
\hline$\omega$ & 1 & 1 \\
\hline$\&$ & $\underset{\varpi}{\ddagger}$ & $\underset{\sharp}{ \pm}$ \\
\hline$\ddot{\ddot{\sigma}}$ & $H$ & + \\
\hline (1) & $+6^{2}+\ldots$ & $\mp$ \\
\hline$\ddot{i}$ & न & 喍 \\
\hline 4 & $\underset{⿱}{+}$ & $\underset{⿱ 亠 乂}{+}$ \\
\hline$\ddot{\Xi}$ & $\infty$ & $\boldsymbol{v}$ \\
\hline$\ddot{\sigma}$ & $\stackrel{+1}{+}$ & 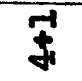 \\
\hline 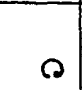 & $-12 x$ & +2 \\
\hline$\ddot{\ddot{b}}$ & 1 & 1 \\
\hline$\ddot{\circ}$ & -1 & $\rightarrow$ \\
\hline$\ddot{z}$ & 轵 & do \\
\hline 芦 & $\infty$ & $m$ \\
\hline$z$ & 4 & क \\
\hline$\ddot{\ddot{z}}$ & $\mathfrak{3}$ & ล \\
\hline & $\dot{m} \dot{m}$ & \\
\hline
\end{tabular}




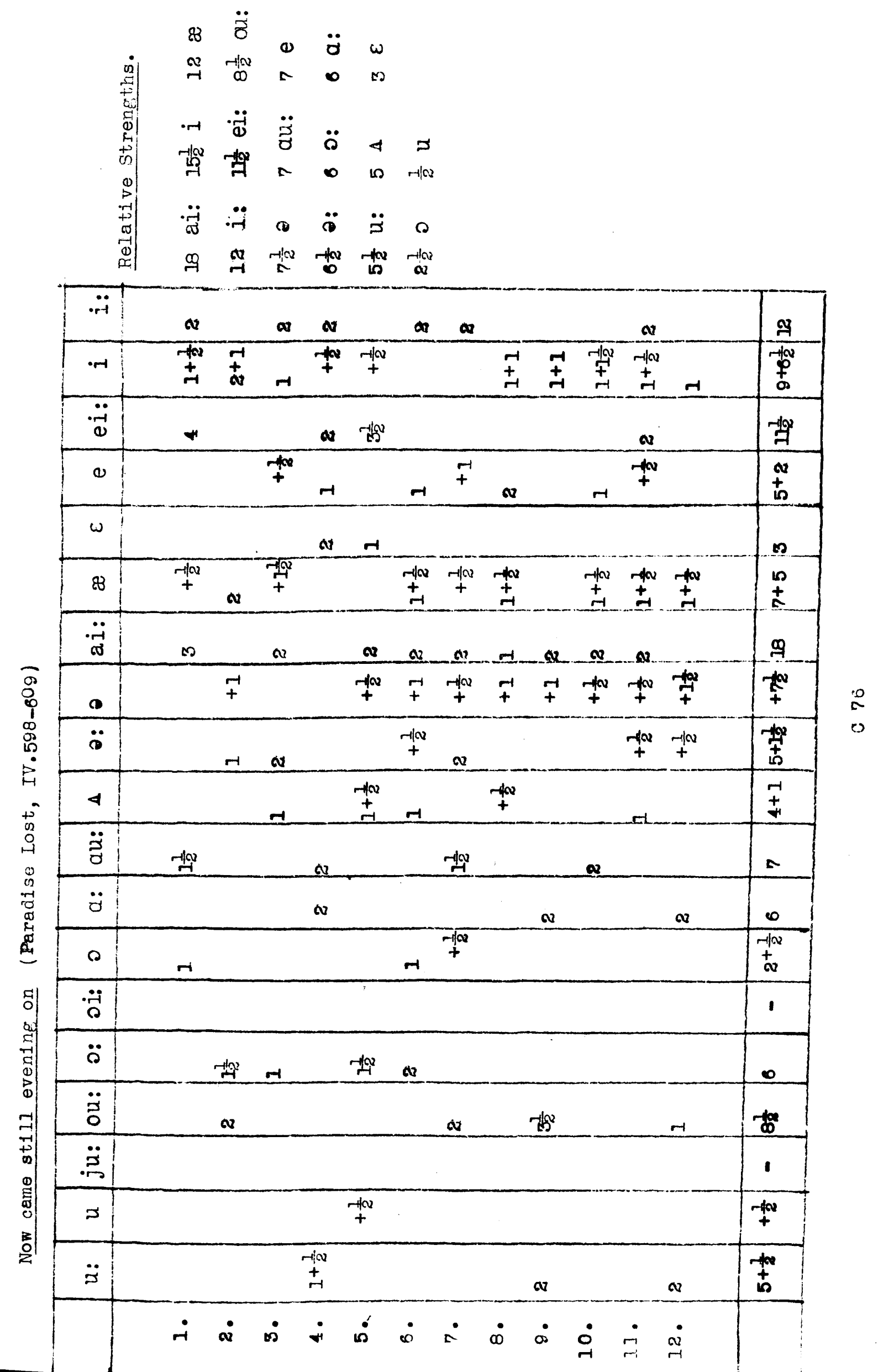




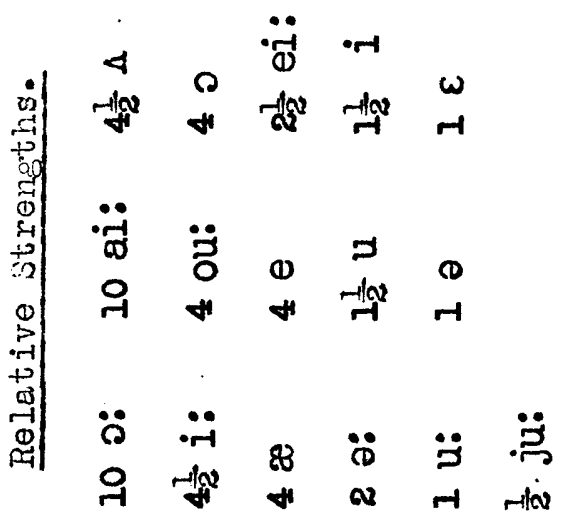

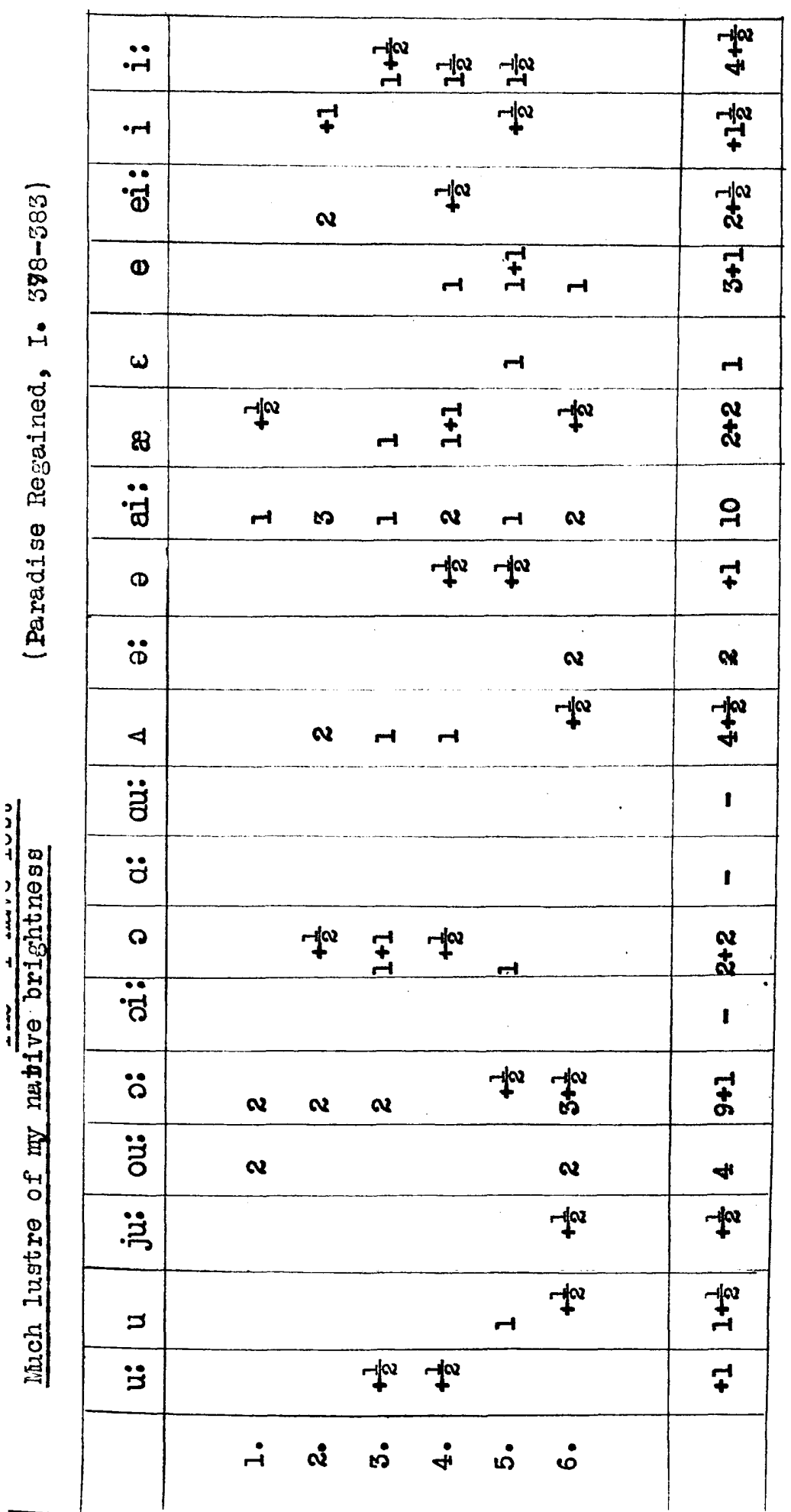




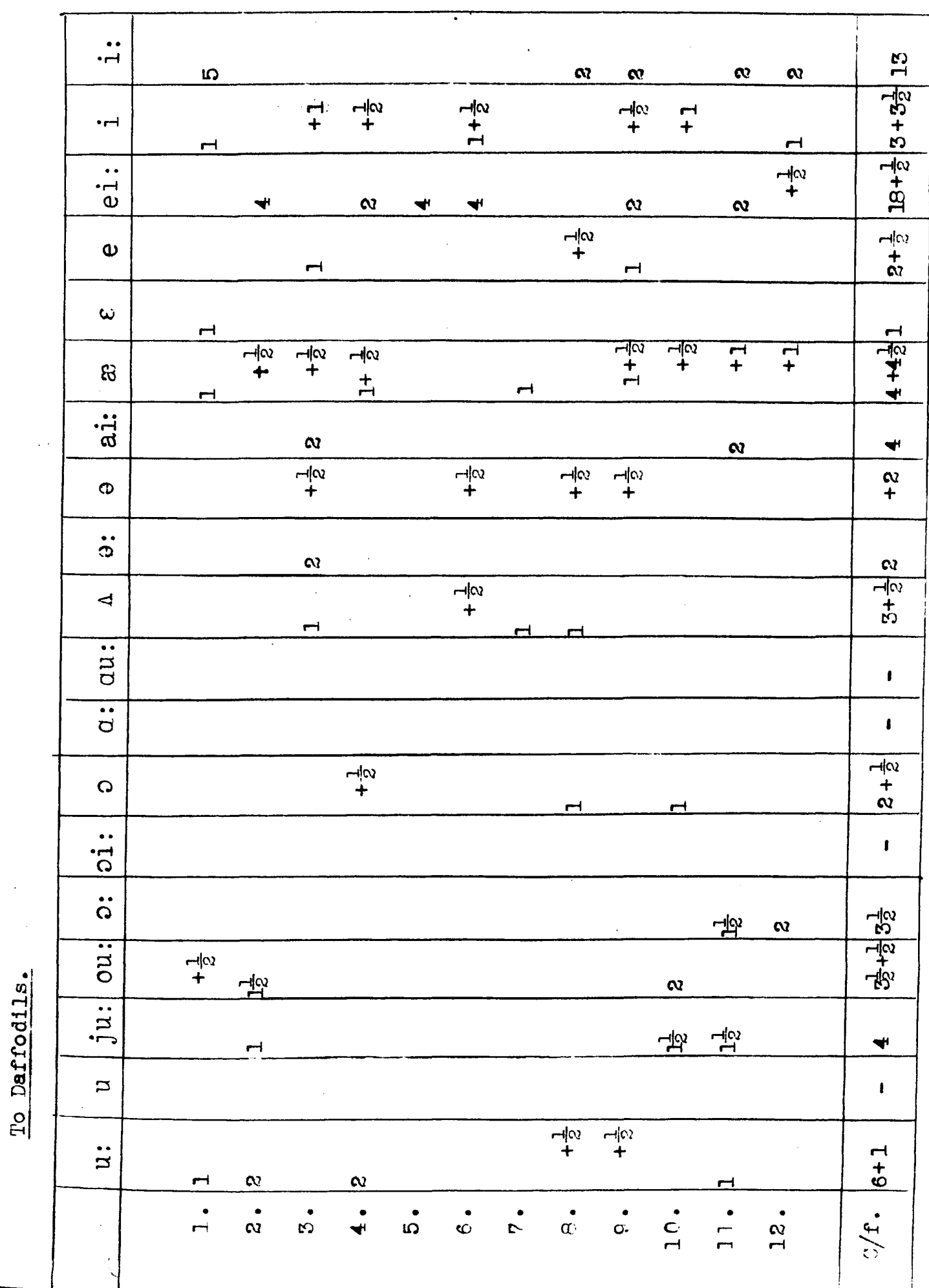




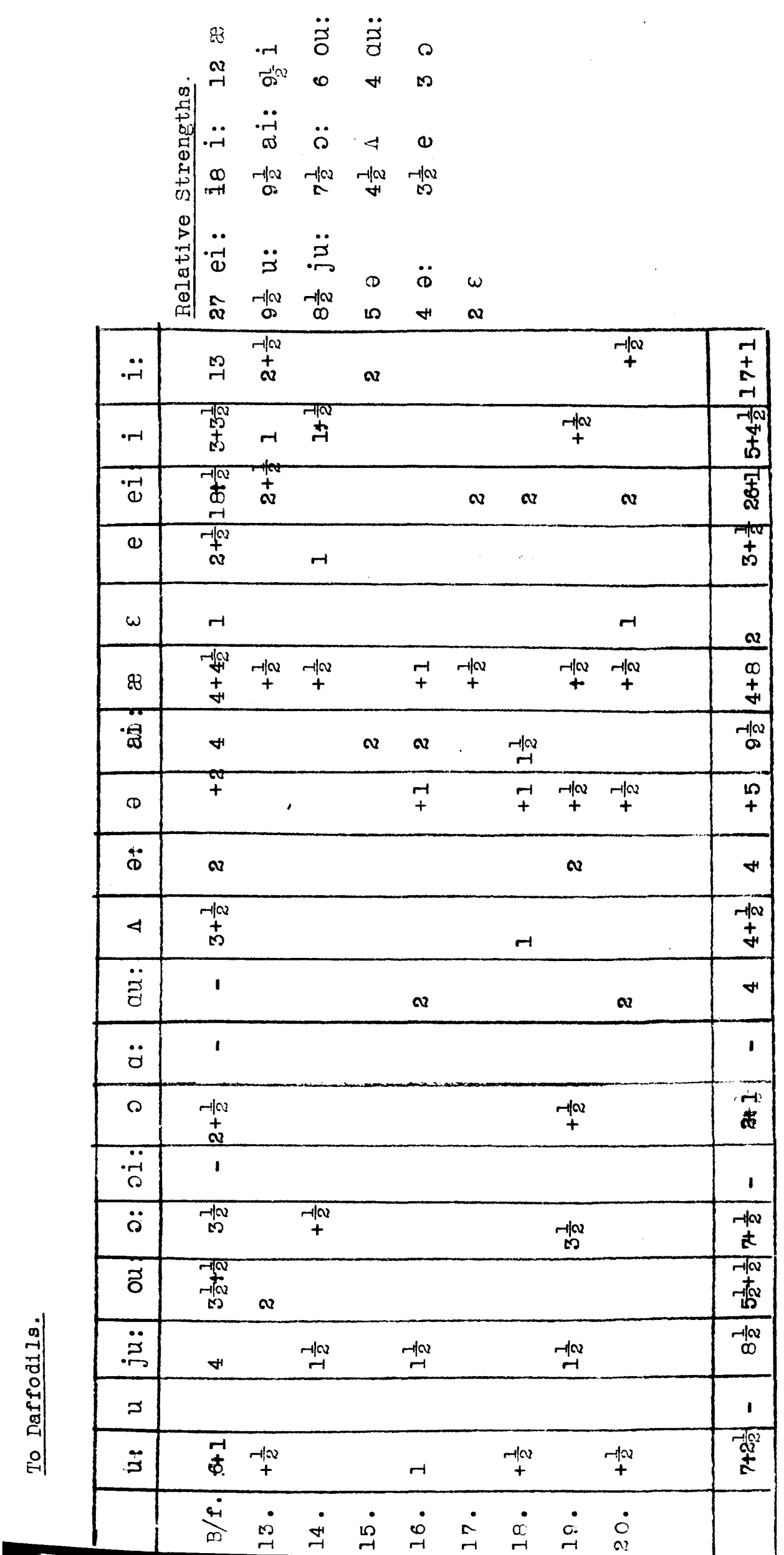




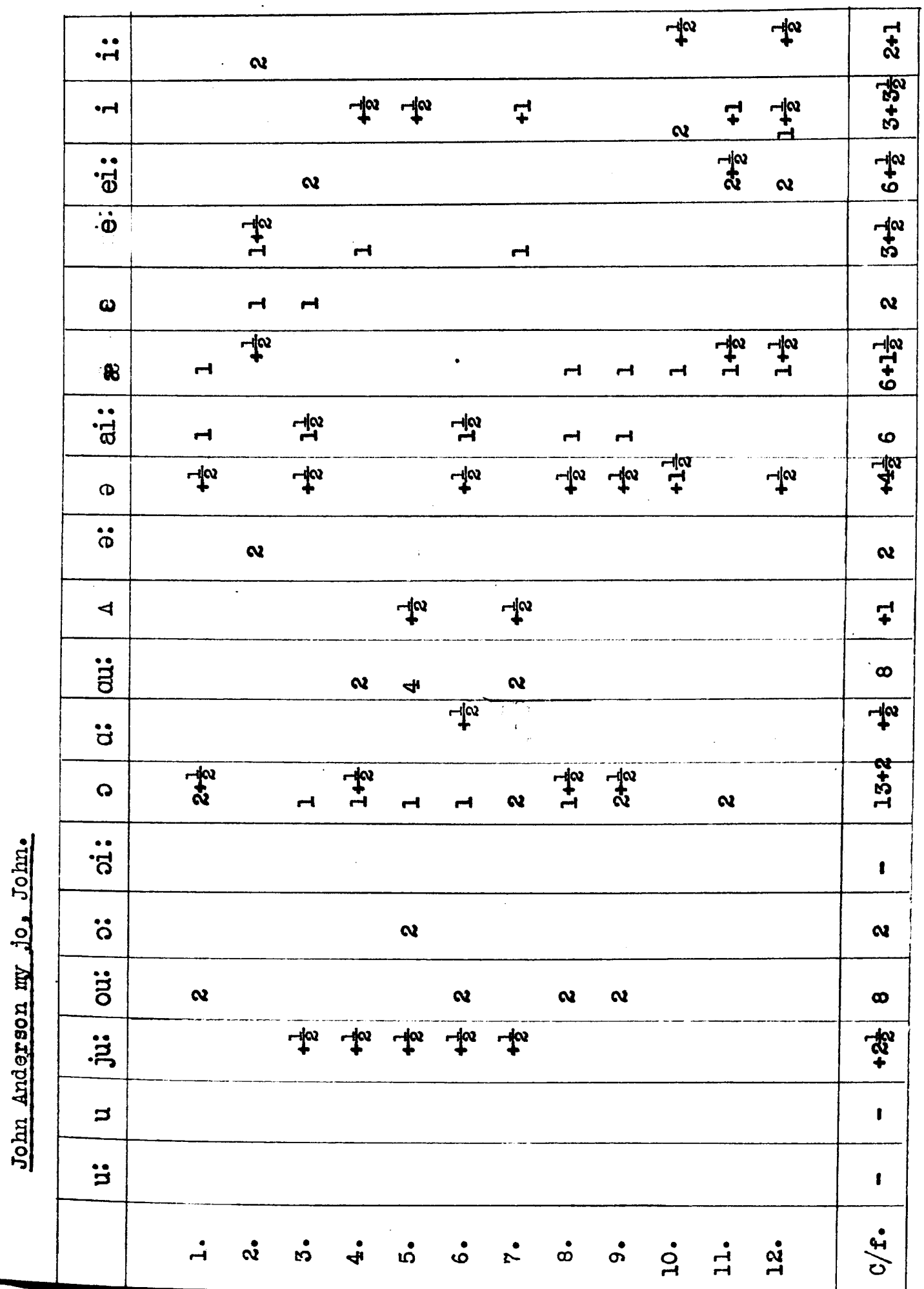




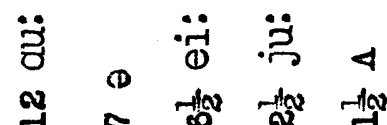

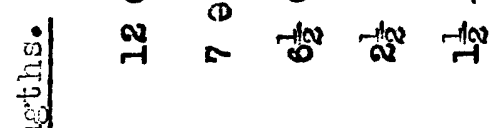

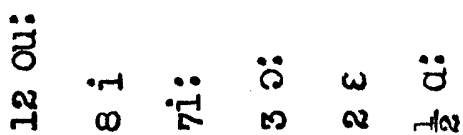

0
5
+-1
+3
-1
0
01

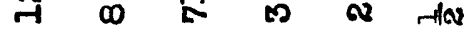

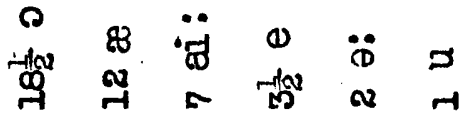

\begin{tabular}{|c|c|c|c|c|c|c|}
\hline تיָ. & $\vec{\ddagger}$ & 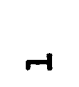 & ot & $\sim$ & & $\stackrel{-1}{+}$ \\
\hline$\cdot r-1$ & 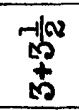 & & $-1 \sqrt{a}$ & -1 & & 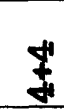 \\
\hline$\ddot{\ddot{\omega}}$ & $\begin{array}{l}-1 \\
1 \\
0\end{array}$ & & & & & $\begin{array}{c}-1+\infty \\
0 \\
0\end{array}$ \\
\hline () & 卢 & & & & & 年 \\
\hline$\omega$ & $\boldsymbol{v}$ & & & & & $v$ \\
\hline 88 & 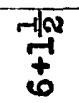 & & $\boldsymbol{v}$ & $\underset{-1}{-1}$ & -1 & $\underset{\gamma}{\tilde{\varphi}}$ \\
\hline$\ddot{\ddot{D}}$ & 0 & & & & $r$ & $\pi$ \\
\hline D & $\underset{7}{7+\infty}$ & $-1+\infty$ & & $\stackrel{-1 / w}{+}$ & -70 & $\uparrow$ \\
\hline$\ddot{d}$ & $v$ & & & & & $\boldsymbol{v}$ \\
\hline 4 & 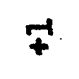 & & $-1+\infty$ & & & $\frac{-19 x}{4}$ \\
\hline$\ddot{\Xi}$ & $\infty$ & + & & & & $\underset{\sim}{\mathfrak{N}}$ \\
\hline$\ddot{z}$ & $7 \rightarrow$ & & & & & $+\infty$ \\
\hline 0 & $\underset{+}{a}$ & $\boldsymbol{v}$ & & & $\underset{-1}{+\infty}$ & $\begin{array}{l}\text { नdra } \\
\vdots \\
\vdots\end{array}$ \\
\hline$\ddot{\ddot{\theta}}$ & 1 & . & & & & 1 \\
\hline$\ddot{\rho}$ & $\boldsymbol{\alpha}$ & -1 & & & & $\boldsymbol{B}$ \\
\hline$\ddot{z}$ & $\infty$ & & $\boldsymbol{N}$ & & $\boldsymbol{N}$ & $\underset{\sim}{\tilde{H}}$ \\
\hline 芦 & $\begin{array}{c}-19 \\
+ \\
+\end{array}$ & & & & & 管 \\
\hline$x$ & 1 & & & -1 & & $r-1$ \\
\hline$\ddot{g}$ & 1 & & & & & 1 \\
\hline & $\dot{\leftrightarrow}$ & $\dot{\leftrightarrow}$ & $\underset{H}{\dot{H}}$ & $\dot{\sim}$ & $\dot{\leftrightarrow}$ & \\
\hline
\end{tabular}




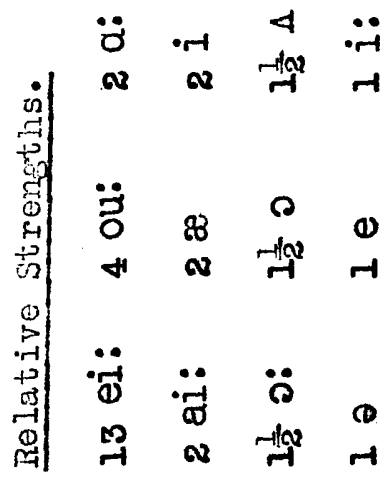

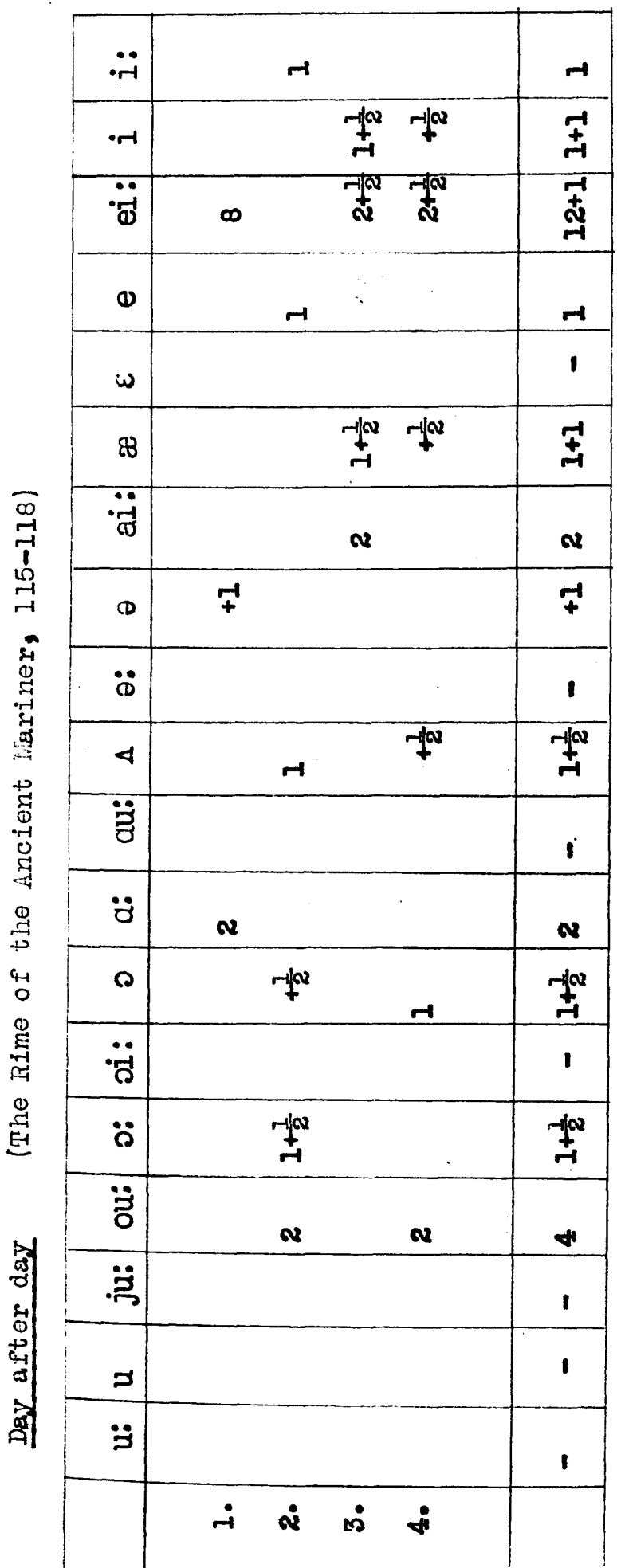




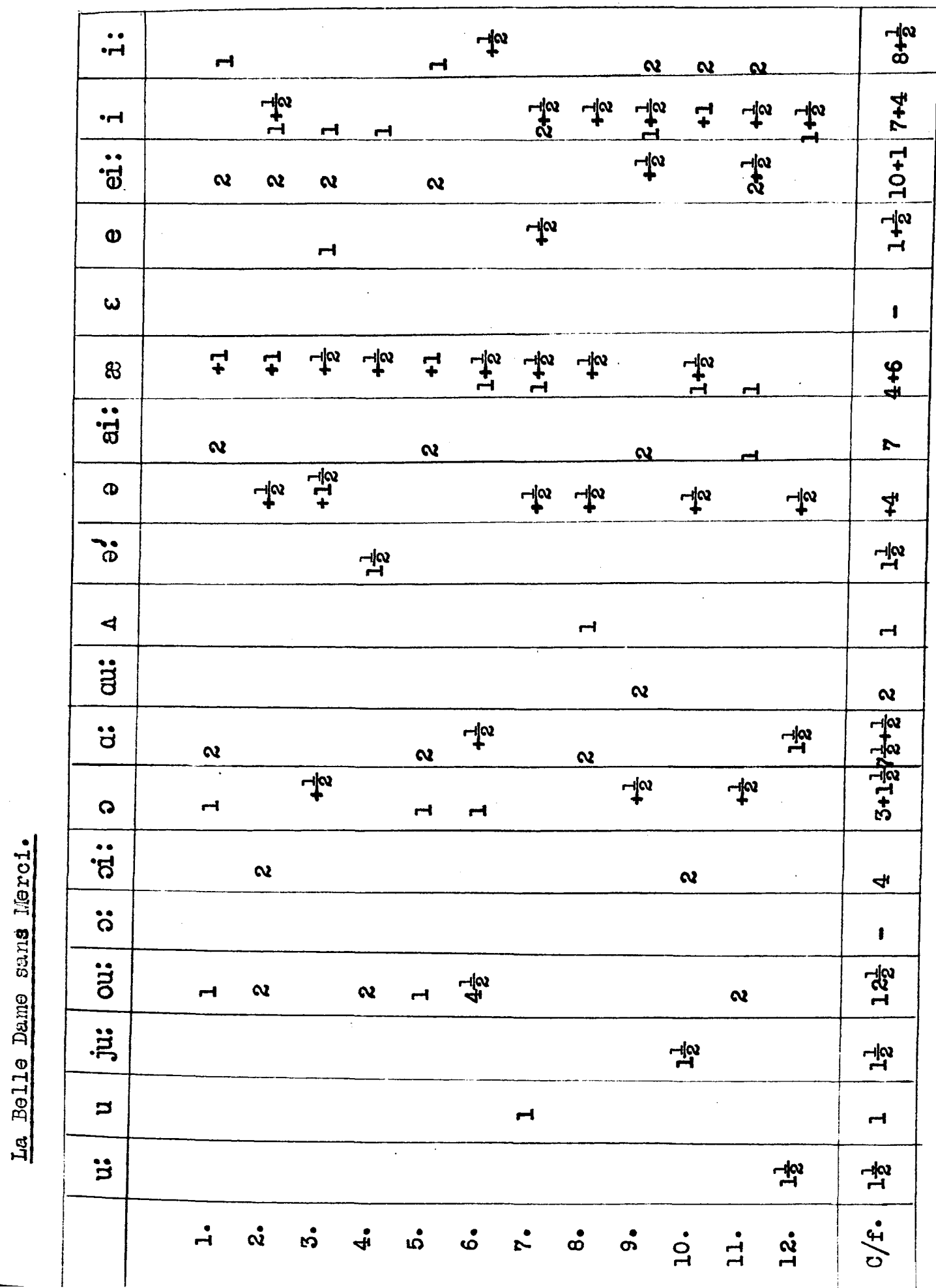




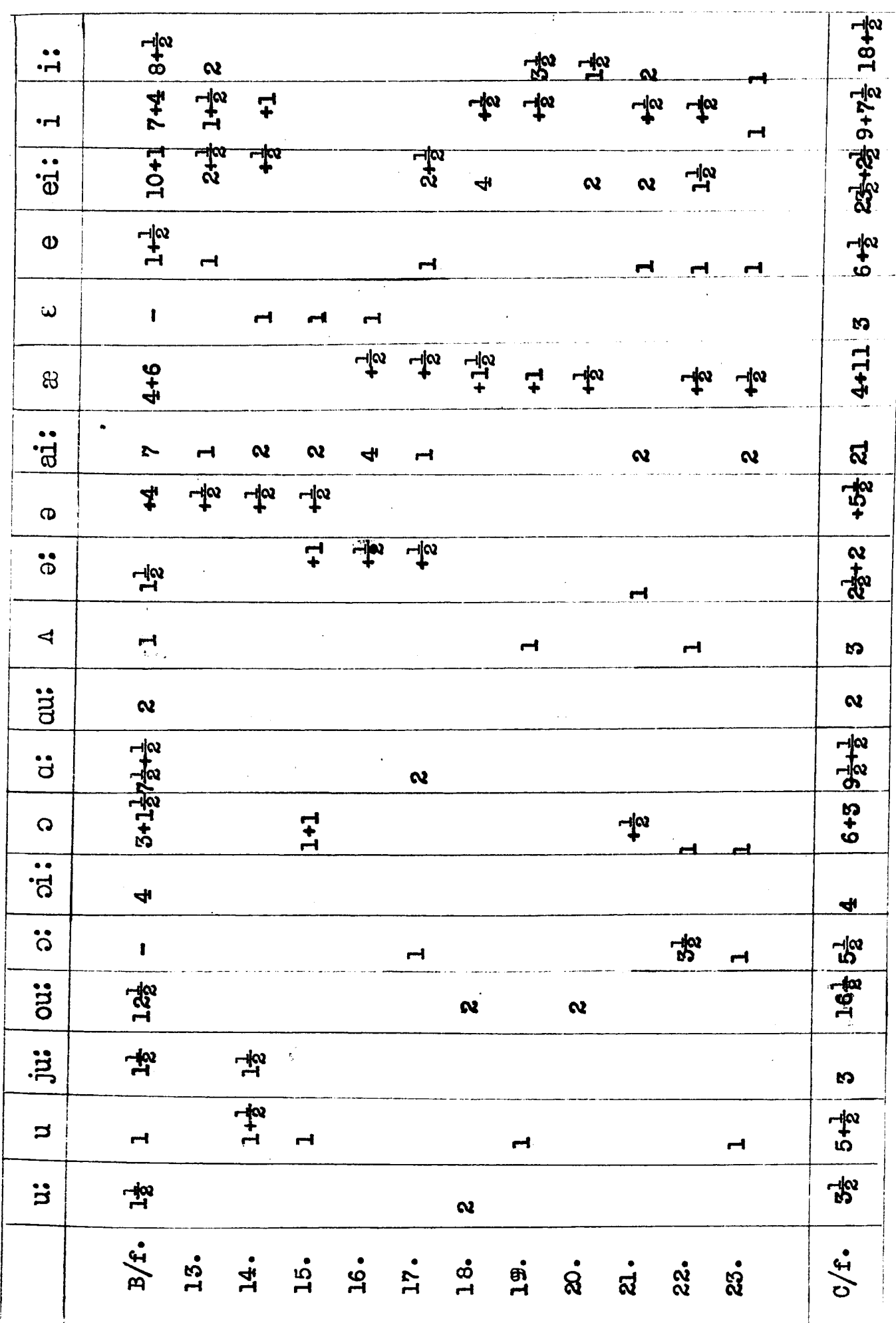




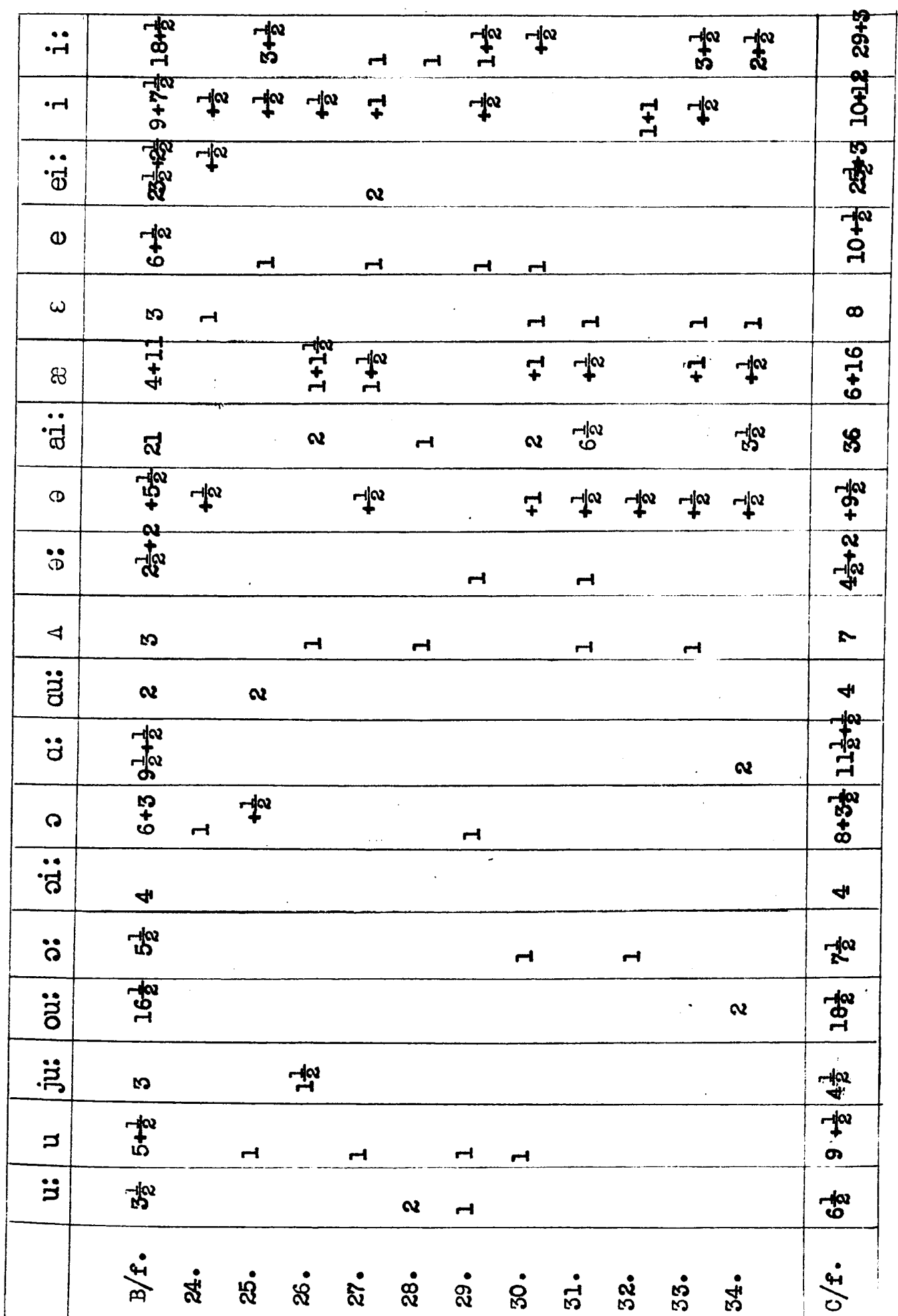




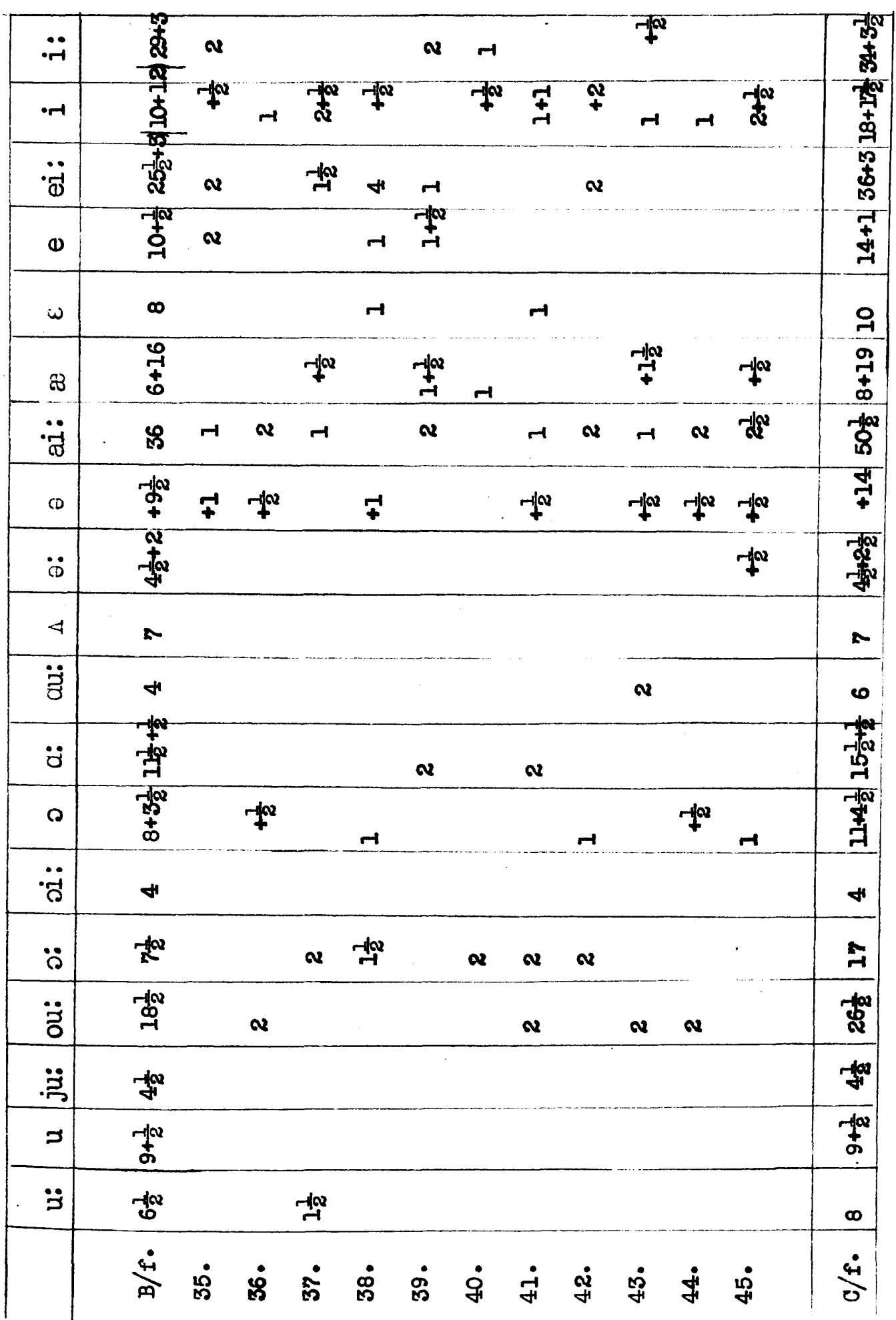

ㅁำ
ณิ
v 


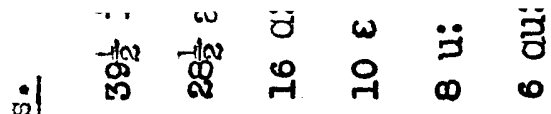

$\begin{array}{llllll}\ddot{0} & \ddot{z} & 0 & 0 & \ddot{0} & \ddot{0}\end{array}$

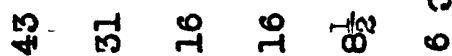

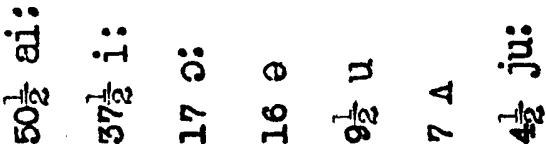

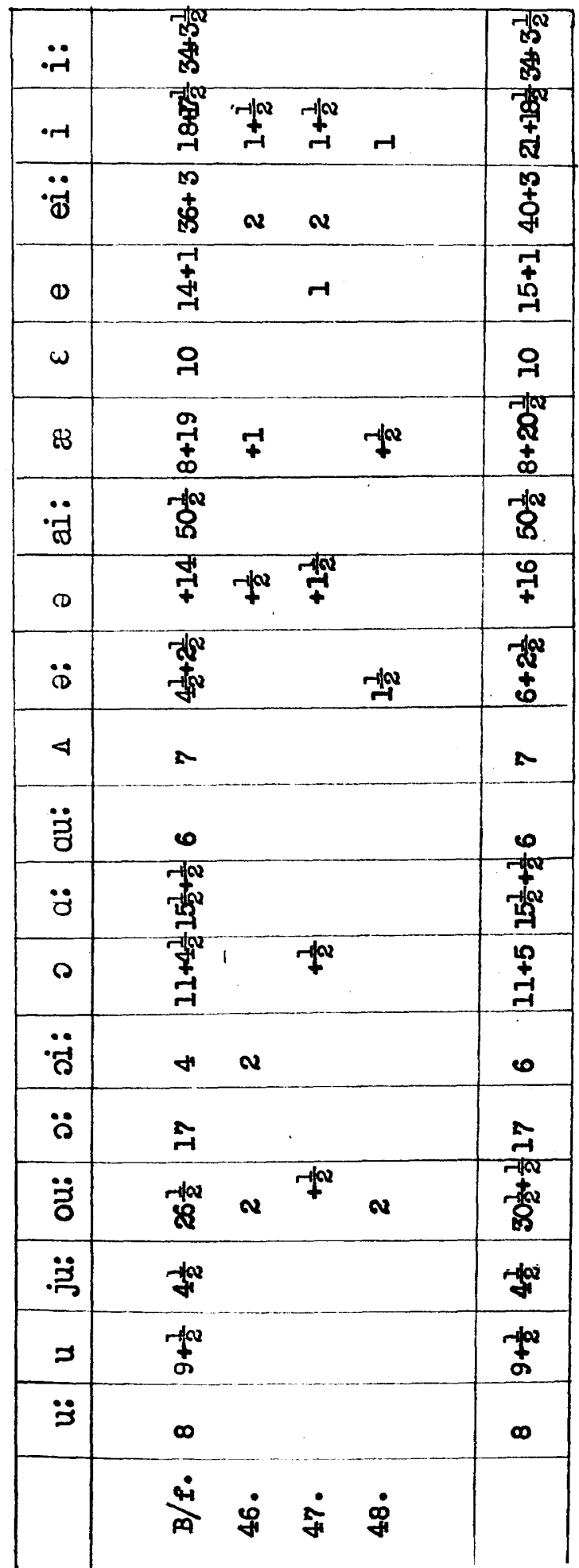




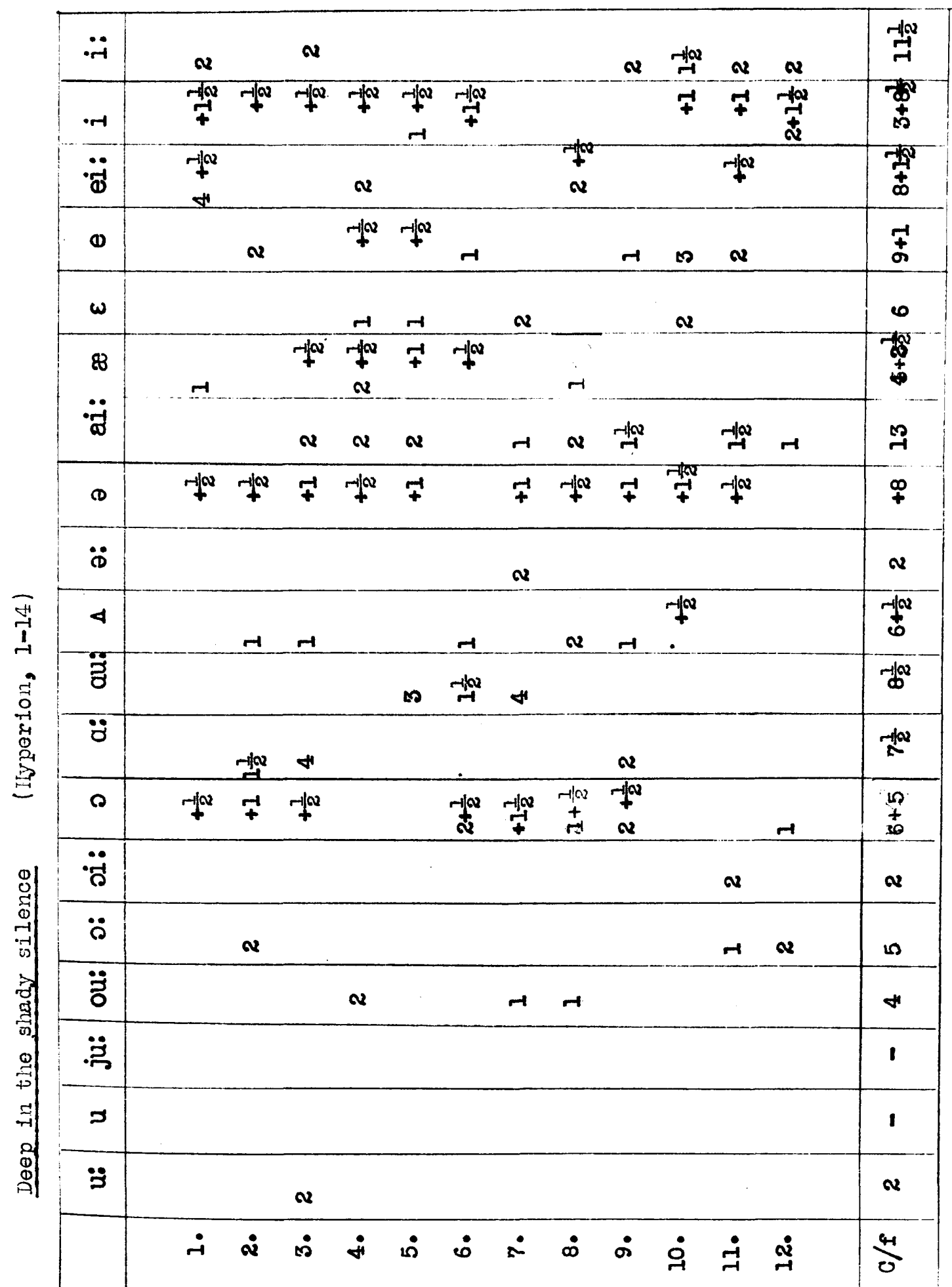




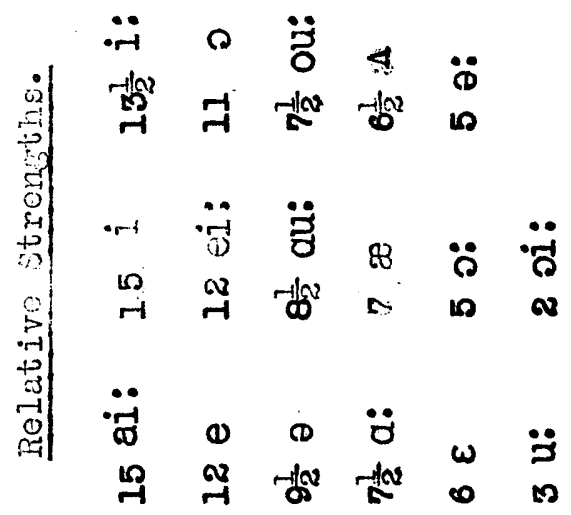

\begin{tabular}{|c|c|c|c|c|}
\hline$\ddot{~}$ & $\underset{F}{r-1 / N}$ & $v$ & & 片 \\
\hline$\cdot r-r$ & $\begin{array}{l}\text { rlda } \\
\text { के } \\
+\end{array}$ & $\stackrel{+1}{+\infty}$ & $\boldsymbol{\sim}$ & @) \\
\hline$\ddot{\ddot{d}}$ & $\underset{+}{+\frac{1 N}{1}}$ & $\begin{array}{l}-1 / x \\
N\end{array}$ & & 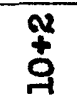 \\
\hline $\boldsymbol{\omega}$ & 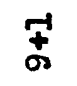 & $\boldsymbol{H}$ & -1 & $\vec{\ddagger}$ \\
\hline$\omega$ & $\omega$ & & & 0 \\
\hline 18 & 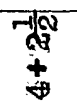 & -10 & & 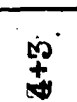 \\
\hline$\ddot{\ddot{\sigma}}$ & $\ddot{F}$ & $\boldsymbol{N}$ & & $\underset{\pi}{10}$ \\
\hline (D) & $\stackrel{\infty}{+}$ & -7 & 7 & - \\
\hline
\end{tabular}




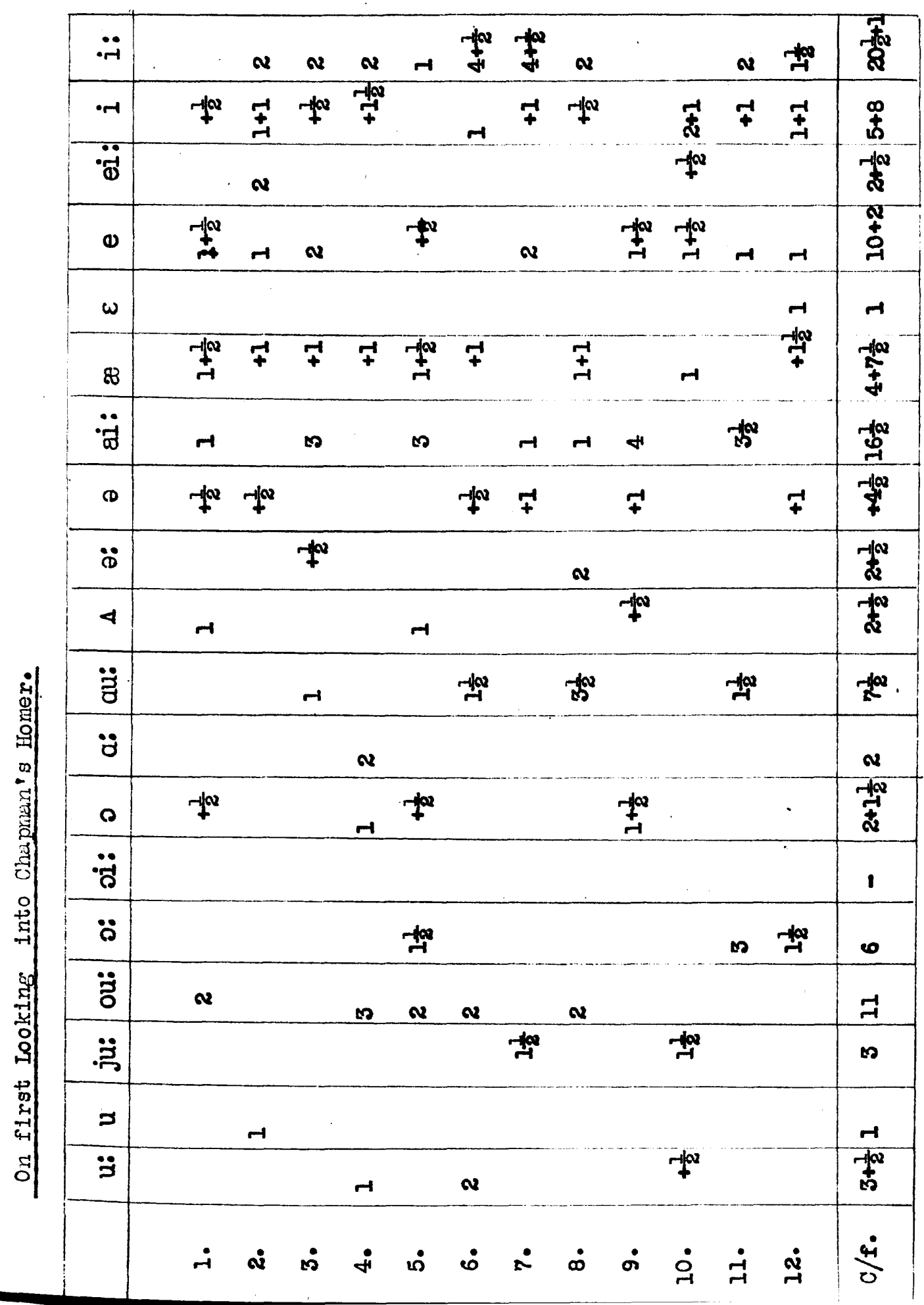




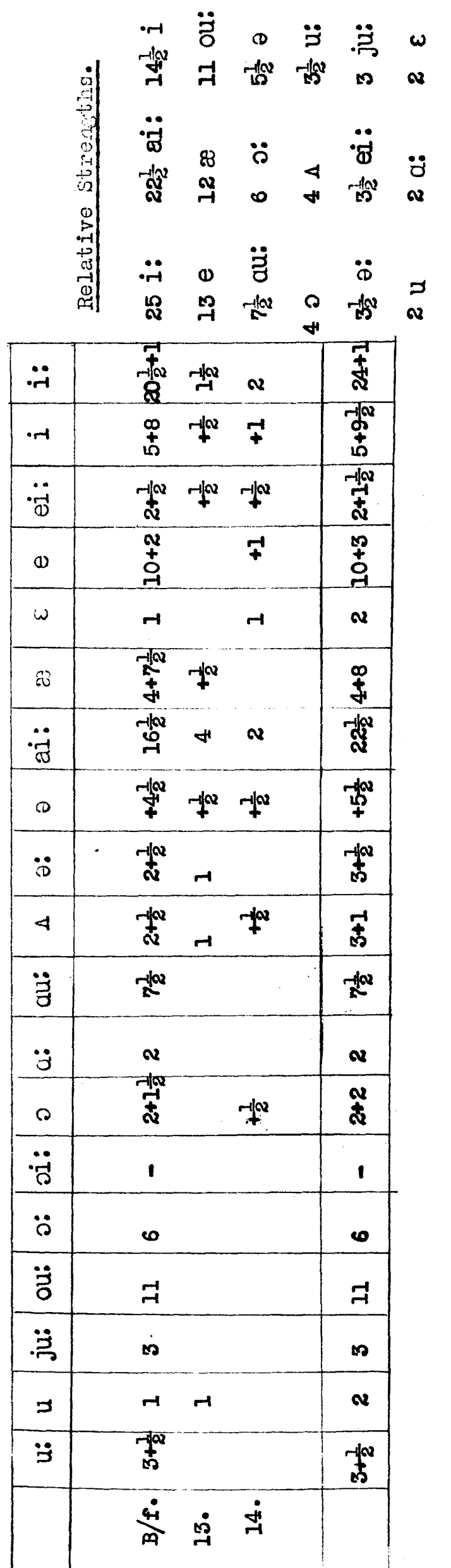




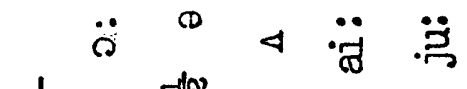

i.

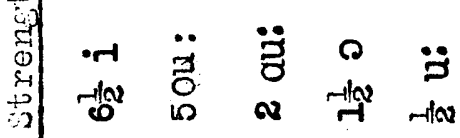

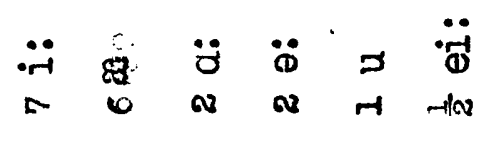

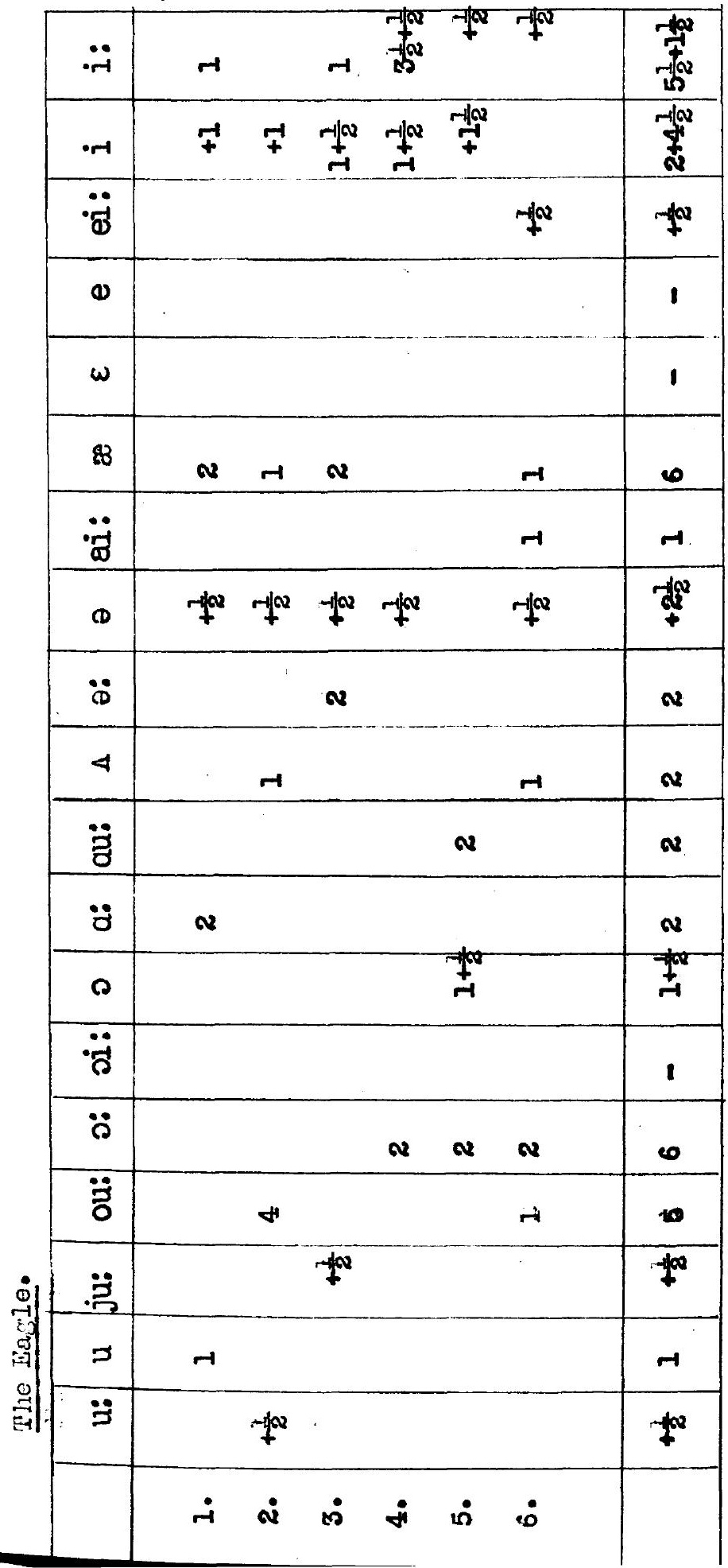




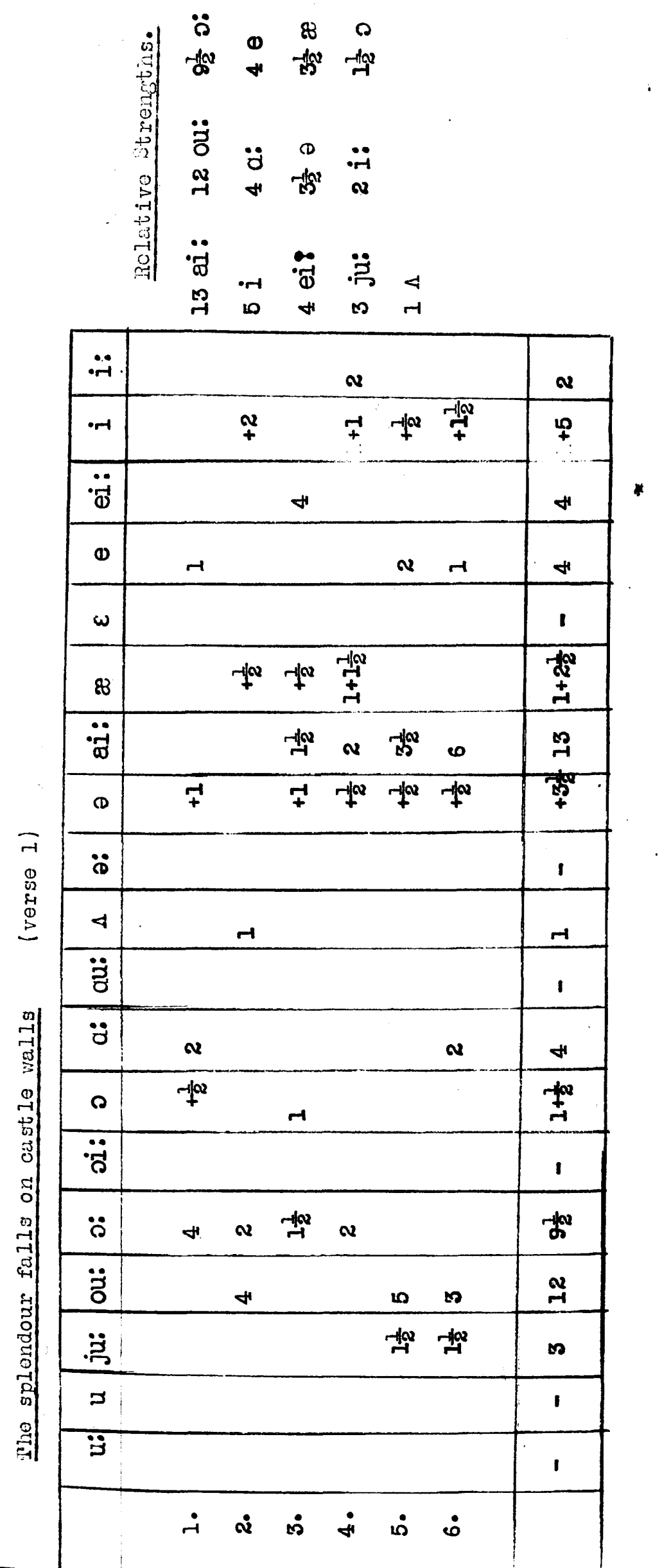




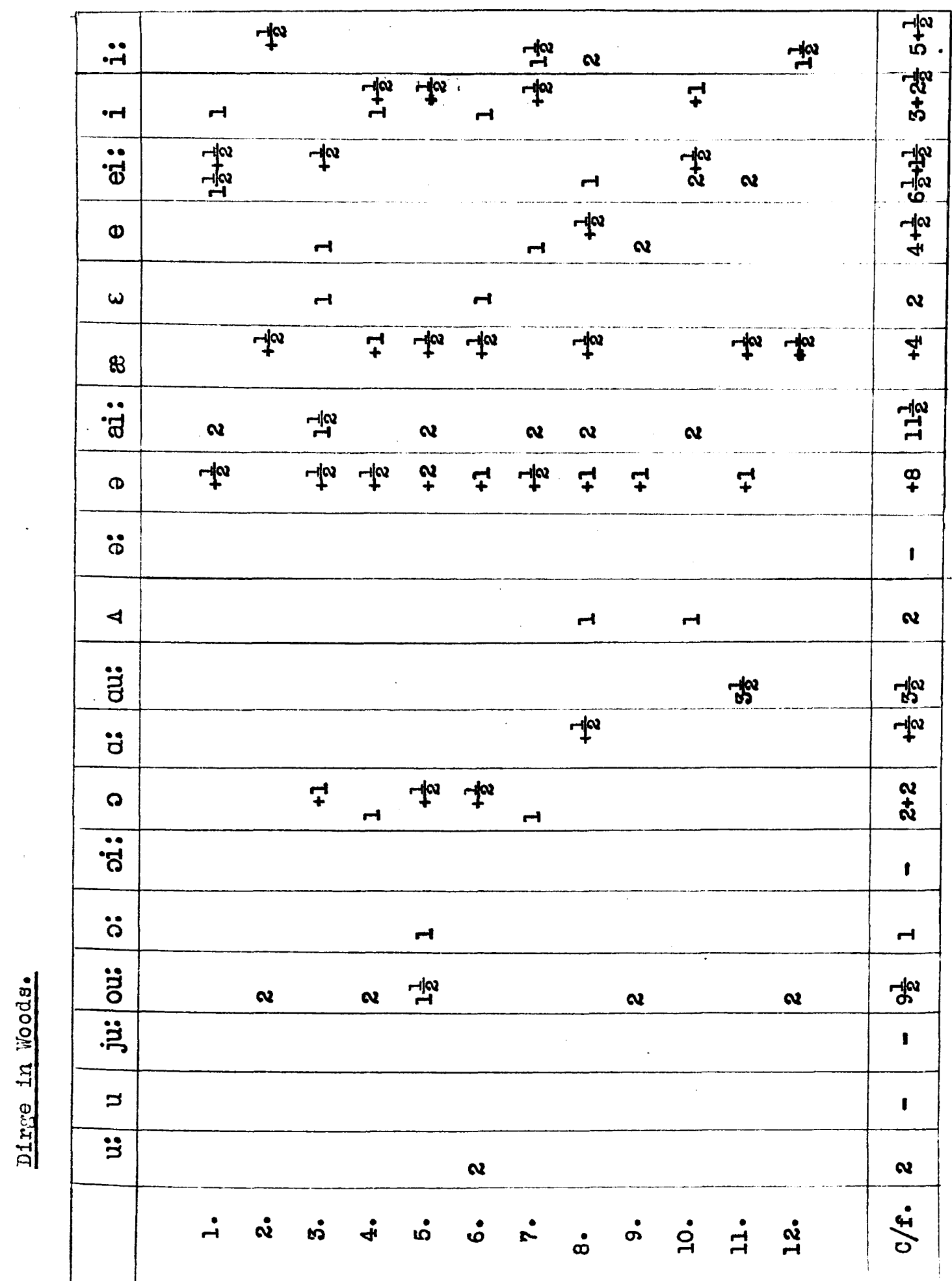




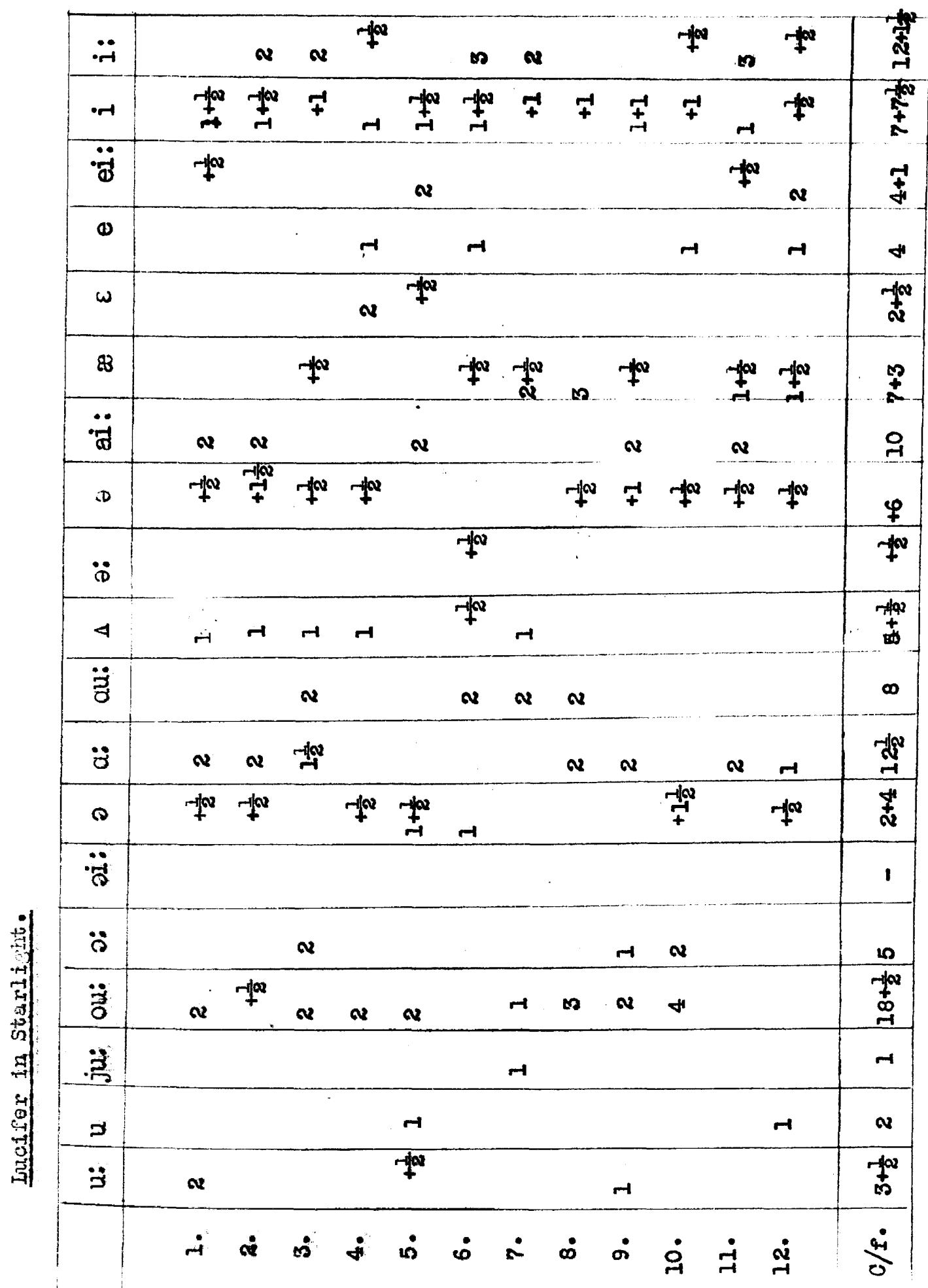




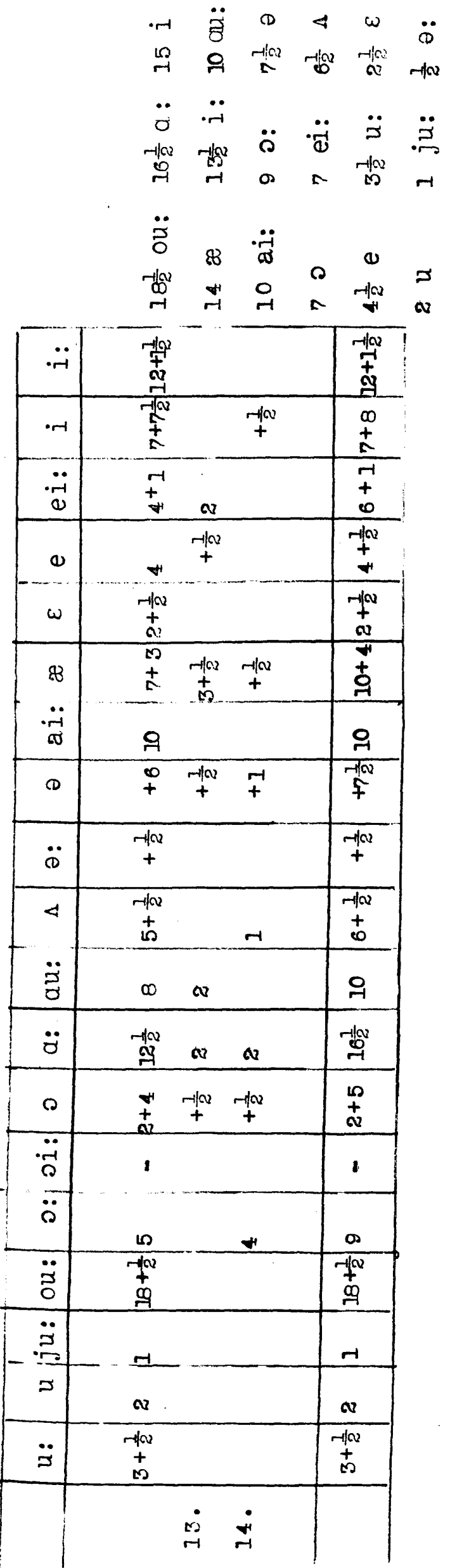




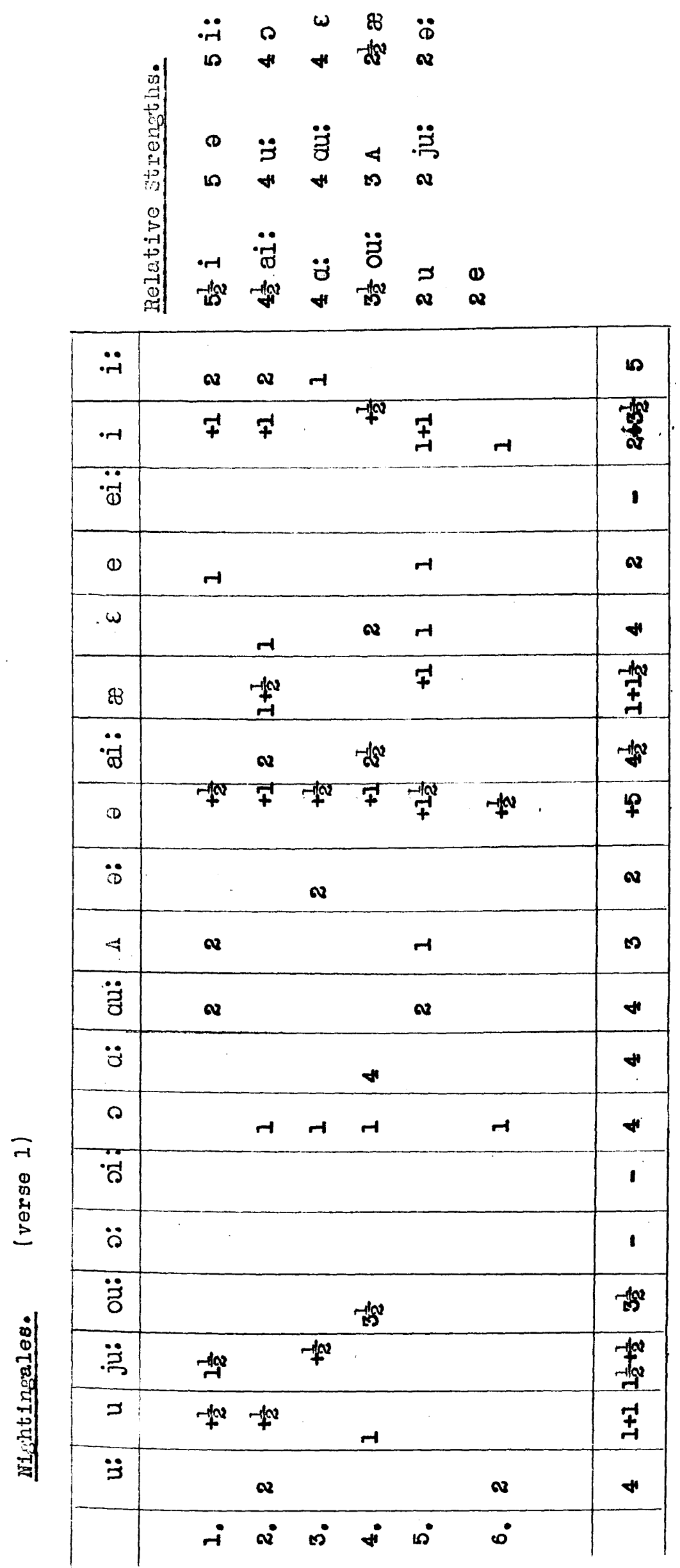




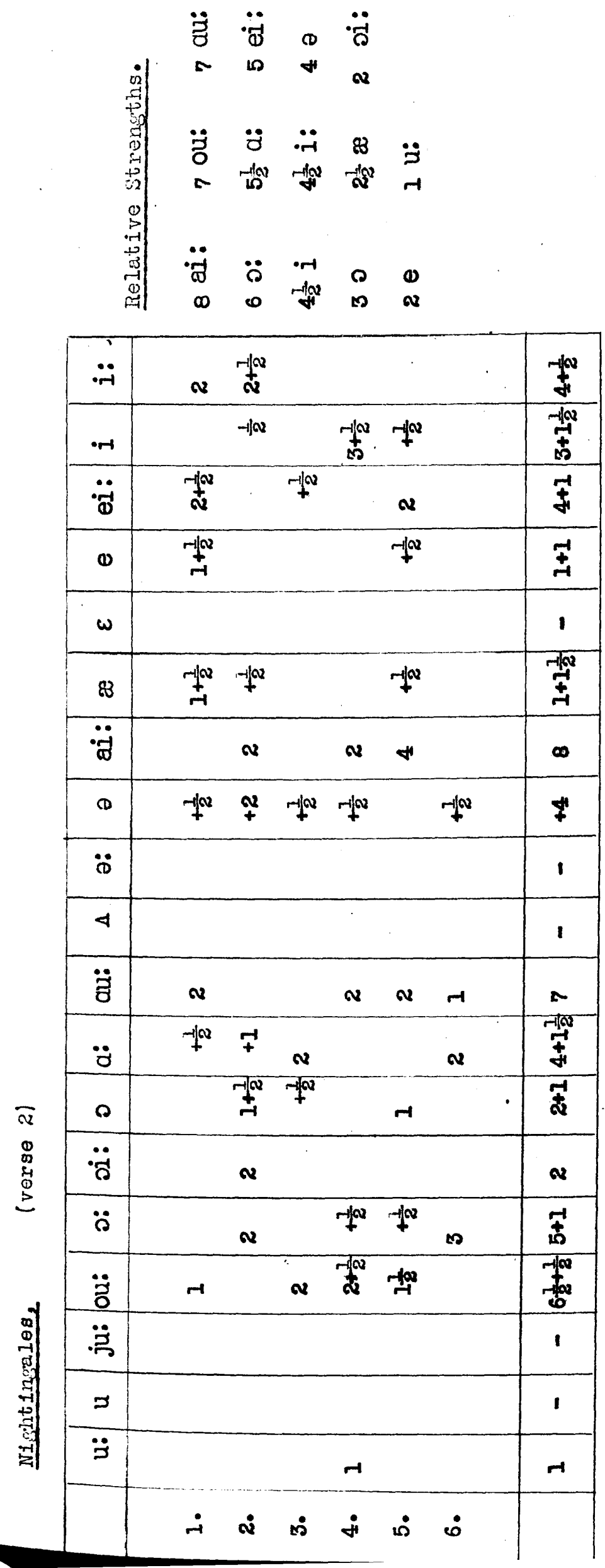




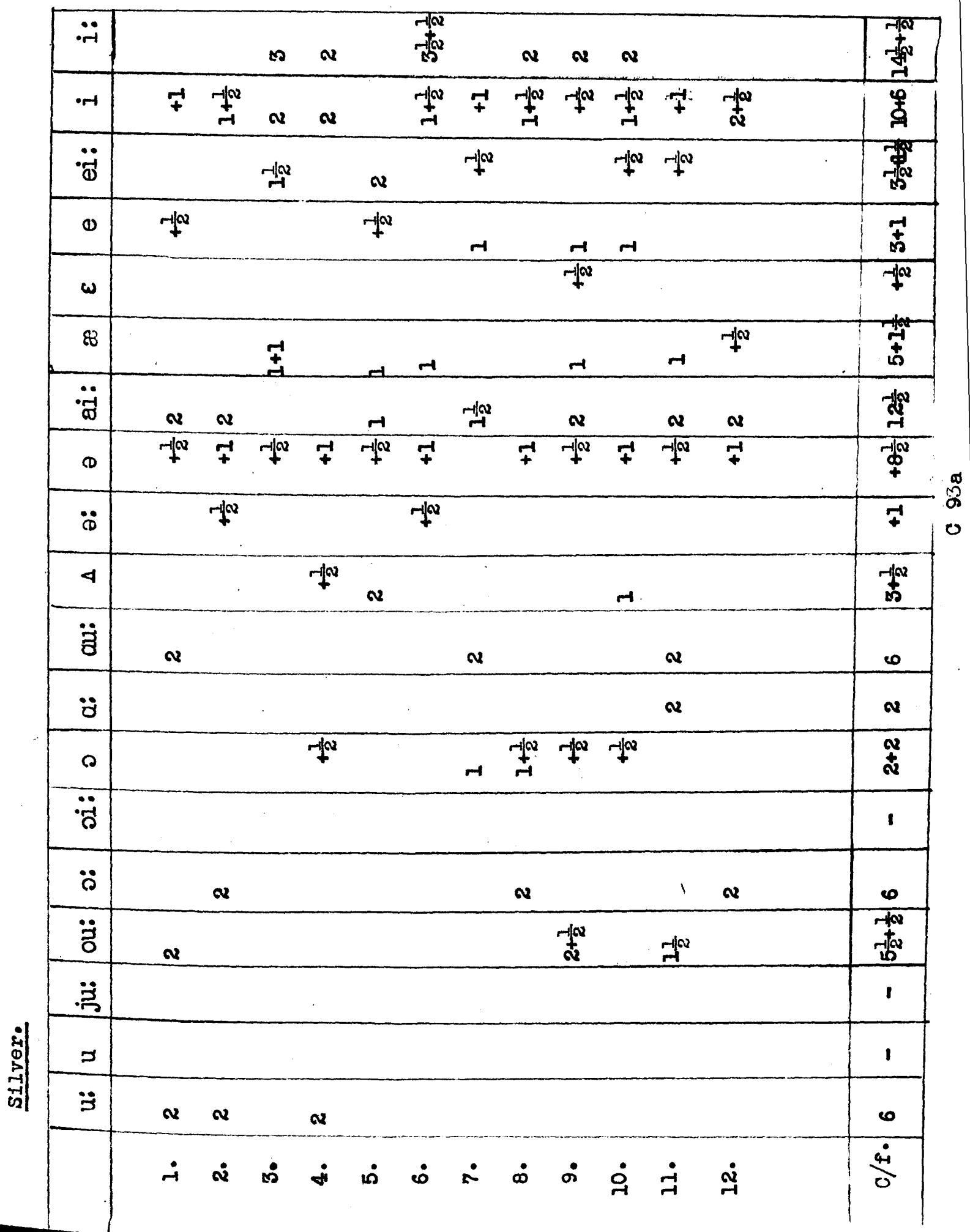




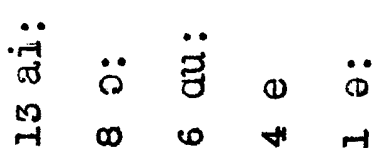

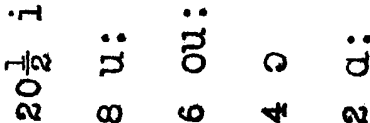

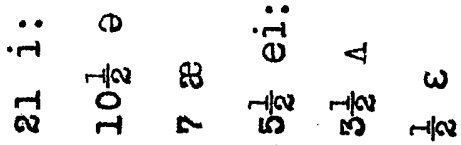

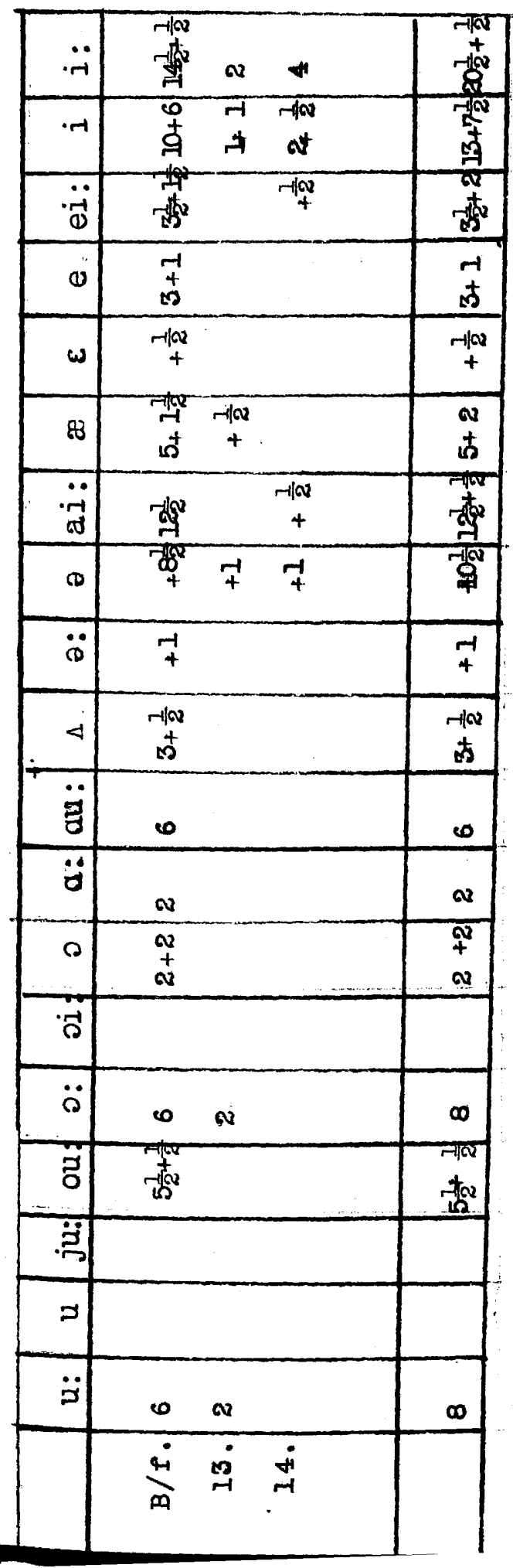




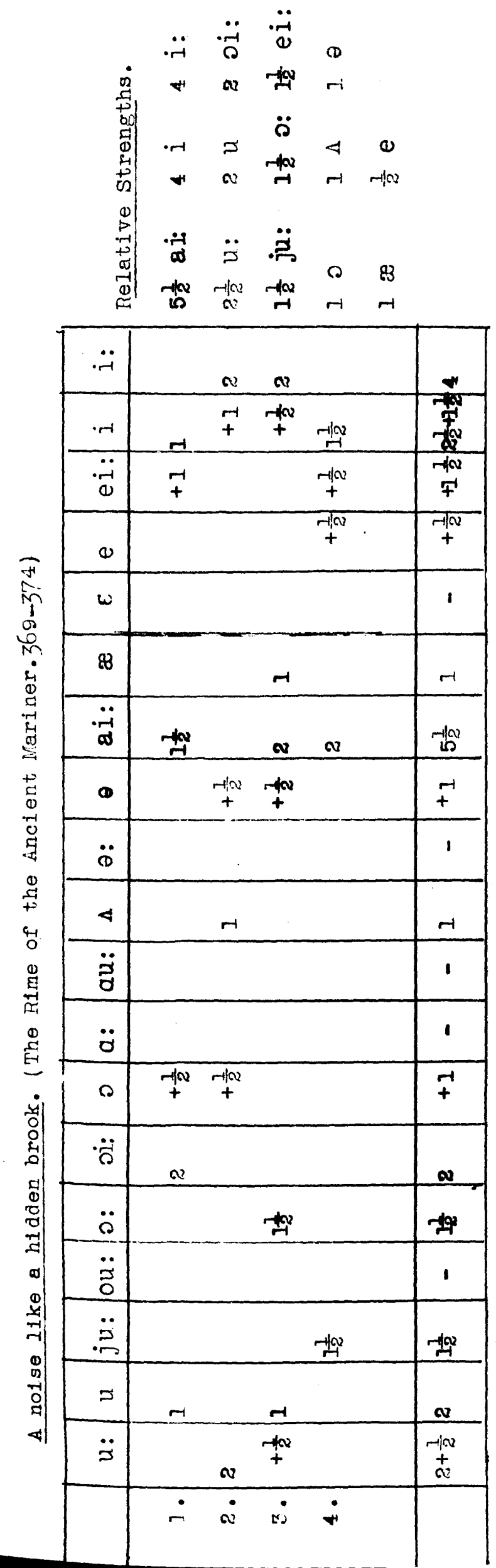




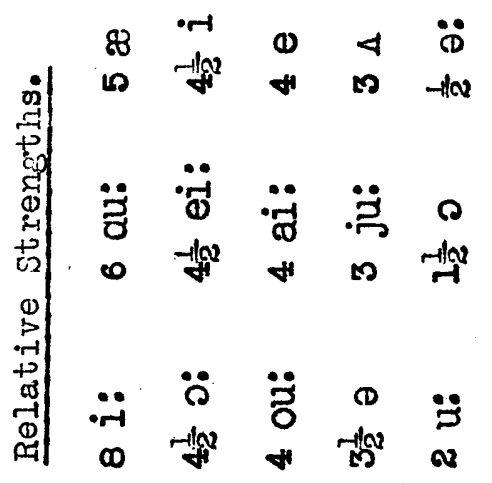

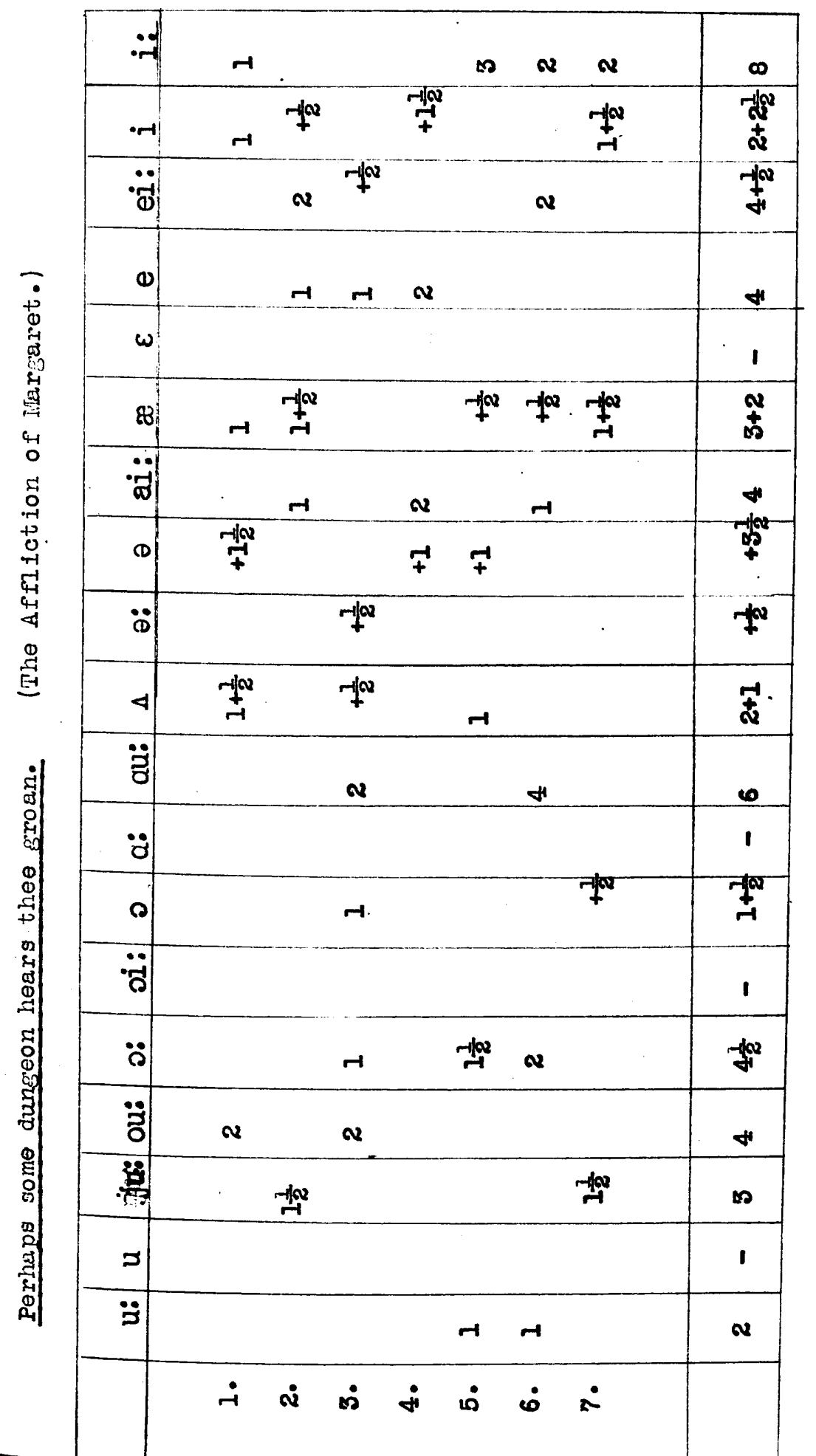




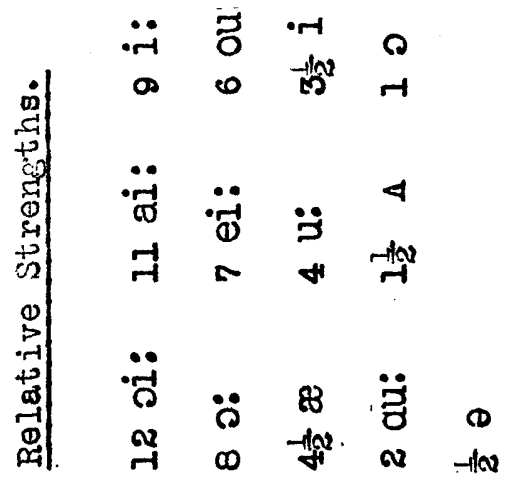

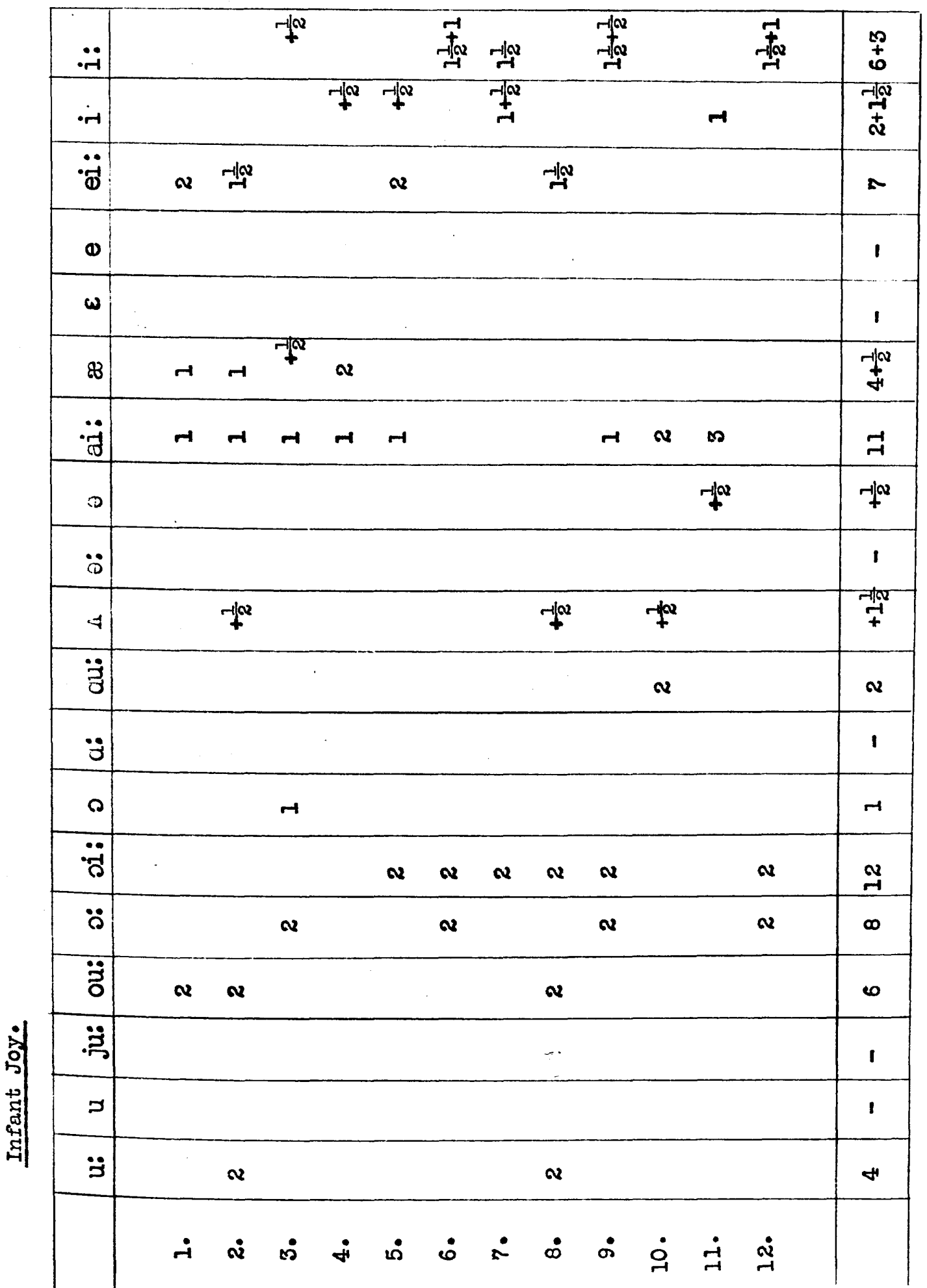




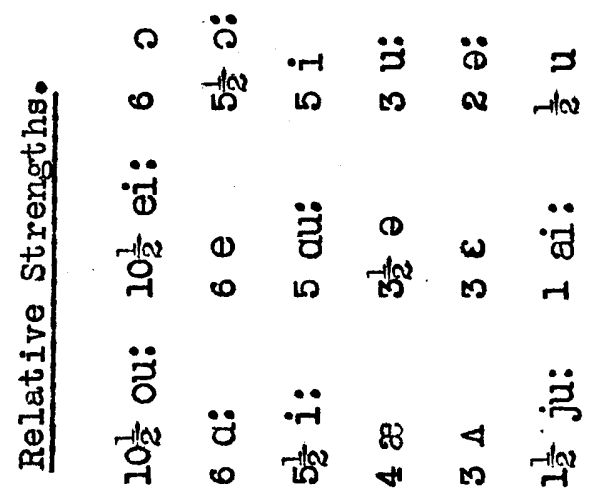

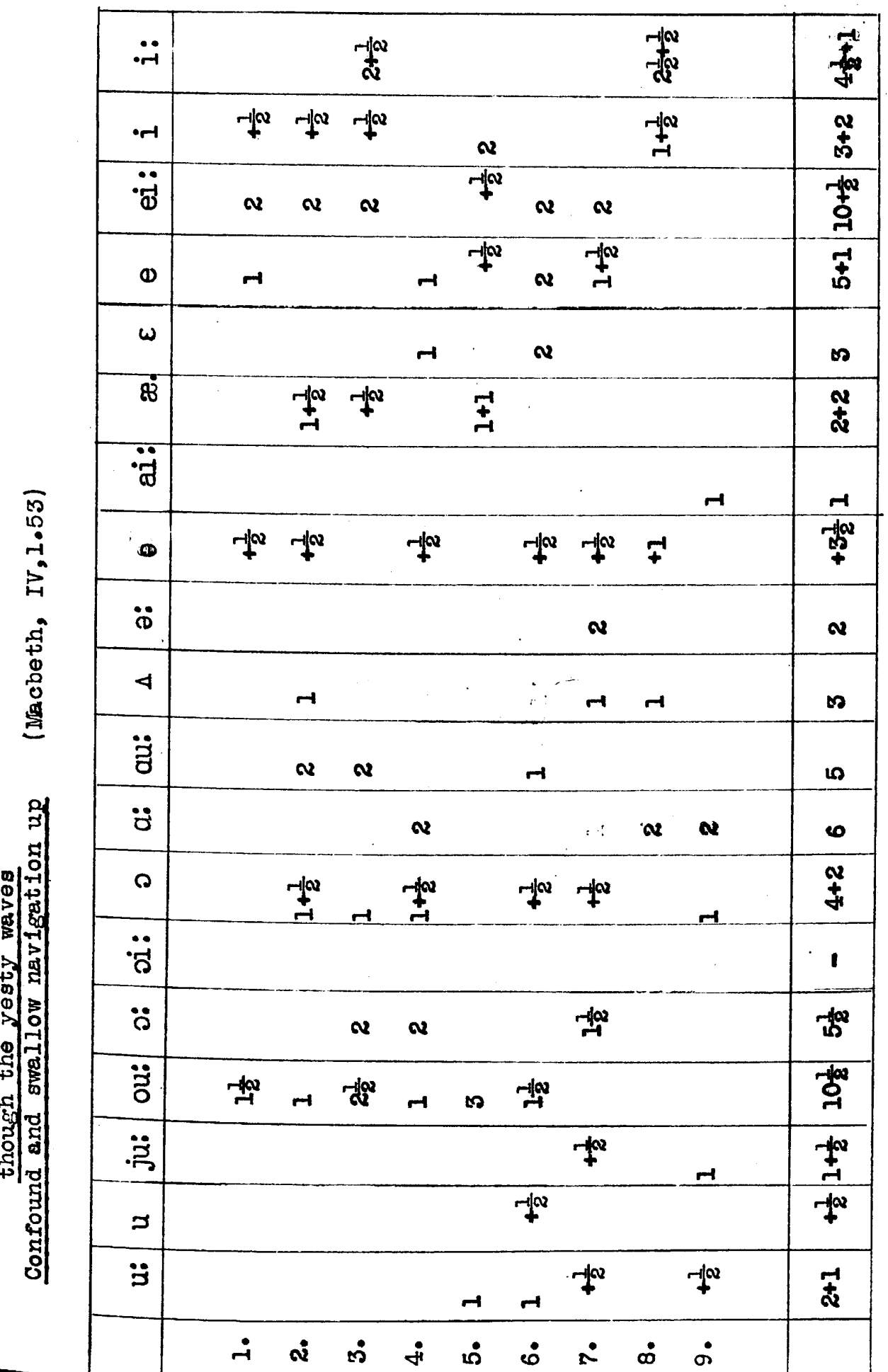




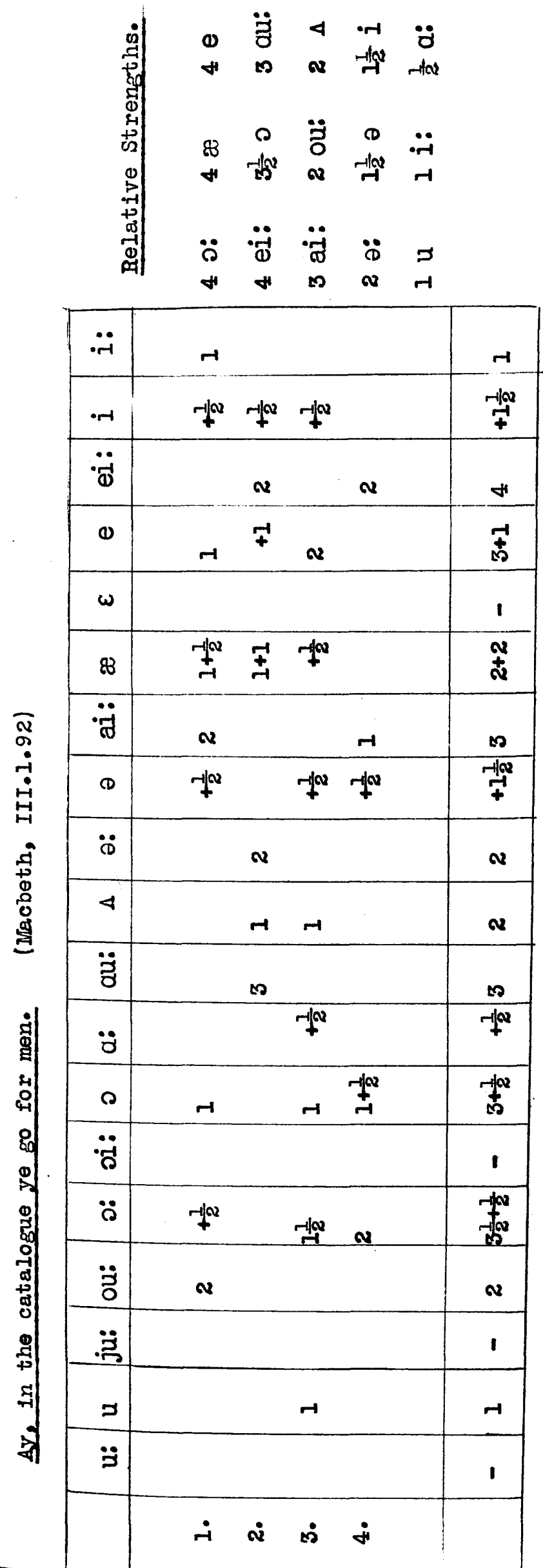

$\stackrel{\infty}{\infty}$ 


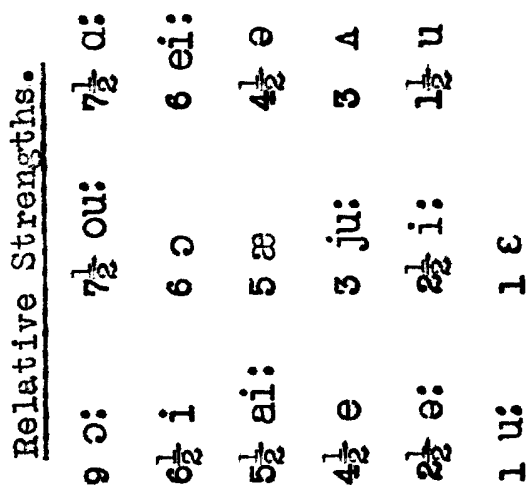

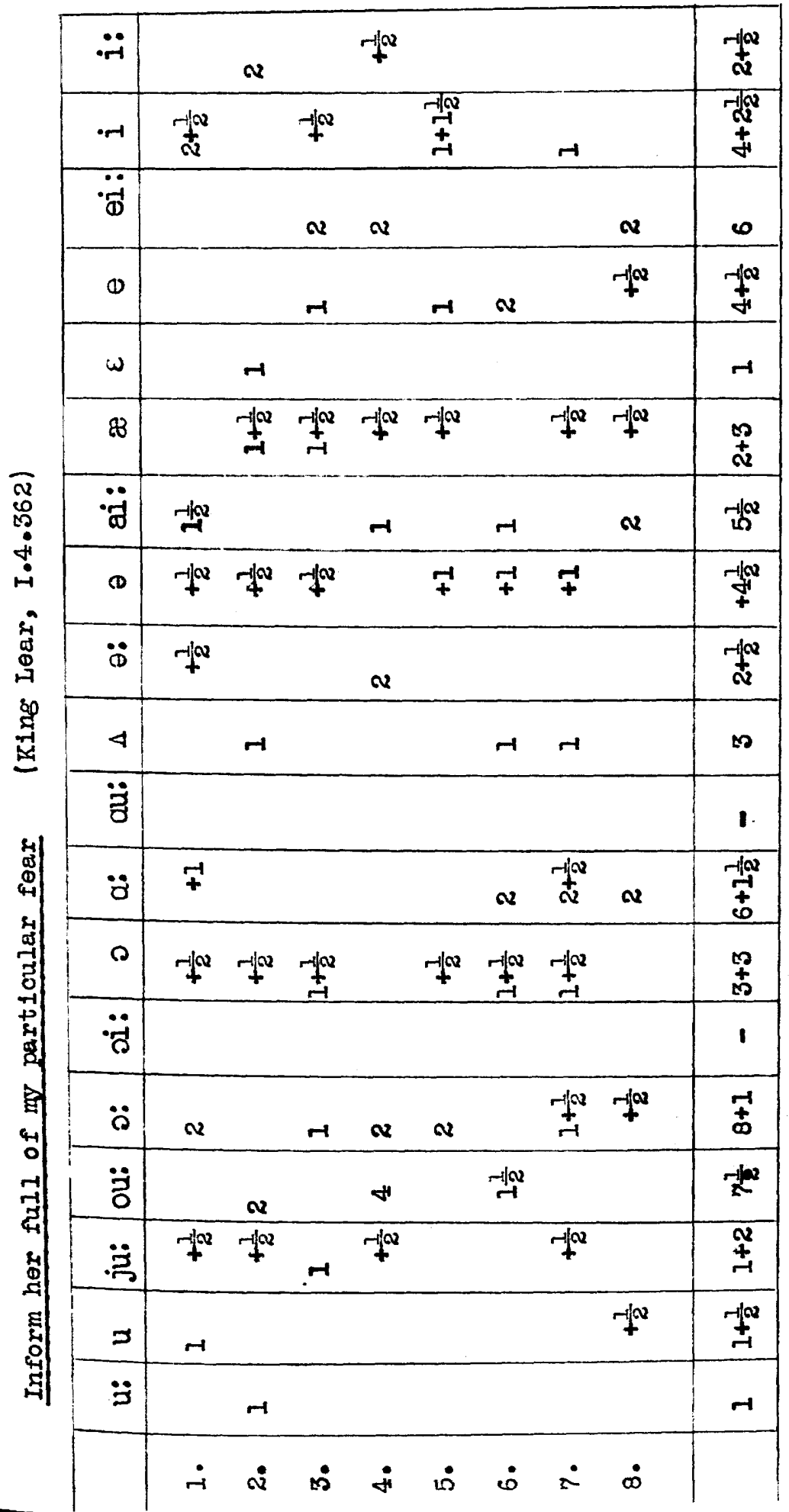




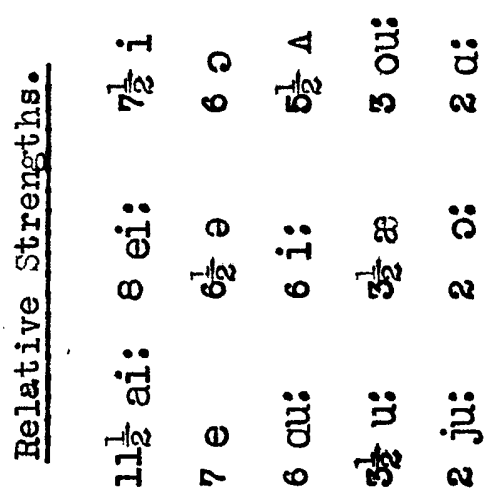

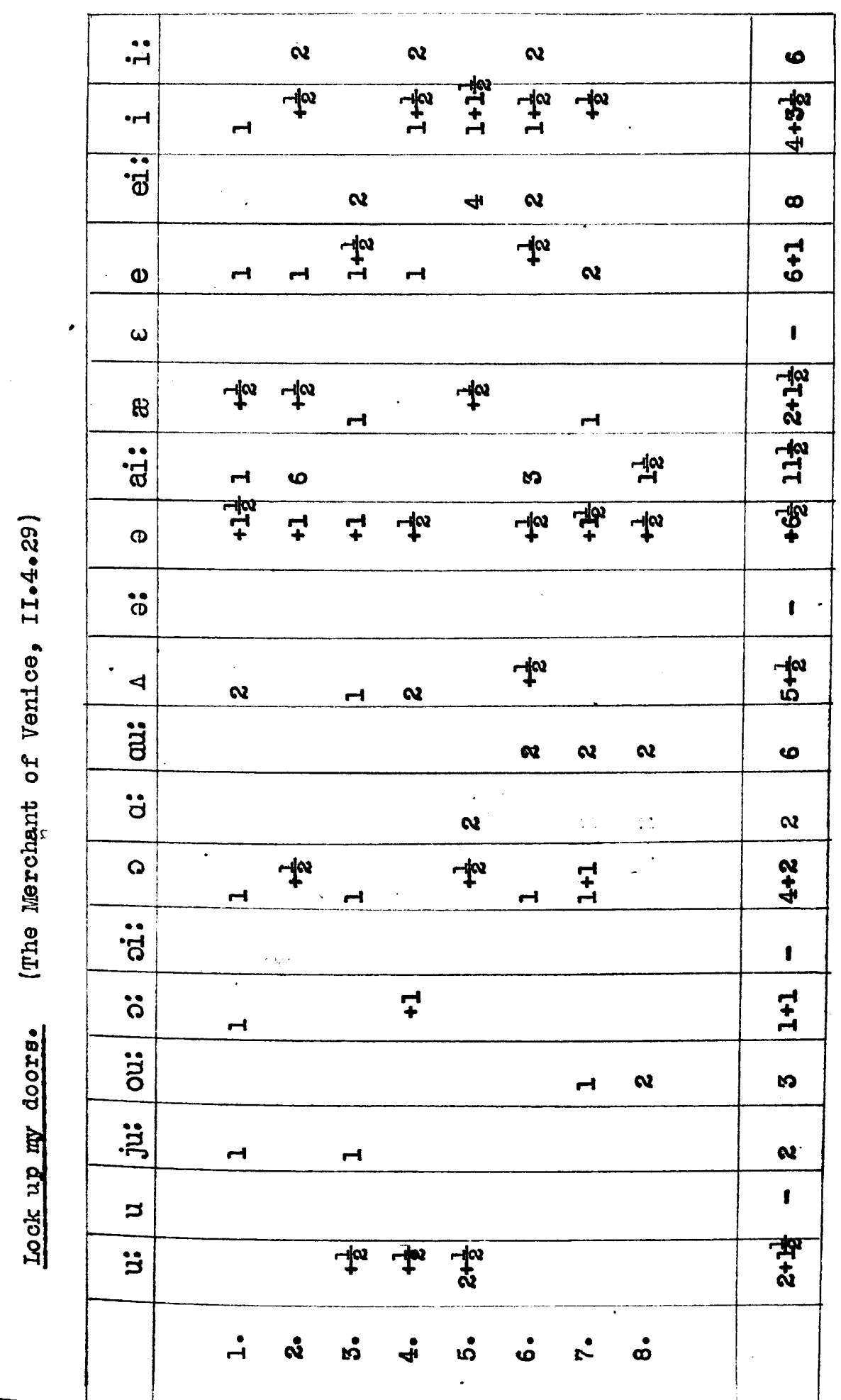




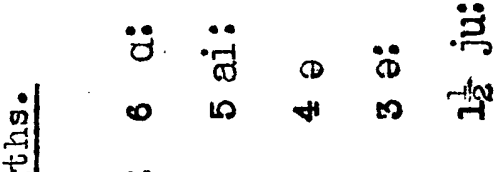

0

.

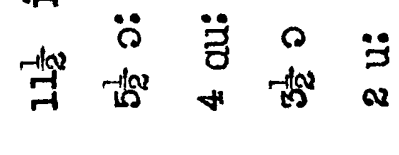

落

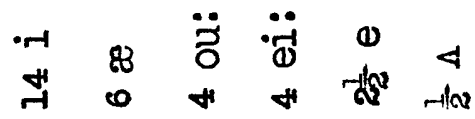

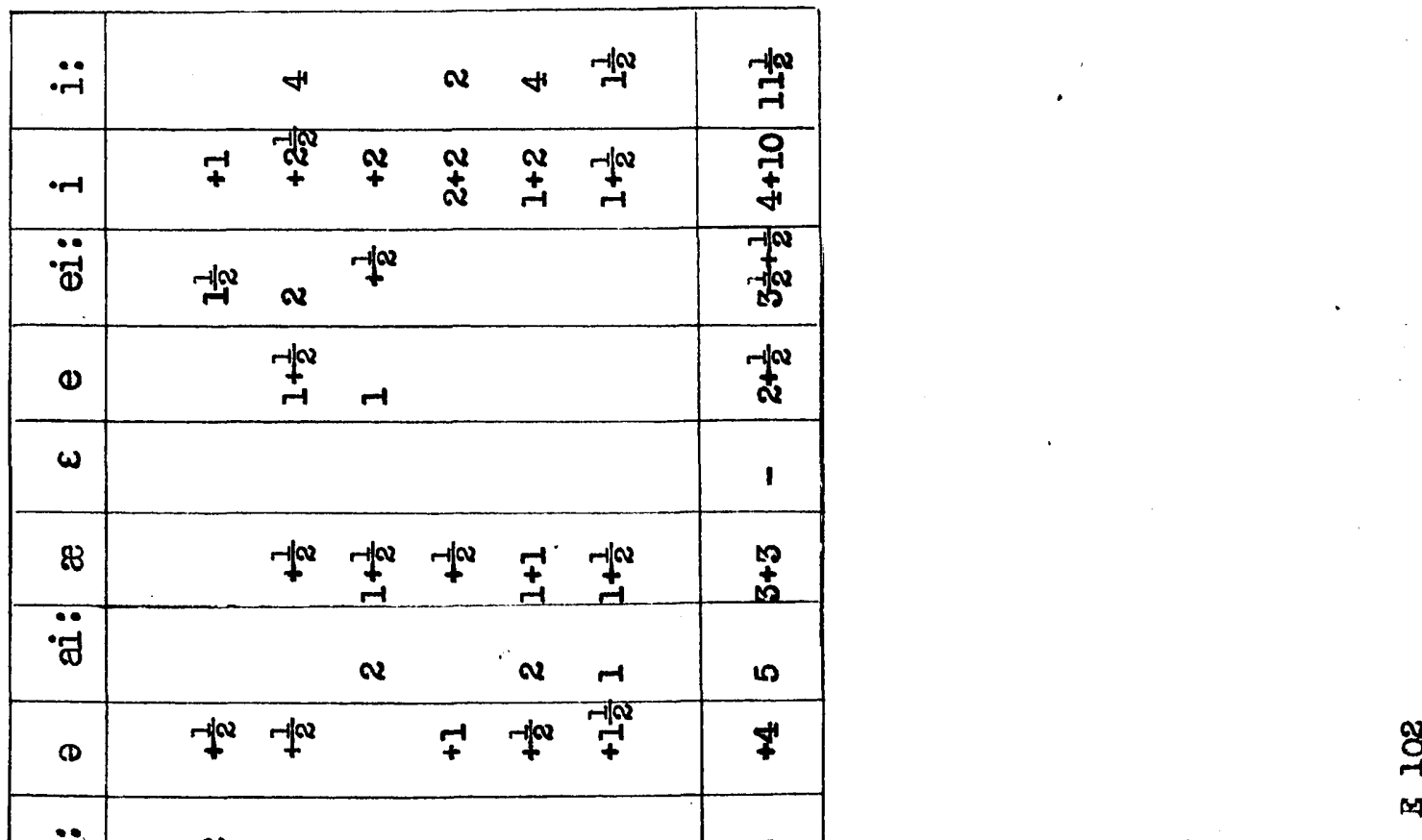




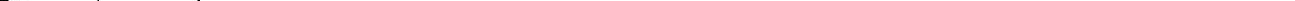




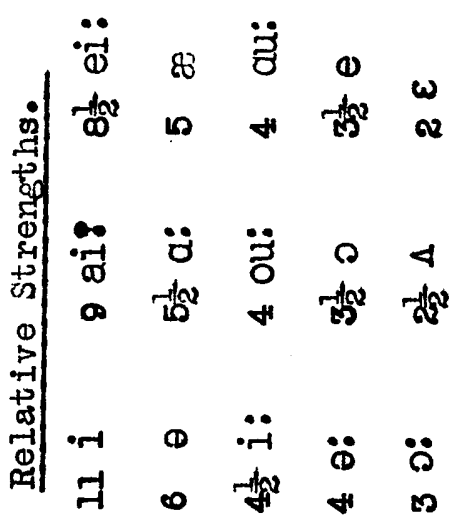

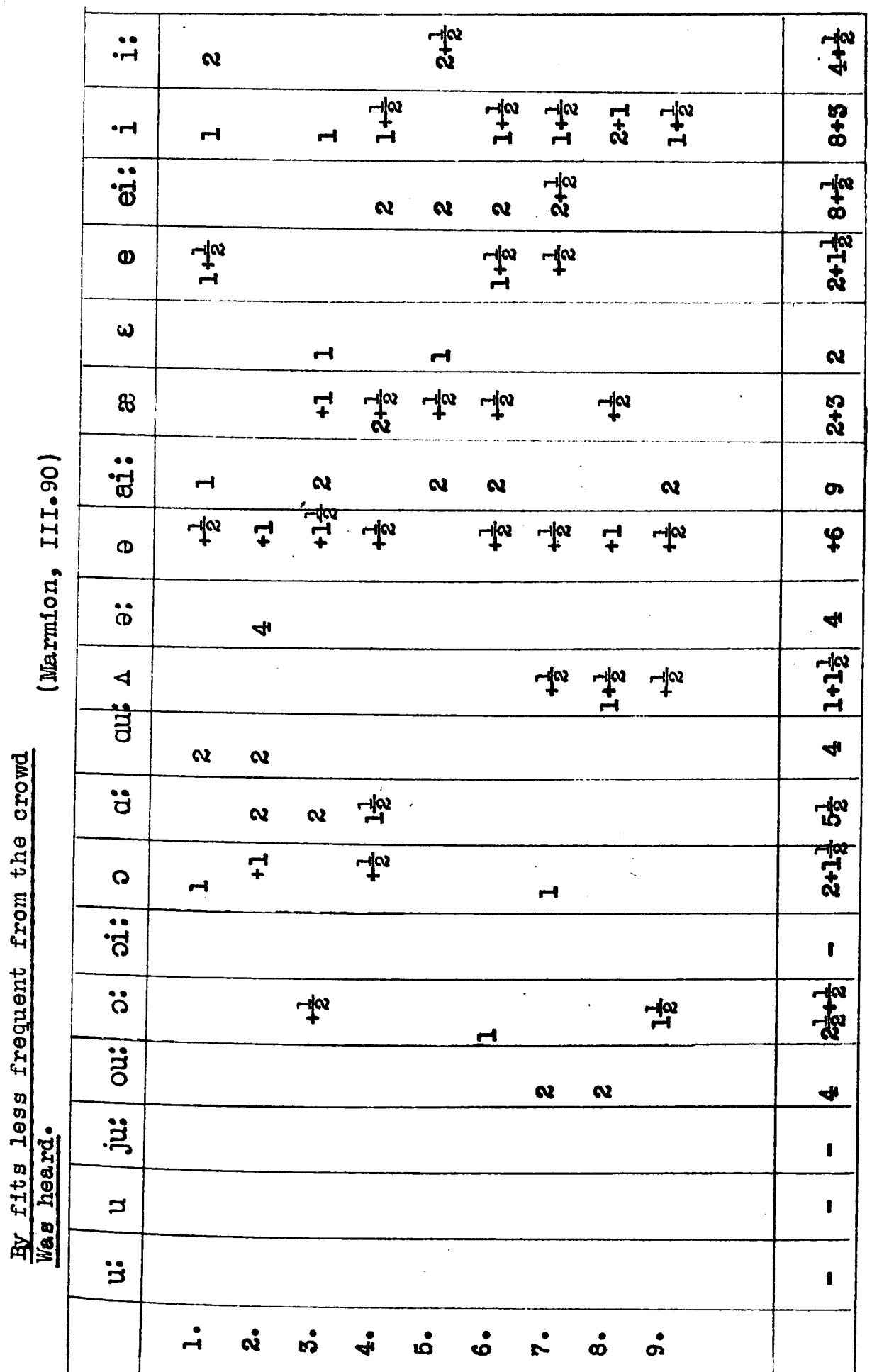




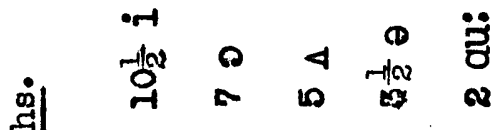

b0

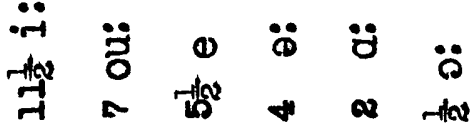

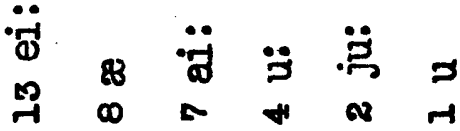

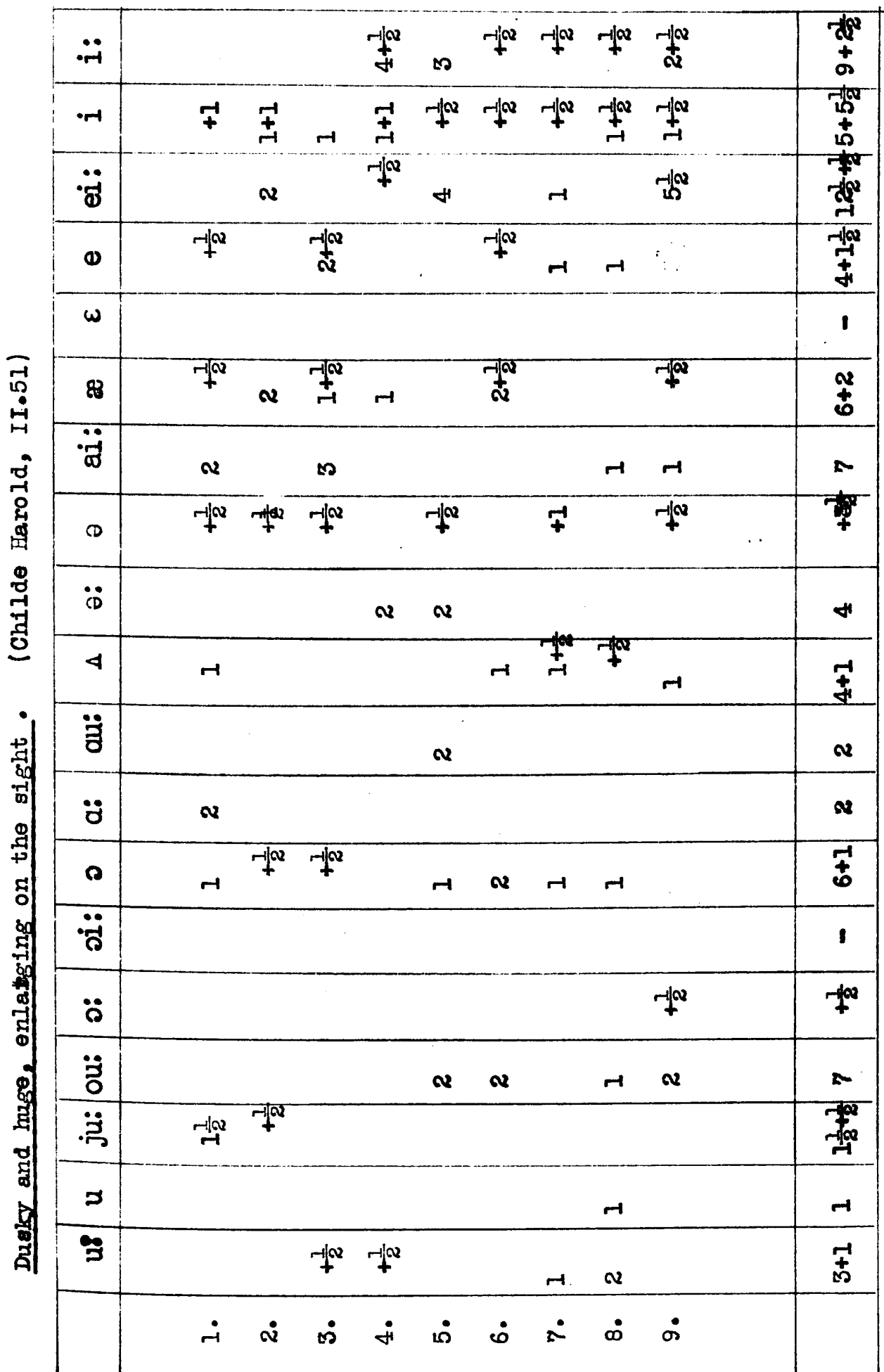




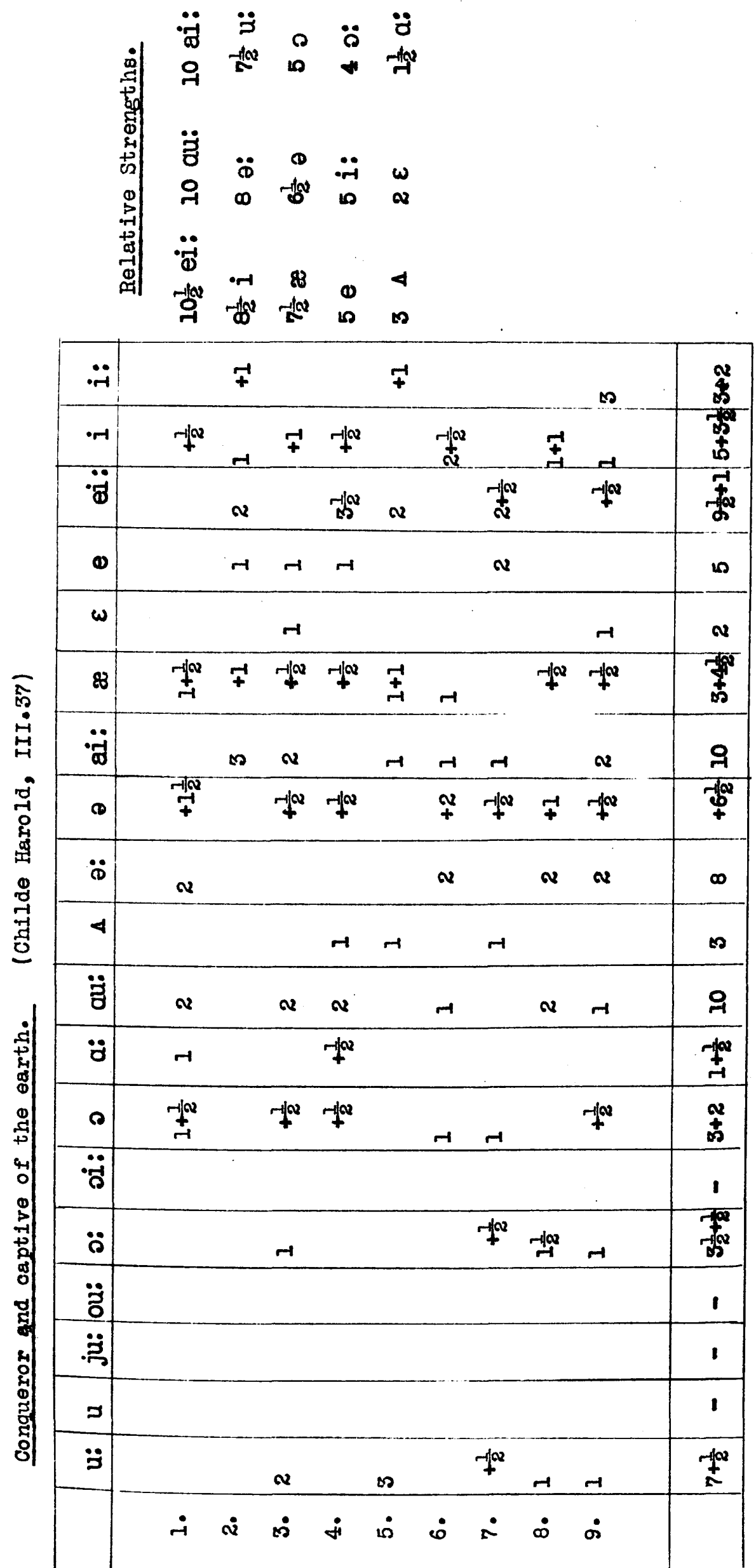




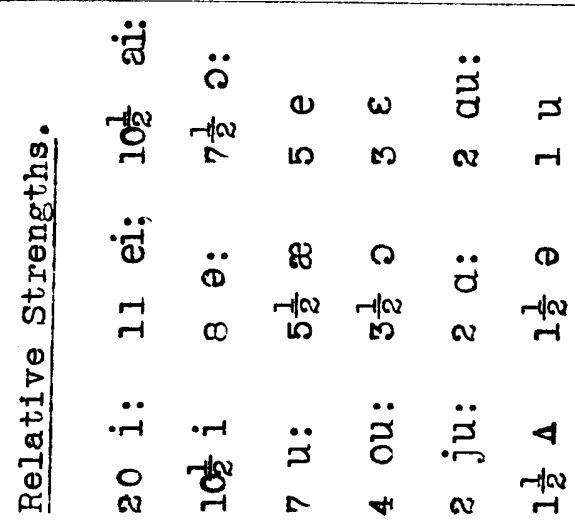

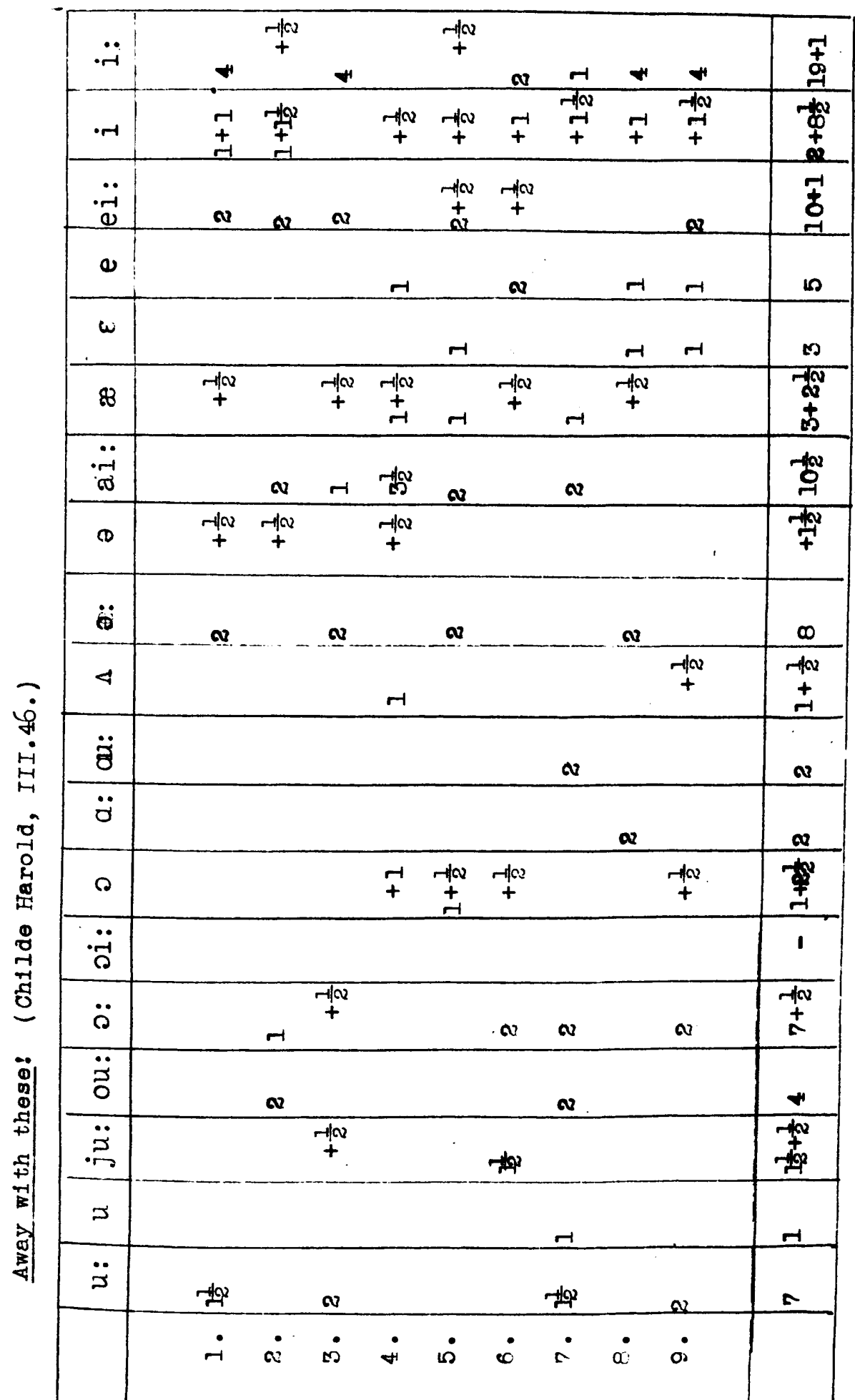




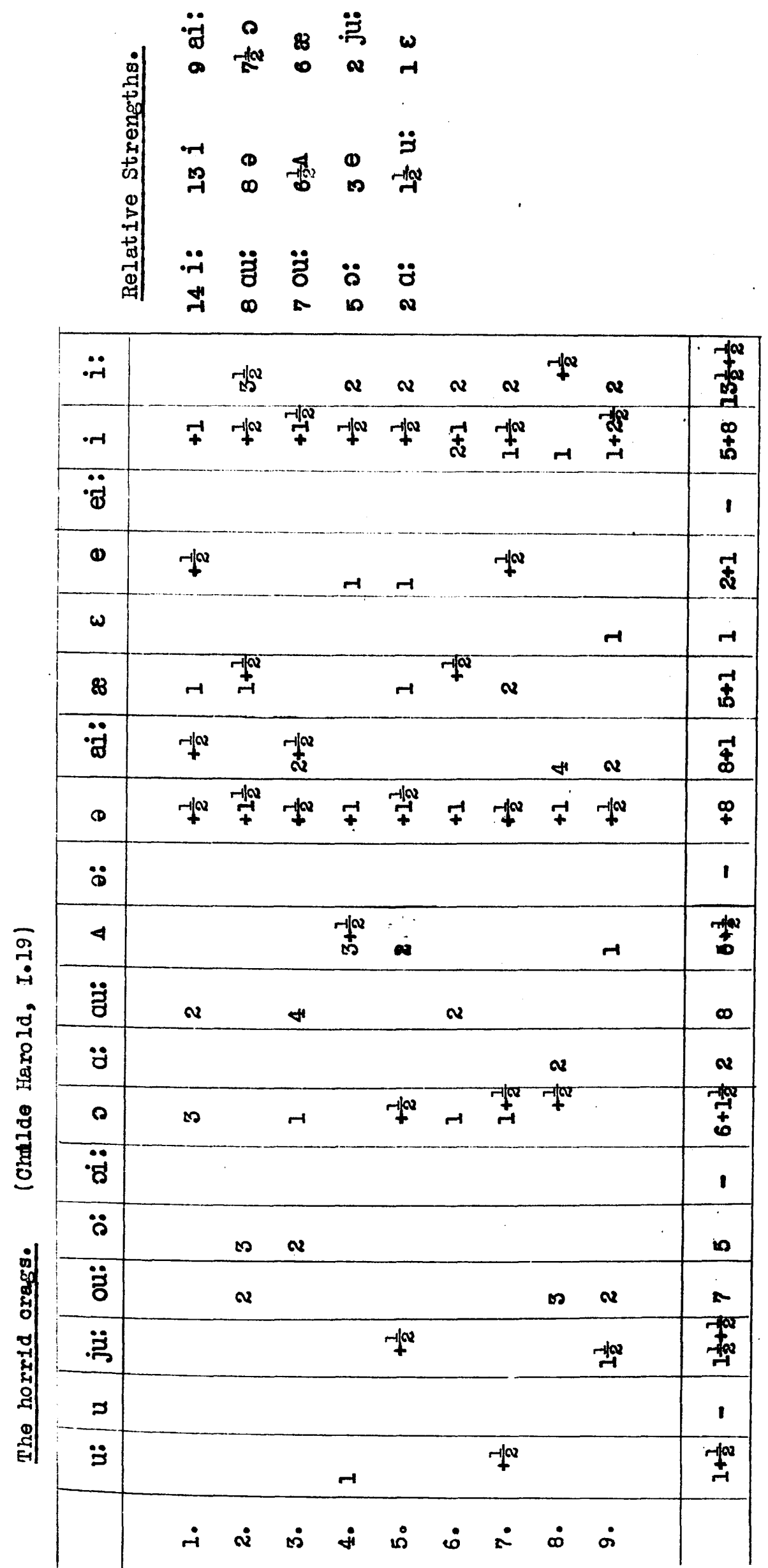




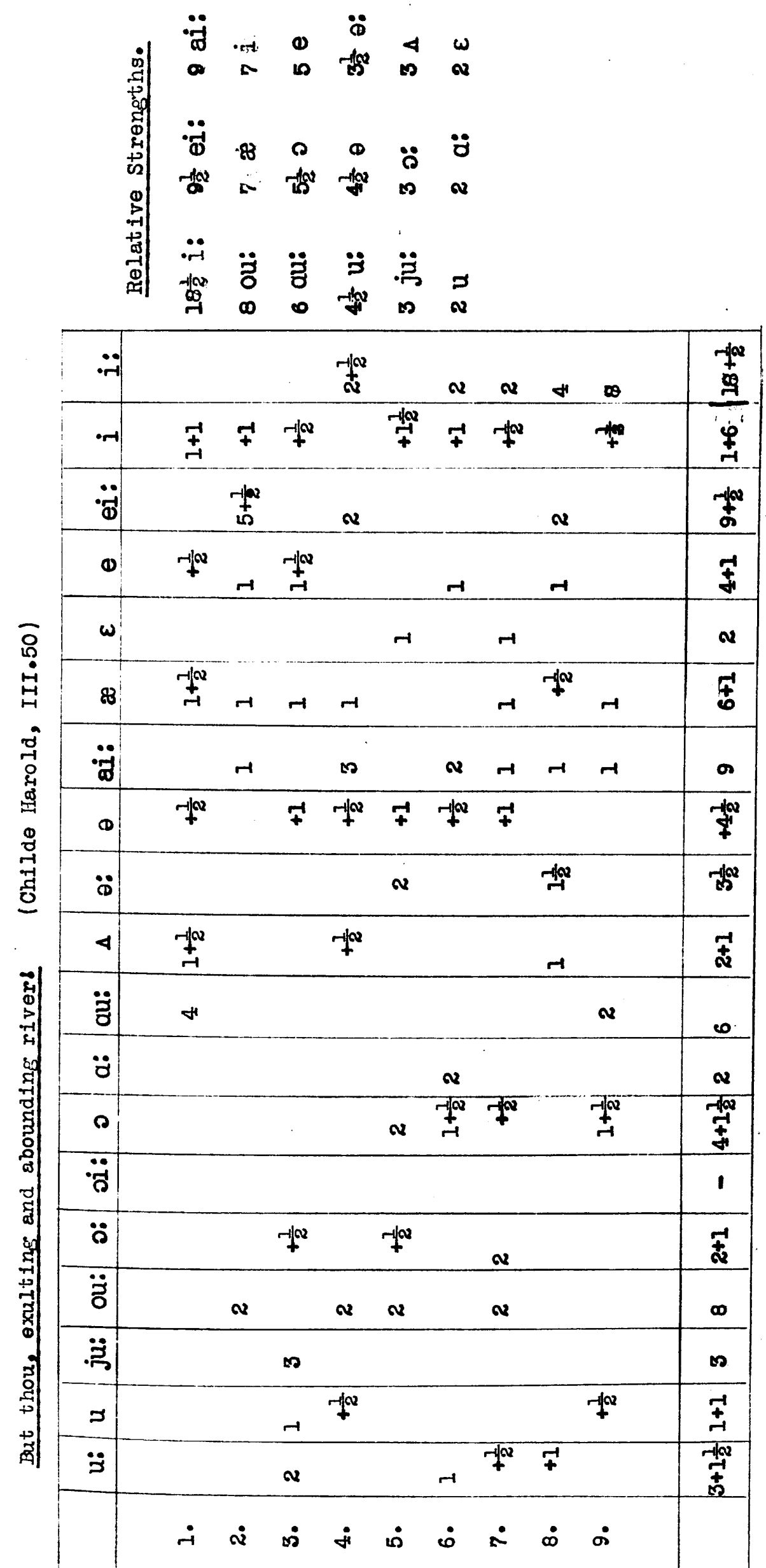




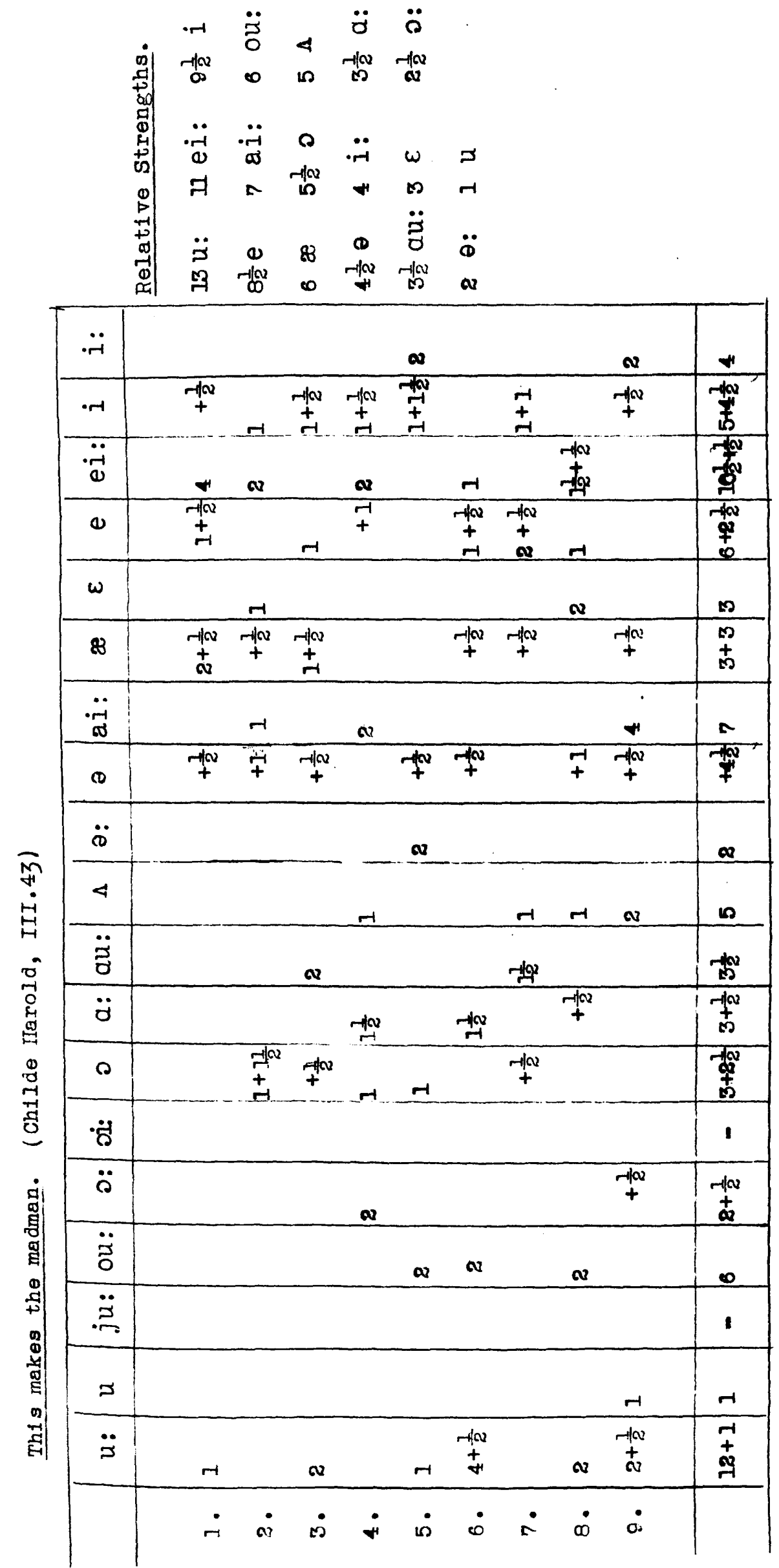




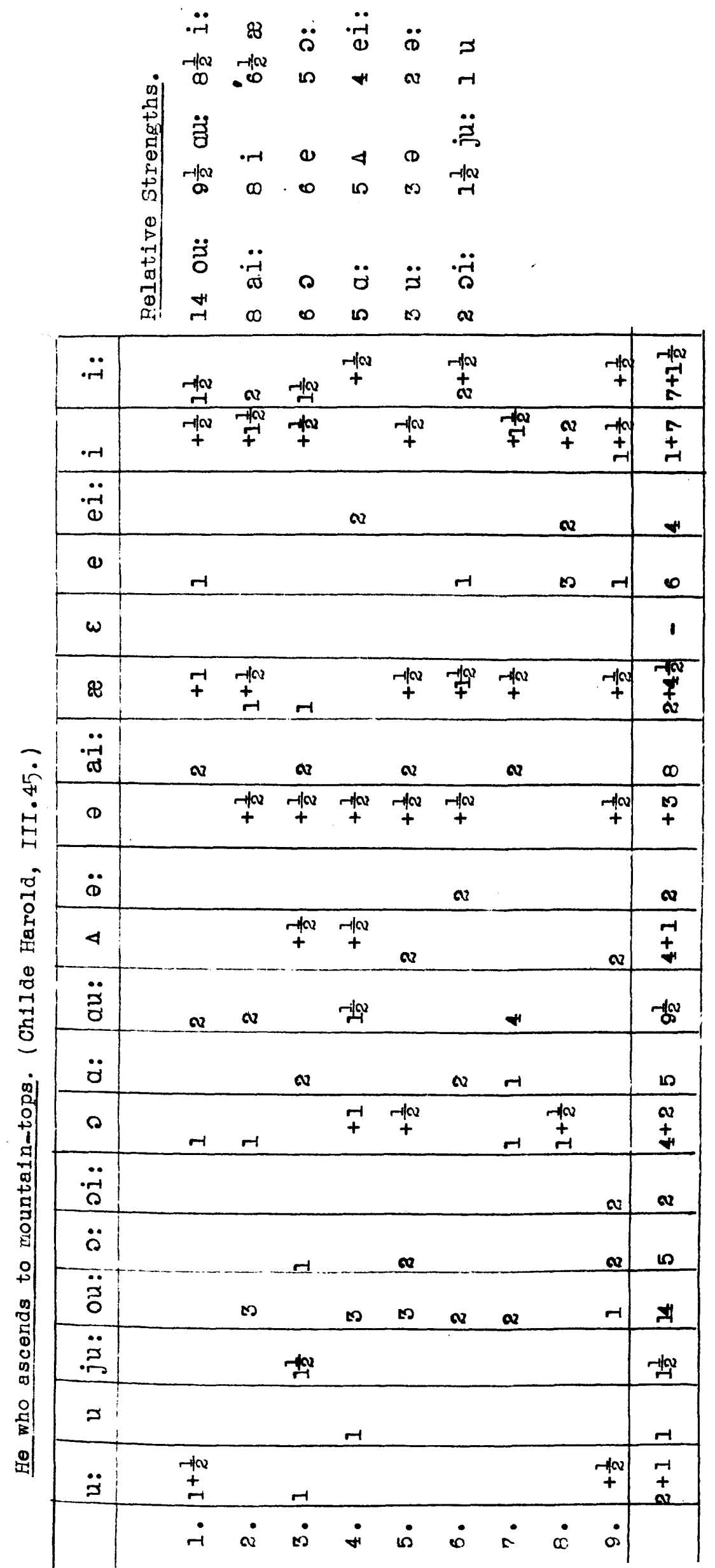




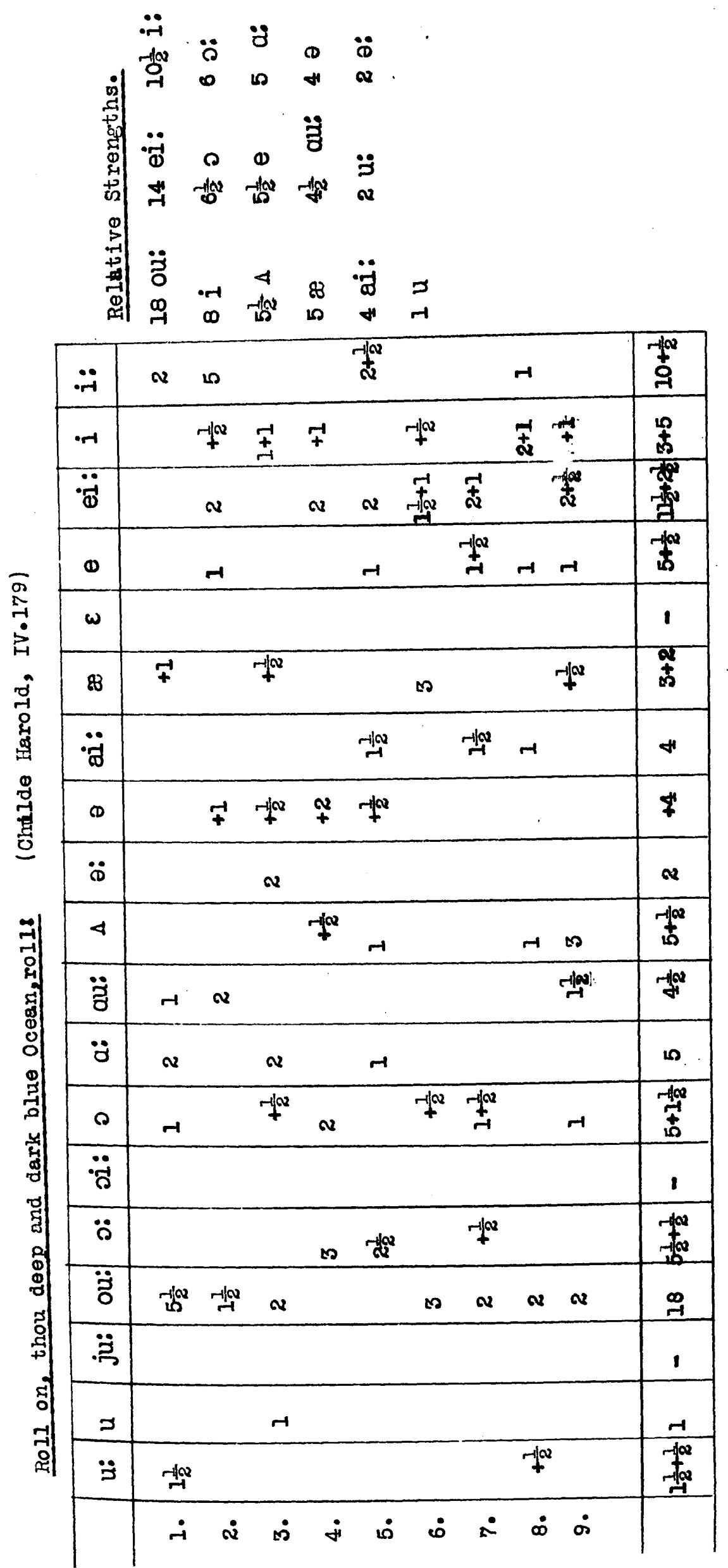




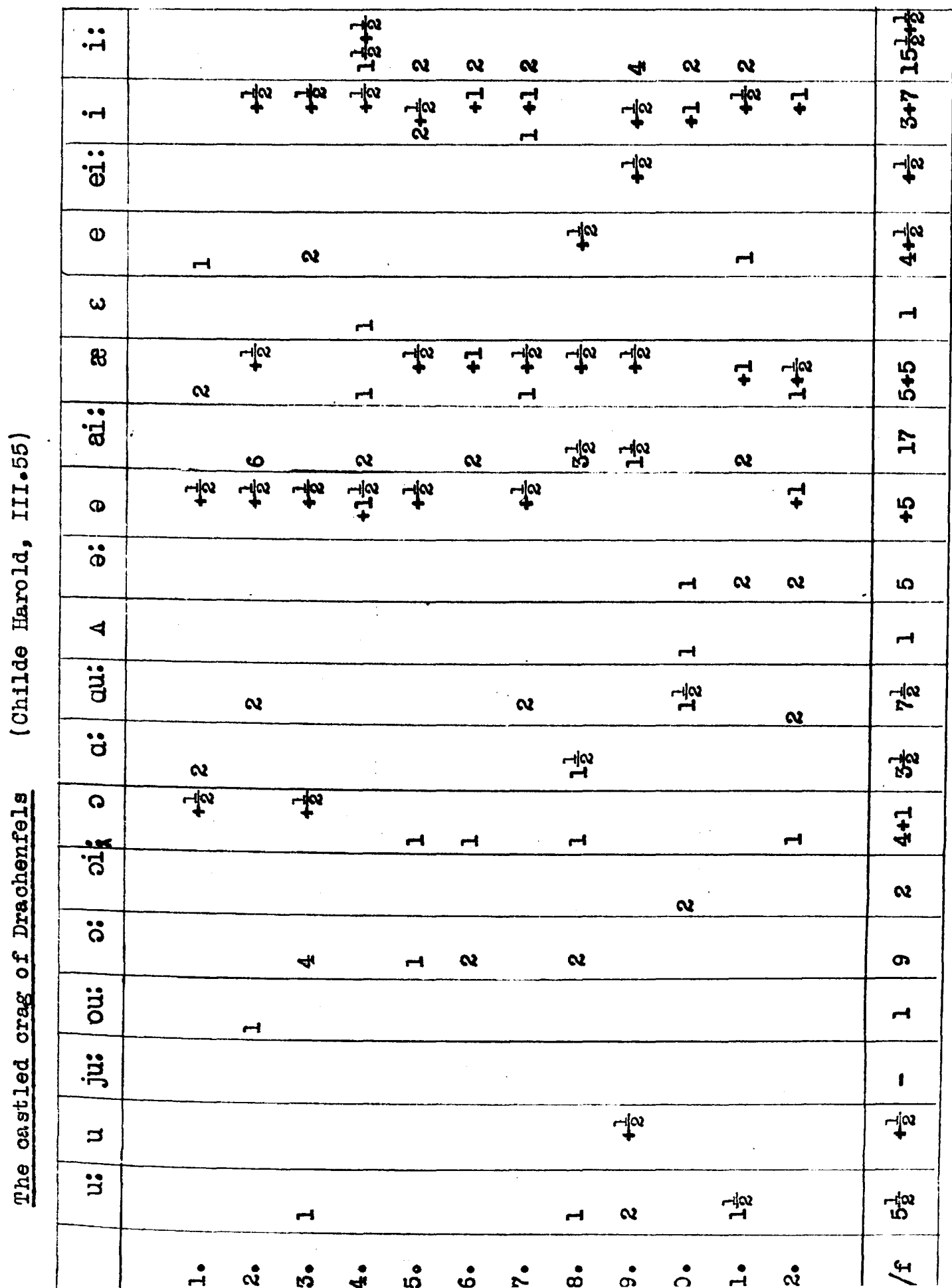




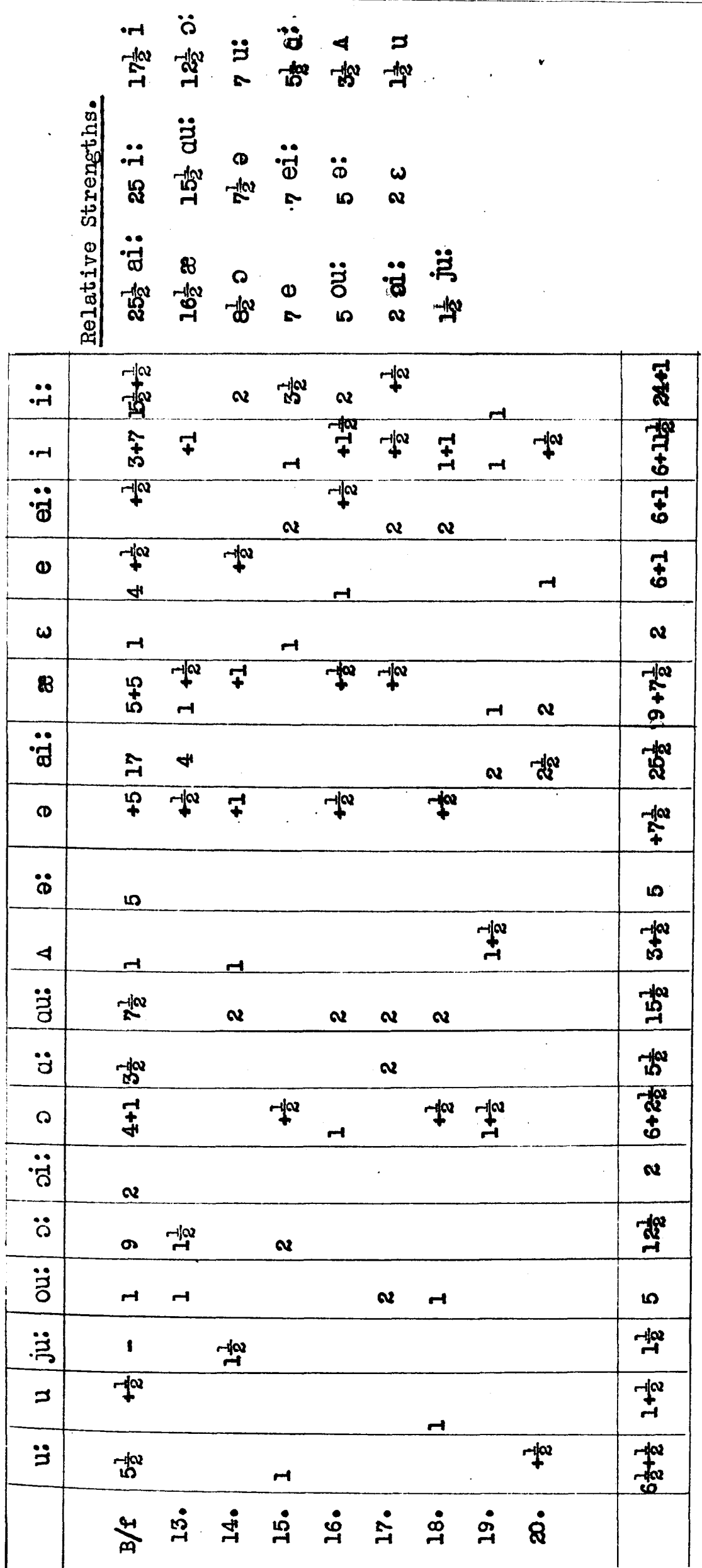




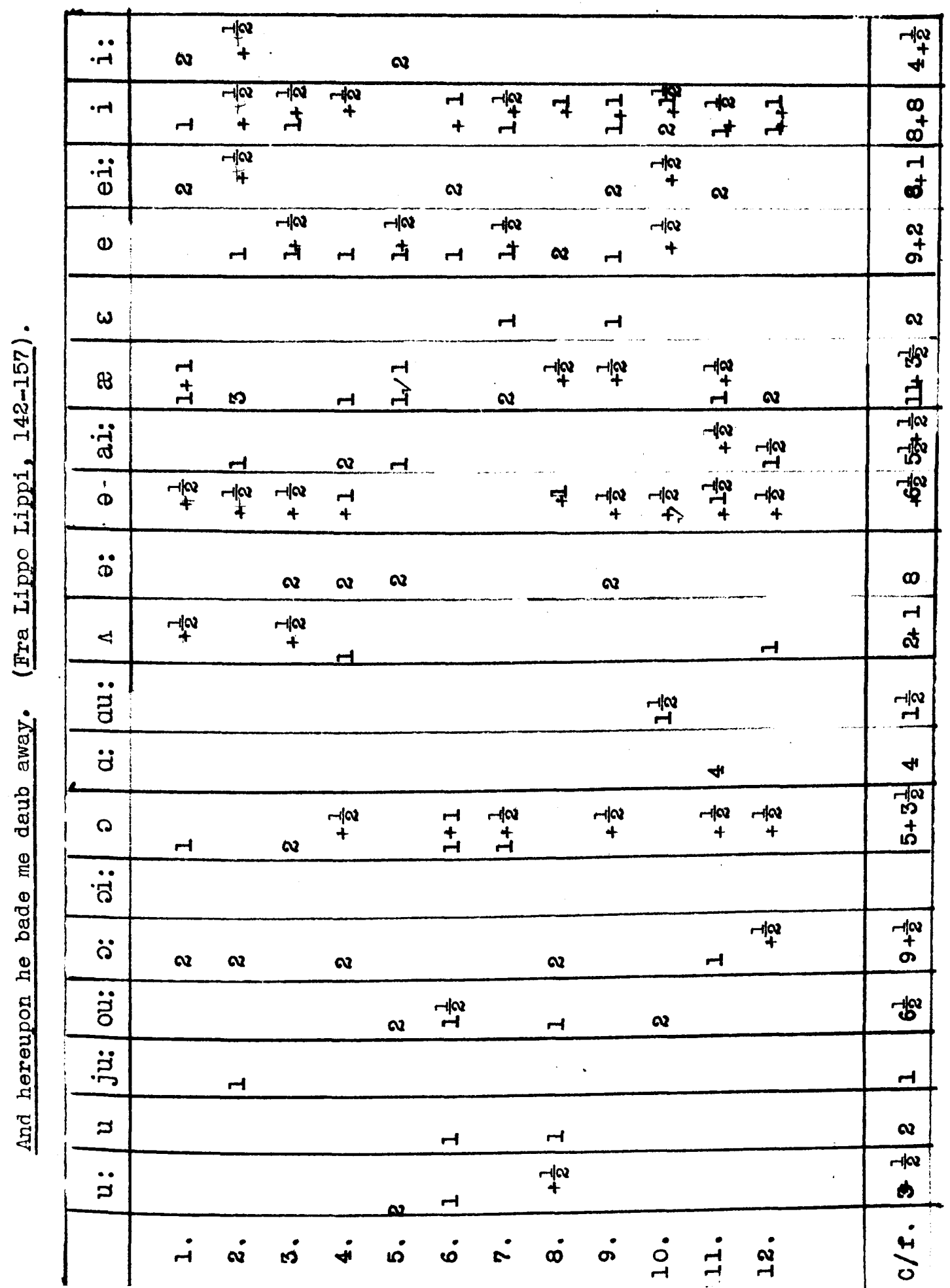

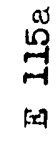




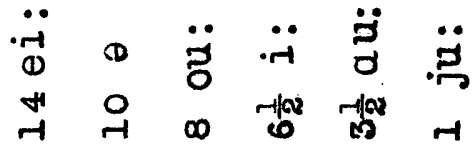

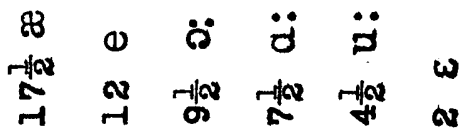

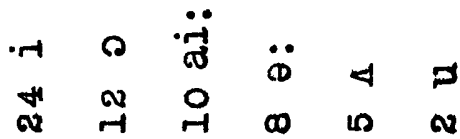

\begin{tabular}{|c|c|c|c|c|c|c|}
\hline$\ddot{r-1}$ & $\begin{array}{l}\text { Hid } \\
\text { to }\end{array}$ & & $f a$ & $\stackrel{-1100}{-10}$ & & 点 \\
\hline$\cdot r-1$ & $\begin{array}{l}\infty \\
+\end{array}$ & $\begin{array}{c}\text { rige } \\
\text { * }\end{array}$ & $\stackrel{\sim}{+}$ & $\underset{H}{+-1 / \alpha}$ & -1 & สี \\
\hline$\ddot{\ddot{0}}$ & +1 & $\dddot{r i s}_{i \infty}^{+\infty}$ & & $v$ & $\begin{array}{c}\text { Hix } \\
+\end{array}$ & $\begin{array}{l}q 4 \\
7 \\
7\end{array}$ \\
\hline $\boldsymbol{0}$ & $\begin{array}{l}q^{\alpha} \\
0\end{array}$ & & $\rightarrow$ & . & & $\begin{array}{l}0 \\
+\end{array}$ \\
\hline$\omega$ & v & & & & & $w$ \\
\hline 83 & 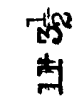 & $\begin{array}{c}+\operatorname{ta} \\
+\end{array}$ & & & $\begin{array}{c}-1 / \alpha \\
+ \\
-1\end{array}$ & ब్ \\
\hline$\ddot{\ddot{d}}$ & $\begin{array}{l}-100 \\
-k^{2}\end{array}$ & & + & & & 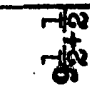 \\
\hline (1) & नाल & $-\|_{+\infty}^{\infty}$ & $\stackrel{r-\infty}{+}$ & $-H_{4}^{+\infty Q 2}$ & $\infty$ & $\begin{array}{r}9 \\
4\end{array}$ \\
\hline$\ddot{B}$ & $\boldsymbol{\infty}$ & & & & & $\boldsymbol{\infty}$ \\
\hline 4 & $\begin{array}{l}-1 \\
+ \\
\infty\end{array}$ & -1 & $H$ & & & 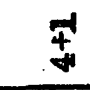 \\
\hline$\ddot{\ddot{\sigma}}$ & $\stackrel{-1}{-1} \alpha$ & & & & 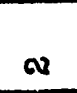 & 跑 \\
\hline$\ddot{d}$ & 4 & $v$ & & & ${ }_{-1}^{-1 N}$ & rikn \\
\hline ه & 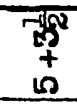 & & $\begin{array}{c}-1+\alpha \\
7\end{array}$ & $\begin{array}{l}-10 \\
-1 \\
-1\end{array}$ & $-{ }_{4}^{4}$ & $\begin{array}{l}10 \\
+ \\
2\end{array}$ \\
\hline$\ddot{\ddot{r}}$ & & & & & & \\
\hline$\ddot{\rho}$ & $\begin{array}{c}-1 / x \\
+ \\
\infty\end{array}$ & & & & & $\begin{array}{c}-1+\infty \\
+ \\
0\end{array}$ \\
\hline$\ddot{\ddot{0}}$ & $-\sqrt{\infty} \alpha$ & & & $\stackrel{r a q}{\rightarrow}$ & & $\infty$ \\
\hline$\ddot{\ddot{z}}$ & -1 & & & & & -1 \\
\hline$D$ & $\boldsymbol{v}$ & & & & & $\infty$ \\
\hline$\ddot{\partial}$ & $\begin{array}{l}\text { rino } \\
\text { of }\end{array}$ & & & -1 & & $\begin{array}{c}-102 \\
+ \\
+\end{array}$ \\
\hline & $\sum_{m}^{4}$ & $\ddot{H}$ & $\underset{+1}{\dot{H}}$ & $\stackrel{0}{\dot{1}}$ & $\underset{r}{\dot{H}}$ & \\
\hline
\end{tabular}




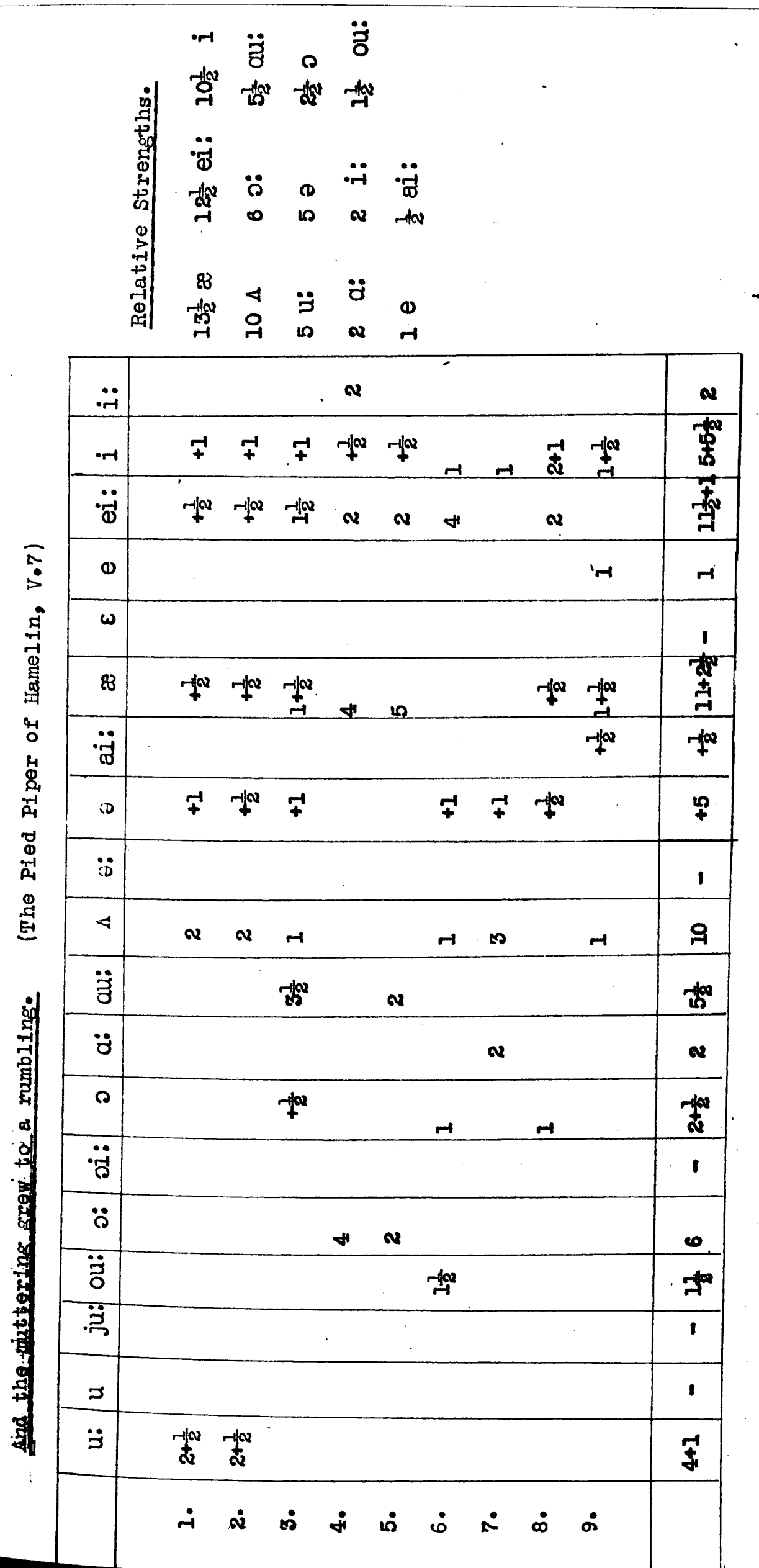




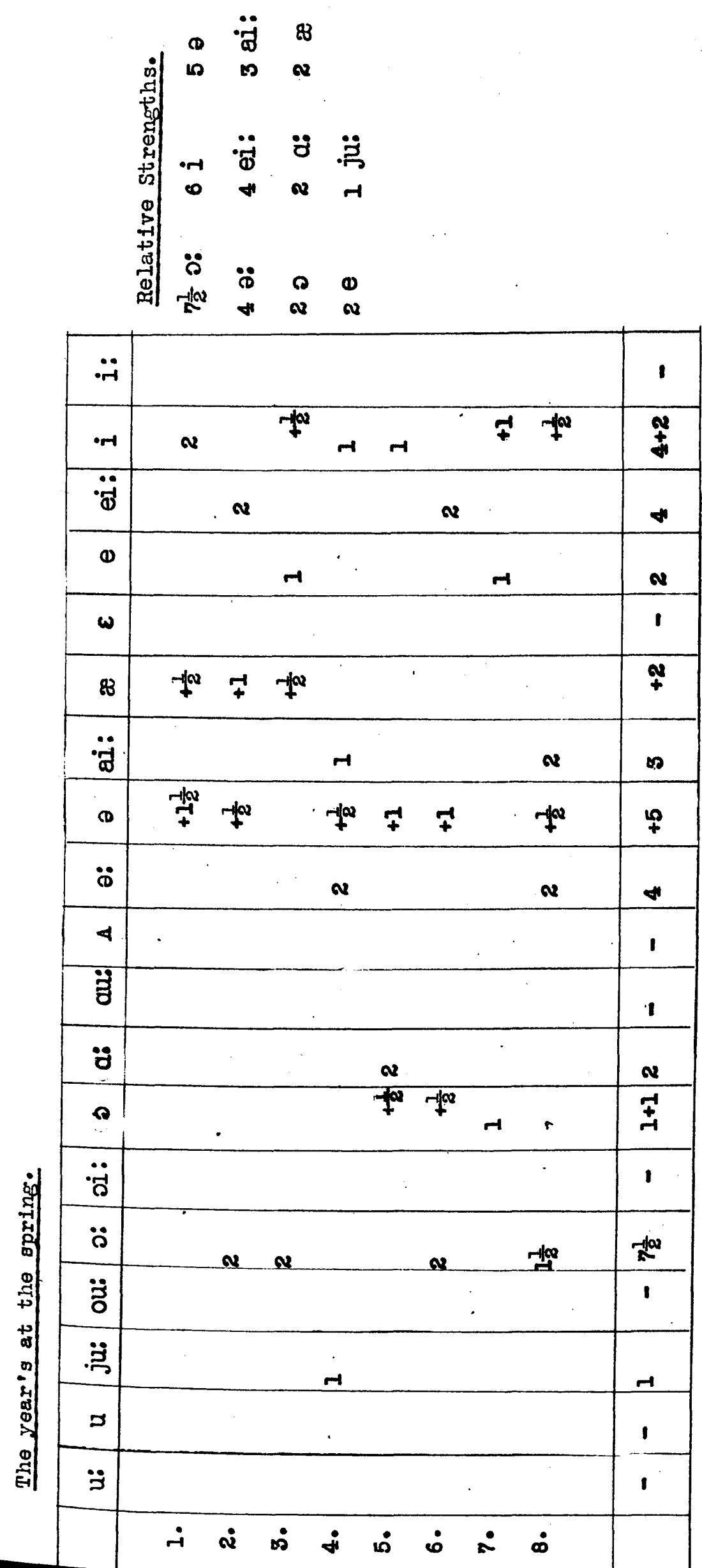




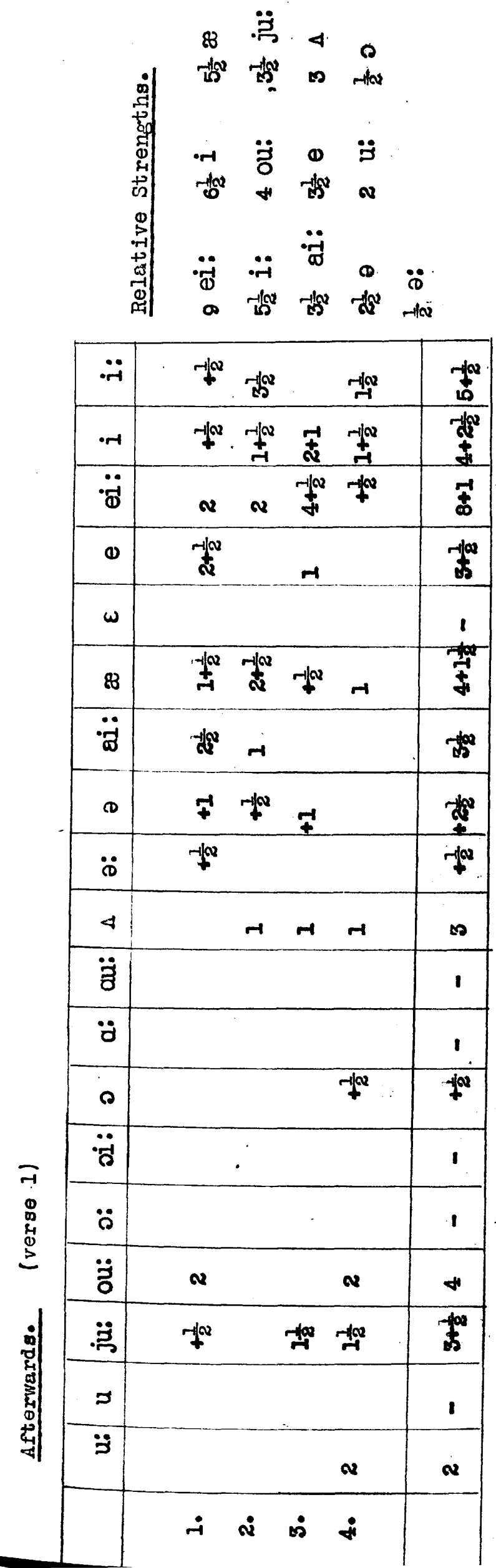




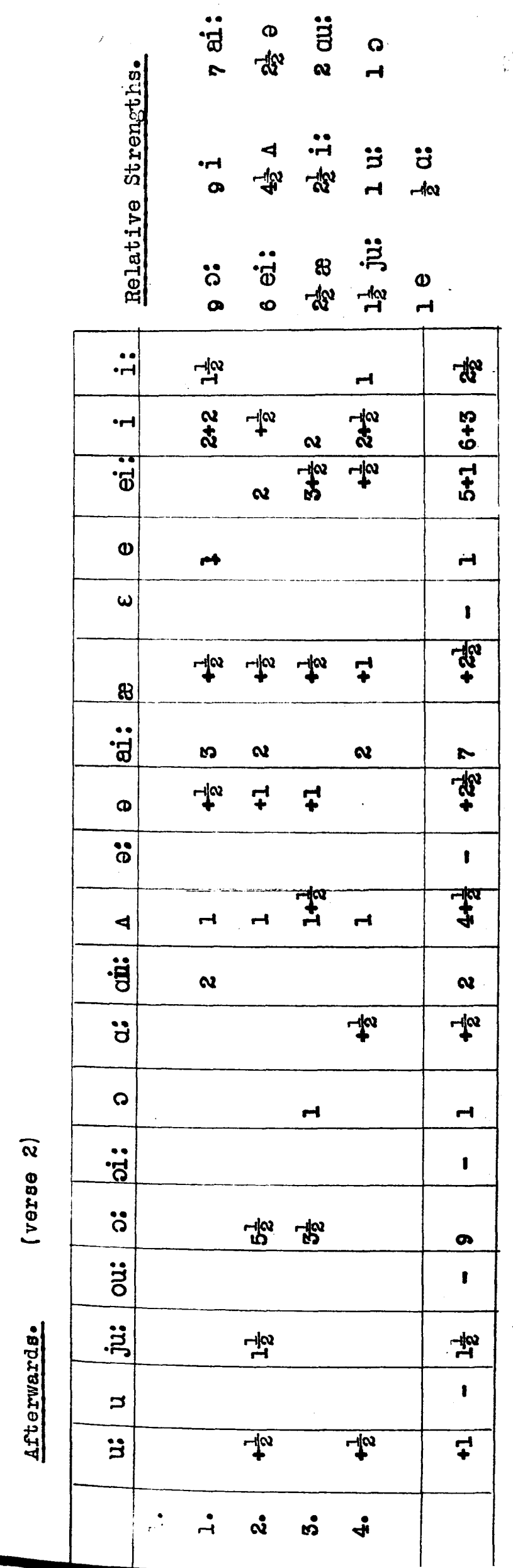




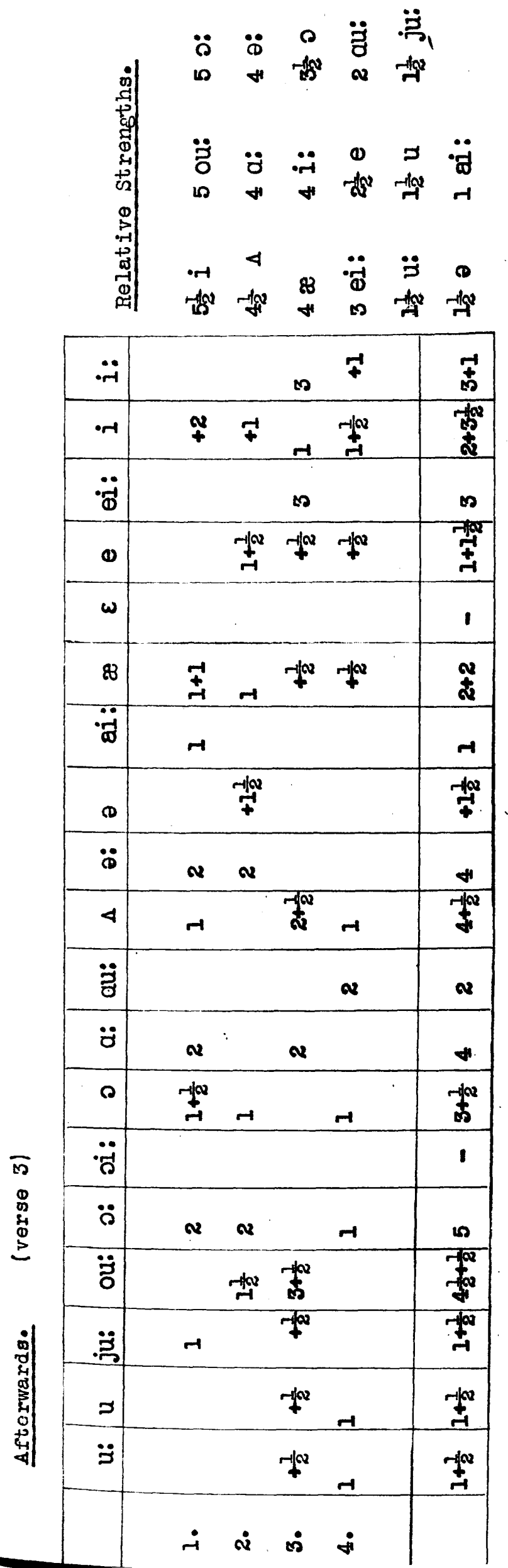




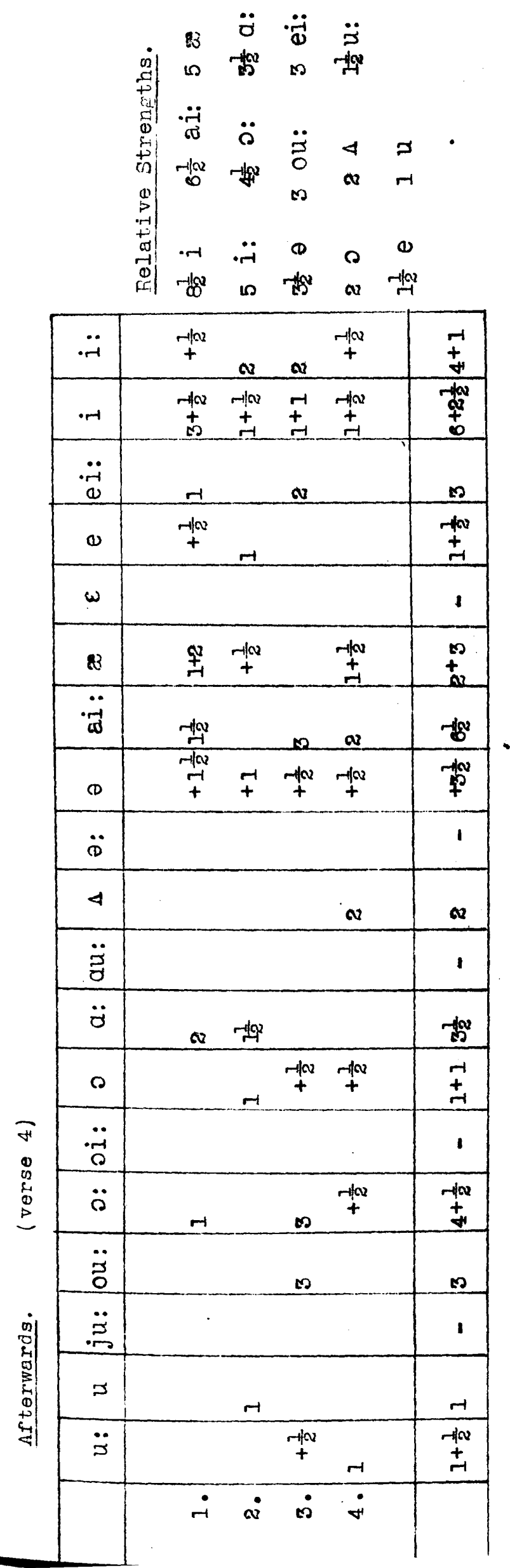



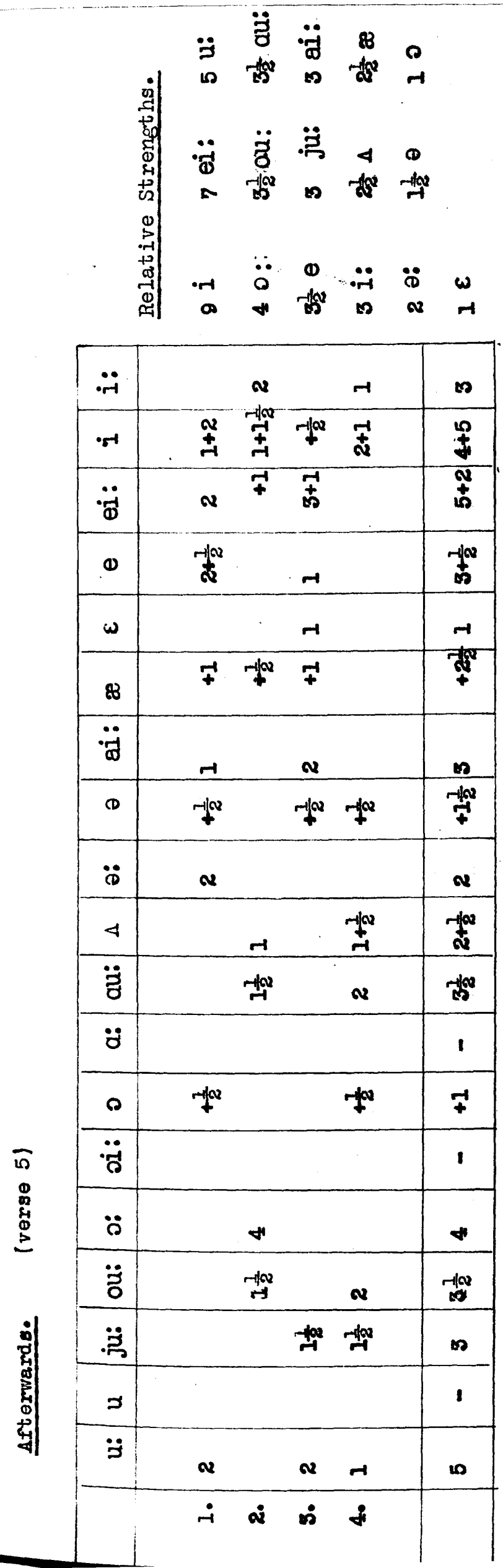


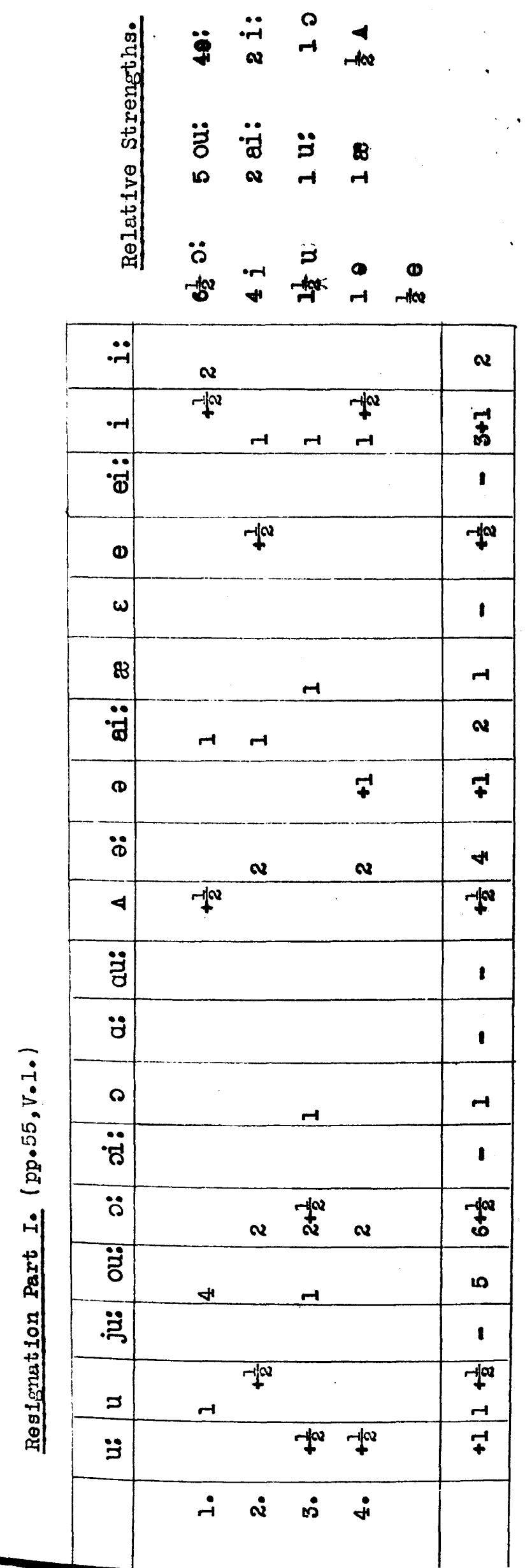




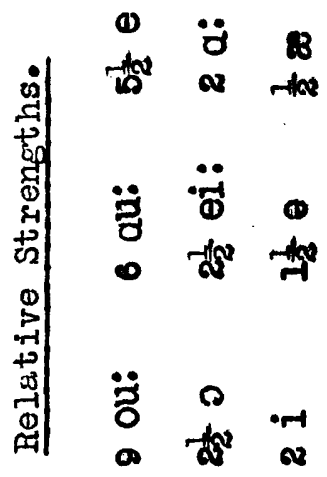

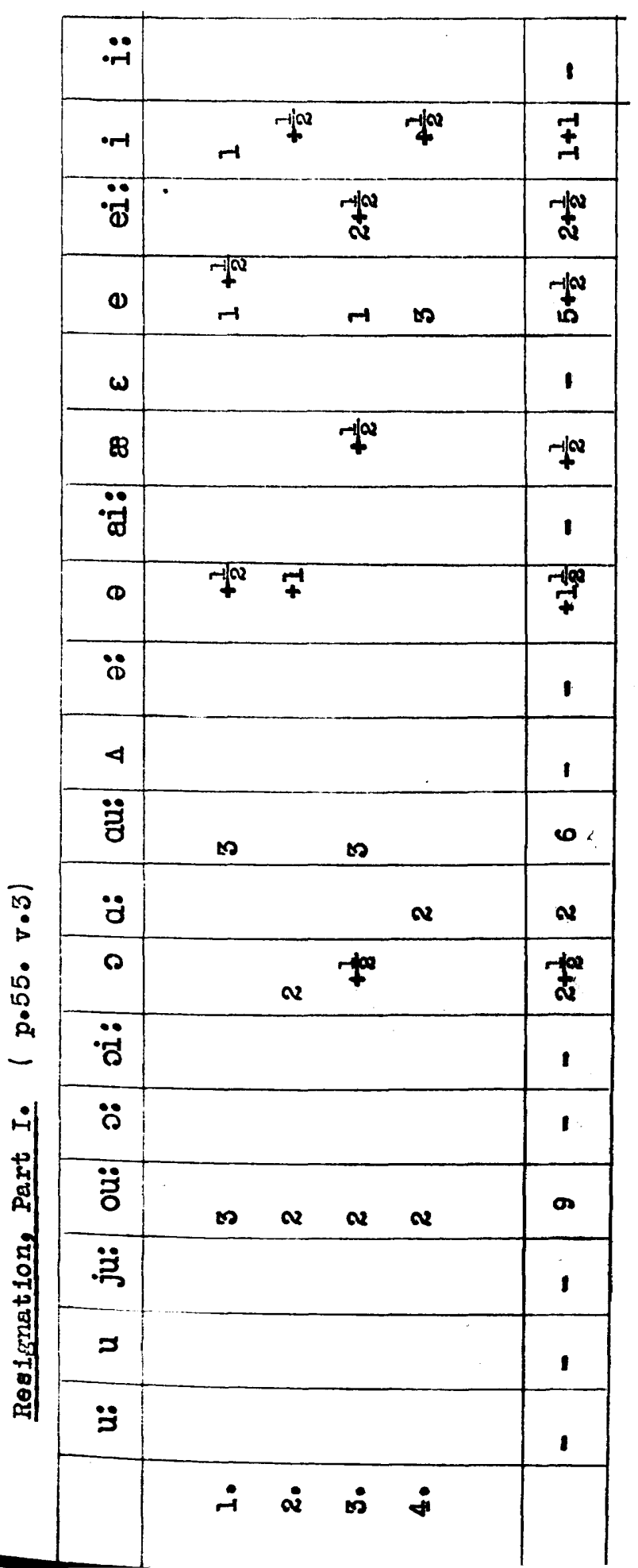

a 


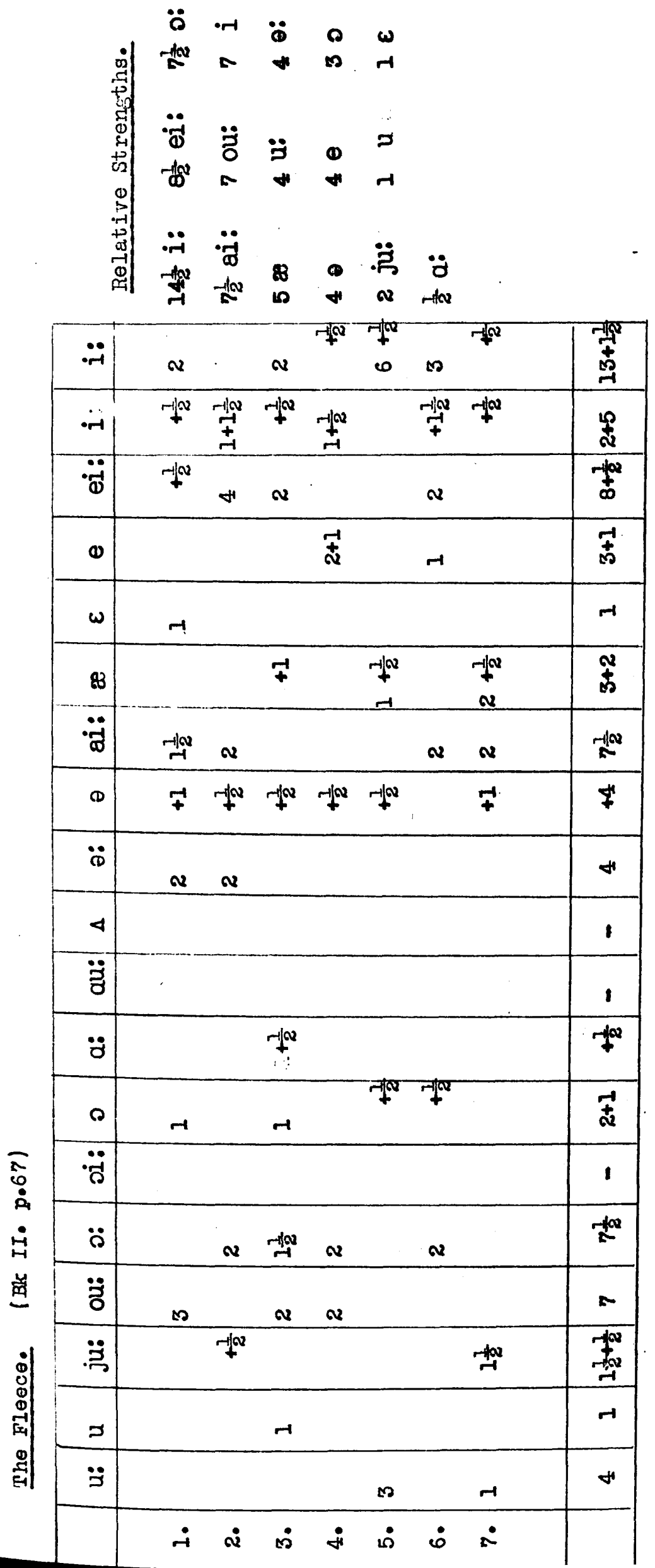




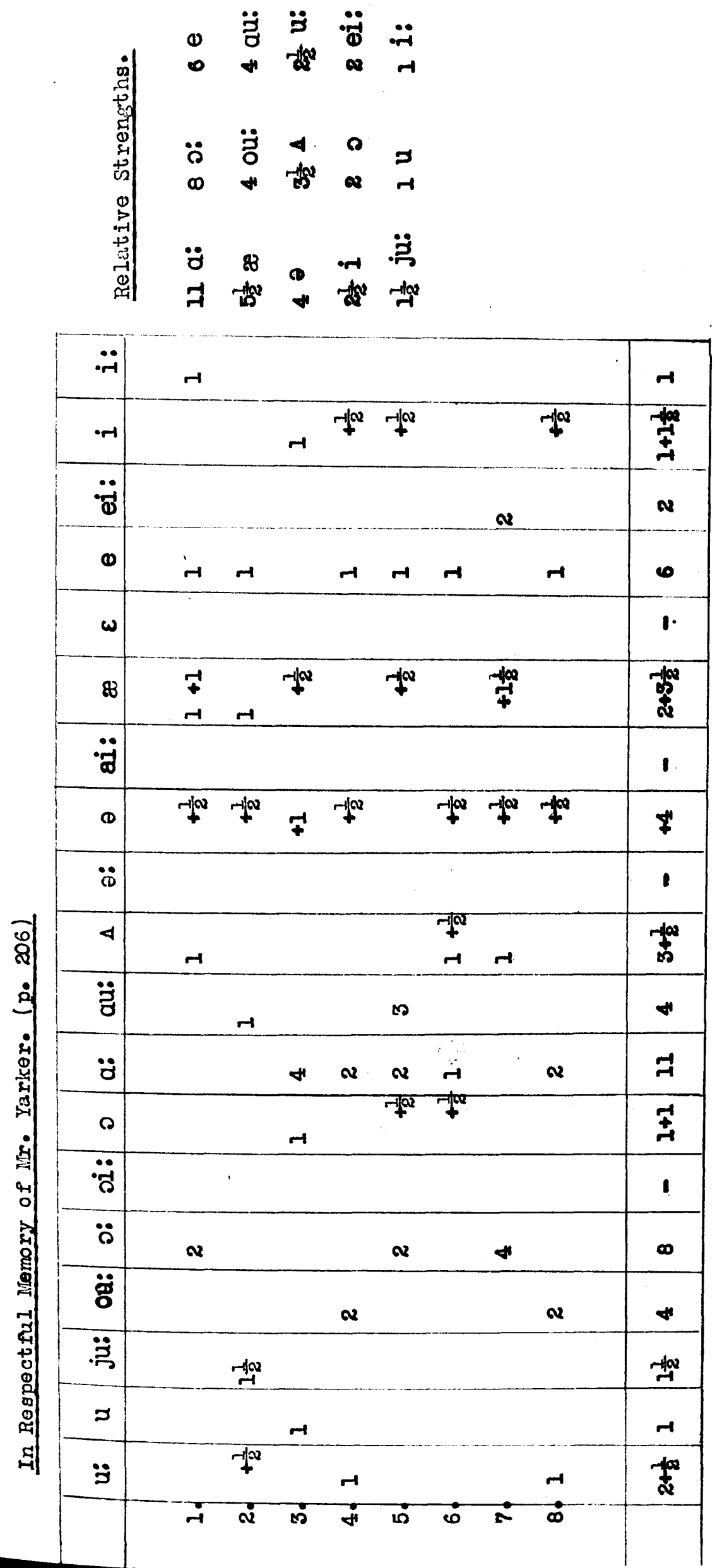




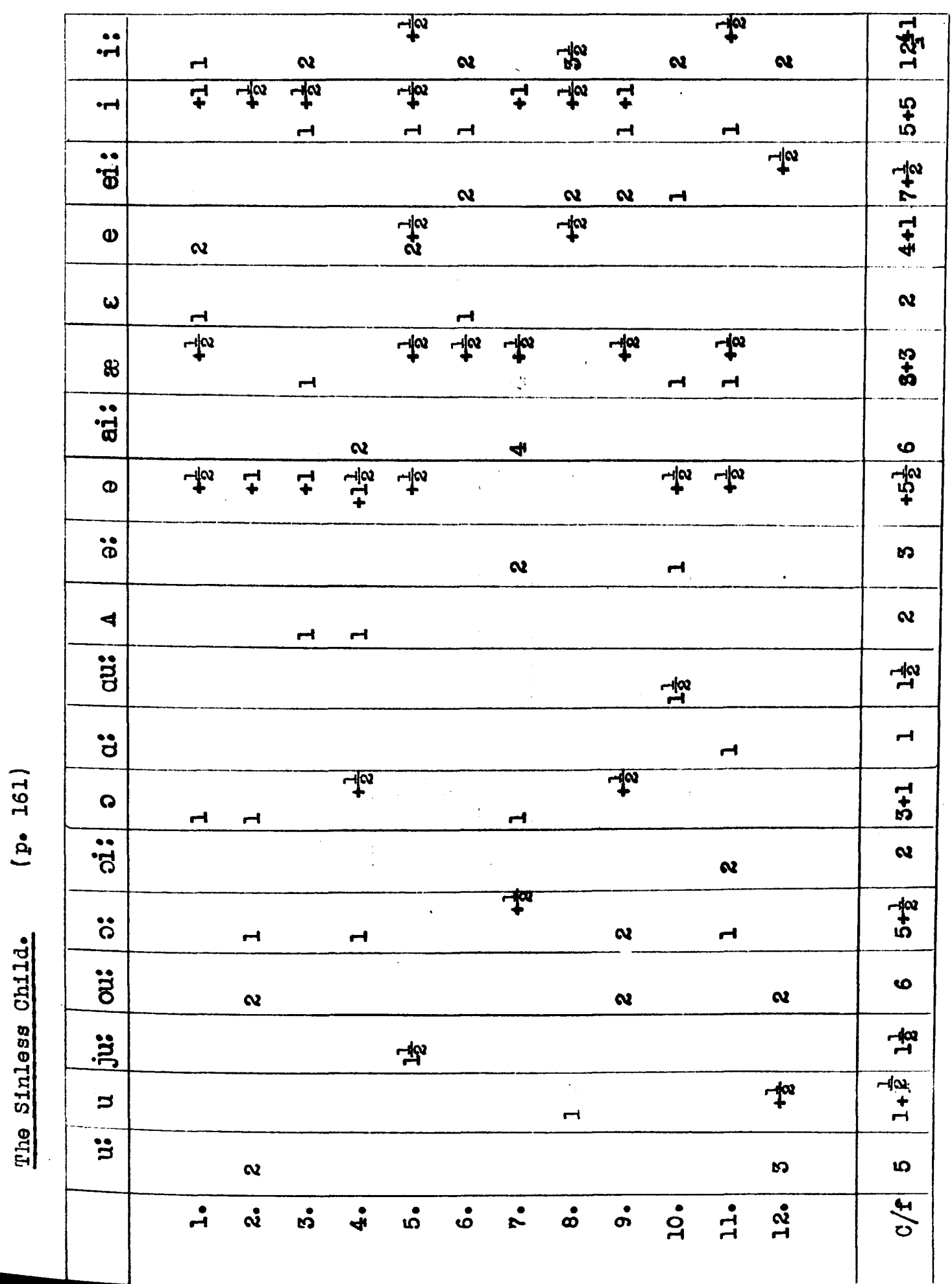




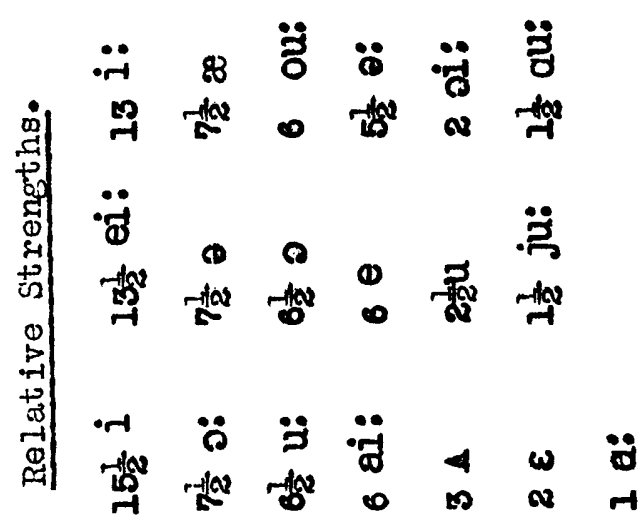

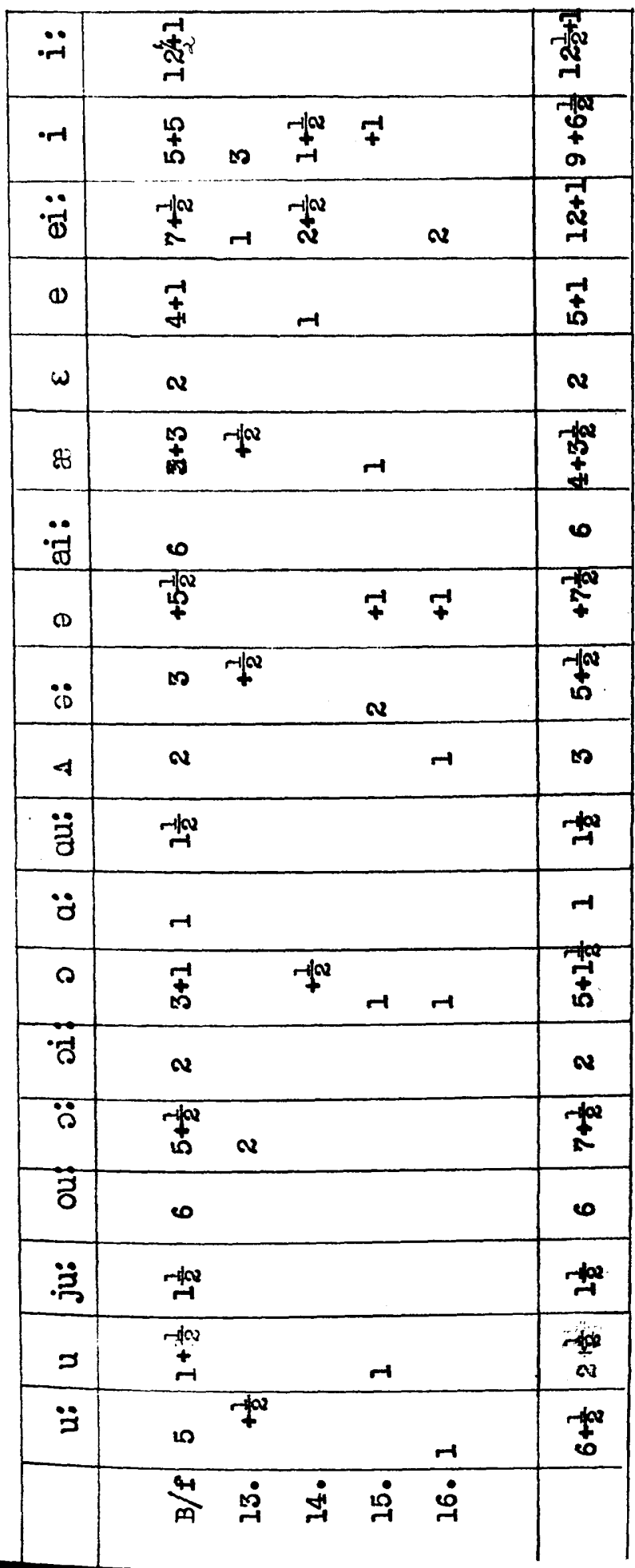




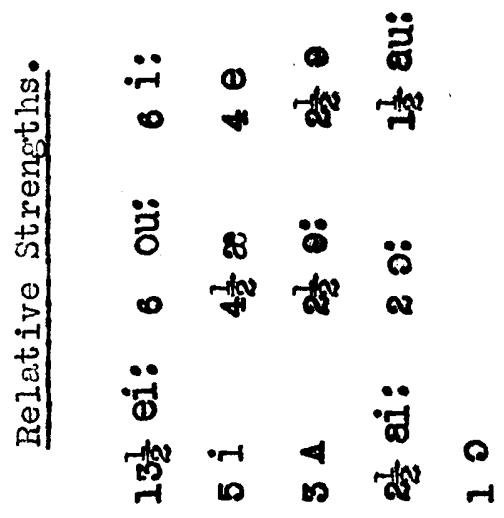

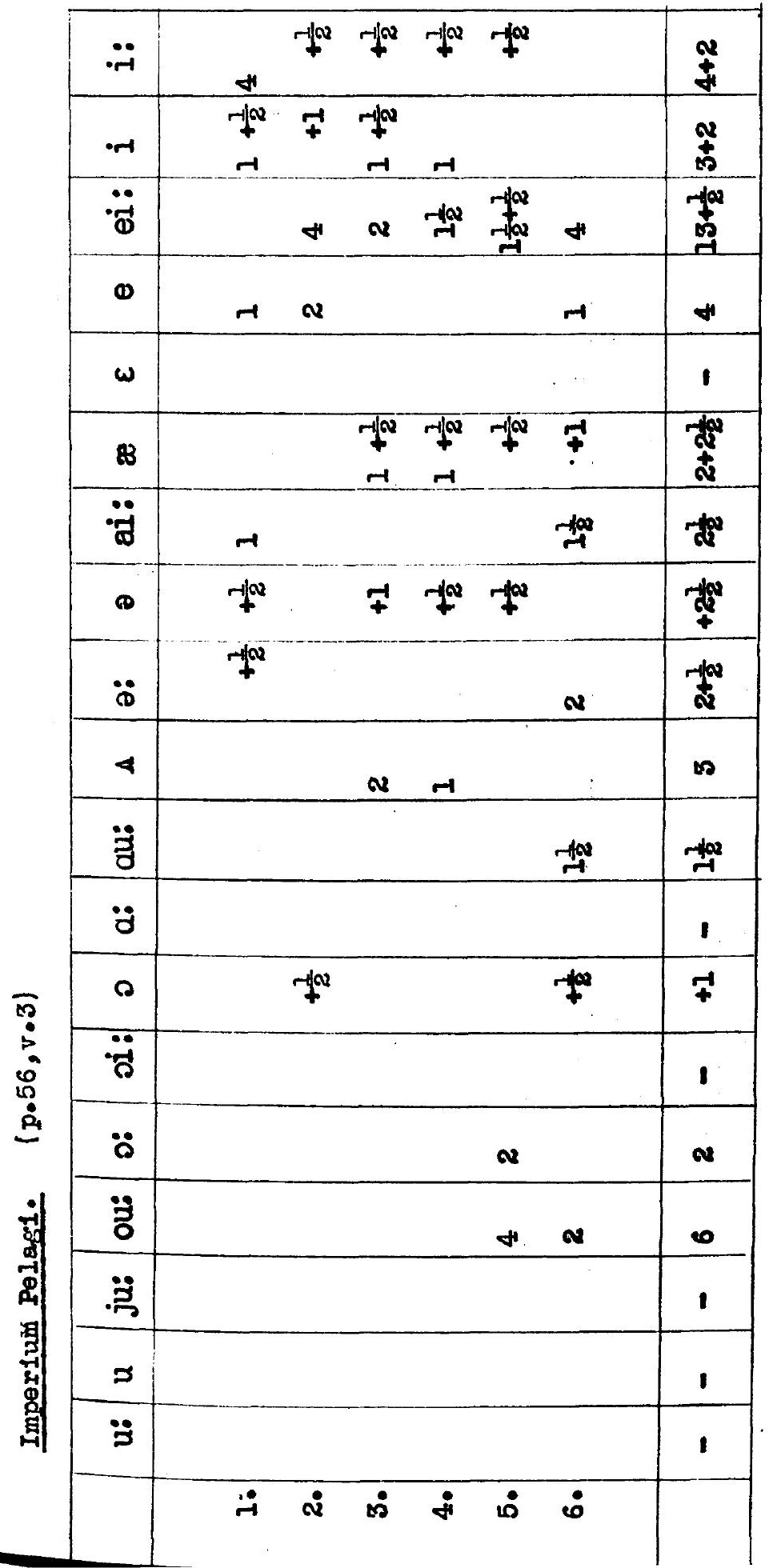




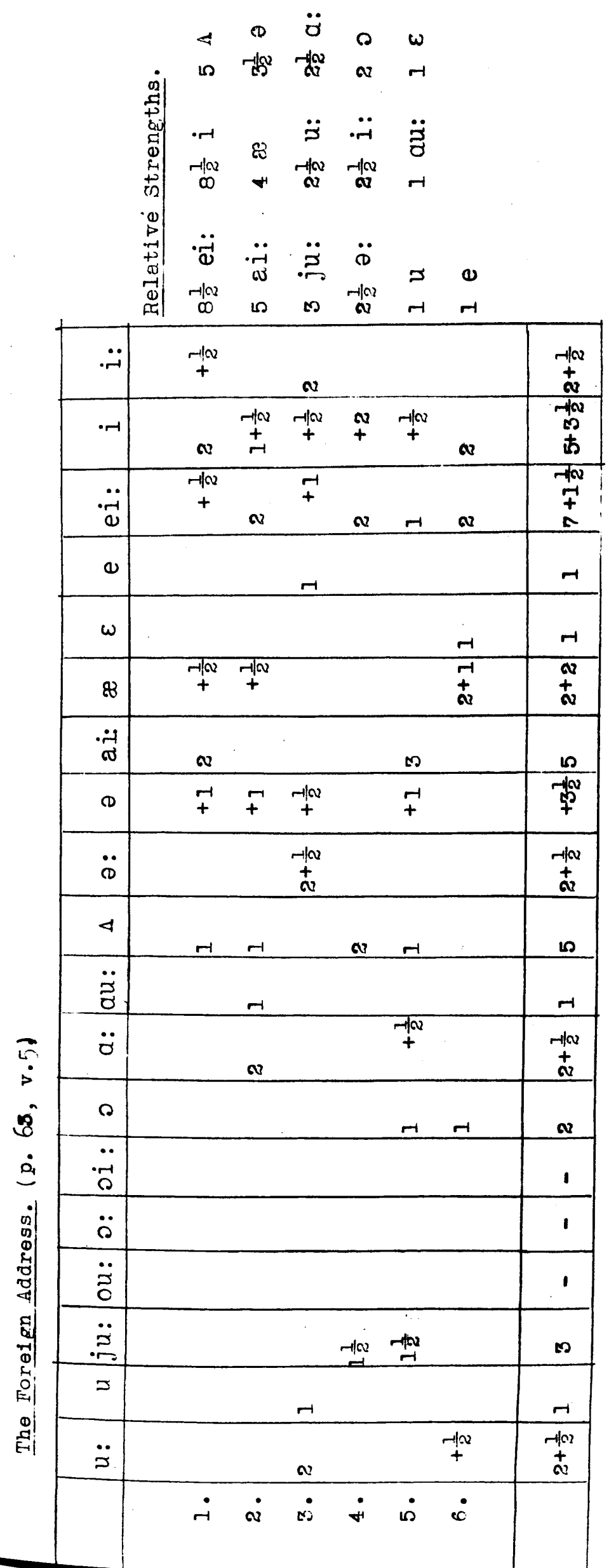




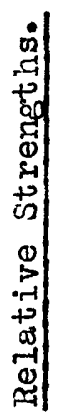

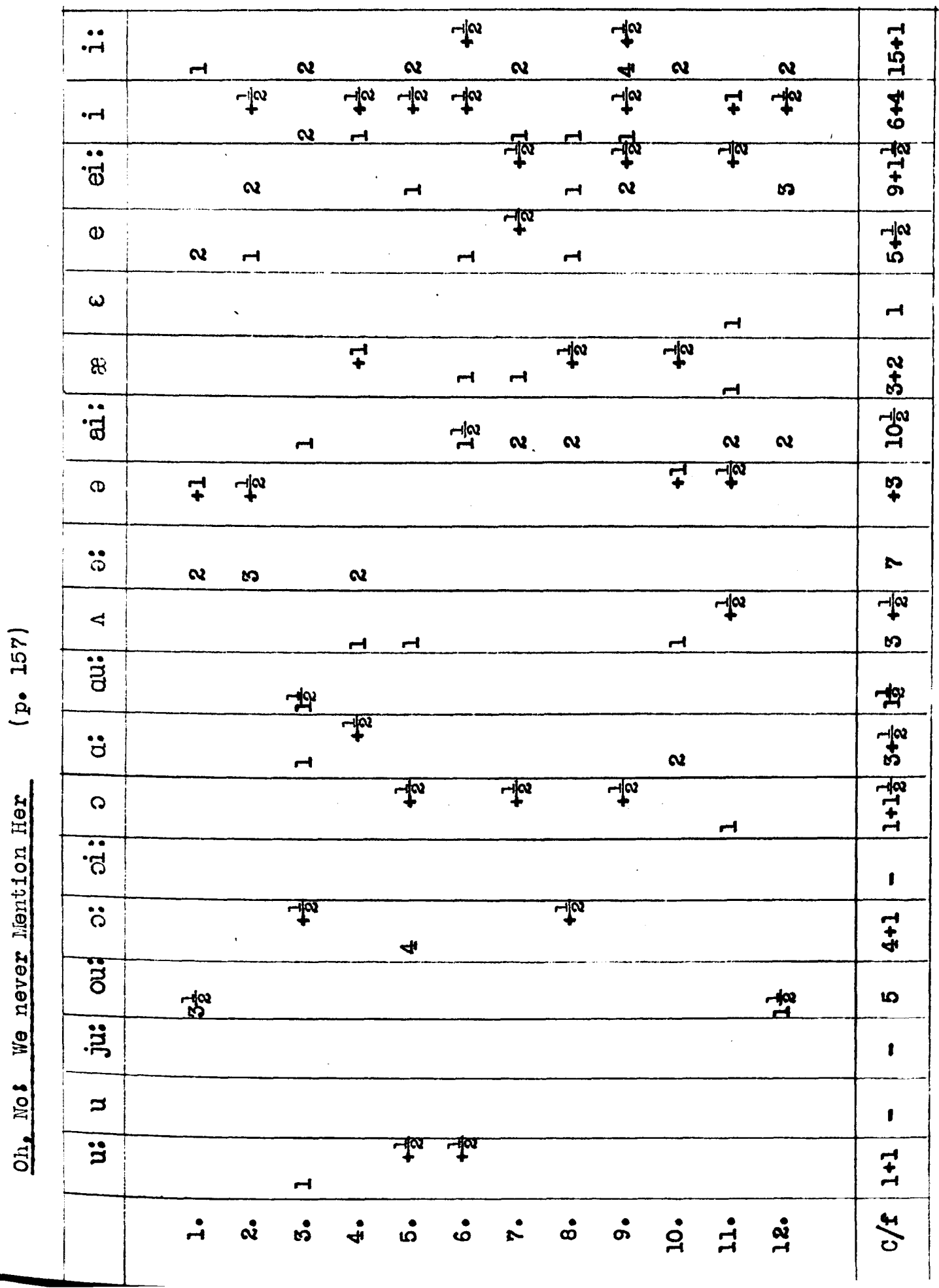

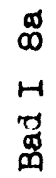




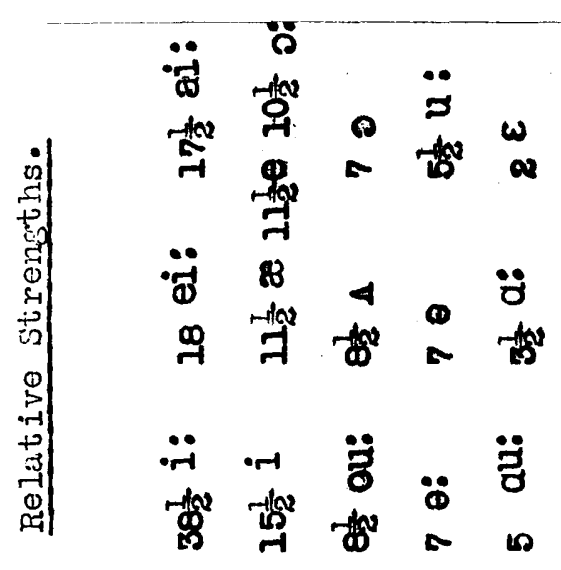

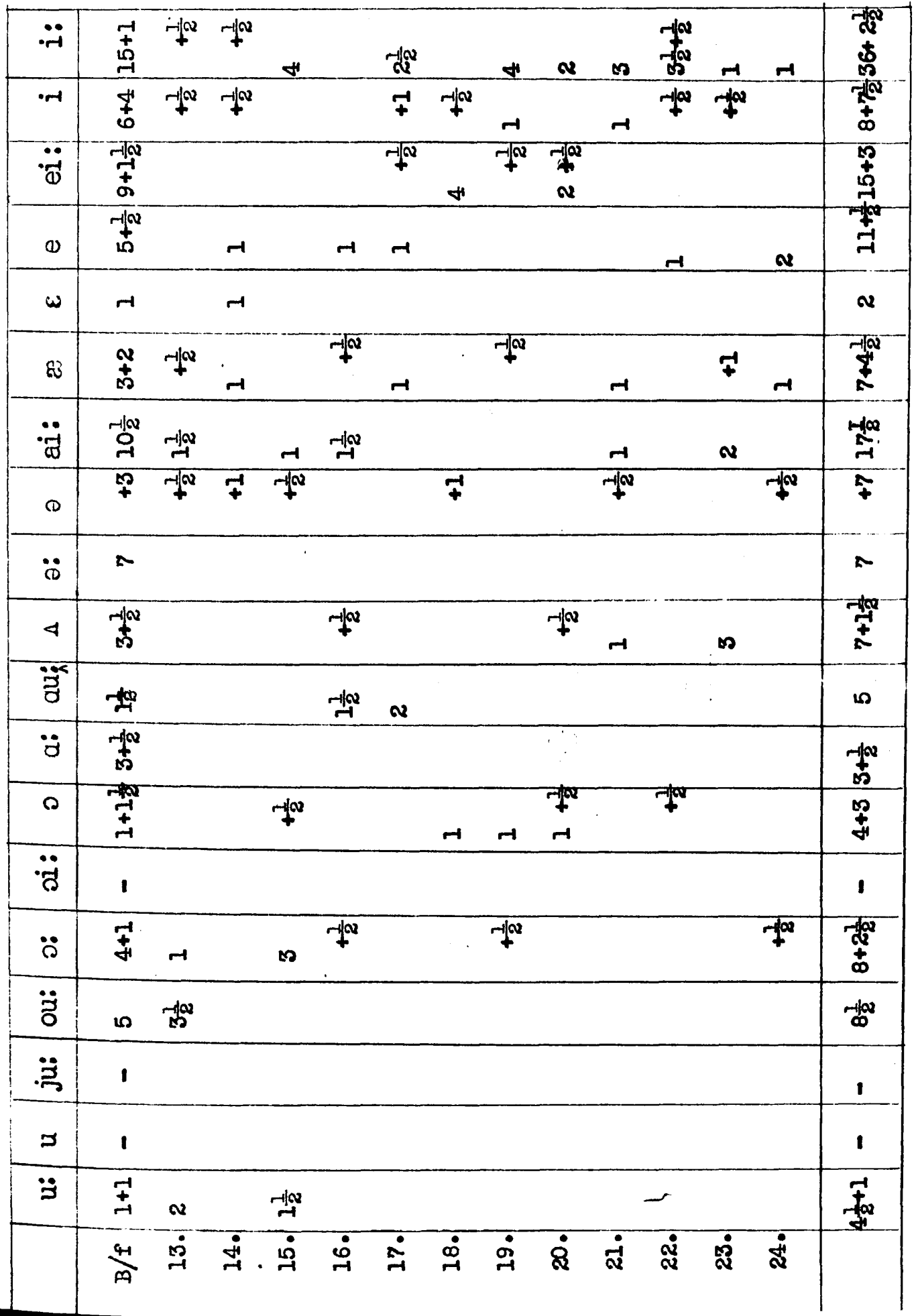




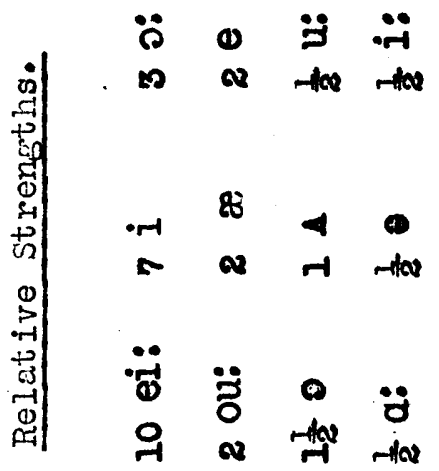

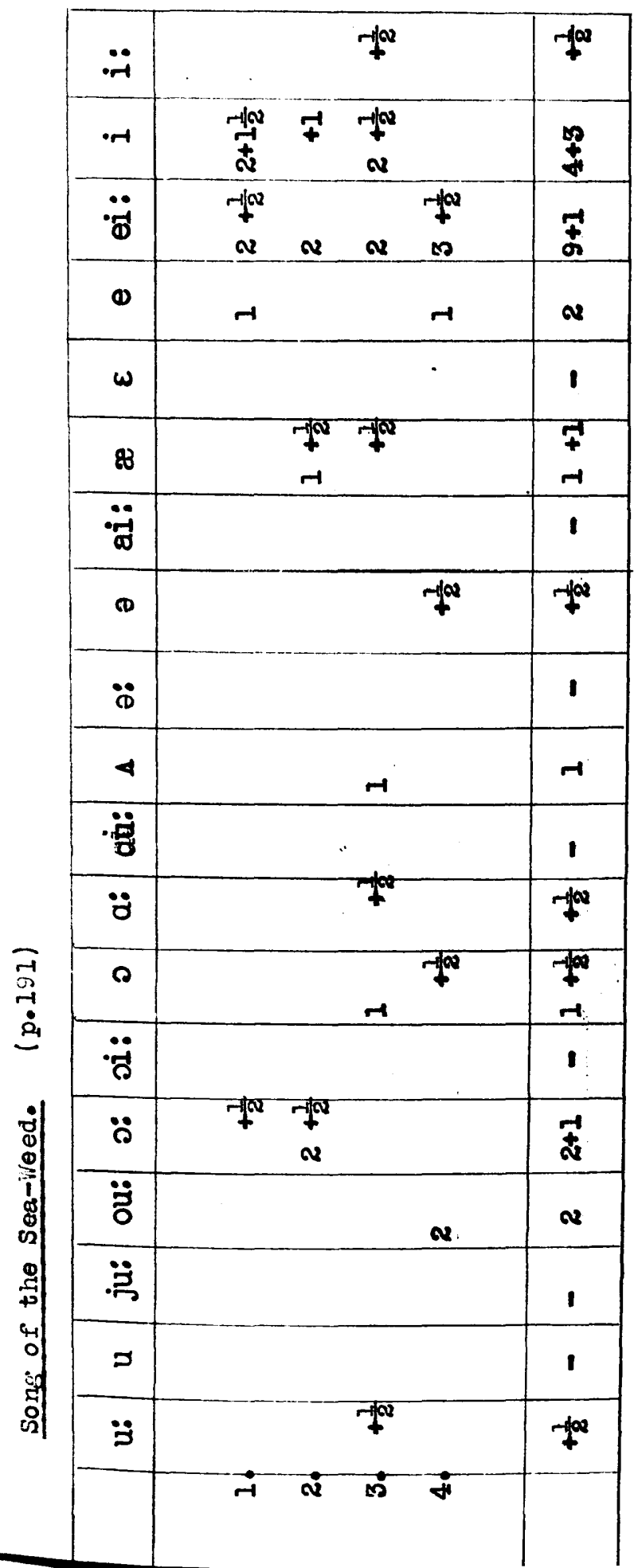

莒 


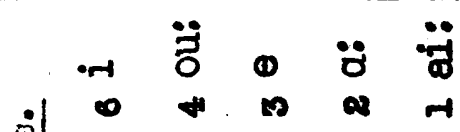

穴

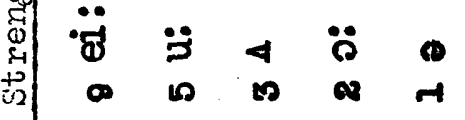

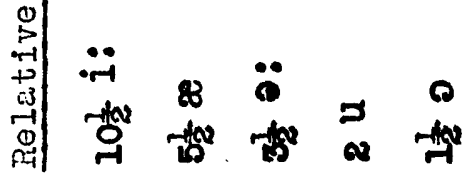

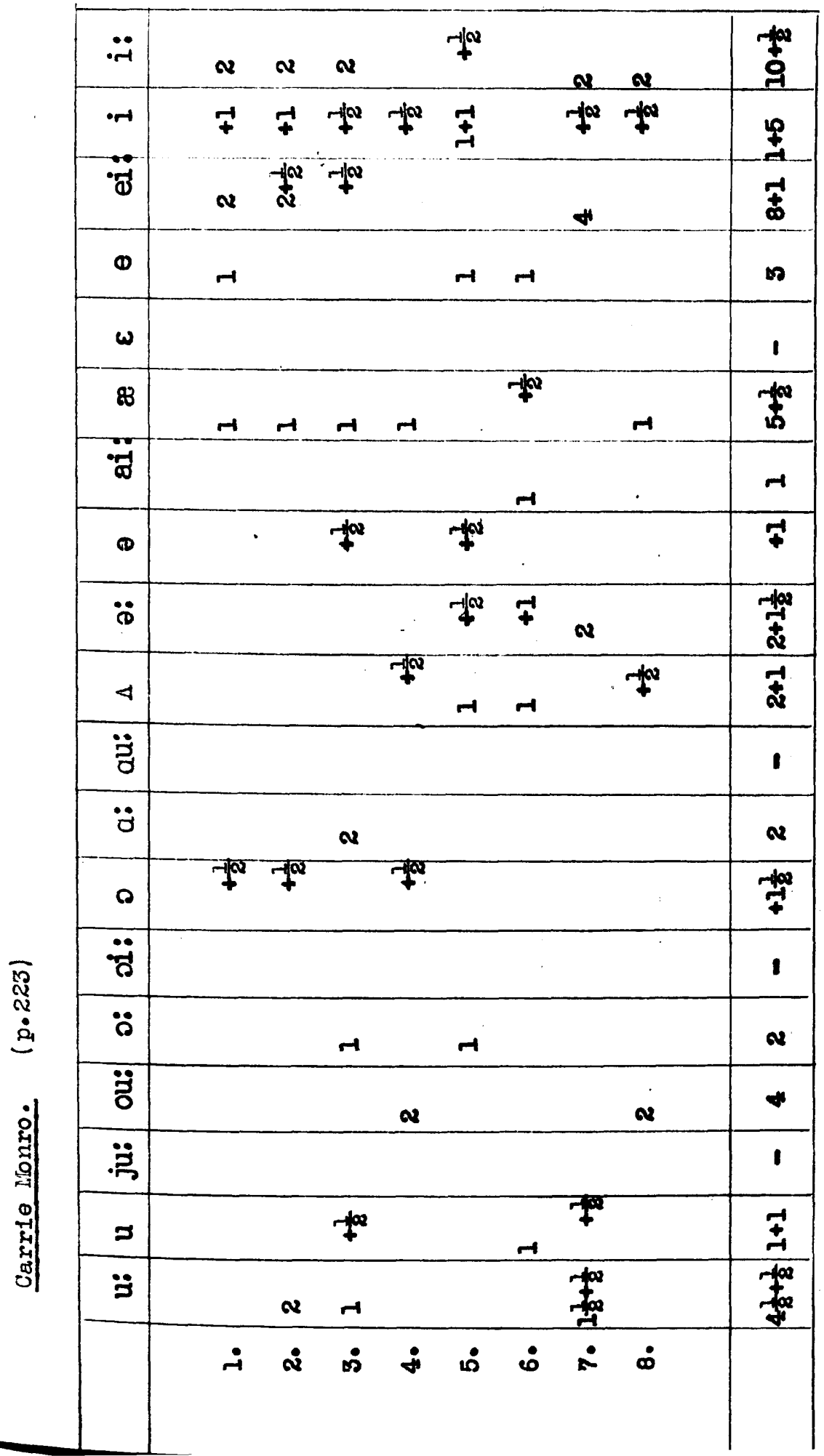




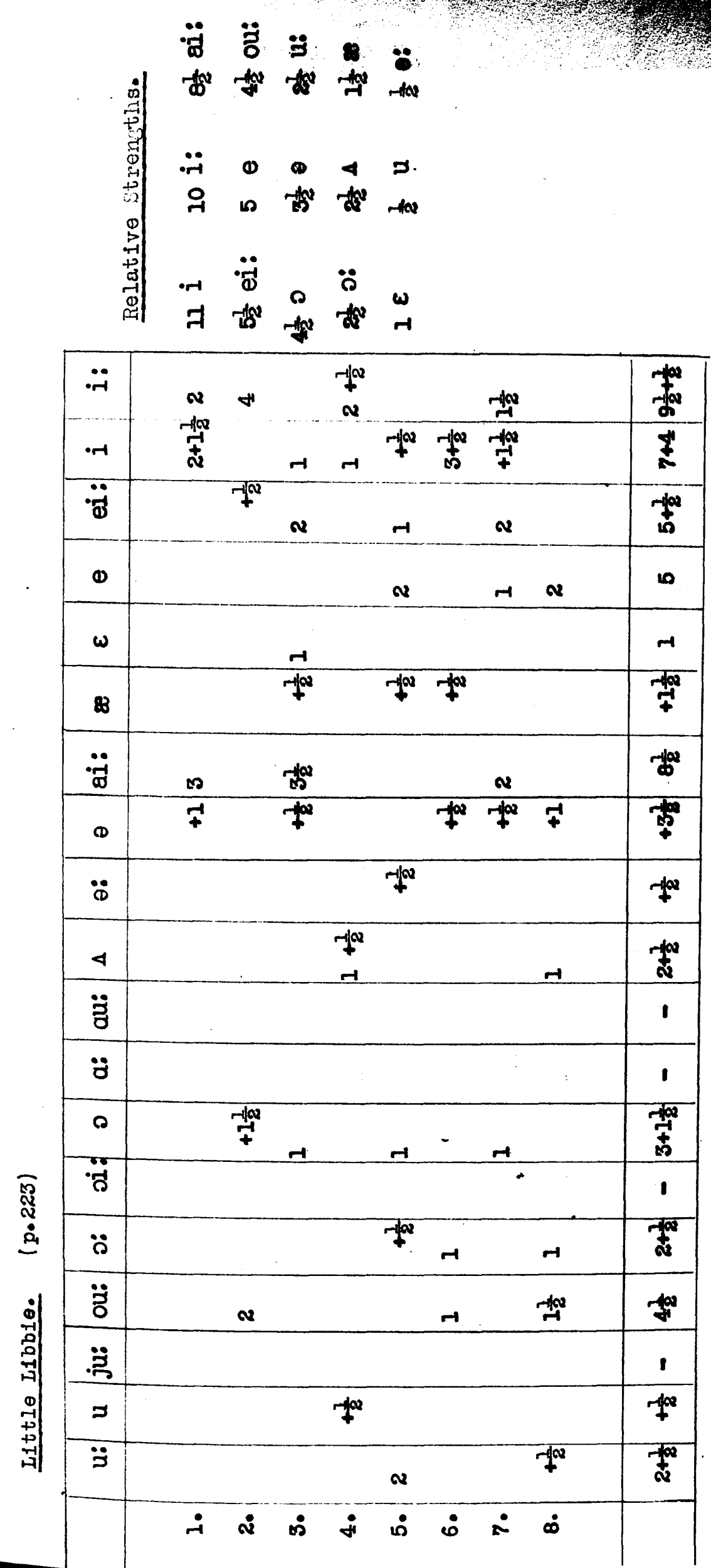




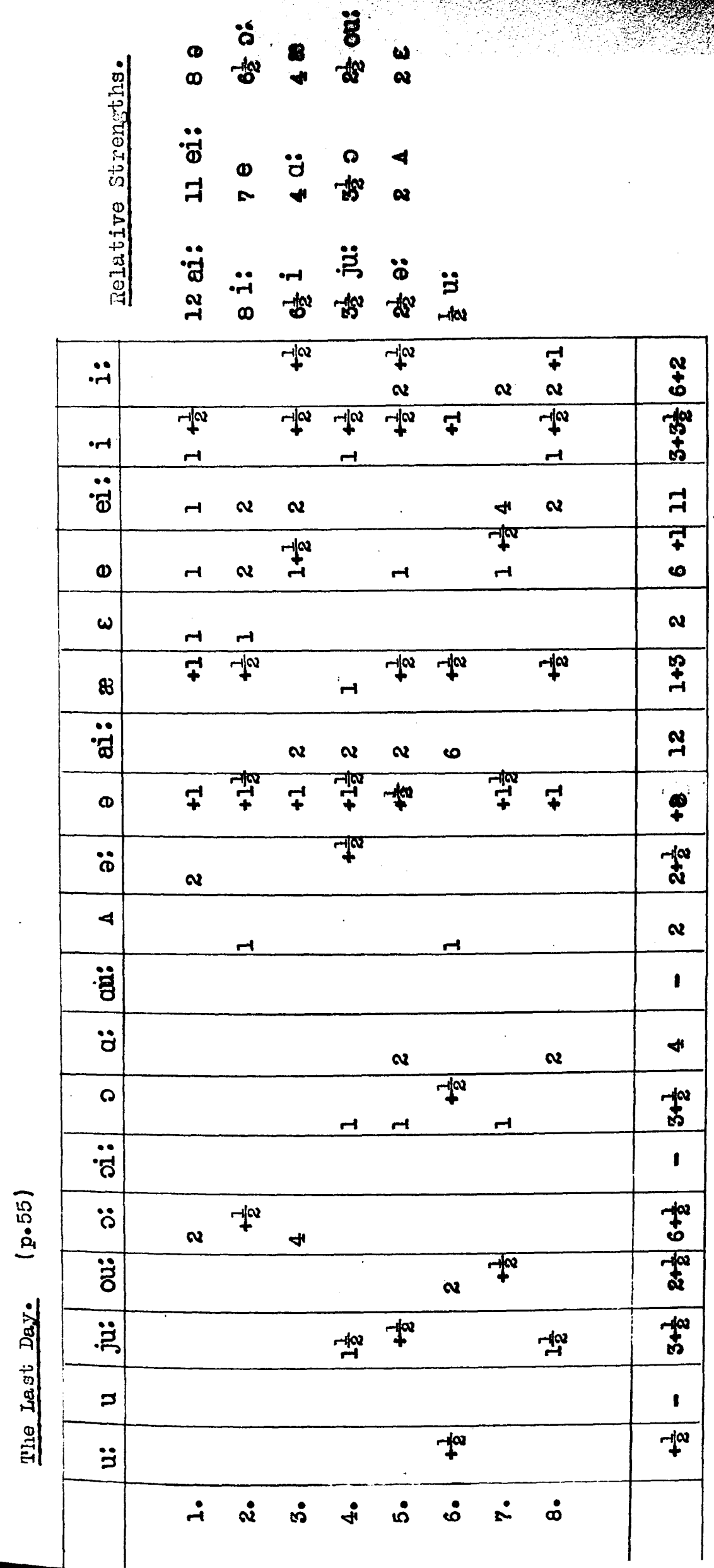




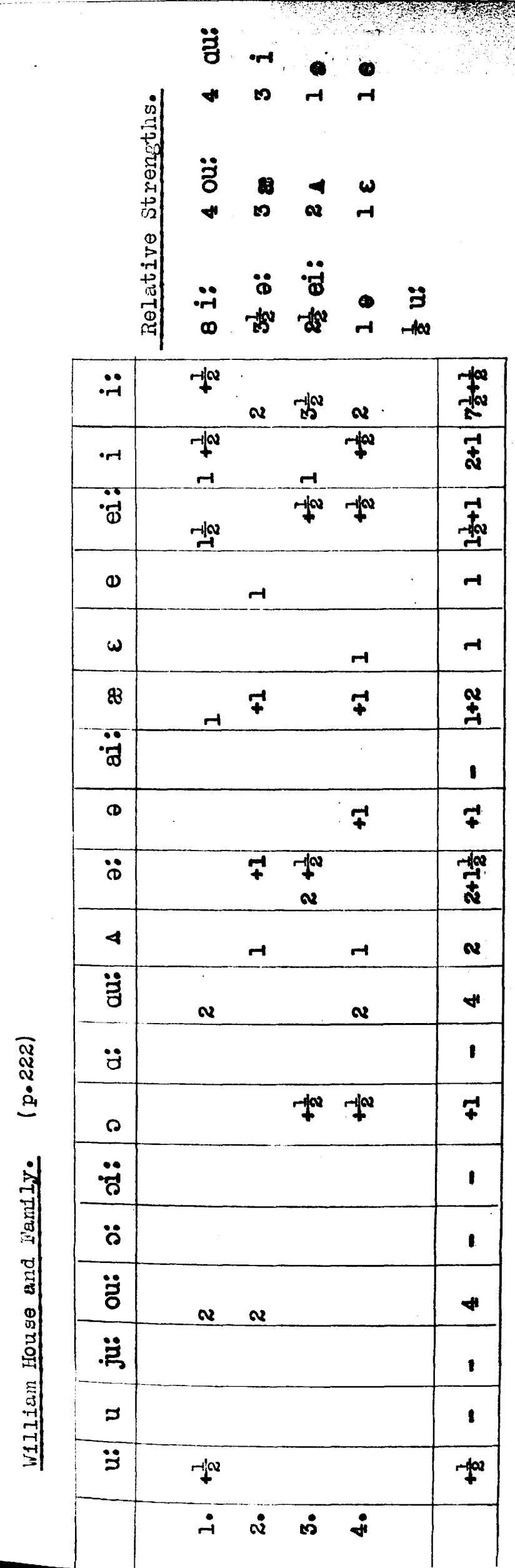

-7
H
吕 


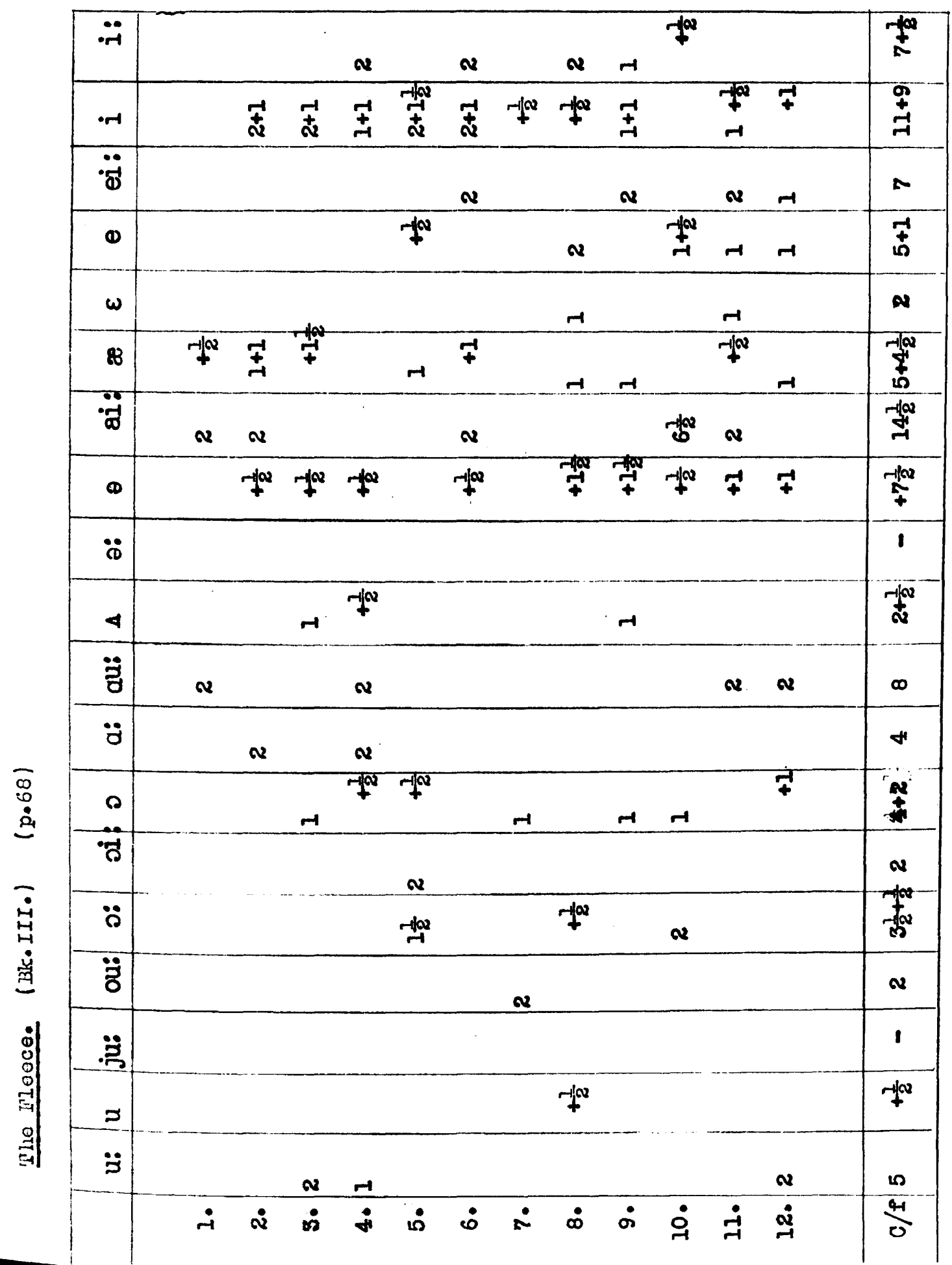




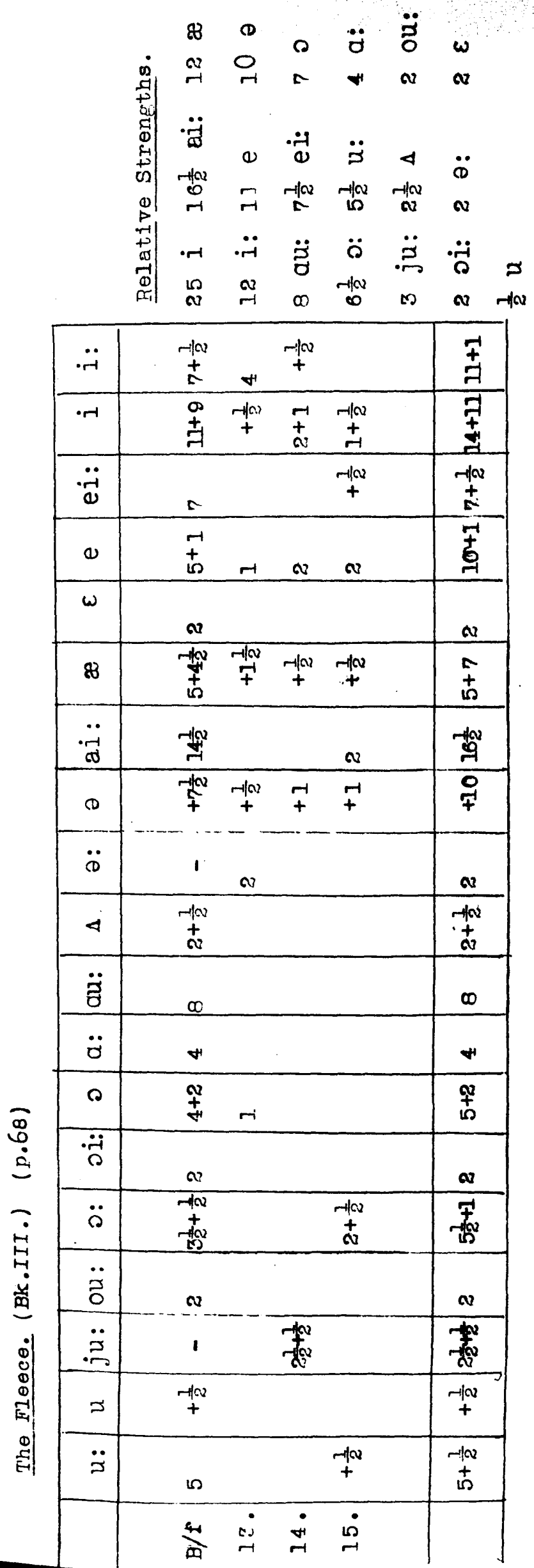




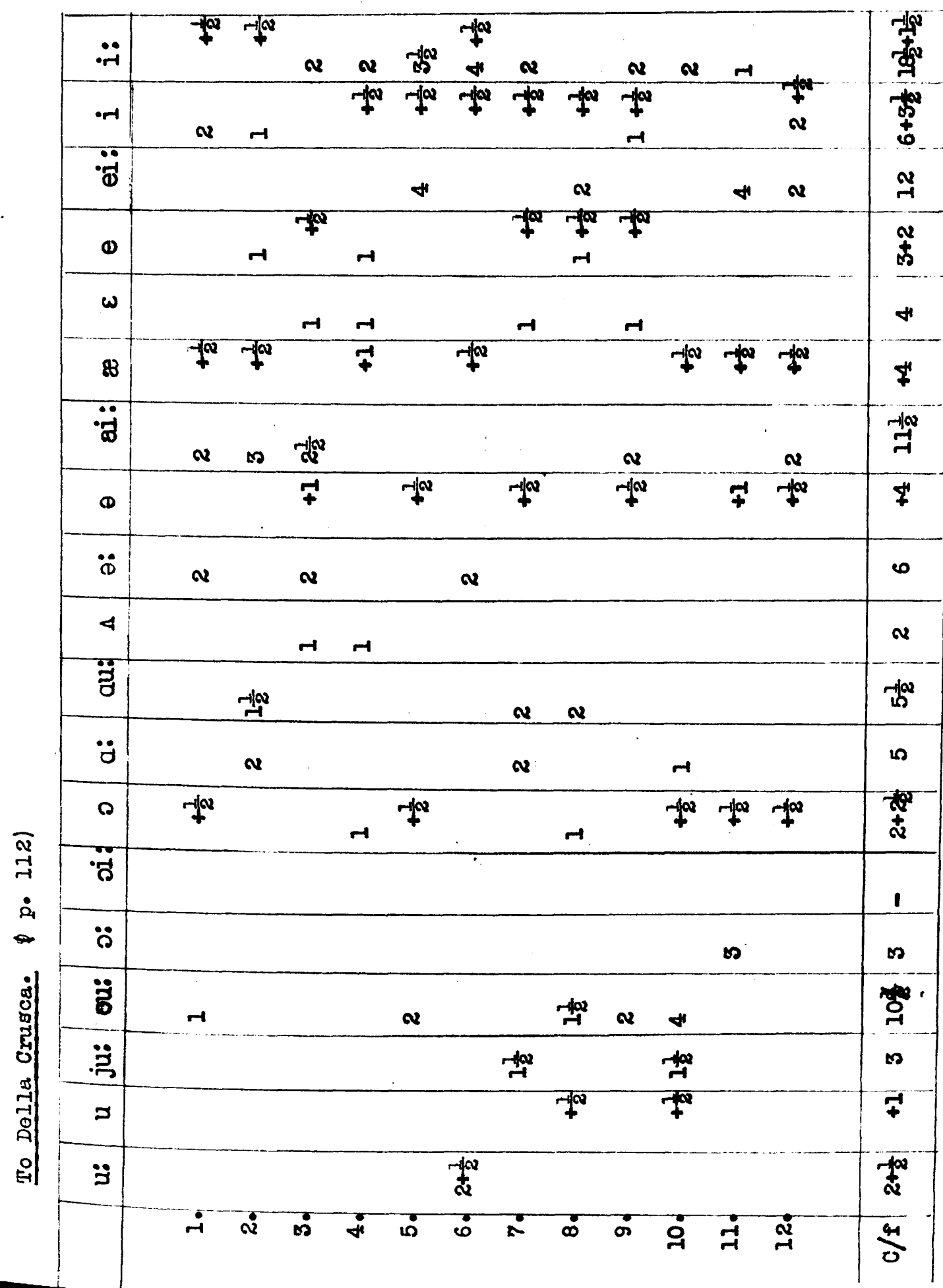




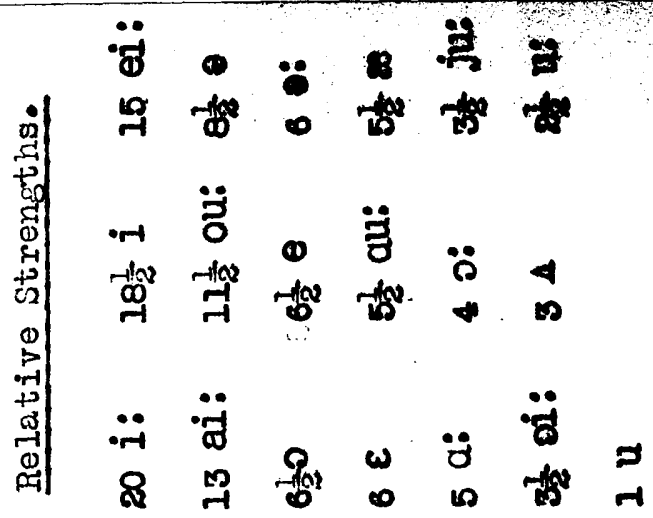

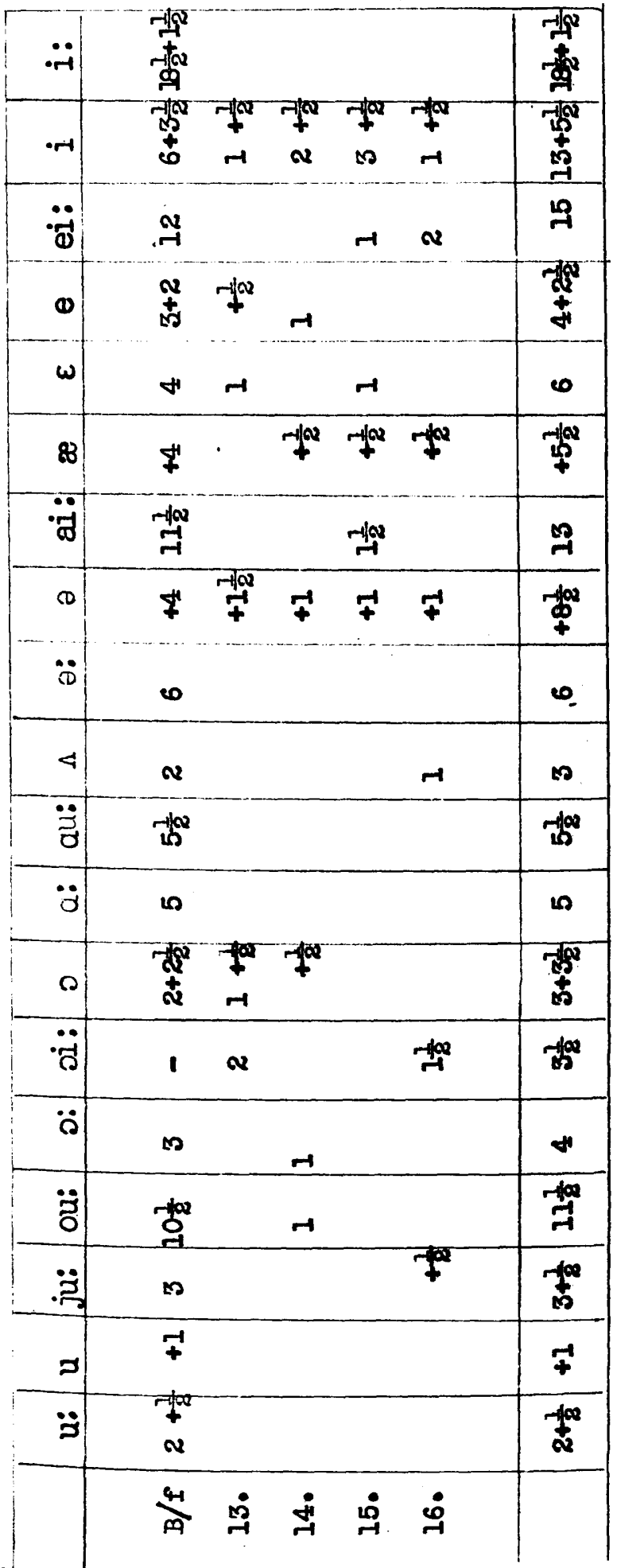




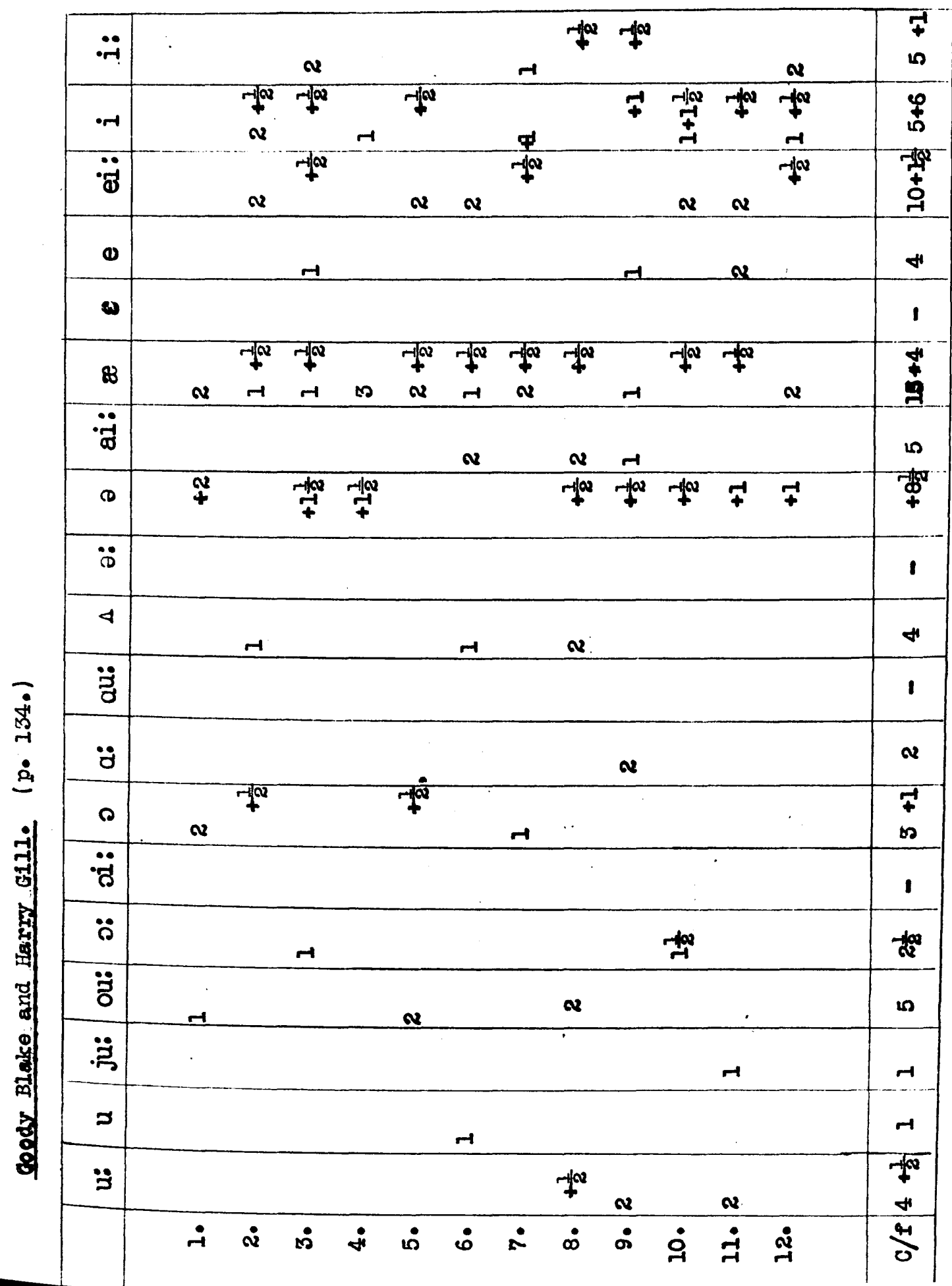




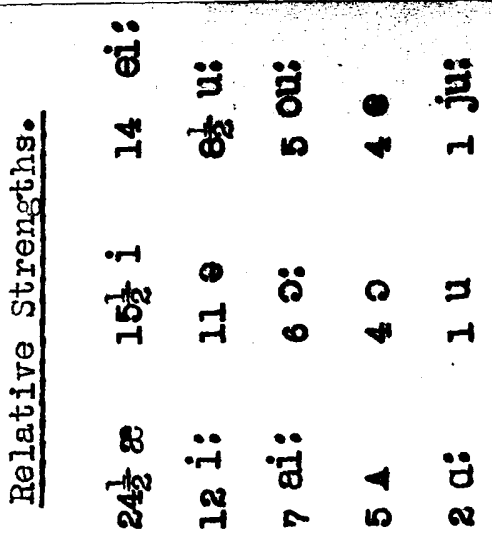

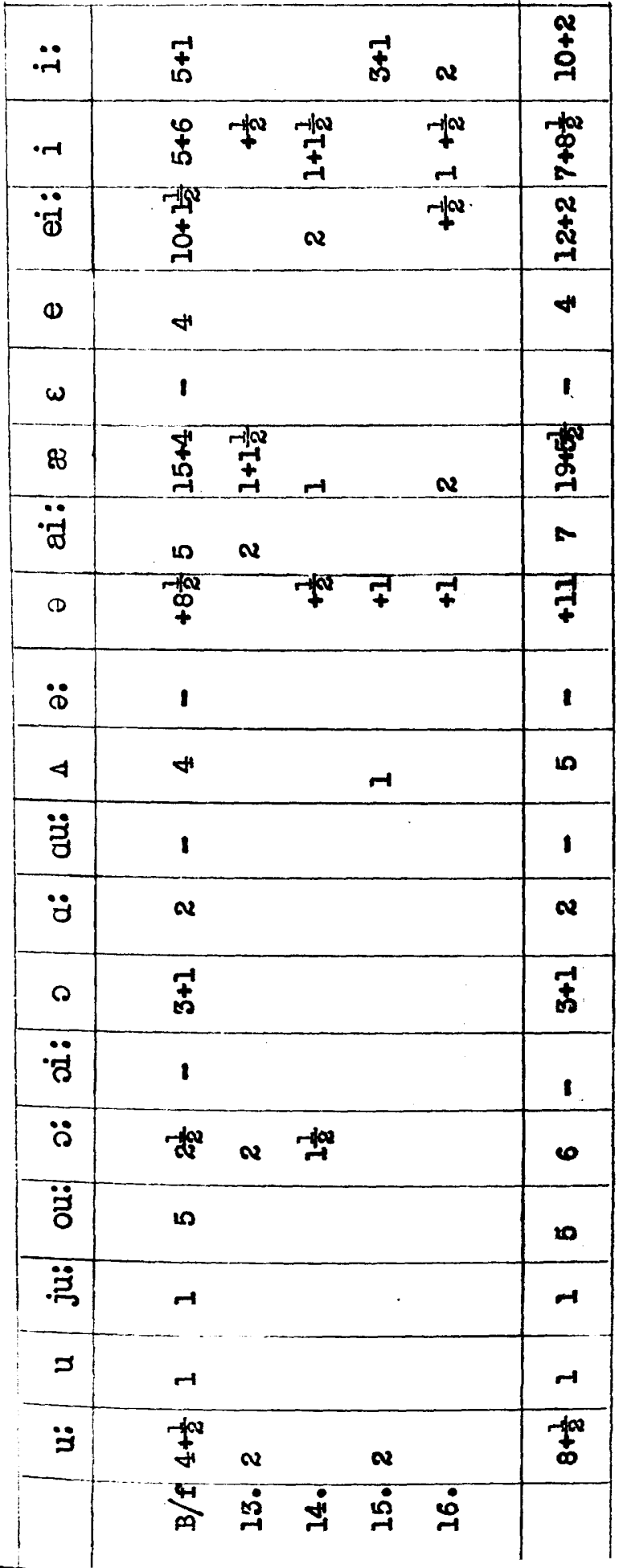

H 


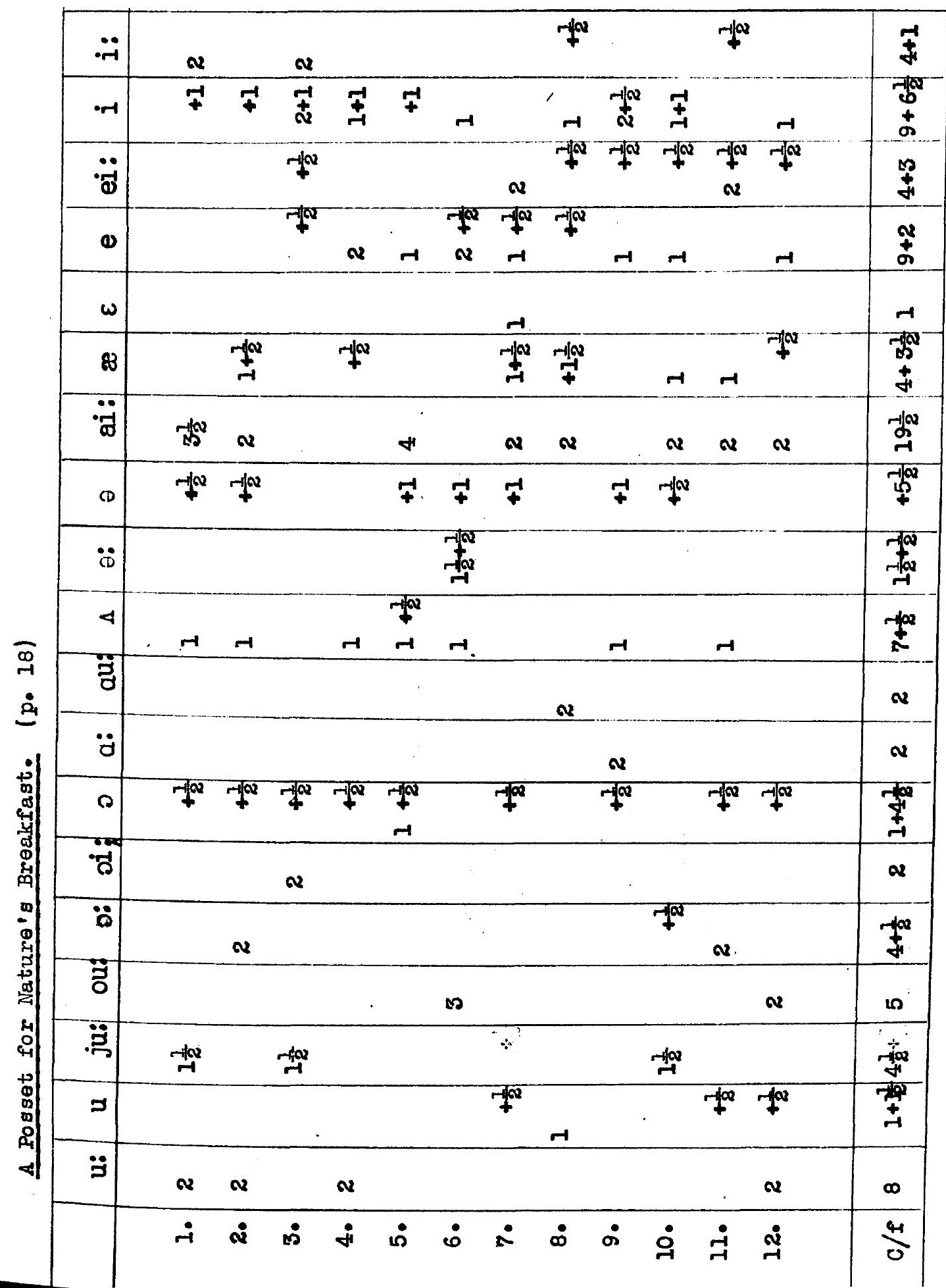




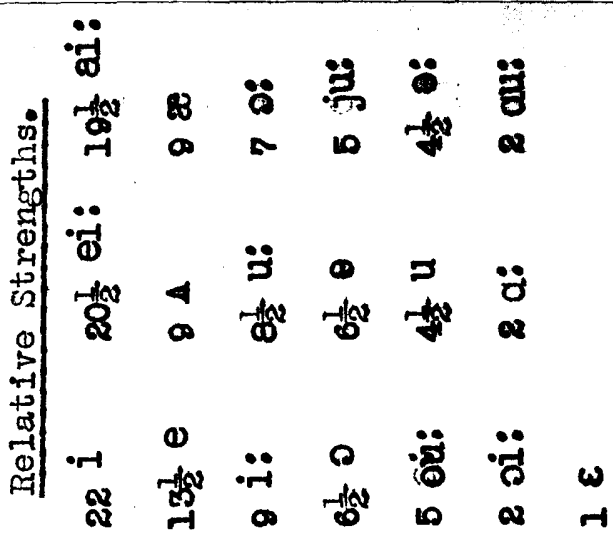

\begin{tabular}{|c|c|c|c|c|c|c|}
\hline$\ddot{r}$ & $\begin{array}{l}+ \\
+\end{array}$ & & & & $*$ & $\underset{\mathbf{D}}{+-1}$ \\
\hline$\cdot r$ & $\begin{array}{l}-1 / \sqrt{10} \\
0 \\
\vdots \\
0\end{array}$ & $v$ & $\begin{array}{l}-\sqrt{2-2} \\
-1\end{array}$ & $\underset{-}{\stackrel{H}{\infty}}$ & $\underset{-1}{-1 \infty}$ & $\stackrel{\infty}{+}$ \\
\hline$\ddot{\ddot{\theta}}$ & $\stackrel{m}{+}$ & $\stackrel{+}{ \pm}$ & & $\stackrel{-1 \times a}{a}$ & $\boldsymbol{x}$ & 敊 \\
\hline $\boldsymbol{\omega}$ & \begin{tabular}{c} 
尔 \\
\multirow{\sigma}{*}{}
\end{tabular} & & $-1 \infty$ & & $\rightarrow$ & 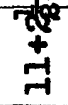 \\
\hline$\omega$ & -1 & & & & & - \\
\hline 88 & $\underset{+\infty}{+\infty}$ & & & +10 & +7 & $\stackrel{6}{+}$ \\
\hline$\ddot{a}$ & 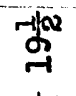 & & & & & नुल \\
\hline$ه$ & 㡀 & & 7 & & & 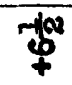 \\
\hline$\ddot{8}$ & $\operatorname{Th}_{-1}^{2}$ & $v$ & & & Fla & Fi \\
\hline 4 & $\underset{2}{+1}$ & & & & $7+\frac{100}{20}$ & $\underset{\infty}{+1}$ \\
\hline$\ddot{z}$ & $\boldsymbol{v}$ & & & & & $\boldsymbol{v}$ \\
\hline$\ddot{g}$ & $\boldsymbol{\alpha}$ & & & & & $\boldsymbol{\sim}$ \\
\hline 0 & $\underset{-1}{ \pm}$ & -ifa & & $-7 \sqrt{a}$ & & 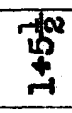 \\
\hline$\ddot{\circ}$ & $\boldsymbol{v}$ & & & & & $v$ \\
\hline$\ddot{\circ}$ & $\underset{f}{4-102}$ & & $\underset{\mathbf{N}}{\mathbf{N}}$ & & . & 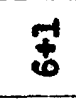 \\
\hline$\ddot{z}$ & $n$ & & & & & $\infty$ \\
\hline 芦 & $\frac{1}{3}$ & & & & $77^{2 x}$ & +\$ \\
\hline 3 & $\underset{-1}{ \pm}$ & & & $\boldsymbol{\alpha}$ & & 怘 \\
\hline$\ddot{z}$ & & + & & & & $\underset{\mathbf{D}}{+\infty}$ \\
\hline & 崮 & $\ddot{\leftrightarrow}$ & $\dot{H}$ & $\dot{\oplus}$ & $\dot{\leftrightarrow}$ & \\
\hline
\end{tabular}




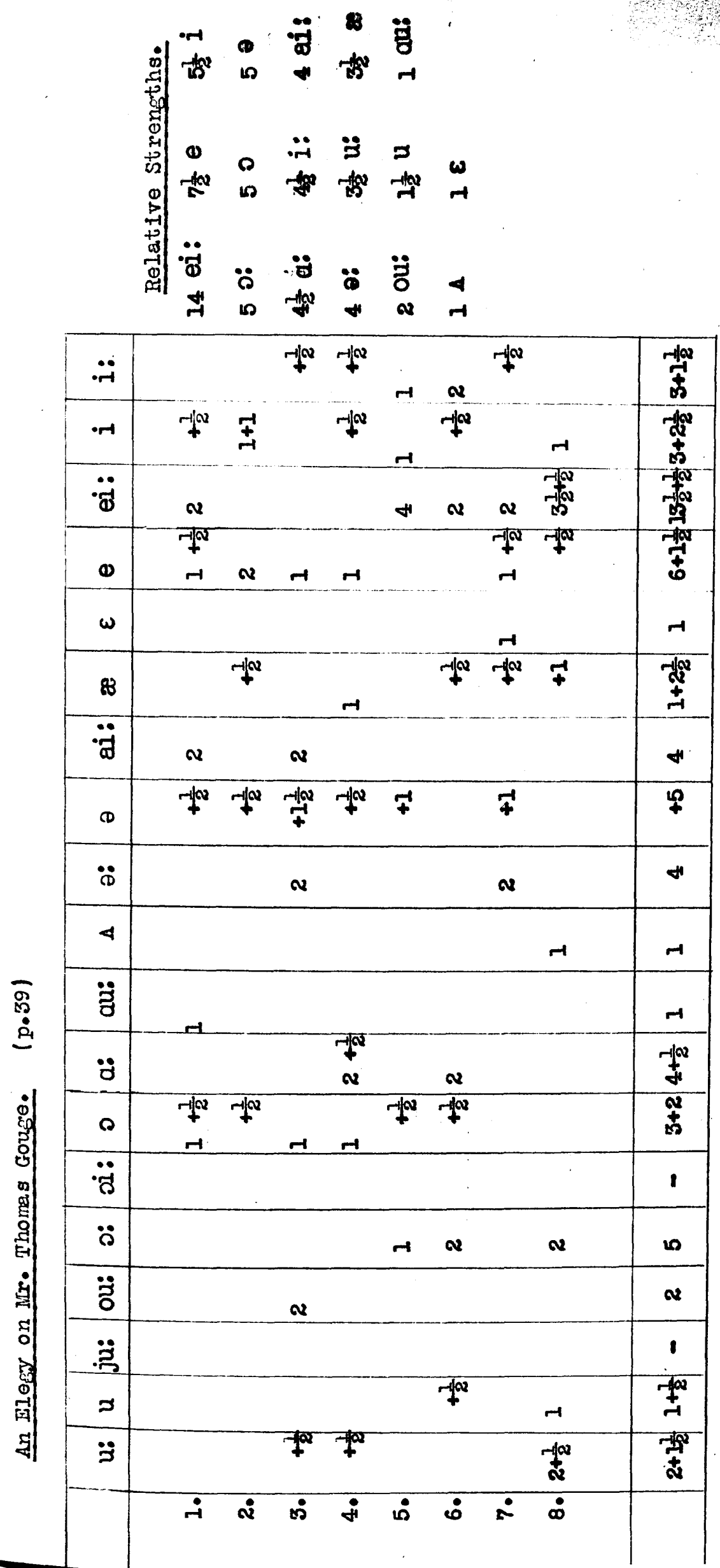




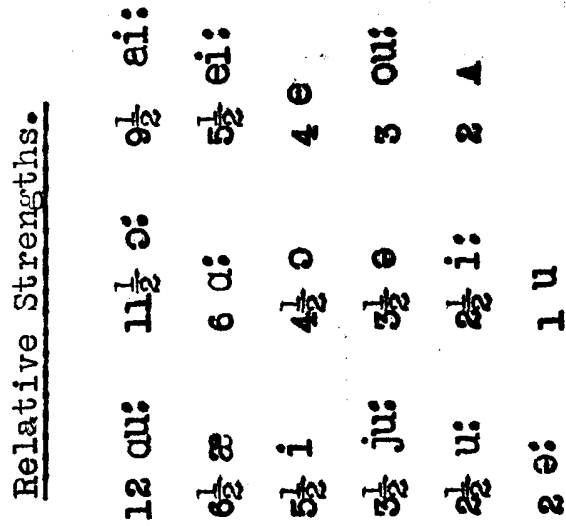

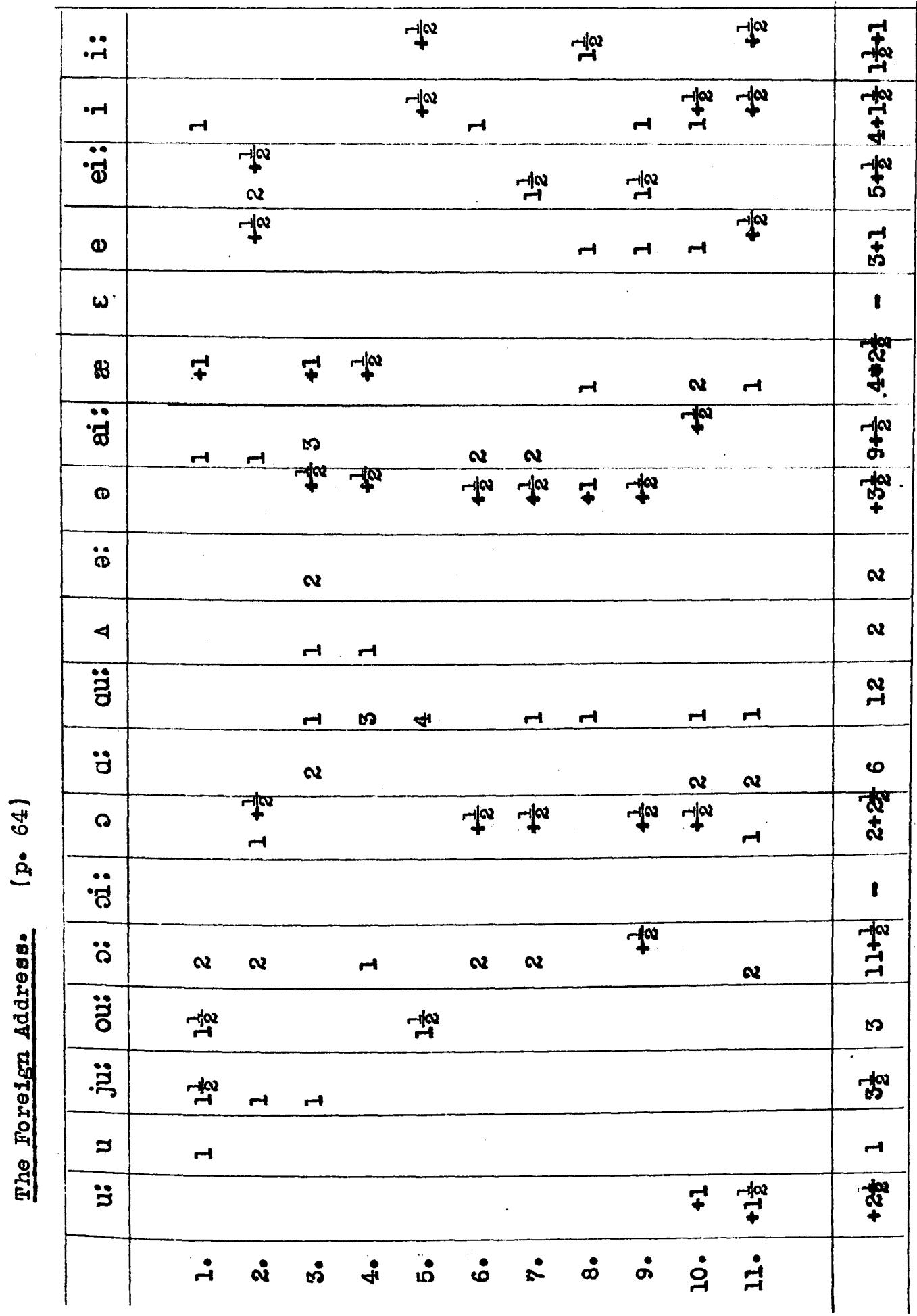




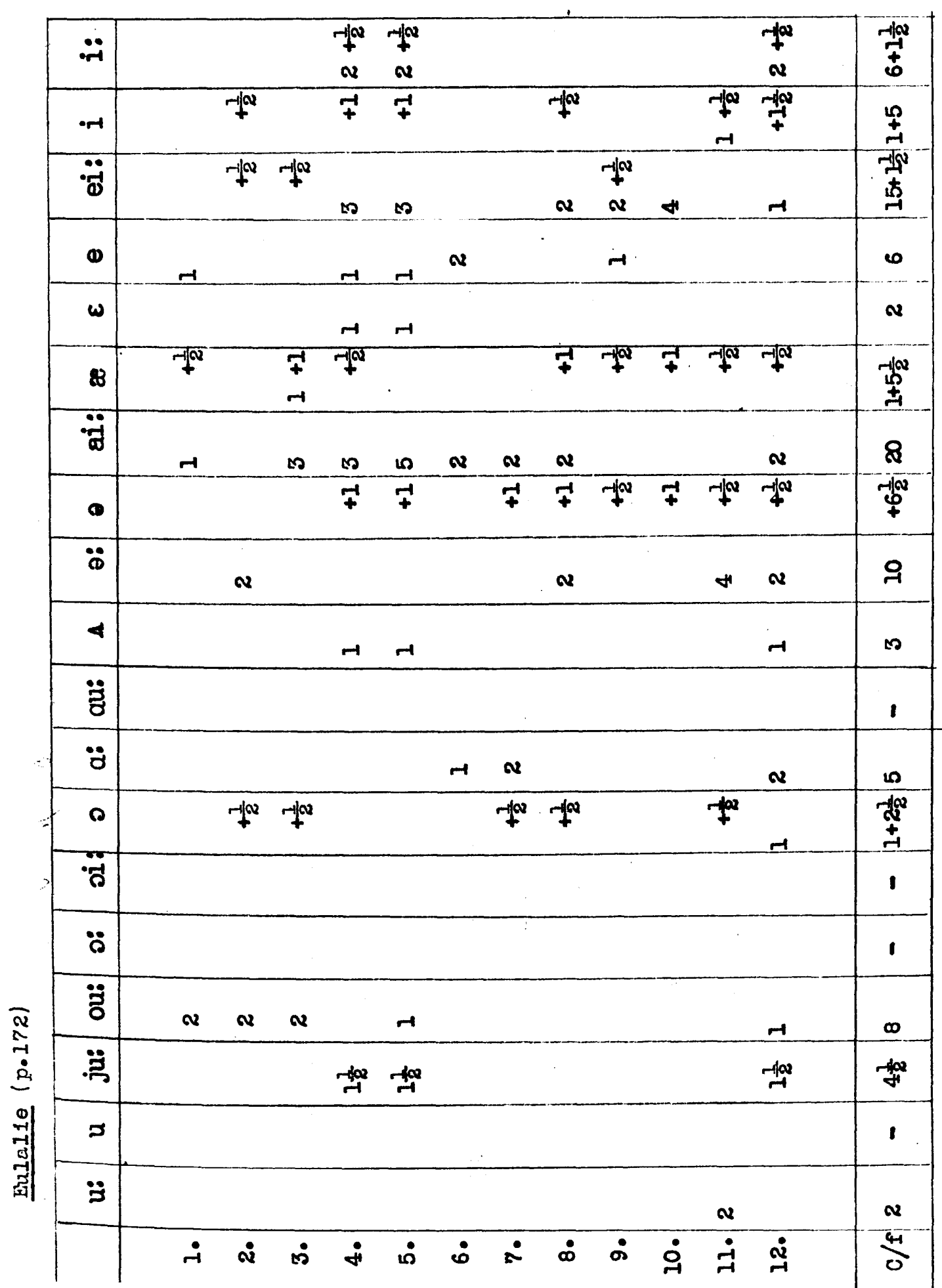

ơ
是
日
g
p 


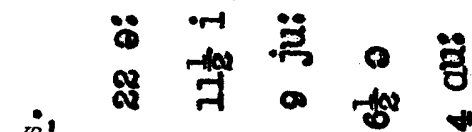

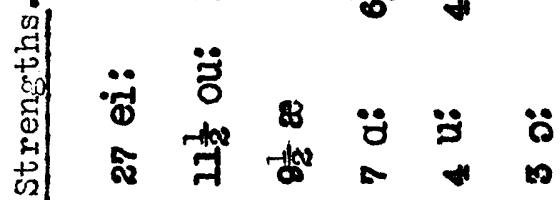

点

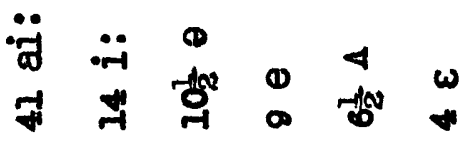

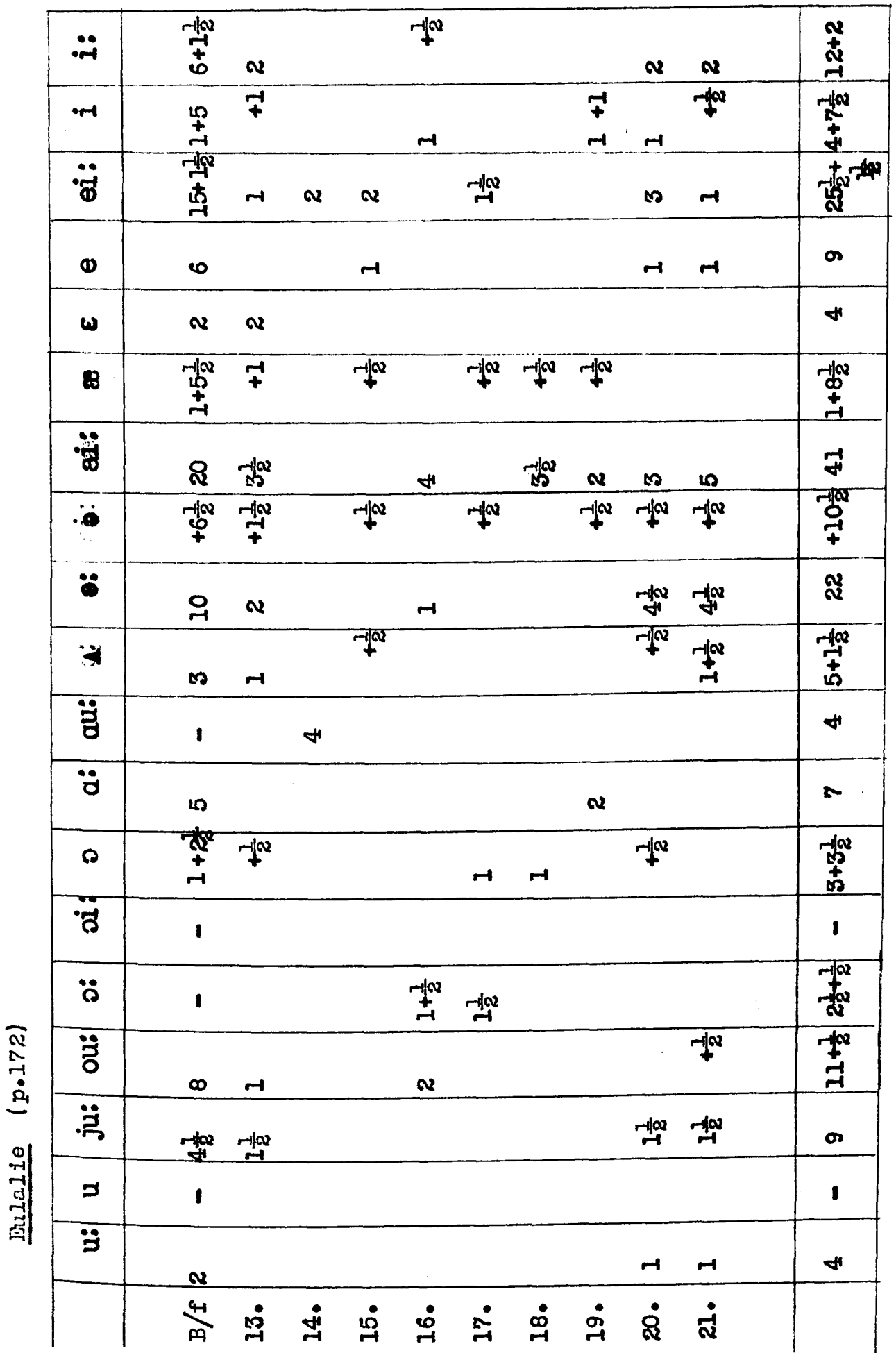




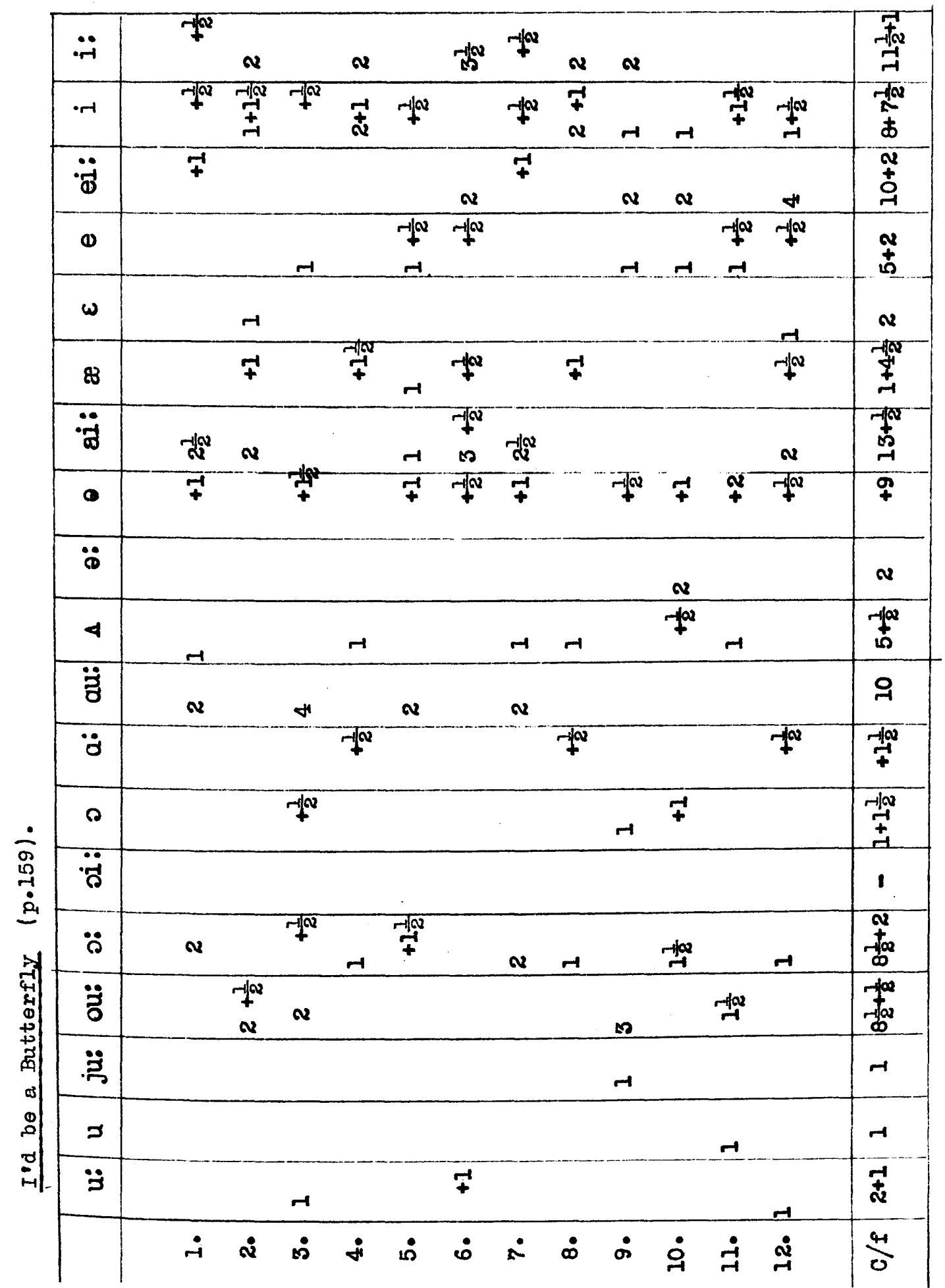

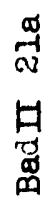




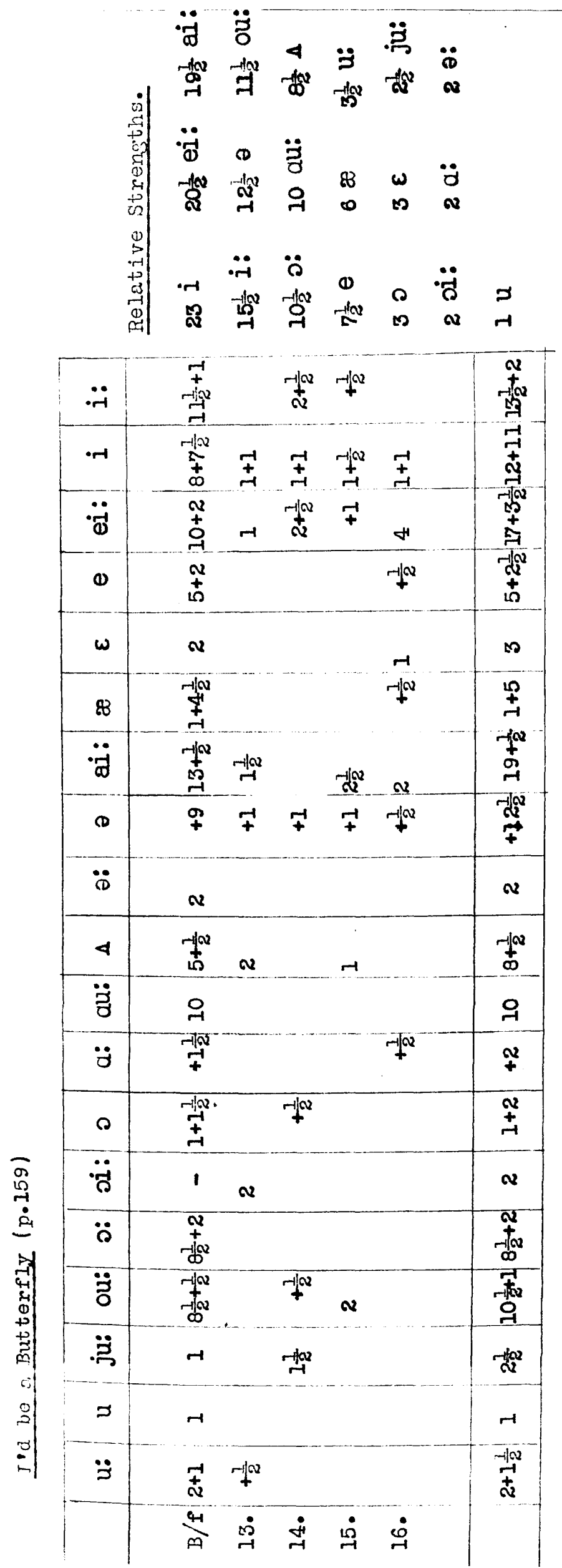

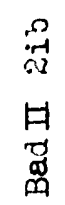




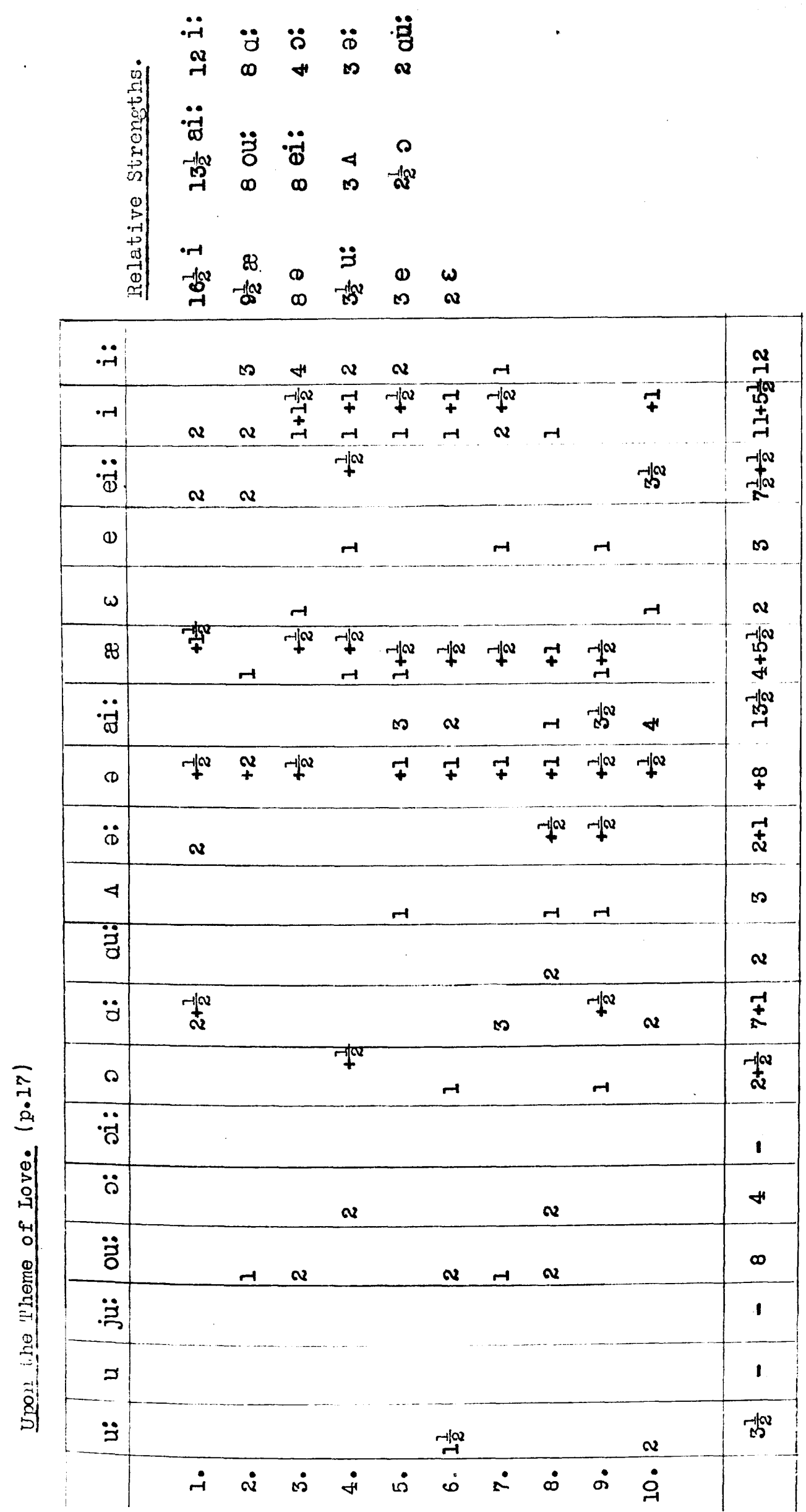

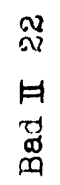




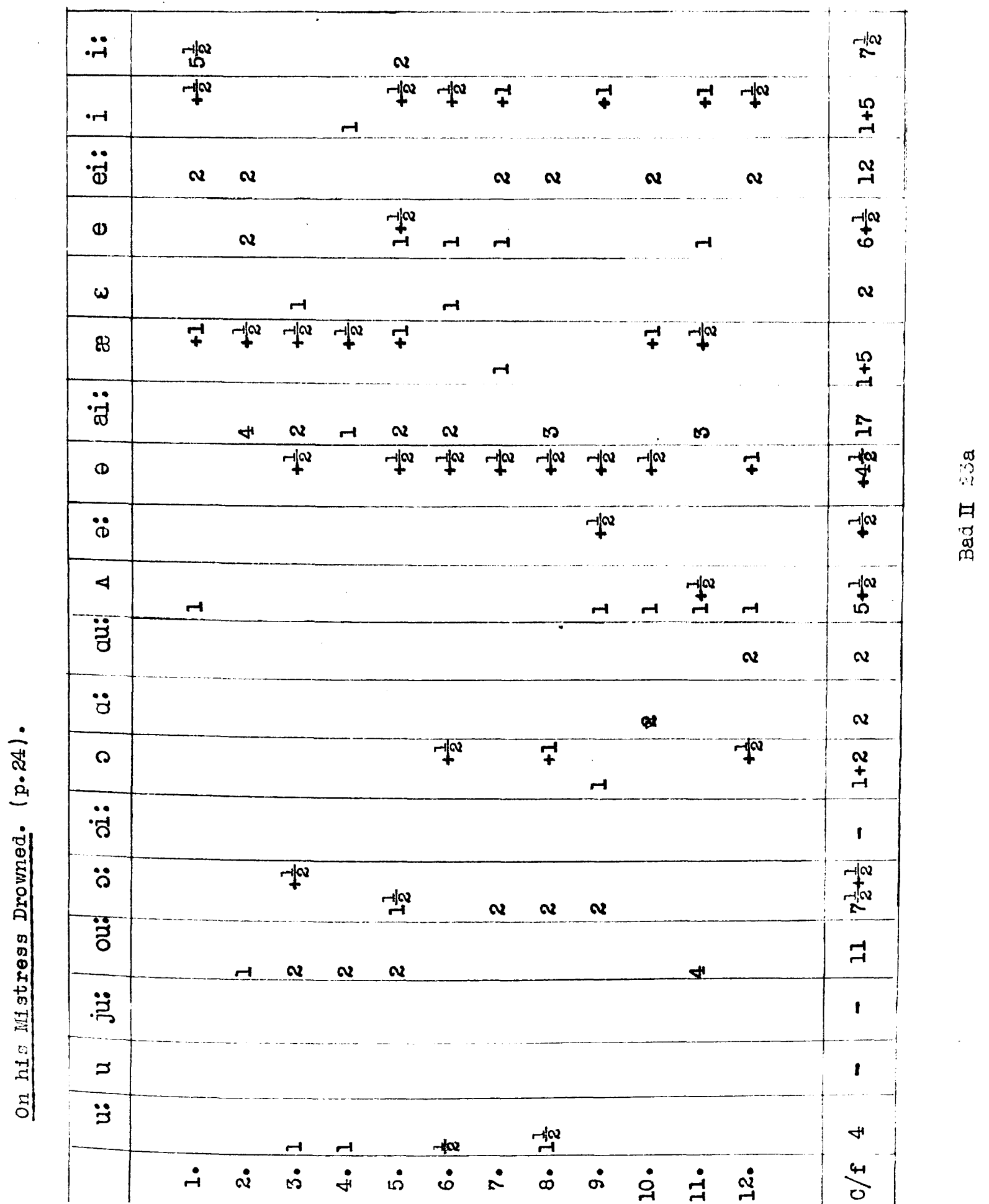




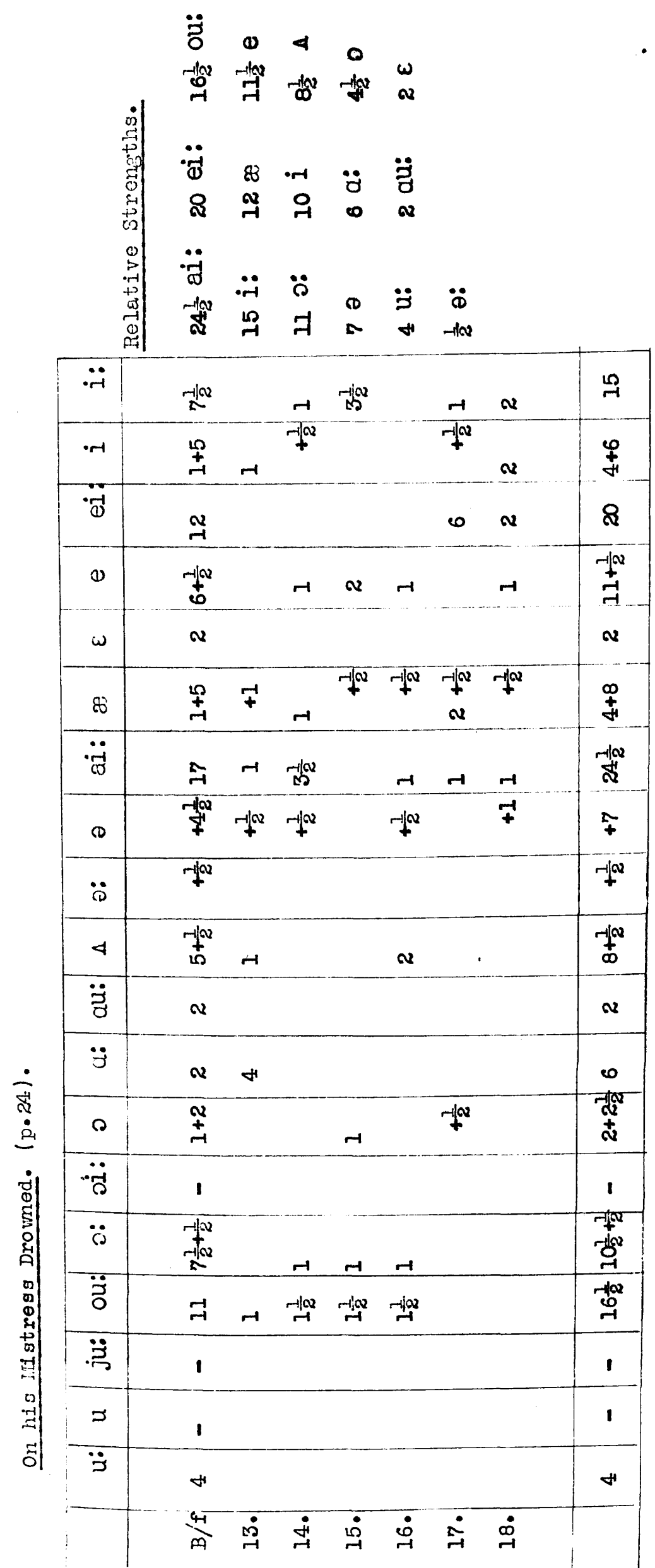

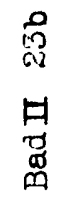




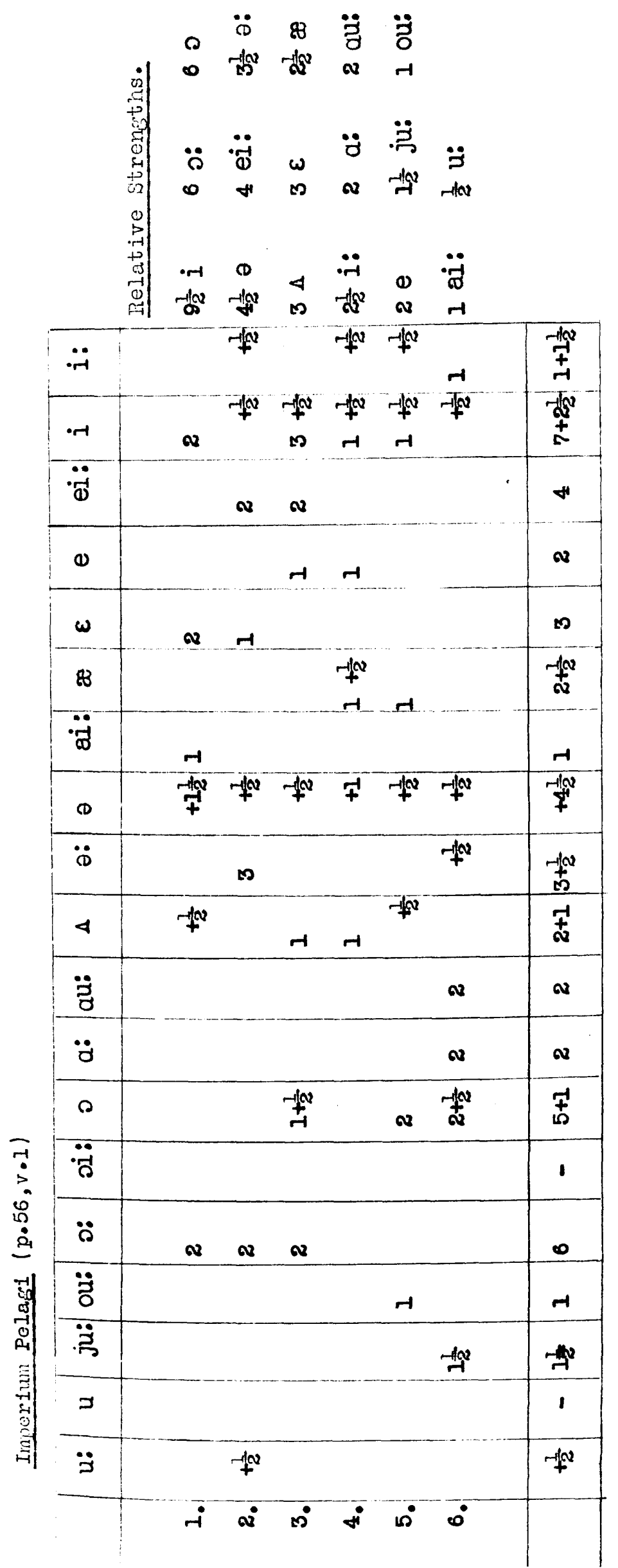




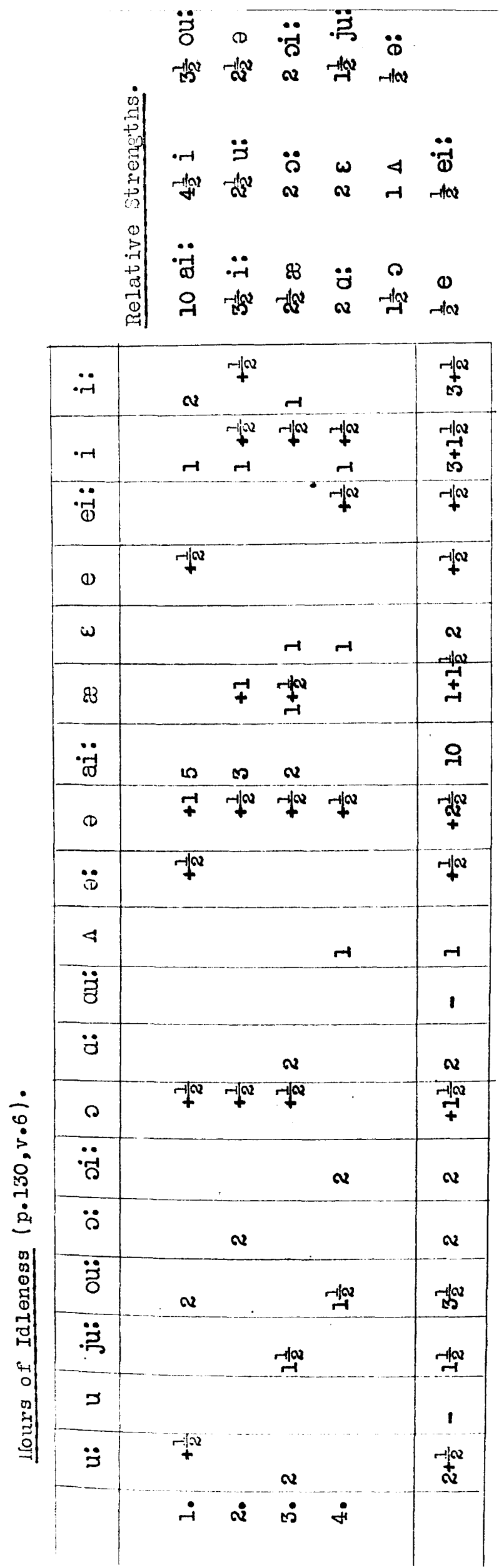




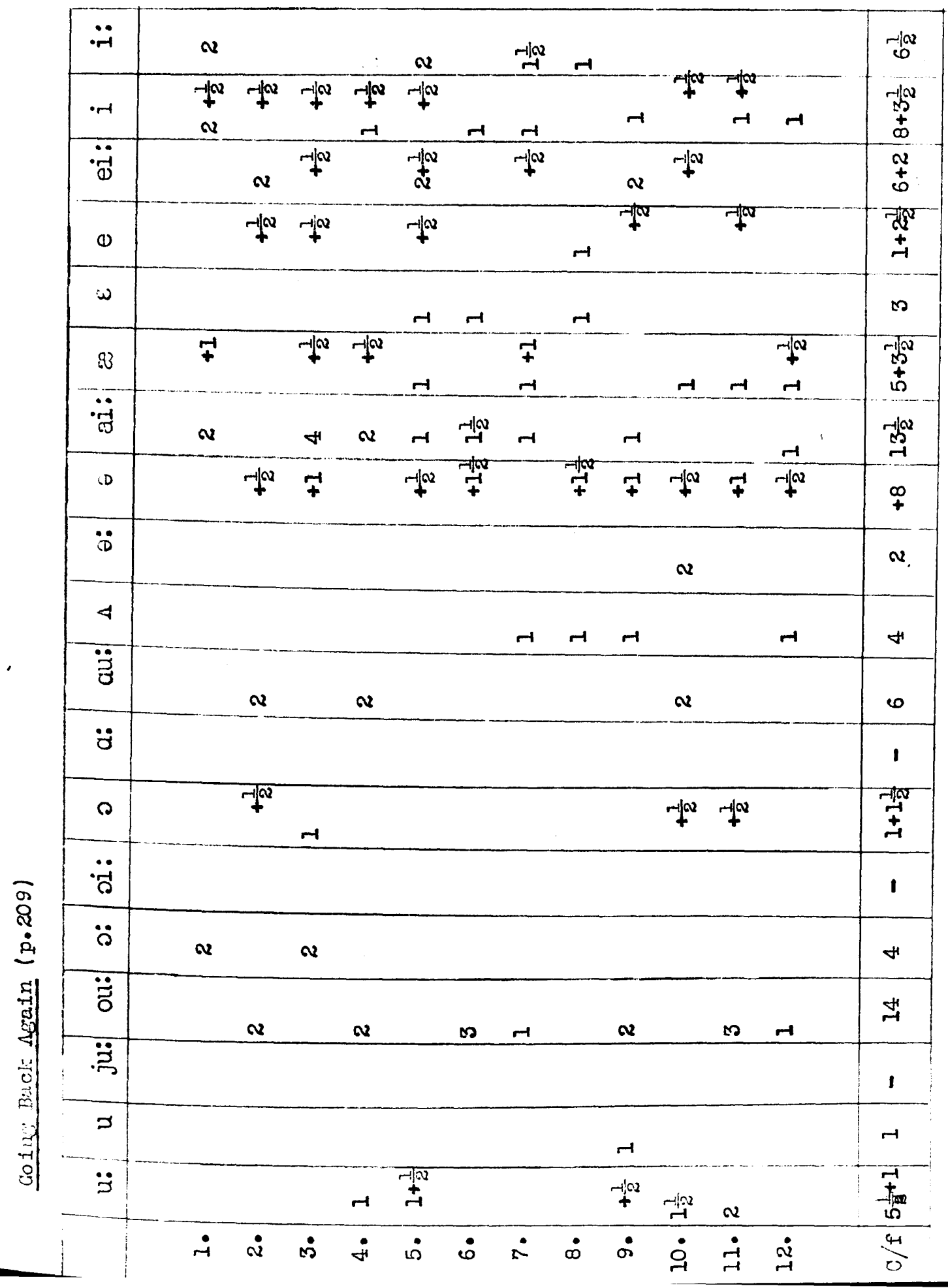




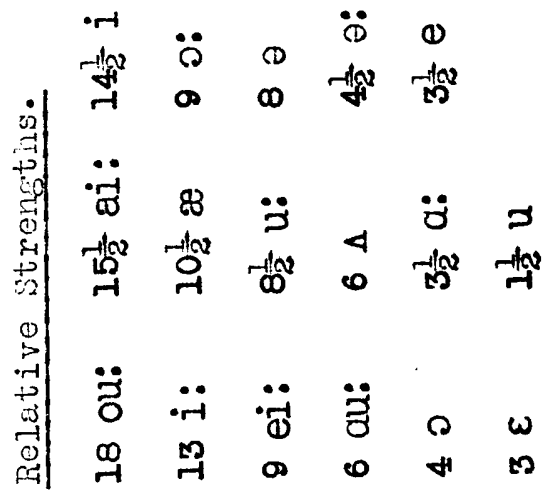

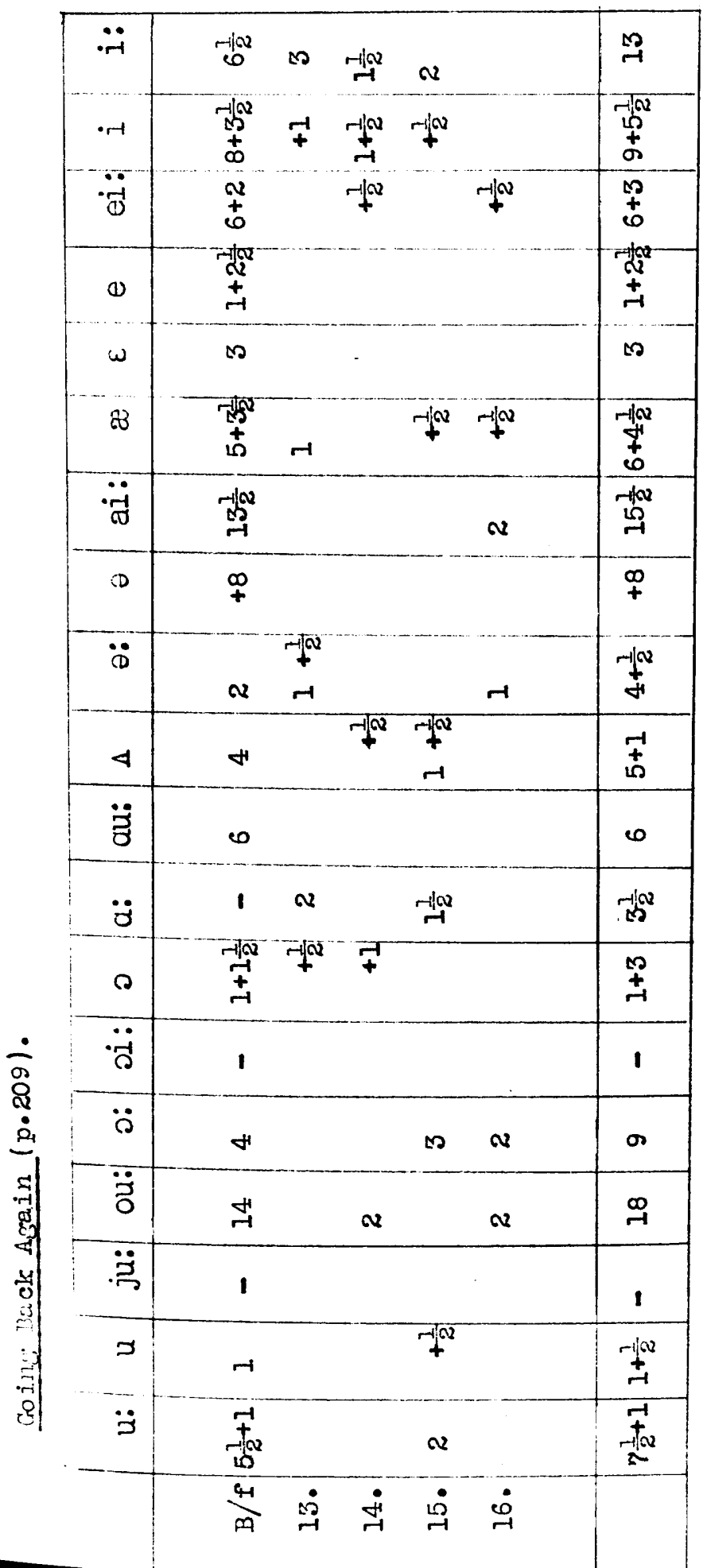




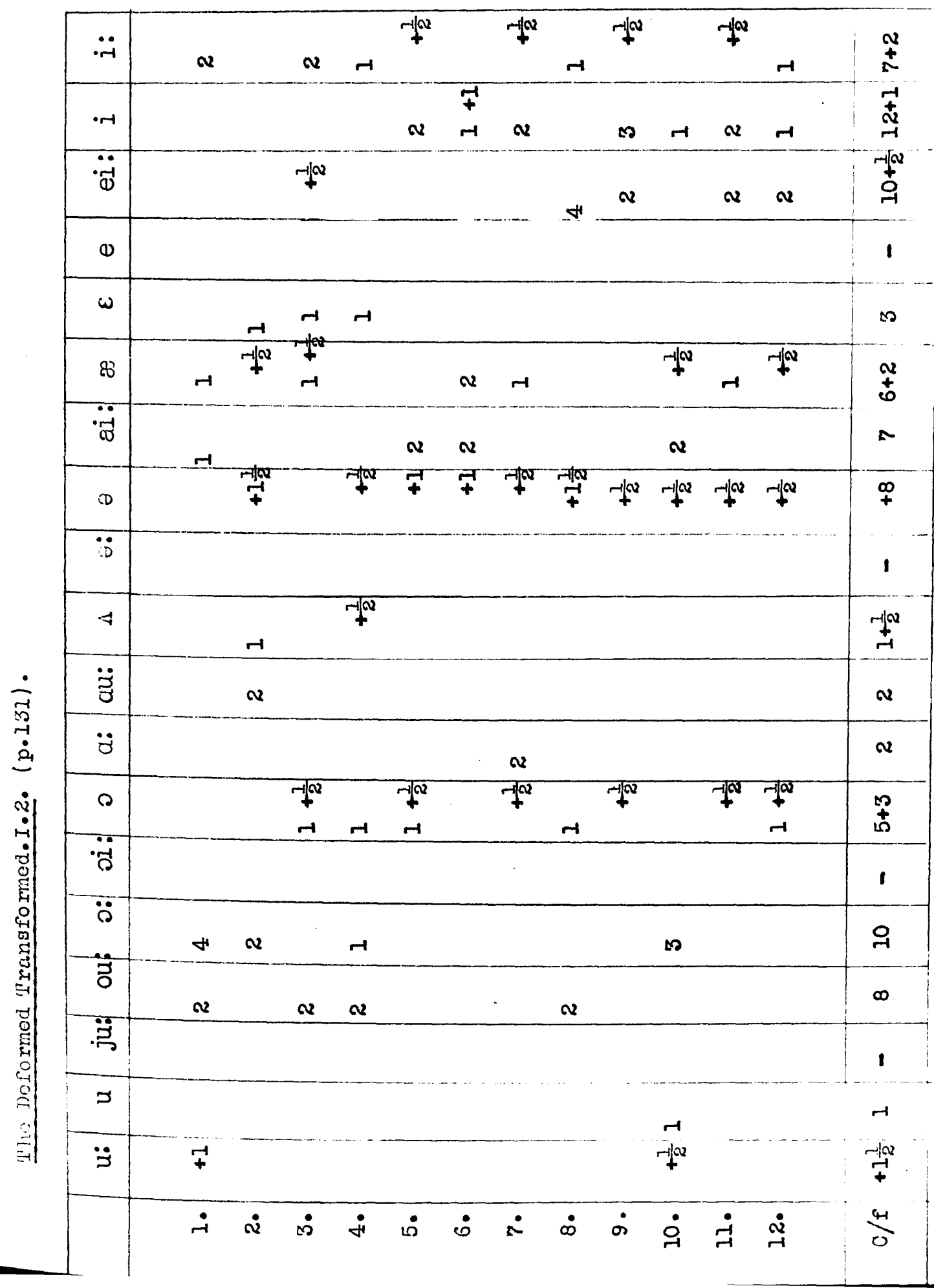


|ân

$\ddot{-r} \cdot \overrightarrow{0}$

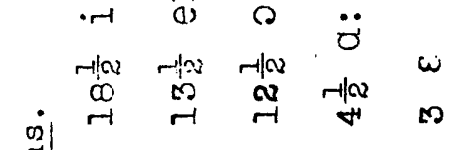

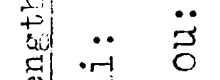

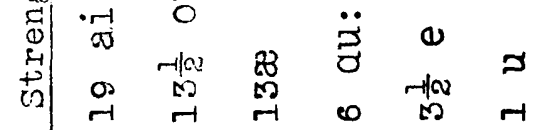

$\stackrel{1}{>}$

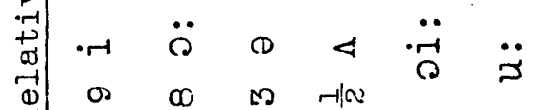

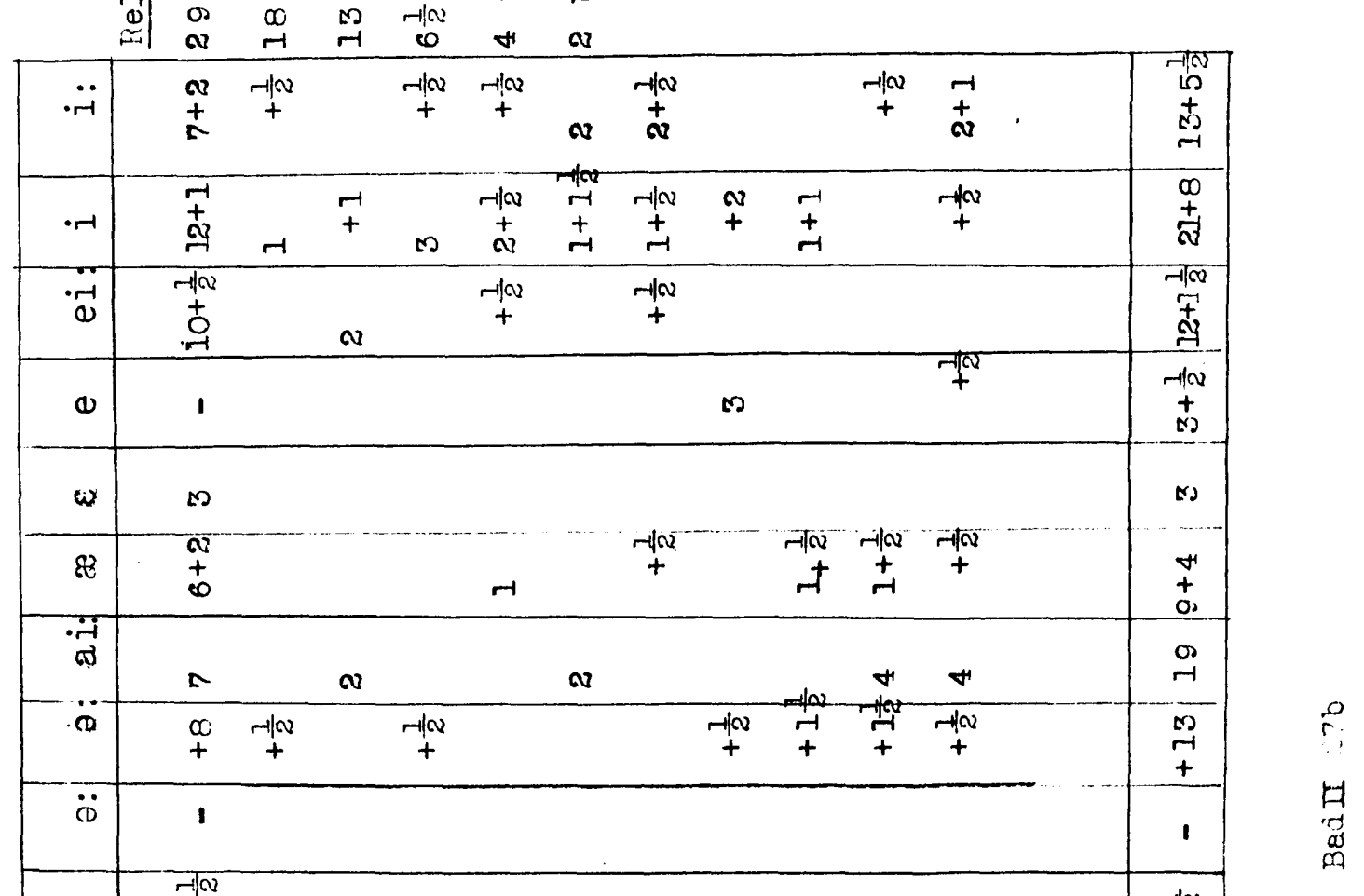

$\stackrel{-1}{+}-4$ $-1$

$-1$

rla

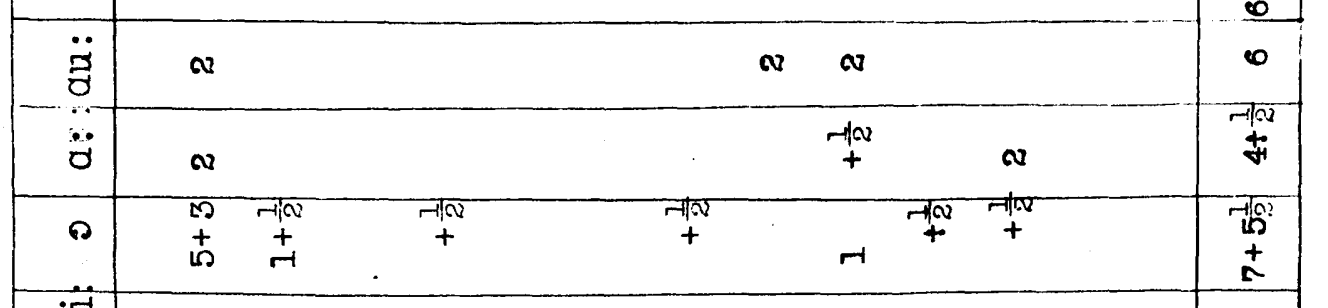

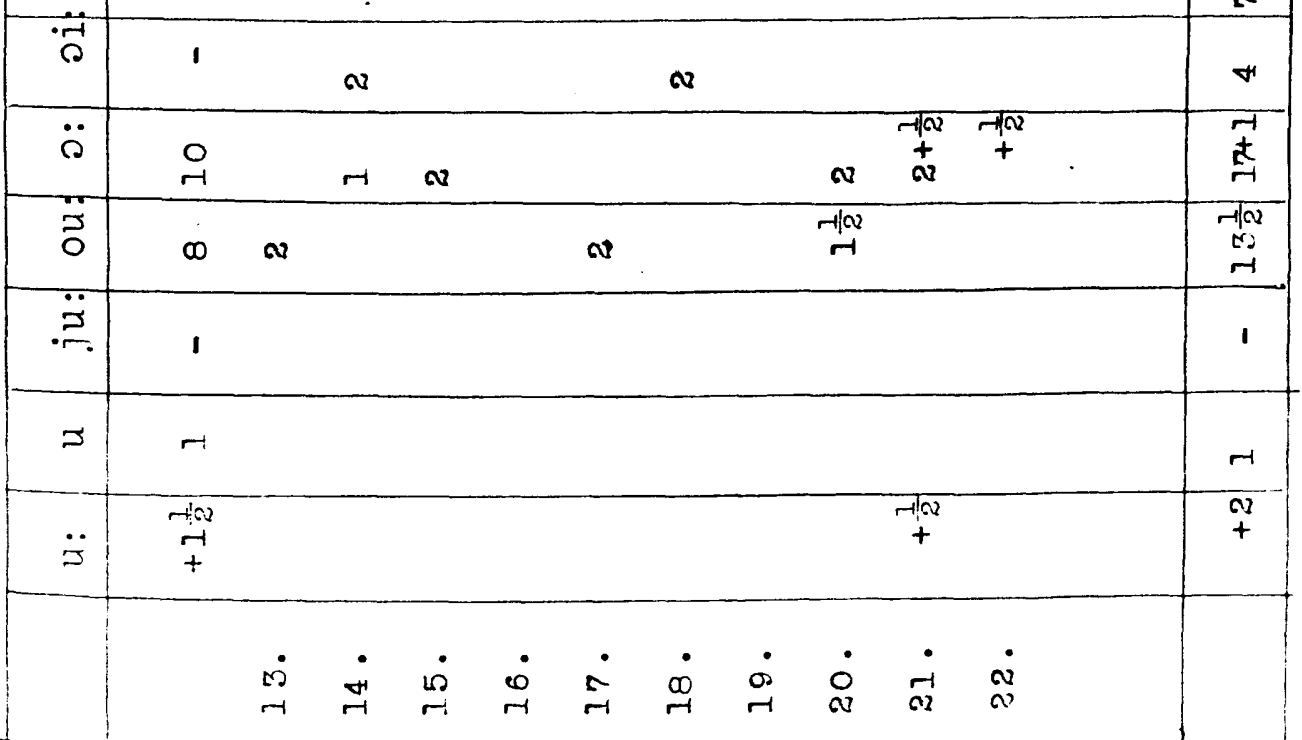




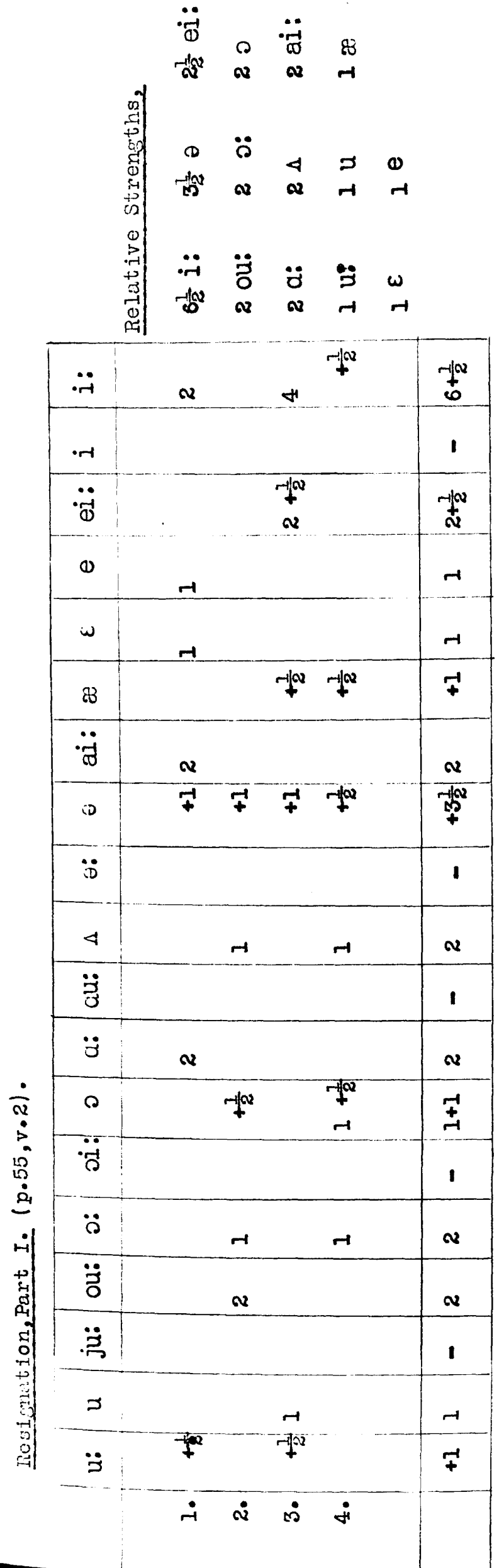




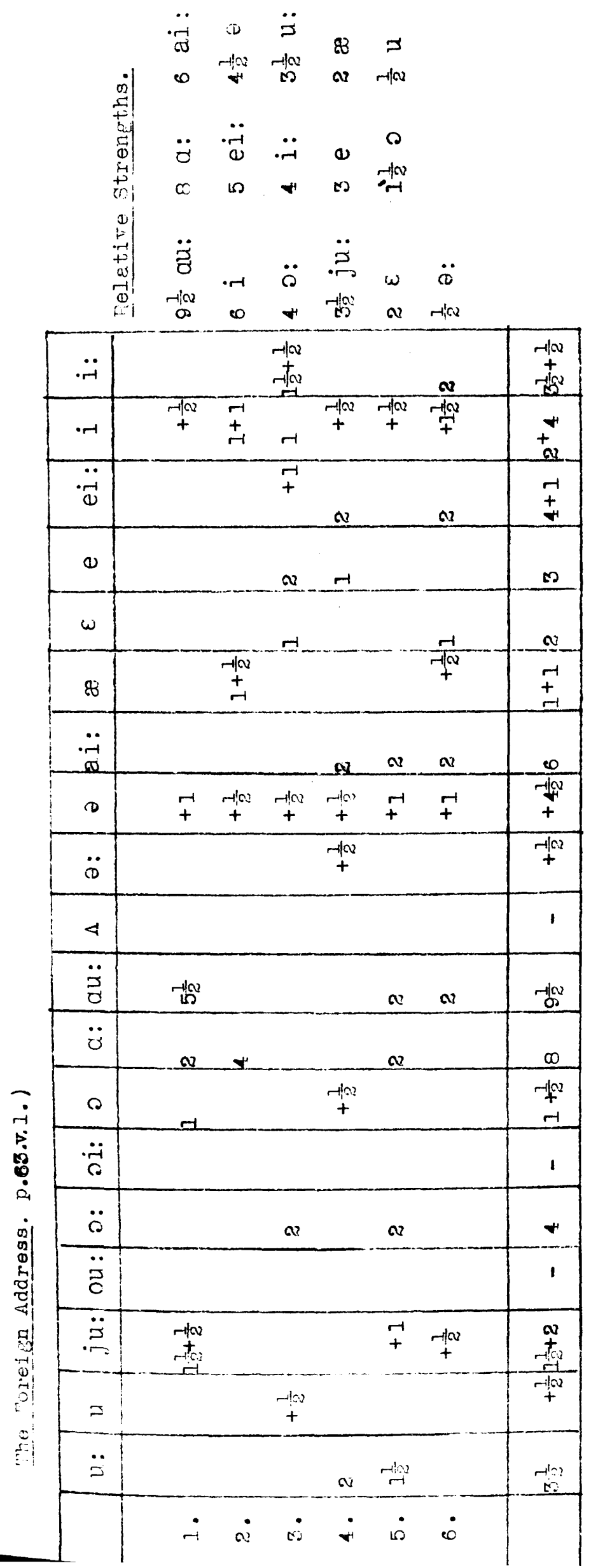




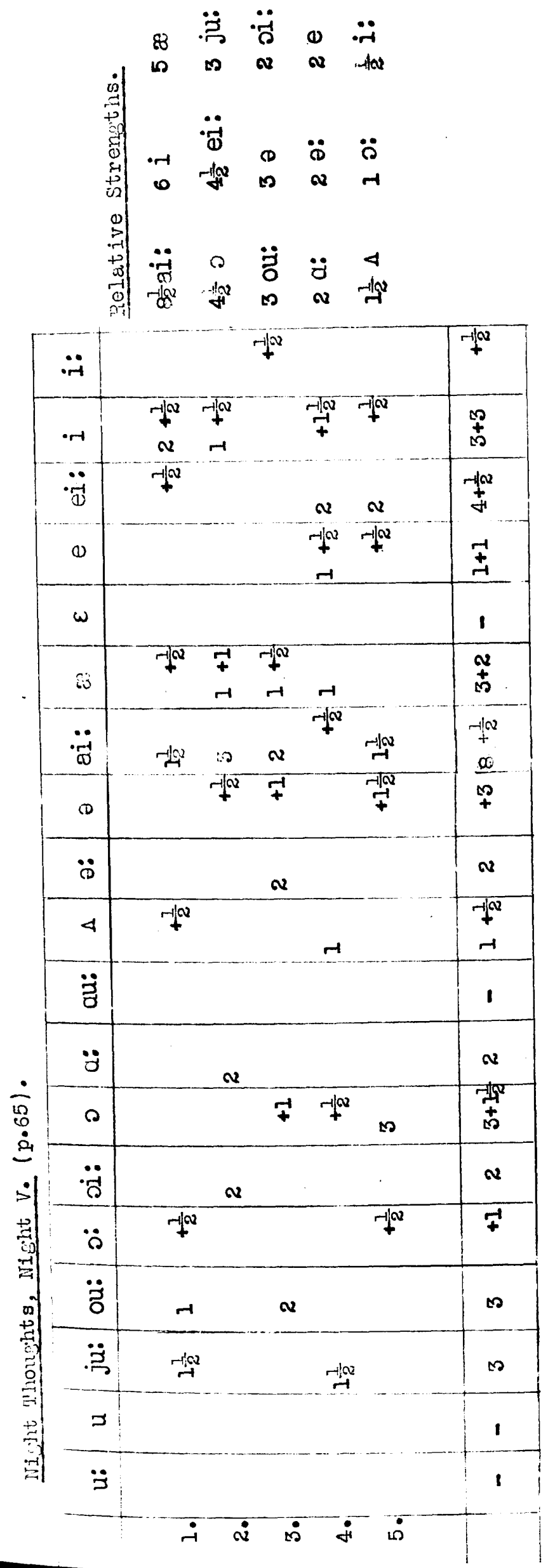




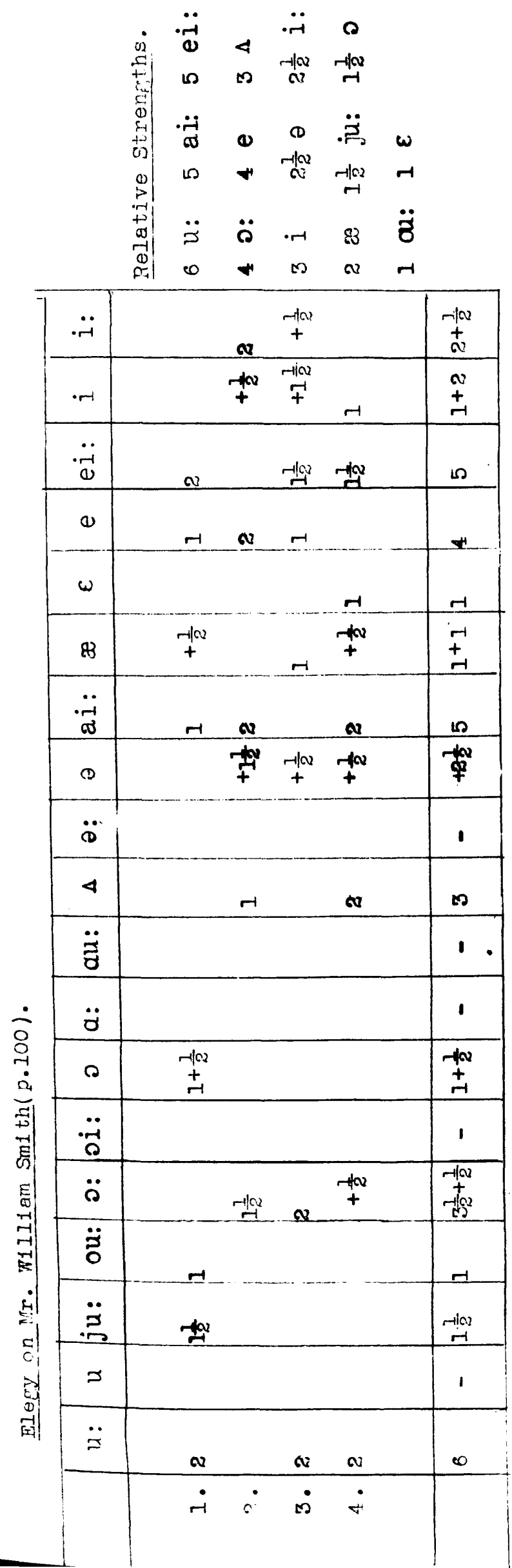



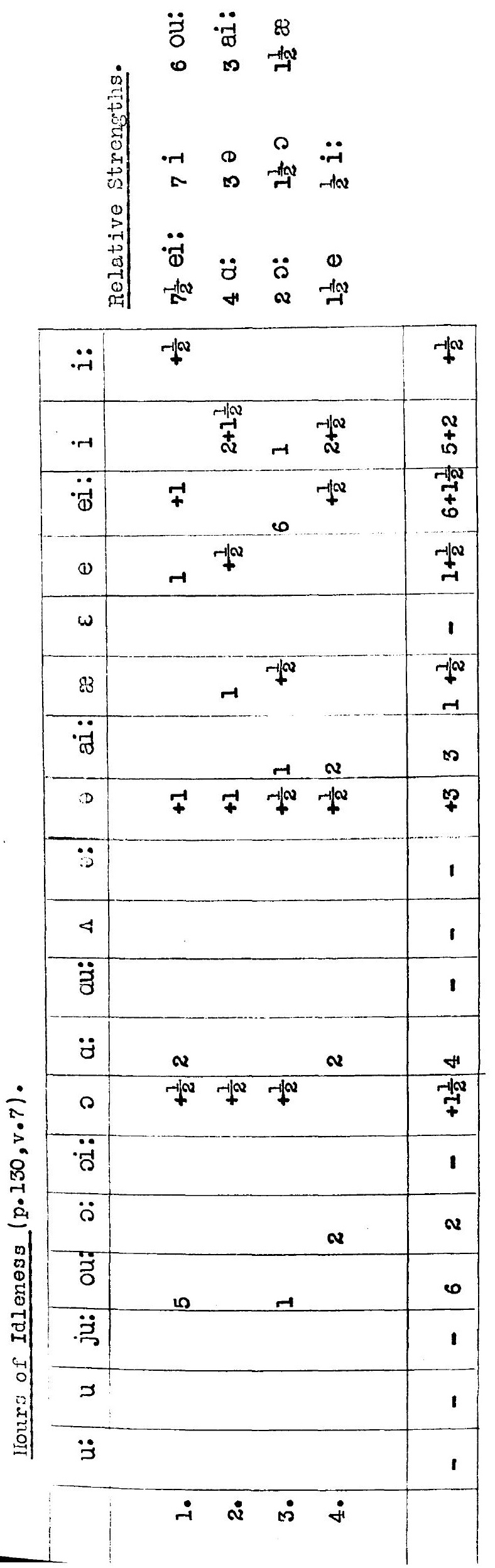


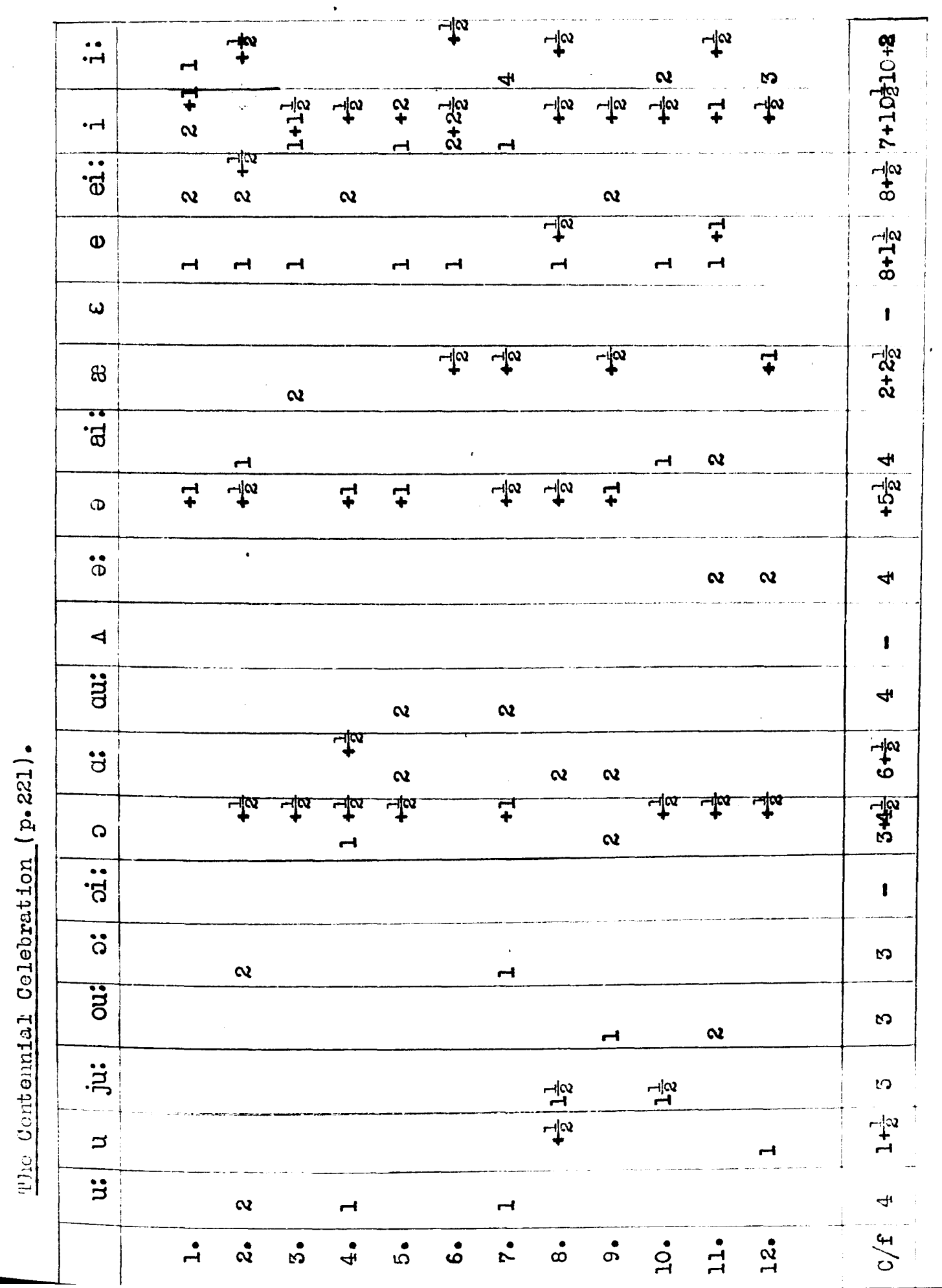




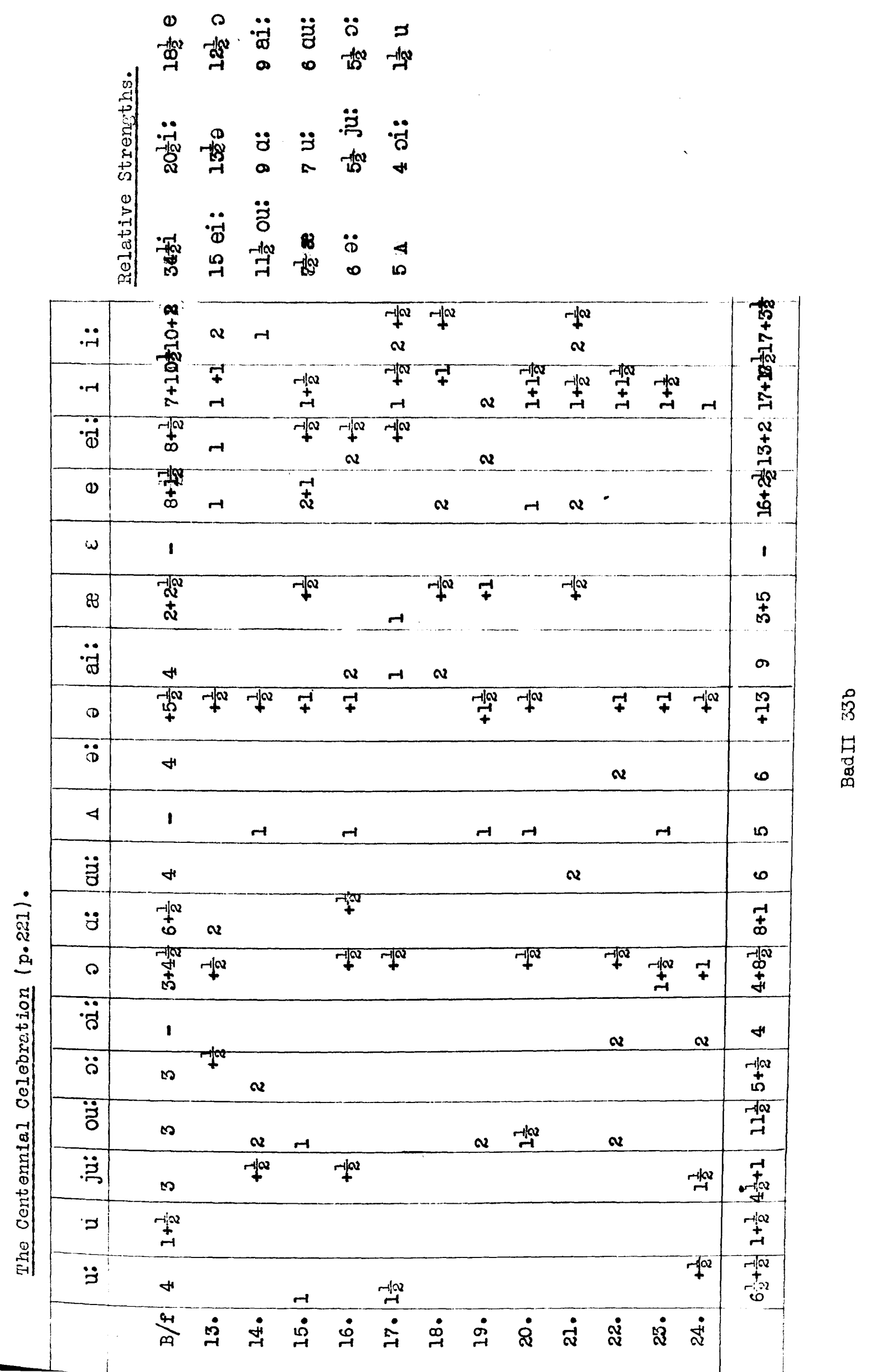




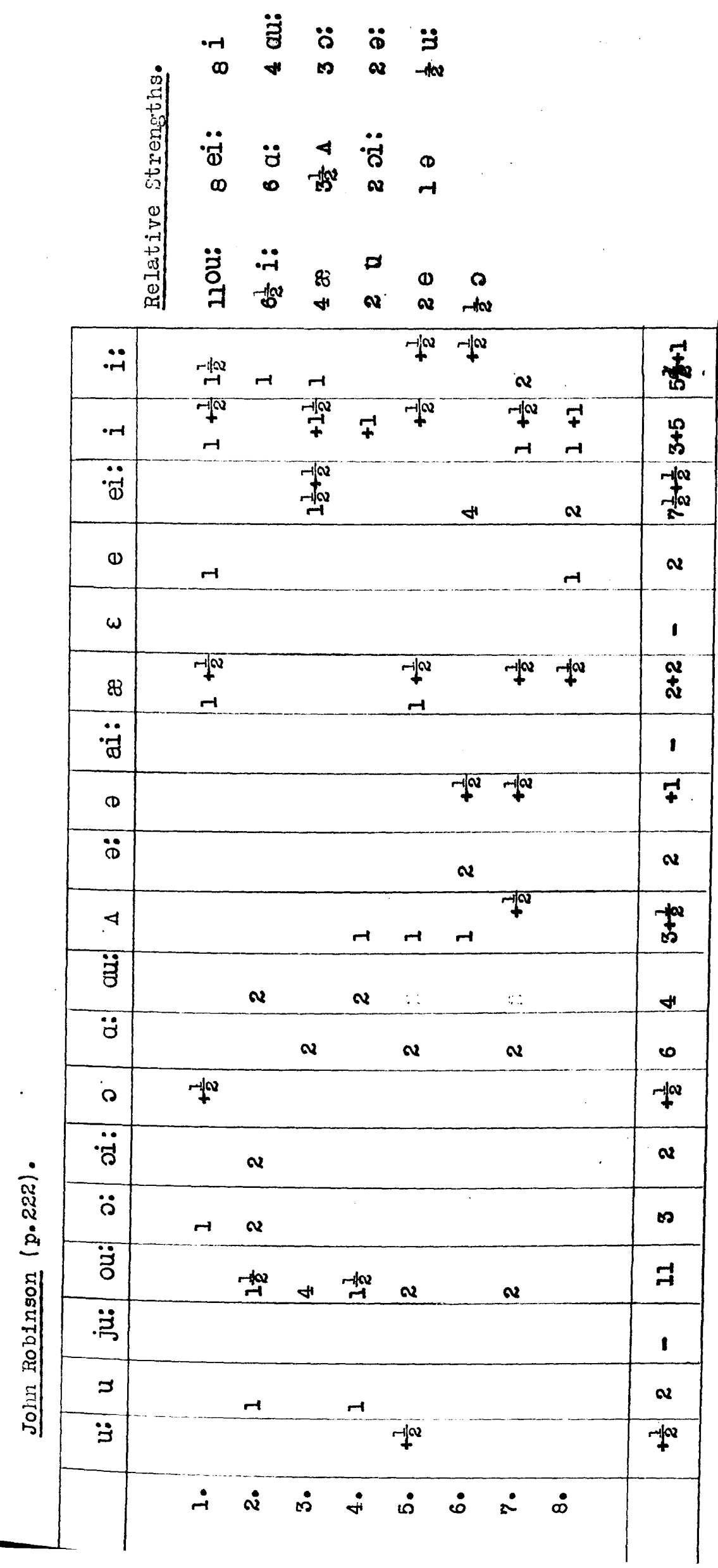

4
$m$
$a$
0
0 

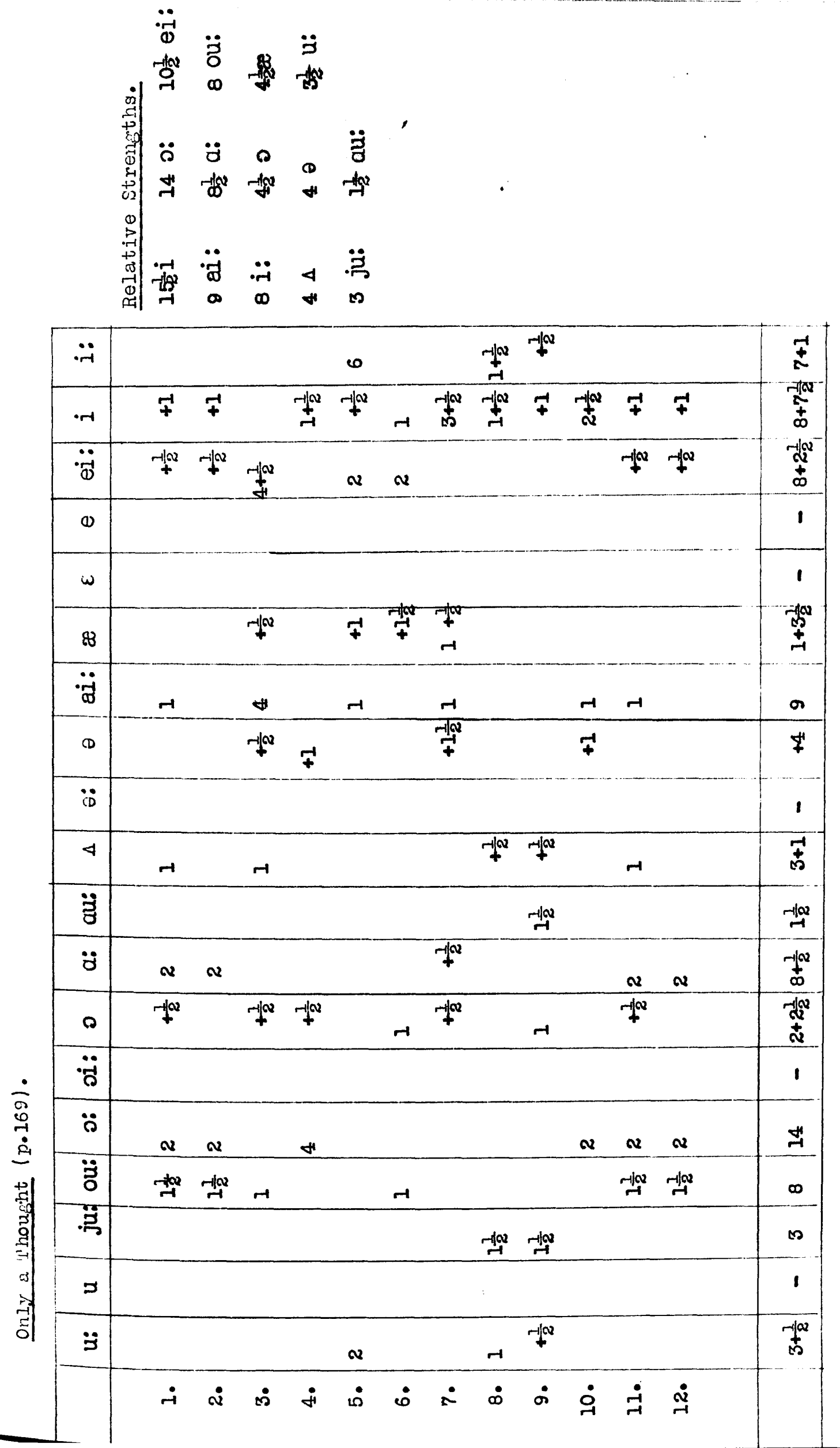

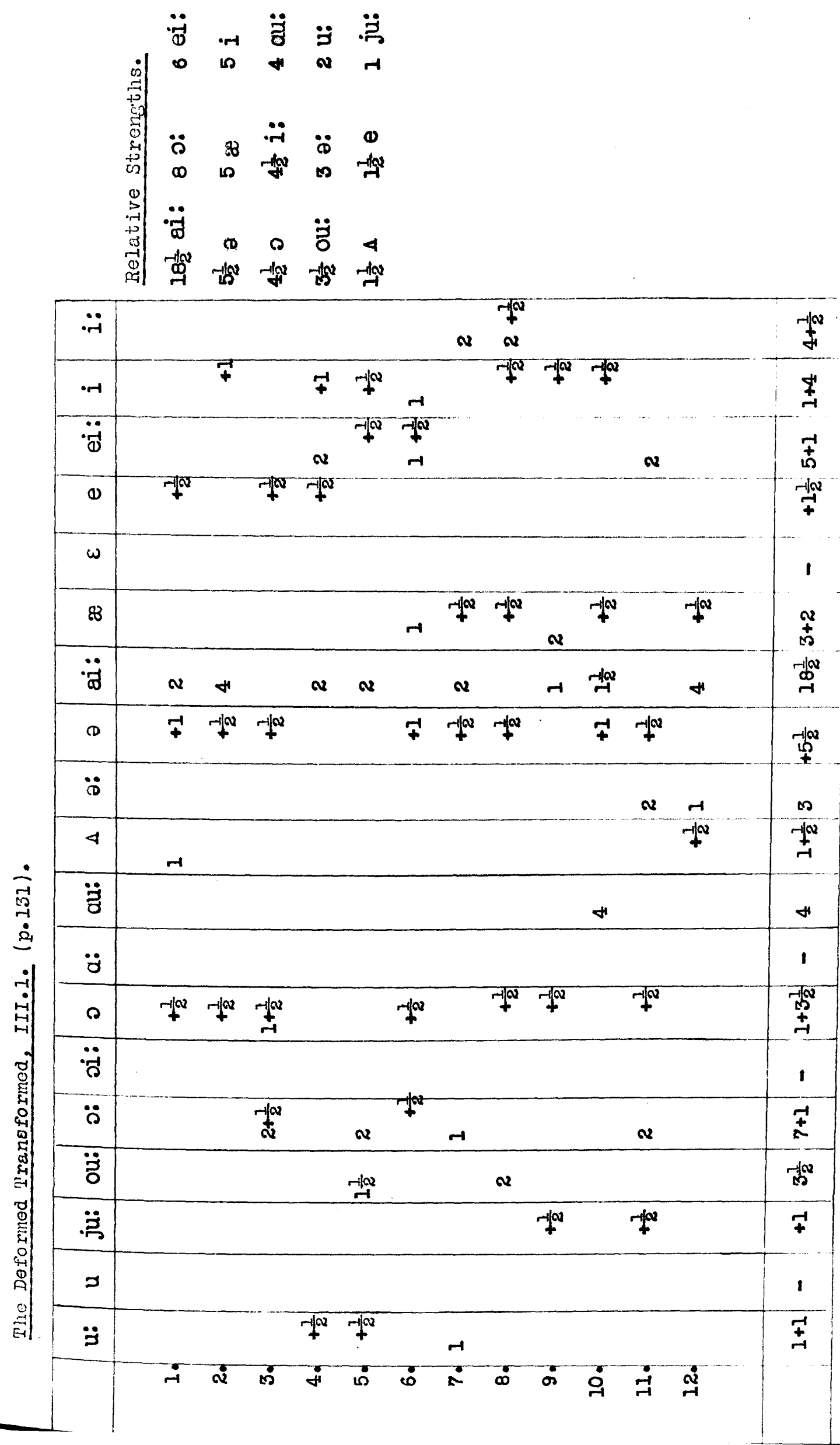


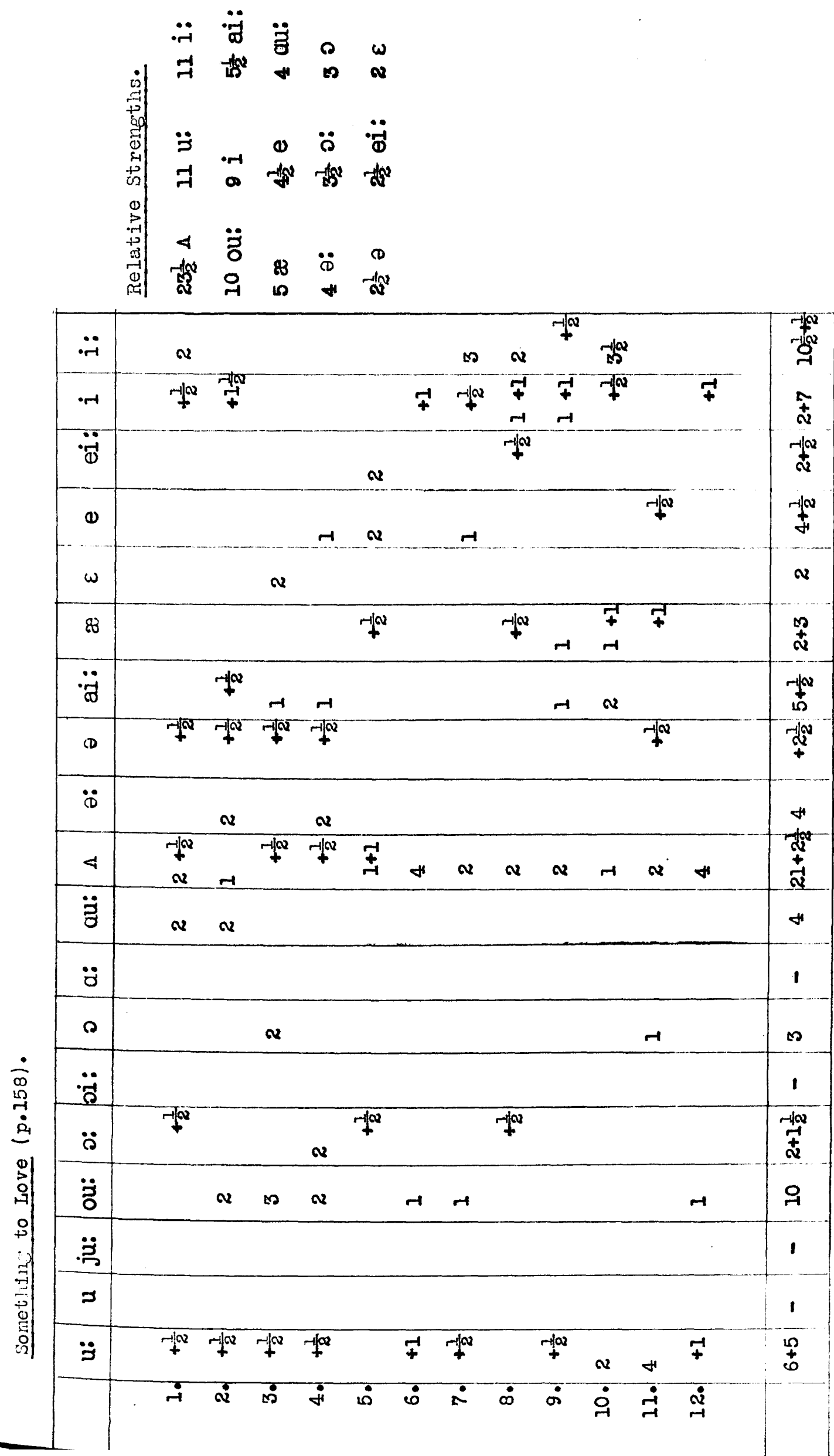




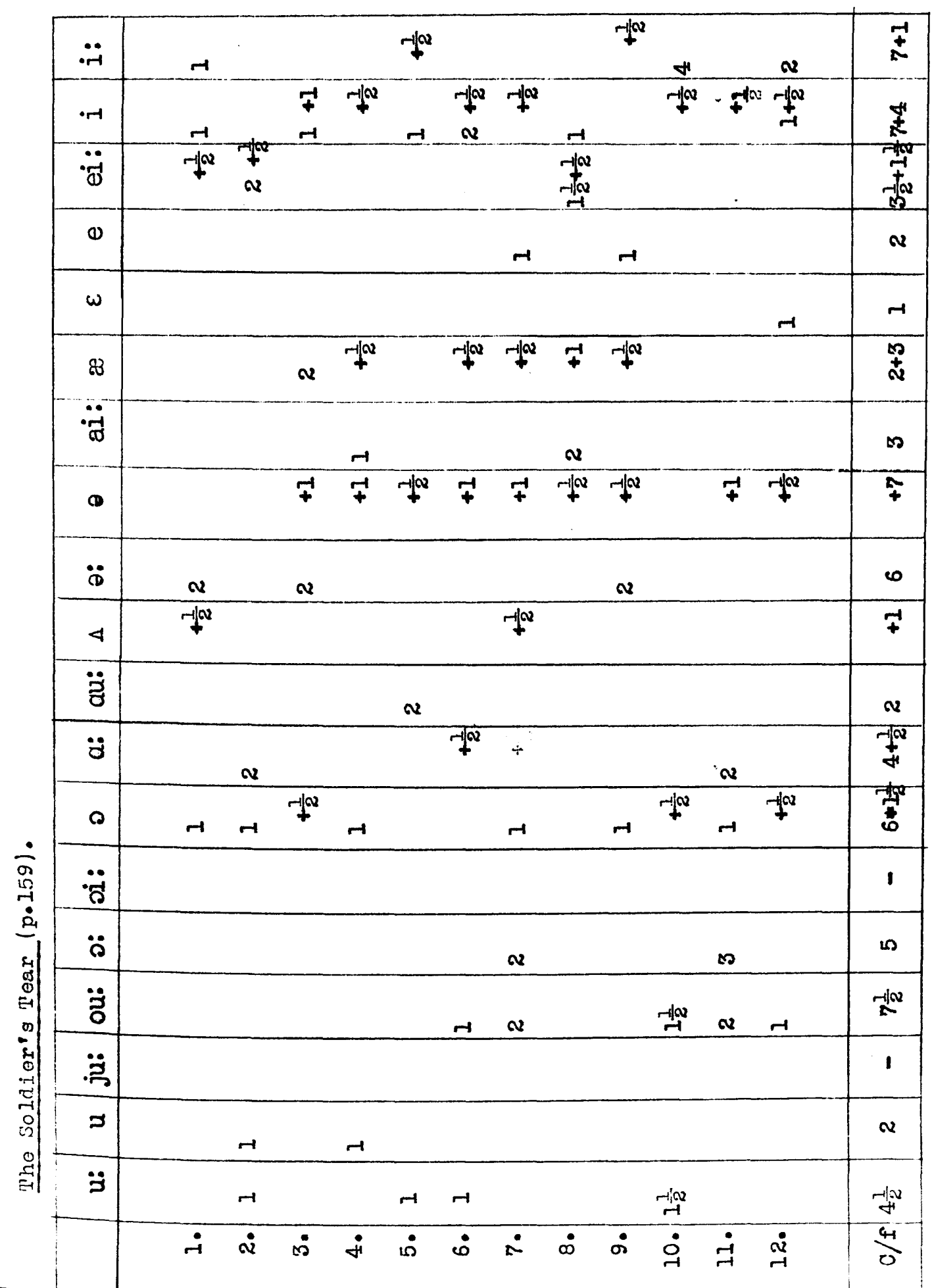




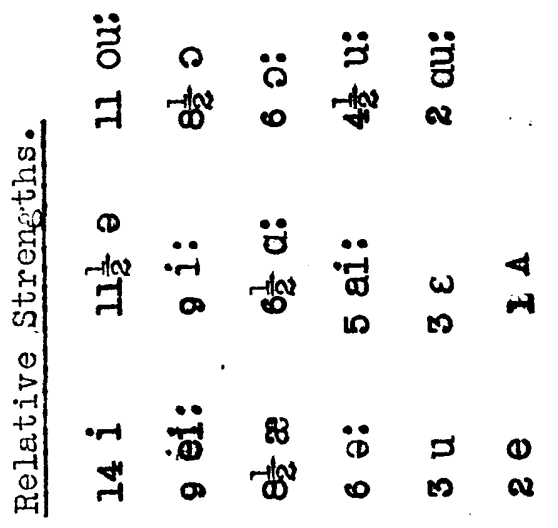

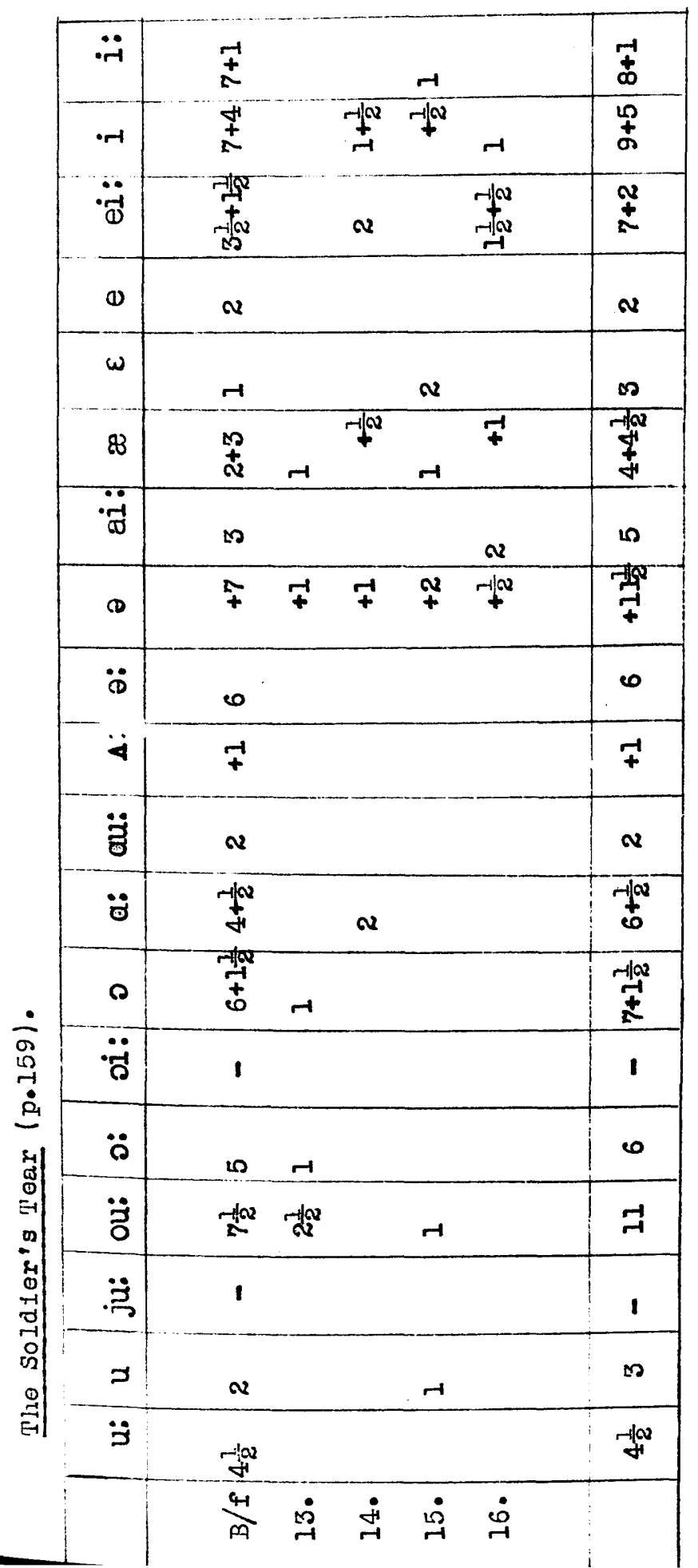




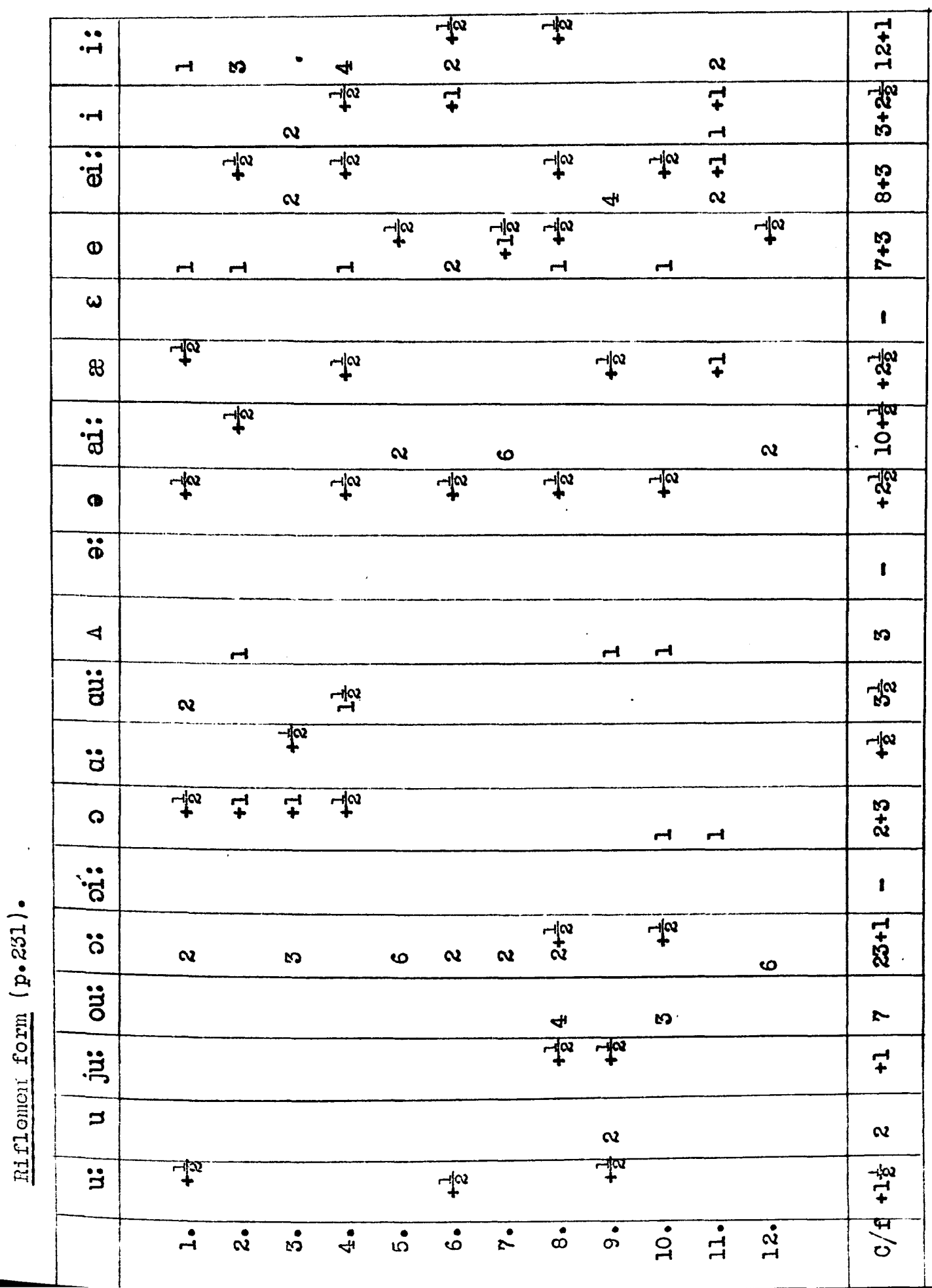




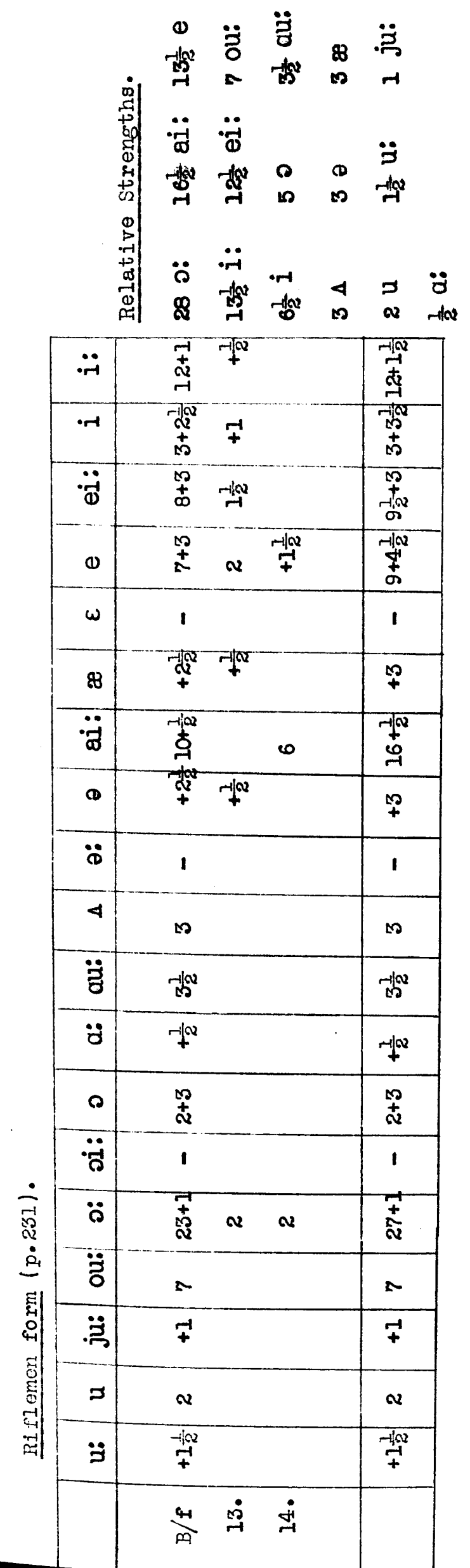




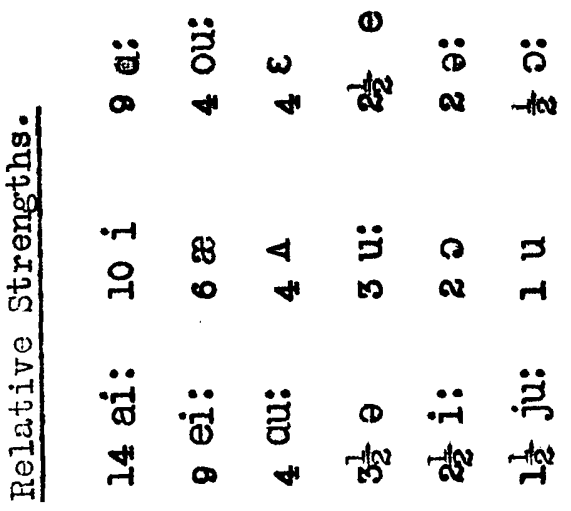

\begin{tabular}{|c|c|c|c|c|c|c|c|c|c|}
\hline$\ddot{\ddot{H}}$ & & -1 & & $+1+\infty$ & & & $r$ & & $\underset{N}{-1 N}$ \\
\hline$\cdot r$ & + & $+\infty$ & + & $\underset{+}{+}$ & $-1+\infty$ & $\begin{array}{l}-1 \\
-1\end{array}$ & & $\underset{-1}{\ddagger}$ & 苛 \\
\hline$\ddot{\ddot{\boldsymbol{d}}}$ & & & $\stackrel{-1 / N}{\mathbb{N}}$ & & $-1 \alpha$ & $\stackrel{+}{\star}$ & $-1 \omega$ & $\stackrel{-10}{\stackrel{+}{N}}$ & $\stackrel{m}{+}$ \\
\hline (1) & & & $r$ & $+N$ & & & $r$ & & $\underset{N}{-1}$ \\
\hline$\omega$ & $r$ & -1 & & & & & $r$ & $r$ & +4 \\
\hline 83 & +1 & +1 & $-1 p^{2}$ & $+1 x^{\alpha}$ & $\underset{-}{-1}$ & & & 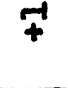 & $\frac{\$}{\alpha}$ \\
\hline$\ddot{\ddot{0}}$ & $v$ & $v$ & $\infty$ & $\infty$ & $\boldsymbol{v}$ & $\boldsymbol{v}$ & & & म \\
\hline (D) & $+1+2$ & -10 & & $+\infty$ & & & + & & t \\
\hline$\ddot{B}$ & & & & & & & $v$ & & $\boldsymbol{v}$ \\
\hline 4 & $\boldsymbol{v}$ & $r$ & & & & & $r$ & & + \\
\hline בี & & & & & $H$ & & & & + \\
\hline$\ddot{0}$ & & $\ln _{-1}^{-10}$ & & $\boldsymbol{v}$ & v & v & & 䄅 & $\infty$ \\
\hline$\Omega$ & & & $r$ & & & 7 & & & $\underset{+}{+}$ \\
\hline$\ddot{\ddot{c}}$ & & & & & & & & & 1 \\
\hline$\ddot{\circ}$ & & +7 & & & & & & & rex \\
\hline$\ddot{\partial}$ & & $\boldsymbol{v}$ & & & & & & $\mathbf{v}$ & + \\
\hline$\ddot{\ddot{n}}$ & & & & $r_{-1}$ & & & $\div$ & & - \\
\hline$\supset$ & & & $+\infty$ & & & & 7 & & 7 \\
\hline$\ddot{g}$ & ${ }^{-1} \mathbb{N}^{2}$ & $r$ & & & $r+a^{2}$ & & & & $f^{a}$ \\
\hline & $\dot{-}$ & $\dot{\alpha}$ & $\dot{0}$ & $\dot{j}$ & เீ & $\dot{0}$ & $\dot{2}$ & $\dot{\infty}$ & \\
\hline
\end{tabular}




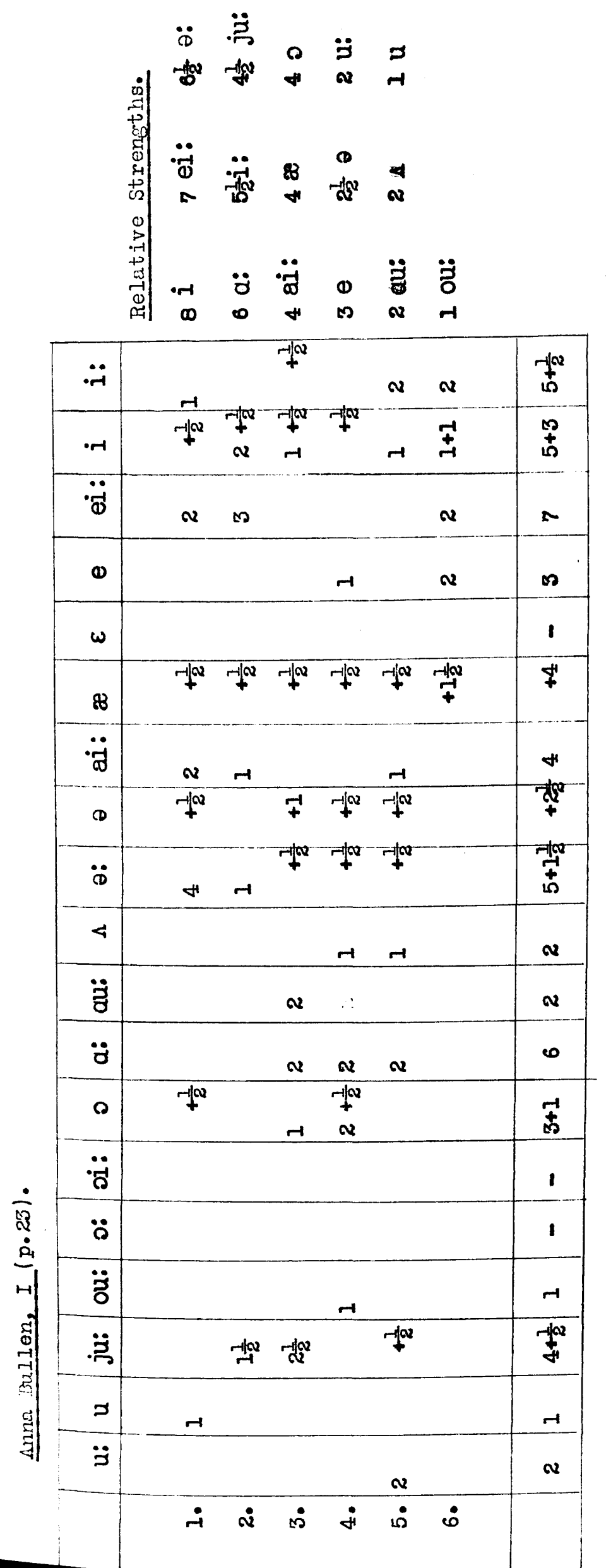




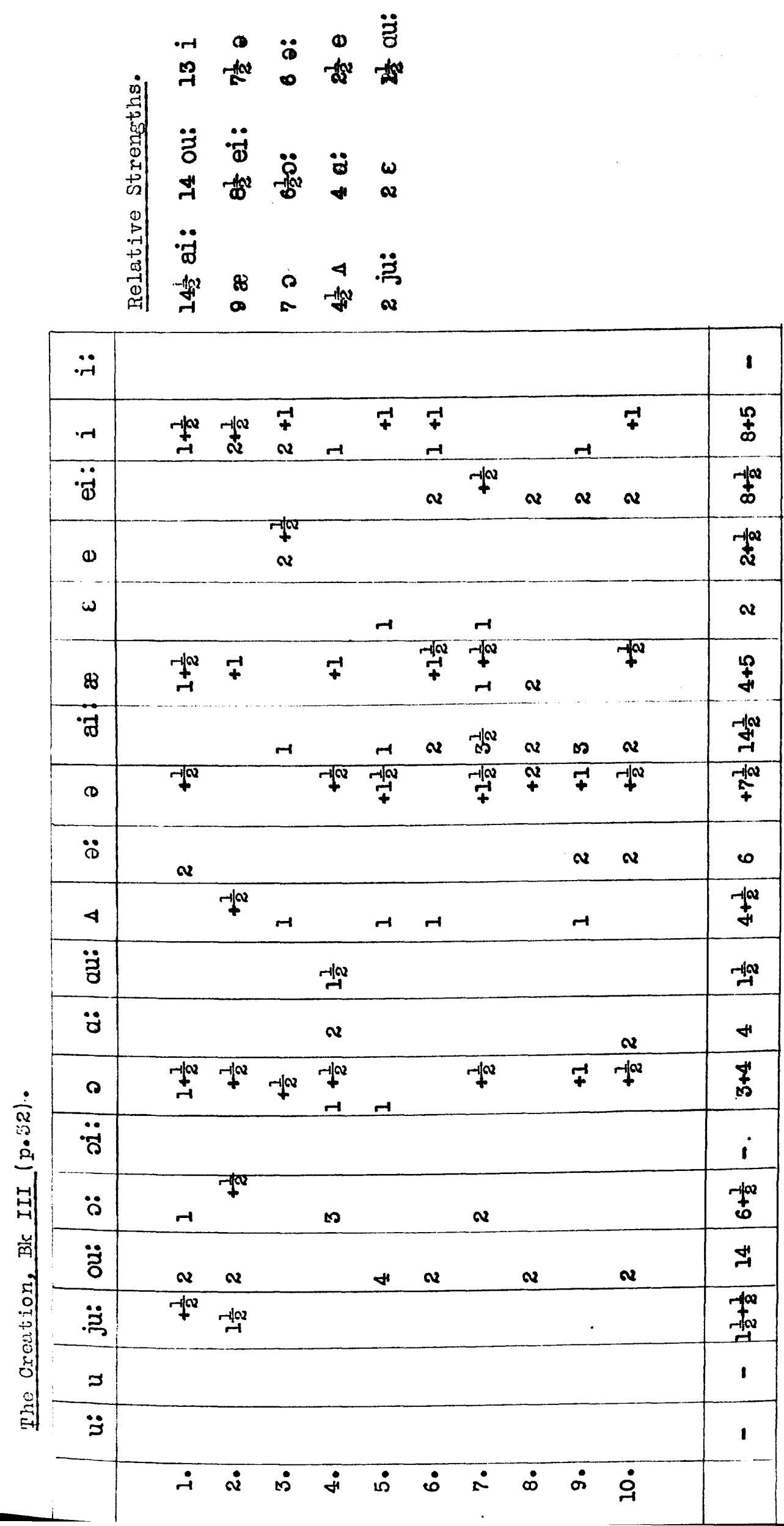




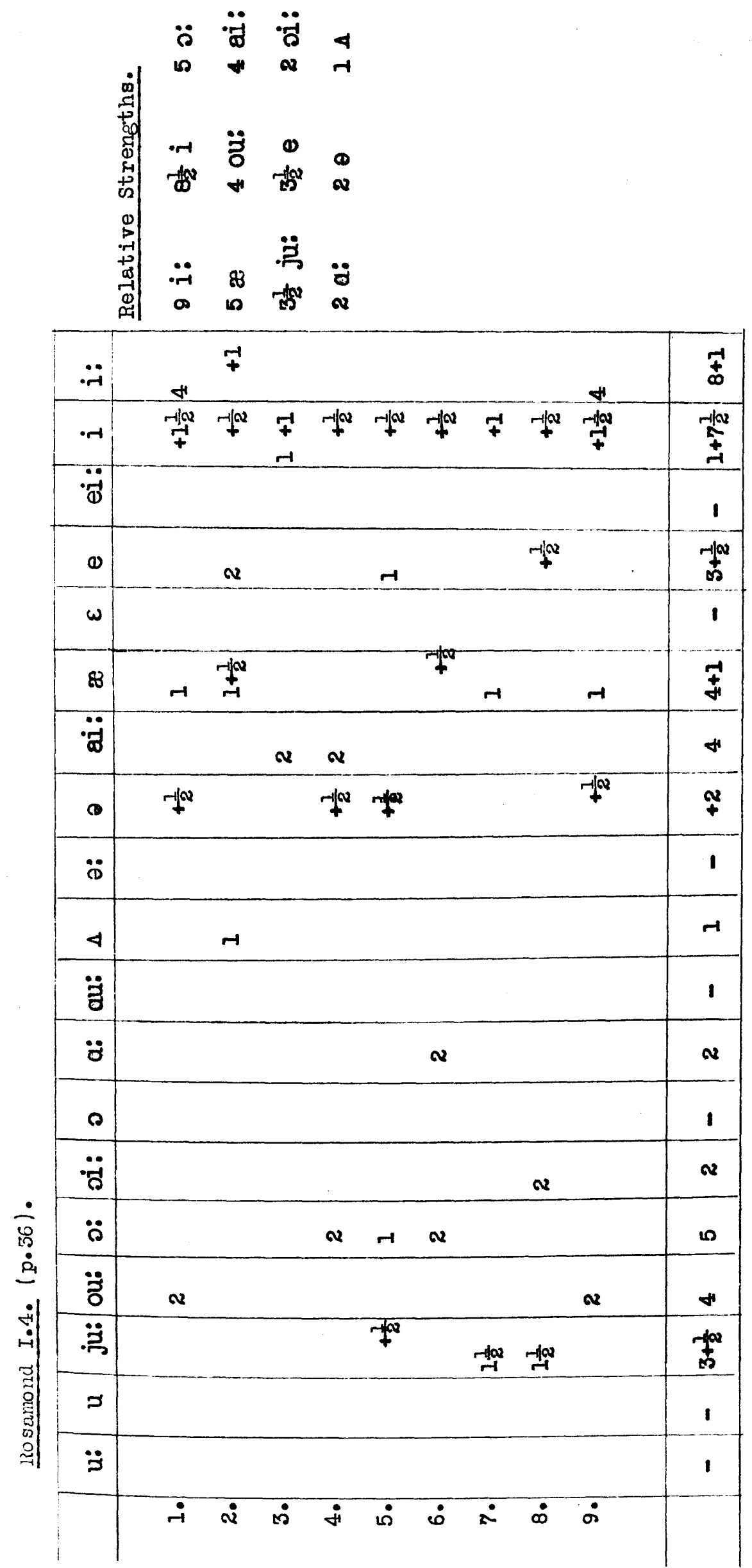




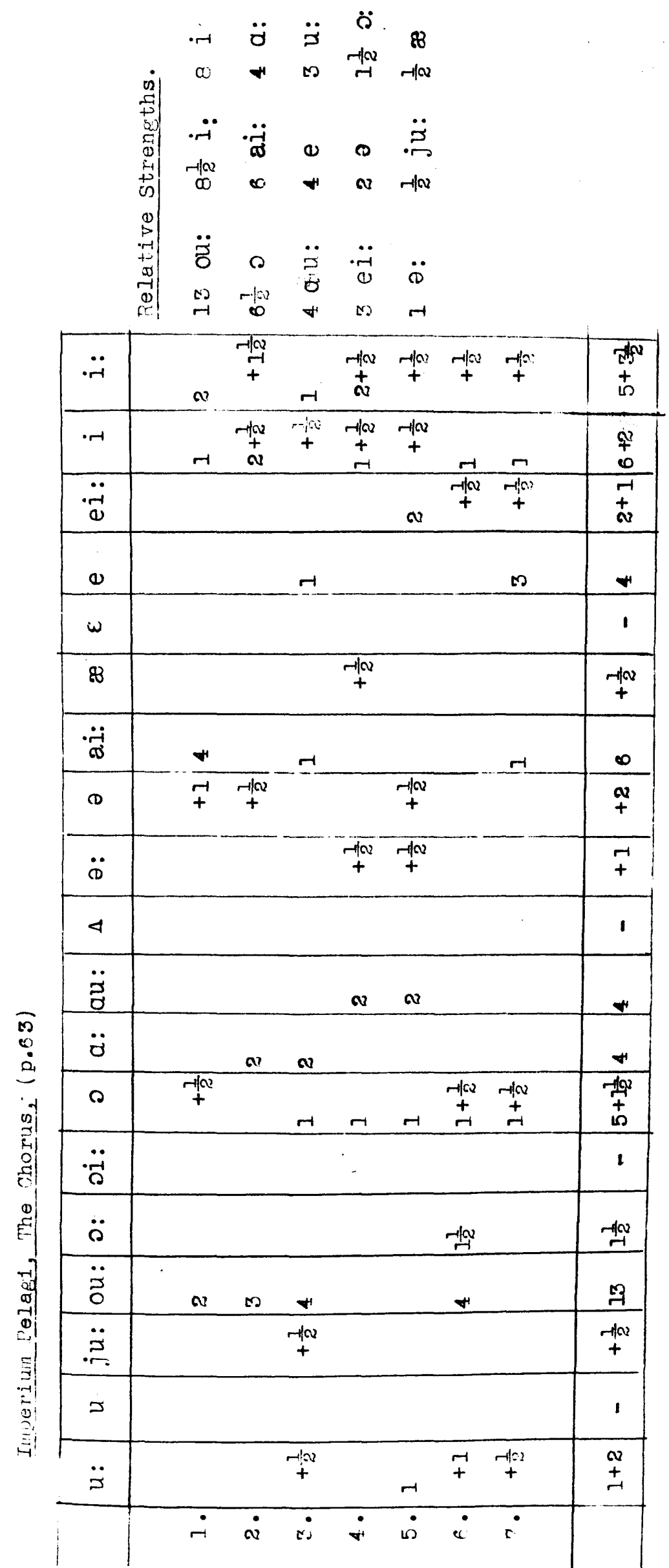




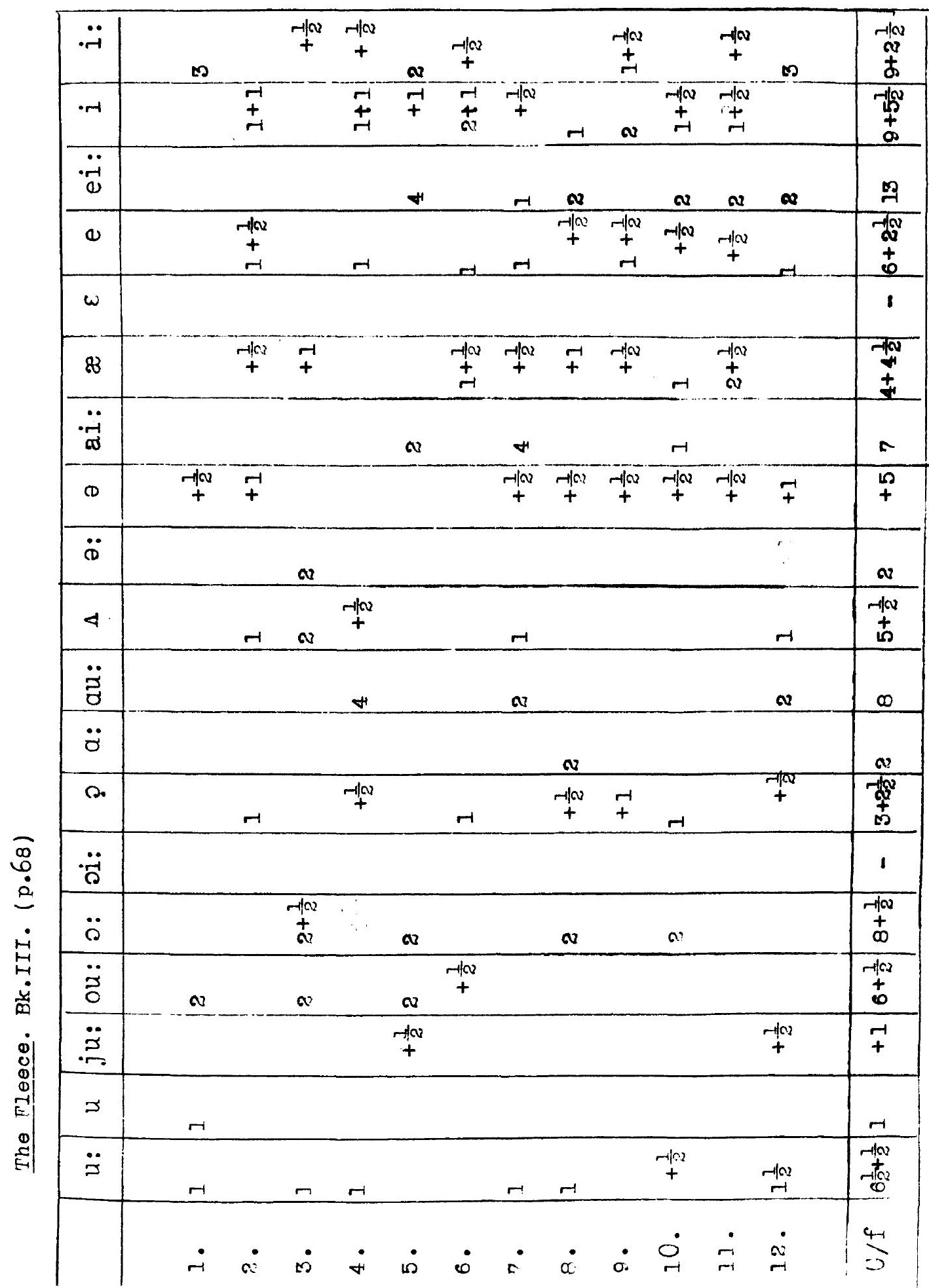

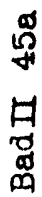




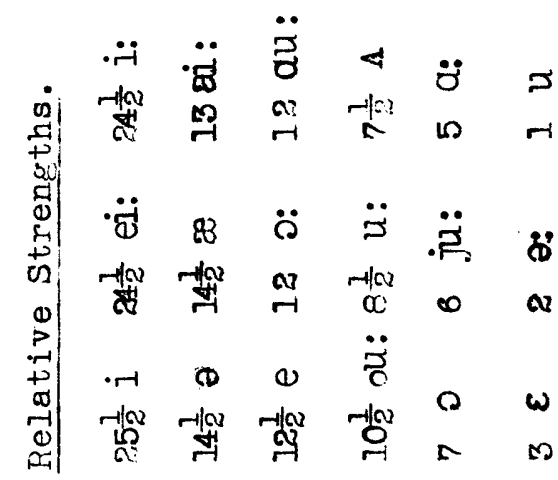

\begin{tabular}{|c|c|c|c|c|c|c|c|c|c|c|}
\hline$\ddot{\ddot{r}}$ & $\begin{array}{c}\text { नhl } \\
0 \\
+ \\
0\end{array}$ & & $\begin{array}{c}-1 / 0 \\
+ \\
\Delta ?\end{array}$ & a & & & $\begin{array}{c}+10 \\
+\end{array}$ & 4 & $H$ & \begin{tabular}{l}
$-1 / 2$ \\
+ \\
\multirow{2}{*}{}
\end{tabular} \\
\hline$\cdot-r$ & 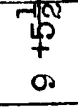 & $\begin{array}{c}\text { नात } \\
7\end{array}$ & $\begin{array}{c}-100 \\
\pm \\
-1\end{array}$ & & $r$ & $\infty$ & $r$ & $\begin{array}{l}+1 \\
0 \\
\end{array}$ & -1 & 惒 \\
\hline$\ddot{\ddot{1}}$ & $\stackrel{M}{9}$ & $r$ & & ni & & a & + & $\mathbf{v}$ & $t$ & $\stackrel{-1+\infty}{+}$ \\
\hline 0 & \begin{tabular}{c}
-10 \\
\multirow{N}{N}{} \\
+ \\
0
\end{tabular} & . & $r$ & & & $\pi$ & $\begin{array}{c}-100 \\
+ \\
-1\end{array}$ & & $+-1 \times$ & $\begin{array}{c}-1 N \\
m \\
+ \\
\infty\end{array}$ \\
\hline$\omega$ & & ou & & & & & -1 & & & $D$ \\
\hline 8 & $\begin{array}{l}F+1 \\
+ \\
+\end{array}$ & $r$ & $r$ & $F$ & & 7 & + & $\begin{array}{l}\text { नI } \\
+\end{array}$ & $\begin{array}{c}\text { rlo } \\
+\end{array}$ & 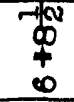 \\
\hline$\stackrel{\ddot{\infty}}{\ddot{\infty}}$ & $\approx$ & 0 & $\omega$ & & & & $\sim$ & & & $\stackrel{\leftrightarrow}{-1}$ \\
\hline (1) & $\begin{array}{l}10 \\
+\end{array}$ & + & + & + & $\stackrel{\omega}{+}$ & 7 & $\stackrel{N}{+}$ & $\begin{array}{c}-1 / v \\
+\end{array}$ & $\mp$ & +7 \\
\hline$\ddot{\nabla}$ & $v$ & & & & & & & & & v \\
\hline 4 & $\begin{array}{c}-10 \\
+ \\
0\end{array}$ & 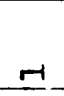 & & & $r$ & & & . & & $\begin{array}{c}-1 / 0 \\
\pm \\
2\end{array}$ \\
\hline$\ddot{\vec{z}}$ & $\infty$ & & & & c. & $a$ & & & & 9 \\
\hline$\ddot{\ddot{\sigma}}$ & 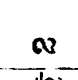 & & & $\omega$ & & & $r$ & & & م \\
\hline$\sigma$ & $\begin{array}{c}-1 \mathfrak{N} \\
+ \\
+ \\
\text { D }\end{array}$ & & $+1+a$ & & $\mp$ & & & & & $\begin{array}{l}+ \\
+\end{array}$ \\
\hline$\ddot{\ddot{\theta}}$ & 1 & & & & & & & & & 1 \\
\hline$\ddot{\rho}$ & $\begin{array}{c}-1 \times \\
+ \\
\infty\end{array}$ & & rla & & a) & & & & & 整 \\
\hline 艿 & $\begin{array}{c}+\infty \\
+ \\
0\end{array}$ & & & $\infty$ & & 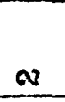 & & & & $\begin{array}{c}+\infty \\
\text { 龺 }\end{array}$ \\
\hline$\ddot{J}$ & $\mp$ & & & $-\sqrt[-1 w]{a r}$ & $\stackrel{H}{-1}(a)$ & $\mathrm{H}+\mathrm{ar}$ & + & & $\begin{array}{c}-100 \\
+\end{array}$ & $\begin{array}{l}m \\
+ \\
m\end{array}$ \\
\hline$=$ & -1 & & & & & & & & & -1 \\
\hline$\ddot{\vec{z}}$ & 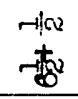 & & & & & & & -1 & +102 & 蛋 \\
\hline & $\frac{4}{\infty}$ & $\dot{r}$ & $\dot{+}$ & $\dot{r}$ & $\ddot{c}$ & $\dot{\varepsilon}$ & 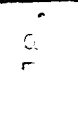 & $\begin{array}{l}\dot{c} \\
\mathrm{r}\end{array}$ & $\dot{0}$ & \\
\hline
\end{tabular}




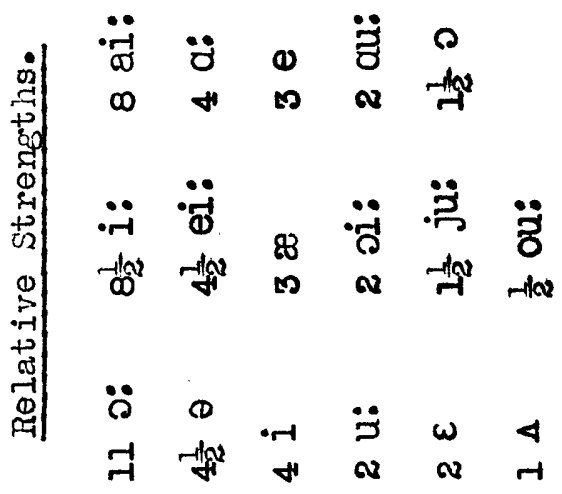

\begin{tabular}{|c|c|c|c|c|c|c|c|}
\hline$\ddot{~} \ddot{H}$ & $\begin{array}{c}-10 \\
+4\end{array}$ & & & & - & & $\underset{-\infty}{+\infty}$ \\
\hline$\cdot r$ & & $v$ & & $-1+v$ & & -10 & $\begin{array}{c}\boldsymbol{w} \\
\mathbf{w}\end{array}$ \\
\hline$\ddot{0}$ & & 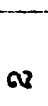 & & & $-1 \times$ & & $\underset{+\infty}{-10}$ \\
\hline $\boldsymbol{\omega}$ & & & $-1 a$ & $-H$ & $\begin{array}{l}-1, \\
-1\end{array}$ & & $\underset{\mathbf{w}}{\mathbf{t}}$ \\
\hline $\boldsymbol{\omega}$ & & -1 & & & & -1 & $\boldsymbol{\infty}$ \\
\hline$\$$ & & & $\begin{array}{l}-10 \\
-1\end{array}$ & $r+10$ & +10 & $-1(n)$ & $\underset{\sim}{\stackrel{\sim}{+}}$ \\
\hline$\ddot{~ \ddot{~}}$ & & & $\boldsymbol{v}$ & Q & $\infty$ & w & $\infty$ \\
\hline C & +10 & 7 & -14 & $\mp$ & & नात् & 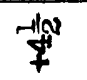 \\
\hline$\ddot{\oplus}$ & & & & & & & 1 \\
\hline 4 & & & & & & $r$ & -1 \\
\hline$\ddot{z}$ & & & & & & $\boldsymbol{v}$ & $\boldsymbol{v}$ \\
\hline$\ddot{\partial}$ & $\mathbf{Q}$ & & & & & $\boldsymbol{v}$ & $H$ \\
\hline$\curvearrowright$ & -10 & -10 & -19 & & & & 7 \\
\hline$\ddot{\circ}$ & & & $v$ & & & & $\boldsymbol{v}$ \\
\hline$\ddot{\rho}$ & $\boldsymbol{H}$ & & $\infty$ & $H$ & 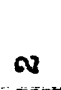 & $\alpha$ & $F$ \\
\hline$\ddot{8}$ & & $+\infty$ & & & & & -10 \\
\hline$\ddot{乃}$ & & $-{ }^{-1}$ & & & & & 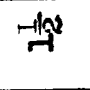 \\
\hline$=$ & & & & & & & 1 \\
\hline$\ddot{\jmath}$ & & & 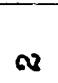 & & & & $\boldsymbol{N}$ \\
\hline
\end{tabular}




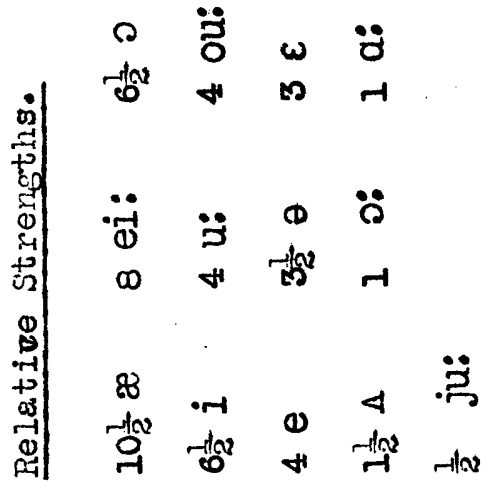

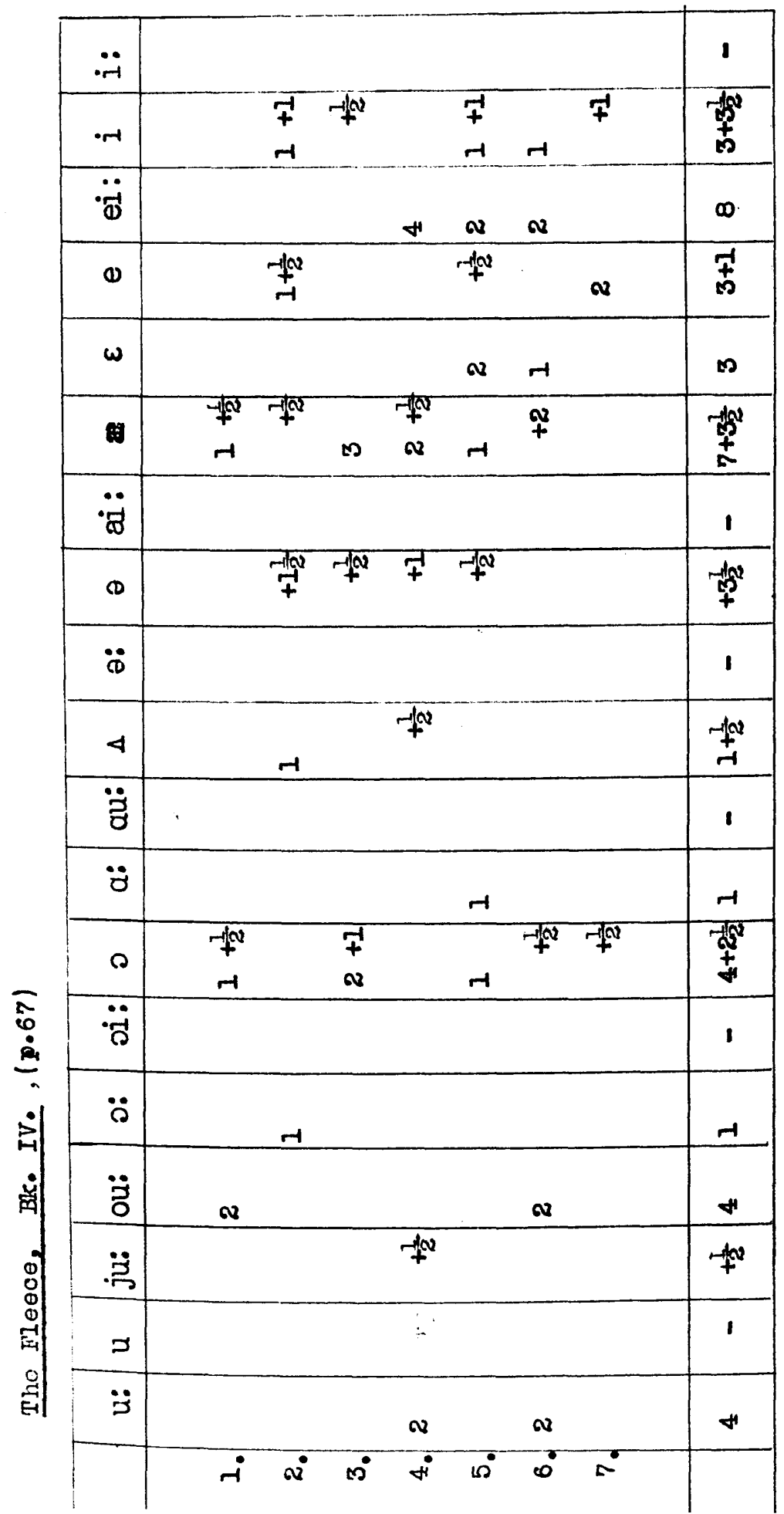




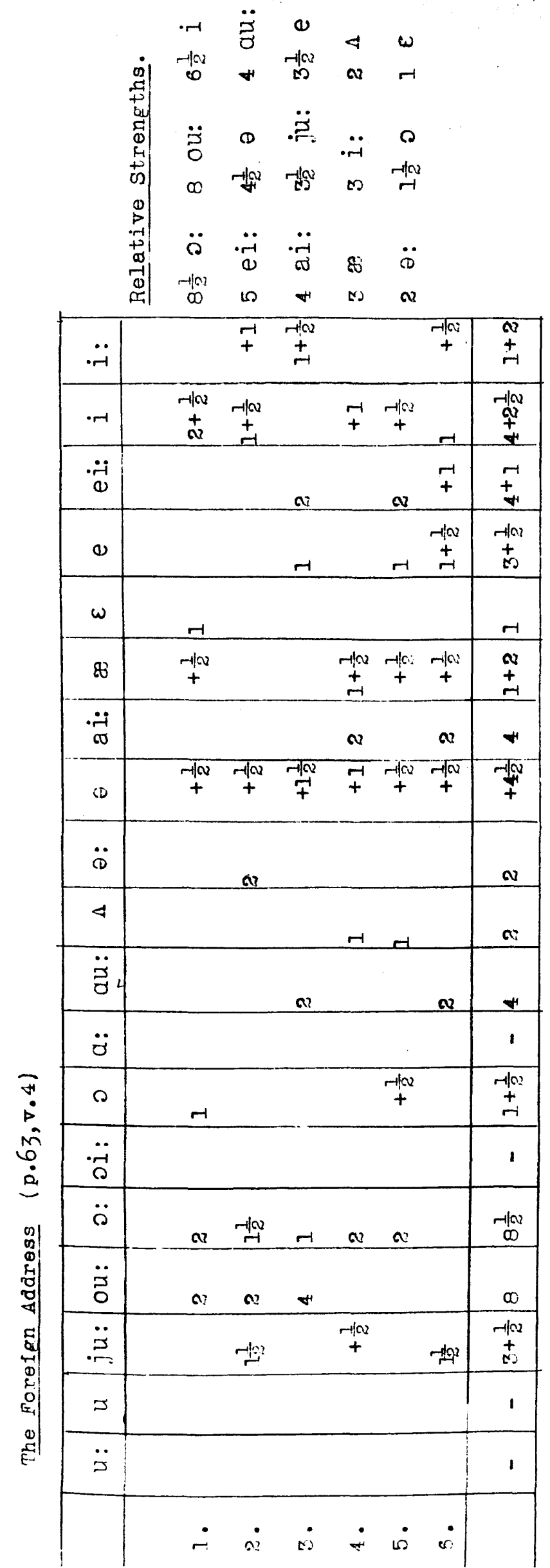

呆 


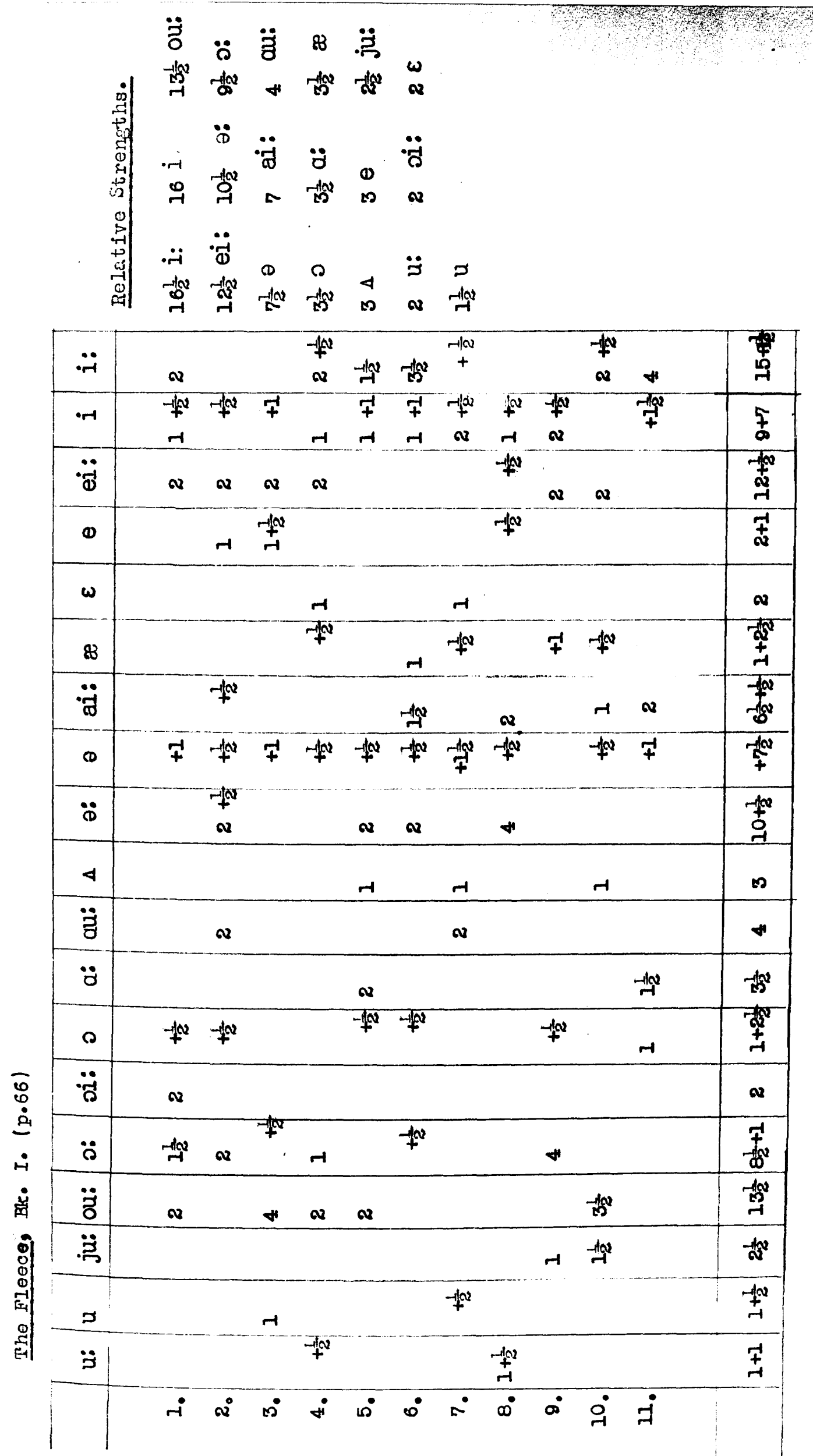




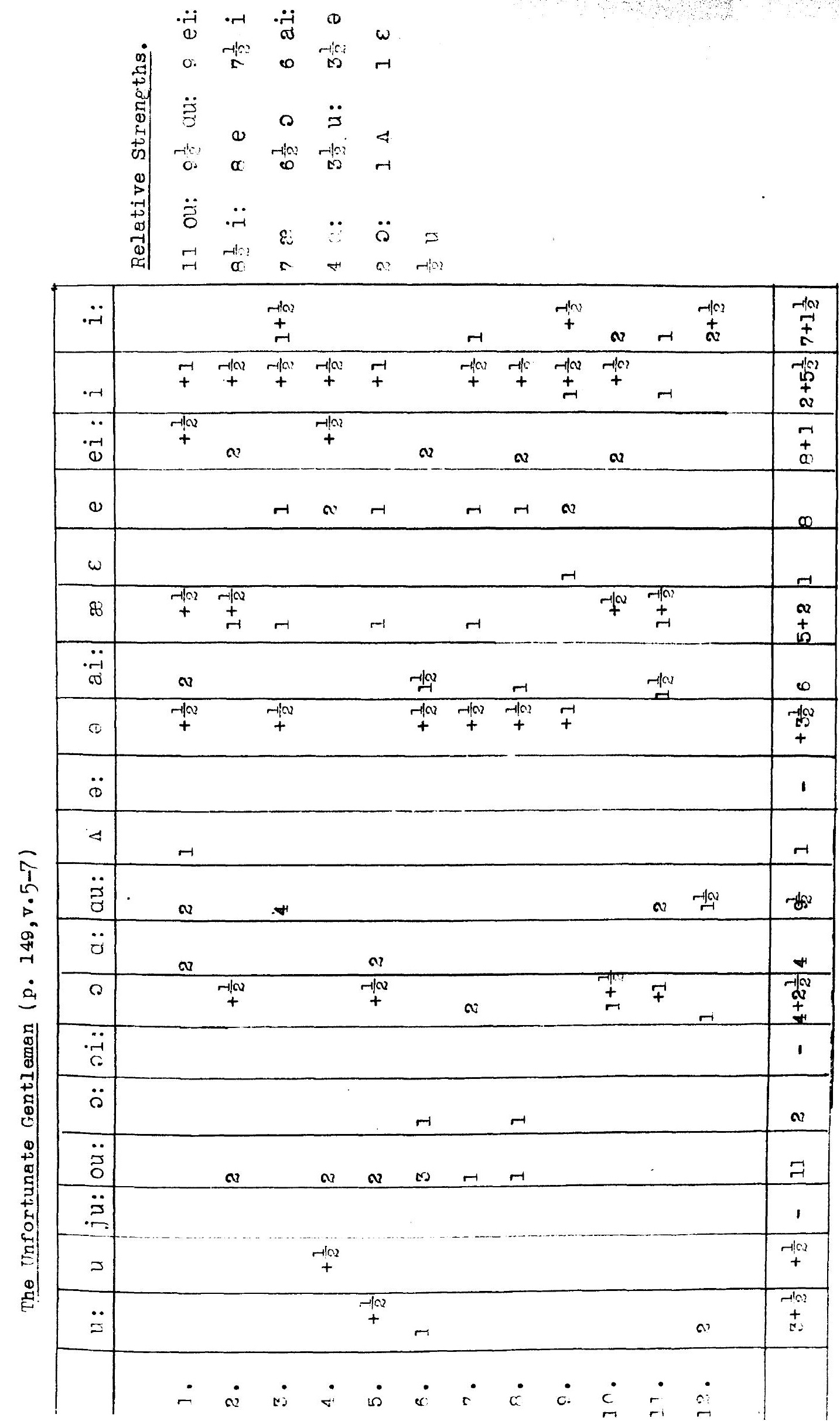

옹 


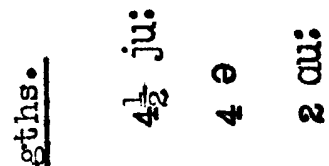

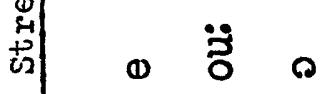

0 ॠ

क्ञ

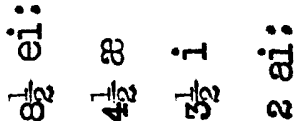

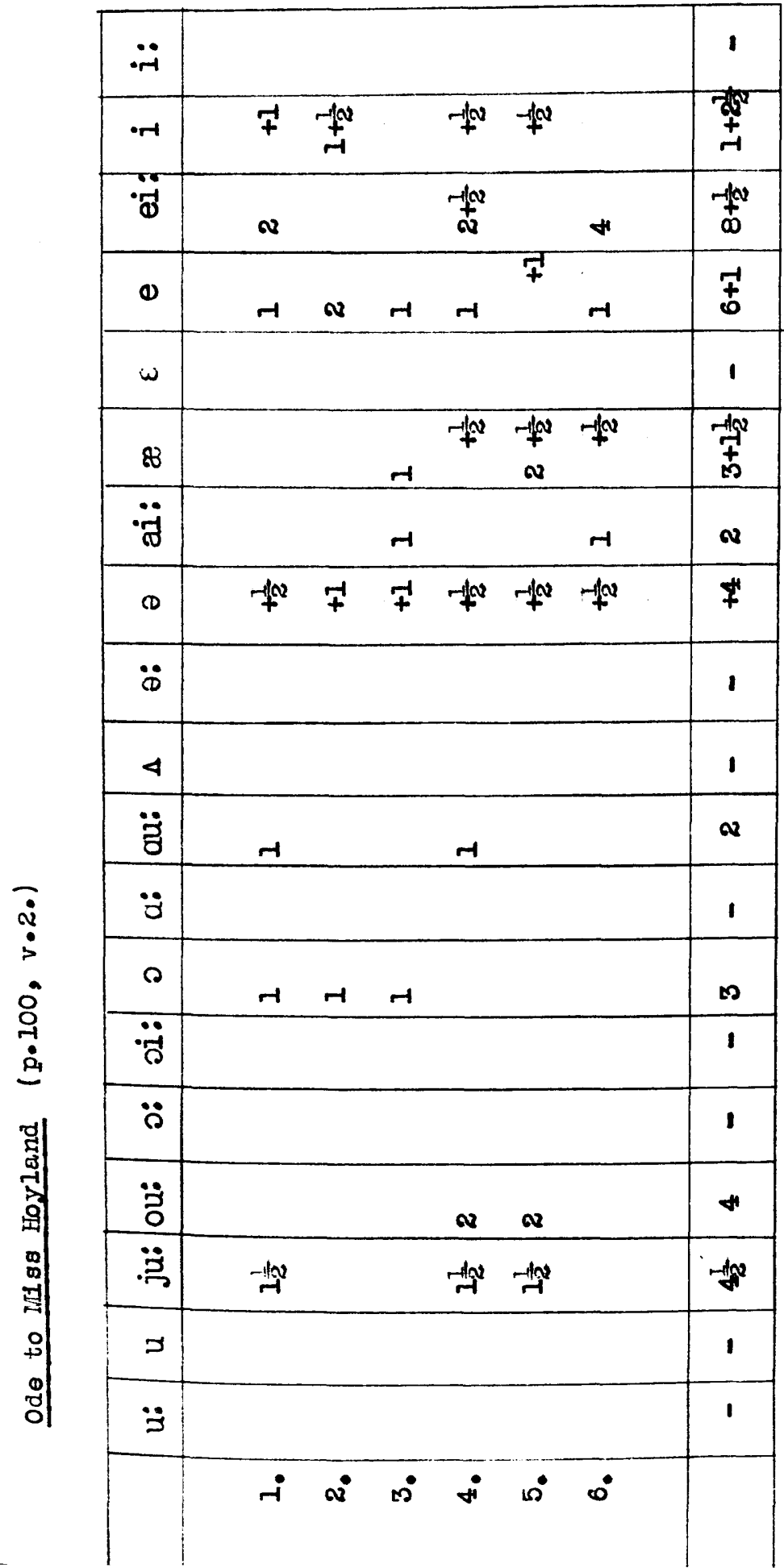




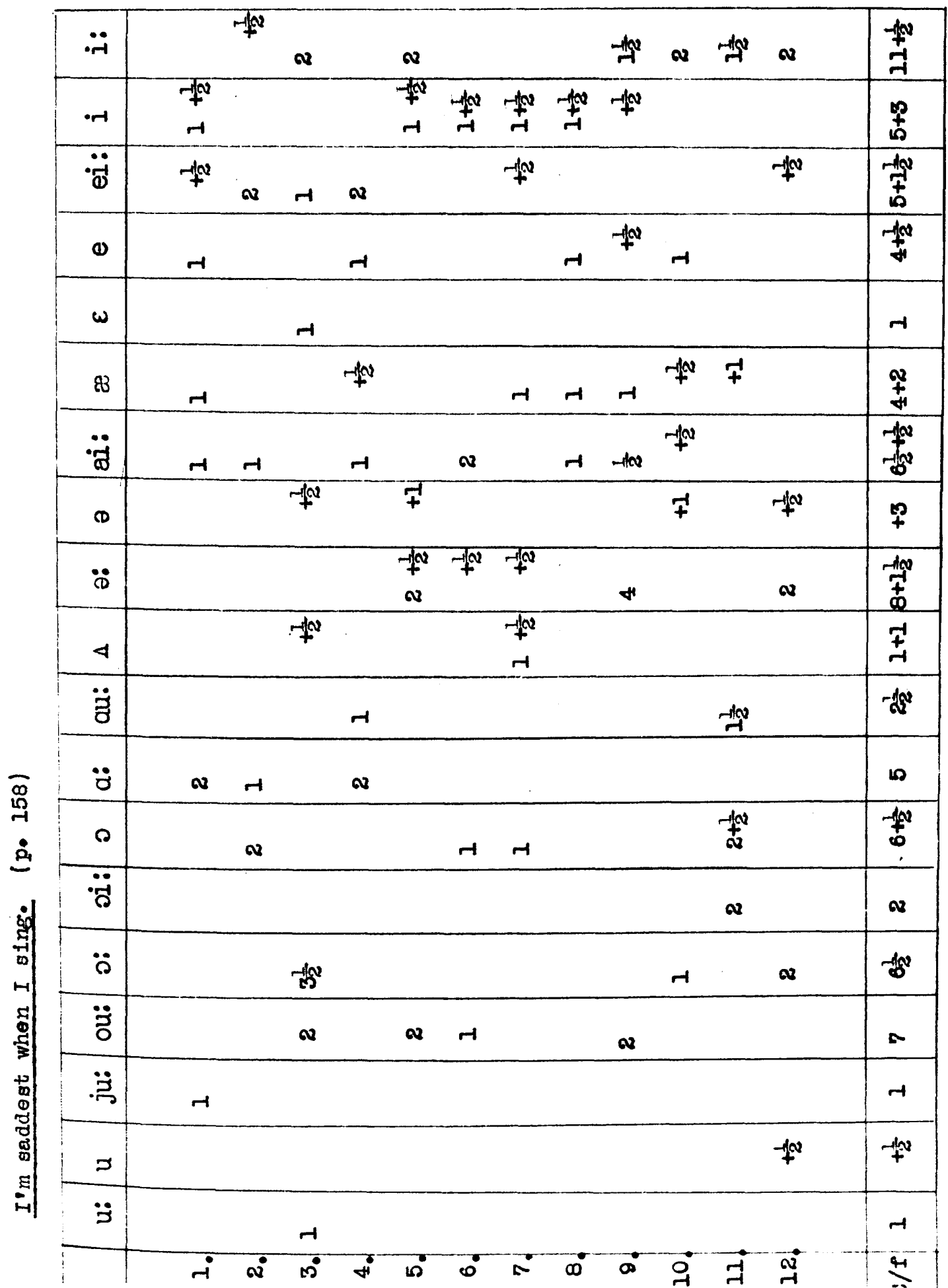

年 


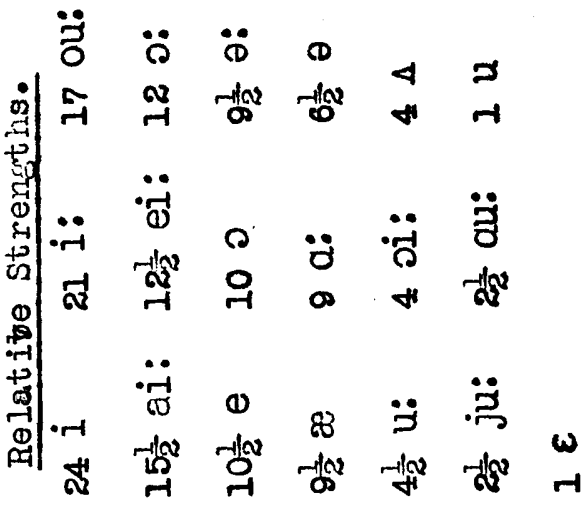

\begin{tabular}{|c|c|c|c|c|c|c|c|c|c|c|c|c|c|c|}
\hline$\ddot{A r}$ & $\begin{array}{l}-1 \times 2 \\
+ \\
+7\end{array}$ & & & 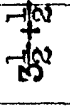 & & & -10 & 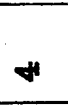 & & & & -1 & & 釆 \\
\hline •rt & $\begin{array}{l}m \\
1 \\
1\end{array}$ & $\underset{-1}{-1}$ & $\pi$ & -1 & $\underset{-1}{-1+4}$ & & & $\stackrel{-1 w}{\rightarrow}$ & & $\boldsymbol{v}$ & $\underset{\omega}{+\infty}$ & $\infty$ & $\underset{-10}{-10}$ & $\begin{array}{l}q \\
q \\
q\end{array}$ \\
\hline$\ddot{\theta}$ & $\begin{array}{l}-1 / 0 \\
+5 \\
\text { in }\end{array}$ & 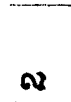 & & & & & $\boldsymbol{N}$ & $\boldsymbol{N}$ & & & & & & $\underset{7}{7}$ \\
\hline $\boldsymbol{0}$ & $\stackrel{-1 n}{+\infty}$ & & & & -1 & $H$ & & & -1 & $\stackrel{-1 w}{+}$ & & -10 & -1 & 吉 \\
\hline $\boldsymbol{\omega}$ & -1 & & & & & & & & & & & & & -1 \\
\hline 83 & $\underset{+}{+}$ & -100 & & & -1 & & $-1 w$ & & -10 & & & & $-r$ & $\left.-\frac{1}{+}\right)_{0}^{2}$ \\
\hline$\ddot{\ddot{D}}$ & 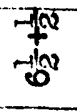 & $\boldsymbol{N}$ & & & -1 & $-1 \omega$ & $r$ & & -1 & $\boldsymbol{v}$ & & & -1 & $\begin{array}{c}-10 \\
\stackrel{10}{H}\end{array}$ \\
\hline CD & px & -10 & -10 & -10 & & $+\infty$ & & & & 7 & & -10 & & $-1 x$ \\
\hline$\ddot{0}$ & $\begin{array}{l}\text { How } \\
+ \\
\text { के }\end{array}$ & & & & & & & & & & & & & 卢 \\
\hline 4 & $\underset{+}{+}$ & & & 10 & & $\mathrm{H}$ & & & & & -10 & & & $\underset{\mathbf{w}}{\mathbf{w}}$ \\
\hline$\ddot{z}$ & -ds & & & & & & & & & & & & & $-d w^{2}$ \\
\hline$\ddot{~} \ddot{~}$ & 10 & $v$ & & & & & $w$ & & & & & & & $\infty$ \\
\hline$\curvearrowright$ & $\begin{array}{c}-100 \\
0\end{array}$ & & 笂 & & & $-1 / 2$ & & & & & -100 & & & $\underset{\mathbf{\Phi}}{\mathbf{w}}$ \\
\hline$\ddot{\circ}$ & $w$ & & & & & & & $N$ & & ${ }^{\circ}$ & & & & + \\
\hline$\ddot{\circ}$ & $-1 / 60$ & & & $\infty$ & & $\rightarrow-190$ & & & & & Q & & & $\stackrel{a}{\vec{d}}$ \\
\hline ̈ㅜㄹ & $\Omega$ & & & $\omega$ & & & $\infty$ & & $\infty$ & -190 & & Ha & & $\tilde{7}$ \\
\hline$\stackrel{\ddot{乃}}{\ddot{n}}$ & -1 & & & & & $\rightarrow$ & & & & & & & & $-d v$ \\
\hline 3 & -12 & & & & & & & $+\infty$ & & & & & & 7 \\
\hline$\ddot{\Xi}$ & $r$ & & -10 & & & -100 & & -1 & -1 & & & -1 & & $\underset{+2}{+n^{2}}$ \\
\hline & m & $\vec{r}^{\circ}$ & $\stackrel{d}{4}$ & $\stackrel{\circ}{\circ}$ & $\stackrel{\bullet}{\circ}$ & $\approx$ & $\stackrel{\infty}{\infty}$ & $\stackrel{\rightarrow}{\circ}$ & 8 & a & న్ & Q & ম & \\
\hline
\end{tabular}




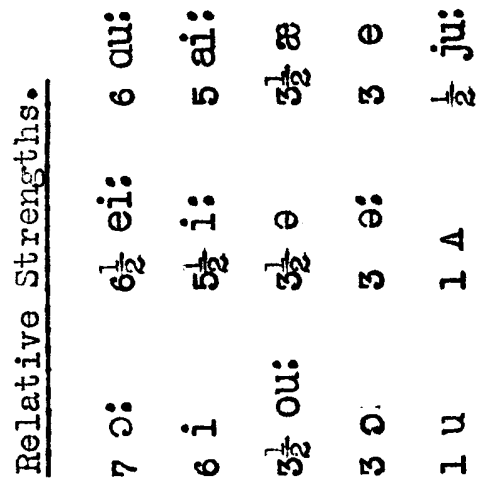

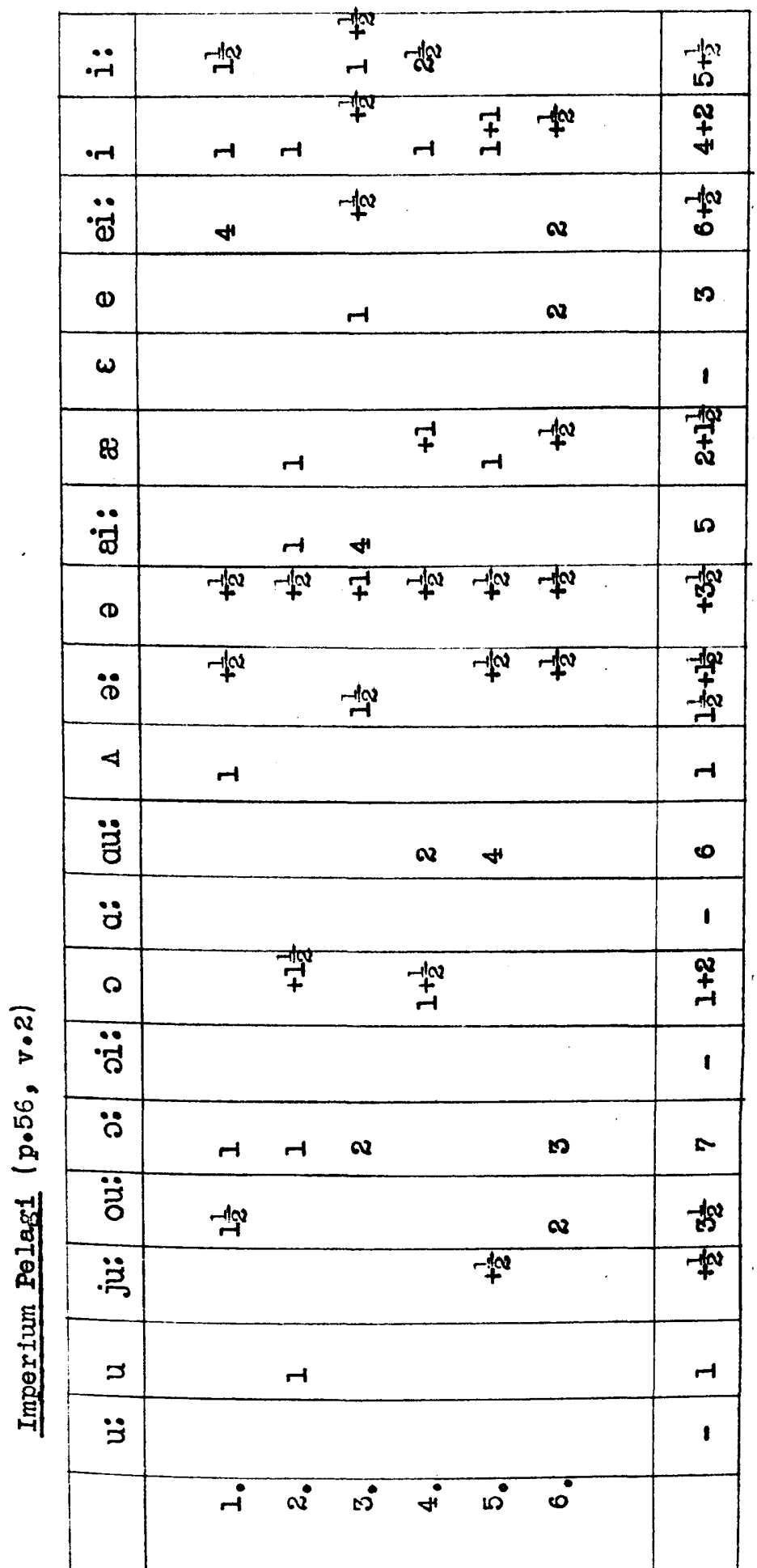




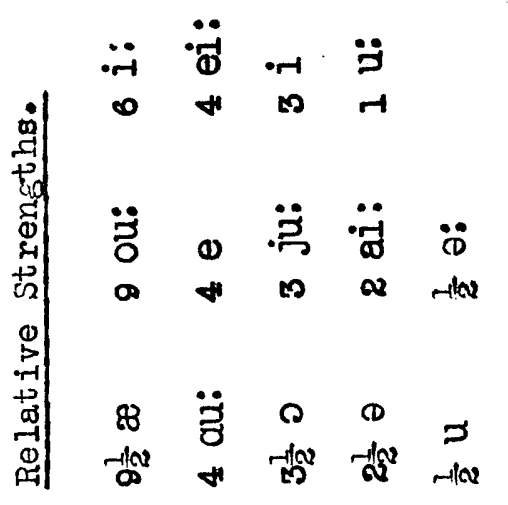

\begin{tabular}{|c|c|c|c|c|c|c|c|}
\hline$\ddot{r}$ & $\boldsymbol{N}$ & & $\infty$ & $w$ & & & 0 \\
\hline •r-1 & & & -10 & -10 & $-1 a$ & $-1+a$ & 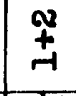 \\
\hline$\ddot{\ddot{d}}$ & -1 & -10 & $-1+$ & & $-1 \omega$ & rlla & 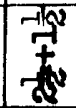 \\
\hline 0 & +1 (a) & & $\boldsymbol{\omega}$ & & & $\stackrel{-1 w}{=}$ & 㽦 \\
\hline$\omega$ & & & & & & & 1 \\
\hline 18 & & $\infty$ & $r$ & $\stackrel{-1 w}{\mathbf{a}}$ & $\underset{+}{ \pm}$ & $\underset{\ddagger}{\mp}$ & 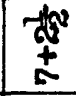 \\
\hline$\ddot{\ddot{\sigma}}$ & $\boldsymbol{v}$ & & & & & & $\boldsymbol{v}$ \\
\hline (1) & -110 & -1 & 7 & -10 & & & 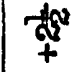 \\
\hline$\ddot{\infty}$ & & $-1 \infty$ & & & & & -10 \\
\hline 4 & & & & & & & 1 \\
\hline 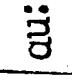 & & & $\infty$ & & & $\infty$ & + \\
\hline$\ddot{\sigma}$ & & & & & & & 1 \\
\hline 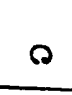 & $-1 \omega$ & & & & -1 & $\infty$ & 热 \\
\hline$\ddot{\ddot{\theta}}$ & & & & & & & 1 \\
\hline$\ddot{\circ}$ & & & & & & & 1 \\
\hline$\ddot{\ddot{z}}$ & s & $\infty$ & $H$ & $\boldsymbol{\alpha}$ & $\infty$ & & $\infty$ \\
\hline :ٌ̈ & $\rightarrow$ & & & & -tha & & $\infty$ \\
\hline ב & & -1 & & & & & -10 \\
\hline$\ddot{3}$ & & & & -1 & & & $r$ \\
\hline & $i$ & $a^{\dot{a}}$ & $\dot{0}$ & $\dot{+}$ & $\dot{\circ}$ & $\infty^{\circ}$ & \\
\hline
\end{tabular}




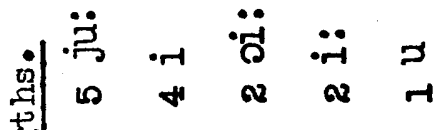

站

$\prod_{\rightarrow=1}^{-10}$ म

点

\begin{tabular}{|llllll}
0 & $\ddot{0}$ & $\ddot{\omega}$ & $\ddot{0}$ & 0 & 4 \\
0 & 0 & 0 & $\mu$ & $r$
\end{tabular}

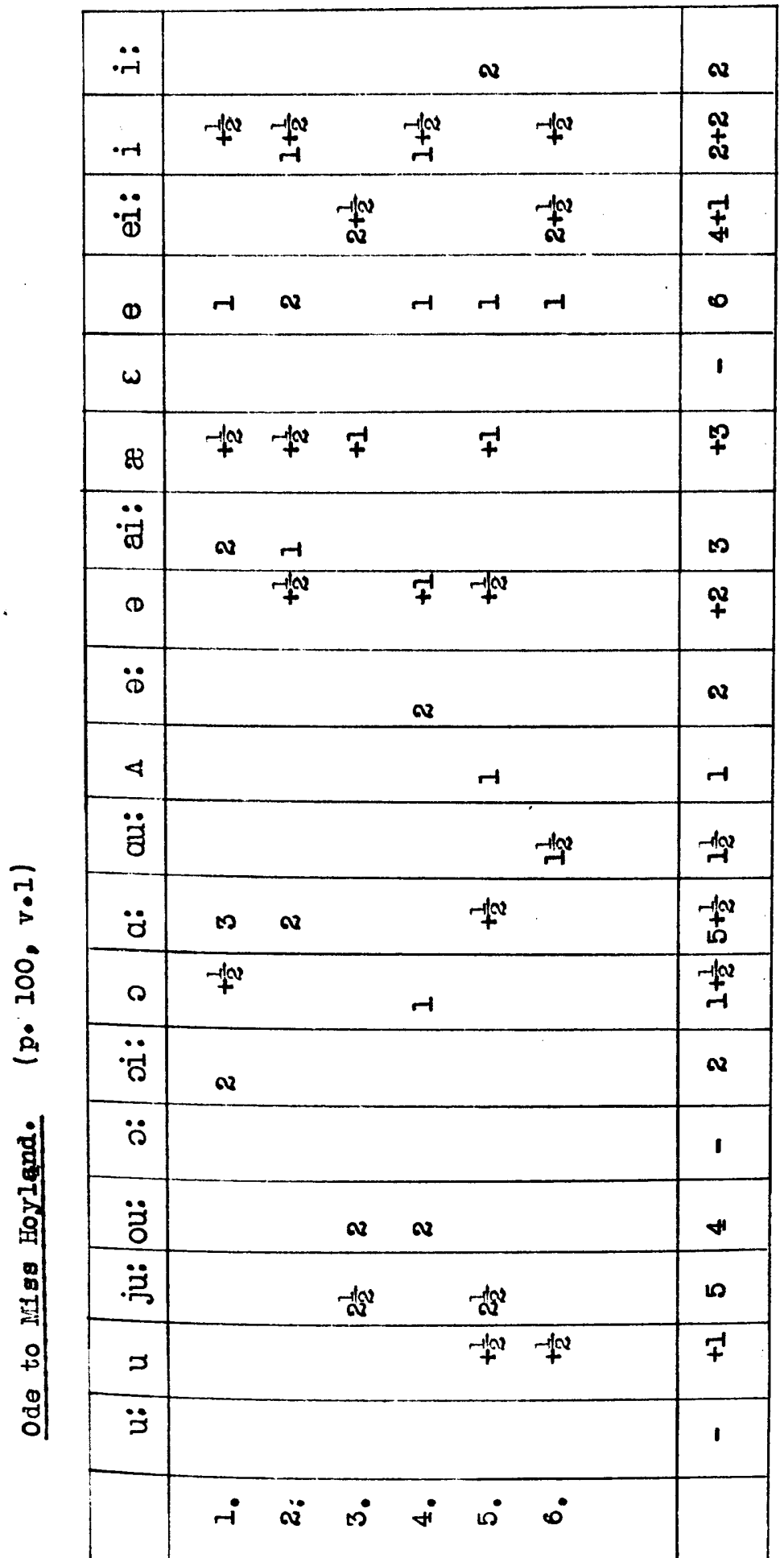




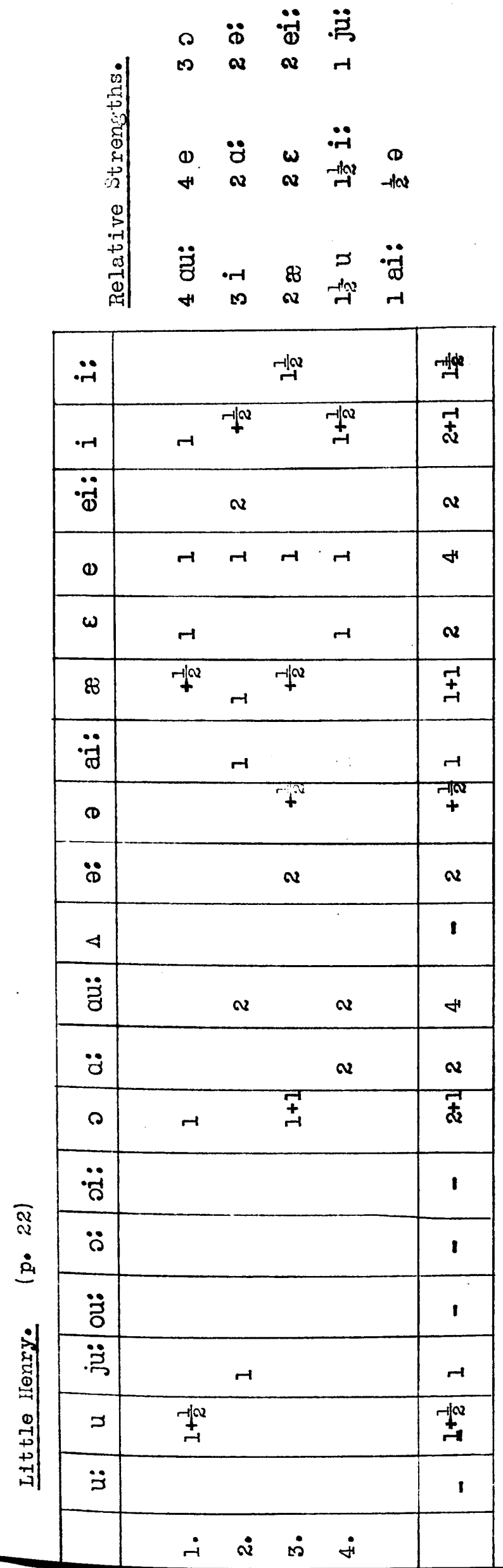




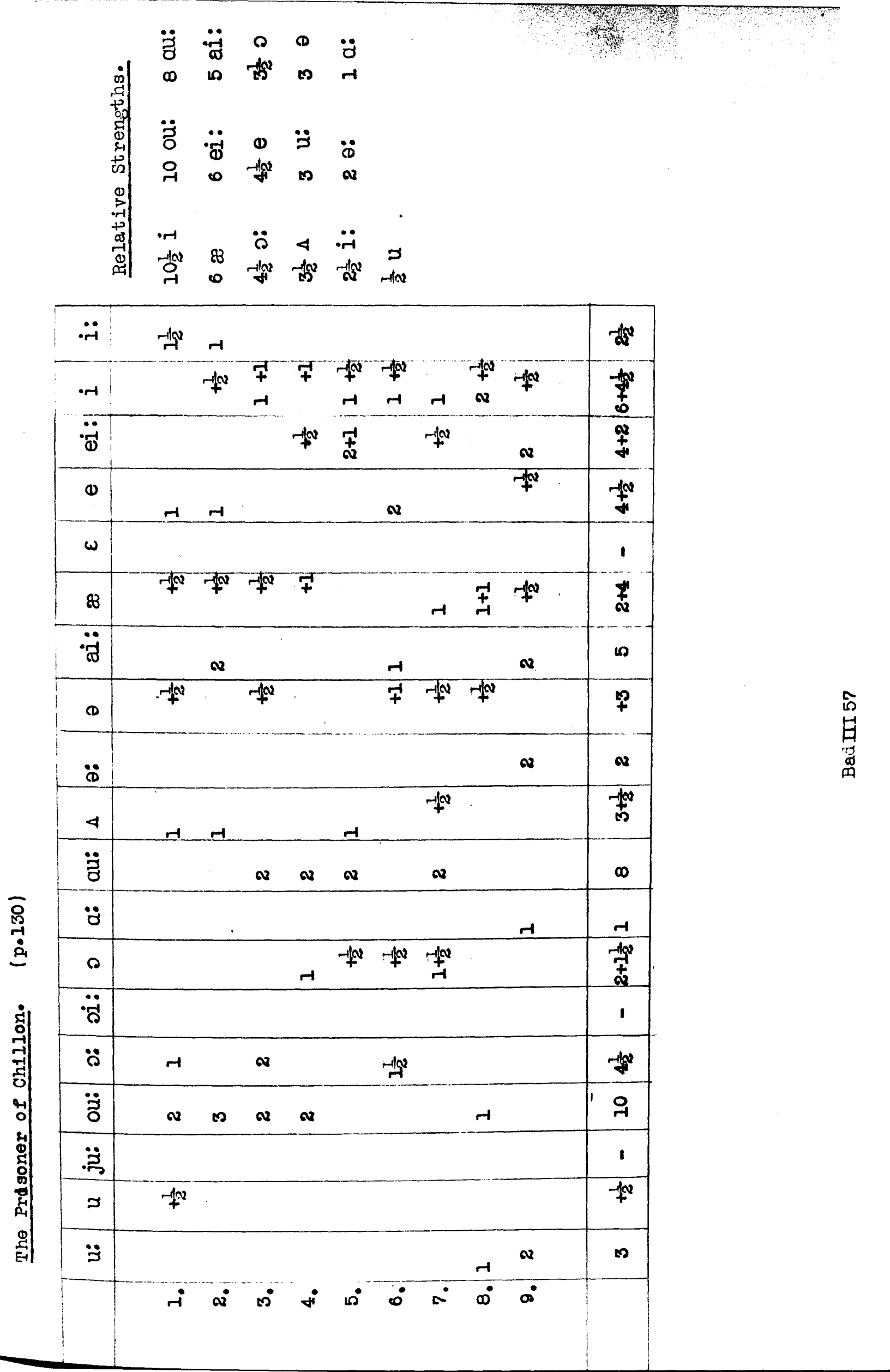




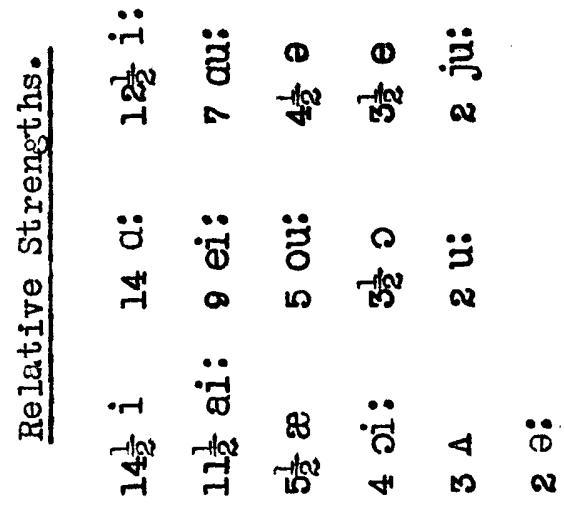

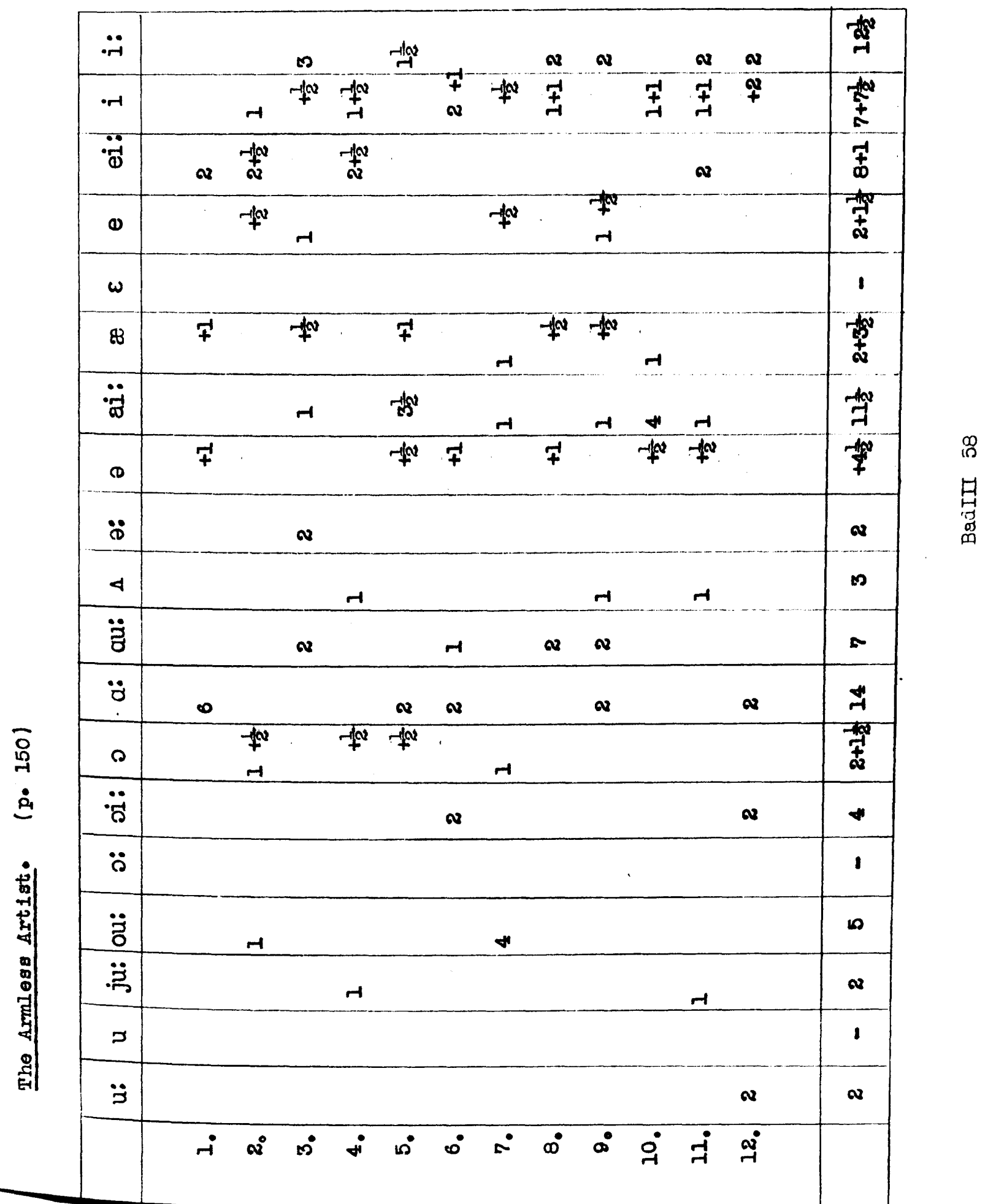




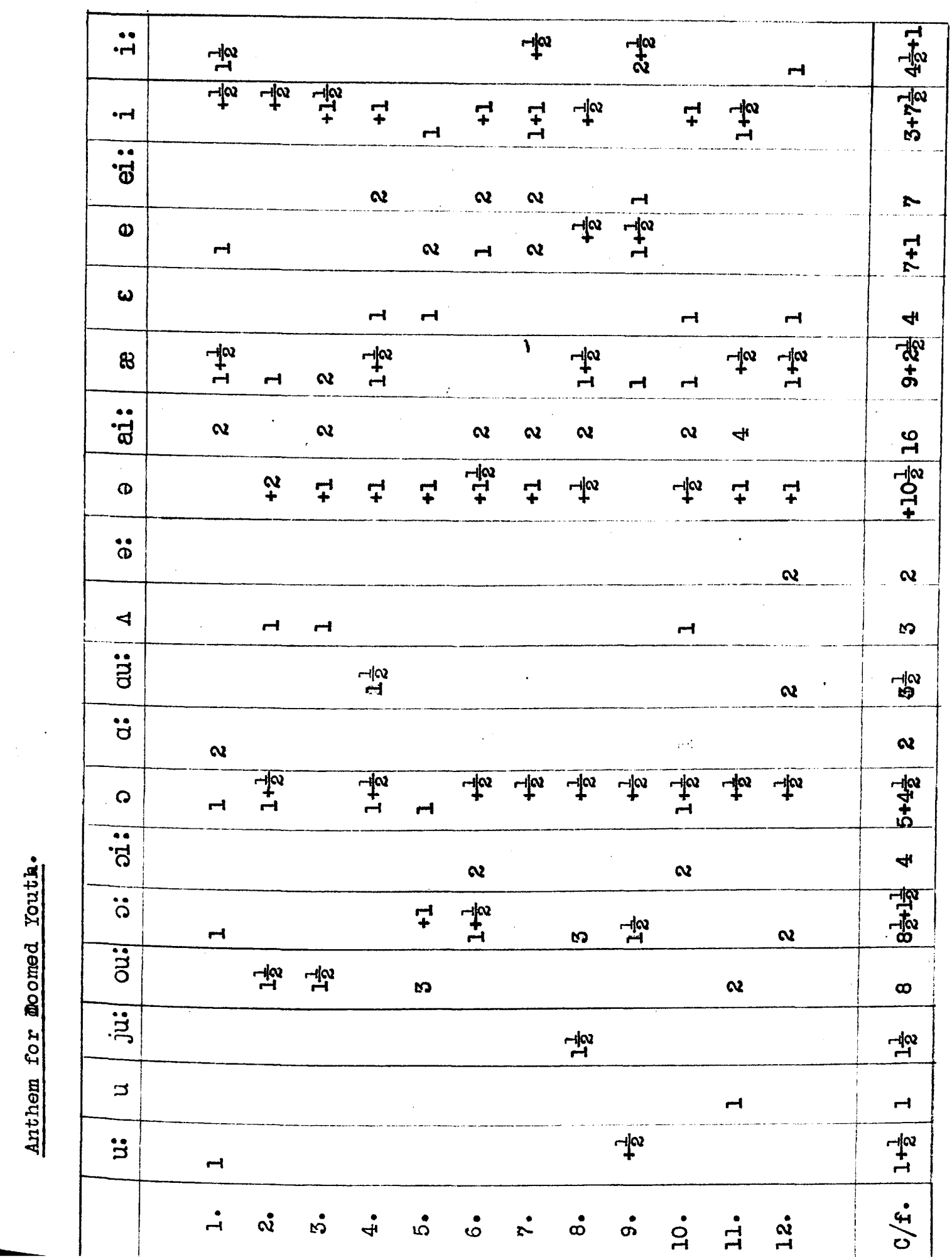




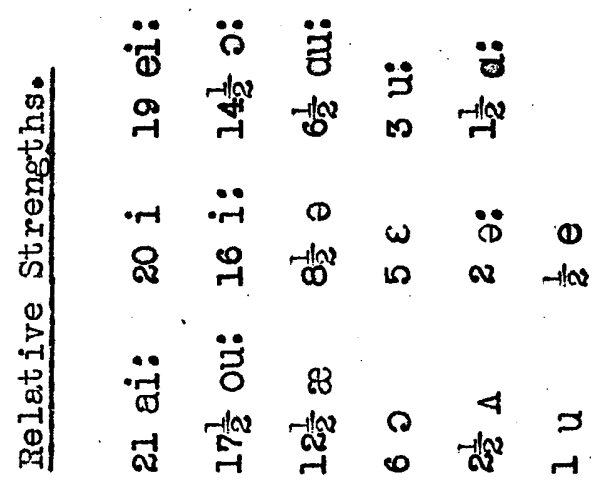

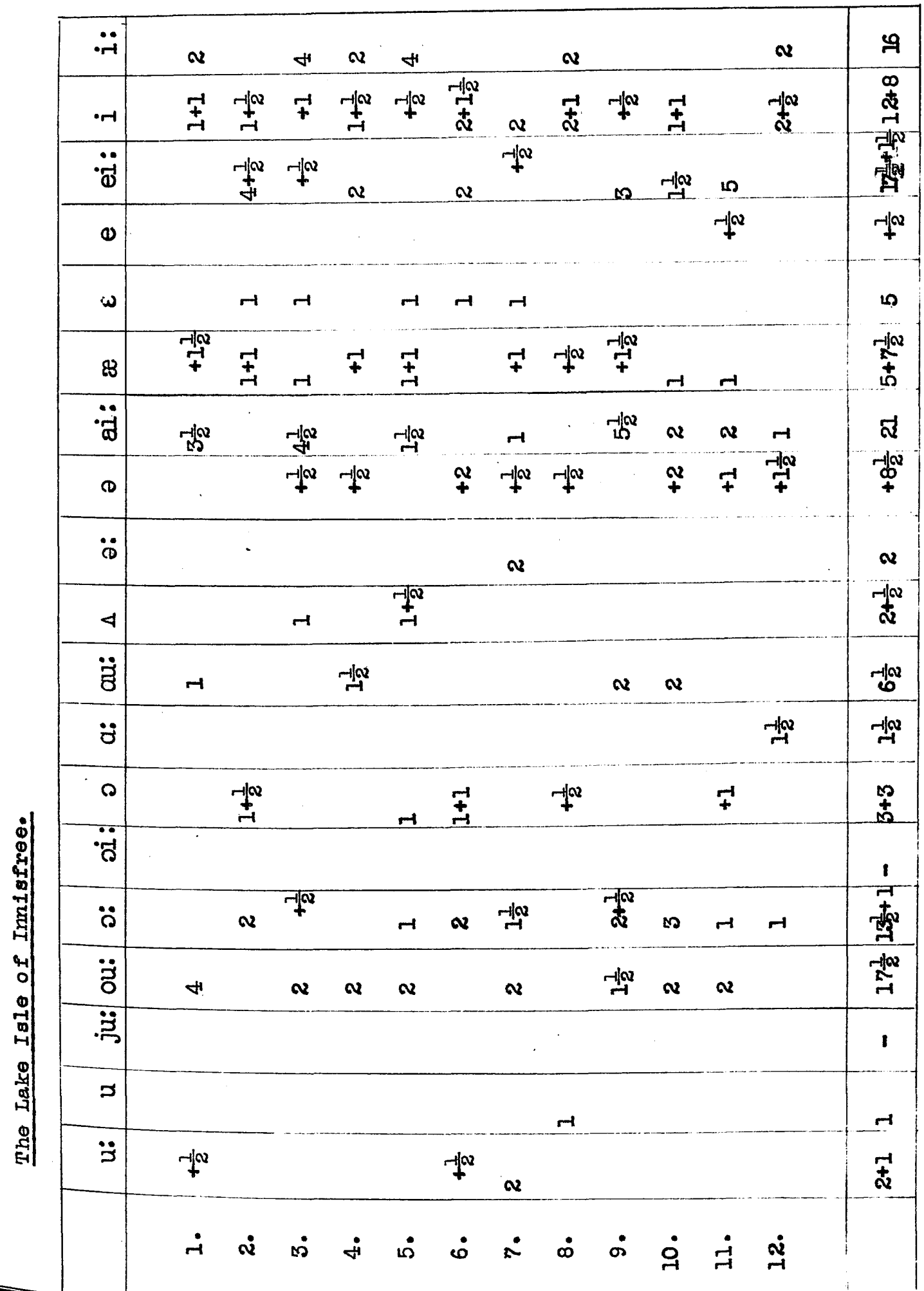




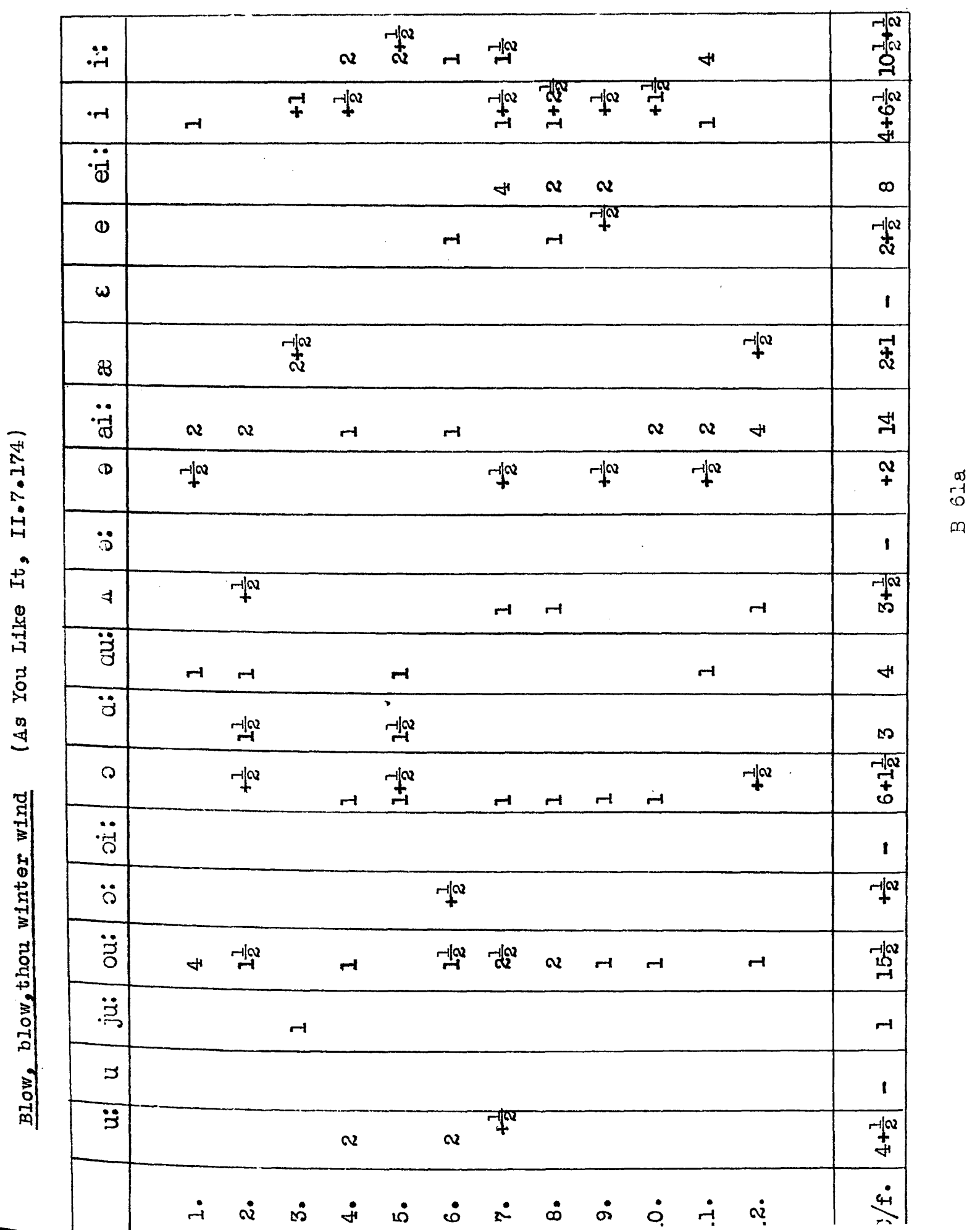




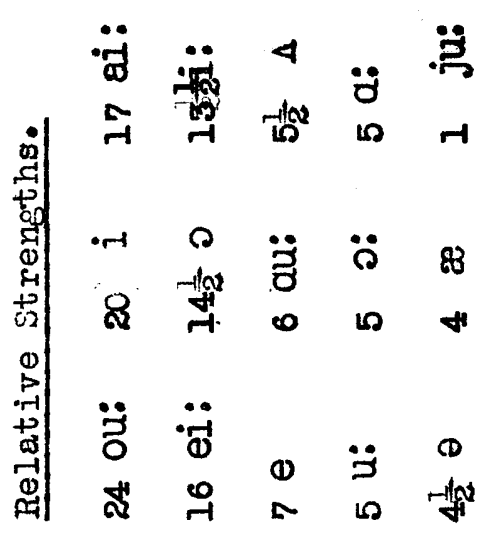

\begin{tabular}{|c|c|c|c|c|c|c|c|c|c|}
\hline$\ddot{-r}$ & - & $\stackrel{-1 / \infty}{+}$ & & & +1 & $\stackrel{r-1}{r_{-1}^{2}}$ & & & 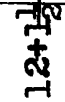 \\
\hline$\cdot r-1$ & $\begin{array}{l}-1 / 0 \\
60 \\
+ \\
+4 \\
4\end{array}$ & $\therefore$ & & 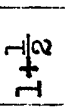 & & $\stackrel{r+a}{=}$ & $\begin{array}{c}-1-1 \\
\text { âa } \\
+ \\
-1\end{array}$ & 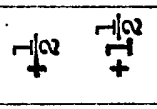 & $\begin{array}{l}\alpha 3 \\
4 \\
\infty\end{array}$ \\
\hline$\ddot{\ddot{0}}$ & $\infty$ & & & & & 4 & $v$ & $v$ & $\stackrel{0}{\oplus}$ \\
\hline $\boldsymbol{\theta}$ & $\stackrel{-1 \times 2}{\vdots}$ & $H$ & & & Q & & $r$ & 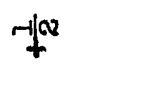 & $\underset{t}{+1}$ \\
\hline$\omega$ & & & & & & & & & $t$ \\
\hline 88 & $\frac{-1}{+}$ & $r+n$ & & & 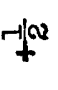 & & & & 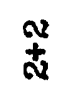 \\
\hline$\ddot{\ddot{x}}$ & $\stackrel{H}{H}$ & & & $r$ & & & & $v$ & $\stackrel{\sim}{\pi}$ \\
\hline (D) & $\stackrel{Q}{+}$ & & $\underset{+}{+}$ & & $-1 x^{\infty}$ & 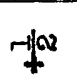 & & $x^{\alpha}$ & $+n^{10 x}$ \\
\hline$\ddot{D}$ & & & & & & & & & 1 \\
\hline 4 & $\stackrel{-10 x}{\infty}$ & & & & & -1 & $r$ & & ம0 \\
\hline$\ddot{z}$ & 4 & & $\sim$ & & & & & & $\omega$ \\
\hline$\ddot{z}$ & $\infty$ & & & $\boldsymbol{Q}$ & & & & & ம \\
\hline 8 & r象 & $r$ & & $r$ & -1 & -1 & -1 & $H$ & 管 \\
\hline "म्م & & & & & & & & & 1 \\
\hline$\ddot{\beta}$ & $F$ & $+t^{\infty}$ & 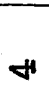 & & & & & & + \\
\hline$\ddot{8}$ & तु & & -1 & $r$ & & -dva & $\infty$ & -1 & 心 \\
\hline בית & $\rightarrow$ & & & & & & & & $\pi$ \\
\hline 5 & & & & & & & & & 1 \\
\hline$\ddot{\jmath}$ & $\stackrel{+10}{4}$ & & & & & $-1 / 2$ & & & $\frac{1}{4}$ \\
\hline & $\frac{4}{9}$ & $\ddot{r}$ & $\vec{H}$ & $\stackrel{\dot{10}}{r-1}$ & $\stackrel{\dot{\sigma}}{\dot{H}}$. & $\dot{i}$ & $\underset{\sim}{\infty}$ & $\dot{\sigma} \quad \dot{8}$ & \\
\hline
\end{tabular}




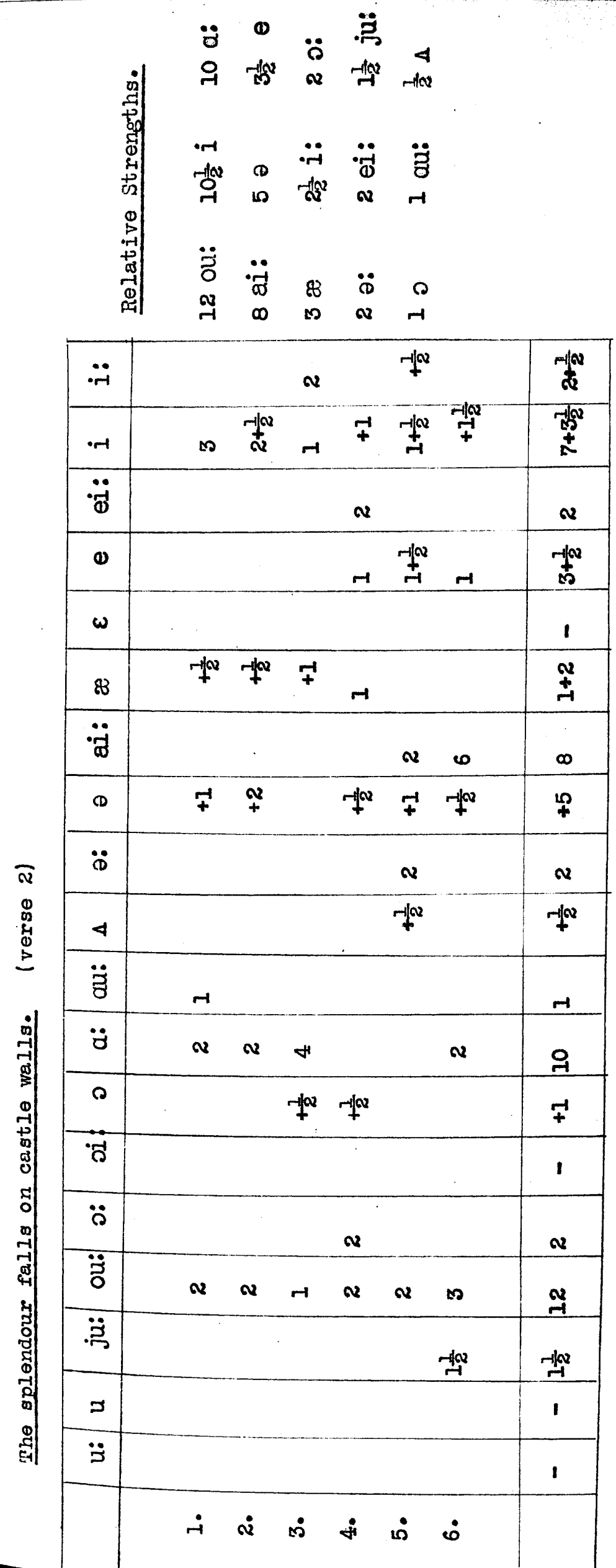




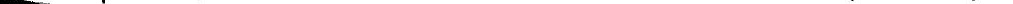




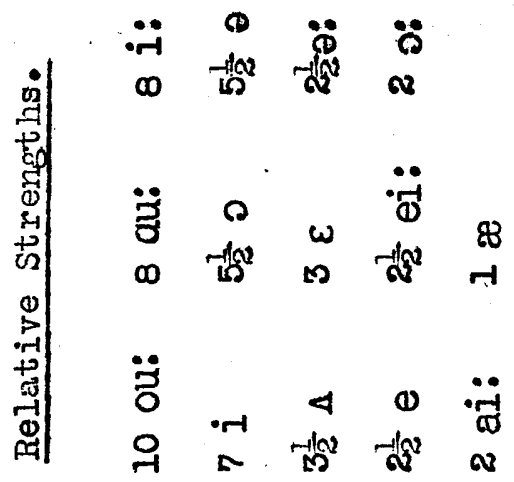

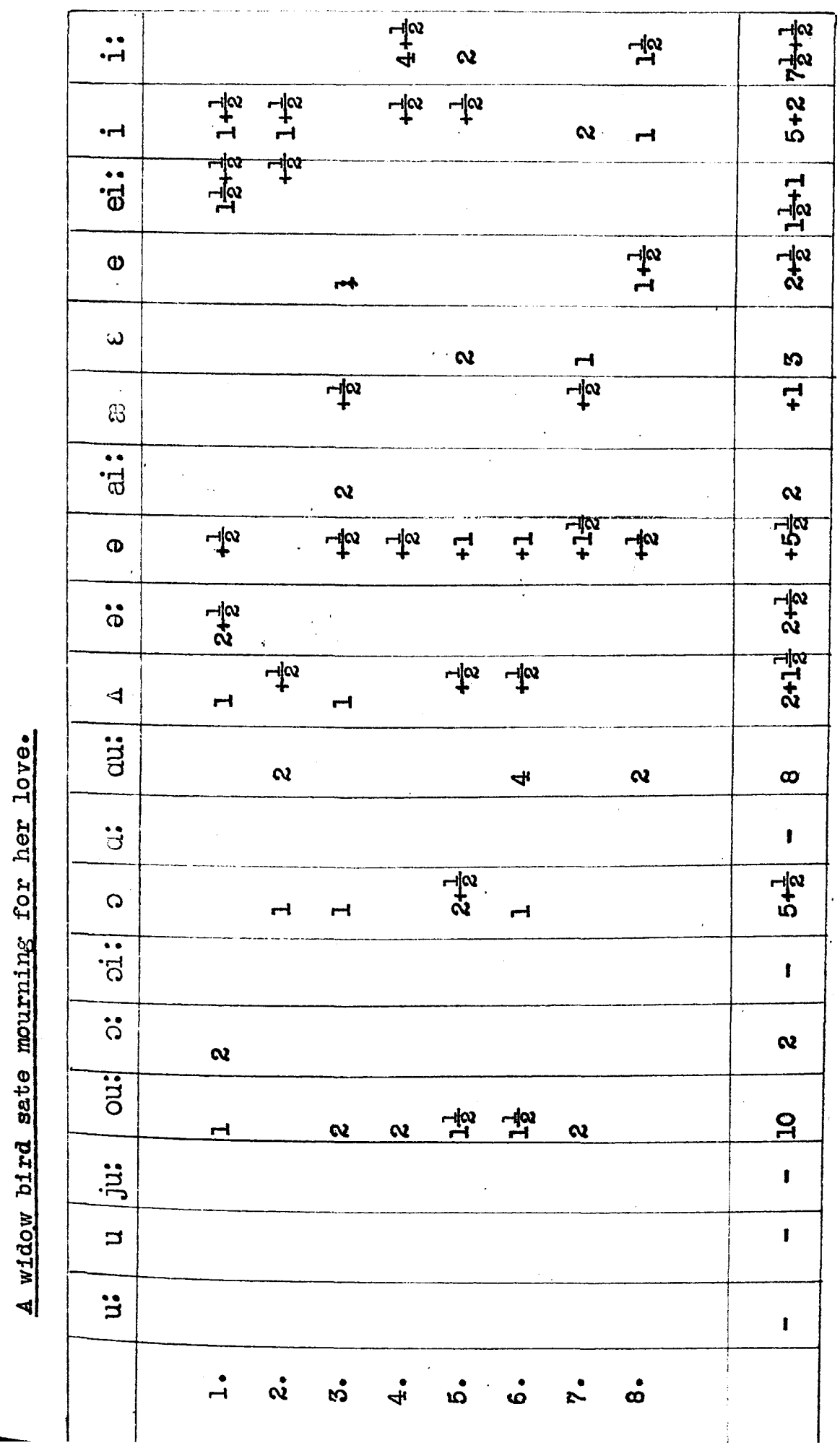




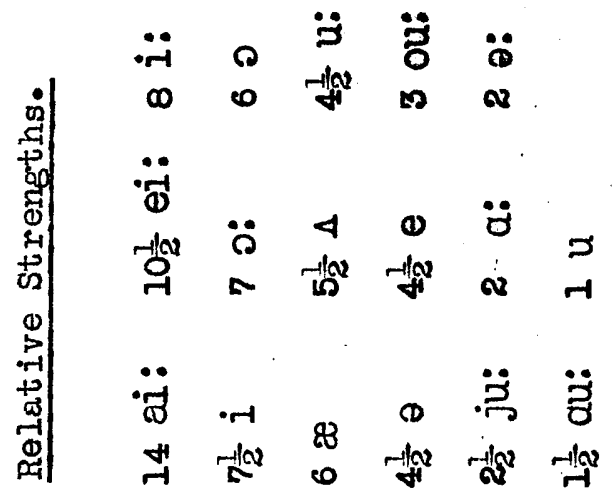

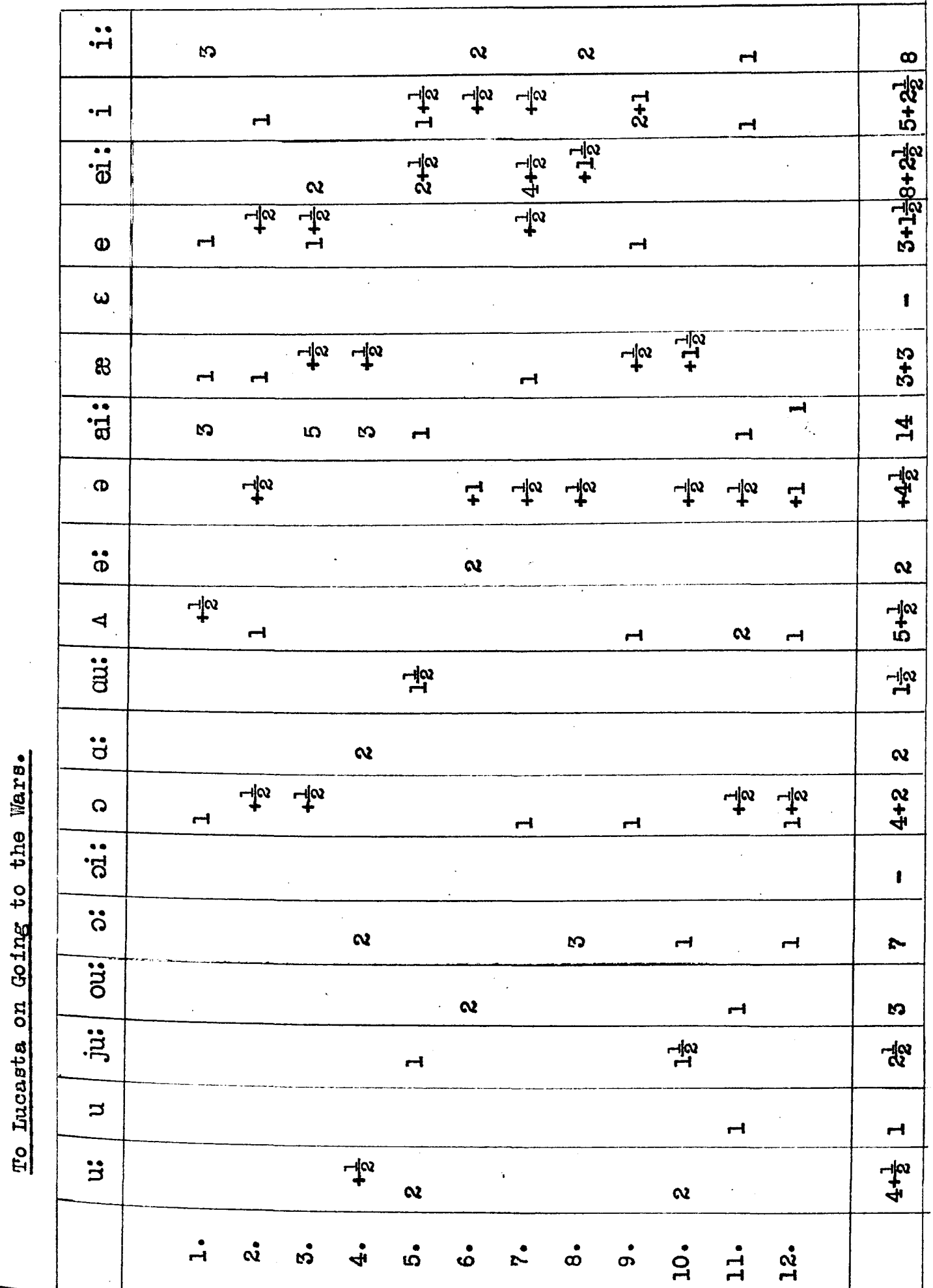




\begin{tabular}{|c|c|c|c|c|c|c|c|c|c|c|c|c|c|}
\hline$\ddot{i-1}$ & & & $-\underbrace{\infty}_{-1 / \infty}$ & & -1102 & s & & $\boldsymbol{v}$ & & $\boldsymbol{N}$ & $\boldsymbol{\Omega}$ & $\stackrel{-102}{-1}$ & 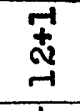 \\
\hline$\cdot r-1$ & $\mp$ & & $-1+a_{2}$ & ${ }^{1 / x}$ & & $\mp$ & & & + & $\rightarrow$ & $-10 x$ & & 踔 \\
\hline$\ddot{\ddot{0}}$ & & $\frac{-1 a x}{\sqrt{2}}$ & & & & $\boldsymbol{v}$ & & $r$ & & $N$ & & & 鉴 \\
\hline $\boldsymbol{0}$ & & $r-1$ & 7 & & & & & $r$ & & & & & $\stackrel{+1}{+}$ \\
\hline$\omega$ & & & & & & & & & & & & & 1 \\
\hline$\$ 8$ & & $7+\infty$ & & $-1+\infty$ & & & & $-1-193$ & & -102 & & $\underset{\rightarrow-1}{-\infty x}$ & 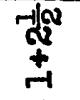 \\
\hline$\ddot{\ddot{\sigma}}$ & & & $\sim$ & 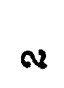 & 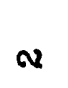 & $\curvearrowright$ & $H$ & & $\boldsymbol{v}$ & & & & $\underset{\sim}{\mathbb{H}}$ \\
\hline D & & -1102 & & & $\mp$ & & $\mp$ & & & & & & + \\
\hline$\ddot{0}$ & $r$ & & & & 10 & & -10 & 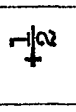 & 10 & & $\infty$ & $\rightarrow$ & $\begin{array}{l}7 \\
+ \\
5 \\
-1\end{array}$ \\
\hline 4 & & & & & & & -11ap & & & & $-7 w^{\infty}$ & & $\vec{t}$ \\
\hline$\ddot{\Xi}$ & & & & & & & & $\boldsymbol{v}$ & & $v$ & & 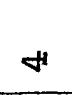 & $\infty$ \\
\hline$\ddot{z}$ & & & & 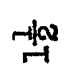 & & & $\boldsymbol{N}$ & & & & & & को \\
\hline 0 & $-1 / 2$ & $-1 \infty$ & & & & $-1 \infty$ & $-1 \infty$ & & $-7^{a}$ & $-1+\infty$ & $-1 / 2$ & & 然 \\
\hline$\ddot{\circ}$ & & & & & & & & & & & & & 1 \\
\hline$\ddot{i}$ & & & & & & & & & & & $+\infty$ & & 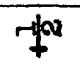 \\
\hline ठ̈ & $H$ & & $\sim$ & & & & & & & & $N$ & & $\infty$ \\
\hline 芦 & & 相 & & & & & & & & & & & $\stackrel{+\infty}{\rightarrow \infty}$ \\
\hline 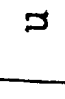 & & & & $r$ & & & & & & & & & $r$ \\
\hline$\ddot{\jmath}$ & $\boldsymbol{v}$ & & & $\boldsymbol{v}$ & & & & & & & & & 4 \\
\hline & $\dot{-}$ & $\dot{v}$ & $\dot{\phi}$ & ji & $\dot{10}$ & $\dot{0}$ & $\dot{R}$ & $\dot{\infty}$ & $\dot{\infty}$ & $\dot{\circ}$ & $\dot{\vec{\rightarrow}}$ & $\underset{\sim}{\stackrel{\leftrightarrow}{r}}$ & $\frac{4}{\delta}$ \\
\hline
\end{tabular}




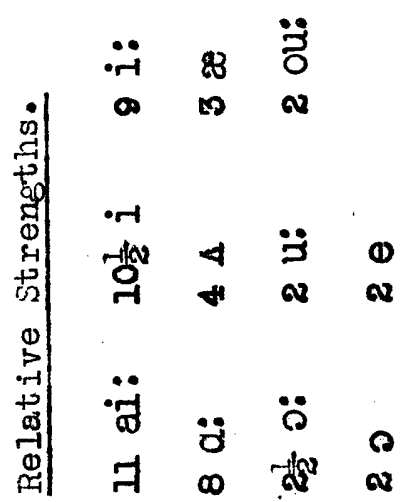

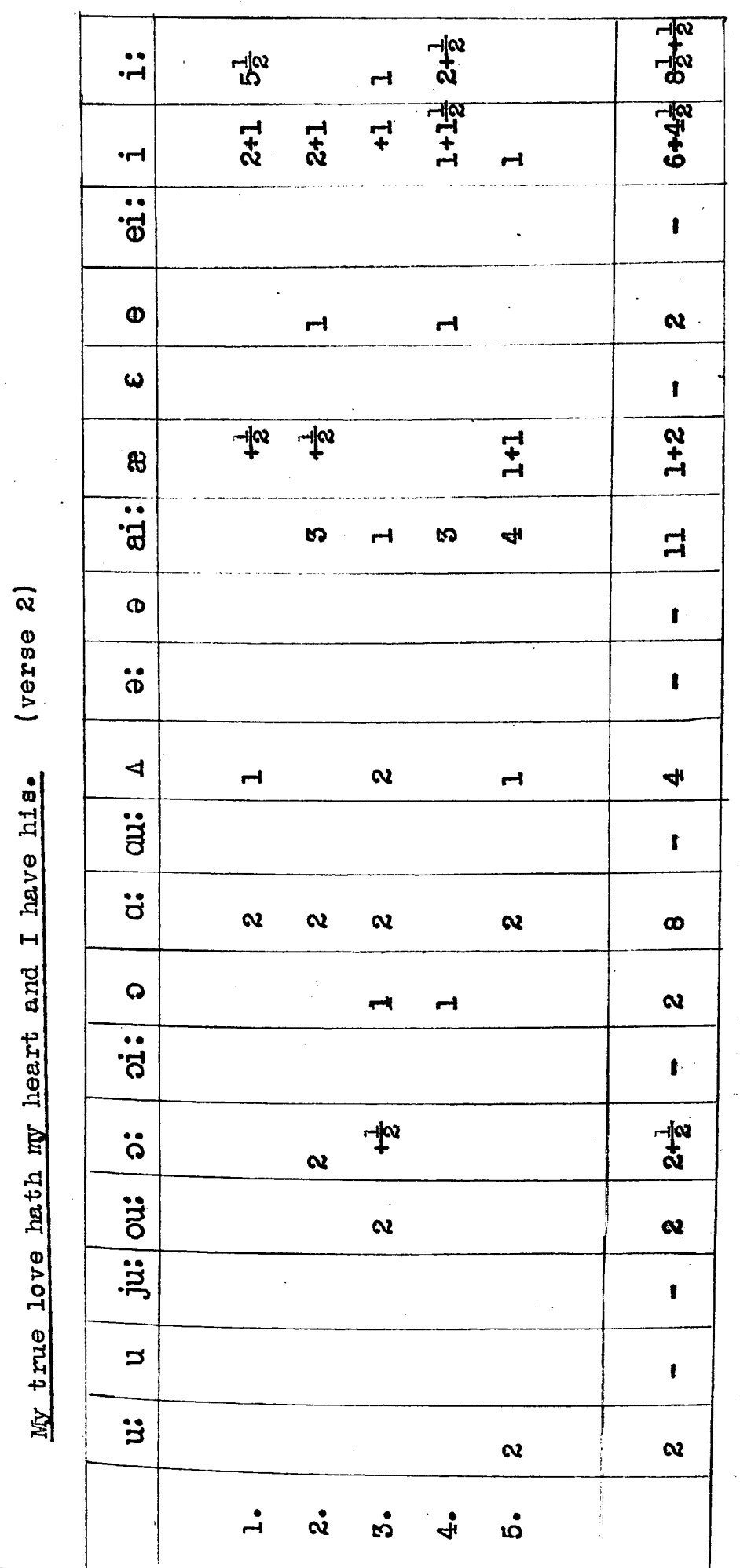




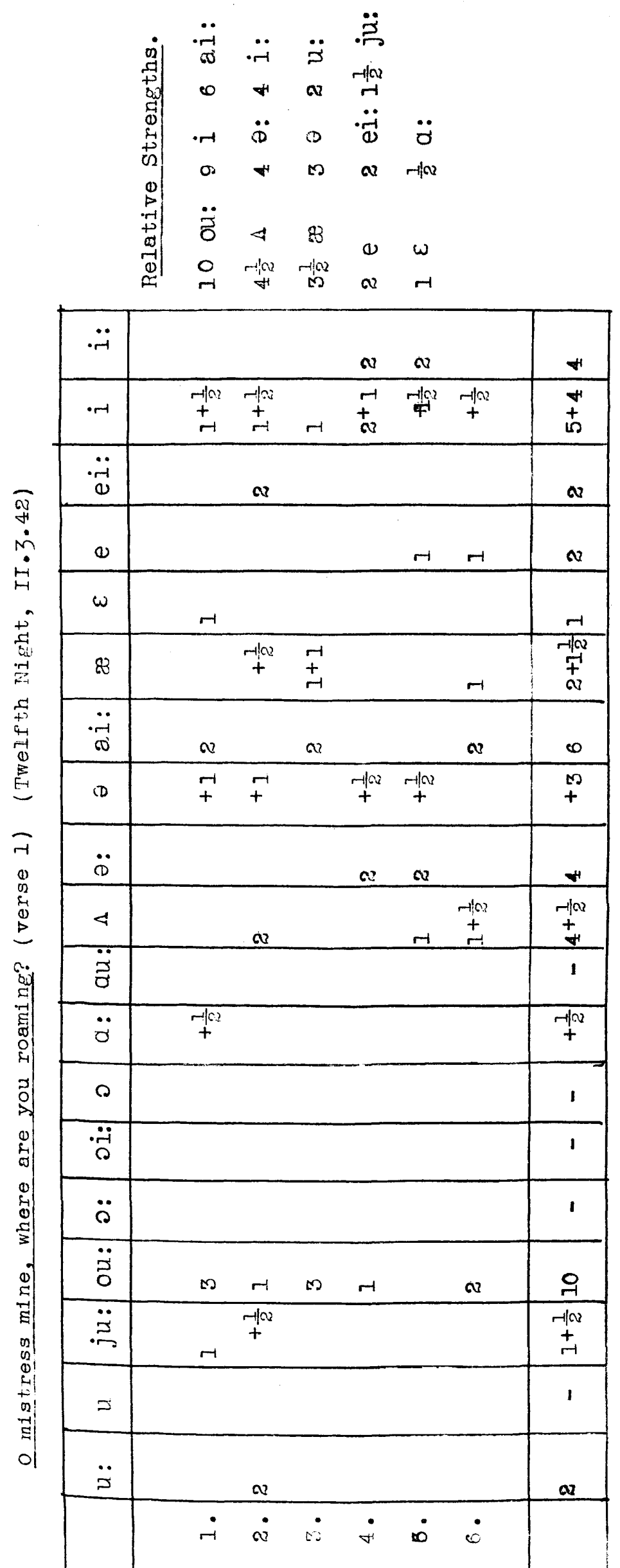




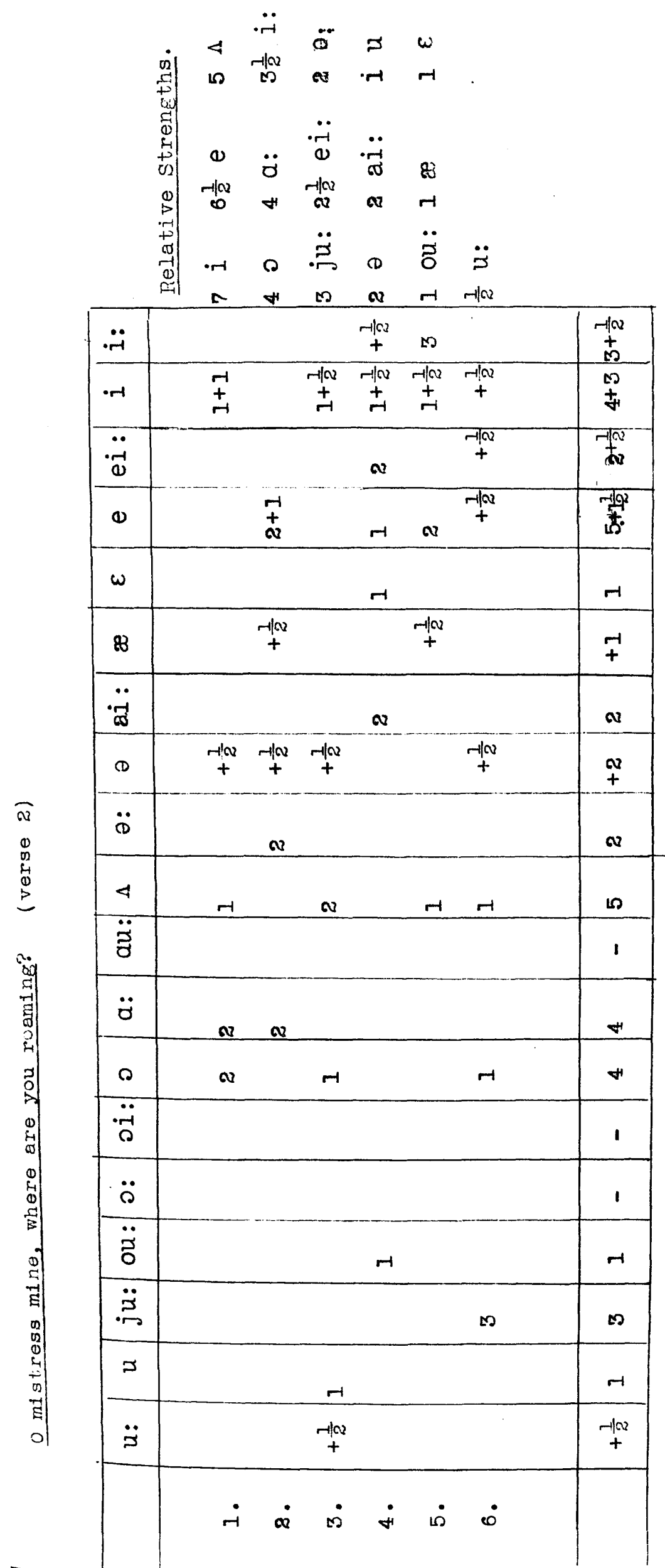




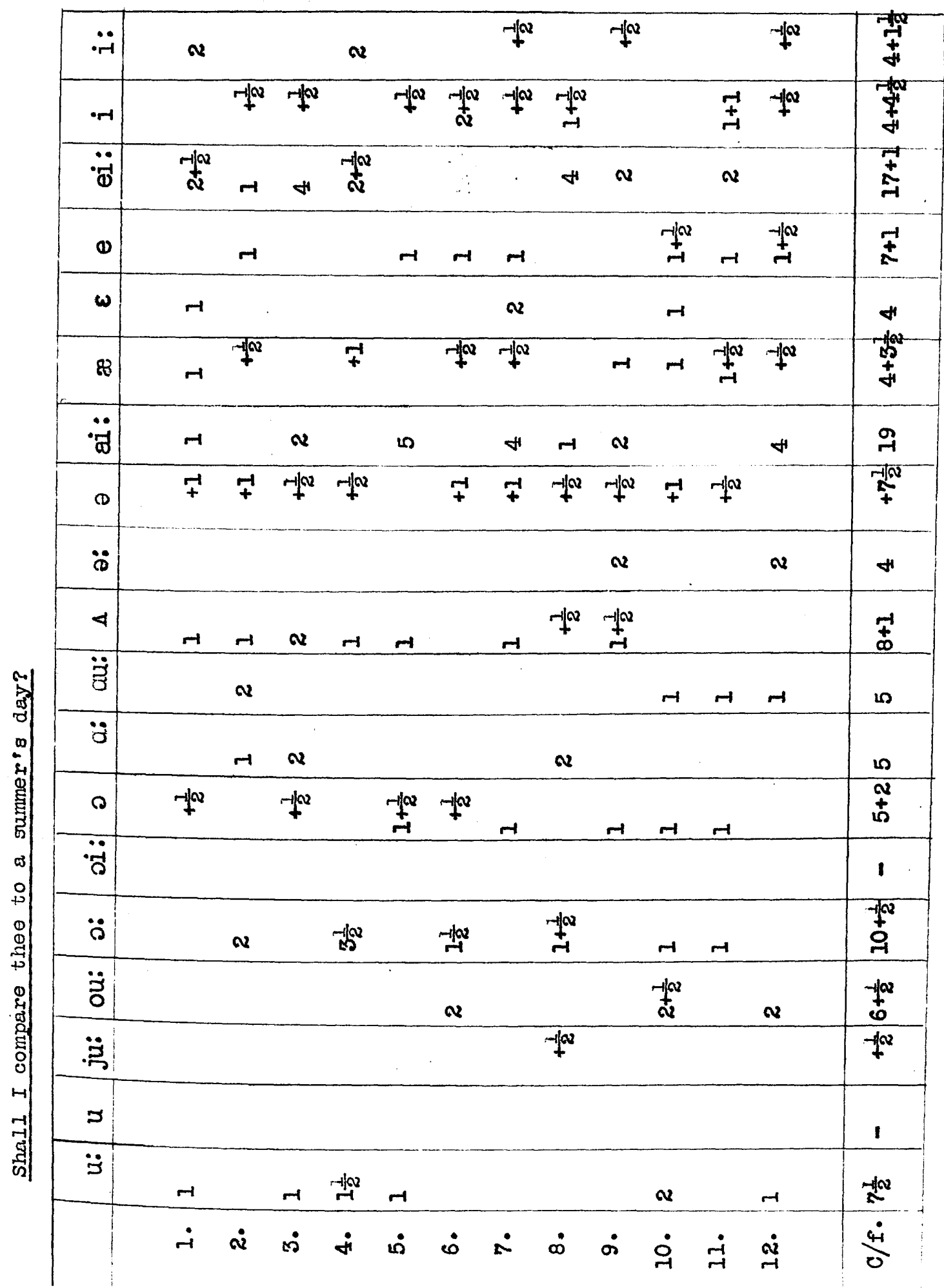




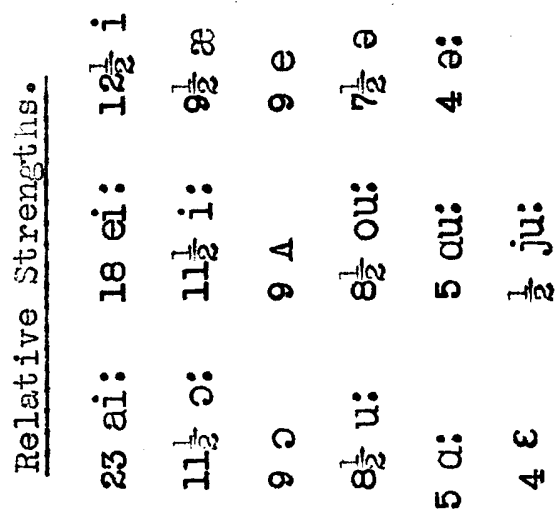

\begin{tabular}{|c|c|c|c|c|}
\hline$\ddot{\ddot{r}}$ & $\stackrel{+}{+}$ & $H$ & Q & ఫ્త \\
\hline$\cdot r-1$ & $\neq$ & & $H$ & $\infty$ \\
\hline$\ddot{\sigma}$ & $\stackrel{+}{ \pm}$ &. & & 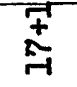 \\
\hline $\boldsymbol{\omega}$ & $\underset{ \pm}{ \pm}$ & $\boldsymbol{H}$ & & $\underset{\infty}{+}$ \\
\hline$\omega$ & 4 & & & 4 \\
\hline $\mathbb{8}$ & $\begin{array}{l}\sqrt[4]{40} \\
+ \\
+\end{array}$ & $\stackrel{4}{4}$ & $-1 / 20$ & 帒 \\
\hline$\ddot{\varpi}$ & 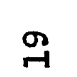 & $v$ & $v$ & $\mathfrak{N}$ \\
\hline (D) & $\underset{+}{-1 / \alpha}$ & & & $\underset{+}{+1 / x}$ \\
\hline$\ddot{8}$ & 4 & & & 4 \\
\hline 4 & $\underset{+}{+}$ & & & $\stackrel{+}{+}$ \\
\hline$\ddot{z}$ & 10 & & & 10 \\
\hline$\ddot{0}$ & ما & & & L \\
\hline ه & 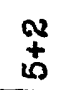 & $r$ & $\rightarrow$ & $\underset{\mathbb{*}}{\mathbb{\sim}}$ \\
\hline$\ddot{\ddot{\gamma}}$ & 1 & & & 1 \\
\hline$\ddot{\beta}$ & 常 & $\vec{r}$ & & $\underset{f-1}{\stackrel{f}{\mid}}$ \\
\hline$\ddot{~}$ & $\stackrel{+1}{6}$ & $r$ & $r$ & $\underset{\infty}{+1 \infty}$ \\
\hline$\ddot{\dot{m}}$ & $-10 x$ & & & -10 \\
\hline 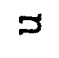 & 1 & & & 1 \\
\hline$\ddot{g}$ & $+\frac{100}{2}$ & & $r$ & 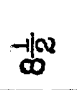 \\
\hline & $\frac{4}{49}$ & $\stackrel{\dot{\sim}}{\sim}$ & $\underset{\sim}{\stackrel{\leftrightarrow}{\rightarrow}}$ & \\
\hline
\end{tabular}




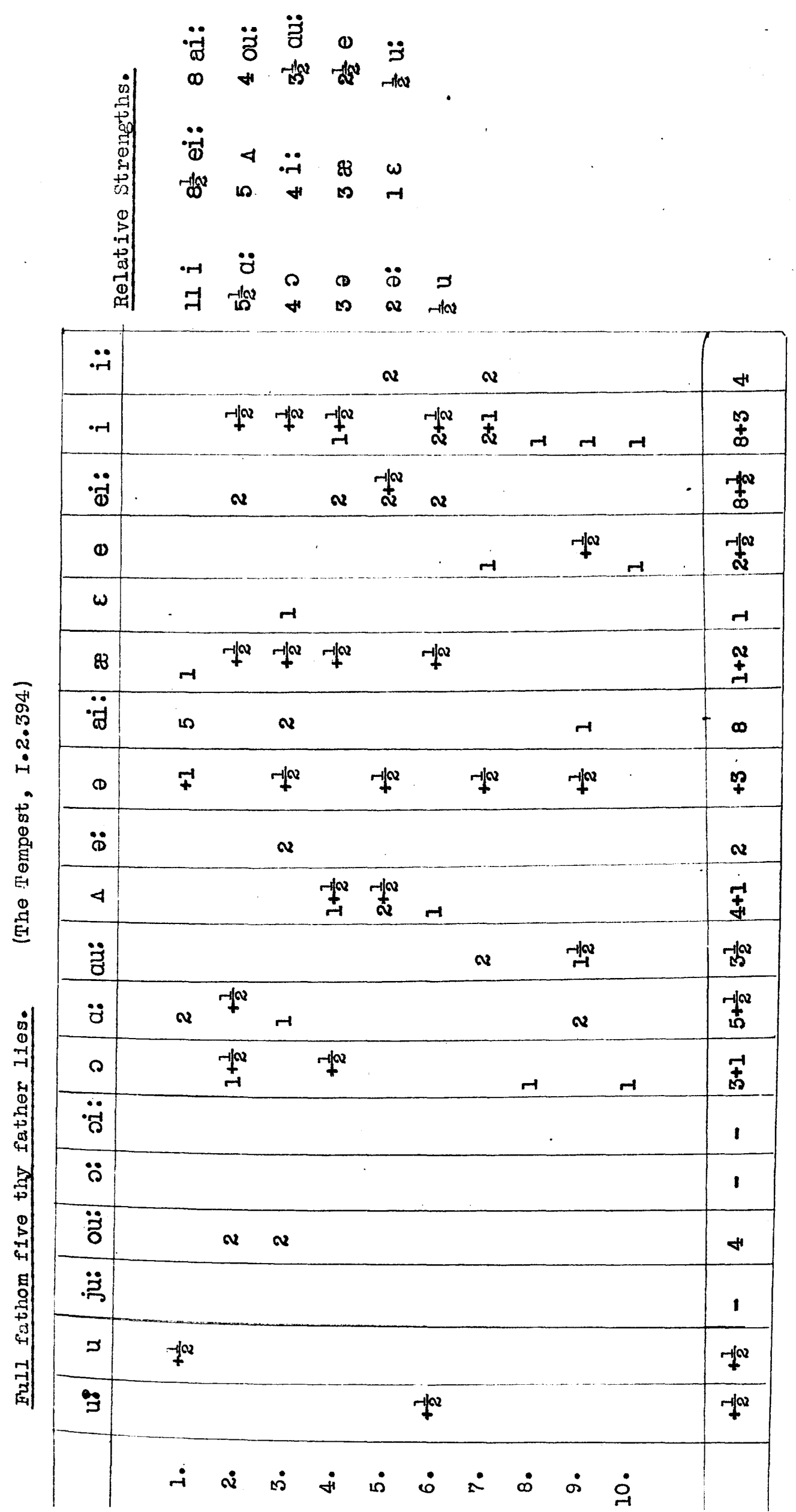




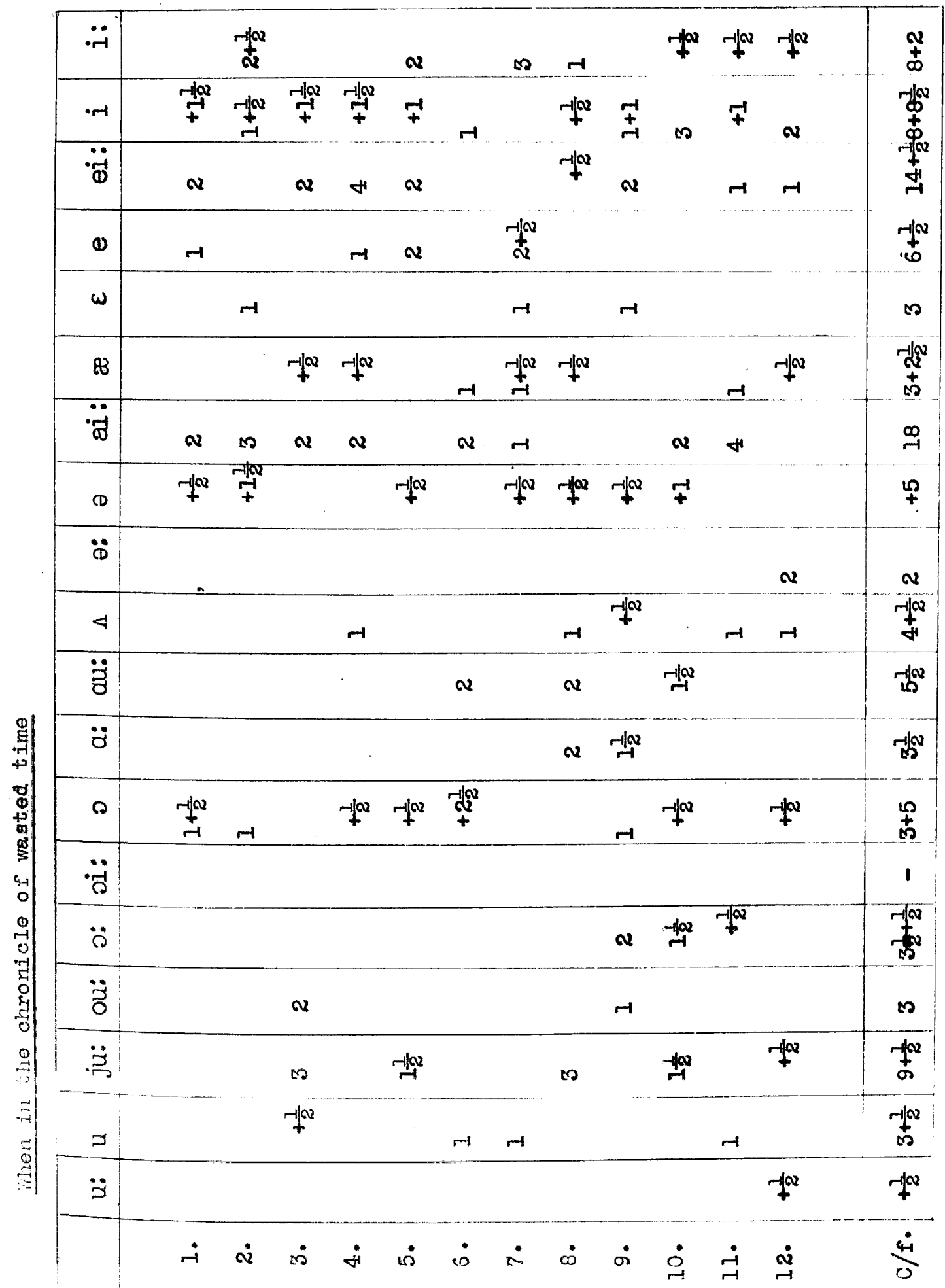




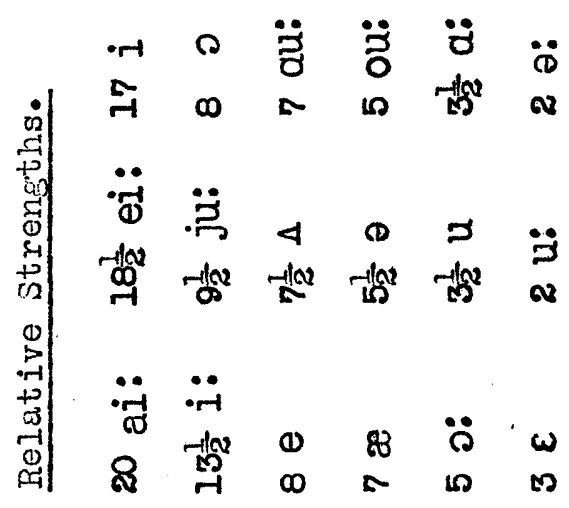

\begin{tabular}{|c|c|c|c|}
\hline$\ddot{-r}$ & $\begin{array}{l}w \\
+ \\
\infty\end{array}$ & rin & 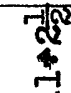 \\
\hline$\cdot-1$ & $\begin{array}{l}\text { ना/ } \\
0 \\
+ \\
\infty\end{array}$ & -10 & $\begin{array}{l}\infty \\
+ \\
\infty\end{array}$ \\
\hline$\ddot{\ddot{1}}$ & $\underset{7}{-10}$ & $N \quad v$ & $\underset{-1}{+\infty}$ \\
\hline $\boldsymbol{\omega}$ & $\underset{6}{-1 \alpha}$ & $\underset{-1}{-1}$ & $\underset{ \pm}{ \pm}$ \\
\hline $\boldsymbol{\omega}$ & $\infty$ & & $\infty$ \\
\hline 88 & $\begin{array}{l}\text { rad } \\
+ \\
\text { m. }\end{array}$ & $\underset{-1}{+\infty}$ & $\stackrel{m}{+}$ \\
\hline$\ddot{\text { के }}$ & $\underset{-1}{\infty}$ & $\boldsymbol{v}$ & 8 \\
\hline (1) & $\stackrel{0}{t}$ & , 7 & rid \\
\hline$\ddot{\theta}$ & $\sim$ & : & $v$ \\
\hline 4 & $\stackrel{4}{+\infty}$ & $M$ & $\stackrel{-1 x}{2}$ \\
\hline 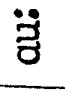 & rex & 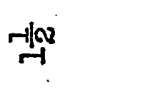 & 2 \\
\hline$\ddot{d}$ & - dot & . & 然 \\
\hline 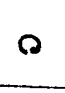 & $\stackrel{10}{10}$ & & $\stackrel{0}{+}$ \\
\hline$\ddot{~}$ & 1 & & 1 \\
\hline$\ddot{\mathrm{r}}$ & $\begin{array}{l}-\sqrt{a} \\
-x^{\infty}\end{array}$ & -1 & $-\sqrt{a x}$ \\
\hline$\ddot{3}$ & $\infty$ & $\boldsymbol{v}$ & 10 \\
\hline$\ddot{\ddot{\partial}}$ & $\stackrel{-1}{+\infty}$ & & $\stackrel{-100}{5}$ \\
\hline 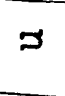 & $\underset{m}{-10}$ & & $\frac{-10}{\infty}$ \\
\hline$\ddot{\beth}$ & -100 & $\stackrel{+}{n}$ & $\ddot{+}$ \\
\hline & $\frac{\dot{4}}{m 9}$ & 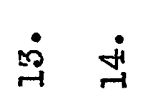 & \\
\hline
\end{tabular}




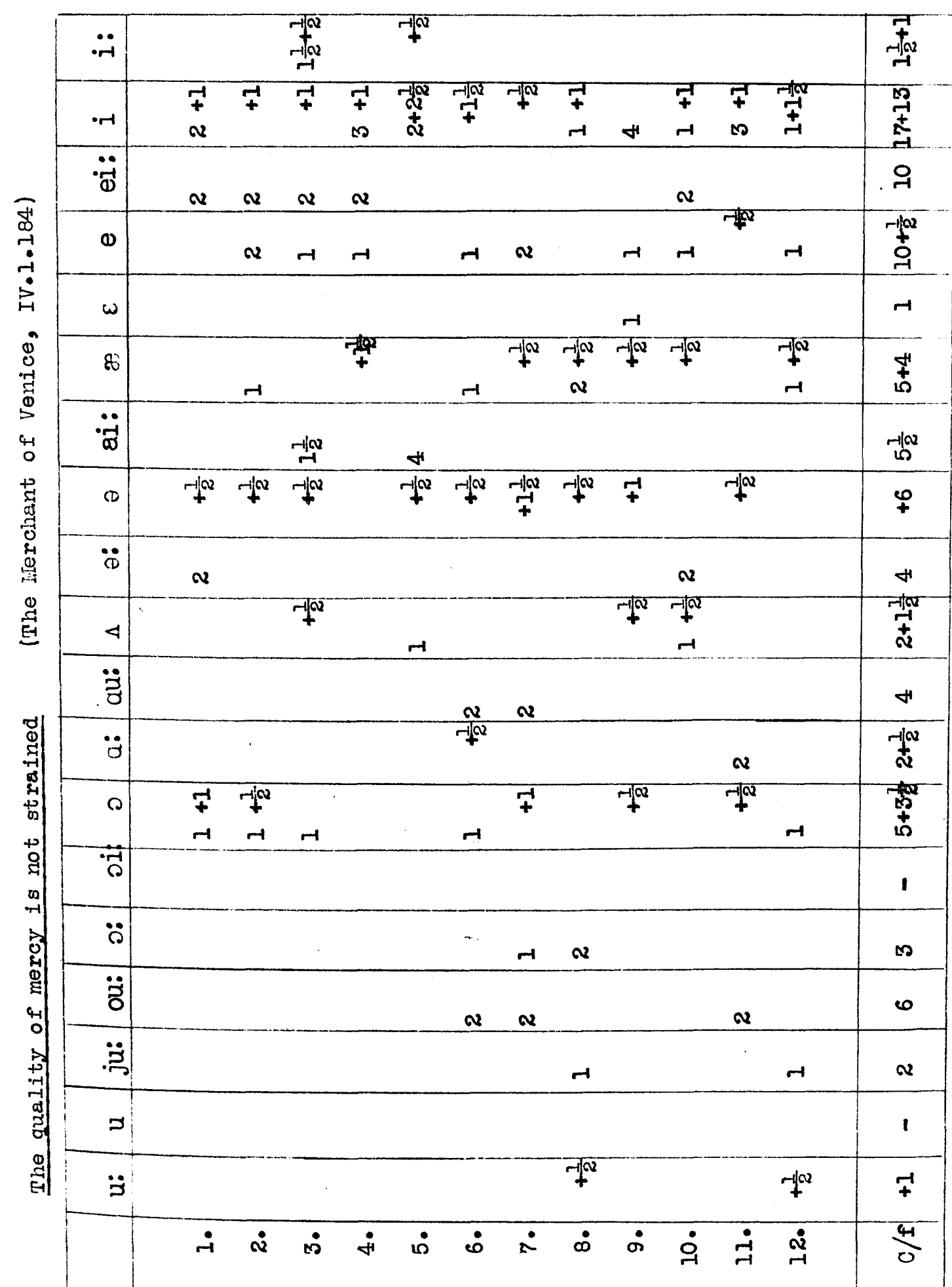




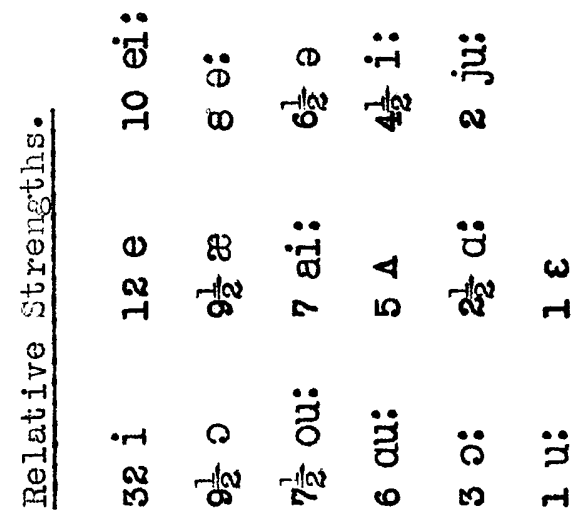

\begin{tabular}{|c|c|c|c|}
\hline$\ddot{-r}$ & $\underset{-1}{r+a}$ & 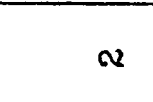 & $\vec{H}^{+1}$ \\
\hline$\cdot r-1$ & 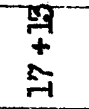 & $7+$ & $\frac{19}{7}$ \\
\hline$\ddot{a d}$ & 욱 & & 우 \\
\hline (1) & $\stackrel{-10}{+0}$ & 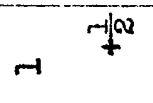 & $\underset{+}{+}$ \\
\hline$\omega$ & -1 & & $H$ \\
\hline 88 & $\begin{array}{l}+ \\
+ \\
5\end{array}$ & F⿻ & $\underset{10}{702}$ \\
\hline$\ddot{\ddot{\sigma}}$ & $\mathrm{H}^{\infty}$ & $\stackrel{-1 / 2}{\rightarrow-1}$ & 2 \\
\hline$\infty$ & $\%$ & $7+2$ & $\begin{array}{c}-10 \\
6\end{array}$ \\
\hline$\ddot{0}$ & 4 & $\sim \quad \sim$ & $\infty$ \\
\hline 4 & 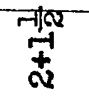 & 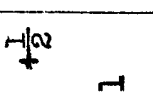 & $\stackrel{v}{+}$ \\
\hline$\ddot{z}$ & + & $v$ & $\infty$ \\
\hline$\ddot{g}$ & $\frac{+\infty}{N}$ & & $\frac{-1 / N}{N}$ \\
\hline م & $\begin{array}{l}\text { reg } \\
50 \\
10 \\
10\end{array}$ & -1 & $\begin{array}{l}\text { नुज } \\
+ \\
\vdots \\
0\end{array}$ \\
\hline$\ddot{\theta}$ & 1 & & 1 \\
\hline$\ddot{\rho}$ & $\infty$ & & $\infty$ \\
\hline$\ddot{0}$ & $\infty$ & $\underset{\rightarrow}{-1 \alpha}$ & 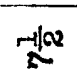 \\
\hline 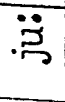 & $\boldsymbol{\Omega}$ & & $v$ \\
\hline 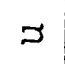 & 1 & & 1 \\
\hline$\ddot{z}$ & + & & + \\
\hline & $\stackrel{4}{m}$ & $\stackrel{\dot{m}}{\sim}$ & 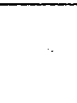 \\
\hline
\end{tabular}




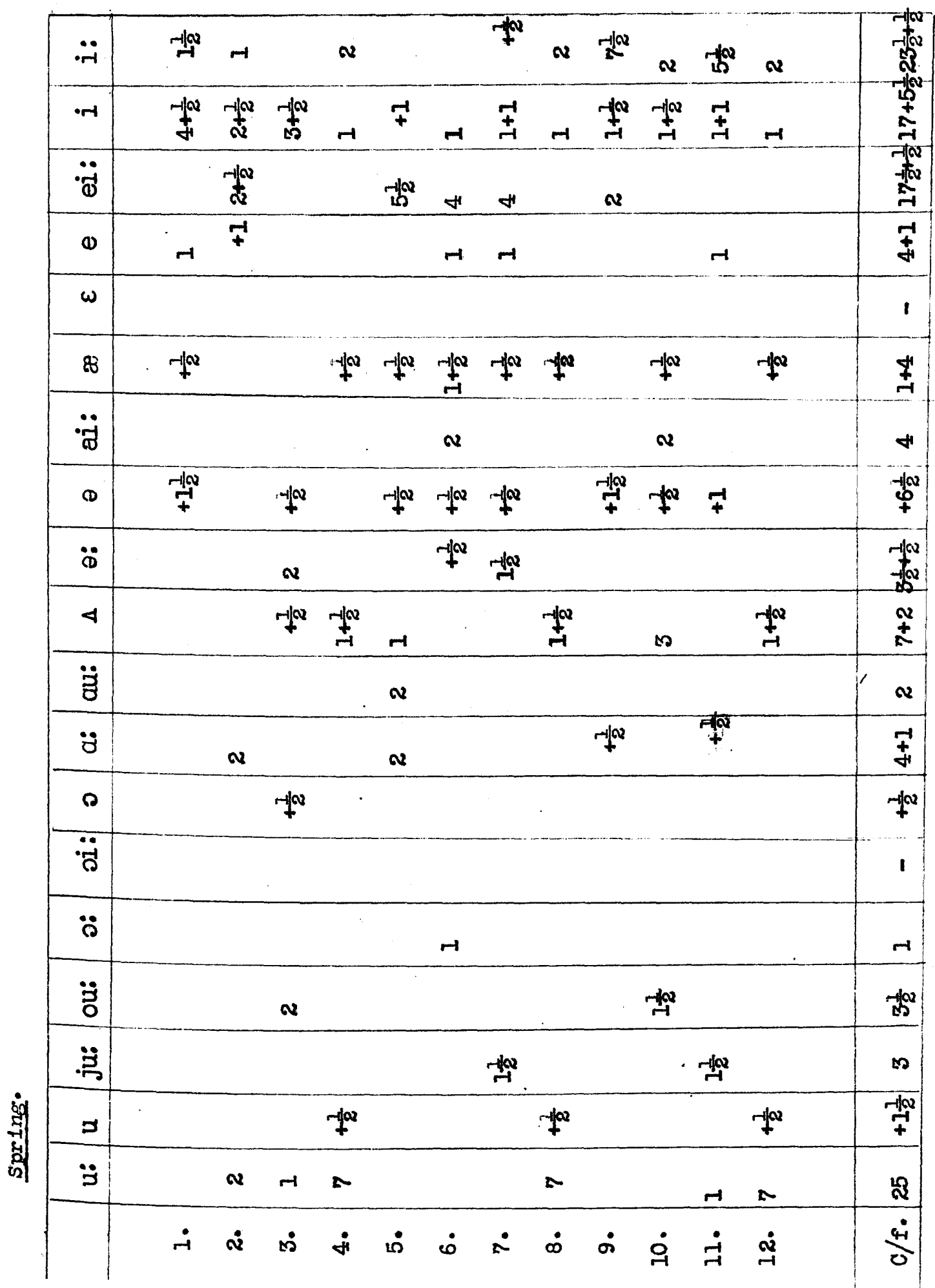




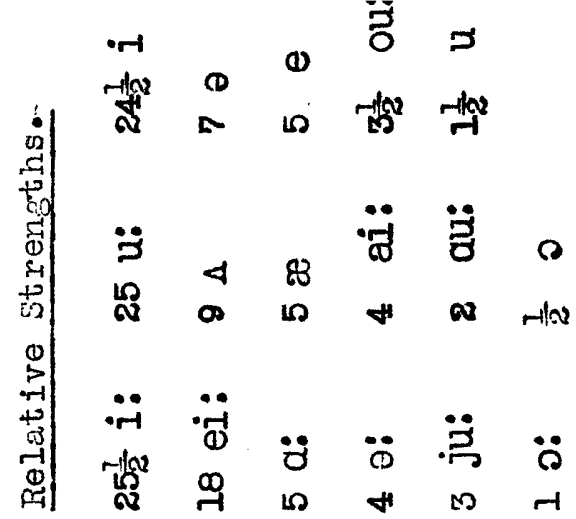

\begin{tabular}{|c|c|c|}
\hline$\ddot{-r}$ & 黛 & 紊 \\
\hline$\cdot r-1$ & Q & な \\
\hline$\ddot{0}$ & rita & - \\
\hline (1) & $\stackrel{+1}{+}$ & $\underset{+}{+}$ \\
\hline$\omega$ & 1 & 1 \\
\hline 83 & $\stackrel{+}{+}$ & $\underset{+}{+}$ \\
\hline$\ddot{0}$ & 4 & +1 \\
\hline () & $\int_{+}^{+\infty}$ & 5 \\
\hline$\ddot{B}$ & $\operatorname{rog}^{2}$ & न- \\
\hline 4 & $\stackrel{N}{ \pm}$ & $\stackrel{a}{+}$ \\
\hline$\ddot{z}$ & $\boldsymbol{v}$ & $\sim$ \\
\hline$\ddot{\partial}$ & $\begin{array}{l}-1 \\
+ \\
+\end{array}$ & 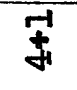 \\
\hline ऽ & 70 & 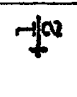 \\
\hline$\ddot{\vec{\rho}}$ & 1 & 1 \\
\hline$\ddot{\rho}$ & $r$ & 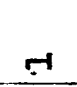 \\
\hline$\ddot{3}$ & - -100 & $d c^{2}$ \\
\hline :ٌ & $\infty$ & $M$ \\
\hline$z$ & $\stackrel{+10}{+}$ & F⿻ \\
\hline$\ddot{\jmath}$ & $\stackrel{12}{3}$ & $\mathfrak{2}$ \\
\hline & $\stackrel{4}{m} \underset{\sim}{\ddot{r}}$ & \\
\hline
\end{tabular}




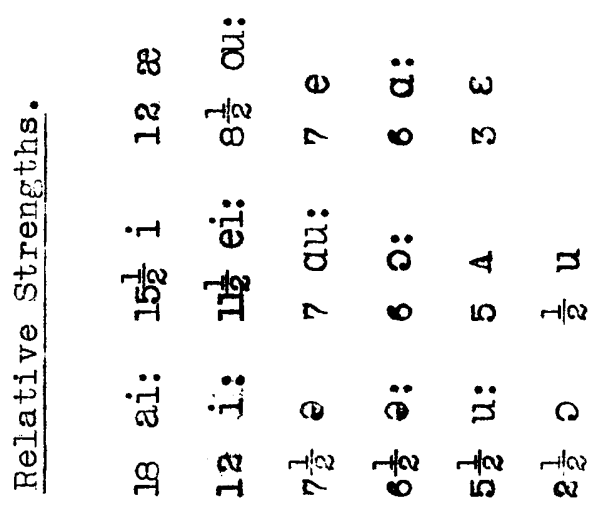

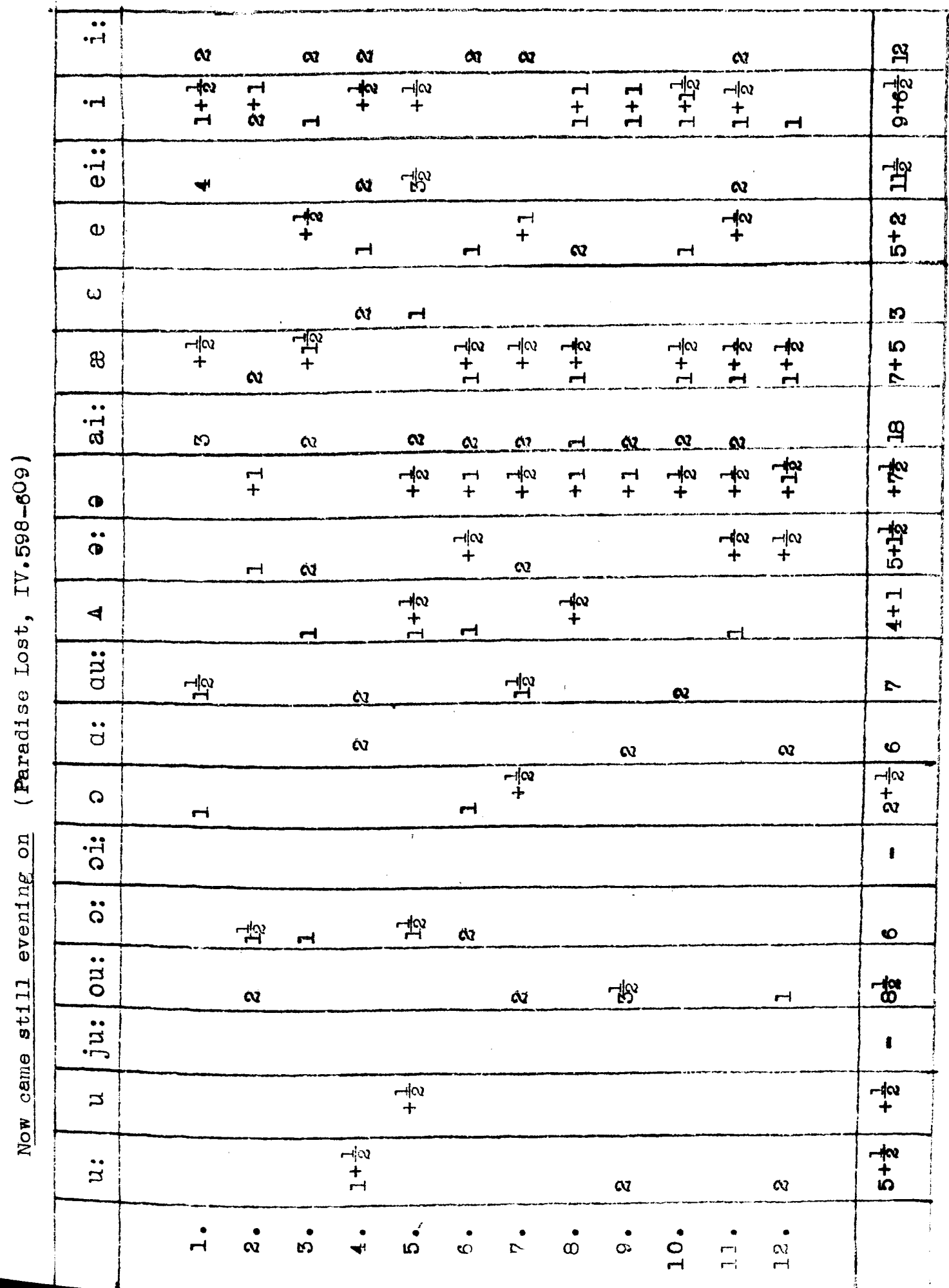



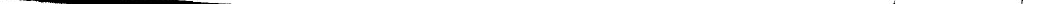


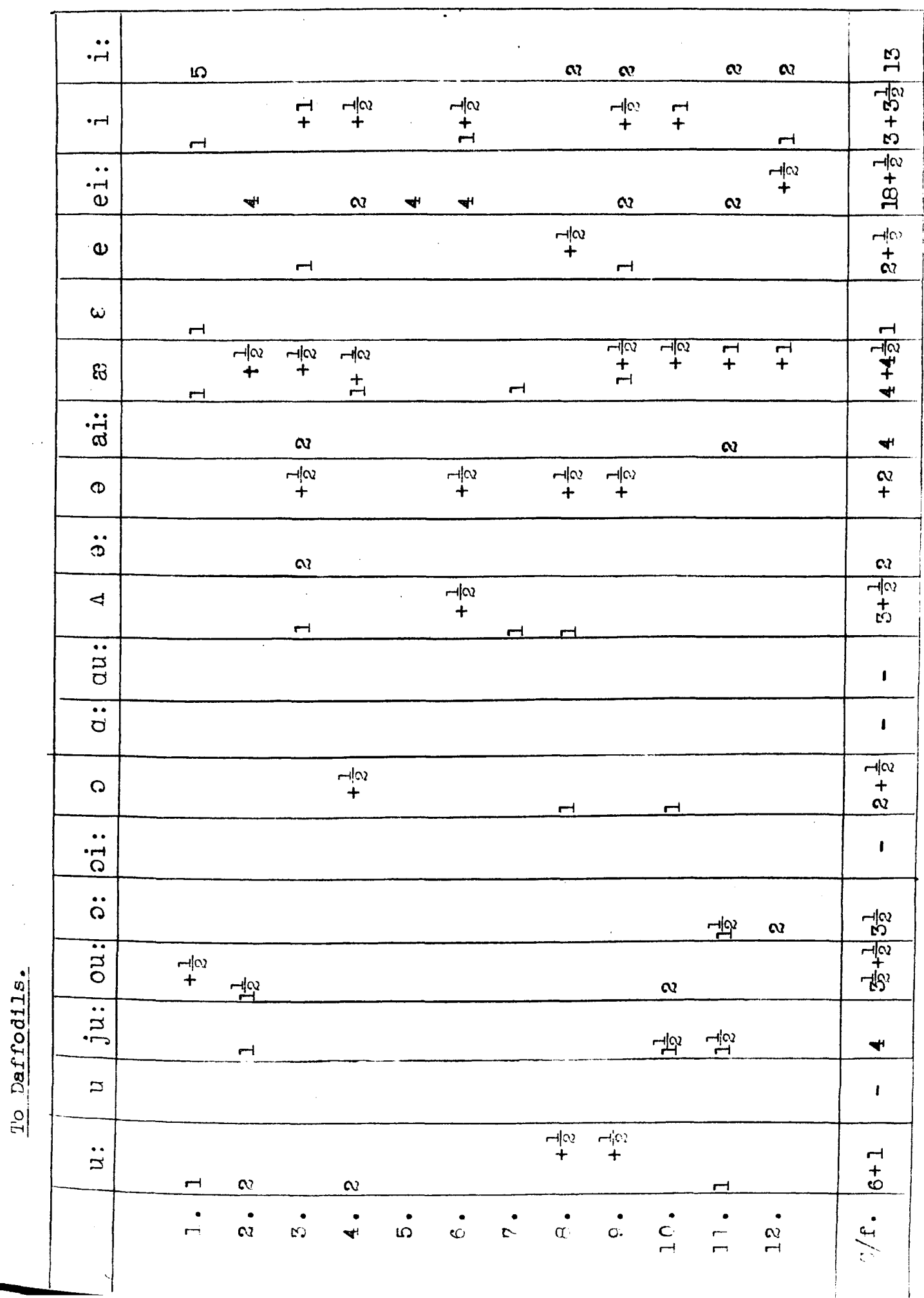




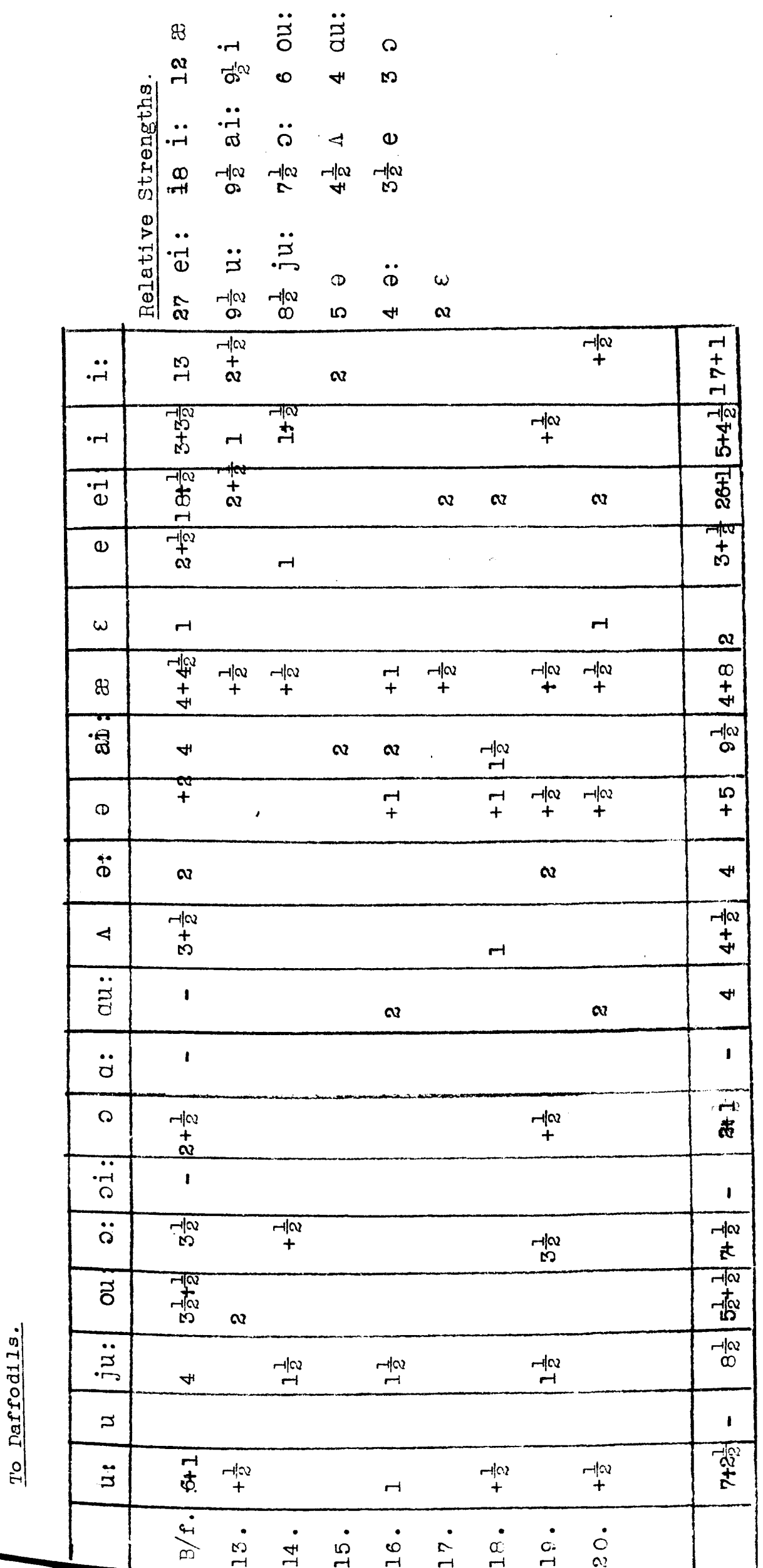




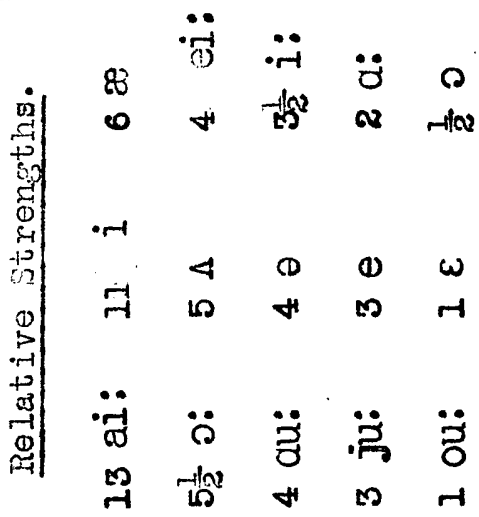

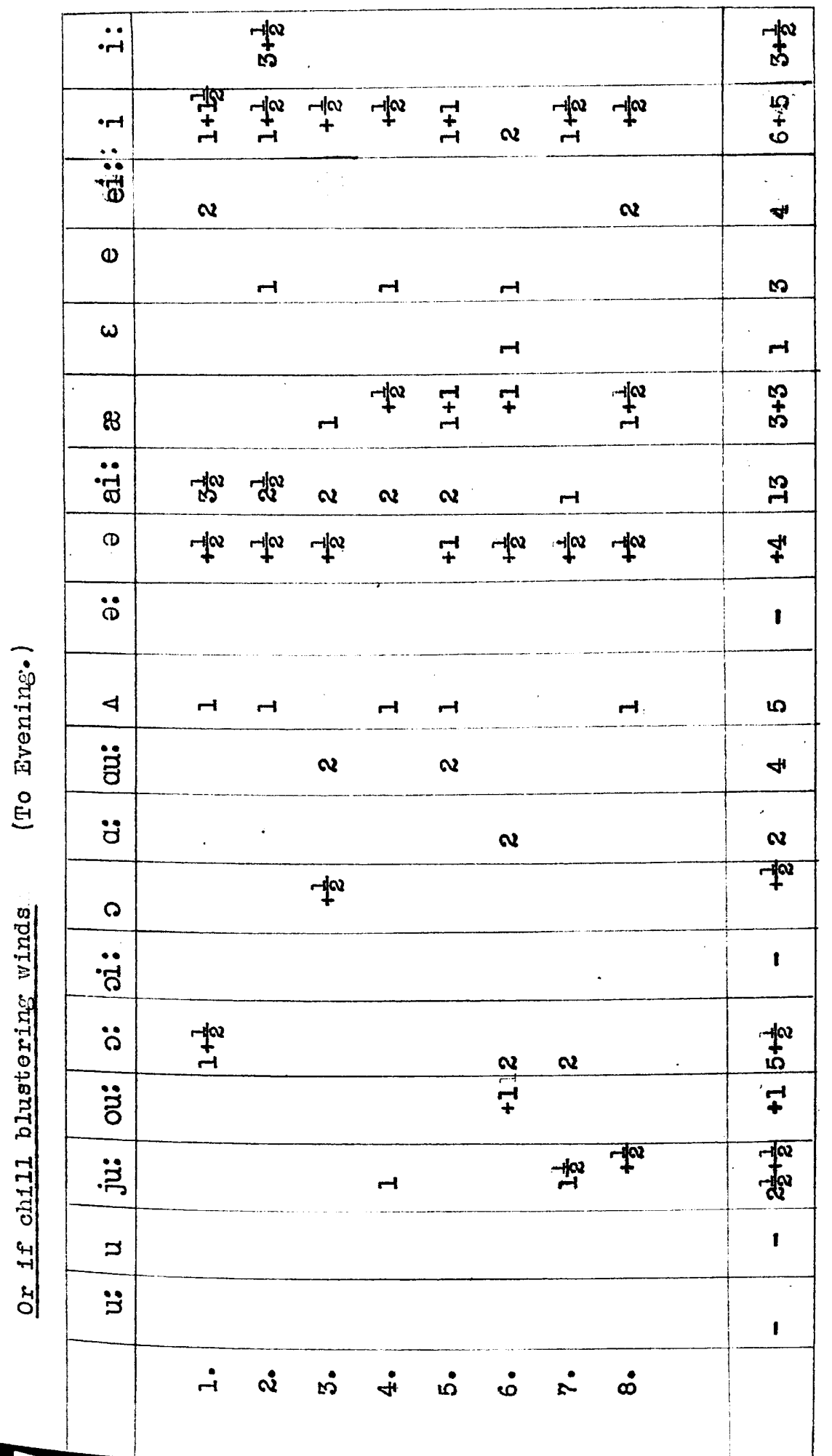




\begin{tabular}{|c|c|c|c|c|c|c|c|c|}
\hline$\ddot{-i}$ & & & & & & $-1 / 2$ & +1 & $\overrightarrow{+}$ \\
\hline$\cdot-1$ & & & & & & $\approx 7$ & $-1+a$ & 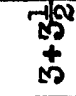 \\
\hline$\ddot{\oplus}$ & & & & & & 㗒禹 & $\alpha$ & $\underset{0}{-1 / \infty}$ \\
\hline$\ddot{\bullet}$ & & & $H$ & $r$ & & & & $\underset{m}{-j a x}$ \\
\hline$\omega$ & & & & & & & & $\approx$ \\
\hline$\otimes$ & & & & & H & $\rightarrow \quad \begin{array}{r}-1 / 2 \\
-1\end{array}$ & $\underset{-1}{+\infty}$ & 击和 \\
\hline$\ddot{\ddot{\sigma}}$ & $\rightarrow$ & & & & $\begin{array}{ll}-1 & -1\end{array}$ & & & $\circ$ \\
\hline D & $-1+\infty$ & & & & $r+10$ & $\stackrel{9}{+}$ & -10 & -7 \\
\hline$\ddot{\phi}$ & & & & & & & & $\propto$ \\
\hline 4 & & & & -1 & & & & 7 \\
\hline$\ddot{z}$ & & & N & N & & & & $\infty$ \\
\hline$\ddot{\theta}$ & & & & $\sqrt{6}$ & & & & $-110^{2}$ \\
\hline 0 & $\frac{-10 w}{a}$ & & $\underset{\rightarrow}{-10}$ & $\rightarrow$ & 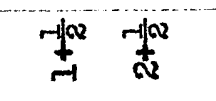 & N & & 龺 \\
\hline$\ddot{\theta}$ & & & & & & & & 1 \\
\hline$\ddot{0}$ & & & & & & & & $\alpha$ \\
\hline$\ddot{\Xi}$ & $\alpha$ & & & v & $\approx \quad \infty$ & & & $\infty$ \\
\hline$\ddot{\ddot{n}}$ & & & +1 & 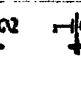 & & & & $\underset{+}{\text { 禁 }}$ \\
\hline 3 & & & & & & & & 1 \\
\hline$\ddot{3}$ & & & & & & & & 1 \\
\hline & & & j & $=$ & $\dot{\infty} \quad \dot{\sigma}$ & $\dot{\AA} \dot{ت}$ & $\dot{\vec{\jmath}}$ & $\frac{\dot{4}}{\partial}$ \\
\hline
\end{tabular}




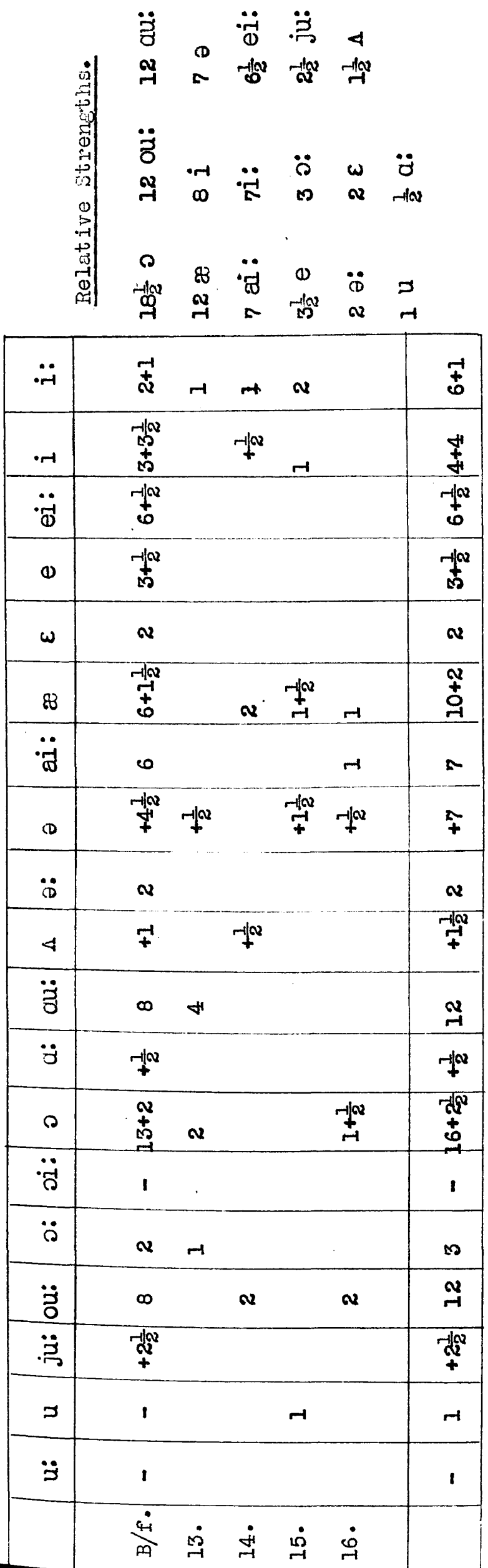




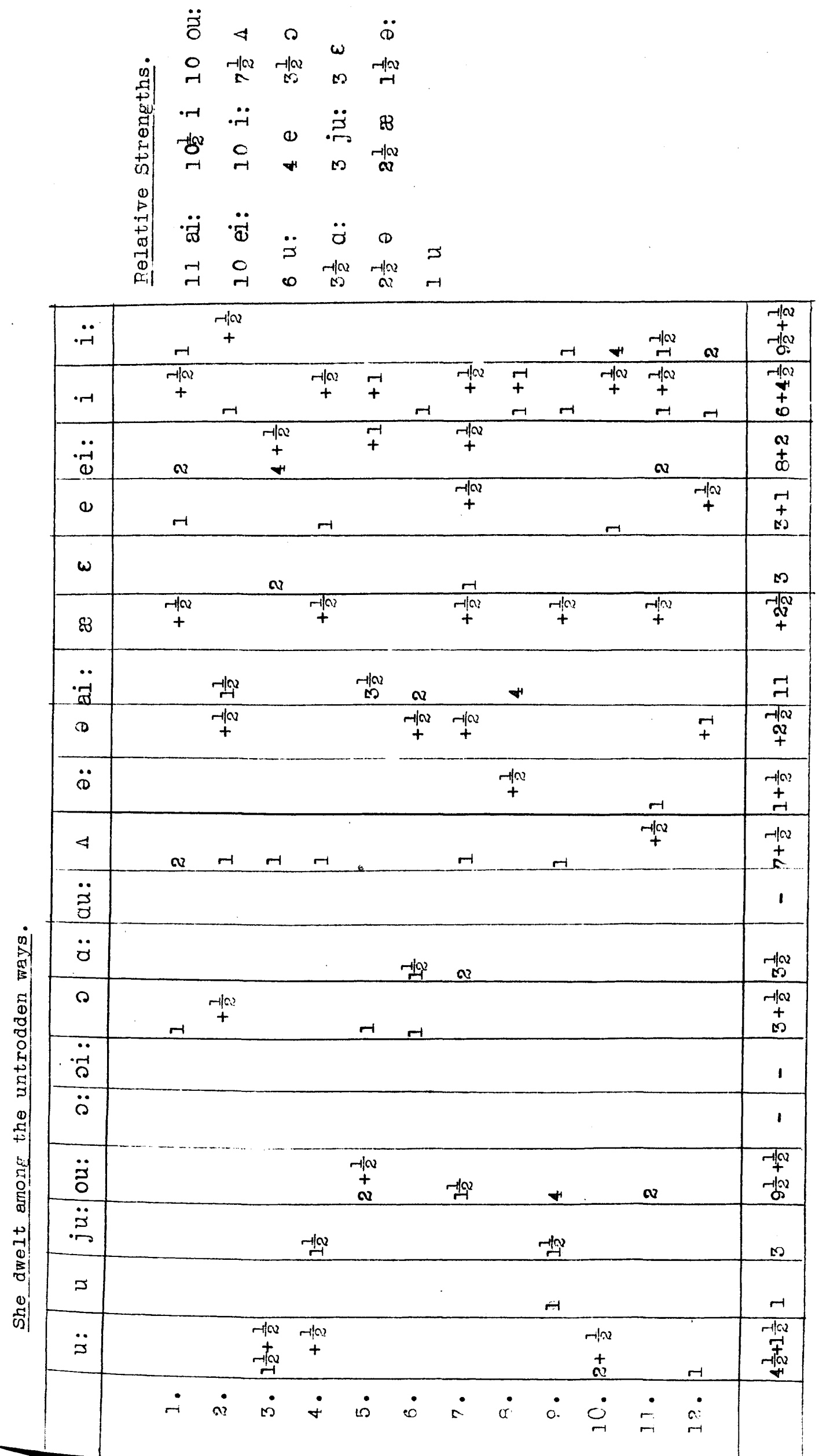




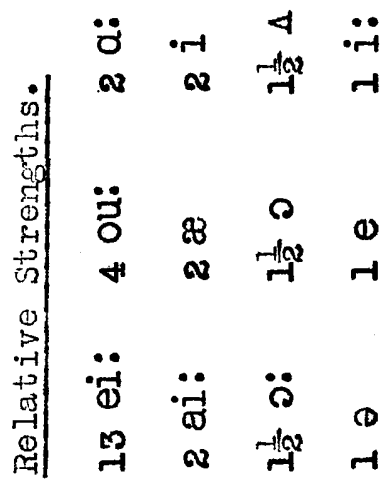

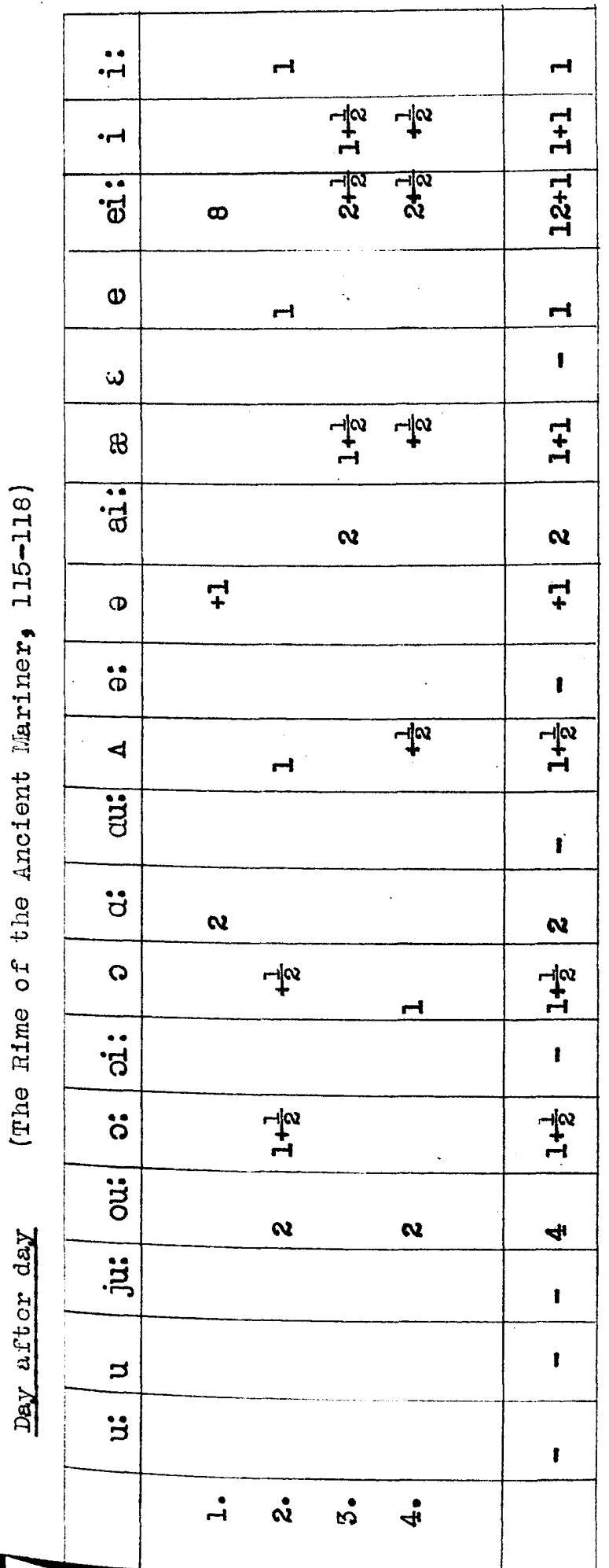




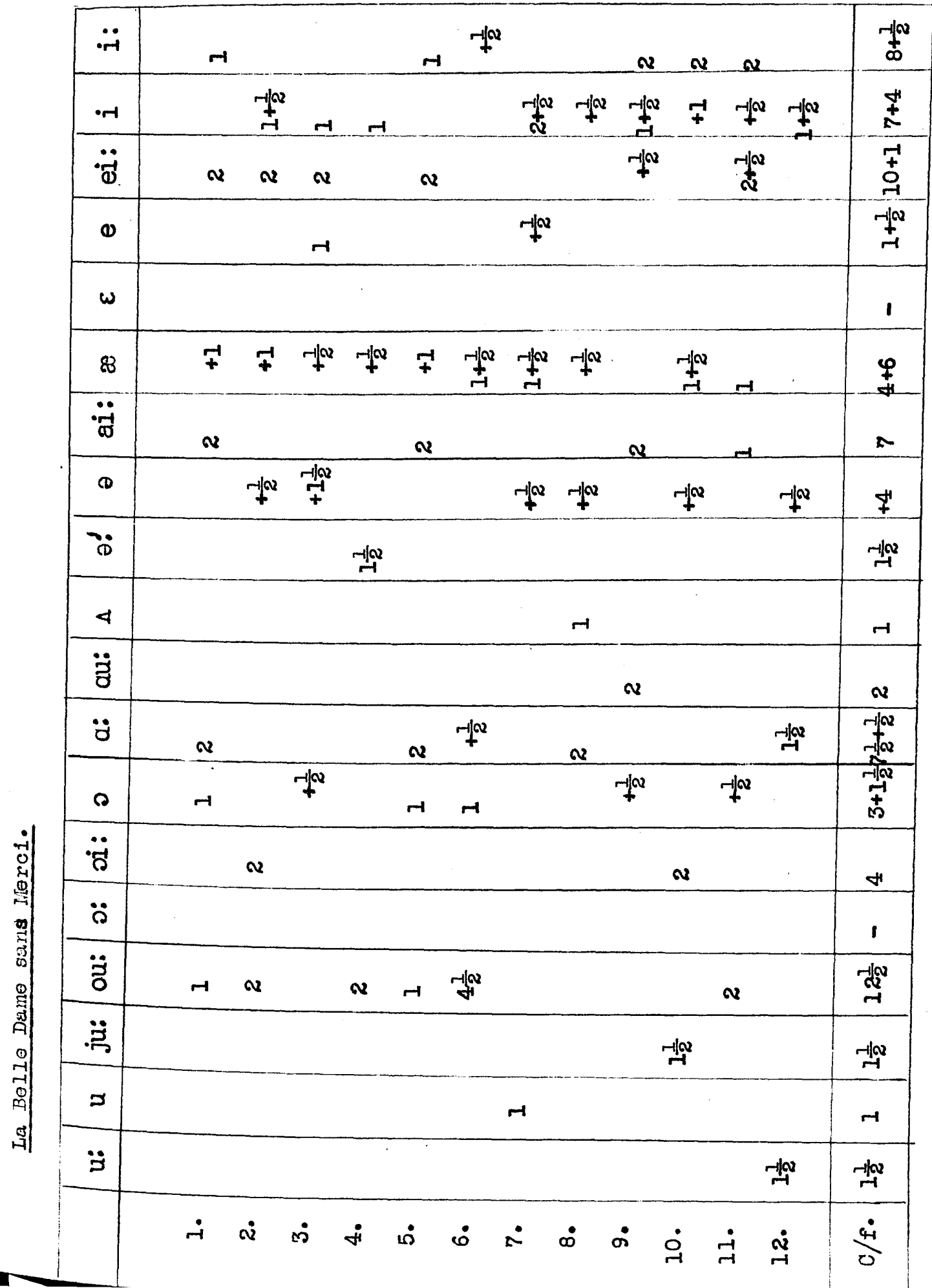




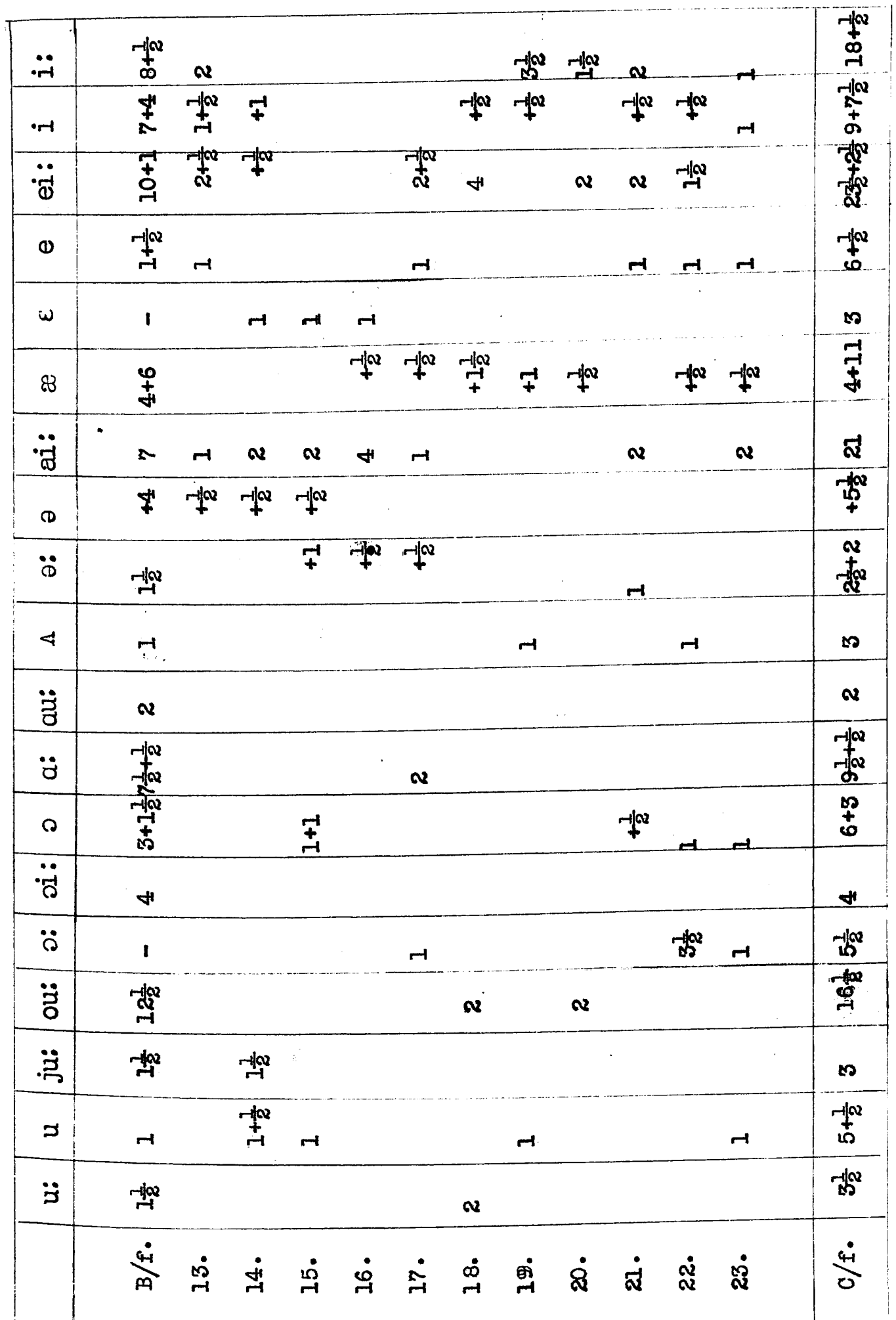




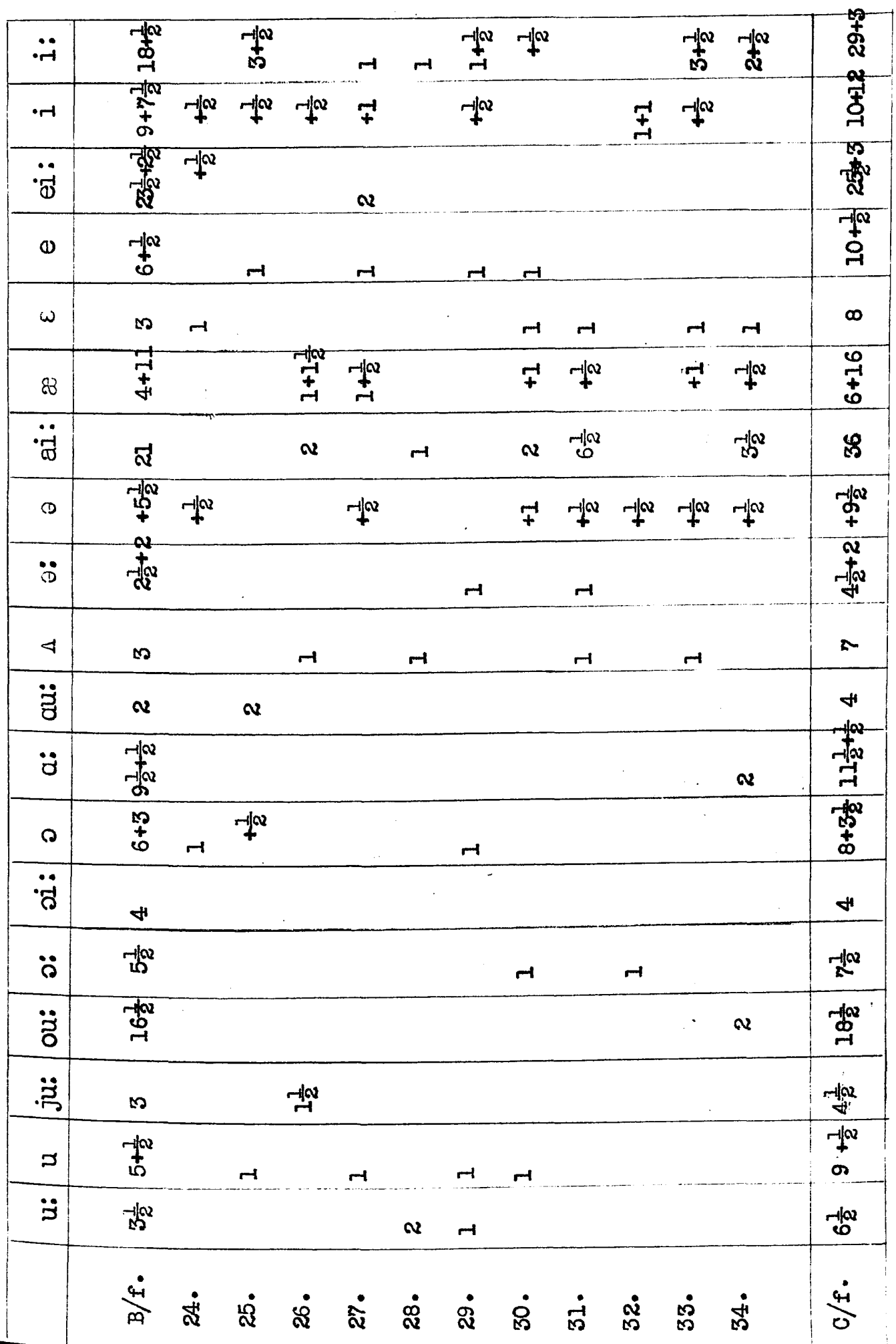




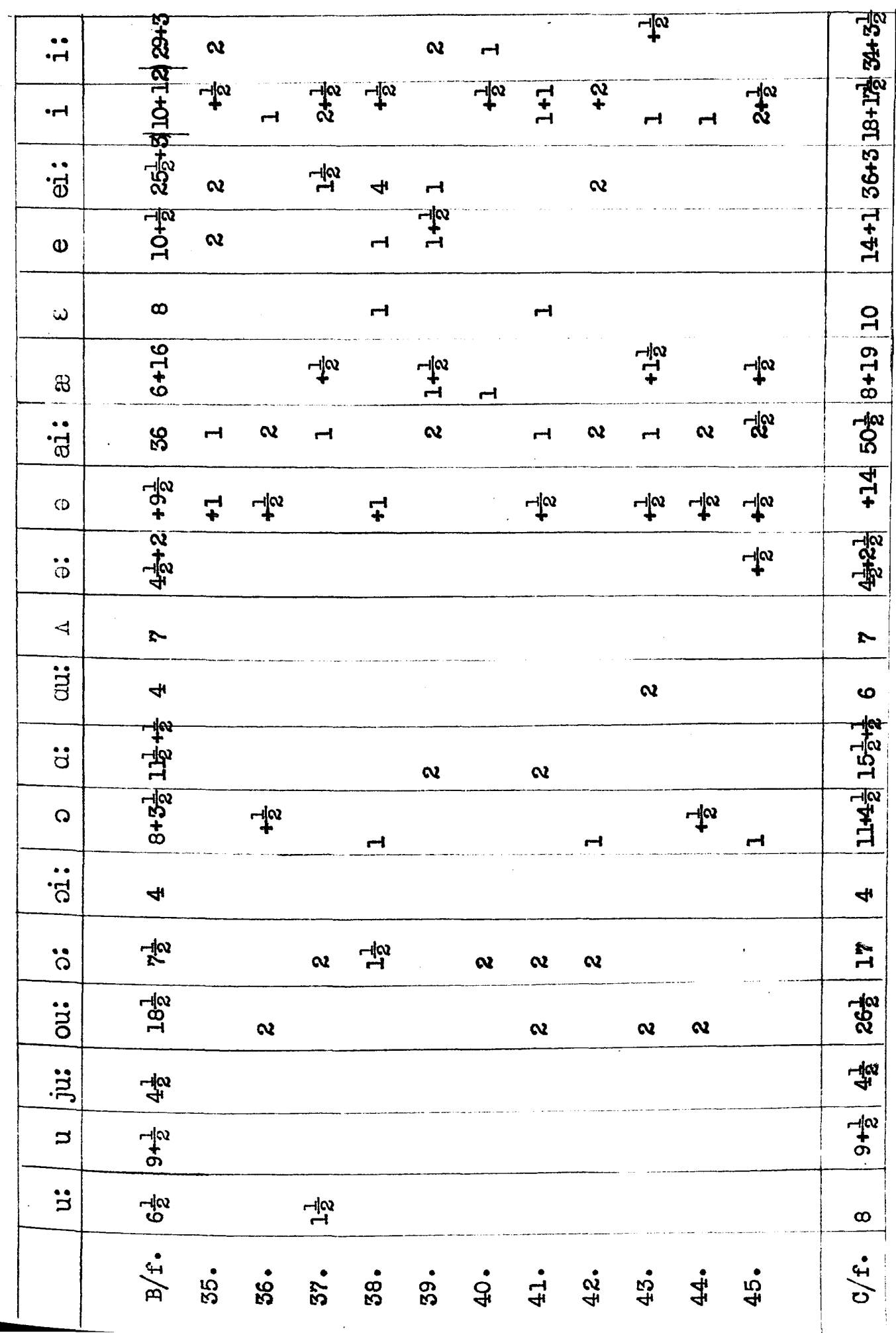




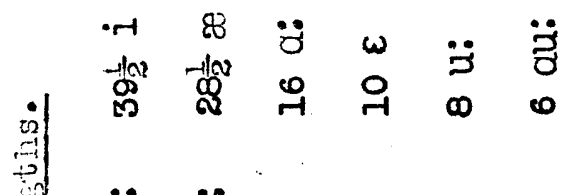

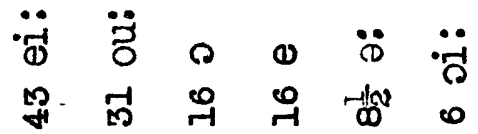

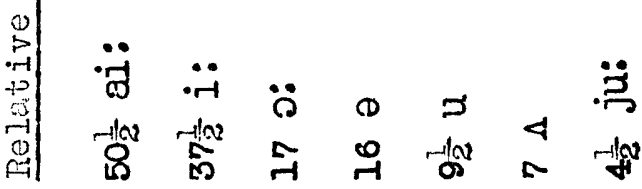

\begin{tabular}{|c|c|c|c|c|c|c|}
\hline$\ddot{~}$ & $\begin{array}{l}\text { नलe } \\
\text { 势 }\end{array}$ & & & & $\begin{array}{l}\text { 贶 } \\
\text { 势 }\end{array}$ & 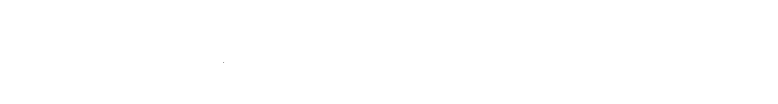 \\
\hline$\cdot r-1$ & 羬 & $\stackrel{+}{\rightarrow}$ & $\underset{-1}{+\infty}$ & $r$ & 趼 & \\
\hline$\ddot{\ddot{0}}$ & 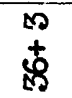 & $\boldsymbol{v}$ & $\boldsymbol{v}$ & & $\begin{array}{l}m \\
\stackrel{9}{q} \\
q\end{array}$ & \\
\hline (1) & $\begin{array}{l}\overrightarrow{+} \\
+ \\
+\end{array}$ & & -1 & & $\begin{array}{l}\overrightarrow{1} \\
+ \\
\text { مै } \\
\text { - }\end{array}$ & \\
\hline$\omega$ & 억 & & & & 욕 & \\
\hline 83 & $\begin{array}{l}\text { O } \\
\underset{+1}{+} \\
\infty\end{array}$ & + & & $F^{\infty}$ & $\begin{array}{l}\text { नाब } \\
\& \\
+ \\
\infty\end{array}$ & \\
\hline$\ddot{0}$ & 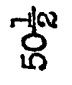 & & & & નîㅇ & \\
\hline CD & $\underset{+}{+}$ & & & & $\begin{array}{l}0 \\
+ \\
+\end{array}$ & $\stackrel{\mathscr{D}}{m}$ \\
\hline
\end{tabular}




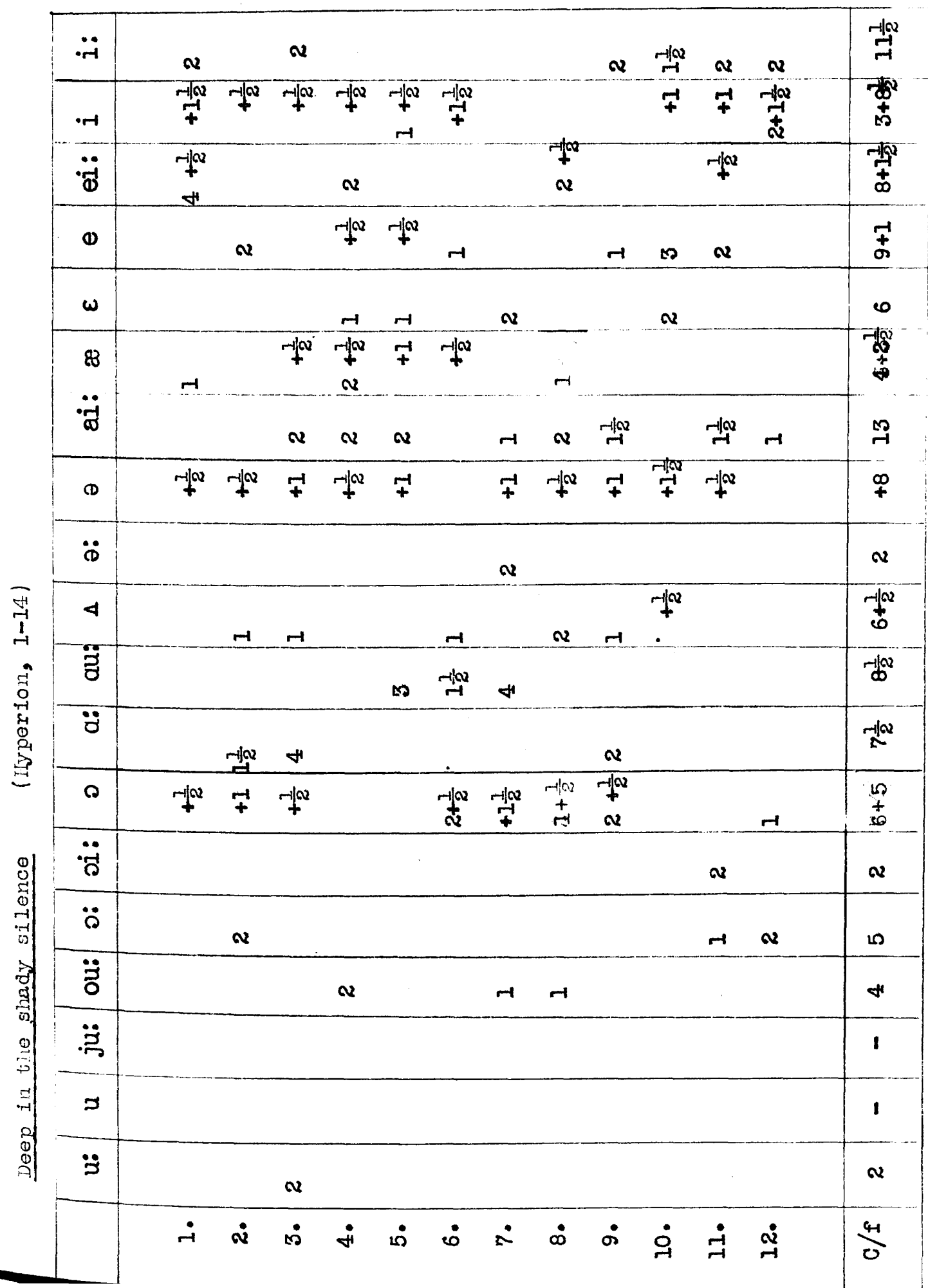




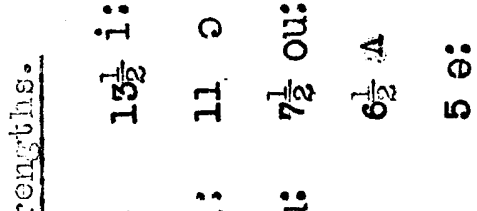

$\cdots \quad \ddot{\ddot{j}} \quad \ddot{z} \quad \mathbb{B} \quad \ddot{\sigma} \quad \ddot{8}$

is

3
+1
+3
6
0
0
9

-

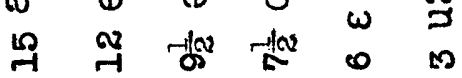

\begin{tabular}{|c|c|c|c|c|}
\hline$\ddot{-r}$ & $\stackrel{r-1 n a}{\stackrel{n}{r}}$ & $\boldsymbol{v}$ & & 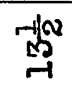 \\
\hline$\cdot \pi$ & $\begin{array}{l}-10 \\
\infty \\
+ \\
\omega\end{array}$ & $\stackrel{+i \alpha}{+\infty}$ & $\alpha$ & 栾 \\
\hline$\ddot{\ddot{D}}$ & $\begin{array}{r}\text { rlw } \\
+ \\
\infty\end{array}$ & $\begin{array}{l}+102 \\
v\end{array}$ & & $\begin{array}{l}0 \\
+ \\
0 \\
0\end{array}$ \\
\hline $\boldsymbol{\Phi}$ & $\begin{array}{l}+1 \\
+\end{array}$ & $r$ & -1 & $\stackrel{+}{\oplus}$ \\
\hline 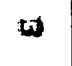 & $\omega$ & & & $\omega$ \\
\hline 88 & $\begin{array}{l}\text { तु } \\
+ \\
+ \\
+\end{array}$ & $-1 / x$ & & $\stackrel{\substack{\oplus \\
+}}{ \pm}$ \\
\hline$\ddot{\ddot{\sigma}}$ & $\underset{H}{M}$ & $v$ & & $\stackrel{10}{n-1}$ \\
\hline (D) & $\Phi$ & $+\infty$ & 7 & $\stackrel{-1 / n}{+}$ \\
\hline$\ddot{\phi}$ & $\checkmark$ & $r$ & $v$ & 10 \\
\hline 4 & $\begin{array}{l}r \mid a \\
0\end{array}$ & - & & $\underset{0}{-1 / N}$ \\
\hline$\ddot{\ddot{z}}$ & -100 & & & $-\gamma_{\infty}^{-10}$ \\
\hline$\ddot{\sigma}$ & $\stackrel{-1 / 2}{\alpha}$ & & & $-\sqrt[1]{2}$ \\
\hline$\Omega$ & + & & & $\stackrel{\varphi}{+}$ \\
\hline$\ddot{\circ}$ & $v$ & & & v \\
\hline$\ddot{8}$ & 10 & & & $\omega$ \\
\hline ஜ̈ & & & -d do & $\mathbb{H}_{2}^{+1}$ \\
\hline 芦 & 1 & & & 1 \\
\hline$\square$ & 1 & & & 1 \\
\hline$\ddot{j}$ & $\boldsymbol{v}$ & & $\rightarrow$ & $\infty$ \\
\hline & $\stackrel{4}{m}^{41}$ & $\ddot{\theta}$ & $\stackrel{\leftrightarrow}{\stackrel{H}{H}}$ & \\
\hline
\end{tabular}




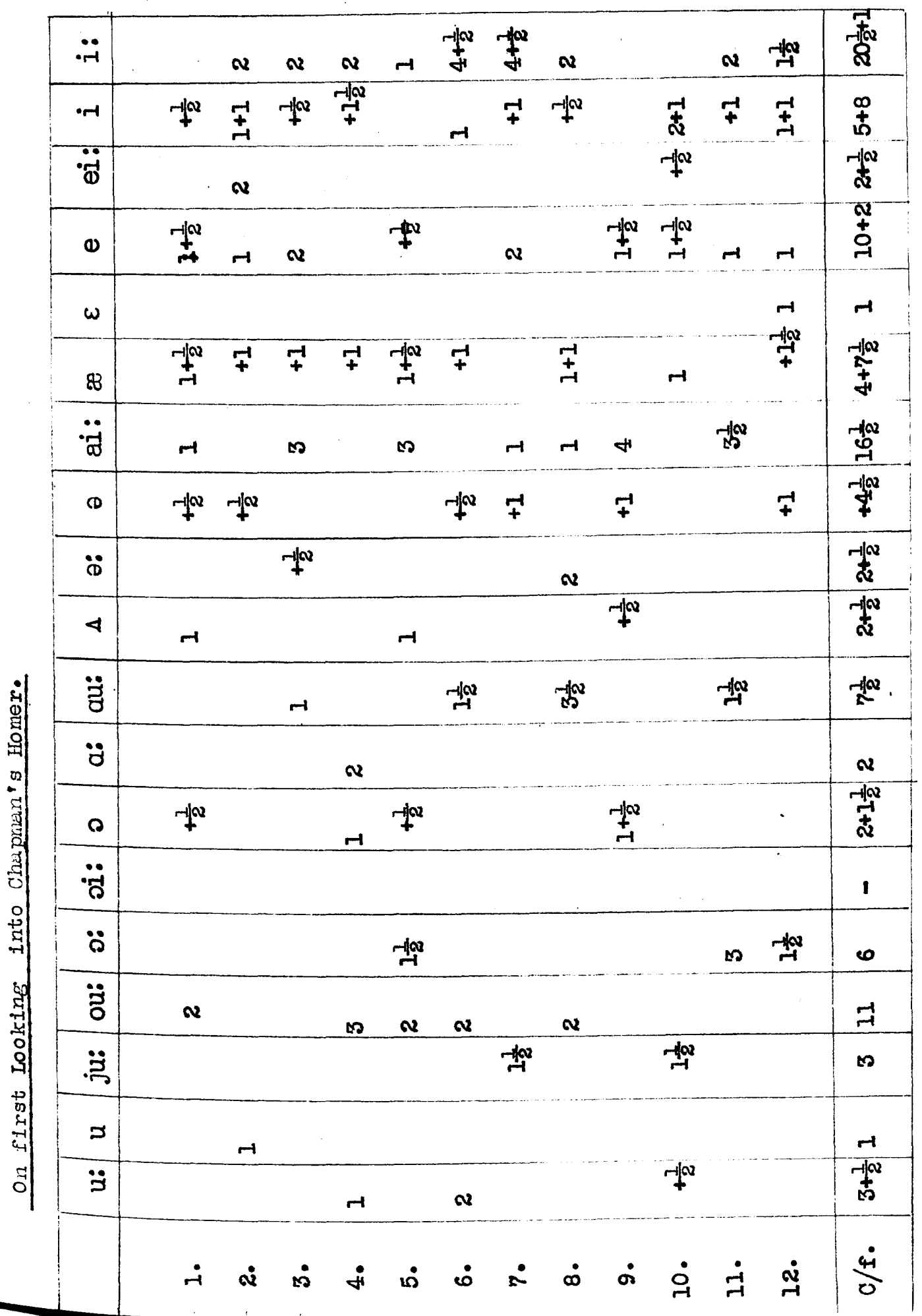




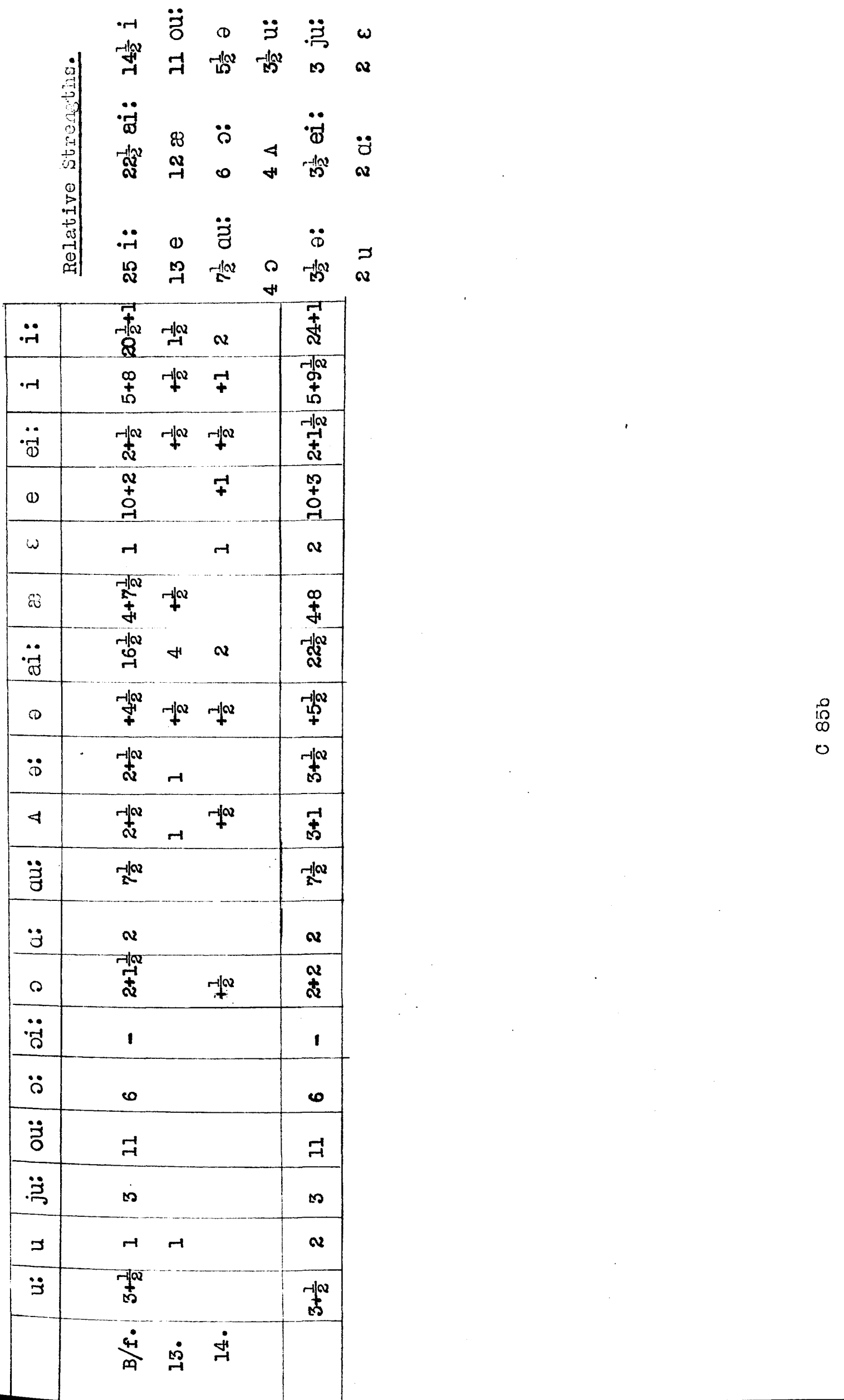




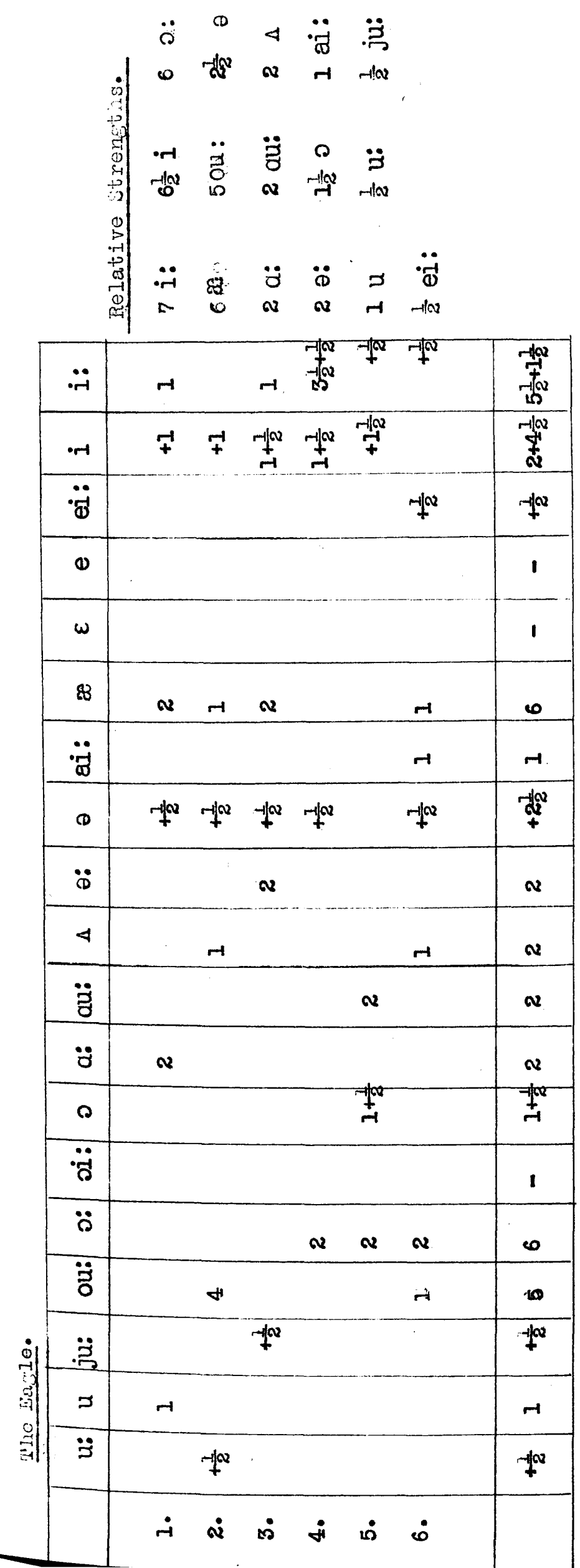




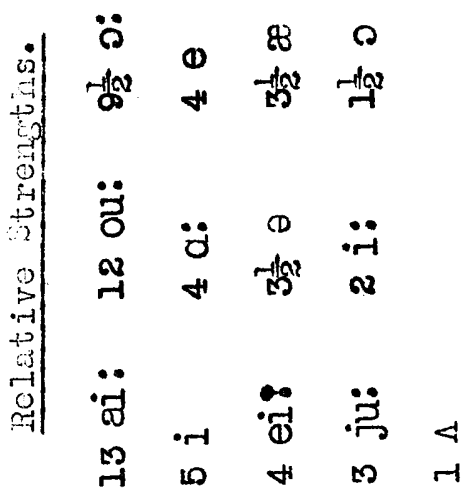

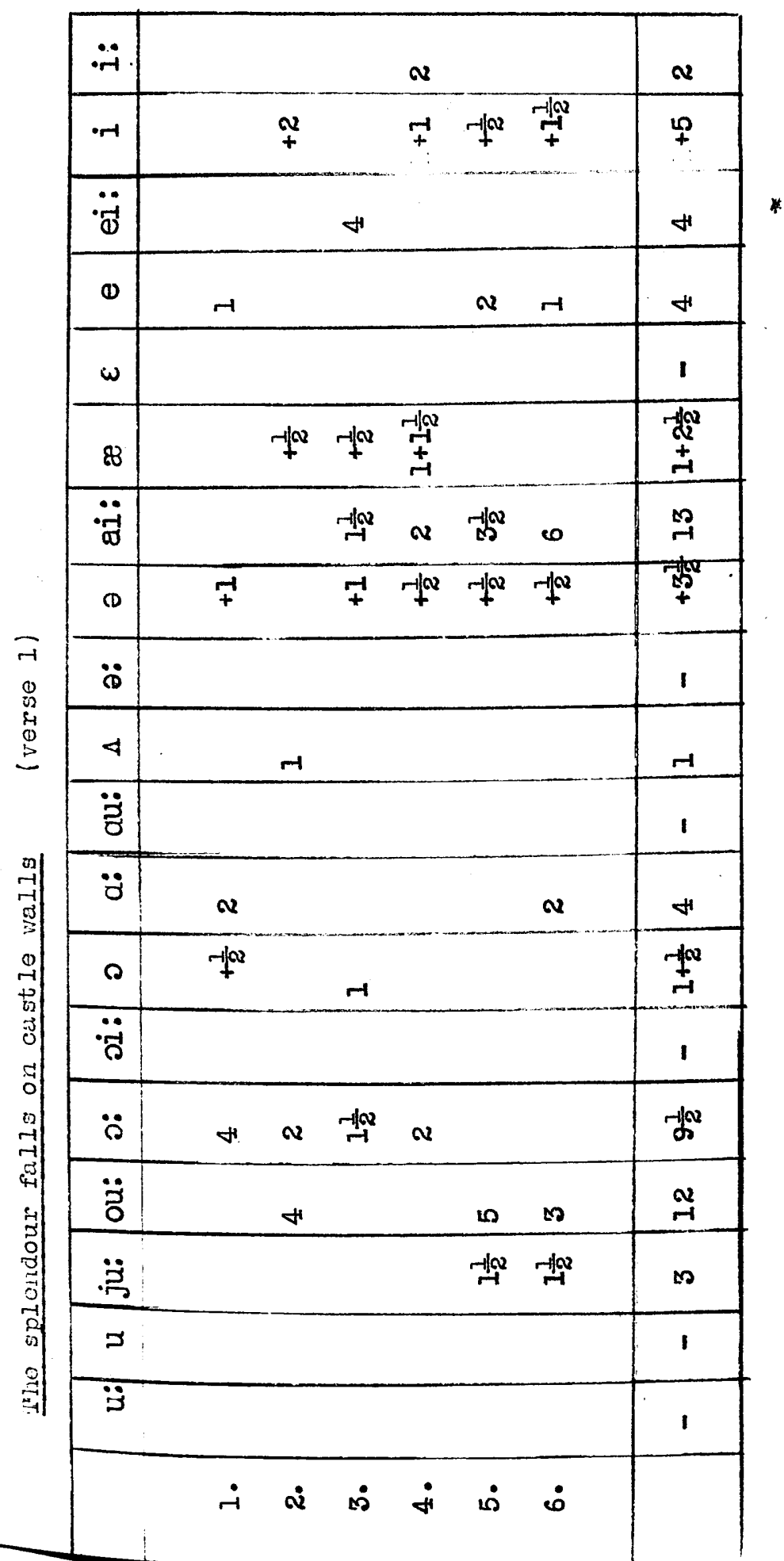




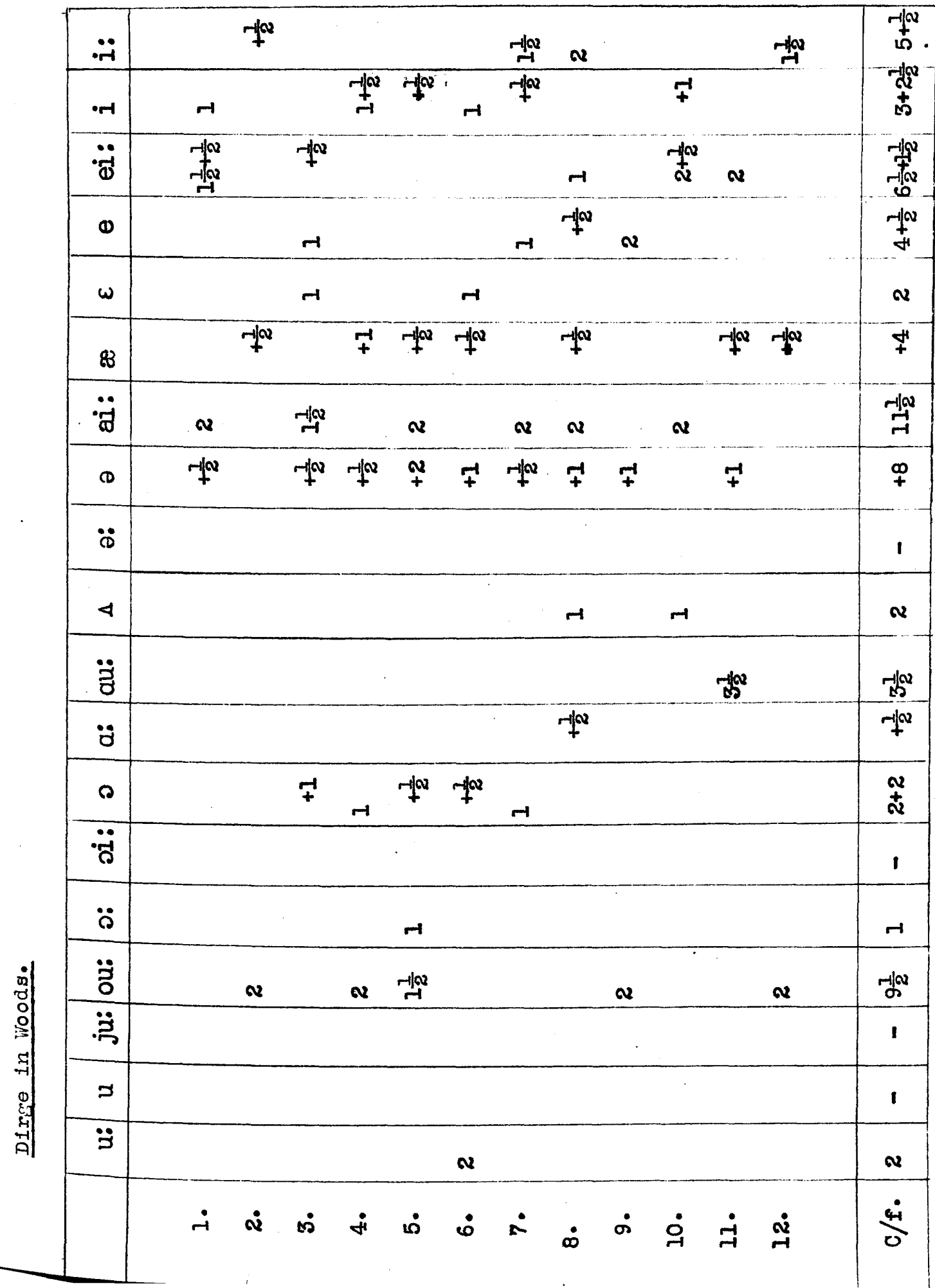




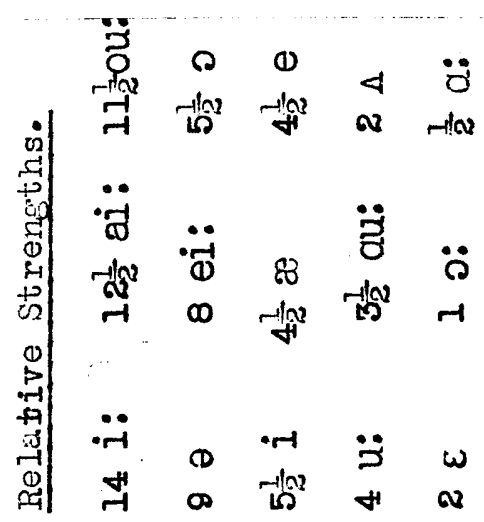

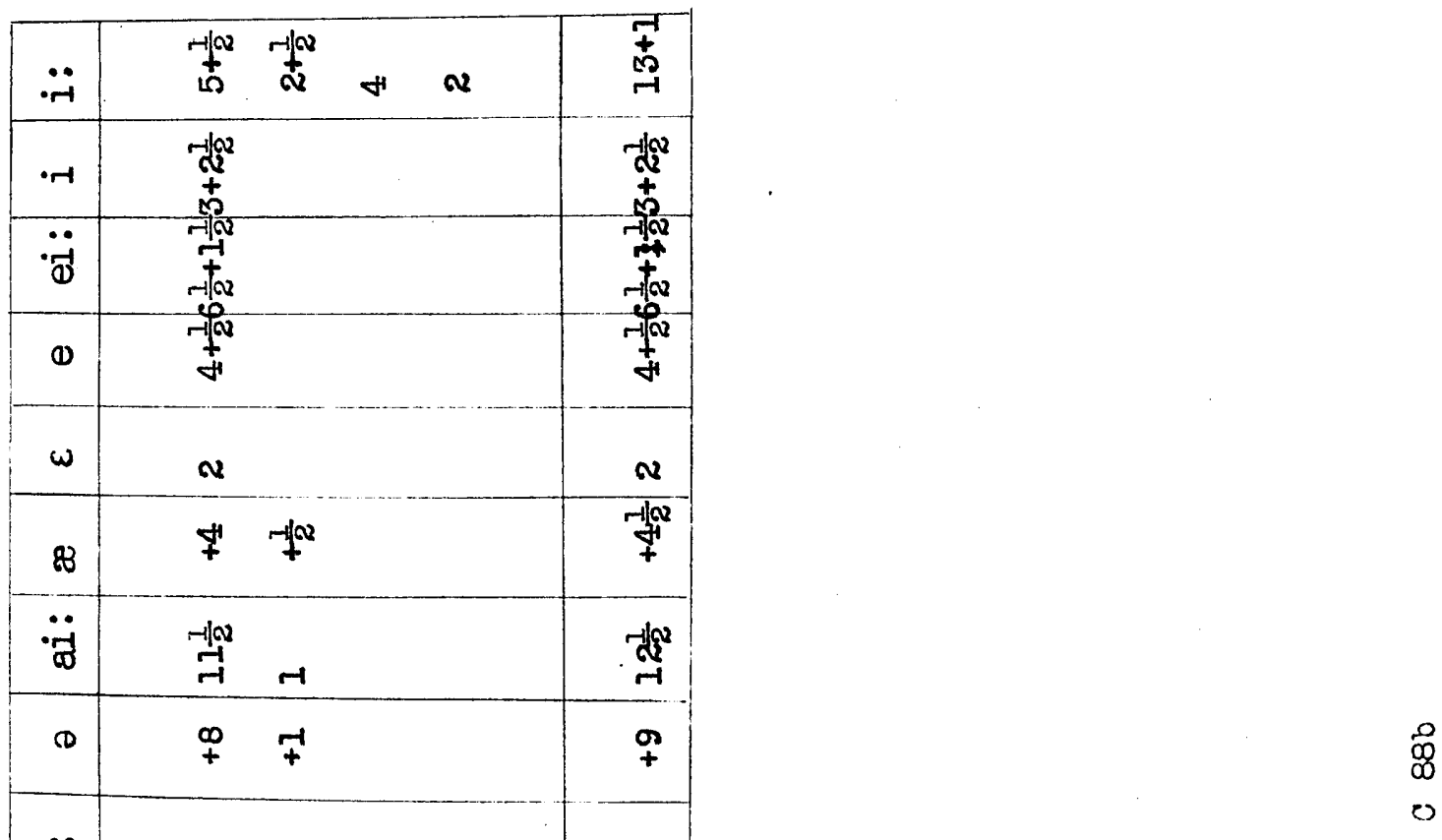




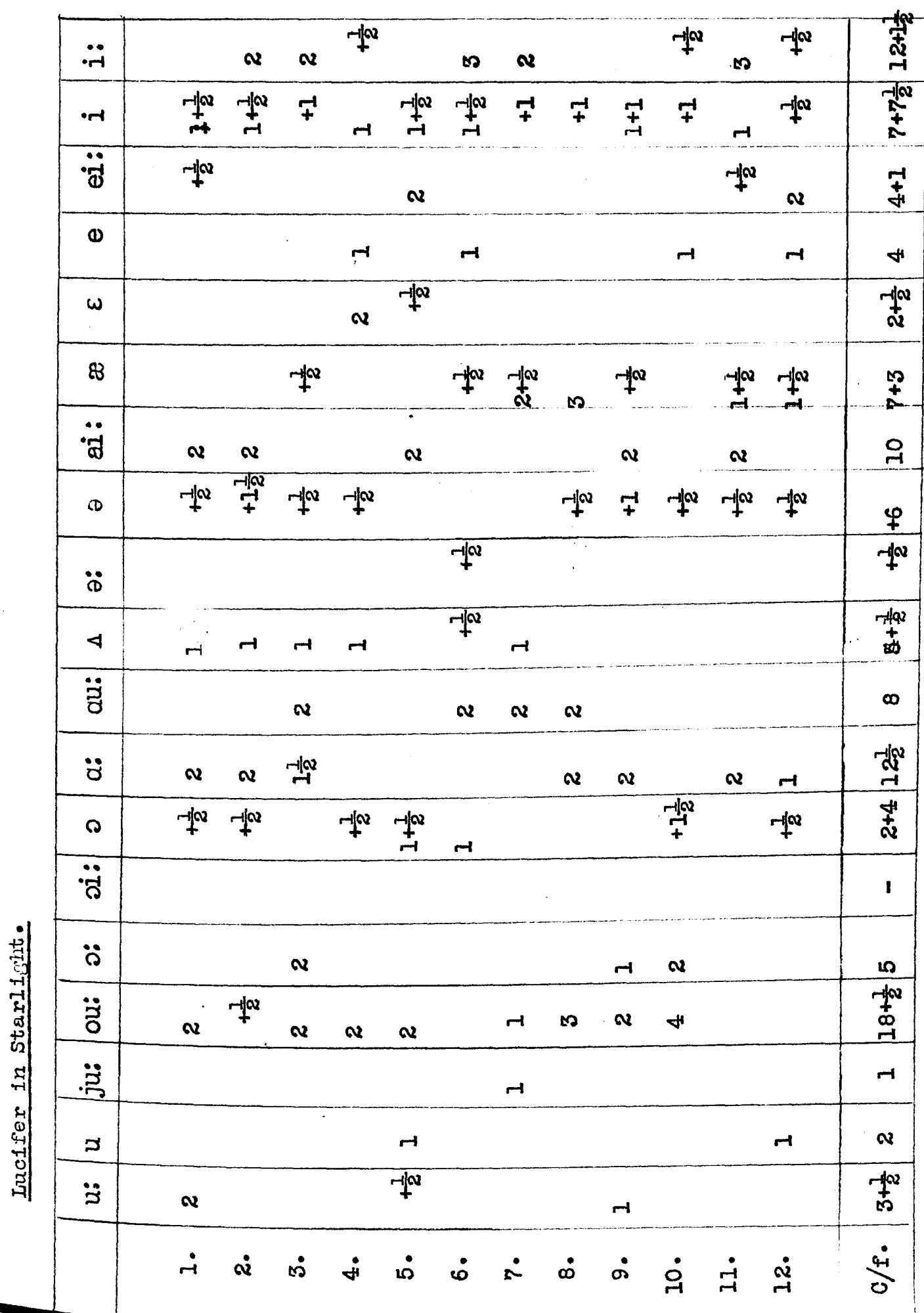




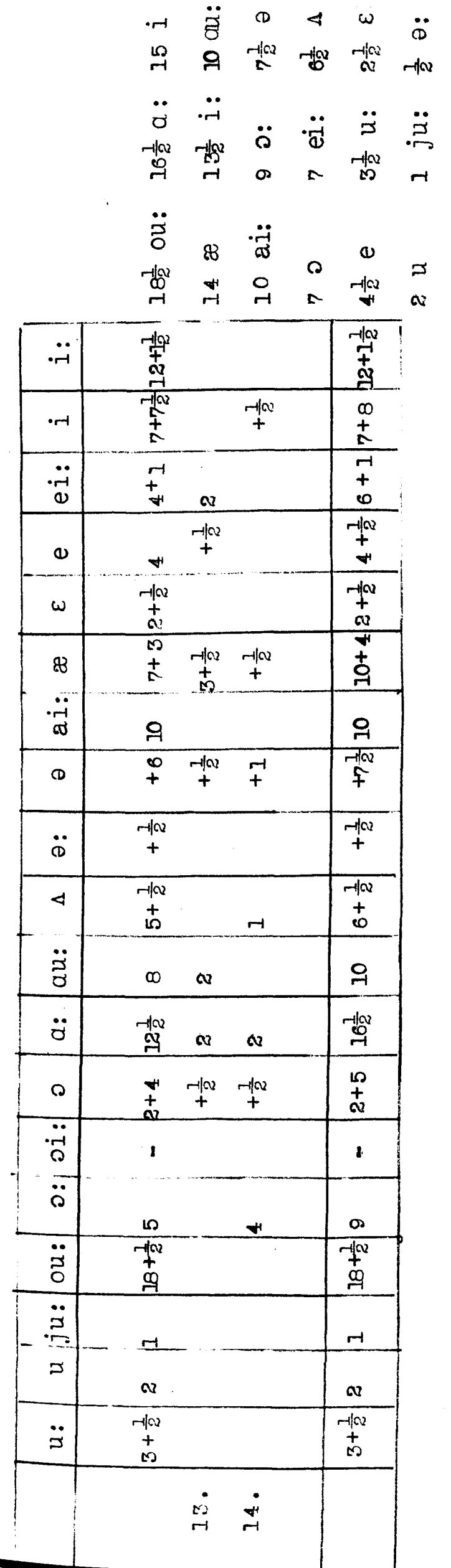




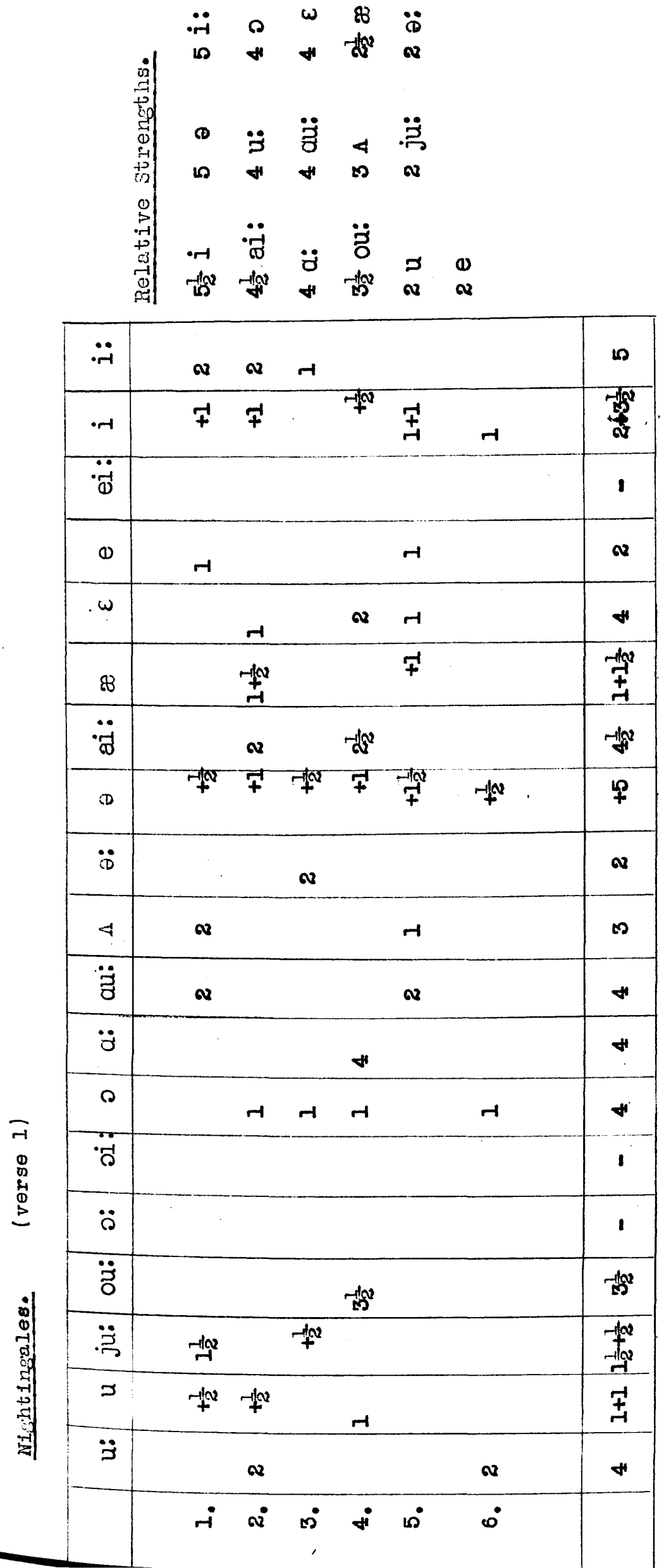


苟

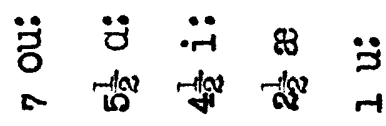

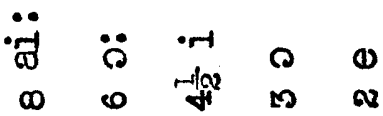

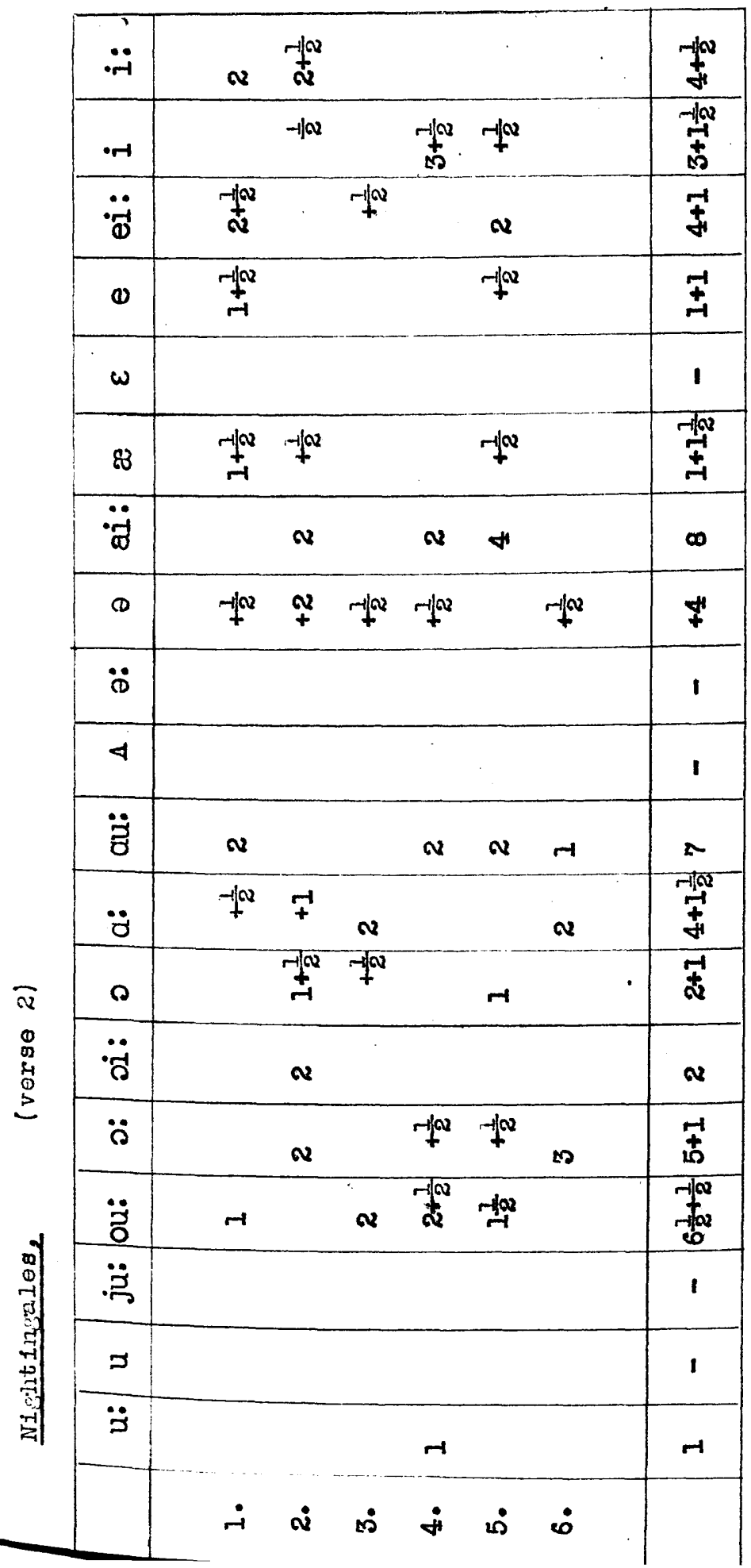




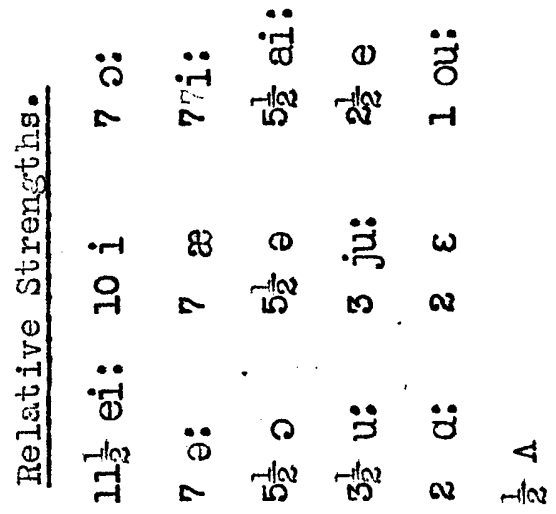

\begin{tabular}{|c|c|c|c|c|c|c|c|}
\hline$\ddot{r}$ & $\boldsymbol{v}$ & & + & $r$ & & & $\pi$ \\
\hline$\cdot r-1$ & $\underset{+}{+}$ & + & $\underset{\sim}{\stackrel{\alpha}{+}}$ & & $\stackrel{v}{+}$ & $\stackrel{\sim}{+}$ & 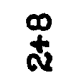 \\
\hline$\ddot{\ddot{\infty}}$ & $\stackrel{-1 / 0}{\rightarrow}$ & $H$ & $\boldsymbol{v}$ & + & & & $\underset{H}{\stackrel{-1}{\rightarrow}}$ \\
\hline (1) & $+f^{\infty}$ & & -1 & $r$ & & & $\stackrel{7}{a}$ \\
\hline$\omega$ & & , & & $\rightarrow$ & & -1 & $\dot{v}$ \\
\hline 8 & $\stackrel{+}{+}$ & & $-1 x^{\alpha}$ & $+f^{a}$ & $\underset{-1}{\stackrel{-1}{a}}$ & 留 & $\stackrel{\infty}{ \pm}$ \\
\hline$\ddot{\ddot{d}}$ & $\boldsymbol{v}$ & $\stackrel{-1 N u}{-1}$ & & & & $\mathbf{N}$ & r. \\
\hline (1) & & 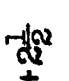 & + & $\stackrel{\mathbb{q}}{+}$ & & & 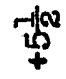 \\
\hline$\ddot{8}$ & & $\sim$ & & & 笖 & r墒 & $\underset{t}{+}$ \\
\hline 4 & 7 & & & & & & $+f^{\infty}$ \\
\hline$\ddot{3}$ & & & & & & & 1 \\
\hline$\ddot{\delta}$ & & & & $v$ & & & $v$ \\
\hline$\curvearrowright$ & $\mp$ & & +10 & $\underset{-1}{t}$ & $\underset{+}{+}$ & -10 & 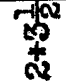 \\
\hline$\ddot{~}$ & & & & & & & 1 \\
\hline$\ddot{\mathrm{O}}$ & $\mathbf{N}$ & $\boldsymbol{N}$ & & & $\infty$ & & 2 \\
\hline อี & & & & & & -1 & -1 \\
\hline :ٌ & & $\stackrel{+10}{\rightarrow-1}$ & & & & - $\prod_{-1}^{\alpha}$ & $\infty$ \\
\hline$\checkmark$ & & & & & & & 1 \\
\hline$\ddot{3}$ & & -1 & & $-1 t^{a}$ & $\boldsymbol{v}$ & & $\underset{\omega}{-10}$ \\
\hline & $\dot{-i}$ & $\dot{\mathfrak{i}}$ & $\dot{\infty}$ & $\dot{H}$ & $\dot{10}$ & $\dot{\omega}$ & \\
\hline
\end{tabular}




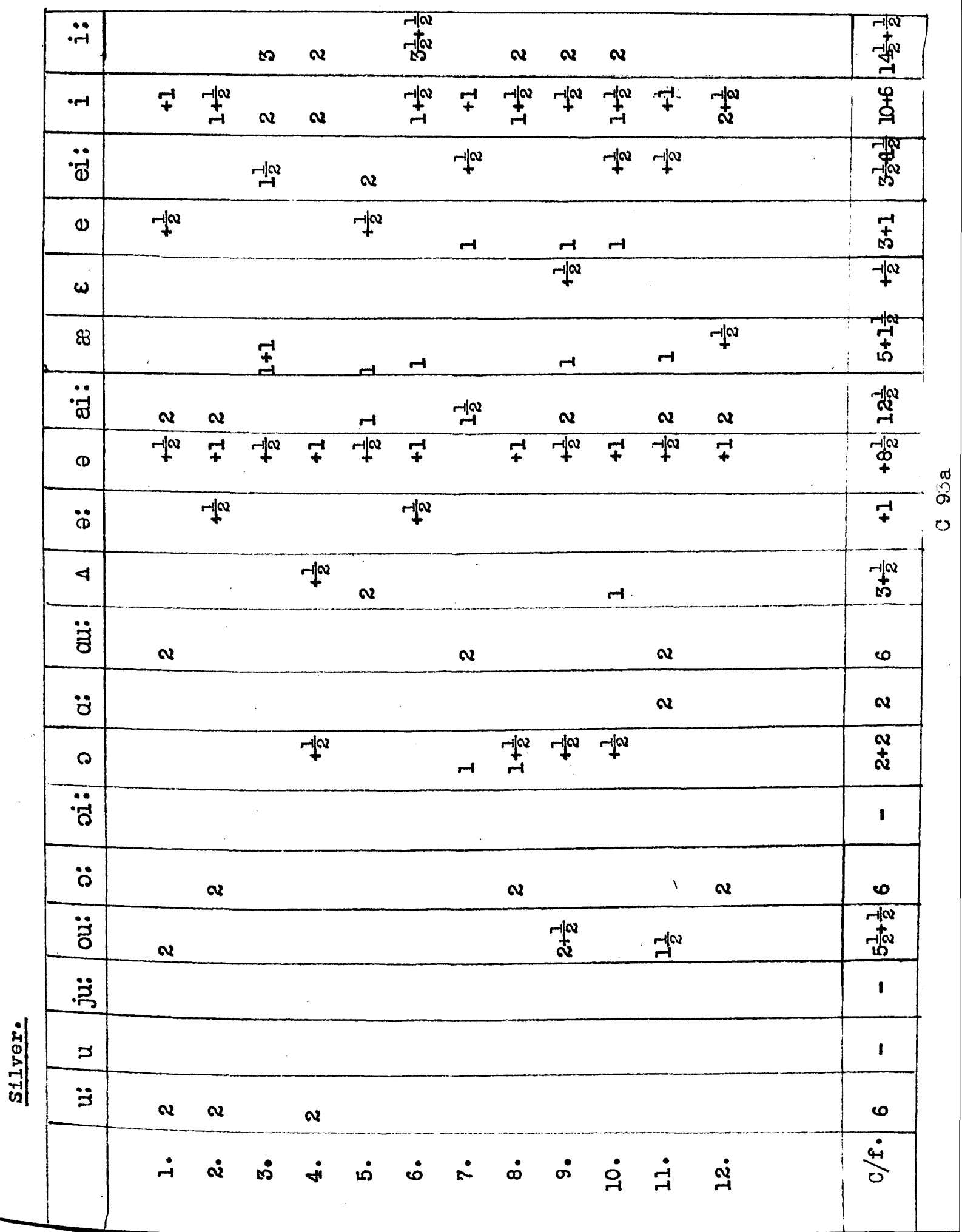


$\begin{array}{ccccc}\ddot{\pi} & \ddot{\beta} & \ddot{z} & \omega & \ddot{\theta} \\ \ddot{\mu} & \infty & \omega & + & H\end{array}$

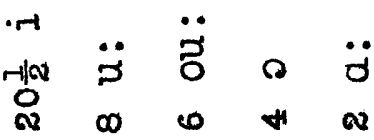

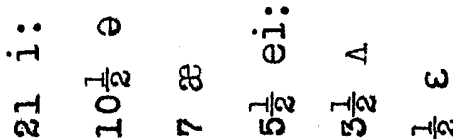

\begin{tabular}{|c|c|c|c|c|}
\hline . & 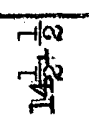 & $\infty$. & + & 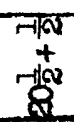 \\
\hline . & $\begin{array}{l}0 \\
0 \\
9\end{array}$ & $\begin{array}{l}7 \\
A\end{array}$ & $\begin{array}{l}-\sqrt{n} \\
\text { at }\end{array}$ & $\begin{array}{l}\text { नुल } \\
\text { 零 }\end{array}$ \\
\hline$\ddot{\ddot{d}}$ & $-\sqrt{42}$ & & $-19 a$ & 栾 \\
\hline 0 & $\begin{array}{l}-1 \\
+ \\
6 \\
0\end{array}$ & & & ने \\
\hline$\omega$ & $-1 / 192$ & & & $\stackrel{-1 / \alpha x}{+}$ \\
\hline 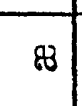 & 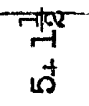 & $\begin{array}{c}-1 \alpha \\
+\end{array}$ & & $\begin{array}{l}\Omega \\
+ \\
+\end{array}$ \\
\hline $\begin{array}{l}0 \\
\ddot{d} \\
\ddot{0}\end{array}$ & $-\overbrace{}^{2}{ }^{2}$ & 7 & $-1+9$ & 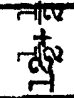 \\
\hline (1) & 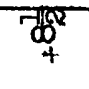 & 7 & 7 & न्ताल \\
\hline$\ddot{\theta}$ & 7 & & & 4 \\
\hline 4 & $\begin{array}{c}-1 / 102 \\
5 \\
5\end{array}$ & & & $\begin{array}{l}-1 / \alpha \\
\text { 南 }\end{array}$ \\
\hline$\ddot{\vec{g}}$ & 0 & & & 0 \\
\hline$\ddot{0}$ & $\infty$ & & & $\alpha$ \\
\hline 0 & $\begin{array}{c}\infty \\
+ \\
\infty \\
-\end{array}$ & & & $\begin{array}{l}\underline{T} \\
\stackrel{N}{N} \\
\end{array}$ \\
\hline $\overrightarrow{0}$ & & & & \\
\hline$\ddot{o}$ & & $\infty$ & & $\infty$ \\
\hline ठํ. & 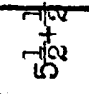 & & & $\pi^{2}$ \\
\hline : & & & & \\
\hline 5 & & & & \\
\hline$\ddot{z}$ & 0 & $\infty$ & & $\infty$ \\
\hline & $\dot{q}$ & $\dot{m}$, & $\stackrel{\dot{H}}{-}$ & \\
\hline
\end{tabular}




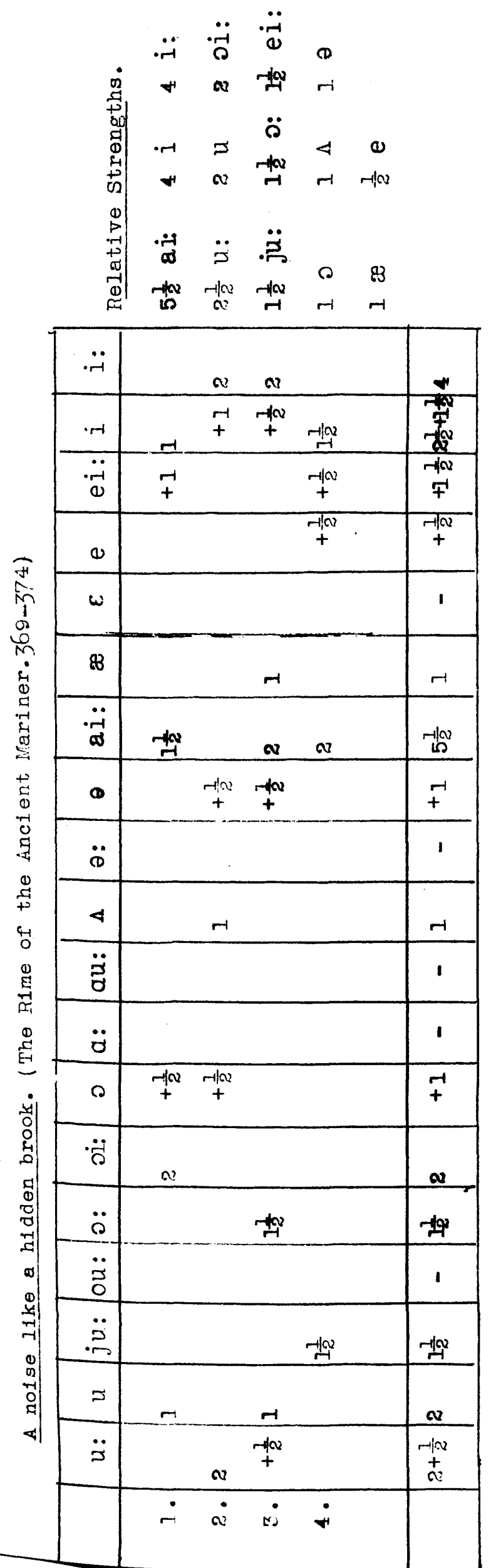




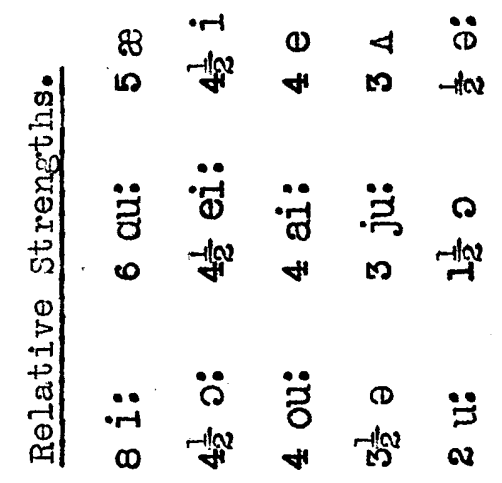

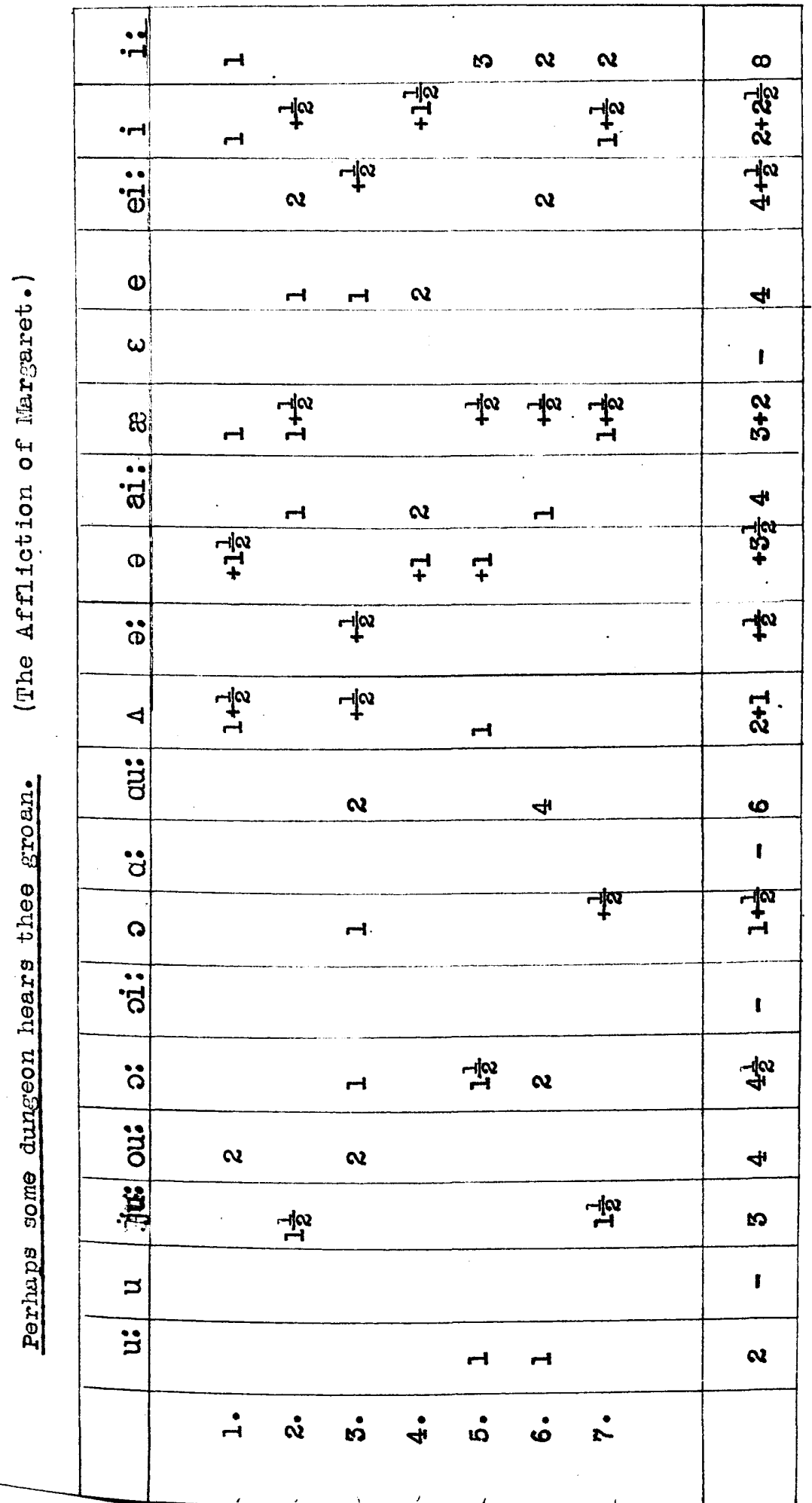




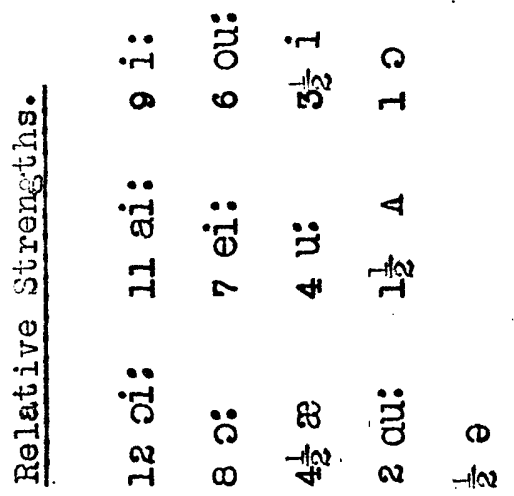

\begin{tabular}{|c|c|c|c|c|c|c|c|c|c|c|c|c|c|}
\hline$\ddot{\ddot{r}}$ & \multicolumn{5}{|c|}{$+I^{\alpha}$} & $\vec{r}$ & \multicolumn{2}{|l|}{$\stackrel{-N}{r}$} & \multicolumn{2}{|c|}{$\underset{-1 / \alpha}{+\infty}$} & \multicolumn{2}{|r|}{$\underset{-1}{-1}$} & \multirow{2}{*}{ 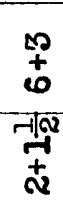 } \\
\hline$\cdot \pi$ & & & & & $7^{-1 / 2}$ & & $\underset{-1}{+\infty}$ & & \multicolumn{4}{|c|}{$H$} & \\
\hline$\ddot{0}$ & Q & ન્|⿱一⿻上丨-口 & & & 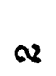 & & & $\stackrel{-1 N}{-1 \alpha}$ & & & & & $\pi$ \\
\hline$\omega$ & & & & & & & & & & & & & 1 \\
\hline$\omega$ & & & & & & & & & & & & & 1 \\
\hline 88 & -1 & $r$ & $F(\mathbb{Q}$ & $\boldsymbol{v}$ & & & & & & & & & $\underset{+}{+100}$ \\
\hline$\ddot{0}$ & $H$ & -1 & -1 & -1 & $r$ & & & & $r$ & $\sim$ & $m$ & & $\vec{F}$ \\
\hline 0 & & & & & & & & & & & -100 & & $r \mid w$ \\
\hline$\ddot{Q}$ & & & & & & & & & & & & & 1 \\
\hline 7 & & 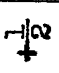 & & & & & & 7 & & $+\underset{t}{*}$ & & & $\underset{+}{+}$ \\
\hline$\ddot{3}$ & & & & & & & & & & $v$ & & & $\boldsymbol{v}$ \\
\hline$\ddot{3}$ & & & & & & & & & & & & & 1 \\
\hline$\curvearrowright$ & & & $H$ & & & & & & & & & & $r$ \\
\hline$\because \ddot{8}$ & & & & & $\mathbf{v}$ & $\boldsymbol{v}$ & $\boldsymbol{v}$ & $v$ & $\sim$ & & & $\boldsymbol{v}$ & $\underset{-1}{N}$ \\
\hline$\ddot{\circ}$ & & & N & & & 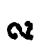 & & & $v$ & & & $\Omega$ & $\infty$ \\
\hline$\ddot{\Xi}$ & $\mathbb{Q}$ & $\mathbf{v}$ & & & & & & $\sim$ & & & & & $\boldsymbol{\omega}$ \\
\hline 苛 & & & & & & & & $\ldots$ & & & & & 1 \\
\hline ב & & & & & & & & & & & & & 1 \\
\hline$\ddot{g}$ & & $v$ & & & & & & $\sim$ & & & & & H \\
\hline & $\dot{-}$ & $\dot{v}$ & $\dot{B}$ & $\dot{j}$ & $\dot{\circ}$ & $\dot{0}$ & $\dot{5}$ & $\dot{\infty}$ & $\dot{\sigma}$ & $\dot{\vec{\theta}}$ & $\underset{-\rightarrow}{\vec{r}}$ & 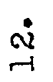 & \\
\hline
\end{tabular}




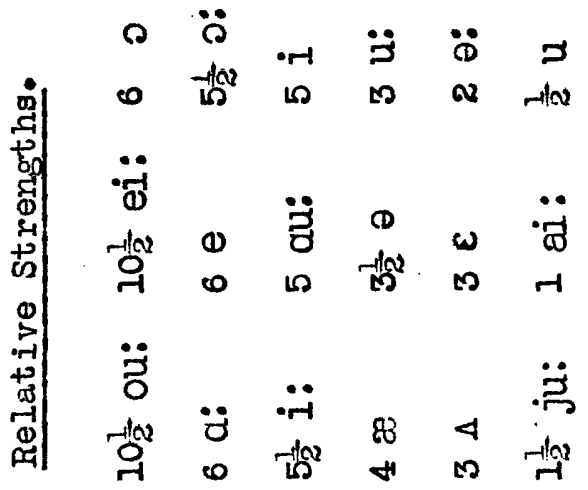

\begin{tabular}{|c|c|c|c|c|c|c|c|c|c|}
\hline$\ddot{~}$ & & & $\frac{1}{\Delta}$ & & & & & $-I^{\infty}$ & $-\frac{1}{H}$ \\
\hline$\cdot r-1$ & -10 & $7^{n}$ & $-1 x^{\infty}$ & & $v$ & & & $\underset{-1}{-1}$ & $\begin{array}{l}w \\
+ \\
\infty\end{array}$ \\
\hline$\ddot{\ddot{\theta}}$ & 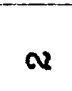 & $v$ & $v$ & & $-\sqrt{2}$ & 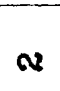 & $\mathbf{v}$ & & -10a \\
\hline (1) & $r$ & & & $H$ & -10 & $\boldsymbol{v}$ & $\underset{-1}{-7}$ & & th \\
\hline$\omega$ & & & & $\boldsymbol{H}$ & & $\boldsymbol{v}$ & & & $\infty$ \\
\hline 88 & & $\underset{-1}{-10}$ & -10 & & $\underset{+}{+}$ & & & & $\begin{array}{l}\mathbf{v} \\
+ \\
\mathbf{\alpha}\end{array}$ \\
\hline$\ddot{0}$ & & & & & & & & -1 & -1 \\
\hline (1) & $-H^{\infty}$ & $-1 \omega$ & & $-1+x$ & & $r+10$ & 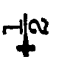 & +1 & $\stackrel{-\sqrt{x^{2}}}{+}$ \\
\hline$\ddot{\nabla}$ & & & & & & & $v$ & & $v$ \\
\hline 4 & & -1 & & & & $\because$ & न & $r$ & $\infty$ \\
\hline$\ddot{z}$ & & Q & $\boldsymbol{N}$ & & & $r$ & & & م \\
\hline$\ddot{z}$ & & & & $v$ & & & & 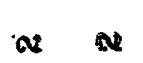 & $\omega$ \\
\hline$\curvearrowright$ & & & & $r+\infty$ & & 7 & -10 & & $\underset{+}{+}$ \\
\hline$\ddot{\ddot{c}}$ & & & & & & & & & 1 \\
\hline$\ddot{\circ}$ & & & $\boldsymbol{N}$ & N & & & - & & rib \\
\hline$\ddot{\check{\partial}}$ & r些 & $r$ & rdva & $\boldsymbol{H}$ & $\infty$ & $\underset{r}{-1}$ & & & 함 \\
\hline$\ddot{\ddot{\partial}}$ & & & & & & & +-102 & $r$ & $\stackrel{-1 \infty}{+1}$ \\
\hline 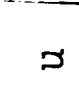 & & & & & & $-1 x^{2}$ & & & +10 \\
\hline$\ddot{J}$ & & & & & $\rightarrow$ & -1 & -10 & $-1 \infty$ & $\underset{⿱}{ \pm}$ \\
\hline & $\dot{-i}$ & $\dot{\infty}$ & $\dot{\infty}$ & $\dot{j}$ & $\dot{0}$ & $\dot{0}$ & $\dot{1}$ & $\dot{\infty} \quad \dot{\sigma}$ & \\
\hline
\end{tabular}




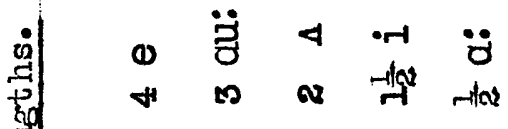

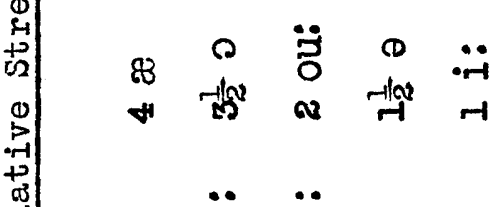

离

\begin{tabular}{|c|c|c|c|c|}
\hline$\ddot{n}$ & $r$ & & & $r$ \\
\hline$\cdot r-1$ & -10 & $+x^{\infty}$ & -10 & $\stackrel{-1 / N}{+}$ \\
\hline$\ddot{\ddot{a}}$ & & $v$ & $\boldsymbol{N}$ & + \\
\hline$\omega$ & $r$ & + & $v$ & +5 \\
\hline$\omega$ & & & & 1 \\
\hline 88 & $\stackrel{+\infty}{-1}$ & \pm & 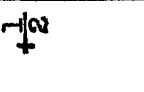 & 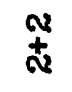 \\
\hline$\ddot{\theta}$ & N & & $r$ & $M$ \\
\hline CD & -70 & & $-1 f^{\alpha}-10$ & $\underset{+}{+\mu_{+}^{-\alpha}}$ \\
\hline$\ddot{i}$ & & v & & $\mathbf{v}$ \\
\hline 4 & & -1 & $\rightarrow$ & $\sim$ \\
\hline$\ddot{\ddot{\partial}}$ & & $\infty$ & & $\infty$ \\
\hline$\ddot{8}$ & & & -10 & -10 \\
\hline$\curvearrowright$ & $H$ & & $\rightarrow \stackrel{+\infty}{\rightarrow}$ & $\frac{f^{n}}{m}$ \\
\hline$\ddot{8}$ & & & & 1 \\
\hline$\ddot{\beta}$ & 70 & & 少 $\alpha$ & 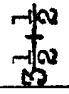 \\
\hline$\ddot{3}$ & $\boldsymbol{v}$ & & & $v$ \\
\hline : 艿 & & & & 1 \\
\hline 5 & & & $H$ & $H$ \\
\hline$\ddot{3}$ & & & & 1 \\
\hline & $\dot{-}$ & $\dot{\mathfrak{N}}$ & $\dot{\infty} \quad \dot{H}$ & \\
\hline
\end{tabular}




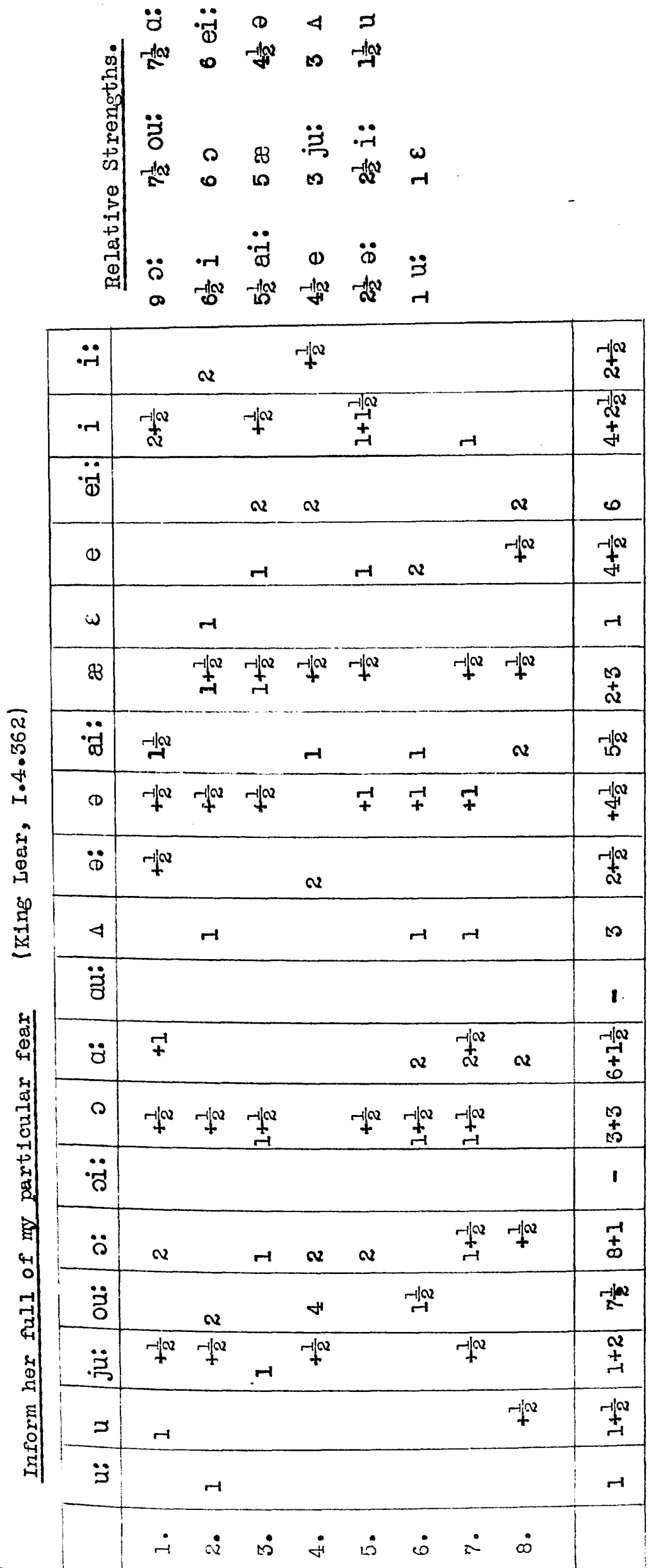




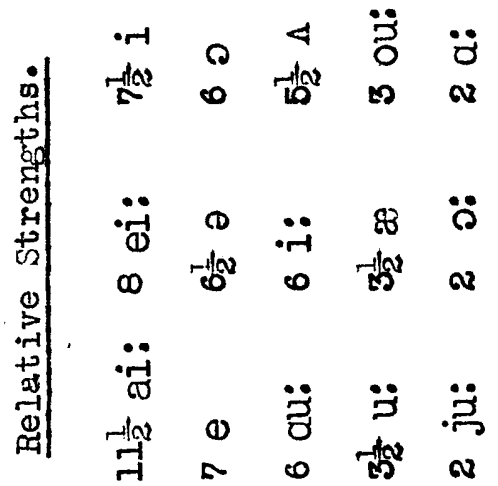

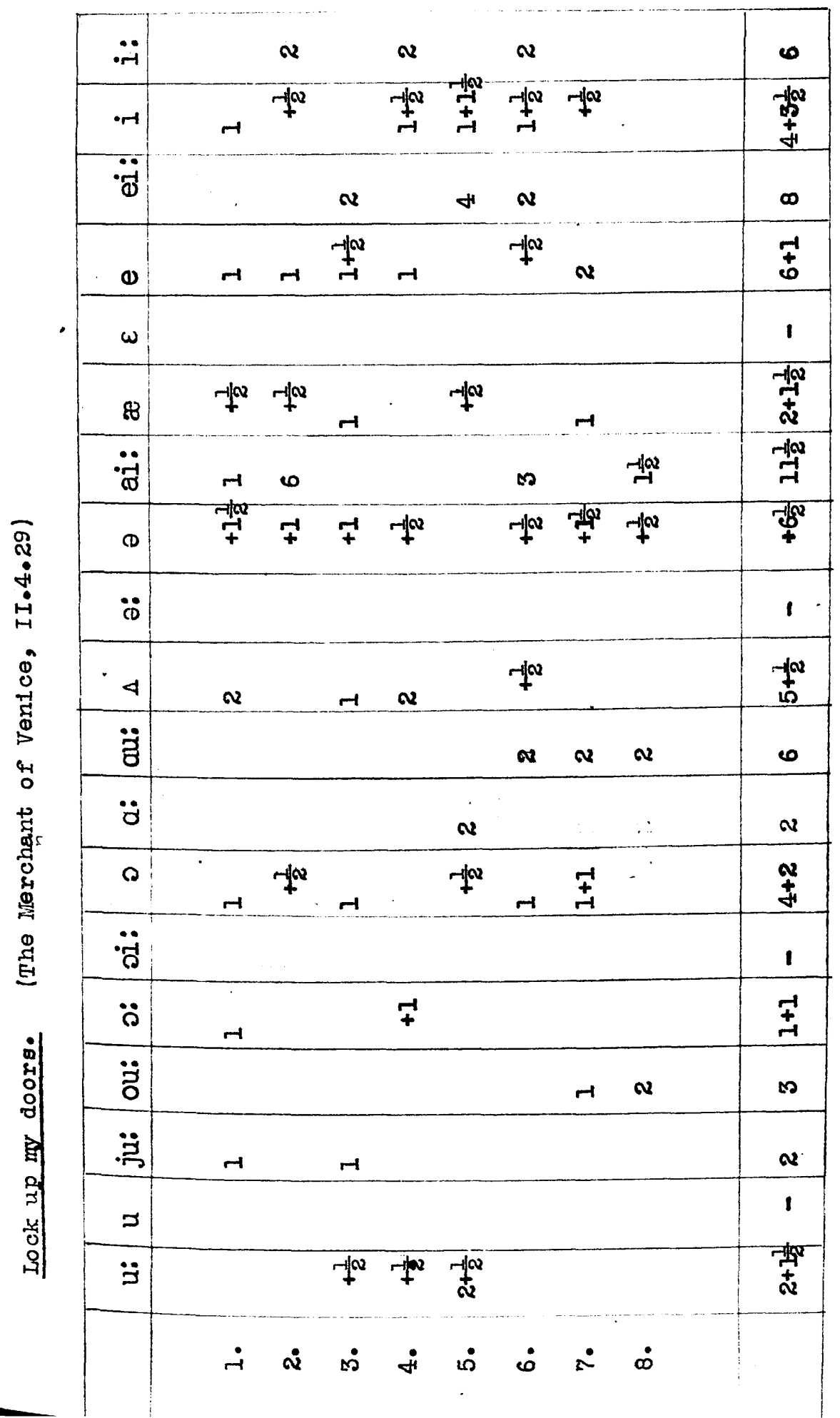




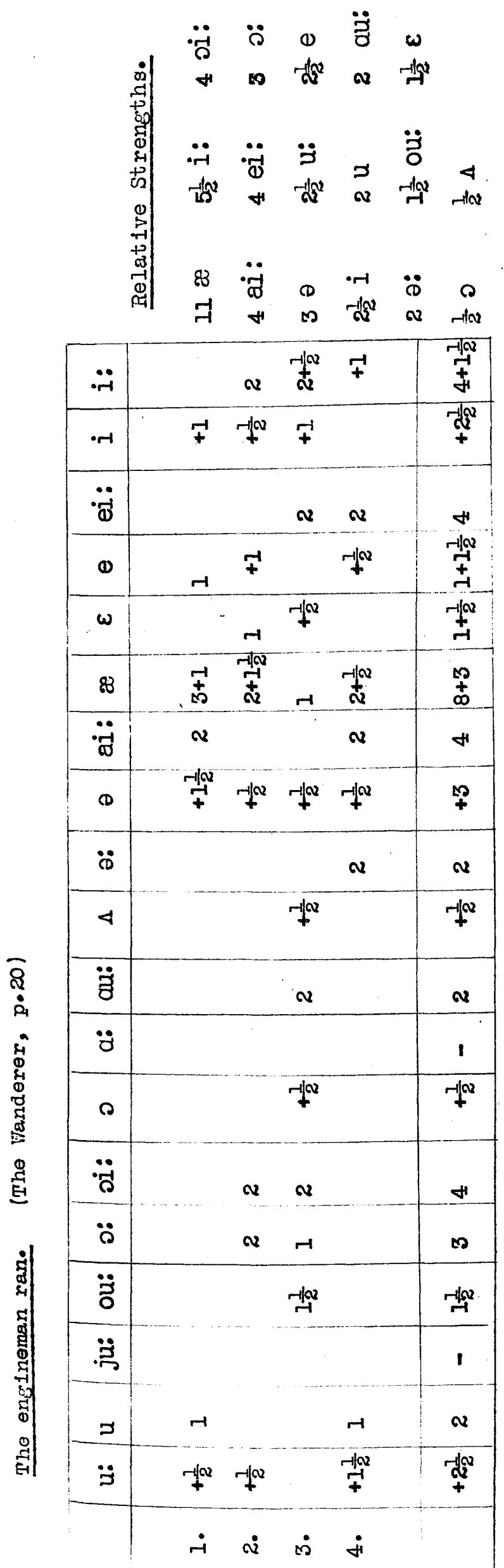




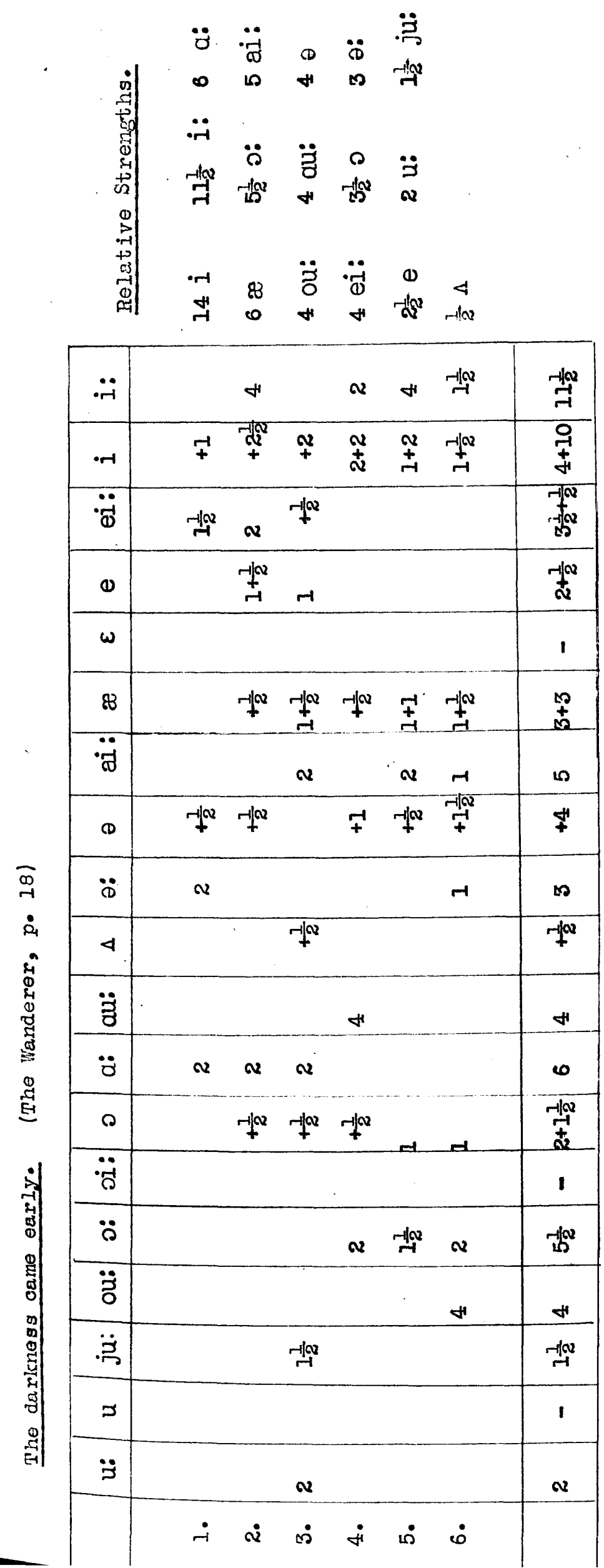




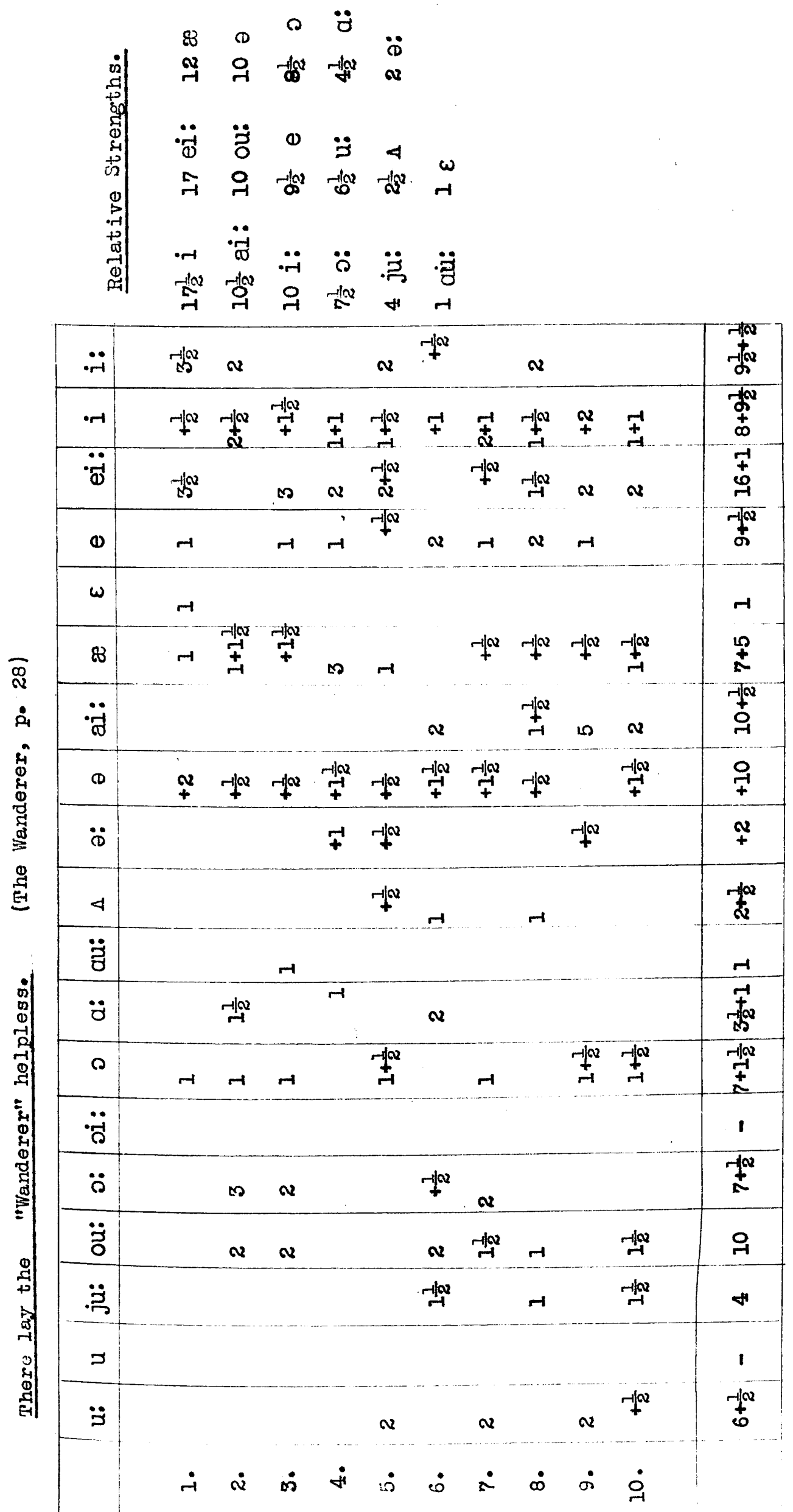




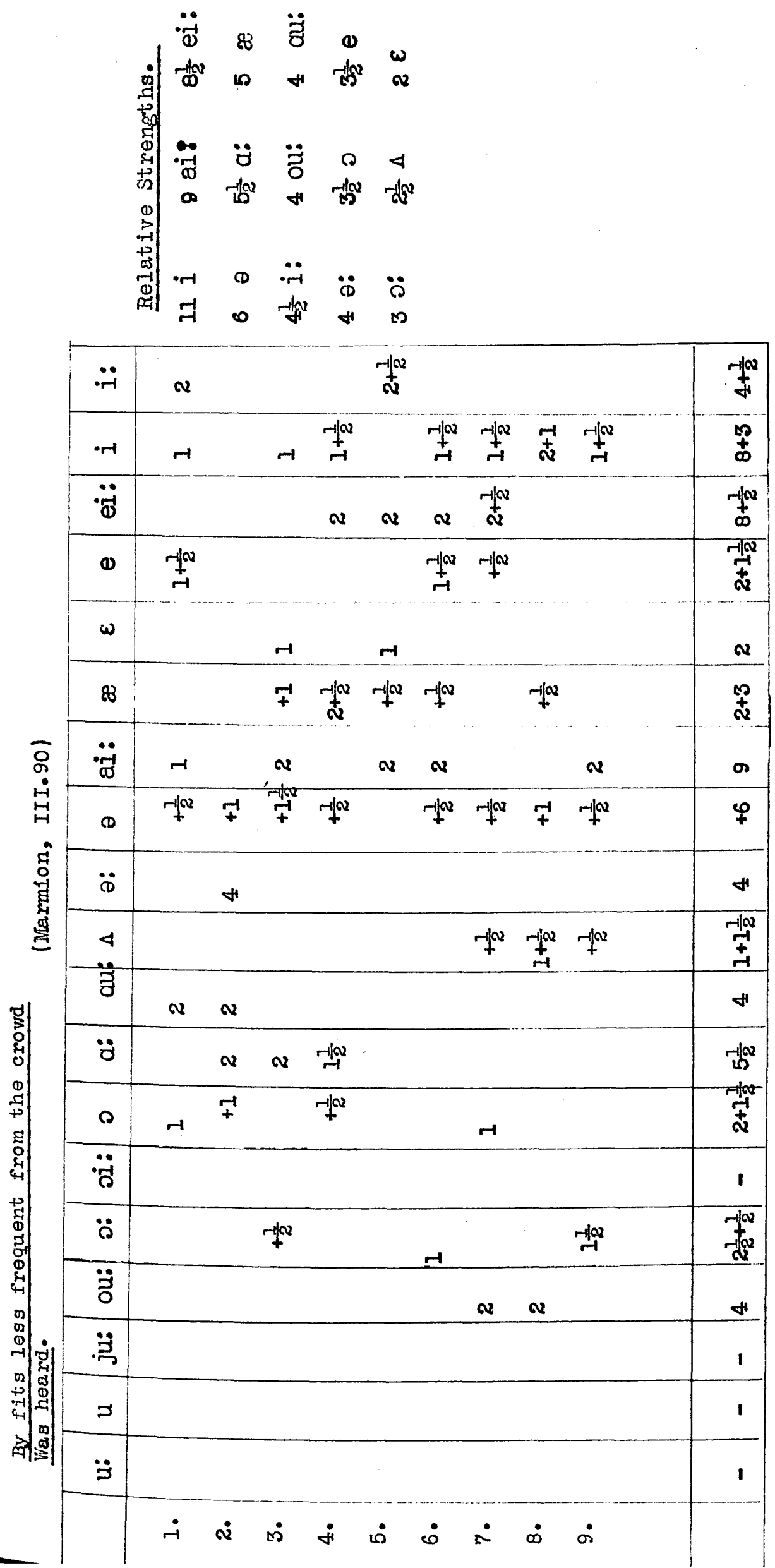




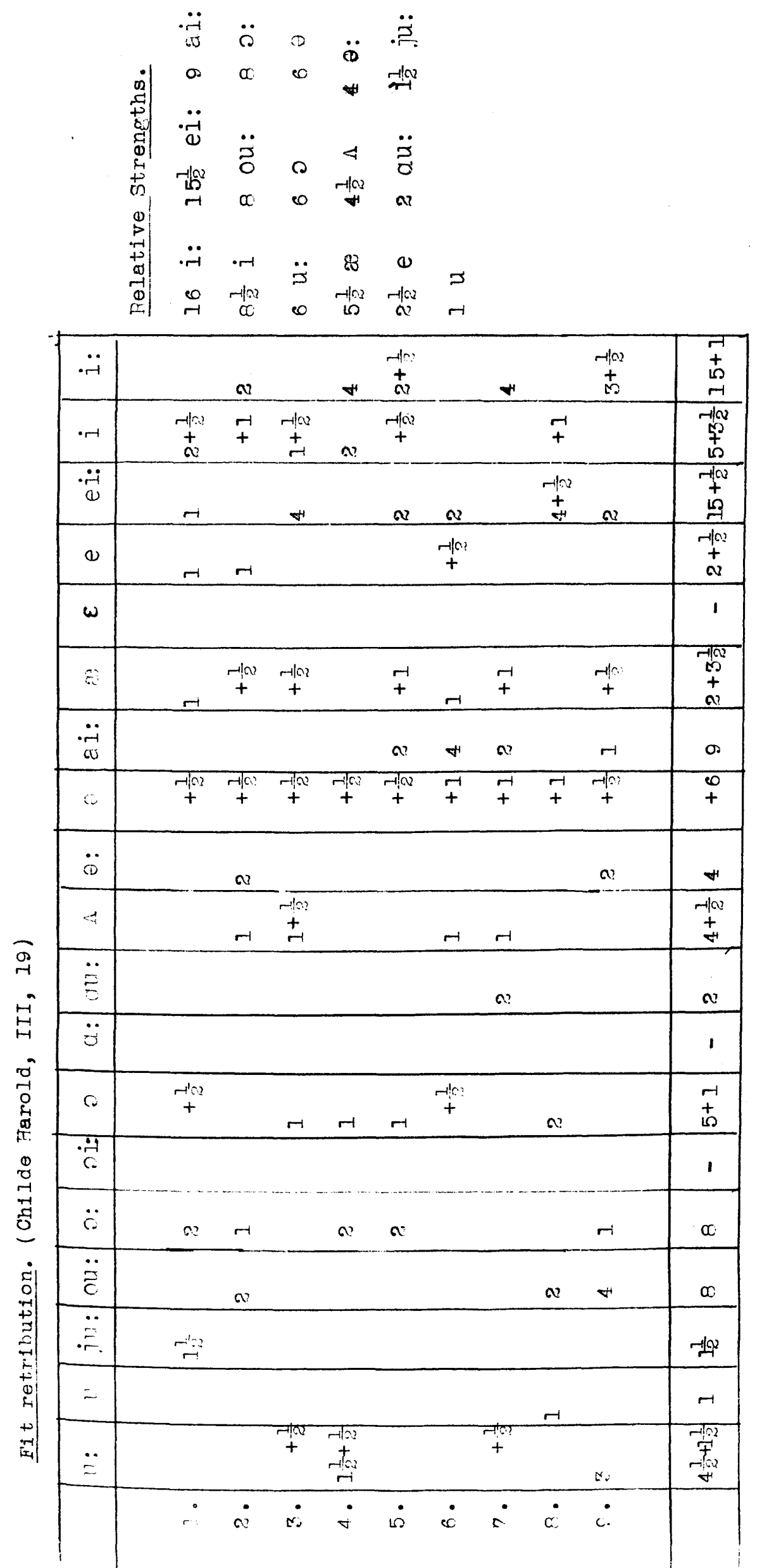




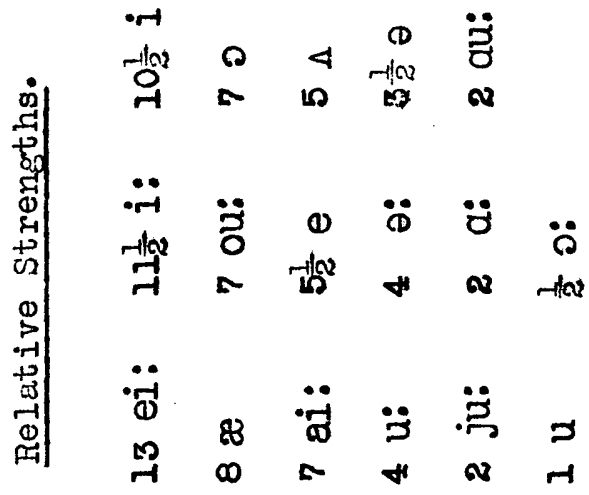

\begin{tabular}{|c|c|c|c|c|c|c|c|c|c|c|}
\hline$\ddot{\circ r}$ & & & & $\stackrel{r-1}{+\infty}$ & $m$ & $-i^{\infty}$ & $-t^{\infty}$ & $-1+\infty$ & $\stackrel{-1 /(a)}{\stackrel{a}{a}}$ & $\begin{array}{l}\text { तd } \\
+ \\
\sigma\end{array}$ \\
\hline$\cdot r-1$ & $\mp$ & $\underset{+}{+}$ & $r$ & $\underset{+}{+}$ & $-f^{\infty}$ & $-1 \infty$ & +1 & $\stackrel{+}{+}$ & $\underset{r-1}{r-1}$ & 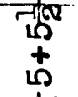 \\
\hline$\ddot{\theta}$ & & 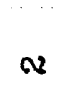 & & 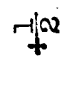 & $H$ & & -1 & & r & $\begin{array}{l}\text { row } \\
\text { dig } \\
\text { du }\end{array}$ \\
\hline (1) & $-1+a$ & & $\frac{-10}{N}$ & & & $-1+\infty$ & -1 & -1 & & $\underset{+}{+}$ \\
\hline$\omega$ & & & & & & & & & & 1 \\
\hline 83 & $\pi$ & 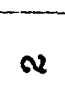 & $\stackrel{\vec{T}}{\overrightarrow{+}}$ & $r$ & & 畓 & & & नाब & $\begin{array}{l}q \\
+ \\
0\end{array}$ \\
\hline$\ddot{\text { वे }}$ & $\checkmark$ & & $\infty$ & & & & & $r$ & $r$ & $\approx$ \\
\hline$D$ & -10 & 7 & $+x^{\alpha}$ & & $f^{\alpha}$ & & $\vec{t}$ & & -10 & 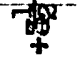 \\
\hline$\ddot{B D}$ & & & & $\Omega$ & $\boldsymbol{N}$ & & & & & $H$ \\
\hline 4 & $r$ & & & & & $\vec{r}$ & $\stackrel{+}{-1}$ & $+f^{*}$ & $r$ & 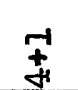 \\
\hline$\ddot{z}$ & & & & & $\checkmark$ & & & & & $\Omega$ \\
\hline$\ddot{0}$ & $v$ & & & & & & & & & 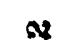 \\
\hline 0 & -1 & $7+\infty$ & $+1 \omega^{2}$ & & $r$ & $v$ & $\vec{H}$ & $r$ & & $\underset{6}{+}$ \\
\hline$\ddot{\ddot{c}}$ & & & & & & & & & & 1 \\
\hline$\ddot{\circ}$ & & & & & & & & & 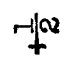 & $-1 \times$ \\
\hline ํㅗ & & & & & $v$ & 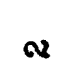 & & $H$ & $v$ & $\pi$ \\
\hline . & $\rightarrow$ & 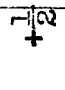 & & & & & & & & नी \\
\hline 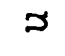 & & & & & & & & -1 & & $r$ \\
\hline 3 & & & 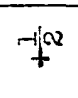 & $r$ & & & $r$ & 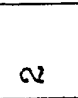 & & $\begin{array}{l}+1 \\
0\end{array}$ \\
\hline & $\dot{-}$ & $\dot{2}$ & $\dot{0}$ & $\dot{q}$ & סڤا & ف & $\dot{2}$ & $\dot{\infty}$ & $\dot{\sigma}$ & \\
\hline
\end{tabular}




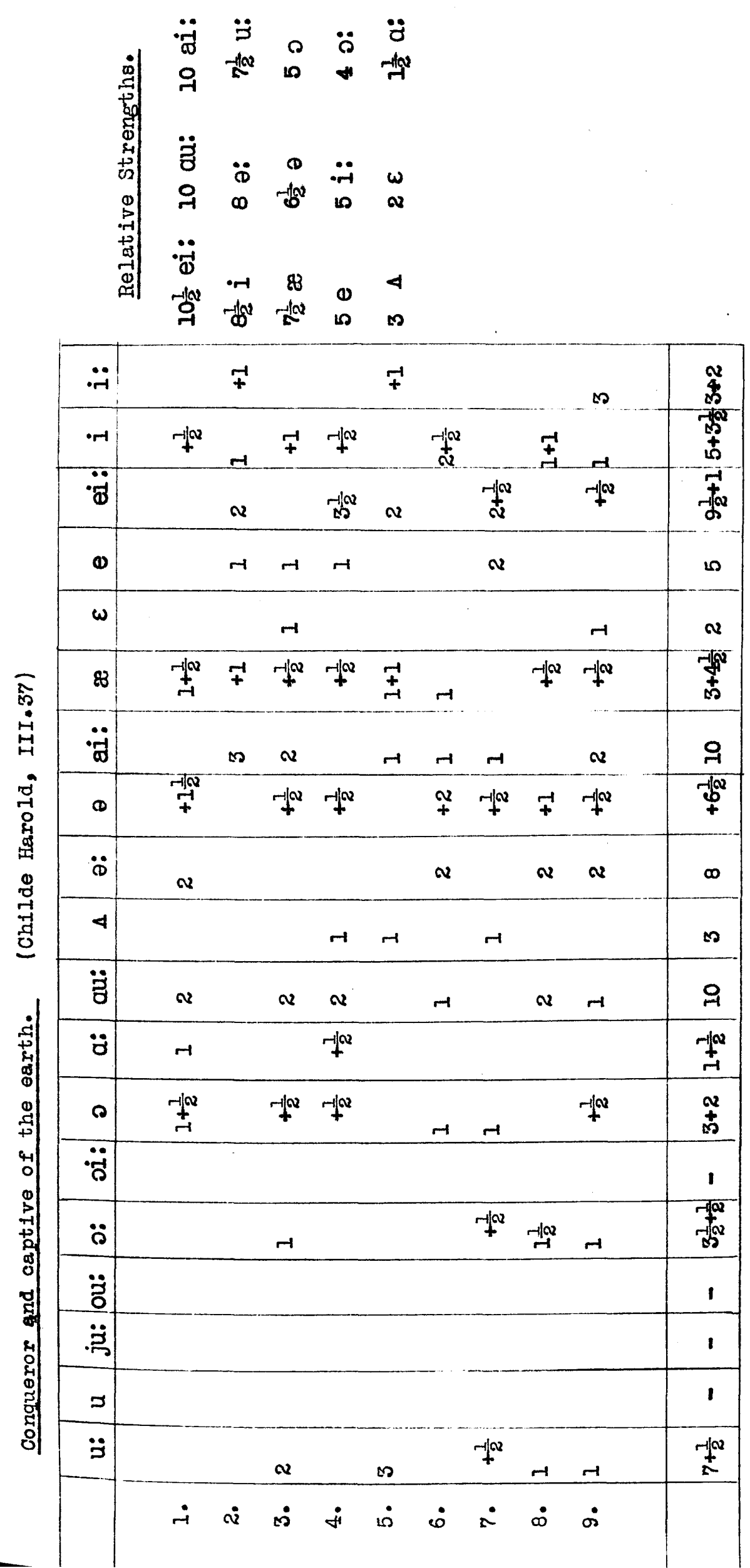




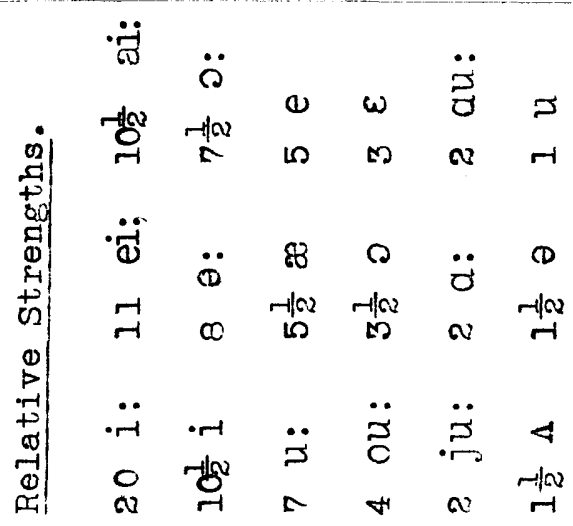

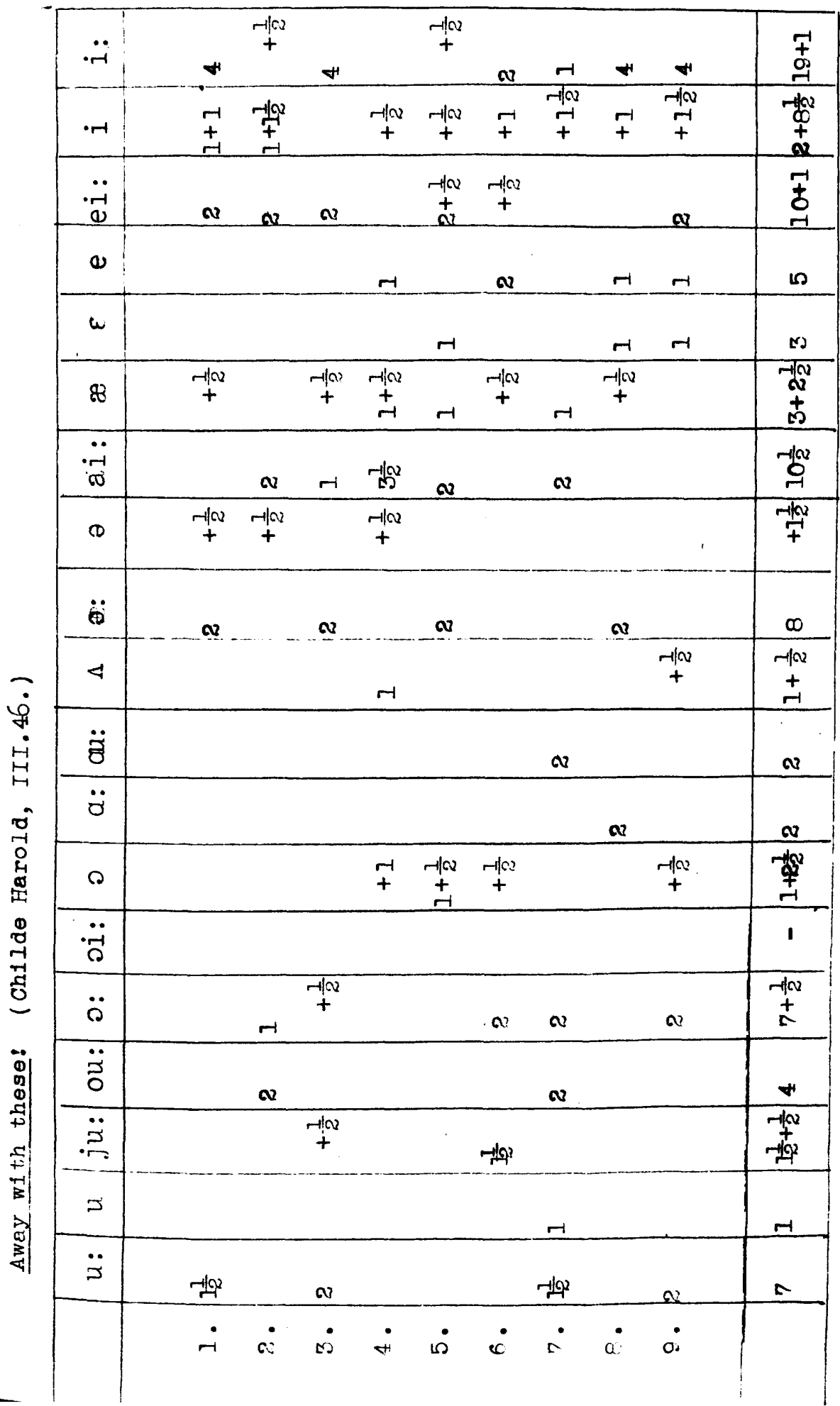




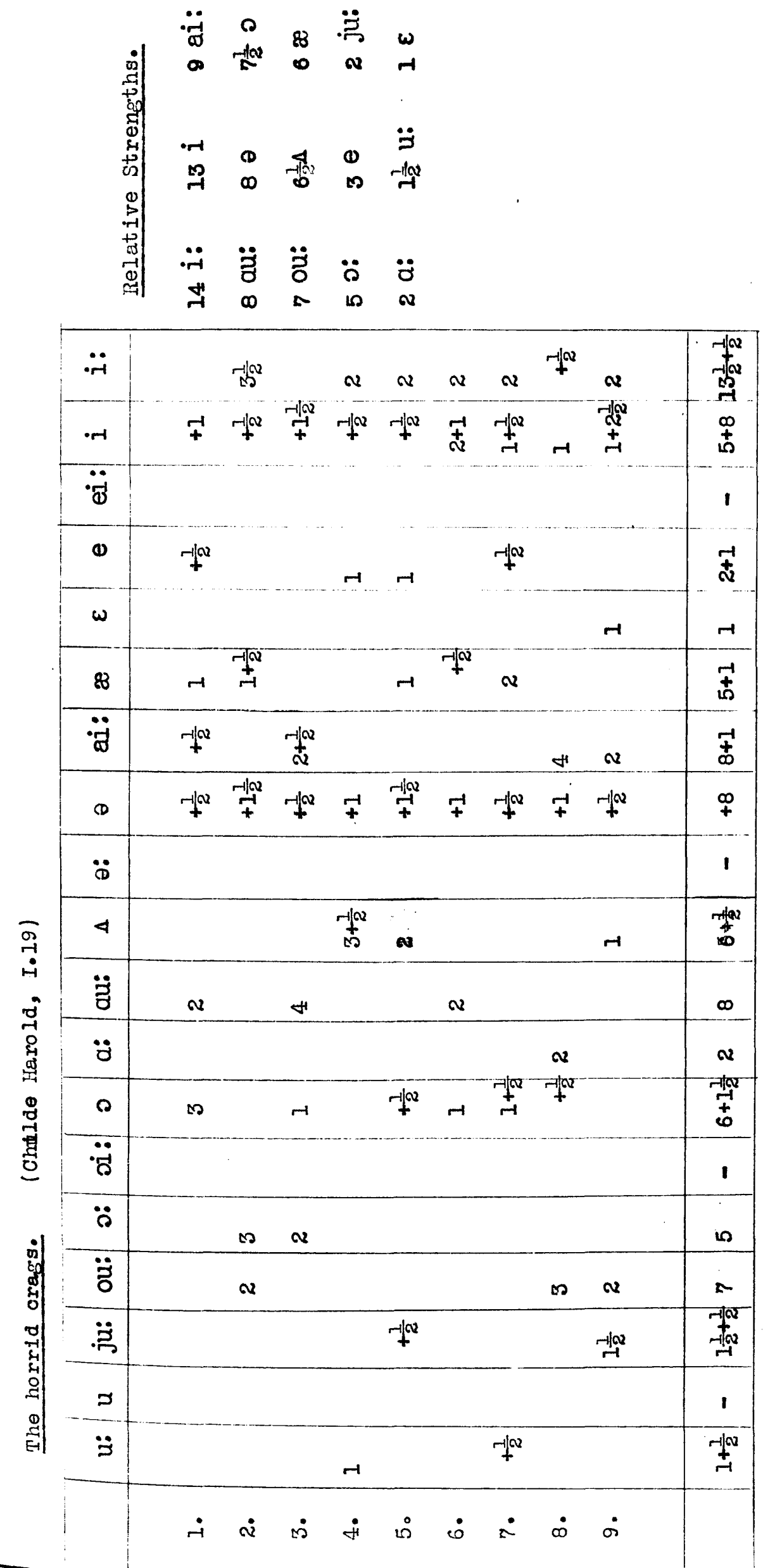




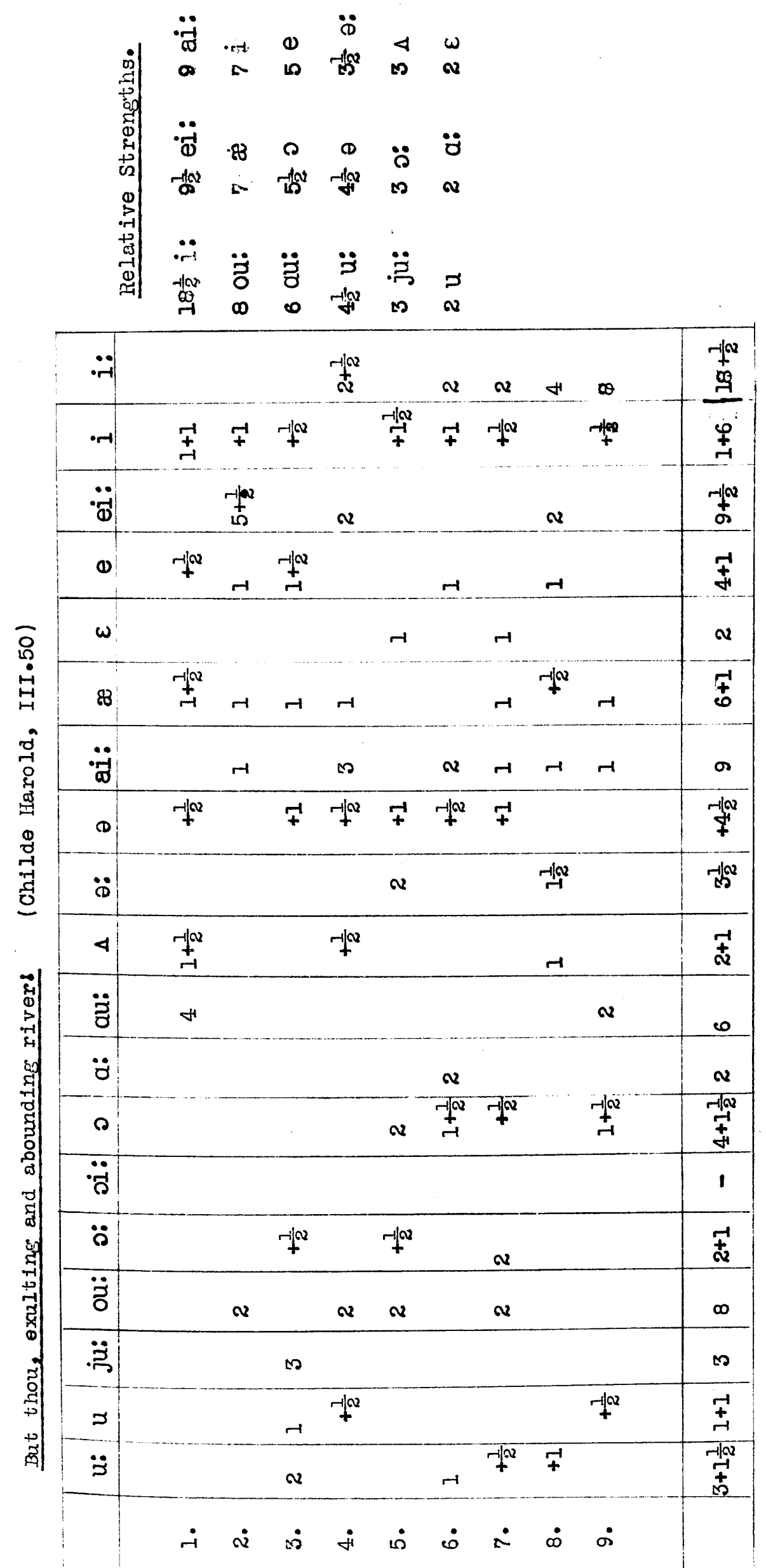




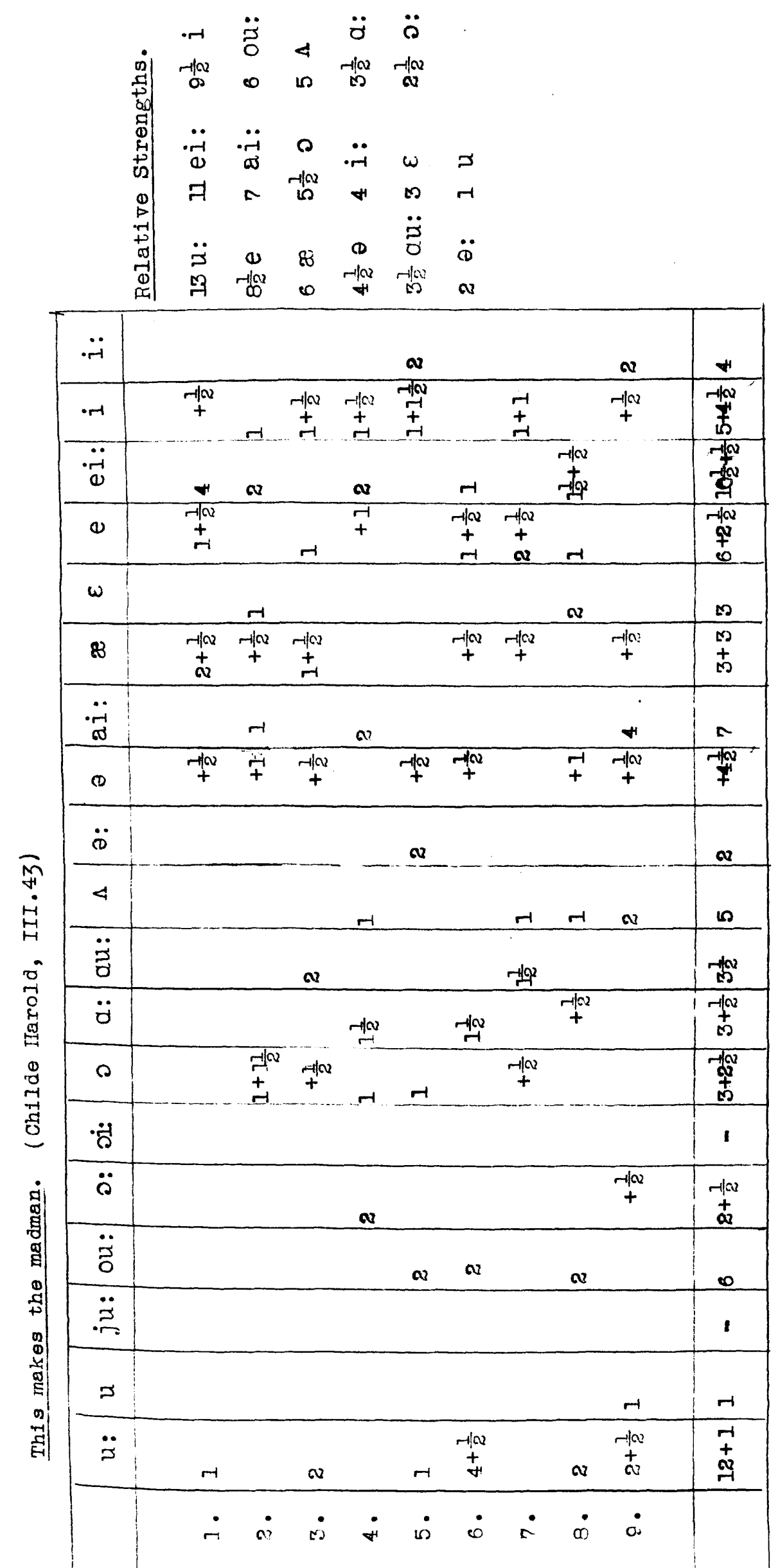




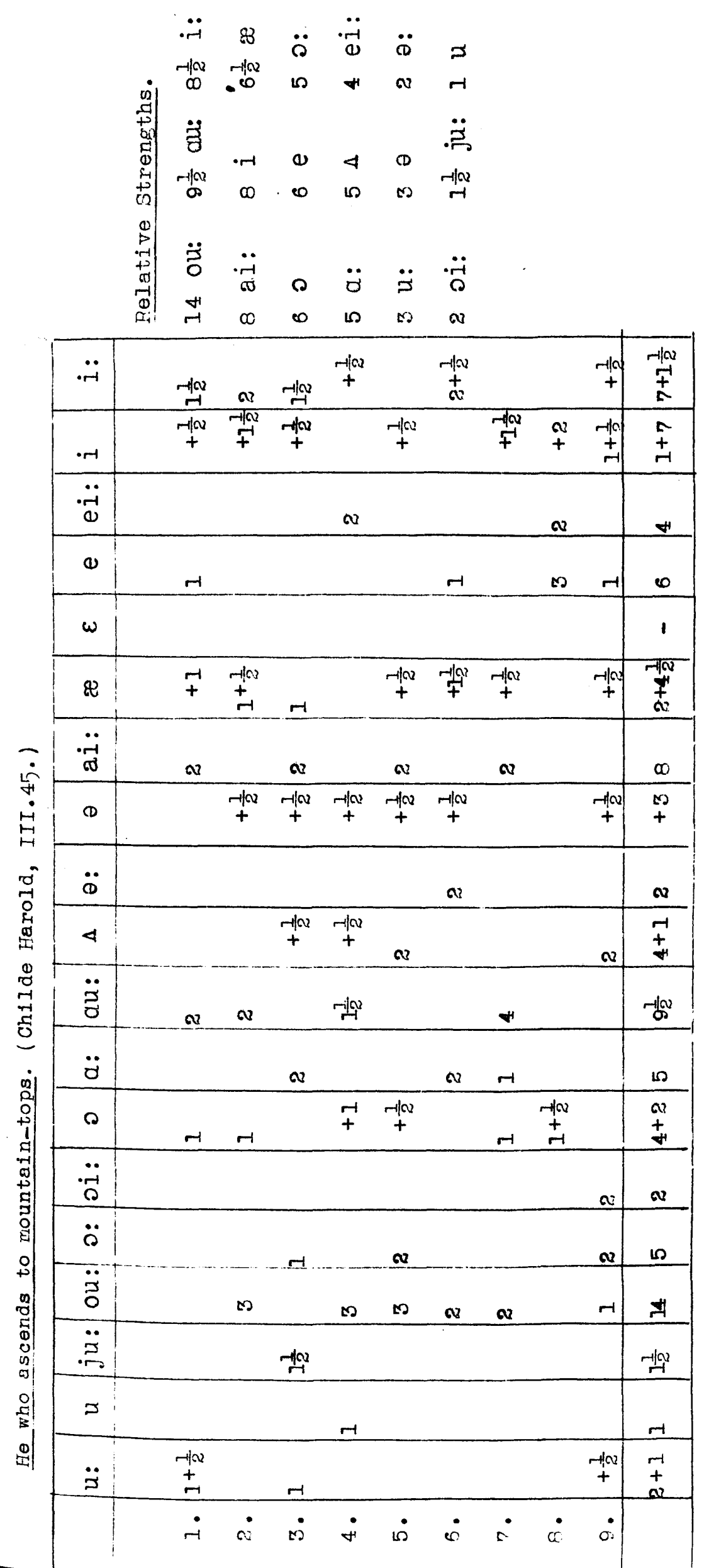




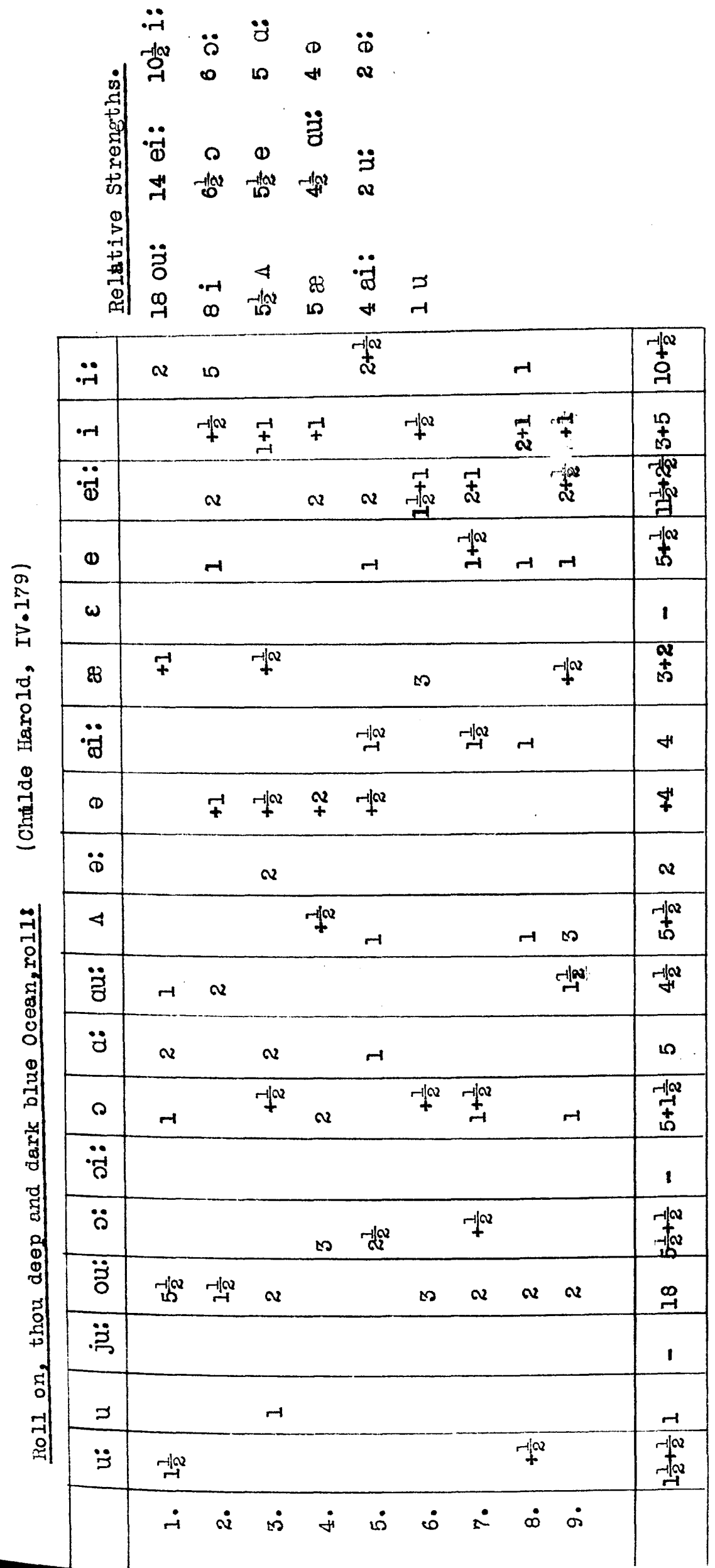




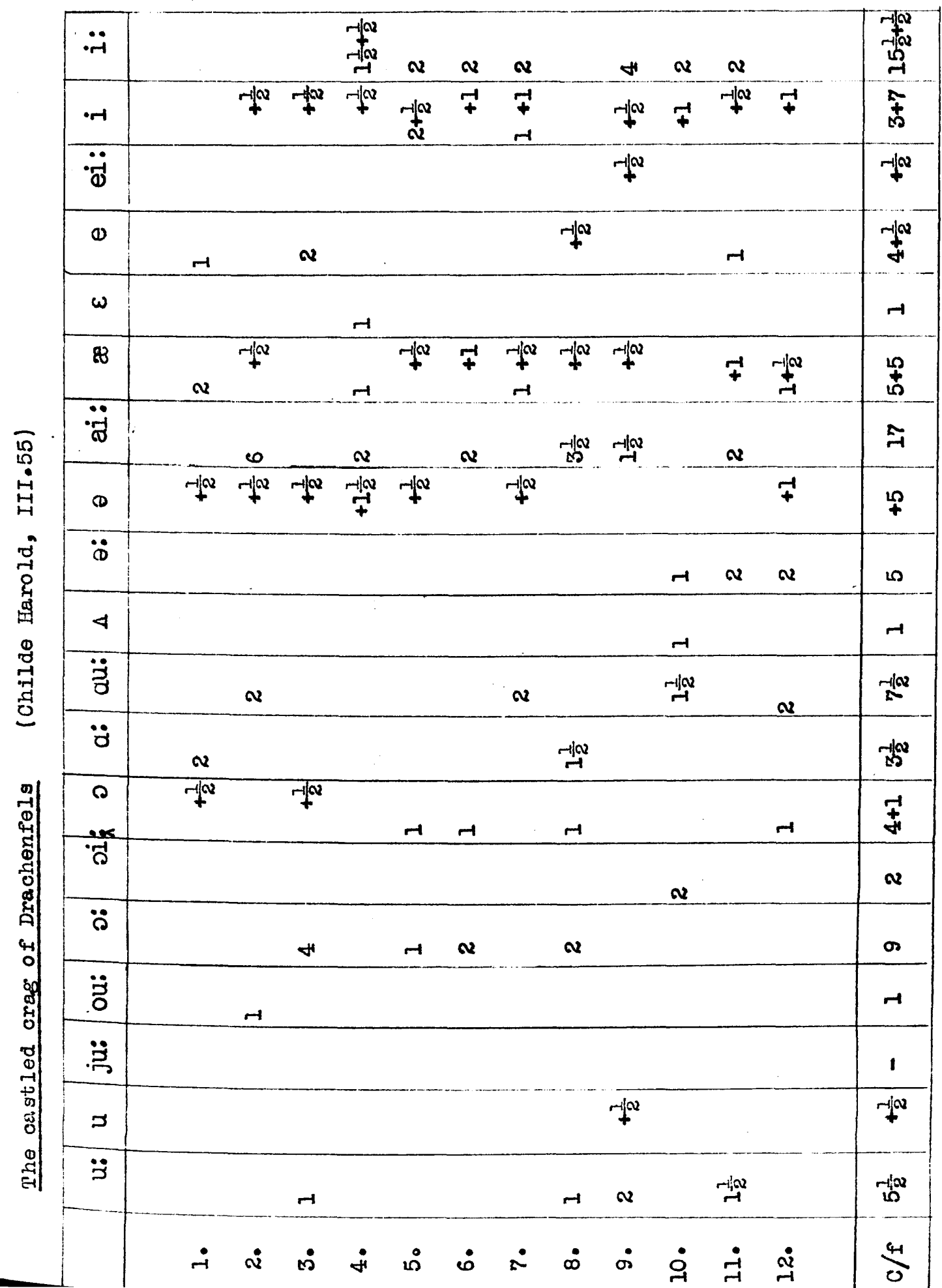




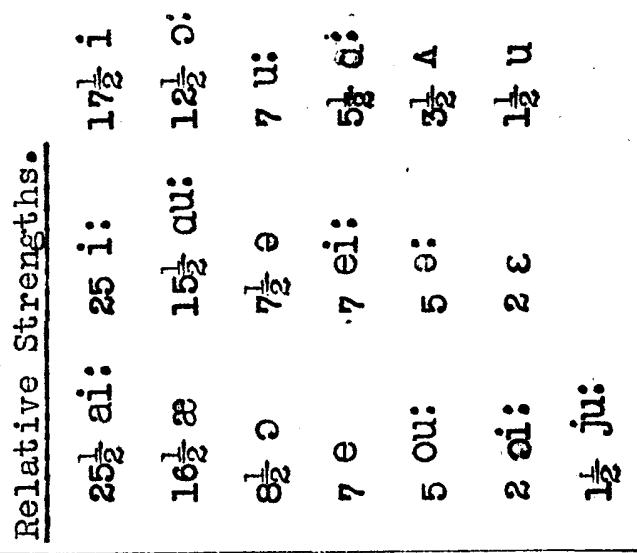

\begin{tabular}{|c|c|c|c|c|c|c|c|c|c|c|}
\hline$\ddot{~}$ & 留 & & $\curvearrowright$ & ryd & 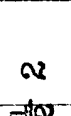 & +1 & & \multicolumn{2}{|l|}{-1} & $\underset{+}{+}$ \\
\hline$\cdot r 1$ & 市 & $\overrightarrow{+}$ & & -1 & $\stackrel{+10}{+}$ & $-1 Q^{2}$ & $\underset{+}{+1}$ & \multirow[t]{3}{*}{-1} & \multirow[t]{3}{*}{ 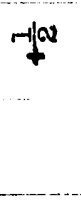 } & $\begin{array}{l}\text { नाँ } \\
\text { है }\end{array}$ \\
\hline$\ddot{\ddot{A}}$ & 7 & & & & $F^{\infty}$ & & & & & $\underset{t}{+1}$ \\
\hline & & & & $v$ & & $\Omega$ & $v$ & & & \\
\hline $\boldsymbol{\omega}$ & $\begin{array}{c}+10 Q \\
+\end{array}$ & & $+t^{2}$ & & -1 & & & & $r$ & $\underset{t}{+1}$ \\
\hline$\omega$ & $r$ & & & -1 & & & & & & $v$ \\
\hline 88 & $\begin{array}{l}\text { L } \\
10 \\
\end{array}$ & $\begin{array}{l}r f^{2} \\
-1\end{array}$ & 7 & & +7 & $\Psi^{\infty}$ & & $r$ & $\mathbf{v}$ & $\begin{array}{l}-10 \\
+\infty \\
+\infty\end{array}$ \\
\hline$\ddot{\ddot{a}}$ & $\stackrel{\pi}{-1}$ & +4 & & & & & & $v$ & rdv & 营 \\
\hline C & 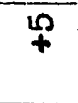 & 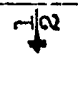 & $\vec{t}$ & & -100 & & -102 & & & $\underset{+}{-102}$ \\
\hline$\ddot{D}$ & م & & & & & & & & & ما \\
\hline 4 & +1 & & -1 & & & & & $\stackrel{-1}{-1}$ & & $\stackrel{H a v}{m}$ \\
\hline$\ddot{3}$ & $\stackrel{r-10 Q}{2}$ & & $\mathbf{v}$ & & $v$ & $v$ & $\mathbf{Q}$ & & & 訔 \\
\hline$\ddot{z}$ & ride & & & & & $v$ & & & & मी \\
\hline$\curvearrowright$ & $\stackrel{+1}{+}$ & & & -10 & & & $-1+a$ & $\underset{+}{-1}$ & & $\begin{array}{c}-y_{a}^{2} \\
t \\
0\end{array}$ \\
\hline$\ddot{\ddot{c}}$ & $\underline{Q}$ & & & & & & & & & $\boldsymbol{v}$ \\
\hline$\ddot{0}$ & $\alpha$ & $\stackrel{-10 x}{-10}$ & & $\mathbf{v}$ & & & & & & $\underset{d}{d x}$ \\
\hline$\ddot{\partial}$ & $r$ & $r$ & & & & $\boldsymbol{\sim}$ & -1 & & & $\boldsymbol{L}$ \\
\hline : & 1 & & $\stackrel{-1 / \infty}{-1}$ & & & & & & & $\stackrel{-10 x}{r}$ \\
\hline 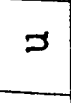 & reg & & & & & & -1 & & & $\underset{r-1}{f+2}$ \\
\hline$\ddot{\exists}$ & ris & & & $H$ & & & & & $r+100$ & $\begin{array}{l}-1 a \\
-\sqrt{a} \\
\infty\end{array}$ \\
\hline & $\sum_{m}^{4}$ & $\stackrel{m}{\rightarrow}$ & $\underset{H}{\stackrel{\leftrightarrow}{*}}$ & $\stackrel{10}{10}$ & $\stackrel{\leftrightarrow}{\circ}$ & $\stackrel{\dot{\pi}}{-1}$ & $\stackrel{\dot{0}}{\dot{-1}}$ & $\underset{\sim}{\vec{r}}$ & $\dot{8}$ & \\
\hline
\end{tabular}




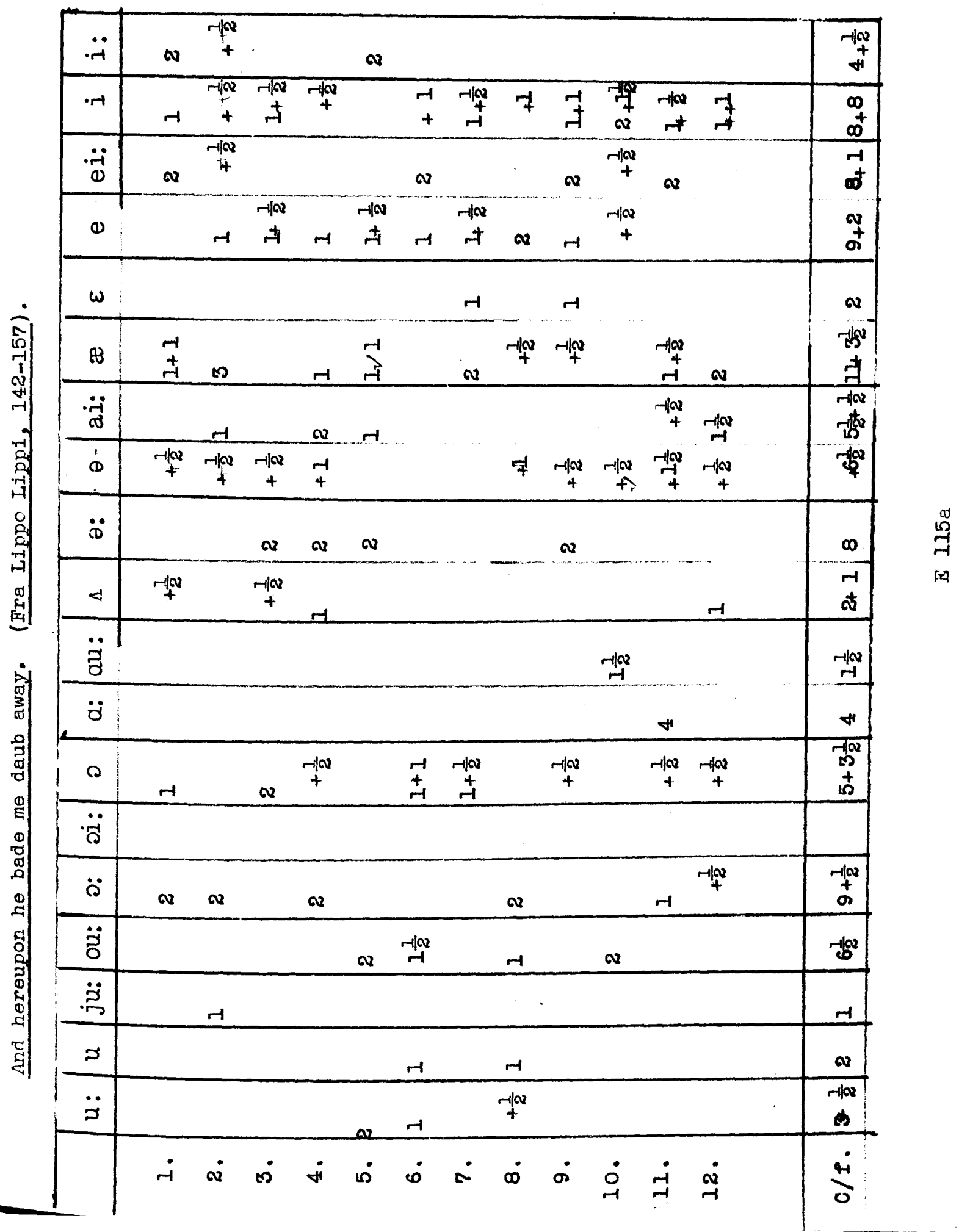




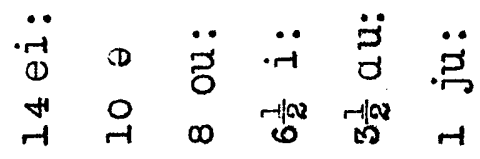

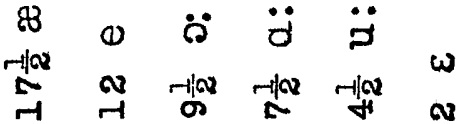

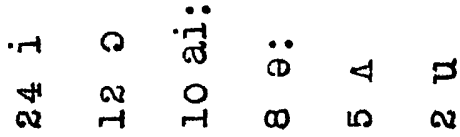

\begin{tabular}{|c|c|c|c|c|c|c|}
\hline$\ddot{\ddot{H}}$ & $\begin{array}{l}-\| \alpha \\
t\end{array}$ & & 7 & $\stackrel{-10 v}{-1}$ & & 啇 \\
\hline$\cdot r$ & $\begin{array}{l}\infty \\
\omega \\
\phi\end{array}$ & 跒 & $\stackrel{\omega}{+}$ & $\begin{array}{c}m \mid \omega \\
H\end{array}$ & $r$ & ते \\
\hline$\ddot{\ddot{\theta}}$ & $\stackrel{+1}{+1}$ & $i_{Q}^{-1 \mid \alpha}$ & & o & $\begin{array}{c}-1 / \infty \\
+\end{array}$ & $\begin{array}{l}0 \\
4 \\
9 \\
9\end{array}$ \\
\hline 0 & $\begin{array}{l}q \\
\sigma\end{array}$ & & -1 & & & $\begin{array}{c}0 \\
+ \\
0 \\
9\end{array}$ \\
\hline$\omega$ & $\infty$ & & & & & v \\
\hline $\mathbb{8}$ & $\begin{array}{l}\text { 施 } \\
\text { 等 }\end{array}$ & $\begin{array}{c}r+w \\
+\end{array}$ & & 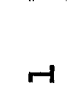 & $\underset{+}{r+\infty}$ & 然 \\
\hline$\ddot{\ddot{r}}$ & $\begin{array}{l}r^{-1 \alpha} \\
r^{2}\end{array}$ & & 4 & & & 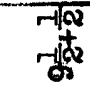 \\
\hline (1) & 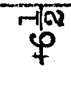 & $-\pi \mid w$ & $\stackrel{r+\infty}{t}$ & 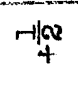 & $\mathbf{O S}$ & $\begin{array}{r}9 \\
+\end{array}$ \\
\hline$\ddot{D}$ & $\infty$ & & & & & $\infty$ \\
\hline$\triangleleft$ & $\begin{array}{l}-1 \\
+ \\
\infty\end{array}$ & -1 & $H$ & & & 4 \\
\hline$\ddot{z}$ & $\stackrel{-1 / \alpha}{-1 \times}$ & & & & 0 & नुल \\
\hline$\ddot{\sigma}$ & + & $\boldsymbol{v}$ & & & $\stackrel{-1 / 00}{H}$ & $\underset{\sim}{-1 N Q}$ \\
\hline$\curvearrowright$ & $\begin{array}{c}7 \sqrt{2}^{2} \\
+ \\
10 \\
\end{array}$ & & $\begin{array}{c}-1 w \\
+5 \\
+5\end{array}$ & $\begin{array}{c}-10, \\
+1 \\
-1\end{array}$ & -100 & $\begin{array}{l}10 \\
\pm \\
5\end{array}$ \\
\hline$\ddot{~} \ddot{\circ}$ & & & & & & \\
\hline$\ddot{r}$ & $\begin{array}{c}\text { ris } \\
+ \\
\sigma^{+}\end{array}$ & & & & & $\begin{array}{c}-10 \\
+1 \\
0\end{array}$ \\
\hline$\ddot{\tilde{z}}$ & $-\|_{0}^{-10}$ & & & ન્ન્ર & & $\infty$ \\
\hline$\ddot{\vec{D}}$ & $r$ & & & & & -1 \\
\hline D & 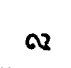 & & & & & $\boldsymbol{N}$ \\
\hline$\ddot{\jmath}$ & 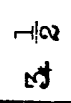 & & & -1 & & $\begin{array}{c}-1 \times 2 \\
4 \\
+\end{array}$ \\
\hline & $\stackrel{4}{m}^{4}$ & $\dot{m}$ & $\underset{-1}{\dot{H}}$ & $\underset{\sim}{0}$ & $\underset{\sim}{\dot{\sigma}}$ & \\
\hline
\end{tabular}




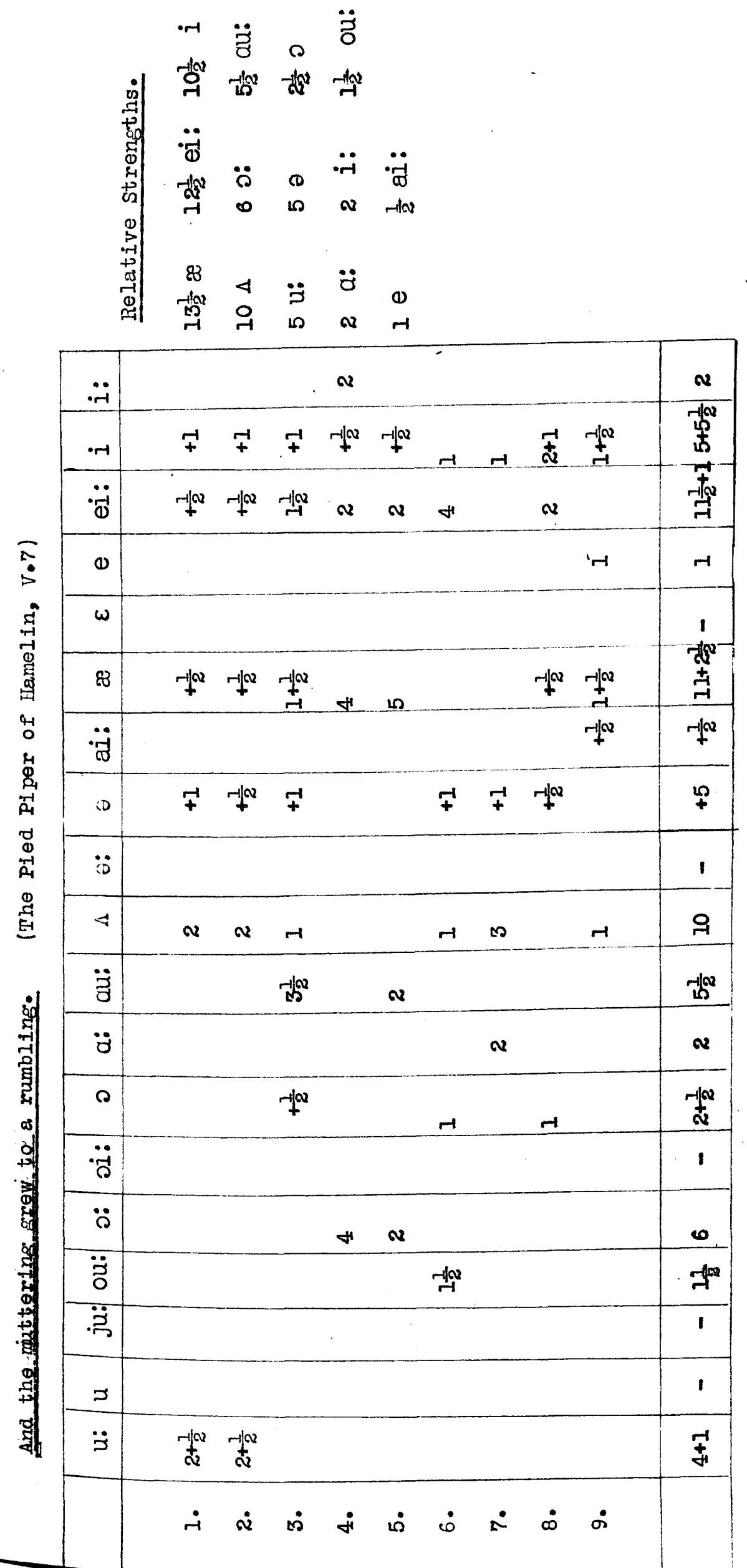




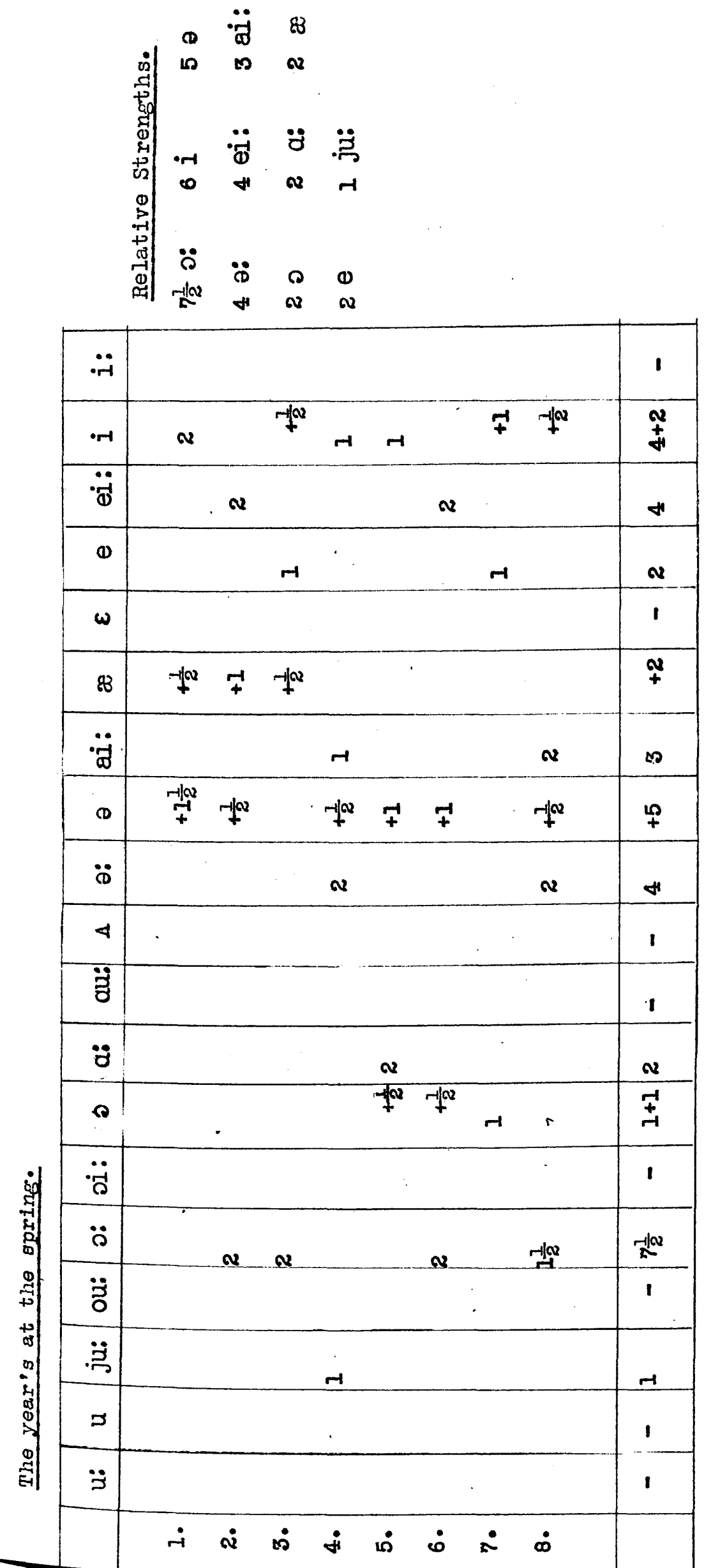




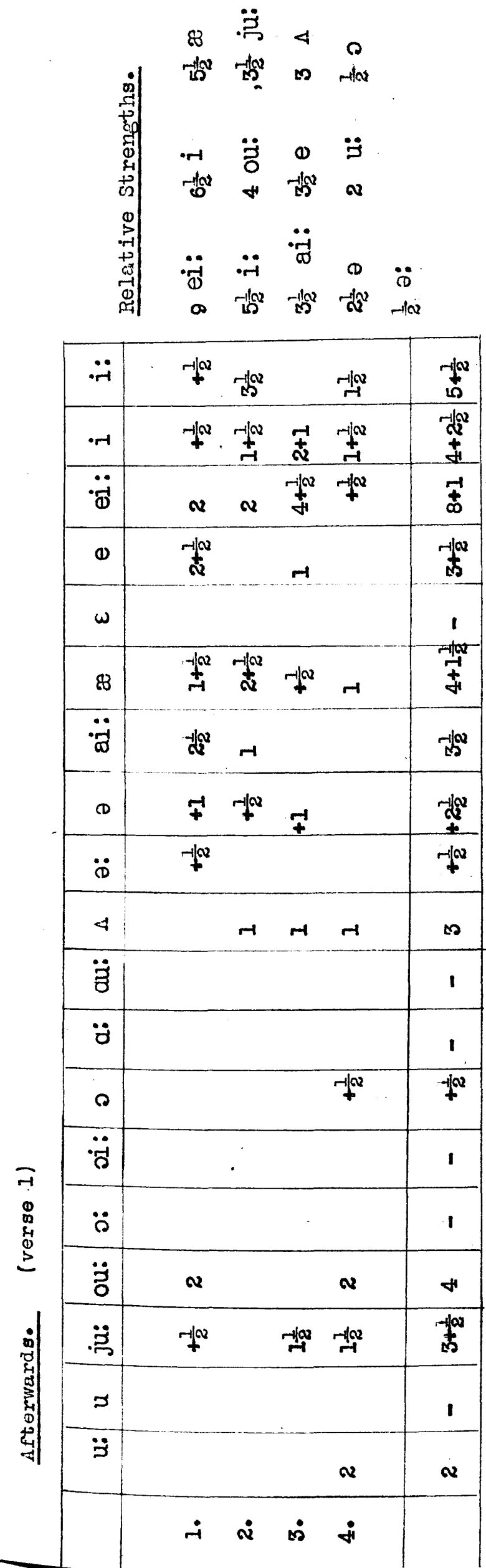




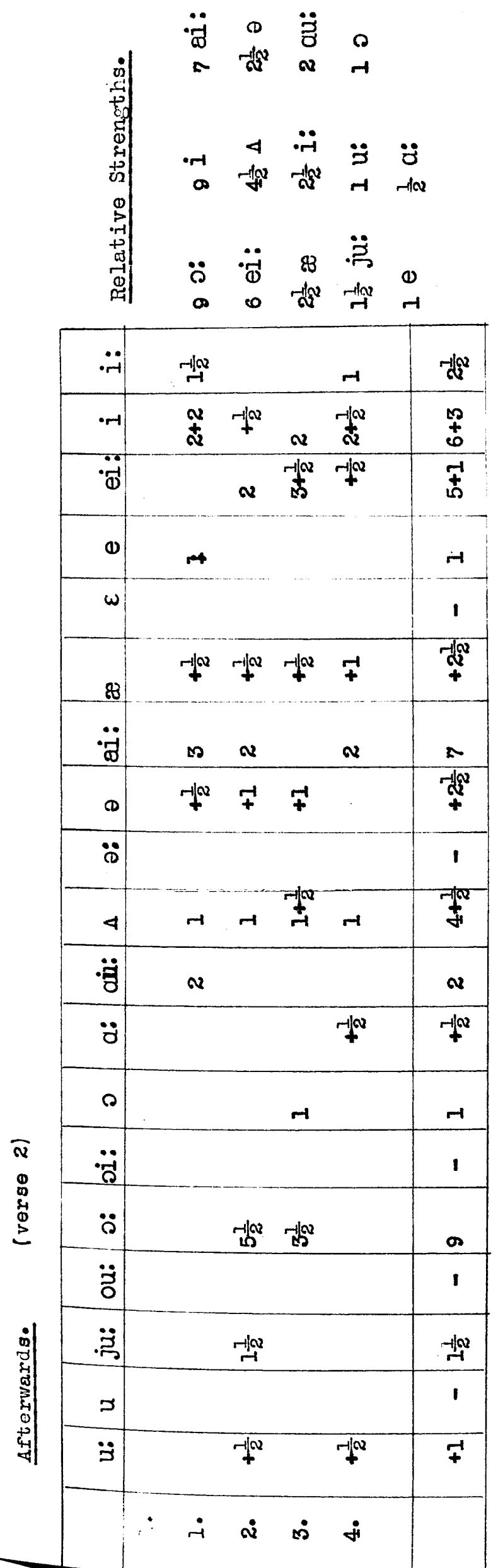




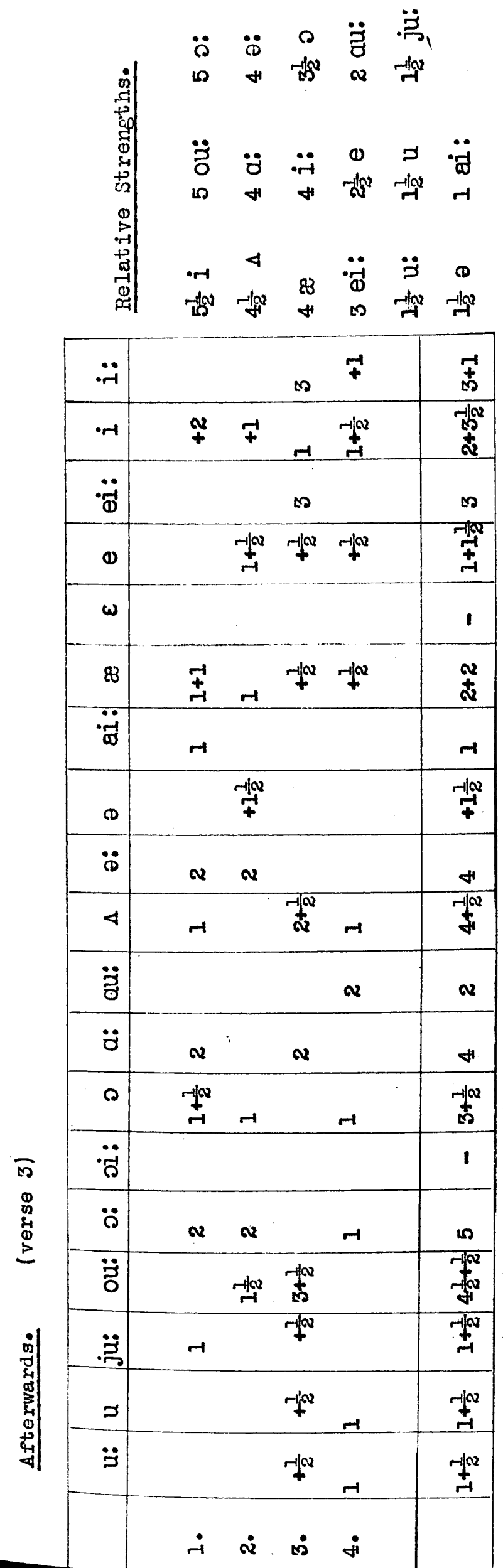




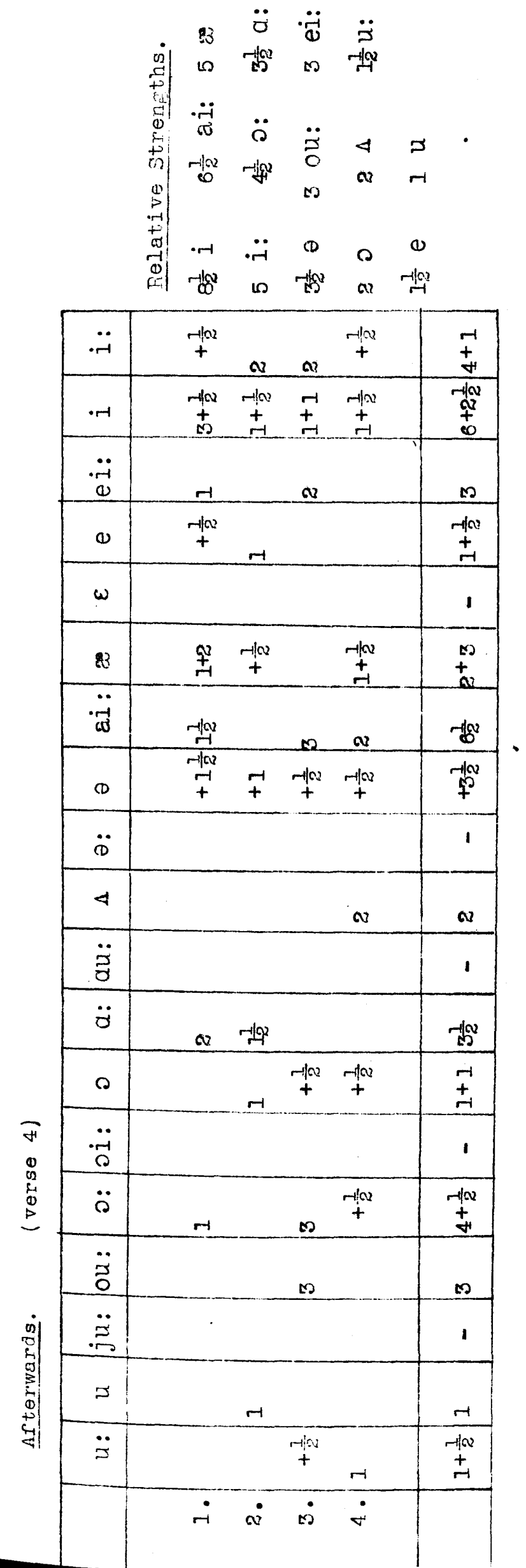




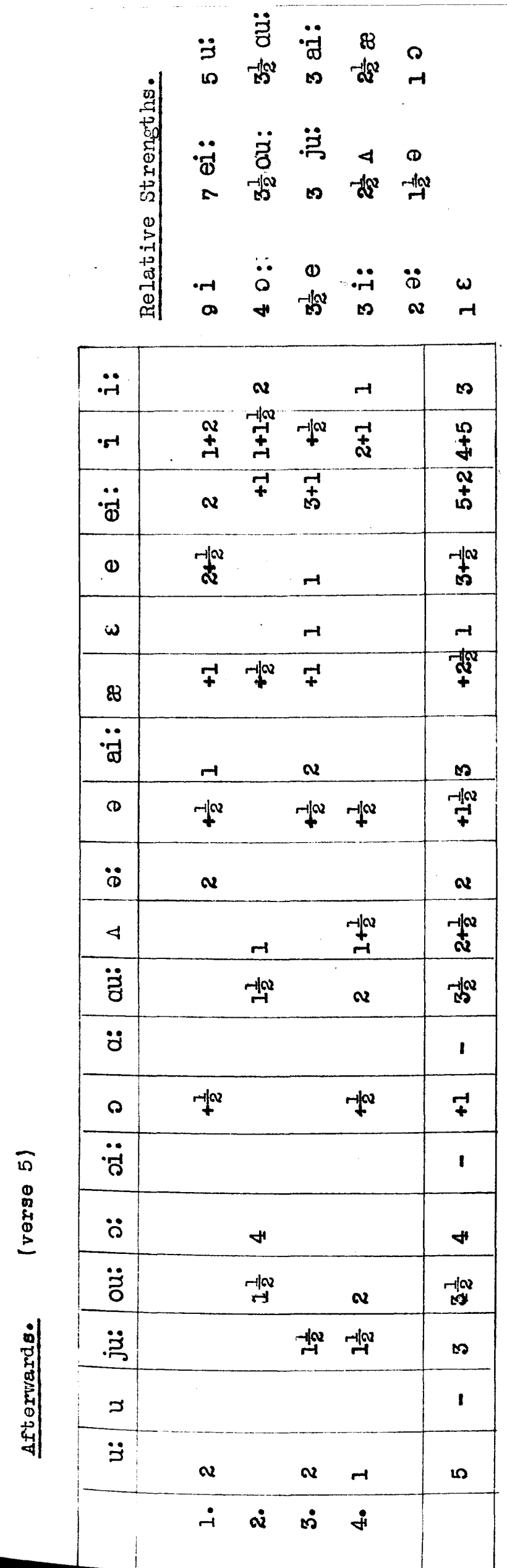




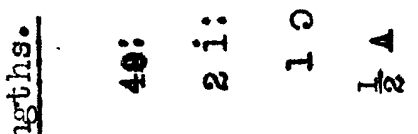

$\begin{array}{llll}\ddot{0} & \ddot{7} & \ddot{b} & 8 \\ 0 & 0 & -1 & -1\end{array}$

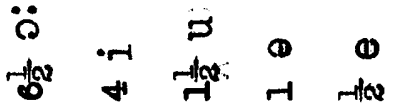

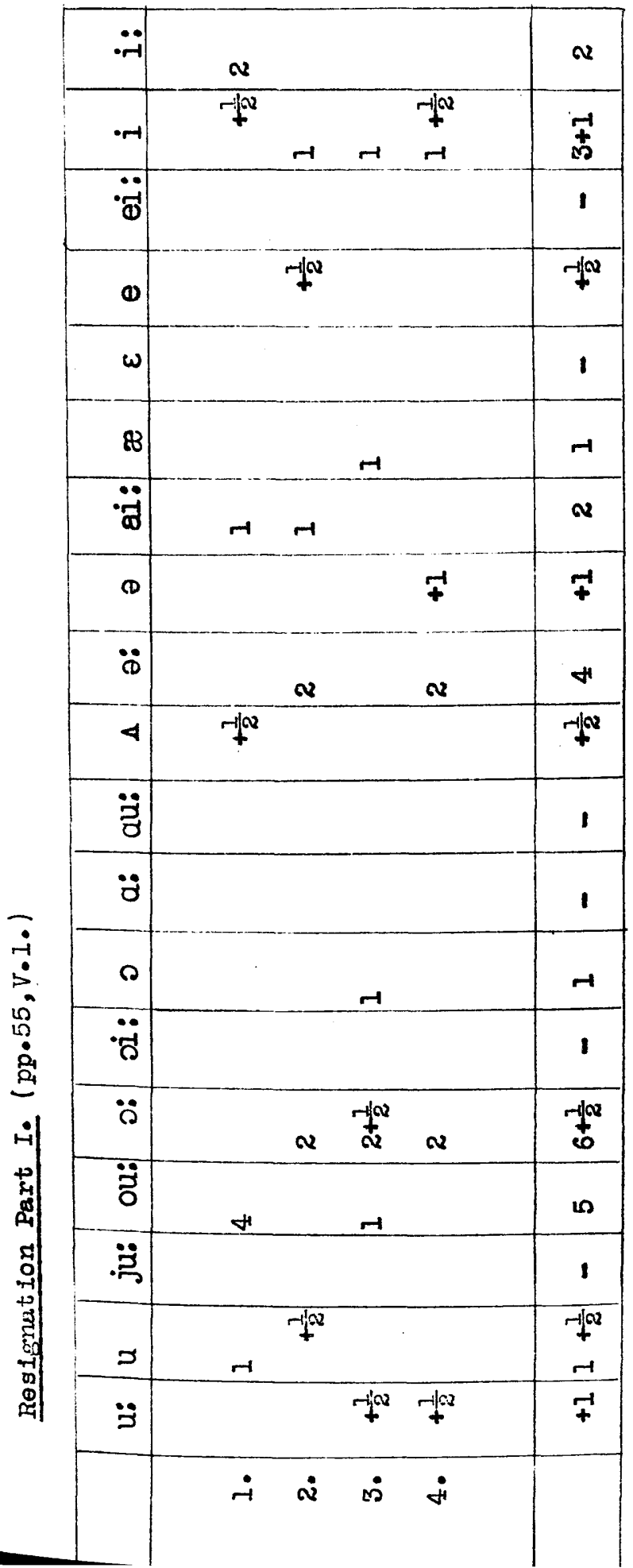



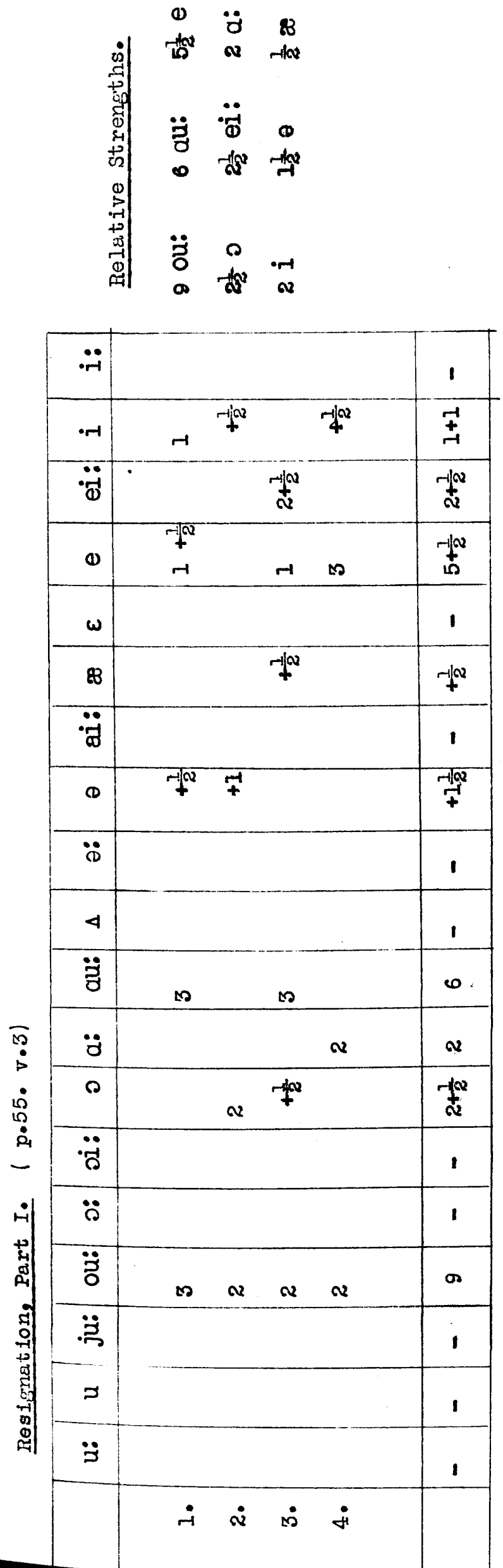


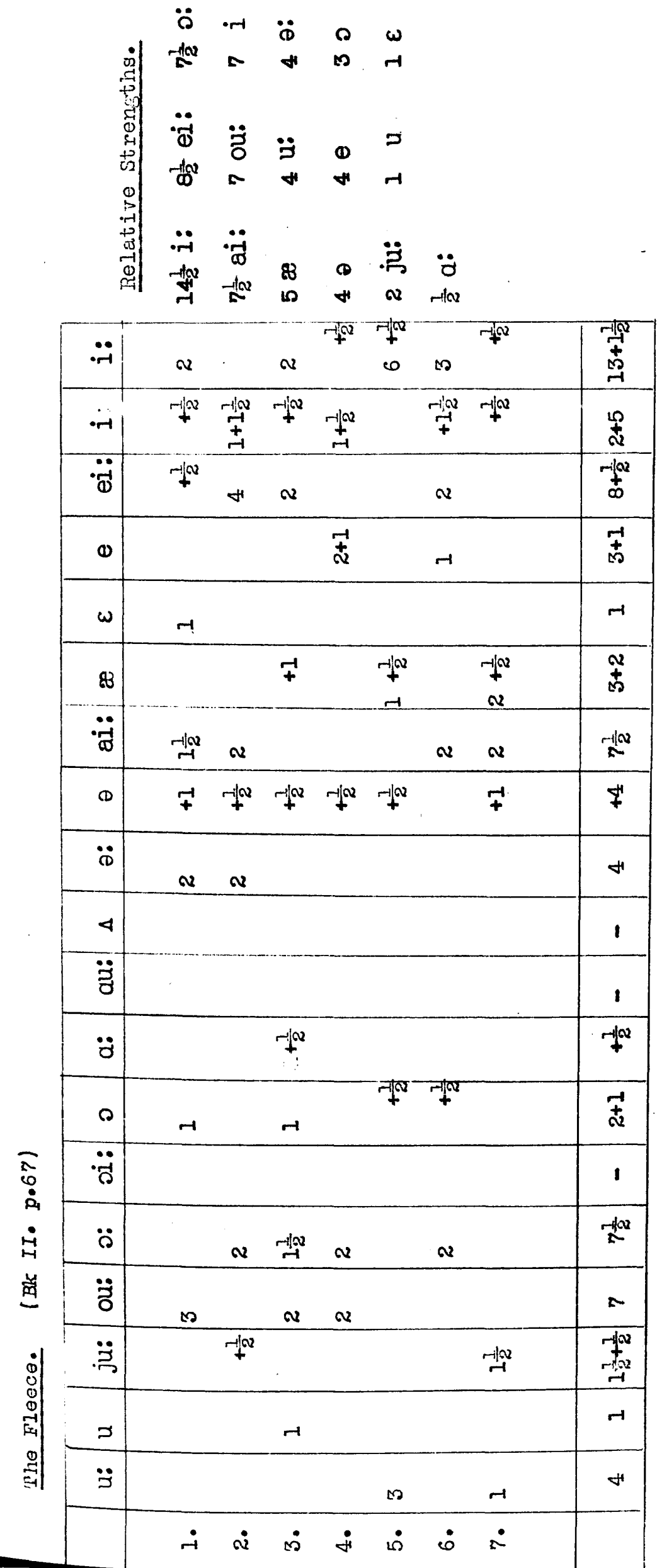




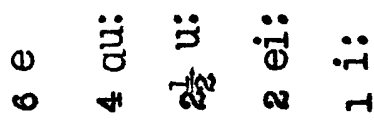

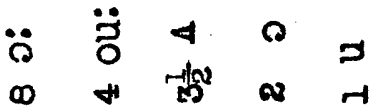

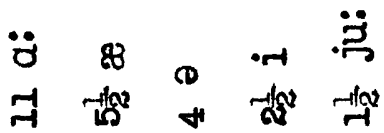

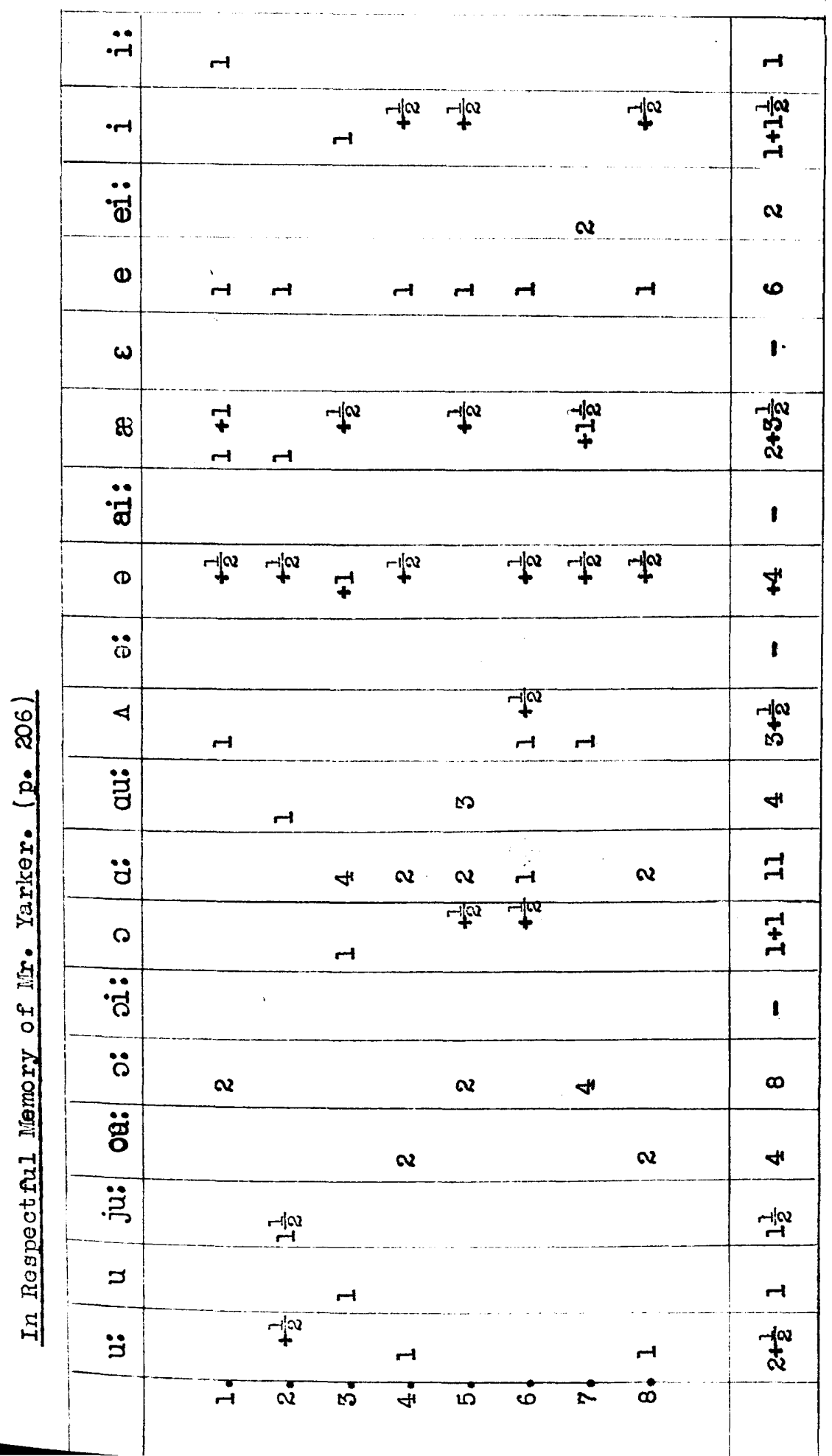




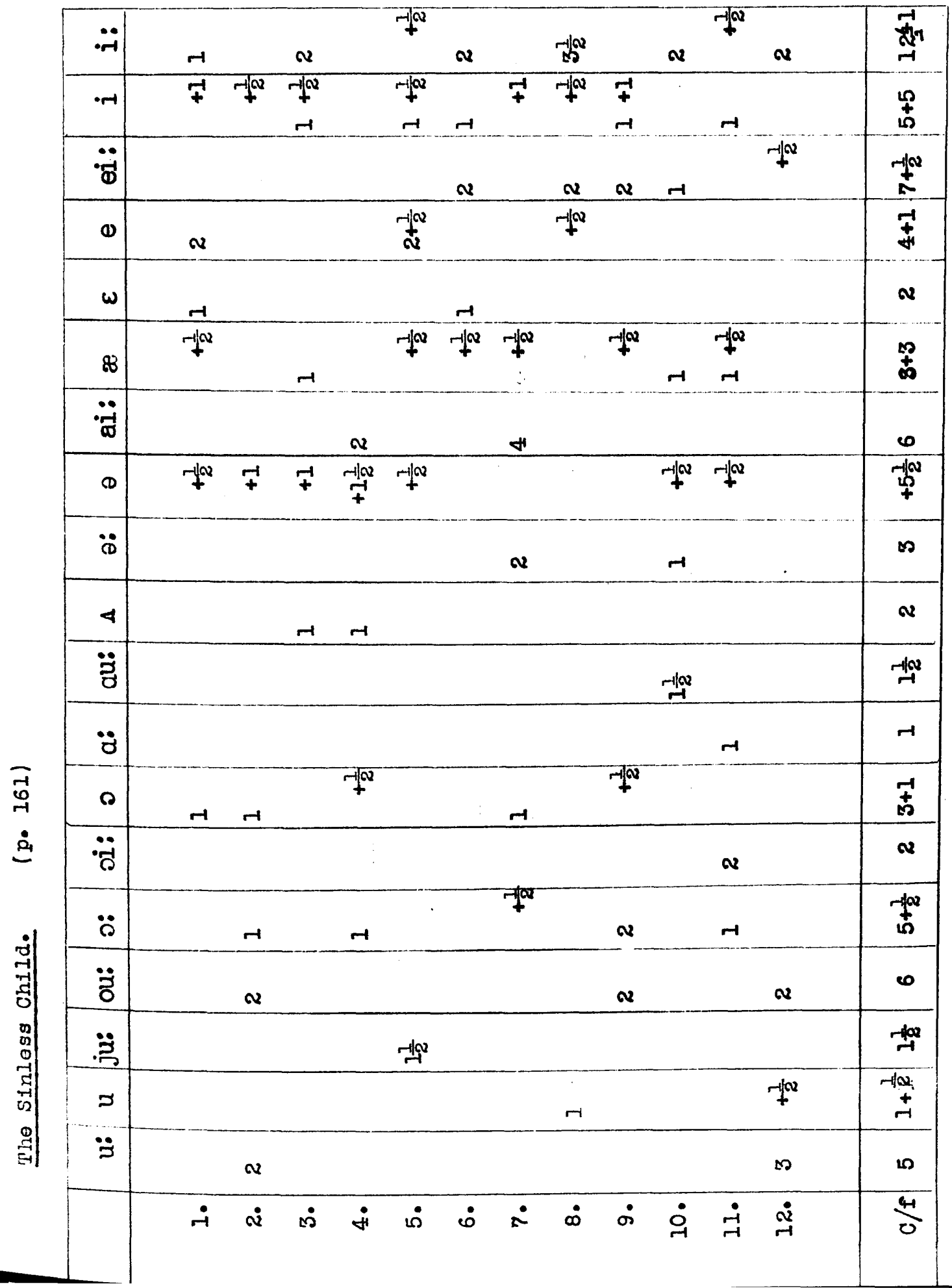

เึ็ 


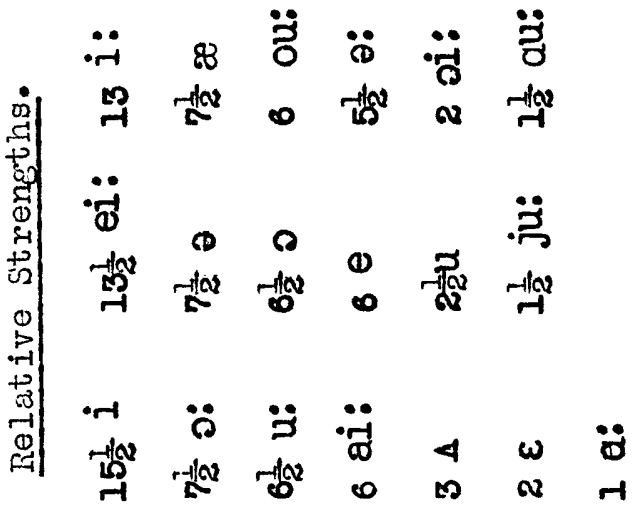

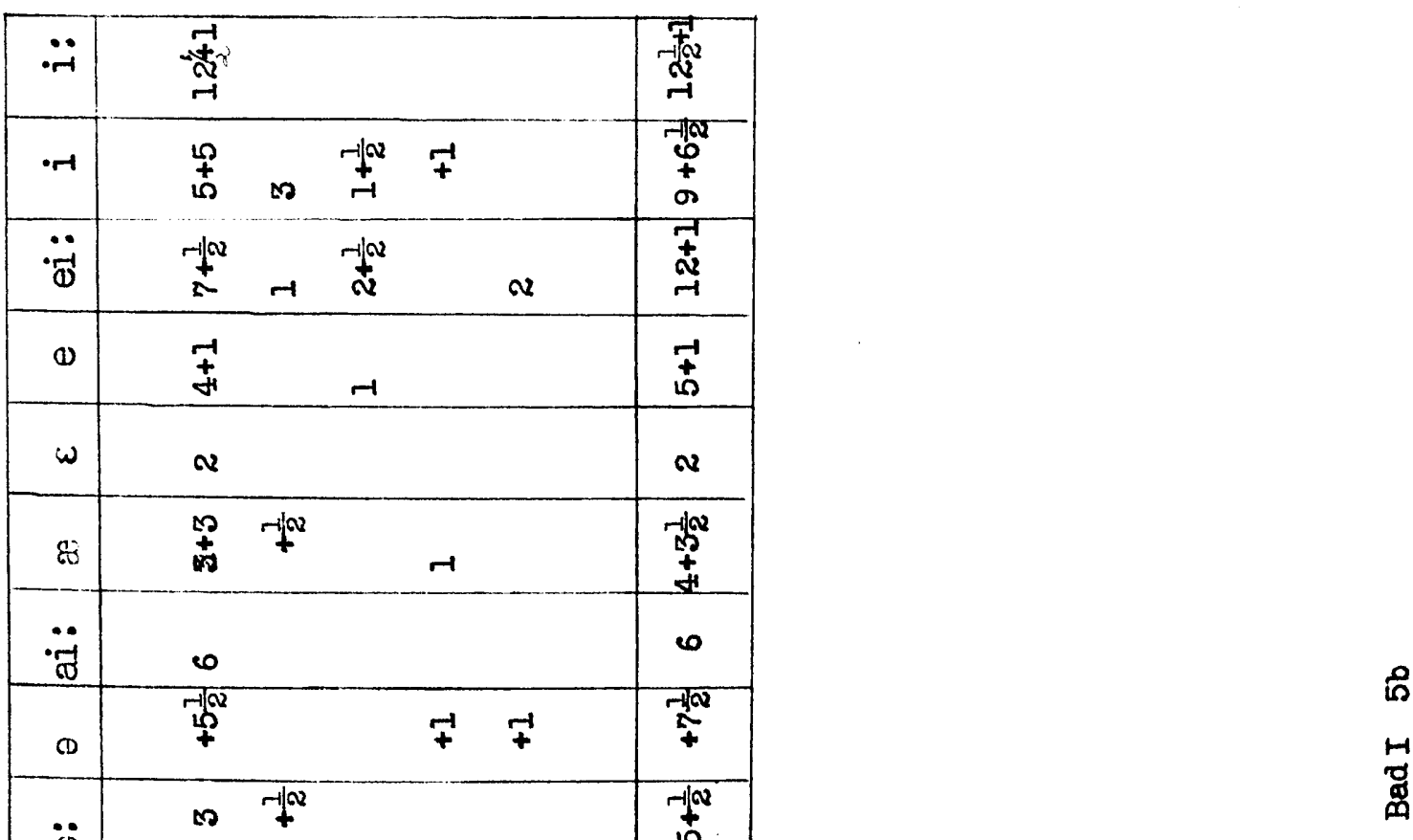




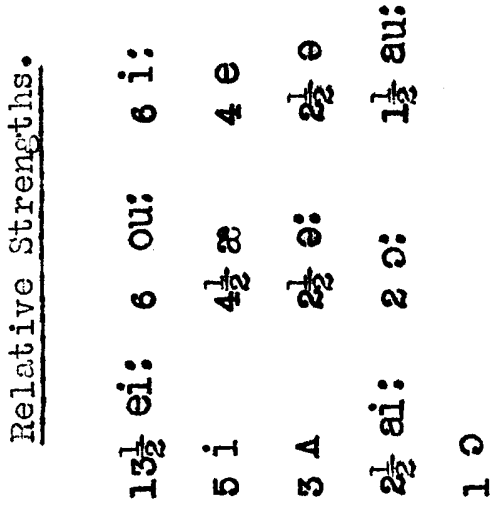

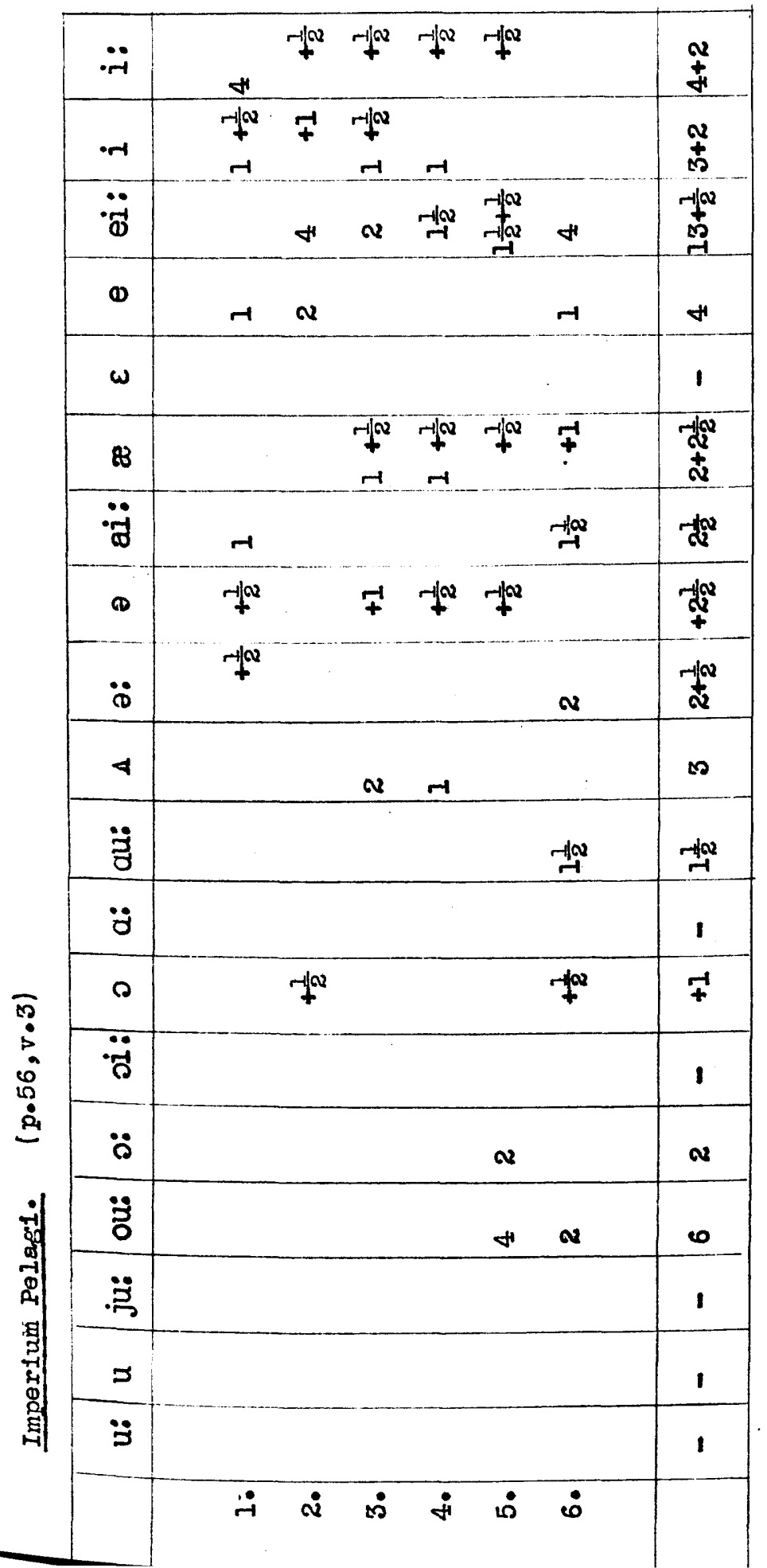




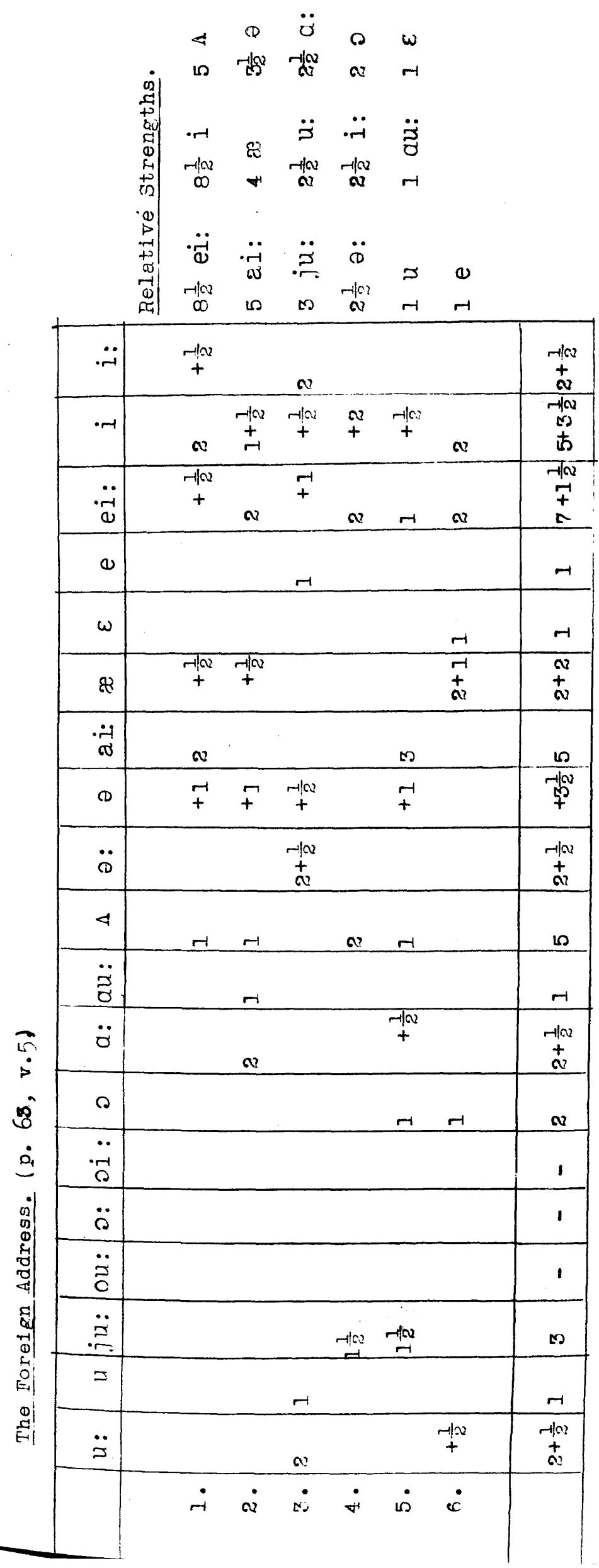




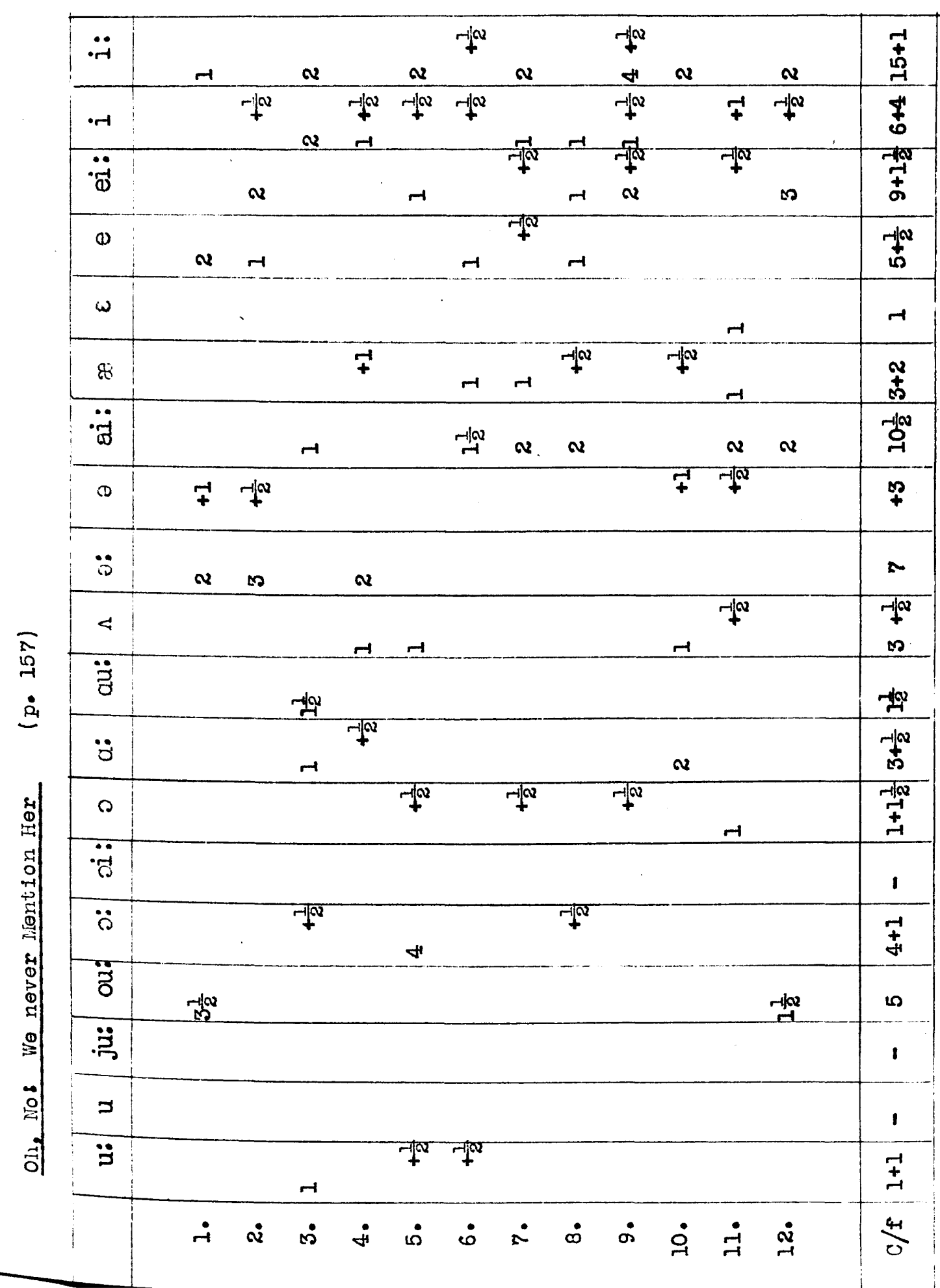




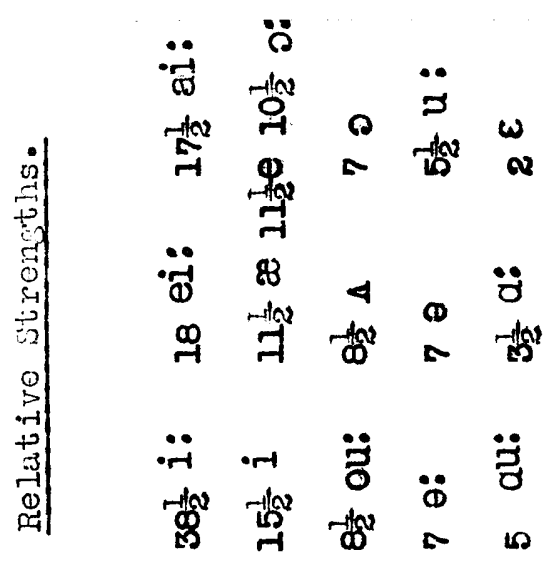

\begin{tabular}{|c|c|c|c|c|c|c|c|c|c|c|c|c|c|c|}
\hline$\because \ddot{1}$ & $\begin{array}{l}-1 \\
+ \\
+5 \\
-1\end{array}$ & $+f^{\infty}$ & +10 & $\theta^{4}$ & & - dev & & $H$ & $\boldsymbol{v}$ & $\infty$ & $-\sqrt{w}$ & -1 & $\boldsymbol{r}$ & 匈 \\
\hline$\cdot m-1$ & $\underset{6}{+}$ & $r+1 x^{\infty}$ & $+1 \infty$ & & & $\mp$ & $+t^{\alpha}$ & $r$ & & -1 & +7 & -10 & & $\begin{array}{l}\text { 选 } \\
+ \\
+\infty\end{array}$ \\
\hline$\ddot{-1}$ & $\begin{array}{c}\text { - } \\
+ \\
+ \\
0\end{array}$ & & & & & $7 \sqrt{N}$ & 4 & 7 & $\begin{array}{l}7^{2} \\
\boldsymbol{N}\end{array}$ & & & & & $\begin{array}{l}m \\
+ \\
5 \\
7\end{array}$ \\
\hline (1) & $\stackrel{r+10}{+\infty}$ & & -1 & & $r$ & $r$ & & & & & -1 & & $\boldsymbol{v}$ & 幂 \\
\hline$\omega$ & -1 & & -1 & & & & & & & & & & & $v$ \\
\hline aj & 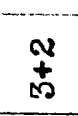 & 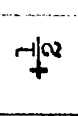 & 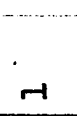 & & $-\sqrt{\alpha}$ & -1 & . & -7 & & $r$ & & + & -1 & $\underset{\$}{\$}$ \\
\hline$\because \ddot{d r}$ & $\underset{-1}{-10}$ & $\stackrel{r-1 / N}{-1}$ & & -1 & $\stackrel{-1 / N}{-1}$ & & & & & -1 & & $v$ & & $\stackrel{-100}{-1}$ \\
\hline 0 & $\stackrel{m}{+}$ & $t^{-102}$ & 7 & $-1 \sqrt{a}$ & & & 7 & & & $+\omega$ & & & -10 & 푸 \\
\hline$\ddot{\mathrm{D}}$ & $\sim$ & & & & & & & & & & & & & 2 \\
\hline 4 & में & & & & $+f^{\alpha}$ & & & & $-1 w^{\infty}$ & -1 & & $\infty$ & & $\underset{ \pm}{\stackrel{4}{4}}$ \\
\hline 苟 & r冓 & & & & 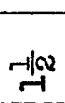 & $v$ & & & & & & & & مـ \\
\hline$\ddot{\partial}$ & $\underset{\infty}{+\infty}$ & & & & & & & & & & & & & 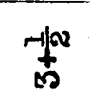 \\
\hline$\Omega$ & $\begin{array}{c}\text { ना/ } \\
+ \\
+1 \\
\end{array}$ & & & $-1 / \infty$ & & & $r$ & -1 & $\begin{array}{l}r+2 \\
r-1\end{array}$ & & 7 & & & $\stackrel{m}{\sharp}$ \\
\hline$\ddot{\ddot{\gamma}}$ & 1 & & & & & & & & & & & & & 1 \\
\hline$\ddot{8}$ & + & $r$ & & $\infty$ & $+1 x$ & & & $-1 x^{2}$ & & & & & ros & $\begin{array}{c}\text { न-ja } \\
+2 \\
+ \\
\infty \\
\end{array}$ \\
\hline$\ddot{z}$ & $\infty$ & ds & & & & & & & & & & & & $-\infty \infty$ \\
\hline$\ddot{\ddot{z}}$ & 1 & & & & & & & & & & & & & 1 \\
\hline 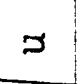 & 1 & & & & & & & & & & & & & 1 \\
\hline$\ddot{\partial}$ & $\stackrel{+1}{\oplus}$ & $\sim$ & & $\stackrel{-1}{\rightarrow}$ & & & & & & & rمس & & & $\overrightarrow{f i n}^{-1}$ \\
\hline & $\sum_{A}^{4}$ & $\dot{\sim}$ & $\underset{-}{\stackrel{\leftrightarrow}{-}}$ & مُ & $\dot{\sigma}_{-1}^{\circ}$ & $\stackrel{2}{\pi}$ & $\dot{\infty}$ & $\stackrel{\dot{r}}{\rightarrow}$ & $\dot{R}$ & $\dot{\vec{\alpha}}$ & $\dot{\mathfrak{Q}}$ & $\stackrel{\mathfrak{Q}}{\mathfrak{Q}}$ & $\dot{\leftrightarrow}$ & \\
\hline
\end{tabular}




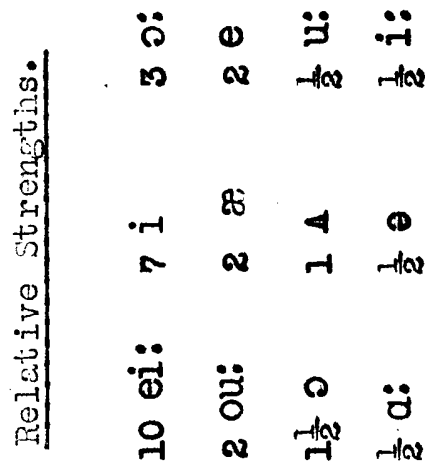

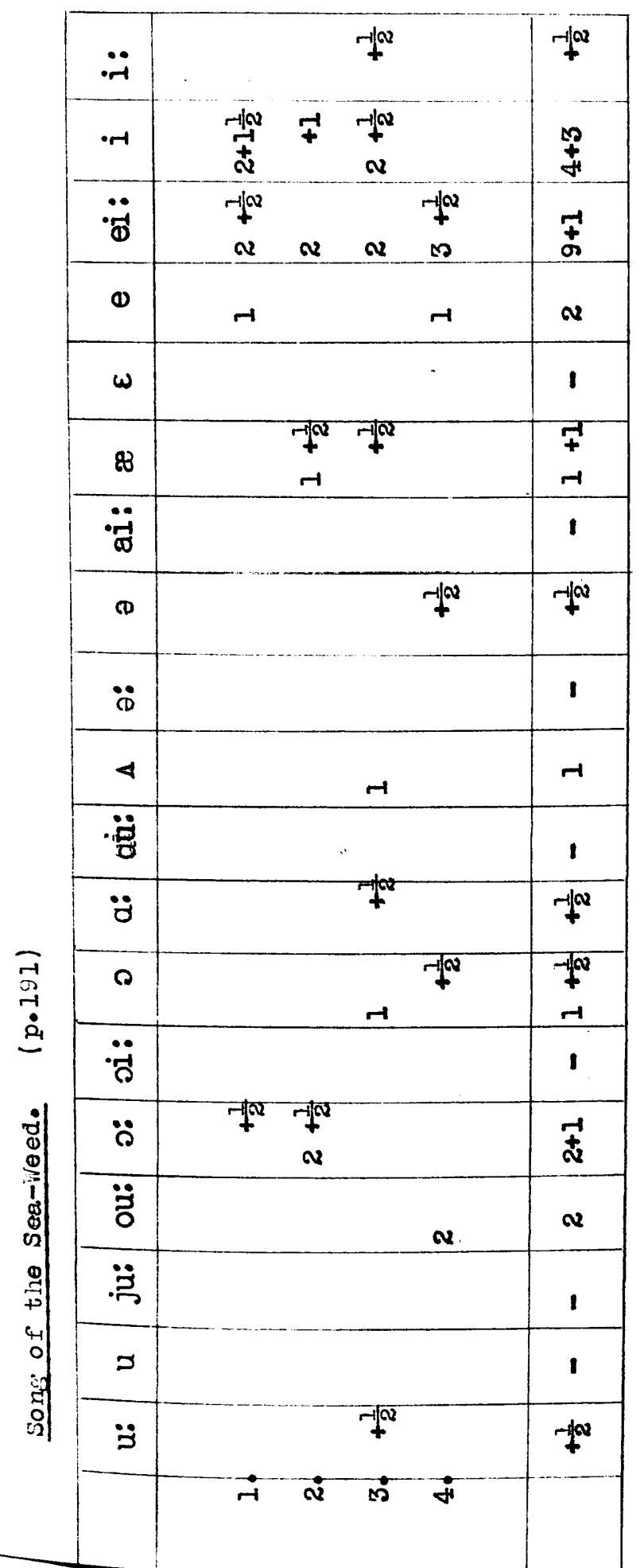

o
H
ต 


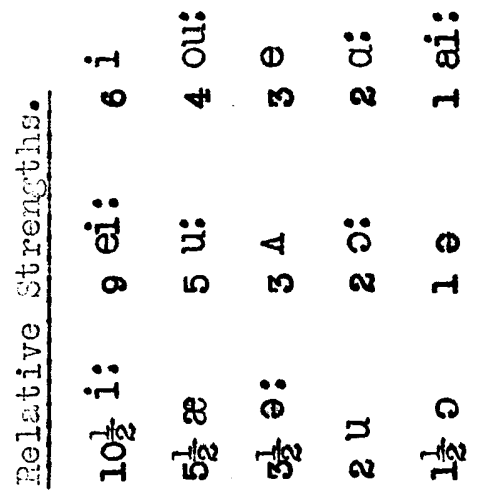

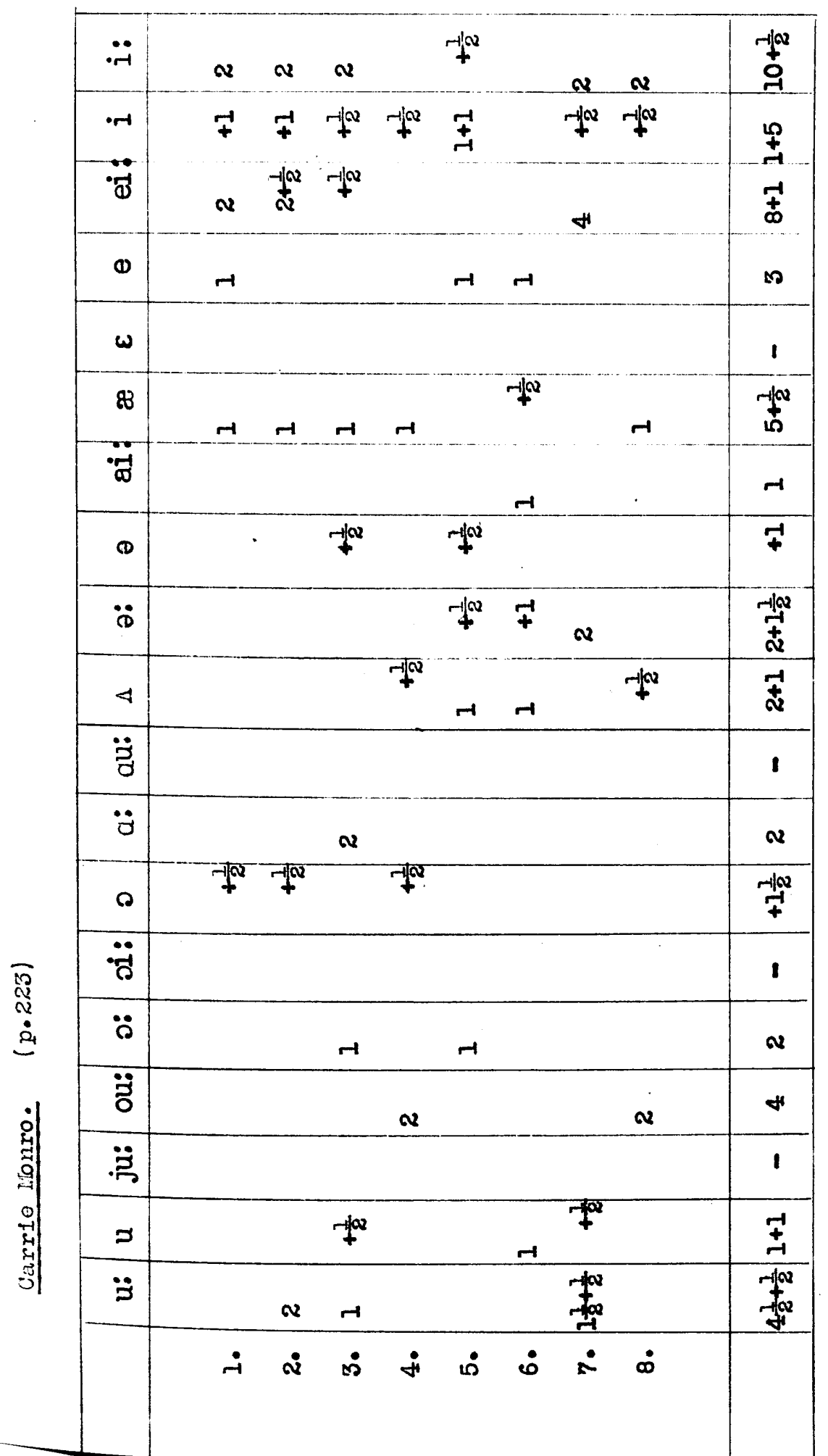




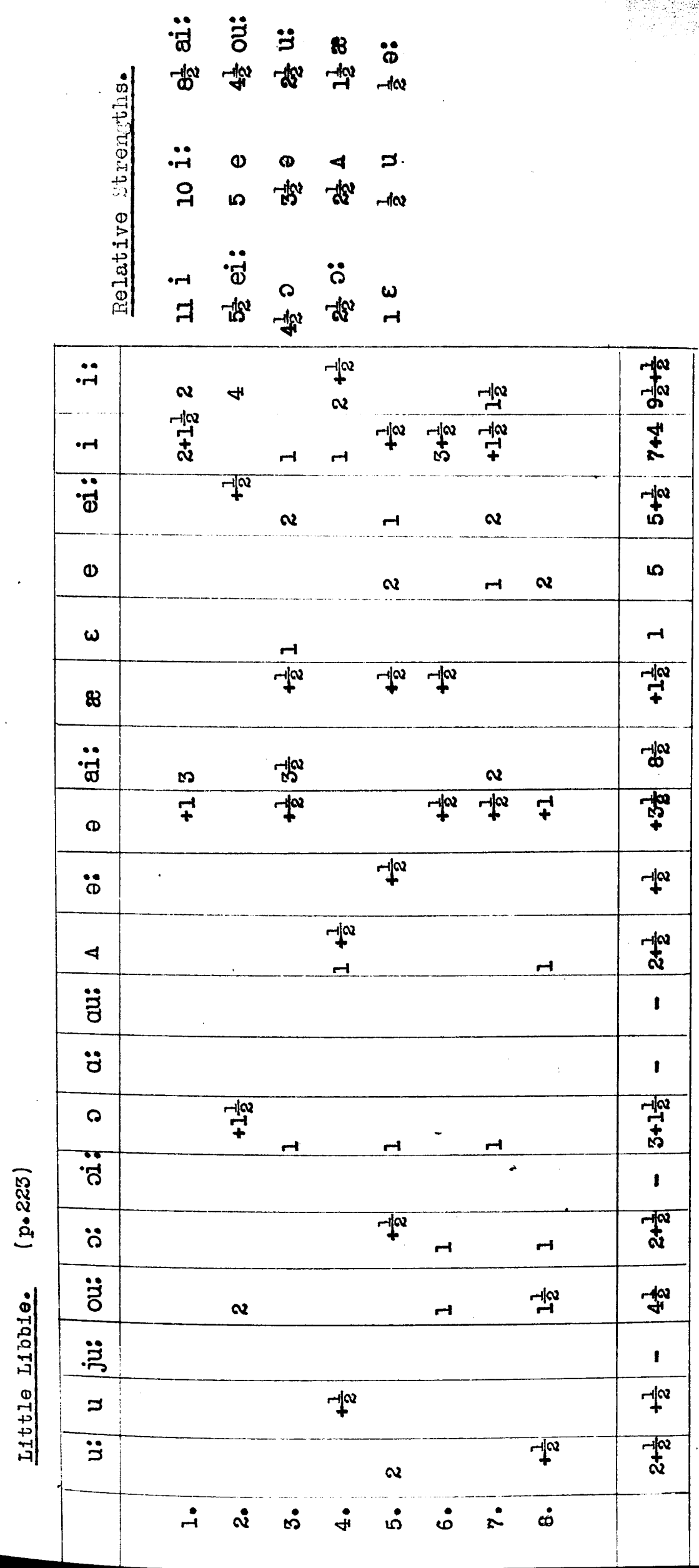




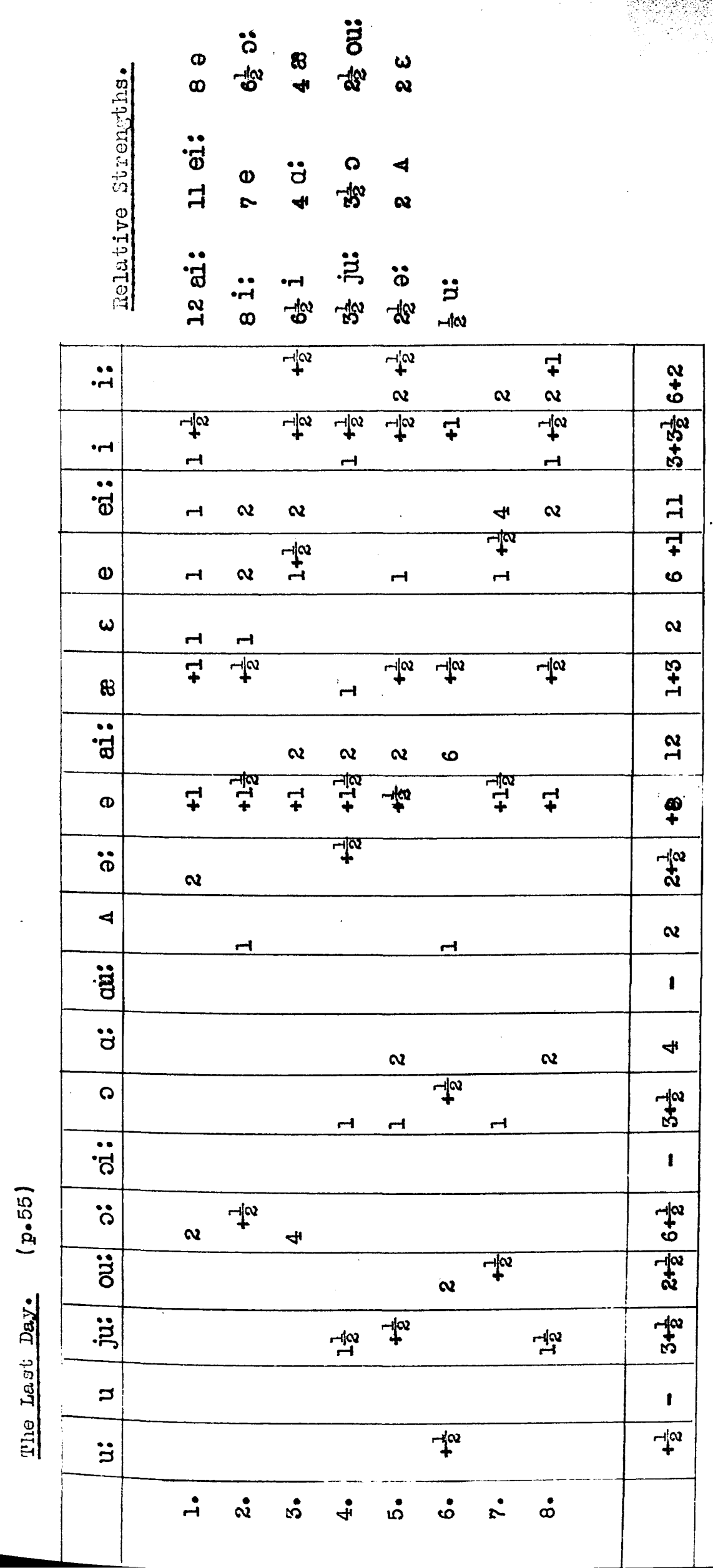




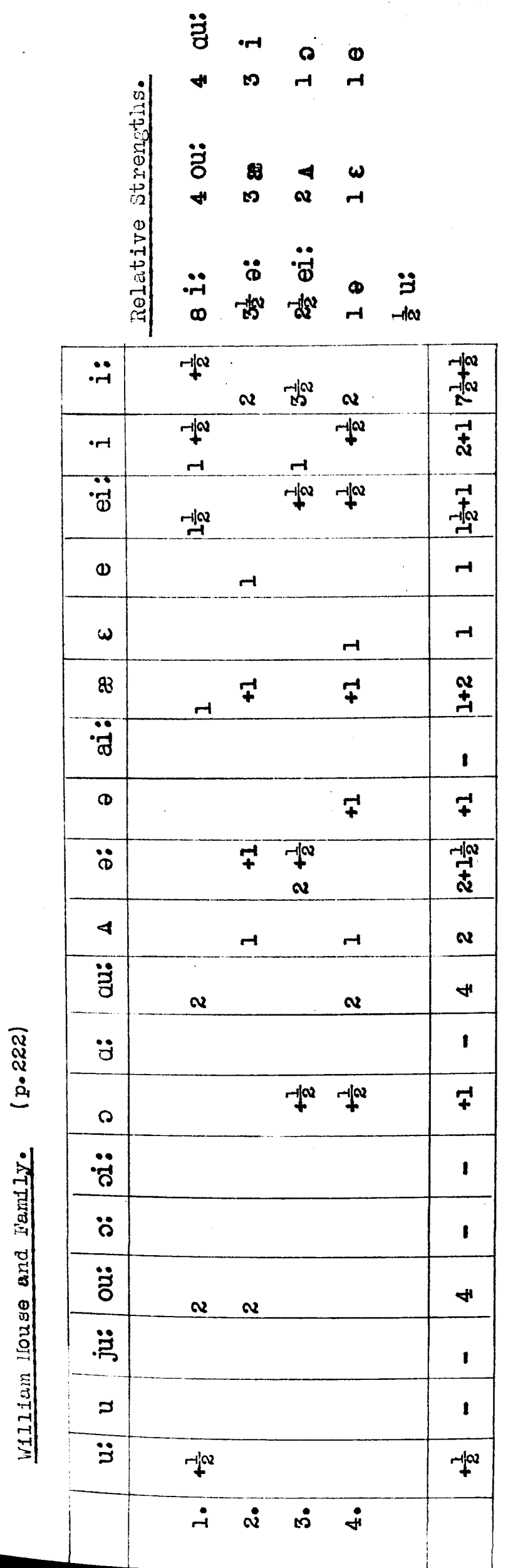




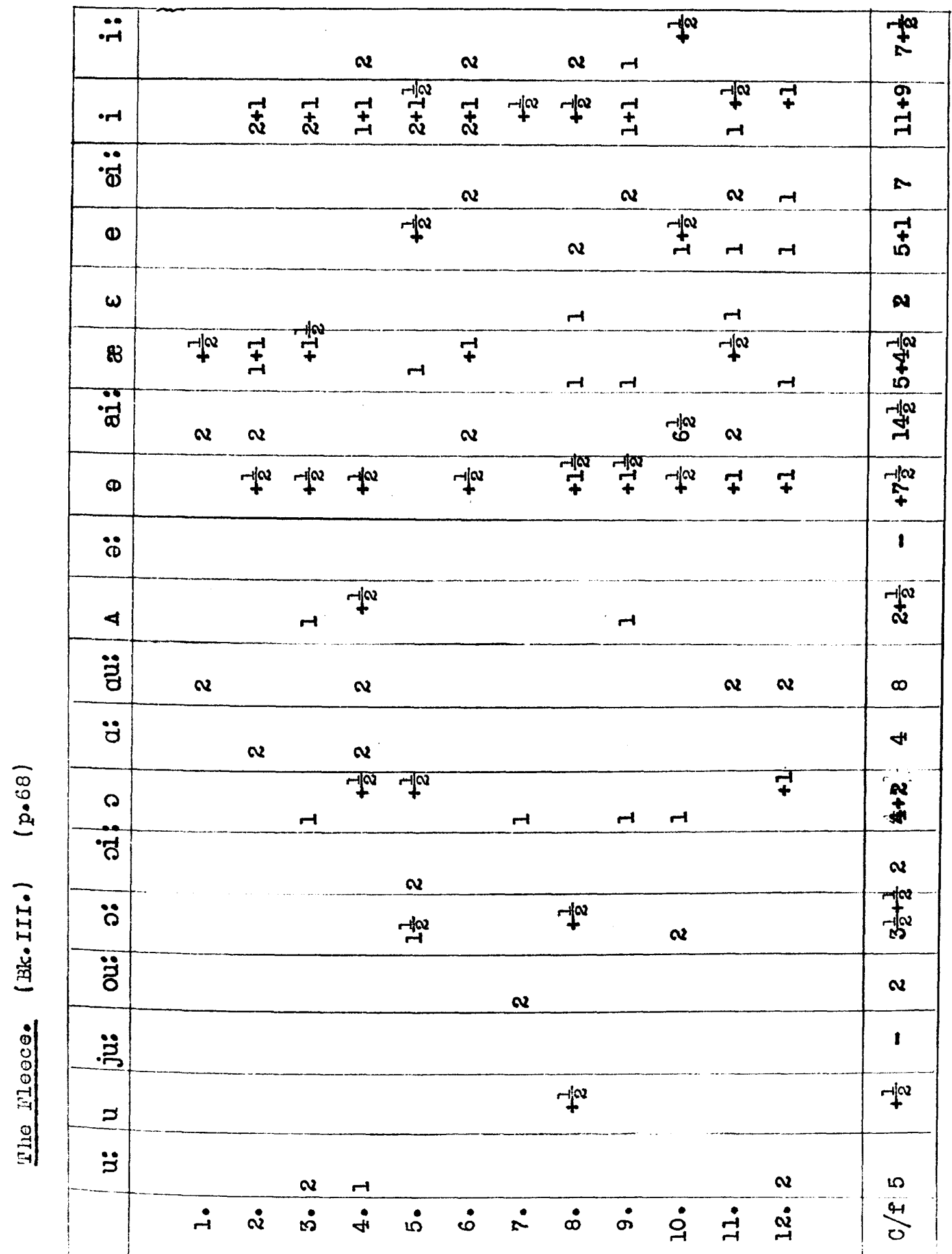

व) 


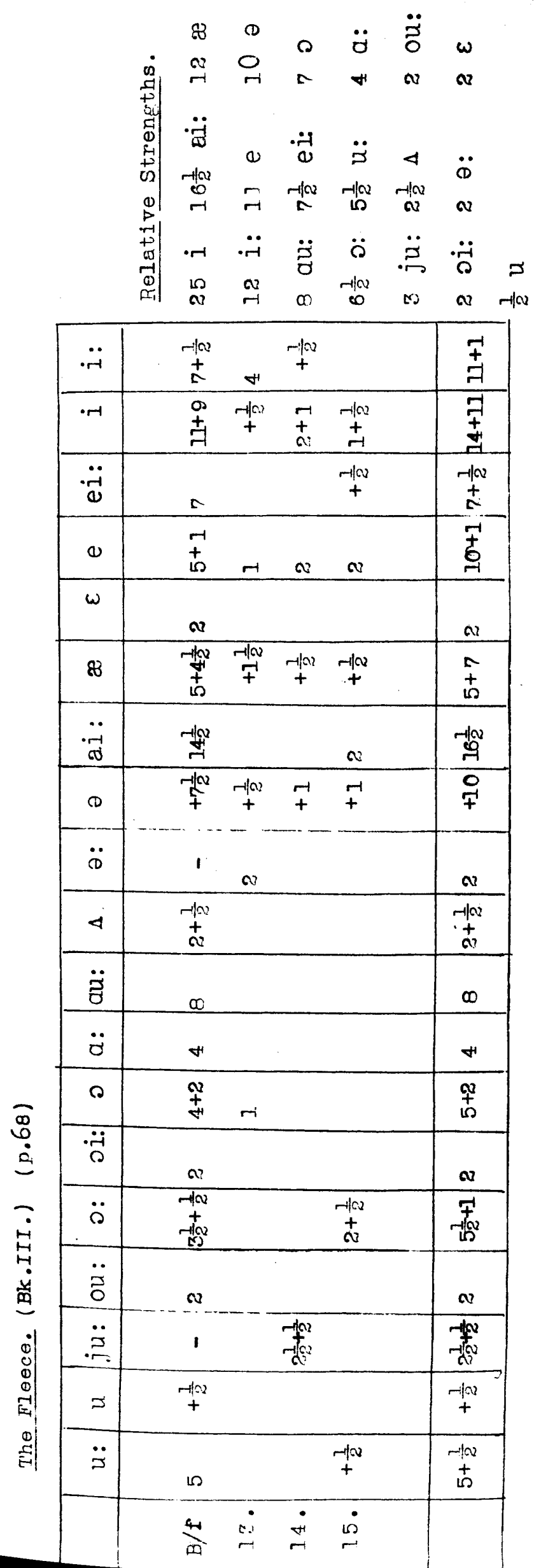




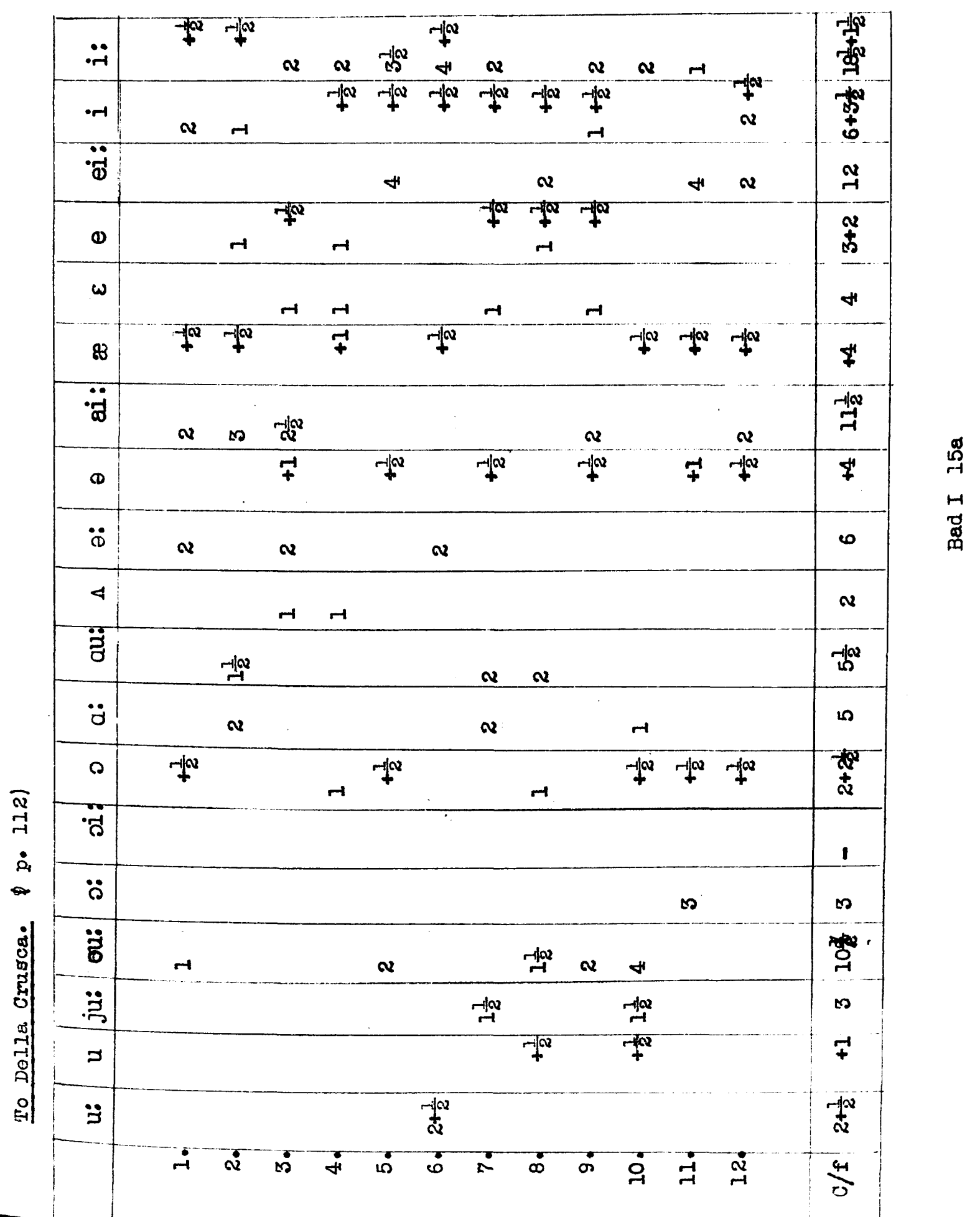




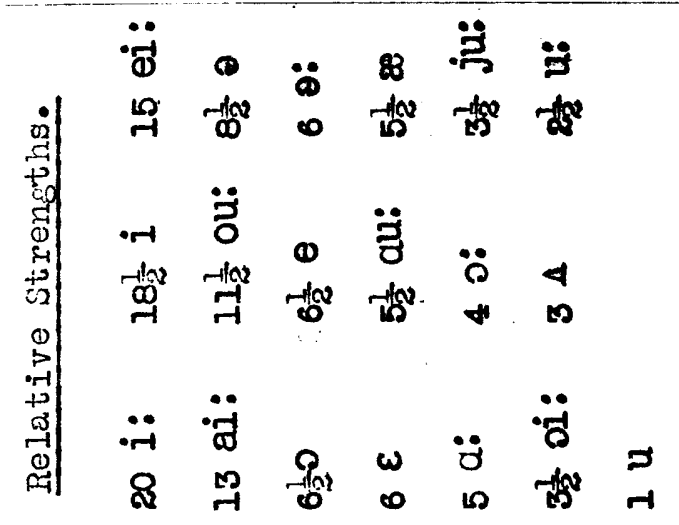

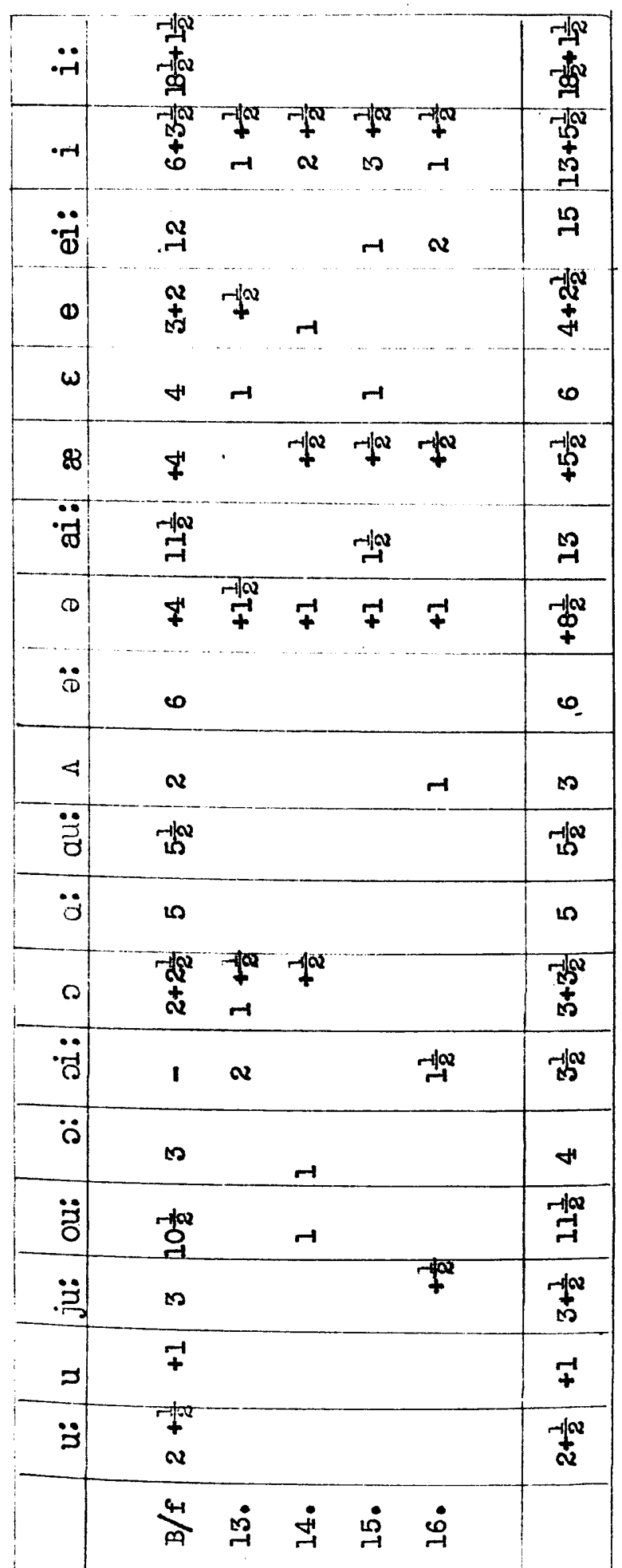




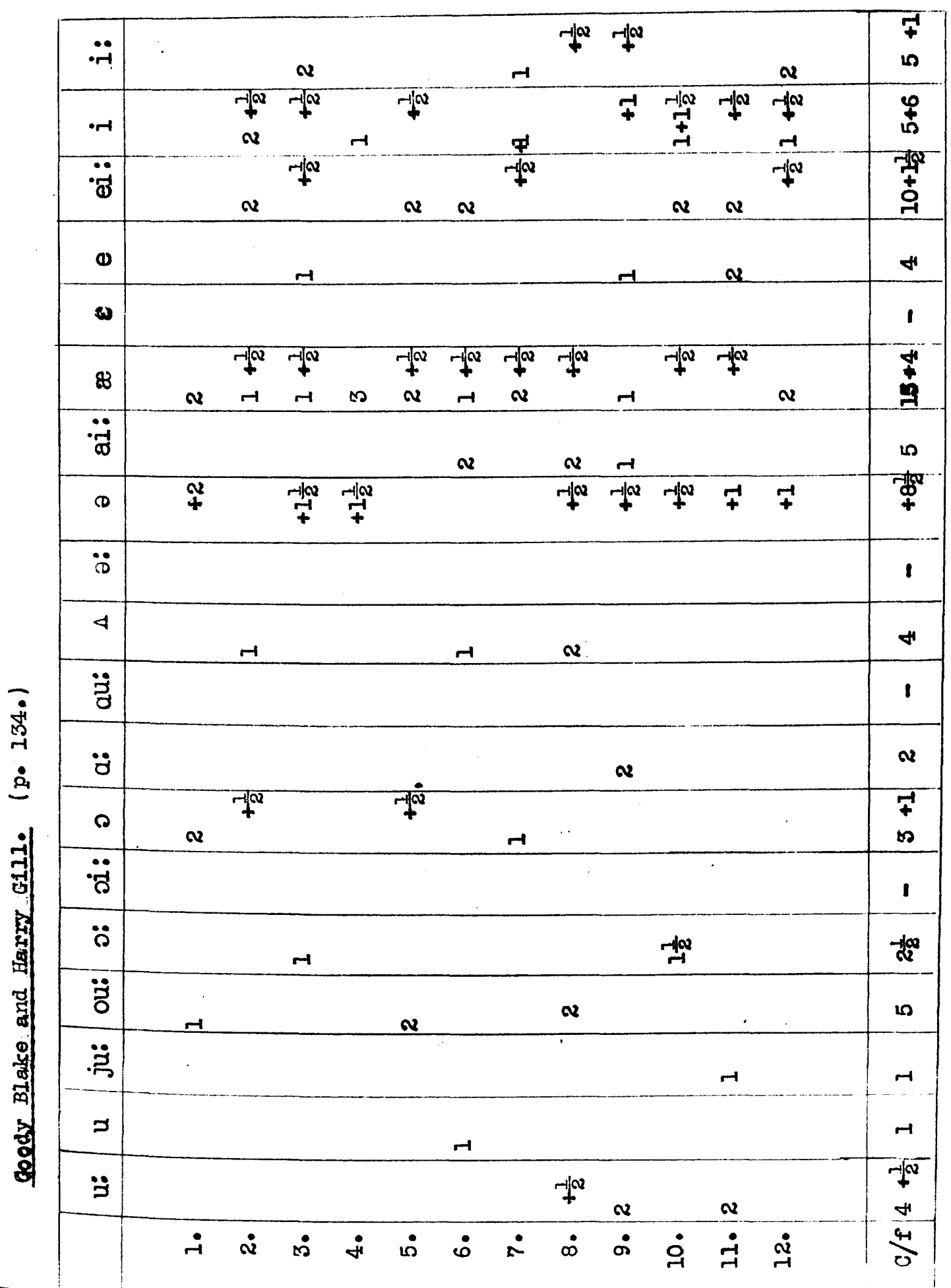




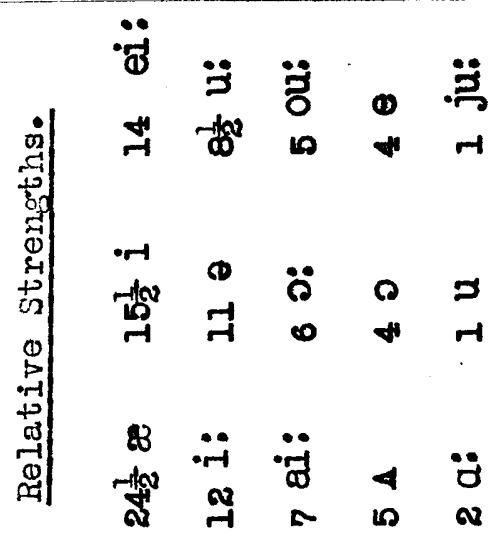

\begin{tabular}{|c|c|c|c|c|c|c|c|}
\hline$\ddot{\sim}$ & $\stackrel{-1}{+}$ & & & mे & $v$ & 品 & \\
\hline$\cdot r-1$ & مै & +4 & 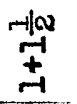 & & $\begin{array}{l}-1 / \alpha \\
-1\end{array}$ & $\begin{array}{c}+1 / \infty \\
\Phi \\
\pm \\
\pm\end{array}$ & \\
\hline$\ddot{\ddot{\omega}}$ & $\begin{array}{l}-1 \\
\text { for } \\
+\end{array}$ & & Q & & $-1+\infty$ & \begin{tabular}{l}
$\checkmark$ \\
\multirow{\sigma}{*}{} \\
$\stackrel{-1}{*}$
\end{tabular} & \\
\hline$\omega$ & 4 & & & & & $H$ & \\
\hline$\omega$ & 1 & & & & & 1 & \\
\hline 83 & $\begin{array}{l}7 \\
\stackrel{7}{7}\end{array}$ & 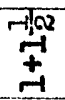 & $\rightarrow$ & & $\mathbf{Q}$ & $\underset{\Gamma}{\stackrel{4}{2}}$ & \\
\hline$\ddot{\ddot{d}}$ & & $\sim$ & & & & $\sim$ & \\
\hline$D$ & $\begin{array}{c}\text { Fin } \\
0 \\
+\end{array}$ & & 7 & & 7 & $\underset{7}{7}$ & \\
\hline$\ddot{\nabla}$ & 1 & & & & & 1 & \\
\hline
\end{tabular}




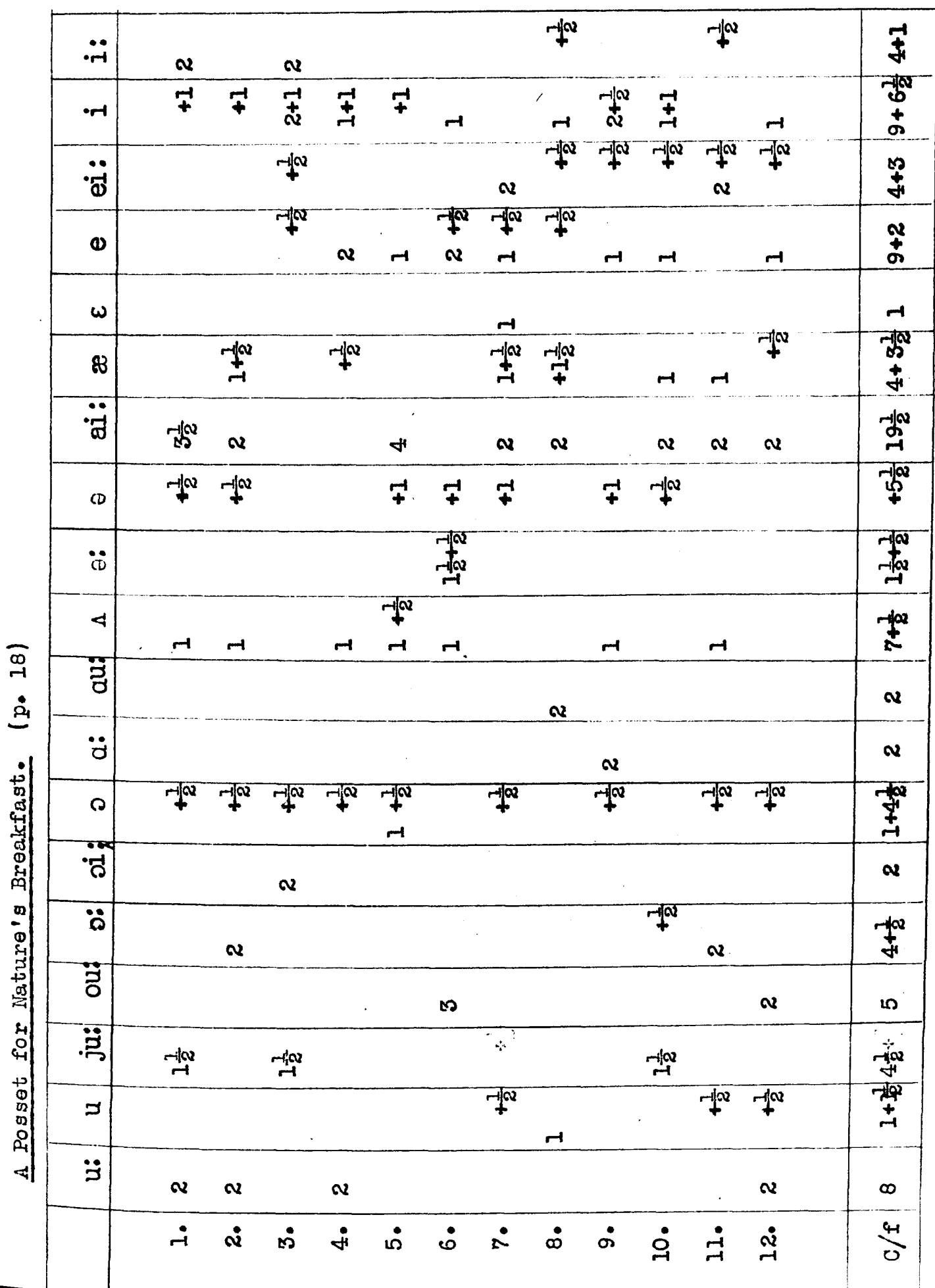




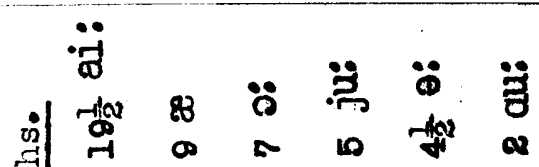

运

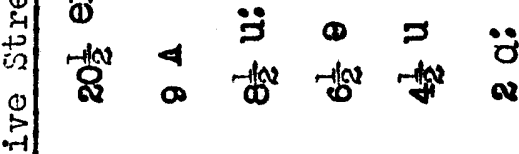

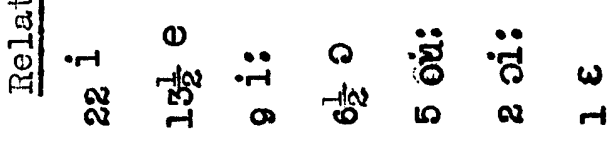

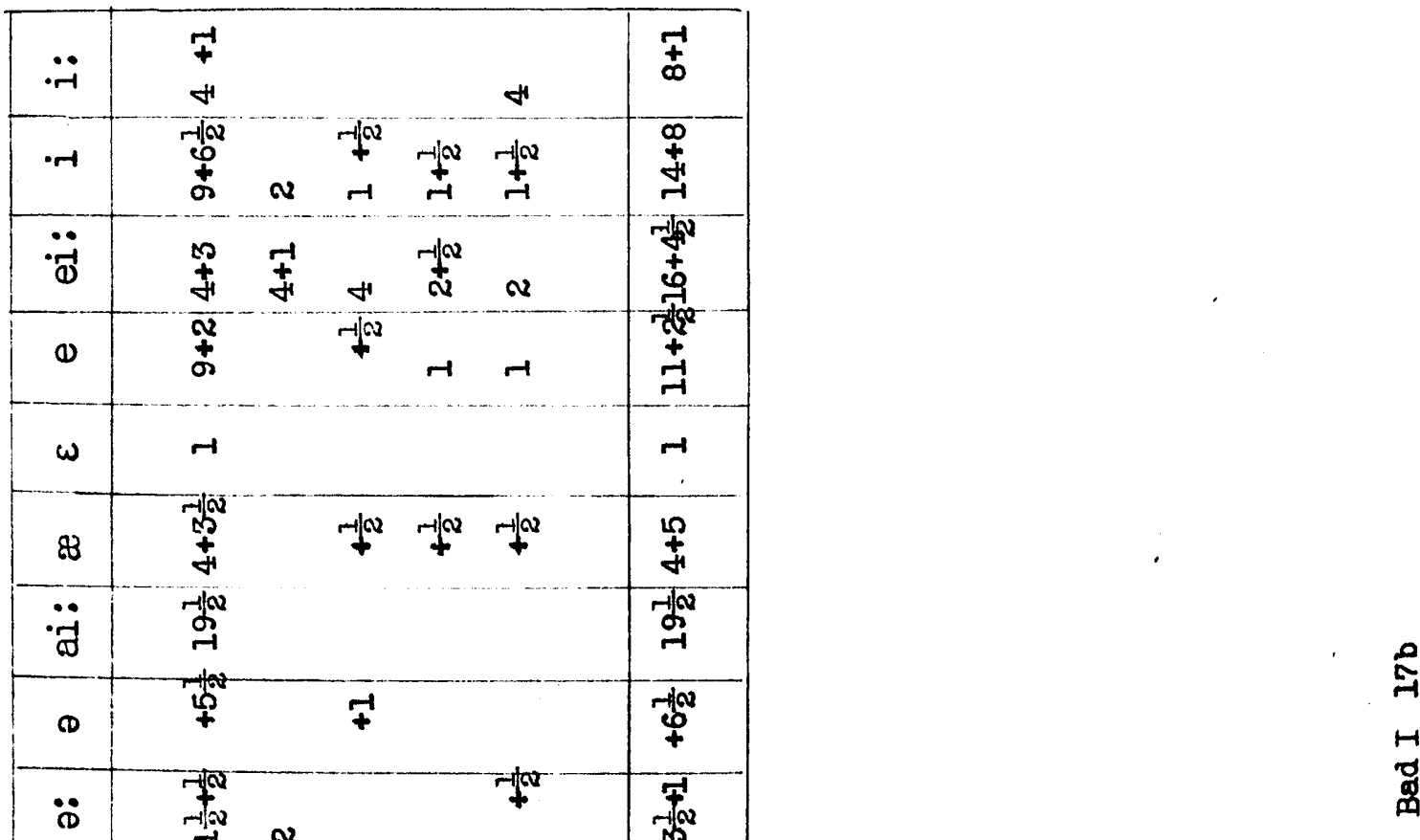




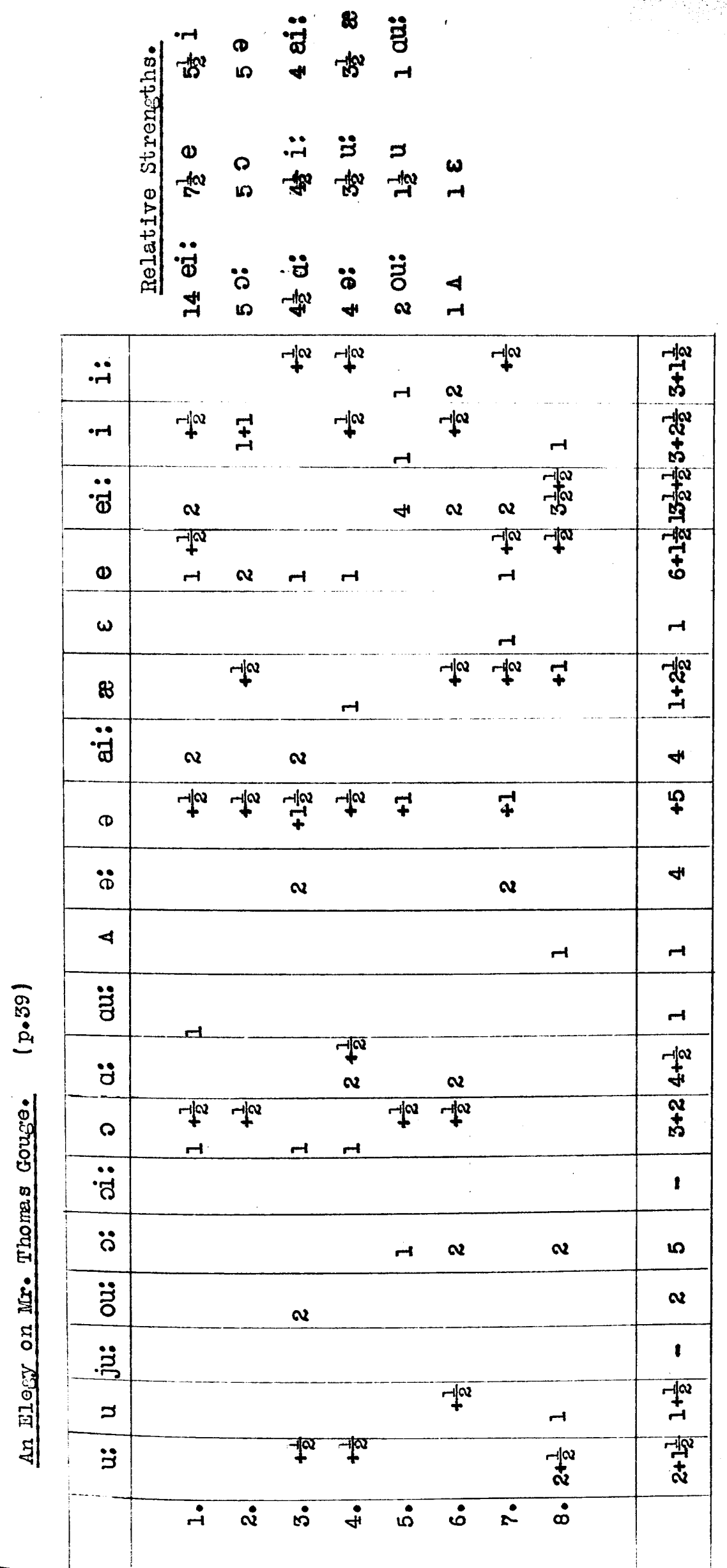

占 


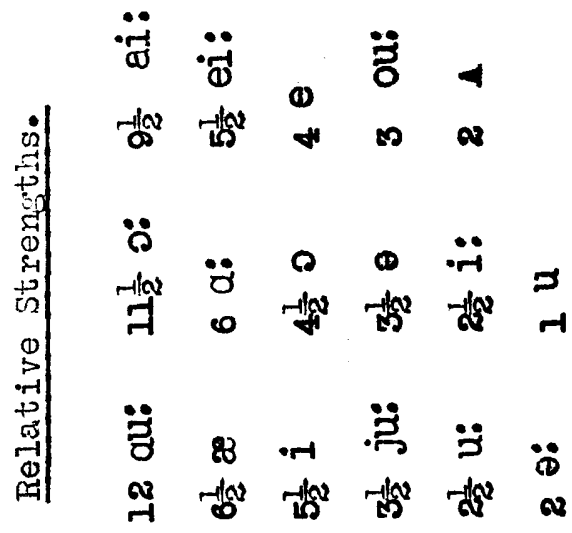

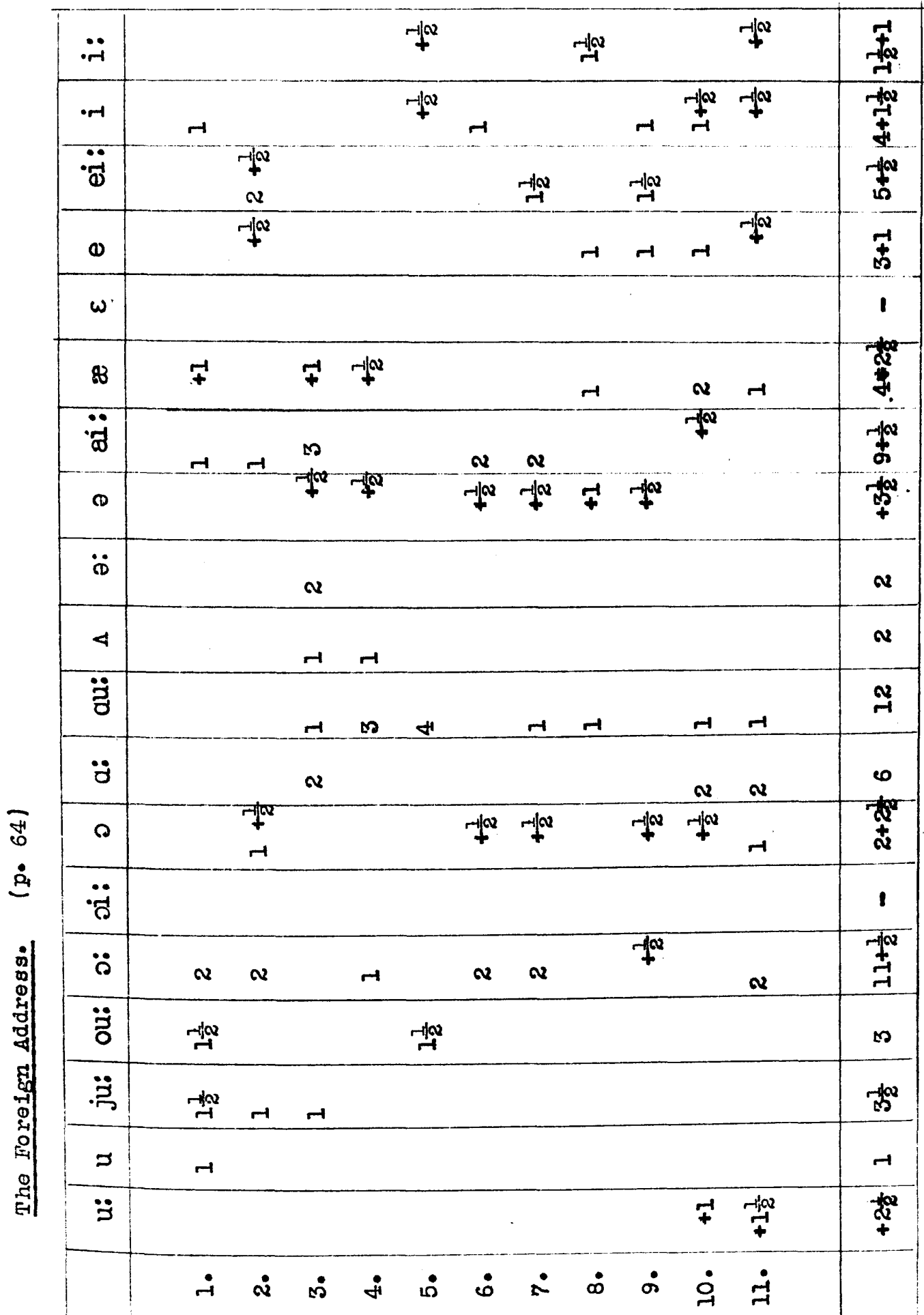




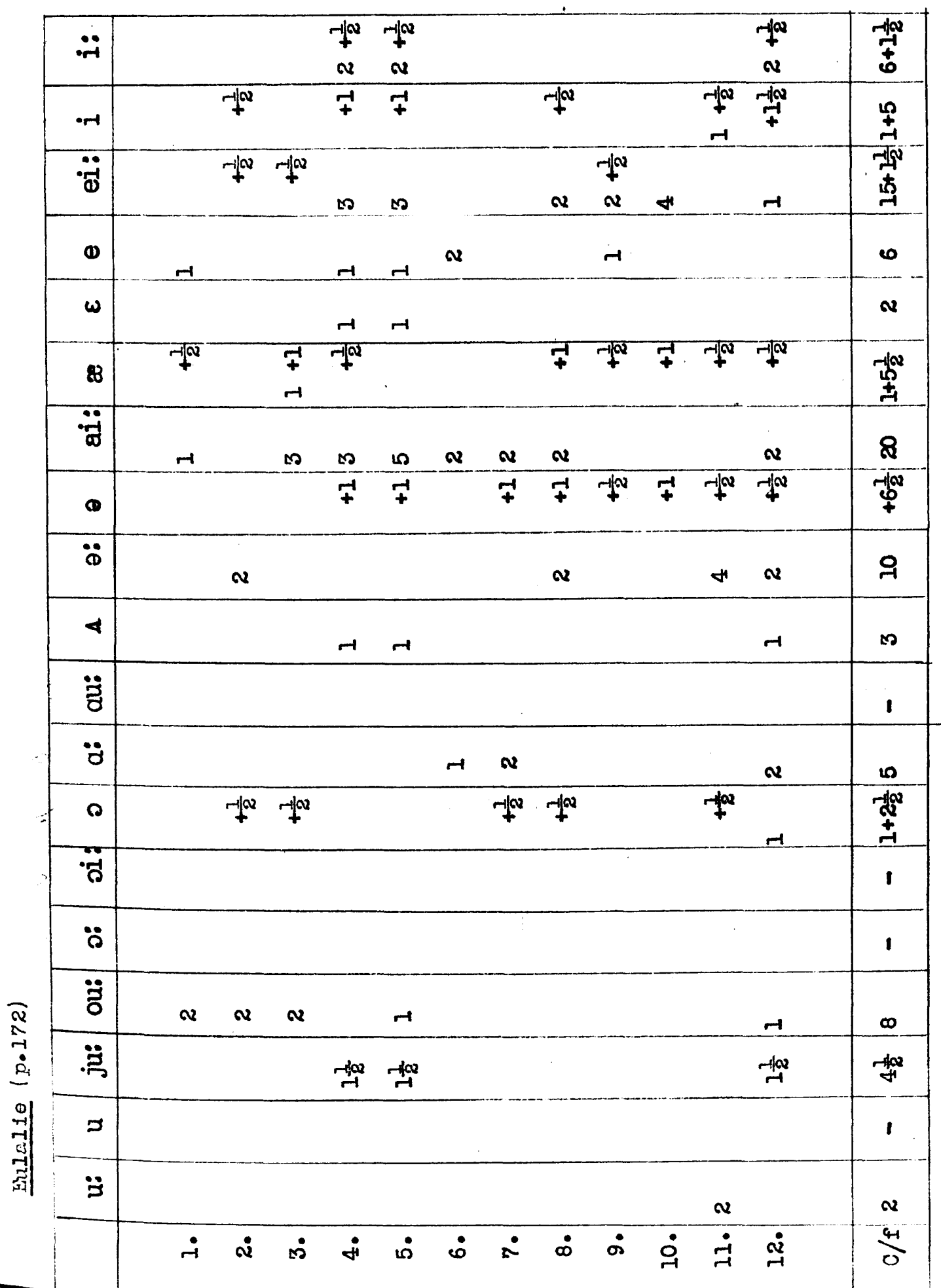




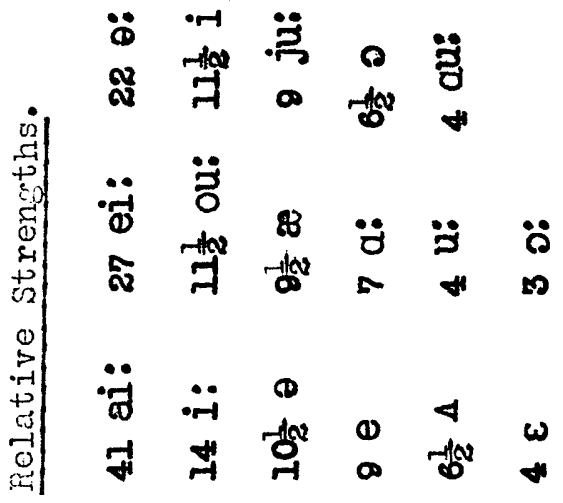

\begin{tabular}{|c|c|c|c|c|c|c|c|c|c|c|c|}
\hline$\ddot{~} \ddot{-r}$ & 管 & 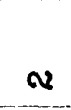 & & & +10 & & & & $\boldsymbol{N}$ & $\boldsymbol{N}$ & 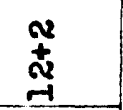 \\
\hline$\cdot r$ & $\stackrel{10}{+}$ & + & & & $\rightarrow$ & & & +1 & - & +0 & $\stackrel{+-10 x}{ \pm}$ \\
\hline$\ddot{\ddot{\theta}}$ & 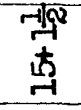 & $r$ & $v$ & 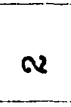 & & $\stackrel{-1 N}{-10}$ & & & $\infty$ & -1 & 萦 \\
\hline $\boldsymbol{\omega}$ & $\omega$ & & & -1 & & & & & $r$ & $r$ & $\sigma$ \\
\hline$\omega$ & $\sim$ & $v$ & & & & & & & & & $H$ \\
\hline 88 & 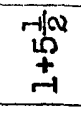 & + & & $-7 x^{2}$ & & $-1 x^{2}$ & $f^{w}$ & -10 & & & $\begin{array}{c}-1 / 0 \\
5 \\
+ \\
-1\end{array}$ \\
\hline$\because 8$ & న & rets & & & $H^{4}$ & 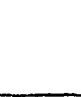 & $-y x^{2}$ & $\boldsymbol{v}$ & $\infty$ & $n$ & F \\
\hline$\ddot{\oplus}$ & -1/x & $\underset{+}{-H a}$ & & $-1 x^{2}$ & & $+-1 x$ & & $-1 \infty$ & 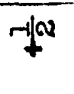 & $+w_{t}^{\alpha}$ & $\begin{array}{l}\text { नुतू } \\
+ \\
+\end{array}$ \\
\hline$\ddot{8}$ & 욱 & $\boldsymbol{N}$ & & & -1 & & & & 柴 & 柴 & ญ્ \\
\hline 3 & $\infty$ & -1 & & $7 \sqrt{2}$ & & & & & $7+\frac{2}{2}$ & $\stackrel{-1}{+\infty}$ & 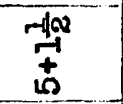 \\
\hline$\ddot{z}$ & 1 & & H & & & & & & & & $H$ \\
\hline$\ddot{d}$ & 10 & & & & & & & $\sim$ & & & $\sigma$ \\
\hline 0 & $\begin{array}{c}\text { ta } \\
+ \\
+1\end{array}$ & +4 & & & & 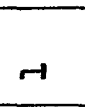 & $r$ & & 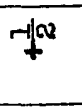 & & 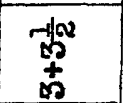 \\
\hline "⿱⺈ & 1 & & & & & & & & & & 1 \\
\hline$\ddot{\circ}$ & 1 & & & & $\underset{+1}{ \pm+1}$ & $\stackrel{-\mu \alpha}{\rightarrow}$ & & & & & - \\
\hline$\ddot{0}$ & $\infty$ & 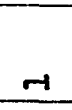 & & & 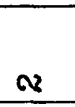 & & & & & -110 & $\underset{7}{+\infty}$ \\
\hline$\ddot{\not}$ & Fa & rlan & & & & & & & rip & - & $\sigma$ \\
\hline $\boldsymbol{x}$ & 1 & & & & & & & & & & 1 \\
\hline$\ddot{\Xi}$ & 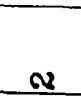 & & & & & & & & $\rightarrow$ & -1 & + \\
\hline & $\stackrel{4 H}{m}^{4+}$ & $\stackrel{\leftrightarrow}{\rightarrow}$ & $\underset{\sim}{\stackrel{\leftrightarrow}{H}}$ & $\stackrel{\leftrightarrow}{\rightarrow}$ & $\underset{\sim-1}{\dot{0}}$ & $\stackrel{\check{m}}{\sim}$ & $\underset{\sim}{\dot{\infty}}$ & $\underset{\sim \rightarrow}{\dot{\sigma}}$ & $\dot{\&}$ & $\dot{\vec{N}}$ & \\
\hline
\end{tabular}




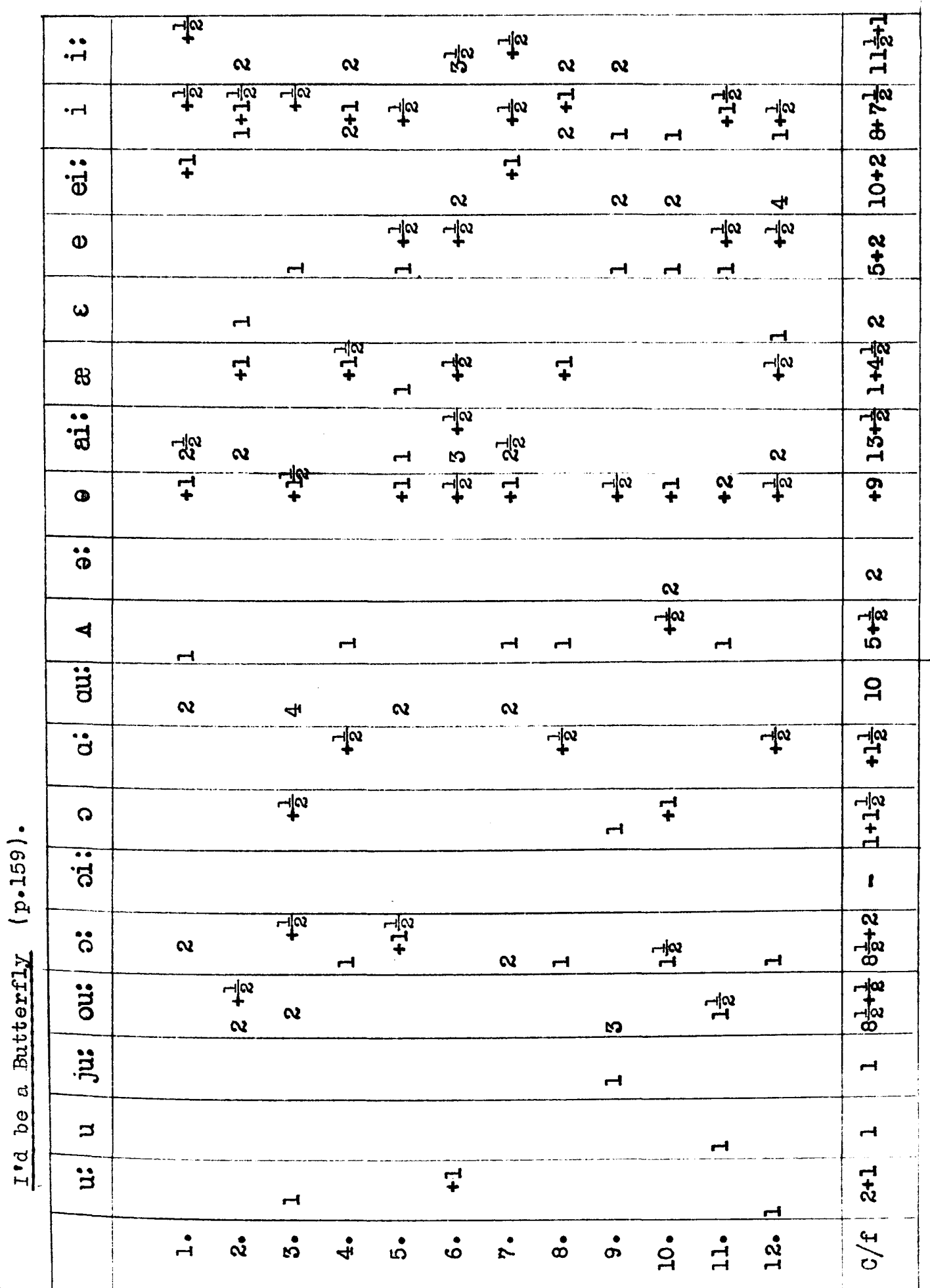




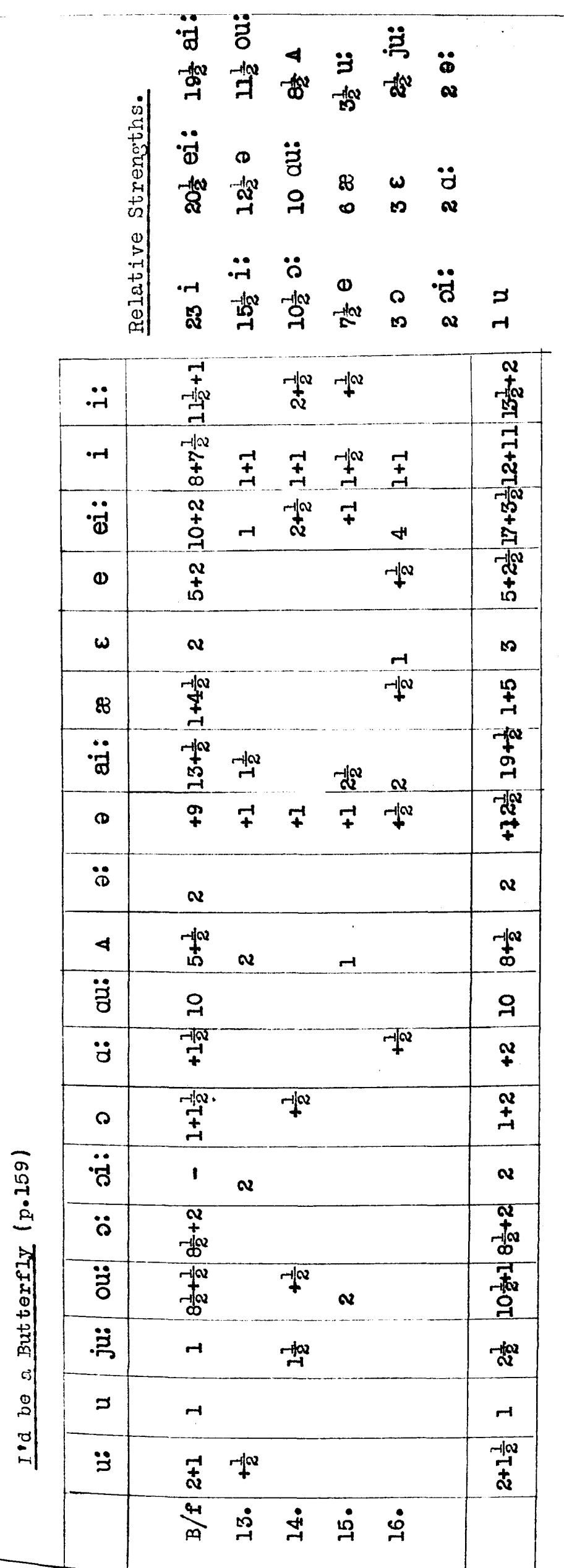




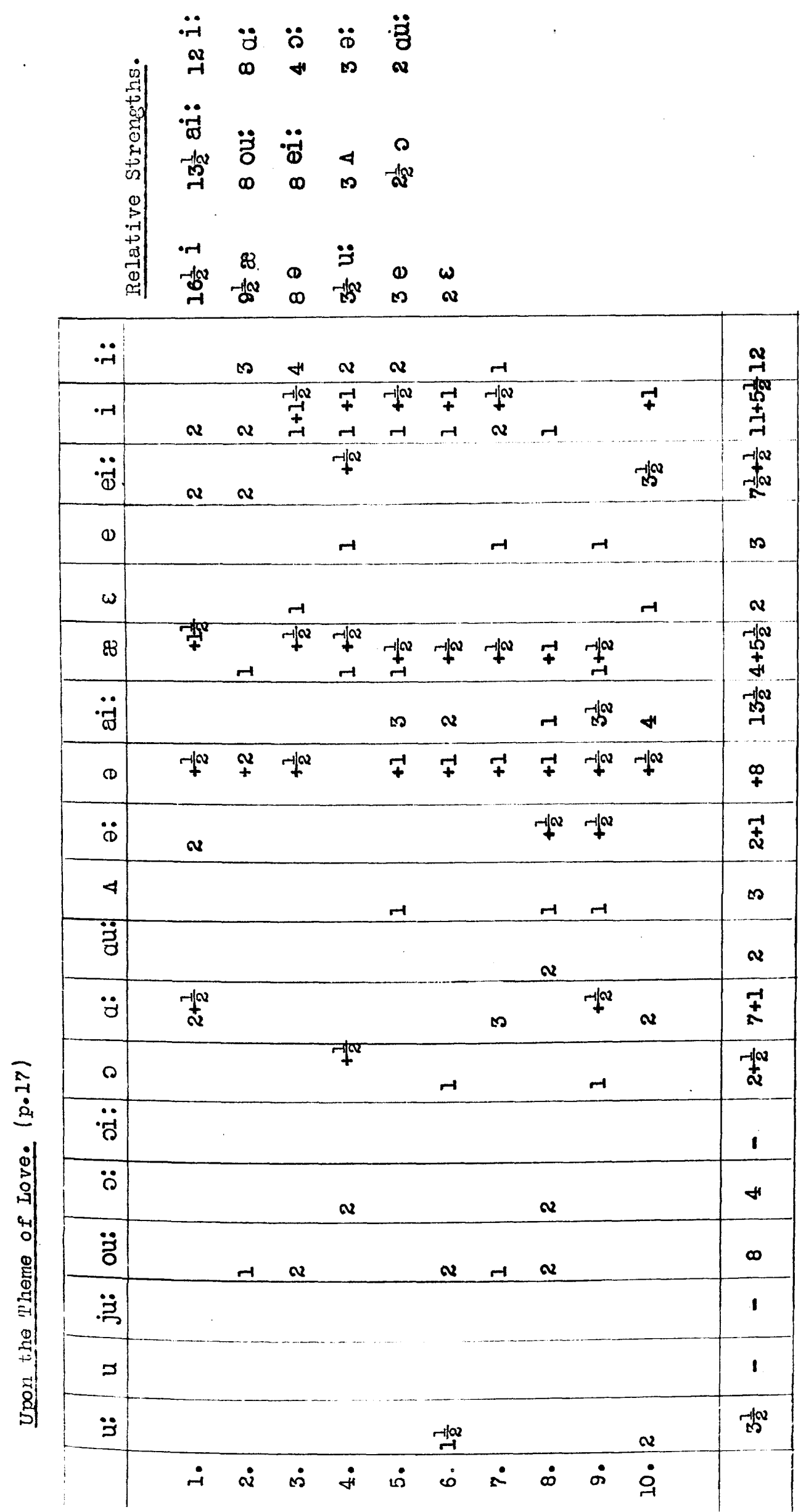




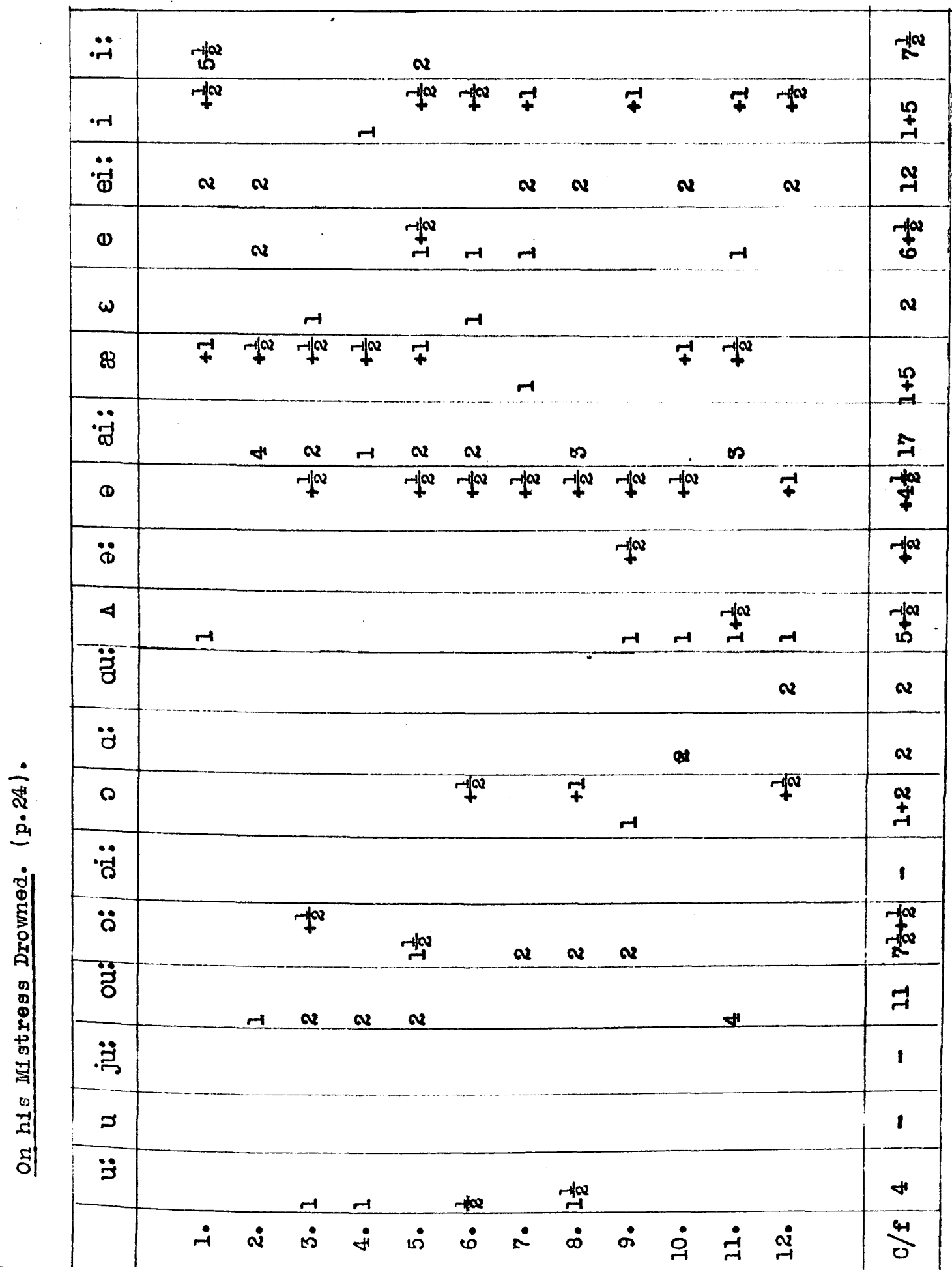

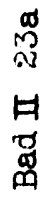




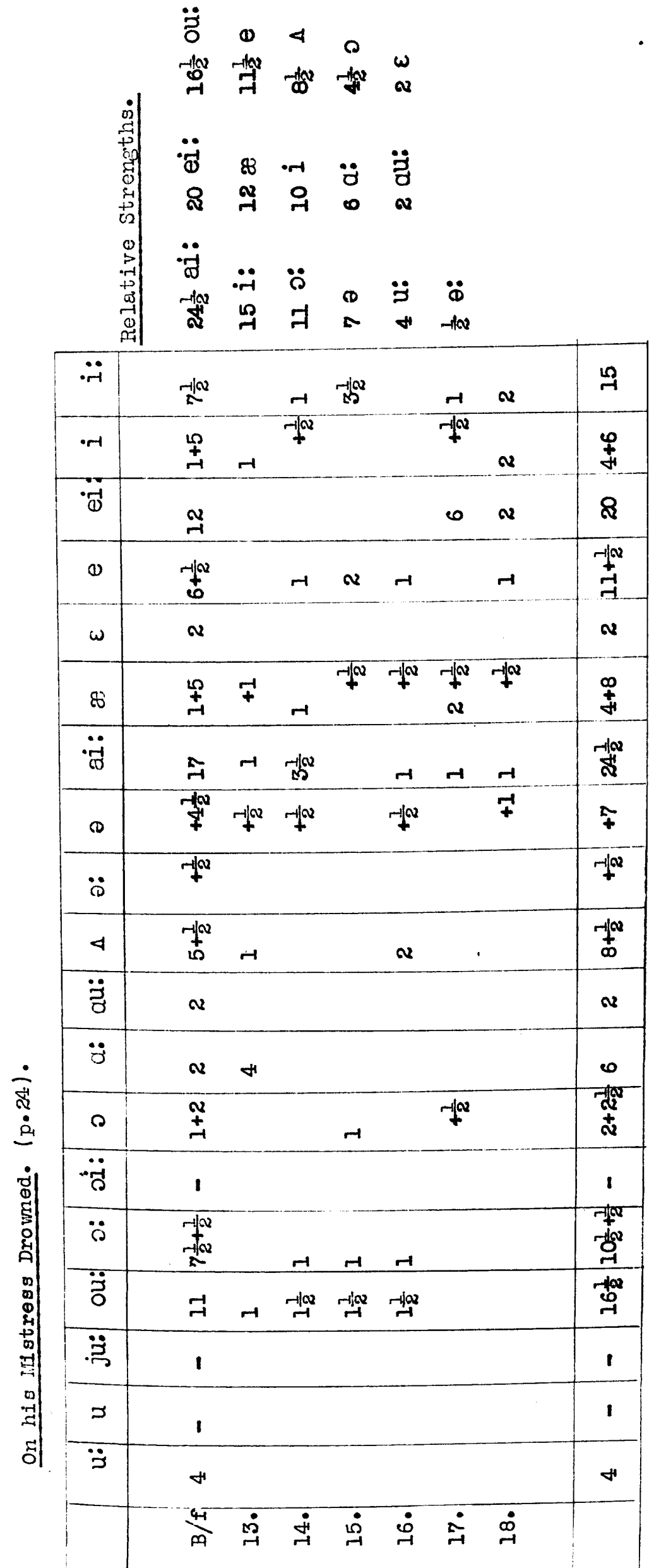




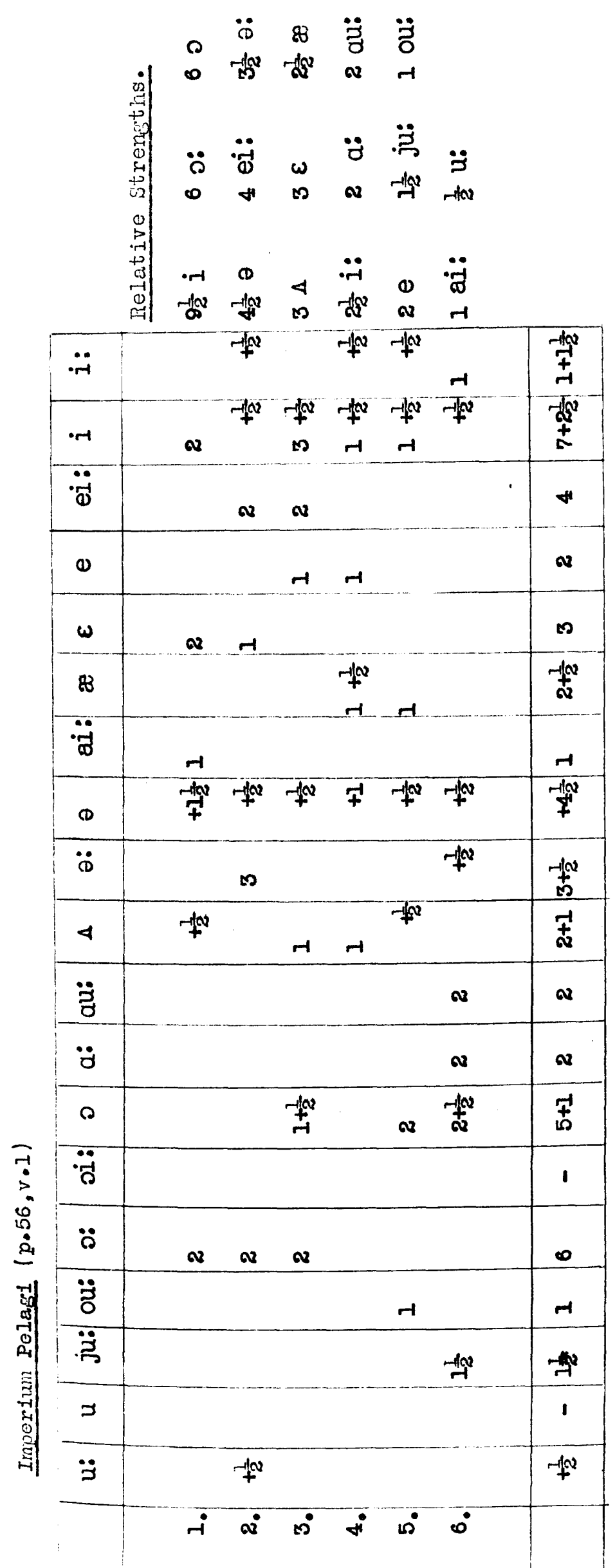




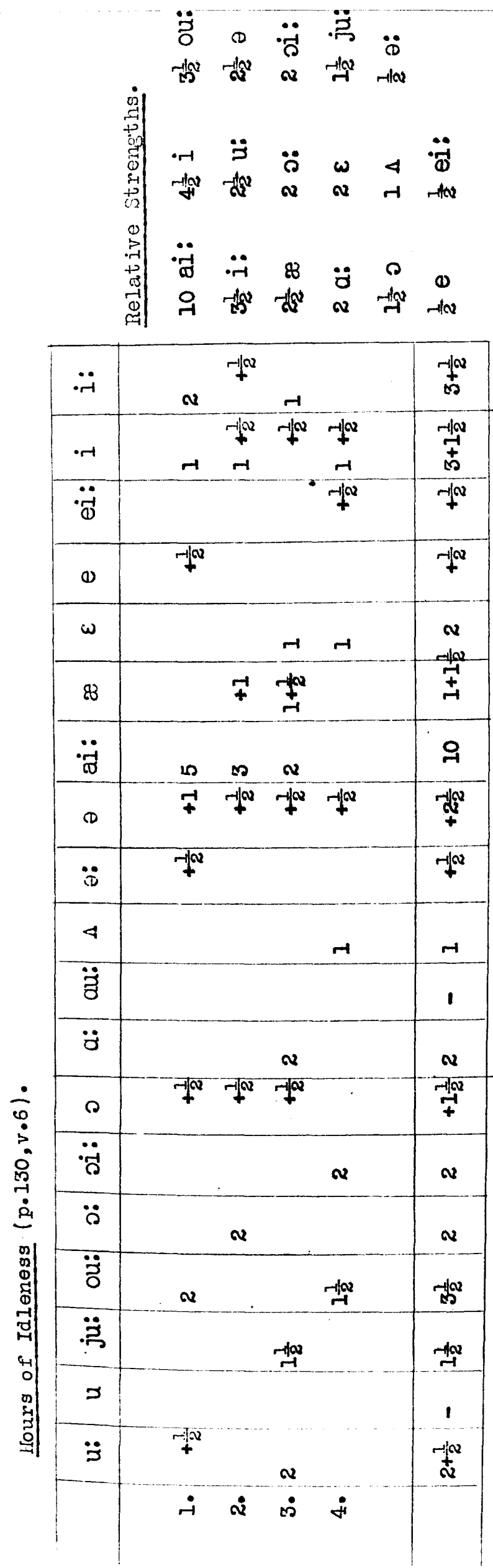

息 


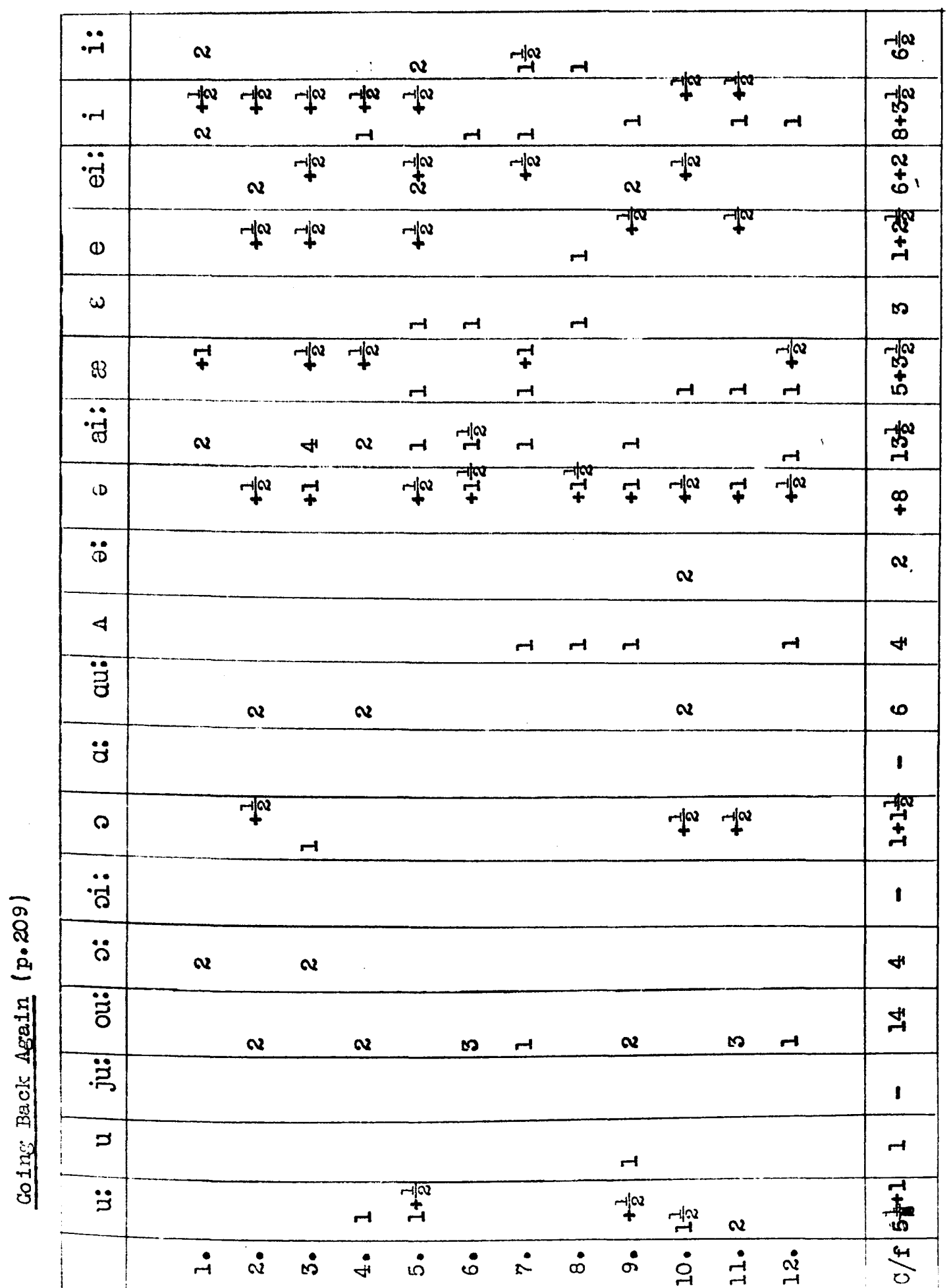




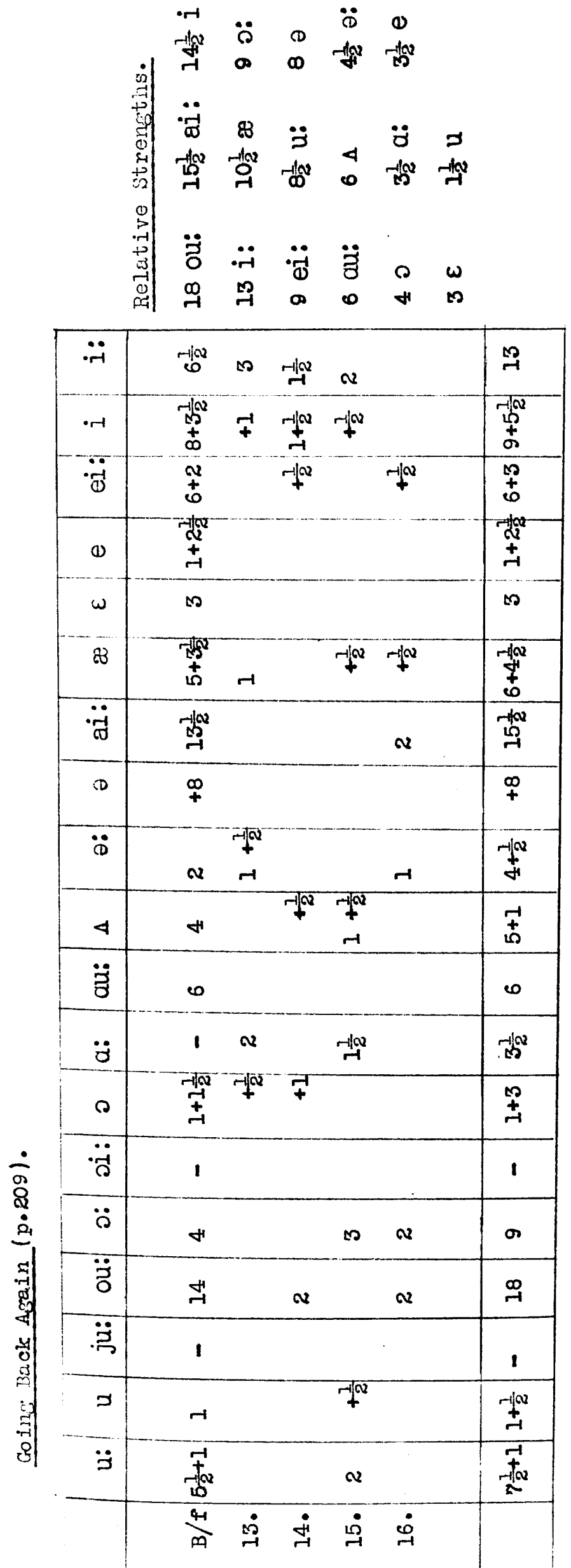

0
0
0
品
品 


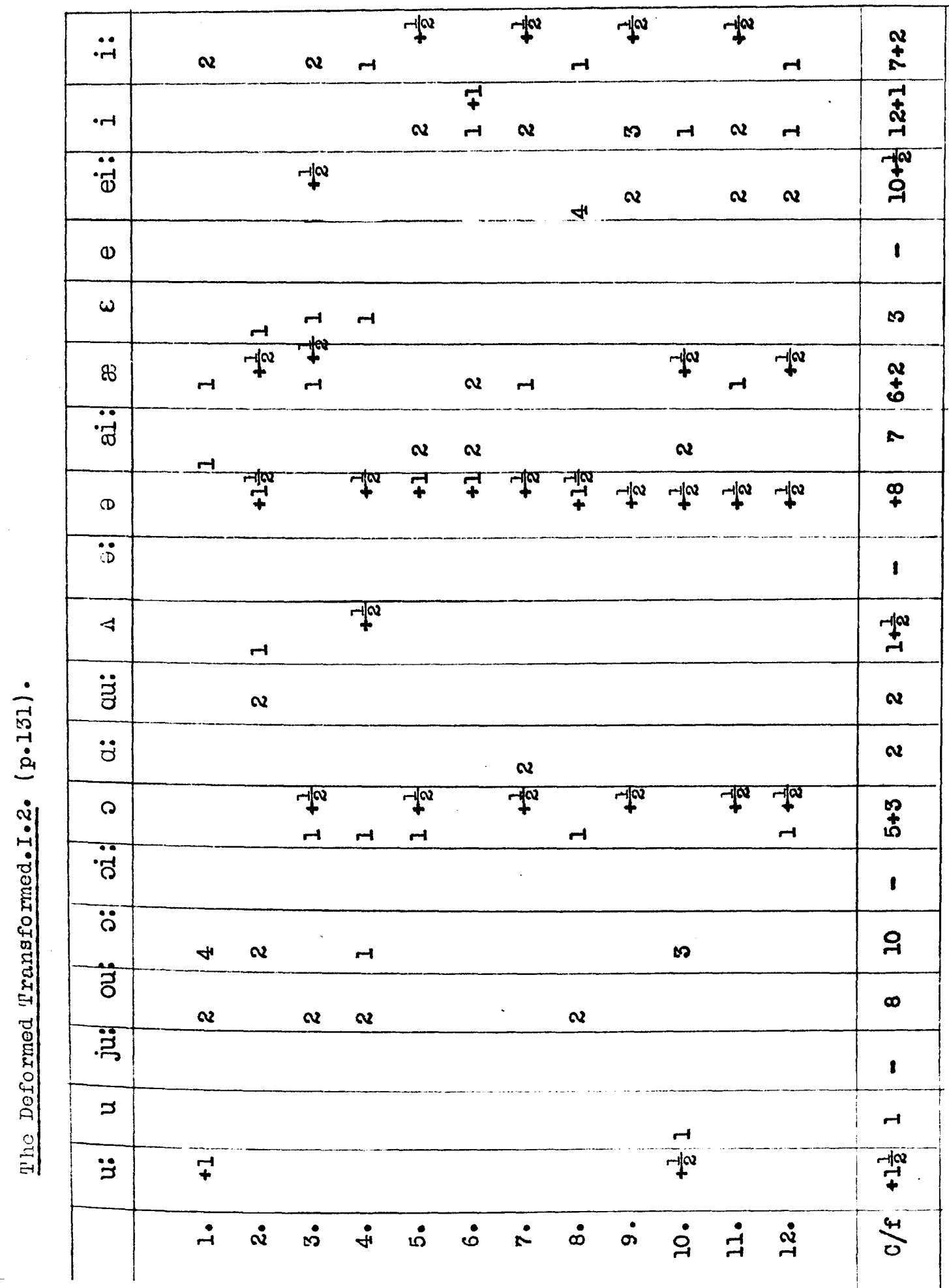

品 


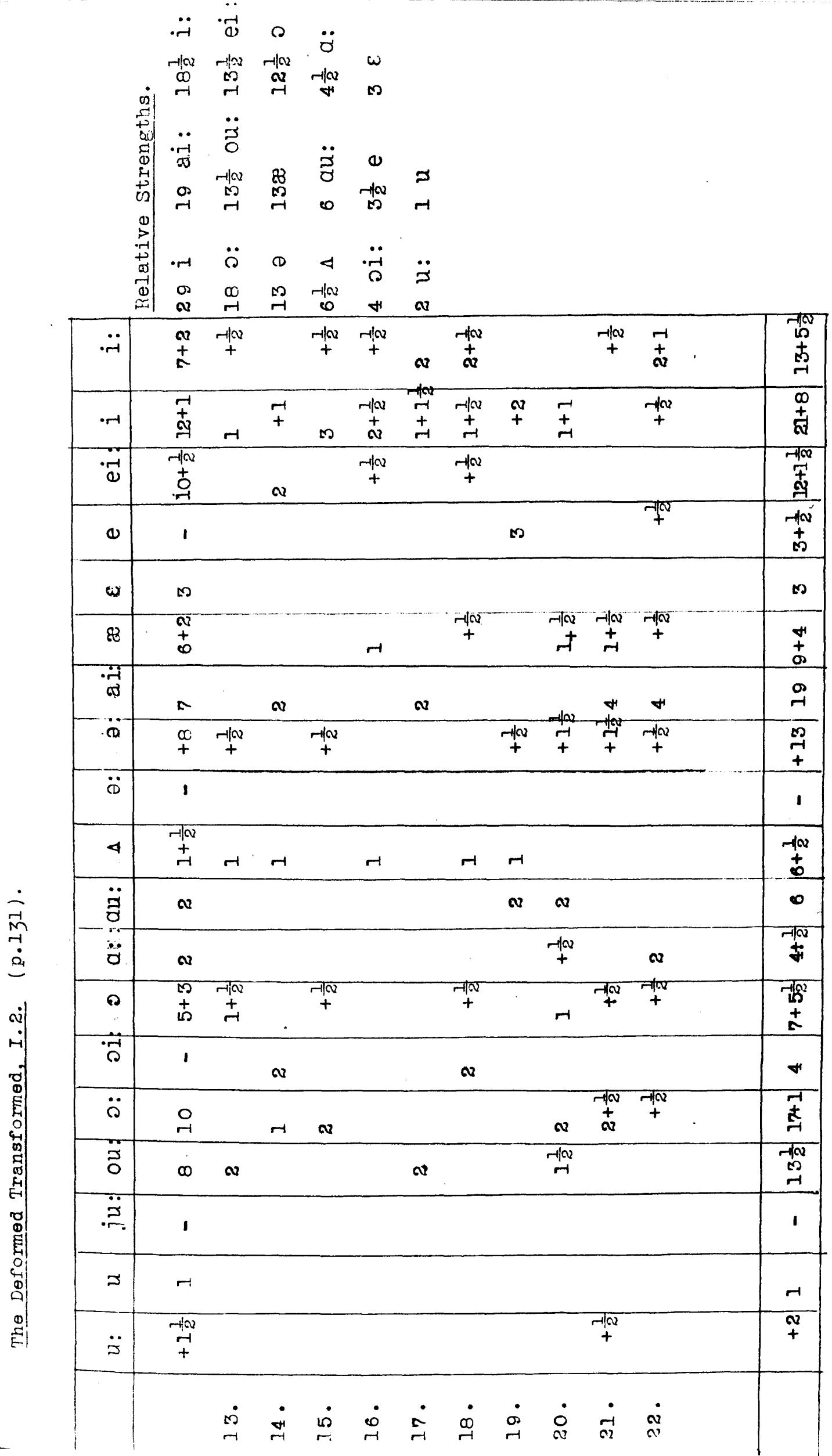




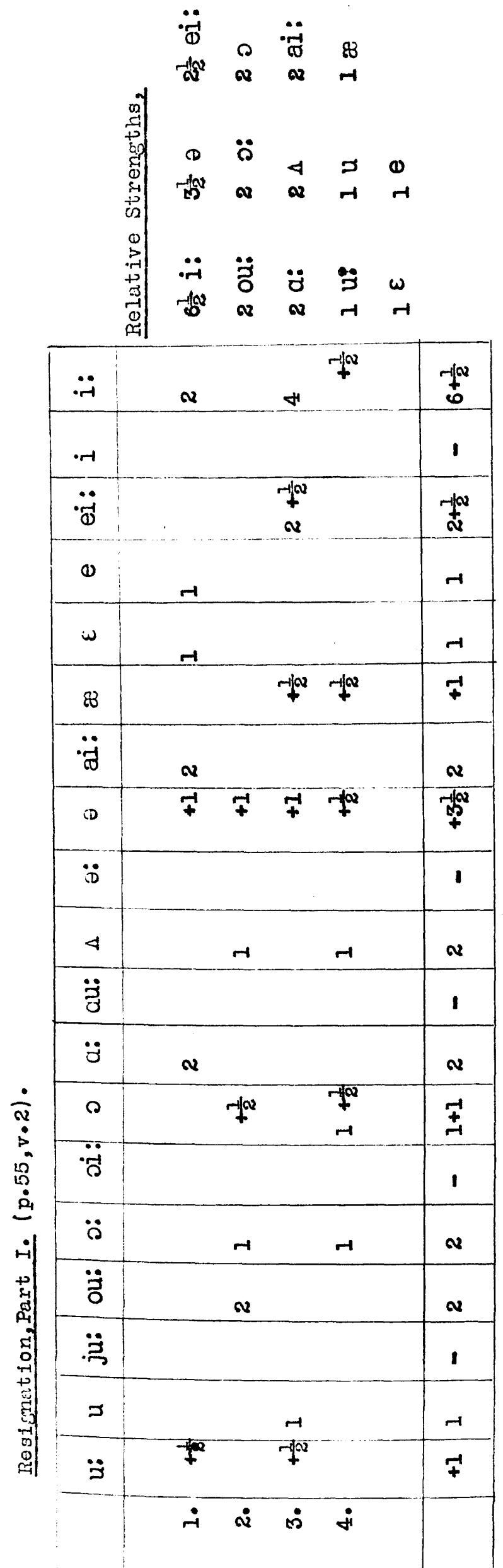

a
H
g్ 


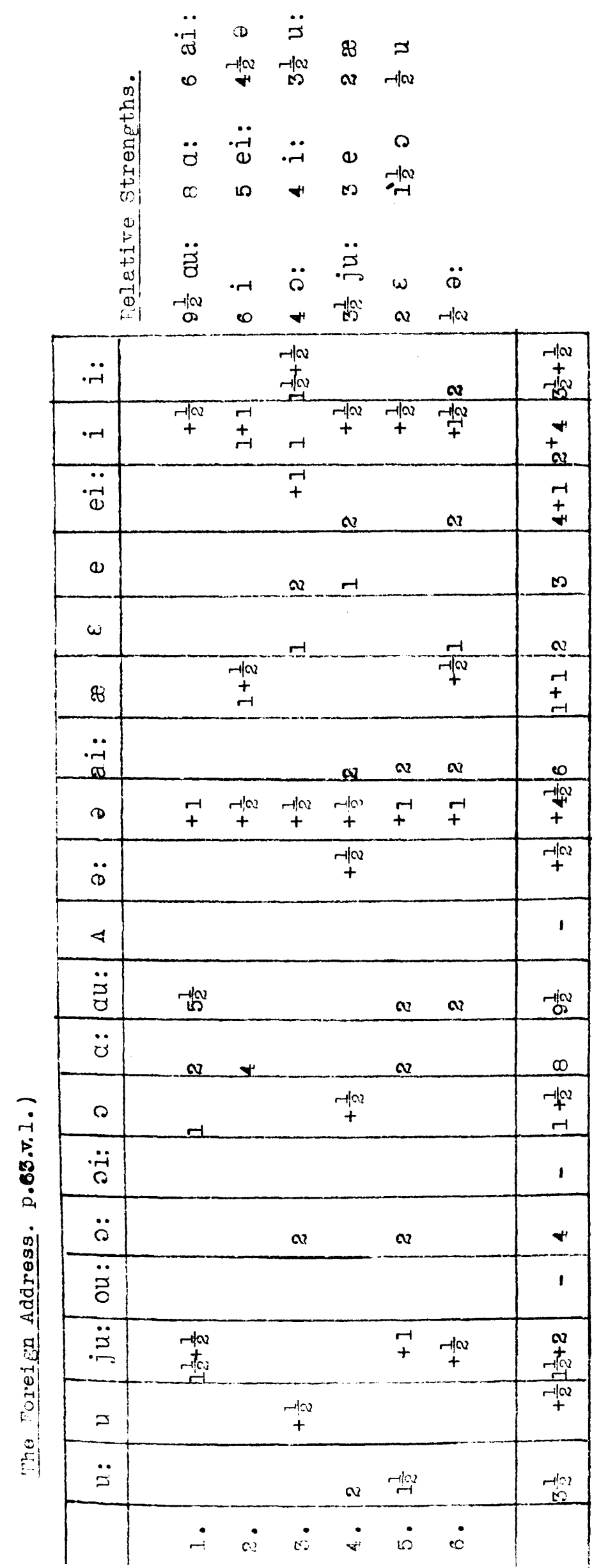

怘 


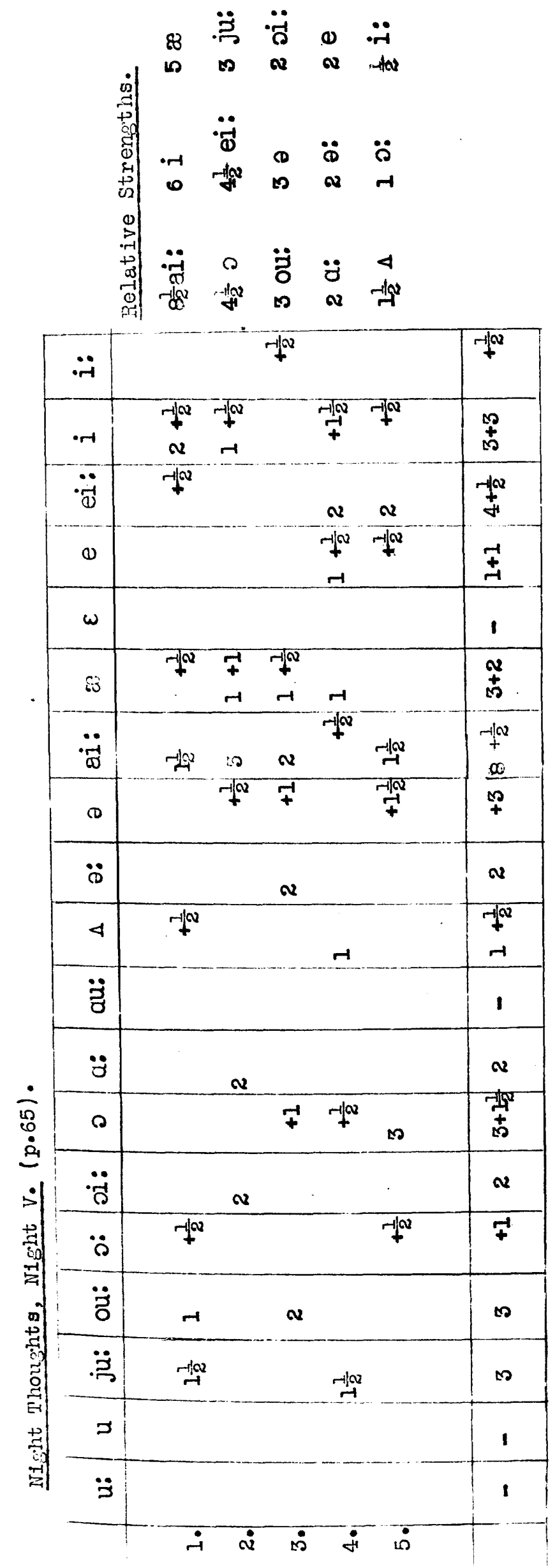

8
昌
品 


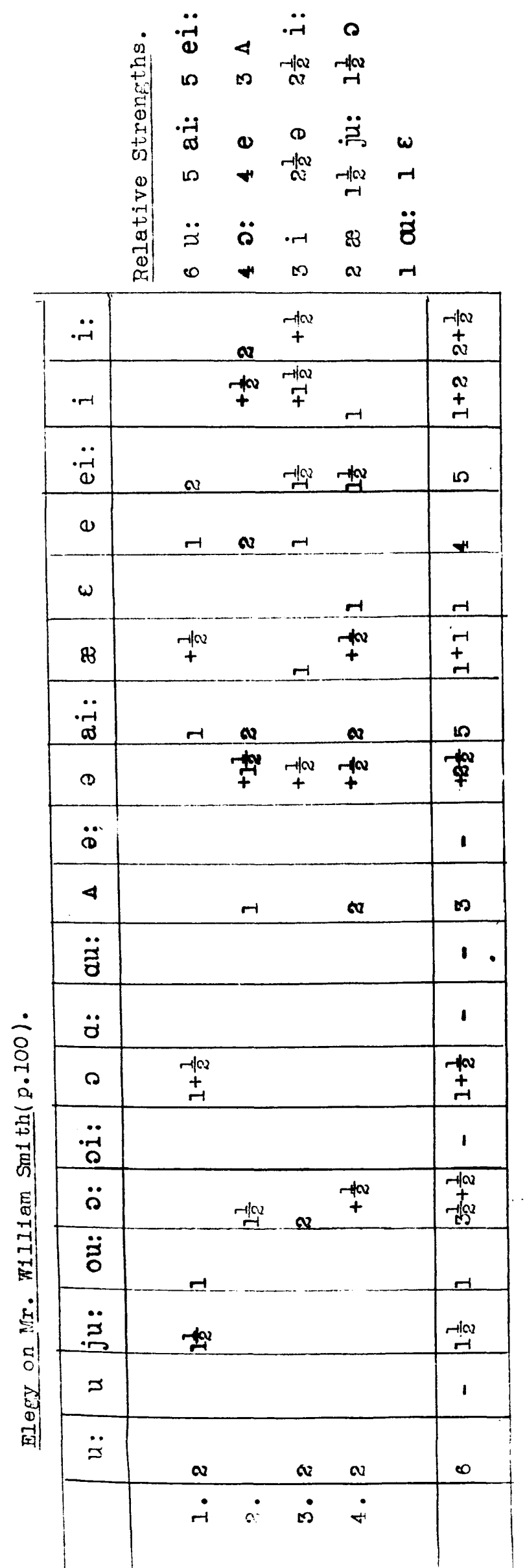



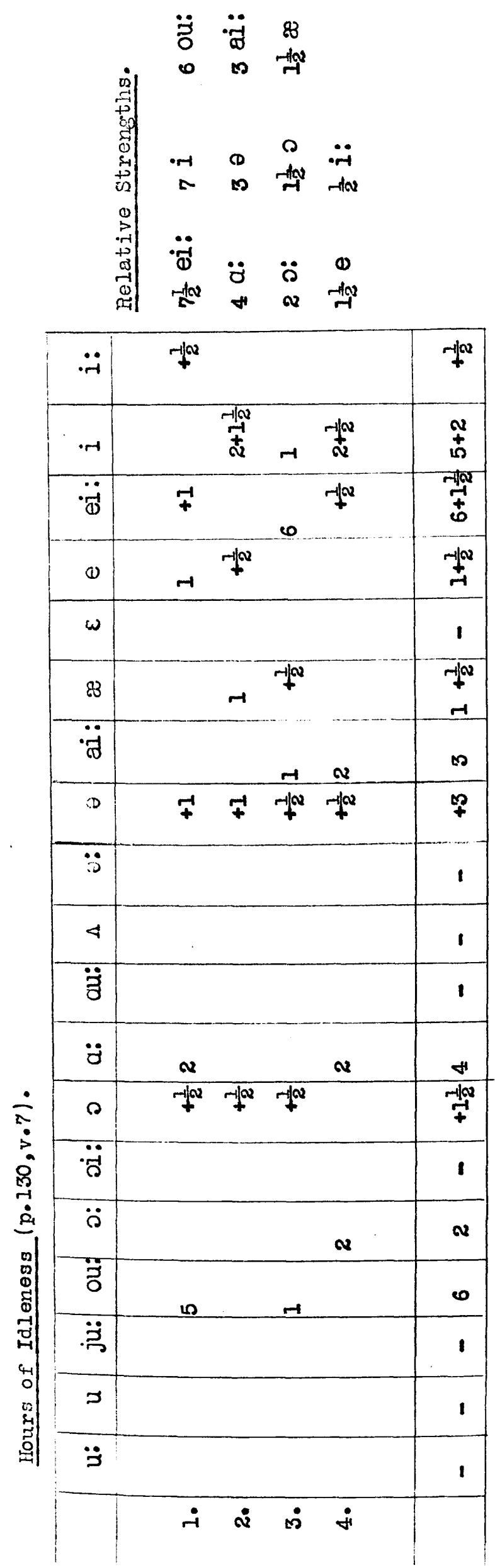


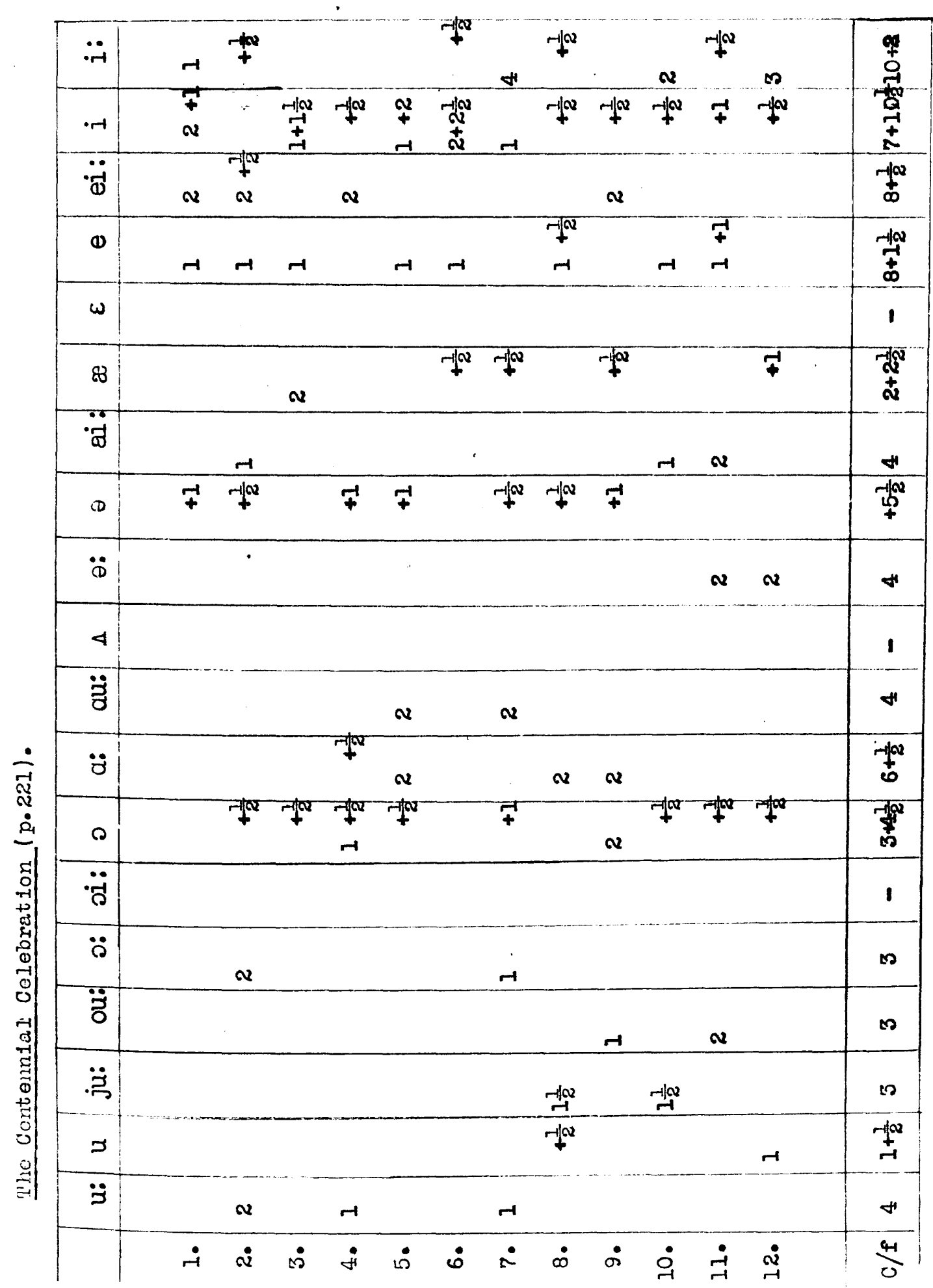

$\infty$
0
$n$
0
01
0
0 


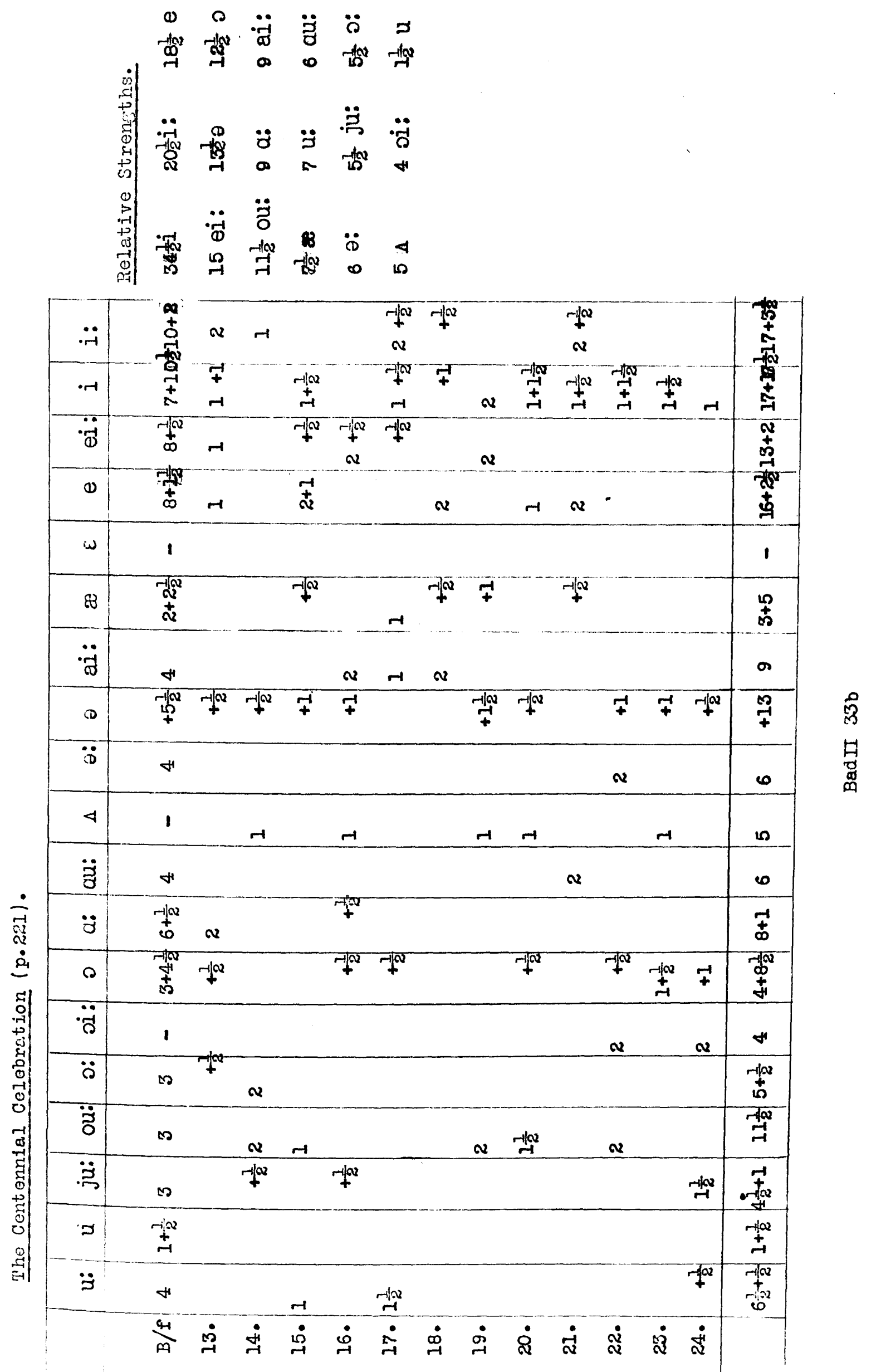




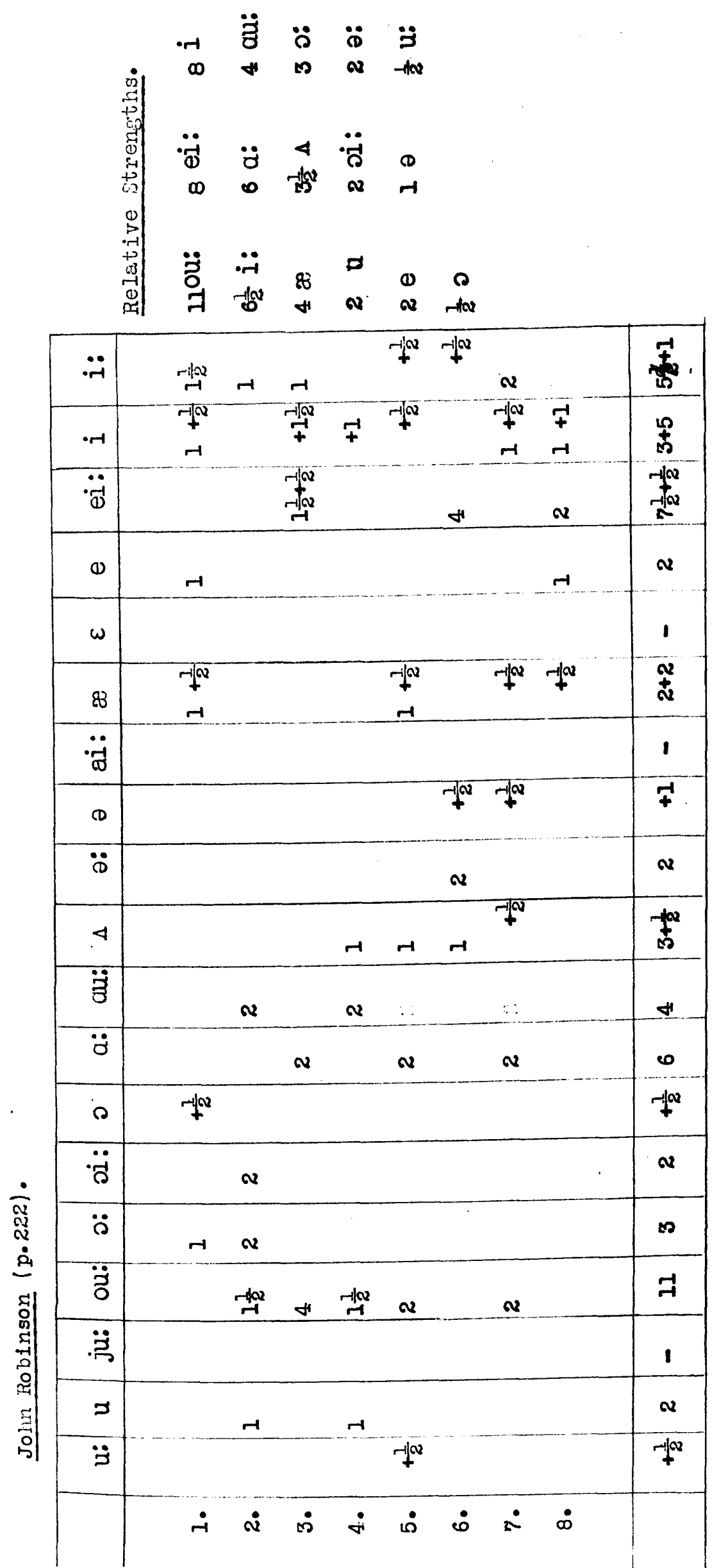



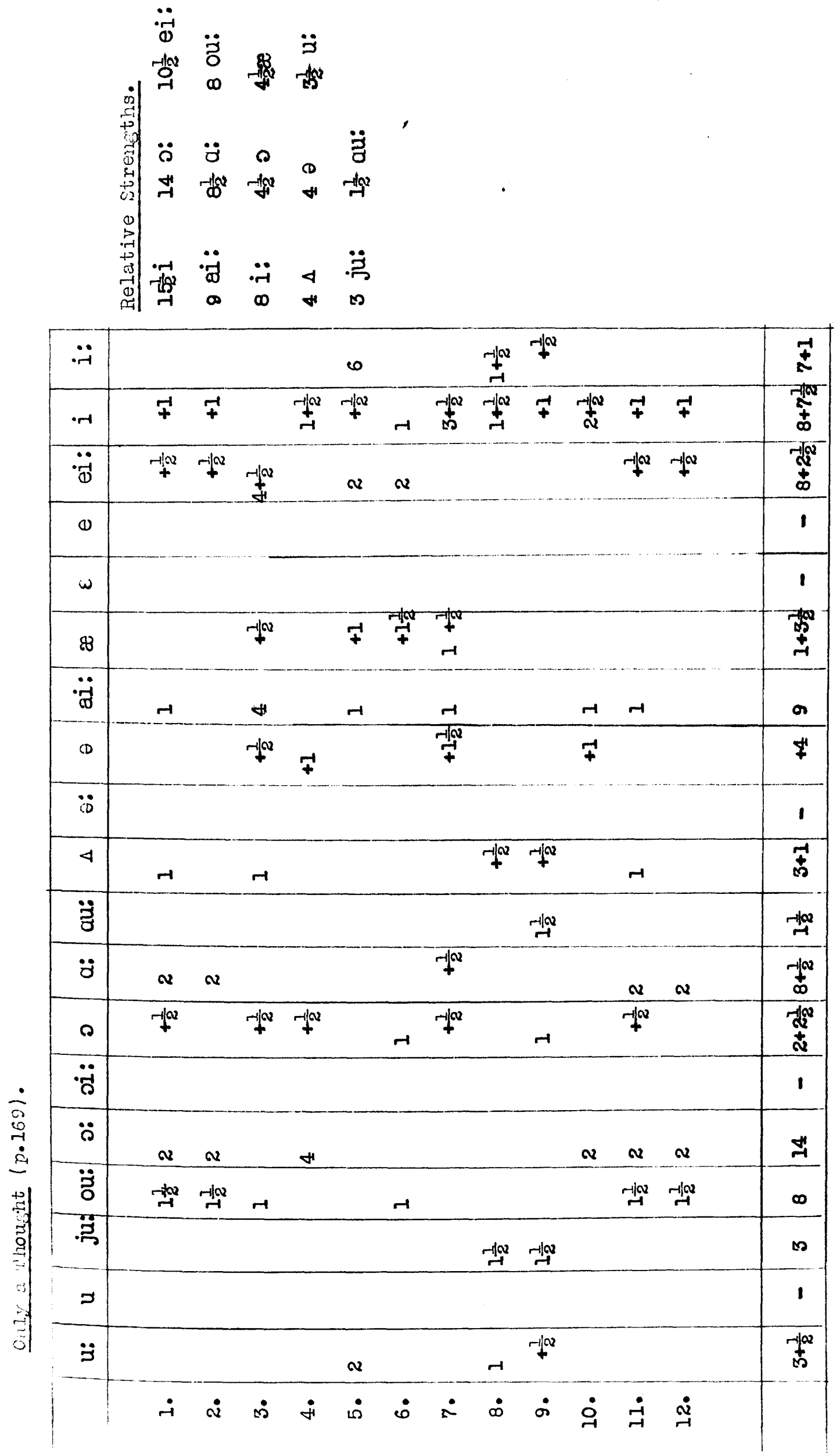

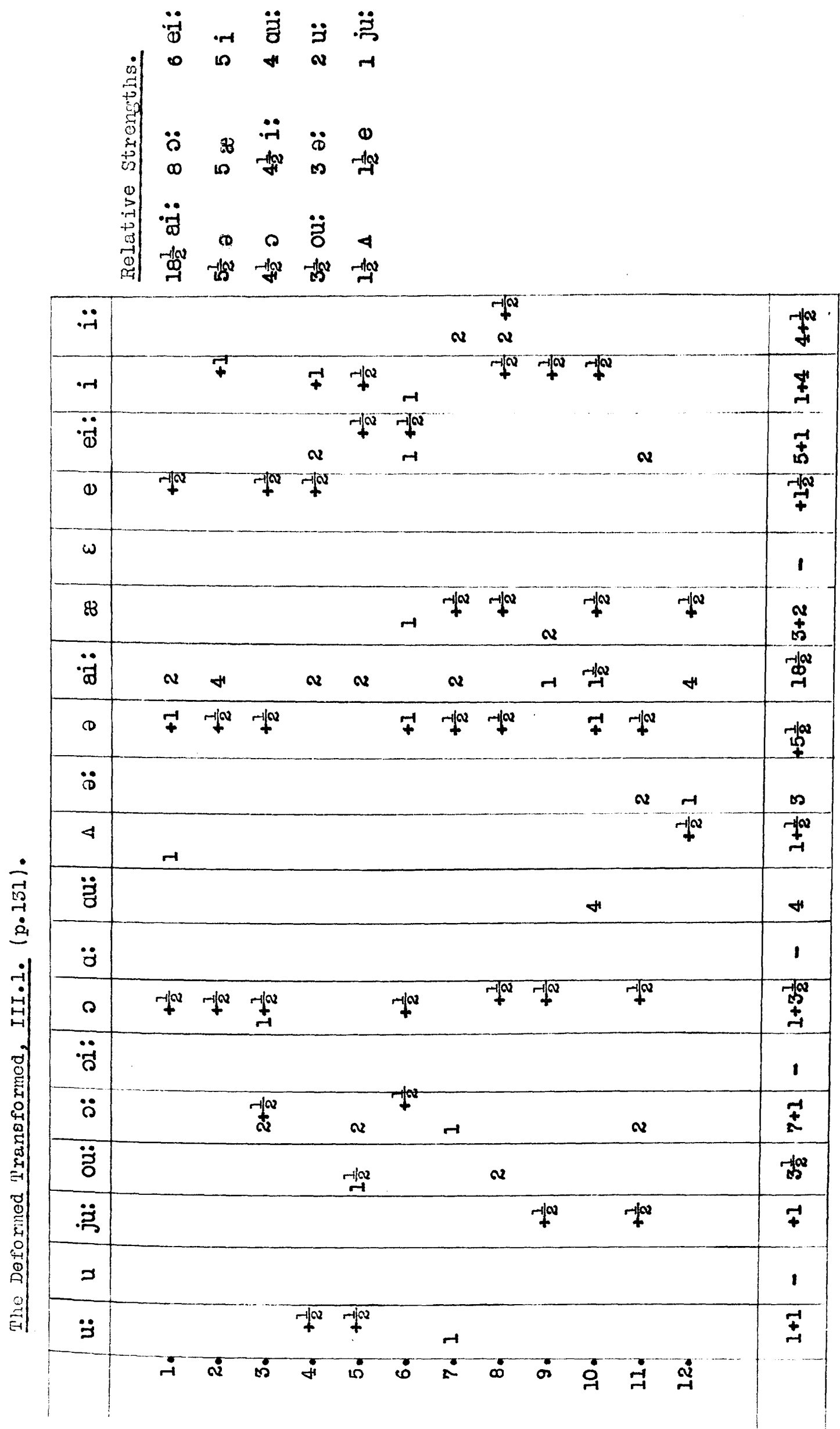


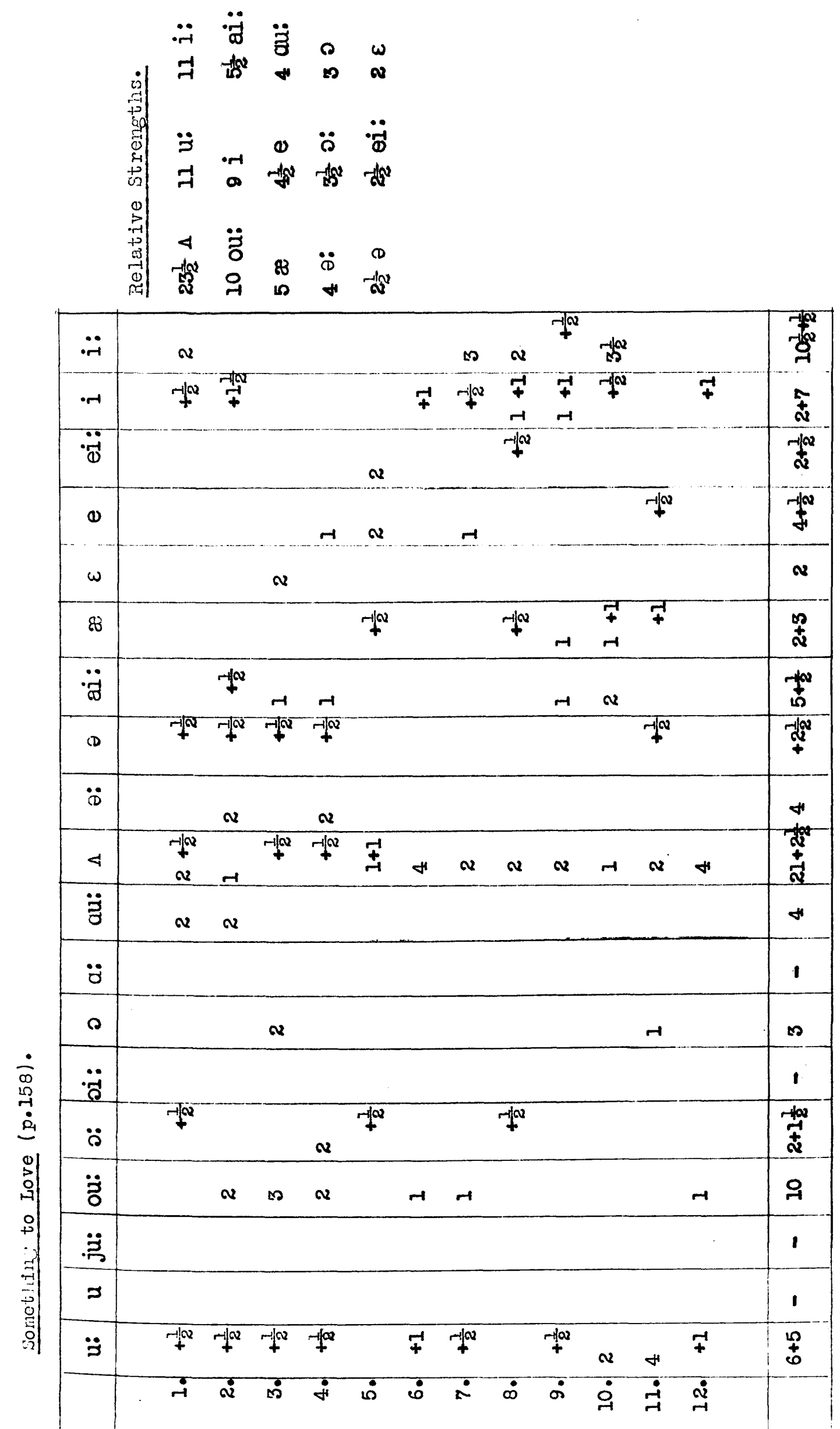




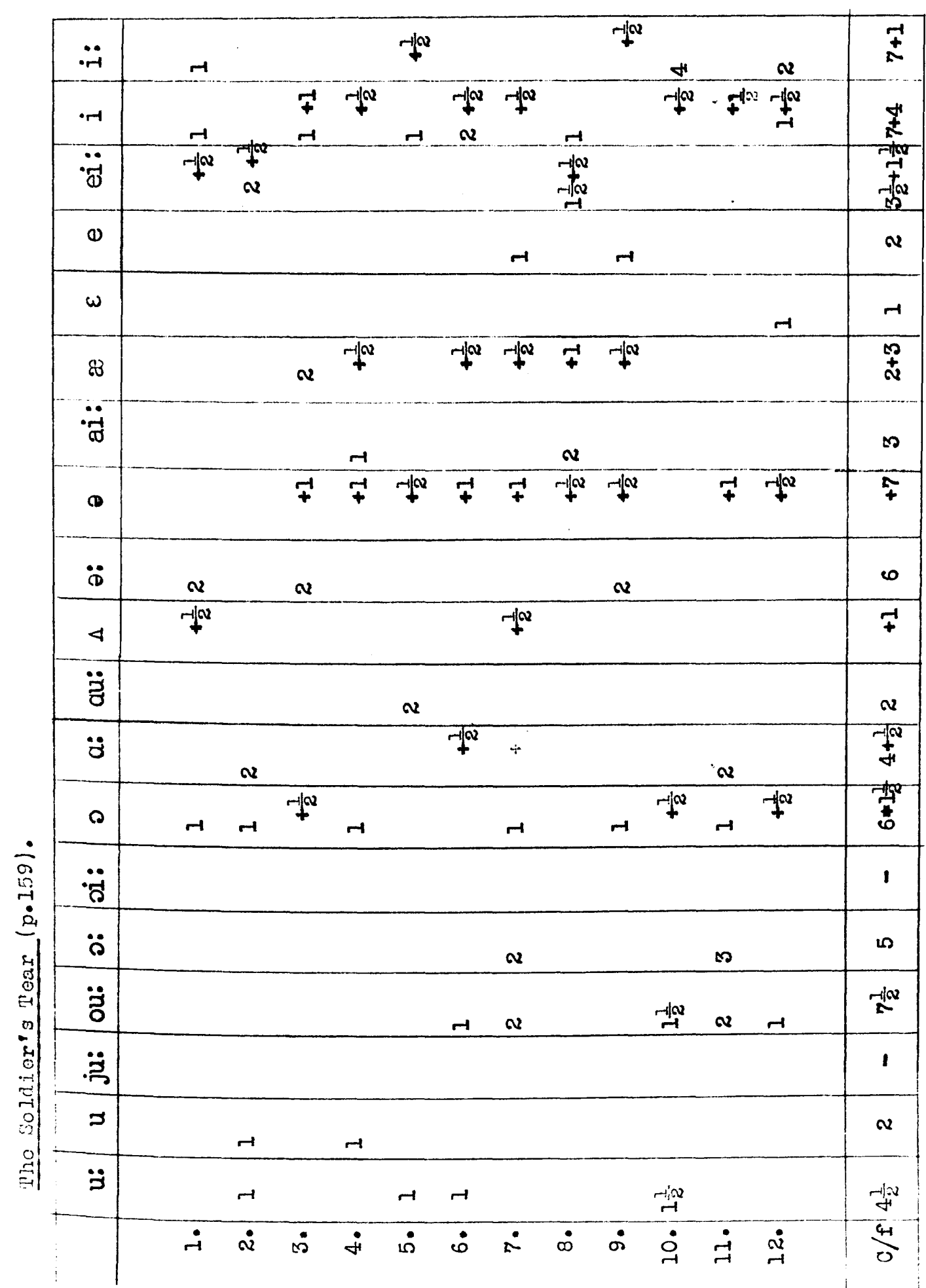




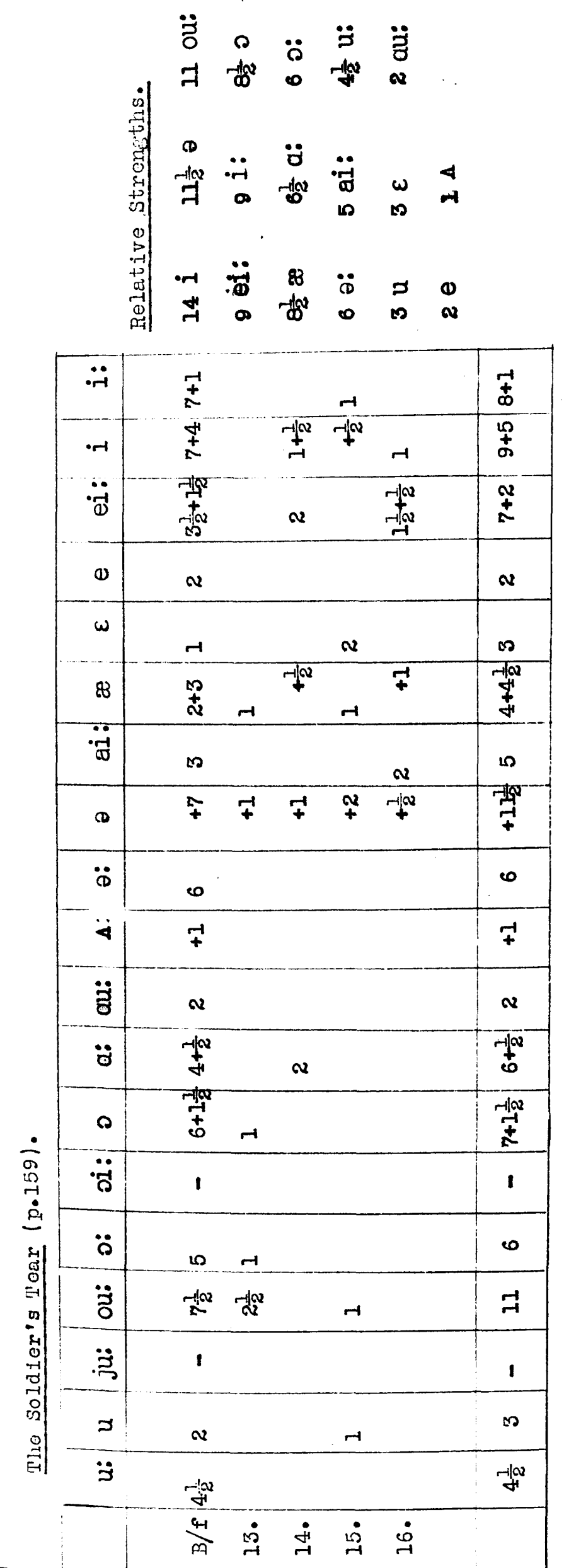




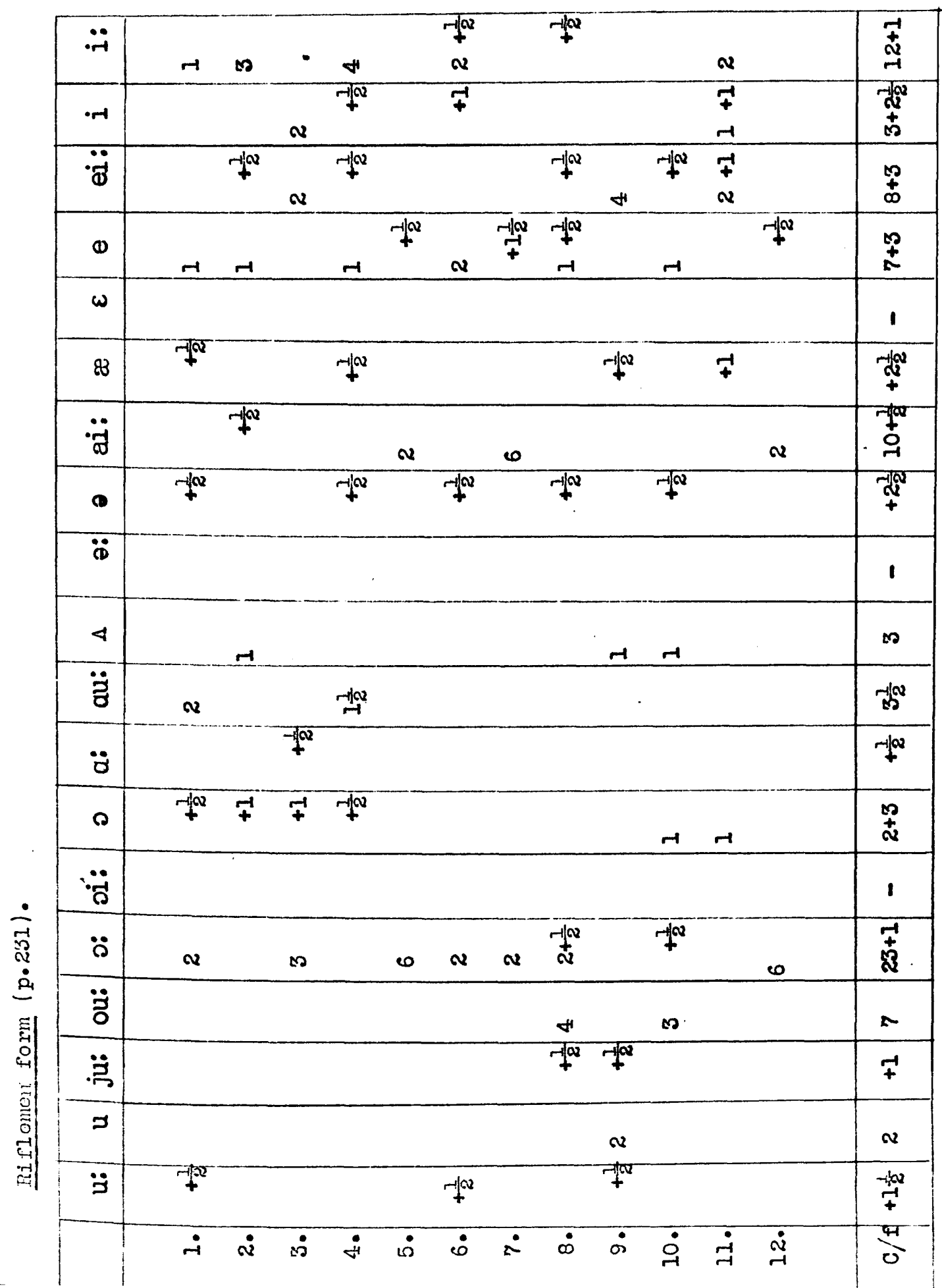




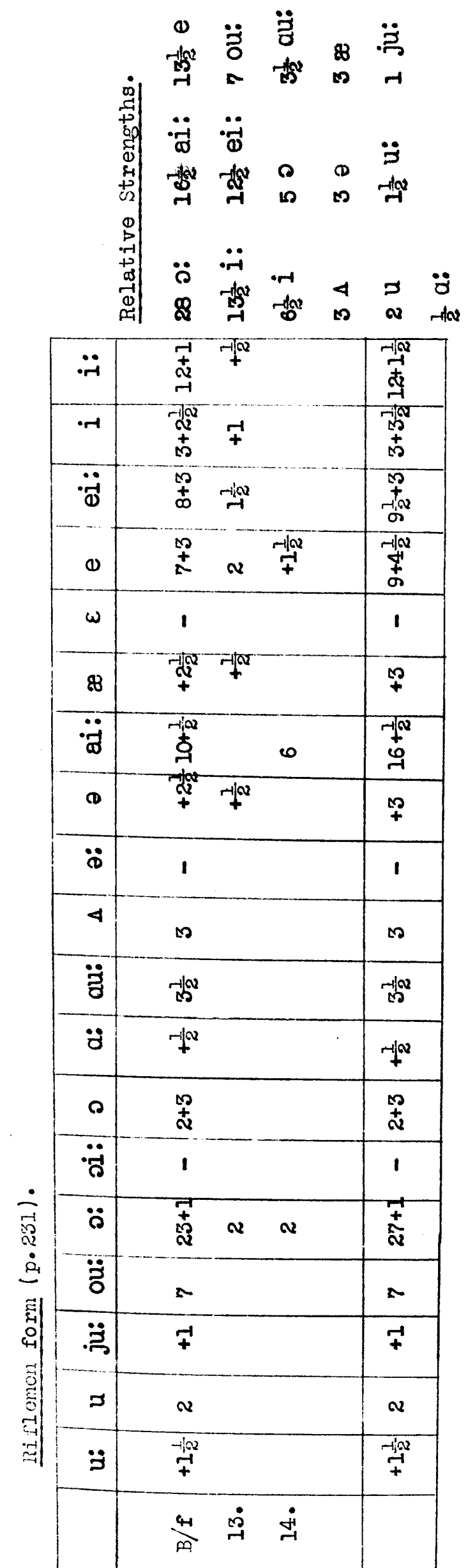




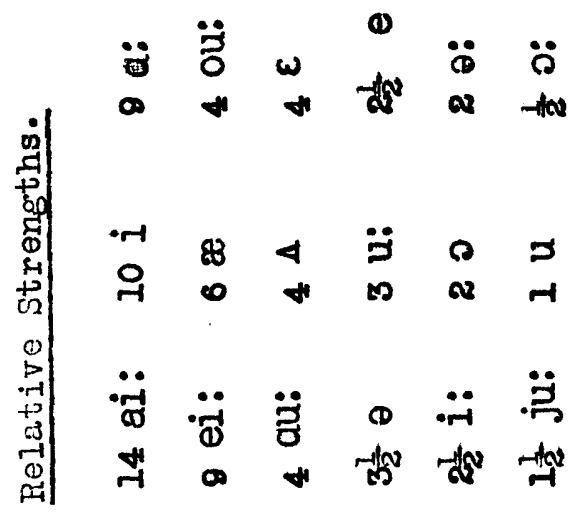

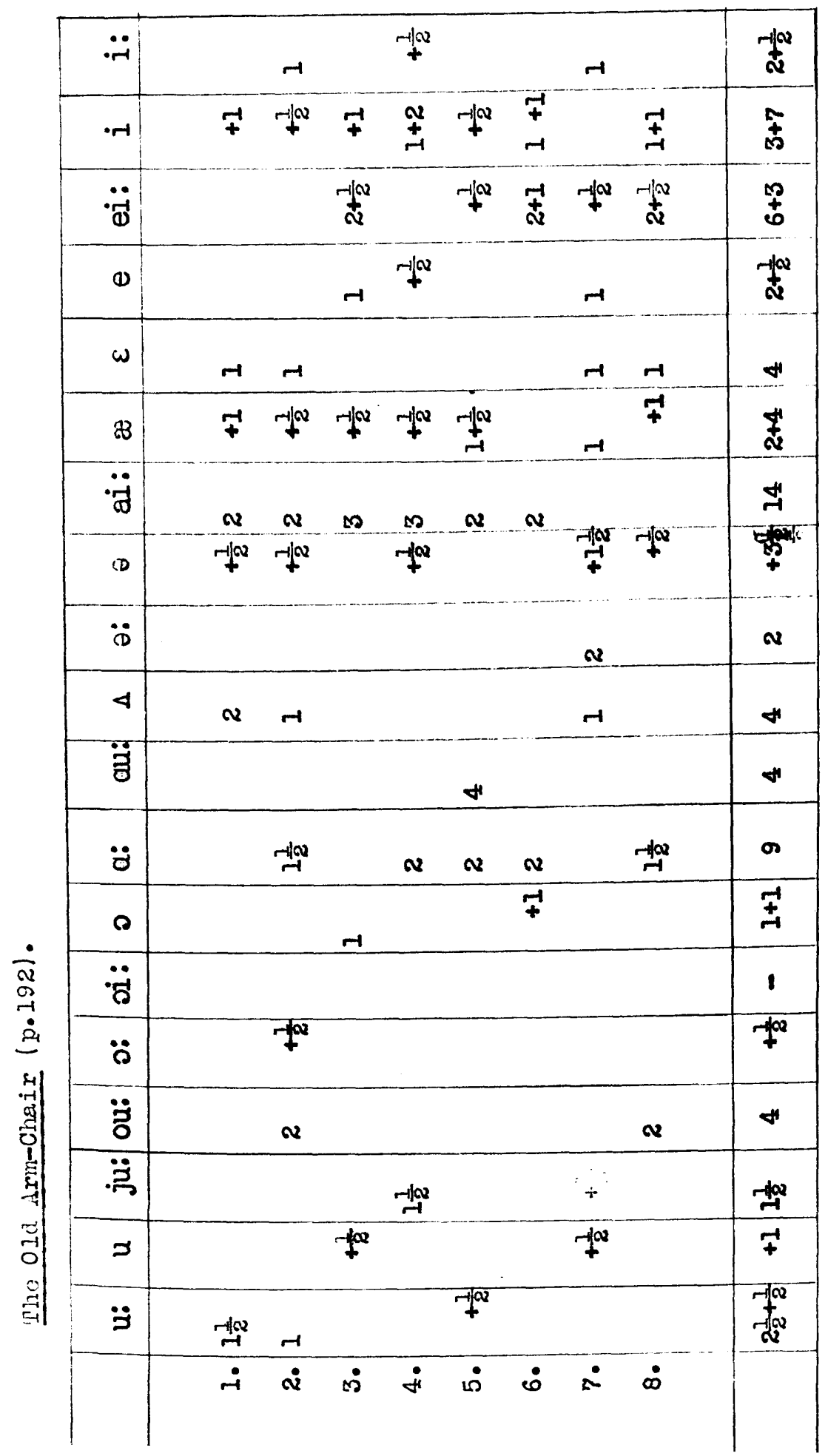




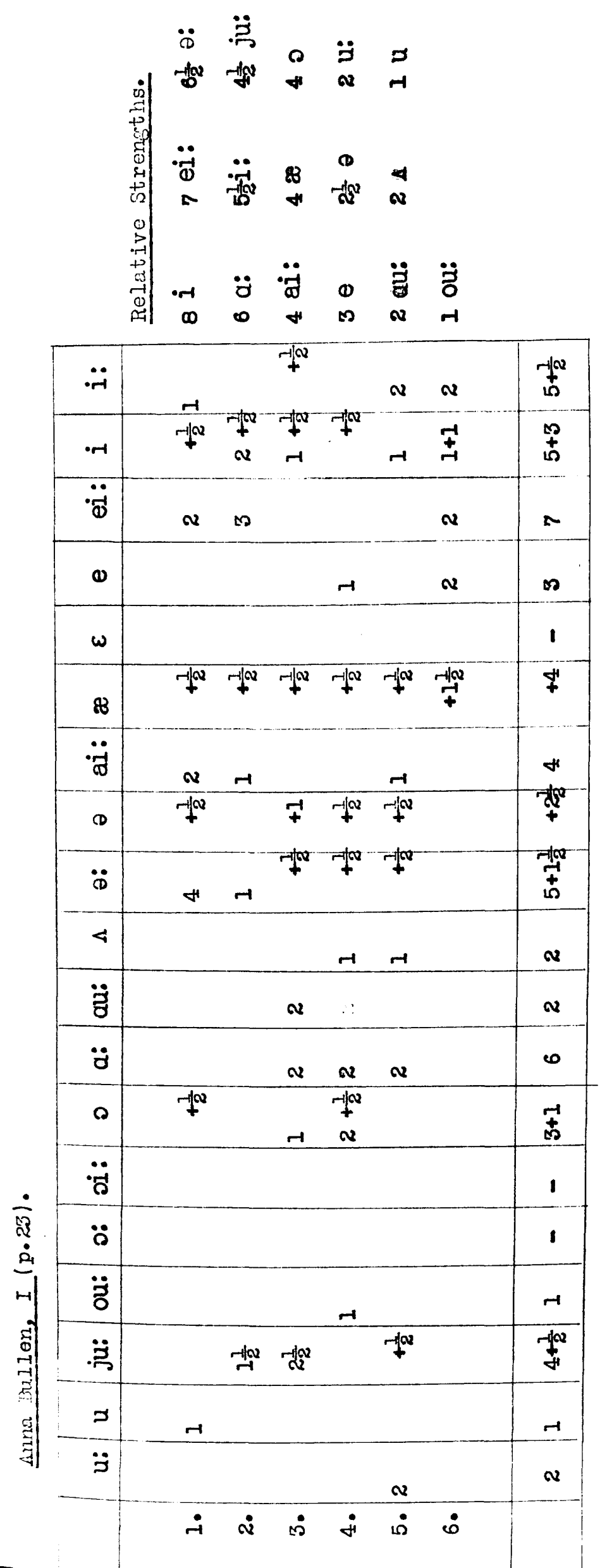




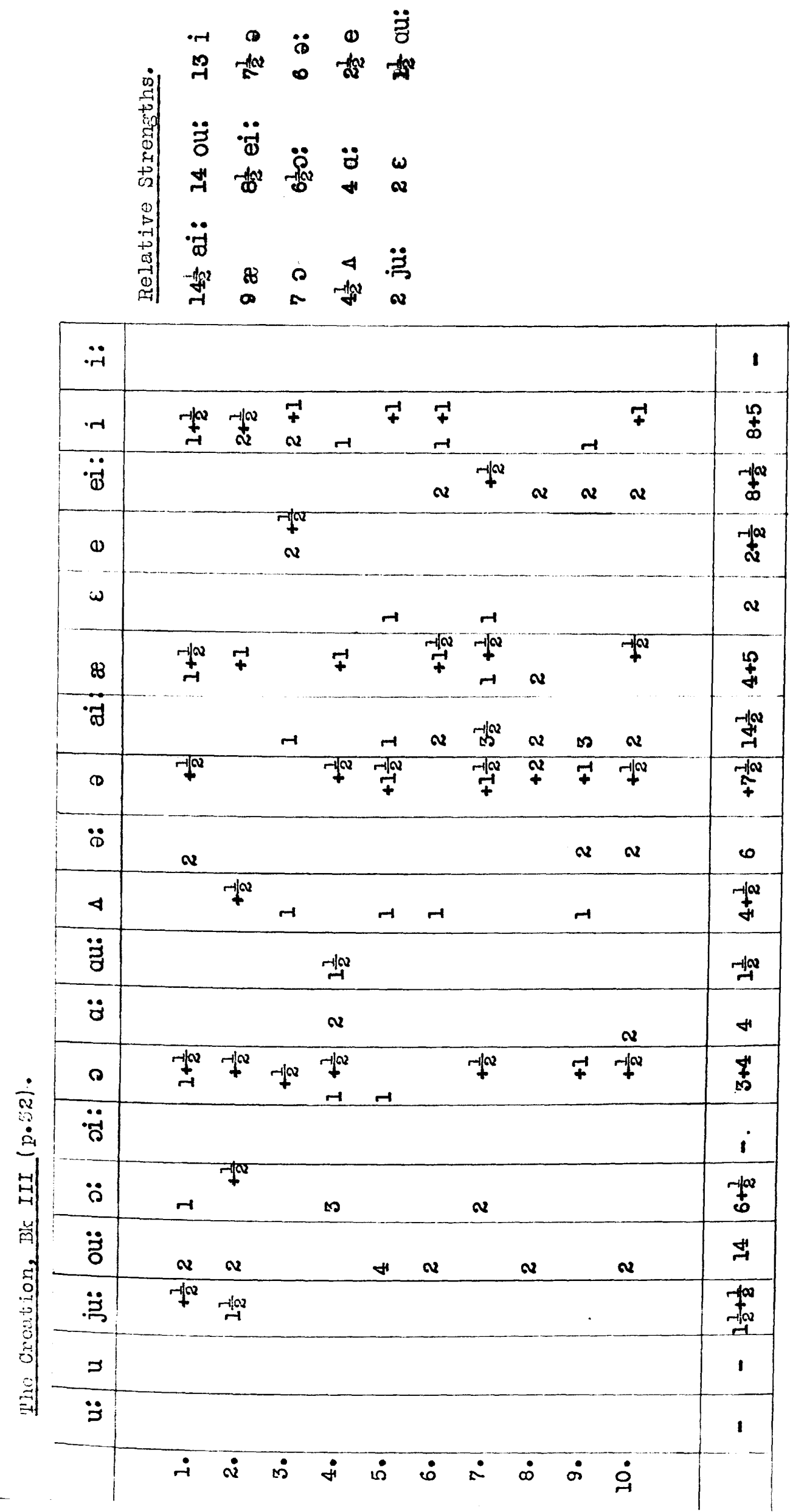




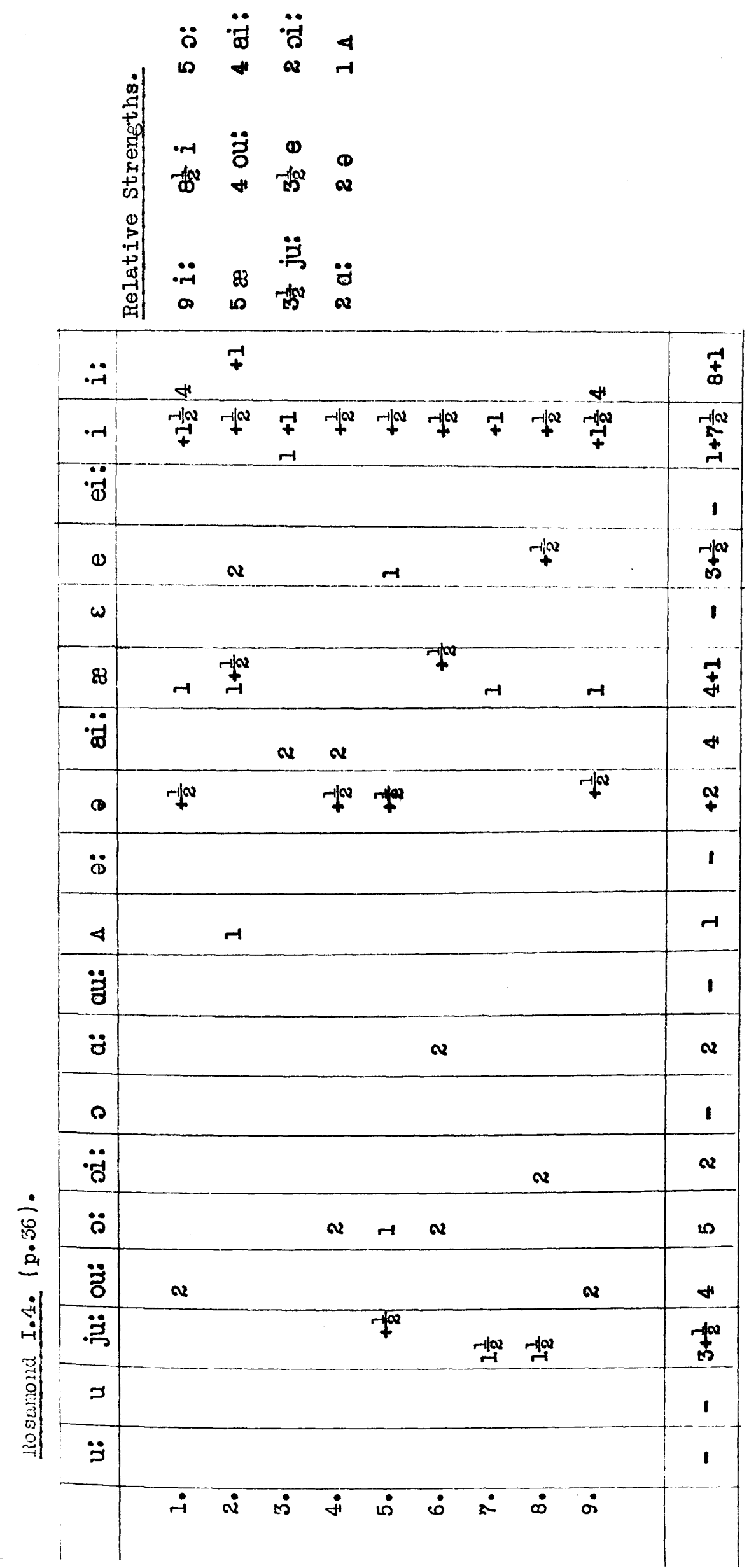




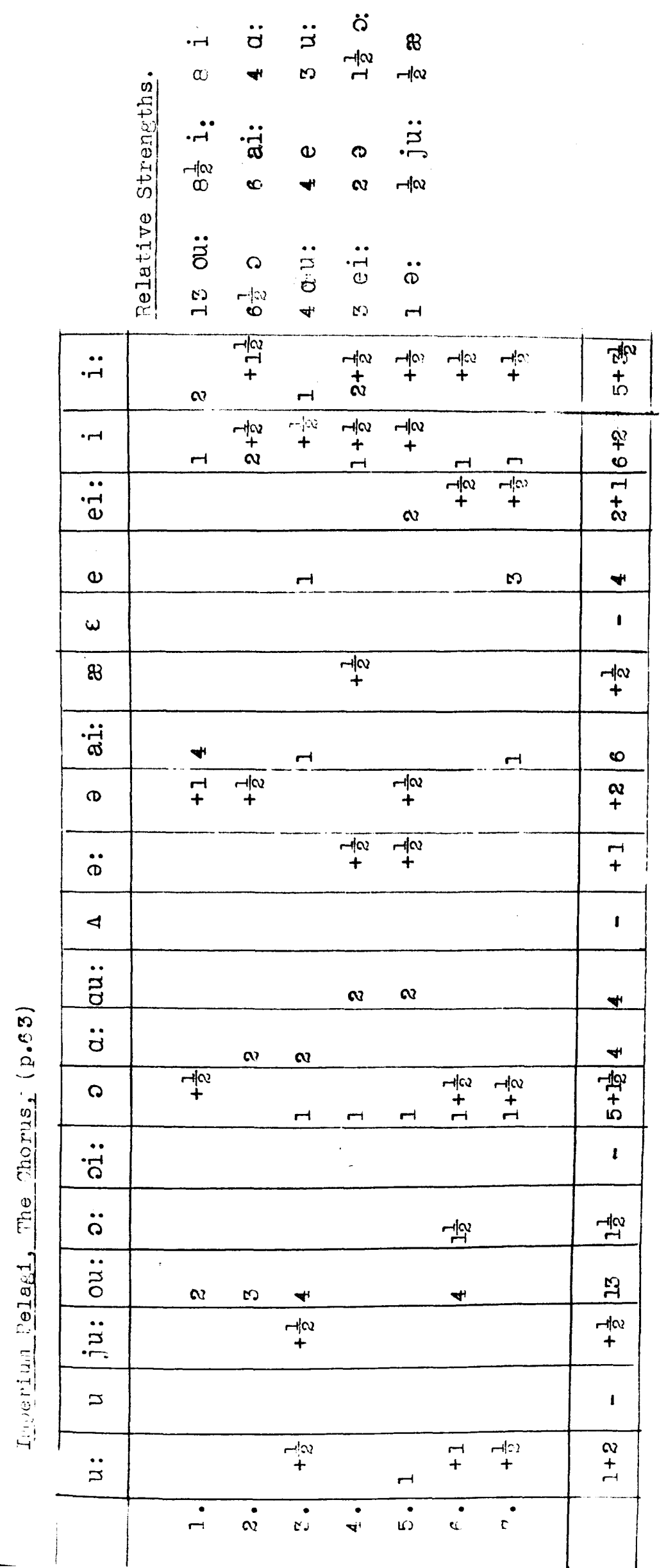




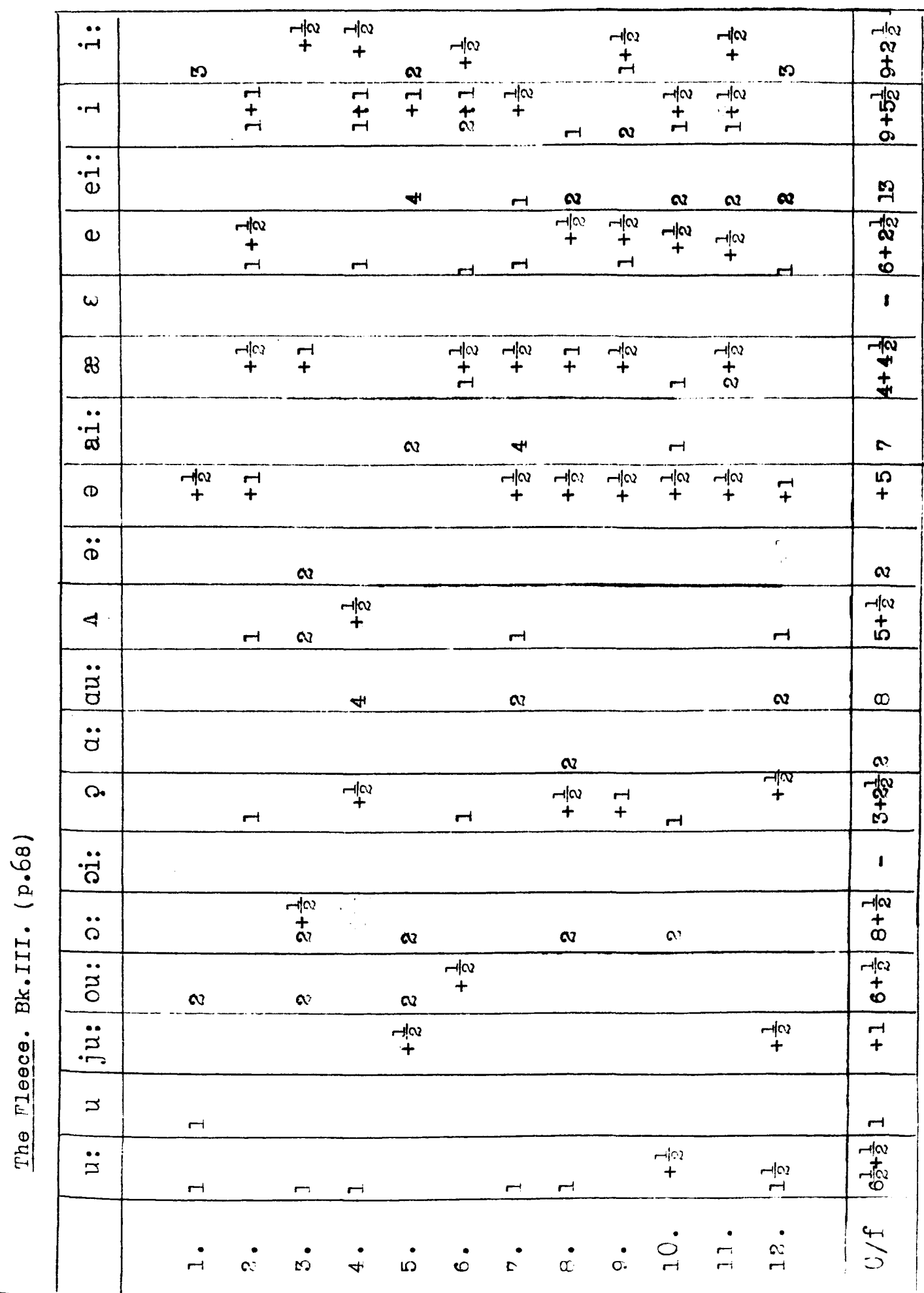

占 


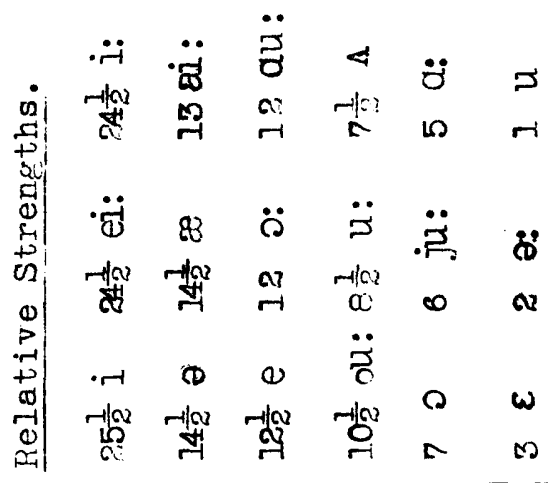

\begin{tabular}{|c|c|c|c|c|c|c|c|c|c|c|}
\hline$\ddot{\ddot{r}}$ & $\begin{array}{c}\text { नll } \\
0 \\
+ \\
0\end{array}$ & & $\begin{array}{c}-1 / 2 \\
+ \\
0\end{array}$ & $a$ & & & + & 4 & $H$ & 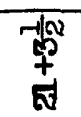 \\
\hline$\cdot r-1$ & $\begin{array}{l}\text { नात् } \\
\text { 㠳 } \\
\text { or } \\
\end{array}$ & $\begin{array}{l}\text { Fa) } \\
7\end{array}$ & $\begin{array}{c}-1 / 00 \\
\pm \\
+\end{array}$ & & $r$ & 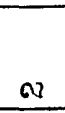 & $r$ & $\begin{array}{l}T \\
N\end{array}$ & $r$ & 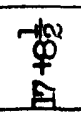 \\
\hline$\stackrel{\ddot{a}}{0}$ & $\stackrel{9}{9}$ & $r$ & & $n$ & & a & + & $\mathbf{Q}$ & + & $\begin{array}{l}+\infty a \\
+ \\
d\end{array}$ \\
\hline 0 & $\begin{array}{c}\text { ric } \\
\text { w } \\
+ \\
0 \\
\end{array}$ & & $r$ & & & - & $\begin{array}{l}-102 \\
+ \\
-1\end{array}$ & & $\begin{array}{l}-110 \\
+\end{array}$ & $\begin{array}{c}-1 / a \\
0 \\
0 \\
0\end{array}$ \\
\hline$\omega$ & 1 & v & & & & & -1 & & & $\infty$ \\
\hline$\$$ & $\begin{array}{l}+\infty \\
+ \\
+1\end{array}$ & $r$ & -1 & Fात & & 7 & + & $\begin{array}{l}\text { न1/0: } \\
+\end{array}$ & $\begin{array}{c}\text { नlos } \\
+\end{array}$ & $\begin{array}{l}\text {. } \\
\$ \\
0\end{array}$ \\
\hline$\ddot{-r}$ & $\Omega$ & 0 & $N$ & & & & N & & & $\stackrel{\mathscr{D}}{\sim}$ \\
\hline C & $\begin{array}{l}10 \\
+\end{array}$ & + & + & + & $\stackrel{w}{+}$ & $\mp$ & $\stackrel{\infty}{+}$ & + & $T$ & 7 \\
\hline$\ddot{0}$ & $N$ & & & & & & & & & $\boldsymbol{N}$ \\
\hline 4 & $\begin{array}{c}-1 \infty \\
+\infty \\
10\end{array}$ & -1 & & & $r$ & & & . & & $\begin{array}{c}-10 \\
+ \\
2\end{array}$ \\
\hline$\ddot{\vec{z}}$ & $\infty$ & & & & $c ?$ & $\infty$ & & & & $\underline{\varphi}$ \\
\hline$\ddot{\ddot{\theta}}$ & $\boldsymbol{v}$ & & & $\omega$ & & & $r$ & & & ما \\
\hline$\curvearrowright$ & $\begin{array}{c}-1 \\
\text {-d } \\
+ \\
+ \\
m\end{array}$ & & $\begin{array}{c}-1 / n \\
+\end{array}$ & & 7 & & & & & $\begin{array}{l}4 \\
+\end{array}$ \\
\hline$\ddot{\ddot{\theta}}$ & 1 & & & & & & & & & 1 \\
\hline$\ddot{\rho}$ & $\begin{array}{c}-1 \omega \\
+\infty \\
+\infty\end{array}$ & & $-f^{\prime} a ?$ & & क? & & & & & 慗 \\
\hline$\ddot{z}$ & $\begin{array}{c}-1+\infty \\
+ \\
0\end{array}$ & & & $\infty$ & & 0 & & & & $\begin{array}{c}-10 \\
6 \\
\end{array}$ \\
\hline$\ddot{\jmath}$ & 7 & & & 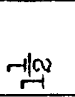 & $\stackrel{r l a}{\rightleftharpoons}$ & $-\mathrm{Fl}_{+}$ & 7 & & $\stackrel{-102}{+}$ & $\begin{array}{l}m \\
+ \\
m\end{array}$ \\
\hline$\Xi$ & - & & & & & & & & & $r$ \\
\hline$\ddot{\vec{r}}$ & $\begin{array}{l}r+\infty \\
-1+\infty \\
-10\end{array}$ & & & & & & & $r$ & $+\infty$ & 7 \\
\hline & $\stackrel{4}{m}$ & $\therefore$ & $\dot{\ddot{r}}$ & $\begin{array}{l}\dot{10} \\
\dot{n}\end{array}$ & $\dot{c}$ & $\stackrel{\circ}{\circ}$ & $\therefore$ & c: & $\dot{C}$ & \\
\hline
\end{tabular}




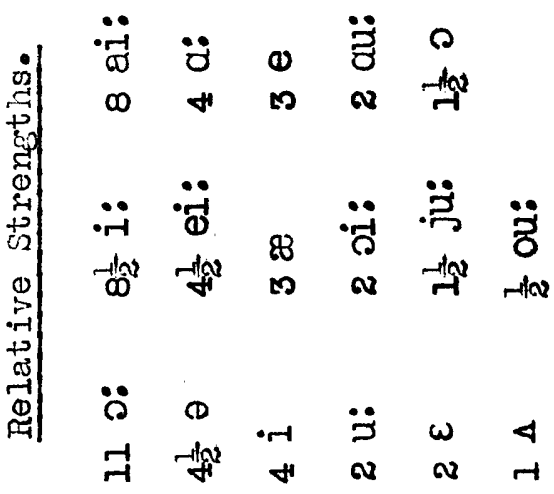

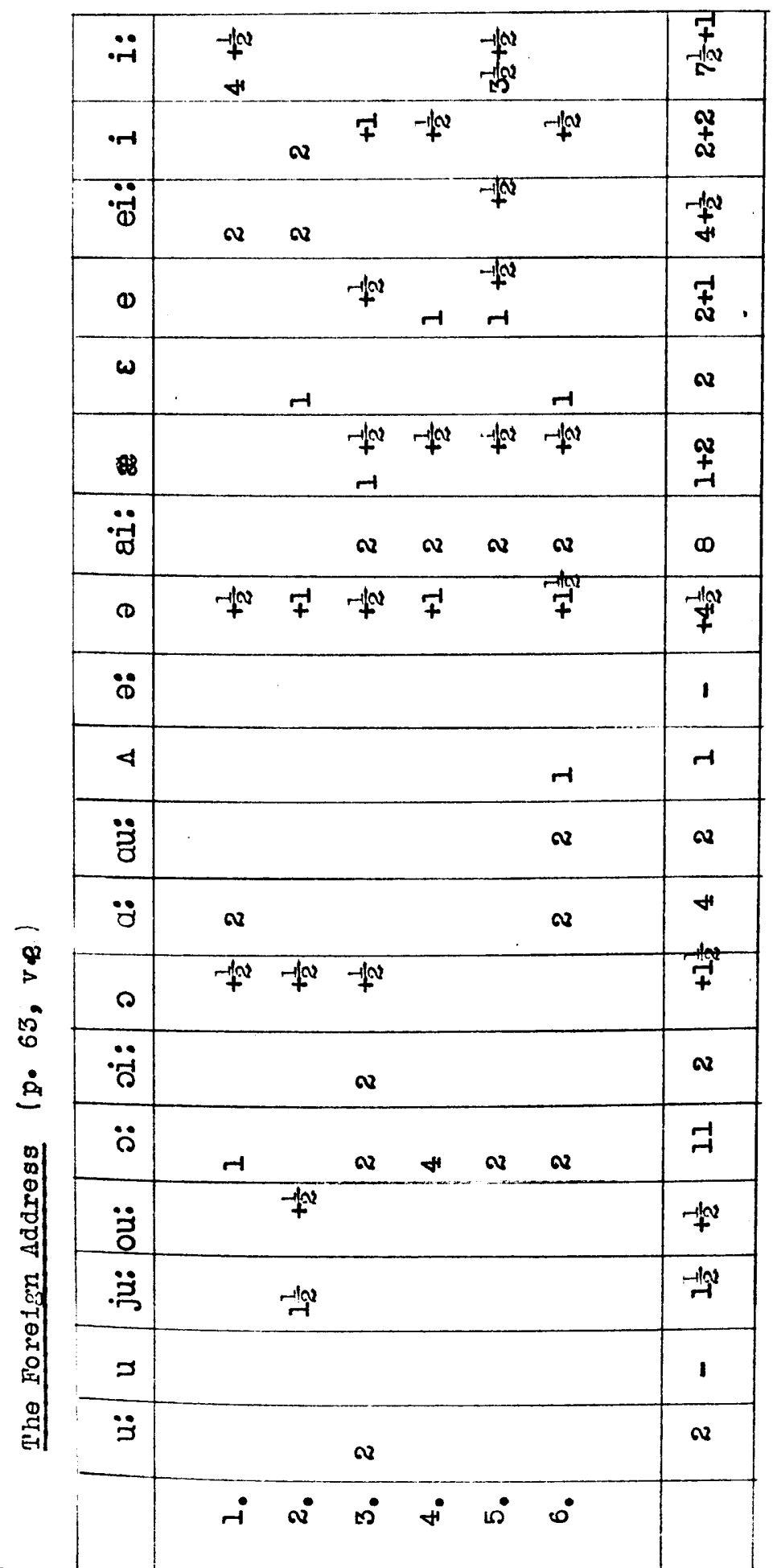




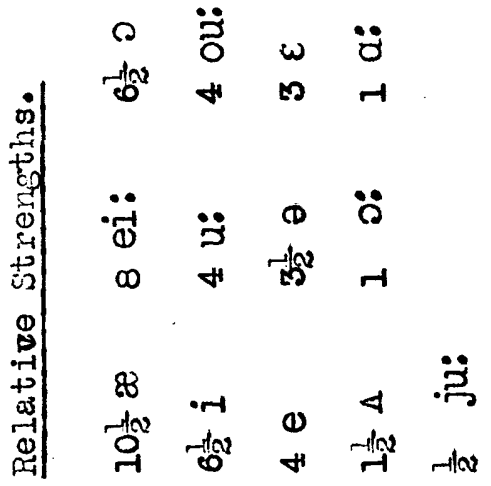

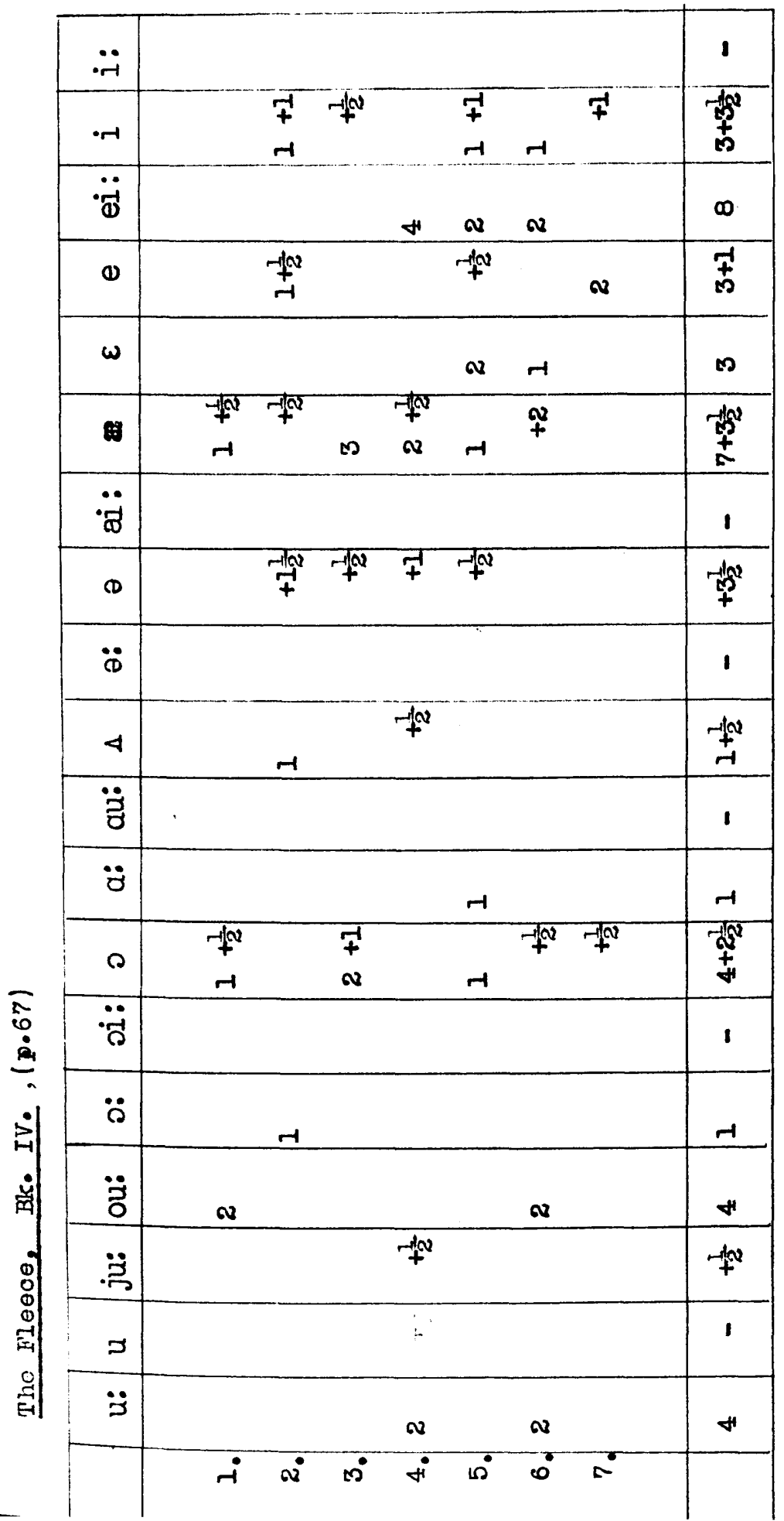




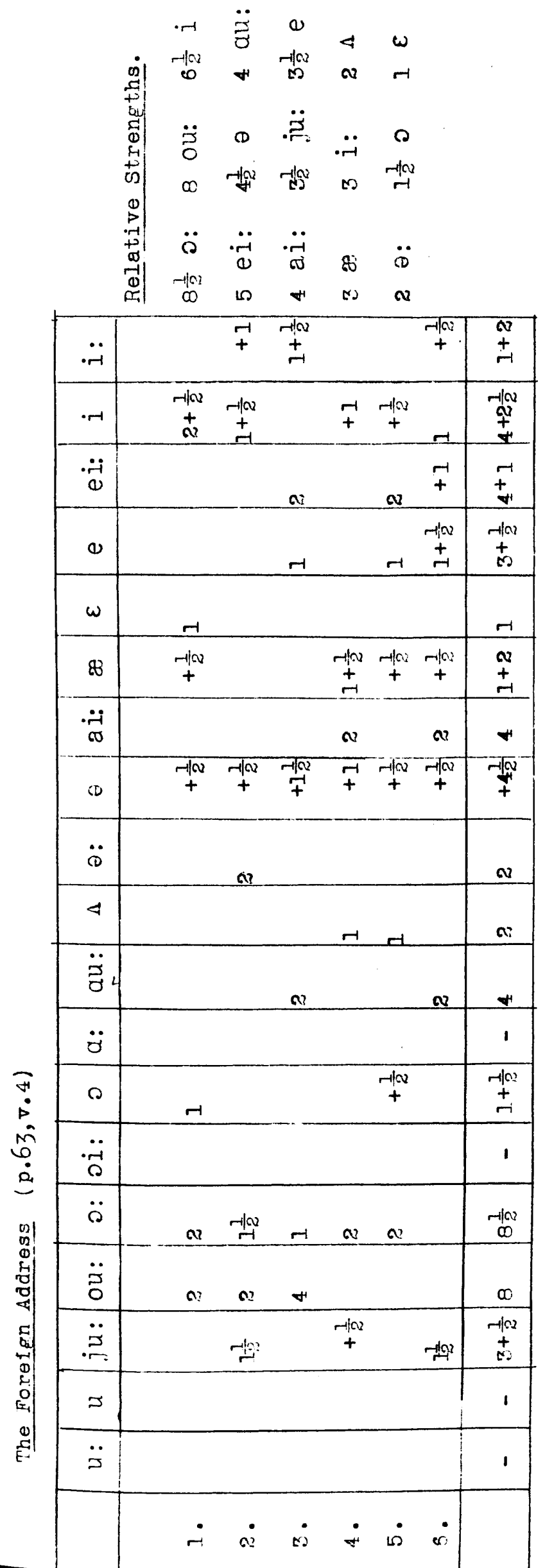




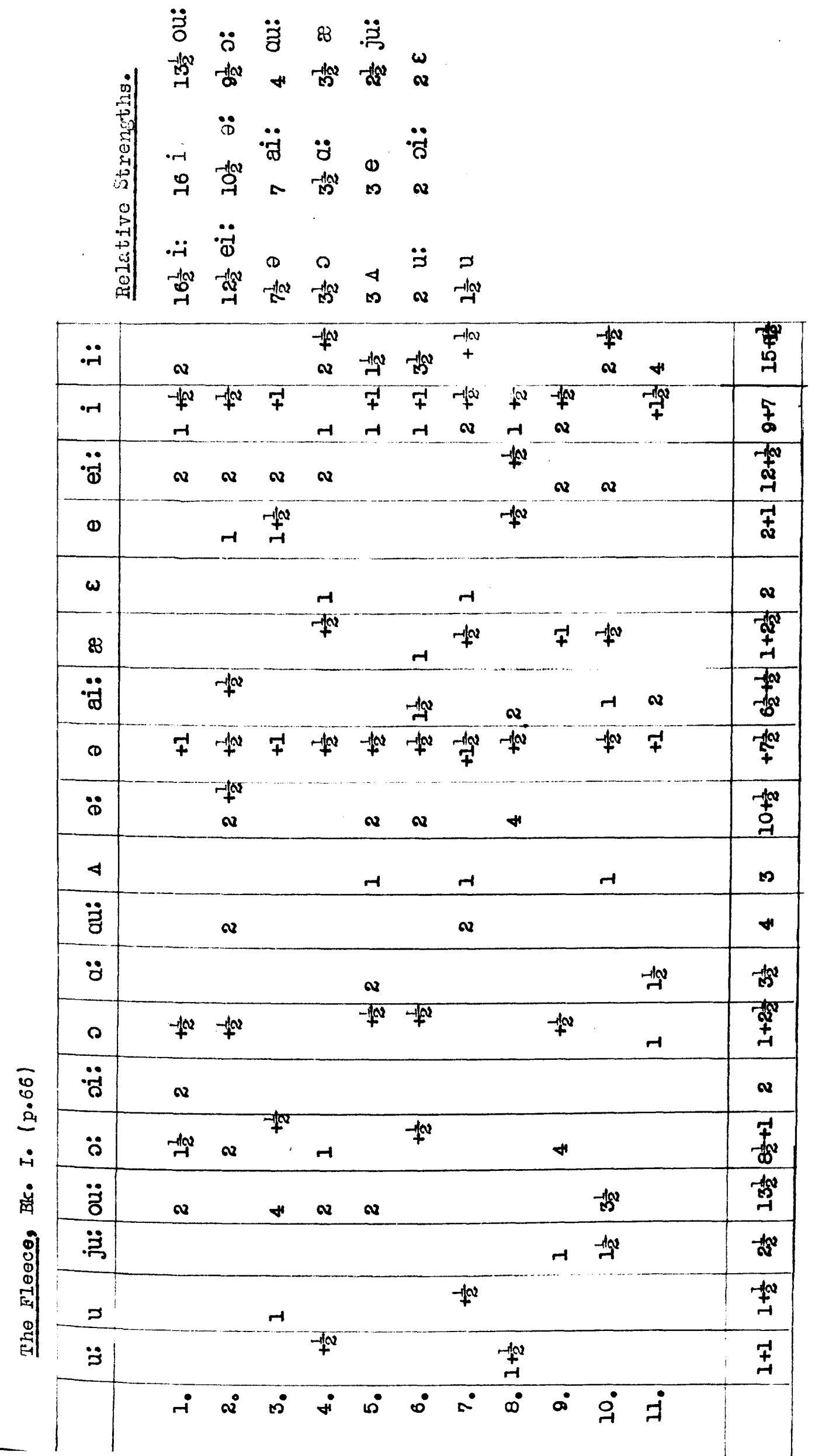




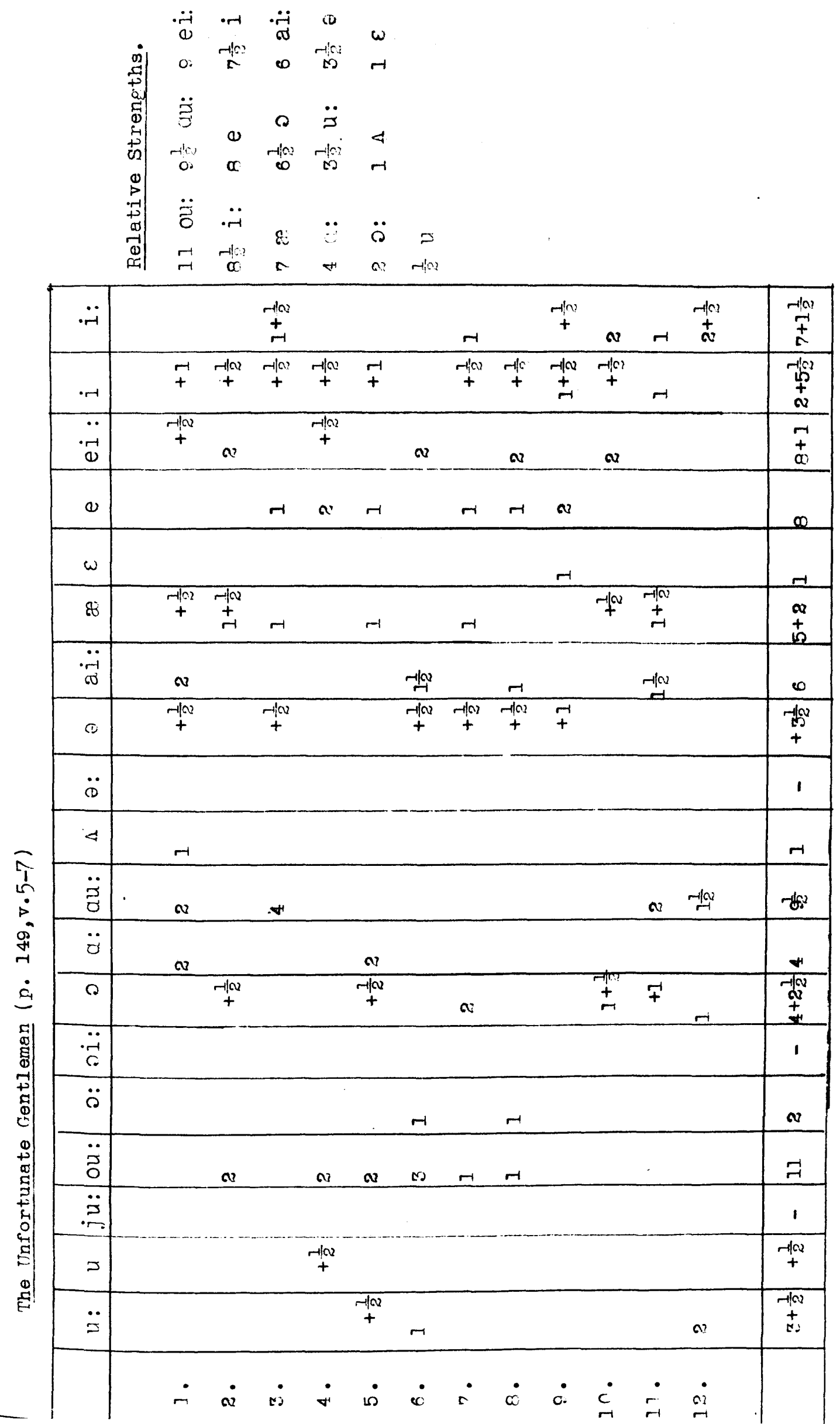

옹
目
总
中 


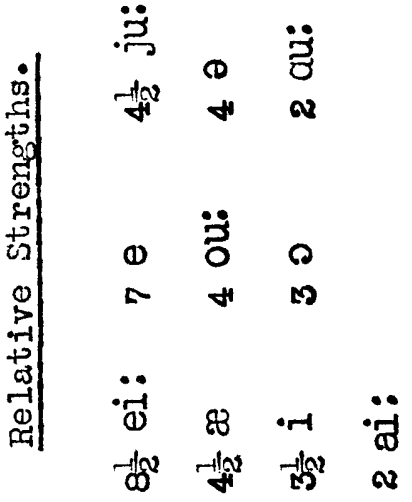

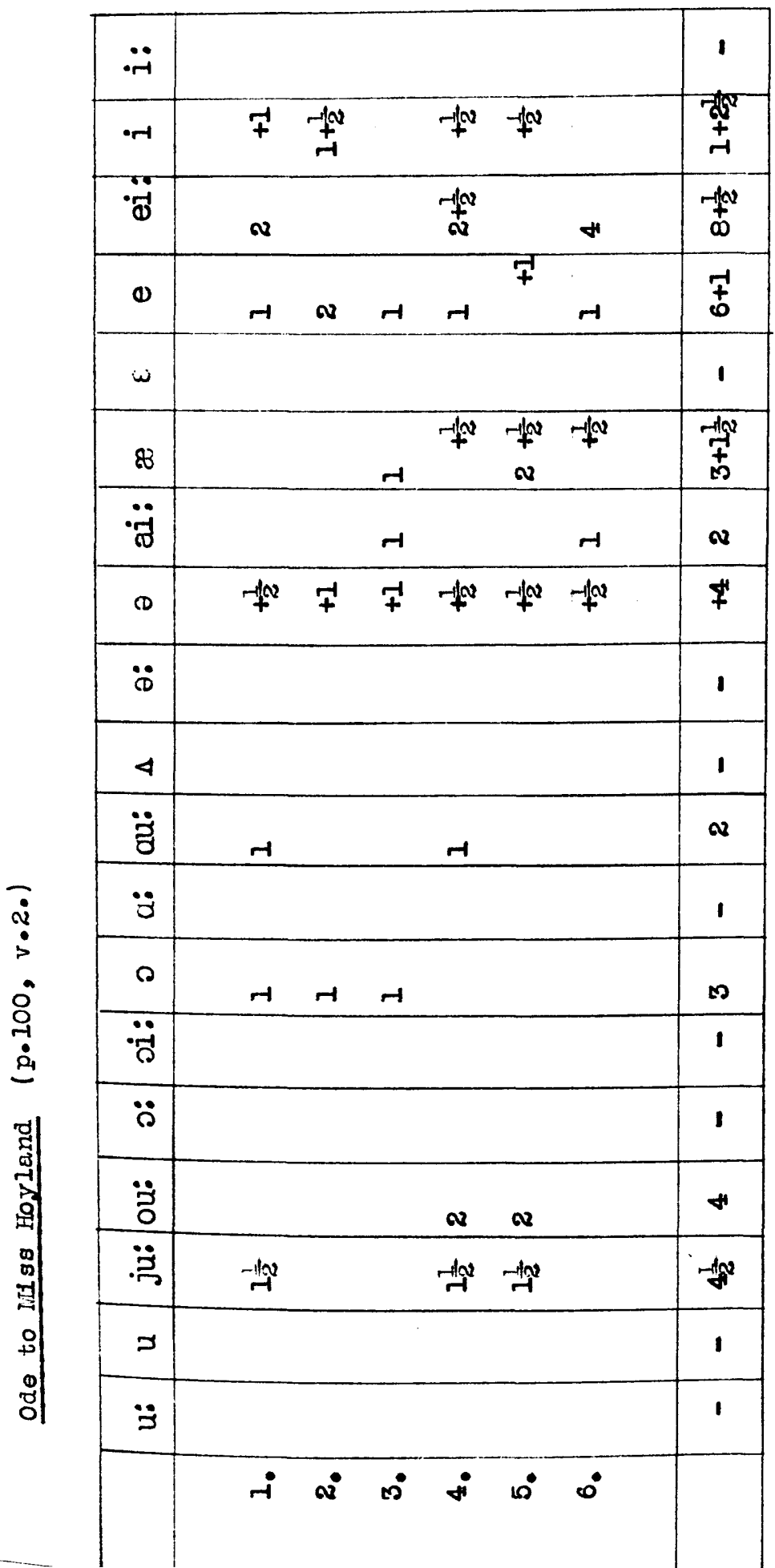




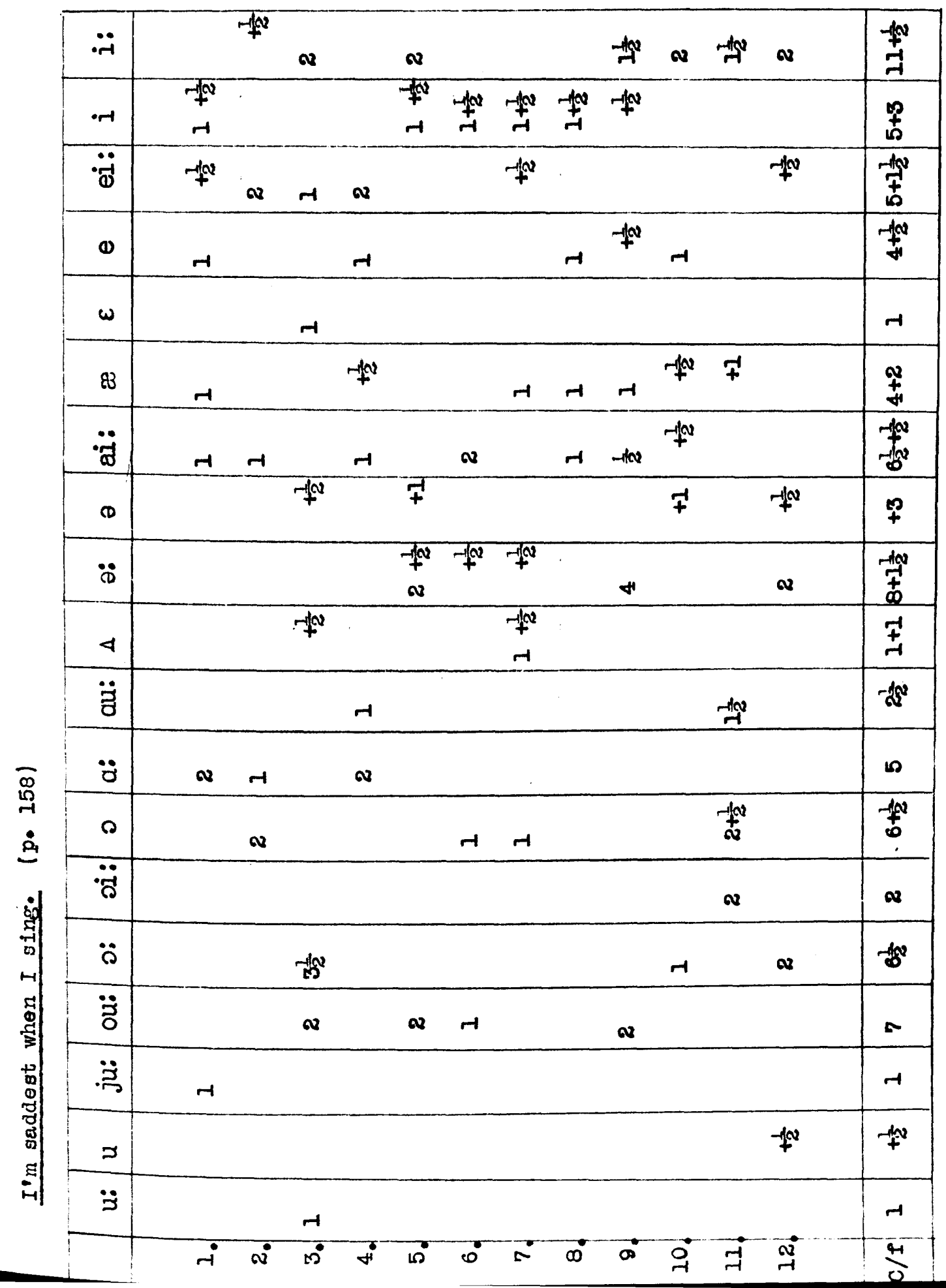




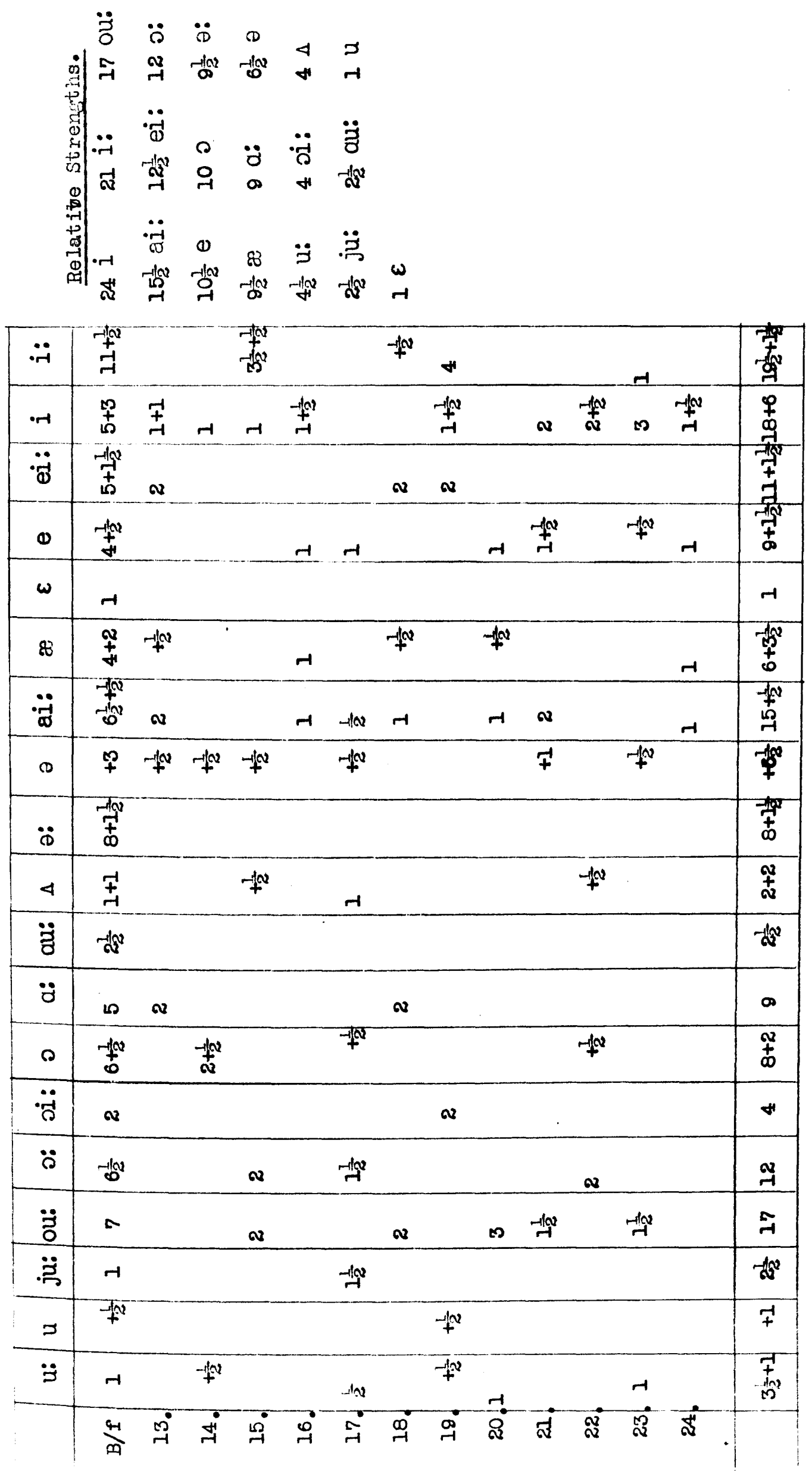




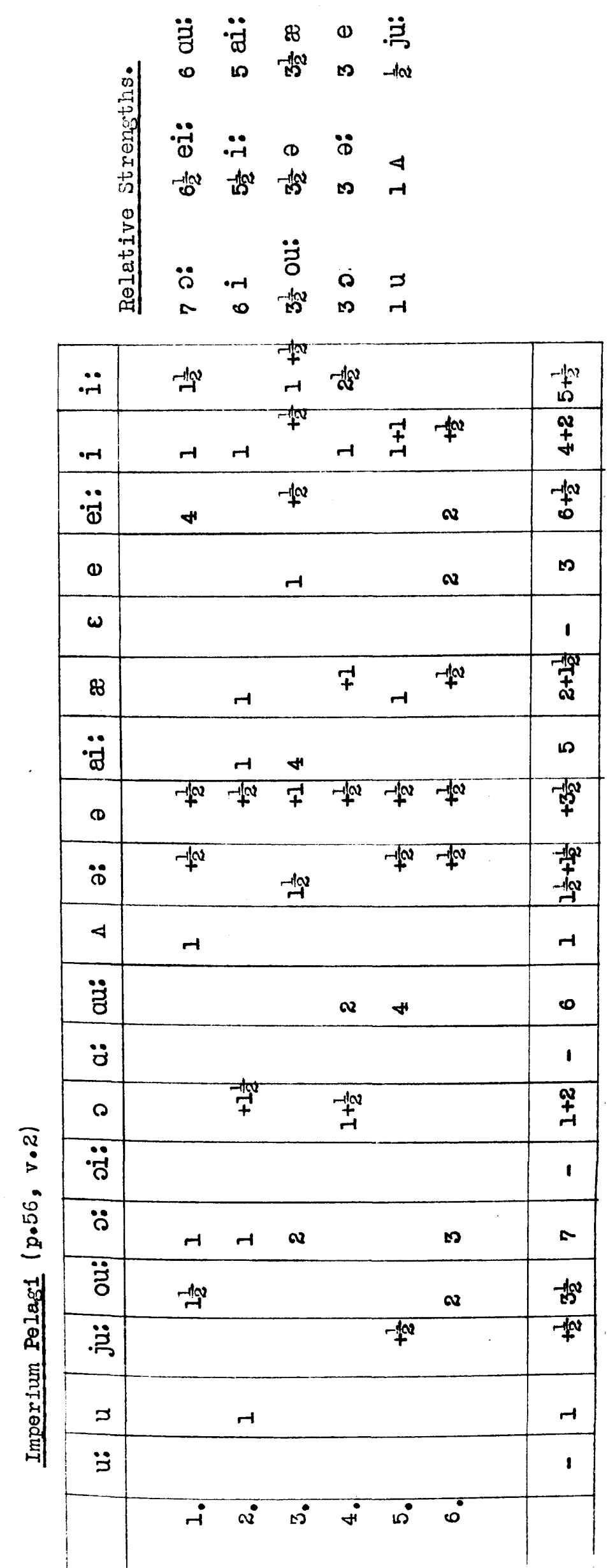

10
is
目
क्
0
0
0 


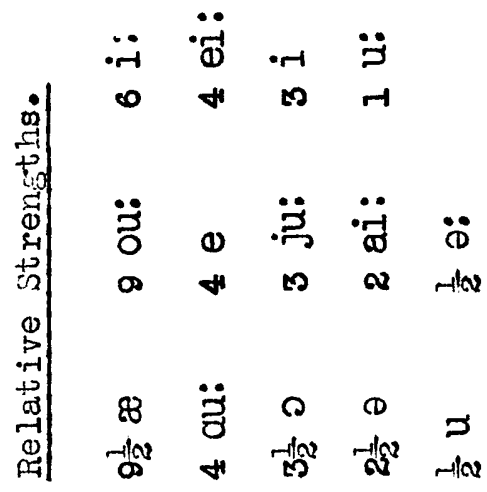

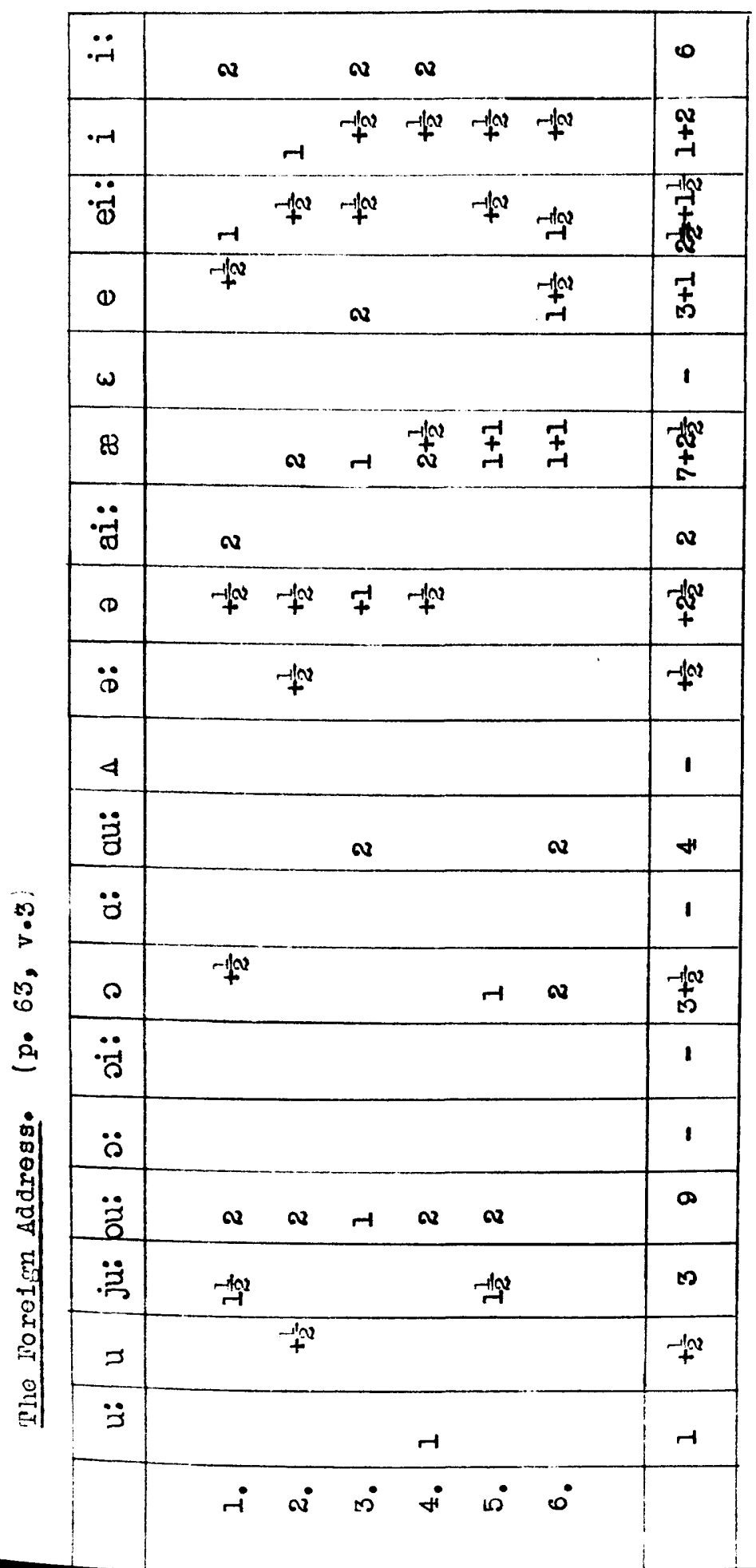




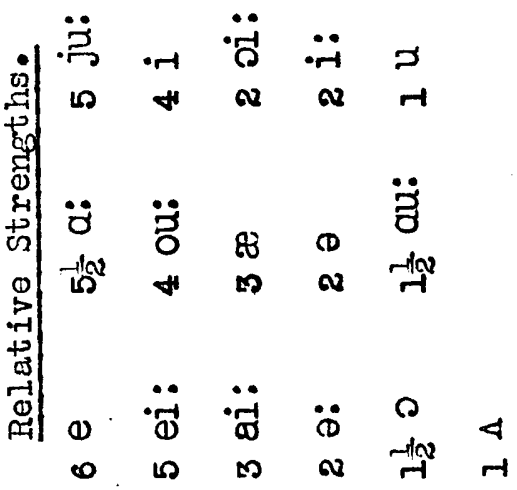

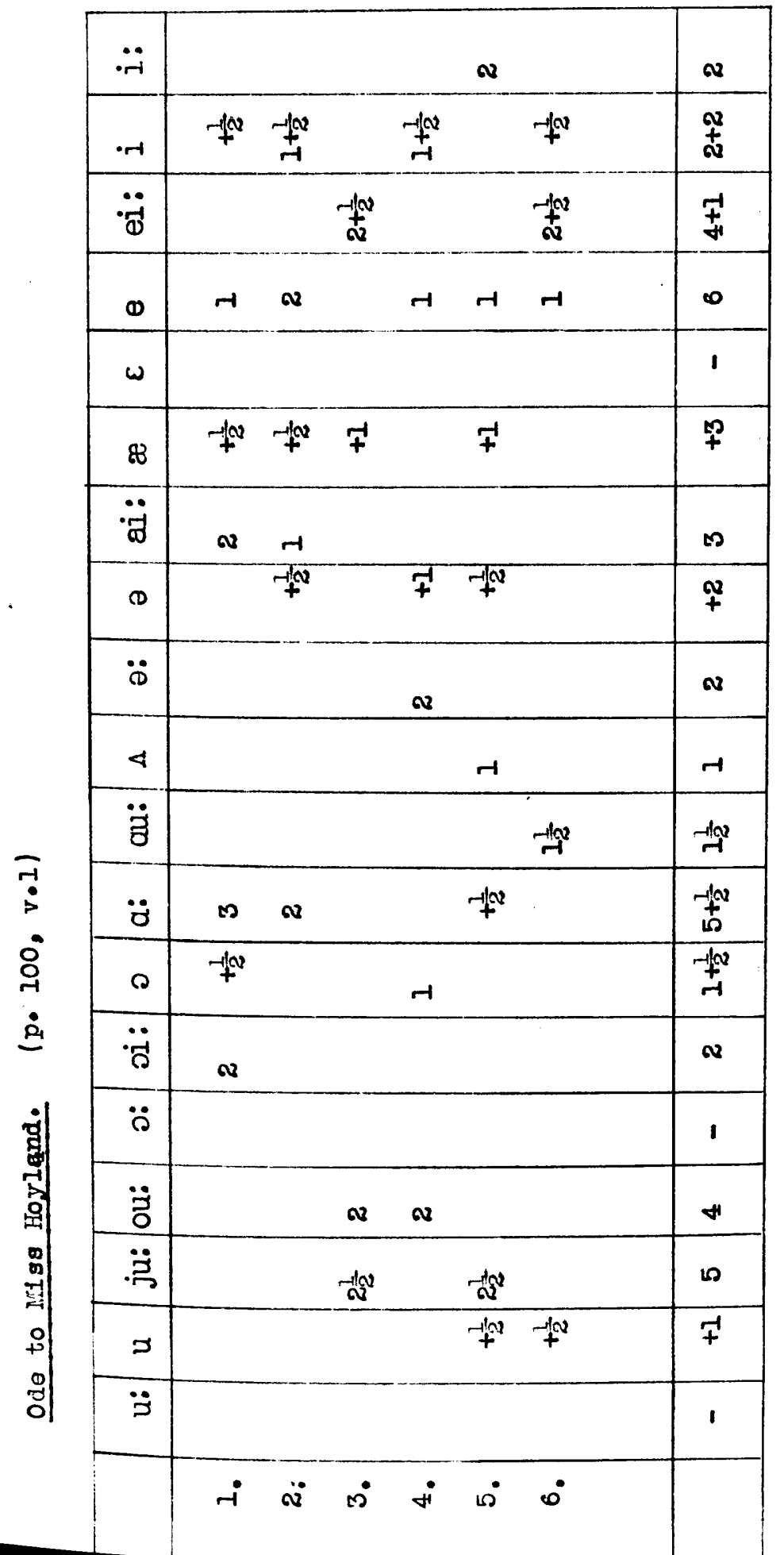




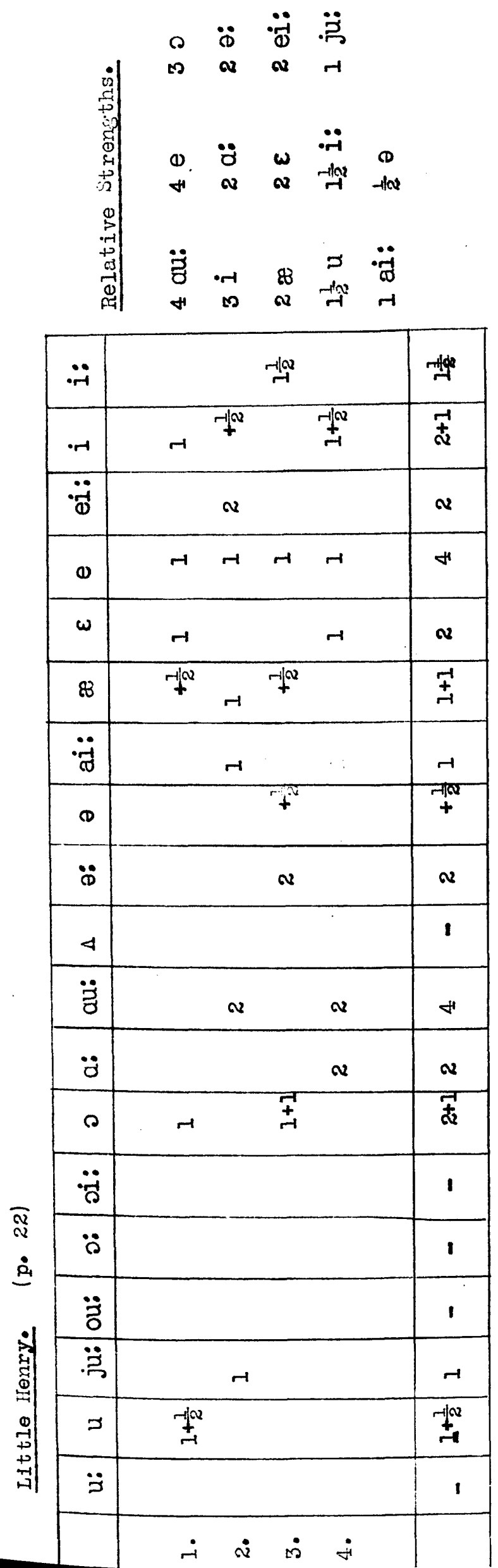




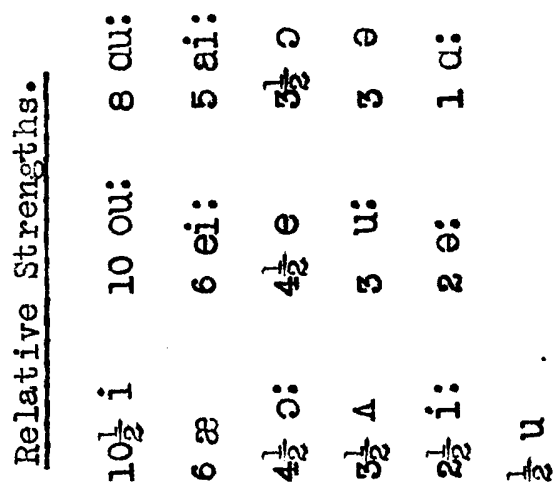

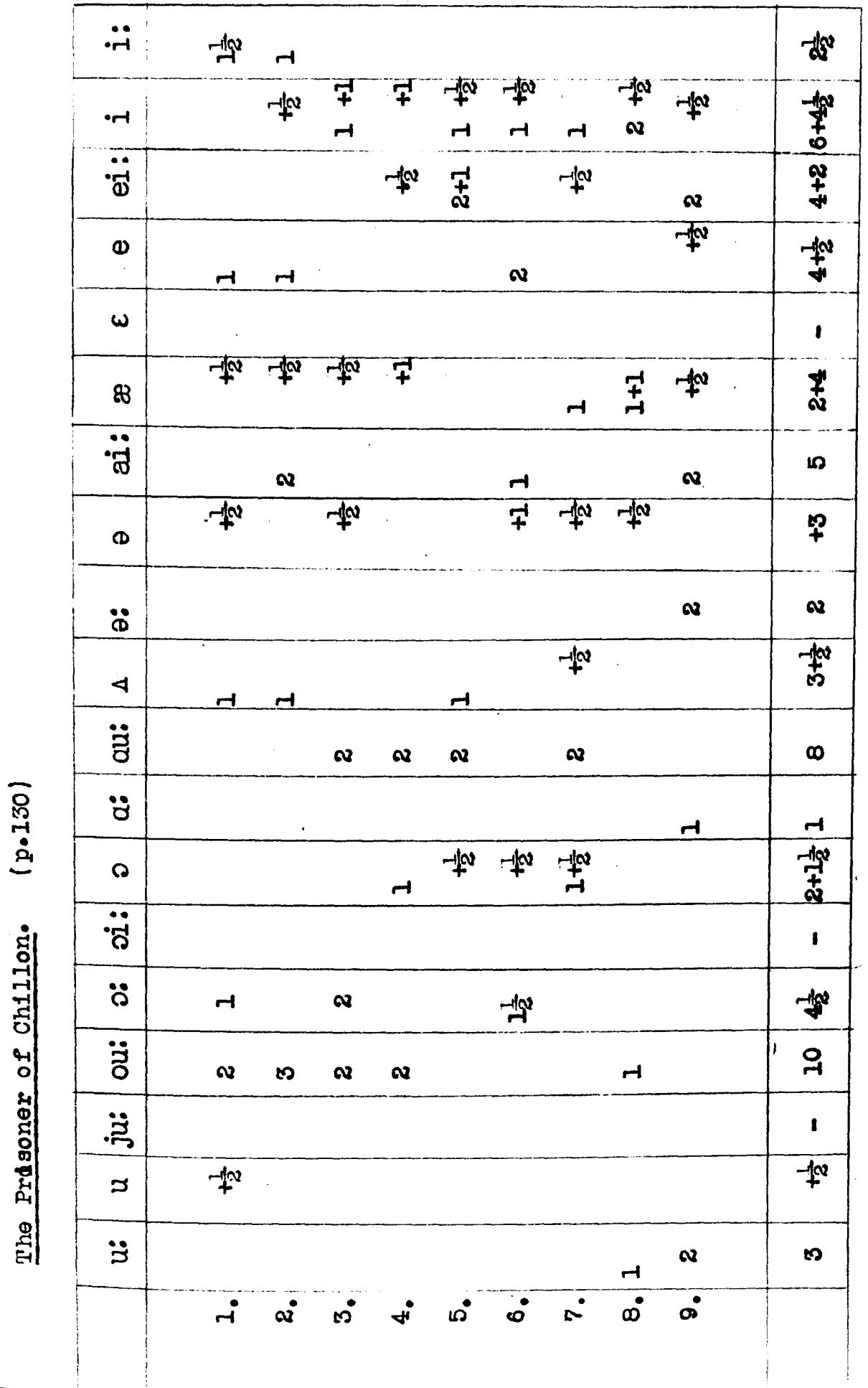




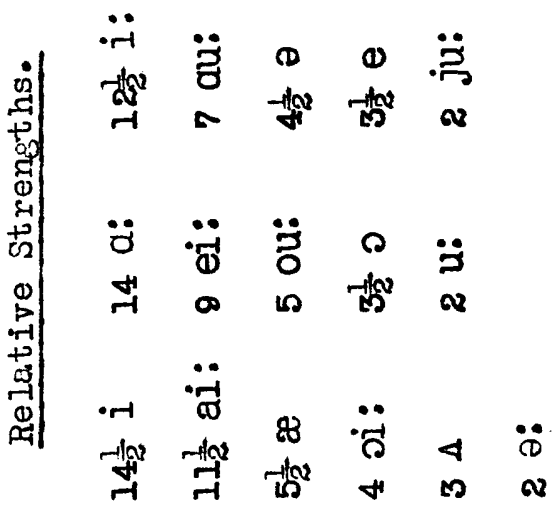

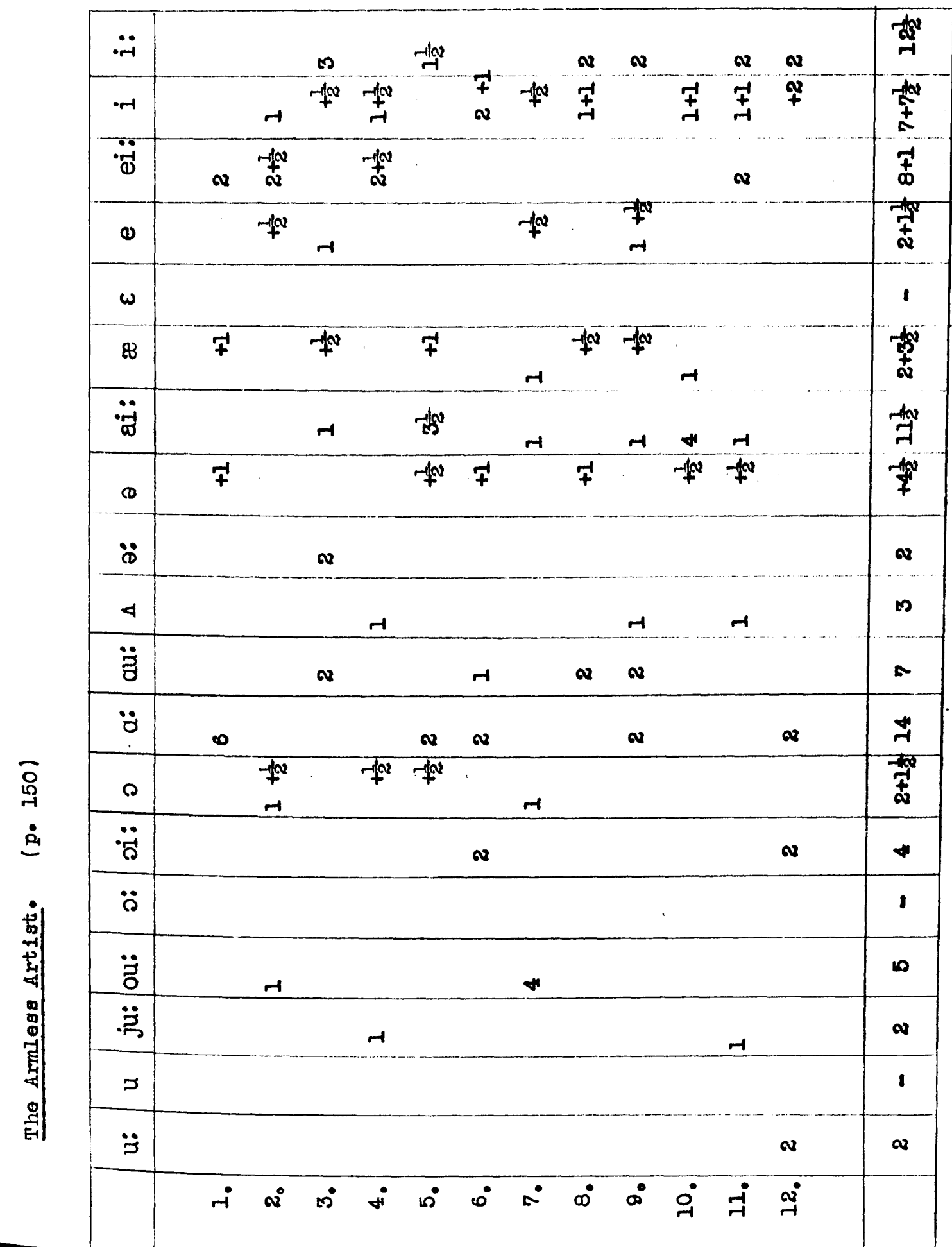




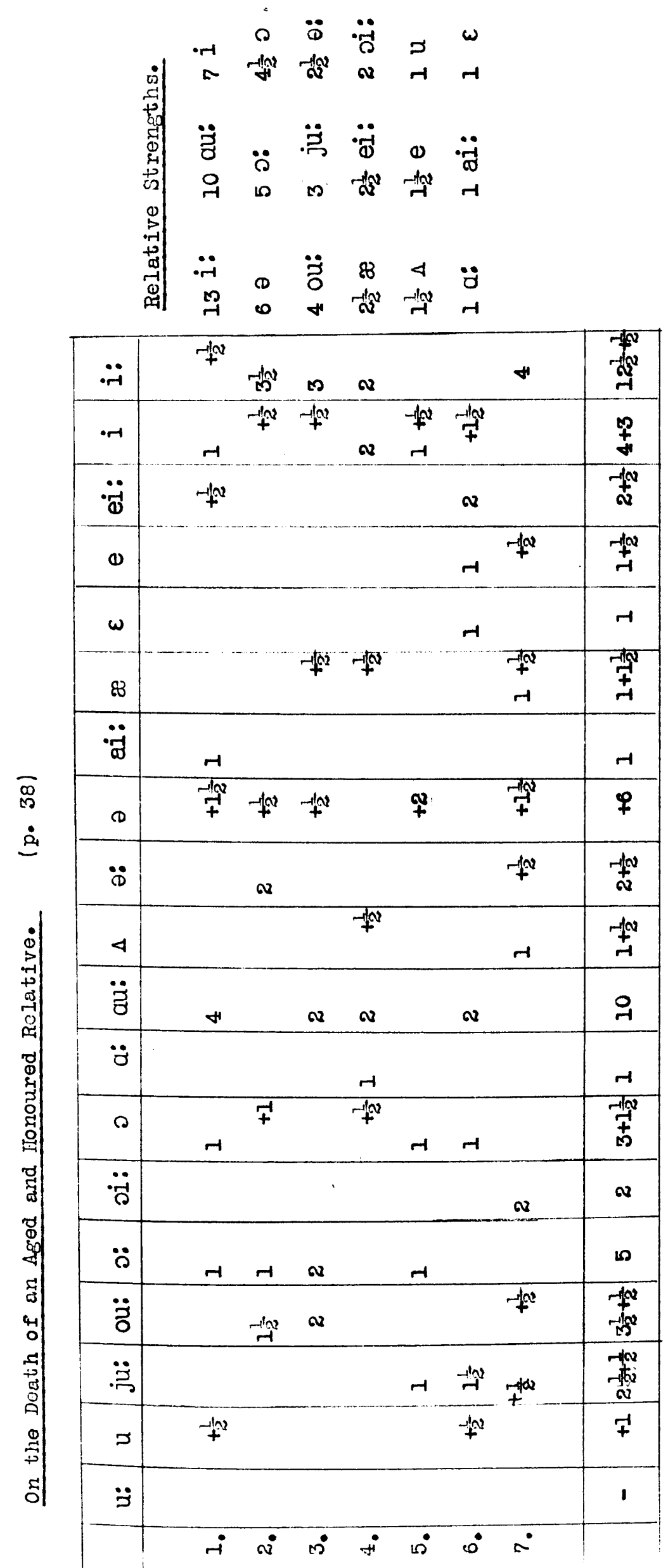




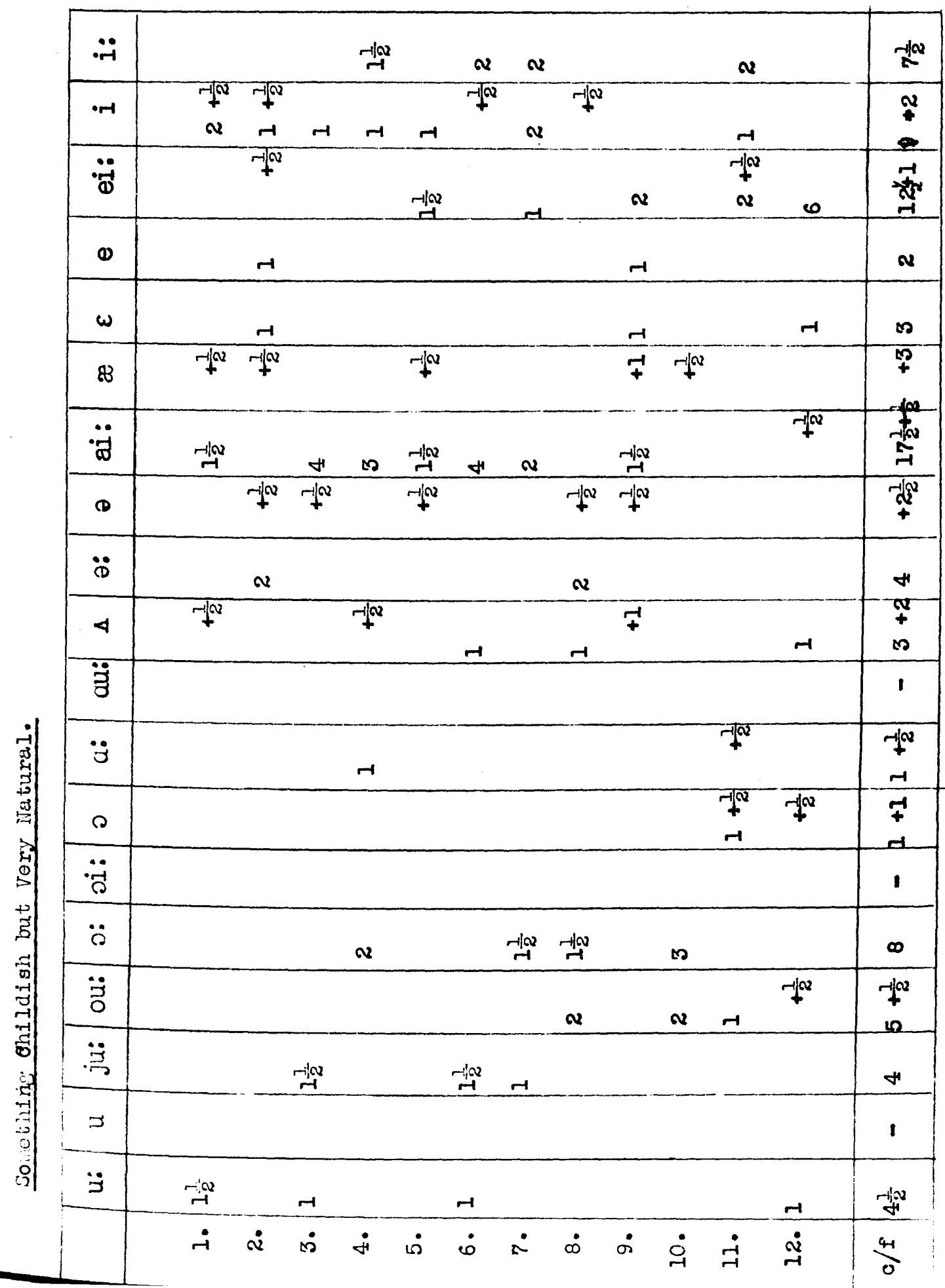




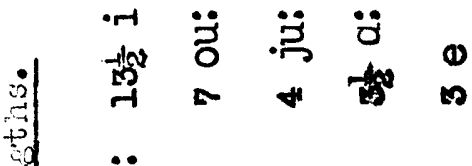

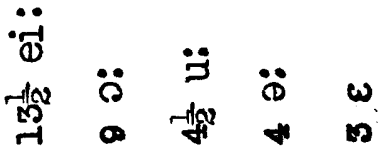

率

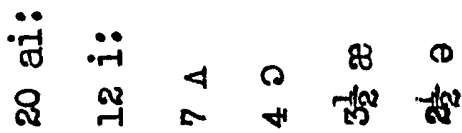

\begin{tabular}{|c|c|c|c|c|c|}
\hline$\ddot{-}$ & $\pi_{2}^{-10 \Omega}$ & $\infty$ & & $\stackrel{-1 x^{2}}{-1}$ & 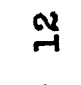 \\
\hline$r$ & $\underset{⿱}{\sim}$ & & $\stackrel{-1}{\underset{-}{+}}$ & $r$ & $\begin{array}{l}\text { 整 } \\
\text { 者 }\end{array}$ \\
\hline$\ddot{\ddot{d}}$ & 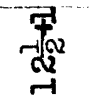 & & & 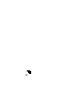 & 焉 \\
\hline () & $\boldsymbol{\alpha}$ & & -1 & & $\infty$ \\
\hline $\boldsymbol{\omega}$ & $\infty$ & & & & r \\
\hline $\mathbb{8}$ & $\stackrel{p}{+}$ & & & $-7 \infty$ & $\stackrel{-10 x}{+}$ \\
\hline$\ddot{a}$ & 吪 & & $\rightarrow$ & & tan \\
\hline (D) & $\underset{\substack{-1 / 20 \\
+}}{+\infty}$ & & & & $\underset{+}{+\infty}$ \\
\hline$\ddot{8}$ & 4 & & & & + \\
\hline 4 & $\underset{m}{\sim}$ & & $\underset{+}{+}$ & & 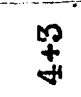 \\
\hline$\ddot{z}$ & 1 & & & & 1 \\
\hline$\ddot{\delta}$ & $\underset{-1}{-1 / a}$ & & v & & $\underset{m}{r+\infty}$ \\
\hline 0 & $\underset{ \pm}{ \pm}$ & - & & $\rightarrow$ & 畐 \\
\hline$\vec{\circ}$ & 1 & & & & 1 \\
\hline$\ddot{o}$ & $\infty$ & -1 & & & 0 \\
\hline$\ddot{\partial}$ & $\begin{array}{l}7 \sqrt{a} \\
0\end{array}$ & न-192 & & & 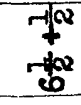 \\
\hline 艿 & & & & & + \\
\hline 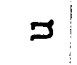 & 1 & & & & 1 \\
\hline$\ddot{z}$ & 势 & & & & $-10 x$ \\
\hline & $\frac{4}{p r}$ & $\ddot{g}$ & $\dot{\sharp}$ & $\stackrel{\leftrightarrow}{\sim}$ & \\
\hline
\end{tabular}




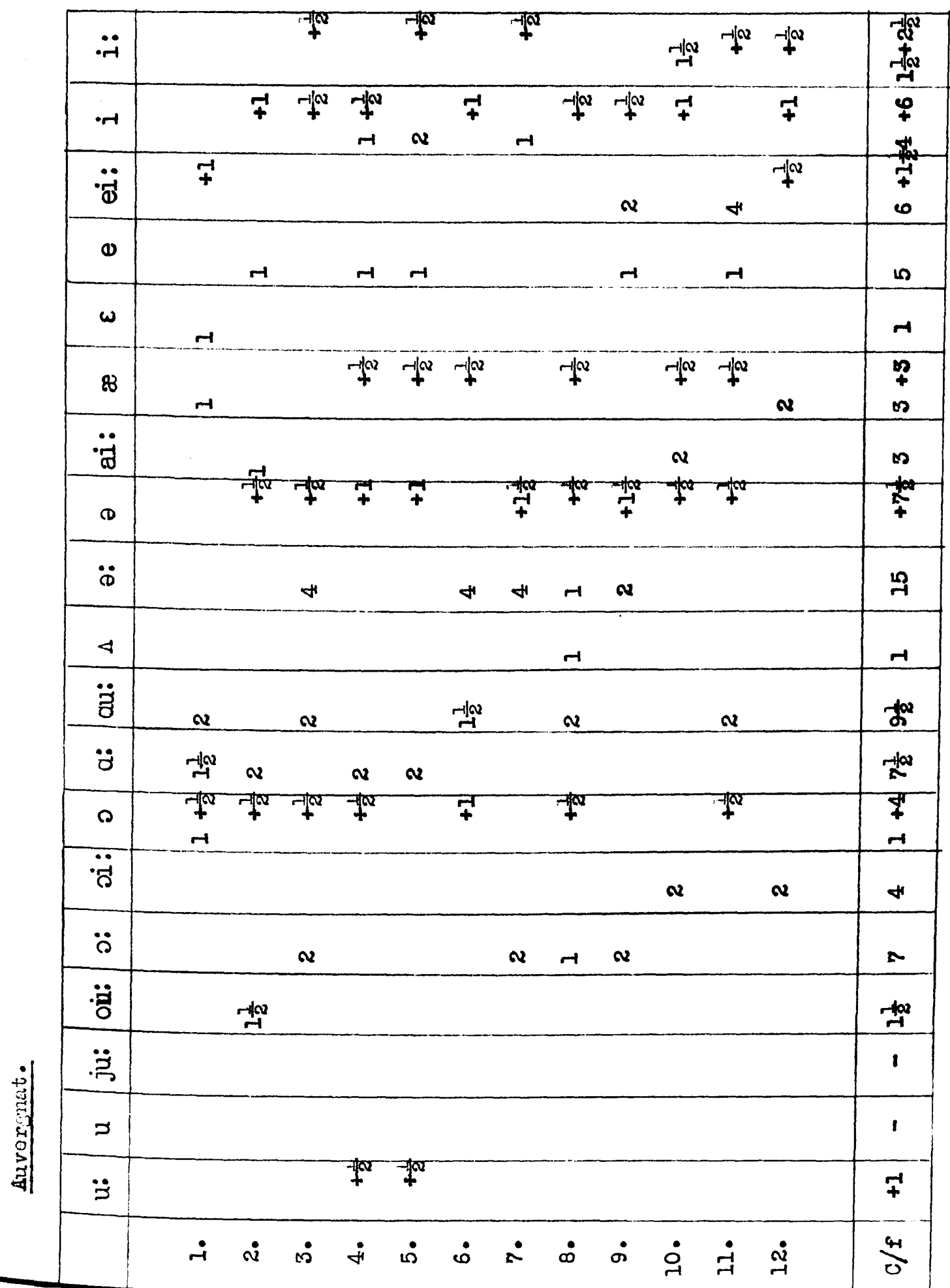




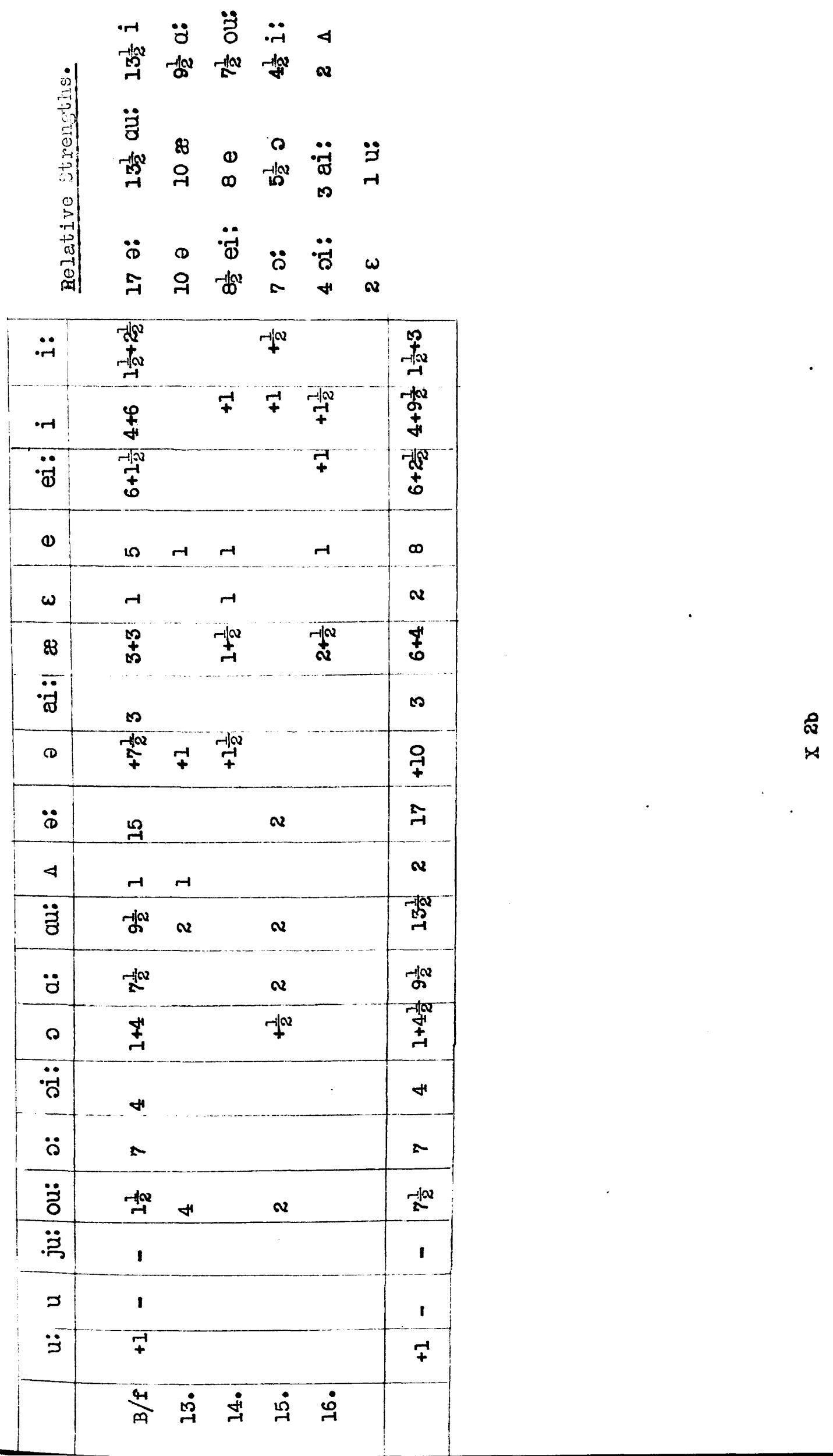




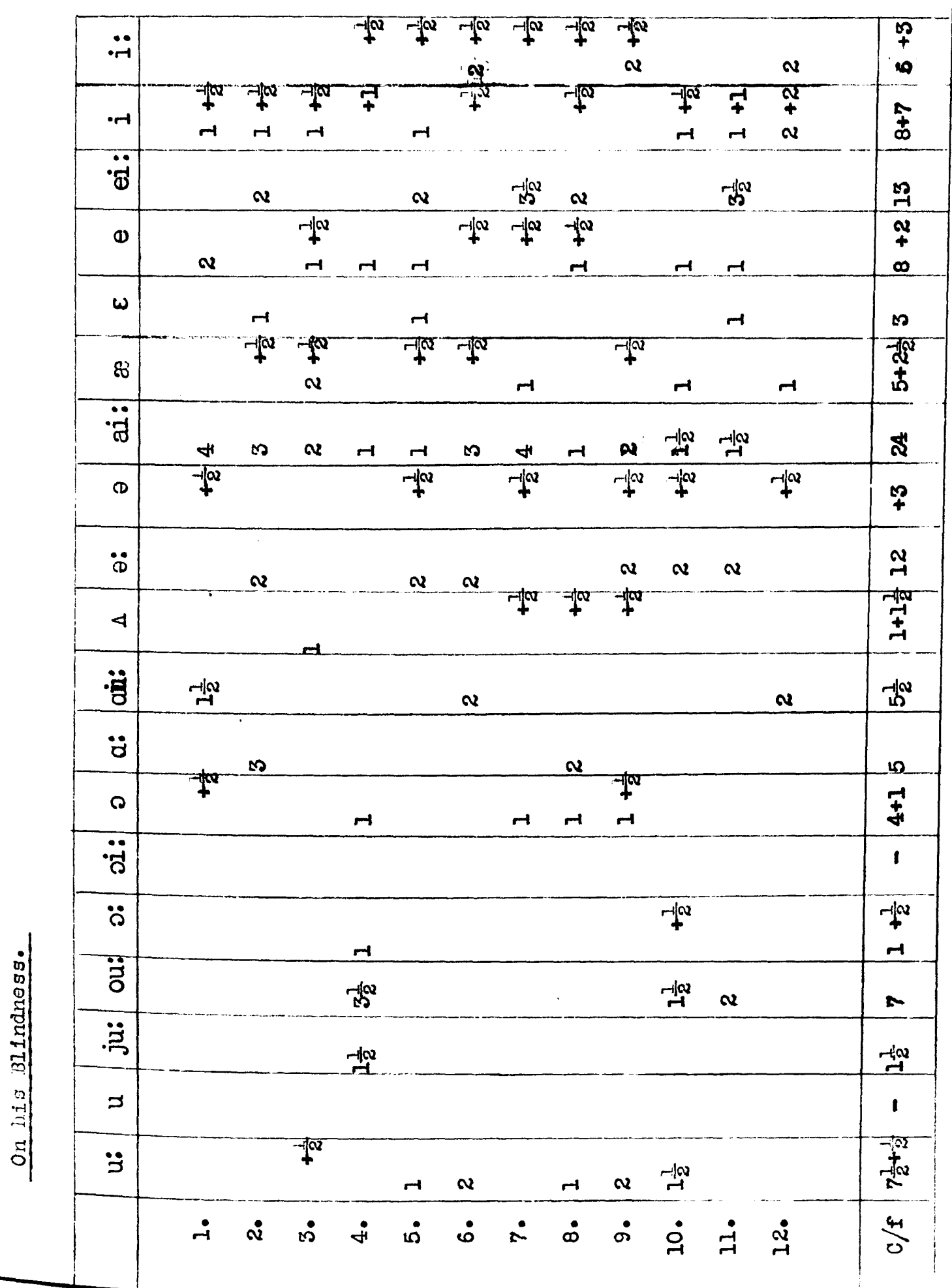




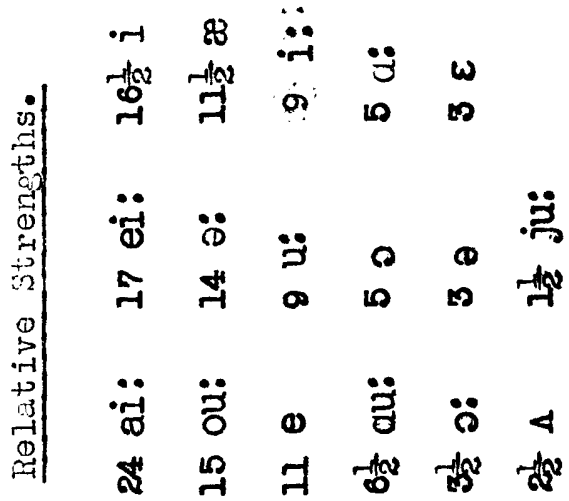

\begin{tabular}{|c|c|c|c|c|}
\hline$\ddot{\ddot{r}}$ & $\begin{array}{l}m \\
+ \\
0\end{array}$ & & & $\begin{array}{l}\infty \\
+ \\
0\end{array}$ \\
\hline$\cdot-1$ & $\stackrel{\infty}{+}$ & -1 & -12 & $\begin{array}{l}\frac{1}{2} \\
\vdots \\
\sigma\end{array}$ \\
\hline$\ddot{0}$ & $\stackrel{M}{\rightarrow}$ & & + & $\stackrel{\sim}{\sim}$ \\
\hline $\boldsymbol{\theta}$ & $\begin{array}{l}\alpha \\
+ \\
\infty\end{array}$ & -1 & & $\begin{array}{l}\alpha \\
+ \\
\sigma\end{array}$ \\
\hline$\omega$ & $\infty$ & & & $\infty$ \\
\hline 83 & $\begin{array}{l}\text { rd } \\
+2 \\
+ \\
5\end{array}$ & $\begin{array}{c}-1 \mid w \\
\overrightarrow{+} \\
+ \\
\overrightarrow{+}\end{array}$ & $\begin{array}{l}-1 / \\
+ \\
-1\end{array}$ & $\underset{2}{+}$ \\
\hline$\ddot{\circ}$ & 芯 & & & S \\
\hline (1) & $\stackrel{\infty}{+}$ & & & $\stackrel{\infty}{+}$ \\
\hline$\ddot{B}$ & $\stackrel{\sim}{\sim}$ & & $v$ & $\stackrel{H}{H}$ \\
\hline 4 & $\underset{\oplus}{\stackrel{H}{q}}$ & & & 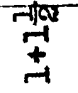 \\
\hline בัכ & $-1 / \sqrt{2}$ & $r$ & & ryox \\
\hline$\ddot{8}$ & 10 & & & 12 \\
\hline 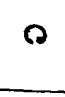 & $\begin{array}{l}+1 \\
+\end{array}$ & & & $\stackrel{+}{+}$ \\
\hline$\ddot{\circ}$ & 1 & & & 1 \\
\hline$\ddot{\beta}$ & $\stackrel{-1+\infty}{+\infty}$ & & $\mathbf{N}$ & 热 \\
\hline$\ddot{~} \ddot{3}$ & & 10 & $\infty$ & $\stackrel{4}{-1}$ \\
\hline$\ddot{\ddot{3}}$ & $\stackrel{-1+\infty}{-1}$ & & & $\underset{-1}{+\infty}$ \\
\hline 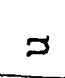 & 1 & & & 1 \\
\hline 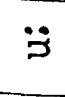 & $f_{\infty}^{+\infty}$ & & $r$ & 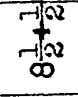 \\
\hline & $\stackrel{4}{m}$ & $\stackrel{\dot{D}}{\rightarrow}$ & $\stackrel{\leftrightarrow}{4}$ & \\
\hline
\end{tabular}




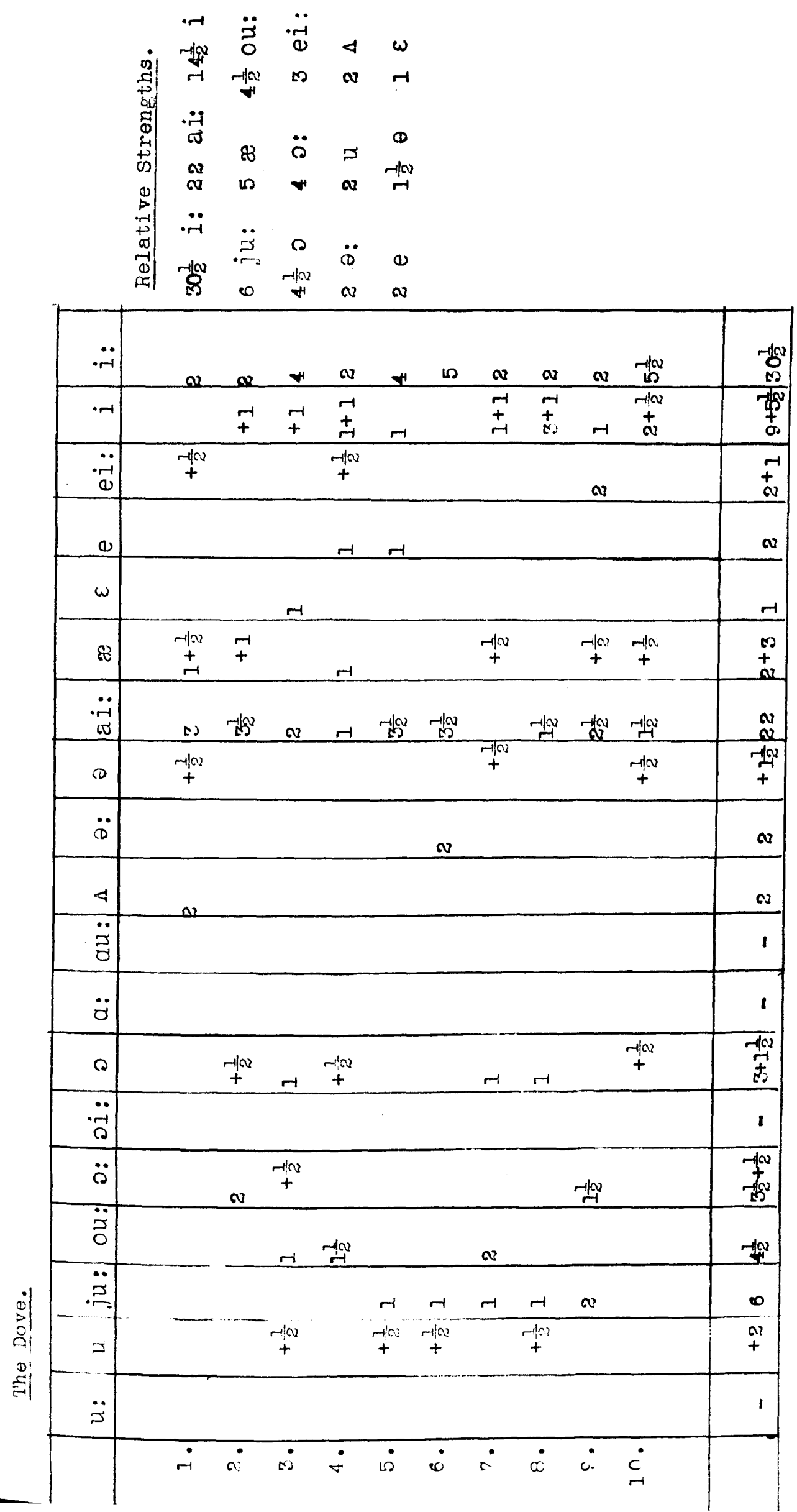




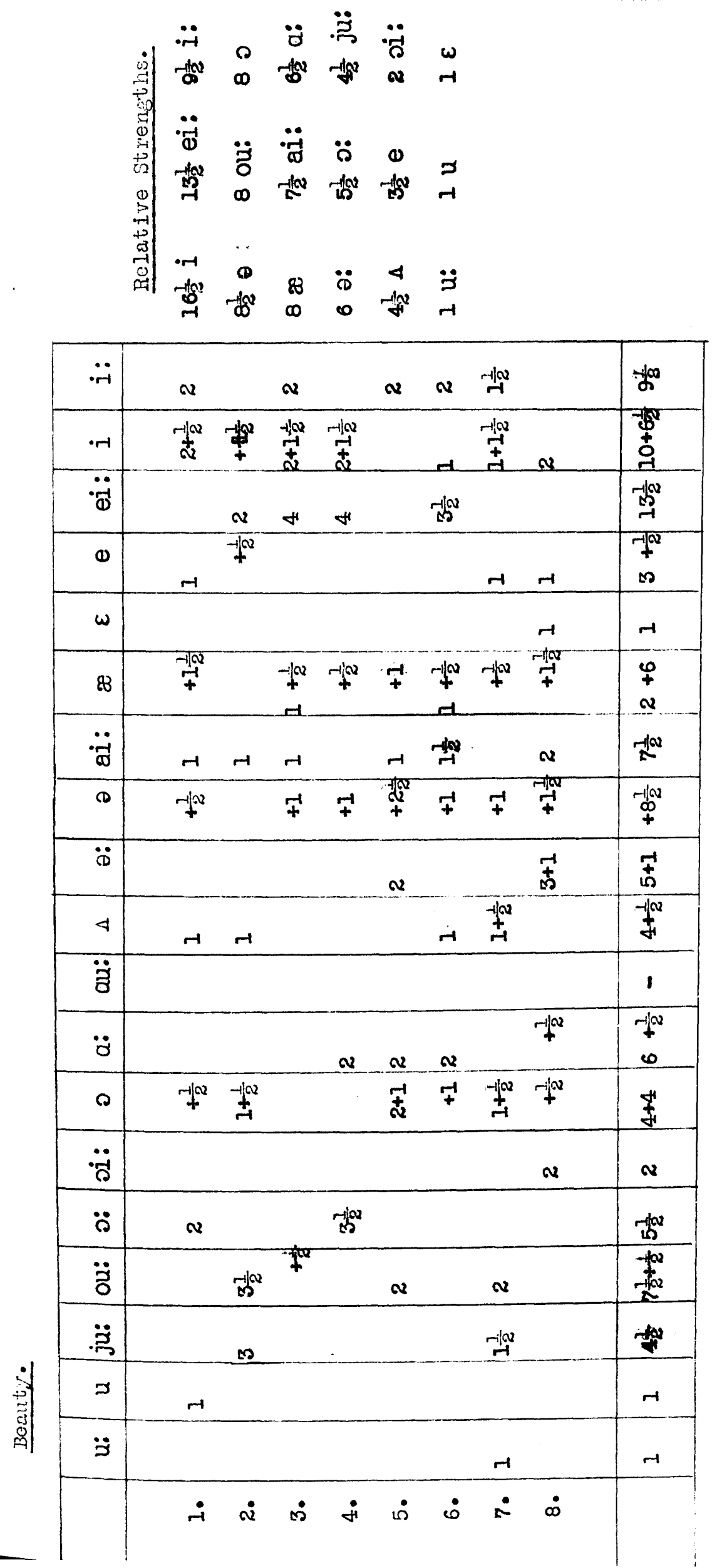




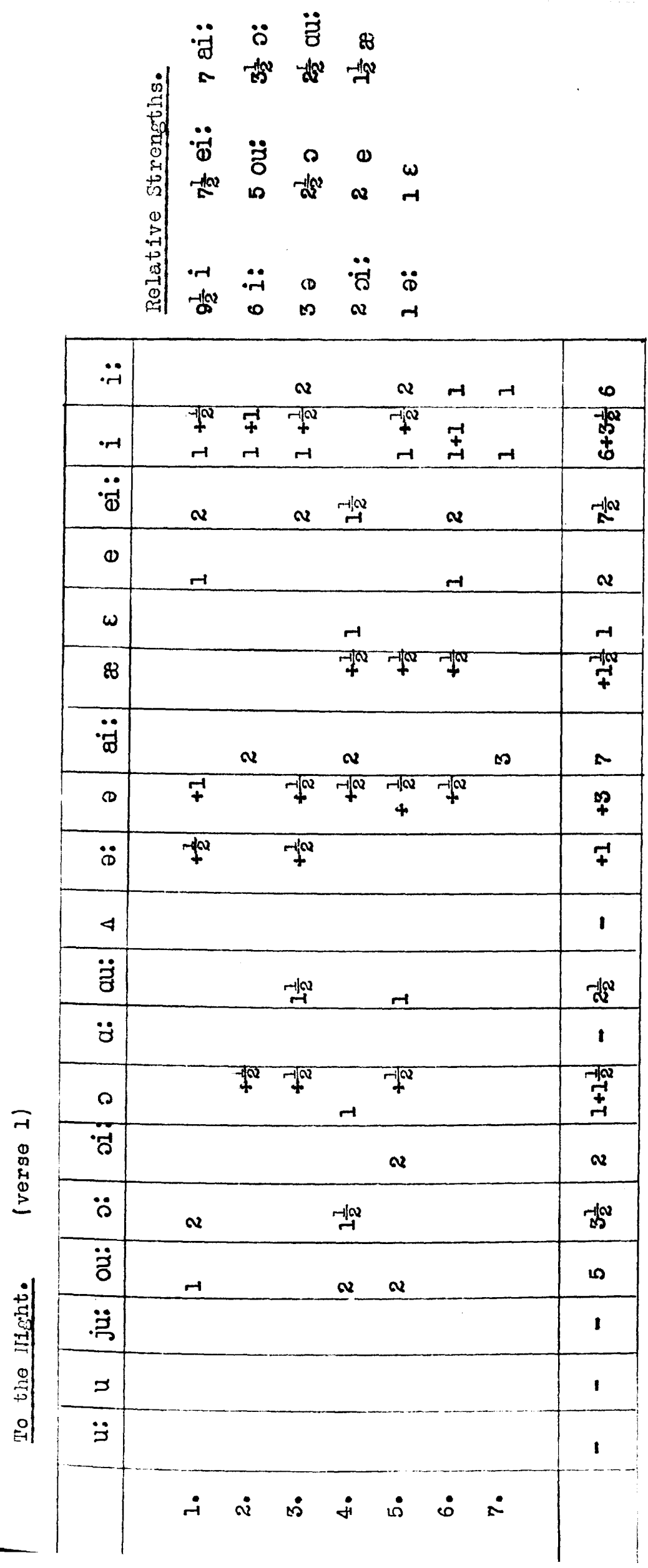




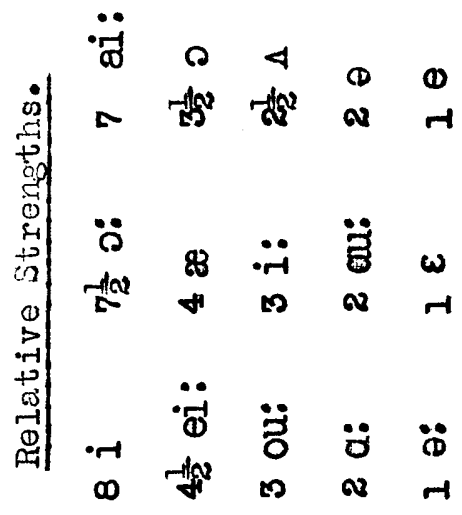

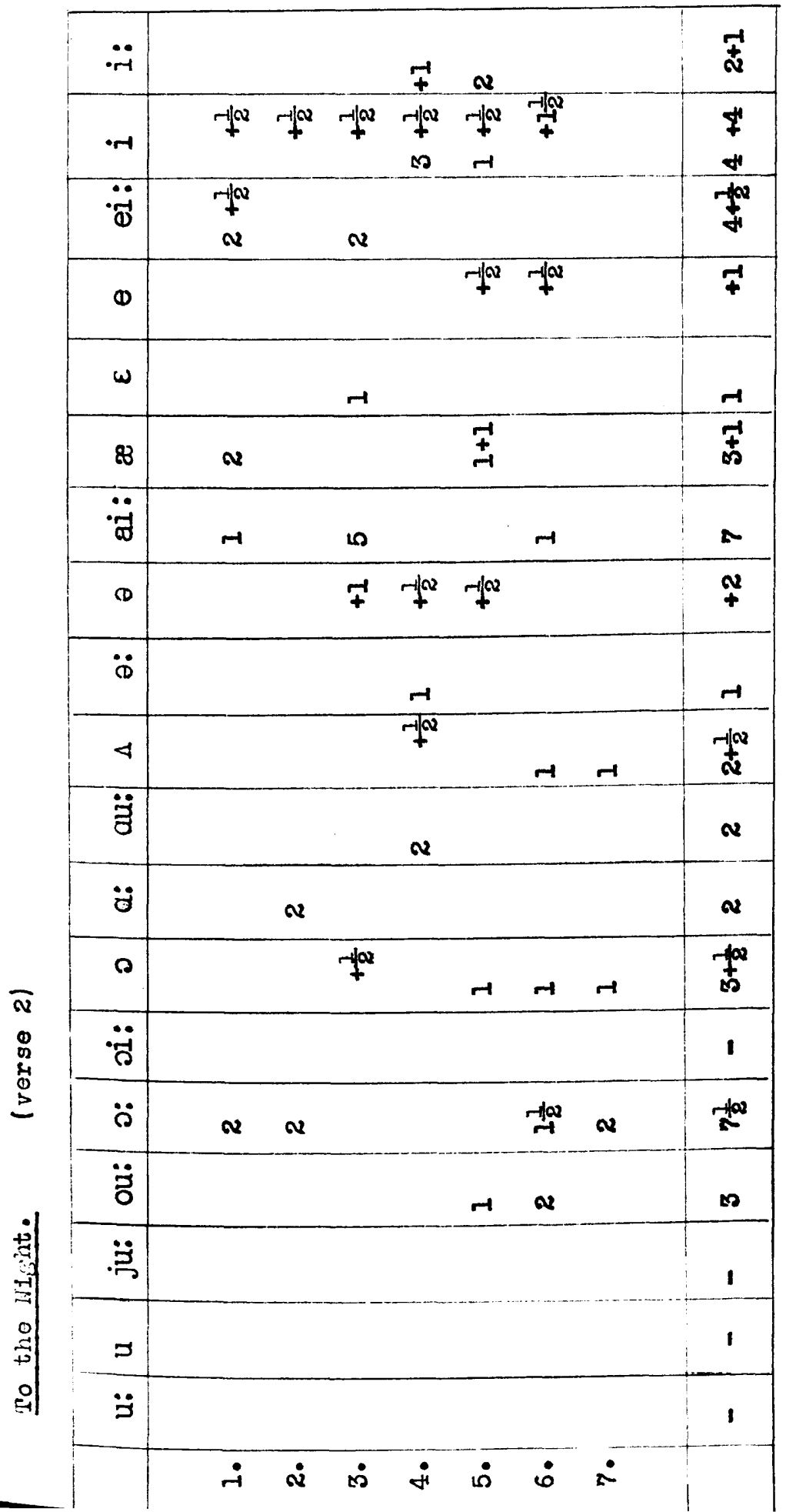




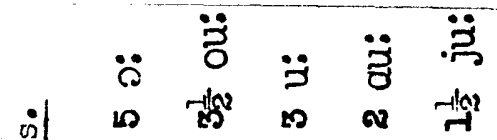

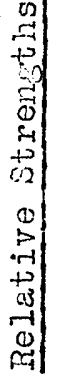

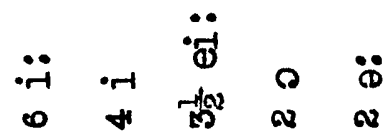

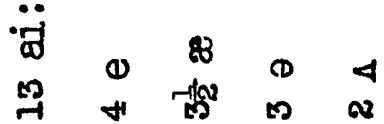

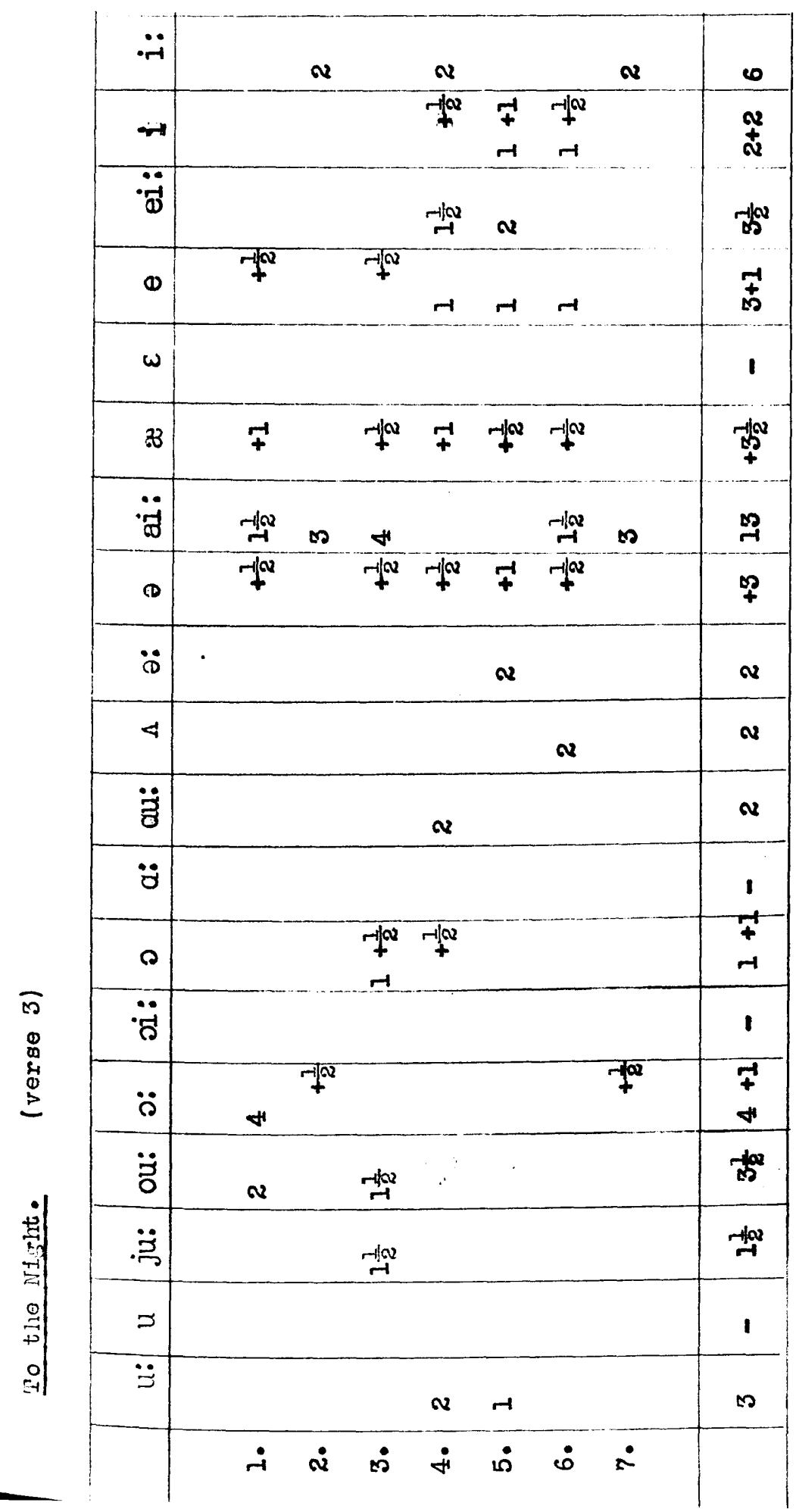




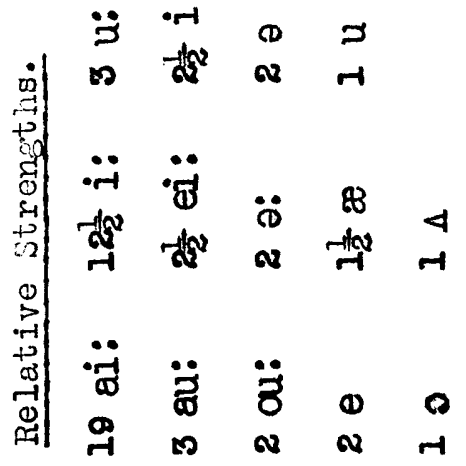

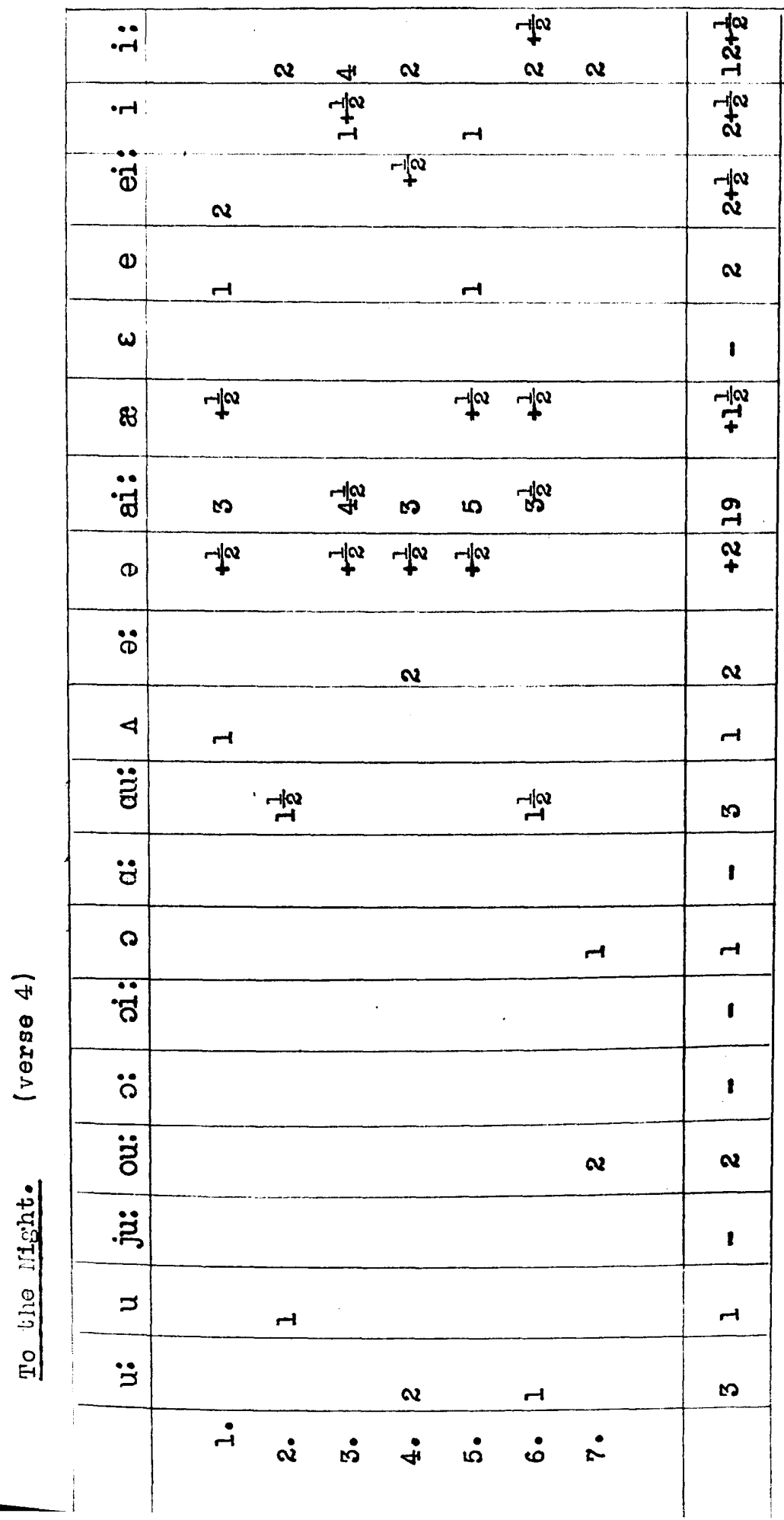




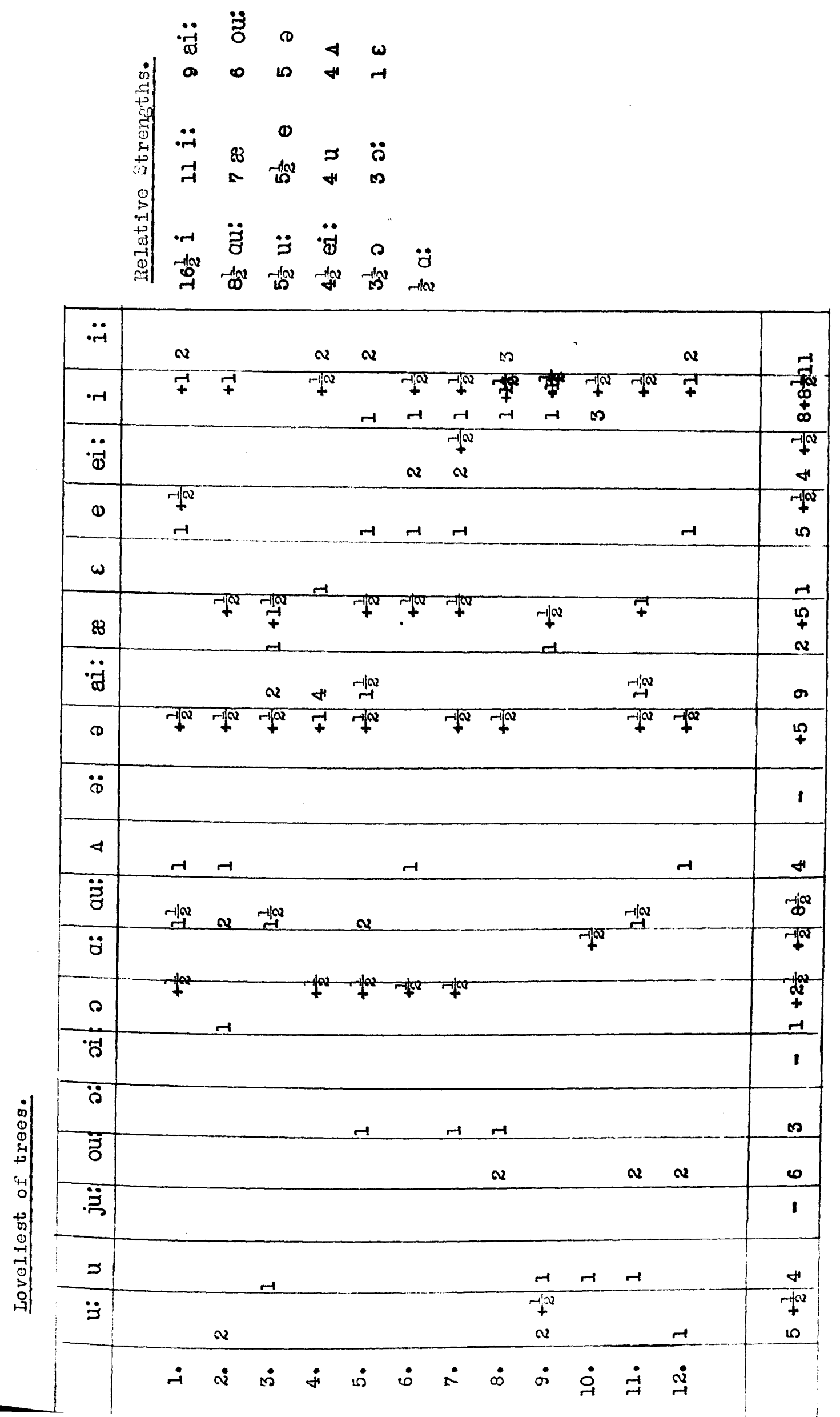




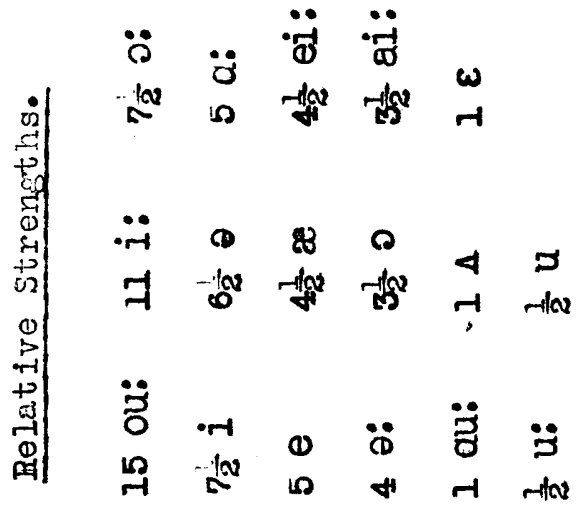

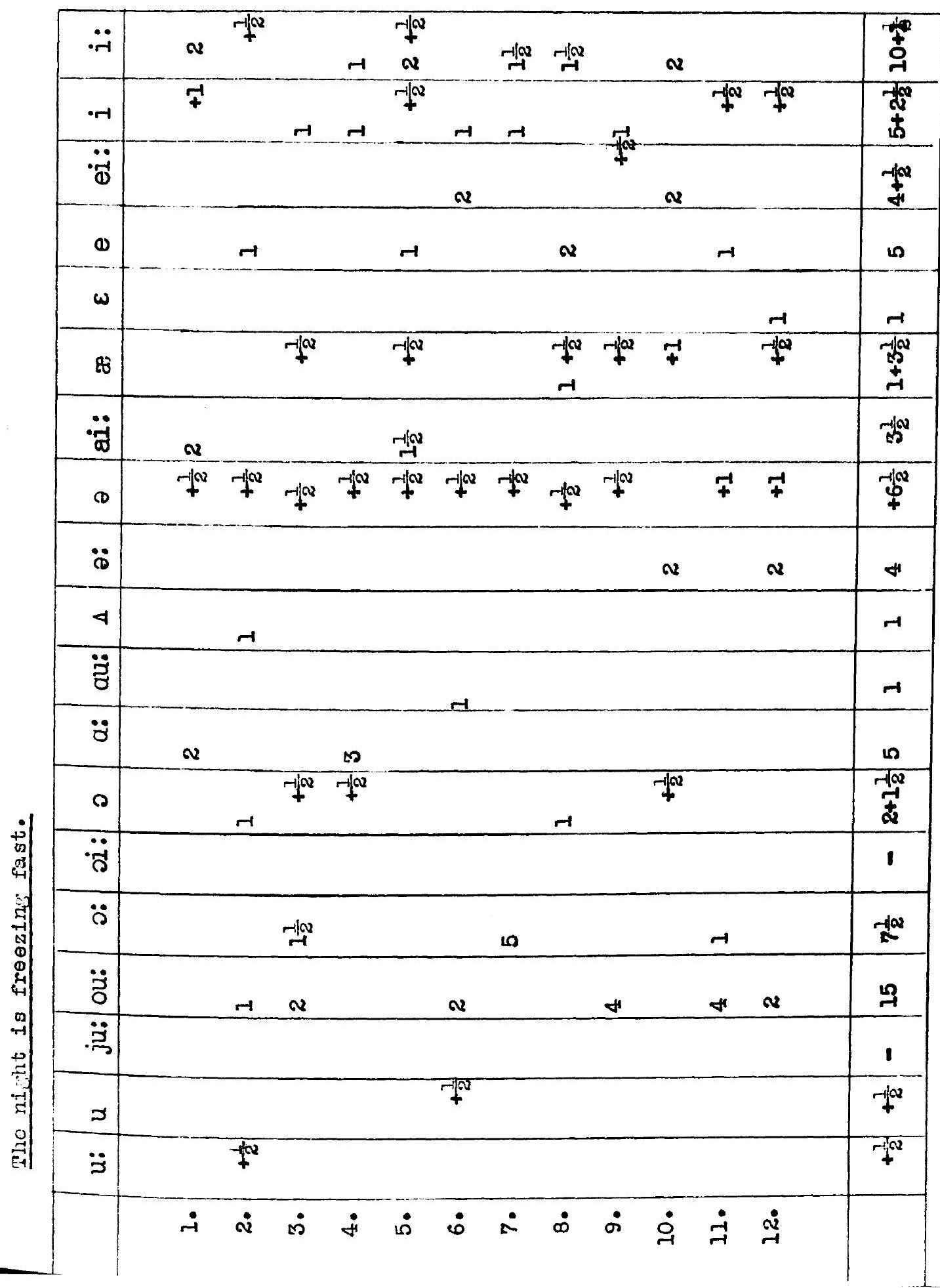




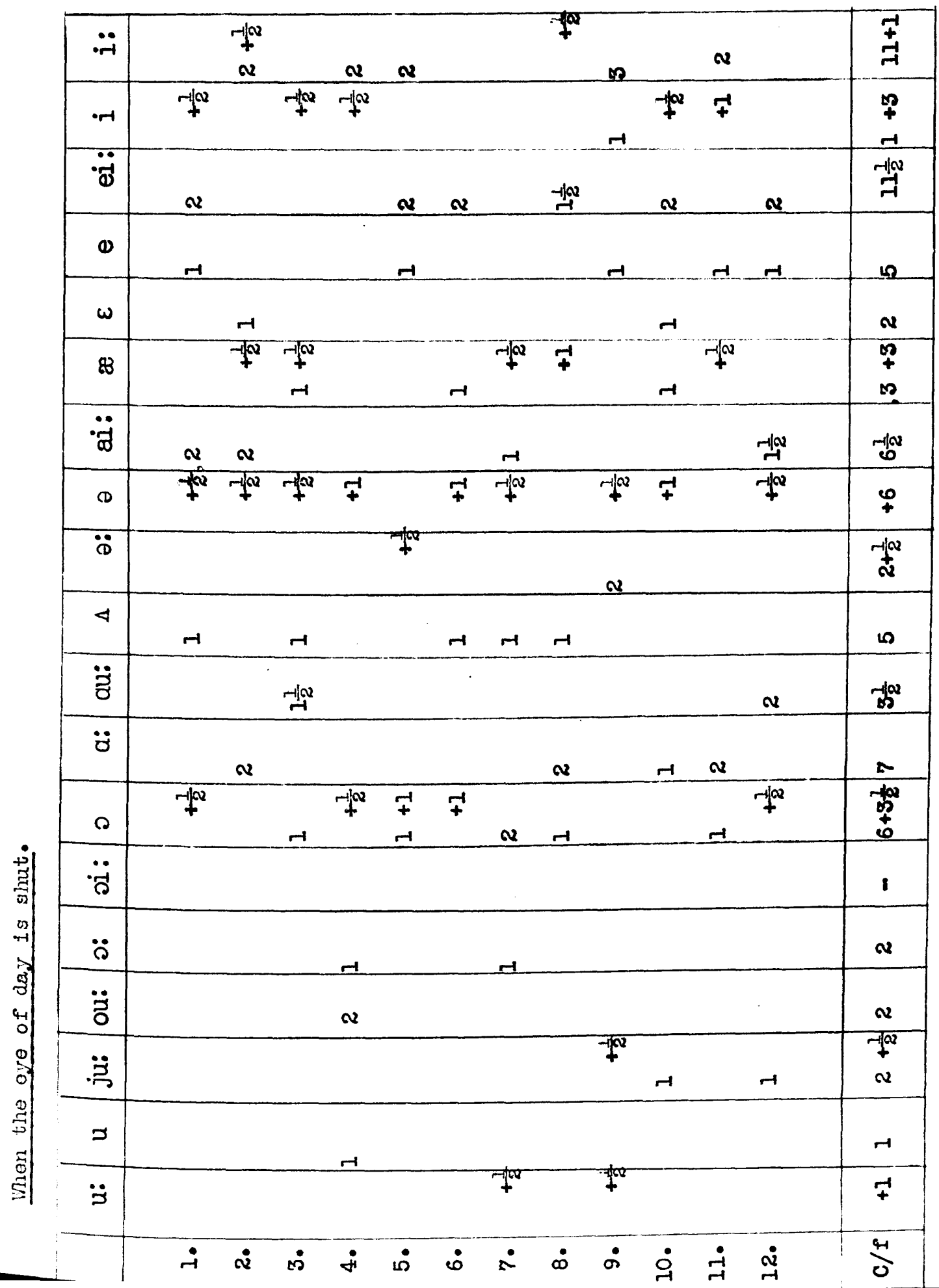




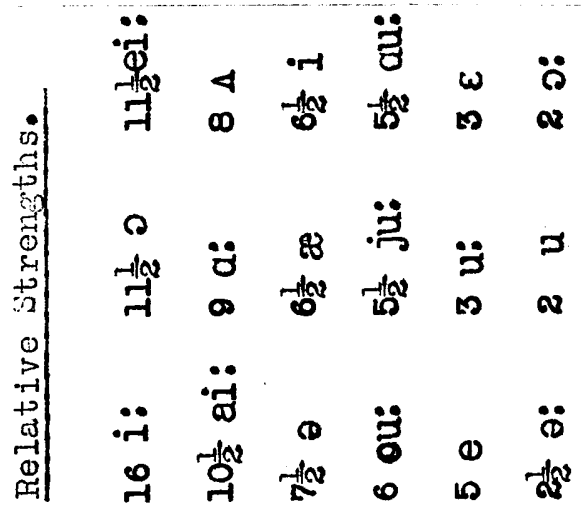

\begin{tabular}{|c|c|c|c|c|c|c|}
\hline$\ddot{r-1}$ & $\underset{+}{\rightleftarrows}$ & & $v$ & & $\boldsymbol{\alpha}$ & 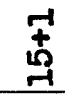 \\
\hline$\cdot r-1$ & $\underset{+}{\infty}$ & + & $-10 x$ & & $+1 x^{\alpha}$ & $\underset{+1}{+\infty}$ \\
\hline$\ddot{\ddot{b}}$ & $\underset{\sim}{\stackrel{-1 \mid}{H}}$ & & & & & $\stackrel{\text { 监 }}{2}$ \\
\hline $\boldsymbol{0}$ & 10 & & & & & 10 \\
\hline$\omega$ & $\boldsymbol{v}$ & & & 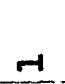 & & $\infty$ \\
\hline 88 & $\underset{m}{\stackrel{p}{+}}$ & & & & 7 & $\begin{array}{c}+\infty \\
5 \\
+5 \\
0\end{array}$ \\
\hline$\ddot{\ddot{\alpha}}$ & $-\| x^{x}$ & & & $\boldsymbol{v}$ & $v$ & 엄 \\
\hline (D) & 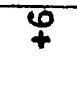 & & + & 7 & & $\underset{4}{+}$ \\
\hline$\ddot{c}$ & $\begin{array}{l}\boldsymbol{A l}^{2} \\
\boldsymbol{N}\end{array}$ & & & & & $\begin{array}{l}+\sqrt{a} \\
\mathbb{N}\end{array}$ \\
\hline 4 & 10 & $H$ & & $\rightarrow$ & $r-1$ & $\infty$ \\
\hline 3 & 此 & & $\sim$ & & & rid \\
\hline$\ddot{\theta}$ & & $\mathbf{Q}$ & & & & 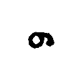 \\
\hline$\curvearrowright$ & $\begin{array}{l}\text { dev } \\
+ \\
\end{array}$ & & +10 & $-1 a^{\circ}$ & $\boldsymbol{H}$ & $\underset{x}{7}$ \\
\hline$\ddot{\circ}$ & 1 & & & & & 1 \\
\hline$\ddot{\leftrightarrow}$ & $v$ & & & & & $\boldsymbol{v}$ \\
\hline$\ddot{z}$ & $\sim$ & + & & & & $\omega$ \\
\hline$\ddot{g}$ & $\begin{array}{l}7 \times \\
\propto\end{array}$ & & & $\boldsymbol{N}$ & -1 & $\begin{array}{c}-10 \\
\text { in }\end{array}$ \\
\hline 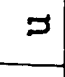 & 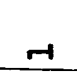 & & & -1 & & $\boldsymbol{N}$ \\
\hline$\ddot{3}$ & $\underset{t}{7}$ & & $v$ & & & 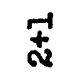 \\
\hline & $\dot{m}_{m}^{4}$ & $\stackrel{\leftrightarrow}{\rightarrow}$ & $\stackrel{\leftrightarrow}{H}$ & $\stackrel{\stackrel{\circ}{\circ}}{\circ}$ & $\stackrel{\bullet}{\circ}$ & \\
\hline
\end{tabular}




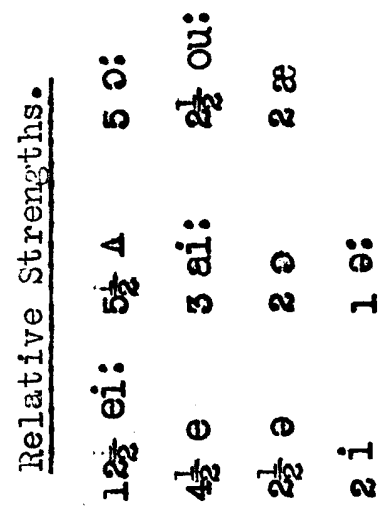

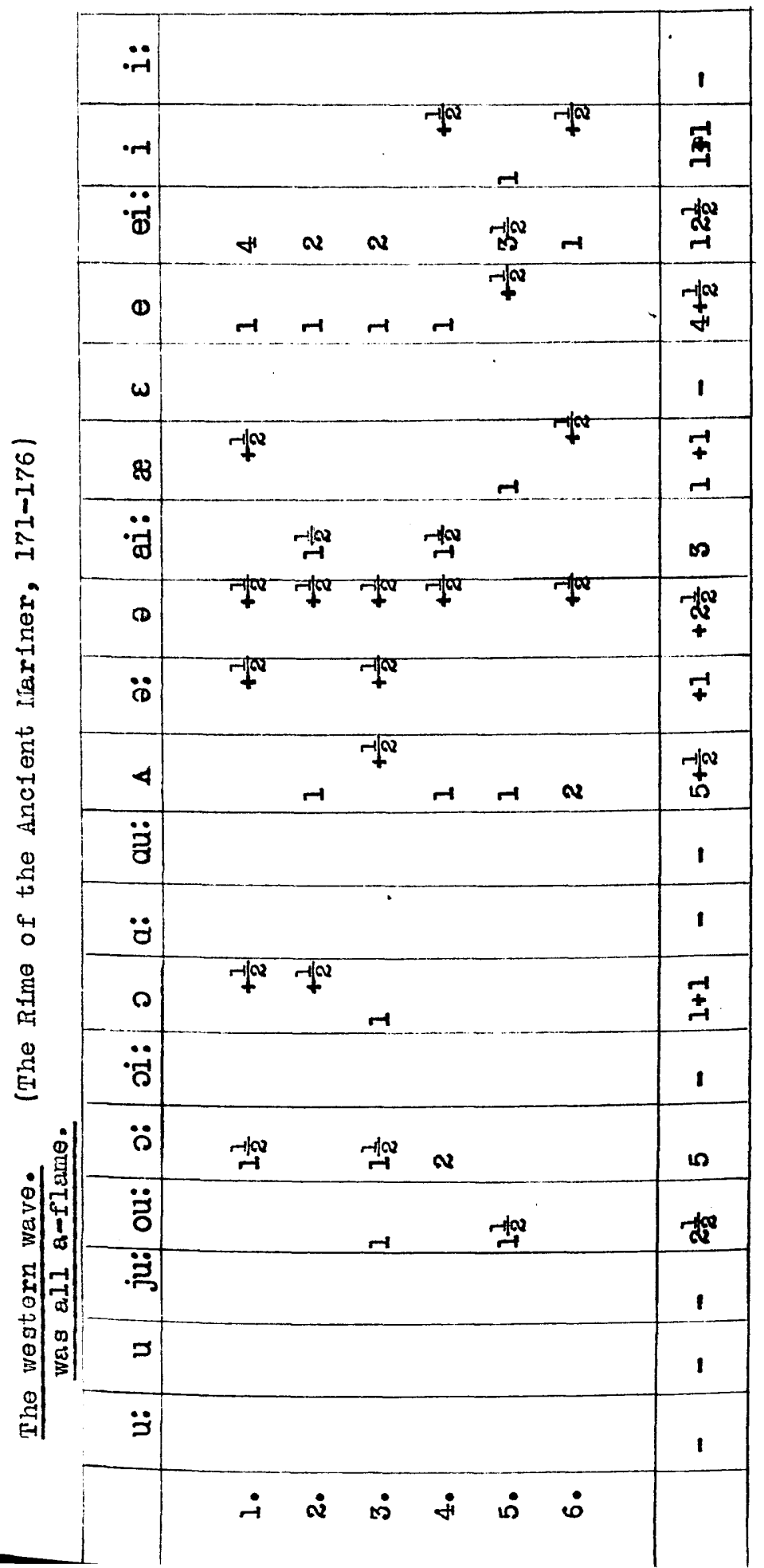



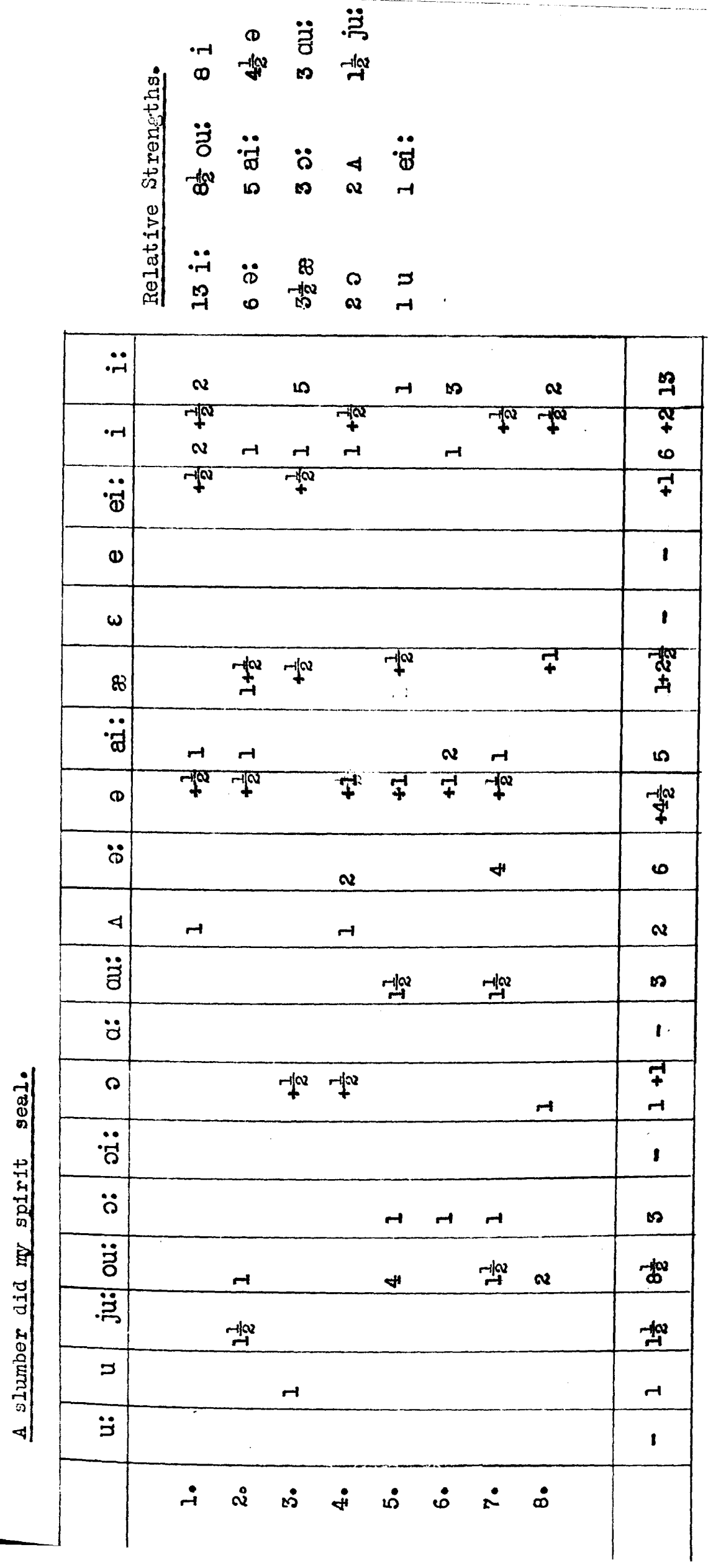


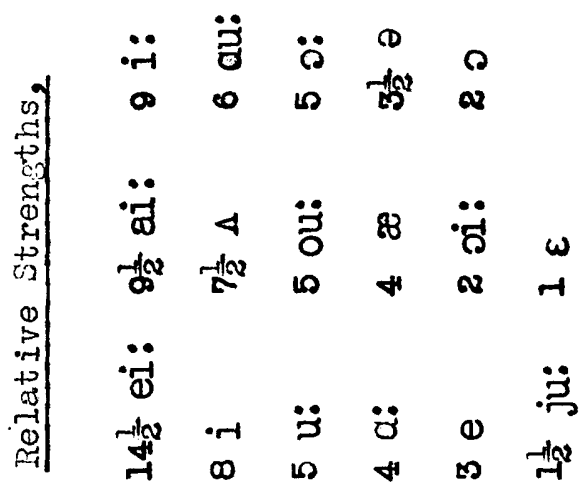

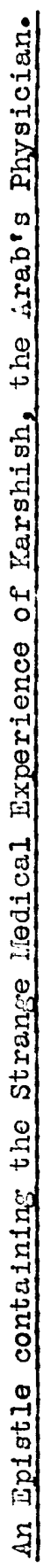

\begin{tabular}{|c|c|c|c|c|c|c|c|c|c|}
\hline$\ddot{r}$ & & & & $\stackrel{-\| N}{-\alpha}$ & $\boldsymbol{Q}$ & $\boldsymbol{Q}$ & -1 & -dָ & $\infty$ \\
\hline$\cdot r$ & $\begin{array}{l}+1 \\
+ \\
N\end{array}$ & + & & $\begin{array}{c}r+a \\
r\end{array}$ & 7 & & -1 & & $\underset{+}{\$}$ \\
\hline$\ddot{\infty}$ & $v$ & $\boldsymbol{N}$ & +102 & 4 & 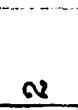 & $\stackrel{-1 w}{=}$ & $\underline{v}$ & & 索 \\
\hline $\boldsymbol{\omega}$ & $r$ & & & & $-r$ & & $H$ & & $\infty$ \\
\hline$\omega$ & & $r$ & & & & & & & -1 \\
\hline 83 & & & $-1 / n$ & & $\alpha$ & 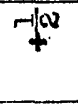 & & 7 & $\begin{array}{l}0 \\
+ \\
\sim\end{array}$ \\
\hline$\ddot{~ \ddot{~}}$ & & & & -1 & $v$ & $v$ & $w_{x}^{-1 / x}$ & $v$ & $d x^{2}$ \\
\hline$C D$ & +10 & $-10 x$ & + & +10 & -10 & $+1 \alpha$ & & & का \\
\hline$\ddot{8}$ & & & & & & & & & 1 \\
\hline$<$ & 7 & -1 & $v$ & & & & $\begin{array}{l}f_{+}^{N} \\
\sim\end{array}$ & $\begin{array}{l}r{ }^{2} \\
-1\end{array}$ & $\begin{array}{c}-1 / 92 \\
7 \\
+1 \\
0\end{array}$ \\
\hline$\ddot{\ddot{z}}$ & -1 & & & & & -ुूs & & $\underset{H}{-1 / \omega}$ & $\omega$ \\
\hline$\ddot{~}$ & & & & $H$ & & & & & $H$ \\
\hline 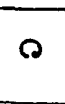 & $-r$ & & & & & 7 & & & $\begin{array}{l}+ \\
+ \\
-1\end{array}$ \\
\hline$\ddot{~} \ddot{\gamma}$ & & & $\underline{\underline{v}}$ & & & & & & 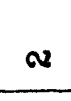 \\
\hline$\ddot{\circ}$ & & $\infty$ & & & & $\rightarrow$ & & -1 & 10 \\
\hline$\ddot{亏}$ & & $\stackrel{-10 x}{-1}$ & $-10 x$ & $H$ & & $\rightarrow$ & & & م \\
\hline$\ddot{\ddot{\beta}}$ & & & $\stackrel{-\mu N}{-10}$ & & & & & & ${ }_{-1}^{+\infty}$ \\
\hline 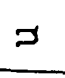 & & & & & & & & & 1 \\
\hline$\ddot{~}$ & & $\stackrel{-\| q}{\rightarrow}$ & -1 & & & & -1 & $\stackrel{-10}{-10}$ & $\omega$ \\
\hline & & $\dot{v}$ & $\dot{\infty}$ & $\dot{4}$ & $\dot{0}$ & $\dot{0}$ & $\dot{2}$ & $\dot{\infty}$ & \\
\hline
\end{tabular}




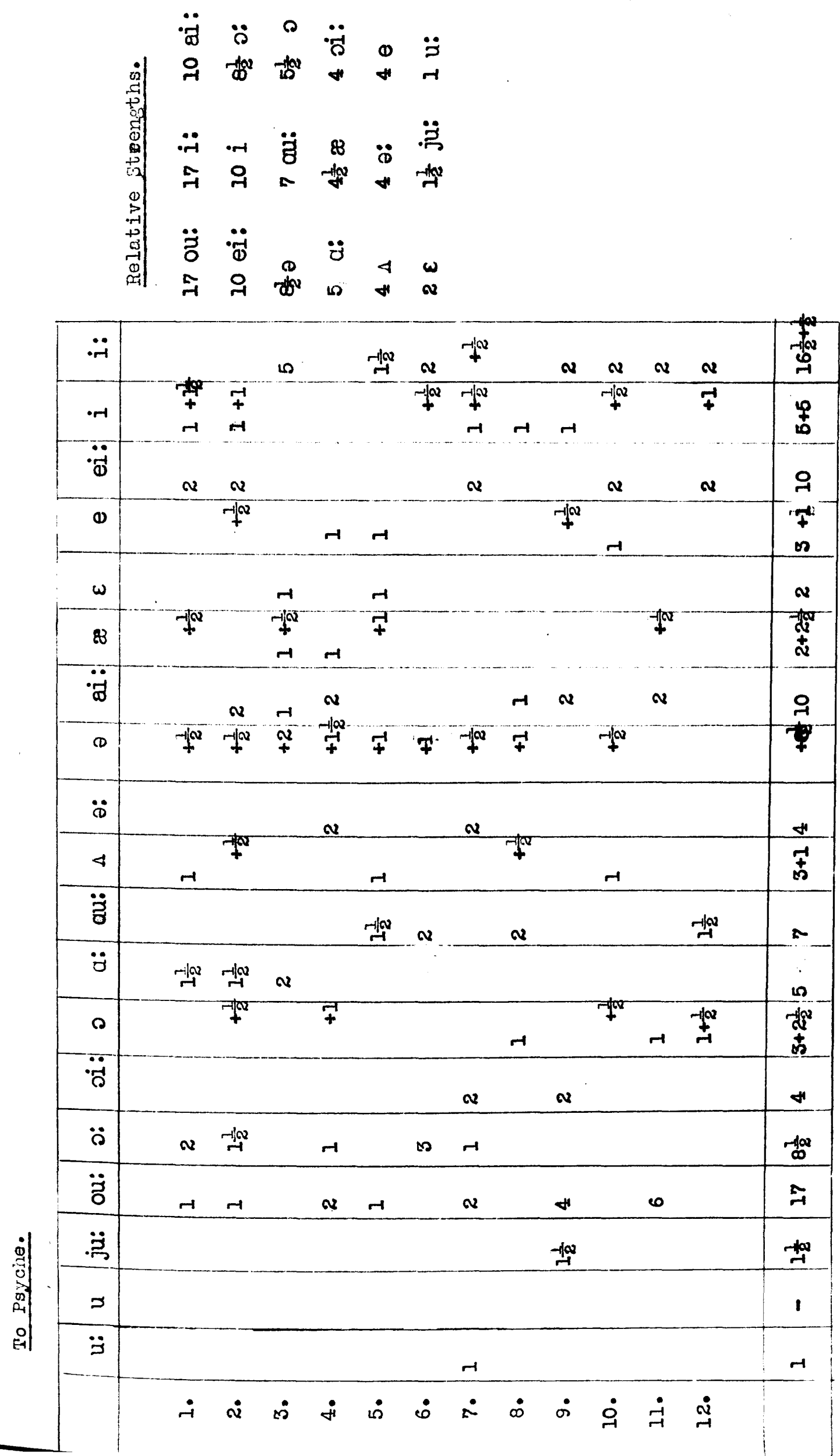




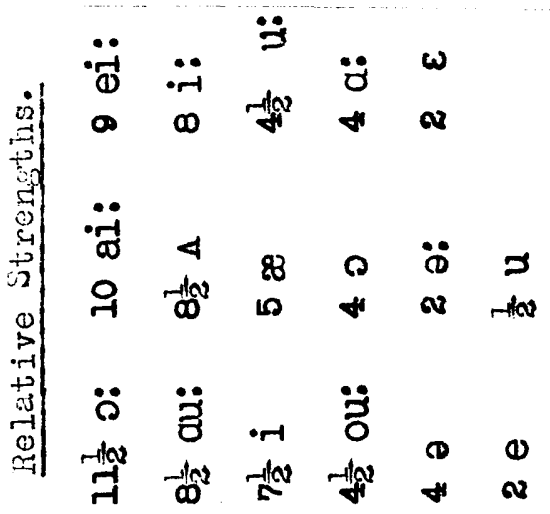

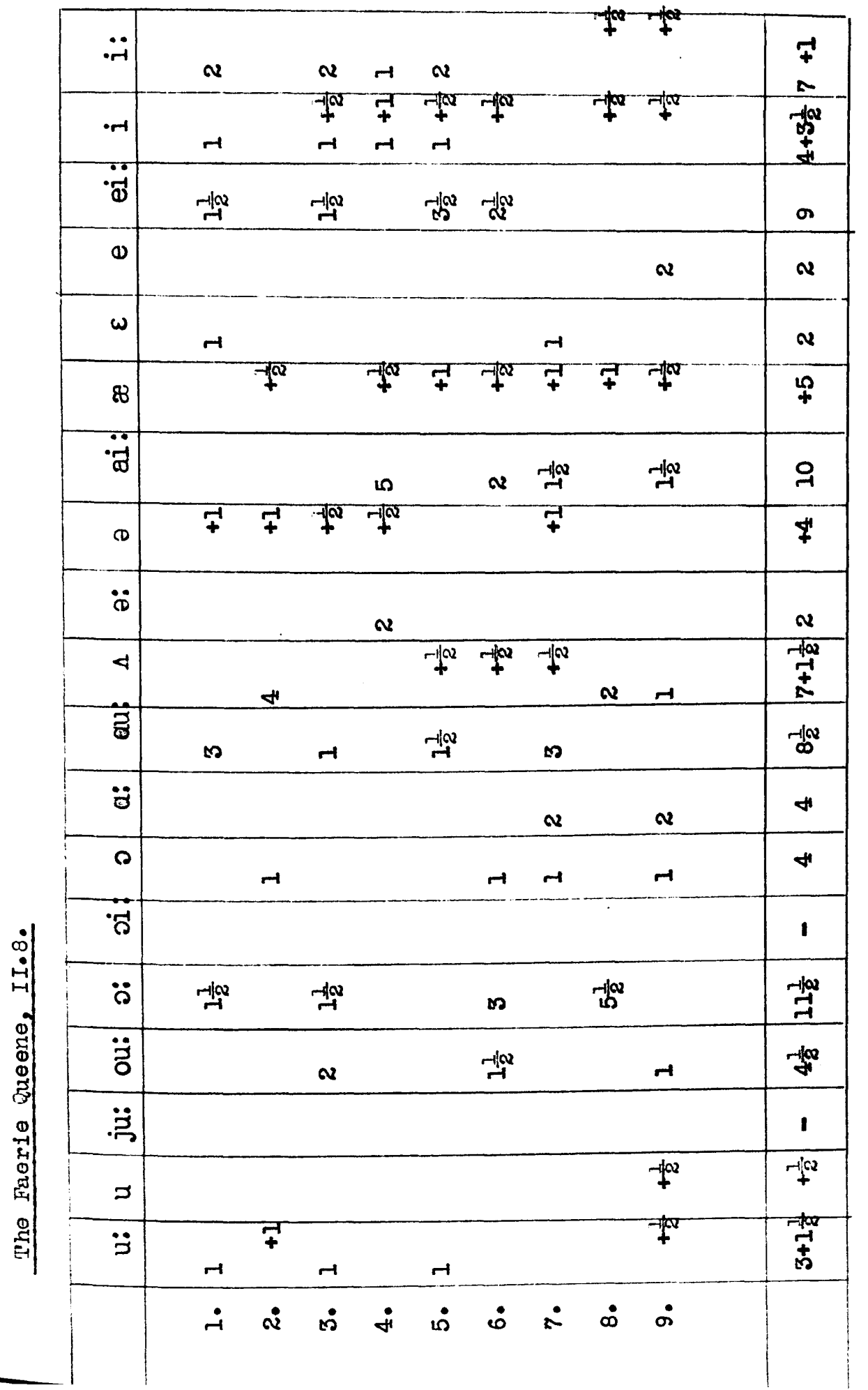




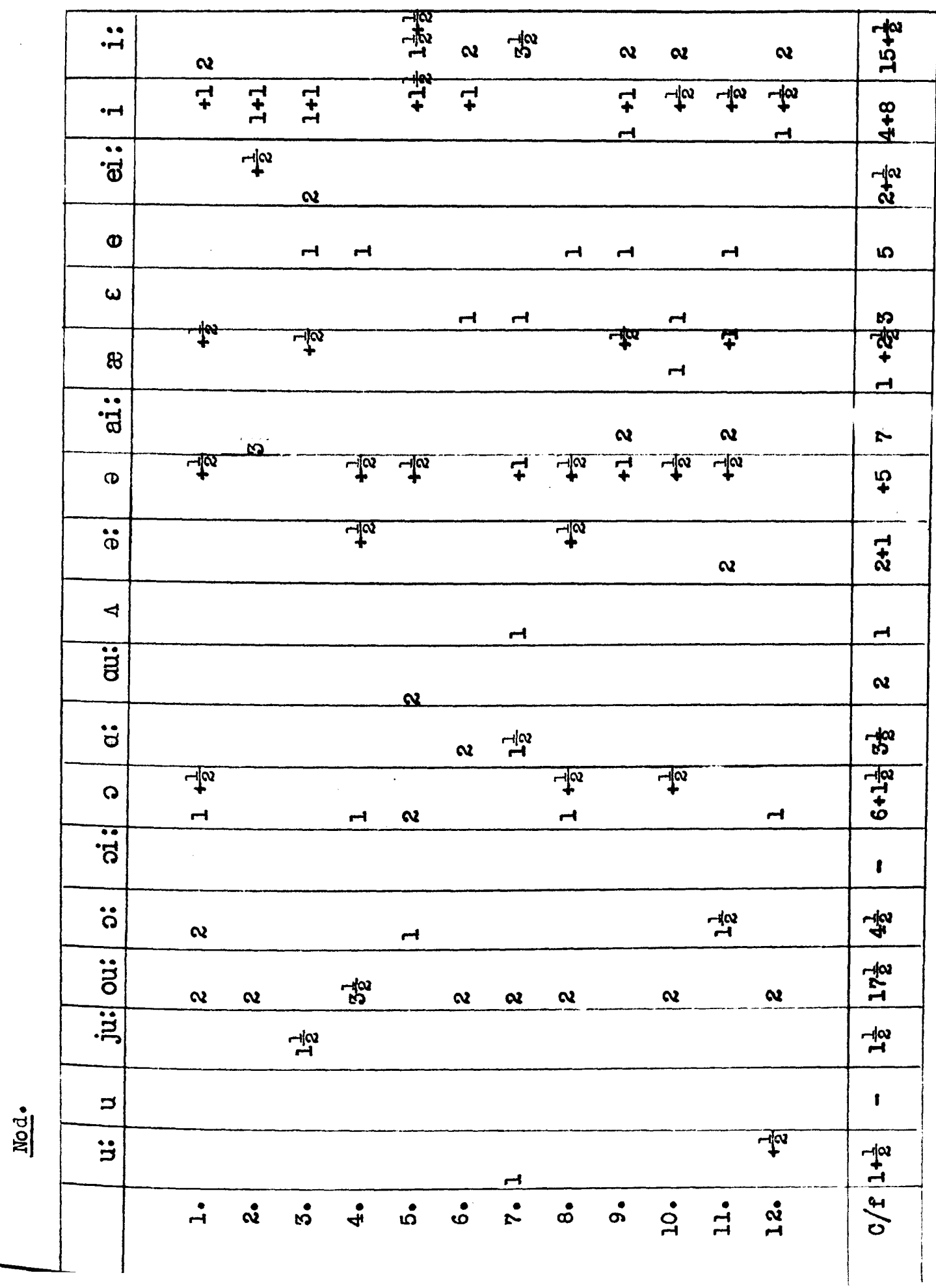




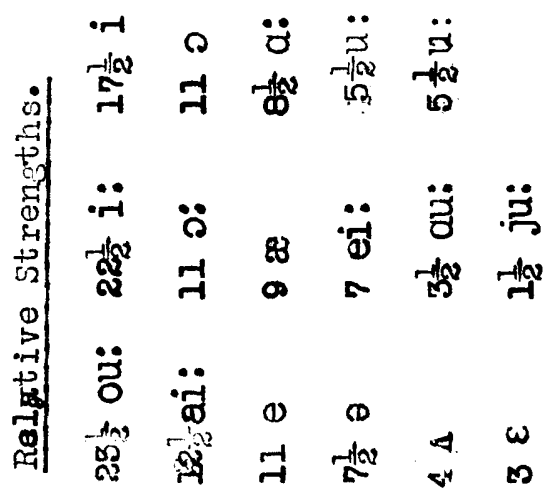

\begin{tabular}{|c|c|c|c|c|c|c|c|c|c|}
\hline$\ddot{-r}$ & $\begin{array}{l}\text { ming } \\
\frac{1}{n} \\
n\end{array}$ & & & $\approx$ & & H & & $H$ & -1an \\
\hline . & $\begin{array}{l}\infty \\
+ \\
+\end{array}$ & + & & +7 & $\begin{array}{l}-7 \\
-1\end{array}$ & -1 & & $\begin{array}{l}-7 \\
+1\end{array}$ & न्तgos \\
\hline$\ddot{0}$ & $\frac{-1}{n}$ & $-1)^{2}$ & & & & & $\boldsymbol{\alpha}$ & $\boldsymbol{v}$ & $\stackrel{+}{t}$ \\
\hline $\boldsymbol{\omega}$ & 10 & & $\begin{array}{c}r-102 \\
+ \\
+\end{array}$ & & & $H^{\alpha}$ & & $\rightarrow \quad m$ & +r \\
\hline$\omega$ & $\infty$ & & & & & & & & $\infty$ \\
\hline 88 & $\begin{array}{c}\frac{\pi n d}{2} \\
+ \\
+1\end{array}$ & -1 & -1 & & & -1 & & $\begin{array}{l}\text { ना } \\
-1\end{array}$ & $\underset{10}{7}$ \\
\hline$\ddot{\ddot{\sigma}}$ & 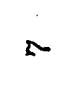 & & $\stackrel{-1 / \omega}{-1}$ & $\boldsymbol{v}$ & & $\boldsymbol{v}$ & & & $\tilde{w}^{2}$ \\
\hline co & $\stackrel{5}{+}$ & $+t^{2}$ & & $-19 a$ & & $-1+Q$ & 7 & & न्मूल \\
\hline$\ddot{B}$ & $\vec{\omega}$ & & & & & & & & $\stackrel{+}{ \pm}$ \\
\hline 4 & $r$ & -1 & & $r$ & $\rightarrow$ & & & & $H$ \\
\hline$\ddot{z}$ & 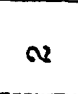 & 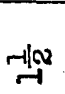 & & & & & & & - \\
\hline$\ddot{d}$ & की & & & & & $r$ & & H & $-\infty$ \\
\hline $\boldsymbol{\rho}$ & 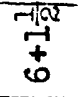 & & & $r$ & $\mp$ & $-1+2$ & $+\infty$ & $-1 n$ & $\underset{7}{7}$ \\
\hline$\ddot{\circ}$ & 1 & & & & & & & & 1 \\
\hline$\ddot{\circ}$ & $\stackrel{-\pi / n}{a}$ & & $v$ & & $\stackrel{-1 \infty}{-1}$ & & $\infty$ & & $\vec{r}$ \\
\hline$\ddot{\partial}$ & $\stackrel{r i a n}{\stackrel{-}{-1}}$ & के & -1 & rig & & & $\stackrel{-100}{\rightarrow}$ & & rav \\
\hline$\ddot{\ddot{z}}$ & $\stackrel{r \mid r q}{\rightarrow}$ & & & & & & & & ${ }_{-1}^{-102}$ \\
\hline $\boldsymbol{x}$ & 1 & & & & & & & & 1 \\
\hline$\because$ & $\stackrel{+102}{\pi}$ & $\infty$ & & $\alpha$ & & & & & $\underset{\mathbf{m}}{+\infty}$ \\
\hline & $\frac{4}{m}$ & $\stackrel{\leftrightarrow}{-1}$ & $\underset{H}{\dot{4}}$ & $\ddot{9}$ & $\underset{\sim}{\dot{\sigma}}$ & $\dot{\pi}$ & 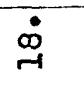 & $\dot{\sigma} \quad \dot{8}$ & \\
\hline
\end{tabular}




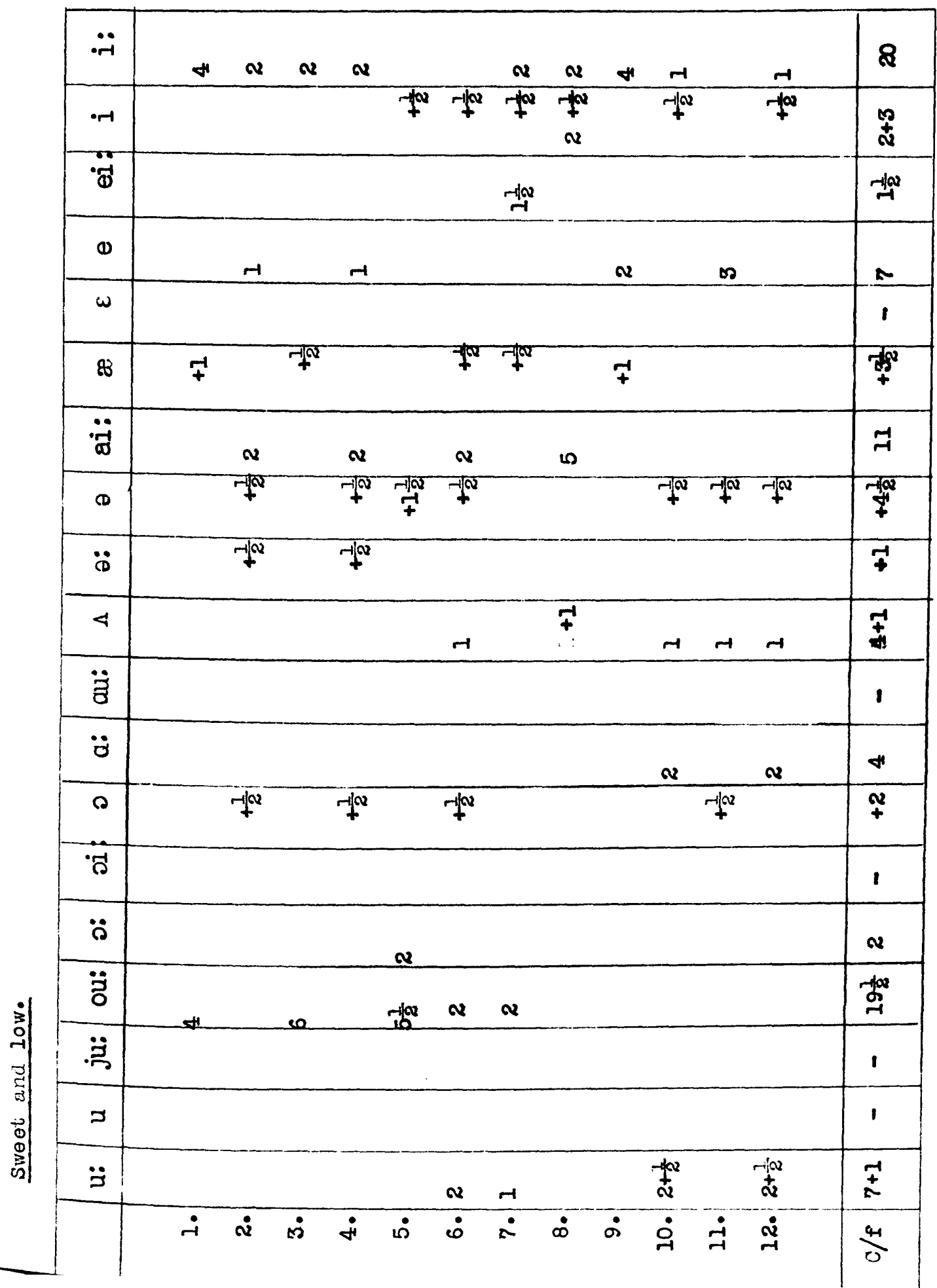




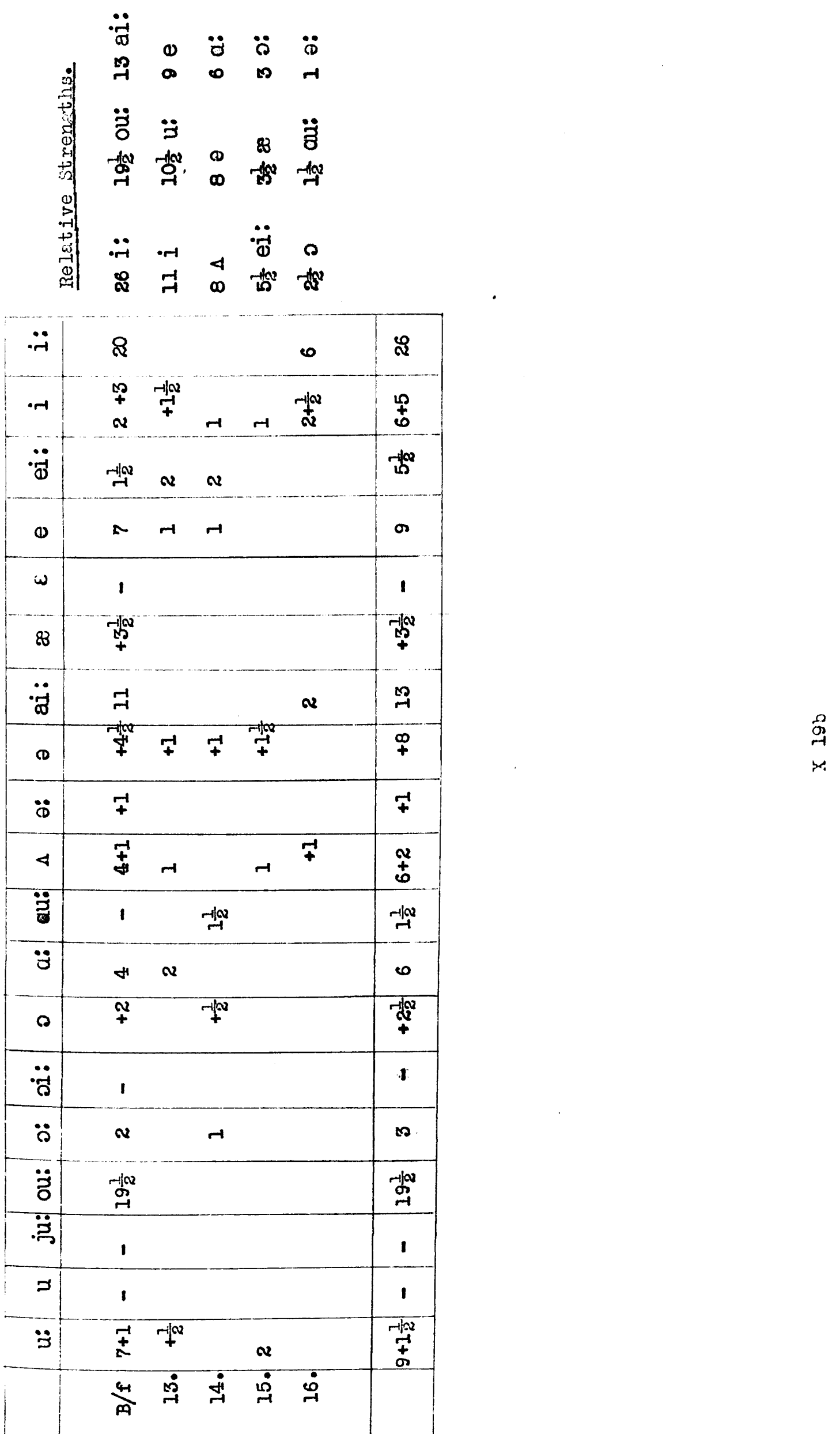




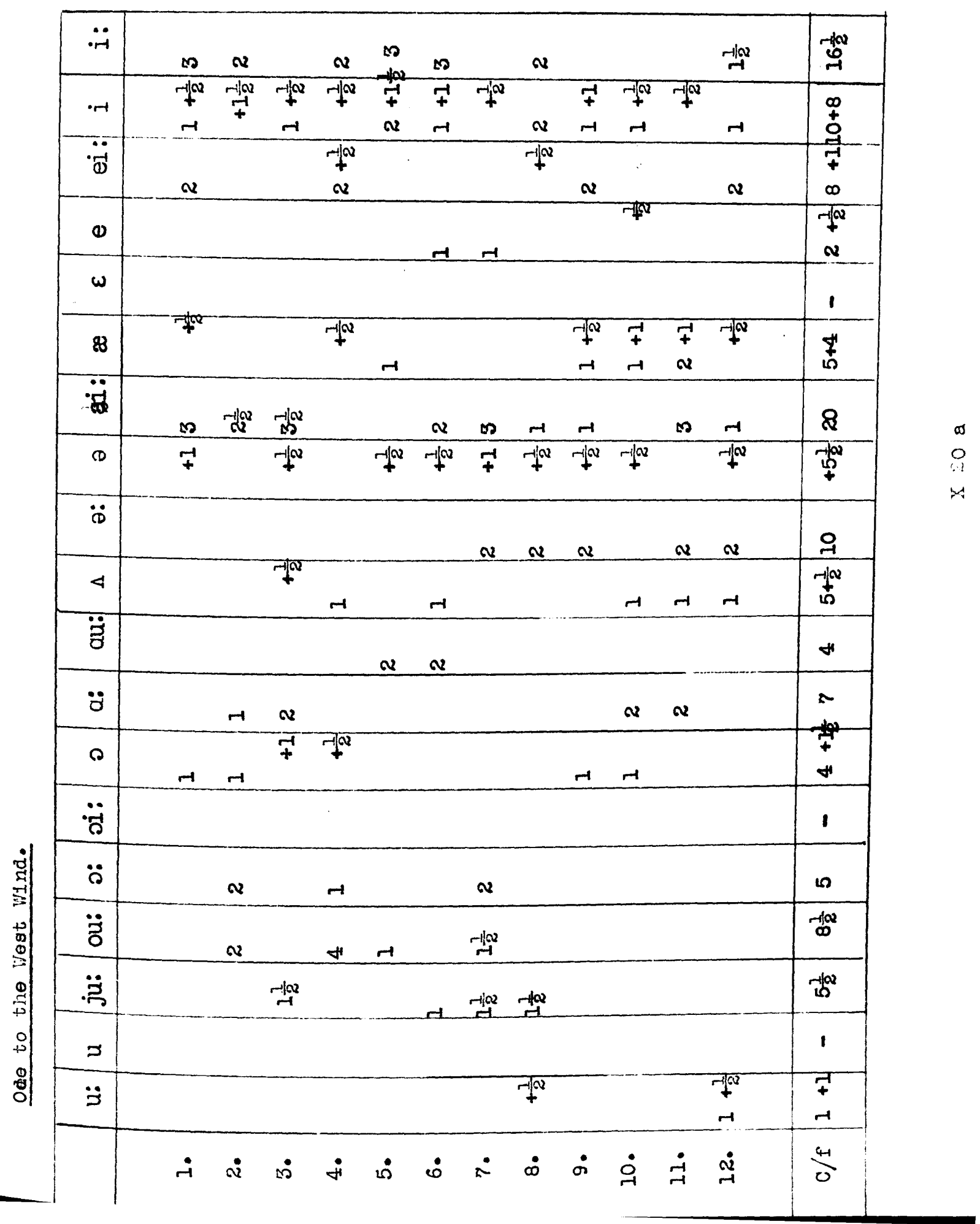




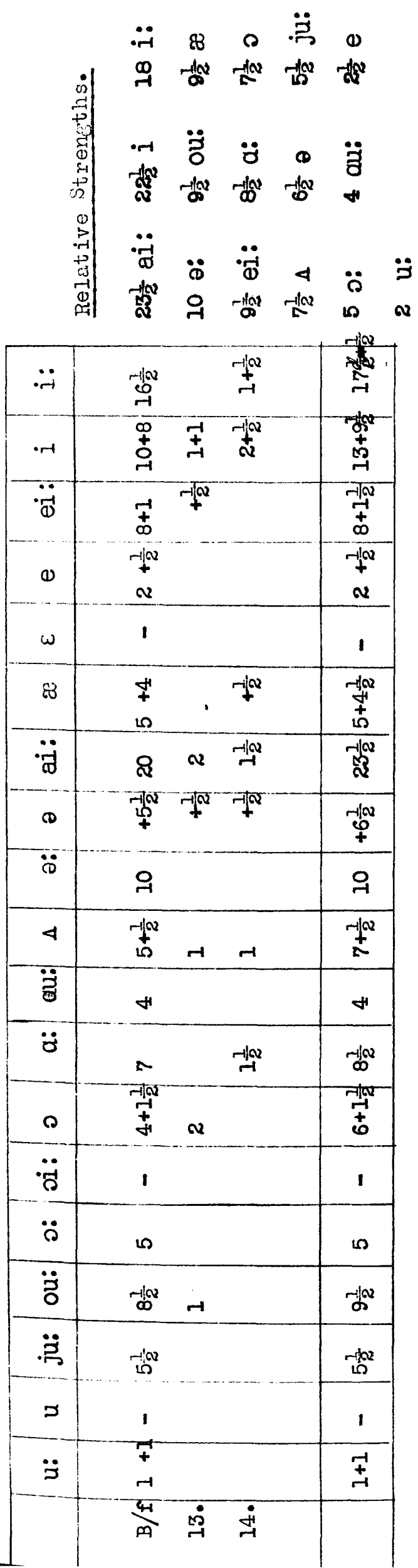




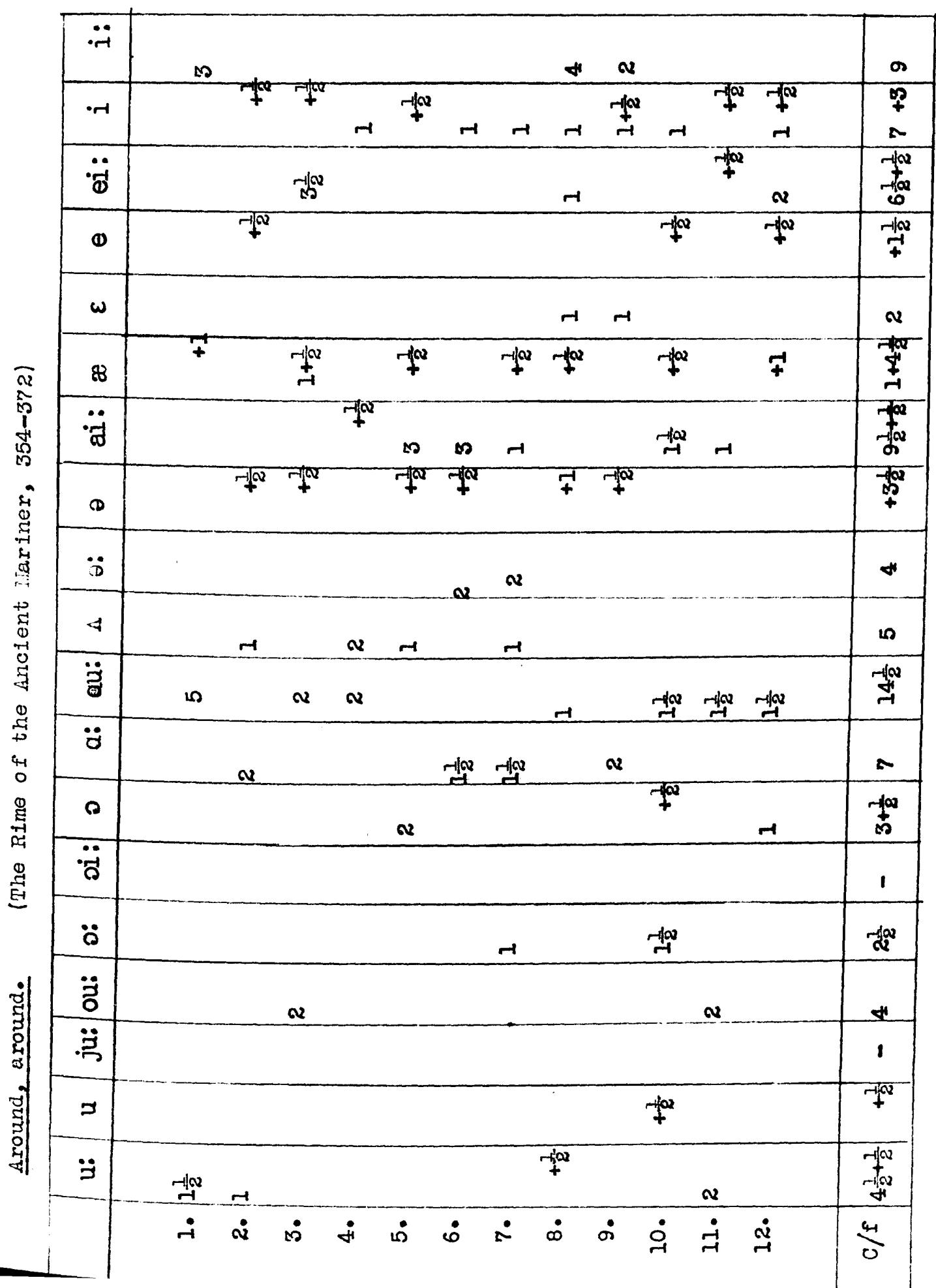




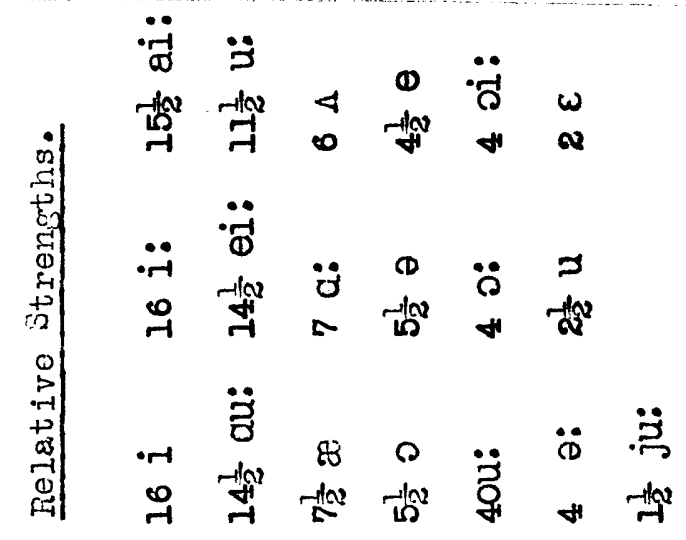

\begin{tabular}{|c|c|c|c|c|c|c|c|c|}
\hline$\ddot{r}$ & $\sigma$ & $r$ & $v$ & & & $\boldsymbol{v}$ & $v$ & $\stackrel{\oplus}{\oplus}$ \\
\hline$\cdot r-1$ & 2 & & +1 & + & $r$ & $\mp$ & $\rightarrow \underset{-10}{+10}$ & $\stackrel{9}{9}$ \\
\hline$\ddot{\ddot{\theta}}$ & नात्र & $v$ & - dx & $f^{\prime \prime \alpha}$ & + & & $-1+\infty$ & $\begin{array}{c}9 \\
7 \\
9 \\
9\end{array}$ \\
\hline (1) & 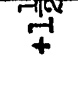 & $r$ & +10 & -1 & & & + & \begin{tabular}{c}
+2 \\
\multirow{2}{*}{} \\
\multirow{2}{*}{}
\end{tabular} \\
\hline$\omega$ & ๙ & & & & & & & $v$ \\
\hline 83 & $\begin{array}{c}-1 / N \\
+1 \\
+ \\
+\end{array}$ & 7 & & 740 & & & -1 & 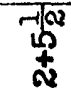 \\
\hline$\ddot{\ddot{\infty}}$ & $\begin{array}{c}-1 / \alpha \\
-10 \\
\sigma\end{array}$ & & & & $\int_{-1}^{-1 w}$ & & $\boldsymbol{v}$ & $\begin{array}{r}-10 \\
7 \\
n \\
\end{array}$ \\
\hline$\infty$ & નid & $7 f^{a}$ & $f^{\infty}$ & & & -10 & $r+\alpha$ & 望 \\
\hline$\ddot{8}$ & +4 & & & & & & & $H$ \\
\hline 4 & 10 & & & & & $r$ & & $\boldsymbol{\omega}$ \\
\hline$\ddot{\Xi}$ & 眐 & & & & & & & $\stackrel{-10 x}{\not}$ \\
\hline$\ddot{\alpha}$ & $\pi$ & & & & & & & $\pi$ \\
\hline 0 & $\begin{array}{l}70 \\
\infty\end{array}$ & & $\rightarrow$ & & 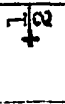 & ${ }^{\prime}$ & & ना \\
\hline$\ddot{~} \ddot{\circ}$ & 1 & & & $\mathbf{v}$ & $\boldsymbol{v}$ & & & + \\
\hline$\ddot{\circ}$ & -1/ & & & & & & 些 & $H$ \\
\hline$\ddot{3}$ & + & & & & & & & +4 \\
\hline$\ddot{\ddot{乃}}$ & 1 & & & & & & - & $\underset{-1}{-12}$ \\
\hline 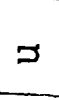 & $7 \pi^{9}$ & & & & $r$ & & -1 & $\frac{r-1 \infty}{N}$ \\
\hline$\ddot{\jmath}$ & $\begin{array}{l}-10 \\
+\infty \\
+1\end{array}$ & $\boldsymbol{v}$ & & $v$ & & 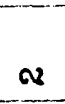 & Fin & 梦 \\
\hline & $\frac{4}{m}$ & $\dot{0}$ & $\underset{H}{\stackrel{\sharp}{*}}$ & เீ่ & $\dot{-1}$ & $\dot{\leftarrow}$ & $\stackrel{\dot{m}}{\dot{\rightarrow}} \dot{\rightarrow}$ & \\
\hline
\end{tabular}




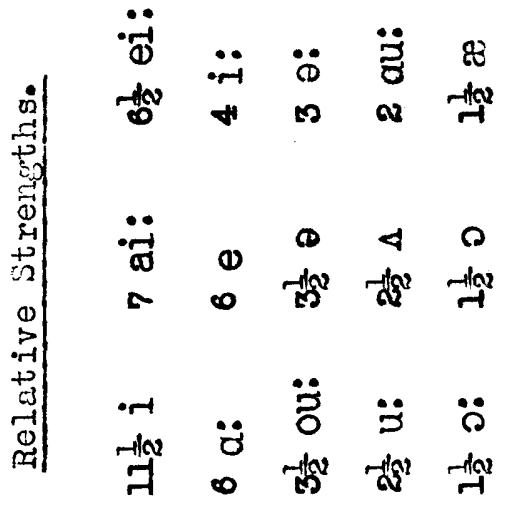

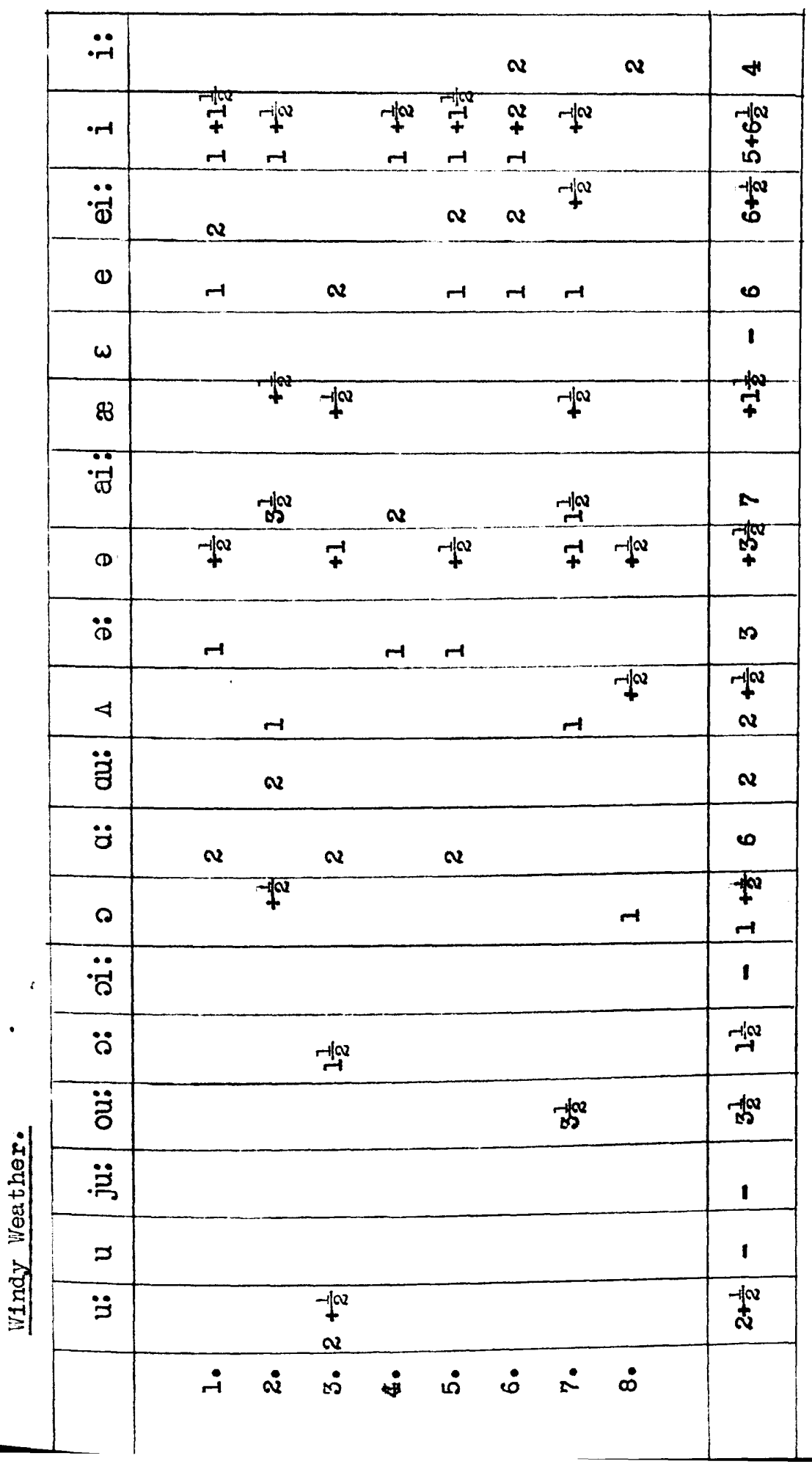




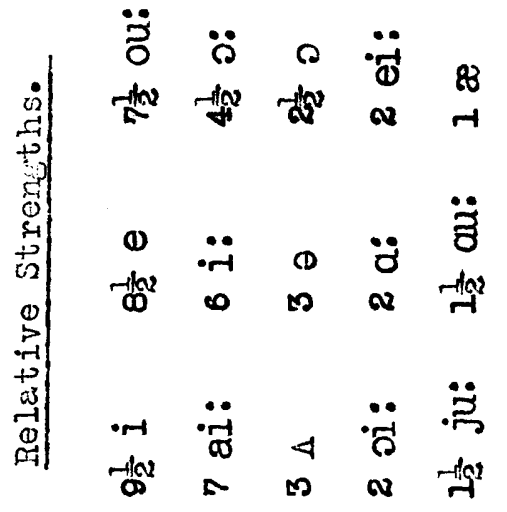

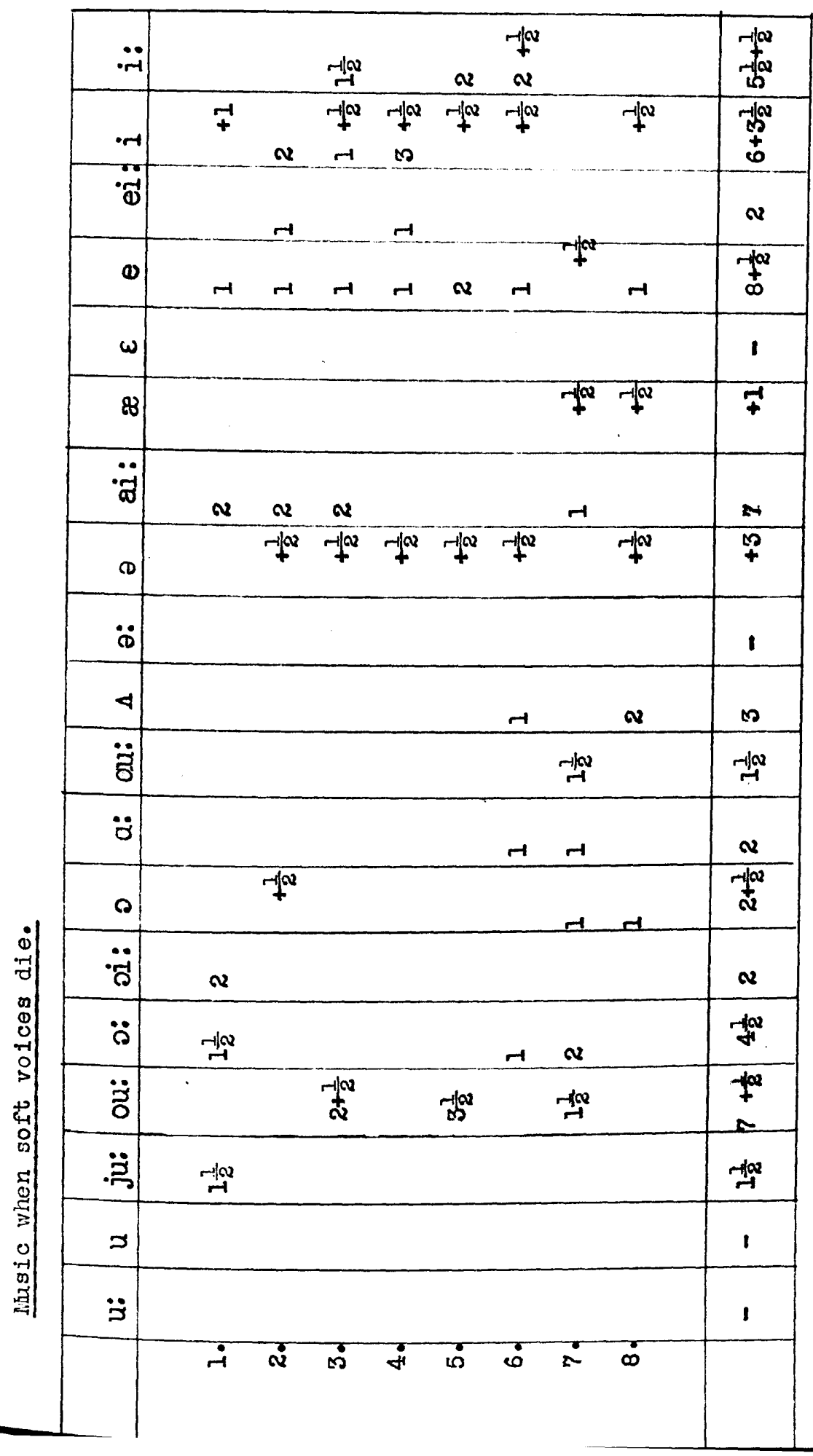



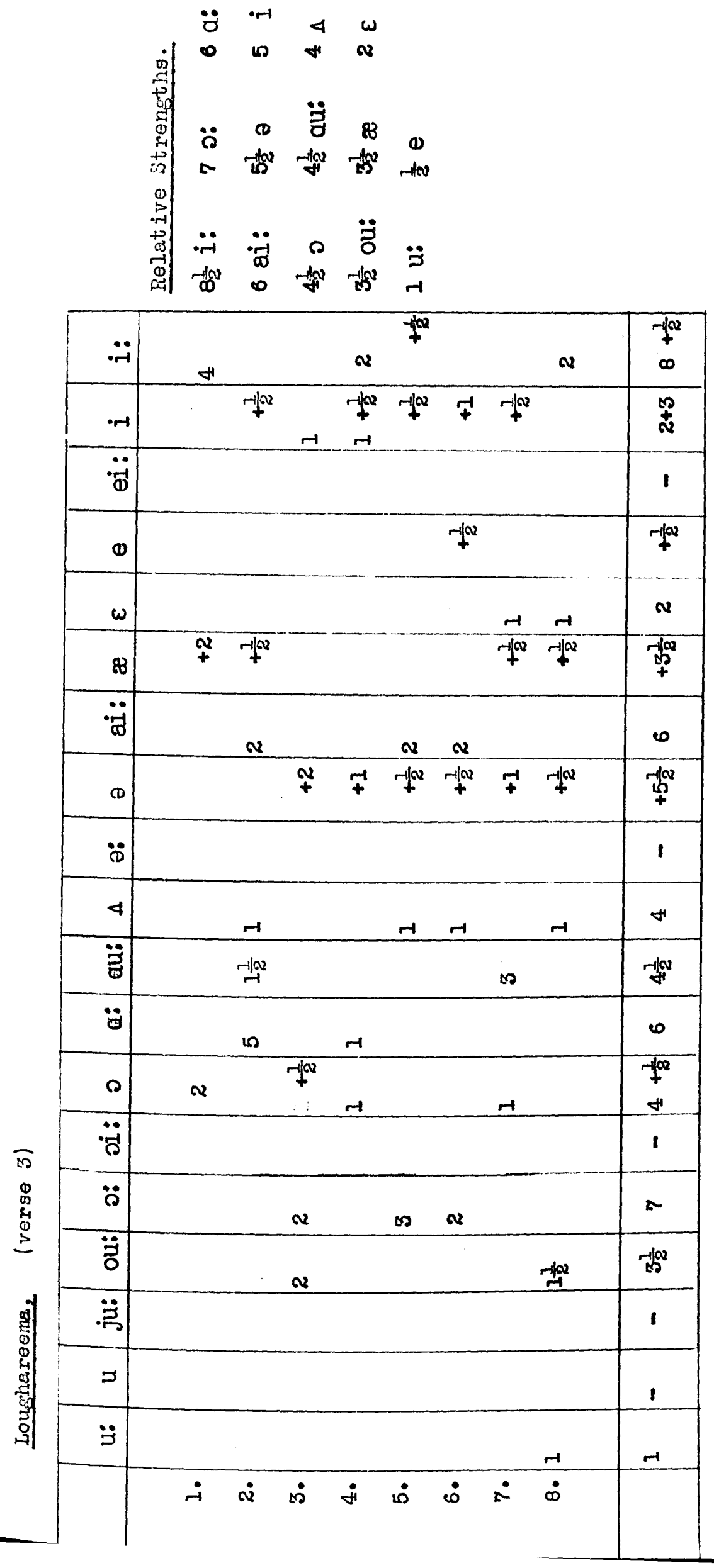


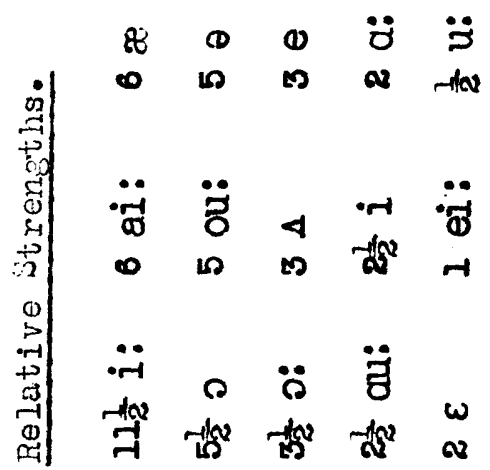

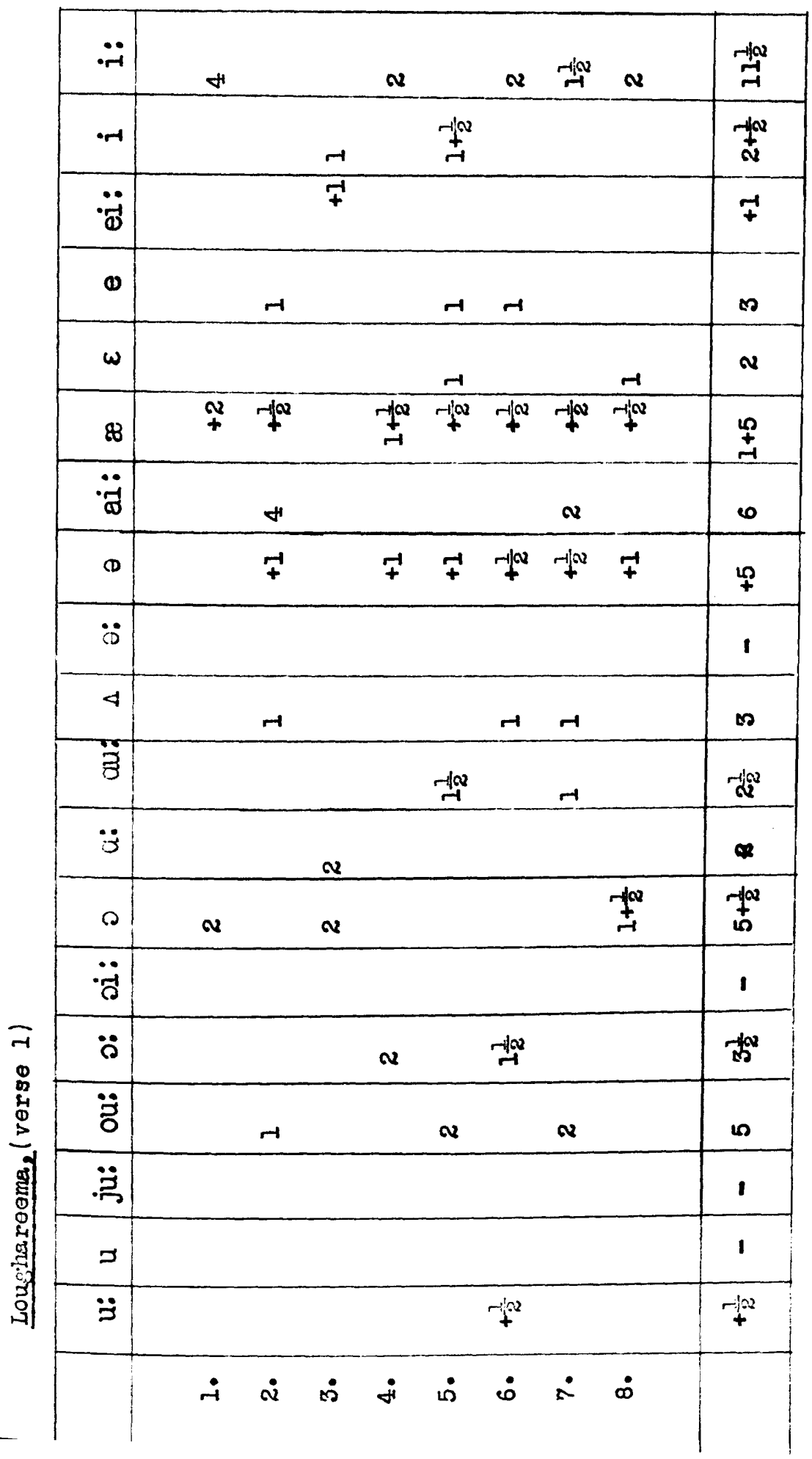




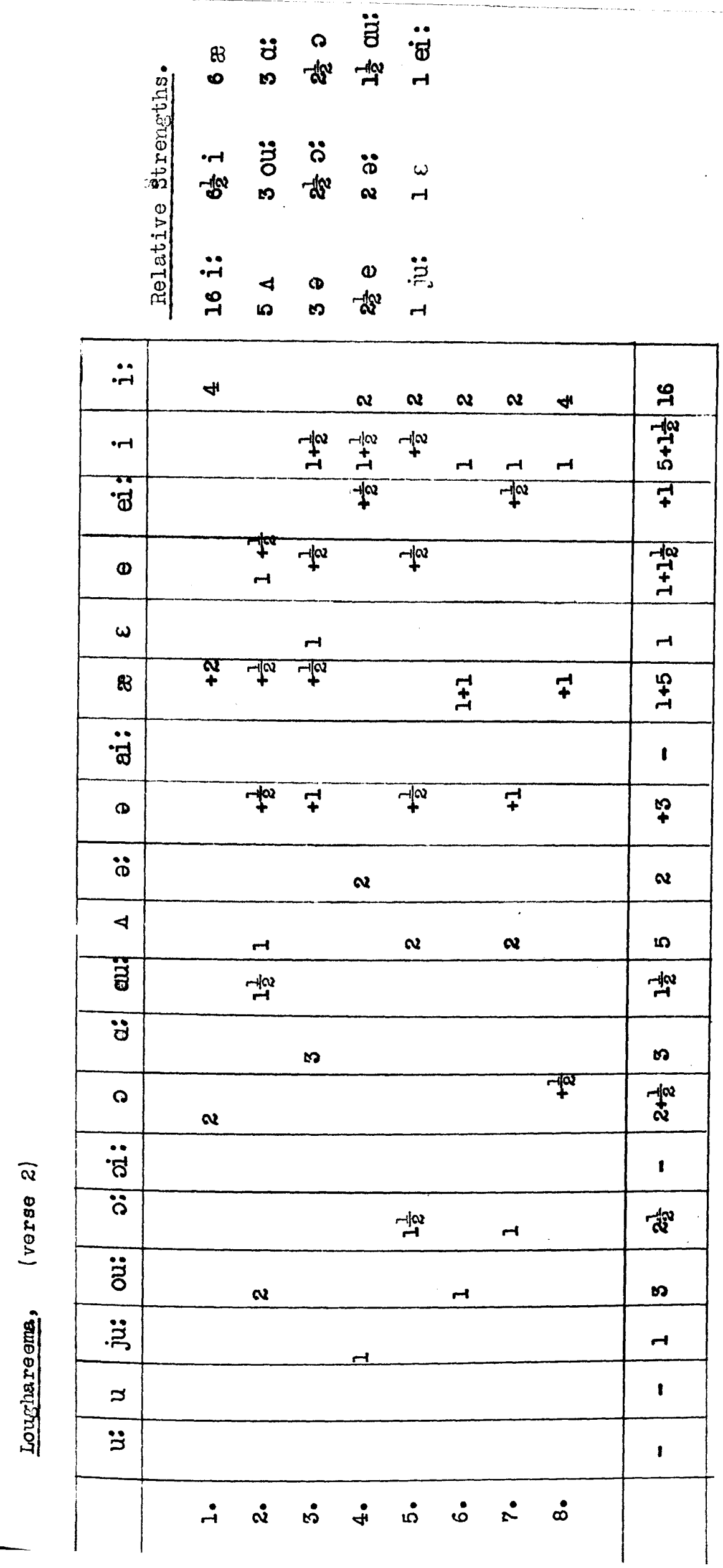




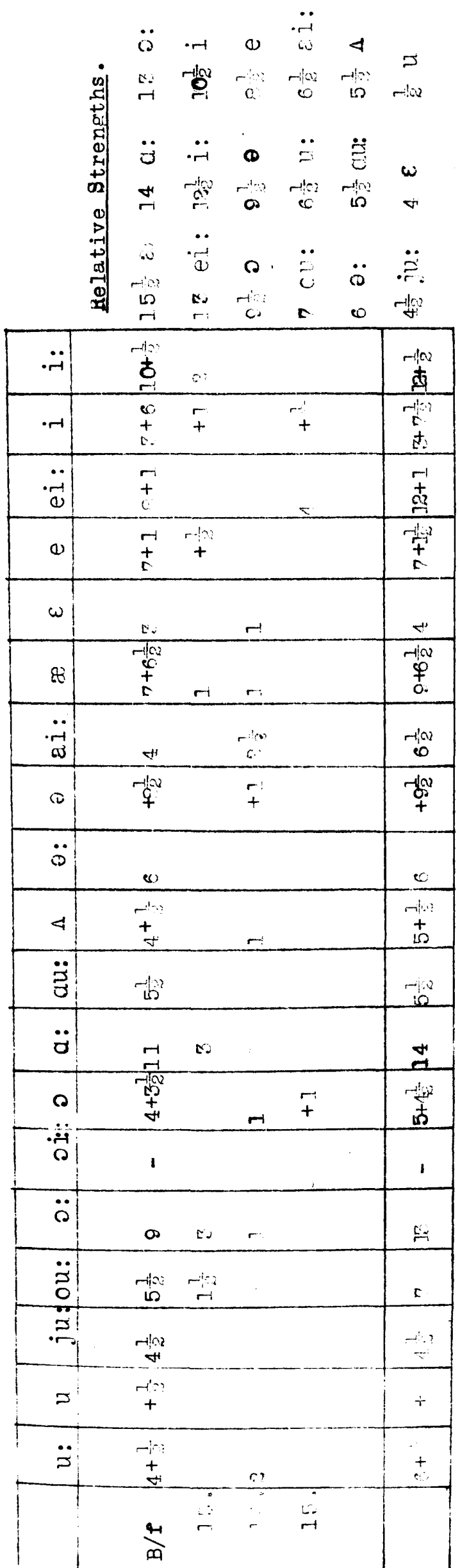




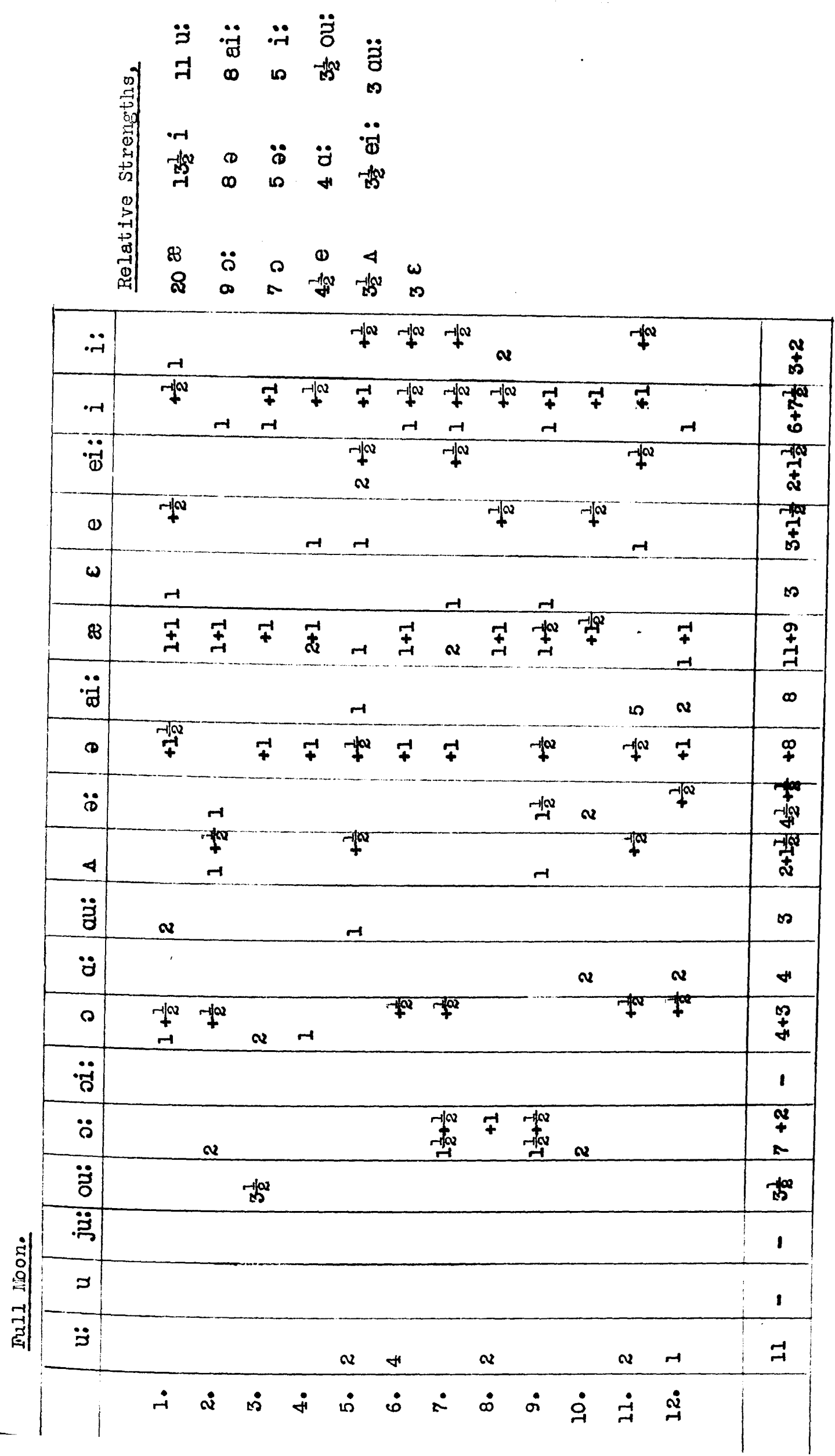




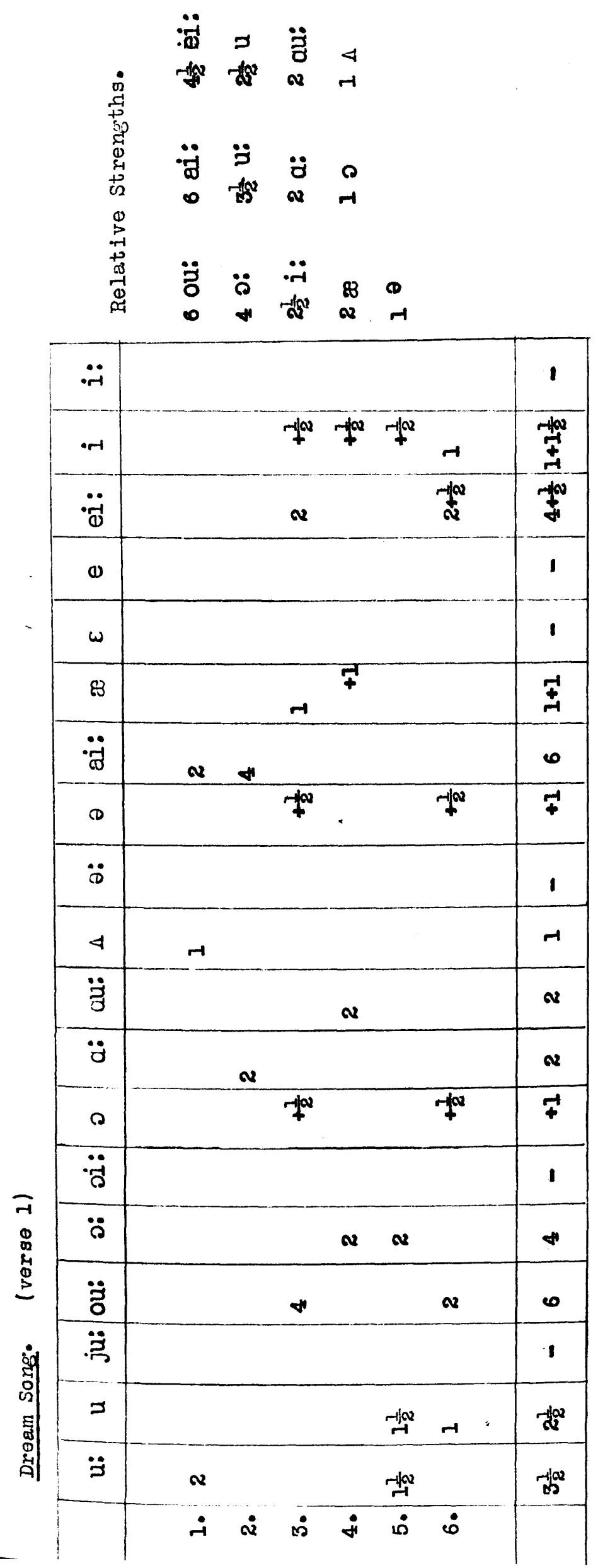




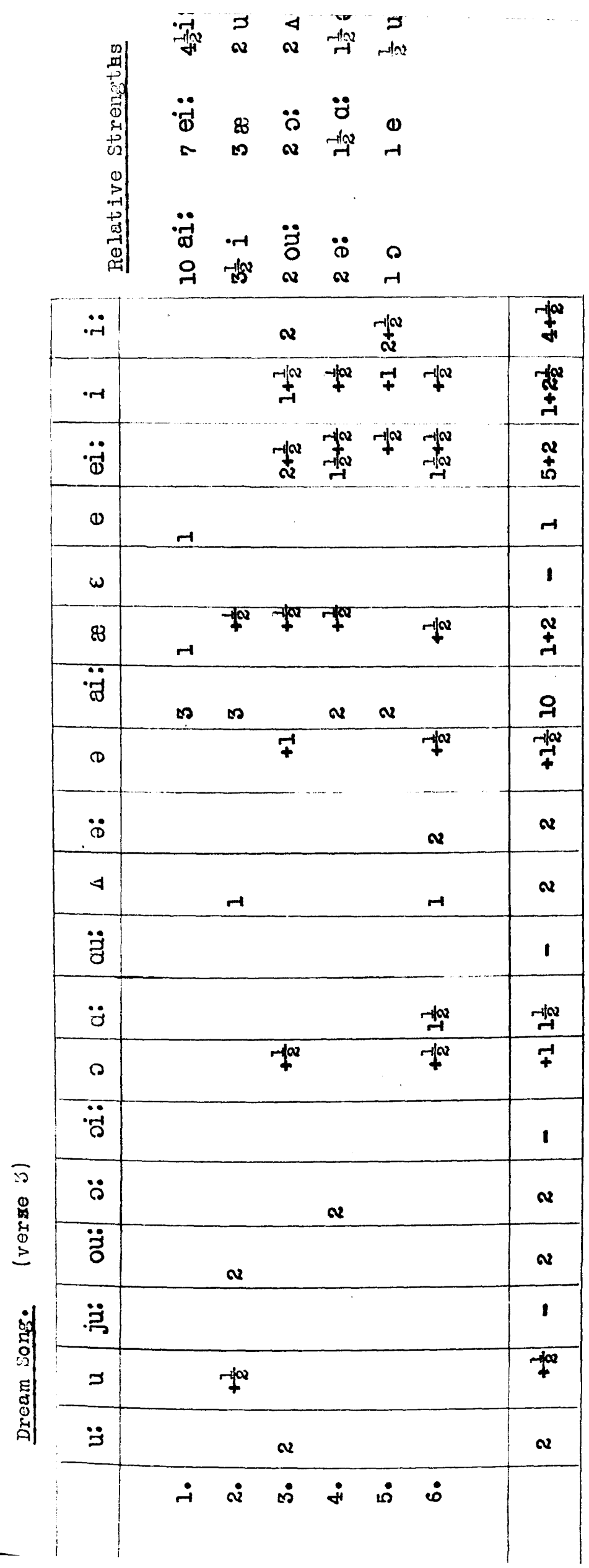



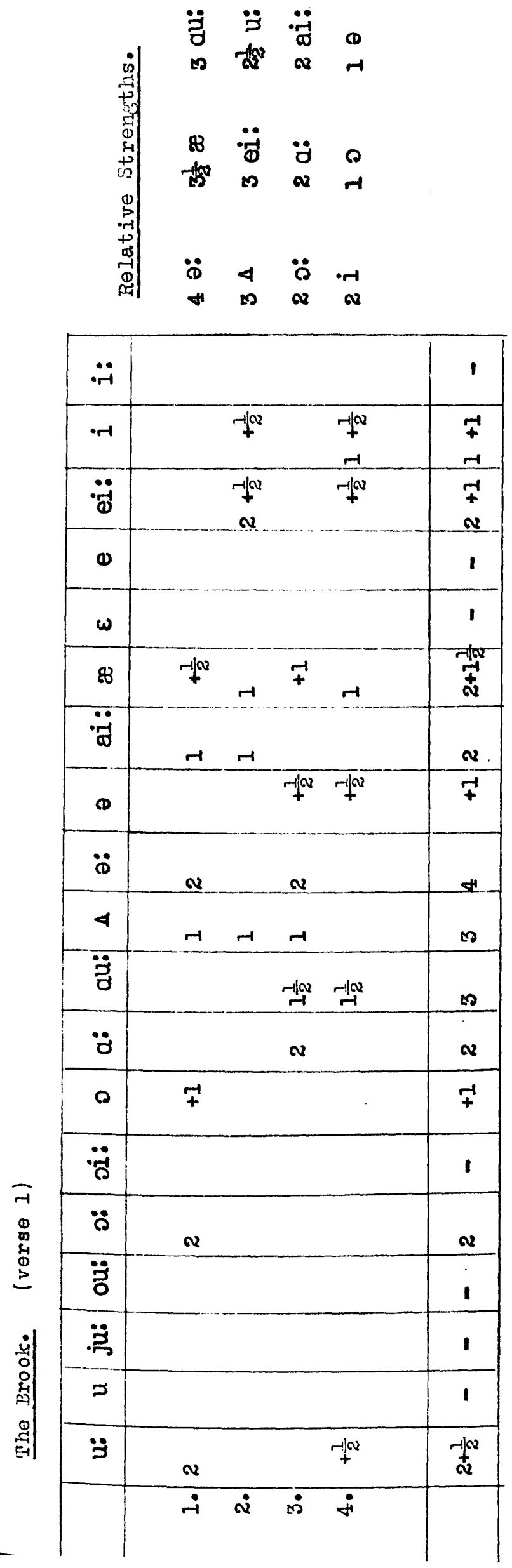

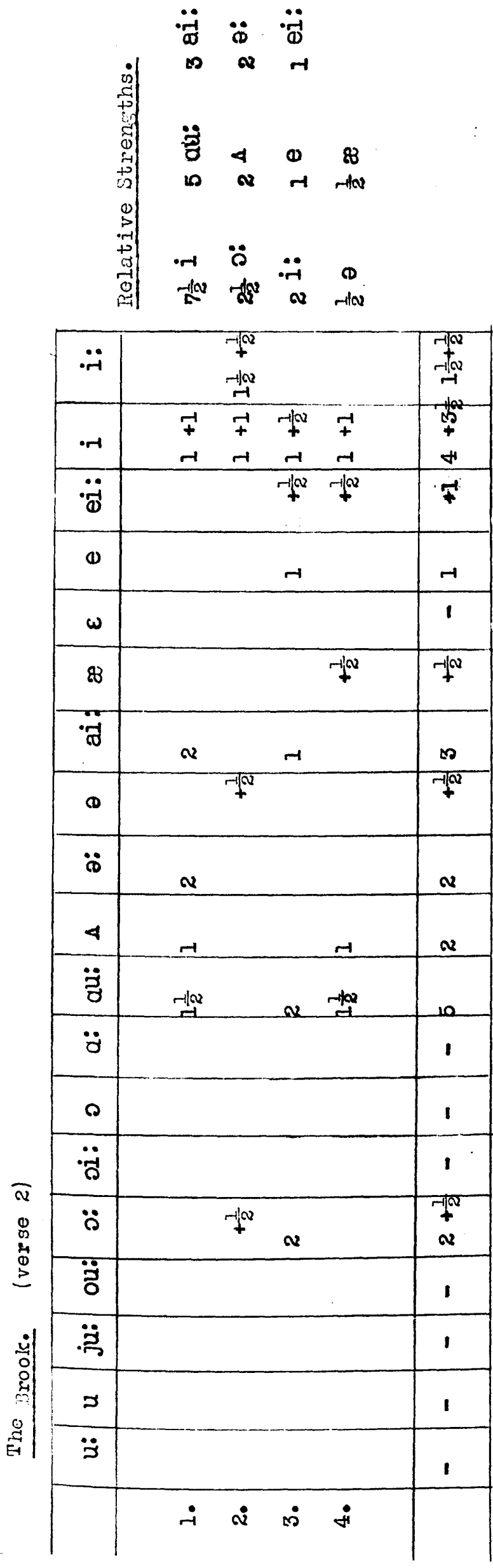


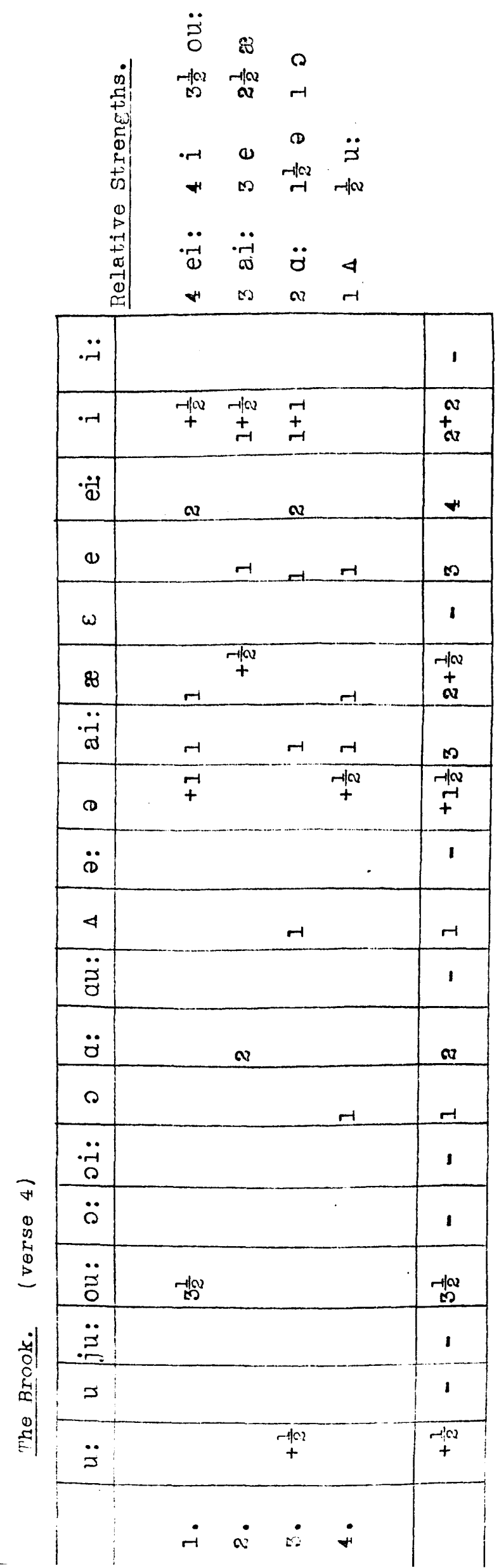




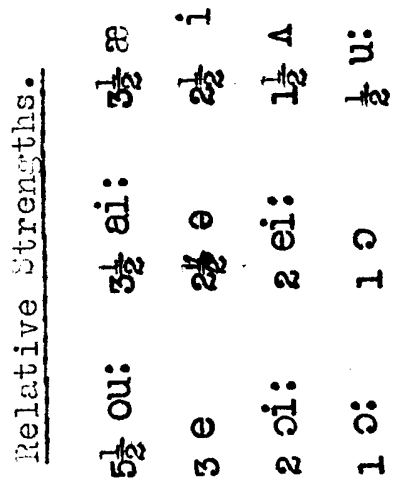

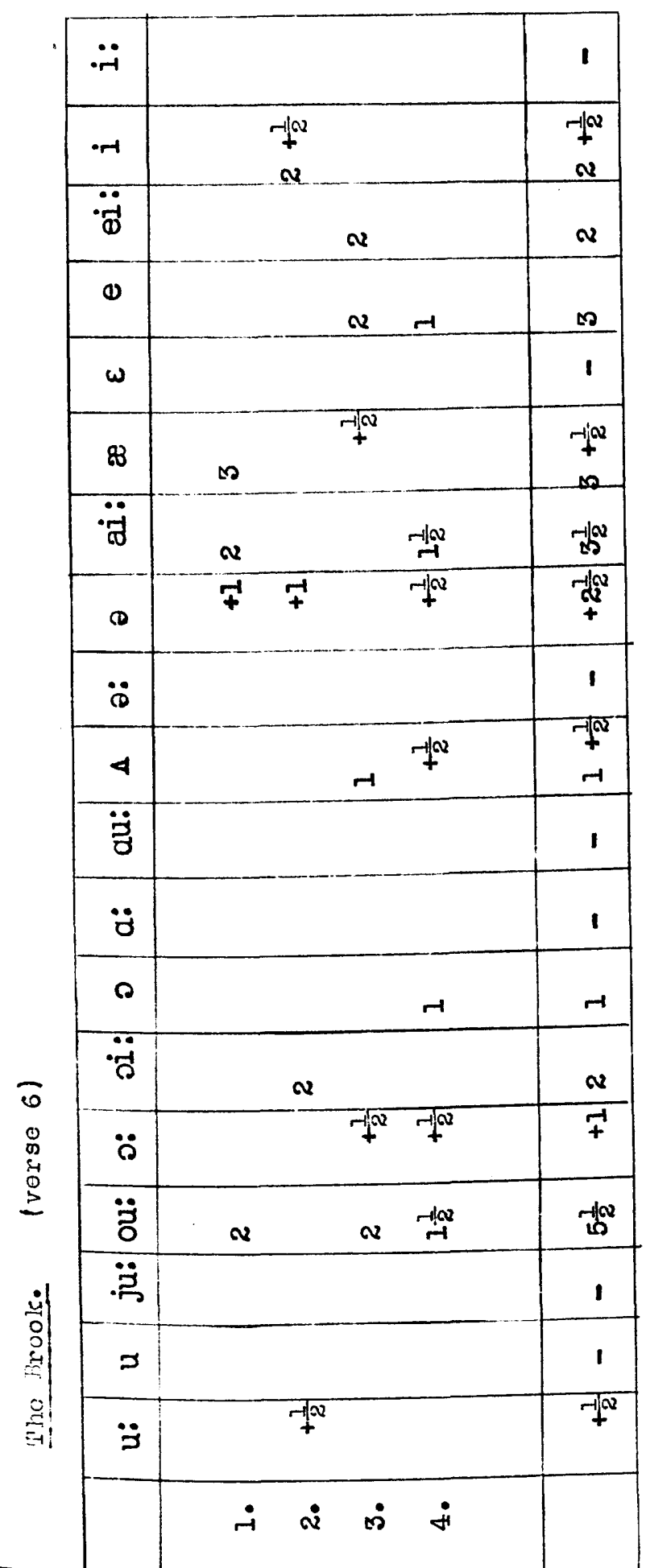




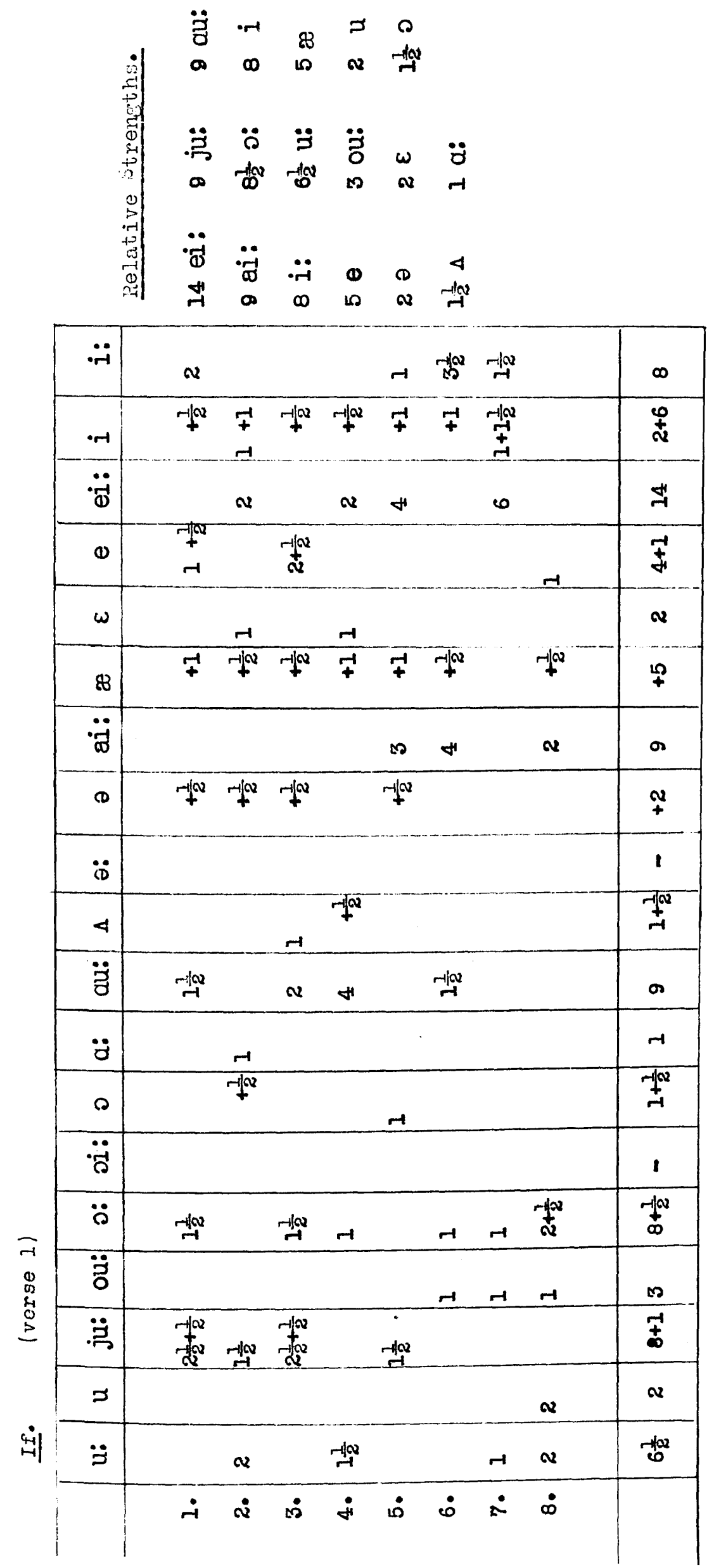




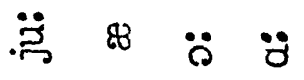

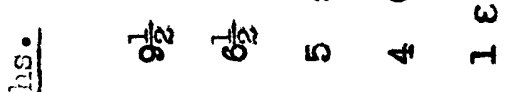

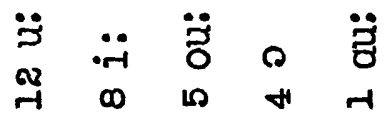

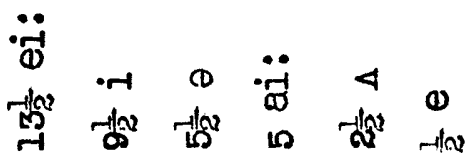

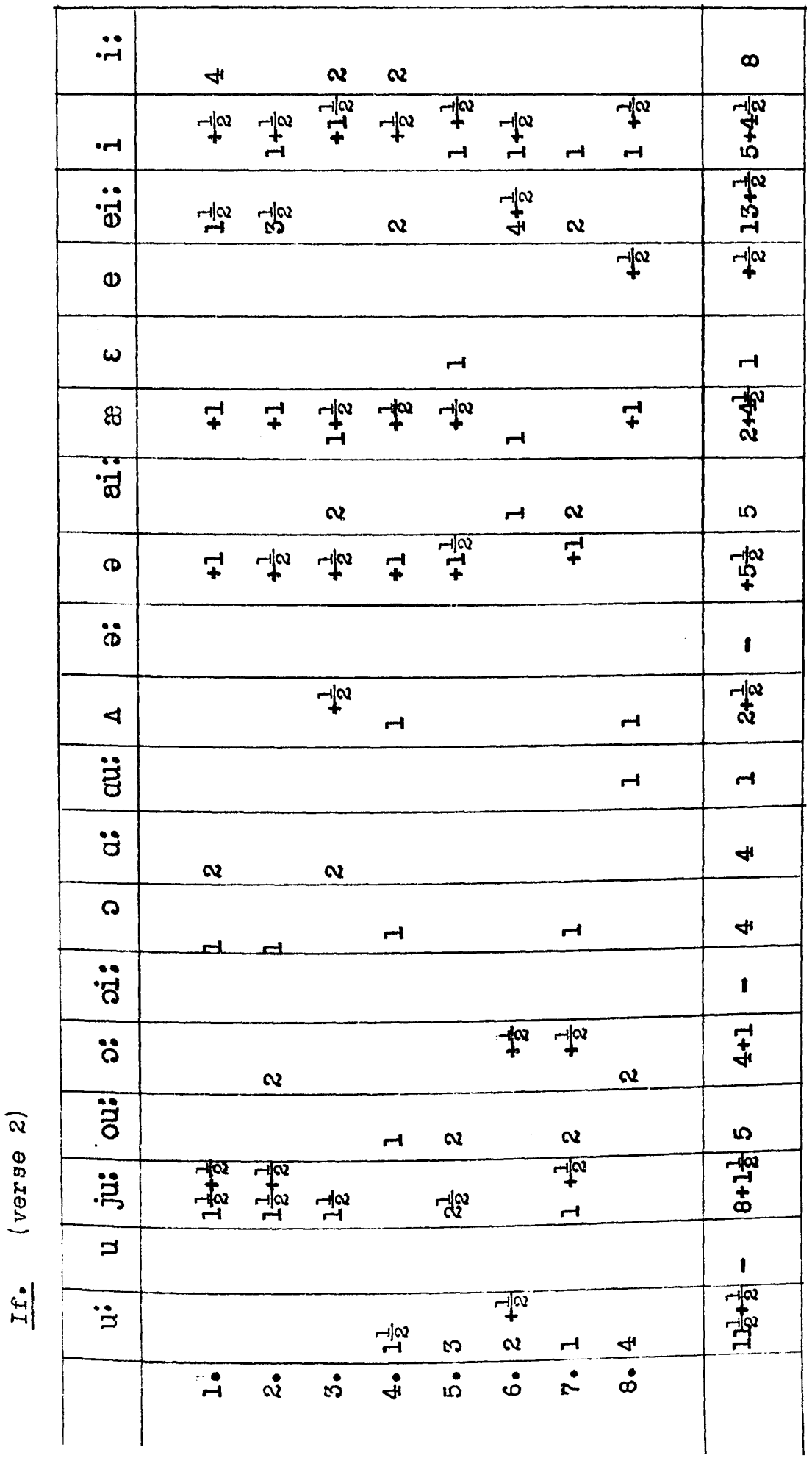




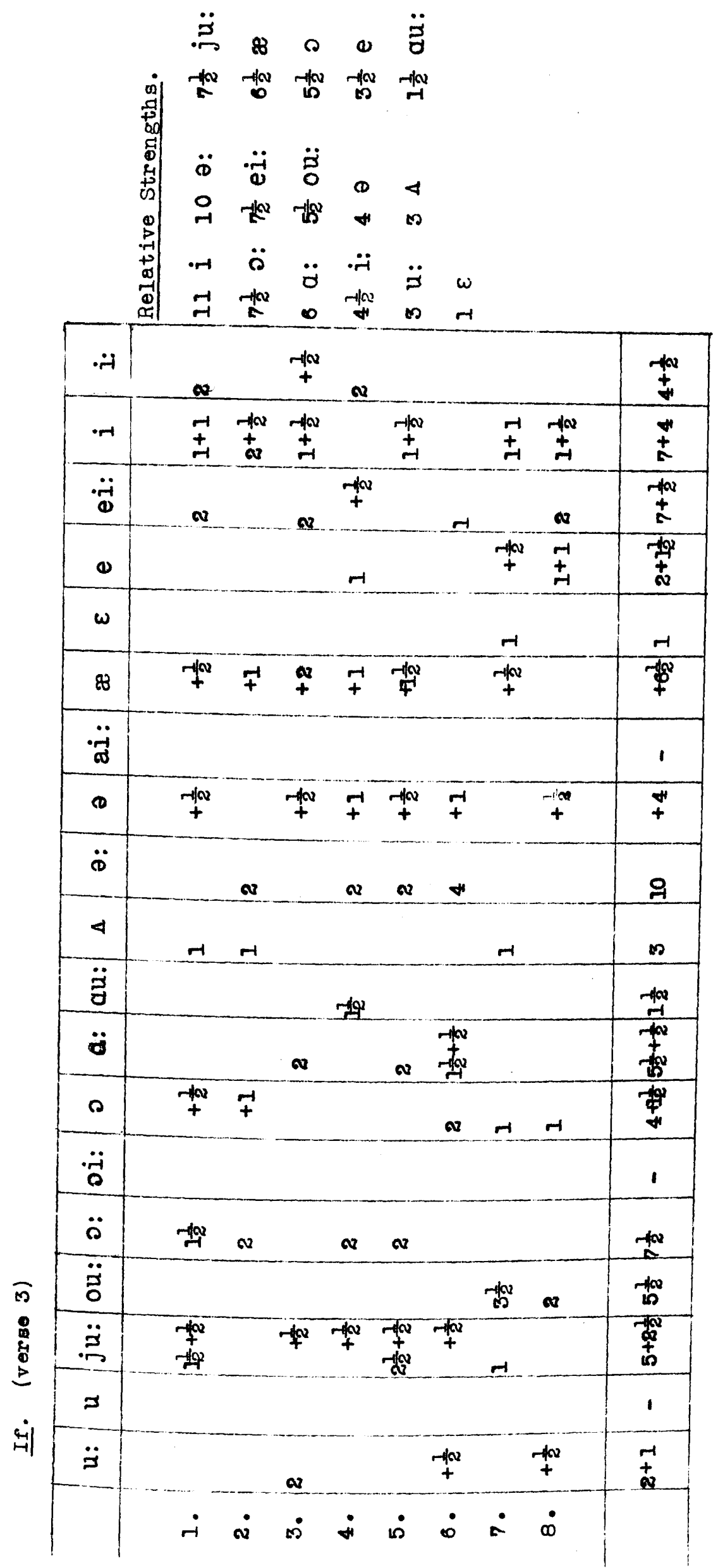



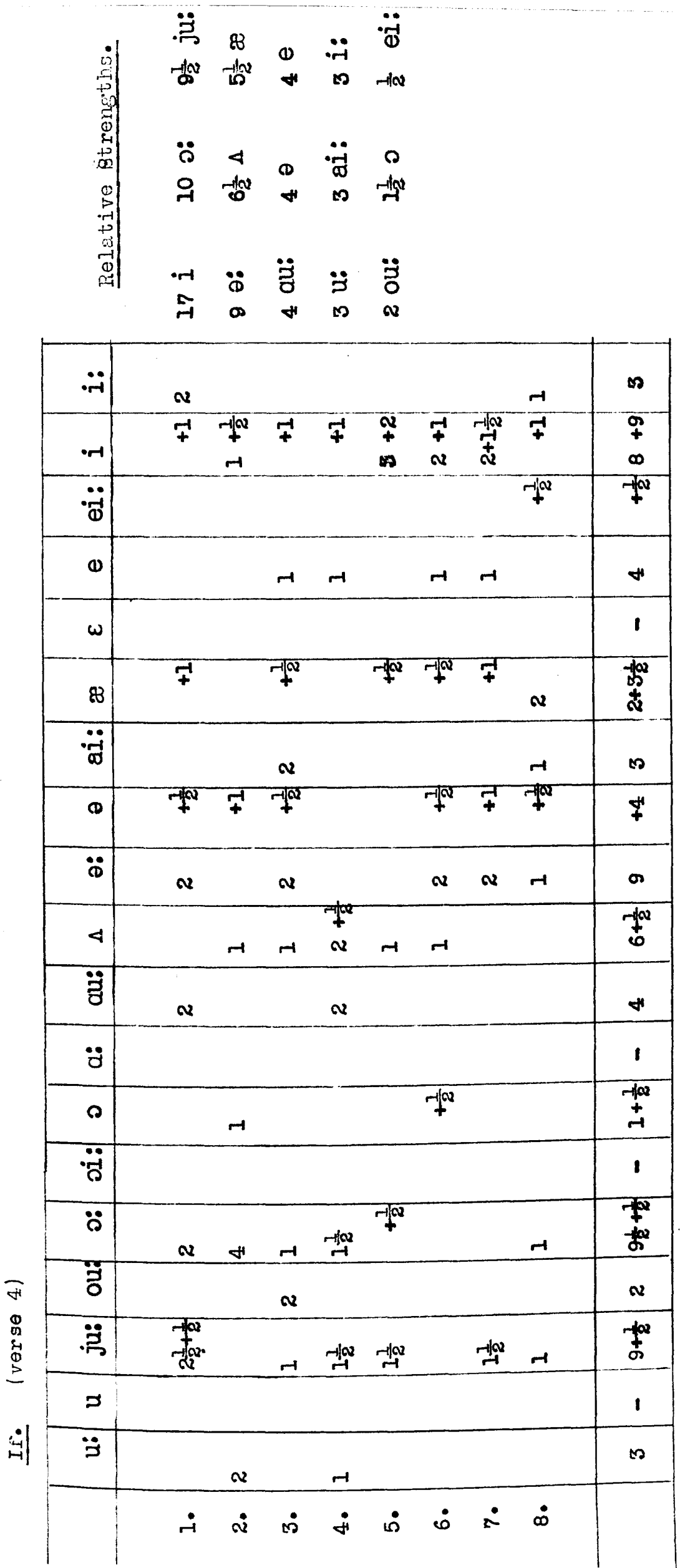


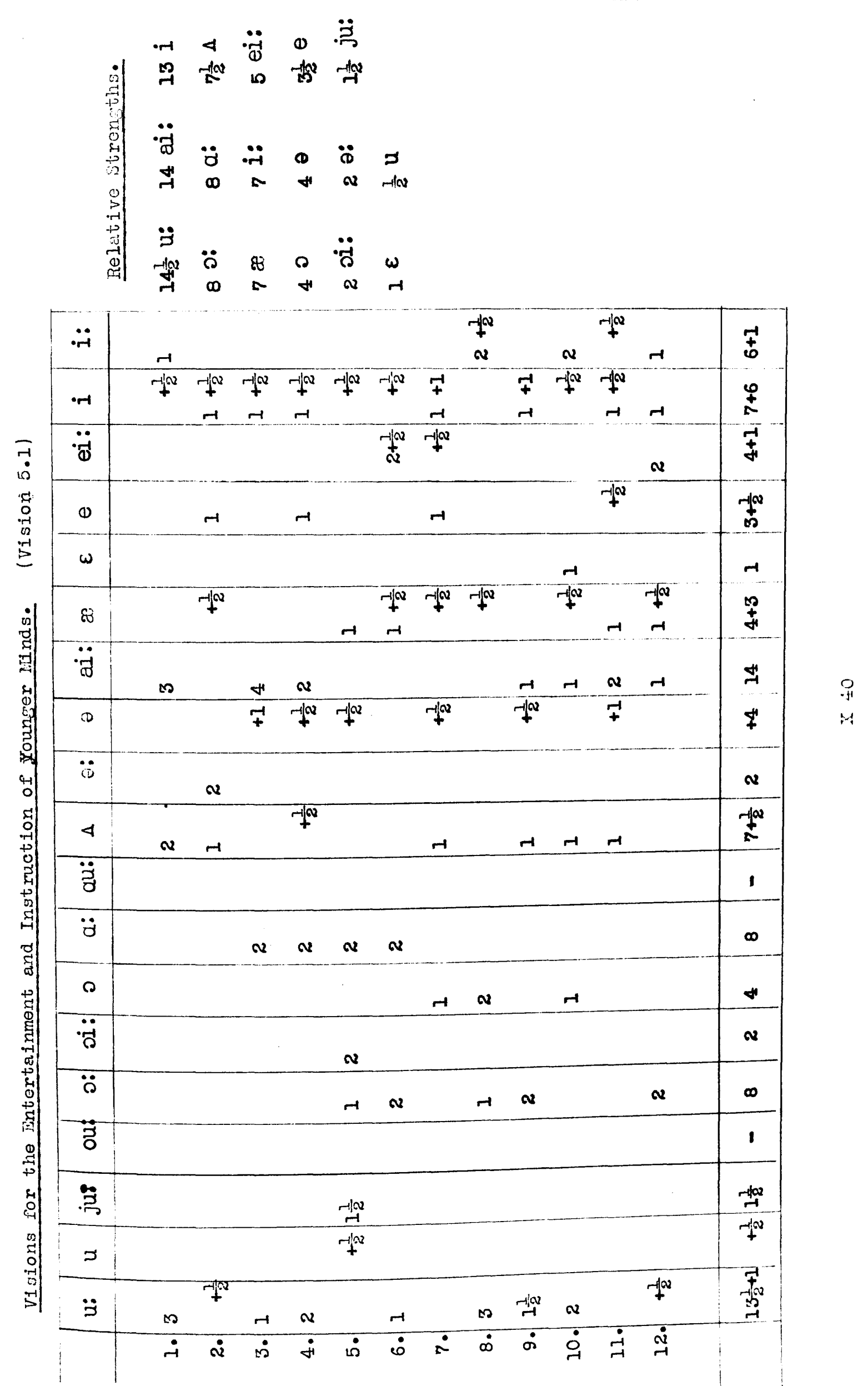




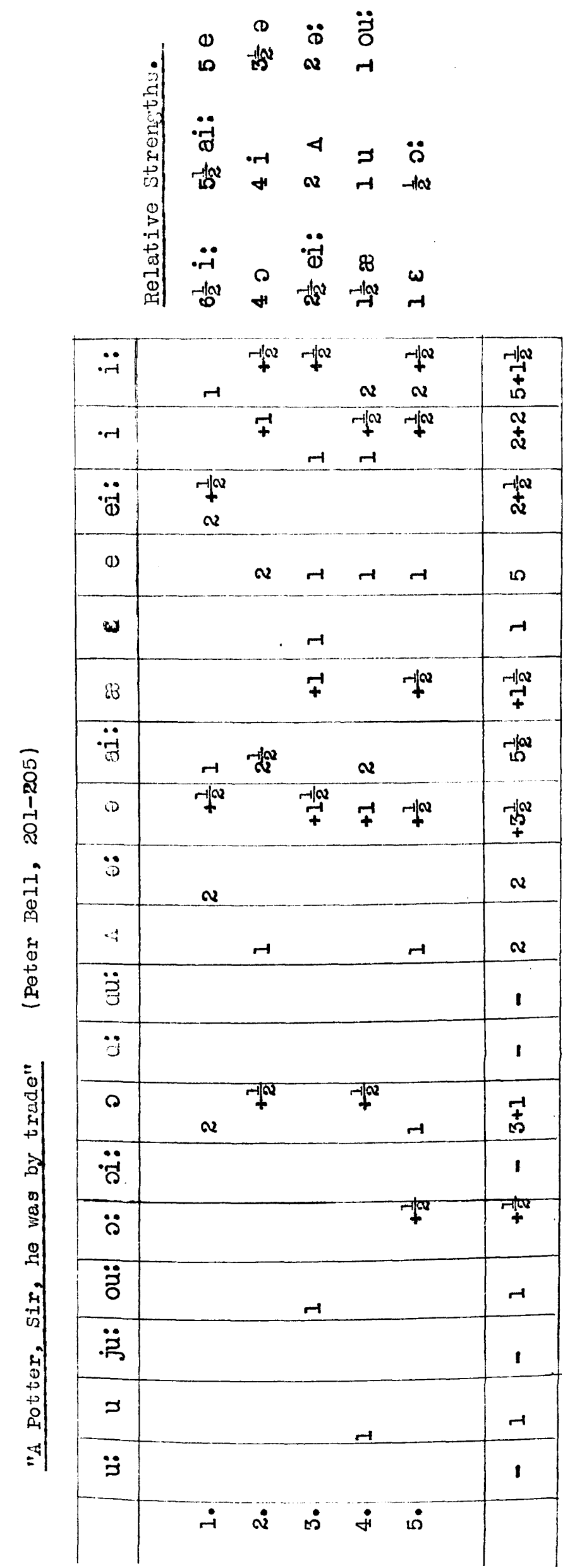



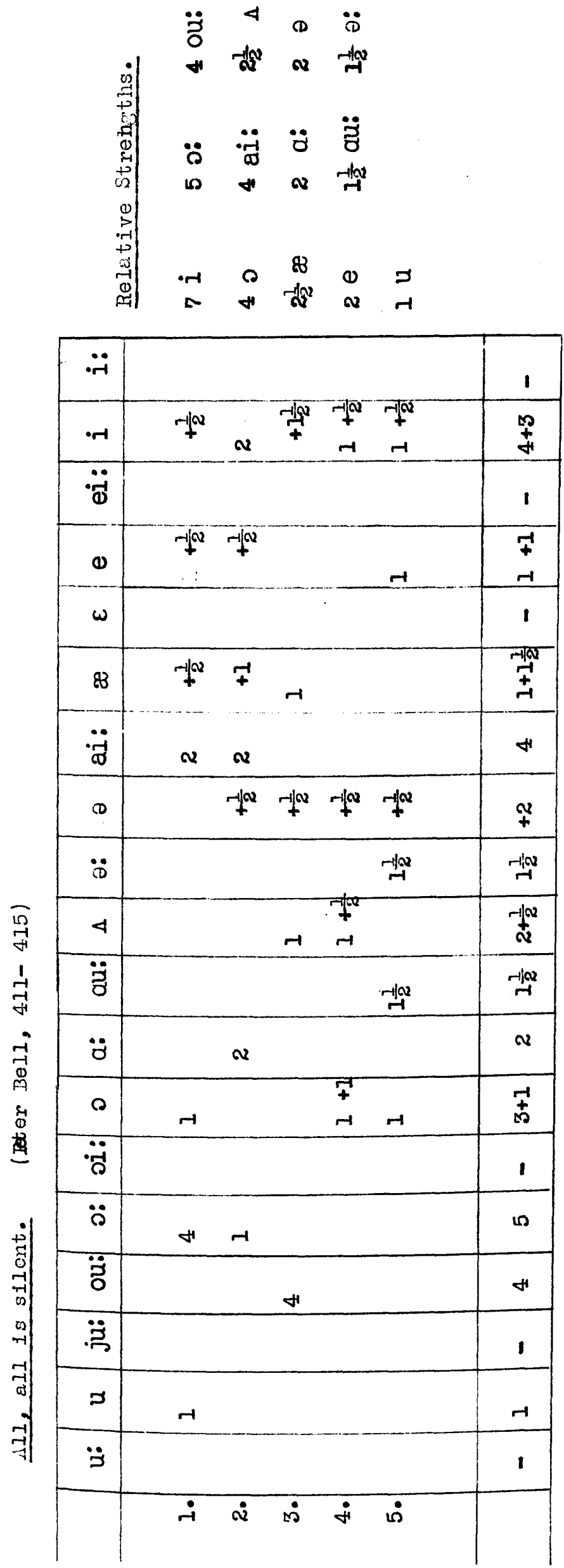


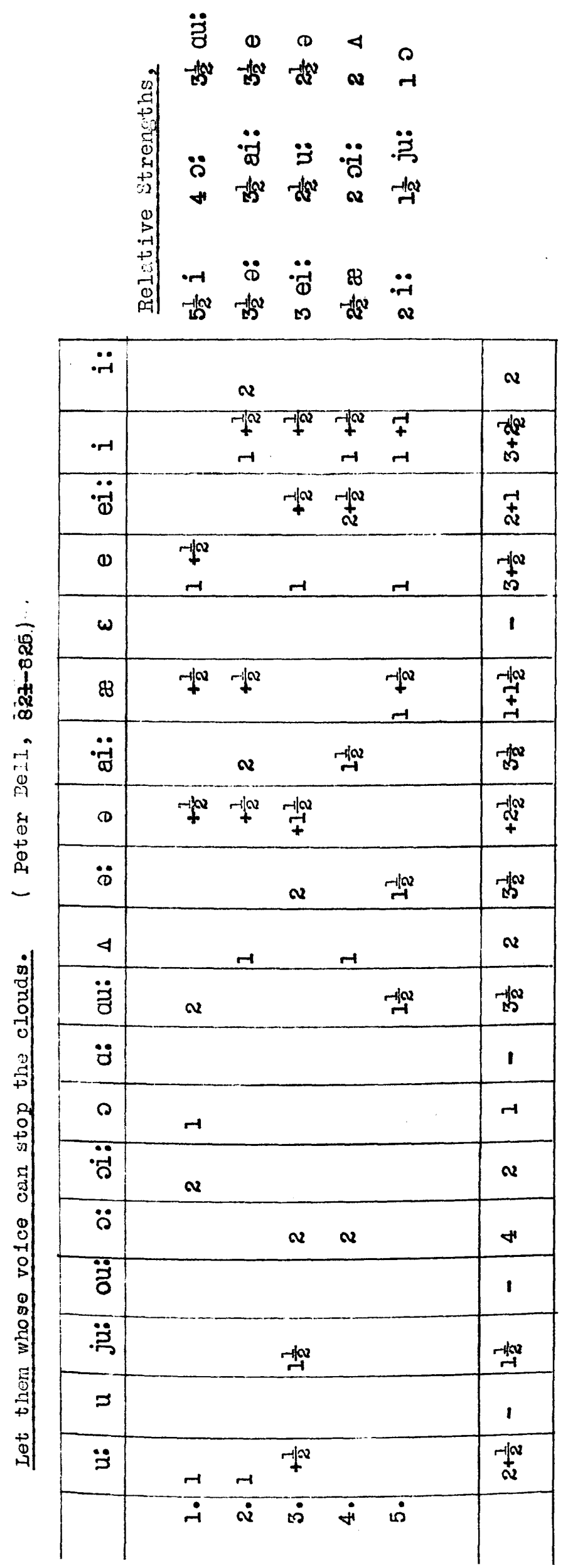




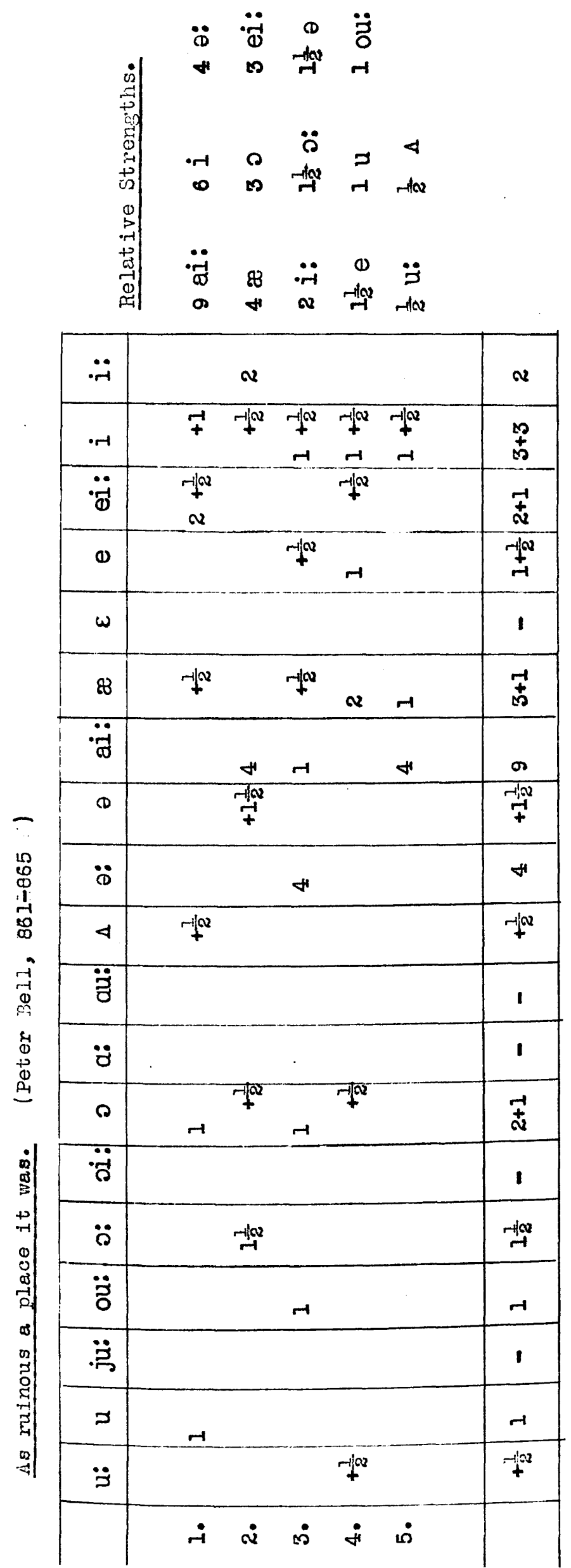




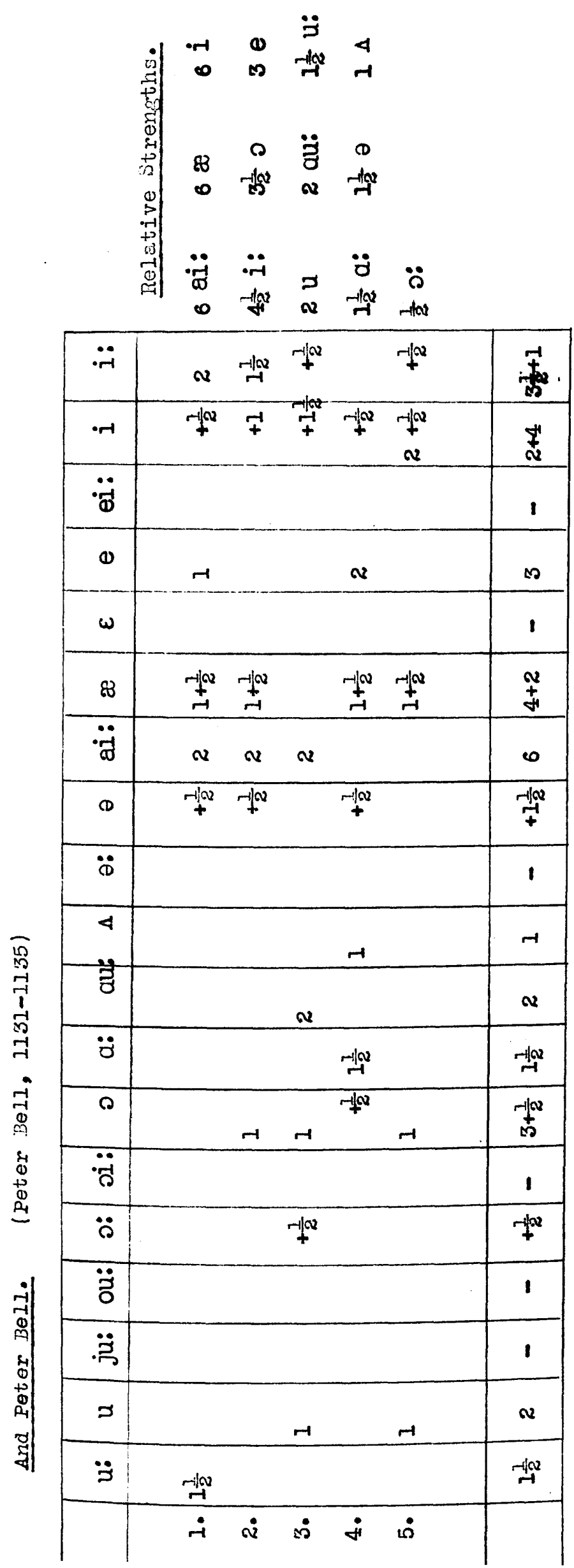




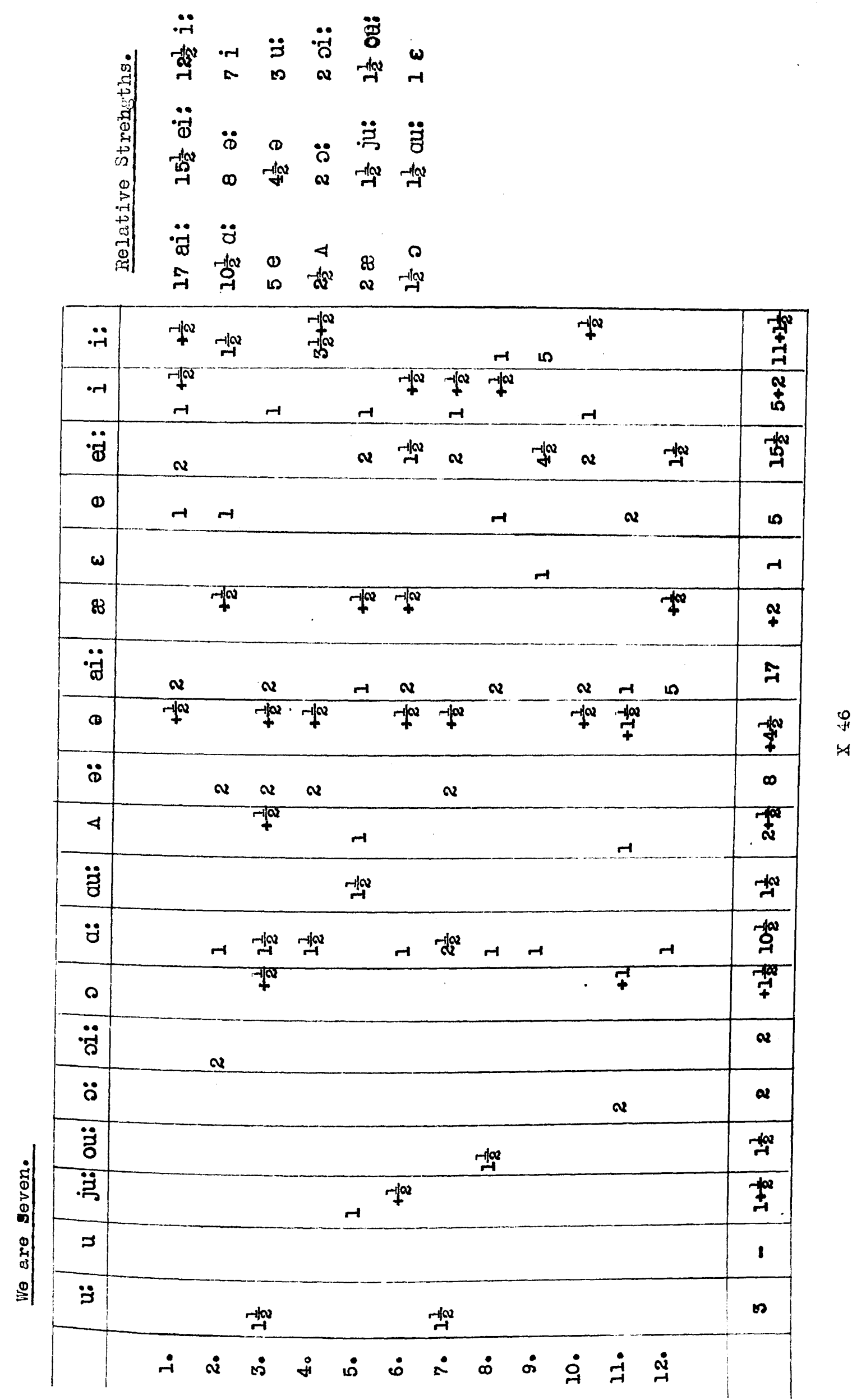




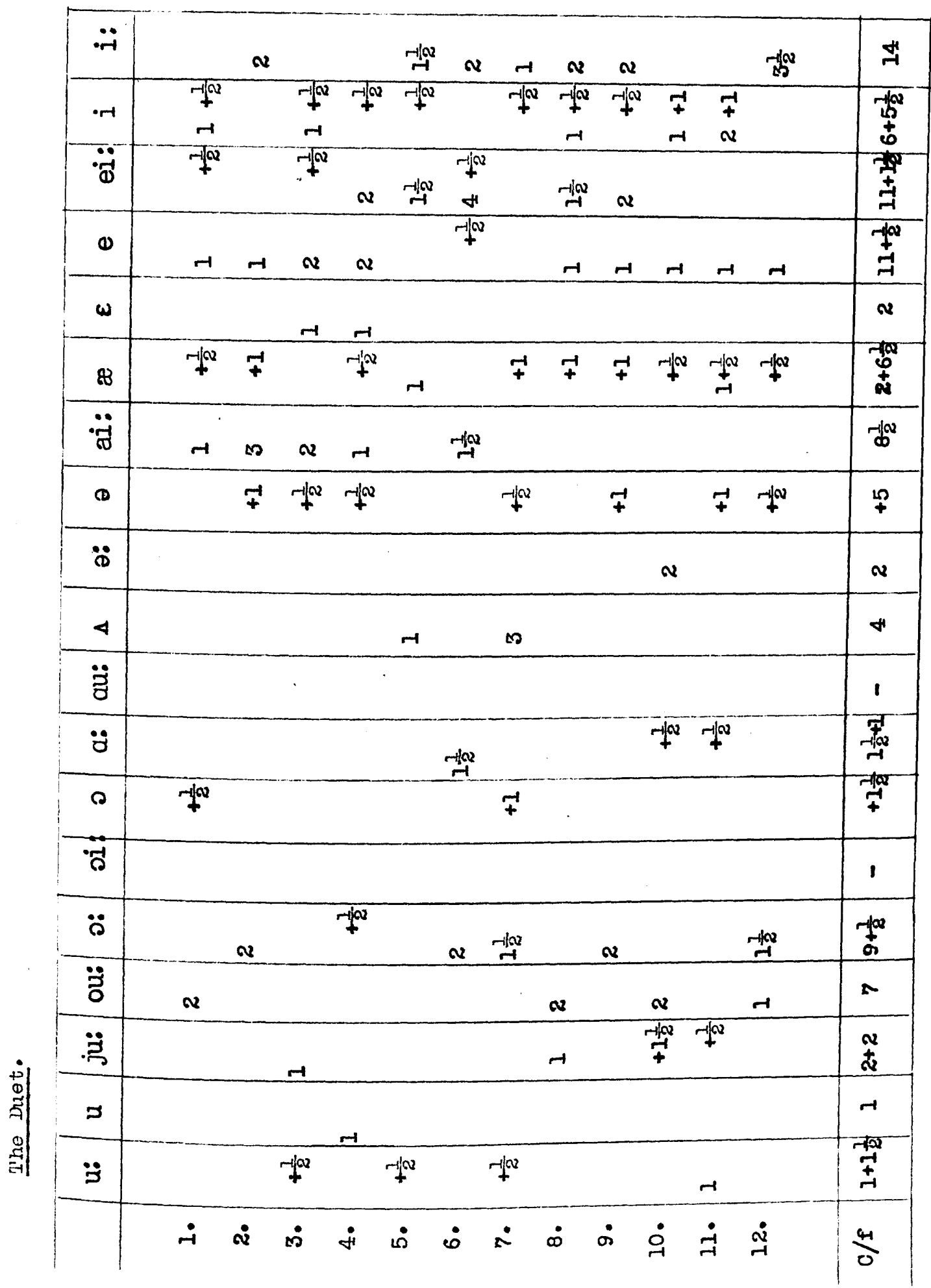




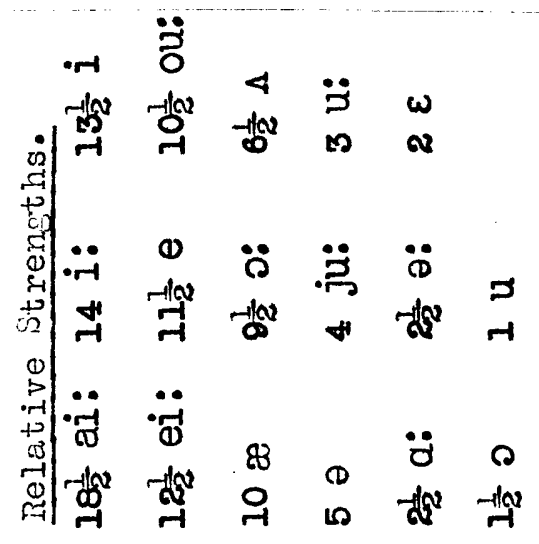

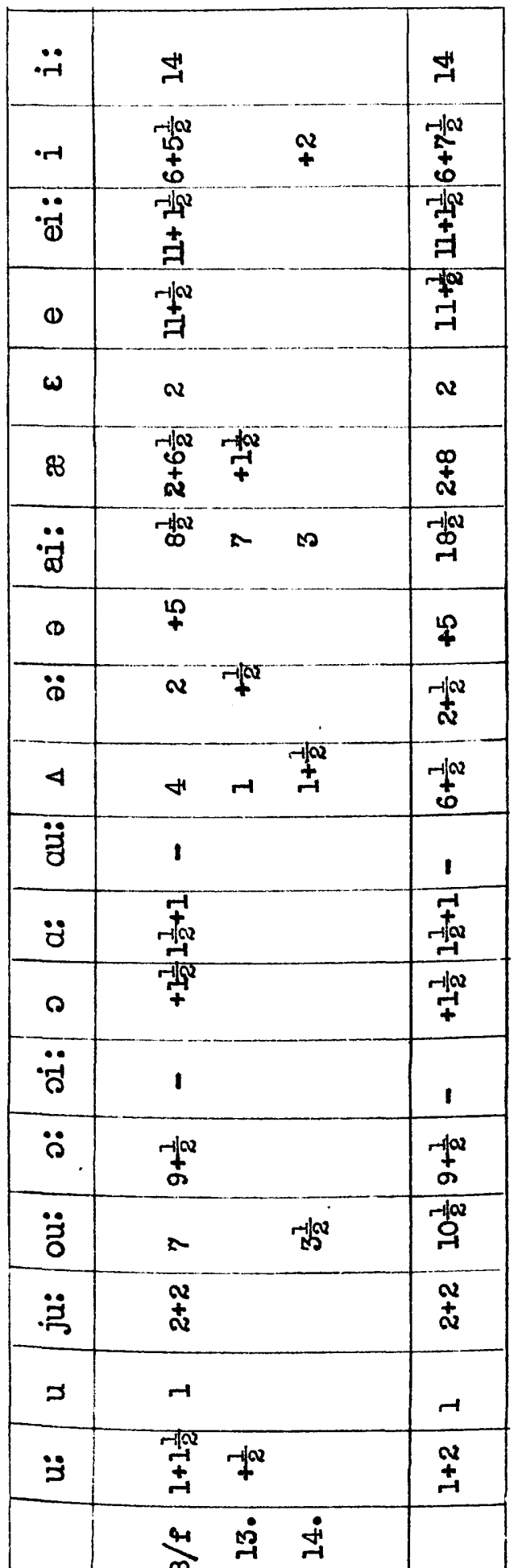




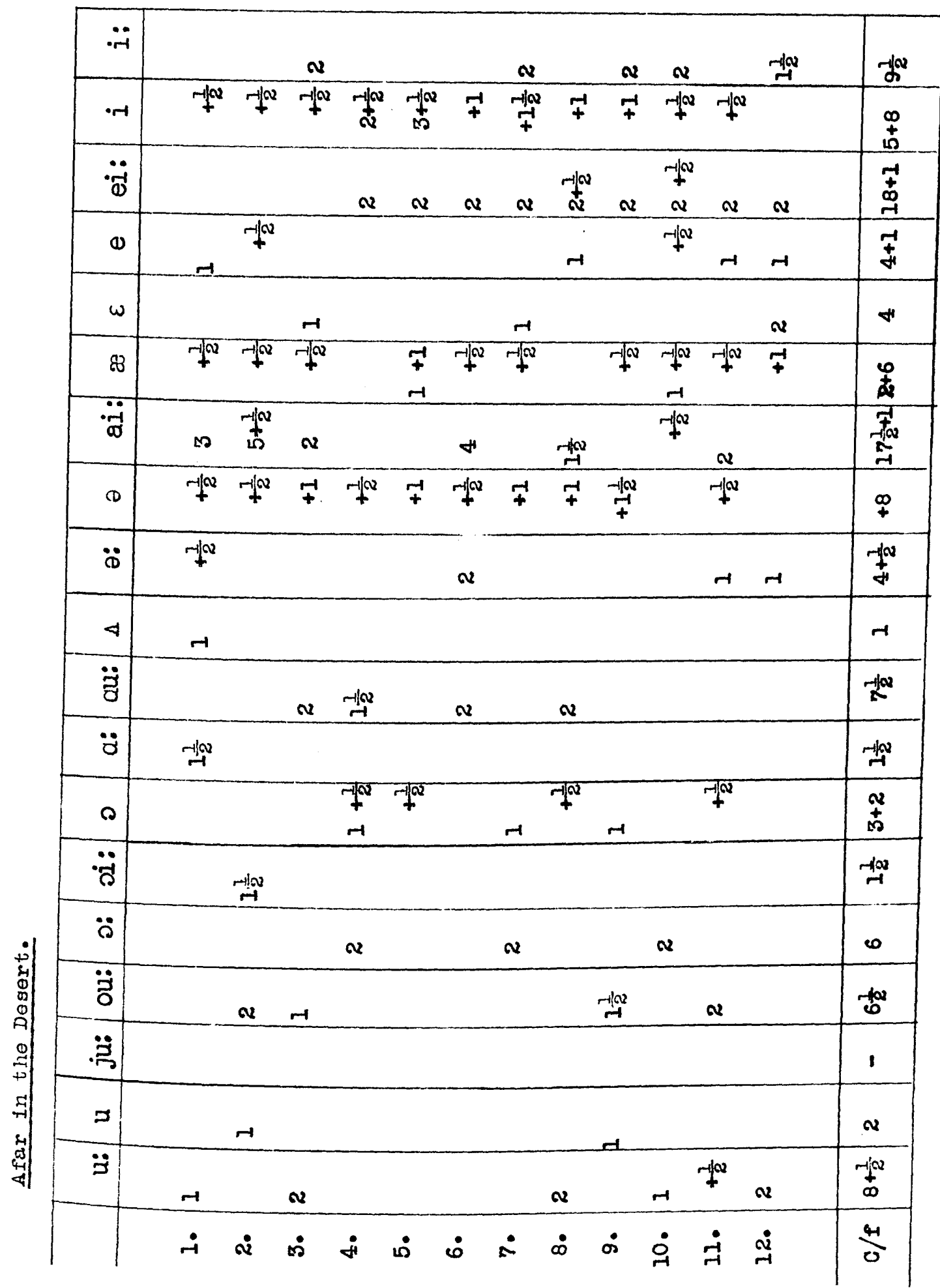




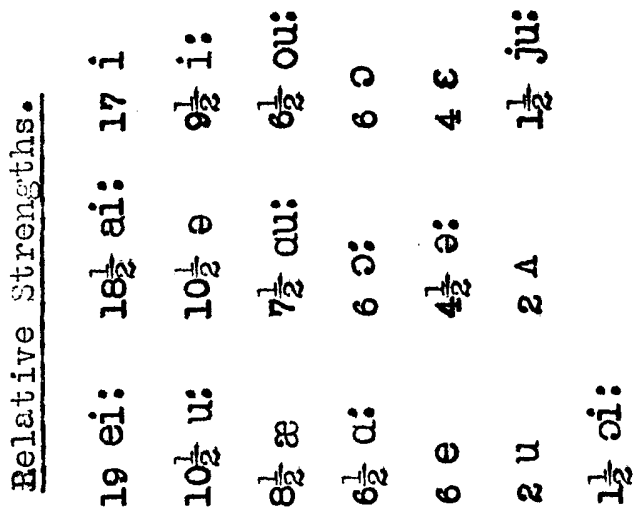

\begin{tabular}{|c|c|c|c|}
\hline$\ddot{\ddot{r}}$ & Hon & & नुळ \\
\hline$\cdot r$ & $\begin{array}{l}\infty \\
\stackrel{+}{+} \\
\stackrel{5}{n}\end{array}$ & $\underset{+}{+}+$ & $\begin{array}{l}0 \\
+ \\
\pm\end{array}$ \\
\hline$\ddot{\ddot{0}}$ & $\begin{array}{c}-1 \\
+9\end{array}$ & & $\begin{array}{c}-1 \\
+ \\
+ \\
-1\end{array}$ \\
\hline () & $\stackrel{+}{+}$ & $H$ & t5 \\
\hline$\omega$ & 4 & & 4 \\
\hline 8 & $\stackrel{0}{+}$ & $-1 / N$ & $\begin{array}{c}-1 / 20 \\
0 \\
\vdots \\
\vdots\end{array}$ \\
\hline$\ddot{\alpha}$ & $\begin{array}{c}7 \\
+\frac{7}{7-1} \\
-1\end{array}$ & & $\underset{2}{\sqrt[7]{-1}}$ \\
\hline$\infty$ & & $\stackrel{-1 N}{+}+$ & $\underset{+}{-102}$ \\
\hline$\ddot{8}$ & $\underset{f}{+\infty}$ & & $\underset{+\infty}{+\infty}$ \\
\hline 4 & -1 & -1 & $v$ \\
\hline$\ddot{z}$ & $-H^{-1} a x$ & & -100 \\
\hline$\ddot{z}$ & $\stackrel{-1 w}{n}$ & $H \quad H$ & en \\
\hline$\curvearrowright$ & 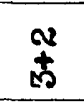 & $7+f^{\infty}$ & $\begin{array}{c}m \\
+ \\
m\end{array}$ \\
\hline$\ddot{\ddot{\theta}}$ & $\stackrel{-1102}{-1}$ & & $\stackrel{-1 \mid \alpha}{-1}$ \\
\hline$\ddot{\circ}$ & $\infty$ & & $\omega$ \\
\hline$\ddot{\vec{z}}$ & -40 & $\because$ & -100 \\
\hline$\ddot{~} \ddot{3}$ & & $\sigma^{2}$ & - \\
\hline 5 & 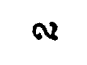 & & $v$ \\
\hline$\ddot{g}$ & rig & $\mathbf{v}$ & 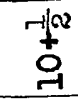 \\
\hline & $\stackrel{4}{M}^{4}$ & $\stackrel{r}{\rightarrow} \stackrel{\dot{H}}{-1}$ & \\
\hline
\end{tabular}




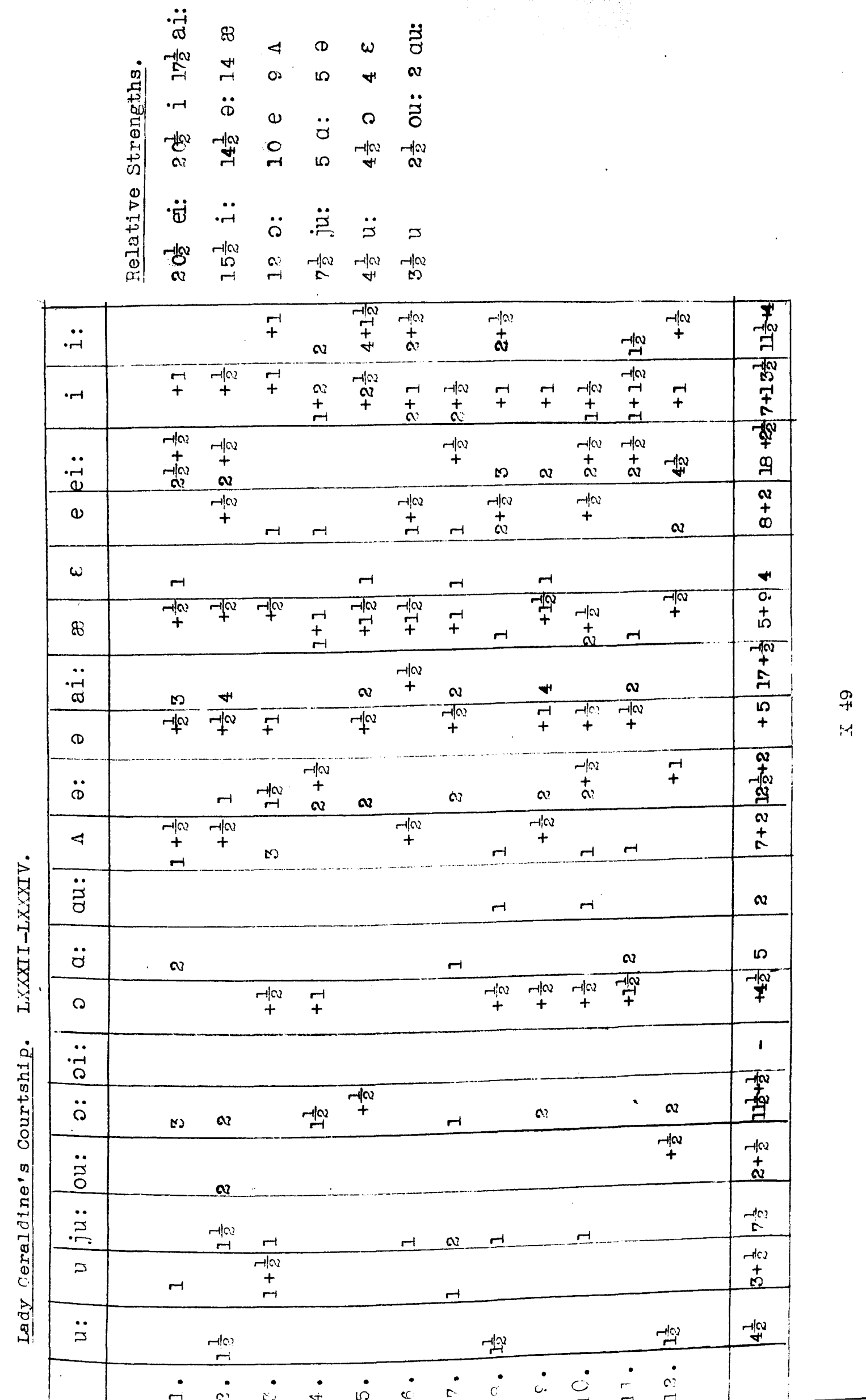




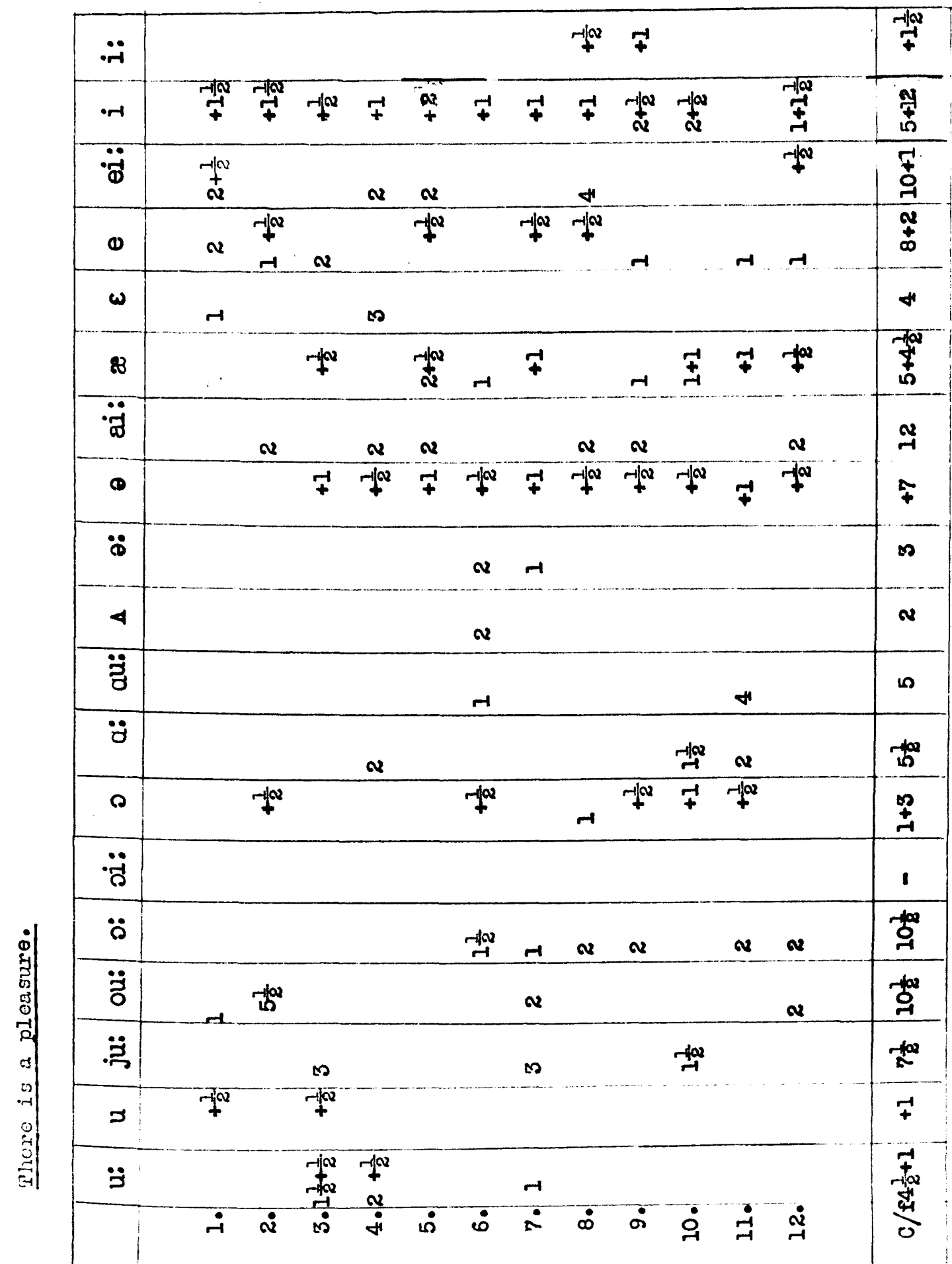




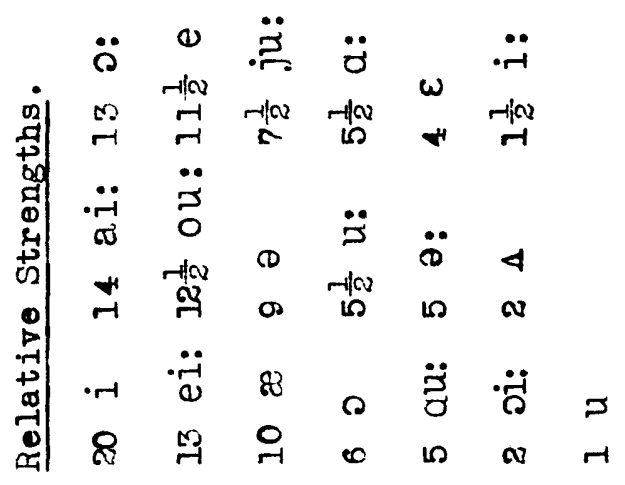

\begin{tabular}{|c|c|c|c|c|}
\hline$\ddot{-r}$ & $\underset{+}{\stackrel{r a w}{+}}$ & & & $\begin{array}{l}F \mid w \\
F\end{array}$ \\
\hline$\cdot r-1$ & \begin{tabular}{l}
\multirow{2}{N}{} \\
+ \\
+ \\
0
\end{tabular} & $\begin{array}{l}-1 \\
+\end{array}$ & $\begin{array}{r}+ \\
+ \\
+\end{array}$ & $\begin{array}{l}H \\
+ \\
0\end{array}$ \\
\hline$\ddot{\ddot{d}}$ & f & & $N$ & 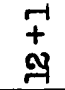 \\
\hline 0 & $\begin{array}{l}\sim \\
+ \\
\infty\end{array}$ & $\begin{array}{c}-1 \omega \\
\pm \\
+\end{array}$ & & $\begin{array}{l}\text { rd } \\
+ \\
+\end{array}$ \\
\hline $\boldsymbol{\omega}$ & + & & & + \\
\hline 8 & $\begin{array}{l}\text { ना/9 } \\
\text { 南 }\end{array}$ & $\begin{array}{c}-100 \\
+\end{array}$ & & $\begin{array}{l}10 \\
+ \\
10\end{array}$ \\
\hline$\ddot{\ddot{d}}$ & $\stackrel{a}{a}$ & v & & $\vec{H}$ \\
\hline$\infty$ & $\hat{+}$ & + & $\stackrel{-1}{+}$ & $\begin{array}{l}\infty \\
+\end{array}$ \\
\hline$\ddot{D}$ & $D$ & $\omega$ & & 10 \\
\hline 4 & 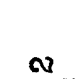 & & & $\mathbf{v}$ \\
\hline$\ddot{\vec{J}}$ & תו & & & 10 \\
\hline$\ddot{\sigma}$ & 㻤 & & & $-1 ; s^{\prime \prime}$ \\
\hline$\curvearrowright$ & $\begin{array}{l}m \\
+\end{array}$ & & $\boldsymbol{N}$ & $\begin{array}{l}m \\
+ \\
m\end{array}$ \\
\hline$\ddot{\leftrightarrow}$ & 1 & & $\boldsymbol{v}$ & $\omega$ \\
\hline$\ddot{\rho}$ & 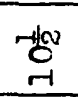 & & $\begin{array}{l}\text { Fan } \\
+ \\
a \\
a\end{array}$ & 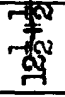 \\
\hline$\ddot{\Xi}$ & $\underset{-1}{+6}$ & $\infty$ & & 抵 \\
\hline$\underset{.}{\ddot{3}}$ & 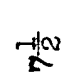 & & & 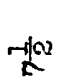 \\
\hline 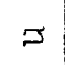 & + & & & + \\
\hline$\ddot{g}$ & $\begin{array}{c}\vec{H} \\
+ \\
+\end{array}$ & & & $\overrightarrow{+}$ \\
\hline & & $\therefore$ & $\dot{\vec{r}}$ & \\
\hline
\end{tabular}




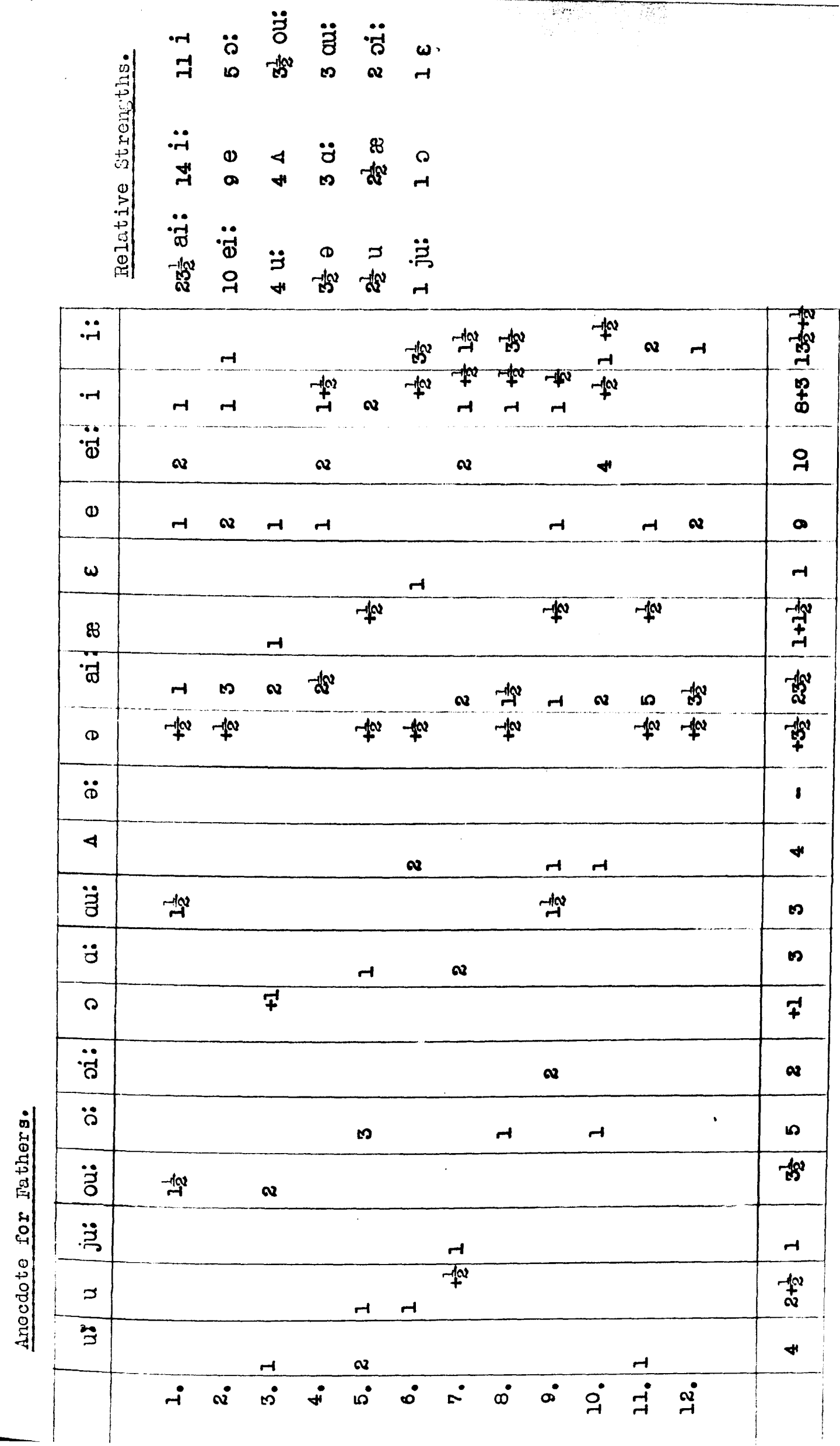




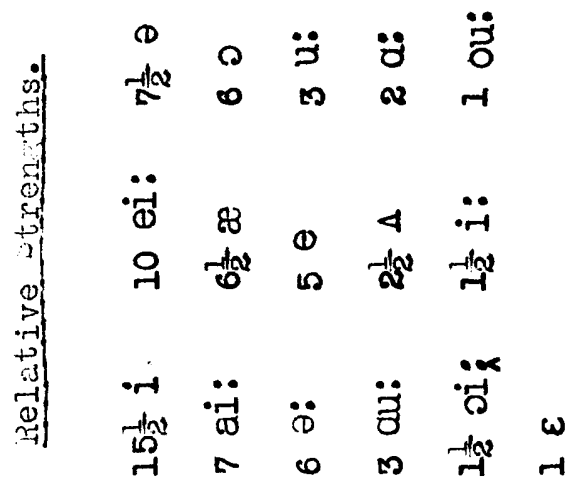

\begin{tabular}{|c|c|c|c|c|c|c|c|c|c|}
\hline$\ddot{-r}$ & & $\stackrel{-1 / N}{N}$ & & & & & & & $\boldsymbol{H}_{-N}^{-N}$ \\
\hline$\cdot r$ & 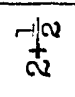 & $\underset{-1}{-110}$ & 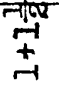 & $\underset{+}{+}$ & $\underset{r-1}{+\infty}$ & + & $\begin{array}{l}N \\
+ \\
+\end{array}$ & $\begin{array}{l}\text { नाब } \\
+\end{array}$ & 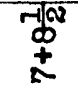 \\
\hline$\ddot{\ddot{d}}$ & & $v$ & 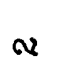 & $\boldsymbol{v}$ & $v$ & & & $v$ & 우 \\
\hline $\boldsymbol{\omega}$ & & & & & & 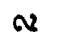 & -1 & $\boldsymbol{N}$ & L \\
\hline$\omega$ & & & & & & $r$ & & & $r$ \\
\hline 88 & $r+\infty$ & $-1 \omega$ & & $r$ & $-1 \infty$ & $\underset{-1}{-1 \omega}$ & & $\underset{-1}{-\infty \omega}$ & $\begin{array}{l}3 \\
4\end{array}$ \\
\hline$\ddot{\ddot{\theta}}$ & Q & $v$ & & $v$ & -1 & & & & $\Omega$ \\
\hline (D) & $-1 f^{\alpha}$ & $-1 \alpha^{\alpha}$ & 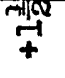 & $\underset{+}{+}$ & $\underset{+}{-1}$ & $-1 x^{2}$ & $\begin{array}{l}\text { नात्w } \\
+\end{array}$ & $+f^{\alpha}$ & नाब \\
\hline$\ddot{\infty}$ & & & Q & & & $\boldsymbol{v}$ & & $\mathbf{v}$ & $\omega$ \\
\hline 4 & +10 & $r-1$ & & & 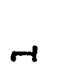 & & & & ${ }^{-j a}$ \\
\hline$\ddot{z}$ & $n$ & & & & & & $N$ & & $m$ \\
\hline$\ddot{d}$ & $\checkmark$ & & & & & & & & $\boldsymbol{v}$ \\
\hline$\beta$ & 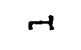 & $r$ & - & -1 & $r$ & -1 & & & 0 \\
\hline$\ddot{\circ}$ & & $\overbrace{-1 / 2}^{-1}$ & & & & & & & $-\|_{-1}$ \\
\hline$\ddot{\beta}$ & & & & & & & & & 1 \\
\hline$\ddot{z}$ & & & & & -1 & & & & 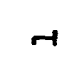 \\
\hline 芦 & & & & & & & & & 1 \\
\hline$s$ & & & & & & & & & 1 \\
\hline$\ddot{\jmath}$ & & & $\sim$ & & $H$ & & & & $\infty$ \\
\hline & $\dot{-}$ & $\dot{\alpha}$ & $\dot{n}$ & $\dot{+}$ & $\dot{\omega}$ & $\dot{\omega}$ & $\dot{2}$ & $\dot{\infty}$ & \\
\hline
\end{tabular}




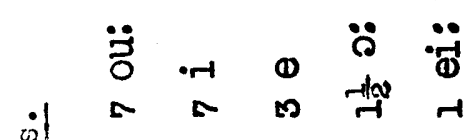

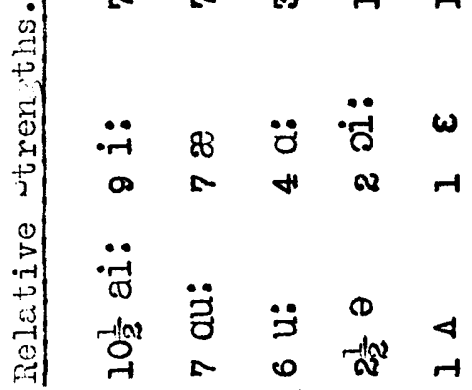

\begin{tabular}{|c|c|c|c|c|c|c|}
\hline$\ddot{\ddot{H}}$ & $\stackrel{-1 / \infty}{\stackrel{N}{N}}$ & 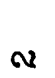 & & $v$ & 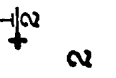 & $\overrightarrow{+}$ \\
\hline$\cdot r$ & $r$ & $-1+\infty$ & 然 & -10 & $\underset{-1}{+} x^{2}$ & $\underset{\infty}{+}$ \\
\hline$\ddot{\ddot{d}}$ & & & & & $-1 \omega r$ & $\mp$ \\
\hline $\boldsymbol{\theta}$ & & $r$ & & & $t_{-1}^{\infty}$ & 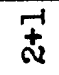 \\
\hline$\omega$ & & & & & $\rightarrow$ & -1 \\
\hline 88 & $\stackrel{-102}{+\infty}$ & -10 & $\boldsymbol{N}$ & & $r^{-1 \alpha}$ & $\stackrel{\infty}{+}$ \\
\hline$\ddot{0}$ & 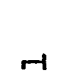 & & $\checkmark$ & $\boldsymbol{v}$ & dos $\sim$ & - \\
\hline $\mathbb{P}$ & & 7 & $-1 \omega$ & & 7 & -nd \\
\hline$\ddot{0}$ & & & & & & 1 \\
\hline 4 & & & & & 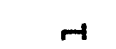 & 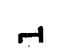 \\
\hline$\ddot{z}$ & $r$ & $v$ & & & $v \sim$ & $\pi$ \\
\hline$\ddot{d}$ & 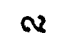 & & $v$ & & & 4 \\
\hline$\curvearrowright$ & & & & & & 1 \\
\hline$\ddot{~} \ddot{~}$ & & v & & & & $\boldsymbol{v}$ \\
\hline$\ddot{8}$ & & & & $\lim _{\rightarrow}^{-\alpha}$ & & 岪 \\
\hline$\ddot{亏}$ & 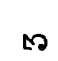 & 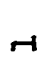 & -1 & & $v$ & 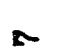 \\
\hline$\ddot{2}$ & & & & & & 1 \\
\hline$x$ & & & & & & 1 \\
\hline$\ddot{3}$ & & $m$ & & 沗 & $7^{2}$ & tr \\
\hline & $\dot{-}$ & $\dot{v}$ & $\dot{\infty}$ & $\dot{4}$ & مَ & \\
\hline
\end{tabular}




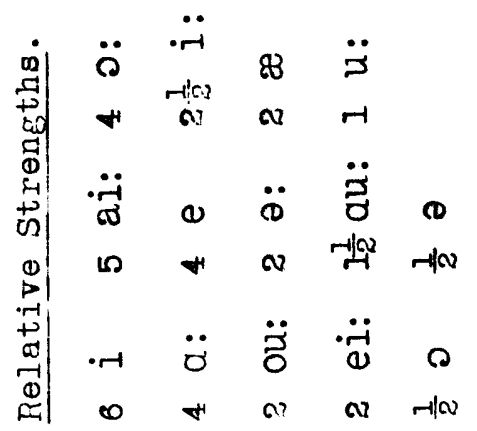

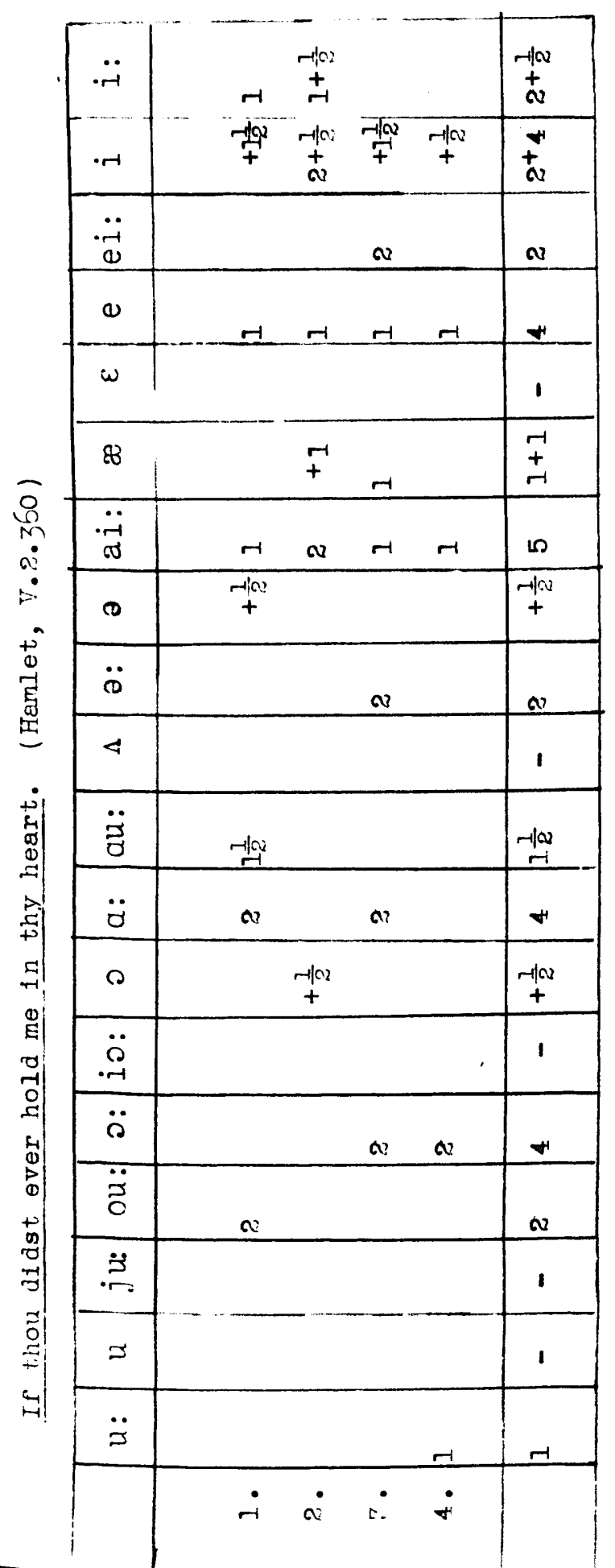




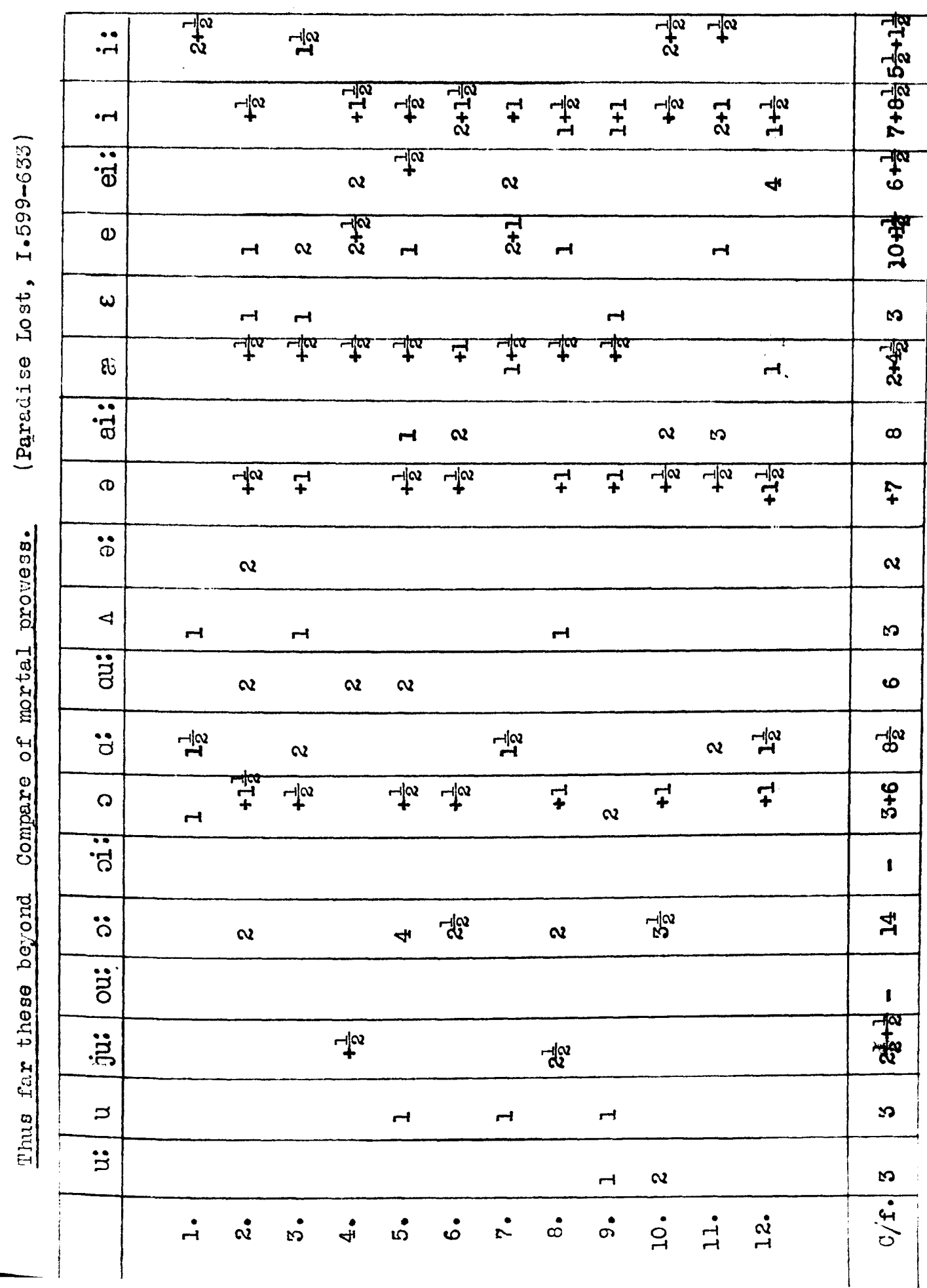




\begin{tabular}{|c|c|c|c|c|c|c|c|c|c|c|c|}
\hline$\ddot{\theta}$ & 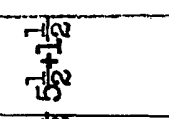 & & $\alpha$ & $\alpha$ & & $-1 / 2$ & $F$ & & -10 & & 霞 \\
\hline$\cdot-1$ & 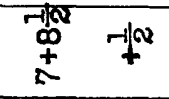 & 7 & -102 & 7 & $\underset{-1}{-t}$ & 7 & & -10 & $\underset{-1}{+\infty}$ & -我 & 裂 \\
\hline$\ddot{\widetilde{\sigma}}$ & $\underset{\infty}{-10}$ & + & & 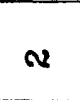 & & $\approx$ & & & & $\alpha$ & ride \\
\hline (1) & 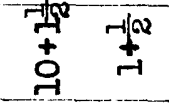 & 7 & -1 & & $-11 \infty$ & -1 & & -1 & $\alpha$ & $\rightarrow$ & 草 \\
\hline$\omega$ & $\infty$ & & 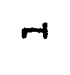 & & & & & & & -1 & ద \\
\hline 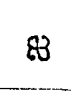 & 誌 & 7 & $F$ & -1 & -102 & 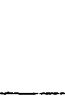 & $\underset{-1}{-1 \infty}$ & & & -1 & 鉴 \\
\hline चै & $\infty$ & & & & $\infty$ & $\alpha$ & $\curvearrowright$ & $\alpha$ & & & $\stackrel{\mathscr{r}}{\sim}$ \\
\hline 0 & $\mp \mp$ & & 7 & $-1 / 2$ & $\sqrt{10 x}$ & 7 & $-1+2$ & $\underset{+}{\sim}$ & -10 & $-1 \infty-1+\infty$ & - \\
\hline$\ddot{0}$ & $\approx$ & & & & & & & & & $\infty$ & + \\
\hline 4 & $\infty$ & $\underset{-1}{4}$ & - & $\underset{\rightarrow-1}{+\infty}$ & -1 & 7 & & & $\alpha$ & & 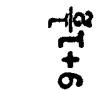 \\
\hline$\ddot{\Xi}$ & 0 & & & $\alpha$ & & & & & & -1 ty & $-1+\infty$ \\
\hline$\ddot{o}$ & 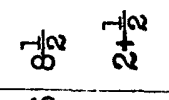 & $\alpha$ & $\alpha$ & & & $\alpha$ & & $\stackrel{-1 \infty}{-1}$ & $r$ & & $\underset{9}{+9}$ \\
\hline 0 & 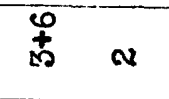 & & 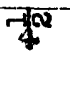 & 7 & $\mp$ & & - & $\underset{-1}{7+n}$ & 7 & -7 & 星 \\
\hline$\ddot{\theta}$ & 1 & & & & & & & & & & 1 \\
\hline$\ddot{o}$ & 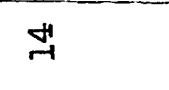 & r|ye & & & $\approx$ & & $\alpha$ & & & 7 & 率 \\
\hline$\ddot{\ddot{z}}$ & 1 An & & & & & & & 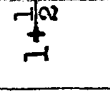 & & & 悸辛 \\
\hline$\ddot{g}$ & 永 & & & & & & & & & & 衰 \\
\hline 3 & $\infty$ & & & & & -1 & & & & & +1 \\
\hline$\ddot{z}$ & $m$ & & & & & & -1 & & & 7 & $\underset{+\infty}{+\infty}$ \\
\hline & $\dot{\leftrightarrow} \dot{M} \dot{g}$ & & & $\dot{\leftrightarrow}$ & $\neg$ & $\stackrel{\infty}{-\infty}$ & $\stackrel{\sigma}{-}$ & $\dot{z}$ & & $\dot{\aleph} \dot{⿱ 亠 ⿰ 冫 欠 ~}$ & $\frac{\dot{q}}{0}$ \\
\hline
\end{tabular}




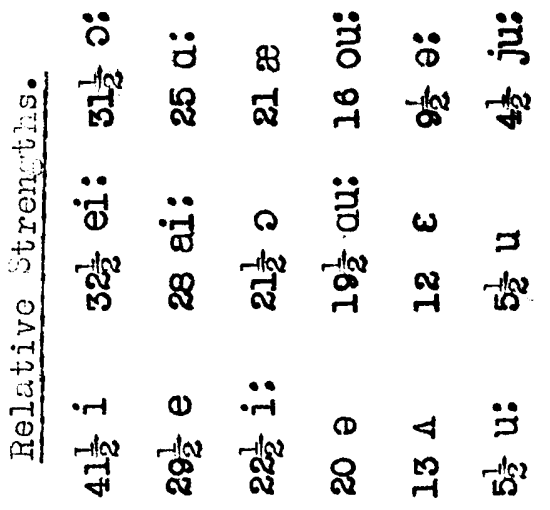

\begin{tabular}{|c|c|c|c|c|c|c|c|c|c|c|c|c|c|c|}
\hline$\ddot{\ddot{r}}$ & - & 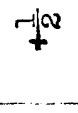 & $7+x$ & & & & $\underset{m}{m}$ & $\underline{v}$ & & & -1 & $\boldsymbol{N}$ & & $\underbrace{5}$ \\
\hline$\cdot r$ & 孛 & & $r$ & $\stackrel{+1}{+}$ & + & $\stackrel{+}{+}$ & 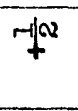 & & $\frac{\pi}{N}$ & $\stackrel{+}{+}$ & $+x$ & -1 & $\stackrel{r+w}{ \pm}$ & $\begin{array}{c}0 \\
+ \\
Q\end{array}$ \\
\hline$\ddot{0}$ & $\begin{array}{c}-1 / \infty \\
\infty \\
-1\end{array}$ & & $M$ & & $v$ & $\alpha$ & & $r$ & & & $v$ & $\boldsymbol{N}$ & 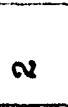 & 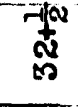 \\
\hline 0 & 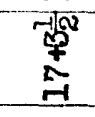 & $v$ & 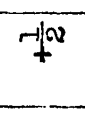 & $\stackrel{r i n}{ \pm}$ & & & & -1 & 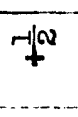 & $\frac{-110}{\mathbf{N}}$ & $-1 n$ & -10 & & ना/ \\
\hline$\omega$ & 10 & & & $r$ & & $\boldsymbol{v}$ & -1 & $N$ & & & & & -1 & $\underset{-1}{\sim}$ \\
\hline is & 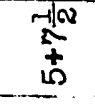 & $\begin{array}{l}F^{\alpha} \\
-1\end{array}$ & & $\pi$ & $-1]^{2}$ & & -1 & 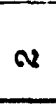 & $-7 x^{\alpha}$ & 7 & 7 & 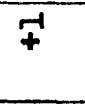 & & 空 \\
\hline$\ddot{\ddot{d}}$ & $\underset{r}{\infty}$ & & & $\boldsymbol{v}$ & $\boldsymbol{v}$ & & & & & & $\boldsymbol{\omega}$ & & $v$ & \& \\
\hline (D) & 留 & $-1 / Q 2$ & & 7 & $7^{\alpha}$ & $-f^{\alpha}$ & 7 & & & 7 & & -10 & $-1 \omega$ & $\stackrel{8}{+}$ \\
\hline$\ddot{D}$ & H & $\mathbf{v}$ & & & & & & & & & & $\overbrace{-1}^{N}$ & $v$ & નू \\
\hline 4 & $\begin{array}{c}\vec{w} \\
\rightarrow \\
+ \\
\sigma\end{array}$ & -1 & & & & & & -1 & & & & $+\infty$ & & $\begin{array}{c}+2 \\
+ \\
-1 \\
-1\end{array}$ \\
\hline 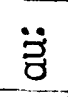 & $-16 x$ & & $\stackrel{r+w}{r}$ & & $\boldsymbol{v}$ & & $\stackrel{-1 \omega}{-1}$ & & $v$ & & & & $\infty$ & $\underset{-\infty}{-\infty}$ \\
\hline$\ddot{z}$ & $\begin{array}{l}7^{2} \\
\stackrel{2}{a} \\
-1\end{array}$ & & & & & & $v$ & & -1a & & & $\boldsymbol{v}$ & & 霖 \\
\hline$\Omega$ & $\begin{array}{l}0 \\
\pm \\
2 \\
\end{array}$ & $\mp$ & & & -1 & $r$ & $7 \sqrt{n}$ & & $\left.f^{\prime}\right)^{2}$ & & $f^{2}$ & & & 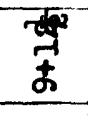 \\
\hline$\ddot{\ddot{B}}$ & 1 & & & & & & & & & & & & & 1 \\
\hline$\ddot{\mathrm{B}}$ & ה & & + & $w$ & $r$ & & & & & $\stackrel{r-1}{-1+\infty}$ & $v$ & $\boldsymbol{v}$ & & F \\
\hline$\ddot{0}$ & 策 & & $\boldsymbol{v}$ & & $\boldsymbol{v}$ & $\infty$ & & & $\boldsymbol{N}$ & & & & $\boldsymbol{\alpha}$ & 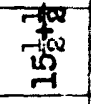 \\
\hline$\ddot{\ddot{n}}$ & नdv & & & & & & & & & $\stackrel{-\| \alpha}{-1}$ & & & & \pm \\
\hline 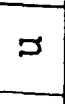 & 4 & & 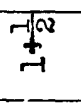 & & & & & & & & & & & $\begin{array}{c}-10 \\
\pm \\
10\end{array}$ \\
\hline$\dddot{\jmath}$ & $\stackrel{+}{+\infty}$ & & & & & & & -1 & & & & & & $\stackrel{-10}{5}$ \\
\hline & $\stackrel{\dot{\varphi}}{m}^{\dot{4}}$ & $\dot{\aleph}$ & $\dot{\mathfrak{R}}$ & $\dot{\$}$ & ڤั่ & 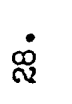 & ঞ্জ & $\dot{\circ}$ & $\dot{B}$ & ல் & $\ddot{~ வ ூ ~}$ & 荡 & $\dot{8}$ & \\
\hline
\end{tabular}




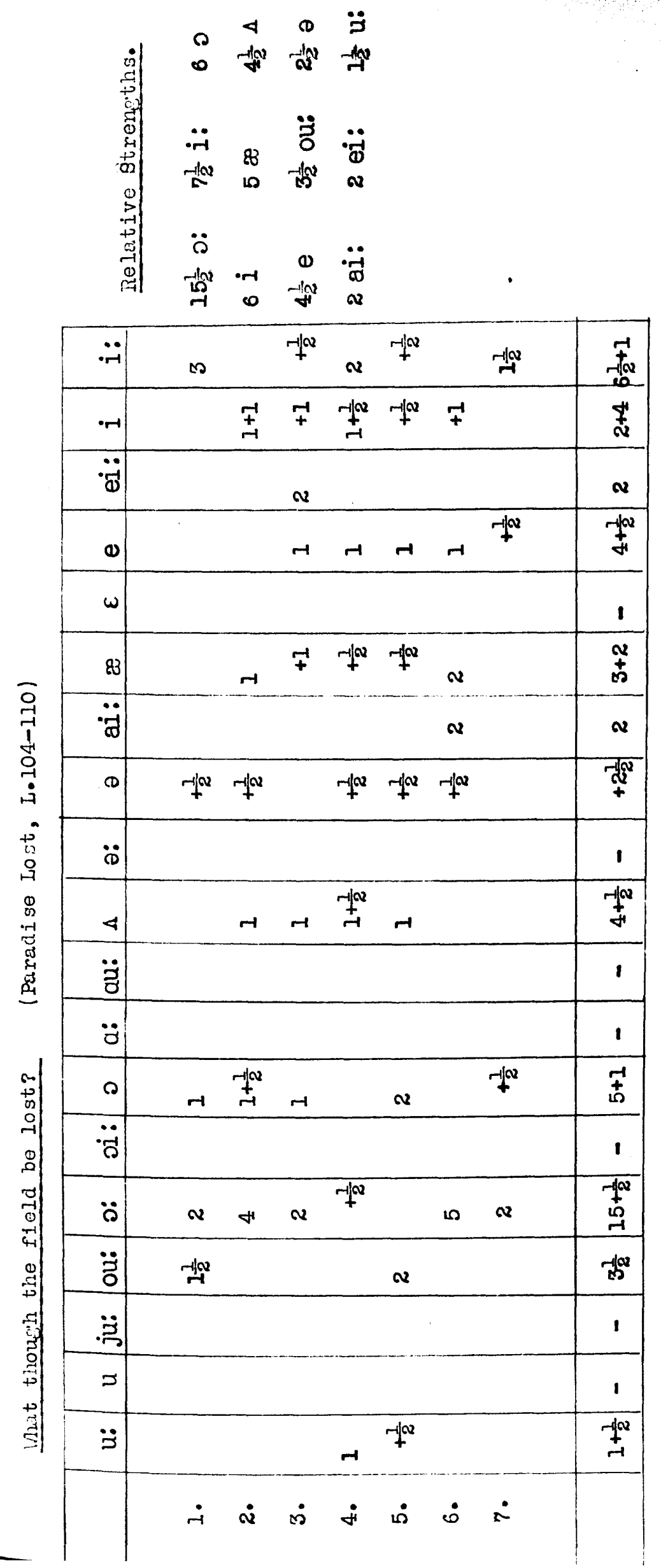




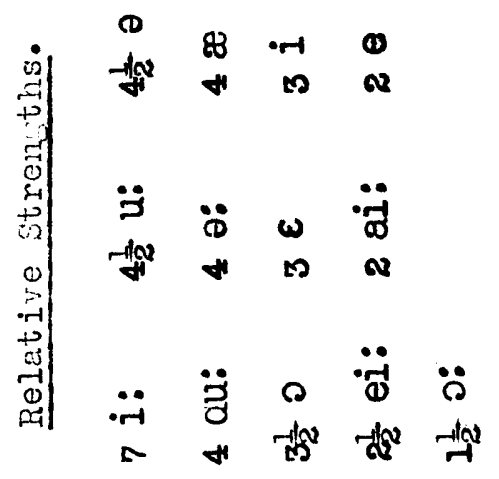

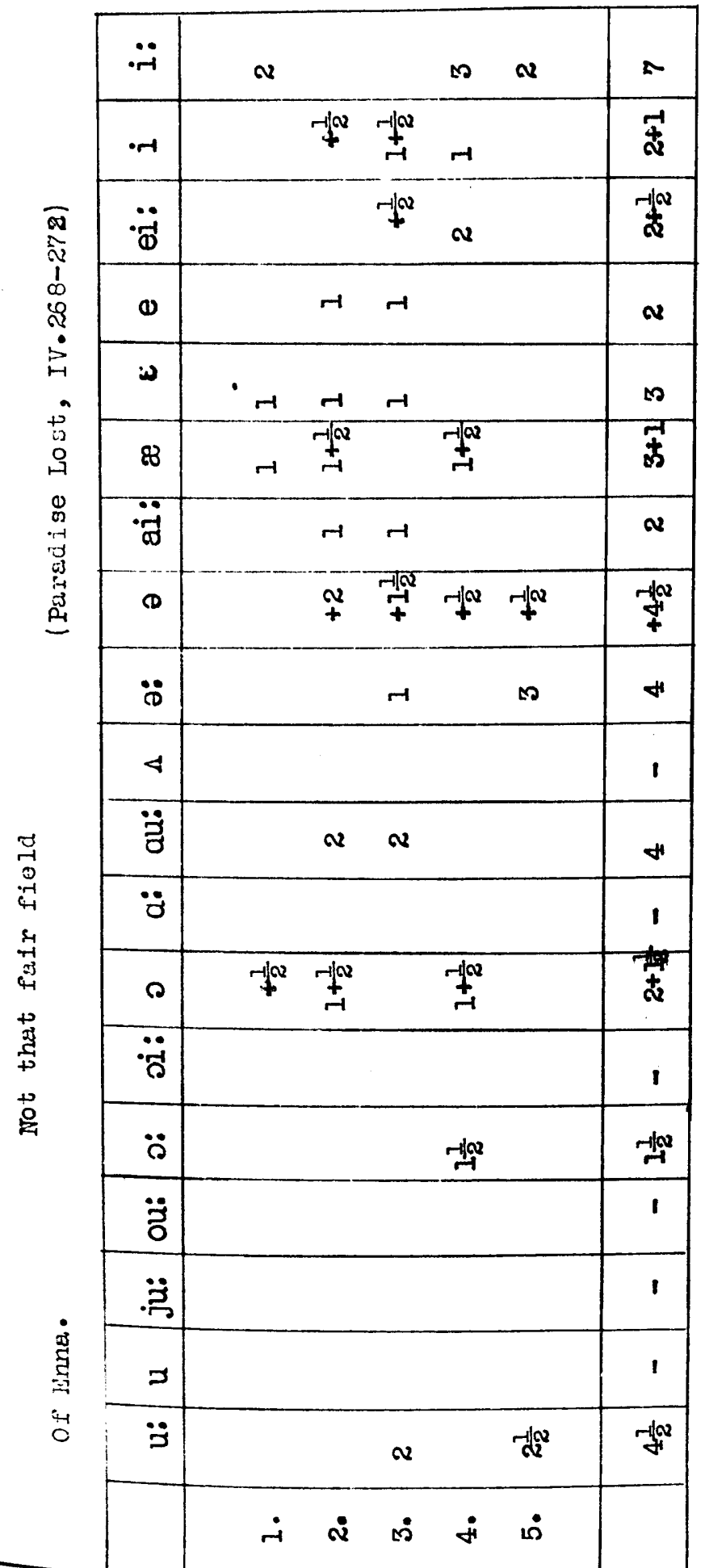




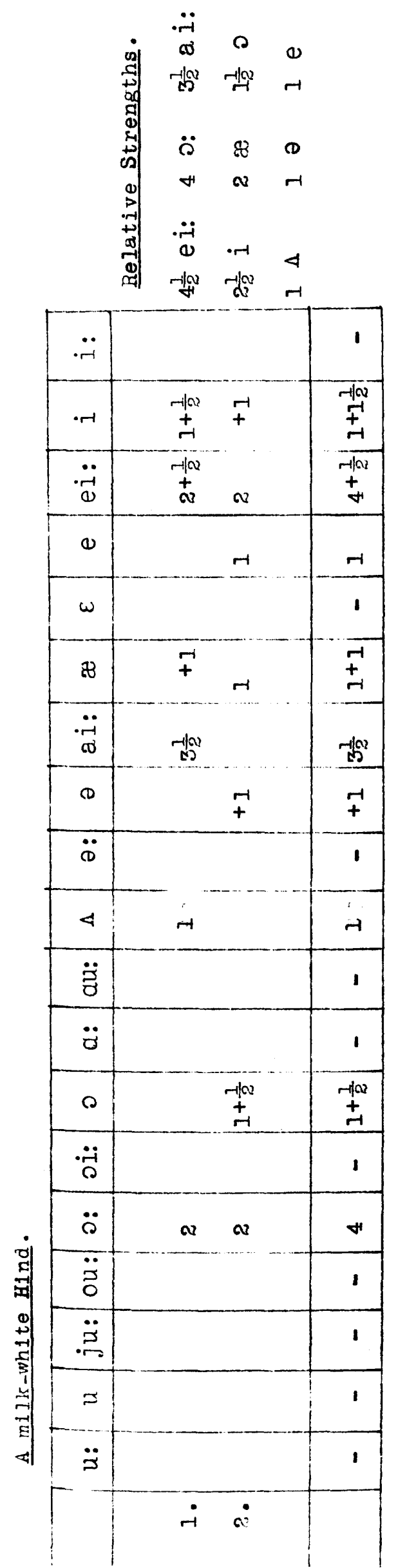




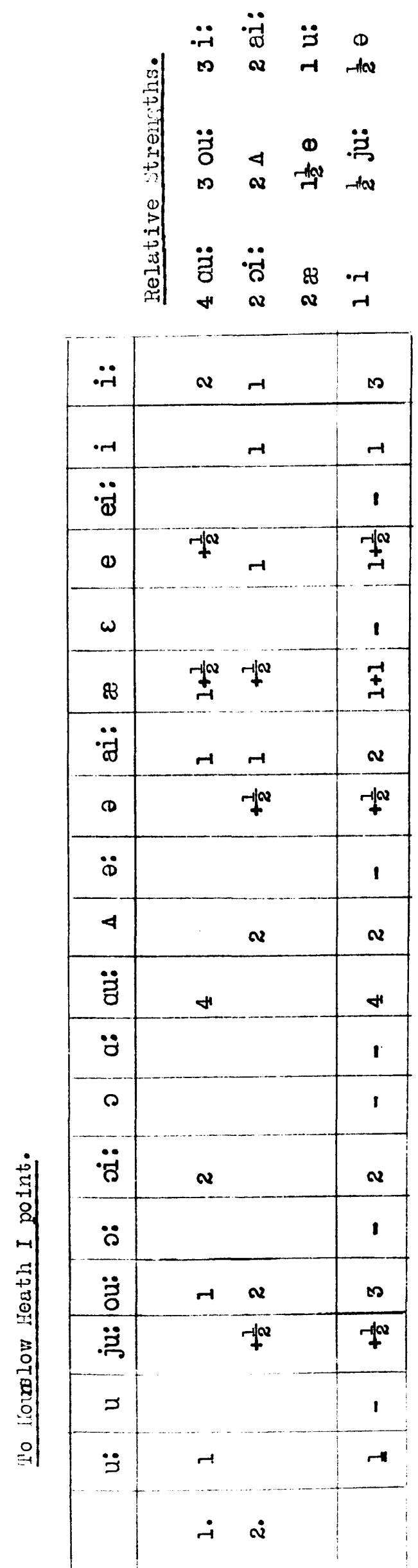




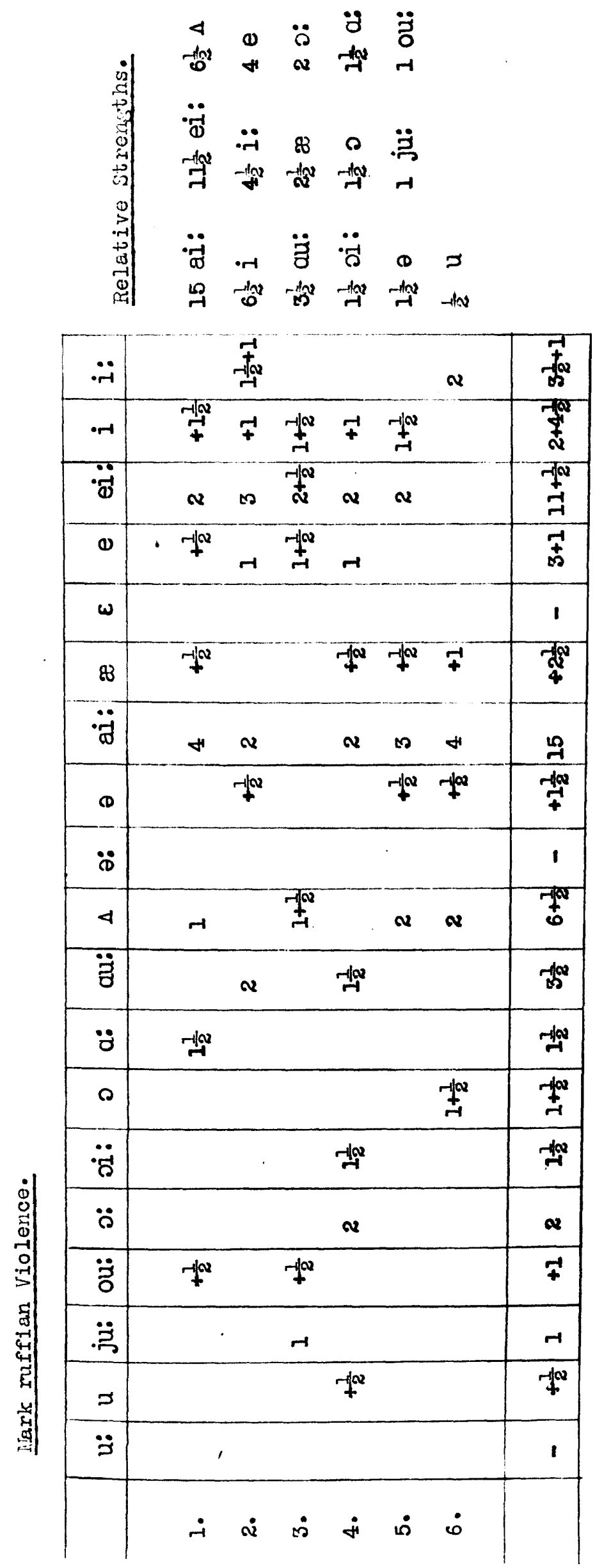



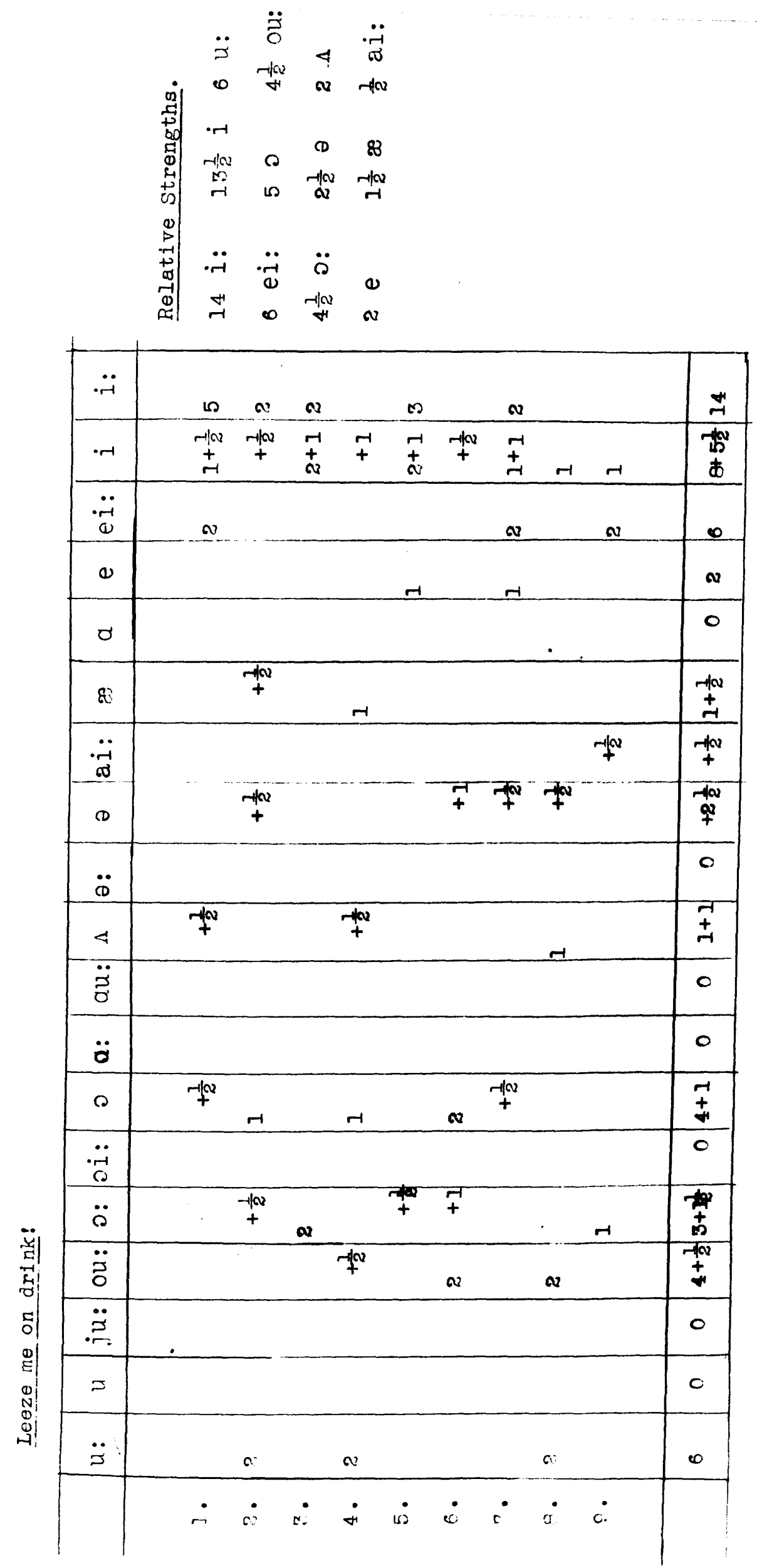


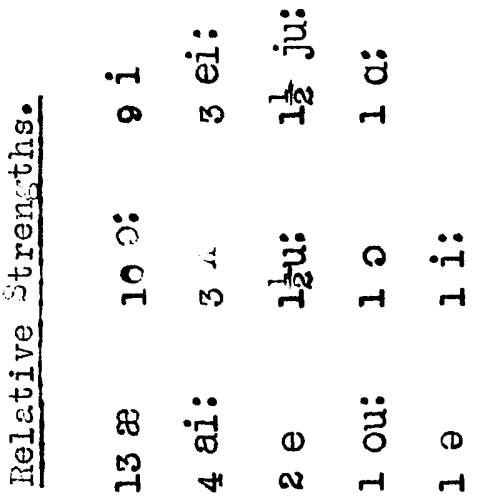

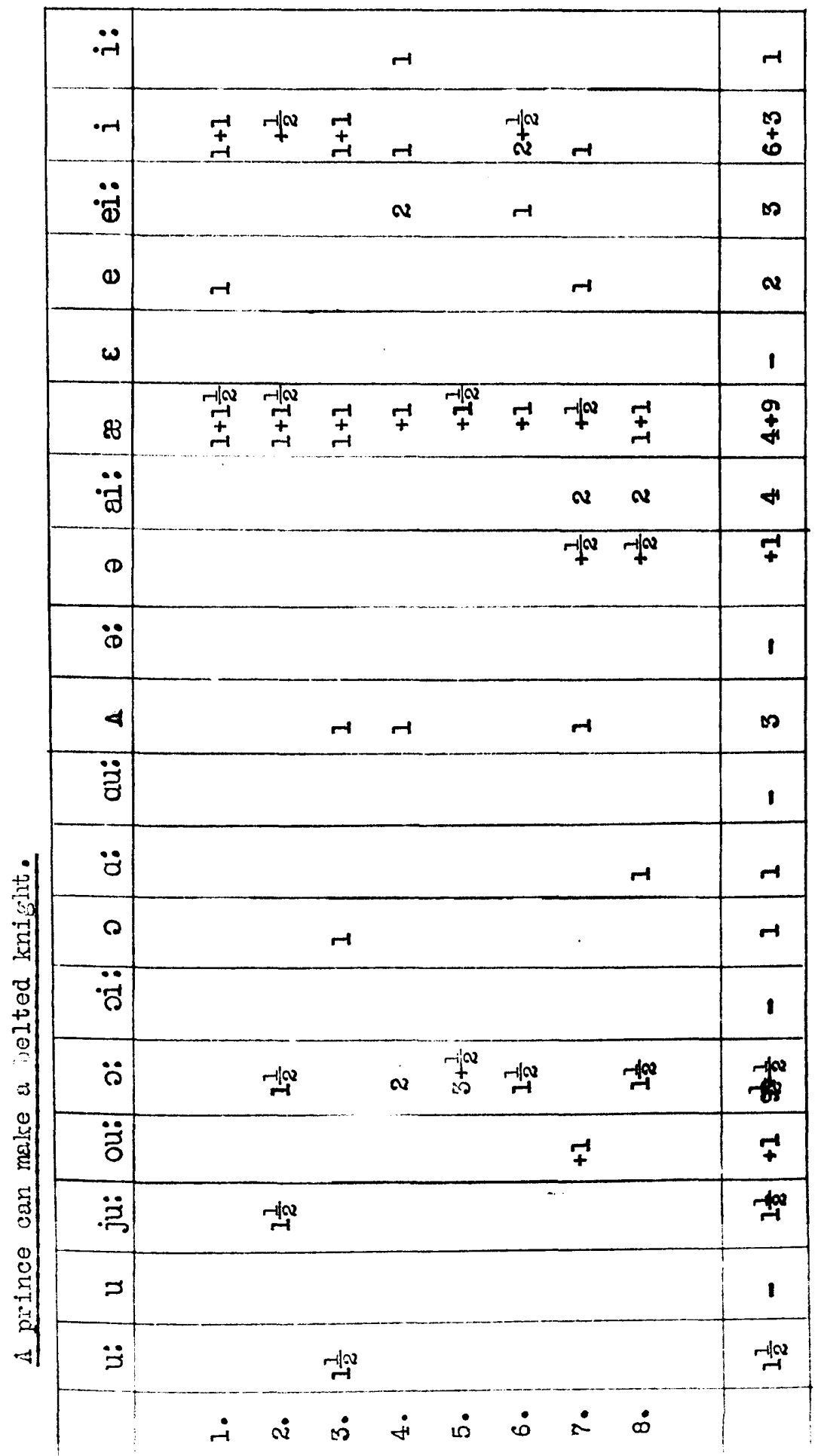




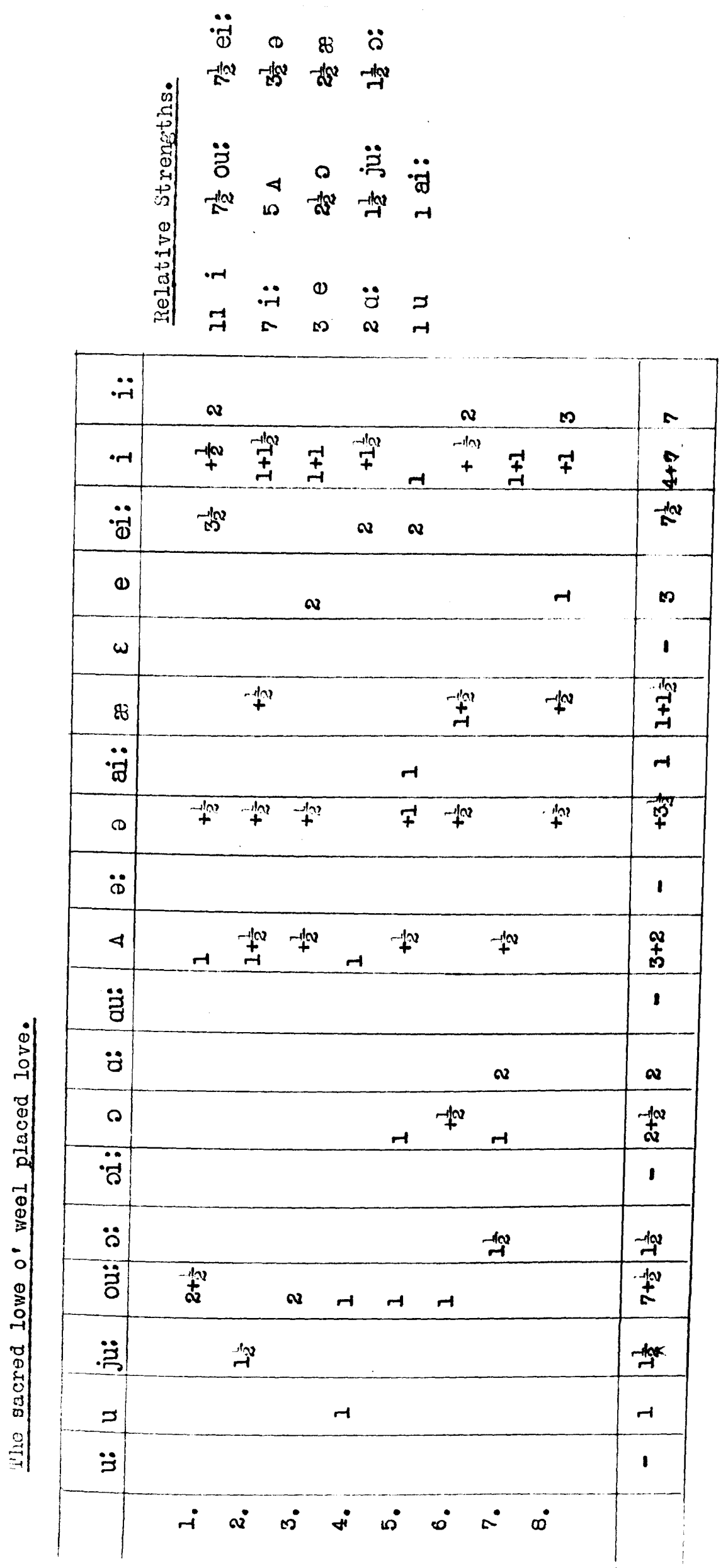




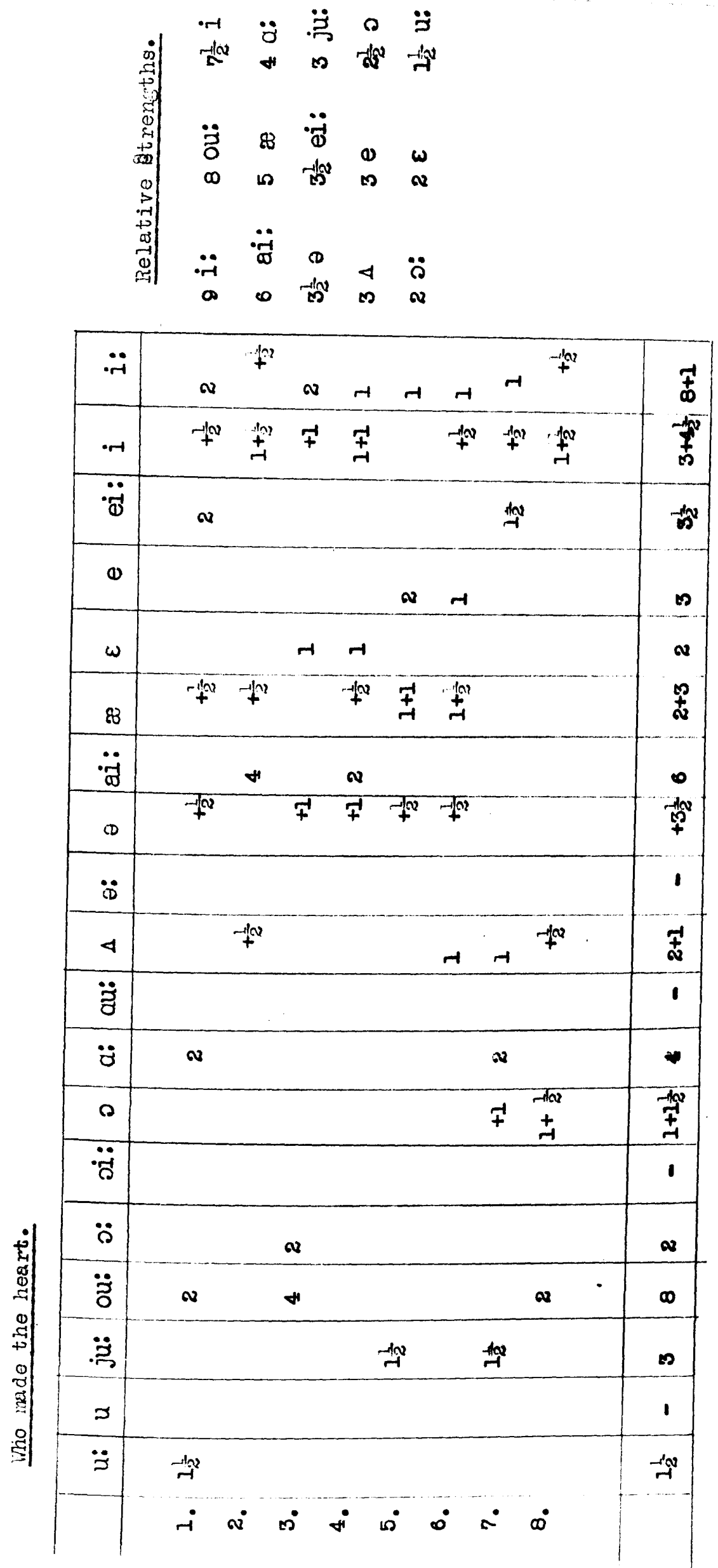



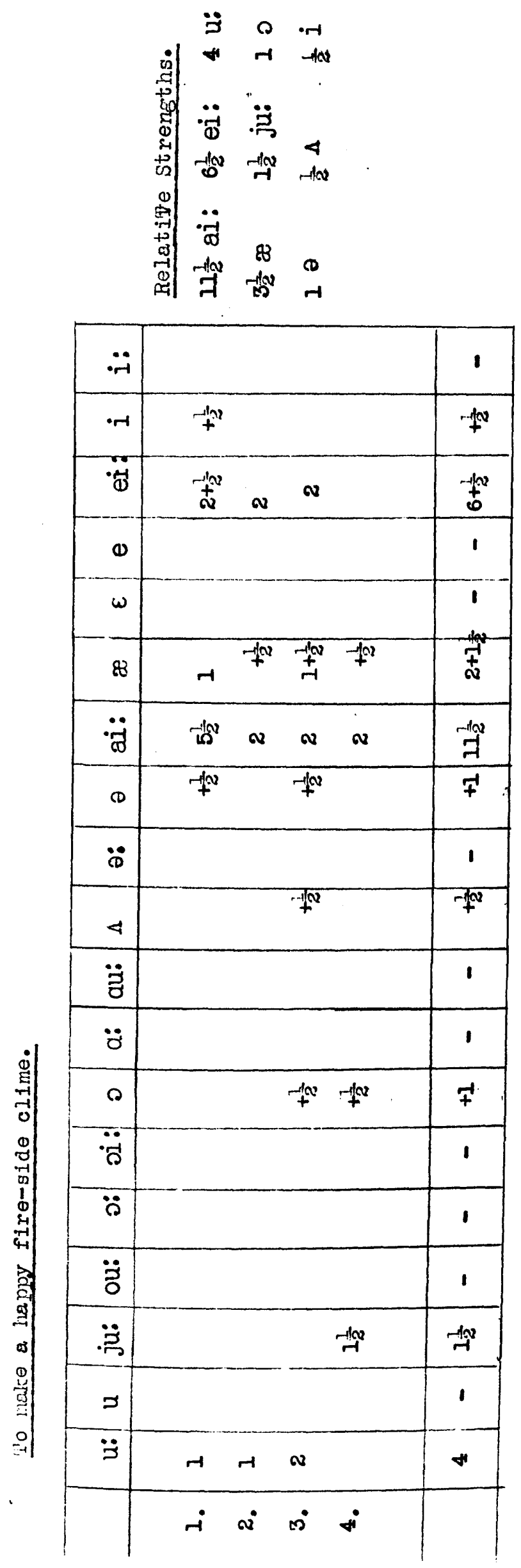


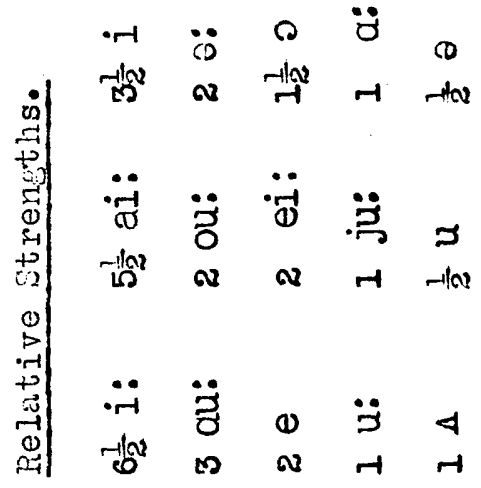

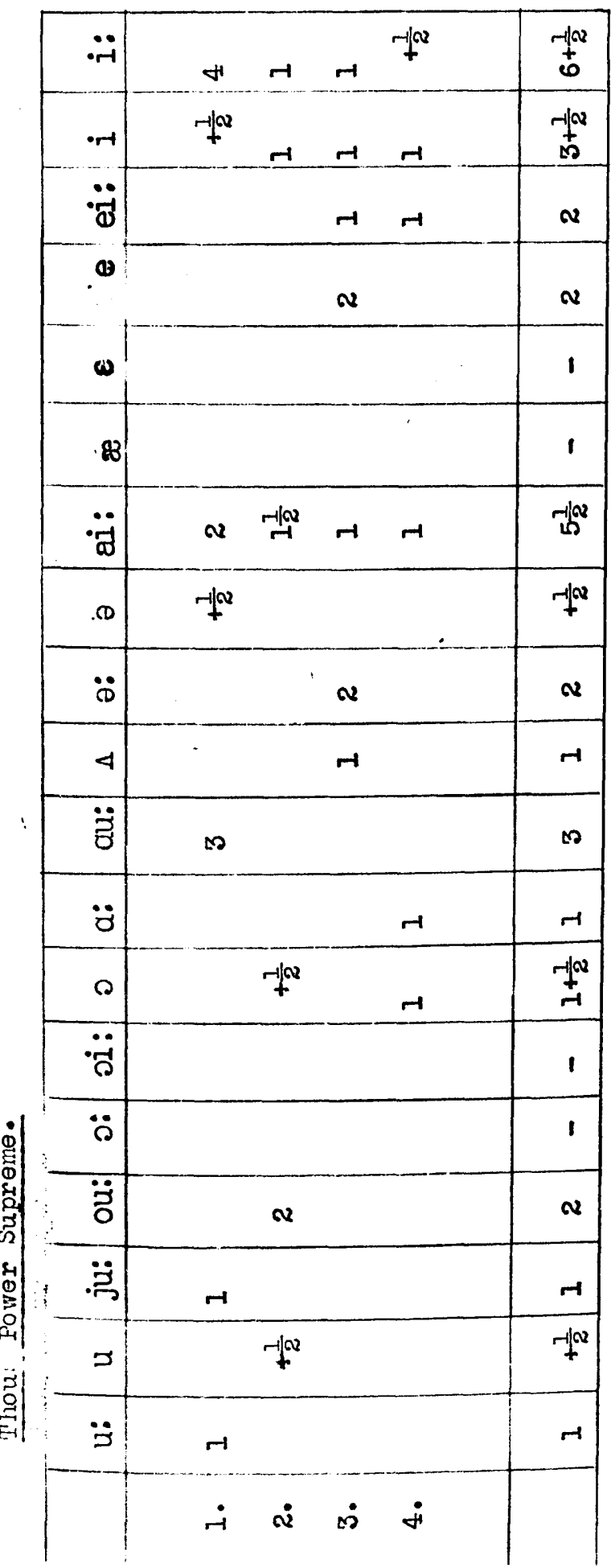




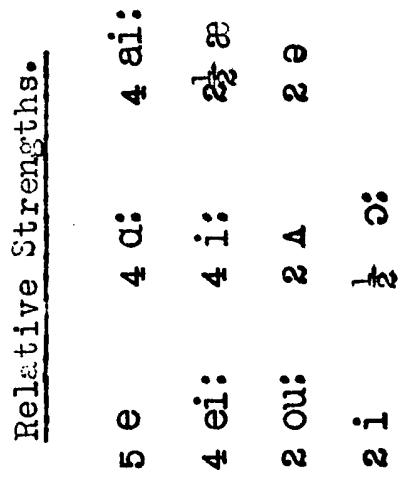

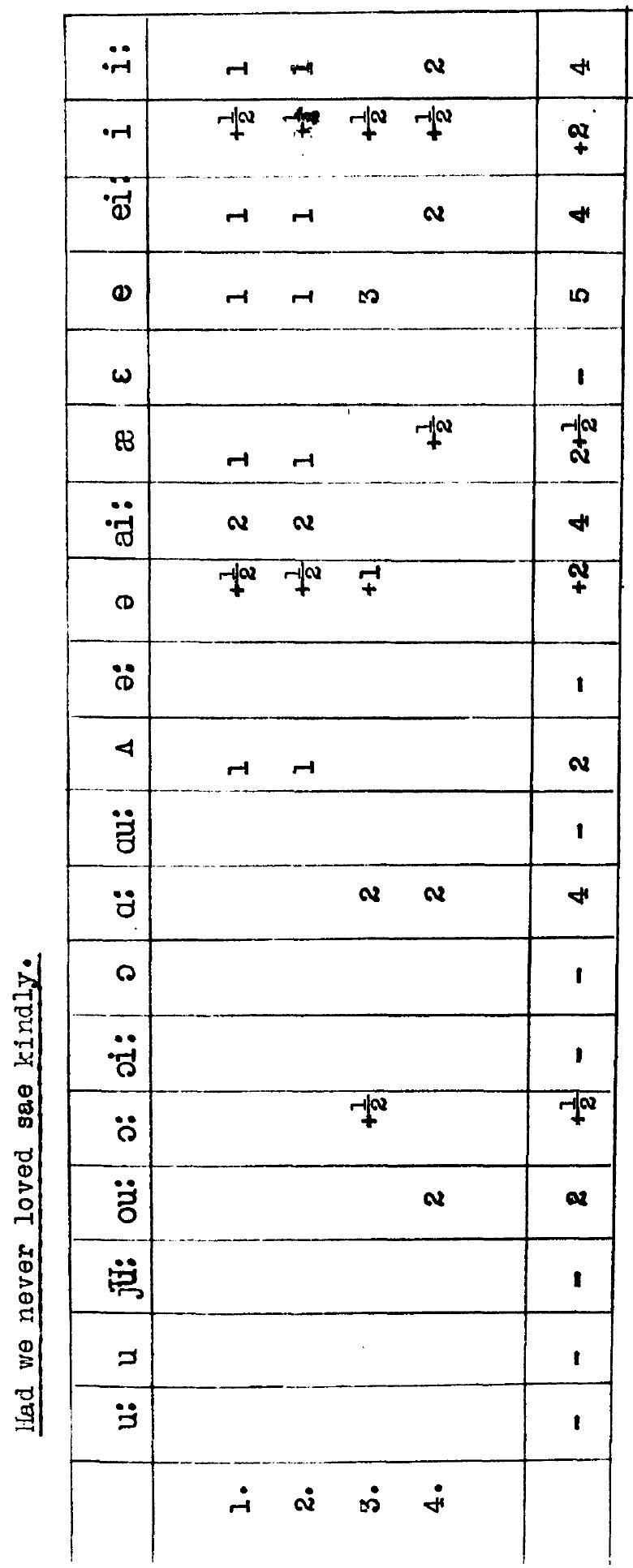




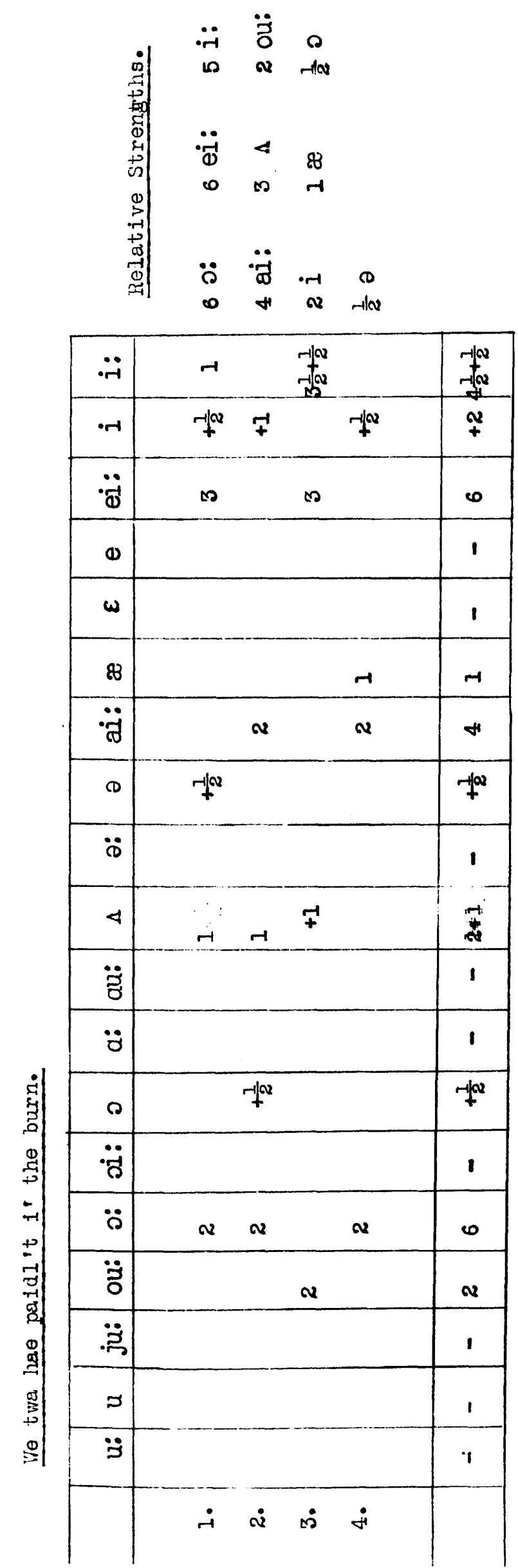




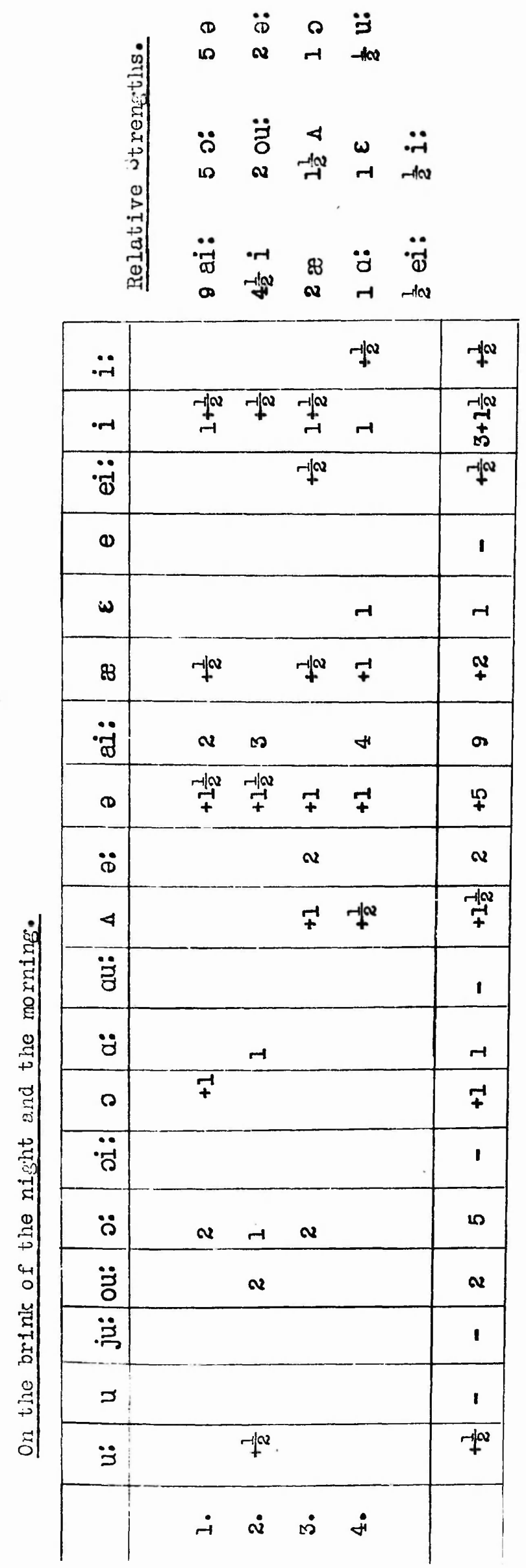




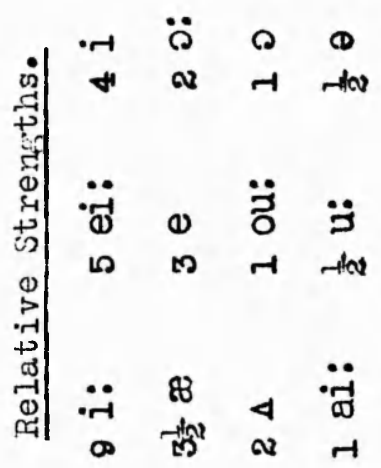

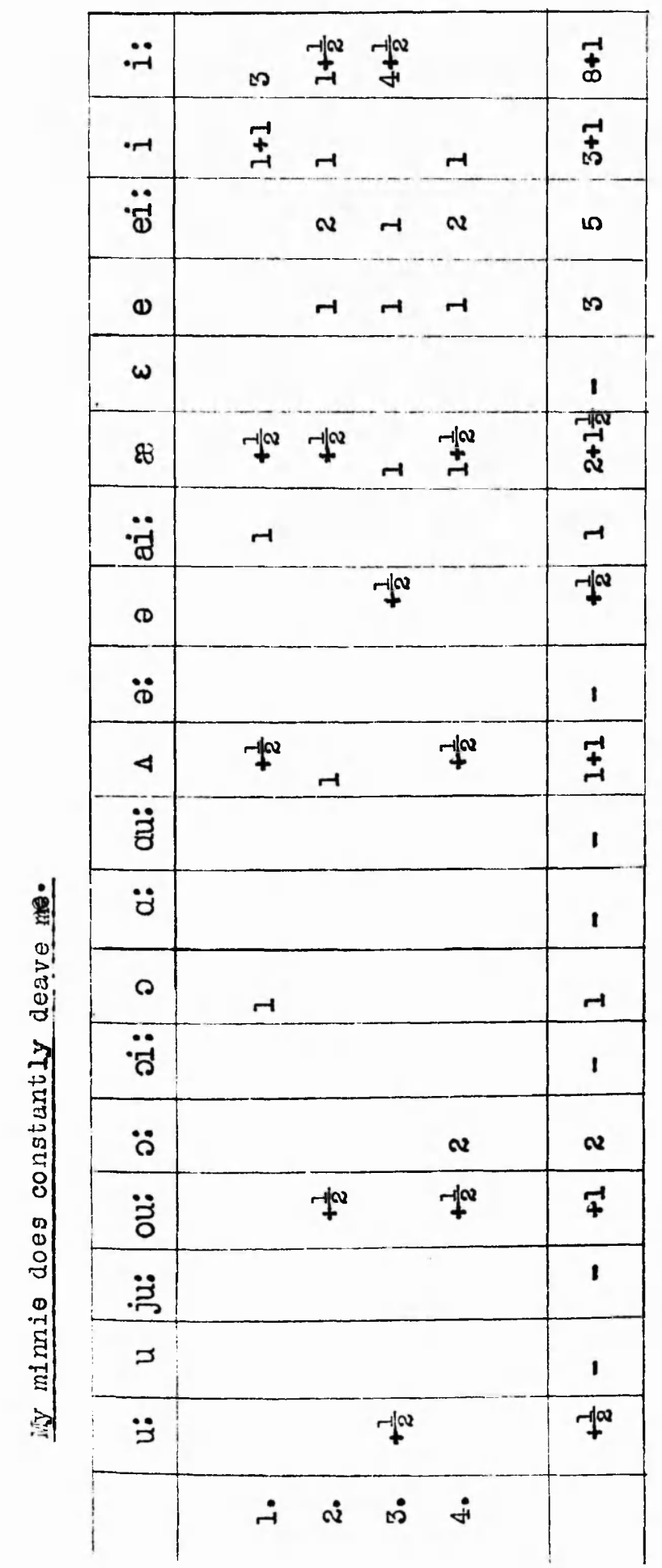




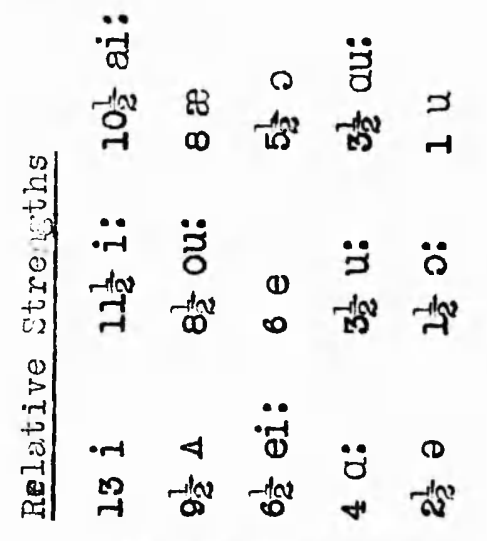

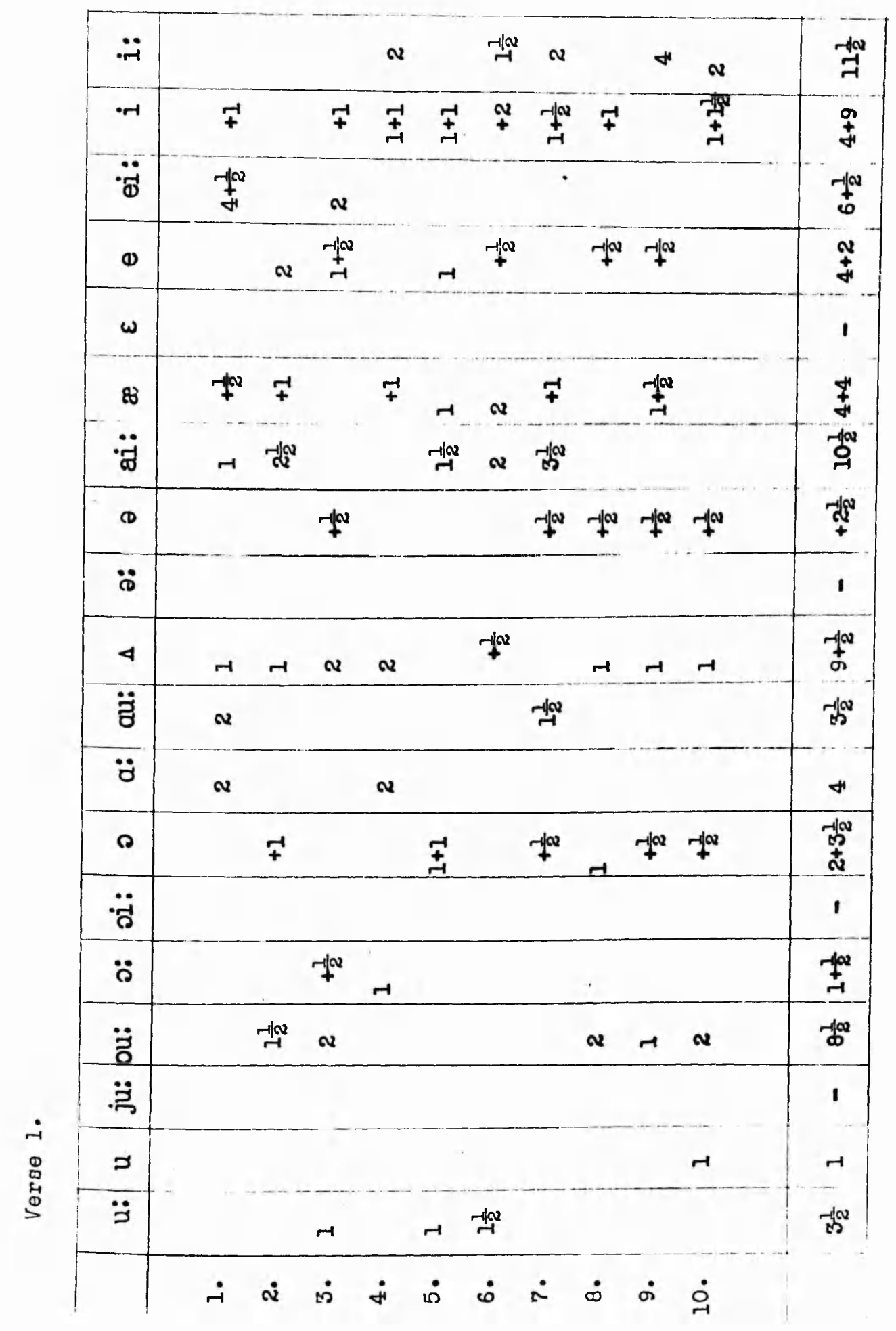




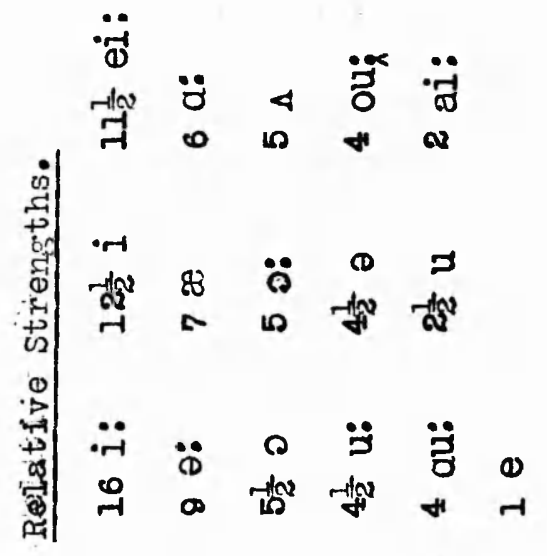

\begin{tabular}{|c|c|c|c|c|c|c|c|c|c|c|c|}
\hline$\ddot{r}$ & $\stackrel{-N}{\sim}$ & $\mathrm{H}_{-1 / 2}$ & $\boldsymbol{v}$ & & $v$ & $v$ & $v$ & & $H$ & $r$ & $\stackrel{9}{0}$ \\
\hline$\cdot-1$ & $\underset{+}{\stackrel{N}{+}}$ & $\mp$ & $\mp$ & & & $r$ & 留 & $-1 \omega$ & -1 & $\stackrel{+1}{\Delta}$ & - $\underbrace{\infty}_{+\infty}$ \\
\hline$\ddot{\ddot{\Phi}}$ & $+f^{N}$ & $\frac{-1}{N}$ & $\boldsymbol{v}$ & & $r \mid \omega$ & & & $\boldsymbol{v}$ & & 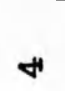 & 水 \\
\hline $\boldsymbol{\omega}$ & & -1 & & & & & & & & & -1 \\
\hline$\omega$ & & & & & & & & & & & 1 \\
\hline 83 & $\mp$ & & $\underset{r}{+\infty}$ & $\stackrel{-N}{+}$ & & & $\tau^{\infty}$ & $7^{-1}$ & $\mp$ & 7 & $\stackrel{\emptyset}{\ddagger}$ \\
\hline$\ddot{a}$ & & & & & & & & & $\boldsymbol{v}$ & & $\boldsymbol{v}$ \\
\hline D & & $r$ & $r-f^{a t}$ & & $\mp$ & + & -10 & & $-1 \omega$ & $t^{\infty}$ & $\underset{7}{+\infty}$ \\
\hline$\ddot{8}$ & & $v$ & & $\infty$ & & & & $\boldsymbol{N}$ & $\boldsymbol{v}$ & & $\sigma$ \\
\hline 4 & & & -1 & -1 & & -1 & $r$ & & $r$ & & 10 \\
\hline$\ddot{8}$ & & & & & $v$ & & & $v$ & & & +4 \\
\hline$\ddot{~} \ddot{z}$ & $\boldsymbol{N}$ & & & + & & & & & & & 0 \\
\hline$\curvearrowright$ & $t^{\infty}$ & $r$ & $-1 \infty$ & $\stackrel{-1 / 2}{=}$ & $f^{2}$ & $7^{-10}$ & & & & -1 & $\begin{array}{l}25 \\
+5\end{array}$ \\
\hline "ृ̈ & & & & & & & & & & & 1 \\
\hline$\ddot{\circ}$ & 7 & & $\boldsymbol{v}$ & & $f^{*}$ & & & & & & \pm \\
\hline$\ddot{\circ}$ & $\boldsymbol{\sim}$ & & & & $\overbrace{-1}^{40}$ & $-1 x^{2}$ & & & & & $-+\infty$ \\
\hline . & & & & & & & & & & & 1 \\
\hline 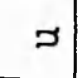 & & & & & -1 & $\stackrel{+\pi}{+\infty}$ & & & & & $-\frac{1}{N}$ \\
\hline$\ddot{3}$ & & $v$ & & & & $\boldsymbol{v}$ & & & & $-1+2$ & $\underset{+\infty}{+\infty}$ \\
\hline & $\dot{-}$ & $\dot{\boldsymbol{v}}$ & $\dot{8}$ & $\dot{+}$ & மீ & $\dot{\omega}$ & $\dot{\Sigma}$ & $\dot{\infty}$ & $\dot{\sigma}$ & $\dot{\rho}$ & \\
\hline
\end{tabular}




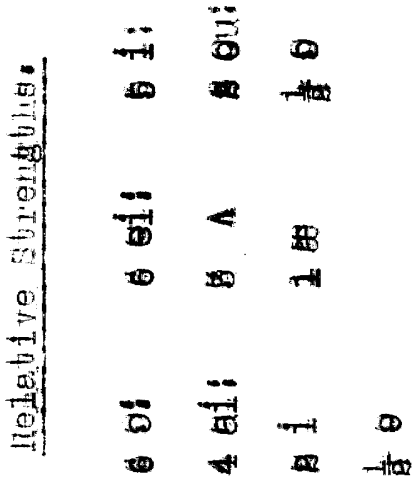

\begin{tabular}{|c|c|c|c|c|}
\hline - & त & & $\underbrace{+\infty}_{-1}$ & + \\
\hline and & + & 7 & $+\infty$ & at \\
\hline 6 & 100 & & 10 & $\infty$ \\
\hline
\end{tabular}

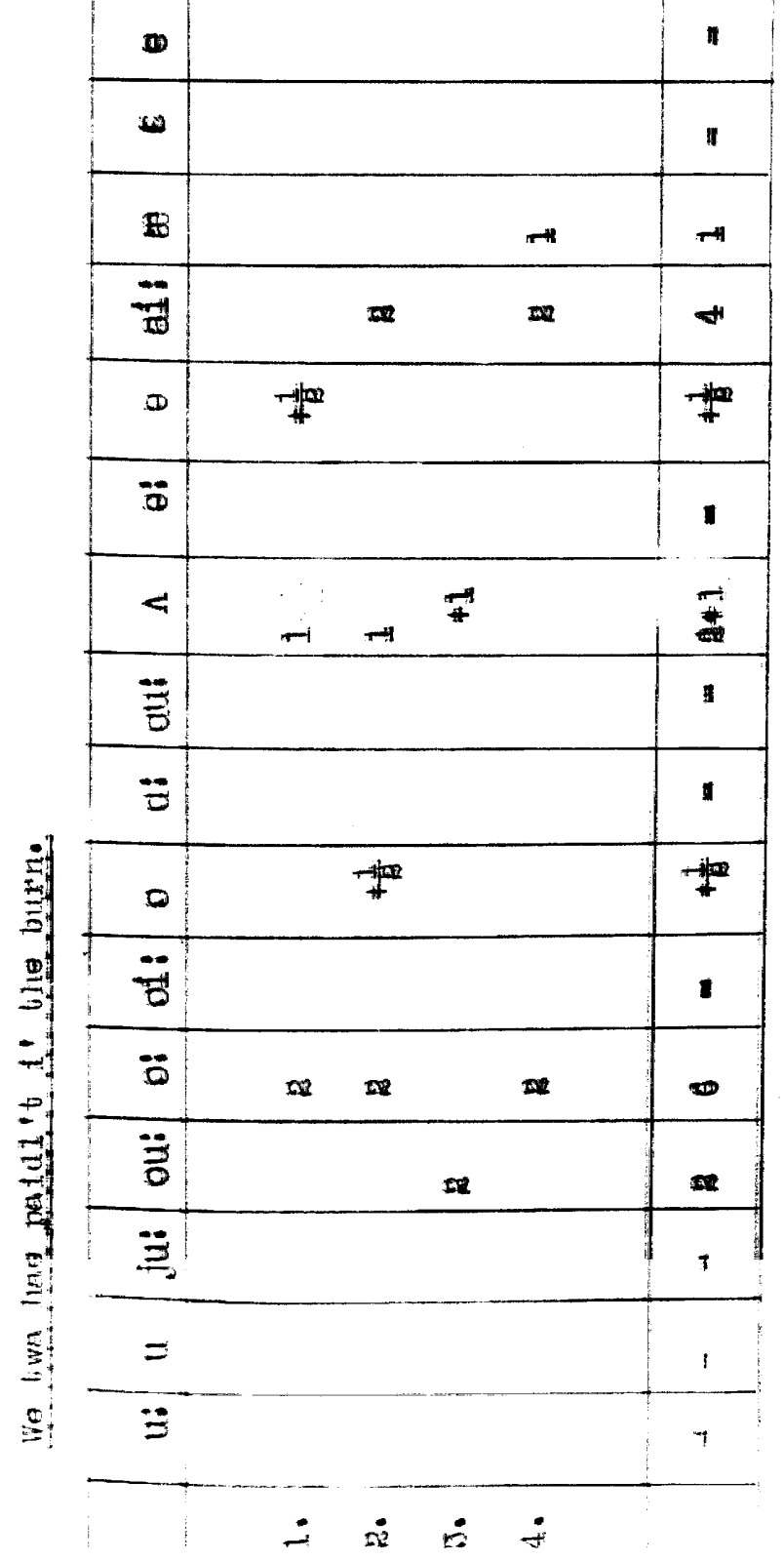




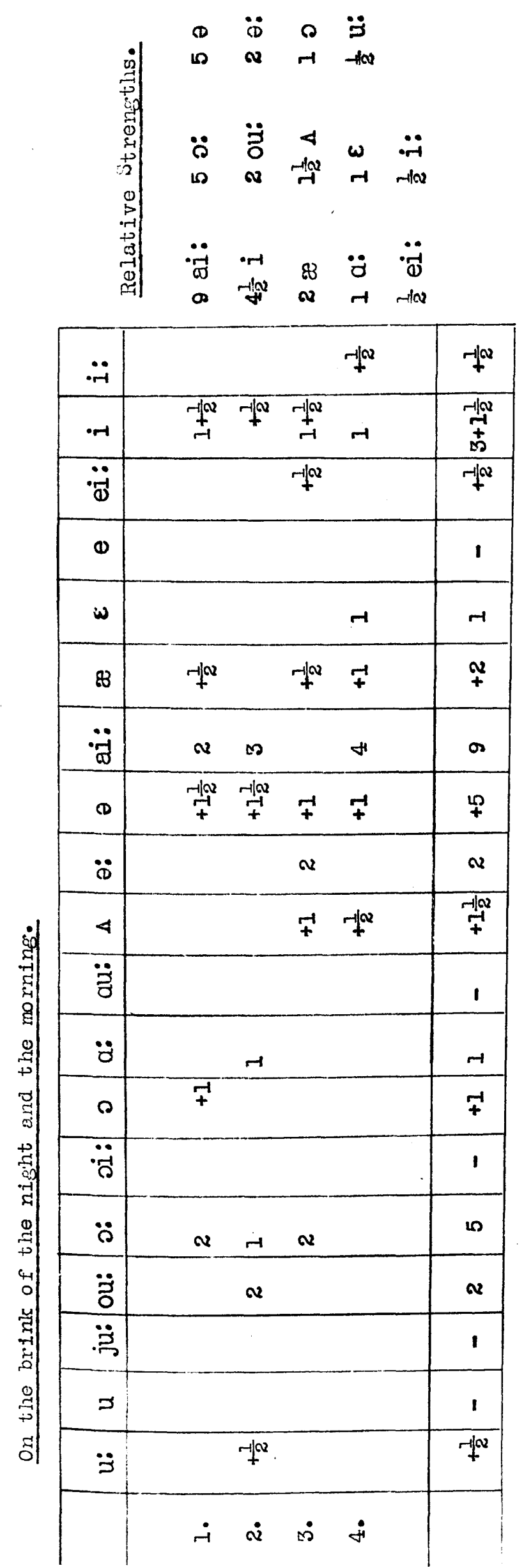




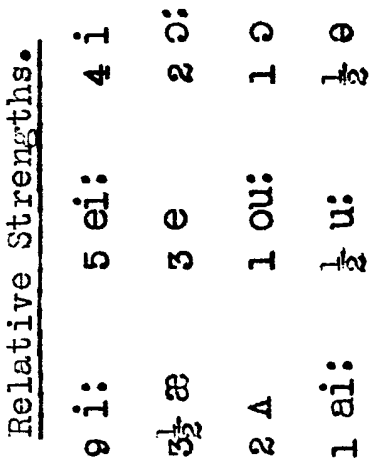

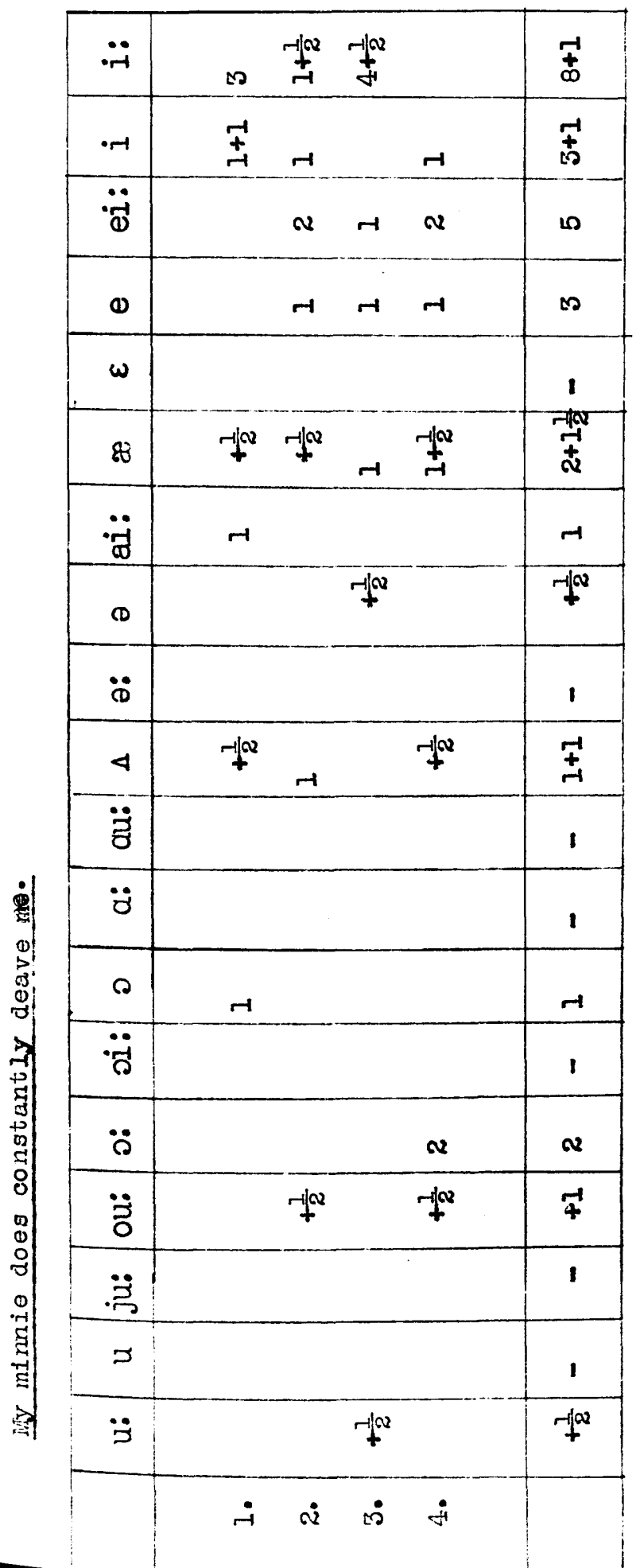




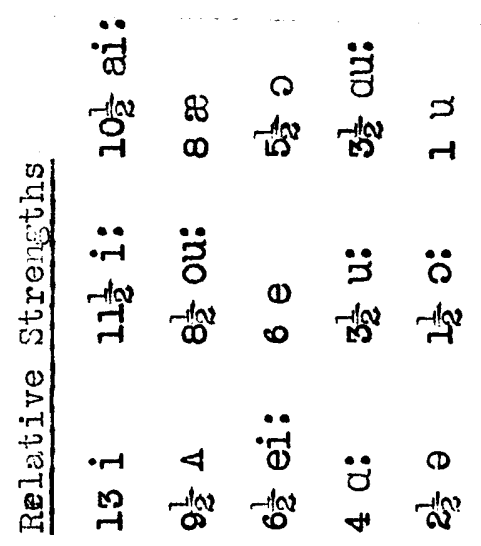

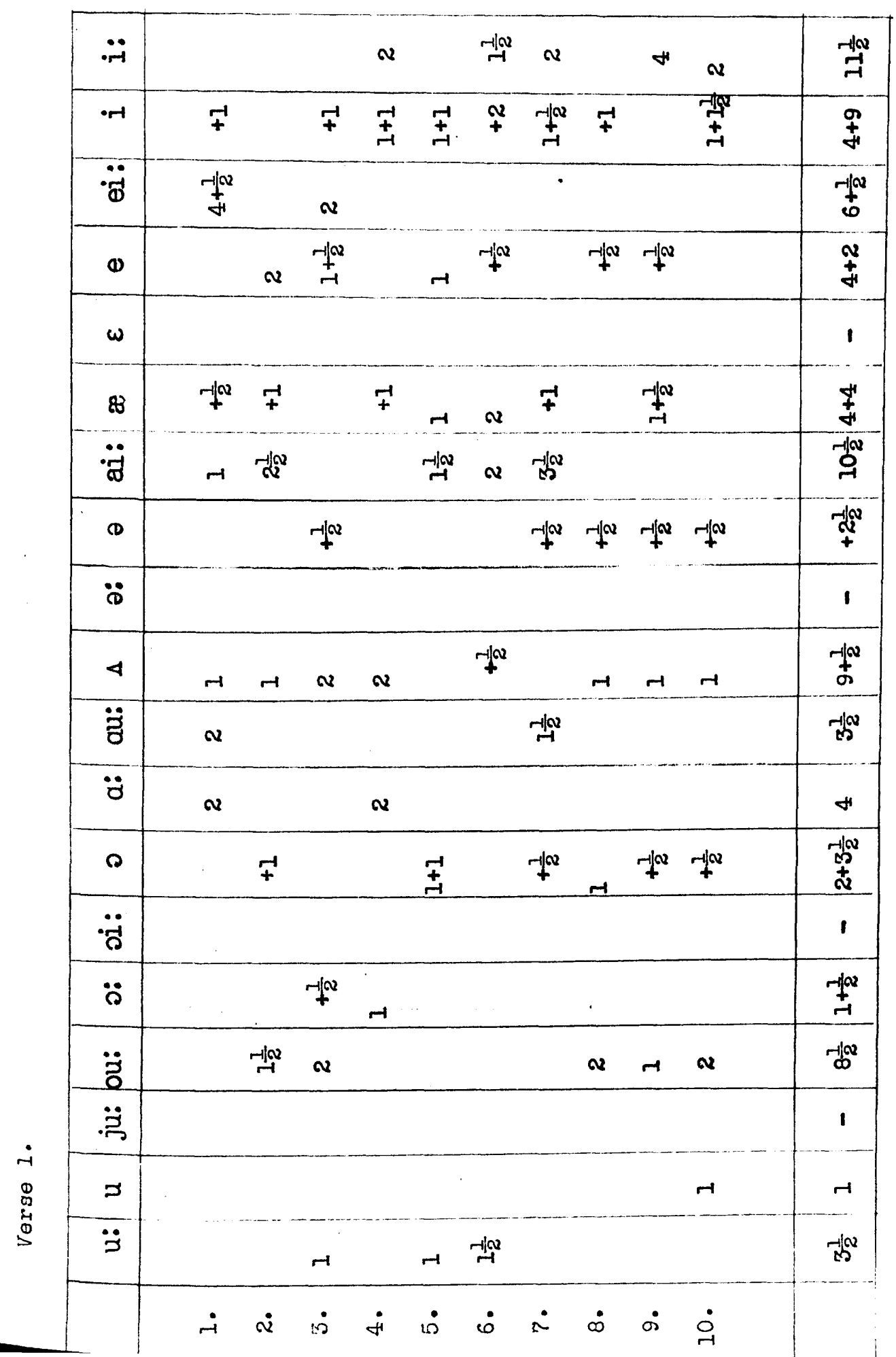




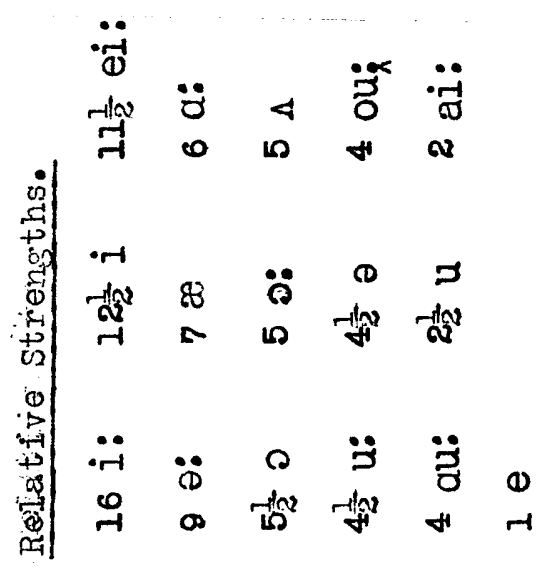

\begin{tabular}{|c|c|c|c|c|c|c|c|c|c|c|c|}
\hline$\ddot{\circ}$ & $\stackrel{-\leftrightarrow}{\sim}$ & -1|N & $\curvearrowright$ & & $v$ & $v$ & $\checkmark$ & & $H$ & $\boldsymbol{r}$ & $\mathscr{c}$ \\
\hline$\cdot-1$ & $\underset{+}{\stackrel{-1 / N}{+}}$ & $\mp$ & + & & & $r$ & $\begin{array}{l}\text { Aा } \\
\text { जे }\end{array}$ & +10 & -1 & $\vec{\ddagger}$ & - \\
\hline$\ddot{\ddot{\omega}}$ & +10 & $\stackrel{-1 / \alpha}{\stackrel{N}{*}}$ & $N$ & & $-1 x^{\alpha}$ & & & $v$ & & 4 & ना/ \\
\hline $\boldsymbol{\omega}$ & & $-r$ & & & & & & & & & -1 \\
\hline$\omega$ & & & & & & & & & & & 1 \\
\hline $\mathbb{8}$ & $\stackrel{-1}{+}$ & & $\stackrel{-1}{\stackrel{1}{\prime}}$ & $\stackrel{-1(\alpha)}{+1}$ & & & $+-\left.1\right|^{Q}$ & $r^{\alpha}$ & + & $\overrightarrow{4}$ & $\stackrel{\oplus}{\ddagger}$ \\
\hline$\ddot{\ddot{d}}$ & & & & & & & & & $\curvearrowright$ & & $v$ \\
\hline D & & $r \|^{\alpha}$ & $r+\infty$ & & + & $\underset{+}{+}$ & $+\infty$ & & $-4^{N}$ & $t^{2 N}$ & $\stackrel{-1 / n}{\sharp}$ \\
\hline$\ddot{8}$ & & $v$ & & $m$ & & & & $\alpha$ & $v$ & & $\sigma$ \\
\hline 4 & & & $r$ & -1 & & $r$ & -1 & & $H$ & & 10 \\
\hline 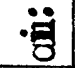 & & & & & $v$ & & & $\boldsymbol{v}$ & & & $H$ \\
\hline$\ddot{z}$ & $\boldsymbol{\alpha}$ & & & +4 & & & & & & & $\omega$ \\
\hline$\curvearrowright$ & $F^{\infty}$ & $r$ & $f^{\infty}$ & $\stackrel{-10 x}{\rightarrow}$ & $-f^{x}$ & $-1 x^{\infty}$ & & & & -1 & 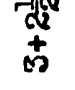 \\
\hline$\ddot{\circ}$ & & & & & & . & & & & & 1 \\
\hline$\ddot{\circ}$ & 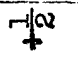 & & $v$ & & -1/a & & & & & & $\stackrel{+}{+}$ \\
\hline$\ddot{亏}$ & $\sim$ & & & & ${ }_{-1}^{-1 / 2}$ & +10 & & & & & 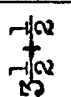 \\
\hline 芨 & & & & & & & & & & & 1 \\
\hline 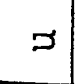 & & & & & $\boldsymbol{H}$ & $\underset{-1}{+\infty}$ & & & & & $\begin{array}{r}+\infty \\
\stackrel{+}{*}\end{array}$ \\
\hline$\ddot{\Xi}$ & & $\infty$ & & & & $\alpha$ & & & & $-10 \alpha$ & $\stackrel{-1}{+\infty}$ \\
\hline & $\dot{-}$ & $\dot{Q}$ & $\dot{0}$ & $\dot{4}$ & 10 & $\dot{0}$ & $\therefore$ & $\dot{\infty}$ & $\dot{\sigma}$ & $\dot{\circ}$ & \\
\hline
\end{tabular}




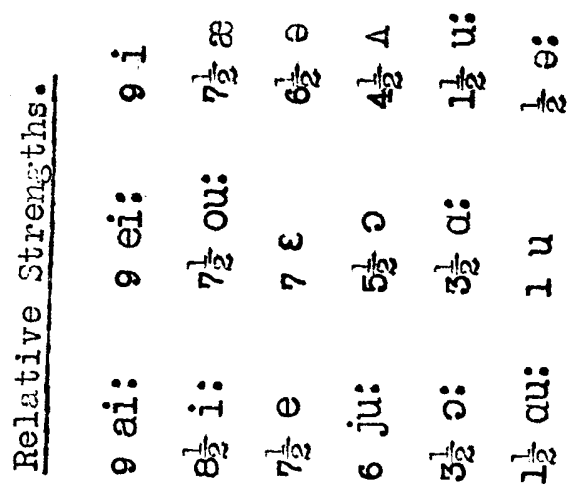

\begin{tabular}{|c|c|c|c|c|c|c|c|c|c|c|}
\hline$\ddot{r}$ & & Q & $\checkmark$ & $H$ & & & $+\infty$ & $+\infty$ & 7 & $\stackrel{-1 / N}{+}$ \\
\hline$\cdot-1$ & $-f^{\alpha}$ & & $\stackrel{-10}{+1}$ & $\infty$ & $-1 \infty$ & - & $\underline{\Omega}$ & & & $\stackrel{v}{ \pm}$ \\
\hline$\ddot{\ddot{d}}$ & $\Delta$ & & & & 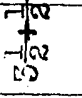 & Q & & & & $\int_{\infty}$ \\
\hline (1) & al & $\vec{r}$ & $\stackrel{+10}{+}$ & $m$ & $\therefore:$ & $r$ & & -1 & $H$ & $\stackrel{-10}{\Sigma}$ \\
\hline$\omega$ & & - & & $\rightarrow$ & $\sim$ & -1 & $r$ & $r$ & & $\boldsymbol{N}$ \\
\hline 88 & $\mp$ & + & -1 & $-7^{2}$ & & + & & -10 & 7 & $\underset{m}{+\infty}$ \\
\hline$\ddot{\ddot{\theta}}$ & $\stackrel{-102}{r-1}$ & & & & & $v$ & & $\boldsymbol{\sim}$ & $\stackrel{-\| \omega}{\sim}$ & $\sigma$ \\
\hline (D) & & & $\begin{array}{l}-1 \\
\text { wa } \\
+\end{array}$ & Fil & 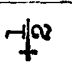 & & & $-1 x^{2}-$ & & - \\
\hline$\ddot{8}$ & & & & & & & & & & $-1+\infty$ \\
\hline 4 & & -1 & & -1 & & & -110 & & $\mathrm{H}$ & $\stackrel{+\infty}{+\infty}$ \\
\hline$\ddot{z}$ & & 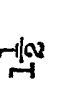 & & & & & & & & $-1+\infty$ \\
\hline$\ddot{d}$ & $\stackrel{-11}{-1}$ & & & & $v$ & & & & & - \\
\hline$\curvearrowright$ & -1 & $7 x$ & & & & & $\stackrel{r}{-1}$ & $r$ & 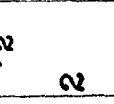 & $\begin{array}{c}-10 \\
+ \\
+ \\
+\end{array}$ \\
\hline$\ddot{~} \ddot{8}$ & & & & & & & & & & 1 \\
\hline$\ddot{\Omega}$ & $7 x$ & & & & $\boldsymbol{v}$ & & & & $r$ & $\underset{00}{-100}$ \\
\hline$\ddot{亏}$ & & $Q$ & & $v$ & & r|l & $H$ & & -1 & - \\
\hline$\ddot{\ddot{B}}$ & & & & & $-n_{-1}^{\infty}$ & $\stackrel{-1 \omega}{-1}$ & & & |x & $\boldsymbol{\omega}$ \\
\hline$D$ & & & & & & & $r$ & & & $r$ \\
\hline$\ddot{\Xi}$ & & & & & & & + & & -10 & $\underset{+}{-1 / x}$ \\
\hline & $\dot{-}$ & ๙ & $\dot{~}$ & $\dot{f}$ & $\dot{0}$ & $\dot{\omega}$ & $\dot{2}$ & $\dot{\infty}$ & $\dot{\sigma} \quad \dot{0}$ & \\
\hline
\end{tabular}




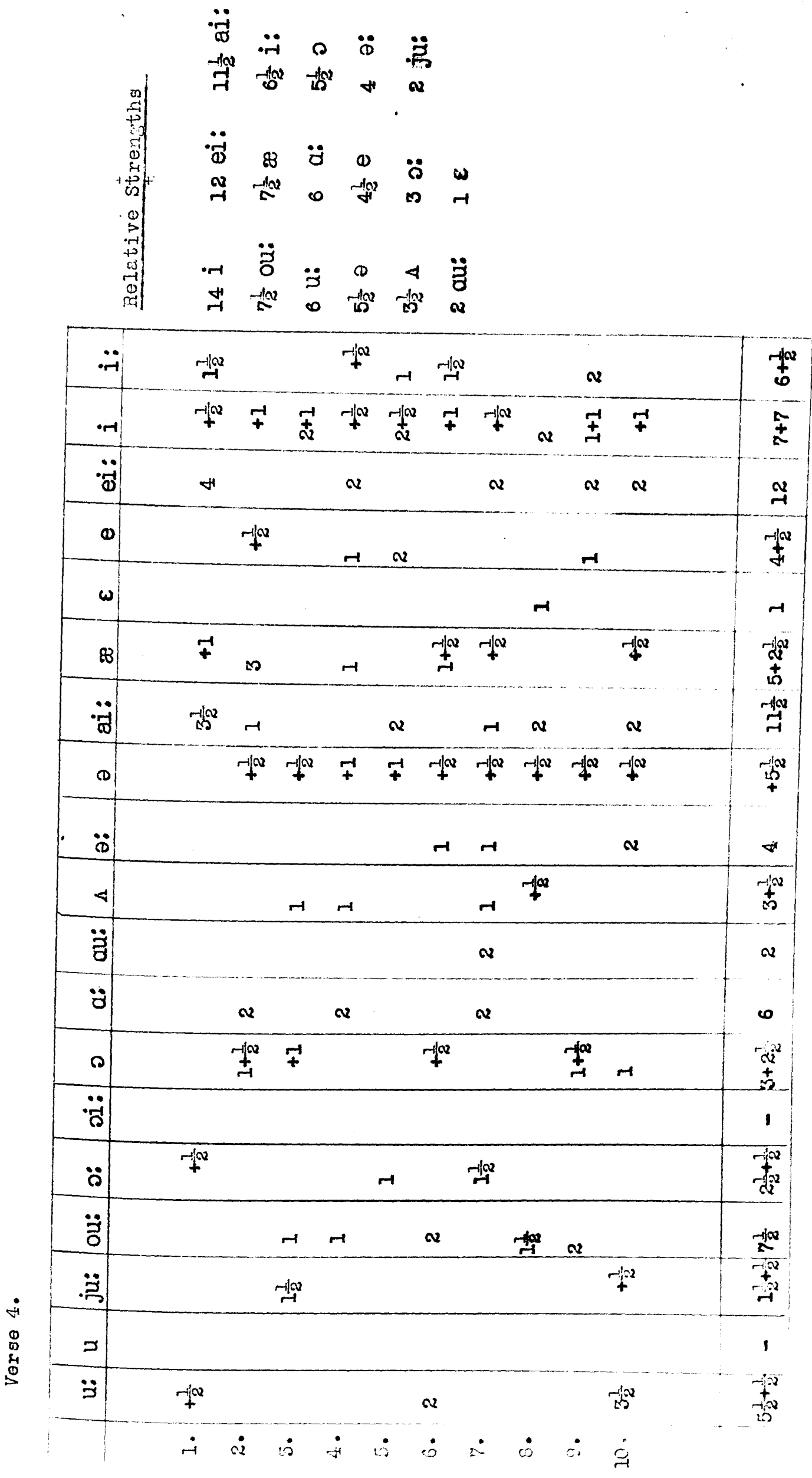




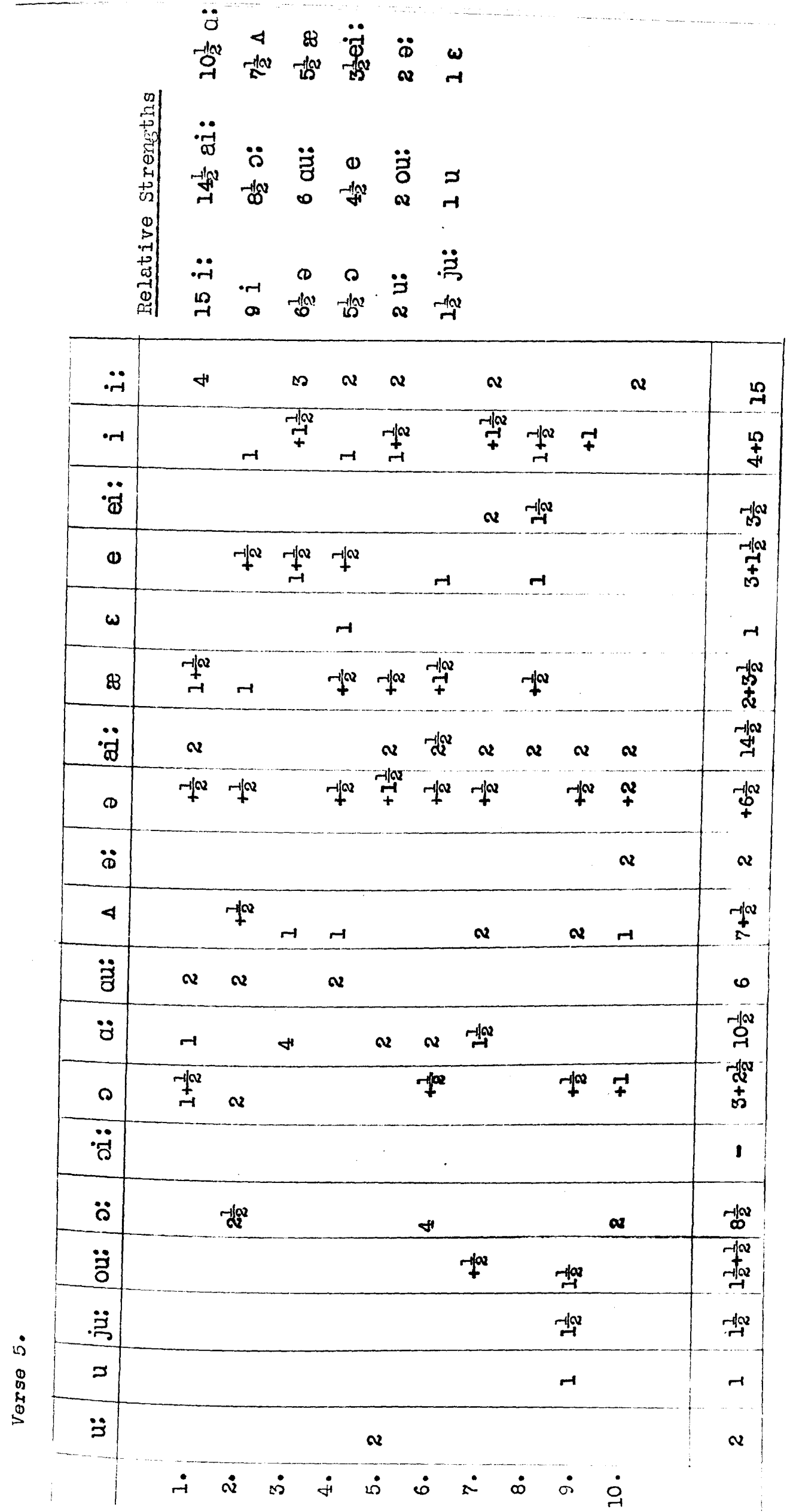




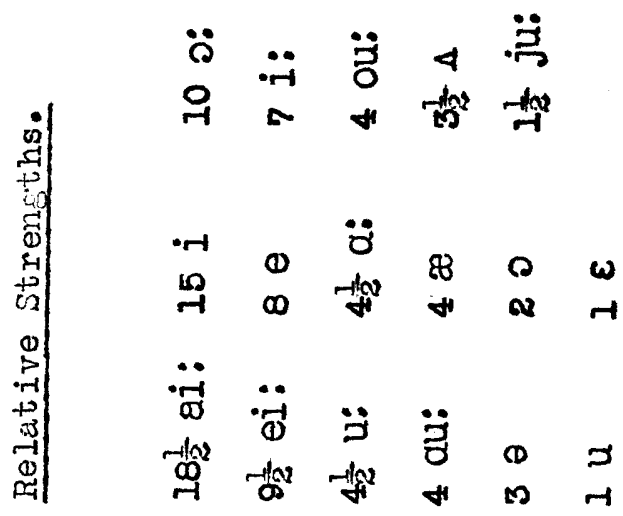

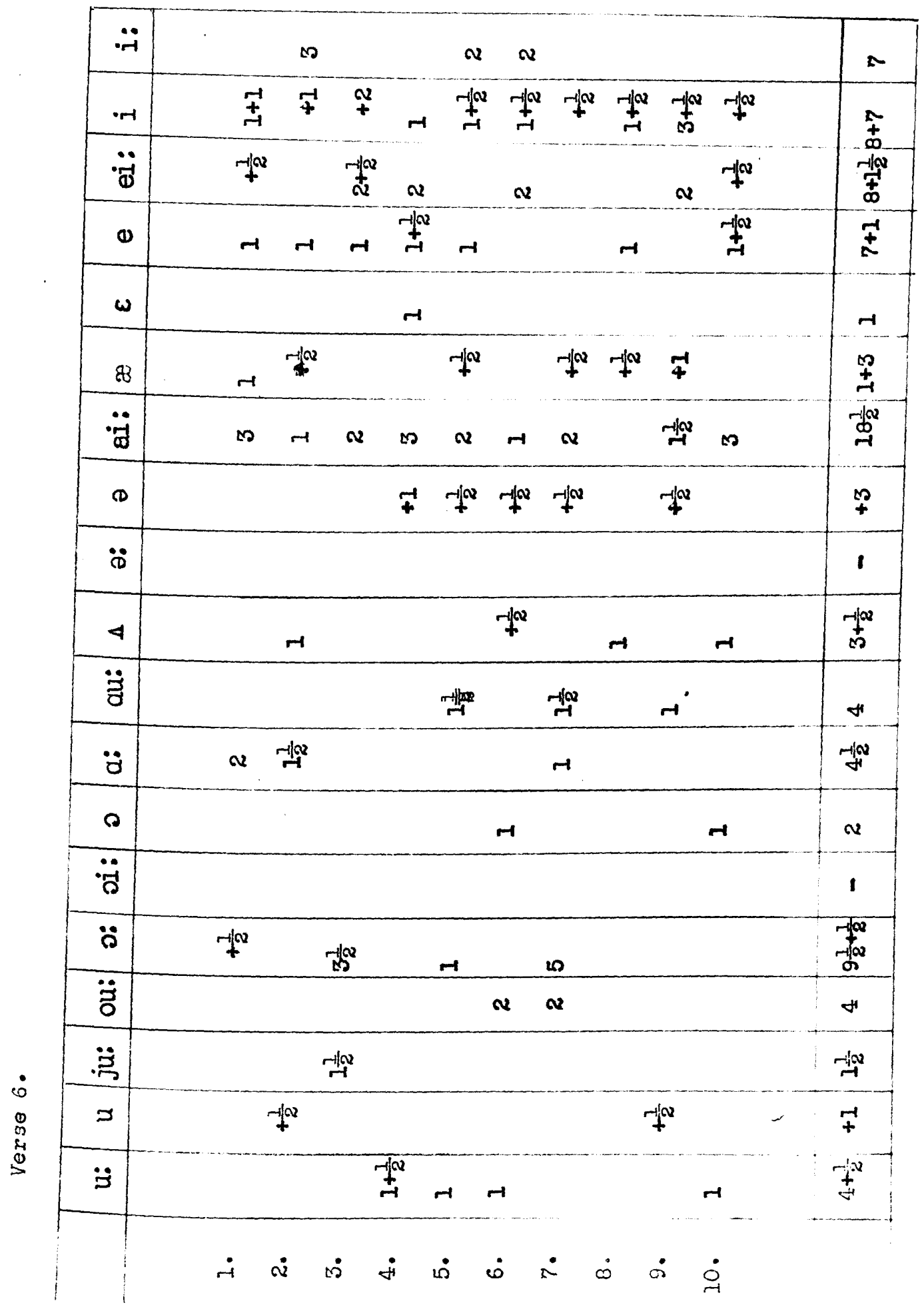




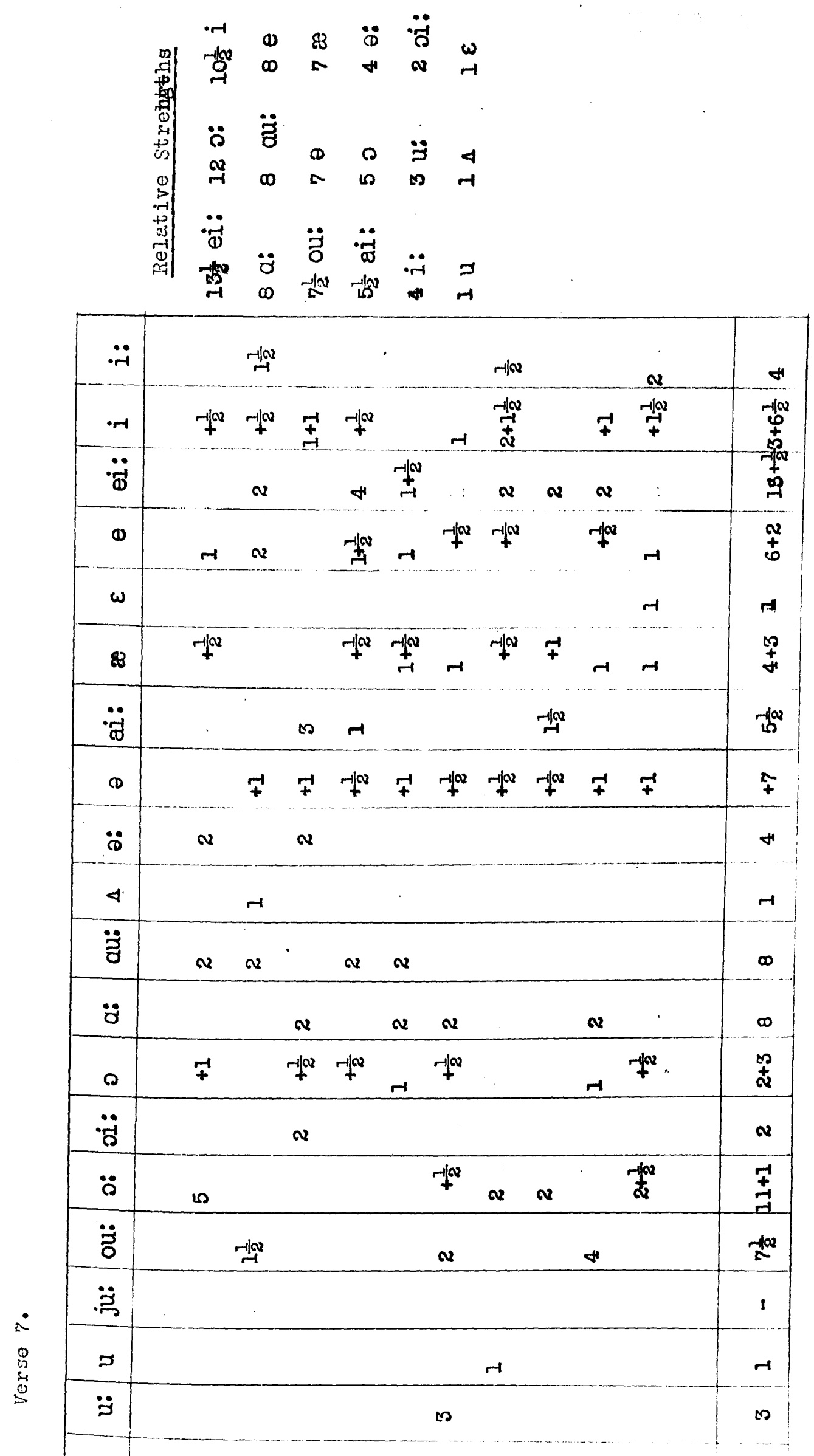

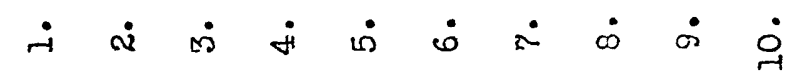




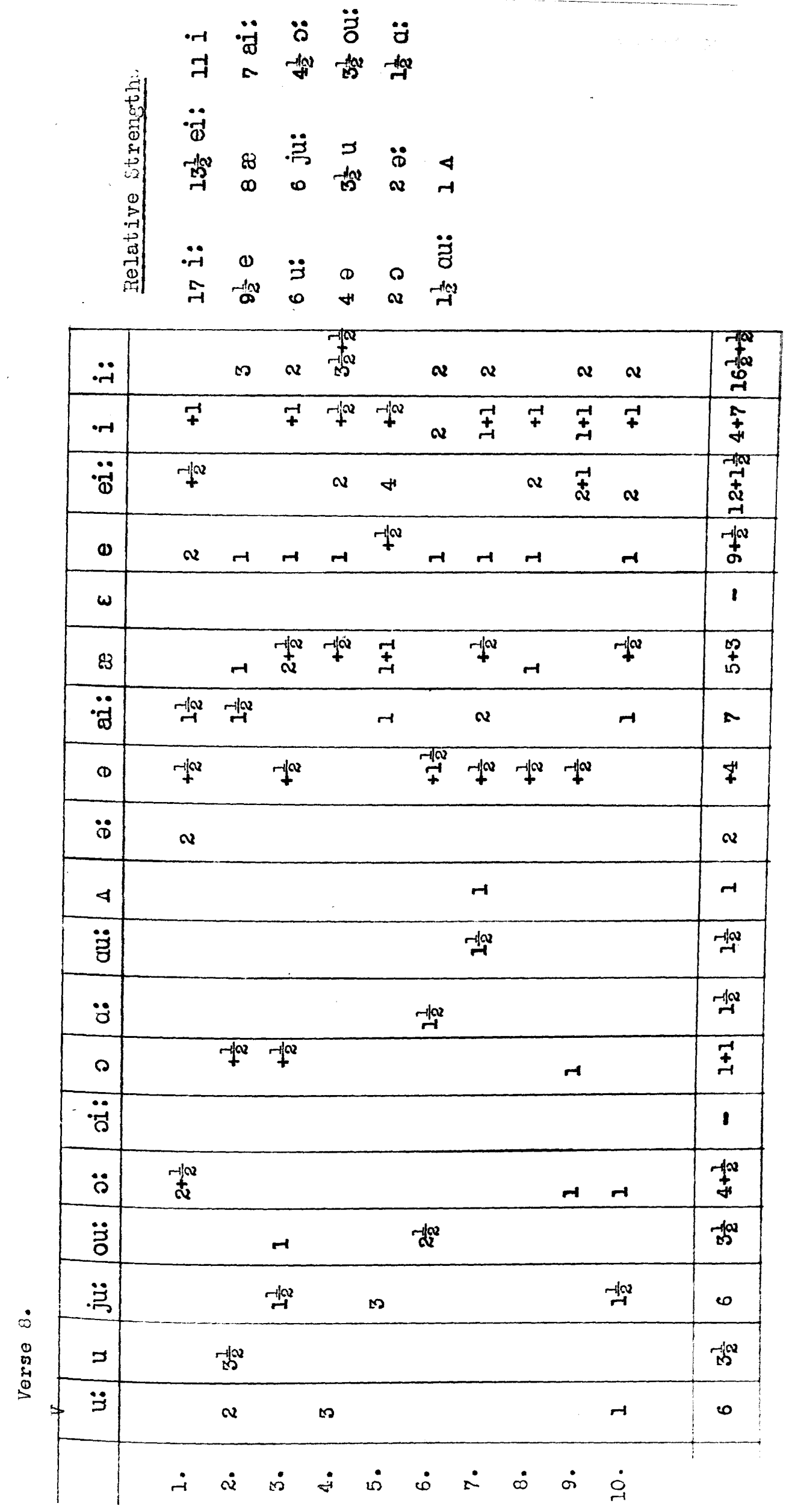




\begin{tabular}{|c|c|c|c|c|c|c|c|c|c|c|c|c|}
\hline$\ddot{-}$ & $\rightarrow$ & -1 & & & 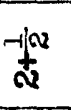 & & 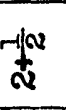 & & & $\rightarrow$ & 7 & 年 \\
\hline.-1 & & $\underset{ \pm}{ \pm}$ & $-7 x$ & $\underset{ت}{ \pm}$ & $-10 x$ & $\approx$ & & 年 & I & 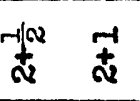 & $\underset{f}{\stackrel{-}{ \pm}}$ & 舅 \\
\hline$\ddot{\ddot{\Phi}}$ & & & & & & 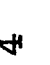 & & & & & & H \\
\hline 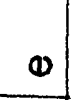 & $\stackrel{-1 / x^{a}}{\rightarrow}$ & - & -1 & & -1 & & $\rightarrow$ & $\propto$ & -1 & $\rightarrow$ & & $\underset{a}{-\infty}$ \\
\hline$\omega$ & & & & & & & & -1 & & & & -1 \\
\hline$\$$ & $r_{f a x}$ & & $f^{1 / 22}$ & $H$ & -1 & \pm & & -1 & $\underset{N}{-\sqrt{\infty}}$ & $\rightarrow+t^{\infty}$ & & \begin{tabular}{c}
$-\sqrt{2 \pi}$ \\
+2 \\
\multirow{2}{*}{}
\end{tabular} \\
\hline$\ddot{a}$ & & $\approx$ & $r$ & & & & & $\approx$ & & 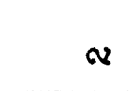 & & A \\
\hline ( & $\mp$ & 7 & & -10 & tava & 然 & $-1 \infty x$ & 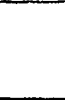 & $-1 \infty$ & -1100 & $F$ & $\stackrel{\infty}{\star}$ \\
\hline$\ddot{\phi}$ & & « & & & & & $\propto$ & & & & & + \\
\hline 4 & $\sim$ & & $\propto$ & & & & & & - & & $\underset{-1}{7 a}$ & $\frac{-190}{6}$ \\
\hline$\ddot{\ddot{z}}$ & & $\cong$ & & & & & & & & & & $\approx$ \\
\hline$\ddot{0}$ & & & $\sim$ & & & & & & & & & $\approx$ \\
\hline 0 & $\rightarrow$ & & & & & + & -10 & 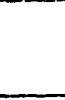 & $-1 \infty x+10$ & $+\infty$ & $\approx$ & 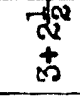 \\
\hline$\ddot{\circ}$ & & & & & & & & & & & & 1 \\
\hline$\ddot{b}$ & $\curvearrowright$ & & & $\curvearrowright$ & $-r$ & & & $-1+\infty$ & -11 & $+\infty$ & $\alpha$ & $\vec{t}$ \\
\hline$\ddot{z}$ & $\alpha$ & & & & $-1 x^{2}$ & & & & & & $\alpha$ & $\underset{f}{f x}$ \\
\hline$\ddot{\ddot{n}}$ & & & t102 & 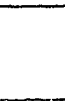 & & & tas & & & tiag & & 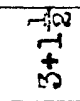 \\
\hline 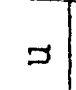 & & & & & & & & & & +4 & & $+a$ \\
\hline$\ddot{3}$ & & & and & $\approx$ & & & -1 & & r & -12 & & $\overrightarrow{ \pm}$ \\
\hline & $\dot{r}$ & ה & $\dot{10}$ & $\dot{H}$ & $\omega$ & 0 & $\therefore$ & $\dot{\infty}$ & $\dot{\sigma} \dot{\rho}$ & $\dot{\oplus} \dot{ت}$ & $\dot{\sim}$ & $\dot{8}$ \\
\hline
\end{tabular}




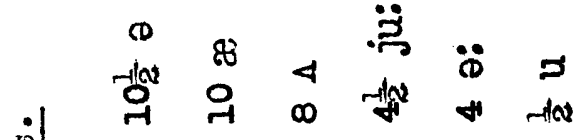

年

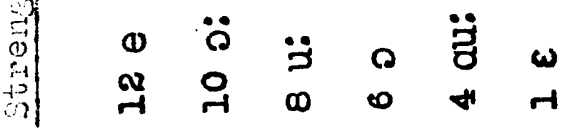

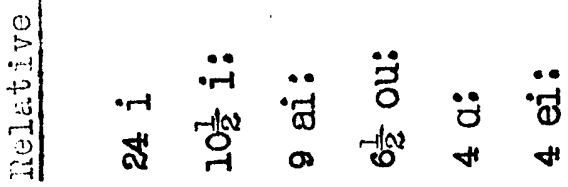

\begin{tabular}{|c|c|c|c|c|}
\hline$\ddot{-r}$ & 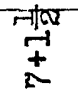 & & $\sim$ & $\begin{array}{c}\overbrace{a}^{-1} \\
+ \\
+ \\
\sigma\end{array}$ \\
\hline 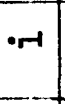 & $\begin{array}{c}\text { ना/ } \\
\infty \\
+ \\
m\end{array}$ & $+1+$ & $\stackrel{+}{+}$ & $\underset{+}{+}$ \\
\hline$\ddot{\ddot{\omega}}$ & \& & & & \& \\
\hline $\boldsymbol{\omega}$ & $\stackrel{r+\infty}{+}$ & v & $+1 \infty$ & $\begin{array}{l}\underset{+}{+} \\
\underset{-}{-1}\end{array}$ \\
\hline$\omega$ & -1 & & & -1 \\
\hline 83 & 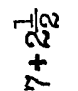 & $-1+\infty$ & & $\stackrel{m}{ \pm}$ \\
\hline$\ddot{~} \ddot{\theta}$ & $\tau$ & 62 & & $\sigma$ \\
\hline$\infty$ & & 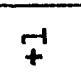 & $\stackrel{\text { नाब }}{+}$ & $\begin{array}{l}\text { नोl } \\
\text { Oे } \\
+\end{array}$ \\
\hline$\ddot{D}$ & 4 & & & $H$ \\
\hline 4 & $\underset{1}{+1 / \alpha}$ & -102 & -1 & \pm \\
\hline$\ddot{~} \ddot{z}$ & ৩ & & $\checkmark$ & $H$ \\
\hline$\ddot{8}$ & 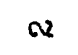 & N & & 4 \\
\hline$\curvearrowright$ & 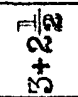 & & $-1 x$ & $\stackrel{m}{+}$ \\
\hline$\ddot{\circ}$ & 1 & & & 1 \\
\hline$\ddot{\theta}$ & $\overrightarrow{+}$ & & & $\stackrel{\vec{t}}{\sigma}$ \\
\hline$\ddot{~} \ddot{\circ}$ & $\underset{d}{+\infty}$ & & $v$ & न \\
\hline$\ddot{~} \ddot{乃}$ & $\begin{array}{l}\stackrel{\text { ताब }}{+} \\
\stackrel{\omega}{\omega}\end{array}$ & & & 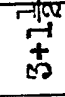 \\
\hline 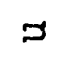 & $-\frac{1}{2} \alpha$ & & & $r+a_{2}$ \\
\hline$\ddot{ذ}$ & $\begin{array}{l}+ \\
\pm\end{array}$ & -r & & \pm \\
\hline & $\underset{F}{\dot{G}}$ & $\dot{\Delta \vec{g}}$ & $\dot{4}$ & \\
\hline
\end{tabular}




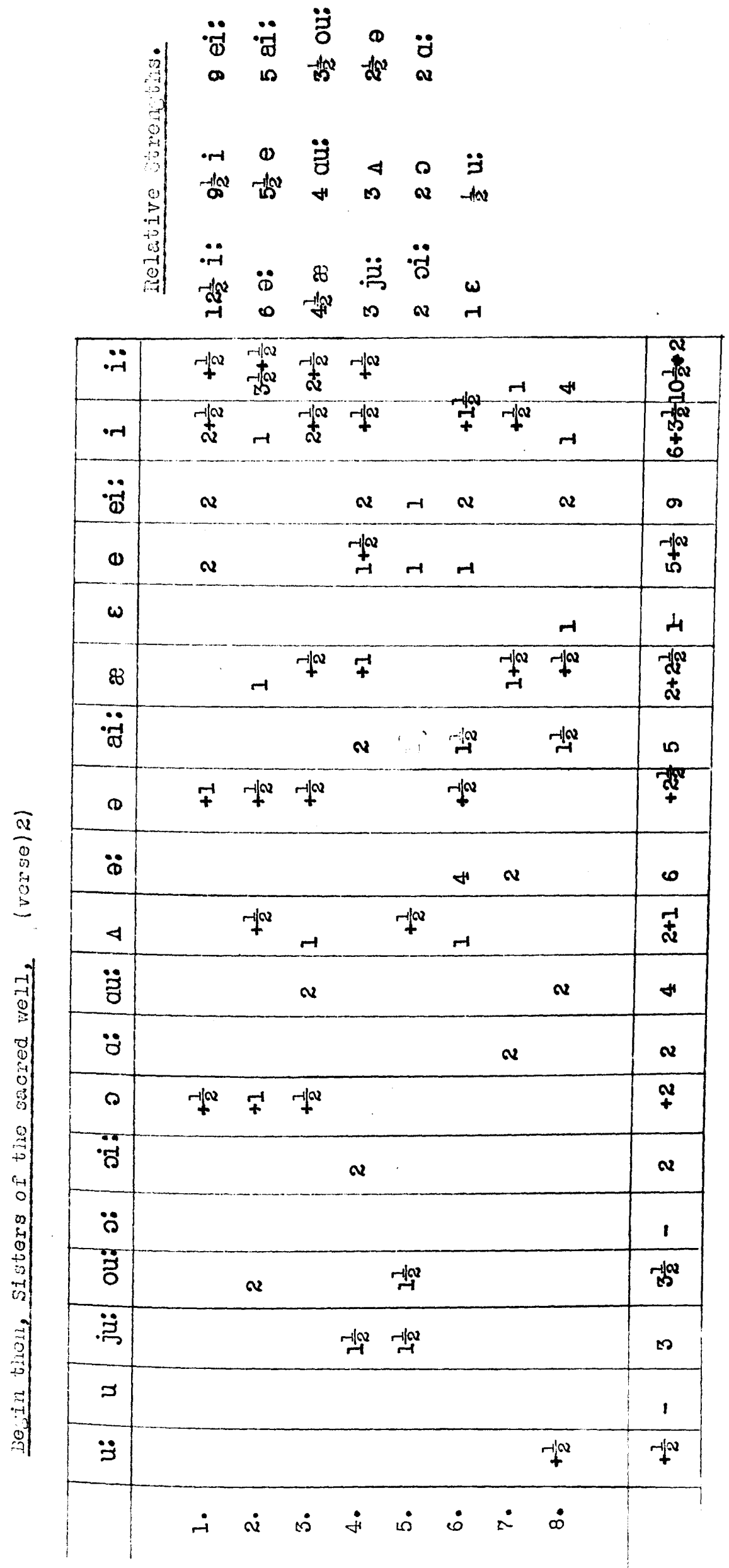




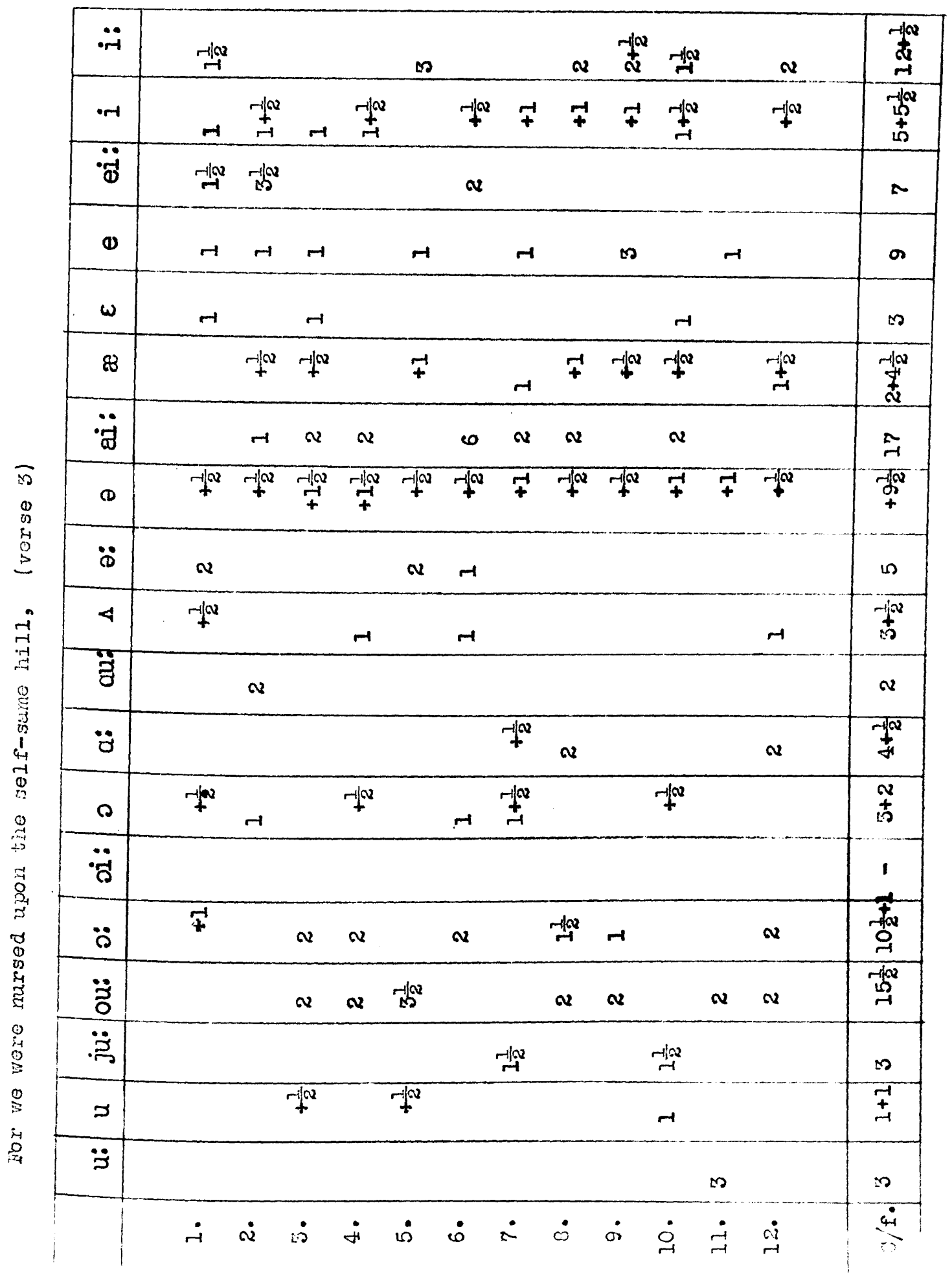




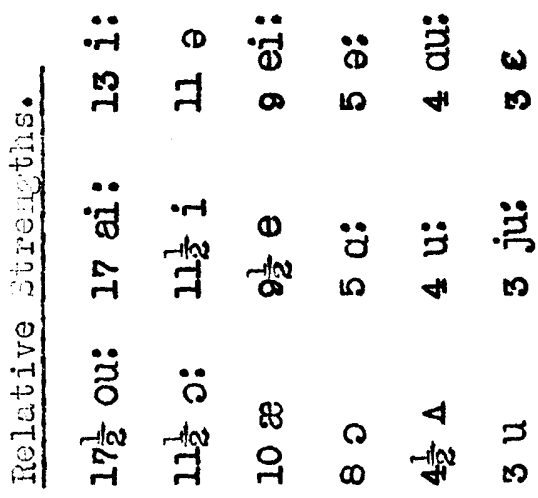

\begin{tabular}{|c|c|c|c|}
\hline$\ddot{\ddot{r}}$ & $\stackrel{-1}{a}$ & $-1 t^{\alpha}$ & \begin{tabular}{c}
-1 \\
+ \\
\multirow{2}{*}{} \\
$r-1$ \\
\end{tabular} \\
\hline$\cdot r-4$ & $\begin{array}{c}-10 \\
5 \\
+ \\
0\end{array}$ & $r$ & $\begin{array}{c}-100 \\
5 \\
5 \\
\end{array}$ \\
\hline$\ddot{\ddot{1}}$ & $\approx$ & s & os \\
\hline$\omega$ & as & $7^{2}$ & $\frac{-10}{6}$ \\
\hline دي & $B D$ & & $M$ \\
\hline 83 & 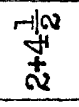 & 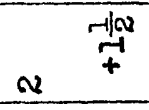 & $\stackrel{\varphi}{+}$ \\
\hline$\ddot{\ddot{d}}$ & $\hat{ت}$ & & $\tilde{-}$ \\
\hline CD & $\begin{array}{r}-10 \\
+\end{array}$ & $-1 / 20$ & $\overrightarrow{-1}$ \\
\hline$\ddot{B}$ & 10 & & 10 \\
\hline$\exists$ & $\underset{m}{m}$ & $r$ & $\stackrel{-\infty}{+}$ \\
\hline క్ర & $v$ & $v$ & 4 \\
\hline$\ddot{3}$ & $\stackrel{r a n}{+\infty}$ & $-1 \omega$ & $\stackrel{-1}{+}$ \\
\hline$\curvearrowright$ & $\begin{array}{l}v \\
+ \\
s\end{array}$ & $\stackrel{\vec{t}}{\overrightarrow{+}}$ & $\begin{array}{l}0 \\
+5 \\
0\end{array}$ \\
\hline$\ddot{~}$ & 1 & & t \\
\hline$\ddot{\circ}$ & rio & & न्त \\
\hline$\ddot{3}$ & 怨 & $\boldsymbol{v}$ & $\frac{-10 x}{\pi}$ \\
\hline 芦 & $\infty$ & & $\infty$ \\
\hline$=$ & \pm & -1 & $\vec{t}$ \\
\hline$\ddot{J}$ & $M$ & -1 & 4 \\
\hline & 出 & $\operatorname{coj}_{-1}$ & \\
\hline
\end{tabular}




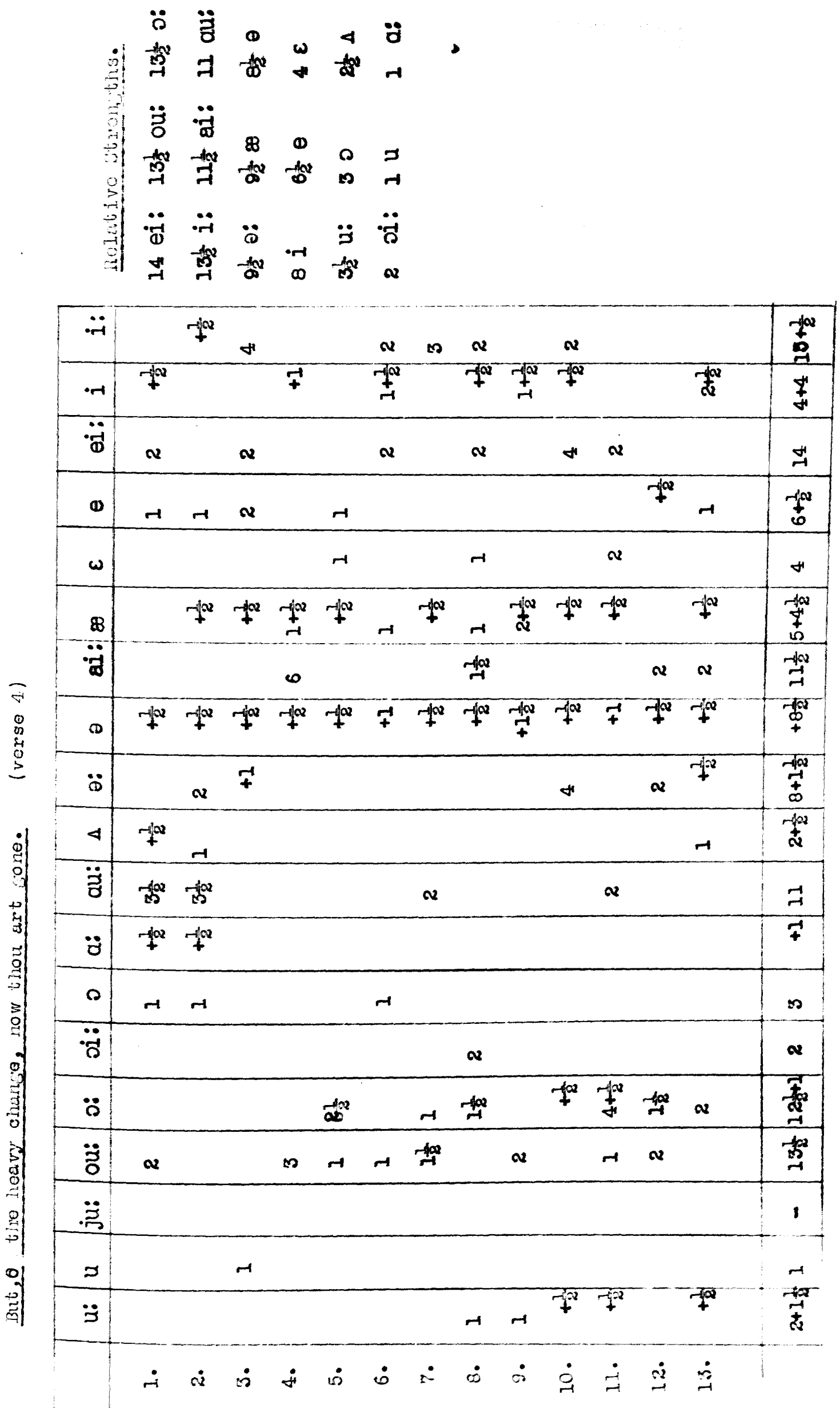




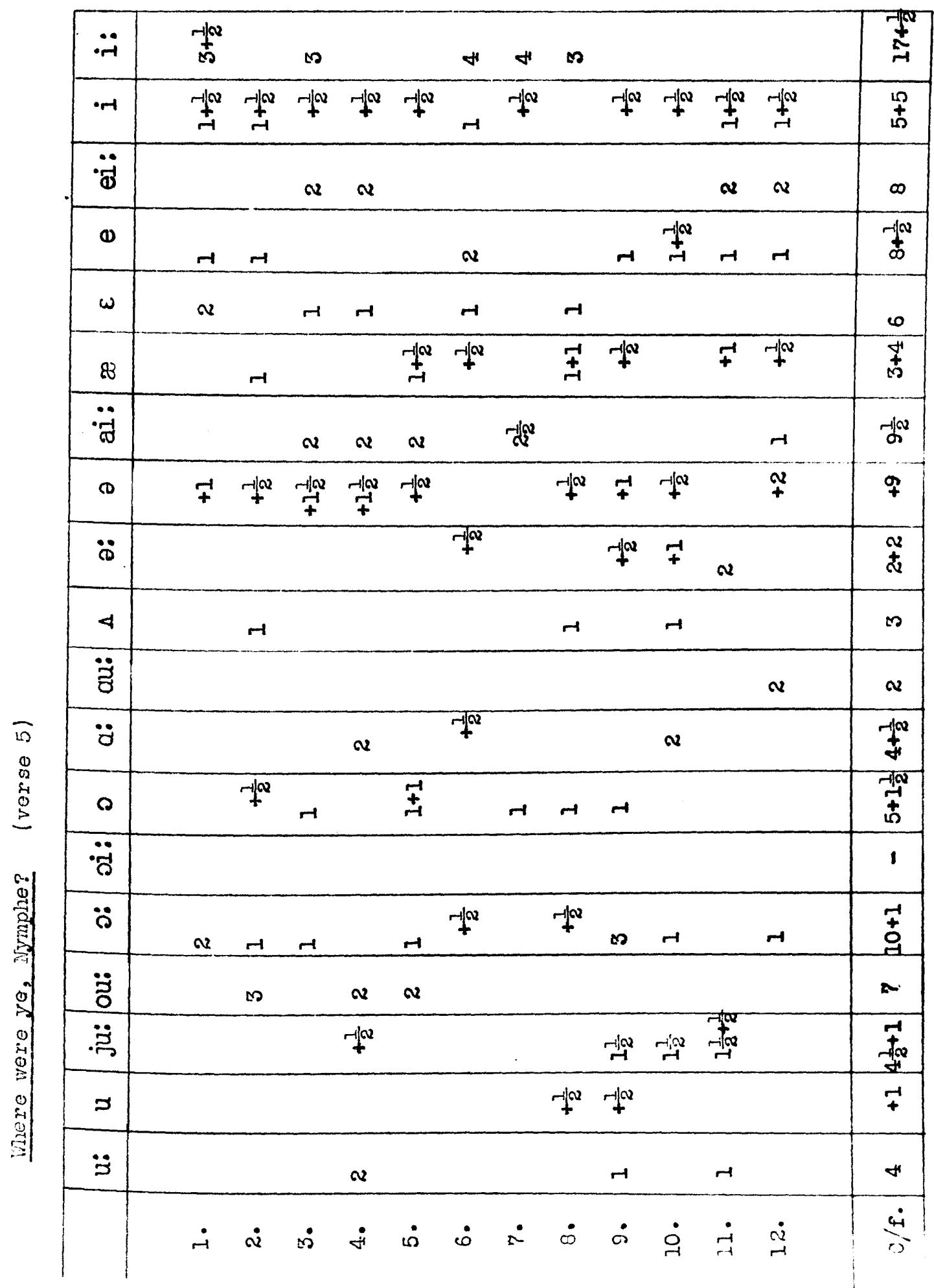




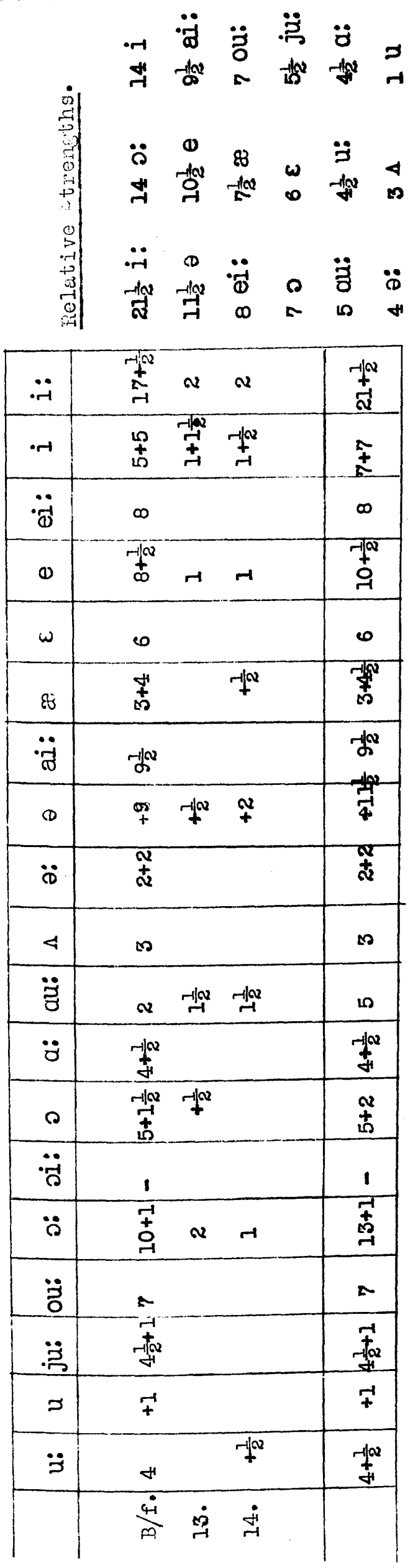




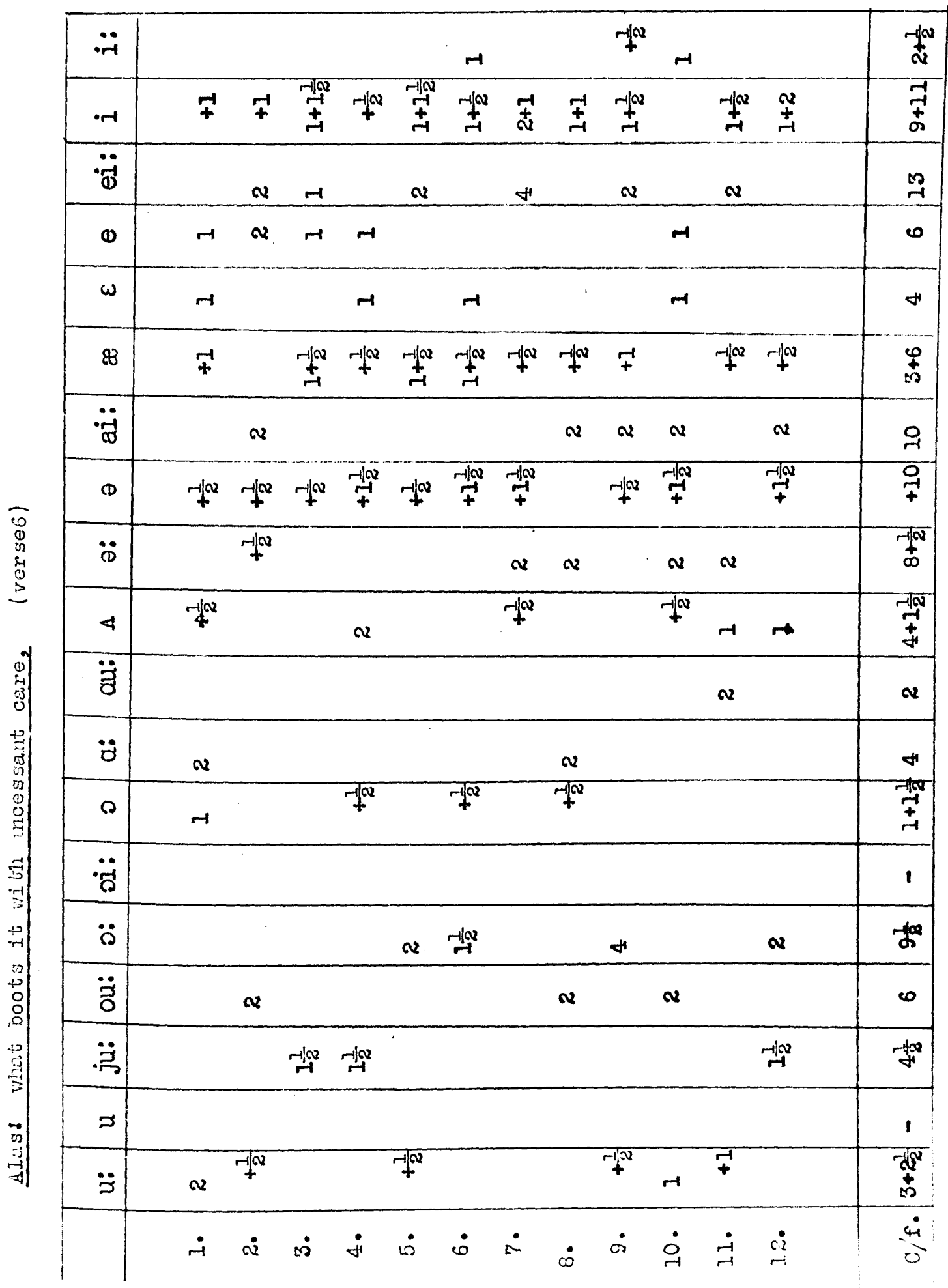




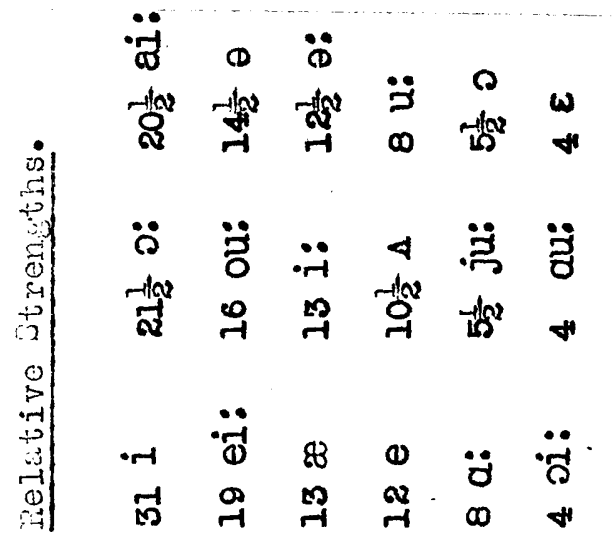

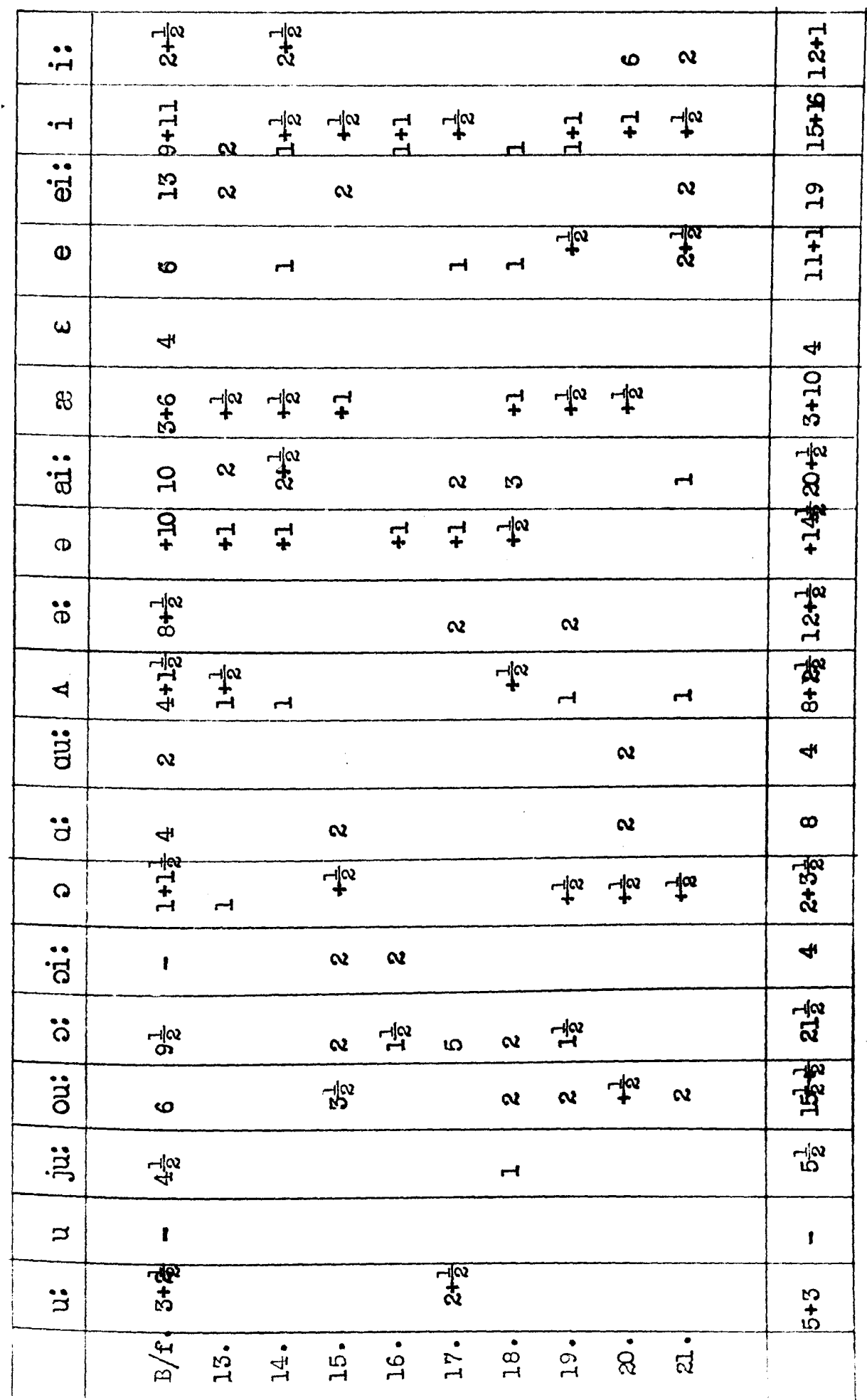




\begin{tabular}{|c|c|c|c|c|c|c|c|c|c|c|c|c|c|}
\hline$\because \ddot{r}$ & & $v$ & & $\boldsymbol{N}$ & $\sim$ & $N$ & 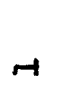 & & & dx & $:$ & $r$ & 热 \\
\hline$\cdot r$ & + & $\begin{array}{c}\text { नात } \\
\pm \\
\pm\end{array}$ & & & $r$ & 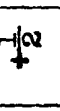 & & + & $\underset{+}{ \pm}$ & + & $F$ & $\stackrel{\substack{\infty \\
+}}{+}$ & $\begin{array}{c}-1 N \\
+ \\
+\end{array}$ \\
\hline$\ddot{\ddot{D}}$ & & & 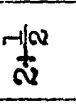 & & & $\mathbf{v}$ & $\boldsymbol{Q}$ & $\boldsymbol{Q}$ & & & -1 & $\sim$ & $\begin{array}{l}+I^{n} \\
\underset{-1}{1}\end{array}$ \\
\hline () & & & & & $r$ & $r$ & $\boldsymbol{H}$ & $H$ & $\boldsymbol{Q}$ & & & & $\boldsymbol{\omega}$ \\
\hline$\omega$ & & & & & & & & & & & & $H$ & -1 \\
\hline 88 & $\underset{-1}{+\infty}$ & $-7 \infty$ & $-1 a^{a x}$ & & $\underset{+}{+}$ & $-1 \alpha^{\alpha}$ & $+\infty$ & $\stackrel{-1 n}{\rightarrow-1}$ & 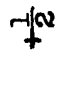 & $-1 x$ & & + & 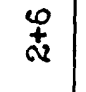 \\
\hline$\ddot{\varpi \sigma}$ & & $\sim$ & $M D$ & $r$ & & & $\mathbf{v}$ & & & & & & $\infty$ \\
\hline$\infty$ & $-x^{2}$ & $-10 x$ & $-1 x^{2}$ & & $\mp$ & & + & & $-1 x$ & & & $f^{\infty}$ & $\underset{7}{-10}$ \\
\hline$\ddot{i}$ & & & v & & & & & & & & & & 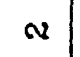 \\
\hline 4 & $-r$ & & & $r^{\prime \prime a ~}$ & & & & & $\boldsymbol{\alpha}$ & & & & नाब \\
\hline$\ddot{z}$ & $\infty$ & $N$ & & 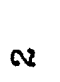 & & & $\therefore$ & & & & & & 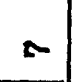 \\
\hline$\ddot{\partial}$ & & & & & & & + & $v$ & & & & $\boldsymbol{v}$ & $\infty$ \\
\hline م & $r$ & & $\underset{r-1}{-1 N}$ & & -10 & & $-1 / x$ & 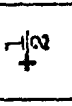 & $+\pi$ & $\begin{array}{c}-\sqrt{a} \\
\stackrel{4}{1} \\
\stackrel{4}{-1}\end{array}$ & $\simeq$ & 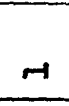 & $\begin{array}{l} \pm \\
+ \\
0\end{array}$ \\
\hline$\ddot{\circ}$ & & & & & & & & & & & & & 1 \\
\hline$\ddot{\circ}$ & & & & & & & & & & $\boldsymbol{v}$ & $\boldsymbol{\alpha}$ & & +4 \\
\hline$\ddot{3}$ & $r$ & $\sim$ & & 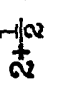 & & & & & & Q & & & $\underset{2}{ \pm}$ \\
\hline$\ddot{\ddot{B}}$ & $r$ & & & & & $r$ & & & & & $\overbrace{-1}^{i a n}$ & & - \\
\hline 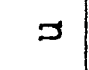 & & & & & & & & & & & & & 1 \\
\hline$\ddot{3}$ & & $\stackrel{-1 N}{-1}$ & $\boldsymbol{v}$ & & $r$ & & & $\sim$ & & & & & $\overbrace{0}^{-1 N}$ \\
\hline & $\dot{-i}$ & $\dot{\sim}$ & $\dot{10}$ & $\dot{r}$ & $\dot{ம}$ & $\dot{\omega}$ & $\check{2}$ & $\dot{\infty}$ & $\dot{\sigma}$ & $\underset{-1}{\dot{0}}$ & $\dot{ت}$ & $\begin{array}{l}\dot{\sim} \\
\overrightarrow{-1}\end{array}$ & $\frac{4}{0}$ \\
\hline
\end{tabular}




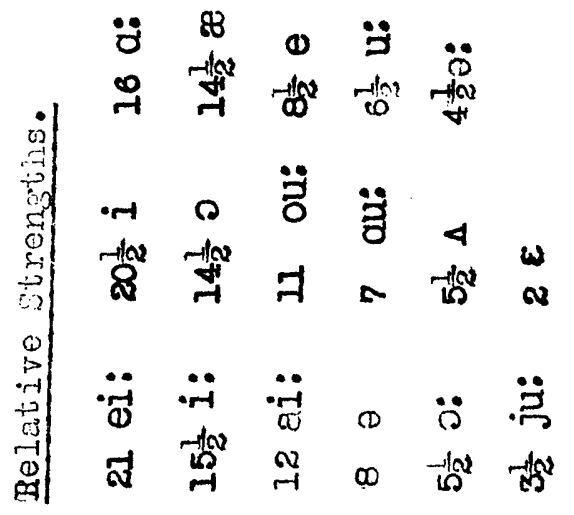

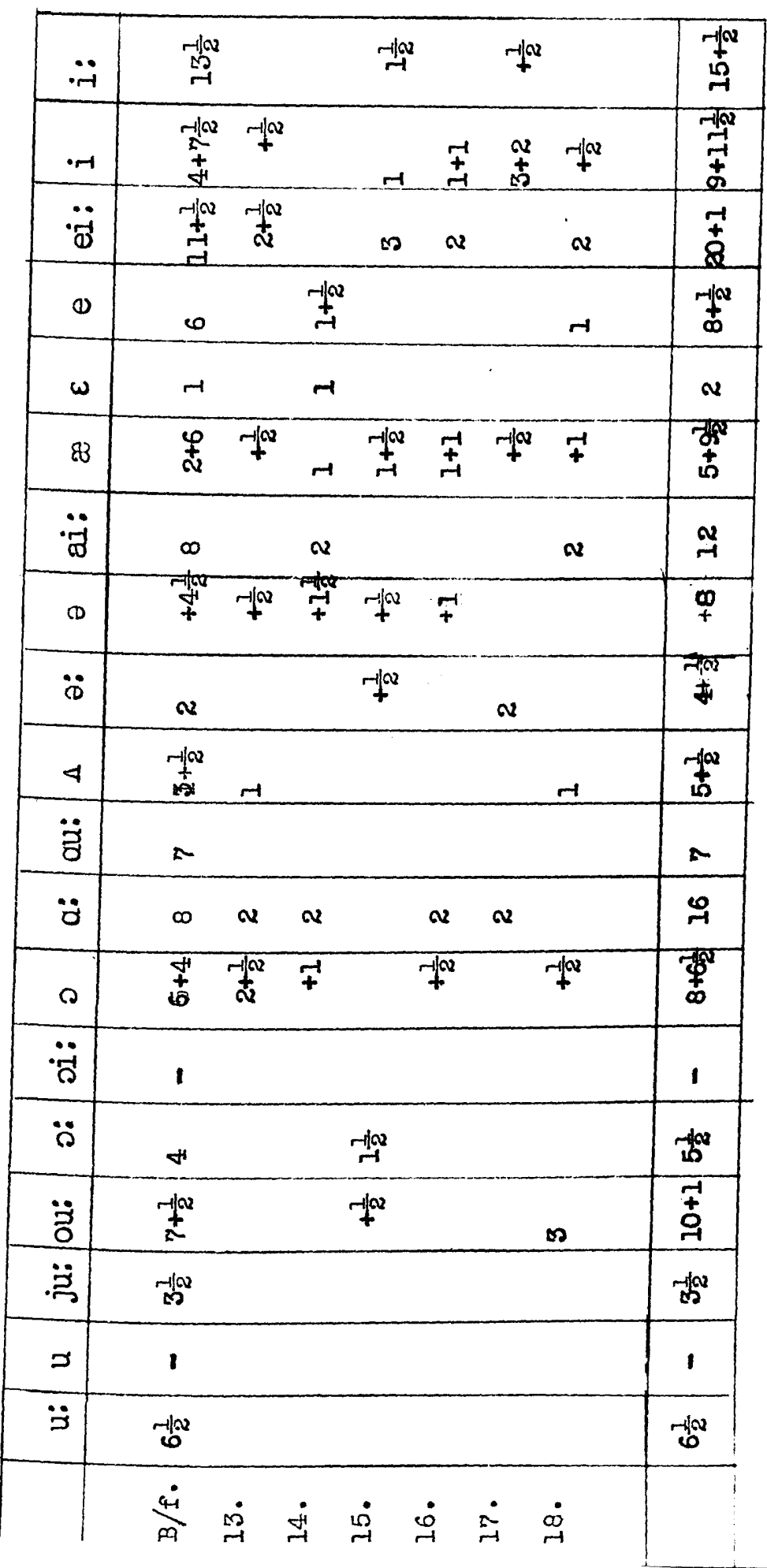




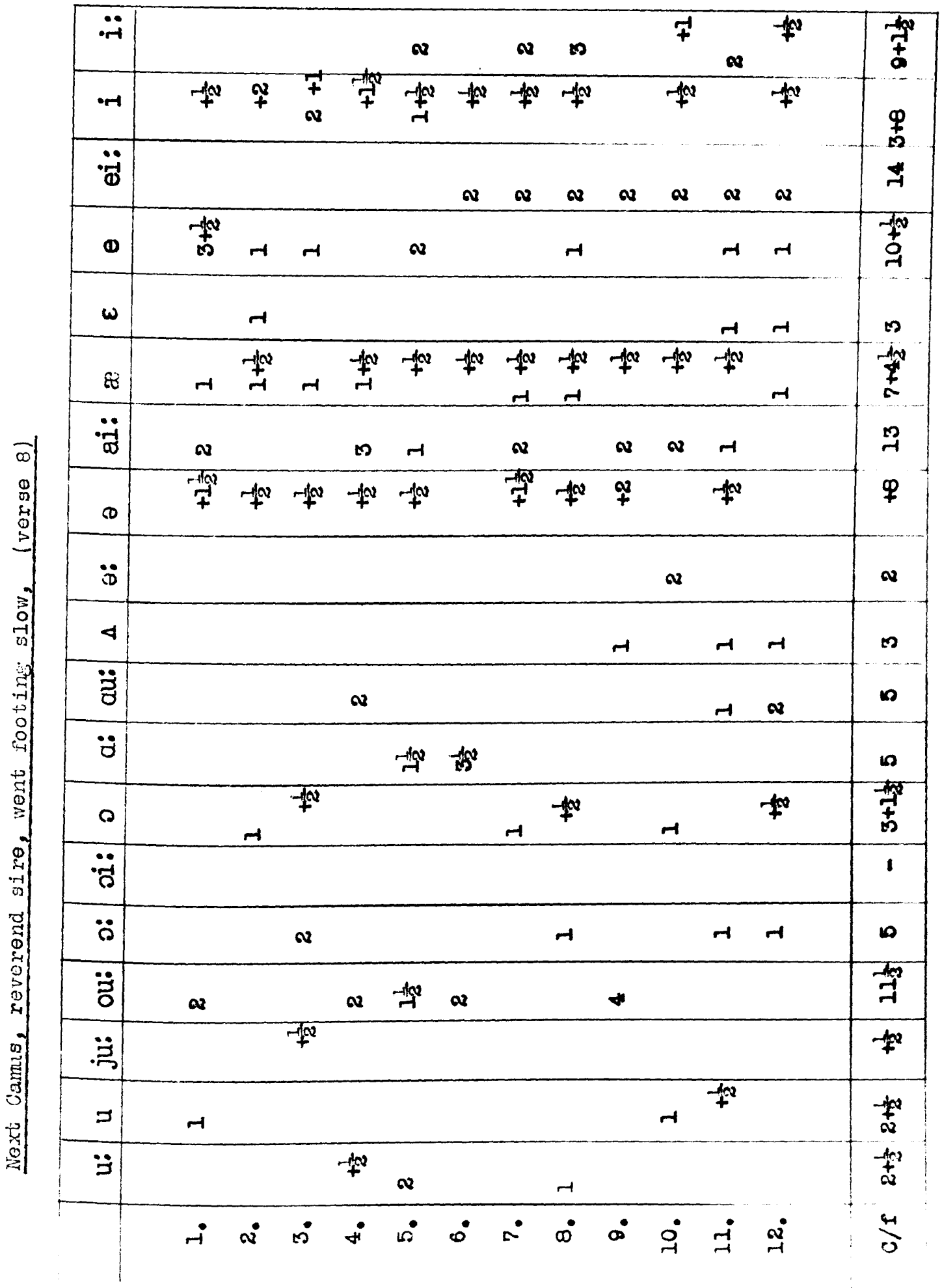




\begin{tabular}{|c|c|c|c|c|c|c|c|c|c|c|c|c|c|}
\hline 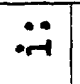 & $\begin{array}{l}4 \\
\Phi\end{array}$ & $\boldsymbol{v}$ & & $w$ & & & $H$ & $-1+9$ & $\alpha$ & $\boldsymbol{\omega}$ & & N & $\stackrel{\omega}{+}$ \\
\hline$\cdot r$ & $\underset{m}{q}$ & $\underset{-1}{-10}$ & $\underset{-1}{ \pm}$ & $H$ & $\underset{-1}{-10 x}$ & & & & $-1+$ & $\underset{-1}{-1 a x}$ & $-1 w$ & -100 & 㕝 \\
\hline$\ddot{\ddot{d}}$ & $\underset{ت}{H}$ & & $M$ & & ๙ & & $-1+\infty$ & $\propto$ & $w$ & -10 & $v$ & & $\mathbb{a}$ \\
\hline () & $\begin{array}{c}-12 \\
+ \\
0 \\
+4\end{array}$ & & -1 & & -1 & $\underset{\rightarrow}{-1}$ & -1 & & $\infty$ & -10 & -1 & -1 & 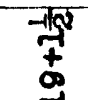 \\
\hline $\boldsymbol{\omega}$ & $B$ & & $H$ & & & -1 & & & & $r$ & -1 & & $\approx$ \\
\hline 88 & $\underset{⿱ 乛}{+10}$ & + & & $\begin{array}{l}-1 \\
+ \\
-1\end{array}$ & 7 & -10 & $-7 w$ & $\begin{array}{c}-10 \\
-1\end{array}$ & & $\begin{array}{c}-1 \\
\infty\end{array}$ & -1 & -fo & 帛 \\
\hline$\ddot{\ddot{\theta}}$ & $\stackrel{\leftrightarrow}{\rightarrow-1}$ & 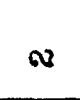 & & & & -1 lad & & & & & $\boldsymbol{N}$ & & $\underset{\sim}{-\infty}$ \\
\hline $\mathbb{D}$ & $q$ & -10 & 势 & -7 & $-1 w$ & -10 & -10 & -10 & & & & +10 & $\underset{+}{+}$ \\
\hline$\ddot{D}$ & 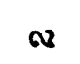 & & & & 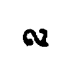 & & $\boldsymbol{v}$ & $\boldsymbol{\otimes}$ & & & & & $\infty$ \\
\hline 4 & $D$ & & $\rightarrow$ & & -1 & & & & & & & $\boldsymbol{v}$ & $n$ \\
\hline$\ddot{z}$ & ها & & & Hils & & 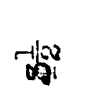 & & & & & & & 0 \\
\hline$\ddot{d}$ & L 10 & & & & & & & $\boldsymbol{\alpha}$ & -10 & & & $-H$ & $\underset{\infty}{+\infty}$ \\
\hline م & 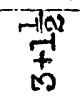 & & $-7 \omega^{2}$ & & & & & & $\overrightarrow{+}$ & $-H$ & $F$ & -10 & 禁 \\
\hline$\ddot{c}$ & 1 & & & & & & & & & & & & 1 \\
\hline$\ddot{b}$ & 10 & & & & & & in & & & & $\boldsymbol{v}$ & . & $\begin{array}{l}+10 \\
-\infty\end{array}$ \\
\hline$\ddot{z}$ & $\stackrel{-10}{7}$ & o & & & & $H$ & & & & & & & $\stackrel{-\infty}{-}$ \\
\hline 苛 & -10 & & & & & & & & & & & & -10 \\
\hline$s$ & $\begin{array}{c}-1+ \\
\infty \\
\infty\end{array}$ & & & & & & -1 & -100 & & & & $r$ & $\underset{f}{+}$ \\
\hline$\ddot{j}$ & $\begin{array}{c}-10 \\
0 \\
0\end{array}$ & $\begin{array}{l}-100 \\
+\infty \\
a\end{array}$ & & $-1 \omega$ & & $\rightarrow$ & & -10 & & & & & $\underset{ \pm}{\stackrel{q}{+}}$ \\
\hline & $\frac{m}{m}$ & $\stackrel{0}{\circ}$ & में & ฉٌ & $\underset{\sim}{\oplus}$ & $\dot{\sim}$ & $\underset{\sim}{\dot{0}}$ & $\underset{-}{\dot{-}}$ & $\dot{a}$ & $\dot{a}$ & $\dot{\mathfrak{w}}$ & $\mathfrak{a}$ & $\frac{4}{0}$ \\
\hline
\end{tabular}




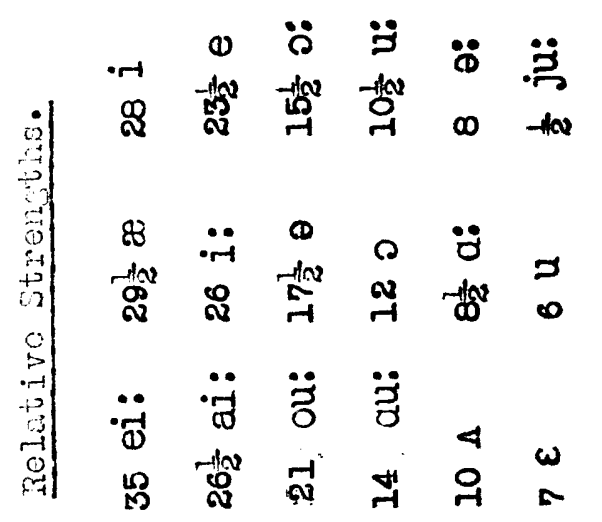

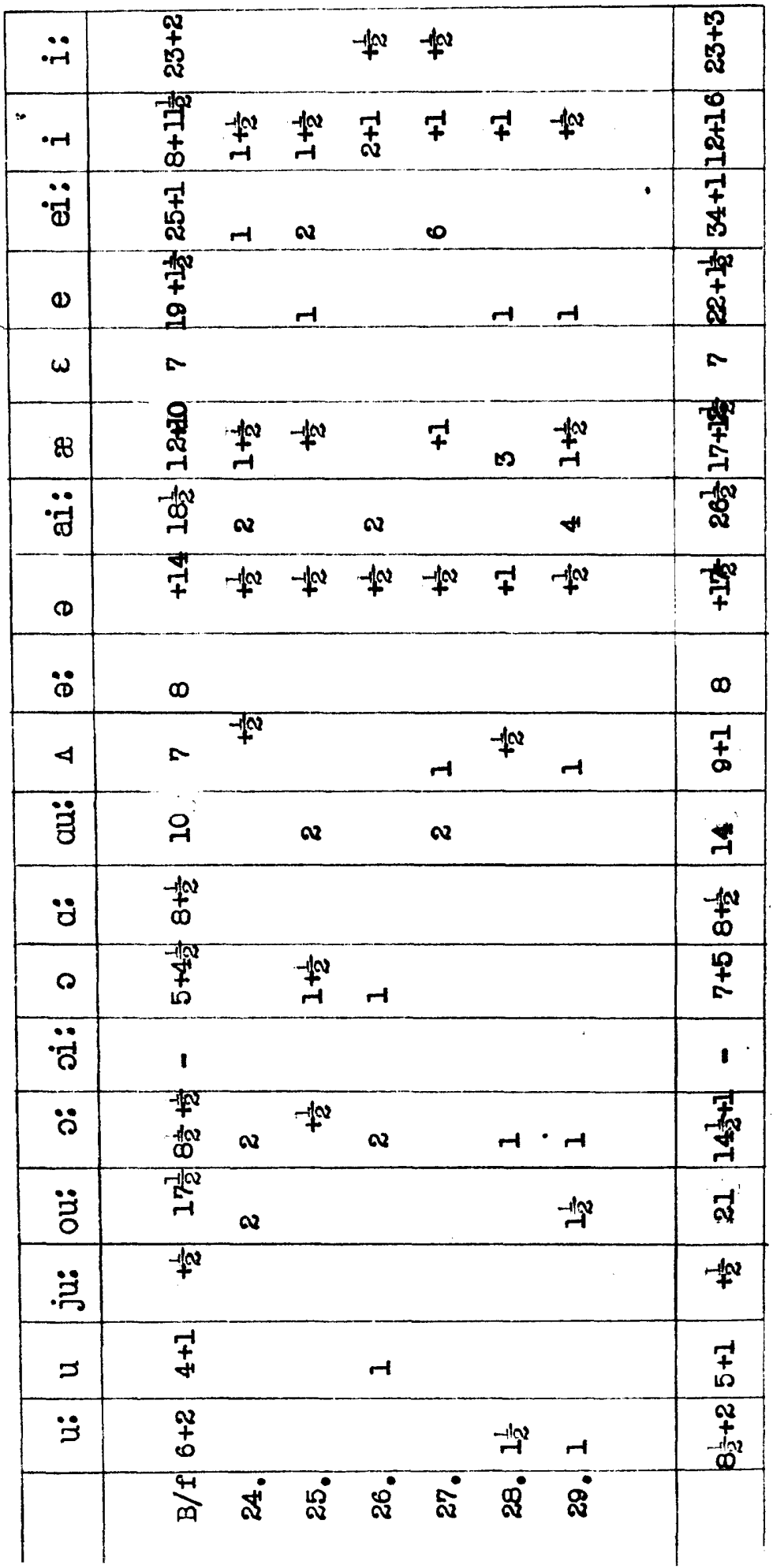




\begin{tabular}{|c|c|c|c|c|c|c|c|c|c|c|}
\hline$\ddot{-i}$ & 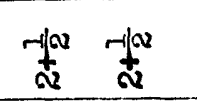 & & $=$ & & & $-11 \infty$ & $a$ & & & $\underset{+}{+1+n}$ \\
\hline$\cdot-1$ & $-I^{2} \underset{+}{-1}$ & & $-1+4$ & $-1 \infty$ & $-1 \infty$ & $\rightarrow$ & $-1+\infty$ & & $-1 \infty$ & $\stackrel{20}{+2}$ \\
\hline$\ddot{\otimes}$ & & $\infty$ & +10 & $\sim$ & & $\alpha$ & & $-\sqrt{d} e_{0}$ & Hiag & $\Rightarrow$ \\
\hline $\boldsymbol{\omega}$ & $\rightarrow$ & $7^{2}$ & $\rightarrow$ & & $r$ & & & & -1 & $\frac{-110}{4}$ \\
\hline$\omega$ & & & $\rightarrow \quad r$ & & $H$ & & & & & $\infty$ \\
\hline 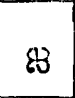 & +10 & 7 & + & 7 & 4 & -1 & $\rightarrow \quad t^{\prime a x}$ & $f^{10}$ & 7 & 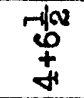 \\
\hline$\ddot{\ddot{\theta}}$ & -1 & ( & $\Omega$ & $\infty$ & & $\alpha$ & & $\alpha$ & $r$ & 9 \\
\hline$\infty$ & 7 & +7 & $-1+27$ & 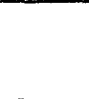 & 7 & 7 & $\stackrel{-1}{+}$ & + & -10 & $\stackrel{+}{+}$ \\
\hline$\ddot{\phi}$ & 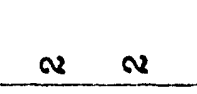 & & & & & & $\infty \quad+$ & & & $\stackrel{9}{9}$ \\
\hline 4 & H & & & $r$ & & & $\alpha$ & & $r$ & מ \\
\hline$\tilde{z}$ & & & + & & & & $\alpha \quad+$ & & & P \\
\hline$\ddot{0}$ & $\approx$ & $\approx$ & & & 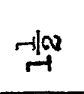 & & & & & -160 \\
\hline 0 & & & $-1+a$ & $\underset{⿱}{ \pm}$ & 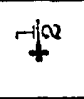 & & $-10 x$ & & & 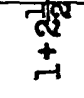 \\
\hline$\ddot{\sigma}$ & 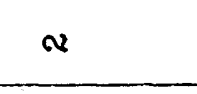 & & & & & & & & & $\approx$ \\
\hline$\ddot{b}$ & & $\sim$ & & & 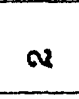 & $\rightarrow$ & $\infty$ & $f_{+}^{1 / 2}$ & & Fia \\
\hline$\ddot{\partial}$ & & & a & & & riged & & $H$ & 4 & $-1 \infty$ \\
\hline$\ddot{\ddot{g}}$ & $H_{1}^{2}$ & 7 & 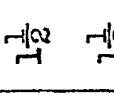 & & & $-10 a$ & & & & 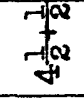 \\
\hline$\Rightarrow$ & & & & & -1 & & & & & 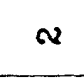 \\
\hline$\ddot{z}$ & & & & & - & & & & & -1 \\
\hline & $\dot{i} \quad \dot{\alpha}$ & $\dot{8}$ & $\dot{4}$ & $\dot{0}$ & $\therefore$ & $\dot{\infty}$ & $\dot{\circ} \dot{\oplus}$ & $\dot{\vec{G}}$ & $\dot{\sim}$ & $\dot{4}$ \\
\hline
\end{tabular}




\begin{tabular}{|c|c|c|c|c|c|c|c|c|c|c|c|c|c|}
\hline$\ddot{~}$ & $\underset{\Sigma}{\stackrel{-1 \alpha}{+}}$ & $\alpha$ & & & & & & & $\stackrel{-110}{+}$ & v & & $\omega$ & $\underset{⿱}{ \pm}$ \\
\hline$\cdot r-1$ & $\underset{⿱ 10}{ \pm}$ & $\underset{ \pm}{+}$ & $-1 \infty$ & & $\underset{-}{ \pm}$ & + & $\stackrel{\vec{t}}{ \pm}$ & $\underset{m}{+1}$ & $\underset{+}{+}$ & & 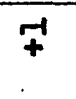 & 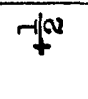 & 离 \\
\hline$\ddot{\vec{j}}$ & $\underset{+1}{+}$ & & & & & & & & & 4 & $\Omega$ & & $\begin{array}{l}+ \\
+ \\
M\end{array}$ \\
\hline (1) & $\underset{+}{-1}$ & -1 & $-1 x^{2}$ & -1 & $\sim$ & $\underset{r}{-1 \times a}$ & -1 & & & & $r$ & & $\begin{array}{l}7+1 \\
+ \\
\pm \\
-1\end{array}$ \\
\hline$\omega$ & $m$ & & & & & $r$ & & -1 & $r$ & & & & 0 \\
\hline 80 & $\begin{array}{c}7 \pi^{2} \\
0 \\
+ \\
+1\end{array}$ & $\underset{-1}{\stackrel{-1}{a}}$ & & $F$ & $\stackrel{-10}{-1}$ & $\underset{+}{+1}$ & $\stackrel{-10 x}{\mathbf{N}}$ & $\underset{+}{ \pm}$ & & & -1 & $-1+\infty$ & $\underset{-}{\stackrel{P}{+}}$ \\
\hline$\ddot{\ddot{\sigma}}$ & 어 & $v$ & $\alpha$ & 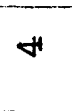 & & & . & & $v$ & 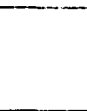 & $\alpha$ & तूd & ना山 \\
\hline $\mathbb{D}$ & नु/ & 7 & $-11 a^{2}$ & $\stackrel{-\pi / a,}{\rightarrow+}$ & $-1 \sqrt{x}$ & $\underset{+}{-1 \pi}$ & $-1 \ldots$ & -10 & $-1 \omega$ & $-1 \infty$ & $-1 \infty$ & $\overrightarrow{+}$ & $\underset{7}{\infty}$ \\
\hline$\ddot{B D}$ & 어 & & & & & & & & $\alpha$ & & $H$ & & $\rightarrow$ \\
\hline 4 & 10 & & & $H$ & & & & -1 & & & & & 2 \\
\hline$\ddot{\Xi}$ & 욱 & & & & 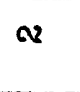 & 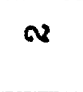 & & & & & & $\boldsymbol{v}$ & $\mathscr{\sim}$ \\
\hline$\ddot{z}$ & - Ho & & & & & & & & & & $-1+\infty$ & & 檚 \\
\hline 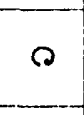 & 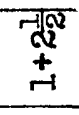 & & & & $r$ & & & & & & & & 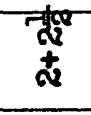 \\
\hline$\ddot{\ddot{c}}$ & $\boldsymbol{v}$ & & & & & $\alpha$ & & & & & & & 4 \\
\hline$\ddot{\rho}$ & $\begin{array}{l}-1 \infty \\
-1 \infty \\
-1 \infty\end{array}$ & & & & & & $-w_{-1}^{-1}$ & & $\boldsymbol{N}$ & -1 & +4 & $\rightarrow$ & $\underset{7}{\stackrel{t}{*}}$ \\
\hline$\ddot{\tilde{z}}$ & $-\omega_{\infty}^{\infty}$ & & 留 & $\boldsymbol{v}$ & & & & & & tho & & & $\underset{-1}{+}$ \\
\hline .̈̈ & 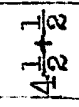 & & & & & & $H_{-1}^{\infty}$ & & & & & & $\underset{0}{+\infty}$ \\
\hline 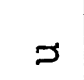 & $\sim$ & & & $H$ & & & & & & & & & $m$ \\
\hline$\ddot{\Xi}$ & $r$ & & & & & & & & o & +1 & & & $\underset{f+\infty}{+\infty}$ \\
\hline & $\frac{4-1}{\rho 9}$ & $\dot{\vec{r}}$ & $\underset{\rightarrow}{\dot{H}}$ & $\dot{\vec{n}}$ & $\dot{\leftrightarrow}$ & $\dot{\Sigma}$ & $\begin{array}{l}\dot{\infty} \\
\vec{r}\end{array}$ & $\underset{\rightarrow}{\dot{\leftrightarrow}}$ & $\dot{8}$ & $\dot{\vec{N}}$ & $\dot{\stackrel{\sim}{N}}$ & $\dot{\mathfrak{a}}$ & $\dot{4}$ \\
\hline
\end{tabular}




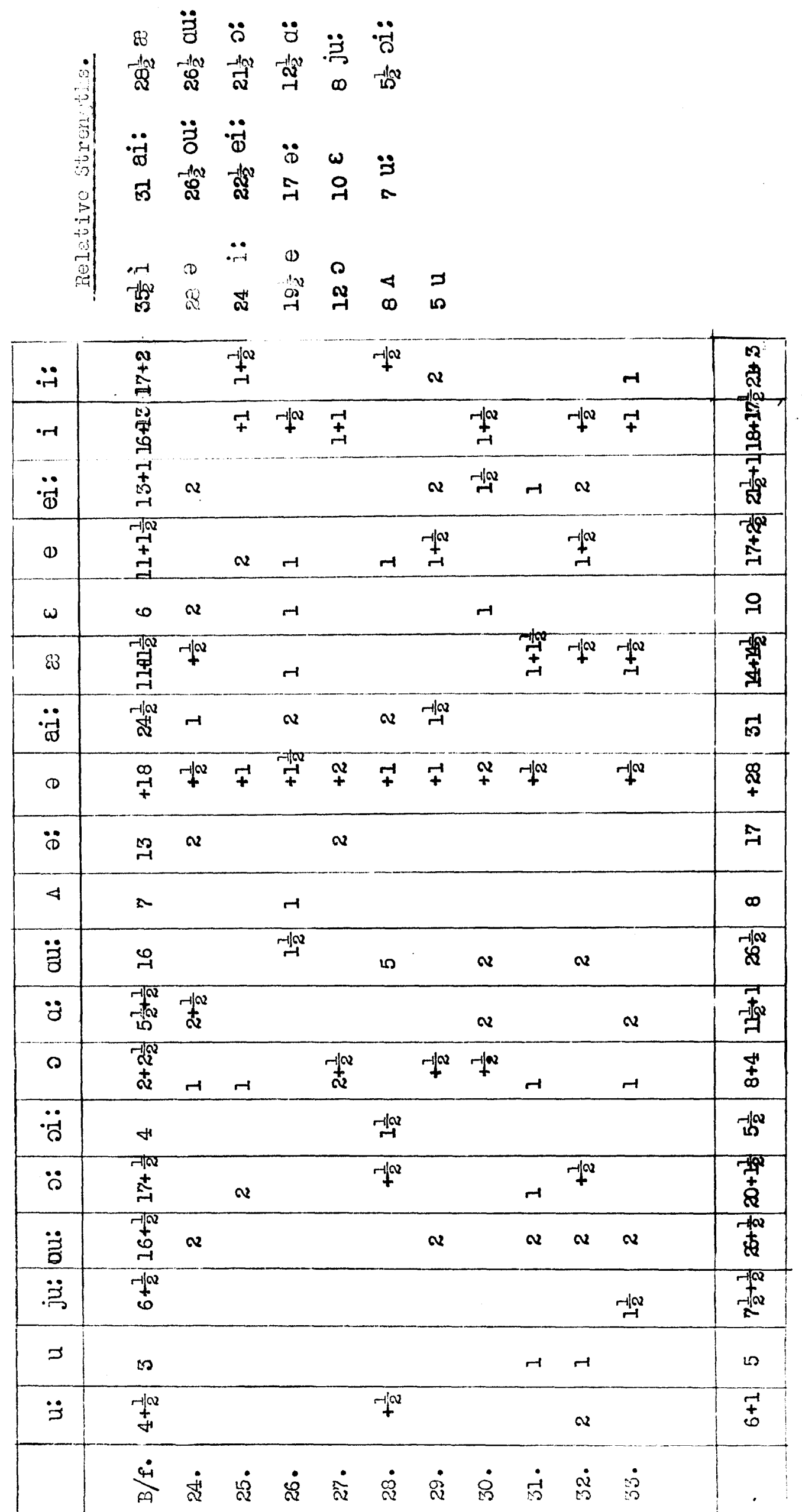




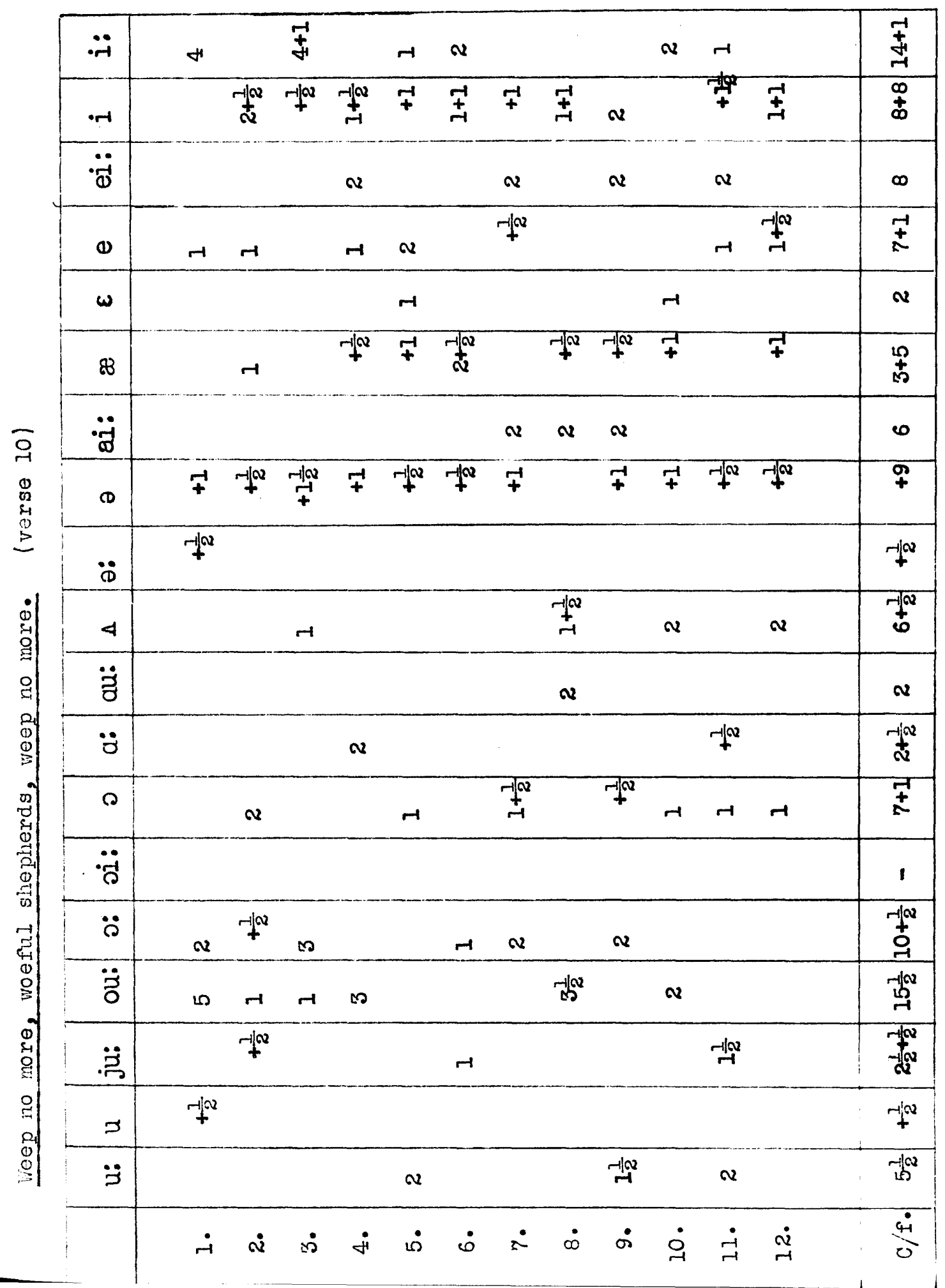




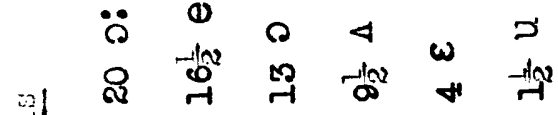

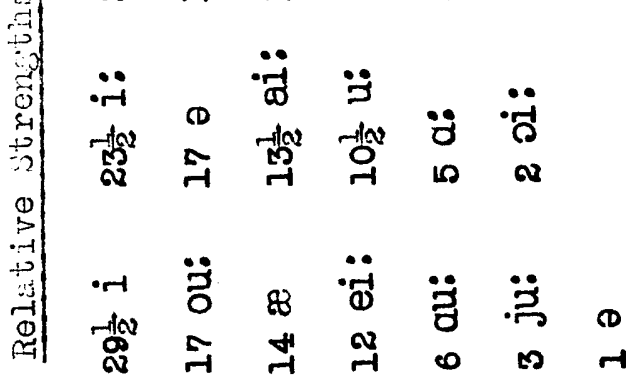

\begin{tabular}{|c|c|c|c|c|c|c|c|c|c|c|}
\hline$\because \because$ & $\begin{array}{l}-+ \\
+ \\
+\end{array}$ & 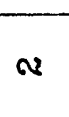 & & $\sim$ & & & $v$ & $v$ & 7 & רָ \\
\hline$\cdot \rightarrow-1$ & $\begin{array}{l}\infty \\
\substack{++\infty}\end{array}$ & $\underset{-1}{-19}$ & $-1 x^{2}$ & $\underset{+}{ \pm}$ & $+r$ & $\underset{-1}{-1 x}$ & $\stackrel{-1+\infty}{\rightarrow}$ & $77^{\infty}$ & $\Gamma^{-1 \alpha} \underset{\sim}{-1 \alpha}$ & 桵 \\
\hline$\ddot{\overrightarrow{0}}$ & $\infty$ & & 4 & & & & & & & $\underset{-1}{\mathfrak{r}}$ \\
\hline (1) & $\underset{ \pm}{+}$ & $r$ & -1 & $-1 x^{2}$ & & -1 & $r$ & -1 & $\sim \quad-1$ & 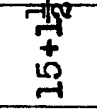 \\
\hline$\omega$ & $\alpha$ & & $r$ & & $r$ & & & & & 4 \\
\hline 8 & $\stackrel{p}{p}$ & $7+10 x$ & $-1 \infty$ & $-1 \alpha^{2}$ & 7 & $-10 x$ & $H$ & & 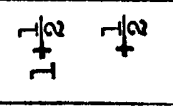 & $\begin{array}{l}9 \\
\stackrel{9}{0} \\
\text { in }\end{array}$ \\
\hline$\ddot{\ddot{d}}$ & 0 & & & $v$ & & 4 & & & $\stackrel{-1 w^{\alpha}}{\rightarrow}$ & -jan \\
\hline (1) & $\Phi$ & 7 & 7 & & & + & & $\stackrel{\text { T }}{+}$ & $\frac{7 \pi}{4}$ & $\stackrel{7}{7}$ \\
\hline$\ddot{0}$ & $-1 / a^{2}$ & & & & & & -7 & & & $F$ \\
\hline 4 & $\pm_{0}^{-1 a x}$ & $r$ & $\rightarrow$ & & & & & & -1 & $\begin{array}{c}-110 \\
\vdots \\
5\end{array}$ \\
\hline$\ddot{z}$ & 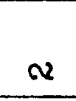 & & & & & & $\sim$ & $\curvearrowright$ & $\therefore$ & 0 \\
\hline$\ddot{8}$ & 留称 & & & & & & & -1 & $\stackrel{-1 \alpha}{-1}$ & ना/ \\
\hline$\curvearrowright$ & \pm & $-1 a$ & & $-r$ & & $\rightarrow$ & & $\rightarrow$ & $\begin{array}{rr}4 x^{2} & \\
& -1 \\
\end{array}$ & $\stackrel{+}{\underset{G}{-}}$ \\
\hline$\ddot{\circ}$ & 1 & $\sim$ & & & & & & & & $\boldsymbol{\alpha}$ \\
\hline$\ddot{\circ}$ & rida & & 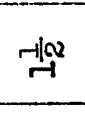 & & $\boldsymbol{v}$ & -1100 & -1 & $\infty$ & $i_{-1}^{-10 x}$ & $\begin{array}{l}7 \\
+ \\
-9 \\
-7\end{array}$ \\
\hline$\ddot{\partial}$ & 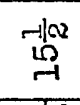 & & & -10 & & & $r$ & & & 禁 \\
\hline$\ddot{\ddot{n}}$ & $\begin{array}{l}7 \sqrt{2} \\
d^{2}\end{array}$ & & & & & & & & & 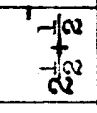 \\
\hline 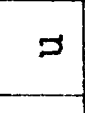 & $-1+a x$ & & & & & & & & $-r$ & $\stackrel{-1 \infty}{-1}$ \\
\hline$\ddot{3}$ & in & & & 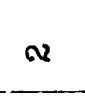 & $\approx$ & & & & $r$ & $\stackrel{-10 x}{0}$ \\
\hline & $\dot{\varphi}$ & $\dot{\vec{q}}$ & $\underset{H}{\dot{H}}$ & $\dot{\leftrightarrow}$ & $\dot{\theta}$ & $\dot{\vec{s}}$ & $\underset{r+}{\dot{\infty}}$ & $\dot{\vec{\sigma}}$ & $\dot{\Sigma} \quad \dot{\vec{N}}$ & \\
\hline
\end{tabular}




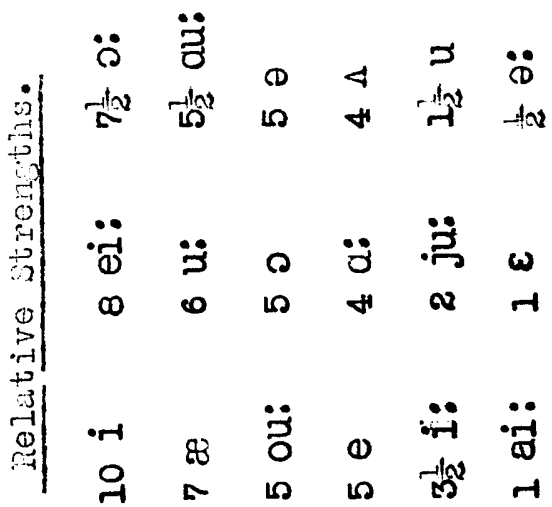

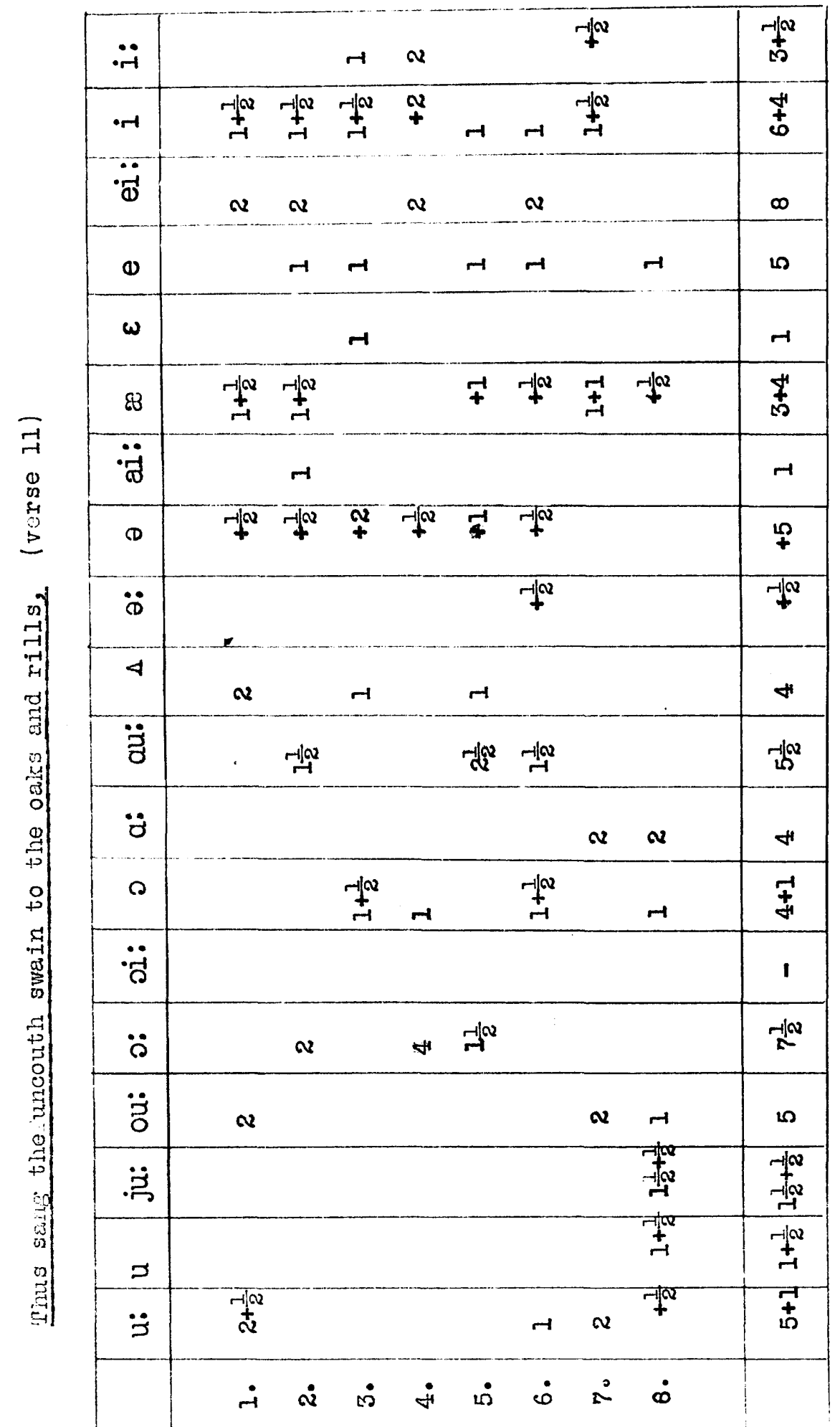


0

$z$

(a)

$D$

$\sigma$

서

o 


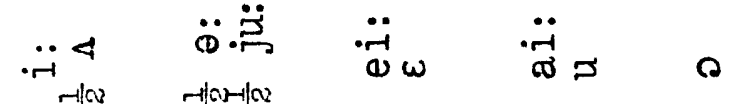

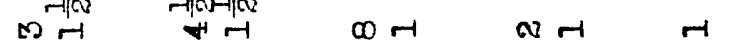

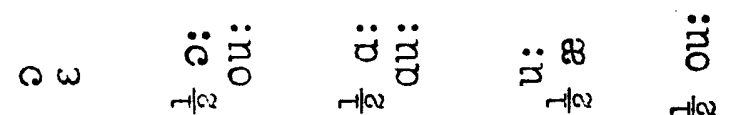

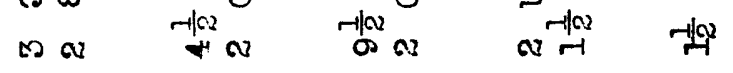

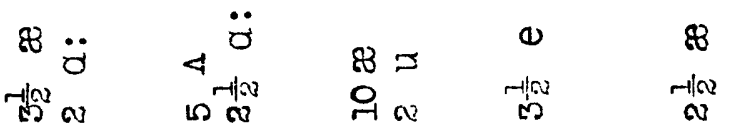

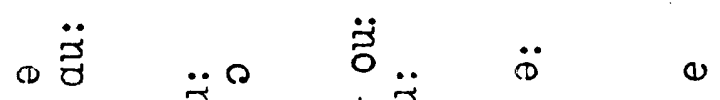

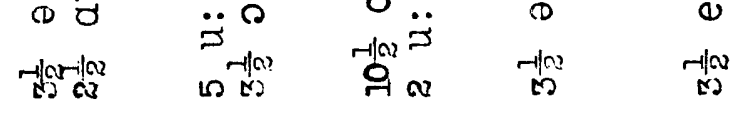

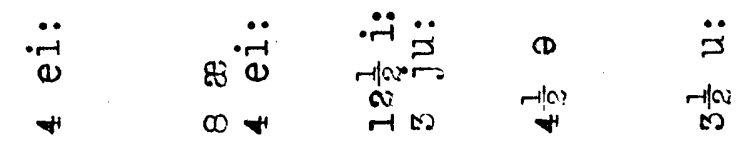

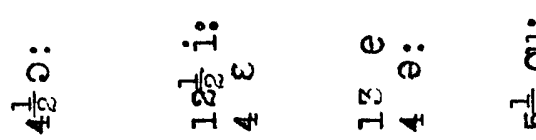

(1)

-

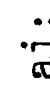

$\infty$

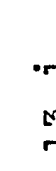

$\ddot{z}$

约

(1)

$\pi / 2$

$4 \quad \ddot{r}$

$-100$

-1 10

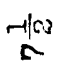

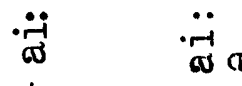

-

anco

4

$\underset{4}{4-100}$

0
-102
$4-4$

$\ddot{-r}$

$-1$

$n-103$
$\infty$
$m$

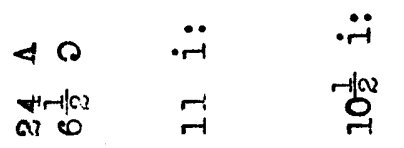

$\underset{\infty}{\ddot{\infty}}$

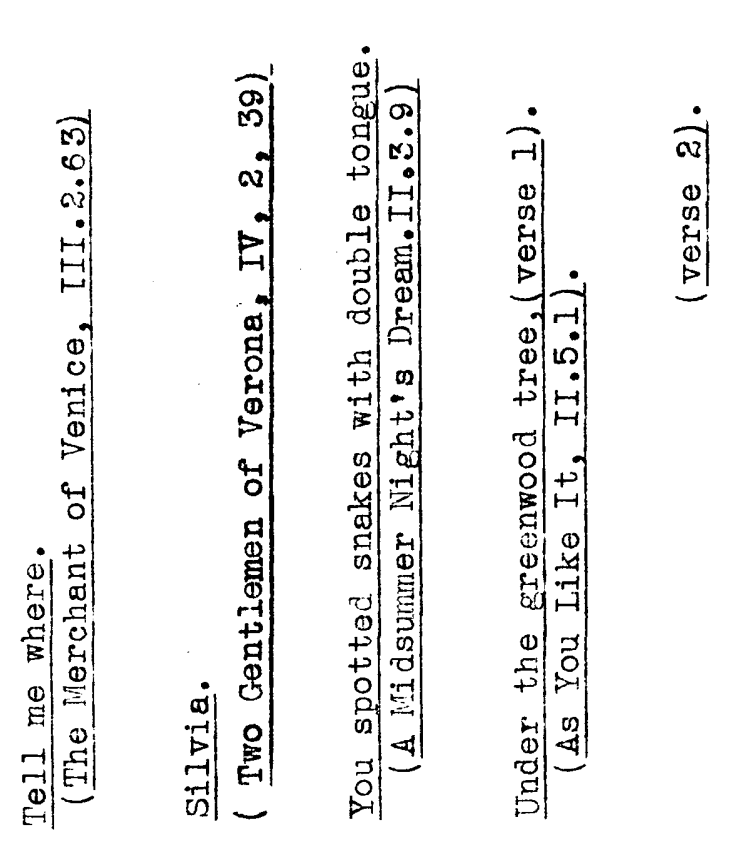

$\ddot{\partial} \ddot{0}$

- $-\| v \quad$ a $\ddot{\sim}$

$\infty \pi$ क

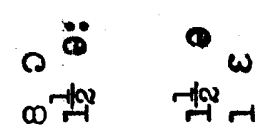

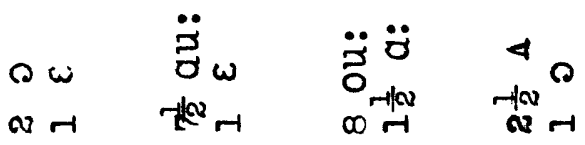

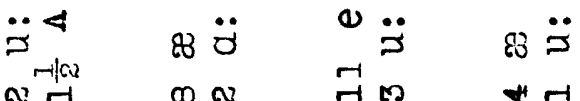

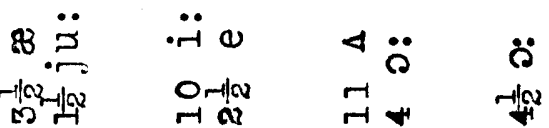

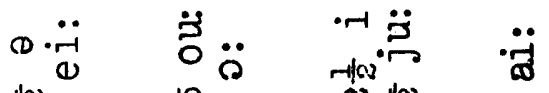

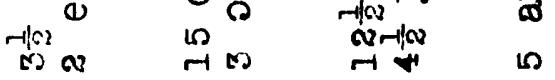

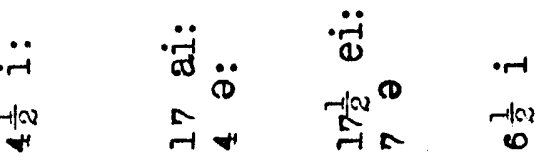

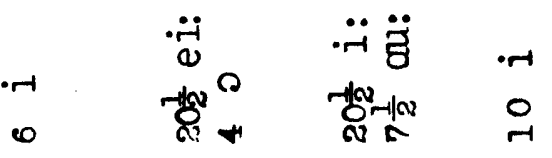

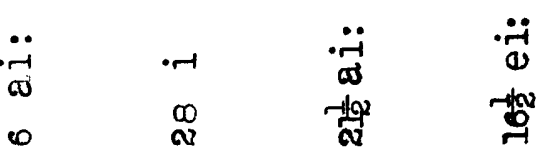




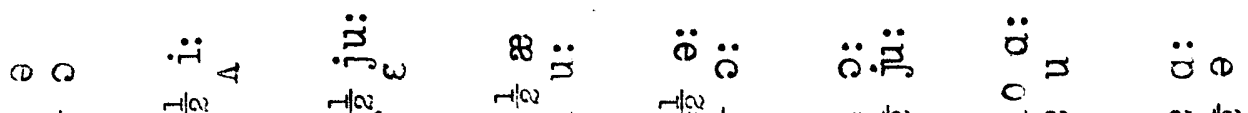

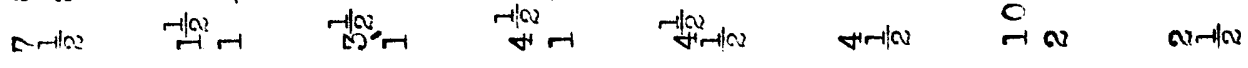

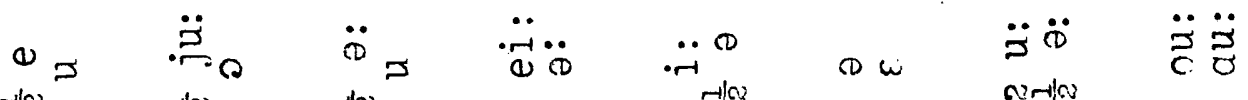

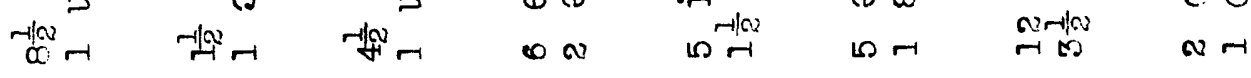

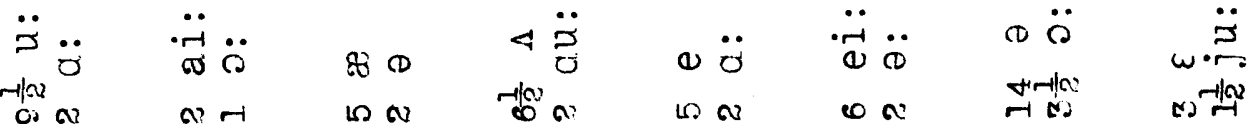

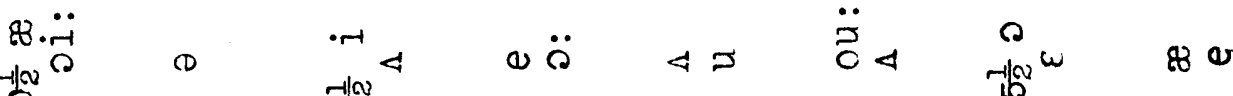

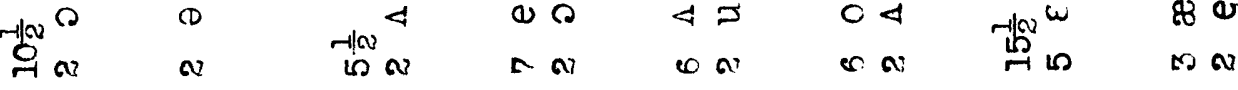

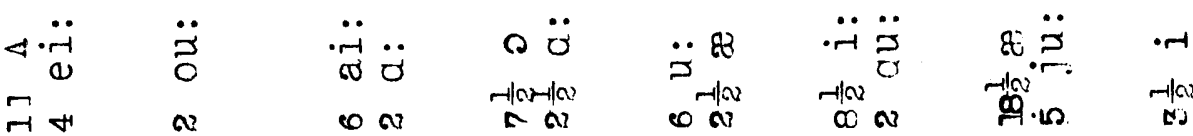

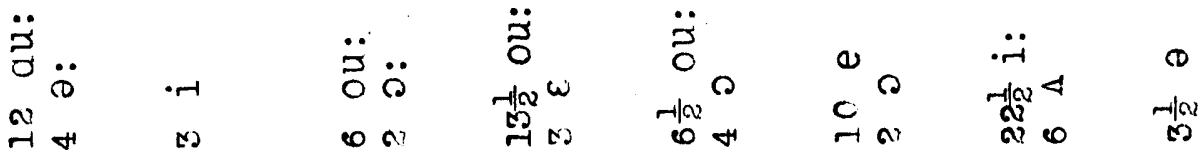

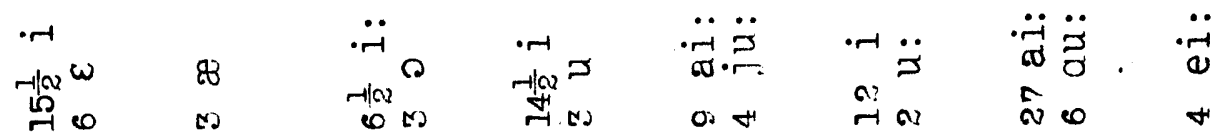

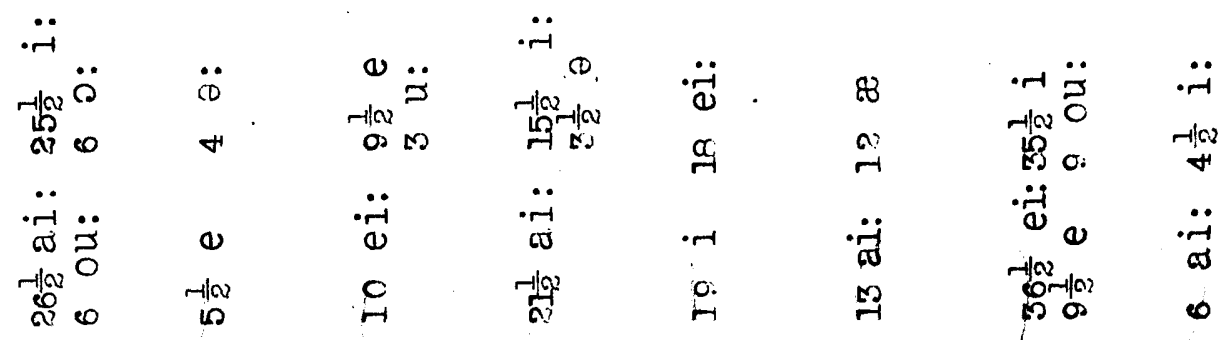

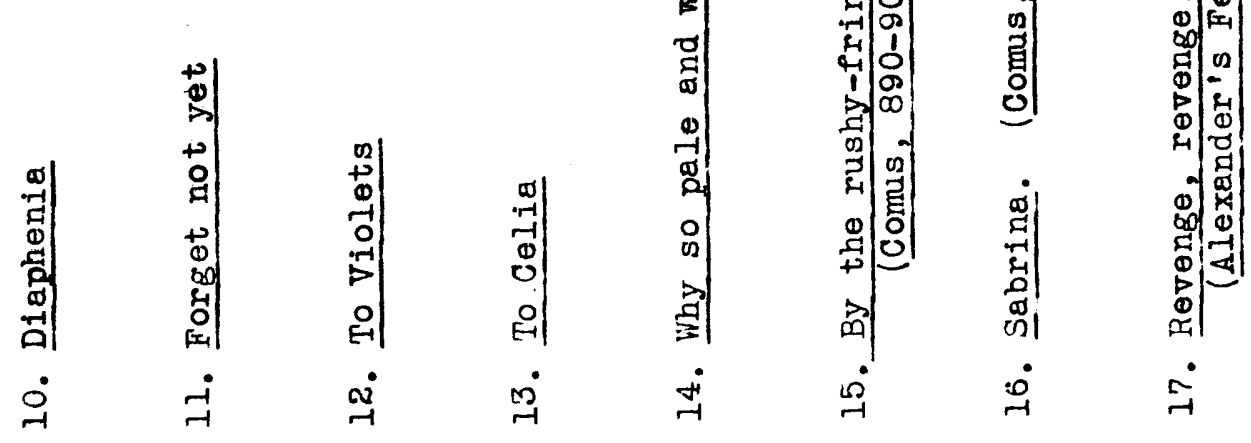


$\ddot{4}$

$\ddot{\theta} \ddot{0} \quad \& \ddot{\theta} \quad 0 \ddot{\ddot{\theta}}$

$-100$

4

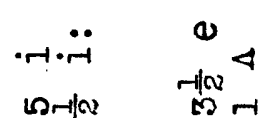

כั) 8

$4 \omega \infty$

$\mathrm{CH}_{1} \mathrm{CO}_{2} \mathrm{ON}$

$m-1$

r

and $\cos ^{-10}$

$\infty r$

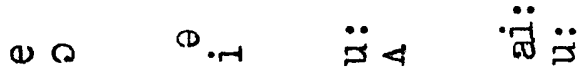

$\omega \ddot{\ddot{z}} \quad$ D $\underset{\ddot{\sigma}}{\ddot{\sigma}}$.r

40

is 0 Ha

L

$\infty r$

मुल

o $\mathrm{H}$

c $\ddot{p} \quad \ddot{\ddot{B}}$

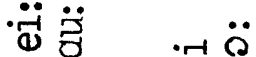

$\ddot{\theta} \ddot{\sim} \quad \ddot{\sigma} \ddot{\rho}$

(1) 8

$\ddot{0}=$

$\ddot{8} \ddot{0}$

$\sim \infty$

त्र

10 열

it $r$

$+\pi$

A

$0 r$

$\ddot{\vec{O}} \ddot{\circ} \quad \circ$

Hos a

$\omega \ddot{\beta} \quad \& \omega$

$\ddot{\sigma}=$

$83 \stackrel{\ddot{0}}{\ddot{0}}$

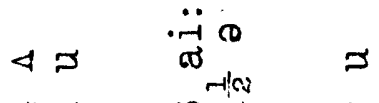

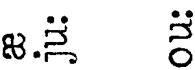

कमी

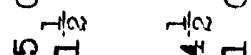

$+n$

is $\mathrm{H}$

$\infty$

O

$8 . \ddot{z}$

$\ddot{\ddot{1}}$

$\curvearrowright \cdot \ddot{\theta} \quad \ddot{z}$

83.户̈ 83

祭然

เ

is $\rightarrow$

- Ho!

$\ddot{\ddot{O}} D \quad \cdot \ddot{\ddot{\alpha}}$

$\begin{array}{ll}4 \omega & \omega \\ H+1 & \omega\end{array}$

10 0

CD

$\ddot{i}$

(艹)

a

c

$\cdot r$

$\cdot r \underset{\ddot{\sigma}}{\ddot{\sigma}} \quad . \ddot{H}$

a)

$\ddot{-1}$

U $\ddot{i} \quad \ddot{0}$

$\ddot{0}$ (1)

$\ddot{0}$

.$\ddot{~}$

$\ddot{\sigma}$

$\infty$

c

$\infty$

$\infty$

$\infty$

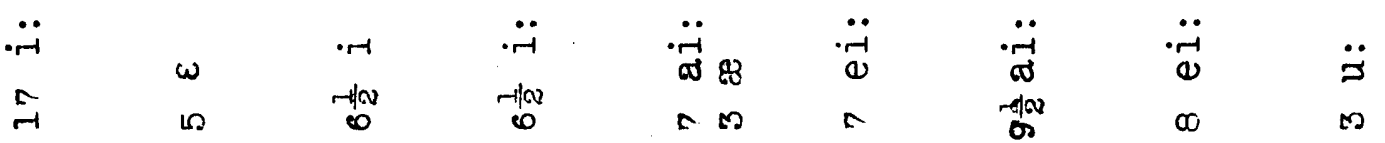

$$
\ddot{a r}
$$

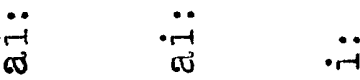

10

n-

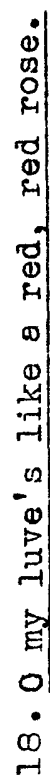

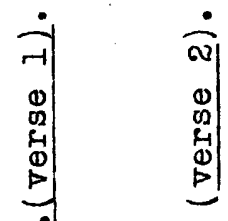

$\ddot{\Xi}$

$\ddot{\infty}$

$\ddot{0}$

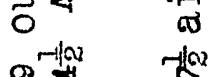

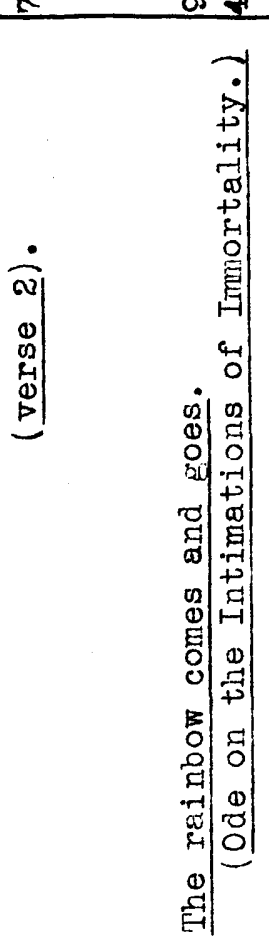

ấ
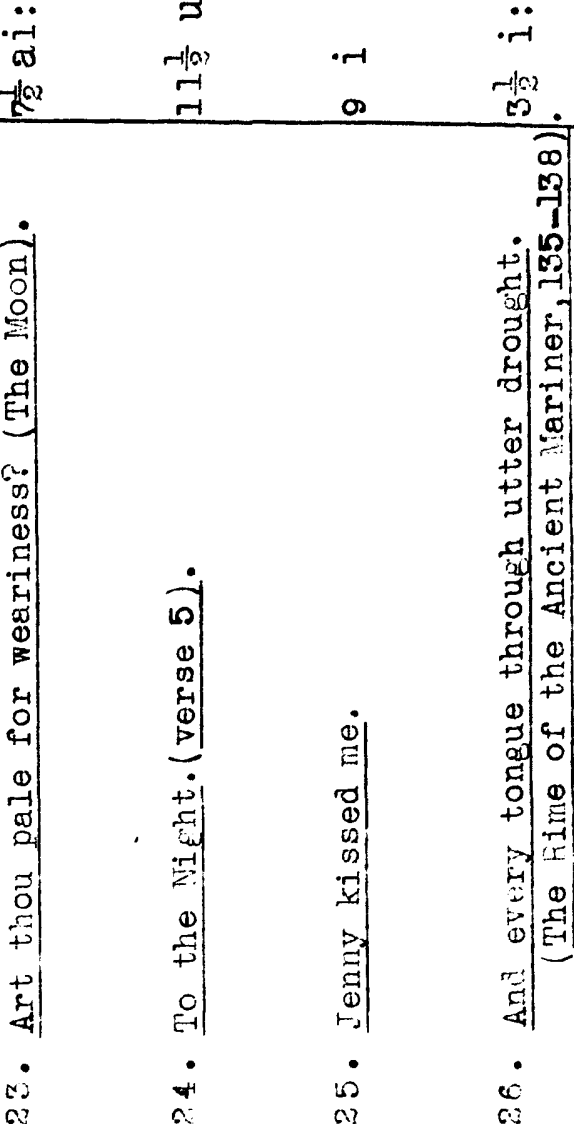

a)
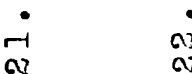

م)

0
0
0
0
0
0
0
0
0
0
0
9
0
-1 


\begin{tabular}{|c|c|c|c|c|c|c|}
\hline$\underbrace{83}_{-1 \mid x} 0$ & $\begin{array}{l}\omega \Omega \\
-H \alpha\end{array}$ & 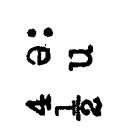 & $\begin{array}{l}\ddot{B} \cdot \ddot{H} \\
m \infty\end{array}$ & 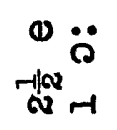 & 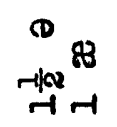 & $\ddot{z} \ddot{\nabla}$ \\
\hline $\boldsymbol{D} \cdot \ddot{H}$ & 18 & $4 w$ & $\ddot{d j} 0$ & o.尹口 & $\ddot{z} \ddot{0} \ddot{ه}$ & $\int_{\infty}^{80}$ \\
\hline$v-1$ & -1 & $10 \mathrm{H}$ & あ5o & va & $v-1$ & $\omega-1$ \\
\hline$\ddot{d} \ddot{p}$ & $\ddot{z}$ & $\ddot{\ddot{\theta}}_{-10} D$ & $4 \ddot{j}$ & $\ddot{z}_{-+\alpha}$ & $\ddot{d} \cdot r-1$ & 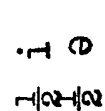 \\
\hline $\mathbf{N}-1$ & -1 & దొ & $H \infty$ & $\checkmark v$ & ט & $\omega \pi$ \\
\hline$\ddot{d}$ & D & $\ddot{\nabla}_{0}$ & $\ddot{g} \ddot{d}$ & $\cdot \ddot{\pi}$ & (1) & $\ddot{0}$ \\
\hline $\boldsymbol{\alpha}$ & $\stackrel{-1 \omega}{-1}$ & r & $+\infty$ & $\boldsymbol{\omega}$ & N & नु० $\alpha$ \\
\hline$\ddot{\rho}$ & $\ddot{-r}$ & $\ddot{\ddot{r}} \cdot \ddot{乃}$ & $\curvearrowright$ & $\ddot{i} \ddot{d} \ddot{d}$ & o & $\ddot{\sigma}$ \\
\hline$\infty$ & $\infty$ & $\sigma$ & $H$ & เ & + & ल \\
\hline (1) & $\begin{array}{c}0 \\
-1 \mid \alpha\end{array}$ & 80 & (D) & (D) & $\ddot{0}$ & 88 \\
\hline$\infty$ & D & का है & 10 & $N$ & $i^{\prime \prime}$ & + \\
\hline •r- & $\cdot \pi$ & $\ddot{\pi}$ & $\mathbb{8}$ & $\Xi$ & $\ddot{\theta}$ & $\ddot{-\ddot{d}}$ \\
\hline ? & $\begin{array}{l}08 \\
+1\end{array}$ & O & भु) & $\mathrm{H}^{\alpha}$ & ת & 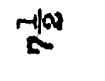 \\
\hline 4 & $\ddot{\vec{b}}$ & 88 & $\cdot 4$ & $\stackrel{\ddot{H}}{0}$ & $\ddot{\ddot{\infty}}$ & $\ddot{\ddot{d}}$ \\
\hline-10 & & -7 & $\stackrel{n}{n}$ & - & $-\sqrt{\alpha}$ & $\stackrel{r-1 a}{\sigma}$ \\
\hline$\underset{\omega}{\ddot{H}}$ & $\cdot r$ & r-1 & $\stackrel{\ddot{d}}{\ddot{0}}$ & $\ddot{\ddot{H}}$ & $\ddot{r}$ & $\ddot{\ddot{H}}$ \\
\hline$-\boldsymbol{n}_{\infty}^{\infty}$ & $\stackrel{r+\infty}{\sigma}$ & $\pi$ & 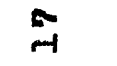 & $\pi$ & $\stackrel{H}{H}$ & ${ }_{\infty}^{-1 j a}$ \\
\hline
\end{tabular}
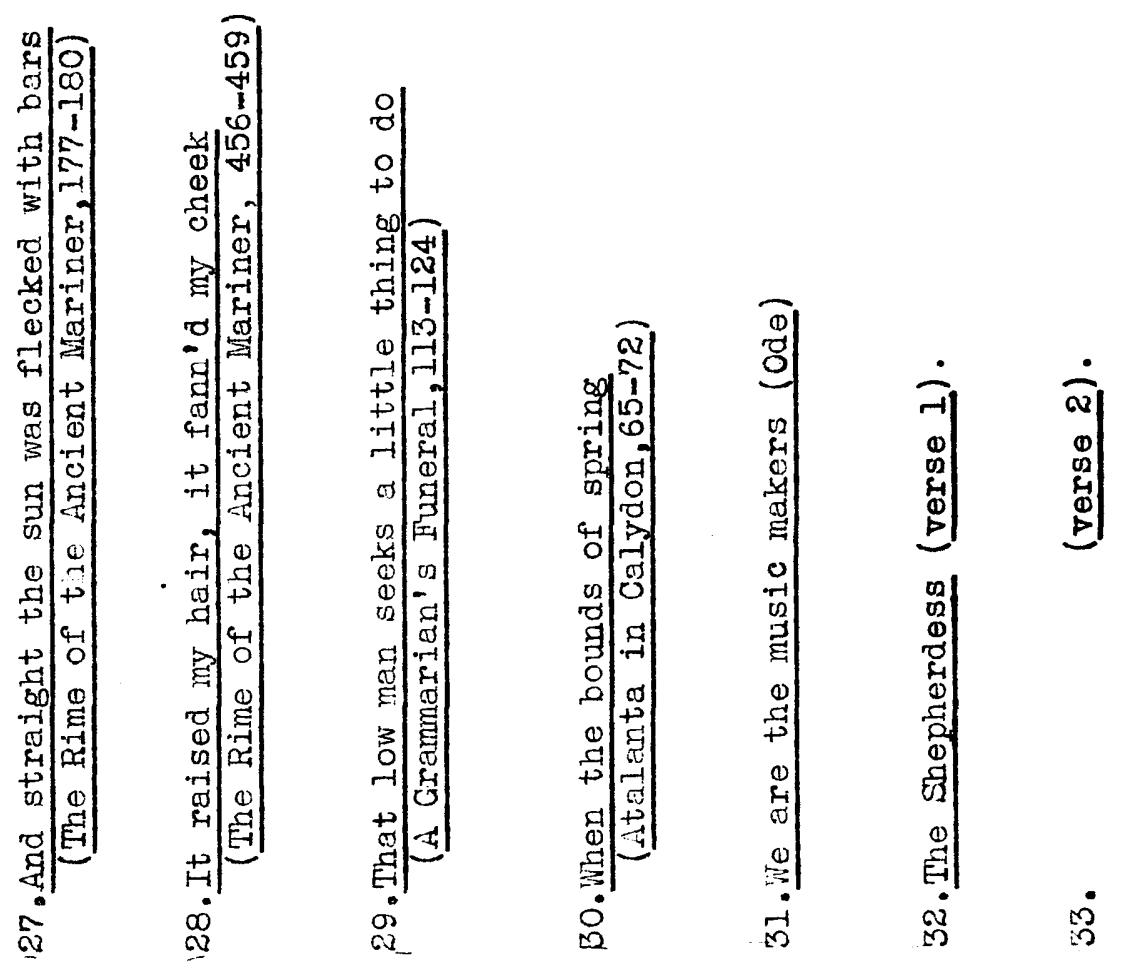


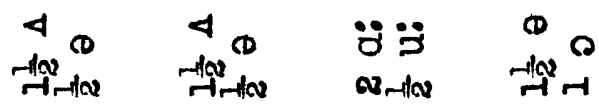

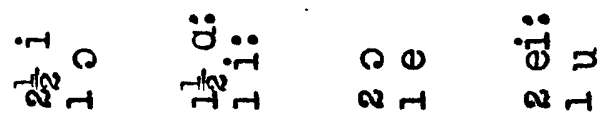

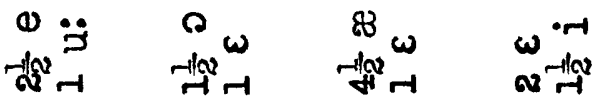

$\ddot{8} 8$ \& $\ddot{8}$ ه

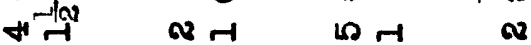

$\begin{array}{llll}\ddot{\beta} & \ddot{z} & \ddot{z} \cdot \ddot{r} & \text { o } \\ \text { H } & \text { v } & 0 & \text { or }\end{array}$

$\ddot{\ddot{0}} \quad 0 \quad$ o

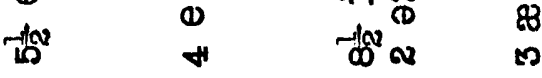

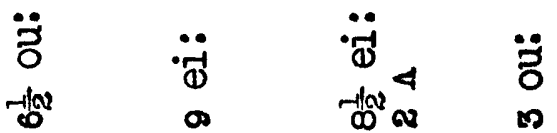

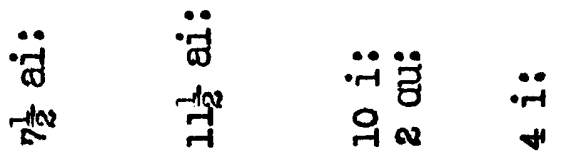

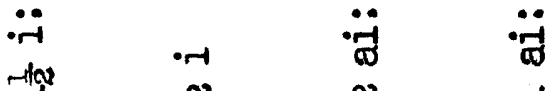

ना नै 


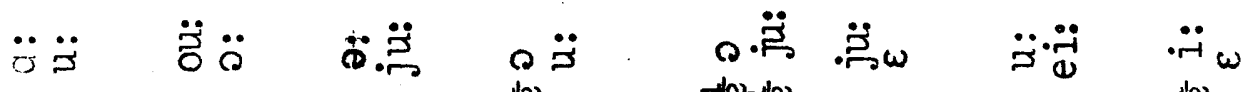

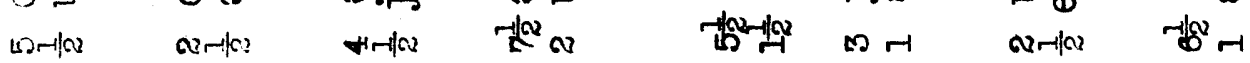

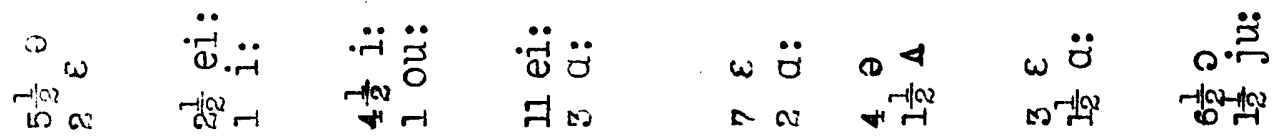

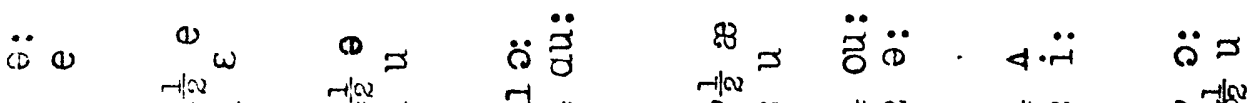

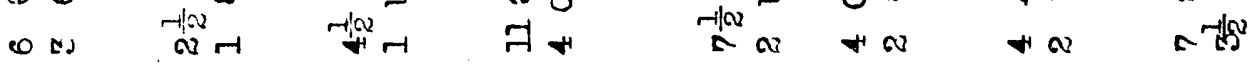

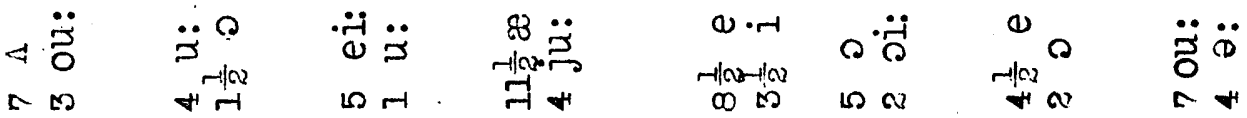

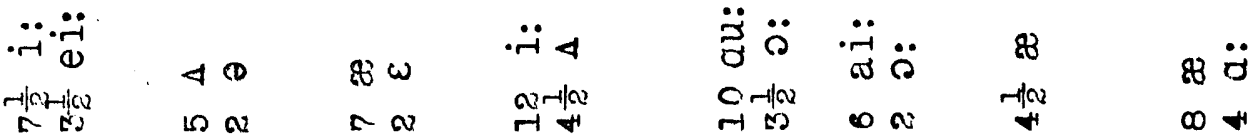

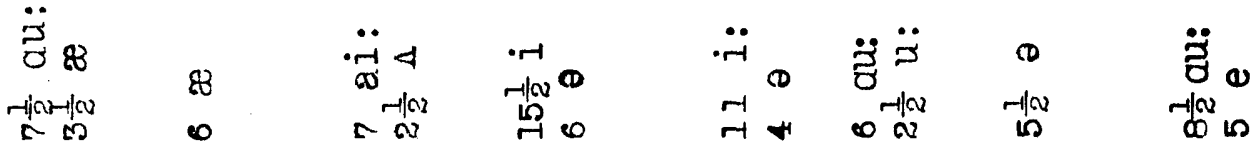

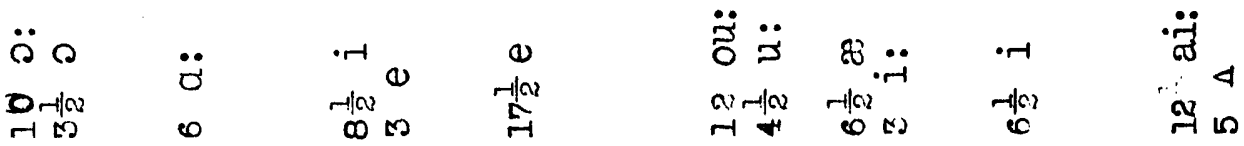

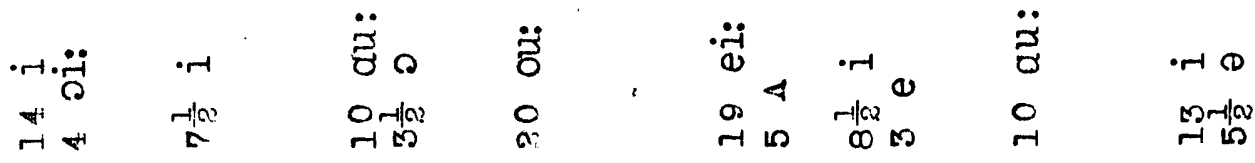

\begin{tabular}{|c|c|c|c|c|c|}
\hline$\ddot{\widetilde{\sigma}}$ & $\ddot{\sigma}$ & $\ddot{\omega}$ & $\ddot{\pi}$ & $\ddot{\ddot{\omega}}$ & $\stackrel{\ddot{\sigma}}{\ddot{\sigma}}$ \\
\hline$\stackrel{\text { flow }}{7}$ & $\underset{\sim}{0}$ & $a_{a, ~}^{a g}$ & O & $\begin{array}{l}0 \\
0\end{array}$ & $\stackrel{\sim}{\sim}$ \\
\hline
\end{tabular}

至

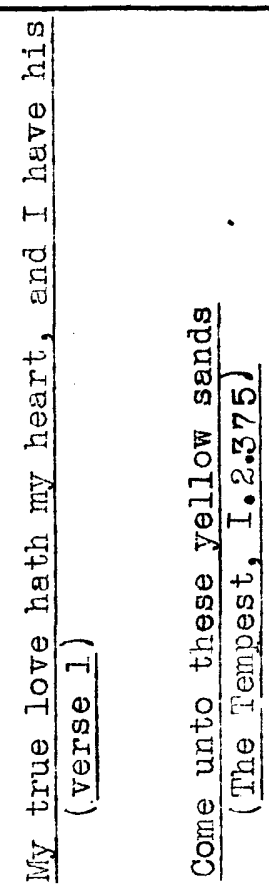

$\dot{8}$

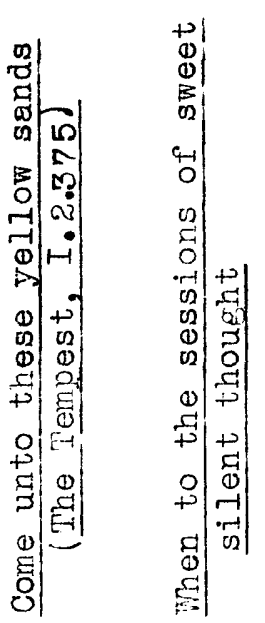

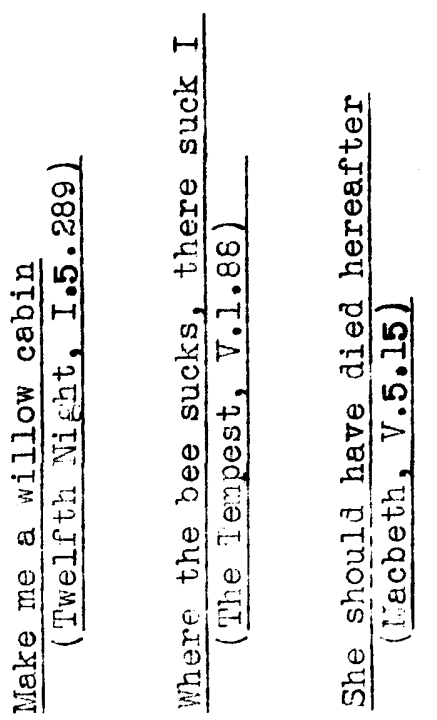

ซु

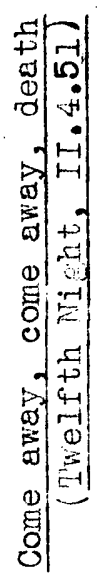

is 


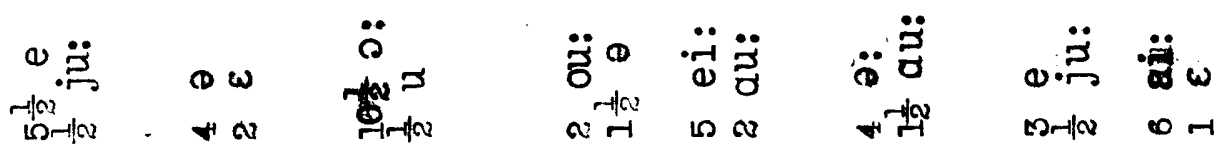
bु- Ha a

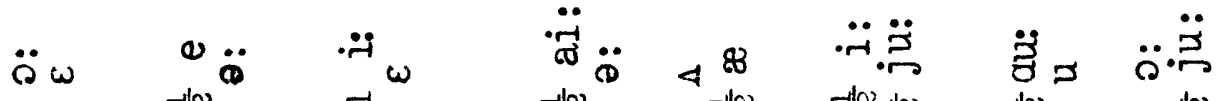

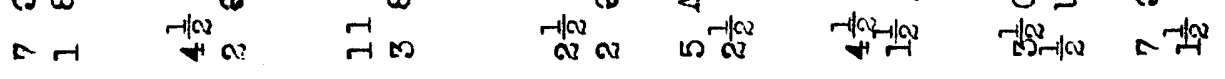

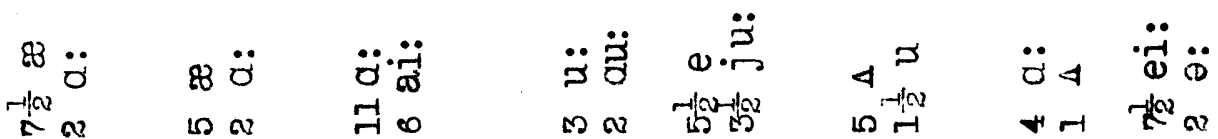

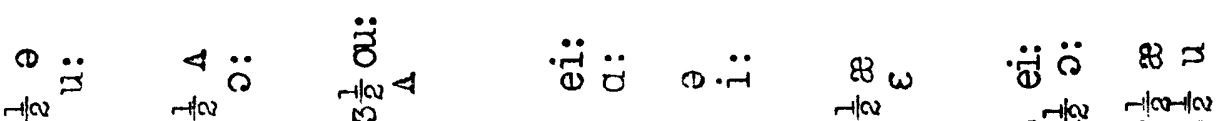

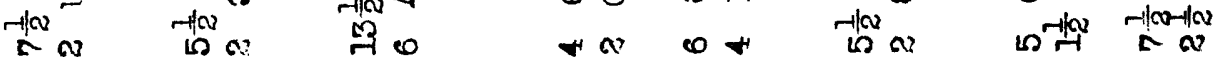

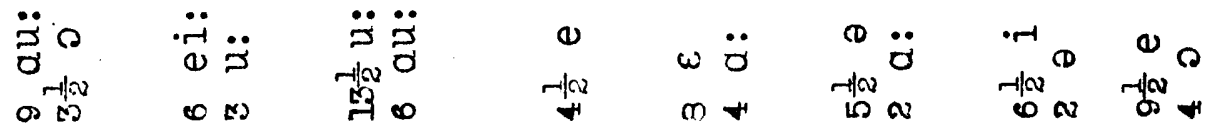

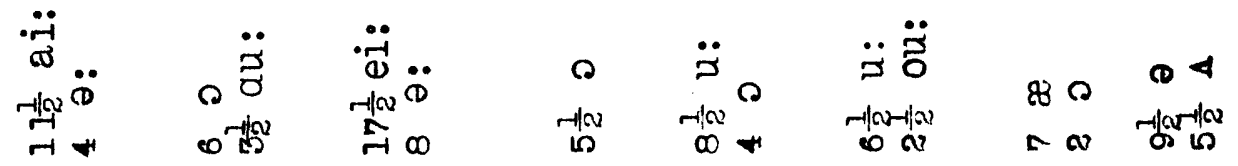

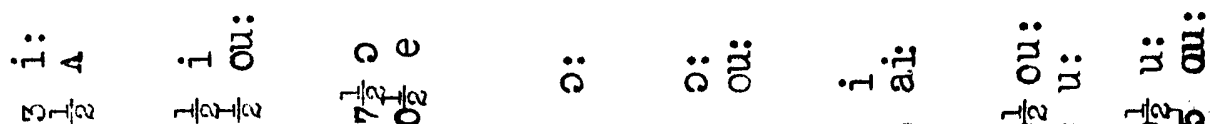

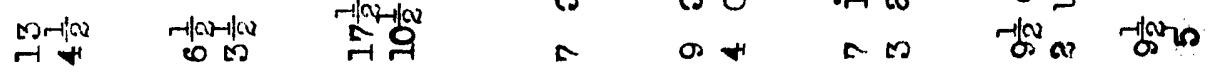

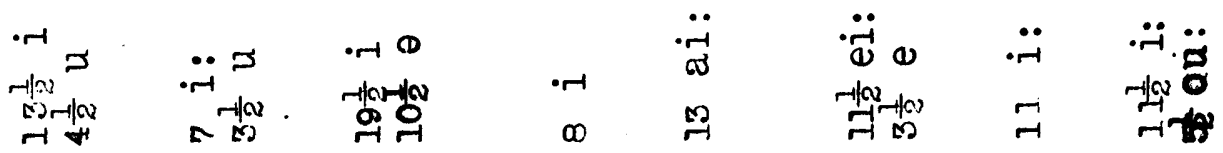

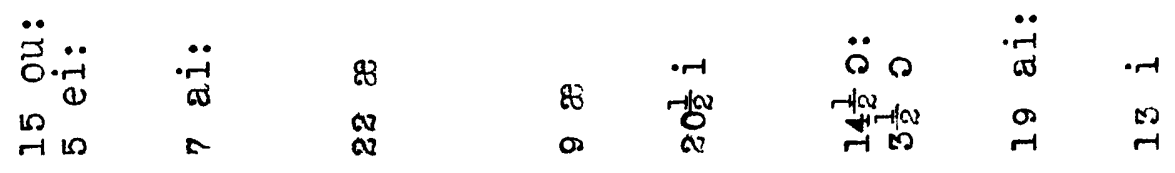
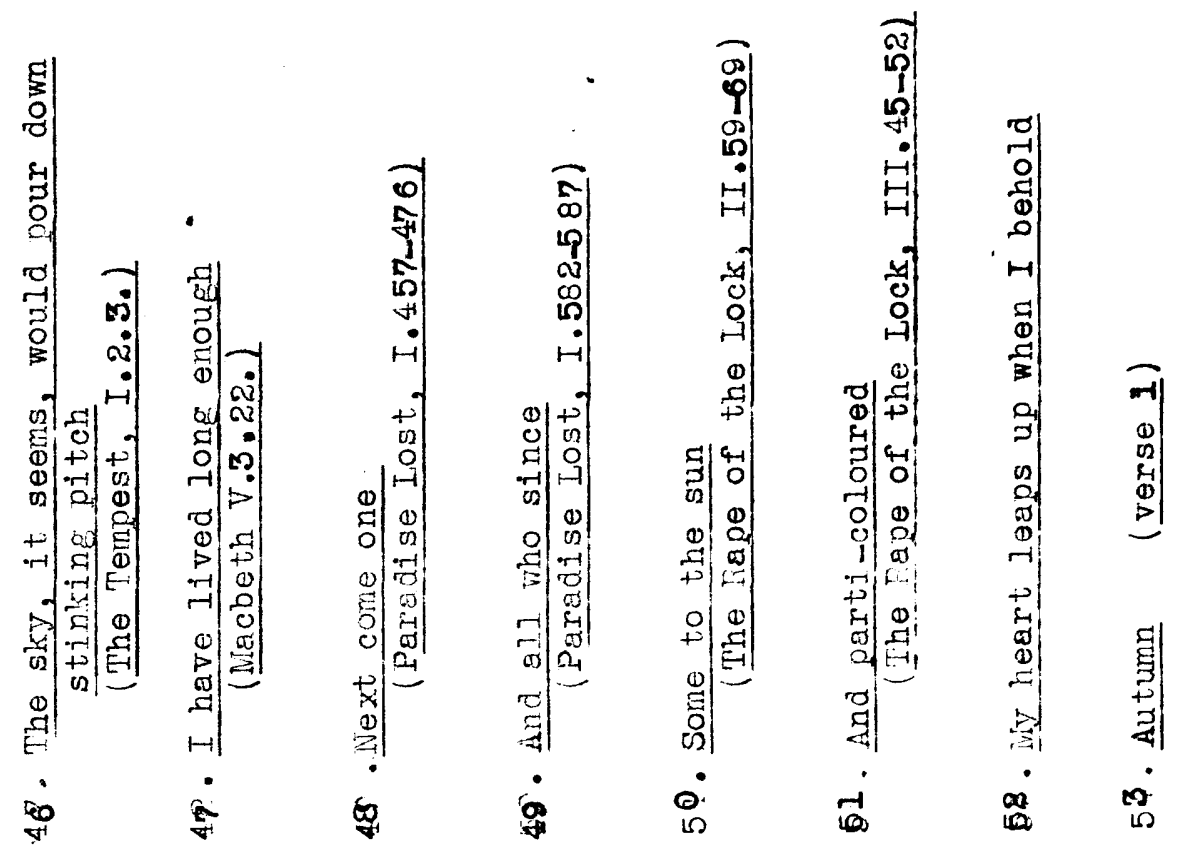


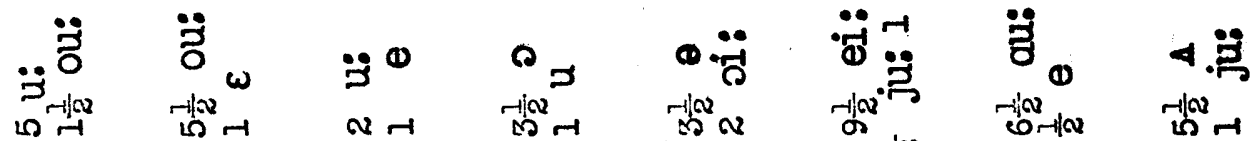
an wa wa

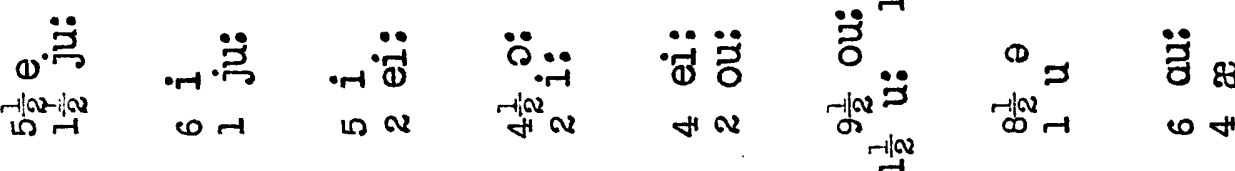

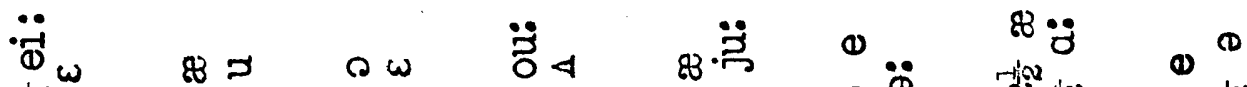
ind

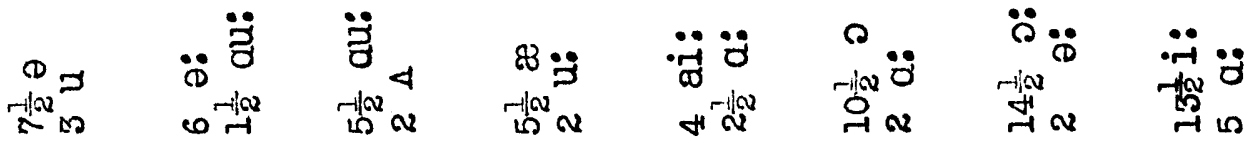

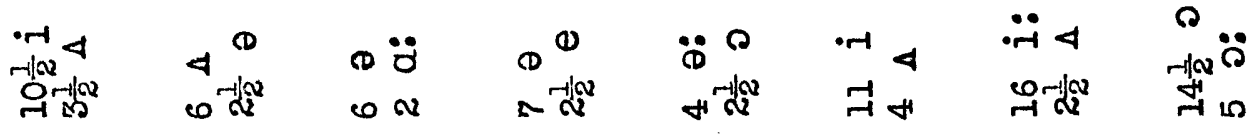

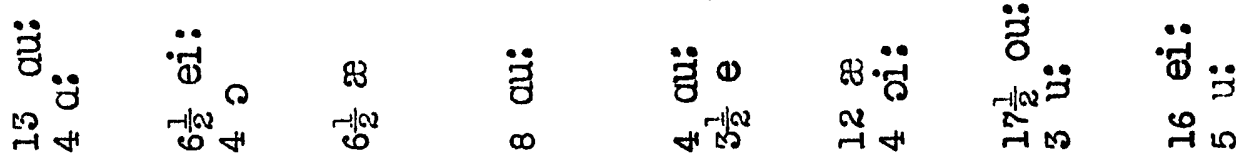

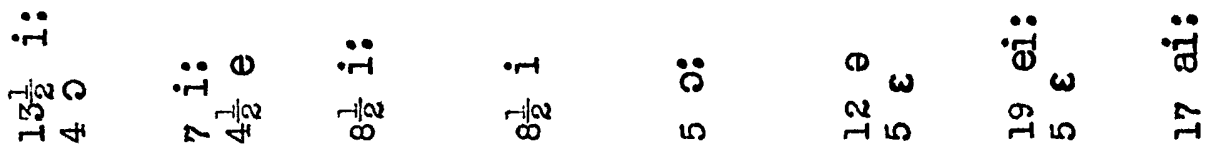

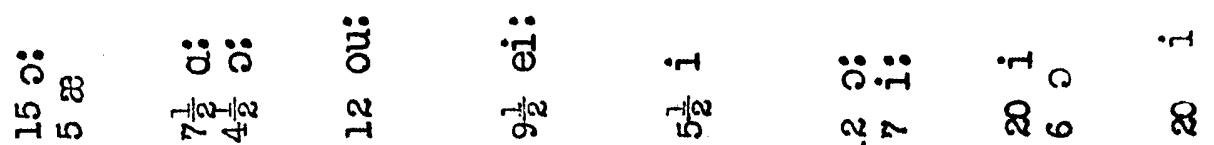

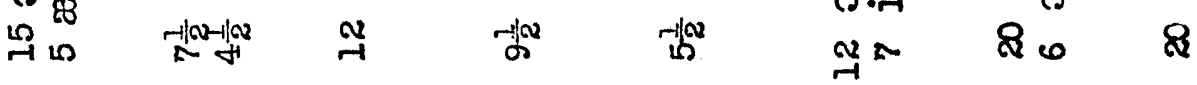

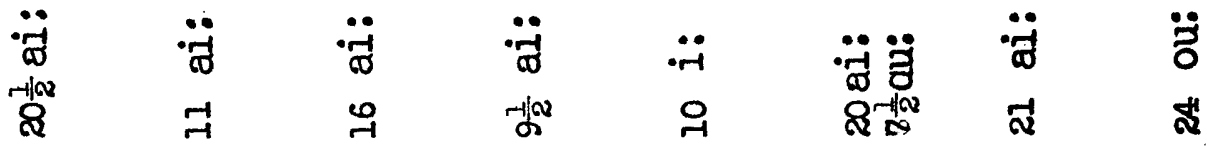

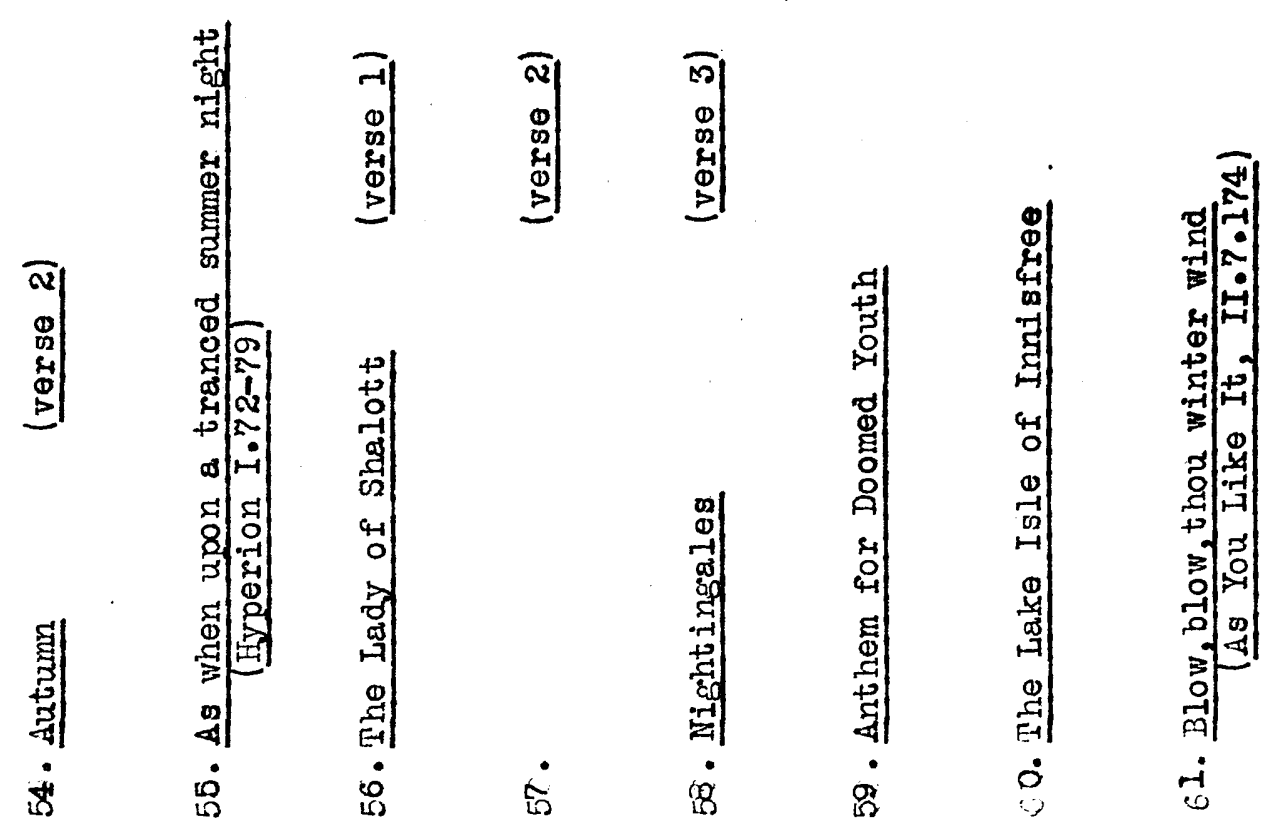




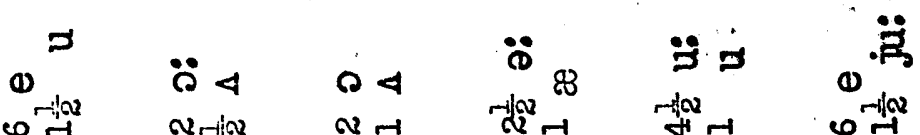

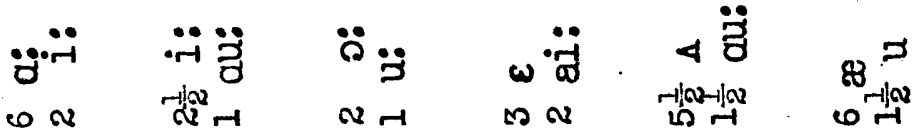

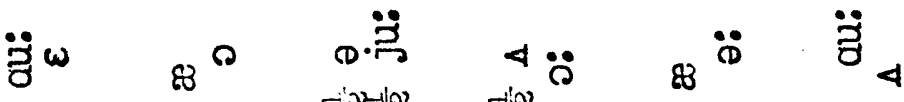

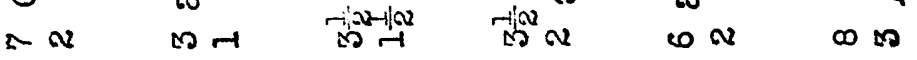

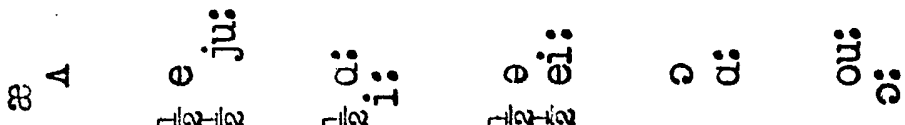

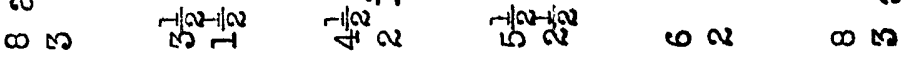

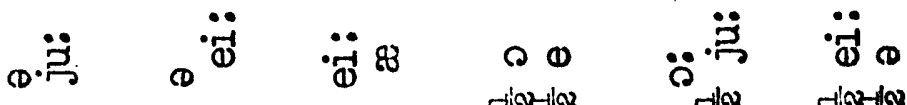

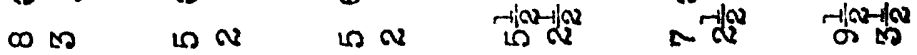

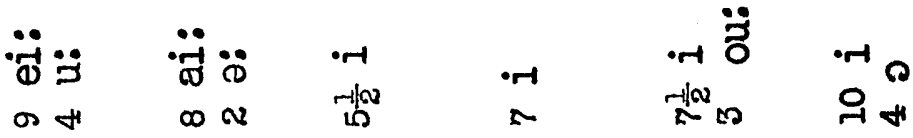

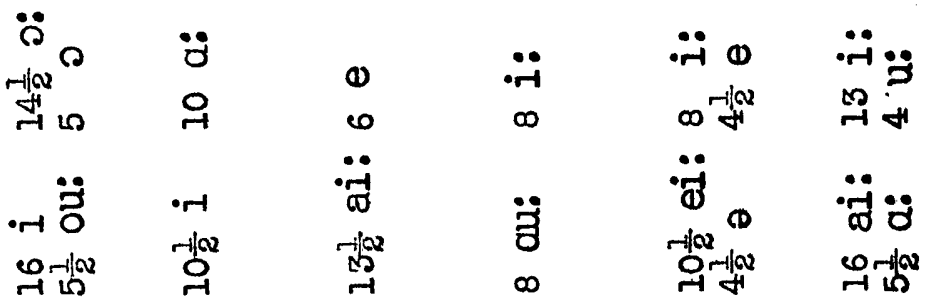

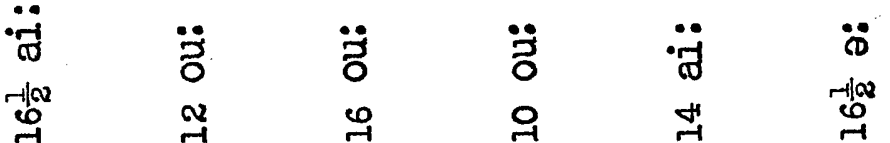

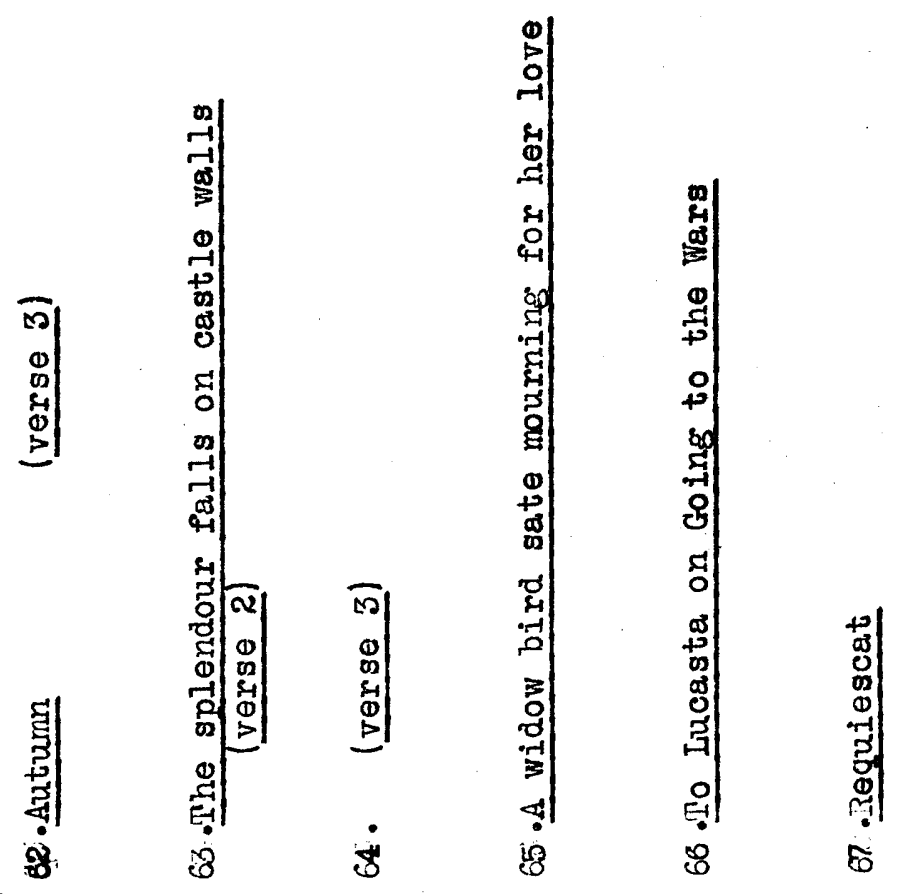




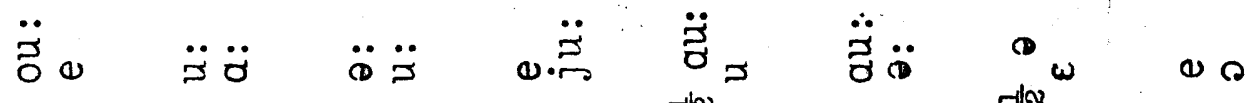

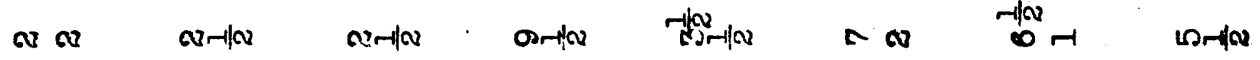

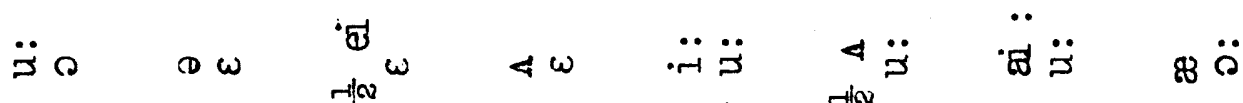

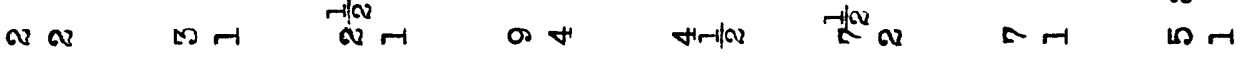

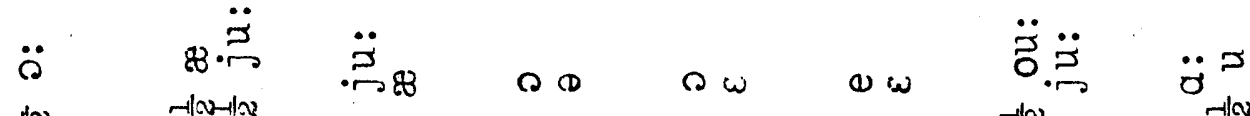
-ing

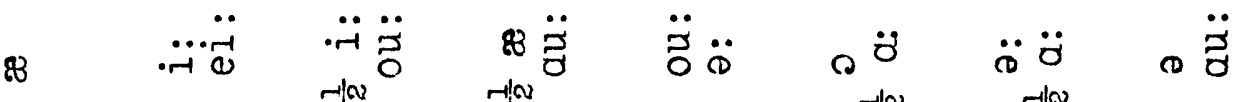

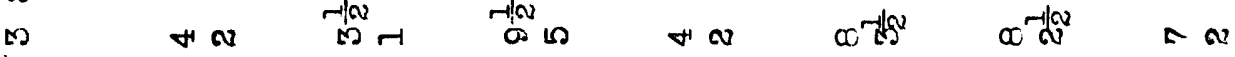

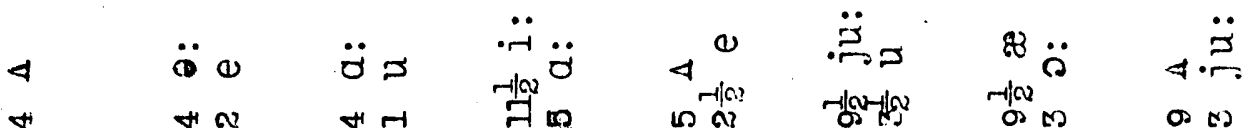

H

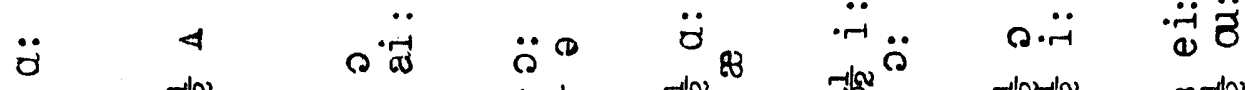
$\infty$. H

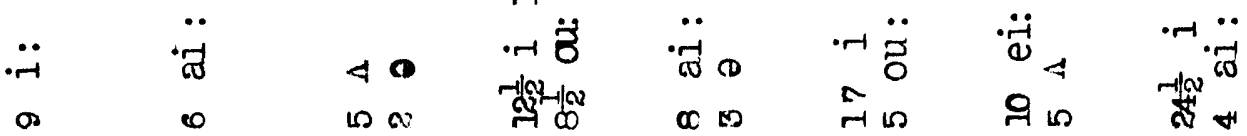

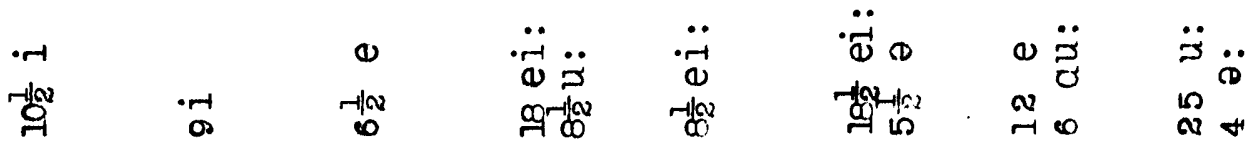
$\underset{7}{\ddot{7}}$
$\ddot{j}$
$\begin{array}{ll}\stackrel{-a}{\sigma} & -r \\ \sim & -1\end{array}$
$\stackrel{\ddot{\sigma}}{8} \approx$
$\ddot{-r}$

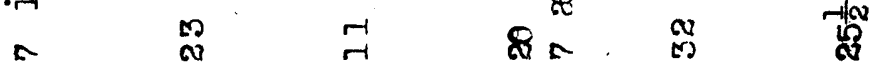

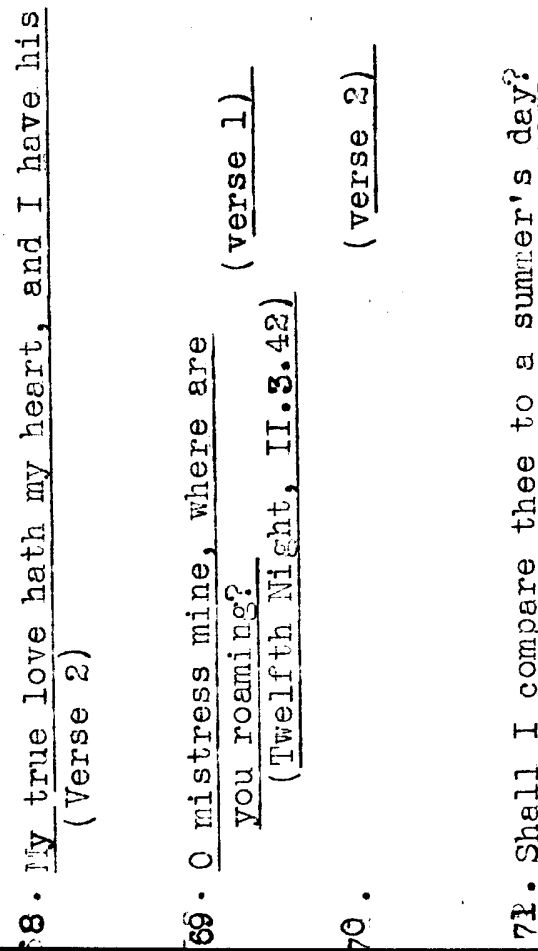

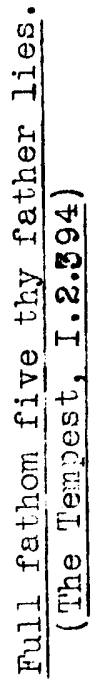

स्त

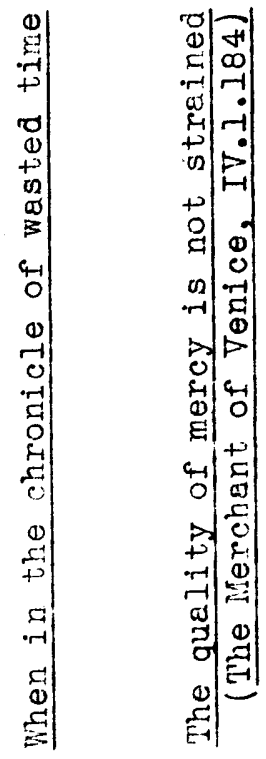

a.

I 


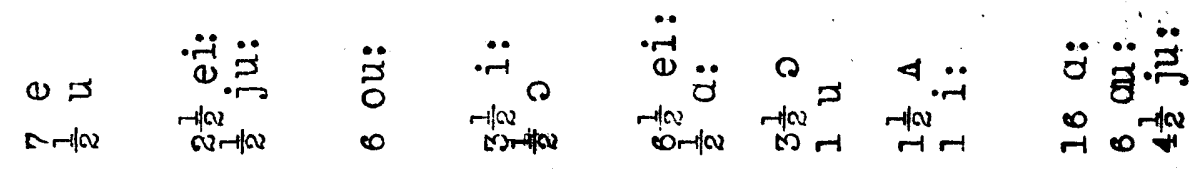

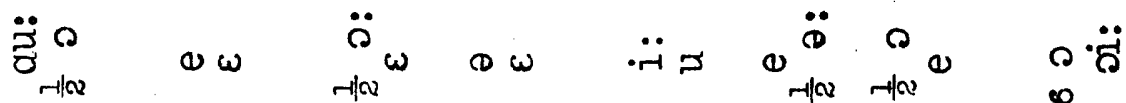

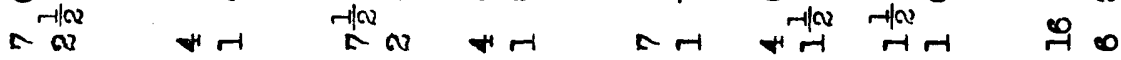

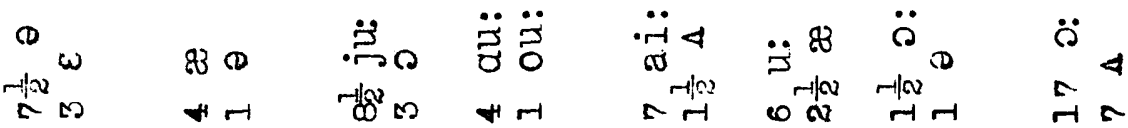

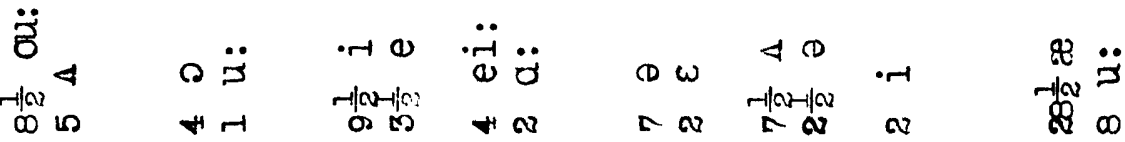

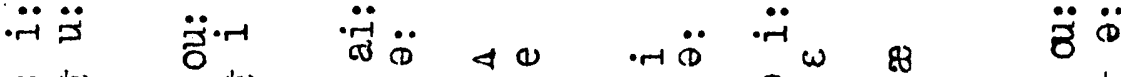

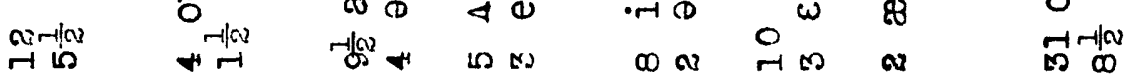

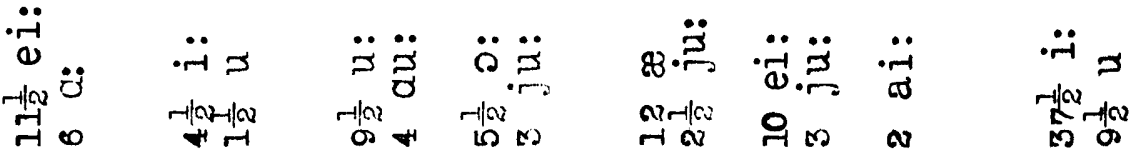

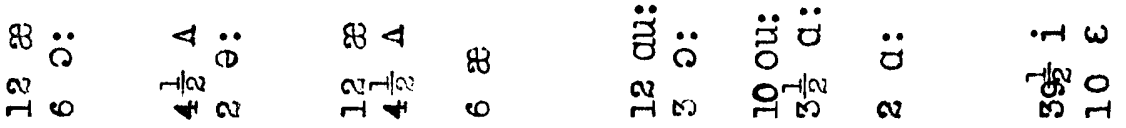

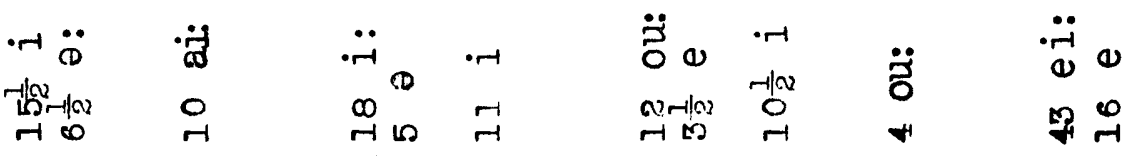

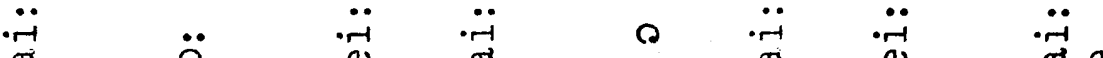

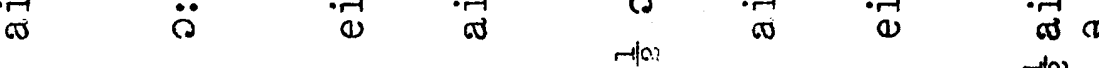

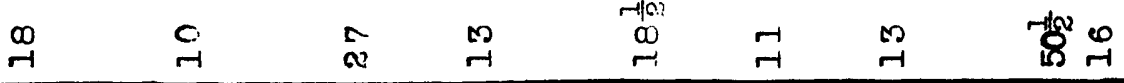

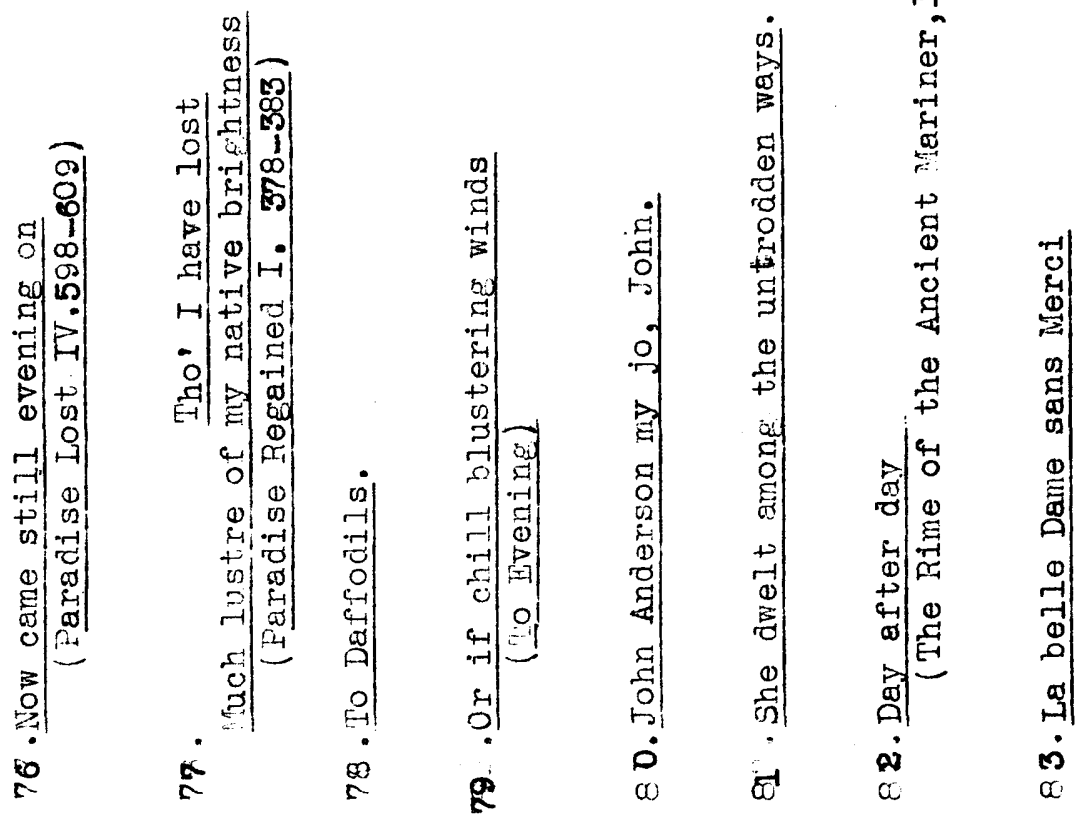


$\ddot{z}:$

갖ㅇㅇ

$\infty \quad \ddot{\ddot{\sigma}}$

834

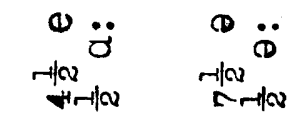

$\omega \boldsymbol{0}$

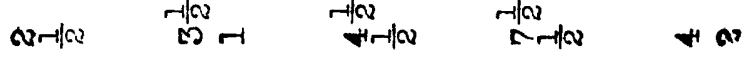

口 $\ddot{3}$

$\ddot{j}$

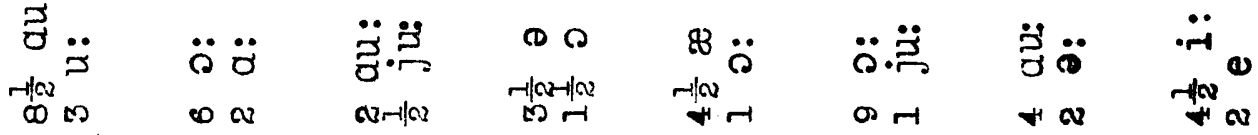

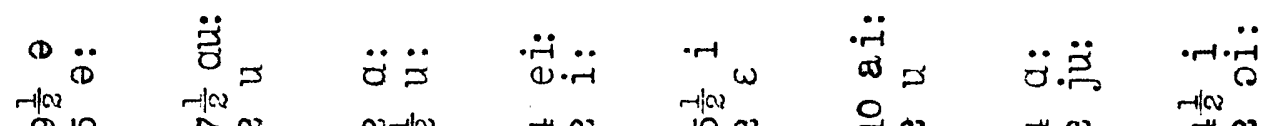

ordion

$+a$

${ }_{108}^{-103} \infty$

위

* o

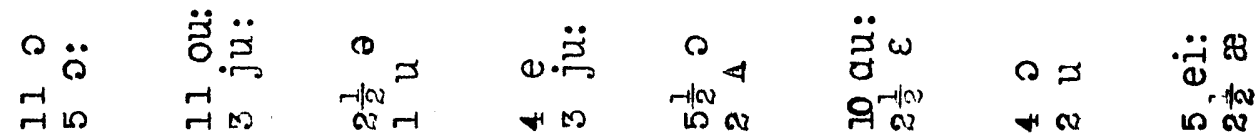

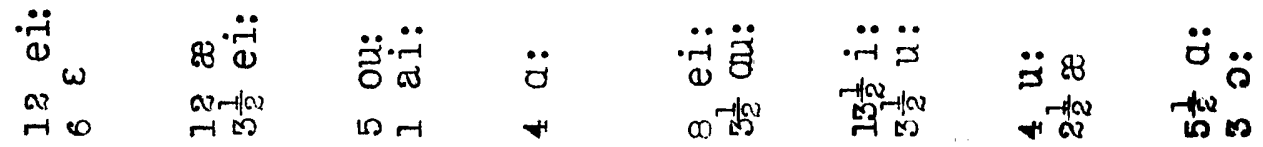

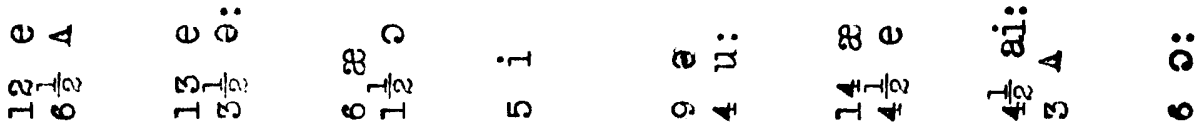

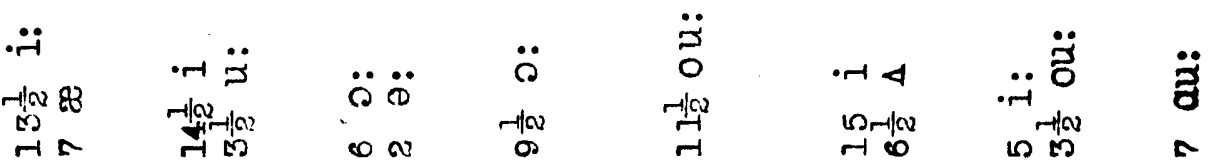

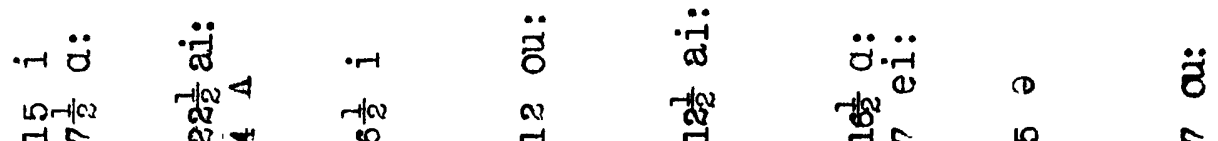

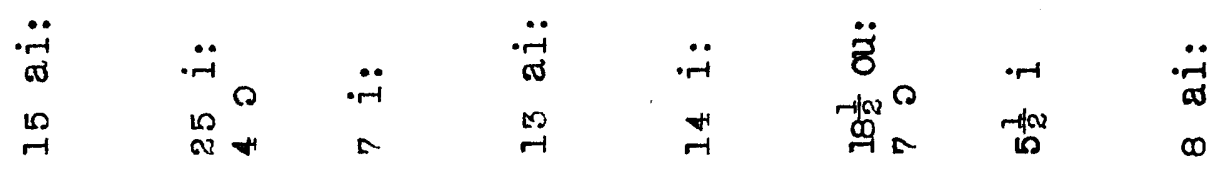

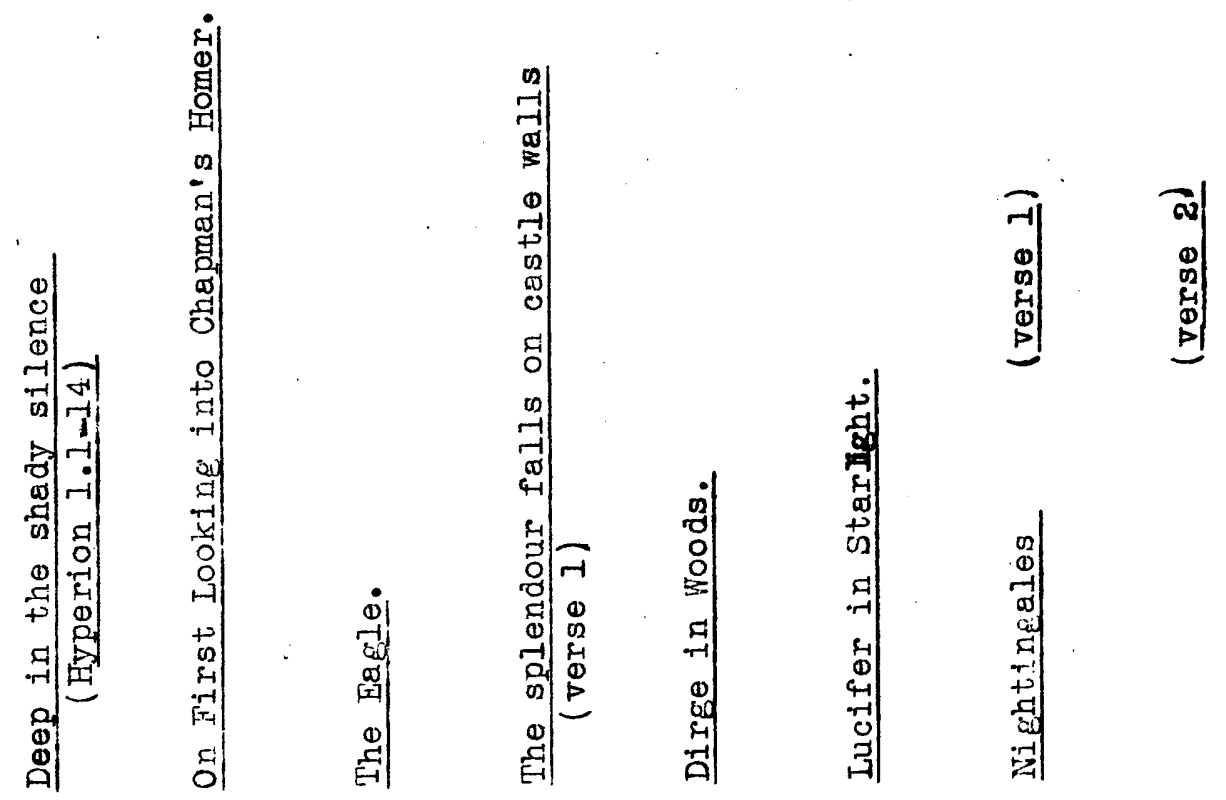




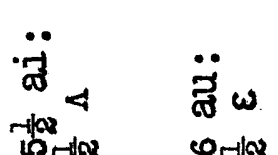

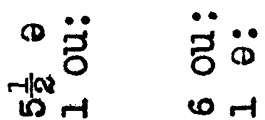

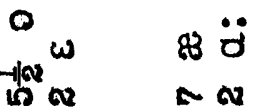

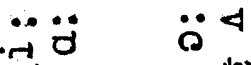

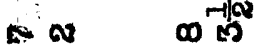

$83{ }_{-10}^{0} \quad \ddot{\nabla} \theta$

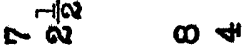

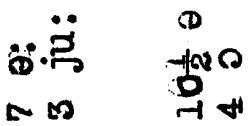

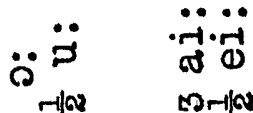

तn

-1
0
0

$\ddot{\ddot{0}} \quad \ddot{\ddot{H}}$

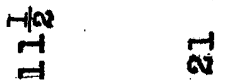

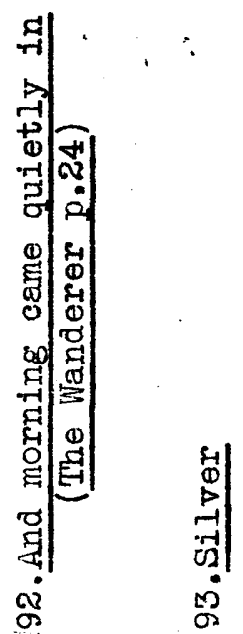

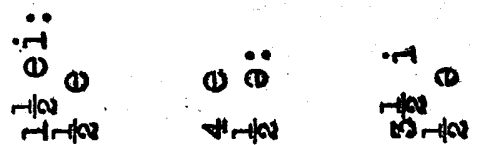

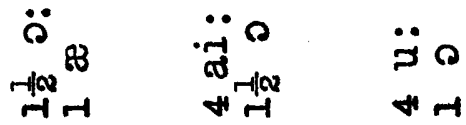

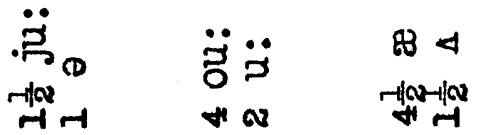

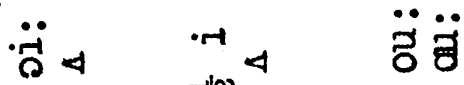

a न म

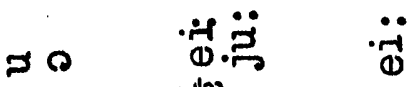

Q

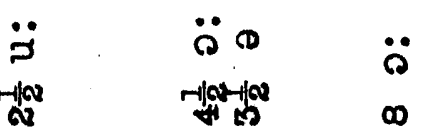

$\begin{array}{ccc}\ddot{H} & \ddot{\theta} & \ddot{r} \\ + & 0 & 0 \\ & \ddot{g} & \ddot{\theta} \\ H & 0 & \ddot{\sigma}\end{array}$

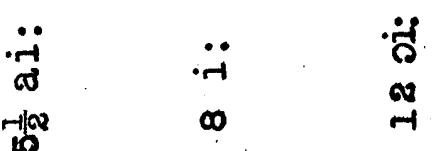

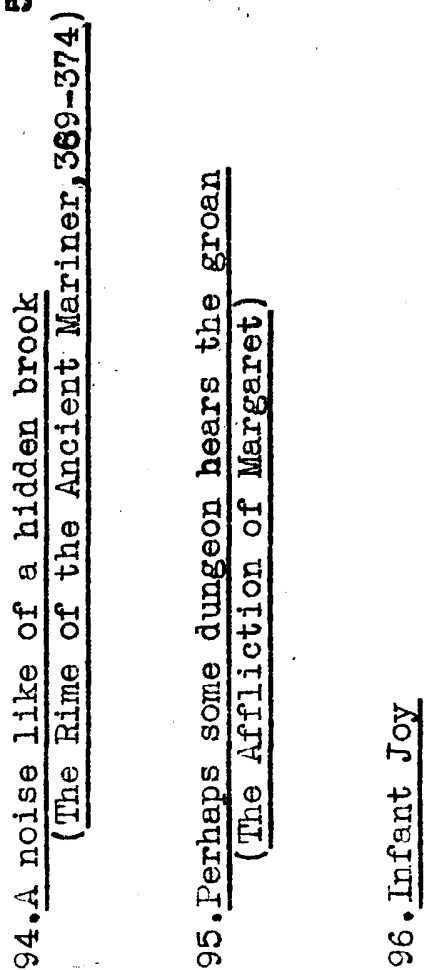




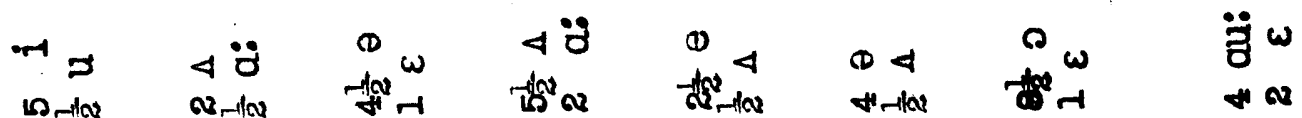

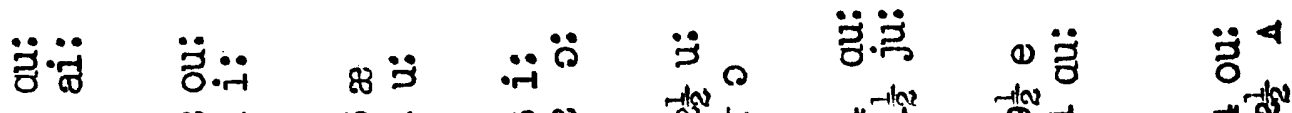
की

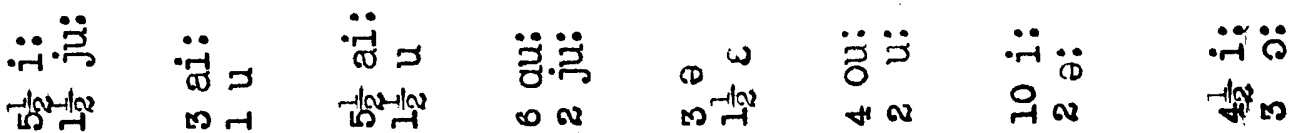

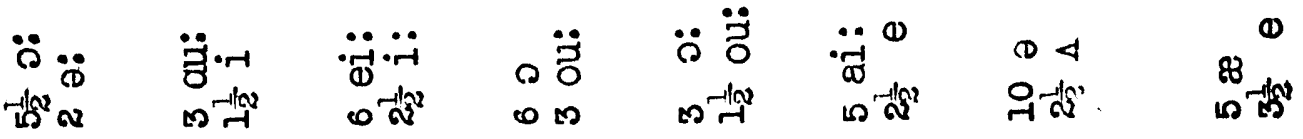
○ш 20

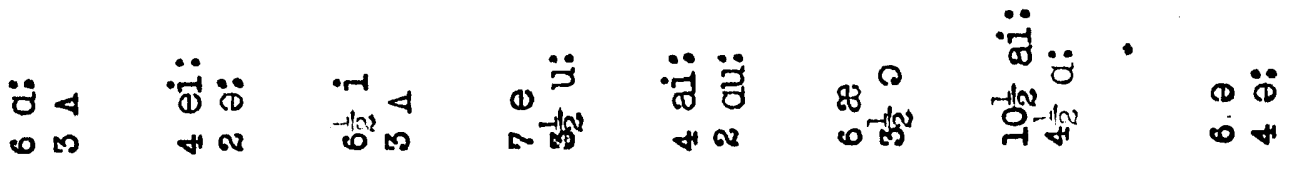

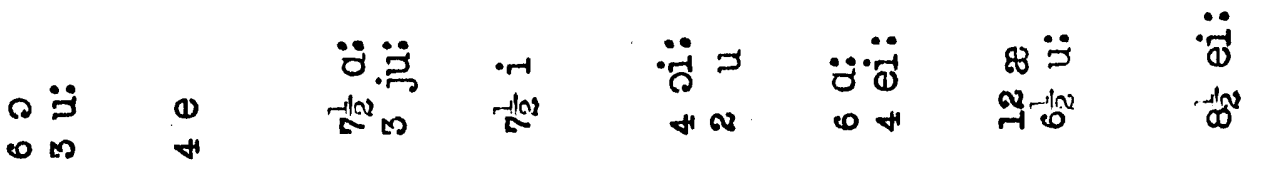

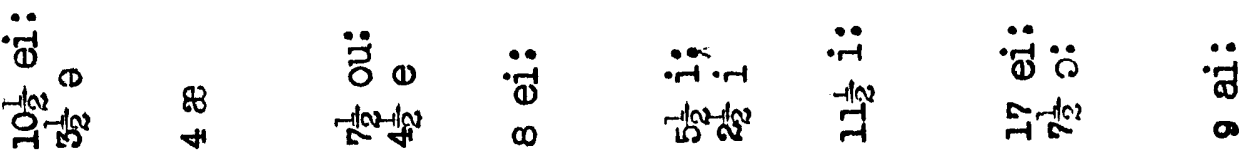

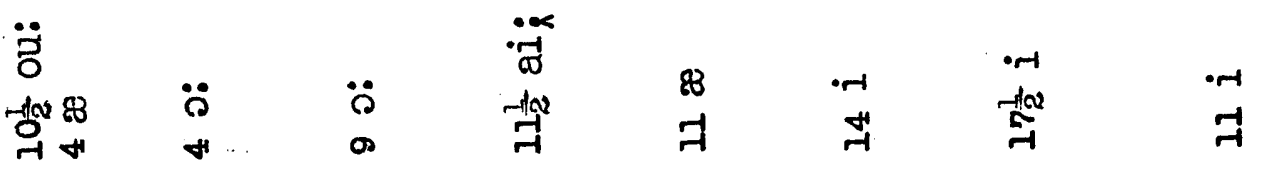

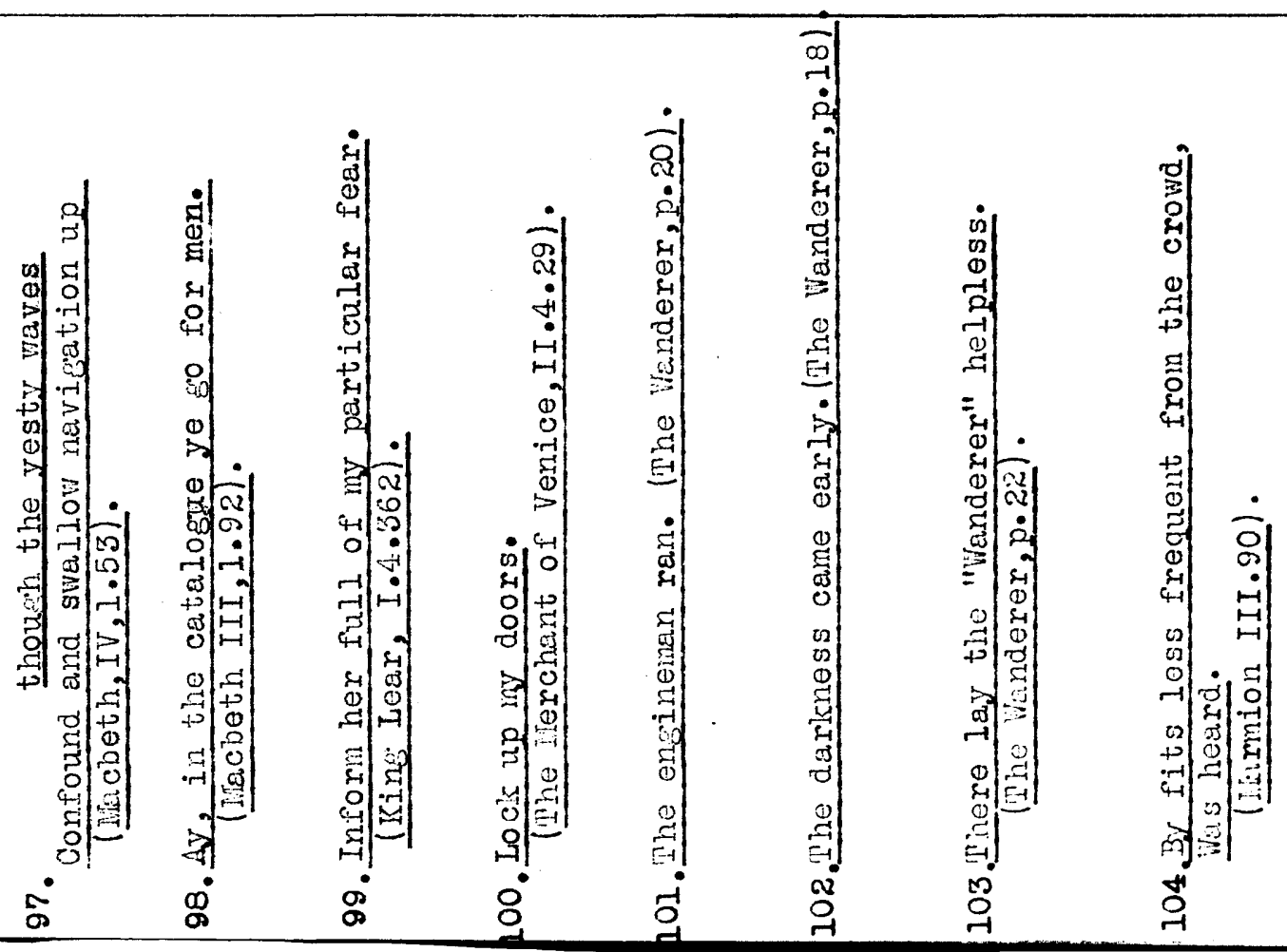




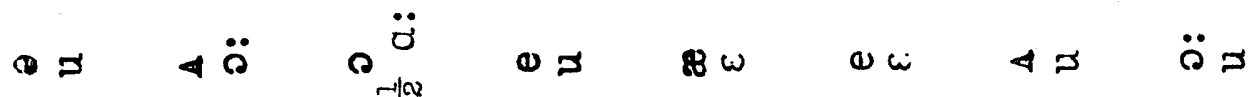

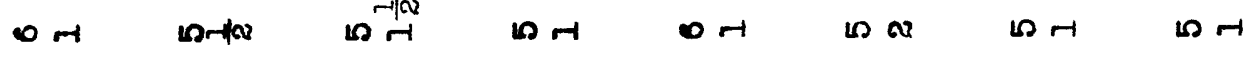

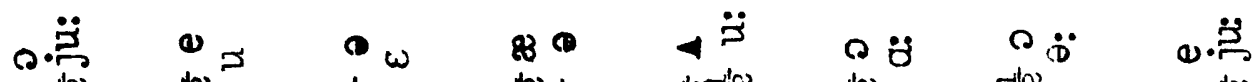

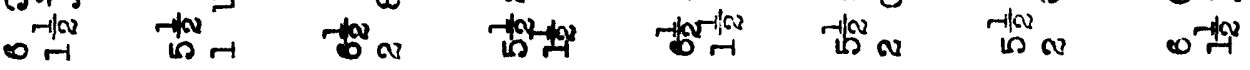

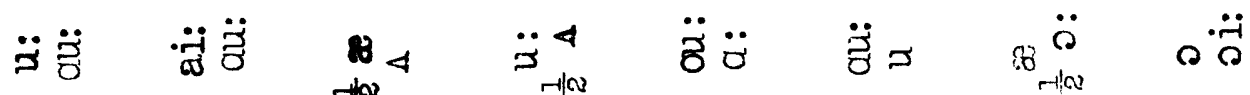

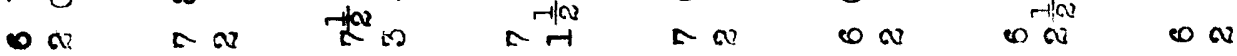

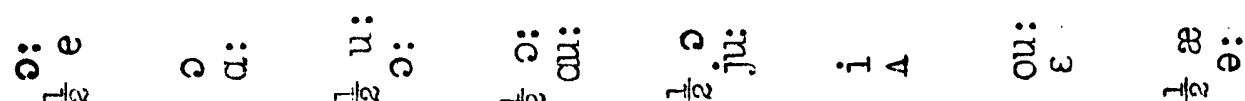

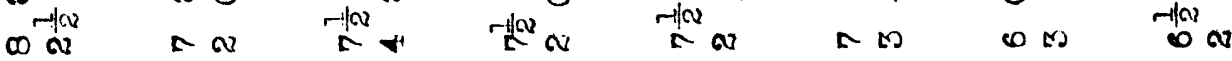

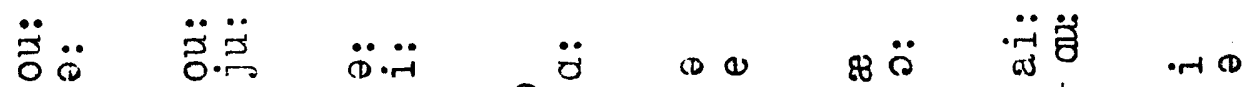

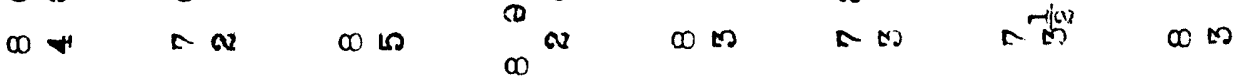

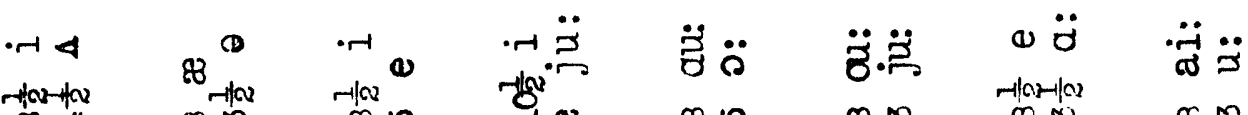

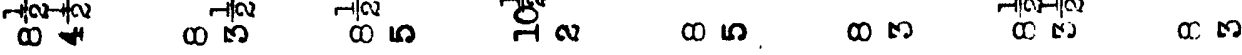

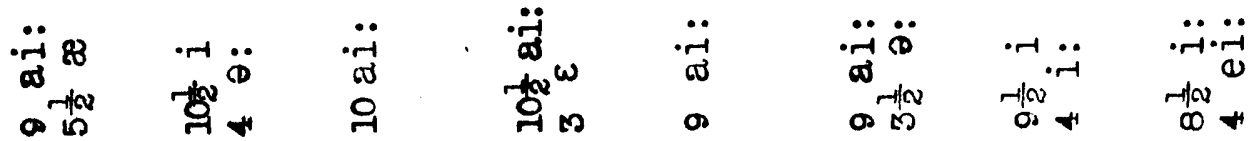

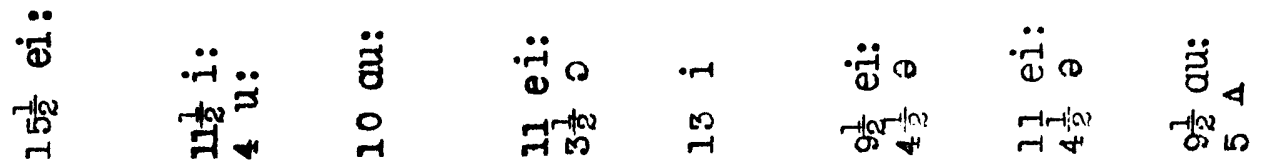

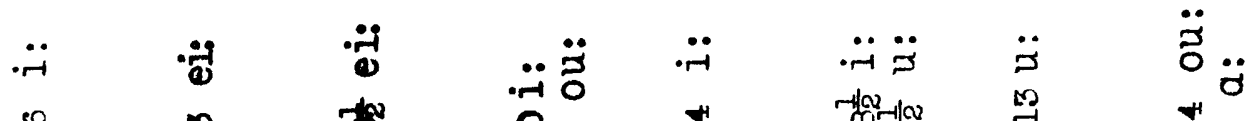




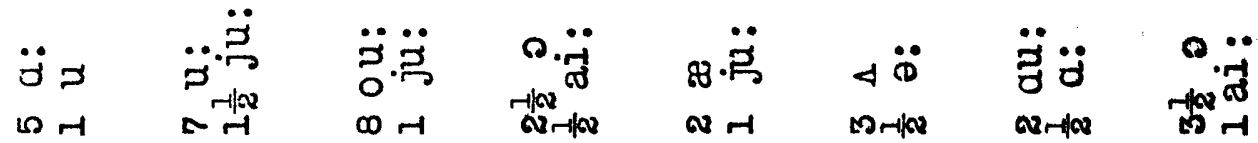

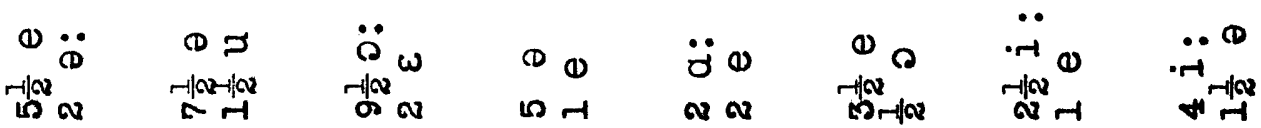

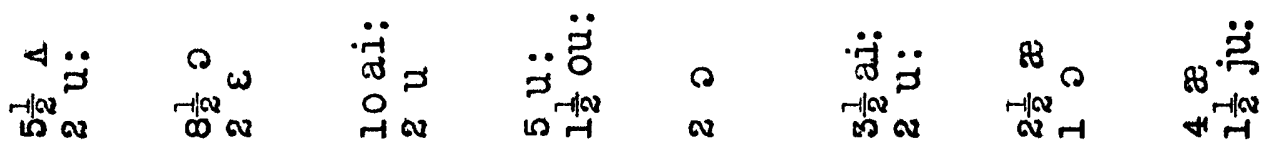

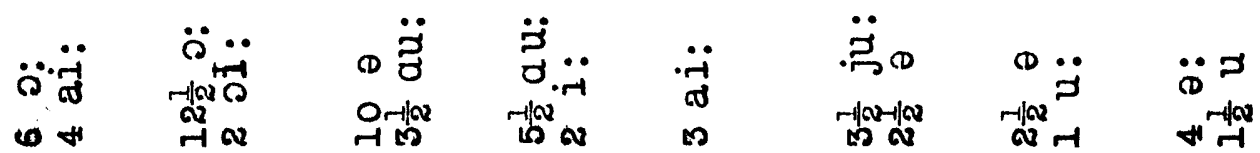

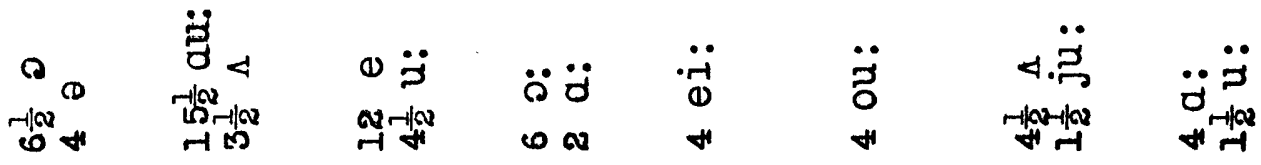

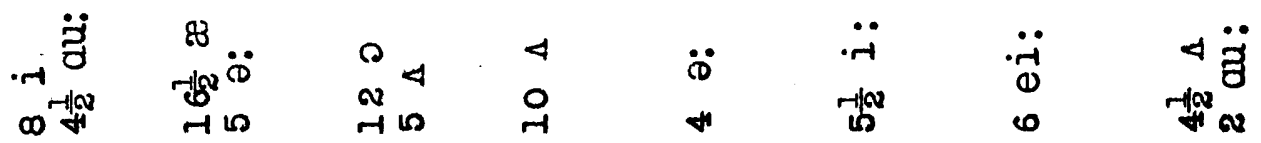

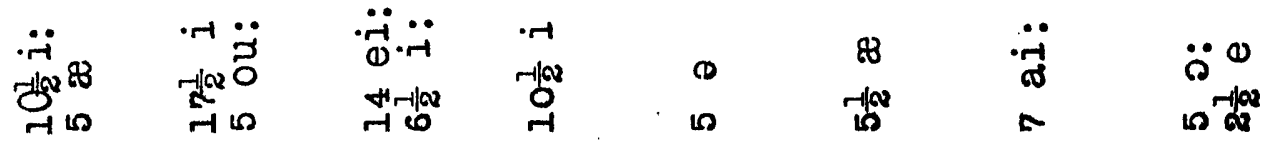

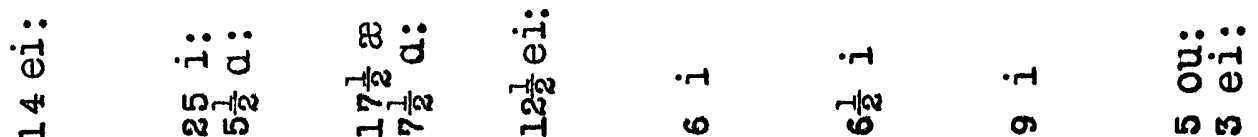

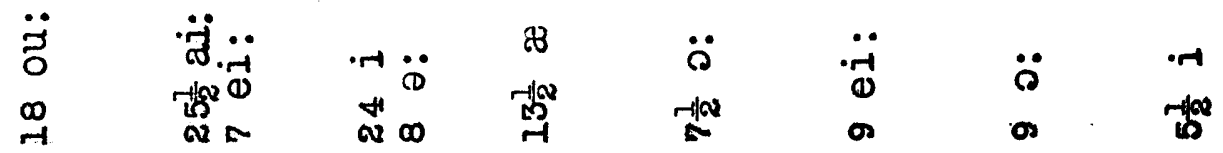

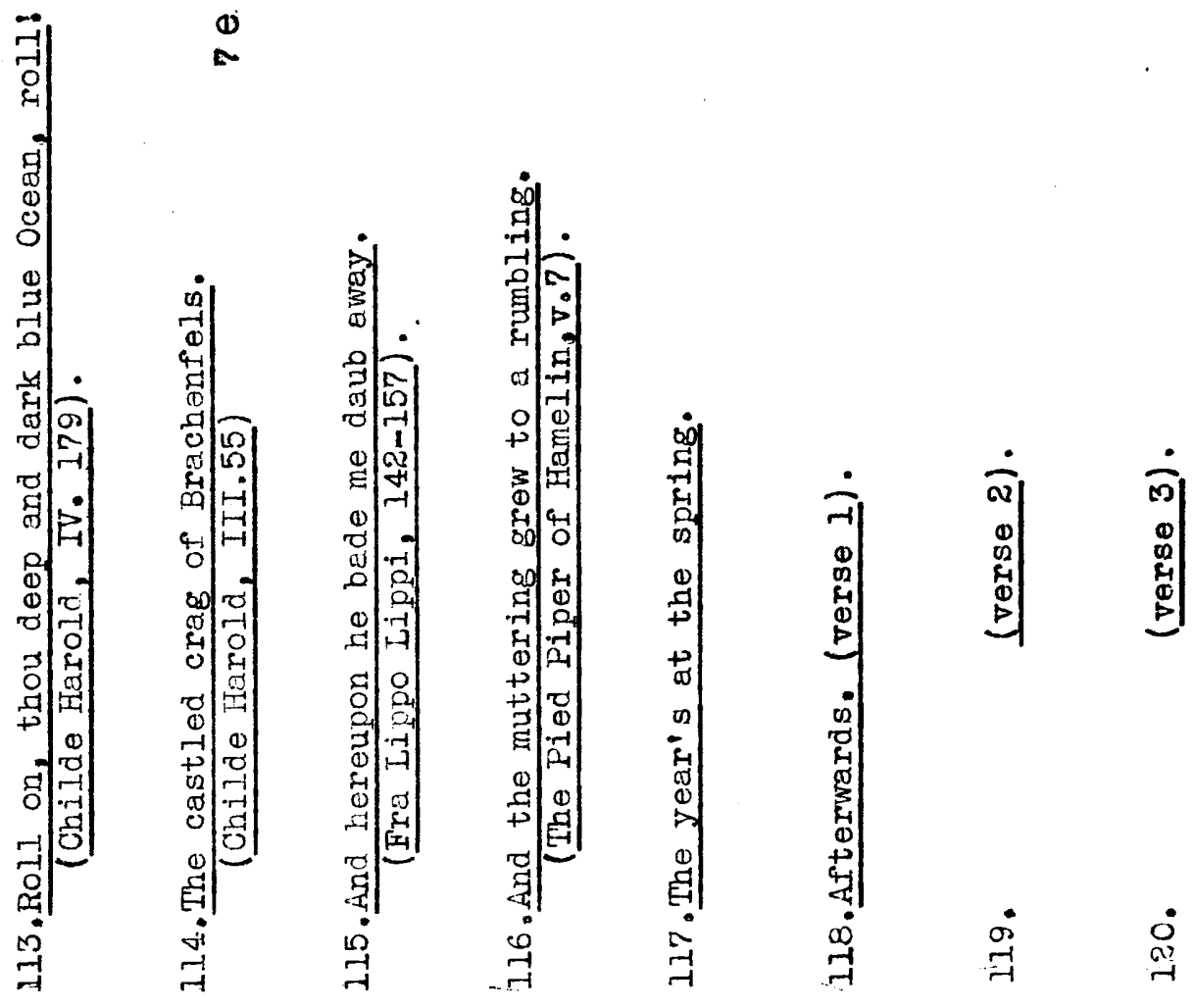




$$
\begin{aligned}
& \stackrel{\ddot{\theta}}{a}=\quad \ddot{r} \omega \\
& \text { ๓ } \bowtie-1 \\
& \ddot{0} 0 \quad \ddot{\ddot{z}} 0 \\
& \text { लन } \\
& \text { C } \because 300 \\
& \text { ming }
\end{aligned}
$$$$
\ddot{\sigma}+\ddot{\vec{\sigma}} \ddot{\mathbb{D}}
$$$$
\text { Da n D }
$$

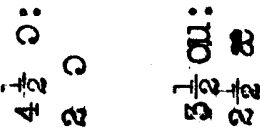$$
\begin{array}{ll}
n & \ddot{\theta}+\infty
\end{array}
$$

$1 \quad \ddot{\nabla} \cdot \ddot{r}$

L $10 \mathrm{~B}$

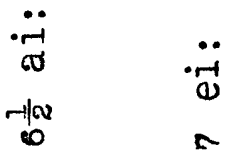

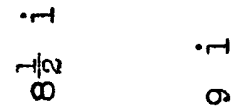

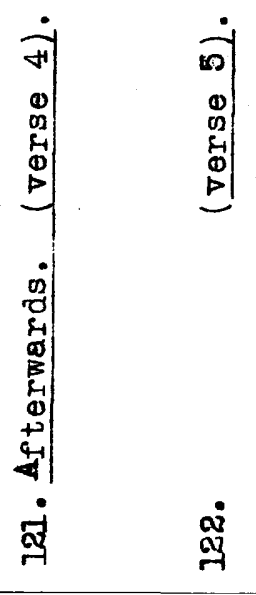




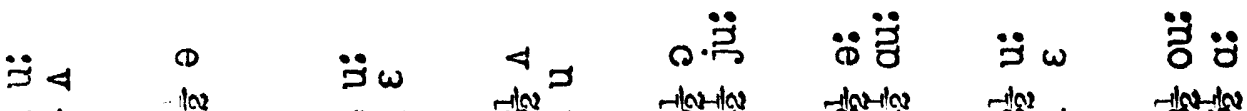

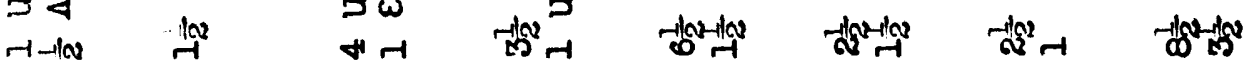

于

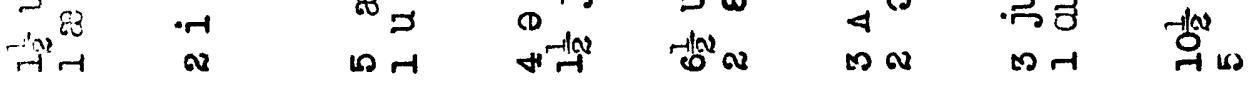

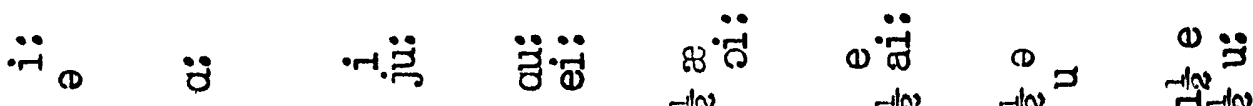

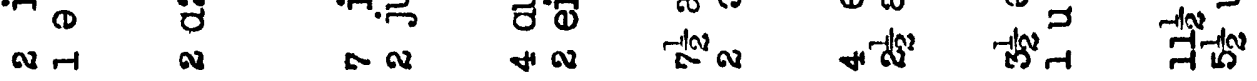

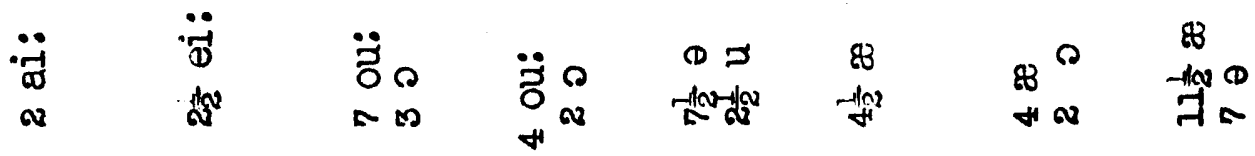

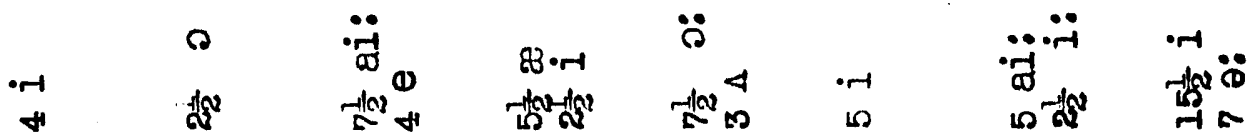

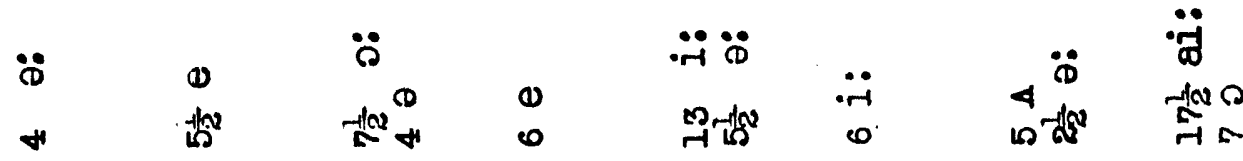

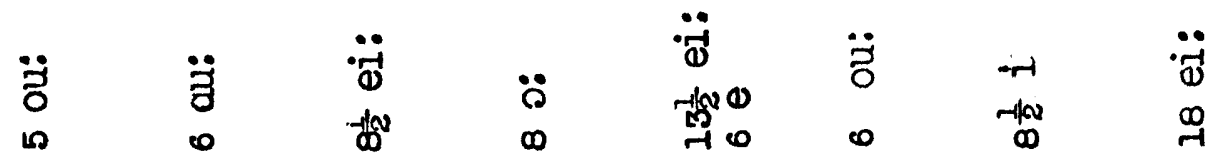

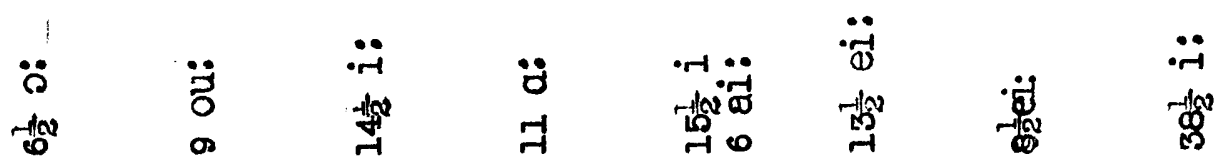
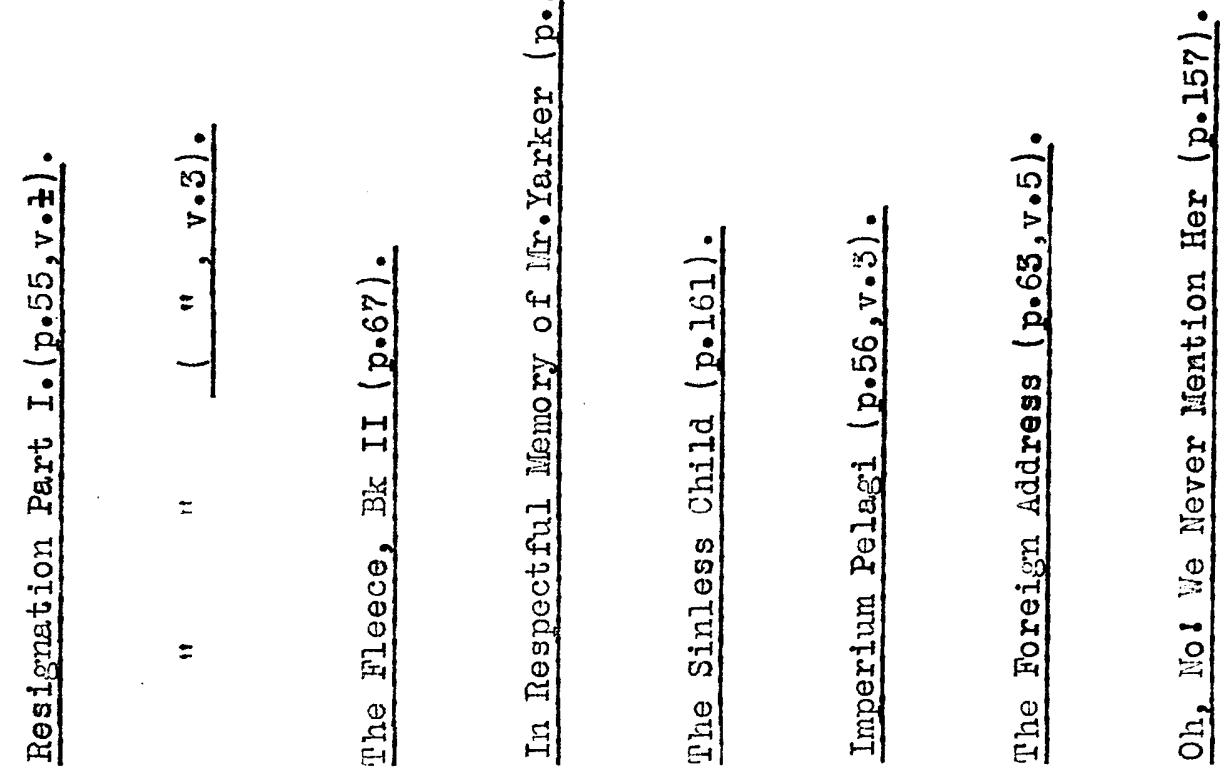

ลं

i०

เค

$\infty^{\circ}$

$\therefore$

$\infty^{\circ}$ 
$x$

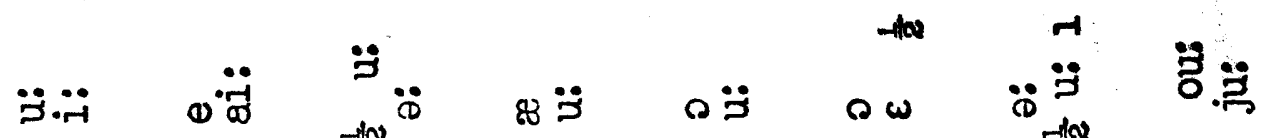

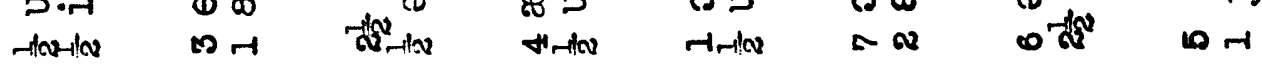

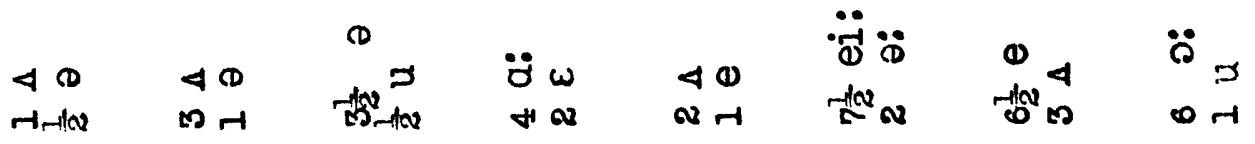

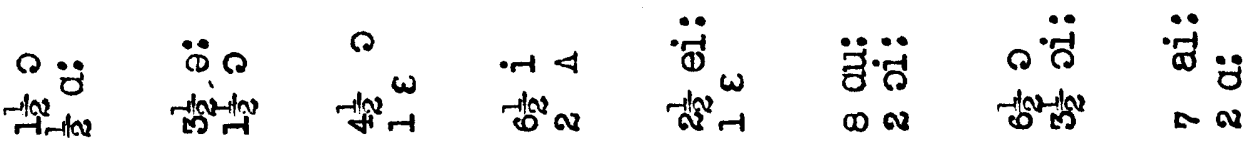

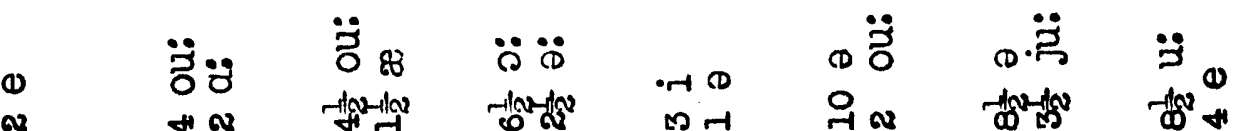

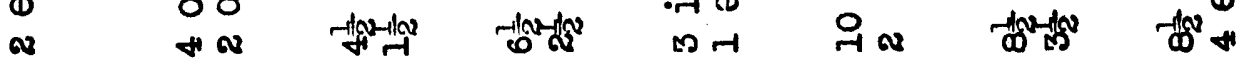

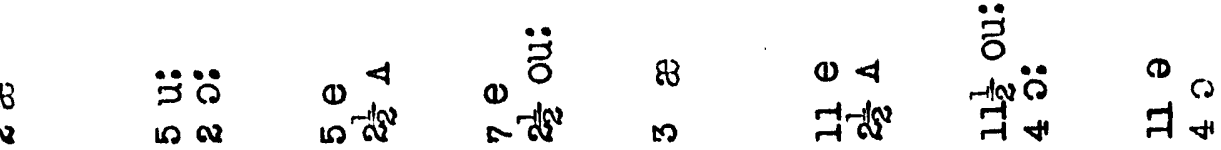
Q $\ddot{z} \quad \& \approx \quad \ddot{q}$

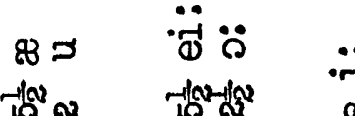

$\mathbf{2}$

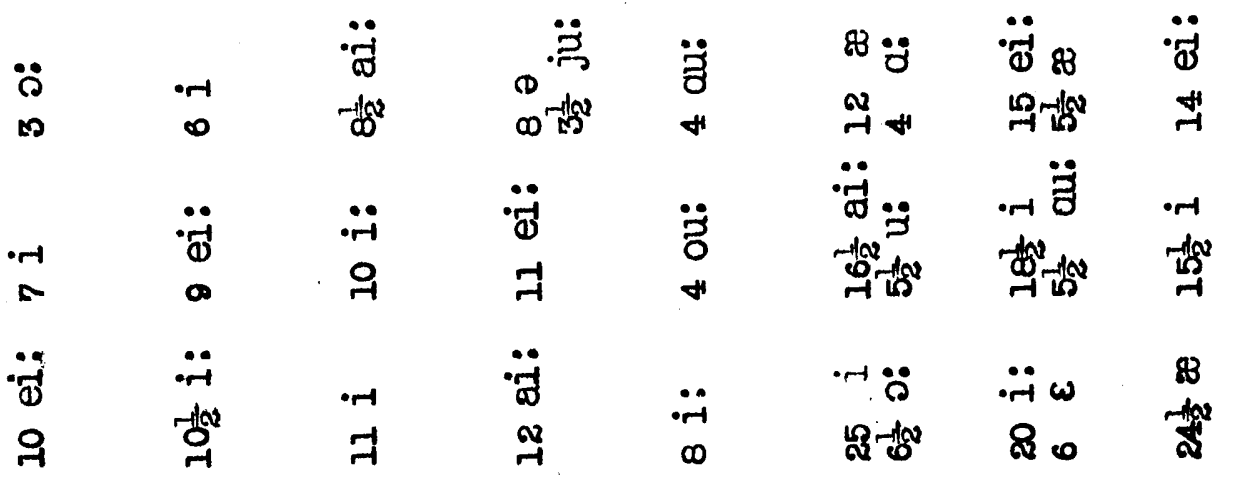

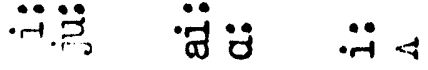

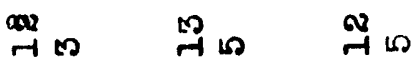

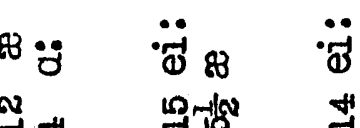
苛. . .

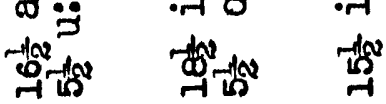

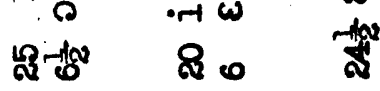

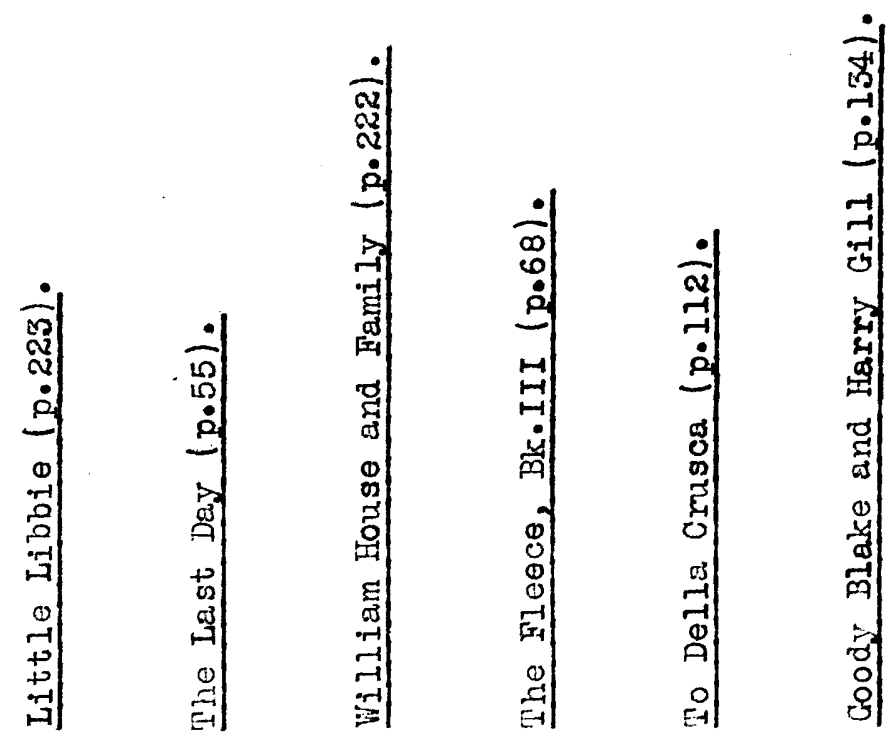

$\infty$ $\dot{9}$ gi 9 เ્ต์ $\stackrel{+}{\circ}$ 


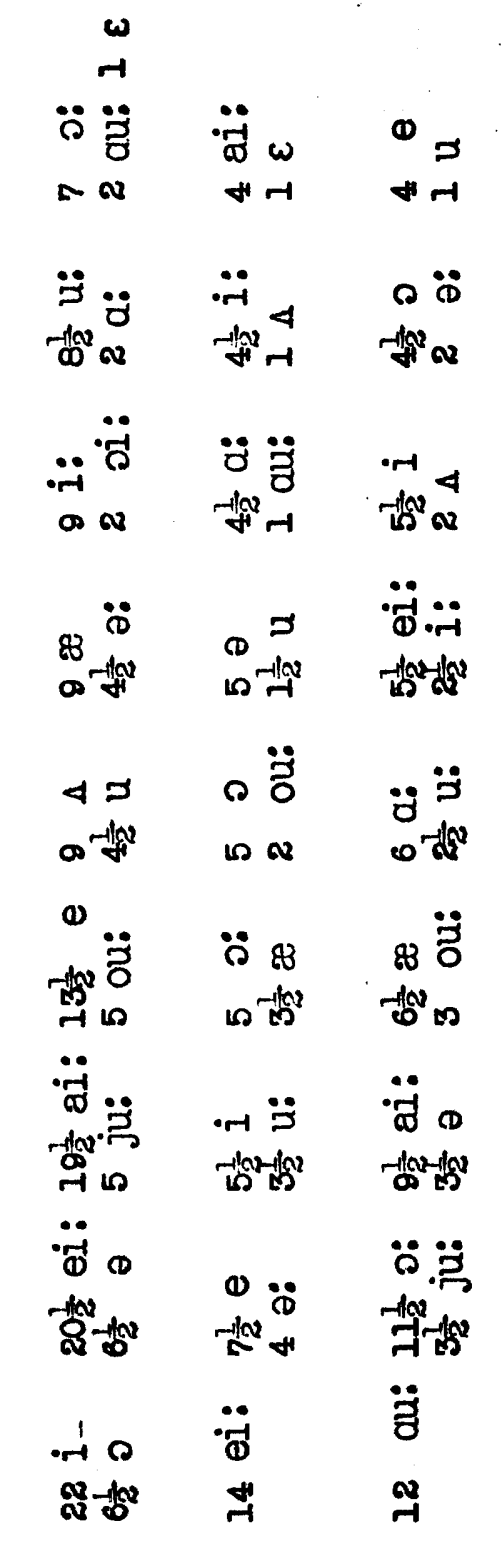

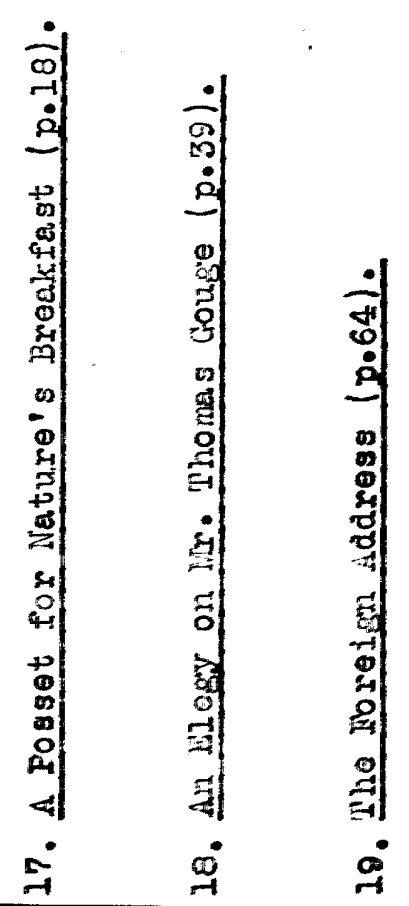




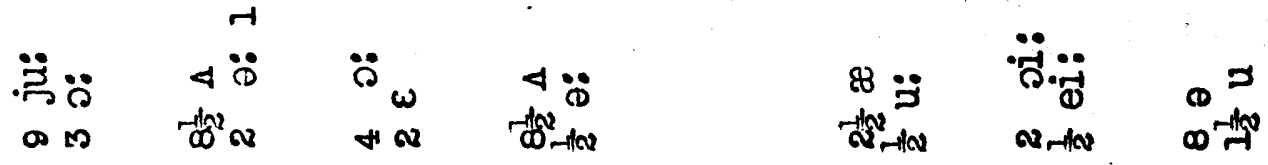

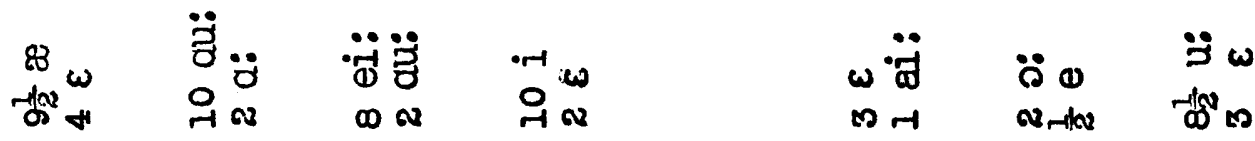

ه

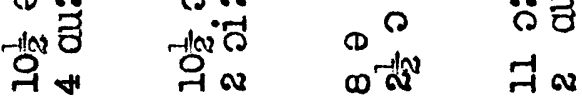

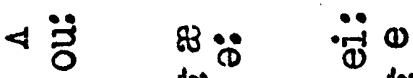

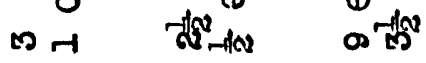

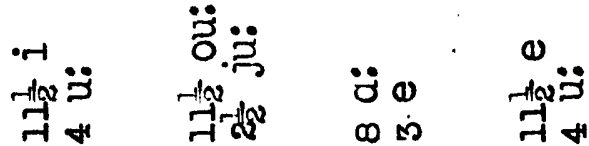

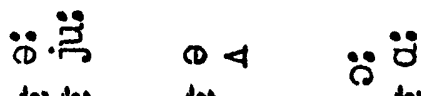

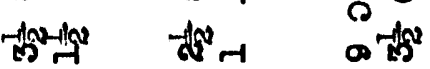

$\ddot{\sigma}$

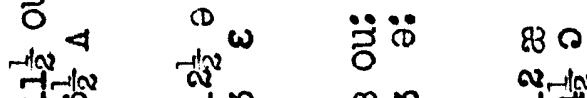

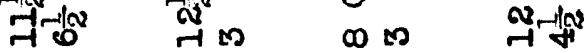

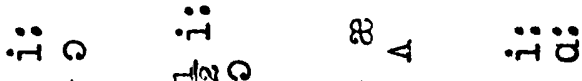

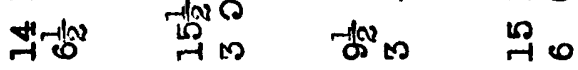

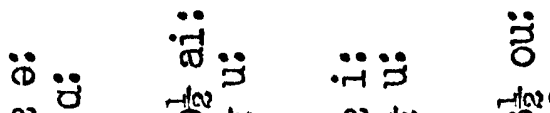

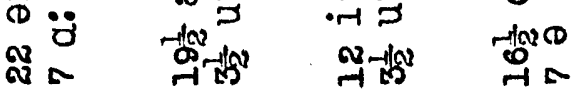

$\because \ddot{0} \quad \ddot{\ddot{\omega}} \quad \ddot{\ddot{\sigma}} \quad \ddot{\oplus}$

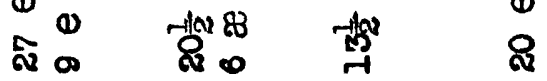

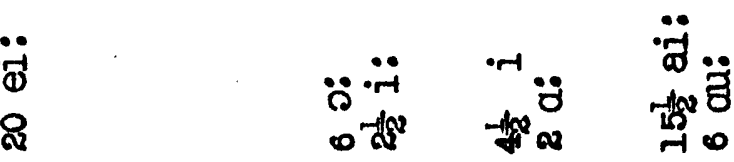

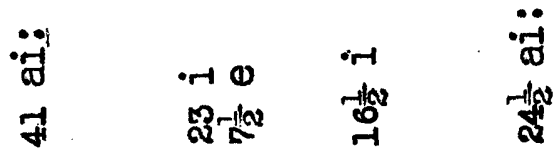

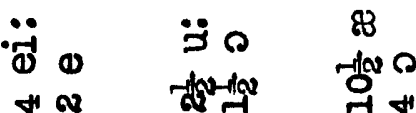

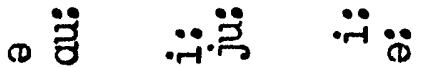

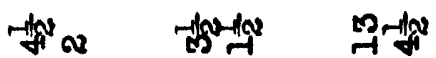

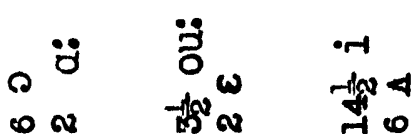

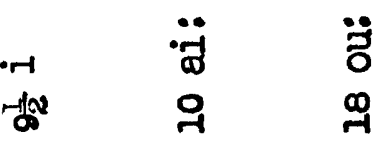

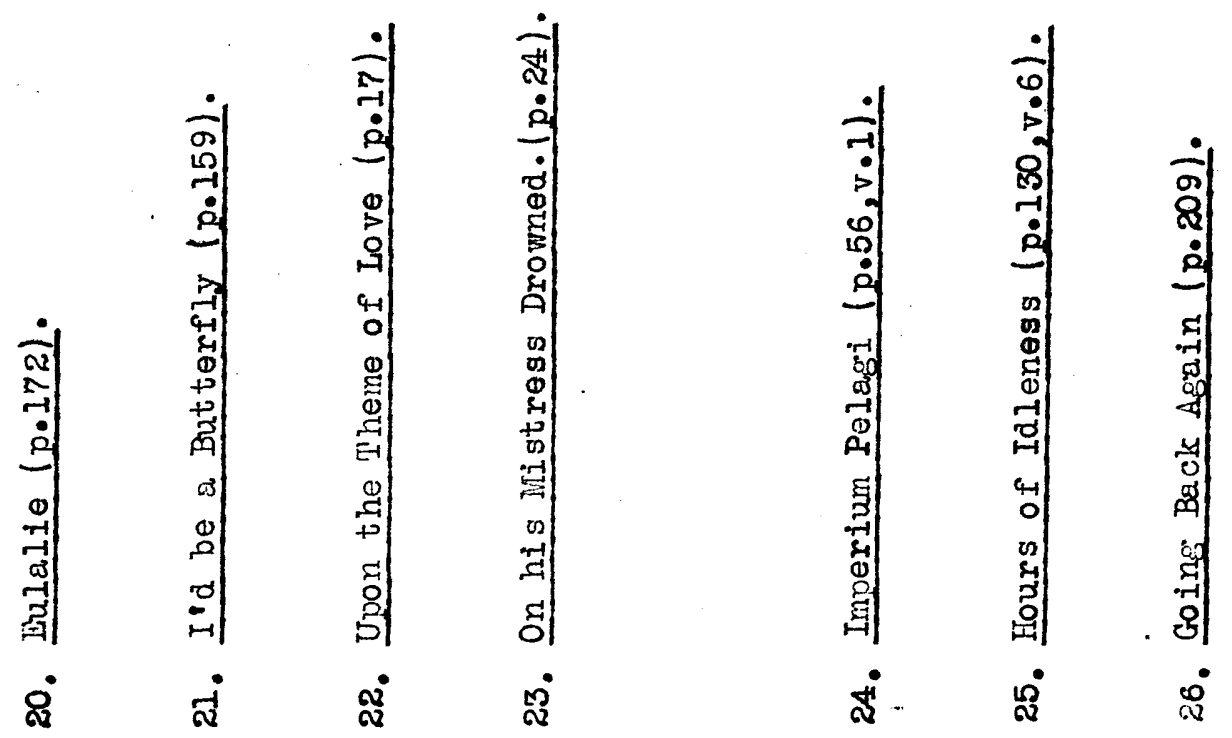


0

-

भु

$8 \ddot{j}$

$m$

(D)

$\rightarrow \infty$

$\stackrel{\ddot{\boldsymbol{T}}}{\omega}$

武-

$\ddot{\ddot{0}} . \ddot{\mu}$

-

9

$\ddot{\rho} \ddot{d}$

$\infty n-1 \infty)$

$\ddot{-r} \ddot{\partial}$

些 $\infty$

$\ddot{a} 4$

orrino

$+\infty$

.

a

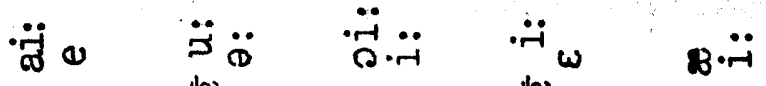

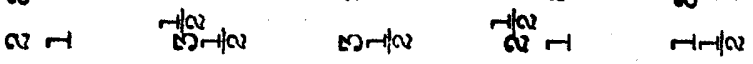

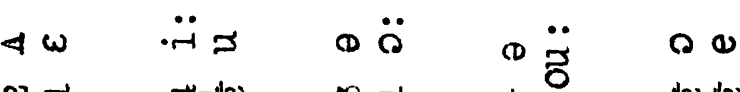

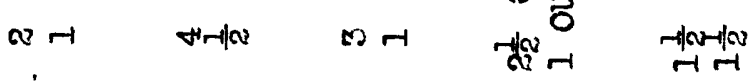

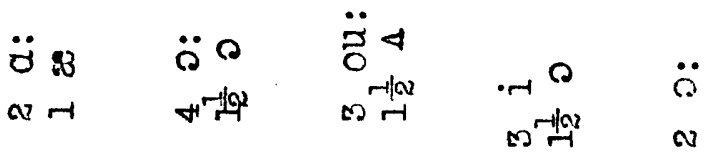

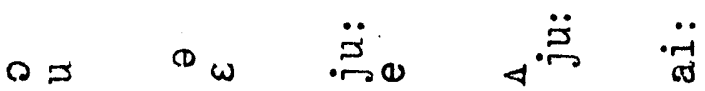

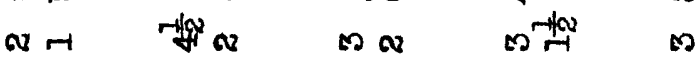

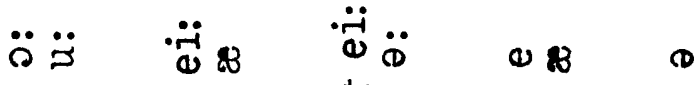

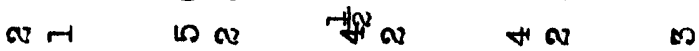

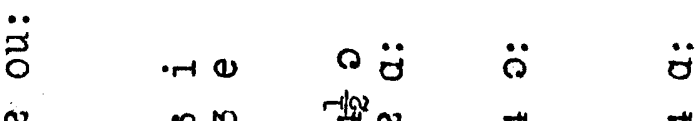

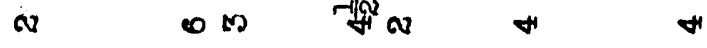

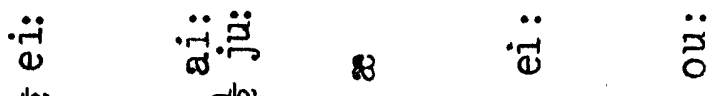

तु 0 些

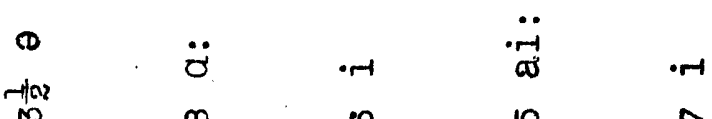

$\infty \quad \infty \quad \infty \quad$ is $\infty$

$\because \ddot{\theta} \quad \ddot{z} \quad \ddot{\ddot{d}} \quad \ddot{\ddot{j}} \quad \ddot{\ddot{d}}$

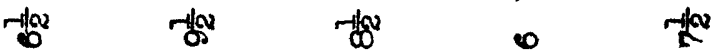

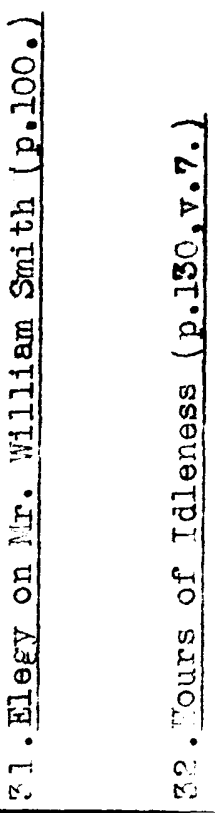




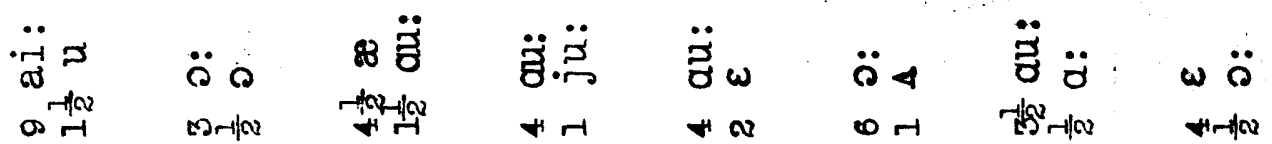

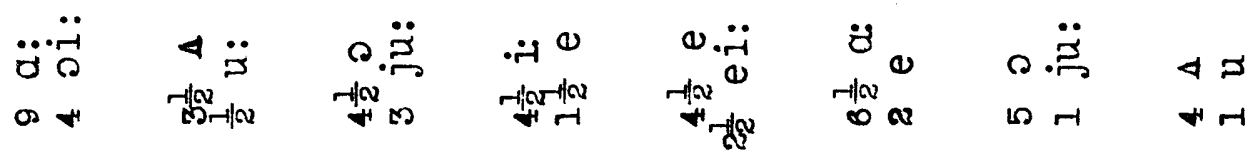
ة

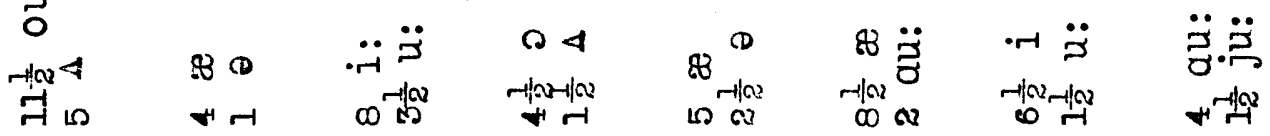

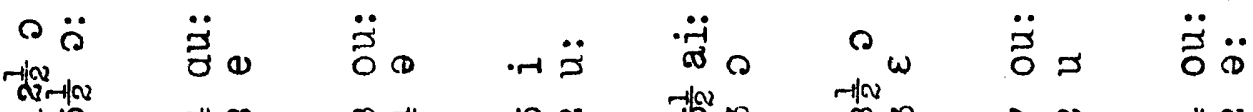

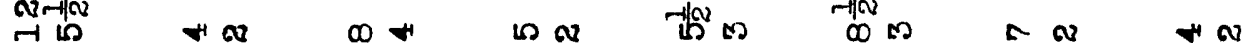

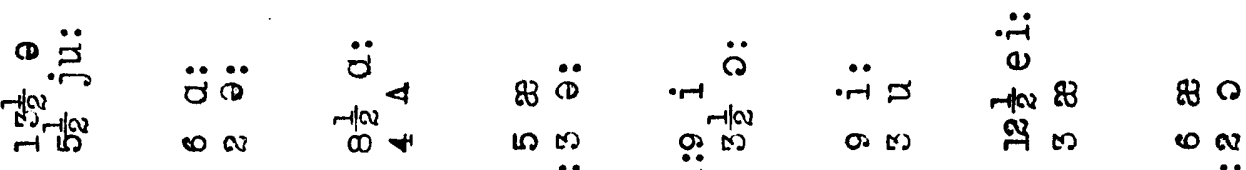

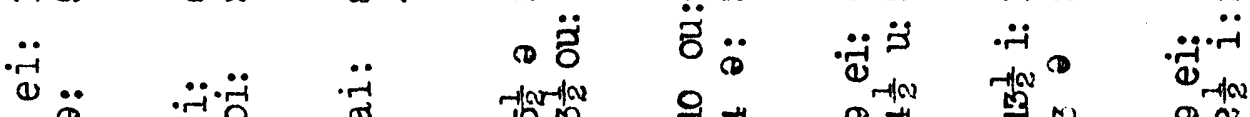

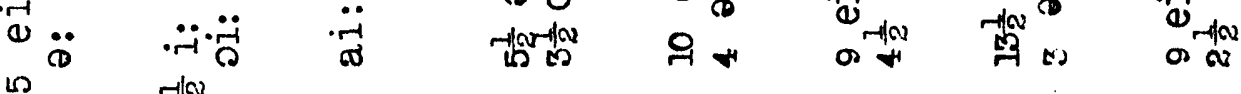
in

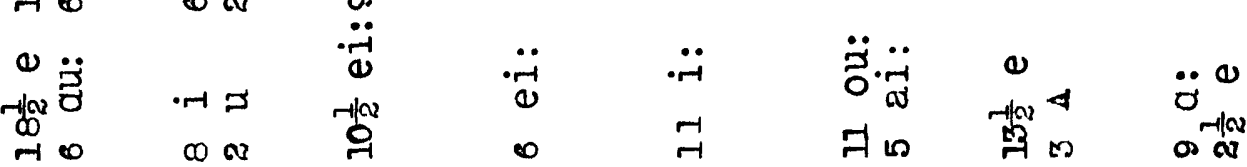

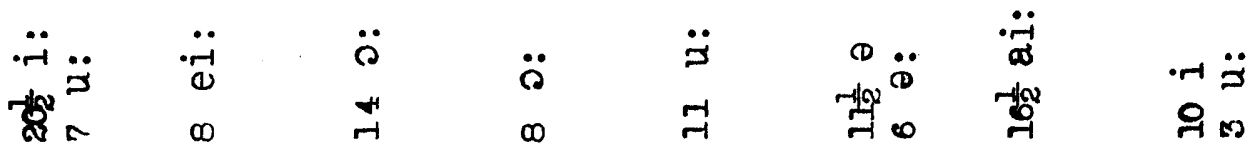

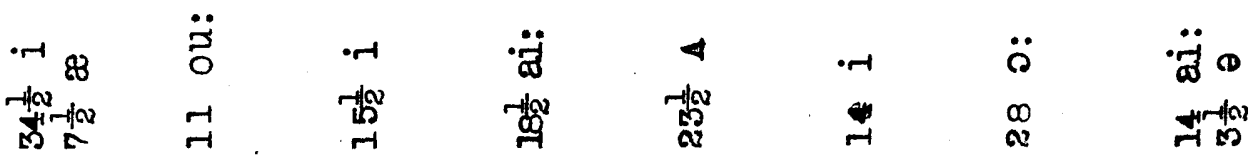

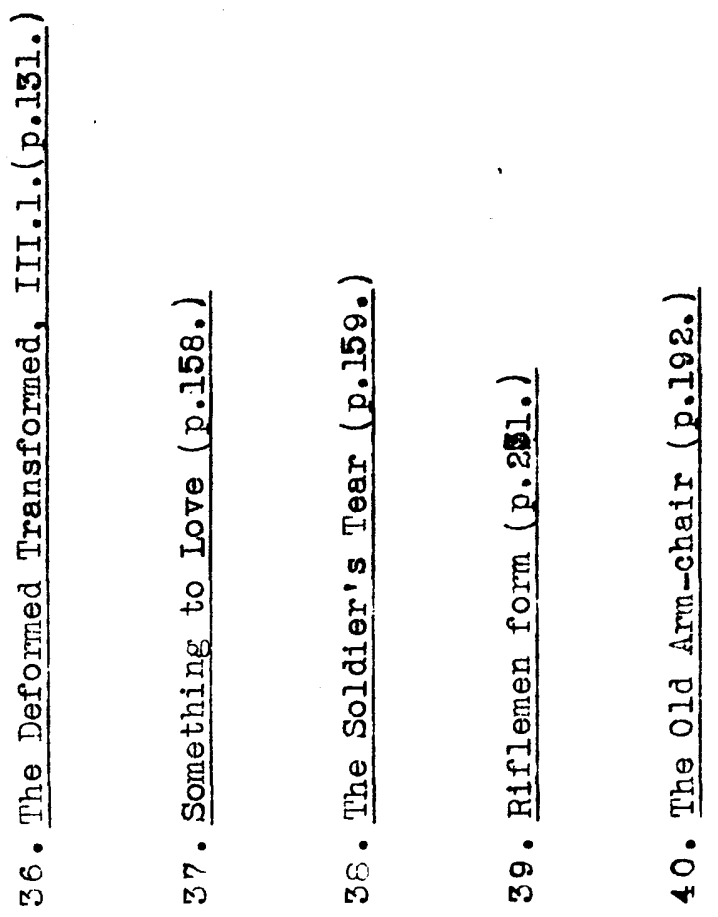

